Universidad PolitéCNICA DE MADRID

ESCUELA TÉCNICA SUPERIOR DE ARQUTTECTURA DE MADRID

DEPARTAMENTO ESTRUCTURAS Y FÍSICA DE EDIFICACIÓN

\title{
INFLUENCIA DE LA CORROSIÓN EN LA ADHERENCIA DE AlAMBRES EN ELEMENTOS Pretensados de Hormigón
}

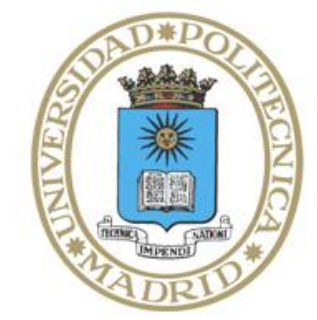

TESIS DOCTORAL

AUTOR

Pablo ANAYA GiL

ARQUiteCTO 

Universidad PolitéCNICA DE MADRID

ESCUELA TÉCNICA SUPERIOR DE ARQUITECTURA DE MADRID

DEPARTAMENTO ESTRUCTURAS Y FÍSICA DE EDIFICACIÓN

\title{
INFLUENCIA DE LA CORROSIÓN EN LA ADHERENCIA DE ALAMBRES EN ELEMENTOS Pretensados de Hormigón
}

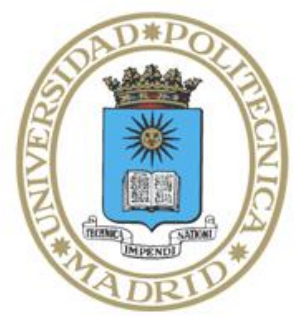

TESIS DOCTORAL

\author{
AUTOR \\ Pablo ANAYA GiL \\ ARquitecto
}

\section{DIRECTORES}

Dr.Carmen ANDrade Perdrix

DR. QUÍMICA INDUSTRIAL

DR. JESÚS RodRÍGUEZ SANTIAGO

DR. INGENIERO DE CAMINOS, CANALES Y PUERTOS 



\section{INFLUENCIA DE LA CoRrosión EN LA AdHERENCIA DE ALAMbres EN ElEMENTOS PRETENSADOS DE HORMigóN \\ AUTOR \\ Pablo ANaya Gil}

El Tribunal, aprobado por la Comisión de Doctorado de la Universidad Politécnica de Madrid en su reunión del , está integrado por los siguientes doctores:

\section{Presidente}

$\mathrm{D} / \mathrm{D}^{\mathrm{a}}$

Vocales

$\mathrm{D} / \mathrm{D}^{\mathrm{a}}$

$\mathrm{D} / \mathrm{D}^{\mathrm{a}}$

$\mathrm{D} / \mathrm{D}^{\mathrm{a}}$

Secretario

$\mathrm{D} / \mathrm{D}^{\mathrm{a}}$

\section{Suplentes}

$\mathrm{D} / \mathrm{D}^{\mathrm{a}}$

$\mathrm{D} / \mathrm{D}^{\mathrm{a}}$

Realizado el acto de defensa y lectura de la tesis, el día de.

de $20 \ldots$, en la Escuela Técnica Superior de Arquitectura de Madrid. El Tribunal acuerda otorgar a la tesis doctoral la calificación de:

Madrid, a de de 20

El/La Presidente/a,

El/La Secretario/a,

$\mathrm{D} / \mathrm{D}^{\mathrm{a}}$.

$\mathrm{D} / \mathrm{D}^{\mathrm{a}}$

Vocal,

Vocal,

Vocal,

$\mathrm{D} / \mathrm{D}^{\mathrm{a}}$

$\mathrm{D} / \mathrm{D}^{\mathrm{a}}$

$\mathrm{D} / \mathrm{D}^{\mathrm{a}}$ 
A mis padres

A mi bermana

A Sofia 


\section{AGRADECIMIENTOS}

Mi más sincero reconocimiento y gratitud se dirige, en primer lugar, a los Directores de esta tesis, Dr. Carmen Andrade Perdrix y Dr. Jesús Rodríguez Santiago, cuya experiencia, consejo y dedicación han permitido que este trabajo llegue a buen término. A Carmen Andrade querría agradecerle no sólo compartir conmigo una pequeña parte de sus vastos conocimientos en el campo de la corrosión de armaduras, sino especialmente, transmitirme su pasión por la investigación. A Jesús Rodríguez le debo su constante apoyo durante los últimos años de mi carrera de arquitectura y mis primeros años en el mundo laboral, así como su asesoramiento durante el largo periodo de elaboración de esta tesis. Sin sus conocimientos en el campo del hormigón estructural, esta investigación no hubiera sido posible.

Un reconocimiento especial lo reservo para la Dr. Beatriz Martín-Pérez, cuya implicación en el desarrollo de este trabajo, más allá de cualquier obligación, la convierten por derecho propio en la tercera directora de esta tesis. A Beatriz Martín-Pérez le agradezco sinceramente su cálida acogida en un país y universidad desconocidos, durante mi estancia de dos años en la Universidad de Ottawa, y su impagable apoyo en el desarrollo del modelo analítico de esta tesis, gracias al cual esta investigación ganó en calidad, coherencia y solidez.

Me gustaría agradecer a la financiación aportada para la realización de esta tesis, sin la cual no hubiera sido viable, tanto por el Consejo Superior de Investigaciones Científicas (CSIC), mediante su beca predoctoral JAE-PREDOC, como por la Comisión Europea, mediante su beca predoctoral NOVA DOMUS, del programa ERASMUS MUNDUS, que permitió mi estancia en el Departamento de Ingeniería Civil de la Universidad de Ottawa.

También me gustaría mostrar mi agradecimiento a todo el personal del Instituto de ciencias de la construcción Eduardo Torroja (IETcc), del Consejo Superior de Investigaciones Científicas, donde he desarrollado la mayor parte de este trabajo. Quiero agradecer a mis compañeros del Departamento de Seguridad y Durabilidad de Estructuras, a Filipe, a Julio, a Nuria, a Antonio, a Leticia, a Ramón, a Miguel, a Carlos, su compañerismo y colaboración, especialmente a Juan Antonio Morales, quien suplió mis manos durante mi estancia en Canadá, y al Dr. Fabiano Tavares, quien desarrolló el intensiostato con el que se llevó a cabo parte de la campaña experimental. Un especial agradecimiento se merece el personal de la Nave de Ensayos, sin el conocimiento y la experiencia de Cecilio López, de Rafa Soldado, de Javier Barroso y de Gabriel Rentero, la extensa campaña experimental de esta tesis no podría haberse llevado a cabo. También me gustaría mostrar mi gratitud al personal de la Unidad de Calidad en la Construcción, a Carlos, a Sonia, a Juan, a Daniel, a Aurelio, a todos, por su apoyo y amistad, y por convertir el Torroja en un lugar interesante en el que trabajar. Por otra parte, quiero manifestar mi agradecimiento especialmente a Guillermo Sotorrío, Luquesio Rodríguez y Miguel Allona, mis compañeros de despacho, por tantos buenos momentos y convertir el acto de trabajar más en una diversión que en una obligación.

Un apartado especial se merece mi familia y amigos, cuyos ánimos han permitido que finalice este trabajo. Gracias a mis padres, que me transmitieron su pasión por el conocimiento, y a mi hermana, porque me animaron en todo momento, aun sin saber muy bien en qué estaba metido, porque 
entendieron la decisión de irme a Canadá, aun a costa de no vernos durante un largo tiempo, y porque, en definitiva, me apoyaron incondicionalmente durante todo el proceso de elaboración de esta tesis.

Por último, quiero agradecer y dedicar esta tesis a Sofía, mi compañera, mi amiga, mi todo. Me apoyaste en los malos momentos, disfrutaste conmigo los buenos, me animaste cuando lo necesitaba, tuviste la paciencia que no merecía, me acompañaste "más allá del muro" cuando las necesidades de la investigación así lo requerían. Por todo ello y mucho más, esta tesis está dedicada a ti. Lo conseguimos. 


\section{RESUMEN}

En elementos pretensados de hormigón, la adherencia entre el acero y el hormigón es una propiedad esencial para garantizar la integridad de la estructura. El acero de pretensar, ya sea en forma de alambres o cordones, tiene una doble función: permitir, por un lado, que parte de la tensión de tracción disponible hasta alcanzar valores próximos a su límite elástico se use para comprimir el hormigón, mejorando su comportamiento en servicio y, por otro lado, que su resistencia a tracción sea utilizada para colaborar con el hormigón en la resistencia de las cargas aplicadas externamente. Para garantizar esta doble función es crucial la existencia de tensiones de adherencia entre los alambres de acero y el hormigón, asegurando la transmisión de las fuerzas de pretensado tras el destesado y el anclaje del alambre durante la vida útil del elemento. Esta adherencia puede verse deteriorada por diferentes motivos, siendo uno de los más recurrentes el daño inducido por procesos de corrosión. Los productos de corrosión, cuyo volumen específico es mayor que el del acero original, generan tensiones en el hormigón que circunda el alambre y propician la aparición de fisuras y desprendimientos en el recubrimiento, reduciendo su capacidad de confinamiento y, consecuentemente, mermando las propiedades adherentes entre el hormigón y el acero.

El parámetro fundamental para caracterizar las propiedades adherentes existentes entre el acero pretensado y el hormigón es la longitud de transmisión o transferencia. La fuerza en un alambre o cordón de pretensado se transfiere por adherencia al hormigón durante la operación de destesado, de manera que las tensiones longitudinales en el acero varían desde cero, en el extremo de la viga, hasta su máximo valor más allá de la longitud de transferencia. Por tanto, la longitud de transferencia se define como aquella necesaria para que la totalidad de la fuerza de pretensado introducida en una armadura pretesa se transfiera por adherencia al hormigón. Esta longitud abarca la distancia existente desde el extremo libre de un elemento pretensado hasta la sección a partir de la cual la tensión en el alambre o cordón es constante, de modo que más allá de dicha sección la fuerza de pretensado mantiene su valor hasta la zona de transferencia del extremo opuesto, en que se produce el fenómeno en sentido inverso.

El cálculo y diseño de elementos pretensados de hormigón con armaduras pretesas requiere una evaluación realista de la longitud de transferencia. Por un lado, valores reducidos de la misma mejoran la capacidad resistente frente a esfuerzo cortante, debido al efecto favorable de las tensiones de compresión introducidas en la sección de hormigón, especialmente en los extremos del elemento, donde el cortante suele ser de mayor entidad. Por otro lado, la reducción de la longitud de transferencia lleva asociado un aumento de las tensiones transversales de tracción en los extremos del elemento, aumentando el riesgo de fisuración por estallido, por exfoliación o por hendimiento. Las expresiones para la caracterización de la longitud de transferencia recogidas en los códigos estructurales cuyo uso está más extendido [Eurocódigo 2; ACI 318-02; EHE-08; Model Code 2010] suelen considerar únicamente el efecto de algunas variables, como el diámetro del alambre o la fuerza de pretensado inicial, omitiendo otros parámetros, como la resistencia del hormigón o el espesor de recubrimiento, cuya influencia ha sido demostrada en numerosos trabajos. Además, en ningún caso, se cuantifica en qué medida afecta el ataque por corrosión a dicha longitud. Por tanto, es patente la necesidad de desarrollar un método racional que permita evaluar la adherencia, y consecuentemente 
la longitud de transferencia, en elementos pretensados de hormigón con distintas configuraciones geométricas y mecánicas, así como con distintos grados de corrosión.

En esta tesis se han investigado los procesos de degradación de la adherencia motivados por la corrosión en alambres lisos e indentados y se ha analizado su influencia en el comportamiento de elementos pretensados de hormigón. Para ello, se ha desarrollado un modelo analítico cuyas variables han sido calibradas mediante ensayos de arrancamiento sobre alambres no tesados y cuyos resultados teóricos han sido verificados gracias a su comparación con los datos extraídos de una campaña experimental sobre elementos pretensados tipo viga.

La metodología seguida, que puede calificarse como teórico-experimental y consistente en varias etapas diferenciadas, se ha mostrado como un procedimiento eficaz para identificar, analizar y cuantificar las principales variables mecánicas y geométricas que intervienen en el fenómeno de la corrosión en elementos pretensados. Las etapas de las que ha constado esta investigación son las siguientes:

- Desarrollo de un modelo analítico bidimensional para la determinación de las tensiones radiales a nivel de sección derivadas de los procesos de corrosión en estructuras de hormigón armado.

- Realización de campaña de ensayos de arrancamiento para la calibración de los parámetros que definen la expansión de los productos de corrosión y las propiedades adherentes entre el hormigón y el acero.

- Extensión del modelo a la dirección longitudinal del elemento (tres dimensiones) para la determinación de las leyes que rigen la relación entre adherencia y deslizamiento, en alambres sanos y corroídos, mediante su comparación con la campaña experimental anterior.

- Elaboración de un modelo analítico integral para la determinación de la longitud de transferencia en estructuras pretensadas sanas y corroídas, acoplando los efectos del pretensado al modelo analítico tridimensional sobre elementos de hormigón armado con corrosión. Algunas de las aportaciones novedosas de este modelo se encuentran en el tratamiento de la capa porosa alrededor de los alambres de pretensado y el volumen de fisuras ocupado por productos de corrosión, determinantes en la capacidad de confinamiento del recubrimiento de hormigón, así como en la incorporación del pretensado a lo largo de la dirección longitudinal del elemento

- Verificación del modelo integral mediante su comparación con ensayos sobre elementos pretensados tipo viga con procesos de degradación por corrosión.

El modelo validado ha permitido estudiar la influencia que tienen en el comportamiento adherente las principales variables geométricas y mecánicas que intervienen en el pretensado, lo que a su vez ha posibilitado el desarrollo de expresiones simplificadas para el cálculo de longitudes de transferencia en elementos pretensados de hormigón, tanto con alambres sanos como corroídos. Los resultados arrojados por la expresión propuesta para alambres sanos han sido comparados con los obtenidos en 
TESIS DOCTORAL INFLUENCLA DE LA CORROSIÓN EN LA ADHERENCLA DE ALAMBRES EN ELEMENTOS PRETENS ADOS DE HORMIGÓN

campañas experimentales de otros autores, mostrando una mejor capacidad predictiva que las expresiones recogidas en los códigos estructurales cuyo uso está más extendido. 


\section{ABSTRACT}

Bond between steel and concrete is an essential property to guarantee the integrity of the structure in prestressed concrete members. Prestressing steel, as either wires or strands, has a double function: on the one hand, allowing that a fraction of the available tensile strength close to its tensile yield strength is used to compress the concrete, improving its service behaviour and, on the other hand, that its tensile strength may be used bearing externally applied loads, along with concrete. To ensure this double function, bond stresses between steel wires and concrete are essential, ensuring the transfer of the prestress force during the prestressing release operation and the anchorage of the wire along the service life of the member. This bond may be degraded due to different reasons, being one of the most frequent ones the corrosion-induced damage. Corrosion products, whose specific volume is greater than that of the virgin steel, produce stresses in the concrete surrounding the wire, and induce cracking and spalling of concrete cover, reducing its confinement capacity and therefore affecting the bond properties between steel and concrete.

Transfer length (or transmission length) is the key indicator to describe the bond properties between prestressed steel and concrete. Prestressing force is transferred by bond during the releasing procedure, so that the longitudinal stresses in steel vary from zero at the free end of the wire to the fully effective value beyond the transfer length. Therefore, such transmission length is defined as the one required to transfer the fully prestressing force by bond from the steel to the concrete. This length includes the distance between the free end of the prestressed concrete member up to the cross section from which the wire stress is constant, so that beyond it the prestress force sustains its value up to the transfer length in the other member end, where the phenomenon takes place too in the opposite direction.

The calculation and design of prestressed concrete members with prestressed wires requires a realistic assessment of the transfer length. Small values of transfer length improve the shear-bearing capacity, due to the favourable effect of compressive stresses in concrete section, especially in the member ends, where the shear tends to be higher. However, the downsizing of the transfer length entails an increase of transverse shear stresses in the member ends, increasing the risk of cracking due to bursting, exfoliation or splitting. Transfer length expressions from the most widespread structural codes [Eurocode 2; ACI 318-02; EHE-08; Model Code 2010] often only consider the effects of some variables, such as the wire diameter or the initial prestressing force, neglecting some other parameters, such as the concrete strength or the cover thickness, whose influence on transfer length has been proved through many research works. Moreover, under no case has it been measured how a corrosion attack affects this length. Therefore, it is critical the need to develop a rational method that allows to assess the bond stress and, consequently, the transfer length in prestressed concrete elements with different mechanical and geometric configurations, as well as different degrees of corrosion.

In this thesis, the processes of bond degradation due to the corrosion of both indented and smooth wires have been studied, and its influence in the behaviour of prestressed concrete members has been analysed. To that end, it has been developed an analytical model whose variables have been calibrated through pull-out test on non-stressed wires, and whose theoretical results have been verified thanks to its comparison with the data extracted from an experimental campaign on pre-stressed beams. 
The methodology followed, which may be described as both theoretical and experimental, and consisting in several distinct stages, has been shown as an efficient procedure to identify, analyse, and measure the main geometric and mechanical variables involved in the phenomenon of the corrosion of prestressed elements. The stages in which this research has consisted are the following:

- Development of a bi-dimensional analytical model for the determination of the tensile radial stresses derived from corrosion at the cross-section level in reinforced concrete structures.

- Conduction of a pull-out test campaign to calibrate the parameters defining the expansion of corrosion products and the bond properties between concrete and steel.

- Extension of the analytical model to the longitudinal direction of the element (three dimensions) to determine the laws governing the relation between bond and slip, in both non-corroded and corroded wires, through its comparison with the previous experimental campaign.

- Development of an integral analytical model to determine the transfer length in noncorroded and corroded prestressed structures, coupling the effects of prestress to the threedimensional analytical model regarding corroded reinforced concrete elements. Some novel features of this model are the treatment of the porous layer around the prestressing wires and the volume of cracks occupied by corrosion products to determine the confinement capacity of the concrete cover as well as the incorporation of prestressing along the longitudinal direction.

- Verification of the integral analytical model by comparing it with test on prestressed beams with corrosion degradation mechanisms.

The proven model has allowed the study of the influence on the bond behaviour of the main geometrical and mechanical variables intervening in prestressing, which in turn has allowed the development of simplified expressions for the assessment of transfer lengths in prestressed concrete members with both non-corroded and corroded wires. The results obtained by the expression proposed for non-corroded wires have been compared with the ones obtained in the experimental campaigns from other authors, showing an improved predictive capability than those included in the main design concrete standards. 
TESIS DOCTORAL INFLUENCLA DE LA CORROSIÓN EN LA ADHERENCLA DE ALAMBRES EN ELEMENTOS PRETENS ADOS DE HORMIGÓN

\section{ÍNDICE DE CONTENIDOS}

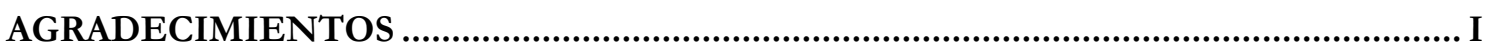

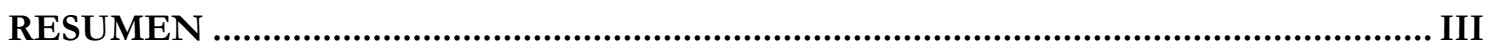

ÍNDICE DE CONTENIDOS ............................................................................

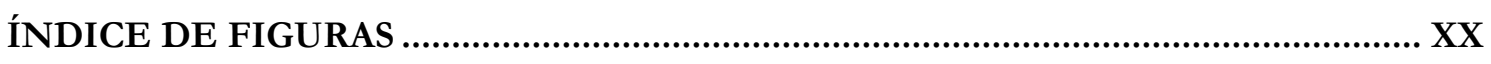

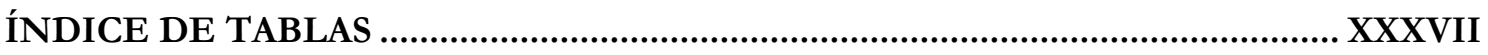

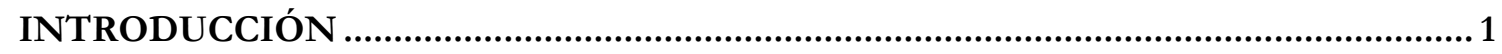

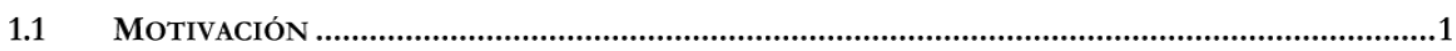

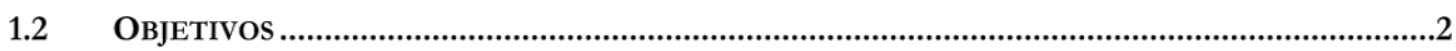

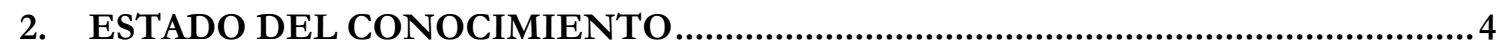

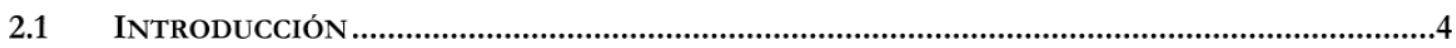

2.2 ADHERENCIA ENTRE ALAMBRES PRETENSADOS Y HORMIGÓN ......................................................

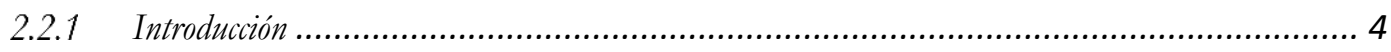

2.2.2 Mecanismos de adherencia entre el hormigón y el acero pretensado ....................................... 5

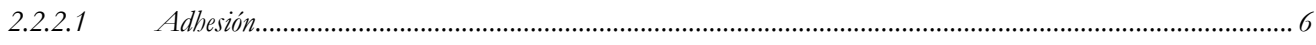

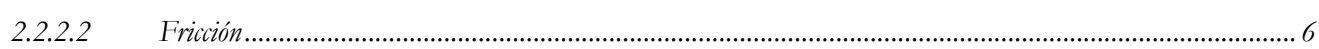

2.2.2.3 Interacción mecánica (engranamiento mecánico) entre el acero y el bormigón.................................................... 7

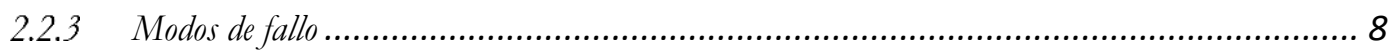

2.2.4 Modelado de la adherencia en pretensado ...................................................................... 9

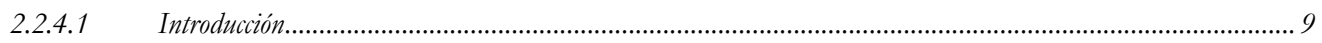

2.2.4.2 Modelos basados en la determ. de $\tau_{b}$ como función del deslizamiento ............................................................. 10

2.2.4.3 Tensión de adherencia como función del confinamiento del hormigón ..........................................................11 
2.2.5 Ensayos para la determinación de la adherencia en pretensado

2.2.5.1 Ensayo de arrancamiento (Ensayo de pull-out)

2.2.5.2 Simulación de la longitud de transferencia y de anclaje (Ensayo de push-in)............................................. 15

2.2.5.3 Medición del deslizamiento de la armadura pretensada ............................................................................. 16

2.2.5.4 Medición de las deformaciones en la superficie del bormigón (Norma 1982)................................................ 18

2.2.5.5 Medición de la fuerza de pretensado (Método ECAD A) .............................................................................20

2.2.6 Caracterización de la adherencia en códigos estructurales ............................................... 21

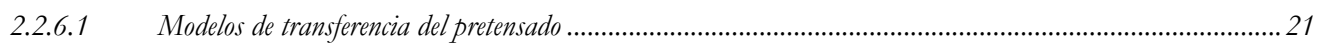

2.2.7 Factores que influyen en la adberencia de alambres pretensados ...................................... 25

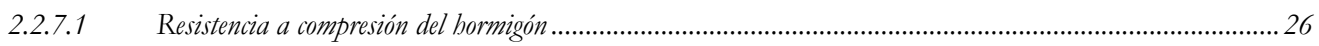

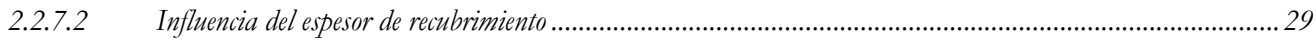

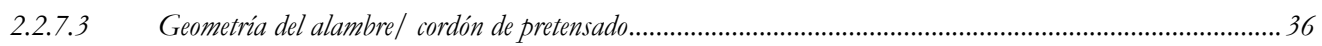

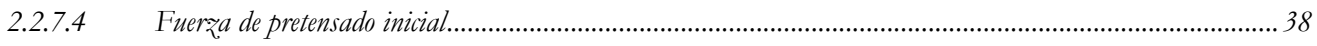

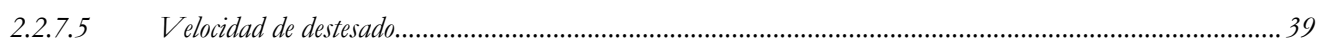

2.2.7.6 Efectos dependientes del tiempo: Retracción, fluencia y relajación...............................................................39

2.2.7.7 Influencia de las propiedades de contacto acero-hormigón ......................................................................41

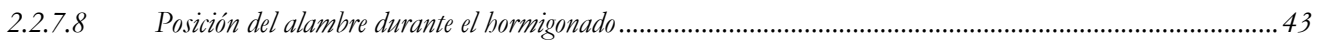

2.3 ADHERENCIA ENTRE ALAMBRES CORROÍDOS Y HORMIGÓN …..............................................43

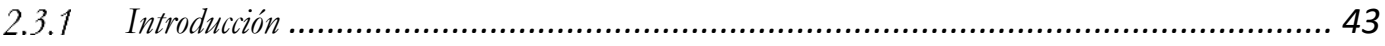

2.3.2 Conceptos básicos de la corrosión del acero........................................................... 44

2.3.2.1 Naturaleza del proceso de corrosión …………......................................................................................4

2.3.2.2 Causas de la corrosión de armaduras........................................................................................................ 45

2.3.2.3 Efectos de la corrosión en el comportamiento mecánico de estructuras de hormigón armado y pretensado............47

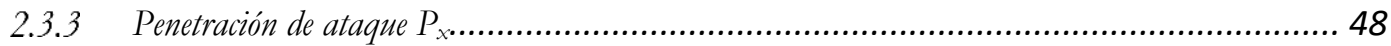

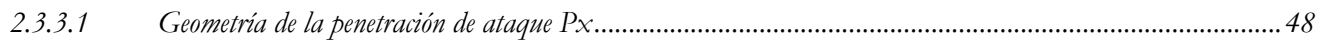

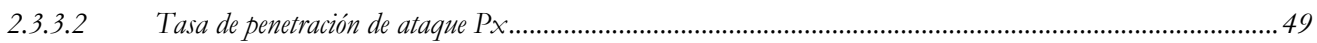


TESIS DOCTORAL INFLUENCLA DE LA CORROSIÓN EN LA ADHERENCLA DE ALAMBRES EN ELEMENTOS PRETENSADOS DE HORMIGÓN

2.3.4 Influencia de la corrosión en la fisuración del recubrimiento............................................ 53

2.3.4.1 Revisión de resultados experimentales .................................................................................................. 53

2.3.4.2 Revisión de modelos propuestos....................................................................................................... 58

2.3.5 Influencia de la corrosión en la adherencia.......................................................... 60

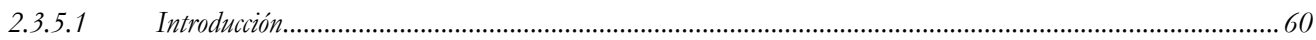

2.3.5.2 Adherencia en barras corrugadas con corrosión ………........................................................................... 62

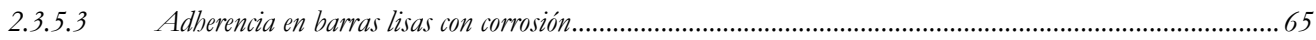

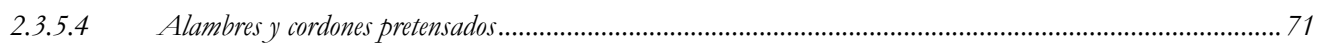

2.3.5.5 Coeficiente de fricción con corrosión ……………............................................................................... 73

2.3.6 Variables relativas a la corrosión que influyen el comportamiento adberente ......................... 76

2.3.6.1 Coeficiente de expansión de óxidos $n$...........................................................................................

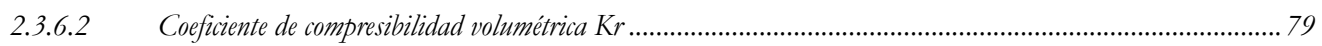

2.3.6.3 Espesor de la zona porosa tp ....................................................................................................... 81

2.3.6.4 Volumen de óxidos en fisuras ............................................................................................................... 86

3. MODELO ANALÍTICO PARA EVALUACIÓN DE LA ADHERENCIA EN ESTRUCTURAS PRETENSADAS DE HORMIGÓN CON PROCESOS DE DETERIORO POR CORROSIÓN …………………………………………………….... 89

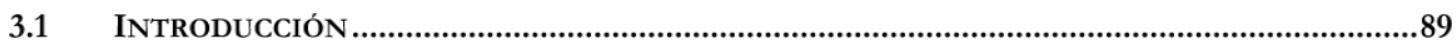

3.1.1 Descripción del modelo analitico desarrollado........................................................ 89

3.2 MODELO DE COMPORTAMIENTO DEL MATERIAL: HORMIGÓN …...........................................93

3.2.1 Hormigón en compresión ......................................................................... 94

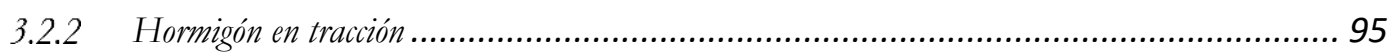

FASE I: DETERMINACIÓN DE TENSIONES RADIALES......................................................97

TENSIONES RADIALES DEBIDAS AL PRETENSADO ..............................................................97

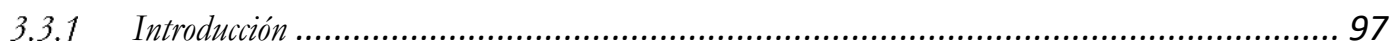




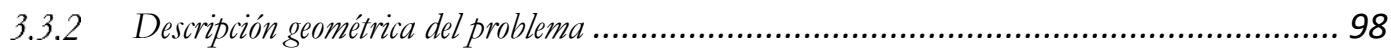

3.3.3 Modelo analítico isotrópico elástico para hormigón sin fisurar........................................... 99

3.3.3.1 Ecuación de equilibrio ....................................................................................................................... 100

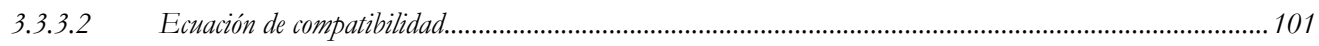

3.3.3.3 Obtención de las tensiones radiales y circunferenciales ......................................................................... 101

3.3.4 Modelo analítico anisótropo para hormigón con fisuración radial.................................. 107

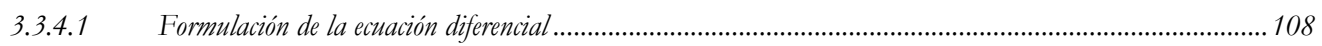

3.4 TENSIONES RADIALES DEBIDAS A LA EXPANSIÓN DEL ACERO POR CORROSIÓN ………........... 115

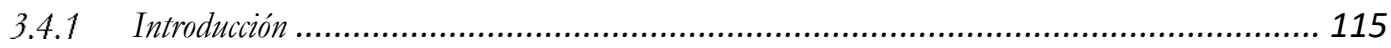

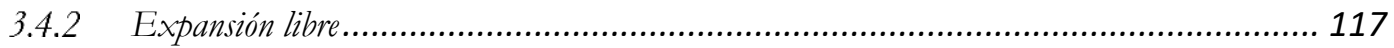

3.4.3 Presión debida a la expansión de los productos de corrosión .............................................. 119

3.4.3.1 Formulación de la ecuación diferencial ............................................................................................... 123

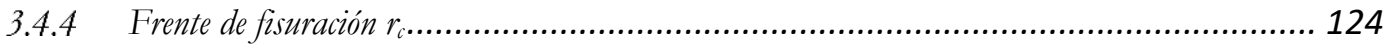

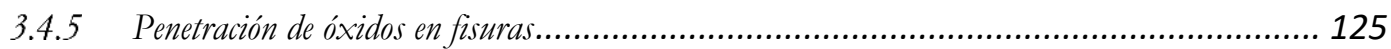

3.5 MODELADO DE LA RETRACCIÓN …………………........................................................... 128

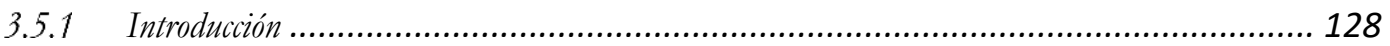

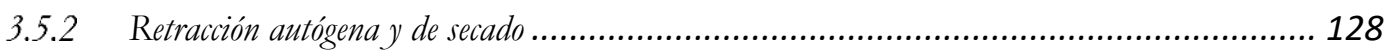

FASE II: SIMULACIÓN DE LOS ENSAYOS DE PULL-OUT .................................................... 131

3.6 MODELADO DE FUERZAS EXTERNAS DE CONFINAMIENTO................................................... 131

3.7 RELACIÓN ADHERENCIA-DESLIZAMIENTO ………............................................................... 132

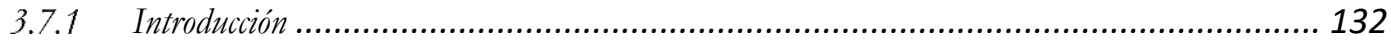

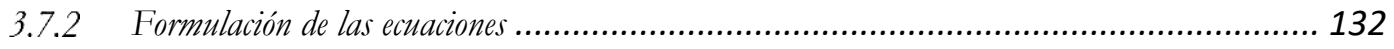

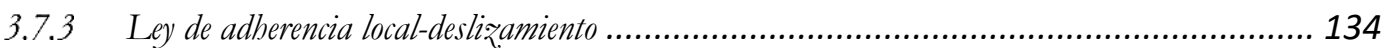

3.7.4 Resolución de las ecuaciones de adherencia a lo largo del alambre .................................... 135

3.7.5 Distribución de deslizamientos, deformaciones y tensiones ............................................. 137 
TESIS DOCTORAL INFLUENCLA DE LA CORROSIÓN EN LA ADHERENCLA DE ALAMBRES EN ELEMENTOS PRETENS ADOS DE HORMIGÓN

FASE III: DETERMINACION DE LA LONGITUD DE TRANSFERENCIA.............................. 150

3.8 DETERMINACIÓN DE LA LONGITUD DE TRANSFERENCIA.................................................... 150

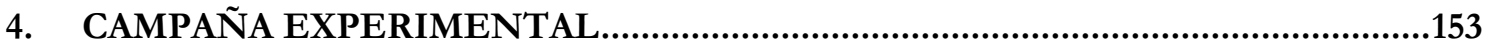

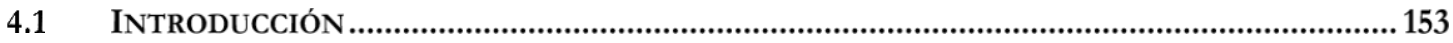

4.2 DESCRIPCIÓN DE LAS VARIABLES UTILIZADAS.................................................................. 154

4.3 PROCEDIMIENTO EXPERIMENTAL ……………................................................................ 154

4.3.1 Tipología de las probetas ................................................................................................154

4.3.2 Fabricación de las probetas ..........................................................................................156

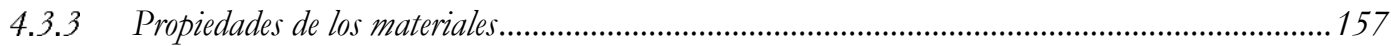

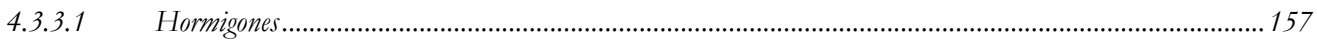

4.3.3.2 Acero

4.3.4 Procedimiento de corrosión acelerada ..................................................................................159

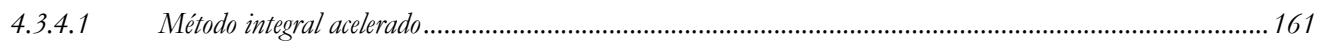

4.3.5 Dispositivo de ensayo y adquisición de datos ........................................................................163

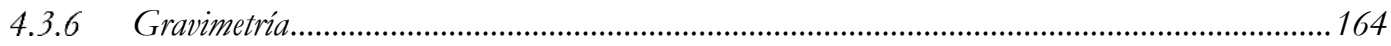

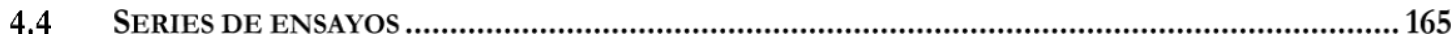

5. RESULTADOS EXPERIMENTALES Y DISCUSIÓN ............................................167

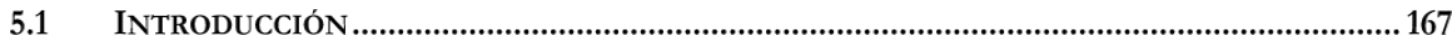

5.2 PÉRDIDAS DE SECCIÓN POR CORROSIÓN ……………........................................................ 168

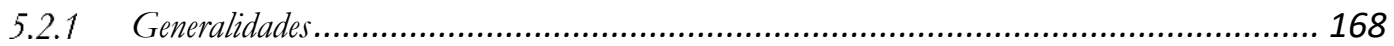

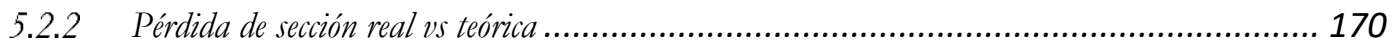

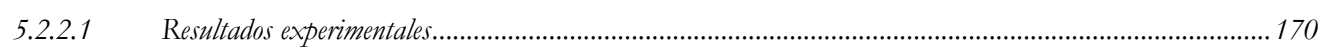

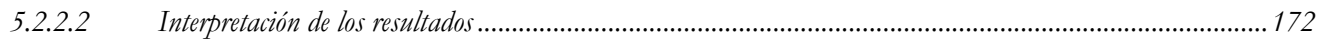


5.2.3 Fisuración asociada al proceso de corrosión............................................................. 174

5.3 ENSAYOS DE PULL-OUT PARA EVALUACIÓN DE LA ADHERENCIA .........................................175

5.3.1 Criterios de interpretación de los resultados experimentales ........................................... 175

5.3.1.1 Tensión de adherencia media ............................................................................................................... 175

5.3.1.2 Ley de adherencia local-deslizamiento Vs Ley de adherencia media-deslizamiento......................................176

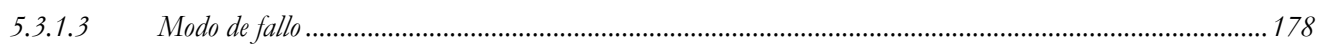

5.3.2 Resultados experimentales de los ensayos de pull-out .............................................. 179

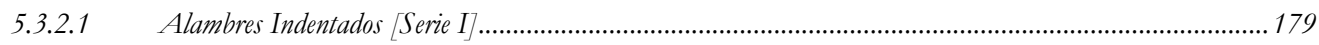

5.3.2.2 Alambres Lisos [Serie L] ………………………...................................................................... 185

5.4 DISCUSIÓN DE LOS RESULTADOS DE LOS ENSAYOS DE PULL-OUT ........................................192

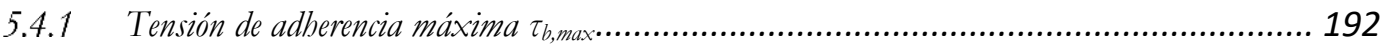

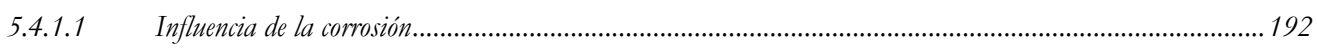

5.4.1.2 Influencia de la capacidad de confinamiento del hormigón ……...............................................................197

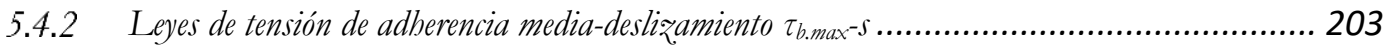

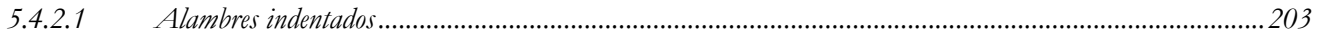

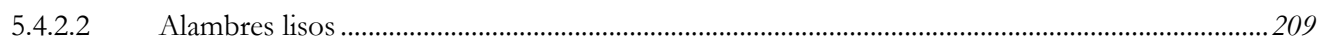

\section{CALIBRACIÓN DEL MODELO ANALÍTICO Y COMPARACIÓN CON LOS} RESULTADOS EXPERIMENTALES ...................................................................213

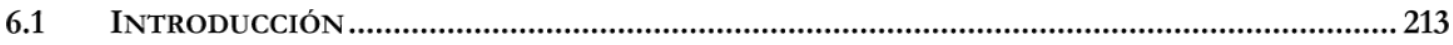

6.2 INFLUENCIA DE LA CORROSIÓN-CALIBRACIÓN DE VARIABLES ............................................ 214

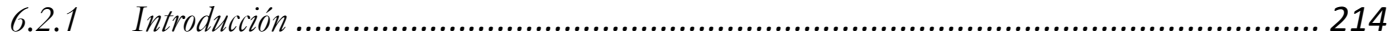

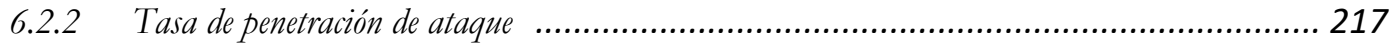

6.2.2.1 Estudio de sensibilidad de la variable.....................................................................................................2218

6.2.2.2 Selección del modelo de penetración de ataque .......................................................................................220

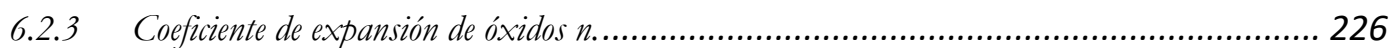


TESIS DOCTORAL INFLUENCLA DE LA CORROSIÓN EN LA ADHERENCLA DE ALAMBRES ENELEMENTOS PRETENSADOS DE HORMIGÓN

6.2.3.1 Estudio de sensibilidad de la variable ....................................................................................................226

6.2.3.2 Calibración del coeficiente de expansión de óxidos ...................................................................................220

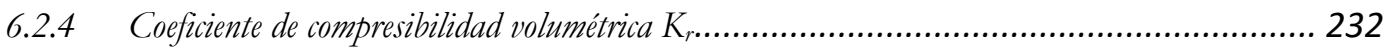

6.2.4.1 Estudio de sensibilidad de la variable .....................................................................................................22 232

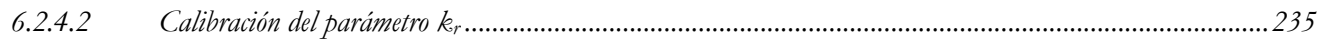

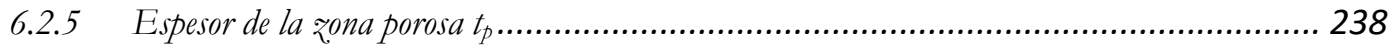

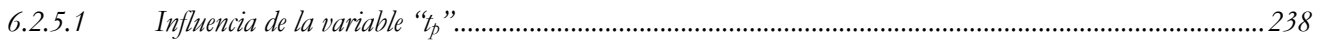

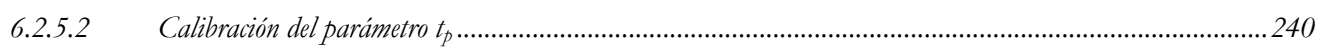

V.2.6 Volumen de óxidos en fisuras ................................................................. 245

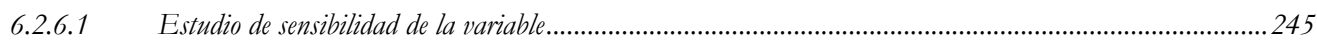

6.2.6.2 Calibración del porcentaje de óxidos en fisuras.......................................................................................248

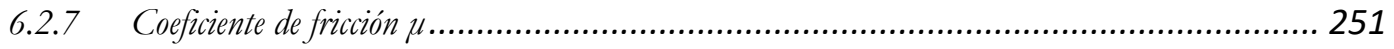

6.2.8 Conclusiones parciales sobre la calibración de parámetros relativos a la corrosión.................. 254

6.3 INFLUENCIA DE LA CAPACIDAD DE CONFINAMIENTO DEL HORMIGÓN...............................255

6.3.1 Propiedades geométricas del hormigón: Espesor de recubrimiento .................................... 255

6.3.2 Propiedades mecánicas del hormigón: Resistencia a compresión ..................................... 259

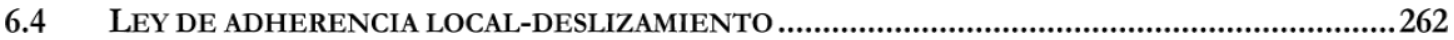

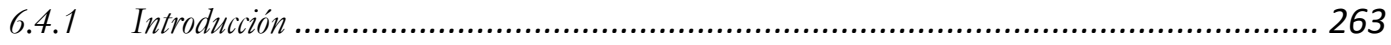

6.4.2 Influencia del deslizamiento en el coeficiente de fricción ............................................ 266

6.4.3 Calibración de la ley de adherencia local-deslizamiento .............................................. 268

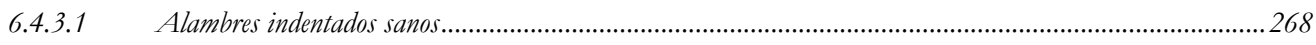

6.4.3.1.1 Relación deslizamiento-desplazamiento radial en alambres indentados sanos: $1^{\text {er }}$ Enfoque 270

6.4.3.1.2 Verificación del modelo: 1er enfoque.

6.4.3.1.3 Relación deslizamiento-desplazamiento radial en alambres indentados sanos: $2^{\circ}$ Enfoque 274 


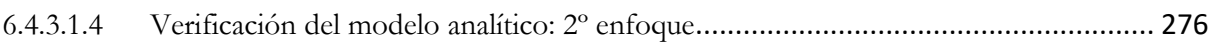

6.4.3.2 Alambres indentados con procesos de corrosión......................................................................................277

6.4.3.2.1 Relación deslizamiento-desplazamiento radial con corrosión: 1er Enfoque ................ 278

6.4.3.2.2 Relación deslizamiento-desplazamiento radial con corrosión: $2^{\circ}$ Enfoque.................. 282

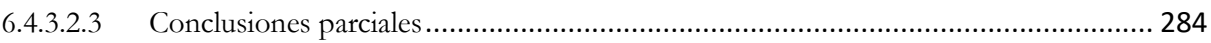

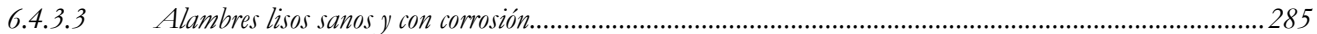

\section{VALIDACIÓN DEL MODELO ANALÍTICO DE ADHERENCIA DE ALAMBRES

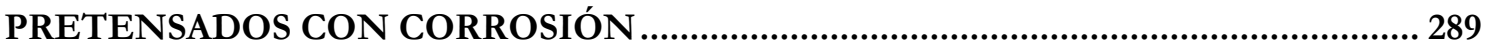

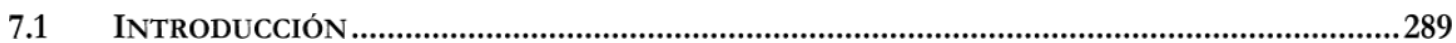

7.2 PROCEDIMIENTO EXPERIMENTAL ...........................................................................................289

7.2.1 Tipología de las probetas ....................................................................................28

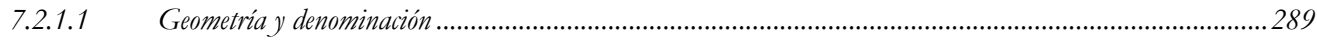

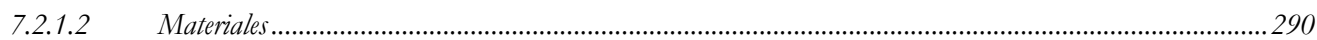

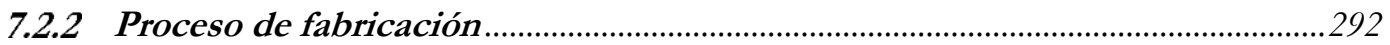

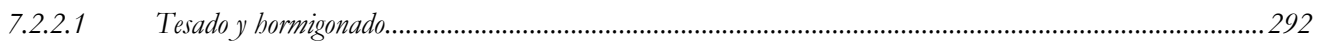

7.2.2.2 Hormigonado, curado y transferencia del pretensado ...............................................................................293

7.2.3 Instrumentación de las vigas pretensadas ............................................................293

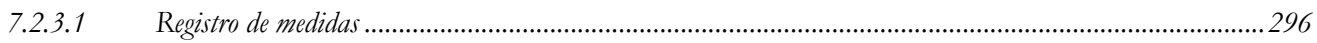

7.2.4 Proceso de corrosión ..................................................................................................226

7.2.4.1 Método integral acelerado ..........................................................................................................297

7.2.4.2 Proceso de corrosión acelerada .................................................................................................................298

7.2.4.3 Instrumentación y toma de datos en vigas pretensadas con corrosión .........................................................299

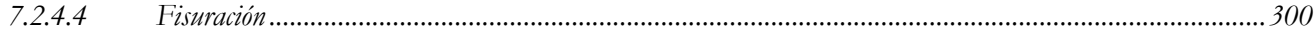

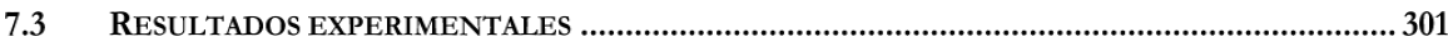

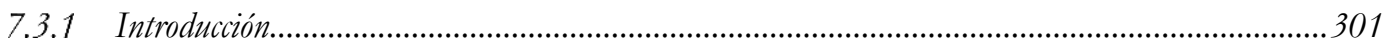

7.3.1.1 Determinación de la longitud de transferencia mediante el perfil de deformaciones .........................................301 
TESIS DOCTORAL INFLUENCLA DE LA CORROSIÓN EN LA ADHERENCLA DE ALAMBRES EN ELEMENTOS PRETENSADOS DE HORMIGÓN

7.3.1.2 Determinación de la longitud de transferencia mediante el deslizamiento de los alambres en el extremo...........302

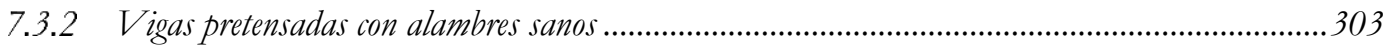

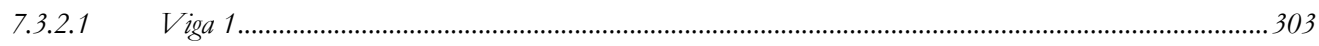

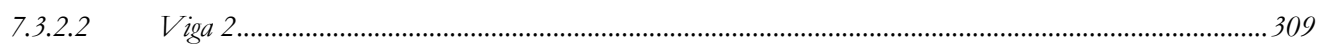

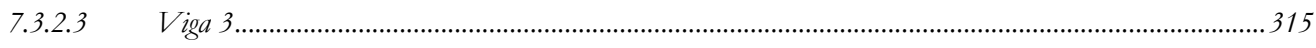

7.3.2.4 Viga 4

7.3.2.5 Discusión de los resultados obtenidos sobre vigas pretensadas sin corrosión ................................................326

7.3.2.6 Comparacion de los resultados experimentales con el modelo analítico ........................................................331

7.3.3 Vigas pretensadas con alambres corroídos .................................................................................337

7.3.3.1 Comparacion de los resultados experimentales en vigas pretensadas con corrosión con el modelo analítico ........339

7.4 INFLUENCIA DE LAS DISTINTAS VARIABLES EN LA LONGITUD DE TRANSFERENCIA ..............343

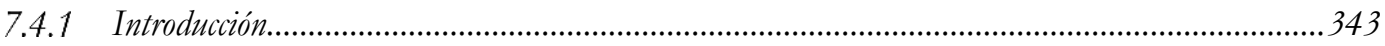

7.4.2 Influencia del diámetro del alambre $\phi$ en la longitud de transferencia.......................................344

7.4.3 Influencia de la resistencia a compresión del hormigón en la longitud de transferencia....................347

7.4.4 Influencia del recubrimiento $(c / \phi)$ en la longitud de transferencia ..............................................351

7.4.5 Influencia de la fuerza de pretensado inicial en la longitud de transferencia.................................354

7.4.6 Influencia de la velocidad de destesado en la longitud de transferencia .........................................357

7.4.7 Influencia de la rugosidad superficial del alambre (coeficiente de fricción) en la longitud de transferencia 358

7.4.8 Influencia de la altura de las indentaciones en la longitud de transferencia 359

7.4.9 Influencia de la corrosión en la longitud de transferencia 360

7.4.9.1 Porcentaje limite de pérdida de sección por corrosión $X_{\text {lim }}$........................................................................363

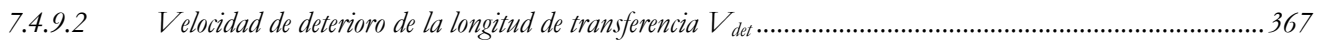

\subsection{EXPRESIÓN SIMPLIFICADA PARA EL CÁLCULO DE LONGITUDES DE TRANSFERENCIA EN} ELEMENTOS PRETENSADOS

7.5.1 Longitud de transferencia en alambres sanos .......................................................................370

7.5.1.1 Análisis de regresión múltiple........................................................................................................... 371 
7.5.2 Longitud de transferencia en alambres corroídos.....

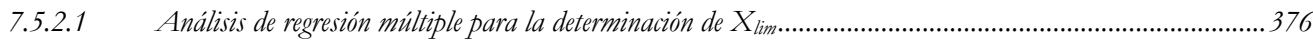

7.5.2.2 Análisis de regresión múltiple para la determinación de $V_{\text {det }}$....................................................................379

7.5.3 Comparación con campañas experimentales de otros investigadores.............................................382

7.5.4 Comparación con códigos estructurales existentes.....................................................................385

8. CONCLUSIONES, CONTRIBUCIONES Y LÍNEAS FUTURAS

8.1.1 Conclusiones generales.

8.1.2 Conclusiones relativas al modelo analítico para la determinación de tensiones radiales en secciones de hormgón armado con procesos de corrosión

8.1.3 Conclusiones relativas a los ensayos de arrancamiento ..............................................................391

8.1.4 Conclusiones relativas a la calibración de parámetros del modelo analítico

8.1.5 Conclusiones relativas a la adherencia de alambres sanos y corroídos en hormigón pretensado.

8.1.6 Conclusiones relativas al modelo para la determinación de la longitud de transferencia en elementos pretensados de hormigón

8.1.7 Conclusiones relativas a las expresiones simplificadas para la determinación de la longitud de transferencia

\section{CONCLUSIONS, CONTRIBUTIONS AND FUTURE RESEARCH LINES}

8.1 ConCLUSIONS

8.1.1 General conclusions

8.1.2 Conclusions derived from the analytical model for the determination of radial stresses in reinforced concrete cross-sections with corrosion. 
TESIS DOCTORAL INFLUENCLA DE LA CORROSIÓN EN LA ADHERENCLA DE ALAMBRES EN ELEMENTOS PRETENSADOS DE HORMIGÓN

8.1.4 Conclusions derived from the calibration of parameters of the analytical model..............................406

8.1.5 Conclusions about bond of non-corroded and corroded wires in prestressed concrete........................408

8.1.6 Conclusions derived from the model for the determination of the transfer length in prestressed concrete elements 411

8.1.7 Conclusions derived from the simplified expressions for the determination of the transfer length ....412

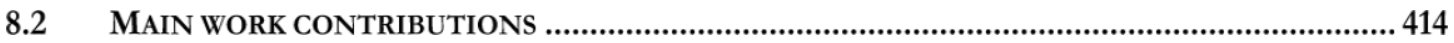

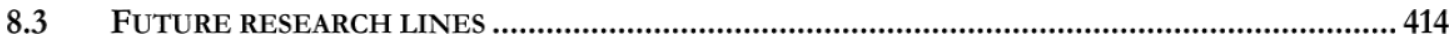

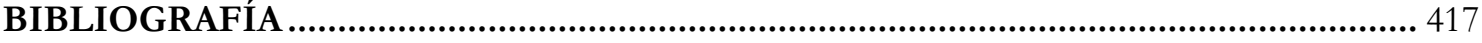




\section{ÍNDICE DE FIGURAS}

Figura 2-1. Relación entre el cambio en las tensiones de la barra y la tensión de adherencia media (J. K. Wight et al, 2012 (Wight, et al., 2012))....

Figura 2-2 Efecto de cuña en el extremo de un elemento pretensado de hormigón. Imagen tomada de (Abdelatif, et al., 2015)

Figura 2-3 Fuerzas de acuñamiento y fisuración inicial en la interfaz acero-hormigón. Primeras etapas del proceso de arrancamiento.

Figura 2-4. Configuración del ensayo de arrancamiento (pull-out). Figura tomada de la Norma UNE-EN 10080:2006 (AENOR-AEN/CTN 36, 2006).....

Figura 2-5. Configuración del ensayo de arrancamiento (pull-out) según S.Moustafa (1974). Figura tomada de Logan (1997).

Figura 2-6 Esquema de ensayo de adherencia push-in ( (Keuning, et al., 1962).....

Figura 2-7 Distribución de tensiones de adherencia a lo largo de la longitud de transferencia para la determinación del coeficiente a en la expresión de Guyon (1953)

Figura 2-8 Determinación de la longitud de transferencia mediante el método del 95\% de la media de las deformaciones máximas (Russell \&o Burns, 1996)....

Figura 2-9 Esquema del ensayo ECADA. Figura tomada de (Marti-V argas, et al., 2003) (Marti-Vargas, et al., 2006).....

Figura 2-10 Tensión de adherencia normalizada $\tau_{b} / f_{c}$ frente a relación recubrimiento/diámetro $c / \phi$. Figura tomada de Schenkel \& Vogel (1997).....

Figura 2-11 Tensión de adherencia para barras lisas de $19 \mathrm{~mm}$ (3/4 inch.) de diametro en función del recubrimiento, para distintos deslizamientos. (Abrams, 1913)

Figura 2-12 Influencia del recubrimiento sobre la carga de fallo por adherencia en ensayos pull-out. Balwin y Clark, 1995. ......

Figura 2-13 Influencia del recubrimiento c sobre la tensión de adherencia $\tau_{b}$ de barras lisas. Ensayos llevados a cabo por Metzinger, H. (izquierda) y Kelly, J. (derecha) (Cairns, 2004).....

Figura 2-14 Influencia del recubrimiento c sobre la tensión de adherencia $\tau_{b}$ de barras lisas. Ensayos llevados a cabo por Spring, D. (izquierda) y V ranas and Gorst (derecha) (Cairns, 2004)........................................................33

Figura 2-15 Influencia del recubrimiento sobre la tensión de adherencia normalizada (Feldman, 2006) ................33

Figura 2-16 Longitud de transferencia relativa $\psi$ en función del recubrimiento efectivo $c_{\text {eff }}$ (den Ujil, 1998)...........34 
TESIS DOCTORAL INFLUENCLA DE LA CORROSIÓN EN LA ADHERENCLA DE ALAMBRES EN ELEMENTOS PRETENSADOS DE HORMIGÓN

Figura 2-17 Correlación existente entre la longitud de transferencia y el diámetro del cordón de pretensado. Resultados obtenidos mediante modelo numérico. (Oh, et al., 2014).....

Figura 2-18 Correlación existente entre la longitud de transferencia y la tensión de pretensado efectiva. Resultados obtenidos mediante modelo numérico. (Oh, et al., 2014).

Figura 2-19 Evolución tras la transferencia del pretensado del perfil de deformaciones del hormigón (Vázquez-Herrero, et al., 2013)

Figura 2-20 Método de ensayo para determinación del coeficiente de fricción desarrollado por Olofsson \& Holmgren (1994)

Figura 2-21 Evolución del coeficiente de fricción en función de la presión normal de confinamiento, según Tastani \& Pantaropoulou (2010).

Figura 2-22 Reacción catódica en medios alcalinos y neutros (Andrade, 2007).....

Figura 2-23 Tipología de la corrosión de la armadura en el hormigón armado: generalizada (carbonatación), localizada (cloruros) y corrosión bajo tensión (en elementos pretensados) (Andrade, 1989).

Figura 2-24 Modelo de vida útil de Tuntti (1982). Figura tomada de (Rodríguez, et al., 2014) 46

Figura 2-25 Consecuencias de la corrosión de las armaduras en el comportamiento estructural. Figura adaptada de Andrade et al. (1993)

Figura 2-26 Morfología de la sección residual de la armadura, adaptado de (CONTECVET, 2001)...... .49

Figura 2-27 Consumo de masa de acero $(\mathrm{kg} / \mathrm{m})$ y velocidad de consumo de masa de acero (kg/year) para la ley de Faraday, el modelo propuesto por Liu y Weyers (1998), y el modelo propuesto por Balafas y Burgoyne (2010). Gráficas tomadas de (Balafas \& Burgoyne, 2010).

Figura 2-28 Relación entre el espesor de ataque por corrosión en la armadura $P_{x}$ y la abertura de fisura en el hormigón, w. Figura tomada de (Rodríguez, et al., 2014).

Figura 2-29 Modelo bilineal de evolución del ancho de fisura bajo una velocidad de corrosión constante. Figura tomada de Pedrosa \& Andrade (2017)

Figura 2-30 Etapa elástica no fisurada y elástica parcialmente fisurada. Figura tomada de (Martín-Pérez̧, 1999)59

Figura 2-31 Variación de la tensión de adherencia con el avance de la corrosión (CEB-FIB_Task Group 2.5, 2000). Figura tomada de (Prieto Rábade, 2014)..... 61

Figura 2-32 Configuración de ensayos de pull-out excéntrico en los trabajos de Rodriguez et al. Figura tomada de (Rodríguez, et al., 1994-b).....

Figura 2-33 Curvas adherencia deslizamiento para armaduras sanas y corroídas (Penetración de ataque entre 76 y $80 \mu \mathrm{m})$. Influencia de la posición durante el hormigonado. Figura tomada de (Cairns, et al., 2006)....... 
Figura 2-34 Influencia de la corrosión en la tensión de adberencia residual $\tau_{b, \text { max, res }}$ en: a) barras situadas en "situación favorable" durante el hormigonado (parte baja del encofrado); b) barras situadas en "situación desfavorable" durante el hormigonado (parte alta del encofrado). Figuras tomadas de (Cairns, et al., 2006)

Figura 2-35 Evolución de la tensión máxima de adherencia $\tau_{b, \max }$ con el aumento de pérdida de sección por corrosión para barras lisas sin cercos (S1) y con cercos (S2), y para barras corrugadas sin cercos (D1) y con cercos (D2). Figura tomada de (Fang, et al., 2004)

Figura 2-36 Diagramas adherencia-deslizamiento para barras lisas (izquierda) y barras corrugadas (derecha), según Jim y Zhao (2001). El número creciente que acompaña a cada una de las curvas señala el nivel de deterioro por corrosión.

Figura 2-37 Influencia de la fuerza de pretensado en distintas etapas de la fisuración por corrosión del hormigón: a) $\left.\varrho_{m}, b\right) \varrho_{p} y$ c) $\varrho_{m}$, para distintos espesores de recubrimiento. Figura tomada de Dai (Dai, et al., 2016)...................72

Figura 2-38 Deterioro de la tensión residual de adherencia con el aumento del nivel de corrosión. Figura tomada de Wang et al. (2017-b)

Figura 2-39 Evolución del coeficiente de fricción $\mu$ frente a: a) Penetración de ataque por corrosión x; b) deslizamiento s. Según (Chermin \& Val, 2009).

Figura 2-40 Evolución del coeficiente de fricción $\mu$ frente a la penetración de ataque (Lundgren, 2005).....

Figura 2-41 Esquema de ensayo de fricción hormigón/ acero para distintos grados de corrosión (Cairns, et al., 2007)

Figura 2-42 Fuerzas laterales necesarias para deslizar las probetas de hormigón en ensayo de fricción de Cairns (2007). Resultados para distintas fuerzas normales y grados de corrosión.....

Figura 2-43 Coeficiente $n$ entre el volumen de los productos de corrosión $\Delta V r$ y el volumen de acero virgen consumido en el proceso $\Delta$ Vscorr. Figura basada en (Nielsen, 1976)

Figura 2-44 Espesor equivalente to de los productos de corrosión difundidos en función de: a) Resistencia a compresión del hormigón; y b) el tiempo para el inicio de la fisuración tor (Chernin, et al., 2010).....

Figura 2-45 Concentración media de productos de corrosión en la matriz cementicia que rodea el acero para: (a) Mortero con relación a/c $=0.5$ e intensidad de corrosión $I_{\text {corr }}=10 \mu \mathrm{A} / \mathrm{cm}^{2}$; (b) Mortero con relación a/ $c=0.3$ e intensidad de corrosión $I_{\text {corr }}=100 \mu \mathrm{A} / \mathrm{cm}^{2}$. [Figura tomada de (Michel, et al., 2014)].

Figura 2-46 Gradientes de porosidad en la región de contacto entre pasta de cemento y acero para distintas edades del hormigón y una relación a/ $c=0,49$ (Horne, et al., 2007).

Figura 3-1 Tensiones tangenciales tb (izquierda-arriba) y radiales or (izquierda-abajo) a lo largo de la superficie cilindrica del alambre. Ley de fricción de Coulomb aplicada a un elemento difeencial de superficie dS. 
TESIS DOCTORAL INFLUENCLA DE LA CORROSIÓN EN LA ADHERENCLA DE ALAMBRES EN ELEMENTOS PRETENSADOS DE HORMIGÓN

Figura 3-2 Modelo de Hognestad para comportamiento de hormigón en compresión. .95

Figura 3-3 Modelo tensión-deformación bilineal para comportamiento de hormigón en tracción.

Figura 3-4 Descripción geométrica del problema. Radios iniciales y finales del acero y del cilindro de pared gruesa de hormigón

Figura 3-5 Elemento diferencial de espesor dr y amplitud d0 en un cilindro de pared gruesa con presión interna p..99

Figura 3-6 Equilibrio de fuerzas en elemento diferencial perteneciente a un cilindro de pared gruesa. 100

Figura 3-7 Deformaciones radiales y circunferenciales del elemento diferencial considerado.....

Figura 3-8 Tensiones radiales y circunferenciales en el cilindro de pared gruesa/recubrimiento de hormigón. Comparación con las resistencias medias a tracción y compresión del hormigón.

Figura 3-9 Discretización del cilindro de pared gruesa en la dirección radial para resolución del problema mediante diferencias finitas....

Figura 3-10 Discretización del desplazamiento radial $\Delta r_{p}$ para el análisis incremental del problema

Figura 3-11 Sección transversal de un alambre corroído con óxidos expansivos (Andrade, et al., 1993) (Martín-Pérez, 2014)

Figura 3-12 Expansión de los productos de corrosión a lo largo del recubrimiento de hormigón. Interpretación de figura contenida en (Balafas \& Burgoyne, 2011) y (Martin-Pérez, 2014)..... 118

Figura 3-13 Cambio en a) el radio del alambre $\Delta r p p$ y b) en el radio interno del cilindro de hormigón $\Delta r c p$, debido a la presión p ejercida por los productos de corrosión.

Figura 3-14 Diferentes estados de fisuración del recubrimiento de hormigón.....

Figura 3-15 Espacio liberado por fisuras triangulares $\Delta V_{\text {crack }}$ en región fisurada del recubrimiento. Fisuras triangulares y trapezoidales.

Figura 3-16 Tensiones radiales de confinamiento originadas por la configuración del ensayo de pull-out.....

Figura 3-17 Tensiones de adherencia a lo largo de un alambre de acero embebido en hormigón (Martín-Pérez, 2014)

Figura 3-18 Ley de adherencia local-deslizamiento utilizada en el modelo.....

Figura 3-19 Deformaciones, deslizamientos y tensiones de adherencia a lo largo de un alambre de acero embebido en hormigón en la Etapa I

Figura 3-20 Deformaciones, deslizamientos y tensiones de adherencia a lo largo de un alambre de acero embebido en hormigón en la Etapa II. 140 
Figura 3-21 Deformaciones, deslizamientos y tensiones de adherencia a lo largo de un alambre de acero embebido en hormigón en la Etapa III

Figura 3-22 Deformaciones, deslizamientos y tensiones de adherencia a lo largo de un alambre de acero embebido en bormigón en la Etapa IV

Figura 3-23 Diagrama del sólido libre aplicado a la barra pretensada entre los puntos de discretización iy i+1. Figura tomada de (Oh, et al., 2006)

Figura 3-24 Variación de las deformaciones en el hormigón y en el acero a lo largo de la longitud de transferencia.

Figura 4-1 Seccion longitudinal y transversal de las distintas probetas: Series L20/I20; Series L10/I10 y Series L4/I4

Figura 4-2 Proceso de fabricación del hormigón y ensayos de caracterización en estado fresco: densidad, aire ocluido y cono de Abrams

Figura 4-3 Encofrados de aglomerado de particulas, con barras de acero embebidas, listos para el vertido del hormigón.

Figura 4-4 Vertido y curado de hormigón en cámara búmeda.....

Figura 4-5 Esquema del procedimiento de corrosión acelerada de alambres, mediante procedimiento galvanoestático.

Figura 4-6 Configuración del procedimiento de corrosión acelerada sobre las probetas del ensayo de pull-out.

Figura 4-7 Esquema de configuración del método integral acelerado aplicado a las probetas del ensayo de pull-out161

Figura 4-8 Imágenes de la configuración del método integral acelerado aplicado a las probetas del ensayo de pull-out, en el laboratorio de corrosión del IETcc.

Figura 4-9 Esquema del dispositivo de ensayo y adquisición de datos en los ensayos de arrancamiento o pull-out. 163

Figura 4-10 Instrumentación de las probetas durante el ensayo de pull-out. 164

Figura 4-11 Proceso de decapado de alambres. Baño de ultrasonidos en disolución de ácido clorbidrico (izq.). Barra antes y después del decapado (Der.).

Figura 4-12 Extracción de las barras de las probetas de hormigón tras el ensayo de pull-out.....

Figura 5-1 Profundidad de ataque Px, diámetro inicial de la armadura sana y diámetro residual de la armadura corroida. Manual CONTECVET (EC Innovation Program IN30902I, 2001).....

Figura 5-2 Diagramas predicción-realización de pérdidas de sección teórica frente a pérdidas de sección real para alambres indentados (irq.) y lisos (der.) 172 
TESIS DOCTORAL INFLUENCLA DE LA CORROSIÓN EN LA ADHERENCLA DE ALAMBRES EN ELEMENTOS PRETENS ADOS DE HORMIGÓN

Figura 5-3 Fisuración de las probetas inducida por la corrosión, previa al ensayo de pull-out.

Figura 5-4 Comparación entre la ley de tensión de adherencia local-deslizamiento y la ley de tensión de adherencia media-deslizamiento procedente del ensayo.

Figura 5-5 Fuerzas de acuñamiento y fisuración inicial en la interfaz acero-bormigón. Primeras etapas del proceso de arrancamiento.

Figura 5-6 Configuración geométrica de las probetas I4 con alambres indentados y recubrimiento mecánico de $20 \mathrm{~mm}$ $(c / \phi=4)$

Figura 5-7 Diagramas tensión de adherencia media-deslizamiento en extremo no cargado en probetas de la Serie I4: con alambres indentados, $20 \mathrm{~mm}$ de recubrimiento minimo y distintos grados de corrosión teórica [a) $0 \%$ de pérdida de sección; a) $2 \%$ de pérdida de sección 7 . 181

Figura 5-8 Diagramas tensión de adherencia media-deslizamiento en extremo no cargado en probetas de la Serie I4: con alambres indentados, $20 \mathrm{~mm}$ de recubrimiento minimo y distintos grados de corrosión teórica [c] 10\% de pérdida de sección; d) $20 \%$ de pérdida de sección]

Figura 5-9 Configuración geométrica de las probetas 110 con alambres indentados y recubrimiento mecánico de $50 \mathrm{~mm}$ $(c / \phi=10)$

Figura 5-10 Diagramas tensión de adherencia media-deslizamiento en extremo no cargado en probetas de la Serie I10: con alambres indentados, 50 mm de recubrimiento minimo y sin corrosión [a) Hormigón 3; a) Hormigón 5] ..... 183

Figura 5-11 Diagramas tensión de adherencia media-deslizamiento en extremo no cargado en probetas de la Serie I10: con alambres indentados, $50 \mathrm{~mm}$ de recubrimiento minimo y distintos grados de corrosión teórica [c] $2 \%$ de pérdida de sección; d) 5\% de pérdida de sección]

Figura 5-12 Diagramas tensión de adherencia media-deslizamiento en extremo no cargado en probetas de la Serie I10: con alambres indentados, $50 \mathrm{~mm}$ de recubrimiento mínimo y distintos grados de corrosión teórica [e] 10\% de pérdida de sección;f) $20 \%$ de pérdida de sección 7 .

Figura 5-13 Configuración geométrica de las probetas I20 con alambres indentados y recubrimiento mecánico de 100 $m m(c / \phi=20)$.

Figura 5-14 Diagramas tensión de adherencia media-deslizamiento en extremo no cargado en probetas de la Serie I20: con alambres indentados, $100 \mathrm{~mm}$ de recubrimiento minimo y sin corrosión [a) $f_{c m}=51,67 \mathrm{MPa}$; a) $b: f_{c m}=48,40$ $\left.M P a, c: f_{c m}=43,72 \mathrm{MPa}\right]$

Figura 5-15 Diagramas tensión de adherencia media-deslizamiento en extremo no cargado en probetas de la Serie I20: con alambres indentados, $100 \mathrm{~mm}$ de recubrimiento minimo y corrosión teórica de un 2\% de pérdida de sección [c) b: $\left.f_{c m}=48,40 \mathrm{MPa}, c: f_{c m}=43,72 \mathrm{MPa}\right]$

Figura 5-16 Diagramas tensión de adherencia media-deslizamiento en extremo no cargado en probetas de la Serie L4: con alambres lisos, $20 \mathrm{~mm}$ de recubrimiento minimo y distintos grados de corrosión teórica [a) $0 \%$ de pérdida de sección; a) $2 \%$ de pérdida de sección]. 
Figura 5-17 Diagramas tensión de adherencia media-deslizamiento en extremo no cargado en probetas de la Serie L4: con alambres lisos, $20 \mathrm{~mm}$ de recubrimiento mínimo y distintos grados de corrosión teórica (c) 5\% de pérdida de sección; d) $10 \%$ de pérdida de sección].

Figura 5-18 Diagramas tensión de adherencia media-deslizamiento en extremo no cargado en probetas de la Serie L4: con alambres lisos, $20 \mathrm{~mm}$ de recubrimiento minimo y 20\% de pérdida de sección teórica.....

Figura 5-19 Configuración geométrica de las probetas L4 con alambres lisos y recubrimiento mecánico de $20 \mathrm{~mm}$ $(c / \phi=4)$..

Figura 5-20 Configuración geométrica de las probetas L10 con alambres lisos y recubrimiento mecánico de $50 \mathrm{~mm}$ $(c / \phi=10)$.

Figura 5-21 Diagramas tensión de adherencia media-deslizamiento en extremo no cargado en probetas de la Serie L10: con alambres lisos, $50 \mathrm{~mm}$ de recubrimiento minimo y distintos grados de corrosión teórica [a] 0\% de pérdida de sección; a) 2\% de pérdida de sección]....

Figura 5-22 Diagramas tensión de adherencia media-deslizamiento en extremo no cargado en probetas de la Serie L10: con alambres lisos, $50 \mathrm{~mm}$ de recubrimiento mínimo y distintos grados de corrosión teórica [ c) 5\% de pérdida de sección; d) $10 \%$ de pérdida de sección].

Figura 5-23 Diagramas tensión de adherencia media-deslizamiento en extremo no cargado en probetas de la Serie L10: con alambres lisos, $50 \mathrm{~mm}$ de recubrimiento mínimo y 20\% de pérdida de sección teórica.

Figura 5-24 Configuración geométrica de las probetas L20 con alambres lisos y recubrimiento mecánico de $100 \mathrm{~mm}$ $(c / \phi=20)$.

Figura 5-25 Diagramas tensión de adherencia media-deslizamiento en extremo no cargado en probetas de la Serie L20: con alambres lisos, $100 \mathrm{~mm}$ de recubrimiento minimo, distintos grados de corrosión teórica [ a) 0\% de pérdida de sección; a) 2\% de pérdida de sección] y distintas resistencias medias a compresión (Sufijo -a: 67,10 MPa; Sufijo -b: $51,98 \mathrm{MPa})$

Figura 5-26 Diagramas tensión de adherencia media-deslizamiento en extremo no cargado en probetas de la Serie L20: con alambres lisos, $100 \mathrm{~mm}$ de recubrimiento mínimo, distintos grados de corrosión teórica [a) 5\% de pérdida de sección; a) 10\% de pérdida de sección] y distintas resistencias medias a compresión (Sufijo -a: 67,10 MPa; Sufijo b: 51,98 $\mathrm{MPa}$ )

Figura 5-27 Comparativa de las tensiones máximas de adherencia normalizada para distintos niveles de corrosión obtenidas de las series de ensayos I4, I10, L4 y L10.

Figura 5-28 Esquema de la evolución de las tensiones máximas de adherencia con el aumento de la corrosión, para distintas relaciones $c / \phi$ y distintos acabados superficiales del acero (liso e indentado)...... 196

Figura 5-29 Tensión máxima de adherencia normalizada $\tau_{b, \max } / f_{c t m}[\mathrm{MPa} / \mathrm{MPa}]$ (izquierda) y Tensión máxima de adherencia $\tau_{b, \max }[\mathrm{MPa}]($ derecha) en alambres lisos e indentados sin corroer, para distintos recubrimientos. 198 
TESIS DOCTORAL INFLUENCLA DE LA CORROSIÓN EN LA ADHERENCLA DE ALAMBRES EN ELEMENTOS PRETENS ADOS DE HORMIGÓN

Figura 5-30 Tensiones máximas de adherencia normalizada $\tau_{b, \max } / f_{c t m}[\mathrm{MPa} / \mathrm{MPa}]$ en alambres lisos (izquierda) $e$ indentados (derecha), para distintas pérdidas de sección por corrosión y distintos recubrimientos

Figura 5-31 Influencia de la resistencia a compresión $f_{\text {cm }}$ en la tensión máxima de adherencia. Alambres lisos (izquierda) e indentados (derecha) sin corrosión.

Figura 5-32 Influencia de la resistencia a compresión $f_{c m}$ en la tensión máxima de adherencia. Alambres lisos (izquierda) e indentados (derecha) con corrosión variable.

Figura 5-33 Relación entre la geometria superficial de los alambres indentados y las gráficas tensión de adherencia media-deslizamiento obtenidas en los ensayos de pull-out. Alambres sin corrosión.

Figura 5-34 Correlación existente entre los deslizamientos $s_{1}$ y $s_{2}$ y el aumento de los niveles de corrosión. Serie de ensayos 110

Figura 5-35 Correlación existente entre los desliæ: $s_{1}, s_{2}$ y $s_{3}$ con el aumento de los niveles de corrosión en los ensayos sobre alambres lisos. 211

Figura 5-36 Estallamiento del recubrimiento de hormigón en la Probeta L4-20-2..

Figura 6-1 Comparación de la penetración de ataque por corrosión $P_{x}$ a lo largo del tiempo distintos modelos de tasa de producción de óxidos: Ley de Faraday; Modelo de Lin y Weyers; y Modelo de Balafas y Burgoyne.

Figura 6-2 Influencia del modelo de tasa de penetr. de ataque en la evolución de distintos parámetros en relación con el aumento de la pérdida de sección por el proceso de corrosión: A) Tensión radial $\sigma_{n}$; B) Evolución del frente de fisuración; C) Deformaciones radiales $\varepsilon_{r}$ en la interfaz acero-hormigón; D) Deformaciones circunferenciales $\varepsilon_{\theta}$ en la interfaz acerohormigón; E) Evolución de los módulos de elasticidad radial $E_{r}$ (compresión) y circunferencial $E_{\theta}$ (tracción) y F) Deformaciones circunferenciales $\varepsilon_{\theta}$ y ancho de fisura w en el perímetro del cilindro de hormigón.

Figura 6-3 Comparación de la evolución en el tiempo de la tensión de adherencia normalizada $\tau_{b, \max } / f_{\mathrm{ctm}}[\mathrm{MPa} / \mathrm{MPa}]$, para distintos modelos de tasa de penetración de ataque, con respecto a los resultados experimentales. 221

Figura 6-4 Diagramas predicción-realización de la pérdida de sección del acero, para los tres modelos de tasa de penetración de ataque considerados: Ley de Faraday, Modelo de Lin \& Weyers y Modelo de Balafas \& Burgoyne.

Figura 6-5 Comparación del radio interno del cilindro de hormigón, con respecto a la penetración de ataque $P_{x}$, para distintos coeficientes de expansión de óxidos n.

Figura 6-6 Influencia del coef. de expansión de óxidos $n$ en la evolución de distintos parámetros en relación con el aumento de la pérdida de sección por el proceso de corrosión: A) Tensión radial $\sigma_{r} ;$ B) Evolución del frente de fisuración; C) Deformaciones radiales $\varepsilon_{r}$ en la interfaz acero-bormigón; D) Deformaciones circunferenciales $\varepsilon_{\theta}$ en la interfaz acerohormigón; E) Evolución de los módulos de elasticidad radial $E_{r}$ (compresión) y circunferencial $E_{\theta}$ (tracción) y F) Deformaciones circunferenciales $\varepsilon_{\theta}$ y ancho de fisura w en el perímetro del cilindro de hormigón. 228 
Figura 6-7 Penetración de ataque $P_{x}$ necesaria para alcanzar la tensión radial máxima $\sigma_{r, m a x}$ (izq.) y tensión máxima radial normalizada $\sigma_{r, \text { max }} / f_{c t m}$ (der.) en función del coeficiente de expansión de óxidos $n$, para distintas relaciones $c / \phi$.

Figura 6-8 Penetración de ataque $P_{x}$ necesaria para fisurar el recubrimiento en función del coeficiente de expansión de óxidos $n$, para distintas relaciones $c / \phi$

Figura 6-9 Comparación de los resultados experimentales con los obtenidos mediante el modelo analítico. Evolución de las máximas tensiones de adherencia normalizadas $\tau_{b, \max } / f_{c t m}[\mathrm{MPa} / \mathrm{MPa}]$, con respecto a la a la pérdida de sección por corrosión [\%], para distintas relaciones $c / \varphi$ y distintos coeficientes de expansión de óxidos $n$.....

Figura 6-10 Diagrama predicción-realización de las tensiones de adherencia normalizadas $\tau_{b, \max } / f_{c t m}[\mathrm{MPa} / \mathrm{MPa}]$, para coeficientes de expansión de óxidos $n$ con valor 2,0 y 2,5.

Figura 6-11 Comparación del radio interno del cilindro de hormigón, con respecto a la penetración de ataque $P_{x}$, para distintos $K_{r}$. . ...

Figura 6-12 Influencia del módulo de deformabilidad $K_{r}$ en la evolución de distintos parámetros en relación con el aumento de la pérdida de sección por el proceso de corrosión: A) Tensión radial $\sigma_{r}$; B) Evolución del frente de fisuración; C) Deformaciones radiales $\varepsilon_{r}$ en la interfaz acero-hormigón; D) Deformaciones circunferenciales $\varepsilon_{\theta}$ en la interfaz acerohormigón; E) Evolución de los módulos de elasticidad radial $E_{r}$ (compresión) y circunferencial $E_{\theta}$ (tracción) y F) Deformaciones circunferenciales $\varepsilon_{\theta} y$ ancho de fisura $w$ en el perímetro del cilindro de hormigón.

Figura 6-13 Comparación de la evolución de la tensión de adherencia normalizada $\tau_{b, \max } / f_{\text {ctm }}[\mathrm{MPa} / \mathrm{MPa}]$, con respecto a la pérdida de sección transversal [\%] debida a la corrosión, para distintos valores del parámetro $K_{r} . . . .236$

Figura 6-14 Diagrama predicción-realización de las tensiones de adherencia normalizadas $\tau_{b, \max } / f_{c t m}[\mathrm{MPa} / \mathrm{MPa}]$, para modulos de compresibilidad volumétrica de los óxidos $K r$ con valor 0,5 GPa y 1,0 GPa.

Figura 6-15 Influencia del espesor de la banda porosa tp en la evolución de distintos parámetros en relación con el aumento de la pérdida de sección por el proceso de corrosión: A) Tensión radial $\sigma_{n}$; B) Evolución del frente de fisuración; C) Deformaciones radiales $\varepsilon_{r}$ en la interfaz acero-hormigón; D) Deformaciones circunferenciales $\varepsilon_{\theta}$ en la interfaz acerohormigón; E) Evolución de los módulos de elasticidad radial $E_{r}$ (compresión) y circunferencial $E_{\theta}$ (tracción) y F) Deformaciones circunferenciales $\varepsilon_{\theta} y$ ancho de fisura $w$ en el perímetro del cilindro de hormigón.

Figura 6-16 Comparación del porcentaje de difusión de óxidos a través de la interfaz. (izquierda) y del porcentaje de productos de corrosión que ejercen presión en el recubrimiento (derecha), con respecto a la distancia a la superficie del acero, para distintas leyes: Constante (Liu \& W eyers, 1998), Lineal y Parabólica (propuesta de esta tesis)....... 241

Figura 6-17 Representación de los distintos modelos analizados en esta: Constante (Liu \& Weyers, 1998), a la izquierda, Lineal, en el centro, y Parabólica (propuesta de esta tesis), a la derecha.

Figura 6-18 Comparación de la evolución de las tensiones radiales, con respecto a la penetración de ataque $P_{x}$, para distintos modelos de capa porosa: Constante (Liu \& Weyers, 1998), Lineal y Parabólico (propuesta de esta tesis). 
TESIS DOCTORAL INFLUENCLA DE LA CORROSIÓN EN LA ADHERENCLA DE ALAMBRES EN ELEMENTOS PRETENS ADOS DE HORMIGÓN

Figura 6-19 Comparación de la evolución de la tensión de adherencia normalizada $\tau_{b, \max } / f_{\text {ctm }}[\mathrm{MPa} / \mathrm{MPa}]$, con respecto a la pérdida de sección transversal [\%] debida a la corrosión, para distintos valores de espesor equivalente de capa porosa.

Figura 6-20 Diagrama predicción-realización de las tensiones de adherencia normalizadas $\tau_{b, \text { max }} / f_{c t m}[M P a / M P a]$,

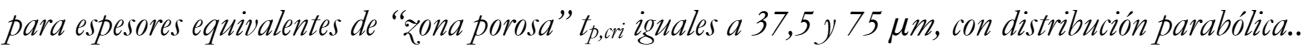

Figura 6-21 Influencia del volumen de óxidos en fisuras, en la evolución de distintos parámetros, en relación con el aumento de la pérdida de sección por el proceso de corrosión: A) Tensión radial $\sigma_{r} ;$ B) Evolución del frente de fisuración; C) Deformaciones radiales $\varepsilon_{r}$ en la interfaz acero-hormigón; D) Deformaciones circunferenciales $\varepsilon_{\theta}$ en la interfaz acerohormigón; E) Evolución de los módulos de elasticidad radial $E_{r}$ (compresión) y circunferencial $E_{\theta}$ (tracción) y F) Deformaciones circunferenciales $\varepsilon_{\theta}$ y ancho de fisura w en el perímetro del cilindro de bormigón.

Figura 6-22 Comparación de volimenes disponibles para la expansión de óxidos en función del nivel de pérdida de sección por corrosión, para distintos porcentajes de óxidos depositados en el espacio liberado por la fisuración

Figura 6-23 Evolución del volumen total de óxidos comprimidos $V_{r}$, del volumen total de fisuras $V_{\text {crack_total }}$ y del volumen de óxidos en fisuras $\Delta V_{\text {crack }}$ para distintos porcentajes de $\Delta V_{\text {crack }}$ con respecto $V_{\text {crack_total. Relación }}$ recubrimiento / diámetro $c / \varphi$ igual a 4 (izquierda) y 10 (derecha). 248

Figura 6-24 Comparación de la evolución de la tensión de adherencia normalizada $\tau_{b, \max } / f_{\mathrm{ctm}}[\mathrm{MPa} / \mathrm{MPa}]$, con respecto a la pérdida de sección transversal [\%] debida a la corrosión, para distintos porcentajes de volumen de óxidos en fisuras.

Figura 6-25 Diagrama predicción-realización de las tensiones de adherencia normalizadas $\tau_{b, \max } / f_{\text {ctm }}[\mathrm{MPa} / \mathrm{MPa}]$, para diferentes porcentajes de volumen de óxidos en fisuras con respecto al volumen total de éstas.

Figura 6-26 Comparación de la evolución de la tensión de adherencia normalizada $\tau_{b, \text { max }} / f_{\text {ctm }}[\mathrm{MPa} / \mathrm{MPa}]$, con respecto a la pérdida de sección transversal [\%] debida a la corrosión, para distintos coeficientes de fricción $\mu$....... 252

Figura 6-27 Diagrama predicción-realización de las tensiones de adherencia normalizadas $\tau_{b, \text { max }} / f_{\text {ctm }}[M P a / M P a]$, para diferentes coeficientes de fricción $\mu$.

Figura 6-28 Influencia de la relación recubrimiento/diámetro y del aumento de la pérdida de sección por el proceso de corrosión en la evolución de: A) Tensión radial $\sigma_{n}$ B) Evolución del frente de fisuración; C) Deformaciones radiales $\varepsilon_{r}$ en la interfaz acero-hormigón; D) Deformaciones circunferenciales $\varepsilon_{\theta}$ en la interfaz acero-hormigón; E) Evolución de los módulos de elasticidad radial $E_{r}$ (compresión) y circunferencial $E_{\theta}$ (tracción) y F) Deformaciones circunferenciales $\varepsilon_{\theta} y$ ancho de fisura w en el perímetro del cilindro de hormigón.

Figura 6-29 Influencia de la relación recubrimiento/ diámetro y del aumento de la pérdida de sección por el proceso de corrosión en la evolución de las tensiones de adherencia $\tau_{b}$.

Figura 6-30 Influencia de la resistencia a compresión del hormigón $f_{\text {cm }} y$ del aumento de la pérdida de sección por el proceso de corrosión en la evolución de: A) Tensión radial $\sigma_{r}$; B) Evolución del frente de fisuración; C) Deformaciones radiales $\varepsilon_{r}$ en la interfaz, acero-hormigón; D) Deformaciones circunferenciales $\varepsilon_{\theta}$ en la interfaz acero-hormigón; E) 
Evolución de los módulos de elasticidad radial $E_{r}$ (compresión) y circunferencial $E_{\theta}$ (tracción) y F) Deformaciones circunferenciales $\varepsilon_{\theta}$ y ancho de fisura $w$ en el perímetro del cilindro de hormigón.

Figura 6-31 Influencia de la resistencia a compresión $f_{c m}$ y del aumento de la pérdida de sección por el proceso de corrosión en la evolución de la tensión de adherencia $\tau_{b}$

Figura 6-32 Diagrama tensión de adherencia local-deslizamiento en las primeras etapas del proceso de arrancamiento.

Figura 6-33 Fuerzas de acuñamiento y fisuración inicial en la interfaz acero-hormigón. Primeras etapas del proceso de arrancamiento. 264

Figura 6-34 Fallo por Pull-out inducido por fisuración. Distribución de fuerzas y plano de deslizamiento.

Figura 6-35 Relación existente entre la carga aplicada P y la fuerza de fricción F, según Hibbeler (2010) 266

Figura 6-36 Modelo de deterioro del coeficiente de fricción con el deslizamiento. Coeficientes de fricción estático $\mu_{s}(0$ máximo $\mu_{\text {max }}$ ) y dinámico $\mu_{k}$ (o residual $\mu_{\text {res }}$. Figura tomada de Tastani \& Pantazopoulou (2010)....

Figura 6-37 Planos de deslizamiento en ensayo de arrancamiento. Geometría de los alambres indentados. 269

Figura 6-38 1er Enfoque: Evolución del estado tensional de un alambre indentado sin corrosión durante el ensayo de arrancamiento. Ley de adherencia local-deslizamiento.

Figura 6-39 Diagrama de adherencia-deslizamiento en extremo no cargado en ensayos sobre alambres indentados, serie I10. Comparación con el modelo propuesto (1er enfoque)

Figura 6-40 2० Enfoque: Evolución del estado tensional de un alambre indentado sin corrosión durante el ensayo de arrancamiento. Ley de adherencia local-deslizamiento.

Figura 6-41 Diagrama de adherencia-deslizamiento en extremo no cargado en ensayos sobre alambres indentados, serie I10. Comparación con el modelo propuesto (2 enfoque).

Figura 6-42 Comparación del estado tensional de un alambre indentado sano (arriba) y corroído (abajo) previo al comienzo del ensayo de arrancamiento. 278

Figura 6-43 Evolución de los diagramas de tensión de adherencia local-deslizamiento con el aumento del nivel de corrosión, según Lundgren (Lundgren, et al., 2012) y Schlune (Schlune, 2006). 278

Figura 6-44 Evolución de los diagramas de tensión de adherencia local-deslizamiento con el aumento del nivel de corrosión (1er enfoque) 280

Figura 6-45 Evolución de los diagramas de adherencia-deslizamiento en extremo no cargado según el modelo desarrollado (1 ${ }^{\circ}$ enfoque). Propiedades mecánicas y geométricas equivalentes a las de las probetas de la serie I10. . 281

Figura 6-46 Evolución de los diagramas de adherencia-deslizamiento en extremo no cargado según el modelo desarrollado $\left(2^{\circ}\right.$ enfoque). Propiedades mecánicas y geométricas equivalentes a las de las probetas de la serie I10. 282 
TESIS DOCTORAL INFLUENCLA DE LA CORROSIÓN EN LA ADHERENCLA DE ALAMBRES EN ELEMENTOS PRETENS ADOS DE HORMIGÓN

Figura 6-47 Comparación de los diagramas de adherencia-deslizamiento en extremo no cargado según el modelo desarrollado (2 $2^{\circ}$ enfoque) con los obtenidos en los ensayos sobre las probetas de la serie I10. Izquierda: $0 \%$ de pérdida teórica de sección. Derecha: 2\% de pérdida teórica de sección.

Figura 6-48 Comparación de los diagramas de adherencia-deslizamiento en extremo no cargado según el modelo desarrollado (2 enfoque) con los obtenidos en los ensayos sobre las. probetas de la serie I10. Izquierda: $5 \%$ de pérdida teórica de sección. Derecha: $10 \%$ de pérdida teórica de sección.

Figura 6-49 Diagramas de tensión de adherencia local-deslizamiento para alambres lisos sin corrosión.

Figura 6-50 Diagrama de adherencia-deslizamiento en extremo no cargado en ensayos sobre alambres lisos sin corrosión, serie L10. Comparación con el modelo propuesto, para distintos niveles de retracción. 288

Figura 7-1 Fotografias del ensayo de tracción indirecta del hormigón sobre probeta cilíndrica $10 \times 20 \mathrm{~cm}$ y de compresión sobre probeta cúbica $15 \times 15 \times 15 \mathrm{~cm}$

Figura 7-2 Configuración de ensayos sobre vigas pretensadas: a) Estribo pasivo de anclaje, b) Detalle de las cuñas de anclaje en el estribo pasivo, y c) Enfilado de cables en el interior de las vigas mediante desviadores.

Figura 7-3 Configuración de ensayos sobre vigas pretensadas: a) Tesado de alambres mediante gato bidraúlico, b) Fleximetro en estribode anclaje activo y c) Galgas extensiométricas adheridas a los alambres de pretensado.

Figura 7-4 Configuración de ensayos sobre vigas pretensadas: a) Hormigonado y vibrado de las probetas, b) Superficie superior de las probetas tras llaneado y c) Probetas desmoldadas.

Figura 7-5 Instrumentación de las vigas pretensadas: a) Fleximetros (relojes comparadores analógicos) ubicados en cada uno de los alambre de las vigas, en ambos extremos, para control de los deslizamientos; y b) Ubicación de las bases de medida para extensometría manual en Viga 3.

Figura 7-6 Vigas A: A) Ubicación de los puntos de medida para extensiometría manual (Cara E) y B) Distribución de las galgas extensiométricas (Cara $G$ ). 295

Figura 7-7 Bañeras de metacrilato con disolución de cloruro sódico y cúprico a ambos lados de las vigas. 296

Figura 7-8 Configuración del método integral acelerado aplicado a las vigas pretensadas.

Figura 7-9 Cardenillo en suspensión sobre la disolución de cloruro sódico y cúprico.

Figura 7-10 Esquema de funcionamiento del procedimiento de corrosión acelerada.

Figura 7-11 Fotografia de las vigas pretensadas durante el proceso de corrosión acelerada.....

Figura 7-12 Evolución de la fisuración en la Viga 3 para distintas etapas del proceso de corrosión: antes del ensayo; y tras un 5\%, un 10\% y un $20 \%$ de pérdida de sección teórica por corrosión. 300

Figura 7-13 Corrección de los deslizamientos medidos por los fleximetros 303 
Figura 7-14 Evolución de la longitud de transferencia lt y de las deformaciones longitudinales $\varepsilon$ en la Viga 1, tras el destesado. Alambres sin corrosión. Deformaciones medidas con extensiometría manual.

Figura 7-15 Evolución de la longitud de transferencia lty de las deformaciones longitudinales $\varepsilon$ en la Viga 1, tras el destesado. Alambres sin corrosión. Deformaciones medidas con galgas extensiométricas.

Figura 7-16 Evolución de los deslizamientos de los alambres en los extremos A (iz..) y B (der.) de la Viga 1, tras el destesado. Alambres sin corrosión. Deslizamientos medidos con fleximetros.

Figura 7-17 Evolución de los valores medios de deformación $\varepsilon_{\max }$ en meseta central (irquierda) y de longitud de transferencia lt (derecha) en la Viga 1, tras el destesado. Alambres sin corrosión. Valores promedio de ambas caras.

Figura 7-18 Evolución de la longitud de transferencia lty de las deformaciones longitudinales $\varepsilon$ en la Viga 2, tras el destesado. Alambres sin corrosión. Deformaciones medidas con extensiometría manual.

Figura 7-19 Evolución de la longitud de transferencia lty de las deformaciones longitudinales $\varepsilon$ en la Viga 2, tras el destesado. Alambres sin corrosión. Deformaciones medidas con galgas extensiométricas.

Figura 7-20 Evolución de los deslizamientos de los alambres en los extremos A (izq.) y B (der.) de la Viga 2, tras el destesado. Alambres sin corrosión. Deslizamientos medidos con fleximetros.

Figura 7-21 Evolución de los valores medios de deformación $\varepsilon_{\max }$ en meseta central (irquierda) y de longitud de transferencia lt (derecha) en la Viga 2, tras el destesado. Alambres sin corrosión. Valores promedio de ambas caras.

Figura 7-22 Evolución de la longitud de transferencia lt y de las deformaciones longitudinales $\varepsilon$ en la Viga 3, tras el destesado. Alambres sin corrosión. Deformaciones medidas con extensiometría manual. 316

Figura 7-23 Evolución de la longitud de transferencia lt y de las deformaciones longitudinales $\varepsilon$ en la Viga 3, tras el destesado. Alambres sin corrosión. Deformaciones medidas con galgas extensiométricas.

Figura 7-24 Evolución de los deslizamientos de los alambres en los extremos A (izq.) y B (der.) de la Viga 3, tras el destesado. Alambres sin corrosión. Deslizamientos medidos con fleximetros.

Figura 7-25 Evolución de los valores medios de deformación $\varepsilon_{\max }$ en meseta central (izquierda) y de longitud de transferencia lt (derecha) en la Viga 3, tras el destesado. Alambres sin corrosión. Valores promedio de ambas caras.

Figura 7-26 Evolución de la longitud de transferencia lty de las deformaciones longitudinales $\varepsilon$ en la Viga 4, tras el destesado. Alambres sin corrosión. Deformaciones medidas con extensiometría manual.

Figura 7-27 Evolución de la longitud de transferencia lty de las deformaciones longitudinales $\varepsilon$ en la Viga 4, tras el destesado. Alambres sin corrosión. Deformaciones medidas con galgas extensiométricas. 322 
TESIS DOCTORAL INFLUENCLA DE LA CORROSIÓN EN LA ADHERENCLA DE ALAMBRES EN ELEMENTOS PRETENS ADOS DE HORMIGÓN

Figura 7-28 Evolución de la longitud de transferencia lty de las deformaciones longitudinales $\varepsilon$ en la Viga 4, tras el destesado. Alambres sin corrosión. Deformaciones medidas con galgas extensiométricas.

Figura 7-29 Evolución de los valores medios de deformación $\varepsilon_{\max }$ en meseta central (izquierda) y de longitud de transferencia lt (derecha) en la Viga 3, tras el destesado. Alambres sin corrosión. Valores promedio de ambas caras. 325

Figura 7-30 Evolución de los valores medios de deformación $\varepsilon_{\max }$ en meseta central (irquierda) y de longitud de transferencia lt (derecha) en las vigas ensayadas, tras el destesado. Alambres sin corrosión. 328

Figura 7-31 Evolución de los valores medios de deslizamiento $\delta$ y del coeficiente a en las vigas ensayadas, tras el destesado.

Figura 7-32 Evolución media de la longitud de transferencia lt y de las deformaciones longitudinales $\varepsilon$ en todas las vigas ensayadas, tras el destesado. Alambres sin corrosión. Deformaciones medidas con galgas extensiométricas y extensometría manual.. 331

Figura 7-33 Comparación del perfil de deformaciones instantáneas tras el destesado ( $t=0$ días) y de las longitudes de transferencia ly obtenidos en los ensayos con los resultados arrojados por el modelo analitico. Alambres sin corrosión.

Figura 7-34 Comparación de los resultados experimentales con el perfil de deformaciones instantáneas tras el destesado $(t=0$ dias) obtenido mediante el modelo analítico, en el Extremo A. Alambres sin corrosión. 334

Figura 7-35 Comparación de los resultados experimentales con el perfil de deformaciones instantáneas tras el destesado $(t=0$ días) obtenido mediante el modelo analitico, en el Extremo B. Alambres sin corrosión. 335

Figura 7-36 Comparación de las leyes de tensión de adherencia a lo largo de la viga según el modelo analítico y el ajuste trilineal AMS de los resultados experimentales. Alambres sin corrosión. 336

Figura 7-37 Comparación de las leyes de tensión de adherencia a lo largo de la viga según el modelo analítico y el ajuste trilineal AMS de los resultados experimentales. Alambres sin corrosión.

Figura 7-38 Promedio de la evolución de las deformaciones longitudinales $\varepsilon_{c}$ del hormigón, para distintas pérdidas de sección teórica por corrosión. Medidas obtenidas con galgas extensiométricas.

Figura 7-39 Comparación de la evolución de las deformaciones en el hormigón obtenidas en los ensayos con los resultados arrojados por el modelo analitico. Alambres con corrosión.

Figura 7-40 Comparación de la evolución de las deformaciones en el hormigón, obtenidas en los ensayos y modificadas para mostrar las atribuibles exclusivamente a la corrosión, con los resultados arrojados por el modelo analítico. Alambres con corrosión. 342

Figura 7-41 Evolución de $l_{t}(a)$, de los deslizamientos en el extremo $\delta_{d}(b)$, del coeficiente a (c), del perfil de deformaciones en el hormigón $\varepsilon_{c}(d) y$ de las tensiones de adherencia $\tau b$ (e) para distintos diámetros del alambre $\phi$ y distintos niveles de corrosión en el hormigón. Resultados arrojados por el modelo analítico. 345 
Figura 7-42 Incrementos relativos de la longitud de transferencia lifrente a incrementos relativos (a) y cambios absolutos (b) del diámetro del alambre de pretensado $\phi$

Figura 7-43 Evolución de $l_{t}(a)$, de los deslizamientos en el extremo $\delta_{d}(b)$, del coeficiente a (c), del perfil de deformaciones en el hormigón $\boldsymbol{\varepsilon}_{c}(d)$ y de las tensiones de adherencia $\tau b$ (e) para distintas resistencia a compresión del hormigón y diferentes niveles de corrosión en el hormigón. Resultados arrojados por el modelo analítico. 348

Figura 7-44 Incrementos relativos de la longitud de transferencia l frente a incrementos relativos (a) y cambios absolutos (b) de la resistencia del hormigón. 350

Figura 7-45 Evolución de $l_{t}(a)$, de los deslizamientos en el extremo $\delta_{d}(b)$, del coeficiente a (c), del perfil de deformaciones en el hormigón $\boldsymbol{\varepsilon}_{c}$ (d) y de las tensiones de adherencia $\tau b$ (e) para distintas relaciones recubrimiento/diámetro $c / \phi$ y diferentes niveles de corrosión. Resultados arrojados por el modelo analitico.

Figura 7-46 Proporcionalidad de la longitud de transferencia lt frente a la relación recubrimiento/diámetro (a). Incrementos relativos de la longitud de transferencia l frente a la relación recubrimiento/diámetro (b).

Figura 7-47 Evolución de $l_{t}(a)$, de los deslizamientos en el extremo $\delta_{d}(b)$, del coeficiente a (c), del perfil de deformaciones en el hormigón $\boldsymbol{\varepsilon}_{c}\left(\right.$ d) y de las tensiones de adherencia $\tau b\left(\right.$ e) para distintas fuerzas de pretensado inicial $f_{p, 0} y$ diferentes niveles de corrosión. Resultados arrojados por el modelo analítico.

Figura 7-48 Proporcionalidad de la longitud de transferencia $l_{t}$ frente a tensión de pretensado inicial $\sigma_{p, 0}(a)$. Incrementos relativos de la longitud de transferencia $l_{t}$ frente a tensión de pretensado inicial $\sigma_{p, 0}(b)$. 356

Figura 7-49 Evolución de lt para distintos niveles de corrosión y diferentes coeficientes de velocidad de destesado $a_{p 1}$. Resultados arrojados por el modelo analítico. 357

Figura 7-50 Evolución de lt para distintos niveles de corrosión $y$ diferentes coeficientes de fricción $\mu$. Resultados arrojados por el modelo analítico. 358

Figura 7-51 Evolución de lt para distintas niveles de corrosión y diferentes alturas de indentación hr. Resultados arrojados por el modelo analítico. 360

Figura 7-52 Porcentaje de incremento relativo de la longitud de transferencia frente a la pérdida de sección por corrosión para distintos valores de diámetros de alambre $\phi$, de resistencias a compresión del hormigón $f_{c}$ de relaciones $c / \phi$ y de fuerza inicial de pretensado $\sigma_{p, 0}$ 361

Figura 7-53 Modelo de deterioro de la longitud de transferencia por procesos de deterioro por corrosión en alambres pretensados. Parámetros $X_{\lim } y V_{d e}$ 362

Figura 7-54 Evolución de $l_{t}(a)$, de los deslizamientos en el extremo $\delta_{d}(b)$, del coeficiente a (c), del perfil de deformaciones en el hormigón $\varepsilon_{c}(d) y$ de las tensiones de adherencia $\tau b(e)$ para distintas niveles de corrosión en vigas con alambres de $5 \mathrm{~mm}$ de diámetro y relación $\mathrm{c} \phi=4$. Resultados arrojados por el modelo analítico. 364 
TESIS DOCTORAL INFLUENCLA DE LA CORROSIÓN EN LA ADHERENCLA DE ALAMBRES EN ELEMENTOS PRETENS ADOS DE HORMIGÓN

Figura 7-55 Evolución del porcentaje de pérdida de sección por corrosión necesario para el inicio del deterioro de la longitud de transferencia $\left[X_{\text {lim] }}\right.$ en función de la relación recubrimiento/ diámetro $c / \phi(i z q$.) y del diámetro $\phi$ (der.)

Figura 7-56 Evolución del inicio del deterioro de la longitud de transferencia $X_{\text {lim }}$ en función de $\sigma_{p, 0}$

Figura 7-57 Evolución de $V_{\text {det }}$ con respecto a distintos parámetros geométricos y mecánicos.

Figura 7-58 Diagramas predicción-realización para las longitudes de transferencia calculadas con la ecuación de la regresión múltiple frente a las arrojadas por la expresión tras su simplificación.

Figura 7-59 Modelo de deterioro de la longitud de transferencia y expresiones simplificadas para su caracterización. 376

Figura 7-60 Diagramas predicción-realización para $X_{\text {lim }}$ calculadas con la ecuación de la regresión múltiple frente a las arrojadas por la expresión tras su simplificación...

Figura 7-61 Diagramas predicción-realización para $V_{\text {det }}$ calculadas con la ecuación de la regresión múltiple frente a las arrojadas por la expresión tras su simplificación.

Figura 7-62 Diagramas predicción-realización para las longitudes de transferencia en alambres corroídos calculadas con la expresión simplificada frente a las arrojadas por el modelo analítico., para varios niveles de pérdida de sección por corrosión.

Figura 7-63 Diagramas predicción-realización para las longitudes de transferencia obtenidas de los ensayos recogidos de la bibliografía frente a las arrojadas por la expresión simplificada.

Figura 7-64 Diagramas predicción-realización para las longitudes de transferencia obtenidas de los ensayos recogidos de la bibliografía frente a las arrojadas por las expresiones de los diferentes códigos analizados y la desarrollada en esta tesis....... 
TESIS DOCTORAL INFLUENCLA DE LA CORROSIÓN EN LA ADHERENCLA DE ALAMBRES EN ELEMENTOS PRETENS ADOS DE HORMIGÓN

\section{ÍNDICE DE TABLAS}

Tabla 2-1 Tabla 70.2.3 de la EHE-08)

Tabla 2-2 Variables que intervienen en la adherencia de alambres pretensados. Influencia en la longitud de transferencia. Tabla tomada de Vázquez. (2000).

Tabla 2-3 Longitudes de transferencia según el recubrimiento geométrico, el diámetro del cordón y la resistencia a compresión del hormigón (Ob \& Kim, 2000)

Tabla 2-4 Longitudes de transferencia según el diámetro del cordón y la resistencia a compresión del hormigón (Oh \& Kim, 2000).....

Tabla 2-5 Valores de kp para valores dados de coeficiente $n_{1 .}$

Tabla 2-6 Nivel de corrosión necesario para provocar el comienzo de la fisuración del recubrimiento. Tabla tomada de (CEB-FIB_Task Group 2.5, 2000).

Tabla 2-7 Capacidad adherente residual en armaduras corrugadas con penetraciones de ataque Px por corrosión de 0,25 mm (CEB-FIB_Task Group 2.5, 2000).

Tabla 2-8 Revisión de la influencia de la corrosión en el comportamiento adherente de barras lisas. Tabla inspirada en (Lundgren, 2007)

Tabla 2-9 Adherencia residual para armaduras corroídas, según Código Modelo 2010 (2011)

Tabla 2-10 Ratio n entre el volumen de los productos de corrosión $\Delta V r$ y el volumen de acero virgen consumido en el proceso $\Delta V$ scorr 78

Tabla 3-1 Valores del coeficiente $\alpha i$ en las ecuaciones (Eq. 3-121) y (Eq. 3-123) 130

Tabla 4-1 V ariables experimentales en la campaña de ensayos de pull-out. 154

Tabla 4-2. Dosificación de los hormigones empleados en los ensayos de pull-out. 158

Tabla 4-3. Propiedades en estado fresco de los hormigones utilizados en los ensayos de pull-out 158

Tabla 4-4 Resistencias a compresión y tracción de los hormigones empleados. 159

Tabla 4-5 Propiedades geométricas y mecánicas de los alambres lisos e indentados 159

Tabla 4-6 Niveles de pérdidas de sección teórica consideradas en los ensayos de corrosión acelerada...... 160

Tabla 4-7 Características de las diferentes series de ensayos de arrancamiento. 166 
Tabla 5-1 Perdidas de sección y profundidad de penetración de ataque por corrosión de la serie de ensayos I4, sobre alambres indentados con recubrimiento mecánico de $20 \mathrm{~mm}$ y distintos grados de corrosión.

Tabla 5-2 Perdidas de sección y profundidad de penetración de ataque por corrosión de la serie de ensayos I10, sobre alambres indentadas con recubrimiento mecánico de $50 \mathrm{~mm}$ y distintos grados de corrosión.

Tabla 5-3 Perdidas de sección y profundidad de penetración de ataque por corrosión de la serie de ensayos I20, sobre alambres indentados con recubrimiento mecánico de $100 \mathrm{~mm}$ y distintos grados de corrosión.

Tabla 5-4 Perdidas de sección y profundidad de penetración de ataque por corrosión de la serie de ensayos L4, sobre armaduras lisas con recubrimiento mecánico de $20 \mathrm{~mm}$ y distintos grados de corrosión. 171

Tabla 5-5 Perdidas de sección y profundidad de penetración de ataque por corrosión de la serie de ensayos L10, sobre armaduras lisas con recubrimiento mecánico de $50 \mathrm{~mm}$ y distintos grados de corrosión. 171

Tabla 5-6 Perdidas de sección y profundidad de penetración de ataque por corrosión de la serie de ensayos L20, sobre armaduras lisas con recubrimiento mecánico de $100 \mathrm{~mm}$ y distintos grados de corrosión. 172

Tabla 5-7 Valores estadísticos vinculados al ratio $M$ para los distintos acabados superficiales del acero..... 173

Tabla 5-8 Resumen de resultados de los ensayos sobre la serie de probetas I4 180

Tabla 5-9 Resumen de resultados de los ensayos sobre la serie de probetas 110 182

Tabla 5-10 Resumen de resultados de los ensayos sobre la serie de probetas I20 184

Tabla 5-11 Resumen de resultados de los ensayos sobre la serie de probetas L4......

Tabla 5-12 Resumen de resultados de los ensayos sobre la serie de probetas L10....... 188

Tabla 5-13 Resumen de resultados de los ensayos sobre la serie de probetas L20........ 190

Tabla 5-14 Datos relevantes en la evolución de la tensión de adherencia $\tau_{b}$ con el aumento de la corrosión 194

Tabla 5-15 Valor medio, desviación estandar, y coeficiente de variación (CoV) de la tensión máxima de adherencia $\tau_{b, \max }[\mathrm{MPa}]$ y de la tensión máxima de adherencia normalizada $\tau_{b, \max } / f_{c t m}[\mathrm{MPa} / \mathrm{MPa}]$, en los ensayos sobre alambres sanos. 198

Tabla 5-16 Valor medio, desviación estandar, y coeficiente de variación (CoV) de la tensión máxima de adherencia $\tau_{b, \max }[\mathrm{MPa}]$ y de la tensión máxima de adherencia normalizada $\tau_{b, \max } / f_{\mathrm{ctm}}[\mathrm{MPa} / \mathrm{MPa}]$, en los ensayos sobre alambres lisos e indentados, para distintos niveles de corrosión.....

Tabla 5-17 Valores medios de los parámetros que definen las leyes de adherencia media-deslizamiento $\tau_{b, \text { med }}-s . .204$

Tabla 5-18 Valores medios de los parámetros que definen las leyes de adherencia media-deslizamiento $\tau_{b, m e d}-s$ en los resultados de los ensayos sobre las probetas de la Serie I4 206 
TESIS DOCTORAL INFLUENCLA DE LA CORROSIÓN EN LA ADHERENCLA DE ALAMBRES EN ELEMENTOS PRETENSADOS DE HORMIGÓN

Tabla 5-19 Valores medios de los parámetros que definen las leyes de adherencia media-deslizamiento $\tau_{b, \text { med }}-s$ en los resultados de los ensayos sobre las probetas de la Serie I10

Tabla 5-20 Valores medios de los parámetros que definen las leyes de adherencia media-deslizamiento $\tau_{b, \text { med }}-s$ en los resultados de los ensayos sobre las probetas de la Serie I20

Tabla 5-21 Valores medios de los parámetros que definen las leyes de adherencia media-deslizamiento $\tau_{b, \text { med }}-s$ en alambres lisos sin corrosión.

Tabla 5-22 Valores medios de los parámetros que definen las leyes de adherencia media-deslizamiento $\tau_{b, m e d}-s$ en los resultados de los ensayos sobre las probetas de la Serie LA.

Tabla 5-23 Valores medios de los parámetros que definen las leyes de adherencia media-deslizamiento $\tau_{b, m e d}-s$ en los resultados de los ensayos sobre las probetas de la Serie L10.

Tabla 5-24 Valores medios de los parámetros que definen las leyes de adherencia media-deslizamiento $\tau_{b, m e d}-s$ en los resultados de los ensayos sobre las probetas de la Serie L20.

Tabla 6-1 Parámetros mecánicos y geométricos con valor fijo utilizados en el estudio paramétrico

Tabla 6-2 Rango de valores de los parámetros relativos a la corrosión utilizados en el estudio paramétrico

Tabla 6-3 Determinación de la tensión de adherencia: Valor de las variables utilizadas.

Tabla 6-4 V alor de los parámetros de entrada en el modelo analítico para la obtención de las gráficas de la Figura 6-3.

Tabla 6-5 Valores estadísticos vinculados al ratio $M$, para los distintos modelos analizados

Tabla 6-6 V alor de los parámetros de entrada en el modelo analitico para la obtención de las gráficas de la Figura $6-9$.

Tabla 6-7 V alor de los parámetros de entrada en el modelo analítico para la obtención de las gráficas de la Figura $6-13$

Tabla 6-8 Valor de los parámetros de entrada en el modelo analitico para la obtención de las gráficas de la Figura $6-19$

Tabla 6-9 V alor de los parámetros de entrada en el modelo analitico para la obtención de las gráficas de la Figura $6-24$

Tabla 6-10 Valores estadisticos vinculados al ratio M para los distintos coeficientes de fricción considerados

Tabla 6-11 Valor de los parámetros relativos a la corrosión calibrados para el modelo analítico de la presente tesis 
Tabla 7-1 Dosificación del hormigón utilizado para la fabricación de las vigas pretensadas

Tabla 7-2 Resistencia media a compresión, resitencia a tracción directa e indirecta y Módulo de Young del hormigón utilizado en los ensayos.

Tabla 7-3 Propiedades geométricas y mecánicas de los alambres de pretensado

Tabla 7-4 Campaña experimental sobre vigas pretensadas: Procesos, tiempos trasncurridos desde el hormigonado y registro de datos.

Tabla 7-5 Parámetros numéricos de los perfiles de deformación en la Viga 1. Deformaciones medidas con extensiometría manual [Cara E]

Tabla 7-6 Parámetros numéricos de los perfiles de deformación en la Viga 1. Deformaciones medidas con galgas extensiométricas.

Tabla 7-7 Incrementos de deformación a lo largo del tiempo en Viga 1. Deformaciones medidas con extensiometría manual.. 306

Tabla 7-8 Incrementos de deformación a lo largo del tiempo en Viga 1. Deformaciones medidas con galgas extensiométricas. 306

Tabla 7-9 Deslizamientos en los extremos registrados por los fleximetros de la Viga 1 307

Tabla 7-10 Incrementos de deformación a lo largo del tiempo en Viga 1. Deformaciones medidas con galgas extensiométricas. 308

Tabla 7-11 Parámetros numéricos de los perfiles de deformación en la Viga 2. Deformaciones medidas con extensiometría manual..

Tabla 7-12 Parámetros numéricos de los perfiles de deformación en la Viga 2. Deformaciones medidas con galgas extensiométricas.

Tabla 7-13 Incrementos de deformación a lo largo del tiempo en Viga 2. Deformaciones medidas con extensiometría manual.

Tabla 7-14 Incrementos de deformación a lo largo del tiempo en Viga 2. Deformaciones medidas con galgas extensiométricas

Tabla 7-15 Deslizamientos en los extremos A y B de la Viga 2, registrados por los flexímetros.....

Tabla 7-16 Incrementos de deformación a lo largo del tiempo en Viga 2. Deformaciones medidas con galgas extensiométricas

Tabla 7-17 Parámetros numéricos de los perfiles de deformación en la Viga 3. Deformaciones medidas con extensiometría manual. 
TESIS DOCTORAL INFLUENCLA DE LA CORROSIÓN EN LA ADHERENCLA DE ALAMBRES EN ELEMENTOS PRETENS ADOS DE HORMIGÓN

Tabla 7-18 Parámetros numéricos de los perfiles de deformación en la Viga 2. Deformaciones medidas con galgas extensiométricas.

Tabla 7-19 Incremento de las deformaciones a lo largo del tiempo en Viga 3. Deformaciones medidas con extensiometría manual.

Tabla 7-20 Incrementos de deformación a lo largo del tiempo en Viga 3. Deformaciones medidas con galgas extensiométricas.

Tabla 7-21 Deslizamientos en los extremos A y B de la Viga 3, registrados por los fleximetros.

Tabla 7-22 Incrementos de deformación a lo largo del tiempo en Viga 3. Deformaciones medidas con galgas extensiométricas.

Tabla 7-23 Parámetros numéricos de los perfiles de deformación en la Viga 3. Deformaciones medidas con extensiometría manual. 321

Tabla 7-24 Parámetros numéricos de los perfiles de deformación en la Viga 2. Deformaciones medidas con galgas extensiométricas. 323

Tabla 7-25 Incremento de las deformaciones a lo largo del tiempo en Viga 4. Deformaciones medidas con extensiometría manual......

Tabla 7-26 Incrementos de deformación a lo largo del tiempo en Viga 4. Deformaciones medidas con galgas extensiométricas.

Tabla 7-27 Deslizamientos en los extremos A y B de la Viga 4, registrados por los fleximetros.

Tabla 7-28 Incrementos de deformación a lo largo del tiempo en Viga 4. Deformaciones medidas con galgas extensiométricas.

Tabla 7-29 Resultados promedio de los ensayos sobre vigas pretensadas: media, desviación y coeficiente de variación

Tabla 7-30 V alor de las principales variables introducidas en el modelo analítico

Tabla 7-31 Promedio de la evolución de las deformaciones en el hormigón, obtenidas de los ensayos, para vigas con procesos de corrosión.

Tabla 7-32 V alor de los parámetros relativos a la corrosión calibrados para el modelo analítico de la presente tesis 340

Tabla 7-33 Deformaciones en el hormigón, obtenidas en los ensayos y modificadas para mostrar las atribuibles exclusivamente a la corrosión. 342

Tabla 7-34 V alor de las variables de la configuración tipo introducidas en el modelo analitico...... 344 
Tabla 7-35 Longitudes de transferencia $l_{t} y$ deslizamientos en el extremo $\delta_{d}$ para distintos diámetros del alambre de pretensado $\phi$ y distintos niveles de corrosión

Tabla 7-36 Longitudes de transferencia lt y de los desplazamientos en el extremo para distintas resistencias del hormigón fo y distintos niveles de corrosión.

Tabla 7-37 Longitudes de transferencia lt $y$ desplazamientos en el extremo de vigas $\delta_{d}$ para distintas relaciones recubrimiento/diámetro $c / \phi$ y distintos niveles de corrosión 351

Tabla 7-38 Longitudes de transferencia lt $y$ desplazamientos en el extremo de vigas $\delta_{d}$ para distintas fuerza de pretensado inicial $f_{p, o} y$ distintos niveles de corrosión.

Tabla 7-39 Longitudes de transferencia lt $y$ desplazamientos en el extremo de vigas $\delta_{d}$ para distintas fuerza de pretensado inicial $f_{p, o} y$ distintos niveles de corrosión.

Tabla 7-40 Parámetros que definen la evolución de la longitud de transferencia con el aumento de la corrosión para distintas relaciones recubrimiento/diámetro

Tabla 7-41 Porcentaje de pérdida de sección por corrosión necesaria para que se inicie el proceso de aumento de la longitud de transferencia..... 366

Tabla 7-42 X $X_{\text {lim }}$ para distintas tensiones iniciales de pretensado. 366

Tabla 7-43 $V$ det para distintos diámetros del alambre de pretensado $\phi$ 369

Tabla 7-44 $V$ det para distintas relaciones recubrimiento/diámetro $c / \phi$ 369

Tabla 7-45 $V_{\text {det }}$ para distintos diámetros tensiones iniciales de pretensado $\sigma_{p, 0}$

Tabla 7-46 $V$ det para distintos resistencias a compresión del hormigón $f_{c}$

Tabla 7-47 Coeficientes de determinación $\mathrm{R}^{2}$. Error estándar. Estadístico F.

Tabla 7-48 Coeficientes de regresión parcial estandarizados y no estandarizados. Error estándar. P-valores. Intervalos de confianza.

Tabla 7-49 Coeficientes de regresión parcial estandarizados y no estandarizados. Error estándar. P-valores. Intervalos de confianza.

Tabla 7-50 Coeficientes de determinación $\mathrm{R}^{2}$. Error estándar. Estadístico F.

Tabla 7-51 Coeficientes de regresión parcial estandarizados y no estandarizados. Error estándar. P-valores. Intervalos de confianza. 378

Tabla 7-52 Coeficientes de determinación $\mathrm{R}^{2}$. Error estándar. Estadístico F. 380 
TESIS DOCTORAL INFLUENCLA DE LA CORROSIÓN EN LA ADHERENCLA DE ALAMBRES EN ELEMENTOS PRETENSADOS DE HORMIGÓN

Tabla 7-53 Coeficientes de regresión parcial estandarizados y no estandarizados. Error estándar. P-valores. Intervalos de confianza. 380

Tabla 7-54 Parámetros geométricos y mecánicos de las campañas experimentales de referencia [Mitchell et al. (1993) y Ob \& Kim (2000)]. Comparación entre resultados experimentales y resultados obtenidos mediante la expresión

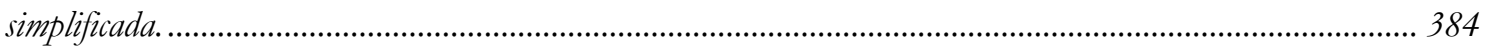

Tabla 7-55 Ecuación de la recta de regresión lineal, coeficiente de determinación, desviación estándar y coeficiente de variación de los resultados arrojados por las expresiones de los códigos analizados. 386 


\section{CAPÍTULO 1}

\section{Introducción}

\subsection{Motivación}

En elementos pretensados de hormigón, la adherencia entre el acero y el hormigón es una propiedad esencial para garantizar la integridad de la estructura. El acero de pretensar, ya sea en forma de alambres o cordones, tiene una doble función: permitir, por un lado, que parte de la tensión de tracción disponible hasta alcanzar su límite elástico se use para comprimir el hormigón, mejorando su comportamiento en servicio, y por otro lado, que una parte de su resistencia a tracción sea utilizada para colaborar con el hormigón en la resistencia de las cargas aplicadas externamente. Para garantizar esta doble función es crucial la existencia de tensiones de adherencia entre los alambres de acero y el hormigón, asegurando la transmisión de las fuerzas de pretensado tras el destesado y el anclaje del alambre durante la vida útil del elemento. Esta adherencia puede verse deteriorada por diferentes motivos, siendo uno de los más recurrentes el daño inducido por procesos de corrosión. Los productos de corrosión, cuyo volumen específico es mayor que el del acero original, generan tensiones en el hormigón que circunda el alambre y propician la aparición de fisuras y desprendimientos en el recubrimiento, reduciendo su capacidad de confinamiento y, consecuentemente, mermando las propiedades adherentes entre el hormigón y el acero.

El parámetro fundamental para caracterizar las propiedades adherentes existentes entre el acero pretensado y el hormigón es la longitud de transmisión o transferencia. La fuerza en un alambre o cordón de pretensado se transfiere por adherencia al hormigón durante la operación de destesado, de manera que las tensiones longitudinales en el acero varían desde cero, en el extremo de la viga, hasta su máximo valor más allá de la longitud de transferencia. Por tanto, la longitud de transferencia se define como aquella necesaria para que la totalidad de la fuerza de pretensado introducida en una armadura pretesa se transfiera por adherencia al hormigón. Esta longitud abarca la distancia existente desde el extremo libre de un elemento pretensado hasta la sección a partir de la cual la tensión en el alambre o cordón es constante, de modo que más allá de dicha sección la fuerza de pretensado mantiene su valor hasta la zona de transferencia del extremo opuesto, en que se produce el fenómeno en sentido inverso.

El cálculo y diseño de elementos pretensados de hormigón con armaduras pretesas requiere una evaluación realista de la longitud de transferencia. Por un lado, valores reducidos de la misma mejoran la capacidad resistente frente a esfuerzo cortante, debido al efecto favorable de las tensiones de compresión introducidas en la sección de hormigón, especialmente en los extremos del elemento, donde el cortante suele ser de mayor entidad. Por otro lado, la reducción de la longitud de transferencia lleva asociado un aumento de las tensiones transversales de tracción en los extremos del elemento, aumentando el riesgo de fisuración por estallido, por exfoliación o por hendimiento. Las expresiones para la caracterización de la longitud de transferencia recogidas en los códigos estructurales cuyo uso está más extendido[Eurocódigo 2; ACI 318-02; EHE-08; Model Code 2010] 
suelen considerar únicamente el efecto de algunas variables, como el diámetro del alambre o la fuerza de pretensado inicial, omitiendo otros parámetros, como la resistencia del hormigón o el espesor de recubrimiento, cuya influencia ha sido demostrada en numerosos trabajos. Además, en ningún caso, se cuantifica en qué medida afecta el ataque por corrosión a dicha longitud. Por tanto, es patente la necesidad de desarrollar un método racional que permita evaluar la adherencia, y consecuentemente la longitud de transferencia, en elementos pretensados de hormigón con distintas configuraciones geométricas y mecánicas, así como con distintos grados de corrosión.

A la vista de lo expuesto anteriormente, esta tesis se propone analizar, mediante la combinación de ensayos experimentales con un modelo analítico desarrollado a tal efecto, la adherencia de alambres pretensados, caracterizada mediante la longitud de transferencia, y su evolución al sufrir procesos de deterioro por corrosión.

\subsection{Objetivos}

Los objetivos de la tesis se concretan en los siguientes puntos:

- Determinar la influencia del recubrimiento, de la relación recubrimiento/diámetro, del acabado superficial de la armadura, de la calidad del hormigón y del grado de corrosión en la adherencia de armaduras lisas e indentadas.

- Investigar los procesos de degradación de la adherencia inducidos por la corrosión y cuantificar su influencia en el comportamiento de elementos pretensados de hormigón.

- Correlacionar los resultados obtenidos en ensayos de arrancamiento sobre alambres no tesados con las capacidades o características adherentes de los mismos en estructuras pretensadas.

- Desarrollar un modelo analítico, validado y calibrado por resultados experimentales, que permita simular el comportamiento adherente de los alambres en elementos pretensados de hormigón con procesos de degradación por corrosión.

- Realizar un estudio paramétrico de sensibilidad de variables para conocer la influencia de cada uno de los parámetros que intervienen en el fenómeno de la adherencia en elementos pretensados de hormigón, tanto en alambres sanos como en alambres con procesos de degradación por corrosión.

- Con base en el modelo analítico, y tras su verificación, desarrollar expresiones simplificadas para el cálculo de longitudes de transferencia en elementos pretensados de hormigón tanto con alambres sanos como corroídos, comparando los resultados obtenidos con campañas experimentales de otros investigadores y con los códigos estructurales cuyo uso está más extendido. 


\section{CAPÍTULO 2}

\section{Estado del Conocimiento}

\subsection{Introducción}

En elementos pretensados de hormigón, la adherencia entre el acero y el hormigón es un factor esencial para garantizar la integridad de la estructura. El acero de pretensar, ya sea en forma de alambres o cordones, tiene una doble función: por un lado, que parte de la tensión de tracción disponible hasta alcanzar el límite elástico del mismo se use para comprimir el hormigón, mejorando su comportamiento en servicio, por otro lado, que una parte de la resistencia a tracción sea utilizada para colaborar con el hormigón en la resistencia de las cargas aplicadas externamente. Para garantizar esta doble función es crucial la existencia de tensiones de adherencia $\tau_{b}$ entre los alambres de acero y el hormigón, posibilitando la transmisión de las fuerzas de pretensado tras el destesado y el anclaje del alambre durante la vida útil del elemento. Esta adherencia puede verse deteriorada por diferentes motivos, siendo uno de los más recurrentes el daño inducido por procesos de corrosión. En esta tesis se analiza, mediante la combinación de ensayos experimentales con un modelo analítico desarrollado a tal efecto, la adherencia de alambres pretensados y su evolución al sufrir procesos de deterioro por corrosión.

En el presente capítulo se lleva a cabo una revisión general del estado actual del conocimiento sobre la adherencia acero-hormigón y, en particular, sobre la adherencia de alambres pretensados y la influencia del fenómeno de la corrosión sobre la misma. Dado que la literatura al respecto es extensa, no se pretende un análisis completo y exhaustivo, sino sintetizar los conceptos generales y las variables que influyen en los aspectos concretos de la adherencia que son tratados en esta tesis, sirviendo de base para el contenido de los capítulos posteriores.

\subsection{Adherencia entre alambres pretensados y hormigón}

\subsubsection{Introducción}

La condición básica para que los alambres y el hormigón conformen un material estructural compuesto es que exista una adecuada adherencia entre ambos. Si el alambre en una viga no está adherido con el hormigón adyacente a lo largo de su longitud y no existe ningún tipo de anclaje en los extremos, la armadura será incapaz de asumir esfuerzos $\left(\sigma_{\mathrm{s}}=0\right)$ y la viga colapsará bajo cargas pequeñas, como si de una viga de hormigón en masa se tratara. Si no existe adherencia, pero por el contrario los alambres se encuentran anclados mecánicamente en los extremos de la viga, una vez que la misma entre en carga, la tensión del acero será constante a lo largo de toda su longitud $\left(\sigma_{s}=\right.$ constante), y la capacidad de carga de la viga mejorará ostensiblemente con respecto al caso anterior. Sin embargo, observando la distribución de tensiones, en este caso la viga actúa más como un arco biarticulado que como una auténtica viga. 
Las tensiones de adherencia deben estar presentes siempre que exista una variación de fuerzas o de tensiones a lo largo del alambre. Esto puede verse en el diagrama del sólido libre representado en Figura 2-1. Si $f_{s 2}$ es mayor que $f_{s 1}$, las tensiones de adherencia $\tau_{b}$ deben actuar en la superficie del alambre de sección circular, de diámetro $\phi$ y longitud $l$, para mantener el equilibrio de fuerzas. Estableciendo el equilibrio de fuerzas horizontales, se puede deducir que la tensión de adherencia media, $\tau_{b, a d h}$, es igual a la siguiente expresión (Eq. 2-1):

$$
T_{1}-T_{2}=\left(f_{s 2}-f_{s 1}\right) \cdot \frac{\pi \cdot \phi^{2}}{4}=\tau_{b, \text { med }} \cdot(\pi \cdot \phi) \cdot l
$$

Sabiendo que $\left(f_{s 2}-f_{s 1}\right)=\Delta f_{s}$, tenemos que (Eq. 2-1):

$$
\tau_{b, \text { med }}=\frac{\Delta f_{s} \cdot \phi}{4 \cdot l}
$$

Y suponiendo que $l$ es equivalente al espesor de un elemento diferencial en la dirección longitudinal del alambre, $d x$, esta ecuación puede ser escrita como sigue (Eq. 2-3):

$$
\frac{d f_{s}}{d x}=\frac{4 \cdot \tau_{b, m e d}}{\phi}
$$

donde $\tau_{b, m e d}$ es la tensión de adherencia media actuando en la longitud $d x$.

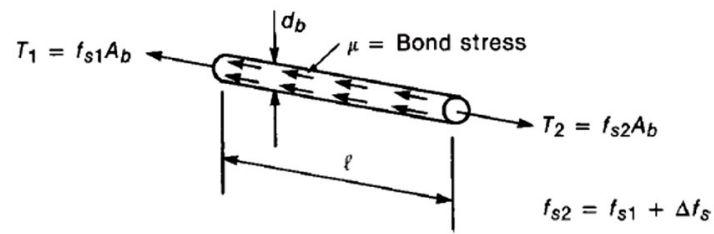

Figura 2-1. Relación entre el cambio en las tensiones de la barra y la tensión de adherencia media (J. K. Wight et al, 2012 (Wight, et al., 2012))

\subsubsection{Mecanismos de adherencia entre el hormigón y el acero pretensado}

Los mecanismos resistentes en los cuales está basado la adherencia acero-hormigón son bien conocidos, debido a los abundantes ensayos y estudios que se han llevado a cabo en los últimos cincuenta años. En 1967, los estudios de Lutz et Al. (1967), determinaron que la fuerza de arrancamiento en una barra de acero es transmitida al hormigón circundante por adherencia mediante tres mecanismos diferenciados: Adhesión, Fricción e Interacción mecánica entre el acero y el hormigón. El grado de contribución de cada uno de estos tres mecanismos está íntimamente ligado al acabado superficial del acero de pretensar considerado. Mientras que la adherencia en alambres 
lisos depende principalmente de los dos primeros mecanismos, aunque existe alguna interacción de origen mecánico debido a la microrugosidad de la superficie del acero (Feldman, 2006), las mayores prestaciones adherentes de los alambres indentados y de los cordones de pretensar se derivan mayoritariamente de la fricción y del engranamiento mecánico entre su perfil (indentado o helicoidal) y el hormigón circundante.

\subsubsection{Adhesión}

Este mecanismo hace referencia a la contribución a la adherencia que procede de la deformación elástica de la capa cementicia que circunda el acero (den Ujil, 1998). La adhesión, tanto química como física, viene acompañada por la interacción micromecánica (microinterlocking) entre las partículas cementicias y la rugosidad microscópica de la superficie del acero. Para valores bajos de tensión de adherencia, ubicados en el rango entre el 20 y el $80 \%$ de la resistencia a tracción del hormigón $f_{c t}$ $\left[\tau_{b}<(0,2-0,8) \cdot f_{c]}\right]$, la adherencia está asegurada principalmente por este mecanismo.

Se debe hacer notar que el deslizamiento del alambre en esta fase consta de dos partes, el deslizamiento relativo en la interfaz acero-hormigón y la deformación elástica, debida a las fuerzas transversales (shear deformations), de la capa cementicia que rodea el alambre (den Ujil, 1998). Por consiguiente, incluso si no existe deslizamiento relativo entre el alambre y el hormigón en contacto, puede medirse un cierto deslizamiento debido a las deformaciones tangenciales localizadas cerca de la interfaz.

El fallo de adhesión tiene lugar para deslizamientos relativos muy pequeños y es siempre de carácter frágil, de manera que una vez superado su límite, la tensión de adherencia debida al mecanismo de adhesión $\tau_{b, a d h}$ pasa a ser nula. En la transferencia del pretensado se producen deslizamientos significativos entre el hormigón y el acero, por lo que, en la práctica, debido a este comportamiento frágil, la adhesión apenas contribuye a la transferencia de la fuerza de pretensado ni colabora en el desarrollo de la adherencia para resistir las tensiones adicionales en el alambre procedentes de cargas externas. En elementos pretensados, la pérdida de adherencia debida al fallo de adhesión es inmediatamente reemplazada por otros mecanismos, como el de fricción.

\subsubsection{Fricción}

Tras el pequeño deslizamiento relativo del alambre que conlleva la rotura del mecanismo de adhesión, se manifiesta el mecanismo de adherencia por fricción. Esta fricción únicamente se desarrolla si existen tensiones de compresión radial $\sigma_{r}$ (Tepfers, 1973). La tensión radial $\sigma_{r}$ necesaria para poner en funcionamiento este mecanismo es proporcionada por la retracción del hormigón, por la rugosidad del plano de deslizamiento del alambre y por el acuñamiento de las partículas de cemento, así como a cambios dimensionales en la sección transversal del acero, derivados del coeficiente de Poisson (Efecto Hoyer).

El efecto Hoyer se denomina así debido a E. Hoyer quien, junto a E. Friedrich, investigó en 1939 el mecanismo que permitía que la fuerza de pretensado se transfiriera al hormigón, incluso en alambres lisos sin indentaciones ni corrugas (Hoyer \& Friedrich, 1939). Cuando el acero es pretensado, el alambre incrementa su longitud y su diámetro se reduce debido al coeficiente de Poisson. Tras el 
vertido y posterior endurecimiento del hormigón, el alambre es liberado y pierde la tensión inicial de pretensado $\sigma_{p, o}$, por lo que trata de acortar su longitud y expandirse lateralmente, recuperando su estado original. A esta expansión se opone el hormigón circundante, generándose tensiones radiales $\sigma_{r}$ en la interfaz acero-hormigón y activándose el mecanismo de fricción entre ambos materiales. Esta fricción actúa contra el acortamiento del alambre de pretensado y mantiene la barra en tracción. A este fenómeno, que mejora la adherencia entre el acero pretensado y el hormigón circundante, es al que se le conoce como efecto Hoyer.

Como resultado de este efecto, la tensión longitudinal en el acero aumenta gradualmente desde el extremo del elemento, donde es nula, hasta alcanzar un valor constante más allá de la denominada longitud de transferencia $l_{t}$. El efecto Hoyer es proporcional al cambio en la deformación longitudinal del alambre, lo que se traduce en una variación gradual del diámetro del alambre a lo largo de dicha longitud, tomando forma de cuña (Ver Figura 2-2). Paralelamente, la distribución de las tensiones de compresión en el hormigón sigue un patrón similar a la del acero, mientras que la tensión radial de compresión comienza con valores altos en el extremo y va decreciendo hasta alcanzar una zona de estabilización más allá de la longitud de transferencia.

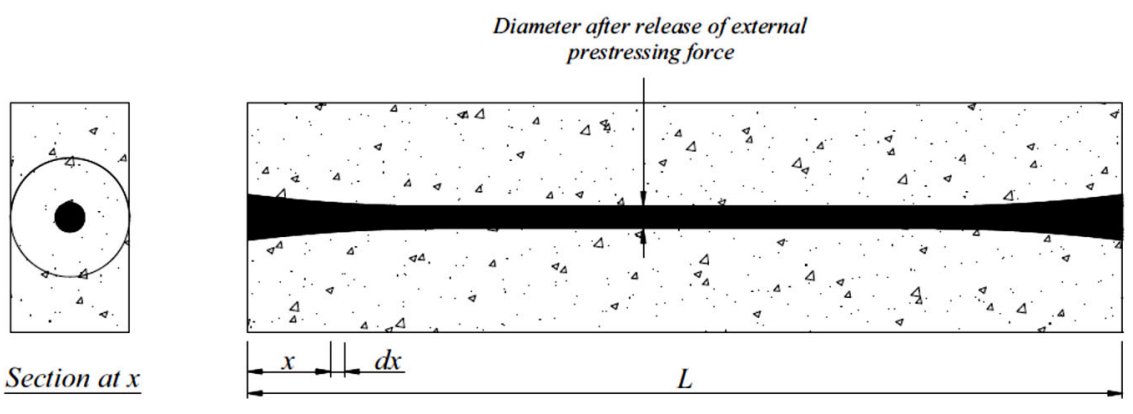

Figura 2-2 Efecto de cuña en el extremo de un elemento pretensado de hormigón. Imagen tomada de (Abdelatif, et al., 2015)

\subsubsection{Interacción mecánica (engranamiento mecánico) entre el acero y el hormigón}

El hormigón vertido sobre un cordón o alambre indentado endurece envolviendo completamente el perfil exterior del acero e imitando sus crestas y/o resaltos. Cuando se produce el destesado o el elemento pretensado es puesto en carga, el alambre trata de deslizar, encontrándose con la resistencia del hormigón así endurecido. Esta resistencia, que mejora las propiedades adherentes entre el hormigón y el acero, se denomina interacción o engranamiento mecánico.

Este mecanismo, que toma protagonismo tras producirse el fallo del mecanismo adherente de adhesión, está gobernado principalmente por el acuñamiento de las indentaciones o resaltos del acero en el hormigón circundante. Las fuerzas de acuñamiento, concentradas en el frente de las indentaciones, causan la formación de fisuras en forma de cono, que comienzan en el extremo de la meseta superior de los resaltos y delimitan los "voladizos" de hormigón que equilibran la fuerza de arrancamiento del alambre. Las fuerzas de acuñamiento, inclinadas con respecto al eje de la barra, puedan ser descompuestas en las direcciones paralela y perpendicular a dicho eje. La componente longitudinal, paralela al eje, equivale a la fuerza de adherencia $\tau$, mientras que la componente perpendicular induce la aparición de tensiones de compresión en la dirección radial $\sigma_{r} \mathrm{y}$ de tracción 
en la dirección circunferencial $\sigma_{\theta}$. Si estas últimas superan la resistencia a tracción del hormigón $f_{c t}$ la capacidad de confinamiento del recubrimiento queda comprometida y comienza la formación de fisuras radiales en el hormigón que pueden derivar en el fallo adherente del elemento (ver Figura 2-3).

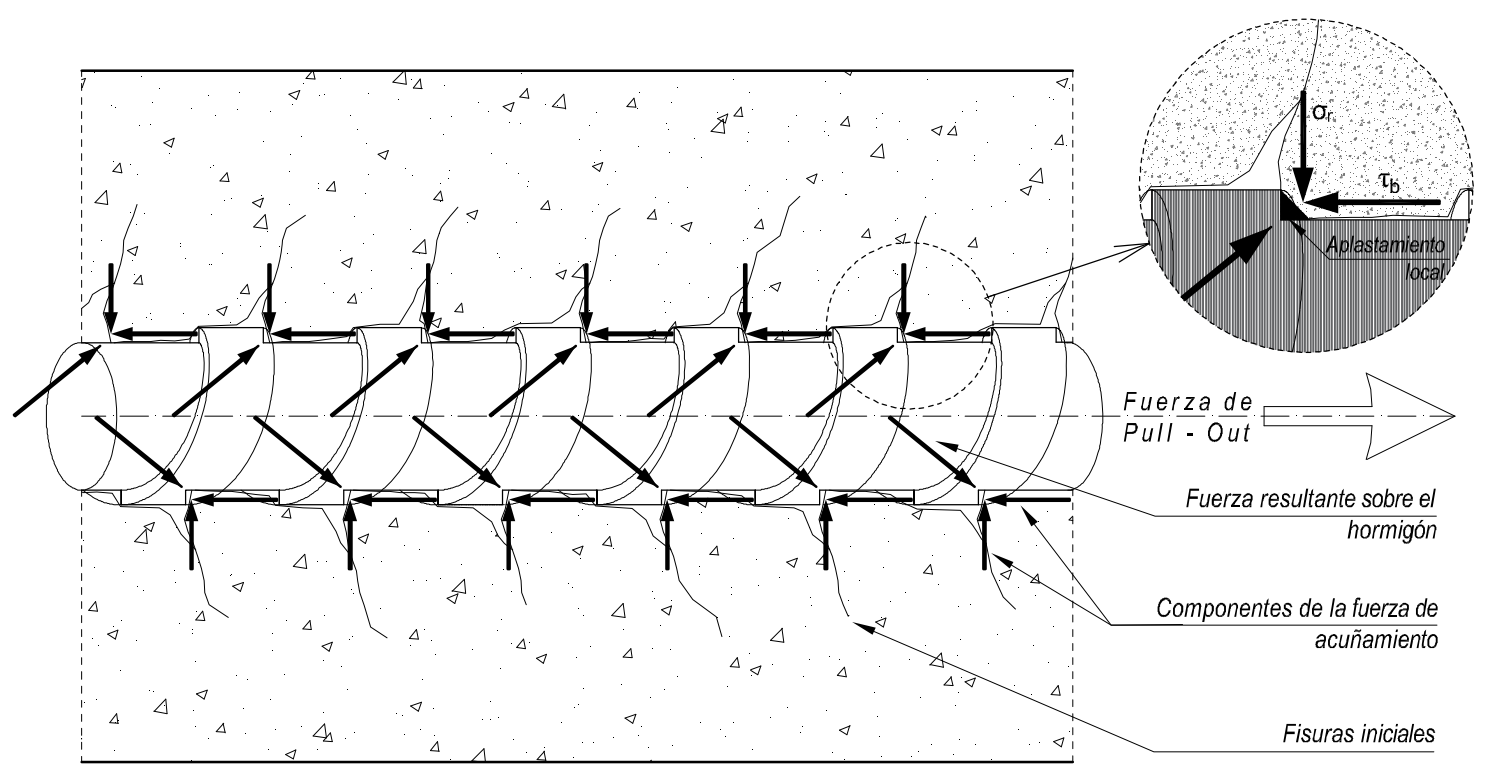

Figura 2-3 Fuerzas de acuñamiento y fisuración inicial en la interfaz acero-bormigón. Primeras etapas del proceso de arrancamiento.

Por último, tal y como indican Rueda \& Contreras (2014), existen otras interacciones acero-hormigón que incrementan las tensiones radiales de compresión necesarias para desarrollar las fuerzas de rozamiento que protagonizan el fenómeno de la adherencia:

- Efecto "Lack-of-fit": después del deslizamiento inicial y el fallo del mecanismo de adhesión, parte de las partículas de cemento de la interfaz pueden adherirse entre el cordón o el alambre y el hormigón. Por tanto, la nueva sección del alambre no es totalmente congruente, lo que se deriva en un efecto cuña cuando tiene lugar el deslizamiento relativo acero-hormigón.

- Efecto "Pitch": El paso de hélice del trazado helicoidal de los alambres exteriores en cordones y el de las indentaciones en alambres individuales varía con los cambios de tensión longitudinal en el acero, lo que contribuye a aumentar por contacto las tensiones de compresión.

\subsubsection{Modos de fallo}

El fallo por adherencia, tanto en estructuras de hormigón armado como pretensado, puede suceder de múltiples maneras, dependiendo del sistema de fuerzas que se establezcan, pero en general pueden distinguirse los siguientes modos de fallo fundamentales, según Fib Bulletin nº10 (CEB-FIB (Task Group 2.5), 2000): 
- Fallo por deslizamiento de la barra con respecto al hormigón (Pull-Out), dejando el recubrimiento prácticamente intacto (sin fisuración). Suele darse cuando existe un alto confinamiento de la armadura y/o un gran recubrimiento.

- Fallo por fisuración del recubrimiento y deslizamiento de la barra (splitting induced pullout) acompañada por el aplastamiento y/o cizalladura del hormigón situado entre las corrugas.

- Fallo por fisuración longitudinal del recubrimiento (splitting) acompañada por deslizamiento en la zona de corrugas. Este tipo de fallo se produce cuando no existe confinamiento o es muy bajo, los recubrimientos son reducidos y/o cuantía de armadura es escasa.

Las armaduras lisas fallan normalmente por deslizamiento de la barra con respecto al hormigón (Pullout) una vez que se han superado los mecanismos de transferencia de fuerzas de adhesión y fricción. El fallo por fisuración longitudinal del recubrimiento (splitting) en este tipo de barras solo concurre en relaciones recubrimiento diámetro muy pequeñas (menores a 1), tal y como indica Chana (1990).

\subsubsection{Modelado de la adherencia en el pretensado}

\subsubsection{Introducción}

La fuerza en un alambre o cordón de pretensado se transfiere por adherencia al hormigón durante la operación de destesado, de manera que las tensiones longitudinales en el acero varían desde cero, en el extremo de la viga, hasta su máximo valor más allá de la longitud de transferencia $l_{t}$. Por tanto, la longitud de transferencia $l_{t}$ se define como aquella necesaria para que la totalidad de la fuerza de pretensado introducida en una armadura pretesa se transfiera por adherencia al hormigón. Esta longitud abarca la distancia existente desde el extremo libre de un elemento pretensado hasta la sección a partir de la cual la tensión en el alambre o cordón es constante, de modo que más allá de dicha sección la fuerza de pretensado mantiene su valor hasta la zona de transferencia del extremo opuesto, en que se produce el fenómeno en sentido inverso.

Tal y como indica Rueda \& González (2014), conocer el valor de la longitud de transferencia $l_{t}$ tiene una gran importancia en el diseño de elementos pretensados. Por un lado, valores reducidos de la misma mejoran la capacidad resistente frente a esfuerzo cortante, debido al efecto beneficioso de las tensiones de compresión introducidas en la sección de hormigón, especialmente en los extremos del elemento, donde el cortante suele ser de mayor entidad. Por otro lado, la reducción de la longitud de transferencia lleva asociado un aumento de las tensiones transversales de tracción en los extremos del elemento, aumentando el riesgo de fisuración por estallido ("bursting"), por exfoliación ("spalling") o por hendimiento (“Splitting").

Por otro lado, por definición, la fuerza de pretensado $F_{p}$ en un alambre de diámetro $\phi$ debe ser equivalente a la integral de la ley de distribución de la tensión de adherencia $\tau_{b}(x)$ que actúa sobre la superficie del alambre a lo largo de la longitud de transferencia $l_{t}$ (Eq. 2-4): 


$$
F_{p}=\sigma_{p, 0} \cdot \frac{\pi \phi^{2}}{4}=\int_{0}^{l_{t}} \pi \phi \tau_{b}(x) d x
$$

Y de (Eq. 2-4) se despeja fácilmente la expresión que define la longitud de transferencia $l_{t}(E q$. 2-5):

$$
l_{t}=\sigma_{p, 0} \frac{\phi}{4} \cdot \frac{1}{\tau_{b, \text { med }}}
$$

En los casos más habituales, de la igualdad anterior (Eq. 2-5) se conocen todos los datos excepto la longitud de transferencia $l_{t}$ y la ley de distribución de la tensión de adherencia a lo largo de la misma $\tau_{b}(x)$. En los códigos estructurales cuyo uso está más extendido [Código Modelo (FIB Special Activity Group 5, 2011), Eurocódigo 2 (CEN, 2004), EHE-08 (Fomento, 2008)] se opta por simplificar esta ley, considerándola constante y dependiente de diversos factores, como la resistencia a tracción del hormigón $f_{c t}$, del tipo de alambre y/o de la posición del mismo durante el hormigonado. Sin embargo, para una comprensión del fenómeno de la transferencia del pretensado se necesita una imagen realista y precisa de la distribución de la tensión de adherencia a lo largo de los alambres de pretensado. Con este fin, en las últimas décadas se han desarrollado modelos de diversa complejidad que, a grosso modo y tal como indica Den Ujil (den Ujil, 1998), pueden ser divididos en dos amplias categorías: determinación de la tensión de adherencia como función del deslizamiento y determinación de la tensión de adherencia como función de la tensión de compresión radial sobre el acero. Un tercer grupo, que no llegaría a conformar una categoría propia ya que siempre aparece combinado con las dos anteriores, sería el correspondiente a los datos experimentales extraídos de ensayos de adherencia básicos, utilizados para la calibración de modelos.

\subsubsection{Modelos basados en la determinación de la tensión de adherencia como función del deslizamiento}

En esta categoría se incluyen aquellos modelos en los que la tensión de adherencia, a lo largo de la longitud del alambre, se ve modificada por la magnitud del deslizamiento. Dentro de los mismos puede destacarse, entre otros, el modelo aportado por Balázs (1992), donde la distribución de la tensión de adherencia $\tau_{b}$ a lo largo del alambre se describe mediante una ecuación diferencial de segundo orden, que considera las condiciones de equilibrio y de compatibilidad, y que supone un comportamiento elástico-lineal de los materiales. La solución analítica de esta ecuación diferencial, suponiendo una función potencial para la Ley de adherencia local-deslizamiento, es la siguiente (Eq. 2-6):

$$
\tau_{b}=\eta_{1} \cdot \eta_{2} \cdot f_{c i}^{0.5} \cdot\left(\frac{\delta}{\phi_{p}}\right)^{\eta_{3}}
$$

donde:
$f_{c i} \quad$ Resistencia a compresión del hormigón en el momento de la transferencia.
$\phi_{p} \quad$ Diámetro del alambre o cordón de pretensado 


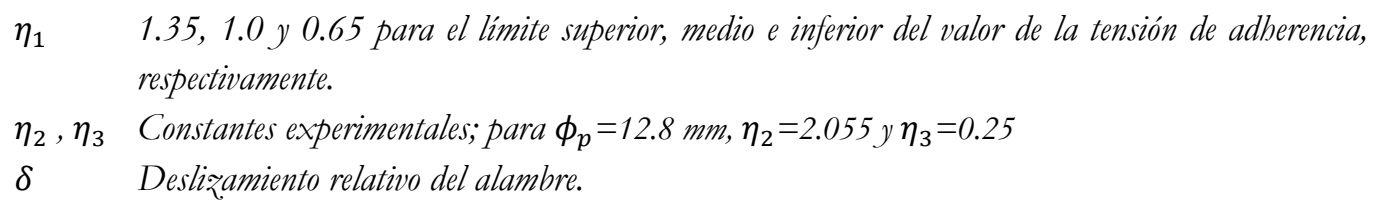

Como puede observarse, en este modelo el valor de la tensión de adherencia $\tau_{b}$ depende únicamente del deslizamiento relativo $\delta$, de la resistencia a compresión del hormigón $f_{c}$, y de coeficientes calibrados experimentalmente, $\eta_{2}$ y $\eta_{3}$. Adicionalmente, y operando de manera similar a como lo hacen la mayor parte de los códigos estructurales, mediante el coeficiente $\eta_{1}$ se establece un límite superior y un límite inferior para la tensión de adherencia $\tau_{b}$, un $35 \%$ mayor y un $35 \%$ menor, respectivamente, al valor medio de dicha tensión. El límite inferior se reserva para la comprobación de tensiones transversales de tracción en el hormigón, mientras que el límite superior se utiliza para comprobaciones en Estado Límite Último (ELU), tales como la resistencia a esfuerzo cortante o el anclaje de armaduras.

Por otro lado, es necesario destacar que, tal y como indica la Monografía 10 "Bond of reinforcement in concrete" del CEB-FIP (2000), la descripción de la relación tensión de adherencia-deslizamiento en base a una función potencial, como resultado de la solución analítica de la ecuación diferencial de segundo orden que caracteriza dicho fenómeno, fue aplicada en primer lugar a barras corrugadas por Martin (1973) y Noakowski (1978), y posteriormente a cordones pretensados por Tassi et al. (1988).

El problema del modelo propuesto por Balázs (1992) es que se supone una Ley de tensión de adherencia local-deslizamiento constante a lo largo de la longitud de transferencia, lo que implica despreciar el efecto de la deformación transversal del acero (efecto Hoyer) sobre la tensión de adherencia. Para evitar esta limitación, den Uijl (1992) propone una expresión empírica más compleja, en la que se incorpora la variación de la tensión del acero $\Delta \sigma_{p}$ :

$$
\tau_{b}=3+0,4 \delta-2,5 \cdot 10^{-3} \Delta \sigma_{p}+1,5 \cdot 10^{-3}\left|\Delta \sigma_{p}\right|
$$

Tal y como indican Rueda \& González (2014), el primer término de la anterior ecuación (Eq. 2-7) recoge la acción de la tensión de adherencia debida al mecanismo de adhesión $\tau_{b, a d b}$, el segundo tiene en cuenta el efecto "lack-of-fit", el tercero modeliza la acción del efecto Poisson ("efecto Hoyer") y el último se corresponde con la acción del "Pitch-effect" (Ver 2.2.2 Mecanismos de adherencia entre el hormigón y el acero pretensado). Las constantes de la ecuación (Eq. 2-7) fueron calibradas mediante ensayos sobre cordones de 9,3 $\mathrm{mm}$ de diámetro y con un hormigón de resistencia a compresión igual a 55 $\mathrm{MPa}$, de manera que para cualquier otro caso se deberían calibrar nuevas constantes de forma experimental.

\subsubsection{Tensión de adherencia como función del confinamiento del hormigón}

Los modelos pertenecientes a esta categoría relacionan la tensión de adherencia local $\tau_{b}$ con la tensión de compresión radial $\sigma_{r}$ actuando en la interfaz acero-hormigón, como respuesta del recubrimiento de hormigón a la expansión radial de los alambres en el momento del destesado. Esta tensión es equilibrada con tensiones circunferenciales $\sigma_{\vartheta}$ de tracción que, una vez superan la resistencia a 
tracción del hormigón, originan la aparición de fisuras radiales. La capacidad de confinamiento del recubrimiento, que es la máxima tensión radial de compresión $\sigma_{r}$ que es capaz de resistir el hormigón, determina la máxima capacidad adherente. Para evaluar el confinamiento, el hormigón que circunda al alambre es a menudo concebido como un cilindro de pared gruesa parcialmente fisurado, tomando en consideración el comportamiento del hormigón en tracción.

Normalmente, el interés en la respuesta del cilindro de pared gruesa se restringe al máximo valor de la presión interna que, si no se tuviera en cuenta la influencia de la ley de adherencia localdeslizamiento, se correspondería con la tensión de adherencia máxima. La ventaja fundamental de estos modelos es que permiten cuantificar la influencia que tienen sobre la adherencia parámetros tales como las propiedades del hormigón o la geometría del elemento (recubrimiento, diámetro, espacio entre alambres, etc). Su principal limitación es que, al estar explícitamente basados en la expansión del alambre de pretensado, en aquellas zonas donde esta expansión no se produce, es decir, más allá de la longitud de transferencia, no se considera ningún tipo de capacidad adherente.

El modelo desarrollado en esta tesis se basa en la teoría del cilindro hueco de pared gruesa, por lo que en este apartado no se expone el desarrollo teórico seguido por los numerosos autores [Tepfers (1973), den Uijl (1998), Oh et al. (October 2006), Weerasekera (2009), Benítez \& Gálvez (2011), Abdelatif et al. (2015)] que en las últimas décadas han recurrido a este modelo para simular el comportamiento adherente de alambres pretensados, ya que será tratado en profundidad en el Capitulo 3 de la presente tesis.

\subsubsection{Ensayos para la determinación de la adherencia en el pretensado}

Existe una gran variedad de ensayos que tratan de simular y predecir las características adherentes de alambres de acero en estructuras pretensadas reales. Normalmente, los resultados permiten calibrar el valor de diversos variables que intervienen en el proceso, tales como el coeficiente de fricción, la ley de adherencia local-deslizamiento o el valor de la tensión de adherencia máxima y residual, y arrojan información sobre la longitud de transferencia (de transmisión) y/o la longitud de anclaje. A continuación se recogen algunos de los más habituales (una revisión exhaustiva puede consultarse en el Boletín 10 de CEB-FIP (2000) y especialmente en el completo trabajo de Miguel et al. (2002)):

\subsubsection{Ensayo de arrancamiento (Ensayo de pull-out)}

Dentro de este grupo se incluyen los ensayos en los que el alambre o cordón, embebido total o parcialmente en una probeta de hormigón, es sometido a una fuerza de arrancamiento desde uno de los extremos. Originalmente desarrollado para armaduras corrugadas, por su sencillez y economía de tiempo y medios es también uno de los ensayos más utilizados en el estudio de la adherencia en alambres y cordones para pretensado. La configuración de este método de ensayo se recoge en el Anexo D "Ensayo de adherencia para el acero corrugado o graficado para armaduras de hormigón armado. Ensayo de arrancamiento" de la Norma UNE-EN 10080:2006 (AENOR-AEN/CTN 36, 2006), basado a su vez en la Recomendación RILEM RC 6: Ensayo de adherencia para el acero para armaduras de hormigón armado - 2. Ensayo de arrancamiento, 1983. El principio del ensayo consiste en aplicar una carga de tracción a una barra o alambre embebido una longitud determinada en el interior de un cubo de hormigón, 
permaneciendo el otro extremo de la barra sin ningún tipo de tensión. La relación existente entre la fuerza de tracción aplicada y el deslizamiento relativo producido entre el acero y el hormigón se mide hasta que se produce el fallo adherente o la rotura del alambre o cordón. La configuración del ensayo de arrancamiento se ilustra en la Figura 2-4.
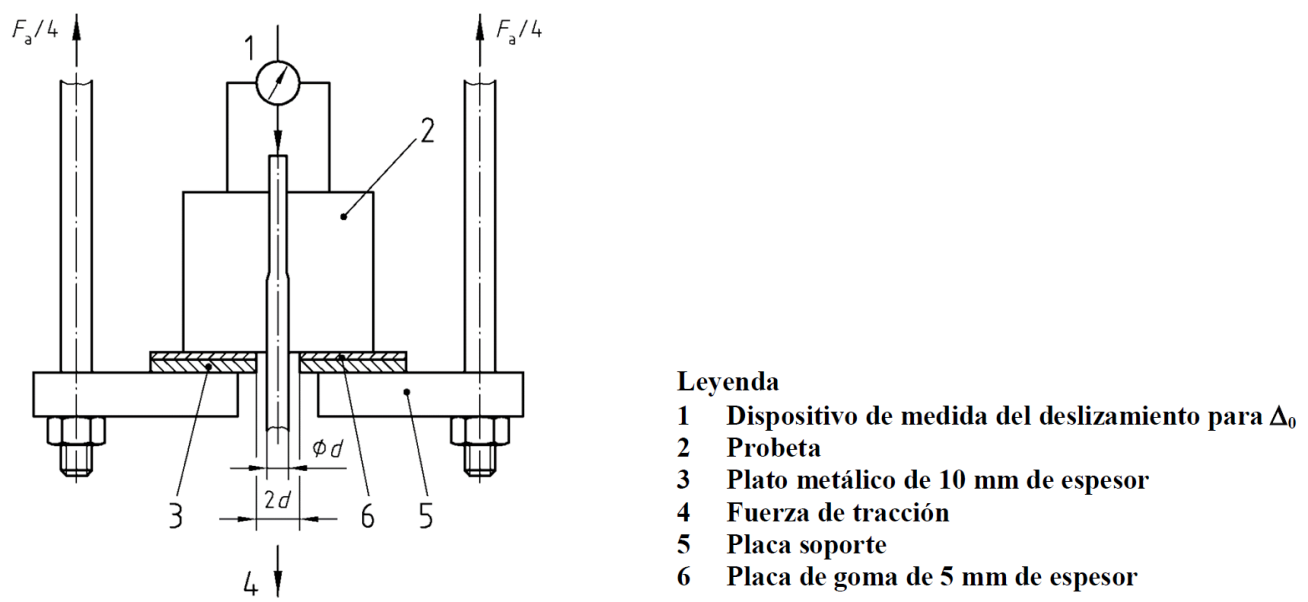

Figura 2-4. Configuración del ensayo de arrancamiento (pull-out). Figura tomada de la Norma UNE-EN 10080:2006 (AENOR-AEN/CTN 36, 2006)

Este tipo de ensayos permite, entre otros datos y con ciertas limitaciones, deducir la ley de adherencia local-deslizamiento $\tau_{b}$-s. Para la obtención de una ley única a lo largo de toda la longitud adherente del alambre es aconsejable utilizar longitudes adherentes cortas $(5 \phi-10 \phi)$, ya que para longitudes mayores la tensión de adherencia $\tau_{b}$ no se distribuye uniformemente a lo largo de toda la longitud. Cuanto más corta sea la longitud adherente, menor será la diferencia entre la tensión de adherencia local $\tau_{b}$ y la tensión de adherencia media $\tau_{b, \text { med. }}$

Tal y como indica la FIB (CEB-FIB_Task Group 2.5, 2000), los ensayos de pull-out son útiles en estudios comparativos, en los que determinados parámetros (diámetro, recubrimiento, grado de corrosión, acabado superficial de la armadura, etc) son modificados, pero la capacidad adherente encontrada con ellos tiene un valor limitado, dado que las condiciones de contorno en las probetas tienen poco que ver con las encontradas en estructuras reales. Sin embargo, si se modifican las condiciones iniciales del ensayo, o los datos obtenidos son tratados con algún modelo que asimile el experimento a las condiciones reales, los resultados pueden ser tomados en consideración.

La principal limitación de este método de ensayo es que no reproduce el efecto Hoyer, característico y diferenciador de la adherencia en elementos pretensados, por lo que muchos autores han descartado su validez para la caracterización de este fenómeno. En esa dirección apunta la monografía sobre adherencia del CEB-CIP (CEB-FIB (Task Group 2.5), 2000), donde se afirma que existe una gran dificultad para correlacionar las medidas de adherencia obtenidas mediante ensayos de arrancamiento con las propiedades adherentes de los cordones de pretensado. Por el contrario, el Precast/Prestressed Concrete Institute (PCI), en su publicación "Interim Guidelines for the Use of Self-Consolidating Concrete in Precast/Prestressed Concrete Institute Member Plants” (PCI, 2003), recomienda su uso como un ensayo auxiliar, adecuado para evaluar las características adherentes de los cordones de pretensado. 
Han sido varios los investigadores que a lo largo de las últimas décadas han estudiado la posibilidad de que ensayos simples de pull-out sirvieran como posible método para evaluar el comportamiento adherente en alambres pretensados. Obviando el efecto Hoyer, los argumentos a favor de este tipo de ensayo inciden en el hecho de que el mecanismo fundamental en la adherencia de alambres, la fricción, es común tanto en alambres pretensados como sin pretensar.

En este contexto, en EEUU, a raíz de algunos estudios como el llevado a cabo en 1986 en la North Carolina State University (NCSU) por Cousins, Johnston y Zia (Cousins, et al., 1990) se puso de manifiesto las grandes diferencias existentes entre las propiedades adherentes de distintos alambres y cordones de pretensado, teóricamente similares, y que hacían que las longitudes de transferencia y de anclaje previstas en la instrucción americana ACI 318-95 estuvieran del lado de la inseguridad. En respuesta a estos estudios, la Federal Highway Administration (FHWA, Compañía para la construcción y mantenimiento de las autopistas y puentes del país) estableció, como medida interna, el incremento en un $60 \%$ del valor de las longitudes de transferencia y anclaje obtenidas mediante la formulación de la ACI e inició varios programas de ensayos para determinar las verdaderas longitudes de transferencia y de anclaje.

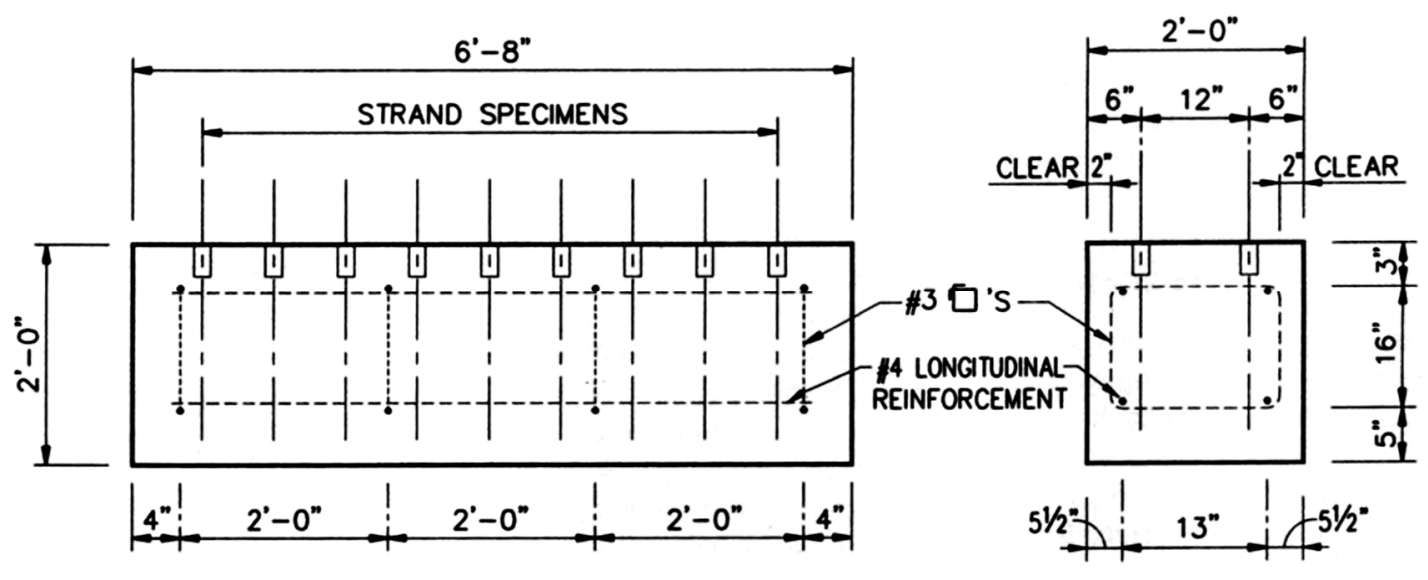

Figura 2-5. Configuración del ensayo de arrancamiento (pull-out) según S.Moustafa (1974). Figura tomada de Logan (1997).

En 1992, al no existir norma de ensayos ASTM ni otro método reconocido de ensayos, el Comité de Acero Pretensado del PCI decidió emprender una campaña experimental usando ensayos simples de arrancamiento sobre aceros sin pretensar procedentes de distintos fabricantes. Los ensayos se llevaron a cabo en la Stresscon Corporation (Colorado, USA) y el método seguido fue el desarrollado en 1974 por S. Moustafa (1974), que presenta algunas diferencias significativas con respecto al recogido en la la Norma UNE-EN 10080:2006 (AENOR-AEN/CTN 36, 2006). El Método Moustafa tiene las siguientes características: cordones embebidos verticalmente más de $457 \mathrm{~mm}$ en un mismo bloque de hormigón (armado transversalmente), con una separación entre los mismos y un recubrimiento suficiente para asegurar un adecuado confinamiento y con la adherencia acerohormigón impedida los últimos $51 \mathrm{~mm}$ del extremo cargado gracias a un manguito antiadherente (Ver Figura 2-5). Las conclusiones de este trabajo fueron recogidas en un informe (Iverson, 1996) que fue distribuido con carácter urgente entre los productores asociados al PCI. En él se afirmaba que, a pesar de la gran disparidad de resultados obtenidos tanto en los ensayos de pull-out como en las longitudes reales de transferencia y anclaje, existía una buena correlación entre ambos. Sin embargo, estas 
conclusiones no fueron aceptadas por algunos de los miembros del PCI, al entender que los resultados de un ensayo de Pull-Out sobre un cordón sin pretensar no eran extrapolables al comportamiento adherente de uno pretensado. Estas objeciones motivaron un nuevo y amplio estudio, realizado en la Universidad de Oklahoma en 1997 y dirigido por Donald R. Logan (1997).

Donald R. Logan (1997) evaluó la efectividad de varios métodos de ensayo en la determinación de las prestaciones adherentes de cordones de 0,5 ”, procedentes de seis fabricantes distintos. Para ello llevó a cabo un total de 216 ensayos, incluyendo 36 de tipo arrancamiento según el método Moustafa y ensayos en vigas, en las que se midieron las longitudes de transferencia reales, utilizando galgas extensiométricas mecánicas. Estas longitudes fueron comparadas con los resultados obtenidos mediante ensayos siguiendo el Método Moustafa, pudiendo concluir que existía una clara correlación entre la capacidad adherente obtenida mediante ensayos simples de Pull-Out y las longitudes reales de transferencia y anclaje. Así, obtuvo que las longitudes de transferencia y anclaje en vigas pretensadas con cordones que presentaban una fuerza de arrancamiento superior a $160 \mathrm{kN}$ eran menores que las determinadas por la expresión del código ACI 318-95. Por el contrario, si los cordones presentaban fuerzas de arrancamiento inferiores a $53.3 \mathrm{kN}$, las longitudes de transmisión y anclaje no cumplían con código americano y se manifestaban fallos prematuros de adherencia en las vigas ensayadas a flexión.

Las conclusiones extraídas por Logan (1997) fueron rebatidas posteriormente por G. Southworth (1997), argumentando por un lado, que se disponían de muy pocos resultados para dar por buena la correlación, y por otro, que no se incluían valores entre 53.3 y $160 \mathrm{kN}$, por lo que, en conclusión, era prematuro adoptar el ensayo de arrancamiento como método de control de las propiedades adherentes en cordones de pretensado.

\subsubsection{Simulación de la longitud de transferencia y de anclaje (Ensayo de push-in)}

Este tipo de ensayos se caracterizan por el hecho de que la longitud de las probetas es tal que, en la operación de destesado, la fuerza de pretensado no se transmite en su totalidad. Consecuentemente, en este tipo de ensayos no se puede determinar de manera directa la longitud de transmisión.

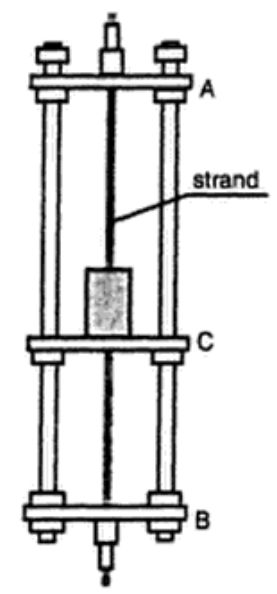

Figura 2-6 Esquema de ensayo de adherencia push-in ( (Keuning, et al., 1962) 
La expansión transversal del alambre tras el destesado (efecto Hoyer), provocando el desarrollo de las tensiones radiales de compresión en la interfaz acero-hormigón, y por tanto, de las tensiones de adherencia, es un parámetro fundamental para la caracterización del fenómeno de la adherencia en elementos pretensados de hormigón. La influencia de esta expansión puede ser estudiada de manera explícita por medio de los denominados ensayos de push-in (Keuning, et al., 1962). Tal y como indica la monografía del CEB-CIP (CEB-FIB_Task Group 2.5, 2000), en estos ensayos el alambre o cordón es pretensado en primer lugar, entre los puntos A y B (ver Figura 2-6), para posteriormente verter el hormigón y dejarlo endurecer. Una vez alcanzada la resistencia deseada, la fuerza de pretensado se va liberando en A, causando un movimiento del alambre en la dirección de B. Dado que la probeta de hormigón se soporta sobre $\mathrm{C}$, este movimiento del alambre genera tensiones de adherencia entre el hormigón y el alambre. La denominación de "push-in" procede del hecho de que se puede crear una situación similar aplicando una fuerza de compresión en A.

Esta técnica de ensayo ha sido utilizada por varios investigadores, tales como den Uijl (1992), Abrishami \& Mitchell (1993), Rose \& Russell (1997) y Vázquez (2000).

\subsubsection{Medición del deslizamiento de la armadura pretensada}

La variación de la tensión del alambre o cordón a lo largo de la longitud de transferencia conlleva un deslizamiento relativo entre el acero y el hormigón circundante. La medida del deslizamiento del alambre en el extremo de la viga $\left(\delta_{\mathrm{d}}\right)$ es un método indirecto para la determinación de la longitud de transferencia, por lo que ha sido propuesto por numerosas normas, entre ellas la española UNE 7436-82 "Método de ensayo para la determinación de las características de adherencia de las armaduras de pretensado" (Instituto Nacional de Racionalización y Normalización - IRANOR, 1982), como método para la caracterización de las propiedades adherentes de armaduras pretesas.

Teóricamente, el deslizamiento del alambre en el extremo de la viga, $\delta_{d}$, puede ser calculado según la siguiente expresión (Balazs, 1993) (Eq. 2-8):

$$
\delta=\int_{0}^{l_{t}}\left(\varepsilon_{p, 0}-\varepsilon_{p}-\varepsilon_{c}\right)
$$

donde $\varepsilon_{p, 0}$ es la deformación debida a la tensión inicial del alambre; y $\varepsilon_{p}$ y $\varepsilon_{c}$ son las deformaciones longitudinales del acero y del hormigón a lo largo de la longitud de transferencia $l_{t}$ (Figura 2-7). La obtención de la longitud de transferencia $l_{t}$ a partir de la expresión (Eq. 2-8) presenta dificultades operativas importantes, siendo necesario implementar algún tipo de modelo para su resolución. Por ello, en los años 50, Guyon (1953) propuso una expresión simplificada en la que, a partir de los deslizamientos relativos $\delta_{d}$ medidos en el extremo de la viga, y suponiendo una determinada ley de distribución de la tensión de adherencia $\tau$, podía hallarse la longitud de transferencia $l_{t}(E q$. 2-9). Esta expresión, que ha sido ampliamente utilizada posteriormente por numerosos autores (Oh, et al., 2001) (Martí-Vargas, et al., 2007), presenta la siguiente forma:

$$
l_{t}=\alpha \frac{\delta_{d}}{\varepsilon_{p, 0}}
$$


donde $\alpha$ es un factor que depende de la distribución de tensiones de adherencia $\tau_{b}$.

Sustituyendo el valor de la deformación longitudinal en el acero $\varepsilon_{p, 0}$ por el cociente entre la tensión inicial de pretensado del alambre $\sigma_{p, 0}$ y el módulo de elasticidad del acero pretensado $E_{p}$, la ecuación (Eq. 2-9) puede escribirse como sigue (Eq. 2-10):

$$
l_{t}=\alpha \delta \frac{E_{p}}{\sigma_{p, 0}}
$$
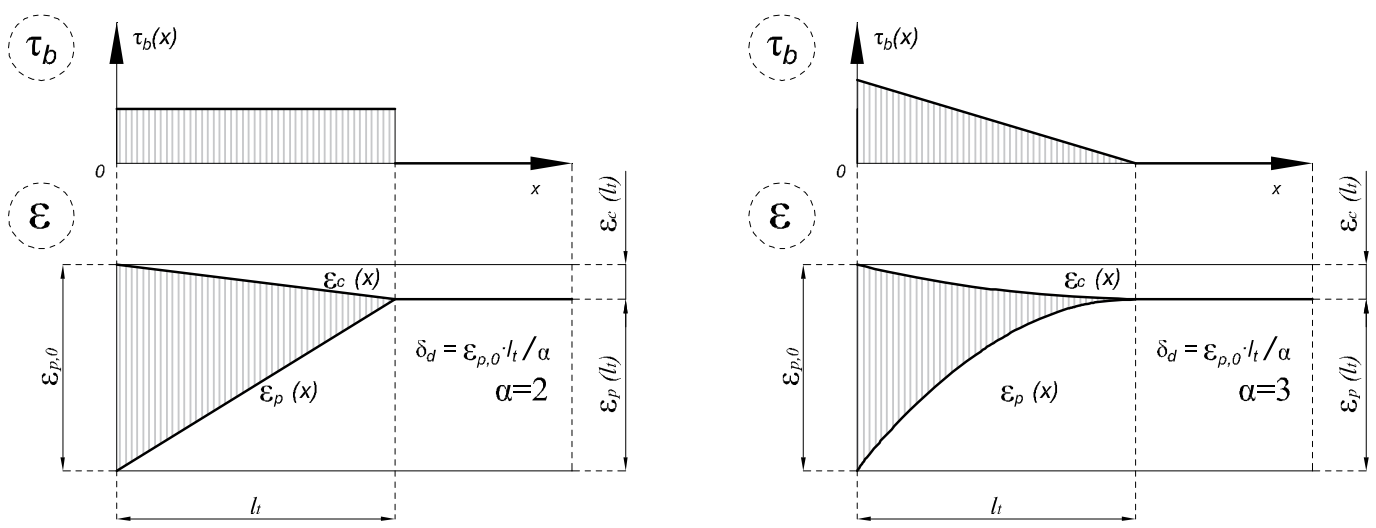

Figura 2-7 Distribución de tensiones de adherencia a lo largo de la longitud de transferencia para la determinación del coeficiente a en la expresión de Guyon (1953)

Como se ha indicado anteriormente, la expresión (Eq. 2-9) puede utilizarse si se supone una determinada distribución de la tensión de adherencia $\tau_{b}$ a lo largo de la longitud de adherencia $l_{t}$. La utilización de un valor igual a 2 para el coeficiente $\alpha$, utilizado por muchos investigadores [ (Guyon, 1953), (Russell \& Burns, 1997), (Logan, 1997)], implica la suposición de una distribución constante de la tensión de adherencia $\tau_{b}$, dando como resultado una variación lineal de las deformaciones en el alambre pretensado (Figura 2-7). Por tanto, la expresión (Eq. 2-8) queda reducida a lo siguiente:

$$
\delta=\frac{\varepsilon_{p, 0} \cdot l_{t}}{2}
$$

Si se utiliza un valor $\alpha=3$ (Guyon, 1953), la variación de la tensión de adherencia a lo largo de la longitud de transferencia es lineal, y como consecuencia, las distribuciones tanto de la deformación longitudinal de acero $\varepsilon_{p}$ como del hormigón $\varepsilon_{c}$ son parabólicas. Por tanto, la expresión (Eq. 2-8) puede escribirse como sigue (Eq. 2-12):

$$
\delta=\frac{\varepsilon_{p, 0} \cdot l_{t}}{3}
$$

También se admite el uso de valores intermedios del coeficiente $\alpha$, comprendidos en el rango entre 2 y 3 (Dang, et al., 2014). Entre los más elevados, Bruggeling (1991) propone un $\alpha=2,94$ mientras que Olesniewicz (1975) indica un valor de 2,86. Por su parte, Balazs (1993), basándose en estudios teóricos, se inclina por un $\alpha=2,67$ y Dang (2014) obtiene las mejores correlaciones para $\alpha=2,44$. 
Coincidiendo con este valor, Martí-Vargas et al. (2007), en un trabajo en el que realizan una extensa revisión bibliográfica de los coeficientes $\alpha$ utilizados previamente por otros autores, concluyen que un valor de $\alpha=2,44$ es el que mejor se ajusta a los resultados de su campaña experimental.

Tal y como indica L.A. Caro (2012) las principales desventajas de este método son la elevada dispersión de resultados experimentales, la dificultad de medir pequeños deslizamientos, la rotura de transductores cuando se aplican procedimientos súbitos o bruscos de destesado, y la excesiva penetración de los alambres en elementos pretensados con compactación defectuosa alrededor de la armadura.

\subsubsection{Medición de las deformaciones en la superficie del hormigón (Norma 1982)}

Este método, que viene recogido en la Norma UNE 7-436-82 "Método de ensayo para la determinación de las características de adherencia de las armaduras de pretensado" (Instituto Nacional de Racionalización y Normalización - IRANOR, 1982) se basa en la medición de las deformaciones en la superficie del recubrimiento de hormigón del elemento pretensado, ya sea mediante sistemas manuales (puntos de medida para extensometría manual) o automatizados (galgas extensiométricas), de manera que la longitud de transferencia es determinada por el perfil de deformaciones del hormigón. La ventaja fundamental de este método es que permite obtener directamente, a escala real, la longitud de transferencia del pretensado.

Tal y como indican Martinez-Abella \& Vazquez-Herrero (2002), existen tres métodos que han sido utilizados tradicionalmente para la determinación de la longitud de transferencia $l_{t}$ a través del perfil de deformaciones del hormigón:

- Método de la deformación constante al 100\% ("100\% Constant Strain Method"): Donde la longitud de transferencia es definida como la mínima distancia desde el extremo del elemento hasta el punto en el que se alcanza la deformación constante media, en el centro del elemento.

- Método de la deformación máxima media al 95\% ("95\% Constant Strain Method"): Igual que el anterior, pero limitando la deformación en el centro del elemnto al 95\% de la deformación constante media. Esta reducción está destinada a tener en cuenta el efecto de corte diferido ("shear lag effect").

- Método del ajuste de la pendiente ("Slope intercept method"): Después de que la meseta de deformación constante es delimitada, los resultados puntuales obtenidos en la zona de transferencia son ajustados mediante regresión lineal.

Sin embargo, el método más utilizado es una combinación de los dos últimos, denominado "Método del 95\% de la media de las deformaciones máximas"("95\% Average Maximun Strain Method (AMS)"), que fue desarrollado en 1993 por Russell \& Burns (1993). Este método, cuya precisión para vigas de sección rectangular ha sido demostrada por numerosos investigadores [ (Russell \& Burns, 1993), (Russell \& Burns, 1996), (Russell \& Burns, 1997), (Vazquez, 2000), (Martinez-Abella \& VazquezHerrero, 2002), (Zhao, et al., 2013)] consta de las siguientes etapas (Martí-Vargas, et al., 2002): 
1. Las deformaciones obtenidas se representan en un gráfico deformación-distancia al extremo del elemento. En el caso de que se haya producido una transmisión del pretensado completa, la curva resultante presenta tres partes: un primer tramo ascendente (deformaciones de compresión positivas), con deformaciones crecientes al aumentar la distancia al extremo del elemento, un segundo tramo sensiblemente horizontal (meseta) definido por las máximas deformaciones alcanzadas, y un tercer tramo descendente, correspondiente a la zona de transferencia del pretensado en el extremo opuesto del elemento.

2. Se calcula la media de las máximas deformaciones alcanzadas (AMS), es decir, la media de las deformaciones en el tramo intermedio o meseta, cuya longitud aproximada debe determinarse mediante estimación por inspección visual.

3. Se representa en el gráfico una recta horizontal de valor $\alpha \cdot A M S$, asignando a $\alpha$ un valor igual a 0,95 .

4. Se obtienen los puntos de intersección de la recta anterior con los tramos ascendente y descendente de la curva. Habitualmente se lleva a cabo un ajuste mediante regresión lineal de los puntos situados en la zona de transferencia, aunque algunos autores han propuesto un ajuste exponencial para determinar la forma de estos tramos (Martinez-Abella \& VazquezHerrero, 2002).

5. La longitud de transferencia se determina, en cada extremo del elemento, como la distancia existente desde el extremo hasta el punto de intersección entre la recta horizontal $\alpha \cdot$ AMS y los tramos ascendente y descendente de la curva, ajustados mediante regresión lineal.

Este procedimiento, que ha sido el utilizado en esta tesis, arroja valores razonables para la longitud de transferencia y evita la interpretación arbitraria de los resultados experimentales.

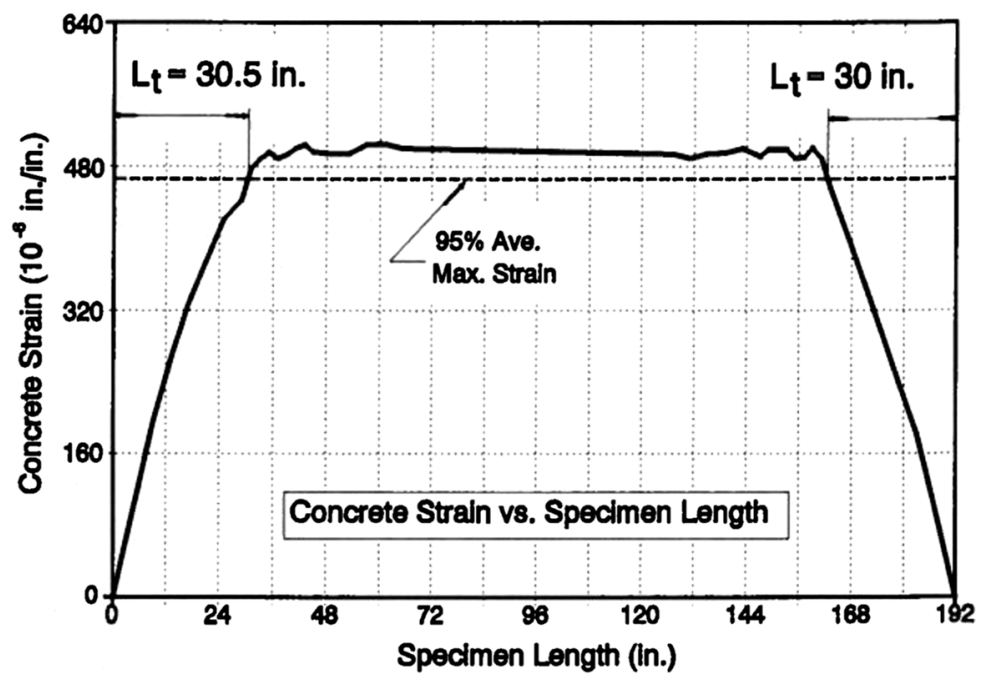

Figura 2-8 Determinación de la longitud de transferencia mediante el método del 95\% de la media de las deformaciones máximas (Russell ¿Burns, 1996) 


\subsubsection{Medición de la fuerza de pretensado (Método ECADA)}

Este método se basa en la obtención de las deformaciones de los alambres pretensados mediante galgas extensiométricas adheridas a la superficie de estos. Teóricamente, este método proporcionaría los datos más precisos y directos de las deformaciones en los alambres y, por tanto, de su estado tensional. Sin embargo, las galgas extensiométricas se dañan fácilmente durante la colocación de los alambres y el posterior hormigonado, y además pueden modificar las propiedades adherentes de los alambres, por lo que no es habitual su utilización.

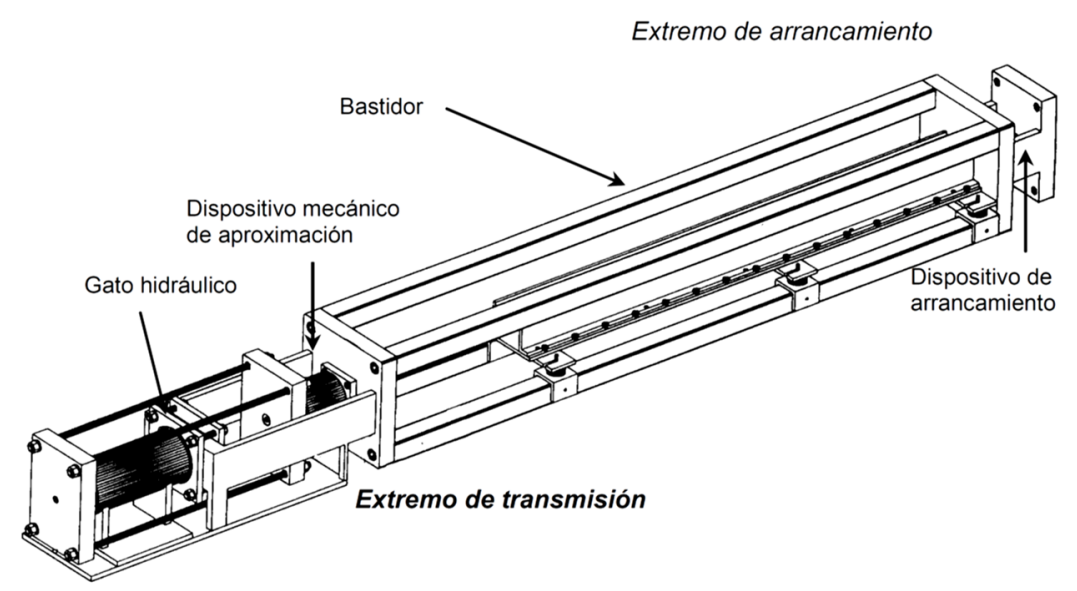

Figura 2-9 Esquema del ensayo ECADA. Figura tomada de (Marti-Vargas, et al., 2003) (Marti-Vargas, et al., 2006)

Como alternativa para evitar estos problemas, en el Departamento de Ingeniería de la Construcción y de Proyectos de Ingeniería Civil, de la Universidad Politécnica de Valencia se desarrolló el Método ECADA (Martí-Vargas, et al., 2003) (Martí-Vargas, et al., 2006). Este método, que pretende reproducir de manera secuencial, sobre una misma probeta, las operaciones de transferencia y de puesta en servicio, permite evaluar las propiedades adherentes, la longitud de transferencia $l_{t}$ y la longitud de anclaje $l_{a n c}$ en elementos pretensados de hormigón. Para ello es necesario que parte del elemento pretensado se sustituya por un sistema de arrancamiento (Ver Figura 2-9), situado en el extremo opuesto a aquél en el que se realiza la operación de transferencia, que debe reunir las siguientes condiciones (Martí-Vargas, et al., 2003):

- Servir de anclaje del alambre o cordón, de manera que permita la transferencia del pretensado en el extremo no eliminado del elemento (extremo de transmisión);

- Poseer una rigidez igual a la de la parte del elemento sustituida, para que la tensión del acero en el sistema de arrancamiento sea igual a la de la zona de tensión constante (meseta) del elemento.

- Permitir la medida de la fuerza que soporta el acero en el extremo en el que se encuentra el sistema de arrancamiento (extremo de arrancamiento); y

- Permitir el acceso al alambre o cordón en el extremo de arrancamiento, de manera que se haga factible llevar a cabo la operación de arrancamiento mediante el dispositivo diseñado a 
tal efecto, aumentando su tensión y, en consecuencia, alcanzando las tensiones tangenciales de adherencia correspondientes al anclaje.

La viabilidad, fiabilidad y repetitividad de este ensayo ha sido verificada en varios trabajos (MartíVargas, et al., 2007) (Martí-Vargas, et al., 2012). Lt.

\subsubsection{Adherencia de alambres pretensados en códigos estructurales}

En los códigos estructurales, la caracterización de la adherencia en elementos pretensados de hormigón se hace principalmente a través de la determinación de la longitud de transferencia. A continuación se recogen los modelos de cálculo de la longitud de transferencia recogidos en los códigos estructurales cuyo uso está más extendido.

\subsubsection{Código Modelo 2010}

El Código Modelo 2010 (FIB Special Activity Group 5, 2011) comienza describiendo el valor de diseño de la tensión de adherencia $f_{\text {bpd }}$ en alambres pretensados (Eq. 2-13):

$$
f_{b p d}=\eta_{p 1} \cdot \eta_{p 2} \cdot f_{c t, d}
$$

donde:

$$
\begin{aligned}
& f_{c t, d} \quad \text { Resistencia de cálculo del hormigón a tracción. } \\
& \eta_{p 1} \quad \text { Coeficiente que tiene en cuenta el tipo de alambre de pretensado. } \\
& \eta_{p 1}=1.4 \text {, para alambres indentados y grafilados. } \\
& \eta_{p 1}=1.2 \text {, para cables o torones de } 7 \text { alambres. } \\
& \eta_{p 2} \quad \text { Coeficiente que tiene en cuenta la posición del alambre. } \\
& \eta_{p 2}=1.0 \text {, para alambres con una inclinación de } 45-90^{\circ} \text { con respecto a la borizontal, y para todos } \\
& \text { los alambres horizontales que disten menos de } 250 \mathrm{~mm} \text { del fondo o que estén situados al menos } \\
& 300 \text { mm por debajo del punto más alto de sección. } \\
& \eta_{p 2}=0,7 \text {, para el resto de casos. }
\end{aligned}
$$

Posteriormente, el Código Modelo determina la longitud básica de anclaje $l_{b p}$, mediante la siguiente expresión:

$$
l_{b p}=\frac{A_{p}}{\phi \pi} \frac{f_{p d}}{f_{b p d}}
$$

donde:

$$
A_{p} \quad \text { Área del alambre de pretensado. }
$$


TESIS DOCTORAL INFLUENCLA DE LA CORROSIÓN EN LA ADHERENCLA DE ALAMBRES EN ELEMENTOS PRETENSADOS DE HORMIGÓN
$\phi \quad$ Diámetro del alambre de pretensado.
$f_{p d} \quad$ Tensión máxima del alambre de pretensado.

Finalmente, se establece el valor de la longitud de transferencia $l_{t}(E q .2-15)$ :

$$
l_{t}=\alpha_{p 1} \cdot \alpha_{p 2} \cdot \alpha_{p 3} \cdot l_{b p} \frac{\sigma_{p, 0}}{f_{p d}}
$$

donde:

$$
\begin{aligned}
& \sigma_{p, 0} \quad \text { Tensión inicial pretensado justo tras la transferencia } \\
& \alpha_{p 1} \quad \text { Coeficiente que tiene en cuenta la velocidad de la transferencia del pretensado. } \\
& \alpha_{p 1}=1.0 \text {, para transferencia gradual; } \\
& \alpha_{p 1}=1.25 \text {, para transferencia súbita. } \\
& \quad \text { Coeficiente que considera el efecto de la acción que se está verificando. } \\
& \alpha_{p 2}=1,0 ; \text { para cálculos de longitud de anclaje en comprobaciones relativas a capacidad a momento } \\
& \text { flector o a esfuerzo cortante (ELU) } \\
& \alpha_{p 2}=0,5 ; \text { para verificación de la tensión transversal debido al desarrollo y distribución del } \\
& \text { pretensado en la zona de anclaje (ELS). } \\
& \text { Coeficiente que considera la influencia de la capacidad adherente } \\
& \alpha_{p 3}=0,5 ; \text { para cordones o cables. } \\
& \alpha_{p 3}=0,7 \text {; para alambres indentados o grafilados. }
\end{aligned}
$$

Como diferencia con respecto a otros códigos, el Código Modelo 2010 introduce la denominada longitud de desarrollo $l_{p}$ (“development length”), entendiéndose ésta como la longitud necesaria para que la distribución de tensiones longitudinales en el hormigón pueda considerarse lineal. Esta longitud es ligeramente superior a la longitud de transferencia. Para una sección rectangular y alambres rectos situados en la parte inferior del elemento de hormigón, la longitud de desarrollo $l_{p}$ puede determinarse como sigue:

$$
l_{p}=\sqrt{h^{2}+\left(0,6 l_{b p t}\right)^{2}}>l_{b p t}
$$

donde:

h Profundidad total de la sección de hormigón 


\subsubsection{Eurocódigo 2 EN 1992-1-1:2004}

La estructura general del cálculo de la longitud de transferencia $l_{t}$ en el Eurocódigo 2 (CEN, 2004) es una adaptación de la recogida en el Código Modelo. El valor de diseño de la tensión de adherencia $f_{b p d}$ en alambres pretensados es determinado mediante la expresión (Eq. 2-13), pero altera el coeficiente que tiene en cuenta el tipo de alambre de pretensado $\eta_{p 1}$, de manera que para alambres indentados toma un valor de 2,7 (frente a 1,4) y para torones de 3 ó 7 alambres, toma un valor de 3,2 (frente a 1,2).

El valor básico de la longitud de transferencia $l_{t}$ se calcula mediante la siguiente expresión (Eq. 2-17):

$$
l_{t}=\alpha_{p 1} \cdot \alpha_{p 3} \cdot \phi \cdot \frac{\sigma_{p, 0}}{f_{b p d}}
$$

En este caso, los valores del coeficiente $\alpha_{p 3}$ también cambian con respecto a los recogidos en el Código Modelo 2010, de manera que para alambres con sección circular toma un valor de 0,25 (frente a 0,7 ) y para torones de 3 ó 7 alambres, toma un valor de 0,19 (frente a 0,5).

El valor de diseño de la longitud de transferencia $l_{t}$ será el resultado de escoger el valor menos favorable de los dos siguientes, en función de la situación de diseño (Eq. 2-18):

$$
l_{t 1}=0,8 l_{t} \quad l_{t 2}=1,2 l_{t}
$$

Normalmente, el valor más bajo se usa para comprobaciones en Estado Límite de Servicio (ELS) y el valor más alto en comprobaciones en Estado Límite Último (ELU).

La longitud de desarrollo $l_{p}$ se calcula según la expresión (Eq. 2-19), teniendo en cuenta que $d$ es la profundidad del alambre con respecto a la cara superior del elemento:

$$
l_{d}=\sqrt{l_{t}^{2}+d^{2}}
$$

Las expresiones del Eurocódigo 2 parten de suponer una distribución constante de la tensión de adherencia $f_{b p d}$ (se denominará $\tau_{b}$ a lo largo de la tesis) a lo largo de la longitud de transferencia $l_{t}$, lo que implica un crecimiento lineal de la fuerza de pretensado en el alambre y de las deformaciones en el hormigón. No obstante, permite utilizar diagramas diferentes al lineal siempre que se justifique adecuadamente.

\subsubsection{Instrucción EHE-08}

En los comentarios al artículo 70.2.3, la EHE-08 indica que la longitud de transferencia de alambres pretensados depende fundamentalmente de tres factores: diámetro del alambre $\phi$, características 
superficiales del mismo y resistencia del hormigón. La Instrucción española de hormigón estructural EHE-08 (Fomento, 2008) opera de manera similar a las dos anteriores a la hora de determinar la longitud de transferencia $l_{t}(E q .2-20)$ :

$$
l_{t}=\alpha_{p 1} \cdot \alpha_{p 2} \cdot \alpha_{p 3} \cdot \phi \cdot \frac{\sigma_{p, 0}}{4 f_{b p d}}
$$

Para los coeficientes $\alpha_{p 1}, \alpha_{p 2}$ y $\alpha_{p 3}$ toma los mismos valores que en el Código Modelo (FIB Special Activity Group 5, 2011), mientras que para la tensión de cálculo de adherencia en el momento de la introducción del pretensado $f_{b p d}$, aporta los valores más representativos arrojados por cordones y alambres grafilados, en función de la resistencia característica a compresión del hormigón $f_{c k}$ (tabla 70.2.3 de la Instrucción) (Tabla 2-1).

Tabla 2-1 Tabla 70.2.3 de la EHE-08)

\begin{tabular}{ccccccc}
\hline \multirow{2}{*}{ Tipo de armadura } & \multicolumn{6}{c}{ Resistencia característica a compresión del hormigón $\mathrm{f}_{\text {ck }}\left(\mathbf{N} / \mathbf{m m}^{2}\right)$} \\
\cline { 2 - 7 } & $\mathbf{2 5}$ & $\mathbf{3 0}$ & $\mathbf{3 5}$ & $\mathbf{4 0}$ & $\mathbf{4 5}$ & $\mathbf{5 0}$ \\
\hline Cordones & 1,4 & 1,6 & 1,8 & 1,9 & 2,1 & 2,2 \\
\hline Alambres grafilados & 1,6 & 1,8 & 2,0 & 2,2 & 2,4 & 2,6 \\
\hline
\end{tabular}

\subsubsection{ACI 318-11}

El Código ACI (ACI Comittee 318, 2002), por su parte, opta por una expresión empírica más simple, basada en investigaciones llevadas a cabo en el final de la década de los 50 y principio de los 60 , con cordones de $1720 \mathrm{MPa}$ de carga unitaria máxima (Tabatabai \& Dickson, 1995). La expresión para el cálculo de la longitud de transferencia $l_{t}$ en el Código ACI es la siguiente (Eq. 2-21):

$$
l_{t}=\frac{1}{21} \sigma_{p, e} \phi
$$

donde:

$\sigma_{p, e} \quad$ Tensión de pretensado efectiva, una vez descontadas las pérdidas de pretensado.

La (Eq. 2-21) es el resultado de adoptar un valor constante de la tensión de adherencia igual a 2,76 $\mathrm{MPa}$. Con dicho valor, al aplicar el equilibrio a cordones de carga unitaria máxima igual $1720 \mathrm{MPa}$, se obtiene dicha expresión.

\subsubsection{Factores que influyen en la adherencia de alambres pretensados}

En su tesis doctoral, Vázquez (2000) lleva a cabo una completa recopilación de los distintos factores mecánicos, reológicos, geométricos y temporales que intervienen en la adherencia de alambres 
pretensados, así como su influencia cualitativa en la longitud de transferencia. En la Tabla 2-2 se resumen dichos factores.

Tabla 2-2 Variables que intervienen en la adherencia de alambres pretensados. Influencia en la longitud de transferencia. Tabla tomada de Várquez. (2000)

\begin{tabular}{|c|c|c|c|c|c|}
\hline Variable & Variación & $\Delta \mathbf{l}_{\mathrm{t}}$ & Variable & Variación & $\Delta \mathbf{l}_{t}$ \\
\hline Diámetro del cordón de pretensado, $\phi$ & $\uparrow$ & $\uparrow$ & Resistencia a tracción del hormigón, $f_{c t}$ & $\uparrow$ & $\downarrow$ \\
\hline Tensión inicial de pretensado, $f_{p, 0}$ & $\uparrow$ & $\uparrow$ & Módulo de rigidez del hormigón, $E_{c}$ & $\uparrow$ & $\downarrow$ \\
\hline Tensión de pretensado en rotura, $f_{p, u}$ & $\uparrow$ & $\uparrow$ & Retracción & $\uparrow$ & $\uparrow$ \\
\hline Pérdidas de pretensado & $\uparrow$ & ¿? & Fluencia & $\uparrow$ & $\uparrow$ \\
\hline Edad de transferencia & $\uparrow$ & $\downarrow$ & Efecto dinámico de cargas aplicadas & $\uparrow$ & $\uparrow$ \\
\hline Rugosidad superficial, $\mu$ & $\uparrow$ & $\downarrow$ & Enfundado parcial del alambre & $\uparrow$ & $\uparrow$ \\
\hline Verticalidad del alambre & $\uparrow$ & $\downarrow$ & Cercanía de la viga a la zona de corte & $\uparrow$ & $\uparrow$ \\
\hline Recubrimiento, $c$ & $\uparrow$ & $\uparrow$ & $\begin{array}{l}\text { Longitud de alambre libre entre } \\
\text { bancadas }\end{array}$ & $\uparrow$ & $\downarrow$ \\
\hline Separación entre alambres & $\uparrow$ & $\downarrow$ & Recubrimiento con mortero epoxi & Sí & $\downarrow$ \\
\hline $\begin{array}{l}\text { Compacidad del hormigón alrededor } \\
\text { del alambre }\end{array}$ & $\uparrow$ & $\downarrow$ & $\begin{array}{l}\text { Tratamiento térmico: curado } \\
\text { acelerado }\end{array}$ & Sí & $\uparrow$ \\
\hline Armadura de confinamiento & $\uparrow$ & $\downarrow$ & Tiempo desde la transferencia & $\uparrow$ & $\uparrow$ \\
\hline Resist. a compresión del hormigón, $f_{c}$ & $\uparrow$ & $\downarrow$ & $\begin{array}{l}\text { Espesor de hormigón fresco debajo } \\
\text { del alambre }\end{array}$ & $\uparrow$ & $\uparrow$ \\
\hline Tamaño de árido, $d_{a}$ & $\uparrow$ & $\uparrow$ & Velocidad de transferencia & $\uparrow$ & $\uparrow$ \\
\hline Relación agua/cemento, $a / c$ & $\uparrow$ & $\uparrow$ & Altura de indentaciones, $b_{r}$ & $\uparrow$ & $\uparrow \downarrow$ \\
\hline
\end{tabular}

Como puede apreciarse, la corrosión no aparece entre los factores que determinan las propiedades adherentes en alambres pretensados, principalmente porque son escasos los estudios que analizan su influencia. Los pocos trabajos existentes [ (Thang, et al., 2007), (Coronelli, et al., 2009), (Dai, et al., 2016) muestran que los productos de corrosión, superado un determinado umbral, inducen el deterioro de las propiedades adherentes de los alambres en elementos pretensados. Esta escasez de trabajos apoya la necesidad de la investigación llevada a cabo en esta tesis.

Con carácter general se puede afirmar que la longitud de transferencia en un elemento pretensado es inversamente proporcional a la tensión de adherencia media $\tau_{b, \text { med }}$ a lo largo de la misma (Eq. 2-5). Por otro lado, aunque se desarrollará en profundidad en el Capitulo 3 de la presente tesis, se sabe que la tensión de adherencia entre el hormigón y el acero es aproximadamente proporcional a la tensión radial $\sigma_{r}$ existente en la interfaz y al coeficiente de fricción $\mu$ entre ambos materiales (obviando la contribución de la tensión de adherencia debida al mecanismo de adhesión $\left.\tau_{b, a d b}\right)$ :

$$
\tau_{b}=\mu \sigma_{r}
$$

Por tanto, cualquier factor o variable que mejore la capacidad de confinamiento del recubrimiento, posibilitará que se puedan alcanzar mayores tensiones radiales $\sigma_{r}$, lo que traerá consigo un incremento 
de la tensión de adherencia $\tau_{b}$ y con ella, una disminución de la longitud de transferencia $l_{t}$ del pretensado. Por el contrario, la variación de un factor que suponga un incremento de las tensiones radiales $\sigma_{r}$ y circunferenciales $\sigma_{\vartheta}$ a las que es sometido el recubrimiento puede derivar en la fisuración del hormigón, con la consiguiente merma de la capacidad de confinamiento y el aumento de la longitud de transferencia $l_{\text {t }}$ Por otro lado, y como consecuencia de la expresión (Eq. 2-22), la longitud de transferencia del pretensado será inversamente proporcional al coeficiente de fricción $\mu, \mathrm{y}$ cualquier factor o fenómeno que lo modifique tendrá repercusión en la longitud de transferencia del pretensado $l_{t}$.

Partiendo de esta consideración, en los siguientes apartados se recogen algunos de los estudios e investigaciones que se han llevado a cabo en las últimas décadas para determinar el grado de influencia de distintas variables, principalmente geométricas y mecánicas, en el comportamiento adherente entre el acero y el hormigón, centrados preferentemente en alambres y cordones pretensados, pero incluyendo también aquellos relativos a armaduras sin pretensar. Entre estos últimos, aunque existe más información relativa a armaduras corrugadas, se han seleccionado aquellos trabajos realizados sobre alambres lisos y/o indentados, dado que esta tesis incluye una completa campaña experimental sobre este tipo de alambres. En definitiva, se considera que el principal factor distintivo del pretensado es el efecto Hoyer, que aumenta las tensiones radiales a las que es sometido el recubrimiento de hormigón en la zona de transferencia, por lo que es razonable que pueda estudiarse la adherencia en elementos pretensados conjuntamente con la existente en elementos de hormigón armado.

\subsubsection{Resistencia a compresión del hormigón}

En 1949, Freyssenet escribió: "El valor máximo de tensión de adherencia que puede alcanzarse depende de la fricción y de la máxima presión que el hormigón puede ejercer sobre el alambre; esta presión depende a su vez de la resistencia a tracción y de la dureza del hormigón que rodea el alambre. Por tanto, el funcionamiento del anclaje por adherencia depende de la calidad del hormigón." La resistencia a compresión del hormigón $f_{c}$ es una propiedad mecánica del recubrimiento de hormigón relacionada estrechamente con la capacidad de confinamiento del mismo, por lo que tiene una gran influencia en el comportamiento adherente de alambres embebidos en hormigón. Cuanto mayor sea la resistencia a tracción del hormigón (vinculada a fo, mayor será la capacidad del recubrimiento para soportar las tensiones circunferenciales $\sigma_{\theta}$ a las que es sometido, retrasando la fisuración y posibilitando que se alcance una mayor tensión radial $\sigma_{r}$ y, en virtud de la (Eq. 2-22), una mayor tensión de adherencia $\tau_{b}$. Esta influencia, tal y como se ha visto en el Apartado 2.2.6, queda reflejada en la mayor parte de códigos estructurales, donde a longitud de transferencia del pretensado es inversamente proporcional a la resistencia a tracción del hormigón $f_{c \text { c }}$

En 1958, Ratz et al. (1958), en ensayos sobre probetas de hormigón pretensadas con cordones de 7 alambres, con resistencias a compresión situadas en el rango entre 20 y $50 \mathrm{MPa}$ en el momento del destesado, encontraron que la tensión de adherencia dependía en "un alto grado" de la resistencia del hormigón. En la misma dirección apuntaron Rüsch \& Rehm (1963), al observar que las longitudes de transferencia de los elementos pretensados ensayados disminuían con el aumento de la resistencia a compresión $f_{c}$, a pesar de la alta dispersión de los resultados obtenidos. 
Kaar \& al. (1963) midieron la longitud de transferencia en 36 probetas fabricadas con el mismo hormigón, pero cuya resistencia a compresión variaba debido a que el destesado se llevó a cabo para distintas edades, de 1 a 30 días. En cuanto a los cordones, se emplearon diámetros en el rango entre 6,6 y 15,2 mm. Para diámetros de cordón de hasta 12,7 mm, los resultados mostraron una variación no sistemática de la longitud de transferencia con respecto al cambio en la resistencia a compresión del hormigón. Para la serie de probetas con cordones de 15,2 $\mathrm{mm}$, la longitud de transferencia decrecía con el incremento de la resistencia a compresión.

Olesniewicz (1975) llevó a cabo una extensa evaluación estadística sobre medidas tomadas en estructuras reales y en ensayos de laboratorio, con hormigones cuya resistencia a compresión en el momento de la transferencia, medida en probeta cúbica $\left(f_{c i}\right)$, oscilaban entre 20 y $50 \mathrm{MPa}$. Los resultados obtenidos le permitieron desarrollar una expresión en la que la longitud de transferencia $l_{t}$ era inversamente proporcional a la raíz cuadrada de la resistencia a compresión del hormigón (Eq. 2-23):

$$
l_{t}=\psi \cdot \phi \cdot \sqrt{\frac{\sigma_{p, i}}{f_{c c i}}}
$$

donde $\sigma_{p, i}$ es la tensión en el alambre justo después de la transferencia del pretensado y $\psi$ es un coeficiente para determinar el límite inferior, medio y superior de la longitud de transferencia $l_{t}$, tomando respectivamente un valor igual a 7, 10 y 13.

Zia \& Mostafa (1977), basándose en una extensa revisión bibliográfica, desarrollaron una nueva ecuación para la determinación de la longitud de transferencia. Esta expresión (Eq. 2-24) dependía del diámetro nominal del cordón $\phi$, de la tensión del alambre justo después del destesado $\sigma_{p, i}$ y de la resistencia del hormigón en el momento del destesado $f_{i ;}$ y era aplicable para hormigones cuya resistencia a compresión se encontraba en el rango entre 40 y $56 \mathrm{MPa}$.

$$
l_{t}=1.3 \cdot \frac{\sigma_{p, i}}{f_{c i}} \phi-58[\mathrm{~mm}]
$$

Balázs (1992) desarrolló un modelo analítico, basado en la relación tensión de adherenciadeslizamiento, que permitía la determinación de la longitud de transferencia $l_{t}$ y del deslizamiento del alambre en el extremo del elemento pretensado $\delta_{d}$, teniendo en cuenta el pretensado inicial $\sigma_{p, 0}$ o el efectivo $\sigma_{p, e}$, la resistencia a compresión del hormigón $f_{c}$ y el diámetro del alambre $\phi$. Para cordones de 12,8 mm de diámetro, Balázs propone la siguiente expresión (Eq. 2-25):

$$
l_{t}=K_{1} \phi \cdot \sqrt[5]{\frac{\sigma_{p, e^{3}}}{f_{c i}{ }^{2}}}
$$

donde $K_{1}$ es un coeficiente complejo, dependiente de parámetros geométricos y mecánicos del hormigón y del acero, que para alambres de 12,8 mm toma un valor de 3,11 (Balazs, 1992). Como puede observarse, Balázs propone que la longitud de transferencia $l_{t}$ sea inversamente proporcional a la resistencia del hormigón en el momento del destesado $f_{c i}$, elevada a 0,4 . 
Mitchell et al (1993) llevaron a cabo una campaña experimental sobre 22 vigas rectangulares, pretensadas excéntricamente con un único cordón. Las variables contempladas fueron el diámetro del cordón $(9,5 ; 12,7$ y $15,7 \mathrm{~mm})$, la tensión de pretensado inicial $\sigma_{p, 0}$ y tras el destesado $\sigma_{p, i}$, así como la resistencia del hormigón en el momento de la transferencia $\left(f_{c i}=21-50 \mathrm{MPa}\right)$. La menor distancia desde el centro del cordón hasta la superficie del hormigón fue en todos los casos de 50 $\mathrm{mm}$. Los resultados obtenidos mostraron que la resistencia del hormigón tenía una clara influencia sobre la longitud de transferencia, similar a la propuesta por Olesniewicz (1975), de manera que podían ser descritos con razonable precisión por la siguiente expresión (Eq. 2-26):

$$
l_{t}=\frac{\phi \cdot \sigma_{p, i}}{21} \sqrt{\frac{20}{f_{c i}}}[\mathrm{~mm}]
$$

Den Uijl (1995), usando los resultados de los ensayos sobre elementos pretensados llevados a cabo por Vossen (1994), evaluó la influencia de la resistencia del hormigón sobre la longitud de transferencia. Para ello utilizó como base la expresión (Eq. 2-23), desarrollada por Olesniewicz, y determinó nuevos valores para el coeficiente $\psi: 14,91 ; 9,76$; 4,61; correspondientes con el límite inferior, medio y superior de la longitud de transferencia $l_{t}$. Por otro lado, tal y como señala la monografía del CEB-FIB (2000), de los resultados obtenidos por Vossen (1994) se puede concluir que para obtener un valor del coeficiente $\psi$ constante, y por tanto una relación de proporcionalidad inversa perfecta entre la longitud de transferencia y la resistencia a compresión del hormigón, habría que tener en cuenta una mayor influencia de este último parámetro. Los resultados experimentales de Vossen requerirían que la resistencia a compresión del hormigón se elevase a 0,8 en el denominador de la ecuación (Eq. 2-23), lo que supone un valor intermedio entre el propuesto por Olesniewicz (1975) y Mitchell et al. (1993), $f_{c}^{0.5}$, y el propuesto por Zia \& Mostafa (1977), $f_{c}^{1.0}$.

Más recientemente, Martí-Vargas et al. (2007) llevaron a cabo una investigación experimental para determinar la longitud de transferencia en elementos pretensados con cordones de 7 alambres, de 13 mm de diámetro y con diferentes calidades de hormigón. Los resultados obtenidos les permitieron desarrollar una expresión simplificada en la que la longitud de transferencia dependía de la resistencia a compresión elevada a 0,67 (Eq. 2-27):

$$
l_{t}=\psi \cdot \frac{4.7 \cdot \sigma_{p, e}}{f_{c i}^{0.67}}
$$

Como puede observarse, la ecuación (Eq. 2-27) depende de la tensión de pretensado efectiva $\sigma_{p, e}$, una vez descontadas las pérdidas de pretensado, y del coeficiente $\psi$ que toma un valor de 1 para el valor medio, y de 0,5 y 1,5 para los límites inferior y superior de la longitud de transferencia. La potencia a la que se eleva la resistencia a compresión del hormigón $(0,67 \approx 2 / 3)$ la relaciona directamente con su resistencia a tracción $f_{c t}$ lo que es coherente con la mayoría de los códigos estructurales. En la misma línea, han sido numerosos los trabajos de investigadores como Goto (1971), Tepfers (1973) o Weerasekera (Weerasekera, 2009), tanto en hormigón armado como pretensado, que han señalado que es la resistencia a tracción, de la que depende la fisuración del 
recubrimiento, y no tanto la resistencia a compresión, el factor fundamental en la adherencia entre el hormigón y el acero, y como consecuencia, en la longitud de trasferencia del pretensado.

\subsubsection{Influencia del espesor de recubrimiento}

El aumento en el espesor de recubrimiento $c$ mejora la capacidad de confinamiento del hormigón, por lo que permite que se alcancen mayores tensiones radiales $\sigma_{r}$, lo que se traduce en un aumento de la tensión de adherencia $\tau_{b}$ y, consecuentemente, en una reducción de la longitud de transferencia $l_{\text {s. }}$

Sin embargo, el espesor de recubrimiento es un factor que suele obviarse en las expresiones para la determinación de la longitud de transferencia recogidas en los códigos estructurales, cuando sí se tiene en cuenta para determinar la capacidad adherente en armaduras sin pretensar. Por ejemplo, en el Código Modelo 2010 (CEB-FIP, 2012), la capacidad adherente de diseño de armaduras en hormigón armado, denominada $f_{b d}$, puede ser modificada, partiendo de la capacidad de adherencia básica $f_{b d, 0}$, si las condiciones reales del elemento difieren de los requerimientos mínimos previstos para factores tales como el recubrimiento de hormigón $c$, el espacio entre barras o la cuantía de armadura transversal. El Código Modelo 2010 propone la siguiente expresión (Eq. 2-28):

$$
f_{b d}=\left(\alpha_{2}+\alpha_{3}\right) f_{b d, 0}-2 p_{t r}<2.0 f_{b d, 0}-0.4 p_{t r}<\left(1.5 / \gamma_{c b}\right) \sqrt{f_{c k}}
$$

donde:

$a_{2} y a_{3}$ representan la influencia del confinamiento pasivo proporcionado por el recubrimiento ( $a_{2}$ ) y por la armadura transversal $\left(a_{3}\right)$. La adopción de los minimos normativos garantiza que $a_{2} y a_{3}$ pueden tomar un valor igual 1, del lado de la seguridad.

ptr es la tensión media de compresión perpendicular a la potencial superficie de fallo por splitting en Estado Limite Último; cuando la compresión transversal perpendicular al eje de la barra actúa sobre una parte de la longitud adherente, la adherencia puede verse incrementada en esa parte. ptr es negativo cuando la tensión transversal es de compresión.

El Código Modelo considera que la armadura no se encuentra confinada si el recubrimiento geométrico es menor al diámetro de la armadura $\phi$. Por el contrario, plantea un confinamiento extra para aquellos recubrimientos que superan ese valor. Por lo tanto, para recubrimientos que difieren de del mínimo normativo propone la siguiente modificación del coeficiente $\alpha_{2}$ (Eq. 2-29):

$$
\alpha_{2}=\left(\frac{c_{\min }}{\phi}\right)^{0.5} \cdot\left(\frac{c_{S}}{2 c_{\min }}\right)^{0.5}
$$

donde $c_{\text {min }}$ es el menor recubrimiento geométrico, y $c_{s}$ es el espacio ente armaduras. Por otra parte, establece un rango de aplicación $c_{\min } / \phi$ entre 0.5 y 3 , lo que implica que para relaciones recubrimiento diámetro por debajo de 1 la capacidad de adherencia básica se ve mermada, mientras que para valores 
por encima 1 se produce un incremento de las prestaciones adherentes. Para relaciones recubrimiento/diámetro superiores a 3 , no se contempla ninguna mejora.

Esta clara influencia del espesor de recubrimiento en la capacidad adherente de armaduras embebidas en hormigón ha sido ampliamente estudiada. En el CEB Bulletin nº151 (CEB, 1982) se recogen los resultados experimentales de diferentes estudios sobre ensayos tipo pull-out con barras corrugadas, para distintos recubrimientos. Los resultados de tensión de adherencia $\tau_{b}$, normalizada mediante la resistencia a tracción del hormigón $f_{c t}$, frente a la relación recubrimiento/diámetro $c / \phi$, muestran una clara tendencia por la cual la tensión de adherencia mejora con el aumento del espesor de recubrimiento.

Schenkel \& Vogel (1997) llevaron a cabo una campaña experimental con ensayos de pull-out sobre probetas con longitudes de anclaje cortas, $l_{b} / \phi=2$, barras corrugadas y distintas relaciones recubrimiento/diámetro $c / \phi$. Los resultados obtenidos permitieron concluir que las prestaciones adherentes mejoraban hasta alcanzar una determinada relación $c / \phi$, comprendida en el rango entre 2 y 3, y que a partir de ese valor límite, el incremento del espesor de recubrimiento no suponía una mejora en el valor máximo de la tensión de adherencia (ver Figura 2-10).

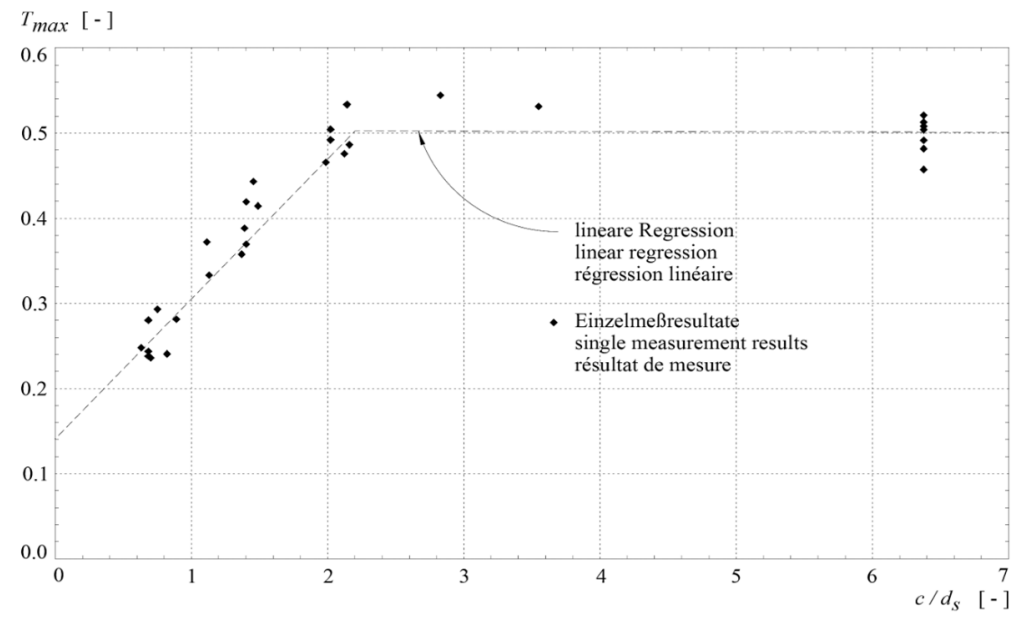

Figura 2-10 Tensión de adherencia normalizada $\tau_{b} / f_{c}$ frente a relación recubrimiento/ diámetro c/ $\phi$. Figura tomada de Schenkel \& Vogel (1997)

En cuanto a los alambres o barras con acabado superficial liso, destaca el trabajo pionero de Abrams (1913), en la Universidad de Illinois, quien en 1913 emprendió una campaña experimental que constaba de 1500 ensayos de pull-out, sobre probetas fabricadas con barras de $19 \mathrm{~mm}$ de diámetro, con una longitud adherente de $203 \mathrm{~mm}$ y recubrimientos variables entre $38 \mathrm{~mm}(\mathrm{c} / \varphi=2)$ y $152 \mathrm{~mm}$ $(c / \varphi=8)$. Los resultados muestran claramente un incremento de la capacidad adherente hasta recubrimientos de $76 \mathrm{~mm}(\mathrm{c} / \varphi=4)$, y un leve descenso cuando los recubrimientos aumentan de 76 a $152 \mathrm{~mm}$ (Figura 2-11). Para L. Feldman (2006), esta observación podría indicar que el fallo en la probeta estuviera controlado por dos modos distintos, fisuración longitudinal (splitting) para recubrimientos pequeños, y fallo por deslizamiento de la armadura (pull-out) para recubrimientos grandes. 


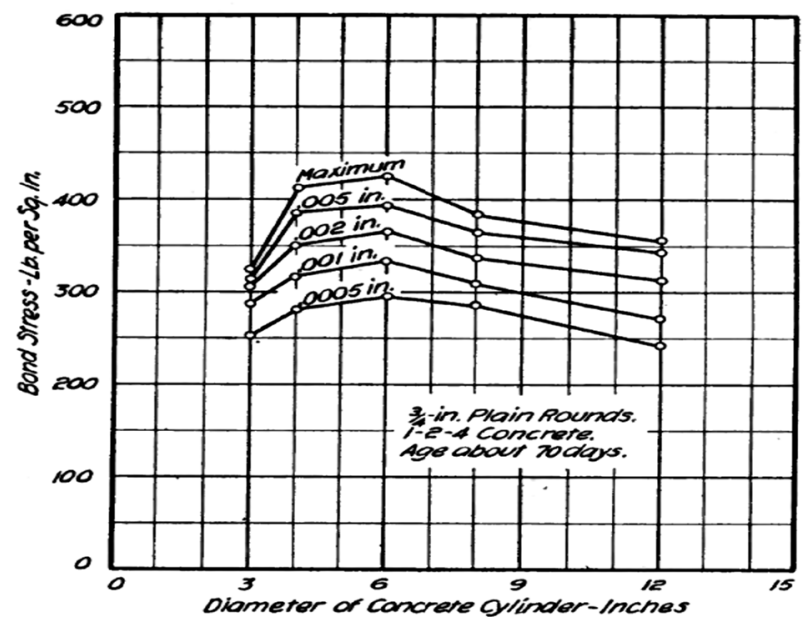

Figura 2-11 Tensión de adherencia para barras lisas de $19 \mathrm{~mm}$ (3/4 inch.) de diametro en función del recubrimiento, para distintos deslizamientos. (Abrams, 1913)

Balwin y Clark (1995) realizaron ensayos de pull-out combinando distintas variables: longitud de adherencia $l_{a d b}$, tipo de acabado superficial de la armadura (lisa y corrugada), resistencia a compresión del hormigón $f_{c}$ y recubrimiento $c$. Analizaron cuatro tipos de recubrimiento: equivalentes a $1,2,4 \mathrm{y}$ 6 diámetros de la armadura $(c / \phi=1,2,4,6)$, observando que mientras que el comportamiento adherente de las barras lisas parece totalmente independiente del recubrimiento, en las barras corrugadas si se puede apreciar cierta influencia del mismo (Figura 2-12). Los autores concluyen que, para barras corrugadas, la resistencia adherente se incrementa con el recubrimiento a razón de $0,18 \mathrm{~N} / \mathrm{mm}$ por $\mathrm{mm}^{2}$ para relaciones recubrimiento/diámetro comprendidas entre 2 y 4 , manteniéndose constante para recubrimientos mayores.

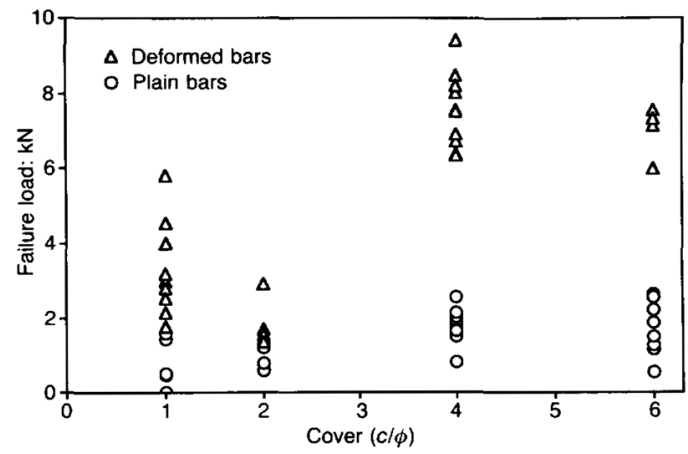

Figura 2-12 Influencia del recubrimiento sobre la carga de fallo por adherencia en ensayos pull-out. Balwin y Clark, 1995.

Ya más recientemente, J. Cairns, en su documento de trabajo "Bond of plain round bars" (2004) para el Task Group 4.5 del FIB expone que las barras corrugadas sometidas a una fuerza de tracción fallan típicamente por fisuración del recubrimiento del hormigón circundante. Este fallo tiene lugar cuando se agota la capacidad del anillo de tracciones alrededor de la barra, por lo que el recubrimiento mínimo es un parámetro determinante en el comportamiento adherente. Sin embargo, el fallo adherente de las barras lisas suele ocurrir por deslizamiento de la barra (pull-out), por lo que tradicionalmente se ha considerado que el recubrimiento no tiene influencia en la máxima tensión de adherencia que 
pueden desarrollar. Cairns recopila varias pequeñas campañas experimentales basadas en su mayoría en pull-out excéntricos sobre barras lisas, llevadas a cabo por diversos investigadores, en las que se aprecia una gran heterogeneidad de resultados. Son las siguientes:

Metzinger H. Internal report, Heriot-Watt University, 2002: Ensayos sobre barras lisas de $16 \mathrm{~mm}$ de diámetro, con $300 \mathrm{~mm}$ de longitud de adherencia $\left(l_{a d h}=18,75 \phi\right)$ y armadura transversal, usando como variables la resistencia del hormigón $f_{c}$, la posición durante el hormigonado y el recubrimiento $c$. Concluyen que los cercos no tienen repercusión en el comportamiento adherente de barras lisas pero, sin embargo, la posición durante el hormigonado y el recubrimiento sí que tienen una significativa influencia. Por ejemplo, detectan un aumento de la tensión de adherencia de cerca de un $40 \%$ entre las armaduras con un ratio $c / \phi=1$ y las que tienen $c / \phi=2,8$, sea cual sea su posición durante el hormigonado (Figura 2-13-irq.)

Caims, Du and Law: Internal report, Heriot-Watt University, 2002: Ensayos con una configuración similar a los anteriores (aunque incluyeron la corrosión como parámetro) en los que se comprobó que en las barras lisas situadas en posición favorable durante el hormigonado (Posición I en normativa española) experimentaban un aumento en la tensión adherente de una 46\% cuando el espesor de recubrimiento aumentaba de un diámetro $(16 \mathrm{~mm})$ a tres diámetros $(48 \mathrm{~mm})$. En las barras situadas en la parte superior durante el hormigonado (Posición II en normativa española) no se apreció que el recubrimiento tuviera una influencia significativa.

También se observó que, para cantidades modestas de corrosión, se eliminaban las diferencias de comportamiento entre las barras con distintas posiciones durante el hormigonado, reflejándose una importante influencia del recubrimiento en ambos casos.

Kelly J.: Internal report, Heriot-Watt University, 2003: Ensayos sobre barras lisas de $16 \mathrm{~mm}$ de diámetro, con $300 \mathrm{~mm}$ de longitud de adherencia $\left(l_{a d h}=18,75 \phi\right)$, usando como variables dos resistencias a compresión del hormigón $f_{c}(26,8 \mathrm{MPa}$ y $36,0 \mathrm{MPa}$ ), la posición durante el hormigonado (favorable y desfavorable), el uso de cercos y distintos recubrimientos ( $16 \mathrm{~mm}, 30 \mathrm{~mm}$ y $45 \mathrm{~mm}$ ). Los resultados obtenidos permiten concluir que la influencia del recubrimiento $c$ sobre la tensión de adherencia $\tau_{b}$ en barras lisas es similar a la recogida para barras corrugadas en el Código Modelo del 90 (Figura 2-13der.).
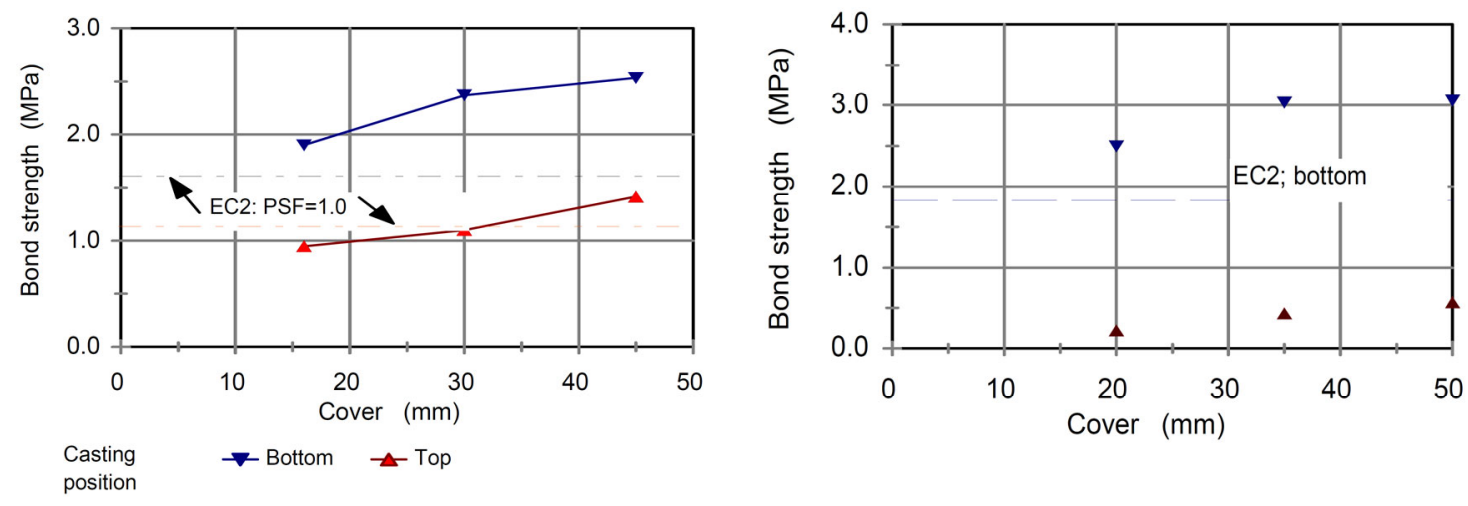

Figura 2-13 Influencia del recubrimiento c sobre la tensión de adherencia $\tau_{b}$ de barras lisas. Ensayos llevados a cabo por Metzinger, H. (izquierda) y Kelly, J. (derecha) (Cairns, 2004) 
Spring D.: Internal report, Herio-Watt University, 2004: Ensayos sobre uniones solapadas de barras de 12 $\mathrm{mm}$ de diámetro ("lapped joints in beam"), con $300 \mathrm{~mm}$ de longitud de adherencia $\left(l_{b}=25 \phi\right)$. Como en el caso anterior, las variables contempladas fueron dos resistencias del hormigón $f_{c}$ (32,0 MPa y 47,5 $\mathrm{MPa}$ ), la posición durante el hormigonado, el uso de armadura transversal y distintos espesores de recubrimiento. Los resultados obtenidos muestran una gran dispersión, pero concluyen que el máximo valor de la tensión de adherencia aumenta de media un $24 \%$ cuando el recubrimiento $c$ aumenta de 1,25 a 2,5 veces el diámetro, similar al contemplado por el MC90 para barras corrugadas (Figura 2-14-irq.).

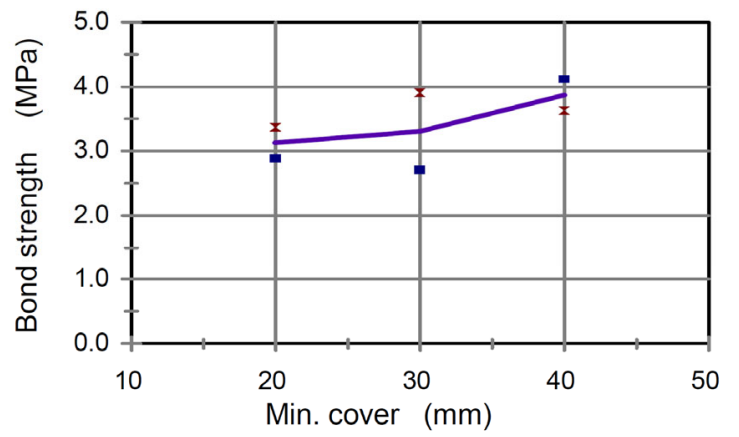

- Series A × Series B - Mean

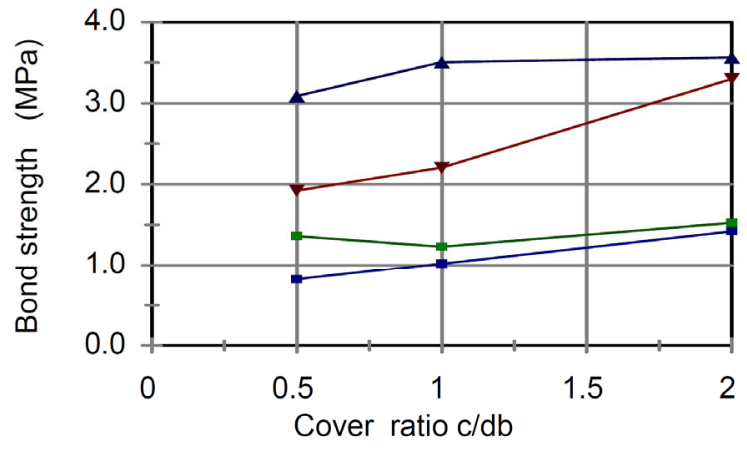

$\leftarrow$ Side $\rightarrow$ - Corner $\rightarrow$-Side $\rightarrow$ - Corner

Figura 2-14 Influencia del recubrimiento c sobre la tensión de adherencia $\tau_{b}$ de barras lisas. Ensayos llevados a cabo por Spring, D. (izquierda) y V ranas and Gorst (derecha) (Cairns, 2004)

Vranas and Gorst: Internal report, University of Birmingham: Ensayos tipo viga sobre barras lisas de 8 y 16 $\mathrm{mm}$ de diámetro, con $150 \mathrm{~mm}$ de longitud de adherencia $\left(l_{a d h}=9,4 \phi\right.$ y $\left.18,75 \phi\right)$, usando como variables la resistencia del hormigón, la posición durante el hormigonado (lateral o en esquina), y el espesor de recubrimiento $c$. Observaron una relación bastante clara entre la tensión de adherencia y el recubrimiento mínimo, particularmente relevante para las ubicadas en esquina (Figura 2-14-der).

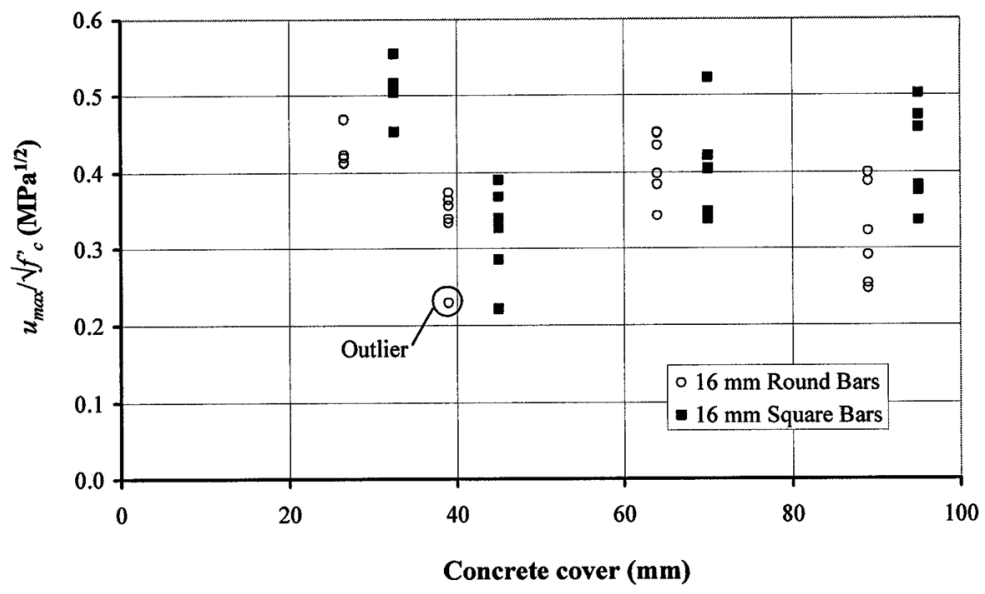

Figura 2-15 Influencia del recubrimiento sobre la tensión de adherencia normalizada (Feldman, 2006) 
Por su parte, L. R. Feldman, en su tesis "Bond of Plain Steel Reinforcement in Concrete" (Feldman, 2006) observó que la relación entre la capacidad adherente normalizada es independiente del recubrimiento del hormigón para armaduras lisas. Esta observación se justifica por el hecho de que en las barras lisas no existe acuñamiento mecánico entre el hormigón y las corrugas, por lo que se reduce la posibilidad de fallo por fisuración (splitting), independizándose la influencia del recubrimiento del hormigón (Figura 2-15).

Cairns et al. (2006) llevaron a cabo una campaña experimental de ensayos de pull-out excéntricos sobre probetas prismáticas de hormigón con una sección transversal de 200x300 mm, con cuatro barras lisas de $16 \mathrm{~mm}$ de diámetro situadas en cada una de las esquinas, una longitud de adherencia de $300 \mathrm{~mm}\left(l_{a d h} \sim 18,75 \phi\right)$ y recubrimientos variables de $16(c / \phi=2), 32(c / \phi=3)$, y $48 \mathrm{~mm}(c / \phi=3)$. Cairns concluyó que el incremento del espesor de recubrimiento incrementa la capacidad adherente de barras lisas, señalando que es un efecto no contemplado en la mayoría de los códigos estructurales.

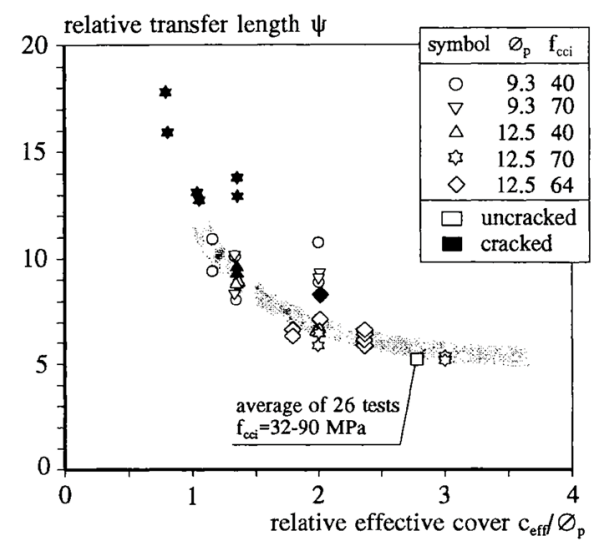

Figura 2-16 Longitud de transferencia relativa $\psi$ en función del recubrimiento efectivo ceff (den Ujil, 1998).

Coherentemente con lo expuesto hasta ahora para barras sin pretensar, los estudios existentes sobre elementos pretensados muestran una mejora de las propiedades adherentes de los alambres/cordones al aumentar es espesor de recubrimiento. En 1995, Den Uijl (1998) llevó a cabo una investigación sobre la longitud de transferencia en elementos pretensados con hormigones de alta resistencia. El principal objetivo de estos trabajos fue estimar el recubrimiento mínimo necesario para prevenir el fallo adherente por fisuración (splitting). Para ello, la longitud de transferencia fue medida sobre 13 probetas rectangulares de hormigón, pretensadas con uno o dos cordones de 9,3 $\mathrm{mm}$ o 12,5 $\mathrm{mm}$ de diámetro. La tensión de pretensado inicial $\sigma_{p, 0}$ fue de $1570 \mathrm{MPa}$ en los cordones de 9,3 $\mathrm{mm}$ de diámetro y de $1340 \mathrm{MPa}$ en los de $12,5 \mathrm{~mm}$, y fue transferida tras 12 y 19 horas de curado del hormigón, con resistencias a compresión $f_{c}$ de 40 y $70 \mathrm{MPa}$, y resistencias a tracción $f_{c t}$ de 4,1 y 5,2 $\mathrm{MPa}$, respectivamente. Por otro lado, se utilizaron distintos recubrimientos geométricos $c \mathrm{y}$ separación entre alambres $s(c / \phi=1,36-3,0$ y $s / \phi=0,4-1,23)$. Con estas condiciones, Den Uijl determinó un recubrimiento efectivo $c_{e f f}$, suponiendo que el hormigón situado entre cordones podía asumir de manera más eficaz las tensiones de tracción circunferenciales $\sigma_{\vartheta}$ derivadas del desplazamiento radial provocado por el efecto Hoyer y por el deslizamiento de los cordones. Para aislar el efecto del recubrimiento efectivo $c_{e f f}$, den Uijl utiliza una longitud de transferencia relativa $\psi$, normalizada en función del diámetro del cordón de pretensado $\phi$, de la resistencia a compresión del 
hormigón en el momento del destesado $f_{c i}$ y de la tensión del alambre justo después de la transferencia $\sigma_{p i}$

Los resultados obtenidos permitieron concluir que la longitud de transferencia relativa $\psi$ disminuía de manera apreciable con el crecimiento de recubrimiento efectivo $c_{e f f}$. Este comportamiento se justificaba por una respuesta no lineal del hormigón al acuñamiento mecánico del cordón de pretensado, de manera que un mayor recubrimiento suponía un aumento en la linealidad de la respuesta. Esta mejora se producía hasta alcanzar relaciones recubrimiento efectivo/diámetro $c_{e f f} / \phi$ entre 3 y 4, límite a partir del cual no se detectaba una reducción significativa de la longitud de transferencia (ver Figura 2-16).

Posteriormente, Oh \& Kim (2000) midieron la longitud de transferencia en 36 vigas pretensadas excéntricamente, de $3000 \mathrm{~mm}$ de longitud, $200 \mathrm{~mm}$ de canto y ancho variable. Las principales variables contempladas fueron el número de cordones por viga (1 ó 2), el diámetro nominal del cordón $\phi\left(12,7\right.$ y 15,2 mm), la resistencia a compresión del hormigón $f_{c}$ (35 y $\left.45 \mathrm{MPa}\right)$, el recubrimiento geométrico mínimo $c(30,40$ y $50 \mathrm{~mm})$ y la separación existente entre cordones $s(3 \phi$, $4 \phi$ y $5 \phi$ ). Para la determinación de las longitudes de transferencia se utilizó el "Método del $95 \%$ de la media de las deformaciones máximas"("95\% Average Maximun Strain Method (AMS)"), expuesto en el Apartado 2.2.5.4. Los resultados obtenidos, para los distintos recubrimientos geométricos, diámetros del alambre y resistencias a compresión del hormigón, así como su comparación con las longitudes de transferencia que predice el Código ACI, se resumen en la Tabla 2-3.

Tabla 2-3 Longitudes de transferencia según el recubrimiento geométrico, el diámetro del cordón y la resistencia a compresión del hormigón (Ob \& Kim, 2000)

\begin{tabular}{|c|c|c|c|c|c|}
\hline & & \multicolumn{3}{|c|}{ Longitud de transferencia media [mm] } & \multirow{2}{*}{$\begin{array}{l}\text { Long. de transf. } \\
\text { (ACI) }[\mathrm{mm}]\end{array}$} \\
\hline & & $\mathrm{c}=30 \mathrm{~mm}$ & $\mathrm{c}=40 \mathrm{~mm}$ & $\mathrm{c}=50 \mathrm{~mm}$ & \\
\hline \multirow{2}{*}{$\phi=12.7 \mathrm{~mm}$} & $\mathrm{f}_{\mathrm{c}}=35 \mathrm{MPa}$ & 781 & 619 & 554 & \multirow{2}{*}{842} \\
\hline & $\mathrm{f}_{\mathrm{c}}=45 \mathrm{MPa}$ & 591 & 523 & 486 & \\
\hline \multirow{2}{*}{$\phi=15.2 \mathrm{~mm}$} & $\mathrm{f}_{\mathrm{c}}=35 \mathrm{MPa}$ & 1006 & 793 & 665 & \multirow{2}{*}{924} \\
\hline & $\mathrm{f}_{\mathrm{c}}=45 \mathrm{MPa}$ & 825 & 675 & 544 & \\
\hline
\end{tabular}

Oh \& Kim concluyeron que la longitud de transferencia aumenta significativamente con la reducción del recubrimiento. También detectaron que las longitudes de transferencia que predice el Código ACI podían ser inseguras en el caso de espesores de recubrimiento pequeños, señalando la necesidad de que los códigos estructurales introdujeran el espesor de recubrimiento como una variable determinante en la adherencia de elementos pretensados.

Por último, tal y como indica Caro Forero (2012), a lo largo de las últimas décadas numerosos investigadores han señalado que la relación recubrimiento/diámetro tiene una influencia fundamental en el modo de fallo adherente (Thorsen (1954), Martí-Vargas (2002) y Kommer (2004)). Así, para relaciones recubrimiento/diámetros superiores a 4, el fallo se produciría por arrancamiento (pull-out), siendo el fallo por fisuración longitudinal (splitting) el mecanismo predominante para relaciones inferiores a 2,5. 


\subsubsection{Geometría del alambre/ cordón de pretensado}

El parámetro fundamental que describe la geometría de un alambre o cordón de pretensado es su diámetro $\phi$. Tal y como se recoge en la monografía dedicada a la adherencia del CEB-FIB (CEBFIB_Task Group 2.5, 2000), bajo la hipótesis de una tensión uniforme a lo largo de la longitud de transferencia y de una magnitud de la tensión de adherencia independiente del diámetro, la longitud de transferencia es directamente proporcional al diámetro del alambre/cordón (Eq. 2-5). La mayor parte de los códigos estructurales de hormigón recogen esta relación [ (CEN, 2004), (Fomento, 2008), (CEB-FIP, 2012), (ACI Comittee 318, 2002)], así como una inmensa mayoría de los modelos desarrollados por investigadores para la determinación de longitudes de transferencia. En este último grupo se incluyen las expresiones propuestas, entre otros, por Zia \& Mostafa (1977), Balázs (1992), Mitchell et al. (Mitchell, et al., 1993), den Uijl (1998) o Martí-Vargas et al. (Martí-Vargas, et al., 2007), que han sido expuestas en el Apartado 2.2.7.1.

En realidad, la tensión de adherencia no es constante a lo largo de la longitud de transferencia, por lo que algunos investigadores han intentado establecer la proporcionalidad exacta entre esta longitud y el diámetro del alambre/cordón de pretensado. Russell \& Burns (1996) midieron la longitud de transferencia en vigas pretensadas con alambres de $12,7 \mathrm{~mm}(0,5$ ") y $15,2 \mathrm{~mm}(0,6$ "), contemplando una amplia variedad de parámetros, tales como la separación entre cordones, la armadura de confinamiento, el número de cordones por viga o el tamaño y la forma de la sección transversal de hormigón. Los resultados obtenidos les permitieron concluir que la longitud de transferencia $l_{t}$ en elementos pretensados era proporcional al diámetro del cordón elevado a una potencia $\alpha$ igual a 1,68 (Eq. 2-30).

$$
l_{t}=K \cdot \phi^{\alpha}=K \cdot \phi^{1.68}
$$

donde $K$ es una constante de proporcionalidad.

Otra de las características geométricas relativas a los alambres/cordones que determinan la longitud de transferencia del pretensado es la relación existente entre el perímetro real $p_{p}$ y el área transversal $A_{p}$ del acero. De la (Eq. 2-4) se puede deducir que la longitud de transferencia $l_{t}$ es proporcional al ratio $A_{p} / p_{p}$ (Eq. 2-31).

$$
l_{t}=\frac{\sigma_{p, 0}}{\tau_{b, \text { med }}} \cdot \frac{A_{p}}{p_{p}}
$$

Russell \& Burns (1996) indican que para cordones de 7 alambres, el área transversal $A_{p}$ es igual a $(7 / 36) \cdot \pi \phi^{2}$ y el perímetro $p_{p}$ es $(4 / 3) \cdot \pi \phi$, mientras que para alambres de sección circular, $A_{p}$ tiene un valor igual a $(1 / 4) \cdot \pi \phi^{2}$ y el perímetro $p_{p}$ es $\pi \phi$. Esto implica una relación $A_{p} / p_{p}=(21 / 144) \phi$, para cordones, y $A_{p} / p_{p}=(1 / 4) \phi$ para alambres. Los autores sugieren que la tensión de adherencia se debería expresar en términos de fuerza por unidad de longitud para evitar la confusión que se genera al expresarla por unidad de área, ya que nunca se tiene la certeza, en tensiones referidas a cordones de 7 alambres reportadas por otros autores, de si han sido determinadas teniendo en cuenta un perímetro igual a $\pi \phi$ o a (4/3) $\cdot \pi \phi$. En ese sentido, el Código Modelo 2010 (CEB-FIP, 2012) indica que se tome 
como perímetro del acero, tanto en alambres como en cordones, la circunferencia de diámetro igual al nominal $\pi \phi$. Por tanto, se propone un factor $A_{p} / \pi \phi$, en sustitución de $A_{p} / p_{p}$, con un valor de $(7 / 36) \cdot \phi$ en cordones de 7 alambres y de $(1 / 4) \cdot \phi$ en alambres de sección circular.

Oh et al. (Oh, et al., 2001), en la campaña experimental sobre elementos pretensados descrita anteriormente (Oh \& Kim, 2000), determinaron que la relación área transversal/perímetro era un 18 $\%$ mayor en los cordones de 15,2 $\mathrm{mm}$ de diámetro que en los de 12,7 mm. Por tanto, los cordones de mayor diámetro tendrían que tener mayores longitudes de transferencia. En la Tabla 2-4 se incluyen las longitudes de transferencia obtenidas en los elementos pretensados para los dos diámetros considerados y las dos resistencias a compresión del hormigón utilizadas.

Tabla 2-4 Longitudes de transferencia según el diámetro del cordón y la resistencia a compresión del hormigón (Oh \& Kim, 2000)

\begin{tabular}{cccc}
\hline \multirow{2}{*}{ Serie de ensayos } & \multicolumn{2}{c}{ Longitud de transferencia media $[\mathrm{mm}]$} & \\
\cline { 2 - 3 } & $\boldsymbol{\phi}=12.7 \mathrm{~mm}$ & $\boldsymbol{\phi}=15.2 \mathrm{~mm}$ & $\mathbf{1}_{\mathbf{t}(15.2)} / \mathbf{1}_{\mathbf{t}(12.7)}$ \\
\hline $\mathrm{f}_{\mathrm{c}}=35 \mathrm{MPa}$ & 651 & 822 & 1,26 \\
\hline $\mathrm{f}_{\mathrm{c}}=45 \mathrm{MPa}$ & 548 & 681 & 1,24 \\
\hline
\end{tabular}

Los resultados de la Tabla 2-4 muestran que las longitudes de transferencia en los elementos pretensados con cordones de 15,2 $\mathrm{mm}$ de diámetro, $l_{t(15.2)}$, fueron de media un $25 \%$ superiores a las obtenidas sobre los elementos pretensados con alambres de $12,7 \mathrm{~mm}$ de diámetro, $l_{t(12.7)}$. Los autores indican que este hecho es debido fundamentalmente a la diferencia existente entre el ratio área transversal/perímetro de los dos cordones utilizados. Mientras que el cordón de 15,2 mm tiene un área transversal un $42 \%$ mayor, y por tanto una fuerza de pretensado de mayor entidad, presenta únicamente un $20 \%$ más de superficie perimetral para el desarrollo de la adherencia. Por último, Oh et al. señalan que, si la longitud de transferencia fuera proporcional al diámetro, tal y como indican los códigos estructurales, la diferencia entre ambos tipos de cordones hubiera sido de un 20\%, y no del $25 \%$ obtenido en los ensayos. Por tanto, concluyen que la relación entre la longitud de transferencia y el diámetro del cordón no es perfectamente lineal.

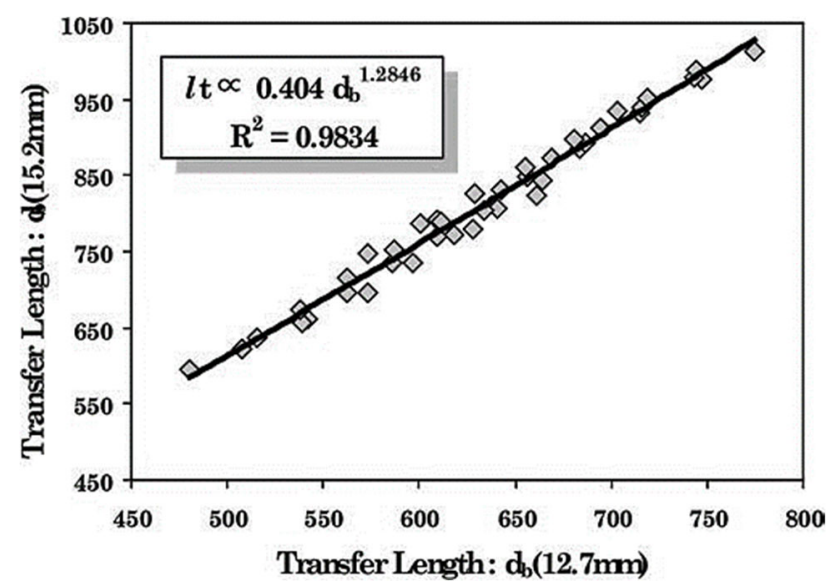

Figura 2-17 Correlación existente entre la longitud de transferencia y el diámetro del cordón de pretensado. Resultados obtenidos mediante modelo numérico. (Oh, et al., 2014). 
Posteriormente, Oh et al. (2014) desarrollaron un modelo numérico para la determinación de longitudes de transferencia, basado en la teoría de los elementos finitos, y compararon los resultados arrojados por el mismo con las longitudes de trasferencia medidas en la campaña experimental llevada a cabo en el 2000 (Oh \& Kim, 2000). Una vez verificado el modelo, los autores concluyeron que existía una buena correlación entre la longitud de transferencia $l_{t}$ y el diámetro del cordón $\phi$ elevado aproximadamente a 1,3 ( 1.2846) (Ver Figura 2-17).

\subsubsection{Fuerza de pretensado inicial}

Suponiendo una distribución uniforme de la tensión de adherencia $\tau_{b}$ a lo largo de la longitud de transferencia $l_{t}$ y despreciando la influencia de la deformación transversal del tendón (efecto Hoyer) sobre la capacidad adherente, la longitud de transferencia sería directamente proporcional a la fuerza de pretensado inicial $\sigma_{p, 0}$ (CEB-FIB_Task Group 2.5, 2000). Sin embargo, la expansión radial del acero tras la transferencia de la fuerza de pretensado, debida al efecto Poisson, está en proporción directa con la magnitud del pretensado inicial. Por ello, el incremento de la fuerza inicial de pretensado provoca un aumento en la magnitud de las tensiones circunferenciales $\sigma_{\vartheta}$ alrededor del acero pretensado, y consecuentemente, una mayor probabilidad de que el hormigón circundante se fisure (Abdelatif, et al., 2015). Debido a este fenómeno, la tensión de adherencia no se distribuye uniformemente a lo largo de la longitud de transferencia, justificando que, por ejemplo, Olesniewicz (1975) y den Uijl (1995) concluyeran que la longitud de transferencia era proporcional a la raíz cuadrada de la tensión de pretensado inicial (Eq. 2-23).

Mientras que numerosos investigadores, como Zia \& Mostafa (1977), Mitchell et al. (1993) o MartíVargas (Martí-Vargas, et al., 2007), así como la mayor parte de los códigos estructurales, han optado por considerar la relación entre la longitud de transferencia y la tensión de pretensado (inicial o efectiva, según los casos) como perfectamente lineal, otros autores han propuesto relaciones alternativas, como Balázs (Balazs, 1992), que propone que la tensión de pretensado efectiva $\sigma_{p, e}$ se eleve a 0,6 u Oh et al. (Oh, et al., 2014), que encuentra buenas correlaciones con la tensión de pretensado efectiva $\sigma_{p, e}$ elevada a $0,56(\sim 0,5576)$ (Ver Figura 2-18).

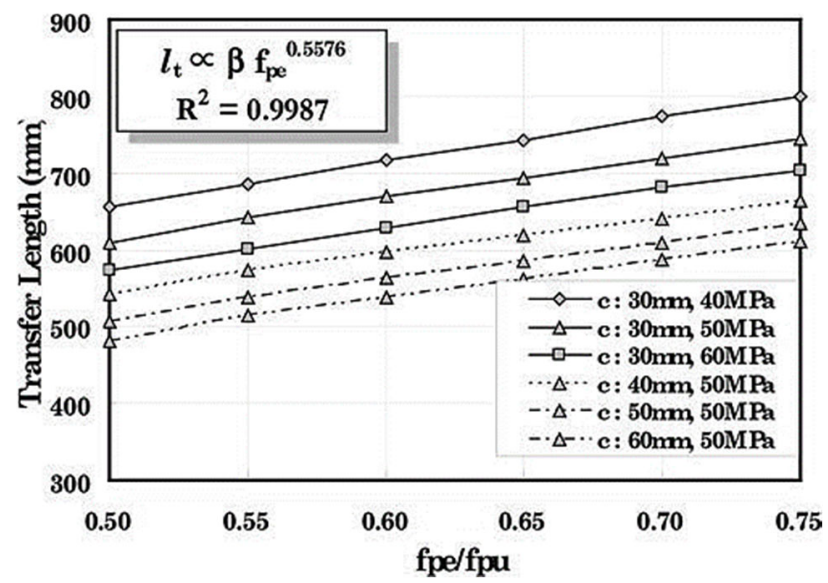

Figura 2-18 Correlación existente entre la longitud de transferencia y la tensión de pretensado efectiva. Resultados obtenidos mediante modelo numérico. (Oh, et al., 2014). 
Por último, es necesario poner en relieve que, tal y como indica el Bulletin $\mathrm{N}^{\circ} 10$ del CEB-FIB (CEBFIB_Task Group 2.5, 2000), el hecho de que en la práctica el rango de tensiones iniciales utilizado en estructuras reales de hormigón pretensado sea reducido, justifica que en la mayor parte de códigos estructurales se omita la no linealidad de la relación entre este parámetro y la longitud de transferencia, puesto que su incidencia es limitada.

\subsubsection{Velocidad de destesado}

Usualmente se consideran dos tipos de destesado en la transferencia de la fuerza de pretensado, el súbito y el gradual. En el primer tipo, los alambres o cordones son cortados, mediante sierra, soplete o cizalla, estando traccionados con la totalidad de la fuerza de pretensado. En el segundo método, el acero se va destesando gradualmente y el corte se produce una vez que la fuerza de pretensado se ha transferido por completo. Generalmente se acepta que un destesado súbito provoca mayores longitudes de transferencia que un destesado gradual. Este efecto es debido a un aumento de la fisuración del recubrimiento, derivada del choque dinámico del alambre con el hormigón. Este incremento en la longitud de transferencia es especialmente significativo en el extremo activo de la viga, el más cercano a la zona de corte de los alambres, y se encuentra mitigado en el extremo pasivo de la misma, donde suelen medirse longitudes de transferencia similares a las derivadas de un destesado gradual.

Numerosos investigadores han estudiado y cuantificado la influencia de la velocidad de destesado en la longitud de transferencia. Hanson \& Kaar (1959) acometieron una campaña experimental sobre vigas pretensadas con cordones de 7 alambres, con distintos diámetros, para investigar sobre la adherencia en flexión. Los resultados obtenidos mostraban un incremento de unos $10 \mathrm{~cm}$ (4 pulgadas) en la longitud de transferencia cuando el destesado se producía de manera súbita. Posteriormente, la campaña experimental llevada a cabo por los mismos autores (Kaar, et al., 1963), descrita en el apartado 2.2.7.1, mostró un incremento de entre un 20 y un $30 \%$ en las longitudes de transferencia cuando el destesado se producía de forma súbita. Russell \& Burns (1997) midieron diferencias de hasta un 34\% entre el extremo activo y pasivo de vigas pretensadas con cordones de $12,7 \mathrm{~mm}(0,5$ in.) de diámetro, mientras que Oh \& Kim (2000) determinaron, de media, incrementos de un 16\% en vigas pretensadas con cordones de $12,7 \mathrm{~mm}$ ( $0,5 \mathrm{in}$.), y de un $13 \%$ en vigas pretensadas con cordones de $15,2 \mathrm{~mm}(0,6$ in.) de diámetro.

Coherentemente con estas observaciones, algunos códigos de hormigón estructural contemplan la influencia del tipo de destesado mediante coeficientes que modifican la longitud de transferencia. De esta manera, el Código Modelo 2010 (CEB-FIP, 2012), el Eurocódigo 2 (CEN, 2004) y la EHE-08 (Fomento, 2008), para el caso de una transferencia súbita del pretensado, incrementan la longitud de transferencia en un $25 \%$ con respecto a la calculada para un destesado gradual.

\subsubsection{Efectos dependientes del tiempo: Retracción, fluencia y relajación}

El tiempo reduce la tensión de un alambre o cordón de pretensado debido, principalmente, a la fluencia y retracción del hormigón y al proceso de relajación del acero. Esta combinación de fenómenos induciría a pensar que el tiempo provocaría una disminución de la longitud de 
transferencia, sin embargo, son numerosos los estudios que han demostrado que en realidad se produce un aumento de la misma.

El Bulletin N¹0 del CEB-FIB (CEB-FIB_Task Group 2.5, 2000) señala una explicación probable para este efecto. La adherencia del acero pretensado depende fundamentalmente del confinamiento proporcionado por el hormigón circundante, que se activa como consecuencia del desplazamiento radial en la interfase. Las altas tensiones y deformaciones locales que se producen en esta zona se ven reducidas por la fluencia y la relajación, provocando una disminución del confinamiento y, consecuentemente, una disminución de la tensión de adherencia y un aumento de la longitud de transferencia.

La revisión bibliográfica ha permitido comprobar que existe una enorme disparidad de resultados a este respecto. Evans (1951) registró que la longitud de transferencia de alambres de $2 \mathrm{~mm}$ de diámetro prácticamente se doblaba (aumento del 115\%) en los primeros 2 años y medio. Por su parte, Base (1957), detectó incrementos de hasta un 10\% en los primeros 4 meses, aunque la mayor parte de los cambios se concentraban en los primeros 10 o 20 días. Base también registró, en sus ensayos sobre alambres de $2 \mathrm{~mm}$ de diámetro, que la longitud de transferencia se incrementaba hasta $76 \mathrm{~mm}$ en los 10 primeros días tras la transferencia, para posteriormente permanecer estable.

Kaar et al. (1963) acometieron una investigación sobre la influencia de la resistencia a compresión del hormigón sobre la longitud de transferencia, concluyendo que eran variables independientes. Sin embargo, detectaron incrementos de hasta un $20 \%$ en probetas pretensadas con cable de 7 alambres, aunque la media obtenida fue de un 6\% durante el primer año. Posteriormente, Tassi \& Erdélyi (1984) registraron un incremento de la longitud de transferencia de entre un 10 y un $25 \%$ dentro de los primeros 7-14 días tras el destesado. Los menores incrementos fueron observados en aquellas vigas que contaban con armadura transversal, por el contrario, los mayores incrementos se midieron en aquellos elementos que fueron fabricados sin cercos.

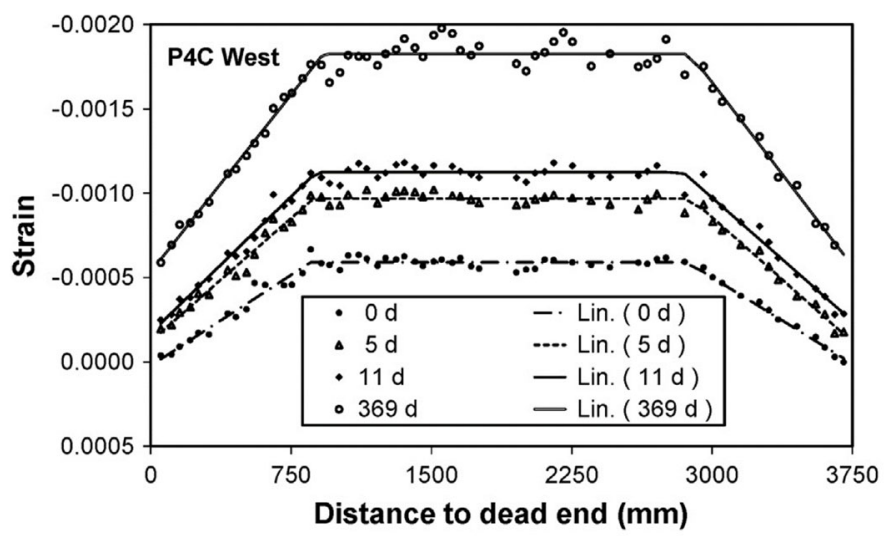

Figura 2-19 Evolución tras la transferencia del pretensado del perfil de deformaciones del hormigón (Vázquez-Herrero, et al., 2013)

Ya en épocas más cercanas, Oh et al. (2001), en su campaña experimental sobre cables pretensados de 12,7 y 15,2 mm de diámetro, registraron incrementos del 2-3 \% en la longitud de transferencia a la edad de 7 días, y de hasta un 5\% a los 90 días. Por su parte, Barnes et al. (2003) detectaron, por un lado, incrementos medios de entre el 10 y el 20\%, llegando algunos de ellos hasta un 50\%, y por otro, 
que la mayor parte de estos se producían los 28 primeros días. En el extremo opuesto, VazquezHerrero et al. (2013) apreciaron que las longitudes de transferencia permanecían con valores relativamente constantes durante el primer año tras el destesado (Figura 2-19).

A la vista de lo expuesto, la causa probable que justifica esta disparidad de resultados es la considerable diferencia existente entre las variables (secciones, resistencias, fuerzas de pretensado, etc) de los procedimientos experimentales utilizados por los diferentes autores. Por el contrario, donde sí existe consenso, independientemente de que se observe o no un crecimiento de la longitud de transferencia, es en el significativo incremento de las deformaciones en el hormigón a lo largo del tiempo (ver Figura 2-19), debido principalmente a la combinación del efecto de la fluencia y la retracción (Oh, et al., 2001) (Vázquez-Herrero, et al., 2013). Este incremento es especialmente importante los primeros días tras la transferencia, y se va atenuando con el paso del tiempo, llegándose a alcanzar variaciones de hasta un 200-300\% tras el primer año (ver Figura 2-19) (Vázquez-Herrero, et al., 2013).

\subsubsection{Influencia de las propiedades de contacto acero-hormigón}

El modelo de fricción de Coulomb (Eq. 2-22) nos muestra que la tensión de adherencia $\tau_{b}$ distribuida en la superficie del acero pretensado depende fundamentalmente de la tensión radial $\sigma_{r}$ en la interfaz acero/hormigón y del coeficiente de fricción $\mu$. Mientras que el primer factor depende de la capacidad de confinamiento del recubrimiento de hormigón y de cómo el alambre o cordón moviliza o compromete dicha capacidad, el segundo factor es una propiedad intrínseca de los dos materiales en contacto y, por tanto, no dependiente del estado tensional del alambre o cordón. Los numerosos estudios destinados a caracterizar el coeficiente de fricción acero/hormigón, tanto en elementos de hormigón armado como en elementos pretensados, han arrojado resultados dispares.

En 1970, M. Stoker y M. Sozen (1970) llevaron a cabo una campaña experimental consistente en 486 ensayos de pull-out y 5 beam-test, cuyo objetivo era la comprensión de la naturaleza de la adherencia entre cordones pretensados y hormigón, así como el desarrollo de una expresión para la determinación de la longitud de anclaje en cordones pretensados. Se investigaron distintas variables, entre la que se encontraban el diámetro del cordón, la resistencia y la retracción del hormigón y la presión de confinamiento. Por otra parte, determinaron el coeficiente de fricción en deslizamiento entre los cordones y el hormigón, suponiendo que la tensión de contacto en los ensayos era igual a la presión aplicada externamente. Suponiendo como probable esta hipótesis, el coeficiente de fricción determinado tenía un valor de 0,30 . Si por el contrario se partía de la hipótesis de que la tensión de contacto excedía la presión externa en un $20 \%$, el coeficiente se veía reducido hasta un valor de $\mu=0,25$. Finalmente, se concluyó que si no existían fuerzas externas aplicadas, la tensión de contacto necesaria para que existiera fricción era proporcionada por la retracción del hormigón.

B.G Rabbat \& H. G. Russell (1985) acometieron una campaña experimental para determinar el coeficiente de fricción entre planchas de acero laminado y hormigón. Se realizaron ensayos modificando distintos parámetros: probetas de hormigón y de mortero; interfaz seca o húmeda; y distintos niveles de tensión de compresión externa; obteniéndose valores que oscilaban entre 0,57 y 0,70. B.G Rabbat y H. G. Russell recomiendan valores de 0,65 para coeficientes estático de fricción 
entre hormigón y placas metálicas con la interfaz húmeda y valores de tensión normal de compresión entre 0,14 y 0,69 MPa; para interfaz seca, el coeficiente estático de fricción debería tener un valor de 0,57 .

Posteriormente, Baltay y Gjelsvik (1990) realizaron una campaña de ensayos con el objetivo de obtener el coeficiente de fricción entre hormigones y aceros de bajo contenido en carbono ("mild steel"), sometidos a diferentes tensiones normales. Se obtuvo un coeficiente de fricción $\mu$ medio igual a 0,47 .
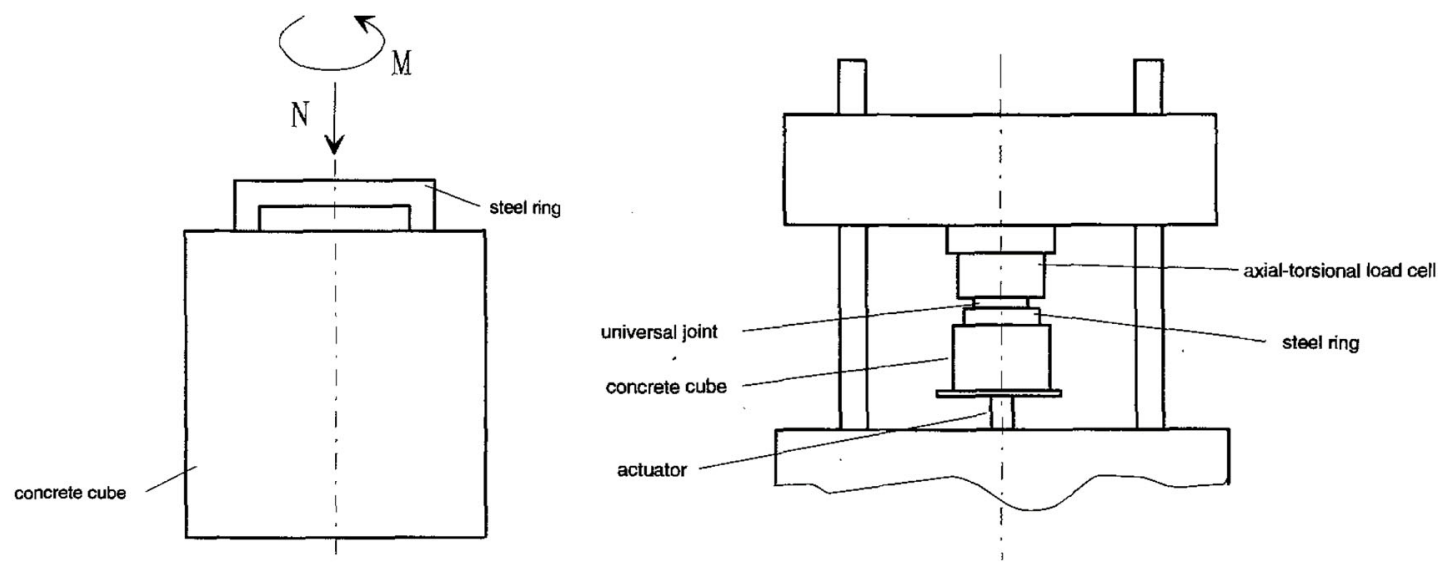

Figura 2-20 Método de ensayo para determinación del coeficiente de fricción desarrollado por Olofsson \& Holmgren (1994)

En 1992, Olofsson \& Holmgren (1994) desarrollaron un método de ensayo para estimar el coeficiente de fricción mediante el cual la presión de contacto y la velocidad de deslizamiento podía mantenerse constantes, midiendo la torsión requerida para girar un anillo de acero presionado contra un cubo de hormigón (ver Figura 2-20). Los autores determinaron que el coeficiente de fricción variaba entre 0,51 y 0,66 , con un valor medio igual a 0,59 .
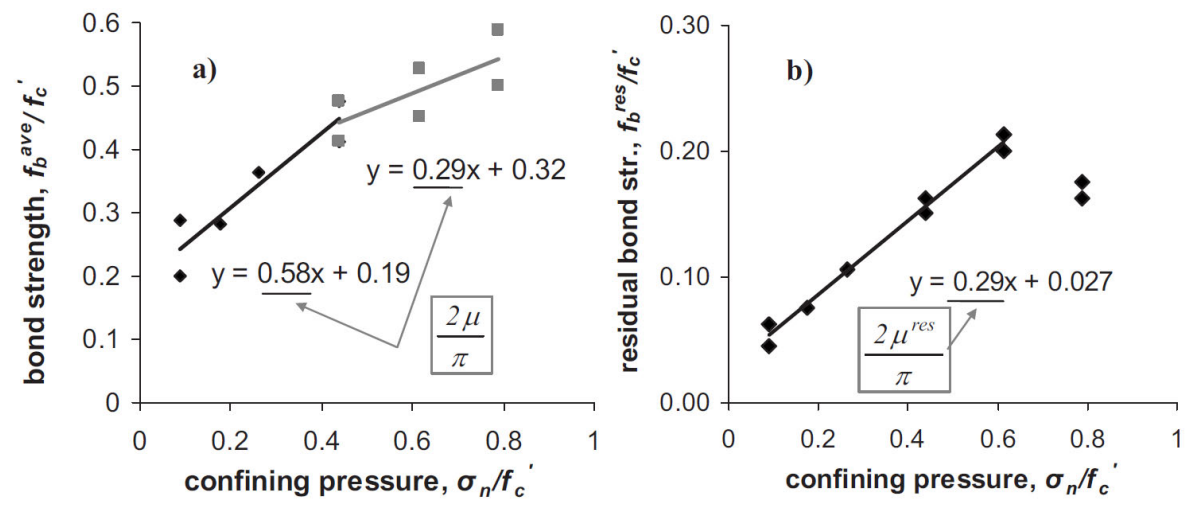

Figura 2-21 Evolución del coeficiente de fricción en función de la presión normal de confinamiento, según Tastani \& Pantazopoulou (2010)

Tastani \& Pantazopoulou (2010) se desmarcan ligeramente de los trabajos anteriores al proponer que el coeficiente de fricción varía con el nivel de tensión normal de confinamiento exterior a la que está sometida la armadura. Los autores acometieron una campaña experimental consistente en ensayos de 
Pull-Out sobre 50 probetas, con distinta altura de corruga y diferentes presiones exteriores de confinamiento, concluyendo, entre otros aspectos, que el coeficiente de fricción $\mu$ era una variable que dependía tanto de la tensión normal de confinamiento $\sigma_{n}$ como del deslizamiento $s$. Para llegar a estas conclusiones se apoyaron también en la campaña de ensayos realizada por Malvar (1991), sobre probetas a las que se les aplicó externamente una presión hidráulica. El valor del coeficiente de rozamiento, según afirma Tastani et al, se reducía cuando la presión normal excedía un valor límite, que cuantificaron en $\sigma_{n}=0,4 f_{c}^{\prime}$. Por debajo de ese nivel de tensión normal, el coeficiente de fricción $\mu$ adquiría un valor igual a 0,58 , mientras que para niveles por encima del límite (pero inferiores a $f_{c}$ ), el valor de $\mu$ se reducía hasta a 0,29 (ver Figura 2-21).

La disparidad de valores propuestos para el coeficiente de fricción por los estudios científicos también se ve reflejada en los códigos estructurales. Mientras que algunos códigos, como el francés (BAEL91, 2000), indican un valor $\mu$ igual a 0,4, otros, como el código ACI-318 (ACI Comittee 318, 2002) recomiendan un coeficiente de fricción con un valor de 0,7 para hormigones no ligeros anclados a perfiles laminados o barras de acero. El Código Modelo 2010 (CEB-FIP, 2012), por su parte, afirma que el coeficiente de fricción entre el hormigón y el acero puede variar desde valores prácticamente despreciables, cercanos a cero, hasta valores cercanos al 0,6 para superficies libres de impurezas.

El MC2010 indica que los valores más frecuentes para la resistencia a fricción son aproximadamente de 0,003 $\mathrm{MPa}$, siendo por tanto mucho más bajas que la proporcionada por adhesión y por acuñamientos en la interfaz. Sin embargo, su contribución no es despreciable ya que se desarrolla a lo largo de toda la superficie de contacto.

\subsubsection{Posición del alambre durante el hormigonado}

Normalmente se acepta, al igual que ocurre con el hormigón armado, que la posición del acero de pretensado durante el hormigonado repercute en la capacidad adherente del alambre o cordón. Los códigos estructurales suelen contemplar dos situaciones:

- Posición I, o de adherencia buena, para las armaduras que durante el hormigonado forman con la horizontal un ángulo comprendido entre $45^{\circ}$ y $90^{\circ}$ o que en el caso de formar un ángulo inferior a $45^{\circ}$, están situados en la mitad inferior de la sección o a una distancia igual o mayor a $30 \mathrm{~cm}$ de la cara superior de una capa de hormigonado.

- Posición II, o de adherencia deficiente, para las armaduras que durante el hormigonado no se encuentran en ninguno de los casos anteriores.

\subsection{Adherencia entre alambres corroídos y hormigón}

\subsubsection{Introducción}

En este apartado se lleva a cabo una revisión bibliográfica no exhaustiva del fenómeno de la corrosión en estructuras de hormigón, centrada especialmente en su influencia sobre las propiedades adherentes del acero. Los estudios que analizan la influencia de la corrosión sobre alambres o cordones en estructuras pretensadas son escasos, por lo que la mayor parte de las investigaciones recogidas en este 
apartado han sido realizadas sobre armaduras no pretensadas. Se ha dado prioridad a los estudios sobre alambres lisos e indentados, al ser el tipo de armadura utilizado en los ensayos de pull-out llevados a cabo en esta tesis.

\subsubsection{Conceptos básicos de la corrosión del acero}

\subsubsection{Naturaleza del proceso de corrosión}

La corrosión es el proceso por el cual un metal pasa de su estado metálico, con valencia "cero", a su estado oxidado, liberando electrones. Generalmente, los metales se encuentran en la naturaleza formando compuestos con otros elementos (óxidos, sulfuros, etc.). Para usarlos en su forma elemental o pura hay que extraer el metal mediante un proceso de reducción, lo que requiere la aportación de cierta cantidad de energía. El metal reducido presenta la tendencia a liberar espontáneamente parte de esta energía para alcanzar un estado energético menor (Andrade, 2007). Desde el punto de vista de la termodinámica, este proceso corresponde a una conversión de un estado ordenado y rico energéticamente a otro estado menos ordenado, más pobre en energía, y por ello, más estable. Para el acero, de forma simplificada, este proceso puede ser escrito como (Eq. 2-32):

$$
F e \rightarrow F e^{2+}+2 e^{-}
$$

El mecanismo de la corrosión de los materiales metálicos en contacto con una disolución acuosa es de naturaleza electroquímica. Esto implica, que la oxidación del metal está compensada por la reducción de otra sustancia en otra región de la superficie metálica, generándose dos zonas con diferente potencial electroquímico (ánodo y cátodo). La zona donde se produce la oxidación del metal actúa como ánodo, liberando electrones que migran a través del metal hacia otra región de la superficie metálica, el cátodo, donde se consumen induciendo la reducción de alguna sustancia presente en el electrolito. En el caso de un medio neutro y alcalino, los electrones reducen el oxígeno disuelto en el electrolito (Figura 2-22), siguiendo la reacción catódica recogida en (Eq. 2-33). Los productos de corrosión resultantes son $\mathrm{Fe}(\mathrm{OH})_{2}$ y $\mathrm{Fe}(\mathrm{OH})_{3}$, o algún oxihidróxido derivado de los mismos (Andrade, 2007).

$$
\mathrm{O}_{2}+4 e^{-}+2 \mathrm{H}_{2} \mathrm{O} \rightarrow 4 \mathrm{OH}^{-}
$$

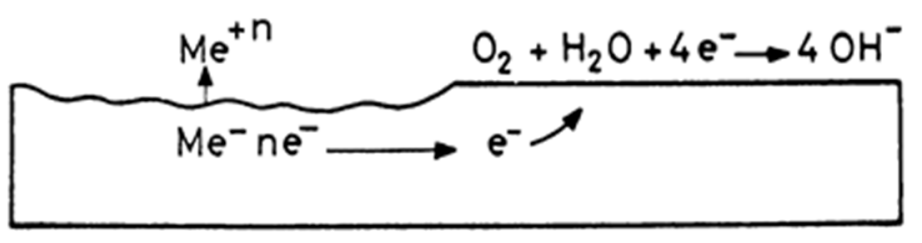

Figura 2-22 Reacción catódica en medios alcalinos y neutros (Andrade, 2007)

En el caso de medios ácidos, la reacción catódica más común es aquella en la que se produce la reducción de protones (Eq. 2-34). 
En cualquier caso, la falta de electrolito o de conexión metálica supondría el freno del proceso de corrosión y, por tanto, del desarrollo de cualquier zona anódica o catódica.

\subsubsection{Causas de la corrosión de armaduras}

Las armaduras embebidas en hormigón se encuentran protegidas de los procesos de corrosión por la acción protectora del recubrimiento, que es de doble naturaleza (Andrade, 1982):

- En primer lugar, el hormigón actúa como barrera física entre el acero y el medio externo. Su eficacia depende tanto de la impermeabilidad o compacidad como del espesor de recubrimiento.

- En segundo lugar, el agua que rellena los poros del hormigón está saturada por el hidróxido cálcico $\mathrm{Ca}(\mathrm{OH})_{2}$ que se forma durante la hidratación de los silicatos del cemento y contiene iones como $\mathrm{Na}^{+}, \mathrm{K}^{+}$y $\mathrm{SO}_{4}=$, que sitúan su $\mathrm{pH}$ en un valor entre 12,6 y 14,0. La alta alcalinidad del medio garantiza la pasivación del acero, al encontrarse recubierto de una capa submicroscópica, compacta y continua, de óxidos transparentes que lo mantiene protegido.

Sin embargo, la acción protectora del hormigón puede verse comprometida por diversas situaciones, como la ubicación del elemento en ambientes agresivos o la incorporación de sustancias dañinas durante la fabricación del hormigón, que pueden desencadenar el proceso de corrosión de las armaduras. Tal y como indica el Manual de evaluación de estructuras afectadas CONTECVET (2001), dos son las causas fundamentales de la pérdida de la capacidad protectora del hormigón, la carbonatación del recubrimiento y la presencia de iones cloruros. Mientras que la carbonatación induce una corrosión generalizada en el acero, la presencia de cloruros produce una corrosión localizada, o por "picaduras" en la armadura (Figura 2-23).

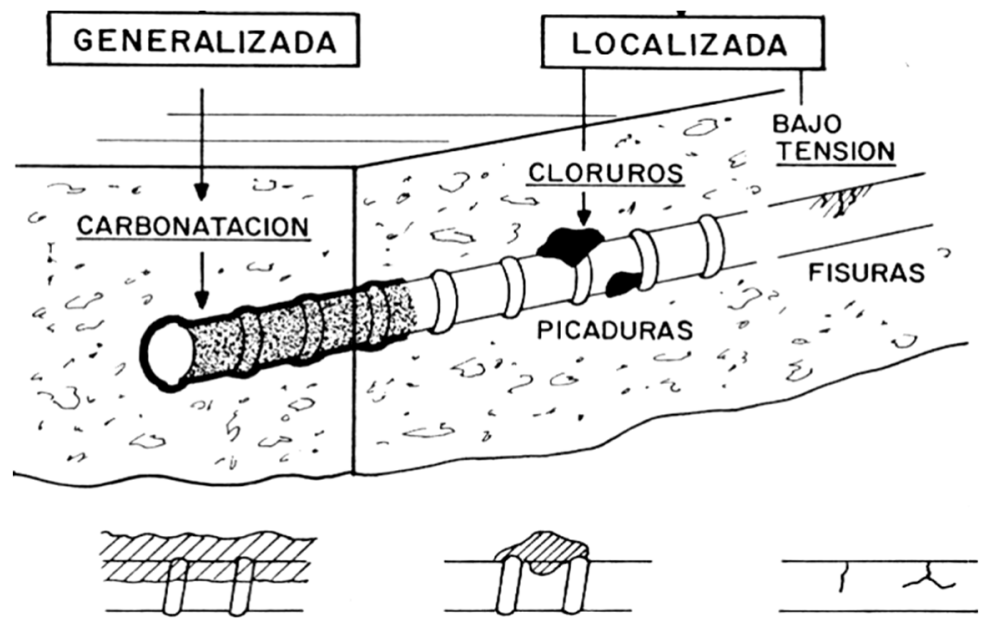

Figura 2-23 Tipología de la corrosión de la armadura en el hormigón armado: generalizada (carbonatación), localizada (cloruros) y corrosión bajo tensión (en elementos pretensados) (Andrade, 1989). 
En el proceso de carbonatación, el dióxido de carbono atmosférico reacciona con el calcio y los hidróxidos alcalinos que existen en el hormigón, formándose mayoritariamente carbonato cálcico, lo que provoca la reducción su $\mathrm{pH}$ hasta alcanzar valores neutros, en los cuales el acero se despasiva. La carbonatación es un proceso de difusión y por lo tanto su avance en el interior del hormigón progresa atenuándose en el tiempo. El modelizado de la carbonatación suele realizarse utilizando una solución de la ley de Fick de la difusión, cuya solución general es de la forma $\mathrm{X}=\mathrm{V}_{\mathrm{CO} 2} \vee_{\mathrm{t}}$, donde $X$ es la profundidad carbonatada, $V_{\mathrm{CO} 2}$ describe la velocidad de carbonatación y $t$ es el tiempo de exposición. El factor $\mathrm{V}_{\mathrm{CO} 2}$ depende del tipo de hormigón y de las características del ambiente. La carbonatación no se desarrolla si el hormigón está saturado en agua o si está totalmente seco. Sin embargo, su avance alcanza el máximo cuando se producen ciclos de humectación - secado, que confieren al hormigón un grado de saturación moderado.

Por otro lado, una concentración suficiente de iones cloruro, $\mathrm{Cl}$, en contacto con la armadura, inducen una destrucción local de la capa que pasiva el acero, ocasionando un ataque localizado que frecuentemente se transforma en picaduras. Los iones cloruros pueden estar presentes en el hormigón si éstos fueron añadidos en la mezcla (en las adiciones, en los áridos o en el agua de amasado), o pueden ingresar desde el exterior, ya sea porque la estructura se encuentre ubicada en un ambiente marino o por el uso de sales de deshielo. La concentración de cloruros necesaria para despasivar el acero y desencadenar el proceso de corrosión depende de numerosos factores, entre los que se encuentran el tipo de cemento, la relación agua/cemento, el curado y compactación del hormigón, el contenido de humedad y su variación, el tipo de acero y la disponibilidad de oxígeno.

Po último, cabe señalar la existencia de otro tipo particular de corrosión localizada, la denominada es corrosión bajo tensión. Este tipo de deterioro tiene lugar solamente en cables tesados debido a la acción conjunta de una tensión elevada (en general cercana al 70\% del límite elástico) y de un medio ambiente agresivo con el material. El proceso comienza con la nucleación de fisuras en la superficie del acero. Una de estas fisuras puede propagarse hasta una determinada magnitud, a partir de la cual la velocidad de propagación es muy elevada, fallando finalmente el cable pretensado de una manera frágil (CONTECVET, 2001).

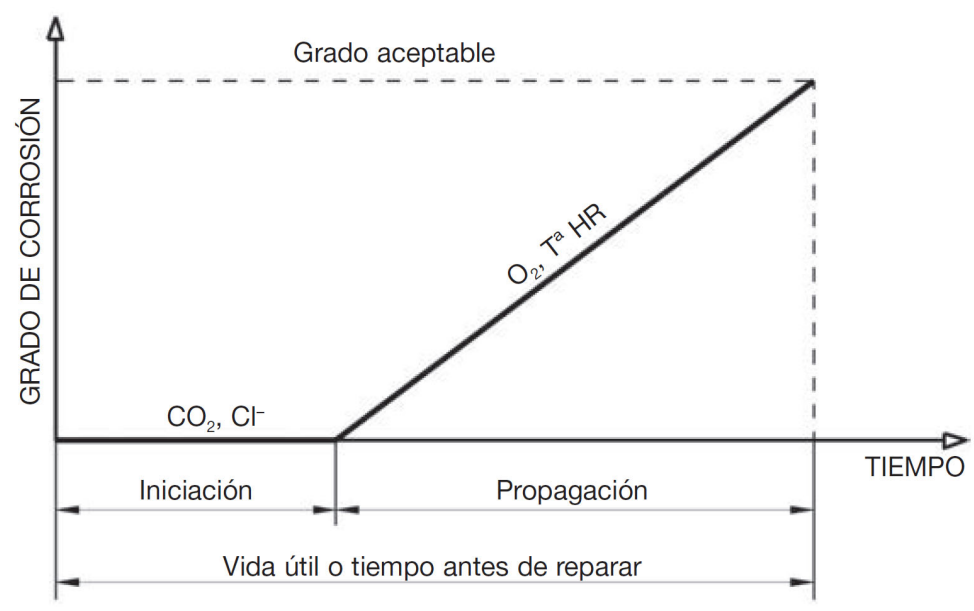

Figura 2-24 Modelo de vida útil de Tuntti (1982). Figura tomada de (Rodríguez, et al., 2014) 


\subsubsection{Efectos de la corrosión en el comportamiento mecánico de estructuras de hormigón armado y pretensado}

El modelo más simple y descriptivo para definir la vida útil de estructuras de hormigón armado y pretensado afectadas por procesos de corrosión es el desarrollado por Tuutti (1982) (Figura 2-24).

El modelo de vida útil de Tuutti que, aunque fue desarrollado específicamente para el caso de corrosión de armaduras embebidas en hormigón, puede extender a cualquier tipo de deterioro, considera dos etapas diferenciadas (Figura 2-24):

- Un periodo de iniciación determinado por el tiempo desde el que se construye la estructura hasta que el agente agresivo que ocasiona el daño (ya sea por carbonatación o por cloruros) alcanza la armadura, despasivando el acero.

- Un periodo de propagación que va desde el momento de despasivación del acero hasta que se supera un determinado nivel de deterioro aceptable en la estructura.

Una vez iniciado el periodo de propagación, los principales efectos de la corrosión en el comportamiento mecánico de elementos de hormigón, tanto armado como pretensado, son los siguientes (Andrade, et al., 1993) (Figura 2-25):

- Reducción de la sección de los alambres debida a la penetración de ataque $P_{x}$. Esta disminución es especialmente importante en el caso de ataque por picaduras producido por la acción de los cloruros.

- Fisuración y desprendimiento del recubrimiento de hormigón del hormigón que rodea la armadura. Los productos de corrosión generados, cuyo volumen específico es mayor que el del acero original, generan tensiones en el hormigón circundante y propician la aparición de fisuras y desprendimientos en el recubrimiento.

- La disminución del efecto compuesto hormigón-acero por el deterioro de la adherencia entre acero y hormigón. La capacidad adherente se ve mermada, por un lado, por la reducción de la capacidad de confinamiento del recubrimiento fisurado, y por otro, por la modificación de las propiedades de contacto entre ambos materiales. Este efecto es más significativo en el caso de un grado avanzado de corrosión generalizada por carbonatación del hormigón.

- La pérdida de ductilidad en el acero, que es atribuida al hidrógeno que se produce por la acidificación que genera la propia corrosión. Ello hace que la tenacidad del material disminuya y rompa con pérdidas de sección menores que si el material no estuviera corroído (Rodríguez, et al., 2014).

- El efecto entalla en los casos de corrosión por picaduras y de tracción excéntrica debido a la falta de simetría de la sección y la concentración de tensiones en el fondo de la entalla (UPC-IETcc-DRAGADOS, 2012). 


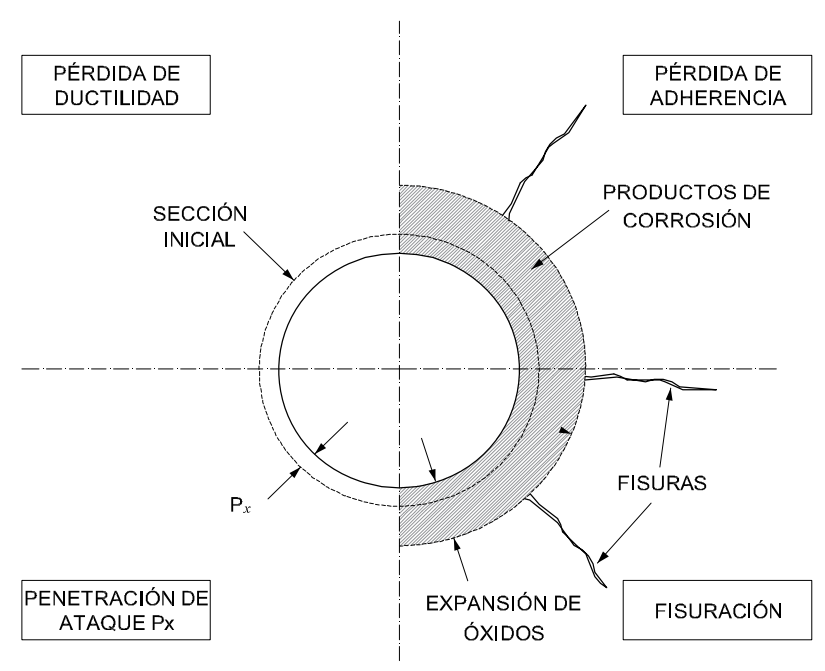

Figura 2-25 Consecuencias de la corrosión de las armaduras en el comportamiento estructural. Figura adaptada de Andrade et al. (1993)

En los siguientes apartados se lleva a cabo una breve recopilación bibliográfica de los estudios relativos a aquellos efectos de la corrosión que han recibido una mayor atención en el desarrollo de la presente tesis: reducción de la sección de los alambres, fisuración del recubrimiento y variación de las propiedades adherentes.

\subsubsection{Penetración de ataque $\mathbf{P}_{\mathrm{x}}$}

\subsubsection{Geometría de la penetración de ataque $P_{x}$}

La penetración de ataque por corrosión, $P_{x}$, que experimenta una armadura de diámetro inicial $\phi_{0}$ en un tiempo de propagación del daño $t$, con una tasa o velocidad de corrosión $V_{\text {corr }}$, puede calcularse según la siguiente expresión (Eq. 2-35):

$$
P_{x}=V_{\text {corr }} \cdot t
$$

Una vez determinada la profundidad de ataque por corrosión $P_{x}$, se puede obtener el diámetro remanente de la armadura, $\phi_{t}$, mediante la siguiente expresión (Eq. 2-36) (CONTECVET , 2001):

$$
\phi_{t}=\phi_{0}-\alpha P_{x}
$$

El valor del coeficiente $\alpha$, denominado factor de picadura, depende del tipo de ataque por corrosión (Figura 2-26). Como se ha visto en el Apartado 2.3.2.2, el agresivo que causa el proceso de corrosión determina el tipo de geometría de la penetración de ataque $P_{x}$ : la carbonatación produce una corrosión uniforme y generalizada, tomando $\alpha$ un valor igual a 2, mientras que el ataque por cloruros produce una corrosión localizada o por picaduras, en la que $\alpha$ se encuentra en el rango entre 5 y 10 . 

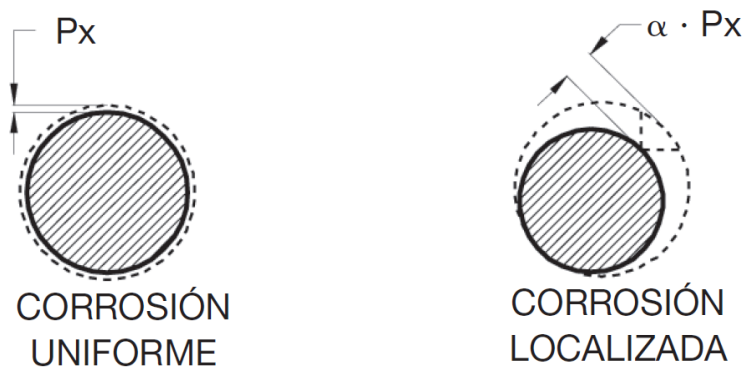

$\alpha \leq[5-10]$

Figura 2-26 Morfología de la sección residual de la armadura, adaptado de (CONTECVET , 2001)

\subsubsection{Tasa de penetración de ataque}

El modelo de penetración de ataque de la corrosión $P_{x}$ o tasa de producción de óxidos, para un determinado periodo de tiempo $t$ y una densidad de corriente de corrosión $i_{c o r r}$, es un importante parámetro en el análisis de la adherencia, ya que por un lado determina la pérdida de sección del acero y, por otro, la evolución de la fisuración del recubrimiento. Habitualmente, el modelo con mayor consenso en la comunidad científica es el basado en la ley de Faraday, el cual arroja una tasa de producción de óxidos que genera una pronta fisuración del recubrimiento. Esta fisuración temprana se aleja significativamente de las observaciones experimentales, por lo que muchos autores, a la hora de modelar el fenómeno de la corrosión, han establecido diferentes estrategias para favorecer el retraso de la misma. Una de ellas ha sido la de variar el modelo de penetración de ataque, y en ese contexto se enmarcan los modelos de Liu y Weyers (1998) y de Balafas y Burgoyne (2011).

En general, se parte de la base de que la penetración de ataque por corrosión $P_{x}$ es uniforme a lo largo de toda la superficie del acero. Por tanto, el volumen de acero corró́do por unidad de longitud $\Delta V_{S}^{\text {corr }}$ de una barra de radio $r_{b}$ viene definido por geométricamente por la expresión (Eq. 2-37):

$$
\Delta V_{s}^{\text {corr }}=\pi r_{b}^{2}-\pi\left(r_{b}-P_{x}\right)^{2}=\pi P_{x}\left(2 r_{b}-P_{x}\right)
$$

Por otro lado, $\Delta V_{s}^{\text {corr }}$ puede expresarse como una función de la masa de acero consumida durante el proceso corrosivo, tal y como sigue (Eq. 2-38):

$$
\Delta V_{s}^{\text {corr }}=\frac{m_{s}}{\rho_{s}}
$$

donde $m_{s}$ es la pérdida total de masa, por unidad de longitud y $\rho_{s}$ es la densidad del acero virgen $\left(\rho_{\mathrm{s}}=7.85 \mathrm{~g} / \mathrm{cm}^{3}\right)$. Igualando (Eq. 2-38) y (Eq. 2-38) se obtiene la siguiente expresión para definir el espesor de penetración de ataque $P_{x}$, simplificada al suponer que $P_{x}$ es un valor muy pequeño (Eq. 2-39):

$$
\pi P_{x}\left(2 r_{b}-P_{x}\right)=\frac{m_{s}}{\rho_{s}} \Rightarrow P_{x} \approx \frac{m_{s}}{2 \pi r_{b} \rho_{s}}
$$


A continuación se analizan los modelos de tasa de producción de óxidos con mayor consenso en la comunidad científica: Ley de Faraday (Andrade, et al., 1993), Modelo de Liu y Weyers (Liu \& Weyers, 1998) y Modelo de Balafas y Burgoyne (Balafas \& Burgoyne, 2011).

\subsection{Ley de Faraday}

El proceso en el que un metal me (ánodo) se deposita en un electrodo (cátodo) siguiendo procedimientos electrolíticos puede representarse mediante la siguiente ecuación (Eq. 2-40):

$$
m e^{n+}(a q)+n e^{-} \rightarrow m e(s)
$$

Según esta expresión, por cada mol de me depositado en el cátodo, han circulado $n$ moles de electrones. La carga eléctrica contenida en un mol de electrones es calculada multiplicando la carga de un electrón e por el número de Avogadro $N_{A}$, y es denominada Constante de Faraday F (Eq. 2-41):

$$
1 F=e \cdot N_{A}=96485 \mathrm{C} \cdot \mathrm{mol}^{-1}
$$

En 1932, U.R. Evans \& T.P. Hoar establecen la relación cuantitativa entre la corriente de la pila de corrosión y la pérdida de peso del metal, a lo largo del tiempo, a través de la Ley de Faraday:

$$
\frac{d m_{s}}{d t_{p}}=\frac{M}{z F} I_{c o r r}
$$

donde:

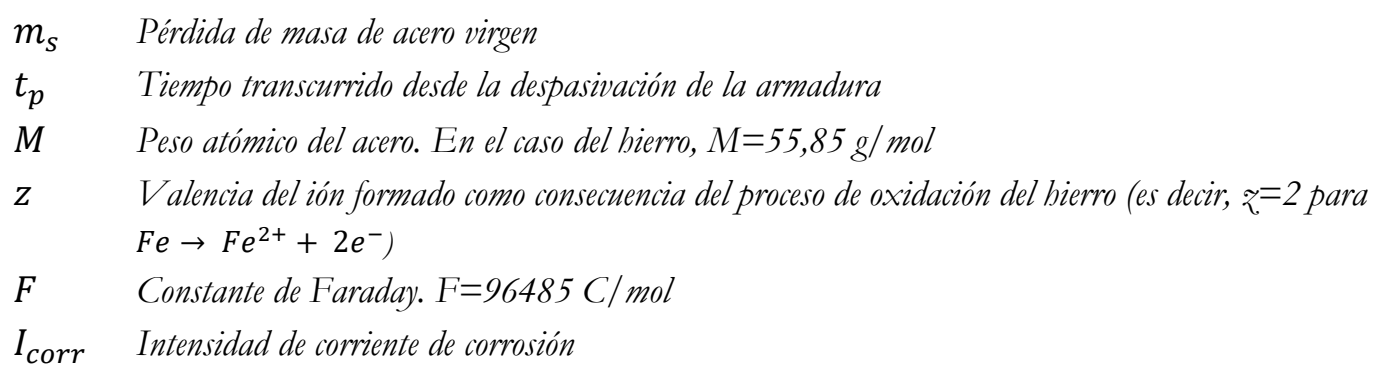

Suponiendo una distribución uniforme de la corrosión a lo largo de todo el perímetro de la sección transversal de la barra, la tasa de pérdida de masa por unidad de longitud $\left(l_{b}=1\right)$ puede ser reescrita como sigue (Eq. 2-43):

$$
\frac{d m_{s}}{d t_{p}}=\frac{M}{z F} \cdot \pi \cdot d_{b} \cdot i_{c o r r}
$$

donde:
$d_{b}$
Diámetro original de la armadura de acero
$i_{\text {corr }}$
Densidad de intensidad de corrosión 
Por tanto, la masa de acero consumida en el ánodo por unidad de longitud de la armadura (Eq. 2-44), $m_{s}$, se obtiene mediante la integración de la ecuación (Eq. 2-43):

$$
m_{s}=\frac{M}{z F} \cdot \pi \cdot d_{b} \cdot i_{c o r r} \cdot t_{p}
$$

Sustituyendo la expresión (Eq. 2-44) en la ecuación (Eq. 2-39) se obtiene la reducción $P_{x}$ del espesor de la armadura de acero por unidad de longitud, transcurrido un tiempo $t$ (Eq. 2-45):

$$
P_{x}(t)=\frac{\frac{M}{z F} \cdot i_{c o r r} \cdot t_{p}}{\rho_{s}}
$$

Por último, operando con los valores de $M, ₹ F$ y $\rho_{S}$ desglosados anteriormente, puede determinarse la penetración de ataque $P_{x}[\mathrm{~mm}]$ para una determinada densidad de corriente de corrosión $i_{c o r r}$ $\left[\mu A / \mathrm{cm}^{2}\right]$, transcurrido un tiempo $t_{p}[a \tilde{n} o s]$ (Eq. 2-46):

$$
P_{x}(t)=0.0116 \cdot i_{\text {corr }} \cdot t_{p}
$$

Por consiguiente, el diámetro reducido de la armadura de acero, trascurrido un tiempo $t_{\mathrm{p}}$, es igual al diámetro original $d_{b}$ menos dos veces la penetración de ataque $P_{x}$, pudiéndose expresar de la siguiente forma (Eq. 2-47):

$$
d_{b}(t)=d_{b}-0.0232 \cdot i_{c o r r} \cdot t_{p}
$$

\subsection{Modelo de Liu \& Weyers (Liu \& Weyers, 1998)}

Los autores llevaron a cabo una amplia campaña experimental sobre losas de hormigón con cloruros $(1180 \times 1180 \times 216 \mathrm{~mm})$, con 5 armaduras embebidas sin continuidad eléctrica, sometidas a corrosión natural durante 5 años, con el objetivo de evaluar la fisuración del recubrimiento y su evolución en procesos de corrosión inducidos por la presencia de cloruros. El diseño experimental consideró los siguientes parámetros: contenido de cloruros, velocidad de corrosión, espesor del recubrimiento de hormigón, diámetro del acero y espaciado entre las armaduras.

La Ley de Faraday se basa en la consideración de que la tasa de producción de óxidos en la superficie del ánodo es continua, sin embargo, su uso para la predicción del comienzo de la fisuración del recubrimiento conlleva la obtención de periodos de tiempos extremadamente cortos, no realistas. Para evitar este fenómeno, Liu \& Weyers, apoyándose en los resultados experimentales obtenidos, desarrollaron un modelo sustentado en la hipótesis de que la tasa de crecimiento de óxidos decrece con el incremento del espesor de éstos, ya que la distancia de difusión de los iones del acero aumenta. De hecho, Andrade et al. (Andrade, et al., 1993) detectaron que, para el mismo ancho de fisura, la penetración de ataque de las probetas sometidas a velocidades de corrosión mayores era más altas que aquellas sometidas a velocidades más bajas. Liu \& Weyers, teniendo en cuenta este fenómeno, desarrollaron la siguiente expresión (Eq. 2-48): 


$$
\frac{d m_{r}}{d t}=\frac{k_{p}}{m_{r}} \Rightarrow m_{r}=\sqrt{2 k_{p} t} \quad\left[\frac{k g}{m}\right]
$$

donde $k_{p}$ está en función de la velocidad de corrosión $i_{c o r r}$ y $t$ viene dado en segundos [s]. Pantazopoulou y Papoulia (Pantazopoulou \& Papoulia, 2001) supusieron una relación lineal entre $k_{p}$ e $i_{\text {corr }}$ y, calibrándola con los resultados experimentales recogidos por Liu y Weyers, propusieron la siguiente expresión (Eq. 2-49):

$$
k_{p}=3.328 \cdot 10^{-10} \pi d_{b} i_{c o r r}
$$

Donde $i_{c o r r}$ es la densidad de corriente de corrosión, en $\left[\mathrm{A} / \mathrm{m}^{2}\right]$, y $d_{b}$ es el diámetro nominal del alambre, en $[\mathrm{m}]$.

\subsection{Modelo de Balafas \& Burgoyne (Balafas \& Burgoyne, 2011)}

El modelo propuesto por Liu y Weyers (1998) parte de la base de que la capa de óxidos está uniformemente distribuida y las propiedades de difusión son las mismas a lo largo de su espesor. Para tener en cuenta las observaciones experimentales consistentes en que los productos de corrosión de depositan en dos capas diferenciadas (Melchers, 2003), siendo la capa interior más densa que la exterior, Balafas y Burgoyne (2011) modificaron la expresión (Eq. 2-48) como sigue (Eq. 2-50):

$$
\frac{d m_{r}}{d t}=\frac{k_{p}}{m_{r}^{n_{l}}} \Rightarrow m_{r}=\left(n_{l} \int k_{p} d t\right)^{\frac{1}{n_{l}}}
$$

Donde el valor del coeficiente $n_{l}$ aumenta progresivamente de 2 a 3 , con el trascurrir del tiempo en el que el acero está sometido al proceso de corrosión. Se debe hacer notar que para $n_{l}=2$, la ecuación (Eq. 2-50) pasa a igualarse a (Eq. 2-48), por lo que la capa de óxidos presenta una densidad uniforme. El valor de $k_{p}$ depende del coeficiente $n$, y decrece mientras el valor de $n_{l}$ se incrementa de 2 a 3 . Los valores de $k_{p}$, dependientes de $n$, fueron evaluados por Balafas y Burgoyne (2010), y se recogen en la siguiente tabla (Tabla 2-5):

Tabla 2-5 Valores de kp para valores dados de coeficiente $n_{l}$

\begin{tabular}{cc}
\hline $\boldsymbol{n}_{\boldsymbol{I}}$ & $\boldsymbol{k}_{\boldsymbol{p}}$ \\
\hline 2,00 & 0,08600 \\
\hline 2,25 & 0,03600 \\
\hline 2,50 & 0,01540 \\
\hline 3,00 & 0,00324 \\
\hline
\end{tabular}

Por otro lado, Balafas y Burgoyne (2010) exponen que, tanto la Ley de Faraday como el modelo propuesto por Liu y Weyers (1998) presenta inconvenientes apreciables. Por un lado, la primera no incluye el gradual engrosamiento de la capa de óxidos y la mayor dificultad para que difundan los iones de acero, por otro lado, la segunda propone, para etapas tempranas del proceso de corrosión, 
tasas de producción de óxidos muy elevadas y, por tanto, poco realistas. Para minimizar los inconvenientes de ambos modelos, los autores proponen una ley de tasa de producción de óxidos que combina ambas distribuciones, tal y como se muestra en la Figura 2-27.
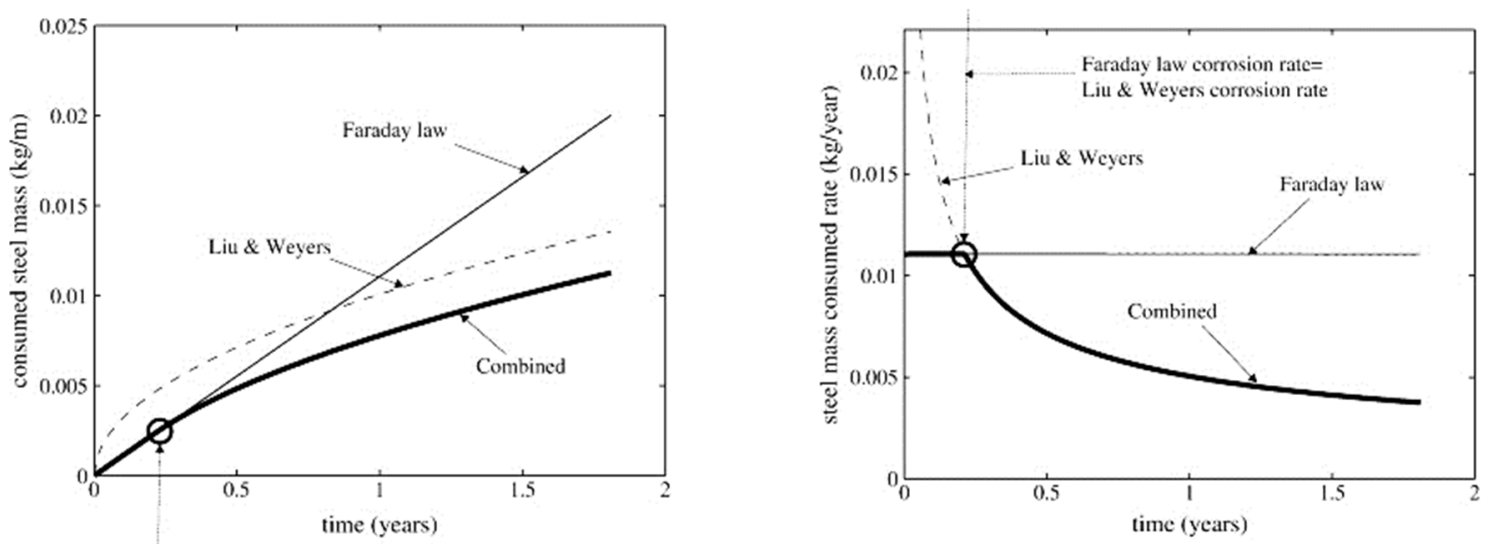

Figura 2-27 Consumo de masa de acero $(\mathrm{kg} / \mathrm{m})$ y velocidad de consumo de masa de acero $(\mathrm{kg} /$ year) para la ley de Faraday, el modelo propuesto por Lin y Weyers (1998), y el modelo propuesto por Balafas y Burgoyne (2010). Gráficas tomadas de (Balafas \& Burgoyne, 2010)

La nueva "Ley combinada" viene dada por la siguiente expresión (Eq. 2-51):

$$
\frac{d m_{s}}{d t}=\min \left(\frac{d m_{s}^{F L}}{d t}, r_{m} \frac{d m_{r}^{L W}}{d t}\right)
$$

donde los índices FL y LW se refieren a la Ley de Faraday y al modelo de Liu y Weyers, respectivamente. Como puede observarse en la Figura 2-27, para etapas tempranas del proceso, la velocidad de masa de acero consumido propuesta por los autores se ciñe a la Ley de Faraday, para posteriormente adaptarse al modelo propuesto por Liu y Weyers.

\subsubsection{Influencia de la corrosión en la fisuración del recubrimiento}

\subsubsection{Revisión de resultados experimentales en la bibliografía}

La expansión volumétrica de los productos de corrosión genera tensiones circunferenciales de tracción $\sigma_{\vartheta}$ en el recubrimiento que rodea la armadura de tal manera que, si éstas superan la resistencia a tracción $f_{c t}$ del hormigón, conducen a la aparición de fisuras longitudinales, paralelas al trazado de la armadura. Esta fisuración reduce la capacidad de confinamiento del recubrimiento, lo que a su vez limita las tensiones radiales $\sigma_{r}$ en la interfaz acero-hormigón y, consecuentemente, provoca la disminución de la capacidad adherente.

Existen numerosos estudios sobre la fisuración del recubrimiento debido a procesos de corrosión, especialmente en armaduras corrugadas. Andrade et al. (1993) sometieron a corrosión acelerada armaduras de $16 \mathrm{~mm}$ de diámetro embebidas en probetas de pequeño tamaño $(38 \times 15 \times 15 \mathrm{~cm})$, en 
cuya dosificación de hormigón fue añadido un $3 \%$ de $\mathrm{CaCl}_{2}$ por peso de cemento, para inducir una corrosión generalizada. Las armaduras se ubicaron, por un lado, centradas en uno de los lados, con un recubrimiento de 2 y $3 \mathrm{~cm}$, y por otro, desplazadas hacia una de las esquinas de la probeta. En cuanto a las corrientes de corrosión, se utilizaron dos densidades distintas, $10 \mu \mathrm{A} / \mathrm{cm}^{2}$ y $100 \mu \mathrm{A} / \mathrm{cm}^{2}$, correspondientes con las máximas velocidades de corrosión registradas en estructuras reales para procesos de corrosión por carbonatación y por cloruros, respectivamente. La apertura de fisura se controló mediante galgas extensiométricas adheridas a la superficie de hormigón. Los resultados obtenidos permitieron concluir que la aparición de las primeras fisuras en la superficie de las probetas se daba para penetraciones de ataque $P_{x}$ de unas $20 \mu \mathrm{m}$ (aproximadamente un $0,5 \%$ de la sección transversal de la barra), con independencia del recubrimiento y de las velocidades de corrosión consideradas.

Rodríguez et al. (1994-a) llevaron a cabo una campaña experimental basada en ensayos de corrosión acelerada sobre elementos de hormigón, fabricados en laboratorio y contaminados con cloruros, en la que, entre otros aspectos, se controló la fisuración del recubrimiento. Los resultados obtenidos permitieron concluir que el desarrollo de las primeras fisuras superficiales se producía para una penetración de ataque $P_{x}$ de entre $15 \mu \mathrm{m}$ y $40 \mu \mathrm{m}$. Esta profundidad del deterioro suponía una reducción del área de la sección transversal por debajo del 2\% para el menor de los diámetros considerados. Posteriormente, Andrade et al. (1995) y Rodríguez et al. (1996) propusieron una expresión empírica mediante modelos de regresión lineal, fruto del análisis estadístico de los resultados anteriores, para la determinación del valor medio de profundidad de ataque por corrosión que producía el inicio de la fisuración, $P_{x 0}$ (valor característico, en micras) (Eq. 2-52):

$$
P_{x o}=83,8+7,4 \frac{c}{\phi}-22,6 \cdot f_{c t, i}\left[P_{x o} \geq 0\right]
$$

donde:
$c / \phi \quad$ Relación recubrimiento/diámetro
$f_{c t, i} \quad$ Resistencia a tracción indirecta del hormigón (ensayo brasileño) [MPa]

Por otra parte, se estableció la relación entre el ancho de fisura $w$ (en $\mathrm{mm}$ ) y la penetración de ataque por corrosión $P_{x}$ (también en mm.) mediante un coeficiente $\beta$ (Eq. 2-53).

$$
w=0,05+\beta\left(P_{x}-P_{x o}\right) \quad[w<1 m m]
$$

Los autores determinaron que $\beta$ dependía principalmente de la intensidad de corrosión $I_{\text {corr }}$ y de la posición de la armadura durante el hormigonado, por lo que propusieron las siguientes expresiones correspondientes al valor medio para las posiciones superior e inferior (Eq. 2-54).

$$
\beta_{\text {sup }}=0,0086-4,9 \cdot 10^{-5} I_{\text {corr }} \quad \beta_{\text {inf }}=0,0104-5,2 \cdot 10^{-5} I_{\text {corr }}
$$

Dado que el valor de las intensidades de corrosión en estructuras reales oscila entre 0,1-0,2 y 1-2 $\mu \mathrm{A} / \mathrm{cm}^{2}$, los autores consideraron que este parámetro, a efectos de la fisuración del recubrimiento, 
era despreciable (Rodríguez, et al., 1999), por lo que propusieron la simplificación del coeficiente $\beta$ en las siguientes constantes (Eq. 2-55).

$$
\beta_{\text {sup }}=0,0086 \quad \beta_{\text {inf }}=0,0104
$$

El valor del coeficiente $\beta$ recogido en (Eq. 2-55) proporciona el valor medio de la apertura de fisura $w$, mientras que para el valor característico (intervalo de confianza del 95\%) proponen los siguientes valores: $\beta_{\text {sup }}=0,01 ; \beta_{\text {inf }}=0,0125$. En la Figura 2-28 se representa el inicio y desarrollo de la fisuración para tres niveles de resistencia de tracción indirecta del hormigón (ensayo brasileño) y distintas relaciones recubrimiento/diámetro (Rodríguez, et al., 1996). Tal y como se puede apreciar, una vez que el agresivo alcanza la barra, las fisuras aparecen casi de manera instantánea $\left(P_{x 0} \approx 0 \mu \mathrm{m}\right)$ en hormigones de alta calidad $\left(f_{c t, i}=4 \mathrm{MPa}\right)$ con relaciones recubrimiento/diámetro bajas $(c / \phi=1)$. Por el contrario, en el caso de hormigones de baja calidad $\left(f_{c t, i}=2 \mathrm{MPa}\right)$, con ratios $\mathrm{c} / \phi$ altos $(c / \phi=3)$, se necesitan penetraciones de ataque $P_{x 0}$ de hasta $60 \mu \mathrm{m}$, ya que los óxidos generados por la corrosión pueden difundirse más fácilmente a través de la red de poros del hormigón.

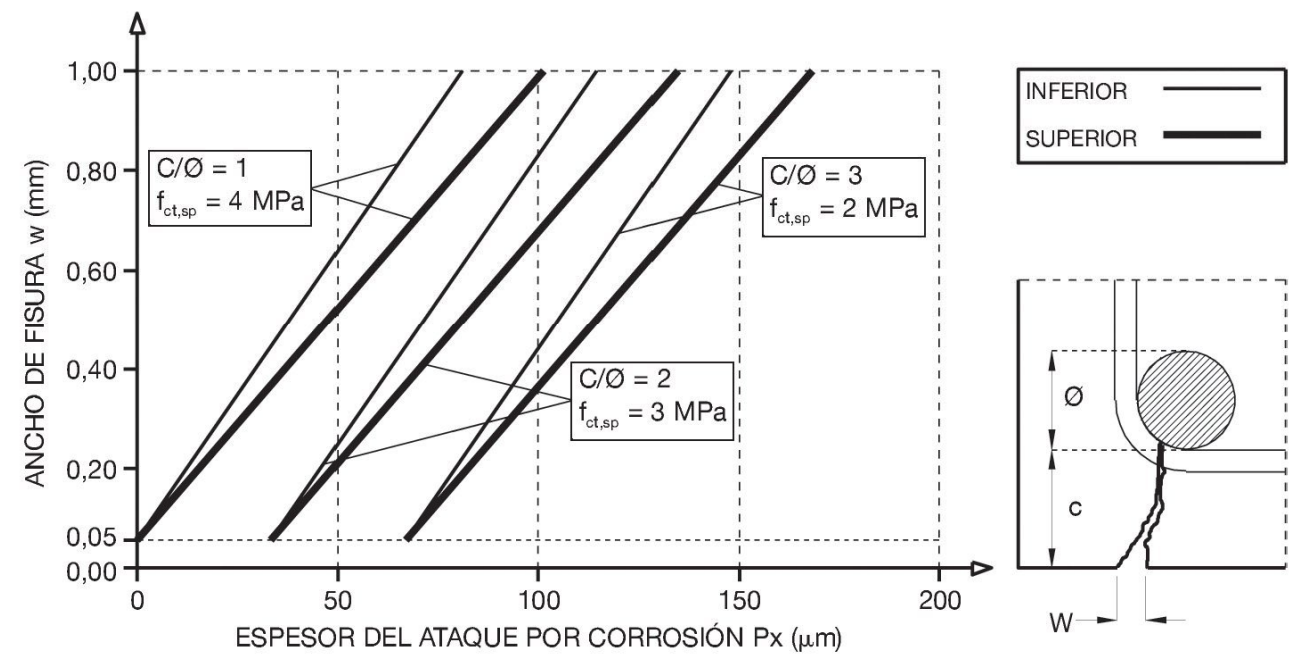

Figura 2-28 Relación entre el espesor de ataque por corrosión en la armadura $P_{x}$ y la abertura de fisura en el hormigón, w. Figura tomada de (Rodríguez, et al., 2014)

Partiendo de las expresiones anteriores [(Eq. 2-52), (Eq. 2-53), (Eq. 2-54)], se pueden deducir las principales conclusiones relativas a la fisuración a las que llegaron Andrade et al. (1995) y Rodríguez et al (1996):

- La relación recubrimiento/diámetro $c / \phi$ tiene una influencia determinante en la penetración de ataque por corrosión necesaria para provocar el comienzo de la fisuración, $P_{x}$, mientras que su efecto no es significativo en la evolución de ésta.

- La intensidad de corrosión $I_{\text {corr }}$ no influye en el inicio de la fisuración, sin embargo, sí que afecta al progreso de la misma. Por tanto, para una intensidad de corriente baja, la penetración 
de ataque $P_{x}$ necesaria para alcanzar una apertura de fisura $w$ determinada, es menor que para intensidades mayores.

- La calidad del hormigón, contemplada mediante su resistencia a tracción indirecta $f_{c t, i}$ afecta al inicio de la fisuración del recubrimiento. Rodríguez et al. (1996) comprobaron que el aumento de la porosidad del hormigón, relacionado con la disminución de $f_{c t, i}$, retrasaba la aparición de las primeras fisuras. Por el contrario, la calidad del hormigón no afectaba a la evolución de la fisuración.

El procedimiento de evaluación de la fisuración del recubrimiento en estructuras corroídas, expuesto en los párrafos anteriores, fue incluido posteriormente en el "Manual de evaluación de estructuras afectadas por corrosión de la armadura" (CONTECVET , 2001).

Alonso et al. (1998), retomando el trabajo realizado por Andrade et al. (1993), estudiaron los factores que influyen en la fisuración del recubrimiento en estructuras con armaduras que experimentan procesos de deterioro por corrosión. Las variables estudiadas fueron la relación recubrimiento/diámetro $c / \phi$, la relación agua/cemento, la posición de la armadura y la intensidad de corrosión $I_{c o r r}$ Al igual que Rodríguez et al. (1996), los autores detectaron que la variación de la relación recubrimiento/diámetro no modificaba la velocidad de propagación de la fisuración. Los resultados obtenidos permitieron deducir una expresión para la determinación de la penetración de ataque necesaria para el inicio de la fisuración, $P_{x 0}$, dependiente exclusivamente de la relación $c / \phi(E q$. 2-56).

$$
P_{x 0}=7,53+9,32 \frac{c}{\phi}[\mu m]
$$

Vidal et al. (2004) estudiaron la fisuración longitudinal del recubrimiento debida a procesos de corrosión en dos vigas corroídas naturalmente, en un ambiente salino y sometidas a ciclos de humectación y secado durante periodos de 14 y 17 años, respectivamente. Vidal et al (2004), partiendo de la expresión desarrollada por Alonso et al. (1998), proponen una ecuación (Eq. 2-57) para determinar la pérdida de sección por corrosión que debe sufrir una armadura de área transversal $A_{s}$ $\left(\mathrm{mm}^{2}\right)$ para provocar la aparición de la primera fisura, $\Delta A_{s 0}\left(\mathrm{~mm}^{2}\right)$, dependiente de la relación $c / \phi$ $(\mathrm{mm} / \mathrm{mm})$ y del factor de picadura $a(E q .2-36)$.

$$
\Delta A_{s 0}=A_{s}\left[1-\left[1-\frac{\alpha}{\phi}\left(7,53+9,32 \frac{c}{\phi}\right) \cdot 10^{-3}\right]^{2}\right]
$$

Por otro lado, Vidal et al. (2004) proponen una expresión (Eq. 2-58) para la determinación del ancho de fisura $w[\mathrm{~mm}]$ en función de la pérdida total de área que ha sufrido la armadura por el proceso de corrosión, $\Delta A_{s}\left[\mathrm{~mm}^{2}\right]$. La ecuación (Eq. 2-58) depende de un factor $\mathrm{K}=0,0575$, cuyo valor fue obtenido por el ajuste mediante regresión lineal de los resultados experimentales. 


$$
w=K\left(\Delta A_{s}-\Delta A_{s 0}\right)
$$

Pedrosa \& Andrade (2017) estudiaron la influencia de la velocidad de corrosión $I_{\text {corr }}$ y del espesor de recubrimiento $c$ en la evolución de la apertura de fisura $w$. Los resultados obtenidos mostraron que el crecimiento de la fisuración constaba de dos etapas diferenciadas, de manera que una curva bilineal podía representar con suficiente precisión la relación existente entre la penetración de ataque $P_{x}$ y el ancho de fisura $w$ (Figura 2-29). A una intensidad de corrosión constante, la primera etapa estaba protagonizada por un crecimiento rápido de la apertura de fisura, con una pendiente $\beta$, que se atenuaba al alcanzar un determinado nivel de penetración de ataque $P_{x}$, tomando una pendiente $\gamma_{\text {que }}$ se mantenía constante a lo largo de la segunda etapa.

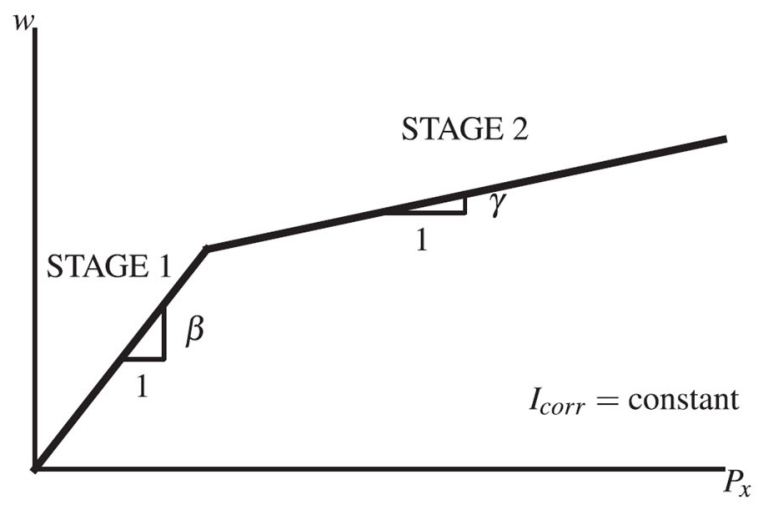

Figura 2-29 Modelo bilineal de evolución del ancho de fisura bajo una velocidad de corrosión constante. Figura tomada de Pedrosa \& Andrade (2017)

A través del análisis de los resultados obtenidos en la campaña experimental, Pedrosa \& Andrade (2017) lograron establecer una relación empírica entre la pendiente $\beta$ de la primera etapa de fisuración y la intensidad de corrosión $I_{\text {corr }}$ (Eq. 2-59)

$$
\beta=a \cdot I_{\text {corr }}{ }^{-k}
$$

donde $a$ y $k$ son parámetros extraídos del ajuste de la curva de regresión de los ensayos, cuyo valor determinado por los autores es $26,76 \pm 4,97$ y $0,32 \pm 0,06$, respectivamente. Finalmente, suponiendo una velocidad de corrosión constante, y conocido el valor de la pendiente $\beta$, la apertura de fisura $w$ en la primera etapa puede expresarse como sigue (Eq. 2-60):

$$
w=\beta \cdot P_{x}
$$

La Tabla 2-6, tomada del Bulletin No10 del CEB-FIP (2000), compara la pérdida de sección transversal y la penetración de ataque por corrosión $P_{x}$, necesarias para el comienzo de la fisuración en varios estudios llevados a cabo por diferentes investigadores (CEB-FIB_Task Group 2.5, 2000). Los resultados sugieren una tendencia a que los recubrimientos con mayor espesor y las velocidades de corrosión elevadas necesiten mayores niveles de corrosión para provocar la aparición de las primeras fisuras. 
TESIS DOCTORAL INFLUENCLA DE LA CORROSIÓN EN LA ADHERENCLA DE ALAMBRES EN ELEMENTOS PRETENSADOS DE HORMIGÓN

Tabla 2-6 Nivel de corrosión necesario para provocar el comienzo de la fisuración del recubrimiento. Tabla tomada de (CEB-FIB_Task Group 2.5, 2000).

\begin{tabular}{|c|c|c|c|c|c|}
\hline Investigaciones & $\begin{array}{l}\text { Diámetro } \\
\text { barra } \\
\phi[\mathrm{mm}]\end{array}$ & $\begin{array}{l}\text { Recubrimiento } \\
\qquad c[\mathrm{~mm}]\end{array}$ & $\begin{array}{l}\text { Intensidad de } \\
\text { corrosión } \\
I_{\text {corr }}\left[\mu \mathrm{A} / \mathrm{cm}^{2}\right]\end{array}$ & $\begin{array}{c}\text { Pérdida de } \\
\text { sección } \\
\%\end{array}$ & $\begin{array}{c}\begin{array}{c}\text { Penetración } \\
\text { de ataque }\end{array} \\
P_{x}[\mu m]\end{array}$ \\
\hline \multirow{3}{*}{ Al-Sulaimani et al. (1990) } & 20 & 3,75 & 2000 & 2 & 100 \\
\hline & 14 & 5,36 & 2000 & 3 & 110 \\
\hline & 10 & 7,50 & 2000 & 5 & 130 \\
\hline Cabrera \& Ghodussi (1992) & 12 & $2,5-4,8$ & 3 voltios & $1-2$ & $30-60$ \\
\hline \multirow{3}{*}{ Clark \& Saifullah (1993) } & 8 & 0,5 & 500 & 0,4 & 8 \\
\hline & 8 & 1,0 & 500 & 0,6 & 12 \\
\hline & 8 & 2,0 & 500 & 1,3 & 26 \\
\hline \multirow{2}{*}{ Andrade et al. (1993) } & \multirow{2}{*}{16} & $1,25-1,88$ & 100 & $0,4-0,5$ & $15-20$ \\
\hline & & 1,25 & 10 & 0,45 & 18 \\
\hline \multirow{2}{*}{ Clark \& Saifullah (1994) } & 8 & 1,0 & 2000 & 0,3 & 6 \\
\hline & 8 & 1,0 & 500 & 0,55 & 11 \\
\hline Rodríguez et al. (1994-a) & 16 & $2,0-4,0$ & $3-100$ & $0,4-1,0$ & $15-40$ \\
\hline Almusallam et el. (1996) & 12 & 5,0 & 10000 & 4,0 & 120 \\
\hline Alonso et al. (1998) & $8-16$ & $1,25-7,0$ & 100 & --- & $15-65$ \\
\hline
\end{tabular}

\subsubsection{Revisión de modelos propuestos}

Además de las expresiones empíricas derivadas de resultados experimentales, recogidas en las páginas anteriores, se han desarrollado numerosos modelos analíticos y numéricos para reproducir la fisuración del hormigón provocada por los procesos de corrosión.

Desde que Bazant (1979) utilizó por primera vez la teoría de cilindros de pared gruesa (Timoshenko, 1956) para el análisis del estado tensional del recubrimiento de hormigón debido a los procesos de corrosión, numerosos autores han abordado este problema desde ese enfoque (Martín-Pérez, 1999) (Pantazopoulou \& Papoulia, 2001) (Bhargava, et al., 2006) (Tastani \& Pantazopoulou, 2013). En el Capitulo 3 se expone en profundidad el cuerpo teórico de los modelos basado en esta teoría, ya que ha sido la base para el modelo analítico desarrollado en esta tesis.

El modelo original desarrollado por Bazant (1979) consideraba el recubrimiento de hormigón que rodeaba el acero como un cilindro de pared gruesa, cuyo radio exterior era igual recubrimiento mínimo de hormigón en la zona analizada. El cilindro estaba sujeto a una presión interna $p$ provocada por la expansión de los productos de corrosión y las tensiones eran calculadas usando la solución analítica proporcionada por la teoría de la elasticidad lineal, considerando el hormigón como un material elástico e isótropo. El modelo partía de la hipótesis de que el recubrimiento fallaba con la aparición de la primera fisura en la superficie de la pared interna del cilindro de hormigón. 
Posteriormente, Liu \& Weyers (1998) desarrollaron un modelo que predecía el tiempo hasta fisuración, en el cual consideraban la cantidad critica de productos de corrosión necesaria para, por un lado, rellenar el espacio liberado por los poros interconectados en la interfaz acero/hormigón (“Capa porosa" t; ; y, por otro, comenzar a generar las tensiones circunferenciales de tracción $\sigma_{\vartheta}$ necesarias para fisurar el recubrimiento. Posteriormente, Martín-Pérez (1999), aunque continúa considerando un comportamiento elástico e isótropo para el hormigón, establece que el recubrimiento conserva su capacidad de confinamiento hasta que la fisura se propaga a través de todo el recubrimiento. Para ello, desde un punto de vista analítico, divide el proceso en dos etapas: una etapa elástica no fisurada, previa al inicio de la fisuración en la interfaz acero/hormigón, y una etapa elástica parcialmente fisurada, en la que la fisura se propaga paulatinamente por el recubrimiento, deteniendo su avance allí donde las tensiones en su extremo podían ser soportadas por el hormigón, hasta alcanzar la superficie exterior del cilindro (Figura 2-30).
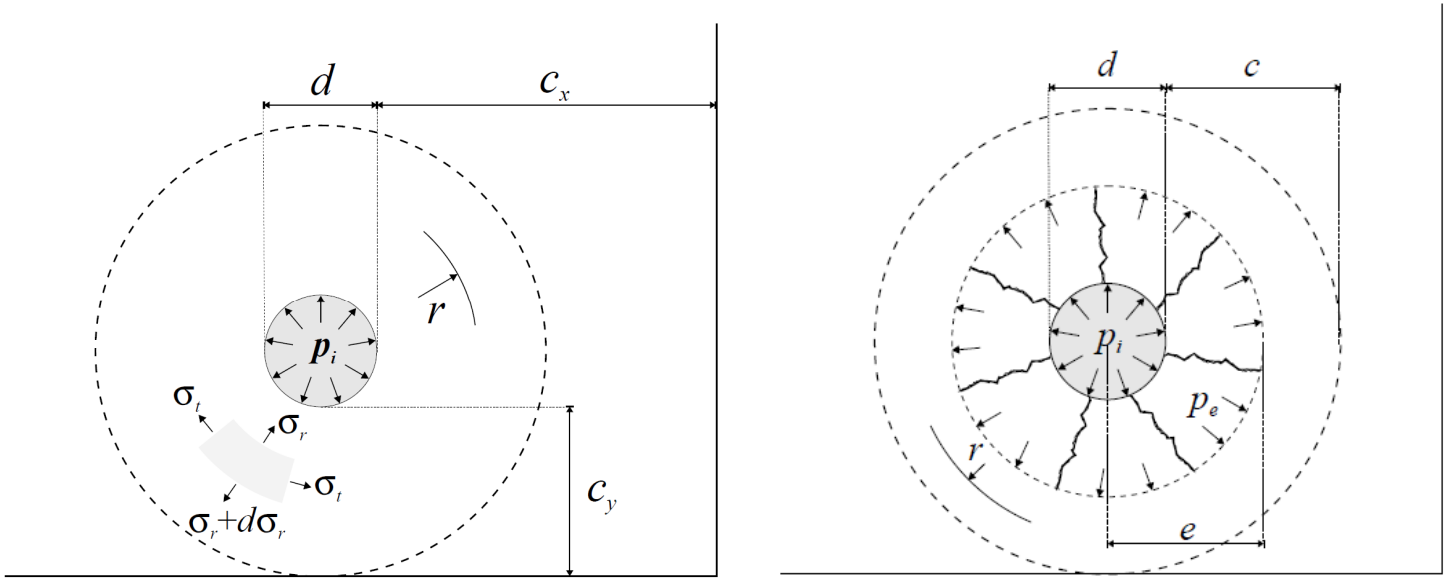

Figura 2-30 Etapa elástica no fisurada y elástica parcialmente fisurada. Figura tomada de (Martín-Pérez, 1999)

Pantazopoulou \& Papoulia (2001) profundizan en el modelo de hormigón fisurado, tratándolo como un material anisótropo elástico no-lineal, con ablandamiento tras la fisuración. La presencia de fisuras y la posibilidad de que parte de los productos de corrosión se acomodaran en el espacio liberado por las mismas reducían la presión de los óxidos e incrementaba el tiempo hasta el fallo. La capacidad de deformación y la resistencia residual en tracción del hormigón fueron derivadas de las propiedades de fractura del material. El comportamiento mecánico del recubrimiento fue analizado mediante diferencias finitas.

Tal y como indican Pantazopoulou \& Papoulia (2001), la utilización de estos modelos conduce a una fisuración del recubrimiento más temprana que la reflejada en observaciones experimentales. Para mitigar esta discrepancia, a lo largo de los últimos años los autores que han abordado este problema han utilizado diferentes estrategias en el modelado, entre las que destacan, sin ser exhaustivo, las siguientes:

- Se ha considerado una región alrededor de la interfaz acero-hormigón en la que los óxidos pueden difundir sin ejercer ninguna presión en el hormigón circundante (región de porosidad infinita), y cuyo espesor aparente $t_{p}$ es equivalente a la suma del volumen de poros en los que 
presumiblemente se difundirían los productos de corrosión. (Andrade, et al., 1993) (Molina, 1993) (Liu \& Weyers, 1998) (Martín-Pérez, 1999)

- Se ha modificado la tasa de penetración de ataque constante que arroja la ley de Faraday (Liu \& Weyers, 1998) (Balafas \& Burgoyne, 2010a).

- Se ha admitido que el recubrimiento de hormigón conserva cierta resistencia residual tras haberse superado su capacidad a tracción $f_{c t}$ (Pantazopoulou \& Papoulia, 2001).

- Se ha considerado que, una vez iniciada la fisuración en el hormigón que circunda el alambre, un porcentaje de los productos de corrosión pueden depositarse en el interior de las fisuras abiertas (Bažant, 1979) (Andrade, et al., 1993) (Pantazopoulou \& Papoulia, 2001) (Coronelli, 2002)

Por otro lado, otros autores han optado por reproducir el estado tensional del recubrimiento de hormigón sometido a la presión de los productos de corrosión mediante el método de los elementos finitos (FEM). Uno de los primeros trabajos desarrollados en esta dirección fue el llevado a cabo por Molina et al. (1993), en el que los autores consideraron una fisuración distribuida uniformemente. La corrosión, que fue entendida como una carga aplicada sobre el recubrimiento, se modeló mediante una combinación de deformaciones iniciales impuestas y cambios en las propiedades mecánicas del material (módulo de elasticidad y coeficiente de Poisson), equivalentes a los procesos de expansión de los productos de corrosión y ablandamiento del hormigón en la interfaz acero/hormigón. Los resultados del modelo fueron comparados con la campaña experimental de Andrade et al. (1993). El análisis de los resultados permitió la obtención de una expresión simplificada con la que determinar, de modo conservador, la suma total de los anchos de fisura $w$, uniformemente distribuidos, con respecto a la penetración de ataque por corrosión $P_{x}$ (Eq. 2-61).

$$
\sum \frac{w}{P_{x}}=2 \pi \cdot(n-1)
$$

donde $n$ es el coeficiente de expansión de óxidos (relación entre el volumen específico de los productos de corrosión y el del acero virgen).

\subsubsection{Influencia de la corrosión en la adherencia}

\subsubsection{Introducción}

El número de trabajos que estudian la influencia de la corrosión en la adherencia de alambres o cordones pretensados es escaso, y los existentes se centran preferentemente en el comportamiento mecánico del elemento, sin profundizar en el análisis de la evolución de las propiedades adherentes. Por ello, en este apartado se llevará a cabo una revisión bibliográfica de las investigaciones que se han realizado sobre elementos de hormigón armado, sin pretensar, cuyas conclusiones son extrapolables en gran medida a estructuras pretensadas. Se comienza reseñando los estudios más destacables realizados sobre armaduras corrugadas, que a la postre son los más numerosos, se continúa con el caso particular de los alambres lisos o indentados (que permite el análisis de los ensayos de pull-out 
acometidos en esta tesis) y se finaliza con algunos de los pocos estudios sobre acero pretensado que se han llevado a cabo.

De forma general, el Bulletin 10 del CEB-FIB "Bond of reinforcement in concrete" (CEB-FIB_Task Group 2.5, 2000) enumera en qué formas afecta la corrosión a la capacidad adherente de las armaduras:

- El incremento del diámetro de la barra corroída provoca un aumento de las tensiones radiales entre la barra y el hormigón circundante $y$, por tanto, un incremento de la componente de fricción de la adherencia. Sin embargo, superado un determinado umbral, la corrosión provoca el desarrollo de fisuración longitudinal que trae consigo una disminución de la resistencia a las fuerzas de ruptura generadas por la acción de la adherencia.

- Los productos de corrosión en la interfaz acero/hormigón afectan al mecanismo de fricción. Algunos estudios indican que, para niveles bajos de corrosión, los productos de corrosión firmemente adheridos pueden contribuir a una mejora en el comportamiento adherente. (Al-Sulaimani, et al., 1990). Para niveles de corrosión más avanzados, el material débil y delaminado existente entre la barra y el hormigón es responsable, al menos en parte, de la reducción de la tensión máxima de adherencia.

- La corrosión puede disminuir la altura relativa de las corrugas sobre la cara externa del núcleo de la barra. Sin embargo, este efecto no es significativo hasta etapas avanzadas del proceso de corrosión.

- La corrosión puede provocar la disminución de la superficie de contacto entre corrugas y hormigón. La capa de productos de corrosión formada por la oxidación del acero puede forzar al hormigón a separarse de la barra y, por tanto, a reducir el área efectiva de contacto de las corrugas.

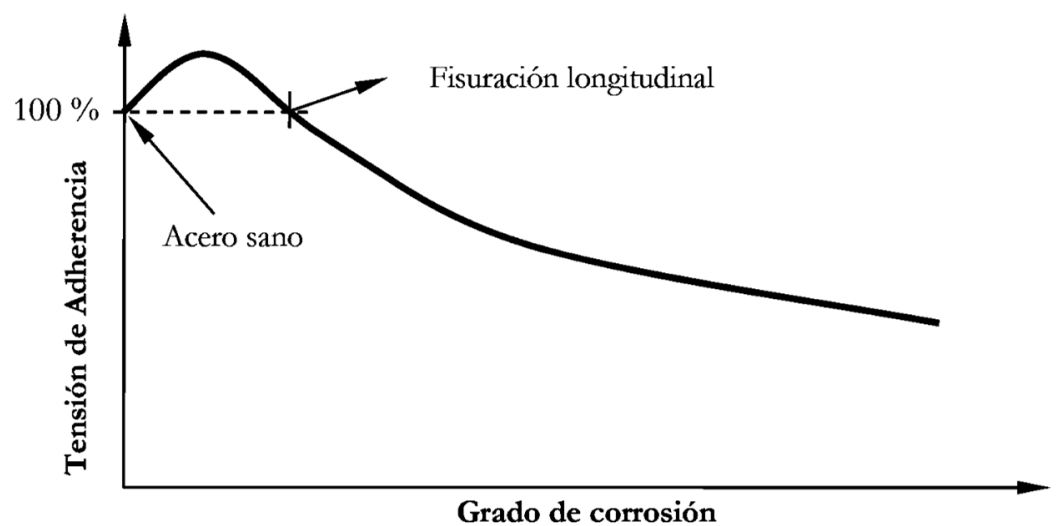

Figura 2-31 Variación de la tensión de adherencia con el avance de la corrosión (CEB-FIB_Task. Group 2.5, 2000). Figura tomada de (Prieto Rábade, 2014)

La mayor parte de los estudios centrados en el análisis de la influencia de la corrosión en la adherencia hormigón/acero han observado un patrón de comportamiento similar, independientemente del acabado superficial de la barra. Inicialmente, para pequeñas penetraciones de ataque por corrosión, 
la tensión de adherencia $\tau_{b}$ se incrementa debido al aumento de las tensiones radiales en la interfaz. Posteriormente, para una mayor acumulación de productos de corrosión, la adherencia comienza a disminuir. Este descenso en la capacidad adherente se debe, por un lado, a la fisuración del recubrimiento, al superarse la resistencia a tracción del hormigón, y por otro, según algunos autores, a la reducción del coeficiente de fricción. En términos de evaluación de la adherencia residual, existe un amplio consenso en el hecho de que la tensión de adherencia no se ve reducida antes de la aparición de la fisuración longitudinal a lo largo del elemento (ver Figura 2-31).

\subsubsection{Adherencia en barras corrugadas con corrosión}

El efecto de la corrosión sobre la adherencia en armaduras corrugadas ha sido ampliamente estudiado. El trabajo más completo realizado hasta la fecha (CEB-FIB_Task Group 2.5, 2000), fue el llevado a cabo por Rodríguez et al. [ (1994-a), (1994-b), (1996)], que permitió el desarrollo de expresiones empíricas para la evaluación de la tensión de adherencia residual $\tau_{b, r e s}$ en este tipo de barras. La campaña experimental de estos trabajos estuvo basada en ensayos de pull-out excéntrico, llevados a cabo sobre probetas cúbicas de hormigón, armadas con cuatro barras situadas en las esquinas, con y sin armadura transversal. La configuración del ensayo (ver Figura 2-32) permitía reproducir el comportamiento adherente real de un fragmento de viga sometido a una fuerza cortante constante.

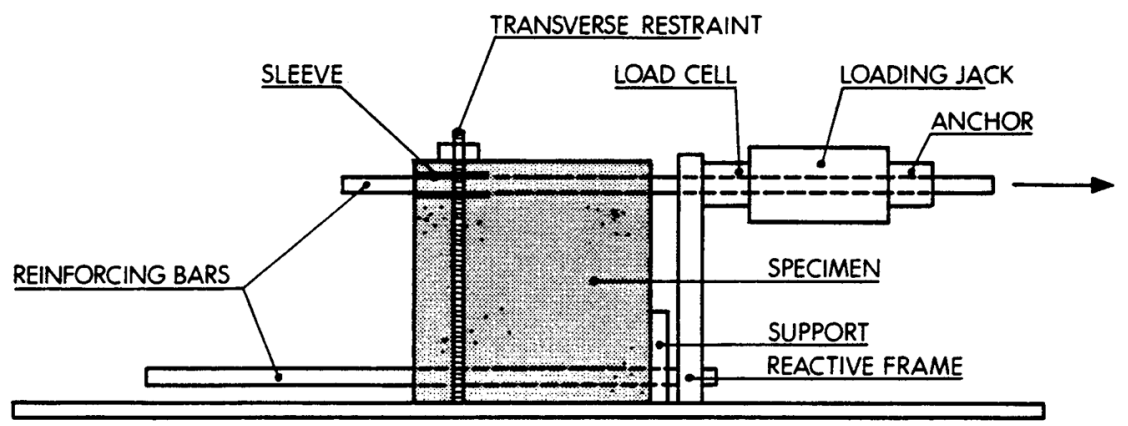

Figura 2-32 Configuración de ensayos de pull-out excéntrico en los trabajos de Rodriguez et al. Figura tomada de (Rodríguez, et al., 1994-b)

Los resultados de los ensayos, que fueron llevados a cabo sobre armaduras de 10 y $16 \mathrm{~mm}$ de diámetro, mostraron que una vez que el recubrimiento estaba fisurado, la capacidad adherente residual dependía de la penetración de ataque por corrosión y de la cuantía de armadura transversal, mientras que la influencia tanto de la calidad del hormigón como de la relación recubrimiento/diámetro no repercutía de manera apreciable. El análisis estadísticos de los resultados experimentales permitió obtener expresiones empíricas para predecir el valor característico de la capacidad adherente residual $\tau_{b, r e s}$ en función de la penetración de ataque $P_{x}$. Para ello, los autores diferenciaron dos casos, dependiendo de la relación $\varrho_{t r}$ existente entre el área de armadura transversal a lo largo de la longitud de anclaje (considerando la reducción del área debida a la corrosión) y el área de las barras principales. En el caso de ratios etr por encima de 0,25 (el mínimo valor establecido en el Eurocódigo 2), la máxima capacidad adherente residual $\tau_{b, r e s}$ (en MPa) podía ser calculada según la siguiente expresión (Eq. 2-62):

$$
\tau_{b, r e s}=4,75-4,64 \cdot P_{x}
$$


Por el contrario, si el ratio @tr está por debajo de 0,25 , el valor de $\tau_{b, r e s}$ podía ser estimado como sigue (Eq. 2-63):

$$
\tau_{b, r e s}=10,04+\left(-6,62+1,98 \frac{\rho_{t r}}{0,25}\right)(1,14+x)
$$

En el caso de ausencia de cercos, Rodríguez et al. proponen que la adherencia residual se estime según la siguiente expresión (Eq. 2-64):

$$
\tau_{b, r e s}=2.50-6.62 \cdot P_{x}
$$

Recientemente, Prieto (2014) llevó a cabo un programa experimental de ensayos tipo pull-out excéntricos sobre diferentes probetas, unas sin corrosión y otras sometidas a procesos de corrosión tanto natural como acelerada, con diferentes grados de deterioro. Los resultados experimentales, junto con una base de datos elaborada en base a la recopilación de estudios de adherencia con armaduras corroídas procedentes de la literatura científica, permitió el desarrollo de una formulación para la evaluación de la adherencia tanto en armaduras sanas como corroídas, a partir de modelos de regresión múltiple. De esta manera, Prieto (2014) propone que el valor medio de la tensión última de adherencia $\left(f_{b m, 0}\right.$, según su notación) de armaduras corrugadas con procesos de corrosión debería ser estimado como sigue (Eq. 2-65):

$$
f_{b m, 0}=\left(\eta_{1} \eta_{2} \eta_{3} \eta_{4} \eta_{5} \eta_{6}-1\right) f_{c m}^{2 / 3}
$$

donde:

$\eta_{1} \quad$ Coeficiente que tiene en cuenta el porcentaje de pérdida de sección por corrosión

1,24 armaduras sin corrosión

1,16 armaduras con $\%$ corrosión $\leq 5 \%$

1,12 armaduras con $5 \%<\%$ corrosión $\leq 20 \%$

$\eta_{2} \quad$ Coeficiente que tiene en cuenta la posición de la armadura durante el hormigonado

1,03 posición I o de adherencia "buena"

1,00 posición II o de adherencia "mala"

$\eta_{3} \quad$ Coeficiente que tiene en cuenta el diámetro de la armadura

1,10 para la serie fina $\phi \leq 10 \mathrm{~mm}$

1,04 para la serie media $10 \mathrm{~mm}<\phi \leq 20 \mathrm{~mm}$

1,02 para la serie gruesa $\phi>20 \mathrm{~mm}$

$\eta_{4} \quad$ Coeficiente que tiene en cuenta el confinamiento por armadura transversal

1,00 sin confinamiento

1,04 confinamiento con $\rho_{t} \leq 0,05$ 
TESIS DOCTORAL INFLUENCLA DE LA CORROSIÓN EN LA ADHERENCLA DE ALAMBRES EN ELEMENTOS PRETENSADOS DE HORMIGÓN

$$
1,06 \text { confinamiento con } \rho_{t}>0,05
$$

$\eta_{5} \quad$ Coeficiente que tiene en cuenta el grado de confinamiento debido al recubrimiento $c$

$$
\begin{aligned}
& 0,97 \text { si } c / \phi \leq 1,5 \\
& 1,06 \text { si } 1,5<c / \phi \leq 3,5 \\
& 1,26 \text { si } c / \phi>3,5
\end{aligned}
$$

$\eta_{6} \quad$ Coeficiente que tiene en cuenta la longitud de adherencia $l_{b}$

$$
\begin{aligned}
& 1,50 \text { si } l_{b} / \phi<10 \\
& 1,04 \text { si }_{b} / \phi \geq 10
\end{aligned}
$$

El Bulletin No10 del CEB-FIP (CEB-FIB_Task Group 2.5, 2000) incluye una tabla resumen en la que se comparan las pérdidas de capacidad adherente por el avance de los procesos de corrosión,

\begin{tabular}{|c|c|c|c|c|c|}
\hline Investigadores & $\begin{array}{c}\text { Recubrimiento/ } \\
\text { Diámetro } \\
c / \phi\end{array}$ & $\begin{array}{l}\text { Intensidad de } \\
\text { corrosión } \\
I_{\text {corr }}\left[\mu \mathrm{A} / \mathrm{cm}^{2}\right]\end{array}$ & $\begin{array}{l}\text { Armadura } \\
\text { transversal }\end{array}$ & $\begin{array}{c}\text { Pérdida } \\
\text { sección } \\
\%\end{array}$ & $\begin{array}{c}\text { Tens. adh } \\
\text { residual } \\
\%\end{array}$ \\
\hline \multirow{3}{*}{ Al-Sulaimani et al. (1990) } & 3.75 & 2000 & No & 5 & 35 \\
\hline & 5.36 & 2000 & No & 7 & 15 \\
\hline & 7.50 & 2000 & $\mathrm{No}$ & 10 & 0 \\
\hline \multirow{3}{*}{$\begin{array}{c}\text { Cabrera \& Ghodussi } \\
\qquad(1992)\end{array}$} & 12 & 3 voltios & No & 8 & 65 \\
\hline & 12 & 3 voltios & Sí & 8 & 95 \\
\hline & 12 & 3 voltios & Sí & 8 & 110 \\
\hline Clark \& Saifullah (1993) & $0.5-2.0$ & 500 & No & 12.5 & 75 \\
\hline \multirow{3}{*}{ Clark \& Saifullah (1994) } & 1 & 40 & No & 12.5 & 60 \\
\hline & 1 & 250 & No & 12.5 & 105 \\
\hline & 1 & 4000 & No & 12.5 & 50 \\
\hline \multirow{3}{*}{ Rodríguez et al. (1994-a) } & 1.5 & 100 & No & $5.4-9.1$ & 20 \\
\hline & $1.5-2.5$ & 100 & Sí & $5.4-9.1$ & 65 \\
\hline & 1.5 & 100 & Sí & 14 & 75 \\
\hline Almusallam et el. (1996) & 5 & 10000 & No & 8 & 15 \\
\hline Coronelli (1997) & 2.5 & 50 & Sí & - & 110 \\
\hline Stanish (1997) & 2.0 & 210 & No & 10 & 60 \\
\hline
\end{tabular}
registradas en algunos de los estudios más representativos (Tabla 2-7). La comparación se establece en base a las pérdidas registradas para penetraciones de ataque de $0,25 \mathrm{~mm}$, lo cual representa un grado de deterioro mucho más allá del necesario para fisurar el recubrimiento.

Tabla 2-7 Capacidad adherente residual en armaduras corrugadas con penetraciones de ataque $P_{x}$ por corrosión de 0,25 mm (CEBFIB_Task Group 2.5, 2000).

La Tabla 2-7 muestra una gran dispersión en las tensiones de adherencia residuales $\tau_{b, r e s}$ obtenidas por los distintos investigadores, con valores que oscilan desde la completa pérdida de la capacidad 
adherente ( $0 \%$ con respecto al valor en armaduras sanas) (Al-Sulaimani, et al., 1990) hasta ligeros incrementos (110\%) [ (Cabrera \& Ghodussi, 1992); (Coronelli, 1997)].

\subsubsection{Adherencia en barras lisas con corrosión}

El distinto acabado superficial de las barras lisas con respecto a las corrugadas les confiere algunas peculiaridades en su comportamiento adherente frente a procesos de corrosión. K. Lundgren (2007) revisó de manera sistemática cuales eran los parámetros que regían el comportamiento adherente de las armaduras y cómo afectaba la corrosión tanto a las armaduras corrugadas como a las barras lisas. En base a un modelo de elementos finitos y a resultados experimentales tomados de la literatura, determinó que los parámetros fundamentales para el estudio y clasificación de la adherencia eran: el tipo de acabado superficial de la barra (lisa o corrugada), la presencia de armadura transversal y la presencia de fisuración en el recubrimiento (splitting). Lundgren dejó fuera del análisis otros parámetros de importancia, tales como el tipo de corrosión (generalizada o picaduras), la cantidad de armadura transversal, la situación de la barra, las presiones laterales de confinamiento o la resistencia a compresión del hormigón, al considerar que tenían una menor influencia sobre el comportamiento adherente.

Tabla 2-8 Revisión de la influencia de la corrosión en el comportamiento adberente de barras lisas. Tabla inspirada en (Lundgren, 2007)

\begin{tabular}{|c|c|c|c|c|}
\hline Tipo de armadura & \multicolumn{4}{|c|}{ Barras lisas } \\
\hline Armadura transversal & \multicolumn{2}{|c|}{ Con armadura transversal } & \multicolumn{2}{|c|}{ Sin armadura transversal } \\
\hline Pull-out sin corrosión & $\begin{array}{l}\text { A) Fisuras en el } \\
\text { recubrimiento }\end{array}$ & B) Sin fisuras & $\begin{array}{l}\text { C) Fisuras en el } \\
\text { recubrimiento }\end{array}$ & D) Sin fisuras \\
\hline Efecto corrosión & $\begin{array}{l}\text { Incremento moderado } \\
\text { de la adherencia }\end{array}$ & $\begin{array}{l}\text { Gran incremento de la } \\
\text { adherencia hasta que el } \\
\text { recubrimiento se fisura. } \\
\text { Posteriormente, } \\
\text { adherencia constante o } \\
\text { ligero incremento }\end{array}$ & $\begin{array}{l}\text { Disminución de la } \\
\text { adherencia desde grados } \\
\text { de corrosión bajos }\end{array}$ & $\begin{array}{l}\text { Gran incremento de la } \\
\text { adherencia hasta } \\
\text { fisuración del } \\
\text { recubrimiento. } \\
\text { Posteriormente, } \\
\text { decrecimiento de la } \\
\text { capacidad adherente }\end{array}$ \\
\hline
\end{tabular}

$\tau_{\mathrm{b}}$ Vs deslizamiento
$\begin{aligned} & \text { Corr. Postfisuración } \\ & \text { (La flecha indica fisuración del } \\ & \text { recubrimiento) }\end{aligned}$

En la Tabla 2-8 se resume, desde un punto de vista cualitativo, el efecto que tienen los procesos de corrosión en las leyes de tensión de adherencia-deslizamiento y en la tensión máxima de adherencia de barras lisas (Lundgren, 2007). Se contemplan los siguientes 4 casos:

A) Con armadura transversal. Recubrimiento fisurado en pull-out sobre armaduras sin corrosión [Tabla 2-8-A)]: El máximo valor de la tensión de adherencia $\tau_{b, \max }$ se incrementa 
monótonamente con el aumento de la corrosión, aunque de manera menos acusada cuando las tensiones circunferenciales son tales que provocan la fisuración del recubrimiento.

En la gráfica adherencia-deslizamiento $\tau_{b-s}$ puede observarse que la corrosión produce un aumento de la rigidez inicial por lo que, a mayor corrosión, menor deslizamiento $s$ necesario para alcanzar la tensión máxima de adherencia. Si las tensiones derivadas del deslizamiento de la barra ocasionan que la fisuración alcance la superficie del hormigón, la tensión de adherencia desciende para cualquier deslizamiento posterior.

B) Con armadura transversal. Recubrimiento sin fisurar en pull-out sobre armaduras sin corrosión [Tabla 2-8-B)]: Generalmente, las barras lisas sanas sometidas a una fuerza de arrancamiento no generan grandes tensiones circunferenciales, por lo que recubrimientos moderados suelen ser suficientes para impedir la fisuración del hormigón. Por lo tanto, esta es la situación más habitual en estructuras reales.

$\mathrm{Al}$ igual que en caso anterior, la corrosión provoca un aumento de rigidez en el tramo inicial de la curva adherencia-deslizamiento $\tau_{b}$-s. Por otro lado, la tensión máxima de adherencia $\tau_{b, \max }$ se incrementa de manera acusada en las primeras etapas del proceso de corrosión, hasta que las tensiones generadas por los productos de corrosión fisuran el recubrimiento. A partir de ese punto, la tensión máxima de adherencia se mantiene constante e incluso, puede experimentar ligeros aumentos.

C) Sin armadura transversal. Recubrimiento fisurado en pull-out sobre armaduras sin corrosión [Tabla 2-8-C)]: Para recubrimientos pequeños, y en ausencia de cercos, el recubrimiento puede llegar a fisurarse cuando la barra sin corroer se somete a fuerzas de arrancamiento, produciéndose un fallo frágil por fisuración (splitting).

Con respecto a las armaduras sanas, la corrosión provoca que se alcance el valor máximo de la tensión de adherencia $\tau_{b, \max }$ para deslizamientos menores en la curva adherenciadeslizamiento $\tau_{b}$-s. Una vez alcanzada la tensión máxima, cualquier deslizamiento posterior provoca caídas significativas en la capacidad adherente, fallando de forma frágil y alcanzando valores prácticamente nulos.

La tensión máxima de adherencia $\tau_{b, \max }$ decrece monótonamente para cualquier aumento del nivel de corrosión.

D) Sin armadura transversal. Recubrimiento sin fisurar en pull-out sobre armaduras sin corrosión [Tabla 2-8-D]]: Como en el resto de casos, la corrosión incrementa la rigidez inicial de la curva adherencia-deslizamiento $\tau_{b}-s$. El confinamiento proporcionado por el recubrimiento sin fisurar posibilita que la pendiente de decrecimiento de la tensión de adherencia, una vez superado su valor máximo, no sea muy acusada.

Para penetraciones de ataque que provocan la fisuración del recubrimiento, la capacidad adherente decrece abruptamente y el modo de fallo pasa de dúctil a frágil. 
Cairns et al. (2006) llevó a cabo ensayos tipo pull-out centrados, por un lado, y pull-out excéntricos con armadura transversal (Beam-Test), por otro, sobre barras lisas de $16 \mathrm{~mm}$ de diámetro. Cairns et al. analizaron como afectaban distintos parámetros al comportamiento adherente de las barras, centrándose en su acabado superficial, en la relación recubrimiento/diámetro (c/ $\phi=1,00 ; 1,25 ; 2,00$; 3;00 y 4;50), en la posición durante el hormigonado (parte superior o inferior de la probeta) y en el grado de corrosión. Según los autores, para niveles de corrosión correspondientes a profundidades de penetración de ataque $P_{x}$ de $76 \mu \mathrm{m}$ y $80 \mu \mathrm{m}$ (pérdida de sección: 1,89-1,99\%), en las barras situadas en la parte superior e inferior respectivamente, se observaba un importante incremento en las capacidades adherentes con respecto a las barras sanas (Figura 2-33). Este incremento era más significativo en las barras que se encontraban en posición desfavorable durante el hormigonado (parte superior) y, por tanto, con unas peores condiciones iniciales de adherencia. Cairns et al. (2006) concluyeron que los productos de corrosión rellenaban los poros del hormigón que circundaban la armadura, así como el hueco liberado por asentamiento plástico que se producía bajo la misma, lo que justificaba el desarrollo más lento de la fisuración longitudinal observado en las barras situadas en la cara superior. Esta observación es consistente con el mayor incremento del ancho de fisura en las barras situadas en la cara inferior detectado por Rodríguez et al. (1994-a).

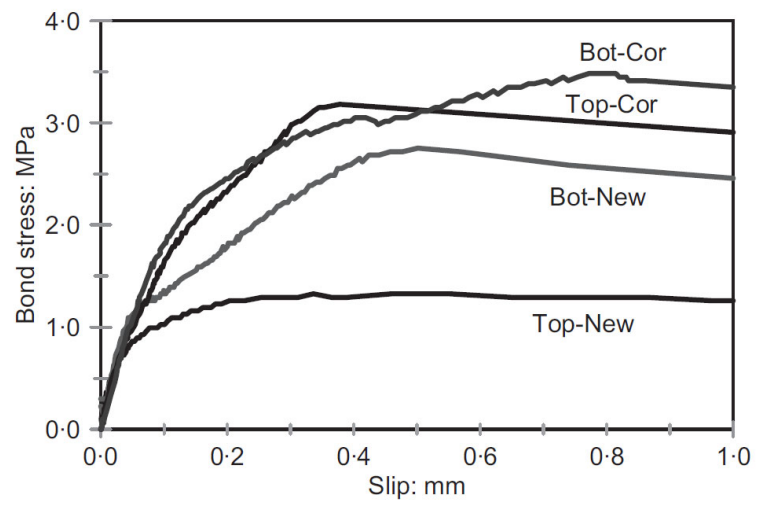

Figura 2-33 Curvas adherencia deslizamiento para armaduras sanas y corroídas (Penetración de ataque entre 76 y $80 \mu \mathrm{m}$ ). Influencia de la posición durante el hormigonado. Figura tomada de (Cairns, et al., 2006)

Por otra parte, Cairns et al. (2006) compara la tensión de adherencia para deslizamientos de 0,15 mm en el lado cargado y para distintos niveles de penetración del ataque por corrosión, observando que en las barras con buenas condiciones iniciales de adherencia (en la parte baja del encofrado), la corrosión apenas influye en el comportamiento adherente. Sin embargo, cerca de la mitad de las barras con presumibles peores condiciones iniciales de adherencia (parte superior del encofrado durante el hormigonado), una vez corroídas, mostraron un valor medio de incremento de la tensión de adherencia de cerca del 100\% (alcanzando valores puntuales de hasta un 600\%). Para los autores, los resultados sugieren que para penetraciones de ataque $P_{x}$ de hasta $200 \mu \mathrm{m}$ (equivalente aproximadamente a un 5\% de pérdida de sección) en estructuras en servicio, la corrosión no es un factor que vaya en detrimento de aspectos mecánicos dependientes de la adherencia. Como resultado del análisis de los ensayos realizados, Cairns et al. (2006) propone una serie de expresiones para la determinación de tensión de adherencia máxima $\tau_{\text {, max }}$ en función de la penetración de ataque $P_{x}$ y de la resistencia a compresión del hormigón $f_{c}$. De esta manera, para barras situadas en "posición 
favorable" durante el hormigonado, los autores concluyen que el máximo valor de la tensión de adherencia residual $\tau_{\mathrm{b}, \mathrm{mes}}^{\max }$ puede calcularse como sigue (Eq. 2-66):

$$
\tau_{b, r e s}^{\max }=\frac{\beta \sqrt{f_{c}}}{1+8 P_{x}}
$$

Mientras que, para barras situadas en posición desfavorable, la tensión residual responde a la siguiente expresión (Eq. 2-67):

$$
\tau_{b, r e s}^{\max }=\frac{1.35 \cdot \beta \sqrt{f_{c}}}{1+8 P_{x}}
$$

En ambos casos, con un valor no mayor a (Eq. 2-68):

$$
\tau_{b, r e s}^{\max }=\beta \sqrt{f_{c}} \cdot\left[0.5+5 P_{x}\right]
$$

donde:

$\beta \quad$ Coeficiente que toma el valor de 0,28 para barras en tracción, incluyendo un coeficiente parcial de seguridad $\gamma_{m}$ de 1,4 (no diferencia entre posiciones de la barra durante el hormigonado).

$\mathrm{P}_{\mathrm{x}} \quad$ Penetración de ataque por corrosión $[\mathrm{mm}]$.

En la Figura 2-34-a) y Figura 2-34-b) pueden observarse las curvas de ajuste derivadas de las expresiones (Eq. 2-66), (Eq. 2-67) y (Eq. 2-68), así como su relación con los resultados obtenidos en los ensayos. Se incluye la curva de valores medios y la de límite inferior, resultado de la aplicación o no del coeficiente parcial de seguridad $\gamma_{m}=1,4$.
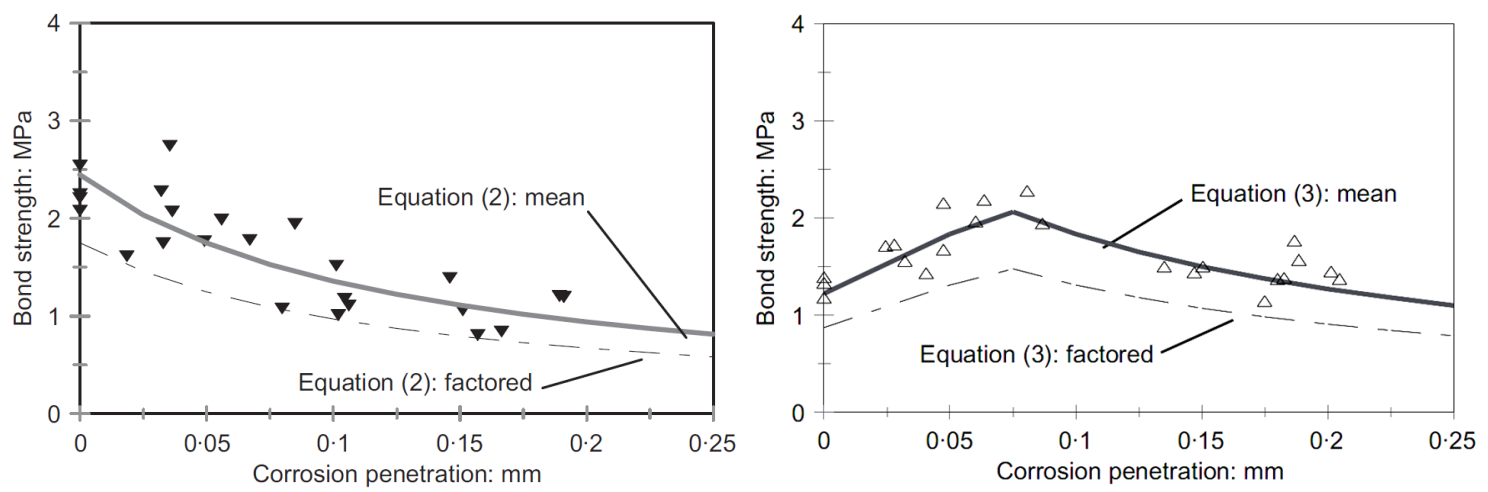

Figura 2-34 Influencia de la corrosión en la tensión de adherencia residual $\tau_{b, \text { max,res }}$ en: a) barras situadas en "situación favorable" durante el bormigonado (parte baja del encofrado); b) barras situadas en "situación desfavorable" durante el hormigonado (parte alta del encofrado). Figuras tomadas de (Cairns, et al., 2006)

Por su parte, Fang et al., (2004) llevaron a cabo ensayos de pull-out sobre barras lisas y corrugadas, de $20 \mathrm{~mm}$ de diámetro, recubrimiento $c$ de $70 \mathrm{~mm}$, relación recubrimiento/diámetro $c / \phi$ de 3,5, en elementos con y sin cercos, y con distintos grados de corrosión (de 0 a $9 \%$ de perdida de sección). La longitud de adherencia $l_{a d h}$ en todas las barras fue de $80 \mathrm{~mm}\left(l_{\text {adh }}=4 \phi\right)$. Los resultados de los ensayos 
mostraron sistemáticamente que las capacidades adherentes en las barras lisas crecían con el aumento de la penetración de ataque por corrosión. En el caso de barras lisas sin cercos, este crecimiento se producía hasta alcanzar grados de pérdida de sección de entre un $2 \%$ y un $4 \%$, momento en el cual comenzaba a descender la tensión máxima de adherencia $\tau_{b, \max }$ (Ver Figura 2-35, curva S1). Por el contrario, en los ensayos sobre barras lisas con cercos, el crecimiento más o menos continuado de la tensión máxima de adherencia tenía lugar hasta pérdidas de sección de hasta el 5\% (Ver Figura 2-35, curva S2). En ambos casos se llegaron a cuantificar incrementos en la tensión máxima de adherencia de hasta 2,5 veces con respecto a las barras sin corroer. Para los autores, estos incrementos se debían a la combinación del aumento de la tensión radial sobre la barra, ocasionada por el incremento de volumen que experimentaban los productos de corrosión, junto con el incremento de la rugosidad de la barra en las primeras etapas del proceso de corrosión, lo que mejoraba la fricción entre la barra y el hormigón circundante. En cuanto a las barras lisas sin corrosión, los autores detectaron que los cercos apenas tenían influencia en el comportamiento adherente, obteniéndose resultados similares para ambos tipos de ensayos.

Por otro lado, Fang et al. (2004) también observaron que la tensión máxima de adherencia de las barras corrugadas sin corroer era entre 3,5 y 6,9 veces mayor que las armaduras lisas en las mismas condiciones. Sin embargo, la capacidad adherente de las barras corrugadas fue muy sensible a pérdidas de sección por corrosión, decreciendo rápidamente con su incremento, en probetas sin armadura transversal; o manteniéndose más o menos estable, en probetas con cercos.

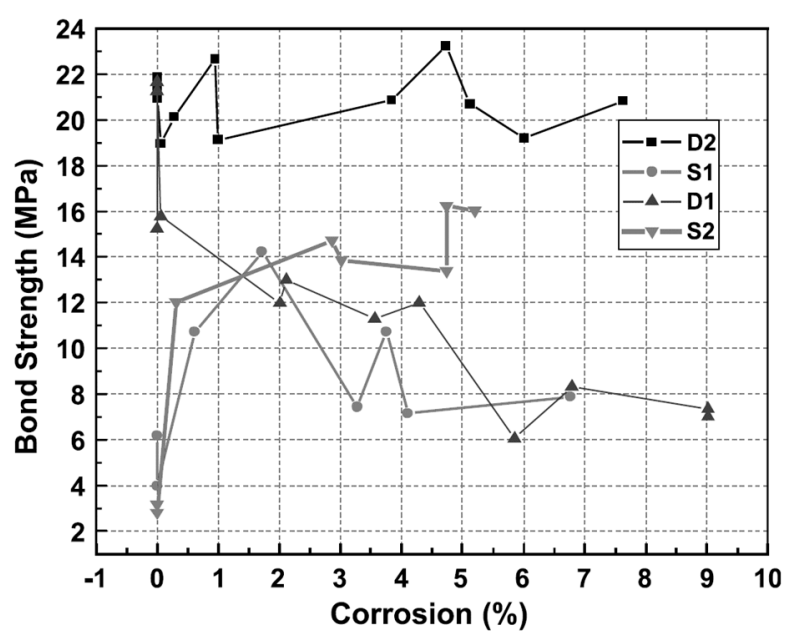

Figura 2-35 Evolución de la tensión máxima de adherencia $\tau_{b, \text { max }}$ con el aumento de pérdida de sección por corrosión para barras lisas sin cercos (S1) y con cercos (S2), y para barras corrugadas sin cercos (D1) y con cercos (D2). Figura tomada de (Fang, et al., 2004)

Otro de los trabajos más significativos en este ámbito, fue el llevado a cabo por Jin \& Zhao (2001), en el que los autores observaron que el comportamiento adherente de las armaduras lisas difería del de las barras corrugadas. Para comprobarlo, llevaron a cabo ensayos de pull-out sobre probetas cúbicas de $100 \mathrm{~mm}$ de lado con barras embebidas de $12 \mathrm{~mm}$ de diámetro, con un recubrimiento mecánico de $50 \mathrm{~mm}$ y una longitud adherente de $80 \mathrm{~mm}$ (6,66 diámetros). La resistencia a compresión media del hormigón $f_{c}$ era de $22,13 \mathrm{MPa}$, el límite elástico del acero $f_{y}$ de las barras lisas era de 389 $\mathrm{MPa}$ y el de las barras corrugadas alcanzaba los $428 \mathrm{MPa}$. 
Coherentemente con lo visto hasta ahora, Jin \& Zhao indicaron que, en barras lisas, con el aumento de los niveles de corrosión, se incrementaban tanto la tensión máxima de adherencia $\tau_{b \text {,max }}$ como la pendiente del primer tramo de la curva adherencia-deslizamiento. Posteriormente, superado un determinado nivel de corrosión (aproximadamente una pérdida del 2-2,5\%), la capacidad adherente decrecía debido a la fisuración del recubrimiento (Figura 2-36; iqquierda). La tensión máxima de adherencia $\tau_{b \text {,max }}$ de las barras corroídas llegaba a ser hasta tres veces superior a la de las barras sin corroer, lo que era coherente con los resultados de Wang \& Teng (1985). En cuanto a los ensayos sobre barras corrugadas, se observó que para niveles limitados de corrosión, la tensión máxima de adherencia $\tau_{b, \max }$ así como la pendiente del primer tramo de la curva adherencia-deslizamiento, se incrementaban ligeramente, aunque siempre menos en términos relativos que lo observado para las armaduras lisas. Cuando el nivel de corrosión superaba un determinado límite (cercano al 1\% de pérdida de sección), tanto la tensión como la pendiente descendían rápidamente. (Ver Figura 2-36; derecha).
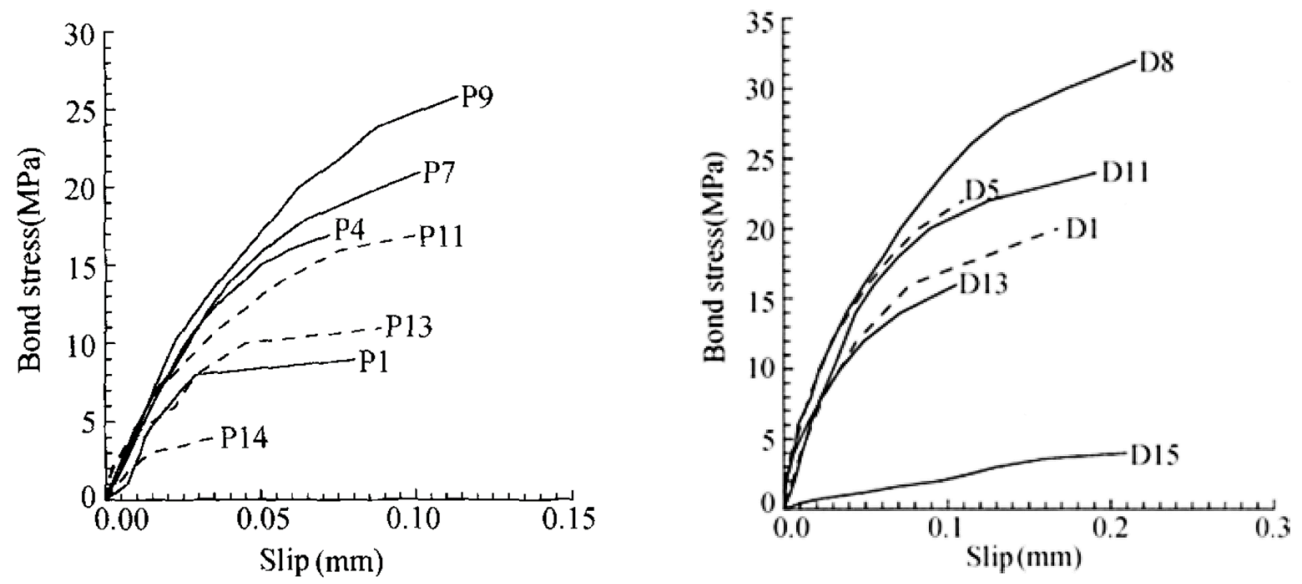

Figura 2-36 Diagramas adherencia-deslizamiento para barras lisas (iqquierda) y barras corrugadas (derecha), según Jim y Zhao (2001). El número creciente que acompaña a cada una de las curvas señala el nivel de deterioro por corrosión.

Por otro lado, el manual CONTECVET (2001), basándose en las expresiones empíricas para barras corrugadas propuestas por Rodríguez et al. [ (1994-a), (1994-b), (1996)], propone de forma simplificada, para su adaptación a la evaluación de la capacidad adherente de barras lisas en estructuras reales, la reducción de su adherencia siguiendo el criterio del Eurocódigo 2 (CEN, 2004), lo que se traduce en minorar las expresiones (Eq. 2-62), (Eq. 2-63) y (Eq. 2-64) por un factor igual a 2,25.

Tabla 2-9 Adherencia residual para armaduras corroídas, según Código Modelo 2010 (2011)

\begin{tabular}{|c|c|c|c|c|}
\hline \multirow{2}{*}{$\begin{array}{l}\text { Penetración de ataque } \\
\qquad \text { Px }[\mathrm{mm}]\end{array}$} & \multirow{2}{*}{$\begin{array}{c}\text { Fisuración superficial } \\
\text { equivalente }[\mathrm{mm}]\end{array}$} & \multirow[t]{2}{*}{ Confinamiento } & \multicolumn{2}{|c|}{$\begin{array}{l}\text { Capacidad residual } \\
\text { (como } \% \text { de } \tau_{b, \max } \text { ) }\end{array}$} \\
\hline & & & Corrugadas & Lisas \\
\hline 0,05 & $0,2-0,4$ & \multirow{3}{*}{ Sin cercos } & $50-70$ & $70-90$ \\
\hline 0,10 & $0,4-0,8$ & & $40-50$ & $50-60$ \\
\hline 0,25 & $1,0-2,0$ & & $25-40$ & $30-40$ \\
\hline 0,05 & $0,2-0,4$ & \multirow{3}{*}{ Con cercos } & $95-100$ & $95-100$ \\
\hline 0,10 & $0,4-0,8$ & & $70-80$ & $95-100$ \\
\hline 0,25 & $1,0-2,0$ & & $60-75$ & $90-100$ \\
\hline
\end{tabular}


Por último, el Código Modelo 2010 (CEB-FIP, 2012) incluye una tabla (Tabla 2-9) para evaluar la capacidad adherente residual de armaduras con procesos de corrosión. El Código Modelo 2010 clasifica según la profundidad de la penetración de ataque $P_{x}$ (o la fisuración superficial que provoca dicho grado de corrosión), el tipo de acabado superficial de la barra (corrugada o lisa) y el confinamiento por armadura transversal (con y sin cercos). De esta manera, en función de los parámetros anteriores, el Código Modelo proporciona el porcentaje de la adherencia residual esperable con respecto a la adherencia básica de una barra sana ( $f_{b d}$, según la notación del Código). Como puede apreciarse en la Tabla 2-9, la propuesta del Código Modelo adolece de una excesiva simplificación del fenómeno, ya que entre otras, no tiene en cuenta la cuantía de armadura transversal, la fisuración equivalente se aporta sin explicitar para que rangos del ratio $c / \phi$ es aplicable y no indica si para mayores profundidades de ataque es posible la extrapolación de los valores propuestos en la tabla.

\subsubsection{Adherencia en alambres y cordones pretensados con corrosión}

Como se indicó al comienzo de este apartado, la revisión bibliográfica no ha permitido detectar estudios sobre la influencia de la corrosión en las propiedades adherentes de alambres y cordones pretensados. Los escasos trabajos existentes se centran preferentemente en la repercusión del nivel de pretensado del alambre en la velocidad de corrosión (Vu, et al., 2009), (Li, et al., 2011) o en la influencia de los procesos de deterioro en el comportamiento mecánico de elementos pretensados [ (Coronelli, et al., 2009), (Rinaldi, et al., 2010)], sin analizar en profundidad los efectos sobre la adherencia.

Coronelli et al. (2009) llevaron a cabo una campaña experimental sobre alambres pretensados de 8 $\mathrm{mm}$ de diámetro (no embebidos en hormigón), tensados con distintas fuerzas de pretensado y sometidos a corrosión acelerada. Por otro lado, desarrollaron un modelo de elementos finitos, basado en los trabajos previos de Coronelli et al. (2004), que fue calibrado mediante los resultados de los ensayos. Dado que el objetivo del trabajo era el análisis de la corrosión localizada (por picaduras) en estructuras pretensadas, el modelado del efecto de la corrosión se limita a la pérdida de sección del acero y a la modificación de las propiedades adherentes de la intefaz, para lo que toman un modelo de adherencia desarrollado previamente por Cleland \& Basheer (2005). Los resultados del modelo mostraron una influencia muy pequeña del deterioro de la adherencia por corrosión en estructuras pretensadas de hormigón. El hecho de que no se tenga en cuenta la fisuración del hormigón provocada por la acumulación de productos de corrosión, limita la utilidad del modelo y dificulta la extrapolación de las conclusiones a los casos de corrosión generalizada (por carbonatación).

Dai (2016) desarrollaron un modelo para predecir la fisuración en el recubrimiento de hormigón inducida por la corrosión en cordones pretensados. El modelo analítico desarrollado, basado en la teoría del cilindro de pared gruesa, constaba de tres etapas diferenciadas: formación de microfisuración en la interfaz acero-hormigón $\left(\rho_{m}\right)$, iniciación de la fisuración del recubrimiento $\left(\rho_{p}\right)$, y crecimiento del ancho de fisura $\left(\rho_{w}\right)$; y fue verificado mediante los resultados experimentales obtenidos de 6 vigas postensadas fabricadas a tal efecto. Las vigas tenían $2000 \mathrm{~mm}$ de longitud y una sección rectangular de 150x220 mm; y fueron pretensadas por un cordón de 7 alambres, de 15,2 mm de diámetro nominal, con un límite elástico de $1830 \mathrm{MPa}$ y ubicado excéntricamente, con un 
recubrimiento geométrico mínimo de 52,4 mm. Las vigas fueron reforzadas con cercos de $8 \mathrm{~mm}$ de diámetro situados cada $100 \mathrm{~mm}$.

Una vez verificado el modelo, los resultados obtenidos por Dai (2016) mostraron que el aumento de la tensión inicial de pretensado $\sigma_{p, 0}$ tenía un efecto adverso en la evolución de la fisuración por corrosión del hormigón. Este efecto era más significativo con el incremento del espesor de recubrimiento $c$ (Figura 2-37) y con la reducción de la resistencia a tracción del hormigón $f_{c t}$, mientras que la influencia del diámetro del cordón $\phi$ y del coeficiente de expansión de óxidos $n$ no era apreciable. Por otro lado, el autor detectó que la pérdida de sección necesaria para el inicio de la fisuración crecía con el incremento de la resistencia a tracción del hormigón $f_{c t} \mathrm{y}$ del espesor de recubrimiento $c$, y decrecía con el aumento del diámetro del cordón $\phi$ y del coeficiente de expansión de óxidos $n$. A pesar de que los resultados son exclusivamente referidos a la fisuración del recubrimiento, dado que este fenómeno está íntimamente ligado a la capacidad de confinamiento del hormigón y ésta a su vez a la tensión de adherencia, las conclusiones son extrapolables, con algunas reservas, a la evolución de la capacidad adherente en elementos pretensados con procesos de corrosión.

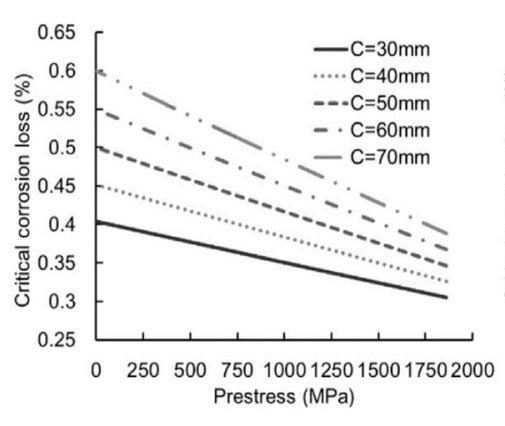

(a)

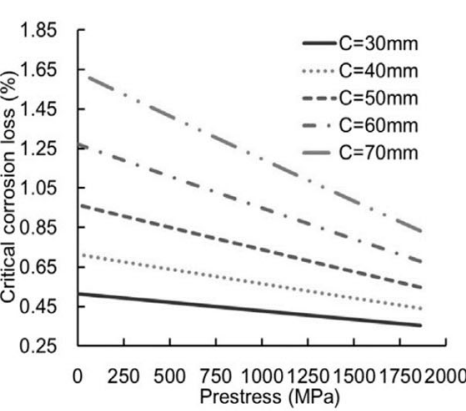

(b)

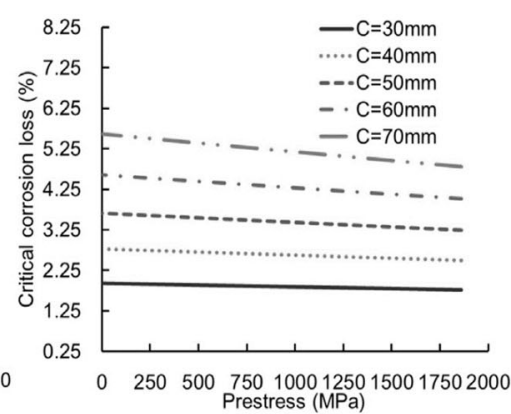

(c)

Figura 2-37 Influencia de la fuerza de pretensado en distintas etapas de la fisuración por corrosión del hormigón: a) $\varrho_{m}$, b) $\varrho_{p}$ y c) $\varrho_{m}$, para distintos espesores de recubrimiento. Figura tomada de Dai (Dai, et al., 2016)

Recientemente, Wang et al. (2017-b) desarrollaron un modelo analítico para predecir el fallo de vigas pretensadas de hormigón con procesos de corrosión, bajo cargas de flexión. Para la evaluación del deterioro de la capacidad adherente con el aumento de la corrosión, los autores utilizan el modelo que desarrollaron en un trabajo anterior (Wang, et al., 2016), en el que el ratio $R(\eta)$ entre el máximo valor de la tensión de adherencia residual $\tau_{\mathrm{b}, \mathrm{res}}^{\max }$ y la tensión máxima de adherencia $\tau_{b, \text { max }}$ en cordones sanos es función del porcentaje de pérdida de sección transversal por corrosión $\eta$, tal y como sigue (Eq. 2-69):

$$
R(\eta)= \begin{cases}1,0 & \eta \leq 6 \% \\ 2,03 e^{-0.118 \eta} & \eta>6 \%\end{cases}
$$

Como puede observarse en la Figura 2-38 y en la expresión anterior (Eq. 2-69), los autores sugieren un modelo en el que la tensión de adherencia se mantiene constante hasta una pérdida de sección por corrosión del 6\%, y decrece exponencialmente cuando el deterioro supera dicho valor. 
El modelo fue verificado mediante una campaña experimental sobre vigas de 150x220x2000 mm, postensadas con cordones de 7 alambres de 15,2 mm de diámetro nominal, y reforzadas con 2 barras corrugadas de $12 \mathrm{~mm}$ de diámetro en la cara inferior, 2 barras corrugadas de $8 \mathrm{~mm}$ de diámetro en la cara superior y cercos de $8 \mathrm{~mm}$ de diámetro cada $90 \mathrm{~mm}$. Una vez corroídas (no se explicitan ni la velocidad de corrosión ni el método utilizado para inducir el deterioro), los autores sometieron las vigas a ensayos de flexión en tres puntos, para investigar la influencia de la corrosión en su comportamiento. A partir de los resultados experimentales y analíticos, Wang et al. (Wang, et al., 2017-b) concluyen que para niveles de corrosión por debajo de un 13\%, el deterioro no ejerce una influencia notable en el comportamiento mecánico a flexión de los elementos analizados.

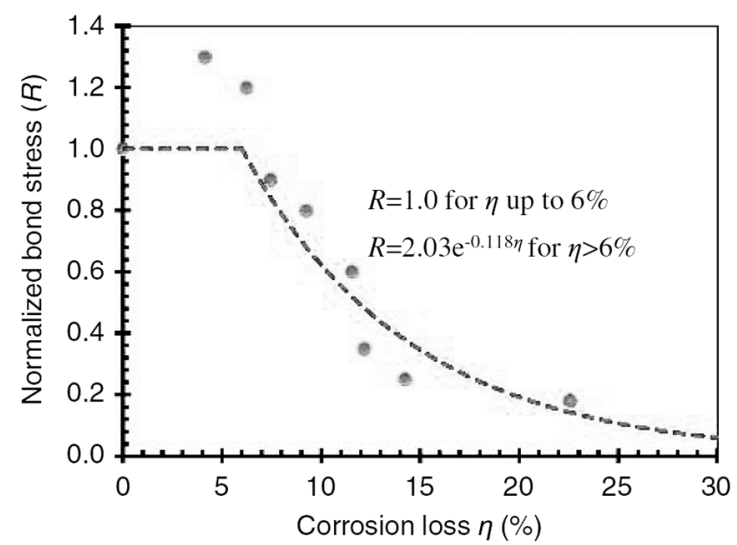

Figura 2-38 Deterioro de la tensión residual de adherencia con el aumento del nivel de corrosión. Figura tomada de Wang et al. (2017-b)

\subsubsection{Coeficiente de fricción con corrosión}

Uno de los principales efectos de la corrosión del acero embebido en hormigón es la modificación de las propiedades de contacto en la interfaz entre ambos materiales, afectando al mecanismo de fricción. Tal y como se vio el Apartado 2.2.7.7, la tensión de adherencia $\tau_{b}$ distribuida en la superficie del acero depende fundamentalmente de la tensión radial $\sigma_{r}$ en la interfaz acero/hormigón y del coeficiente de fricción $\mu$. Mientras que el primer factor depende fundamentalmente de la capacidad de confinamiento del recubrimiento de hormigón, el segundo factor es una propiedad intrínseca de los dos materiales en contacto, y puede verse afectado por el proceso de corrosión

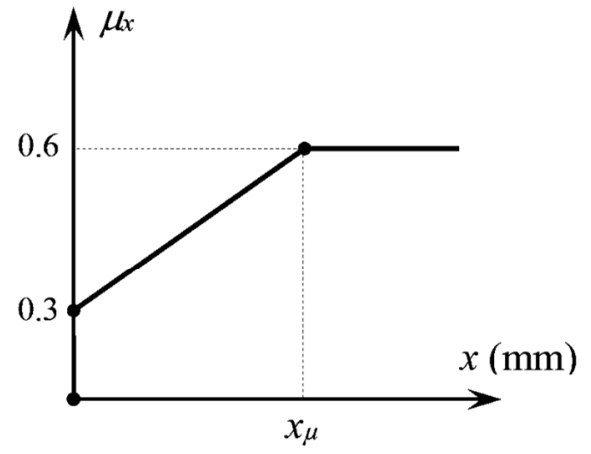

(a)

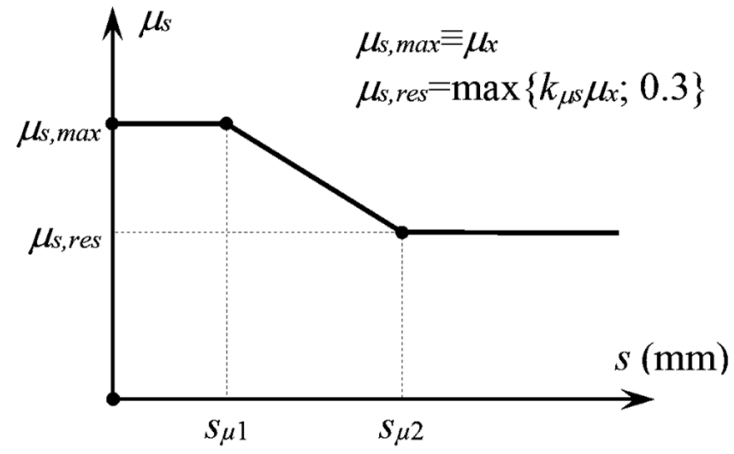

(b)

Figura 2-39 Evolución del coeficiente de fricción $\mu$ frente a: a) Penetración de ataque por corrosión x; b) deslizamiento s. Según (Chermin \& Val, 2009) 
Algunos estudios (Al-Sulaimani, et al., 1990) (Lundgren, 2007) indican que, para niveles bajos de corrosión, los productos de corrosión firmemente adheridos pueden contribuir a una mejora en el comportamiento adherente, mientras que, para niveles de corrosión más avanzados, el material débil y delaminado existente entre la barra y el hormigón es responsable en parte de la reducción de la tensión máxima de adherencia. Sin embargo, otros trabajos afirman que la corrosión no modifica de manera apreciable el valor del coeficiente de fricción $\mu$ (Cairns, et al., 2007).

Entre los trabajos que afirman que la corrosión modifica las propiedades adherentes acero/hormigón existe una gran disparidad en las leyes propuestas para caracterizar la evolución del coeficiente de fricción $\mu$. Chermin \& Val (2009) estudiaron la influencia de la corrosión en las características de fricción de la interfase acero-hormigón. Para ello, modelaron el coeficiente de fricción $\mu$, haciéndolo variar en el rango comprendido entre 0,3 y 0,6, de acuerdo con los resultados experimentales de Xu (1992) . La relación existente entre el coeficiente de fricción, $\mu_{x}$, y la penetración de ataque de la corrosión ( $x$ en la notación de los autores), se representa en la Figura 2-39-a). Como puede observarse, desde un valor inicial igual a 0,3 , el coeficiente de fricción va creciendo con el aumento de la corrosión, según los autores debido a un aumento de la rugosidad de la superficie del acero, hasta alcanzar un valor de penetración límite $x_{\mu}$, en el que el valor del coeficiente se estabiliza en 0,6. En el modelo basado en elementos finitos desarrollado por los autores, el parámetro $x_{\mu}$ toma un valor igual a 100 $\mu \mathrm{m}$. Por otro lado, Chermin \& Val (2009) estudian el descenso del valor del coeficiente de fricción que se produce con el aumento del deslizamiento $s$, debido al ablandamiento de la interfase acerohormigón (Figura 2-39-b). Para los autores, el coeficiente de fricción $\mu$ se mantiene en máximos hasta que alcanza un deslizamiento $s_{\mu 1}$ igual a 1,00 $\mathrm{mm}$ A partir de ese punto, la adherencia comienza a deteriorarse hasta alcanzar un deslizamiento $s_{\mu 2}$ igual a $5,00 \mathrm{~mm}$, donde el coeficiente de fricción toma un valor residual $\mu_{\text {res }}$ que se mantiene constante para deslizamientos posteriores. Los autores establecen un límite inferior para $\mu_{\text {res, }}$ considerando que nunca bajará de un valor igual a 0,3 .

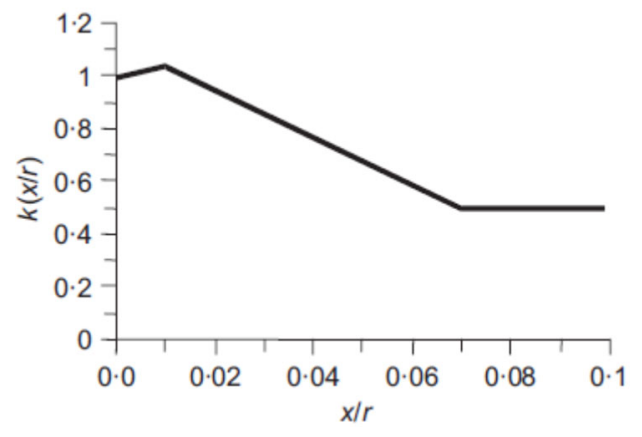

Figura 2-40 Evolución del coeficiente de fricción $\mu$ frente a la penetración de ataque (Lundgren, 2005)

Por el contrario, algunos autores afirman que la acumulación de óxidos en la superficie de la armadura altera negativamente las propiedades de fricción, ya que los productos de corrosión conforman una capa de contacto más débil y tienen cierto efecto lubricante. Para muchos de ellos, el efecto beneficioso derivado del aumento de la rugosidad por la corrosión sólo es perceptible para niveles bajos de penetración de ataque (Jin \& Zhao, 2001). Lundgren (2005), como parte de un modelo numérico desarrollado para el análisis de la adherencia de barras corrugadas con corrosión, propone la siguiente expresión empírica para evaluar el coeficiente de fricción $\mu$ en función de la penetración de ataque (Eq. 2-70): 


$$
\mu(\kappa)=k\left(x / r_{b}\right) \cdot \mu_{0}(\kappa)
$$

donde $\mu_{0}(\kappa)$ es el coeficiente de fricción para barras sanas (el autor proponen valores de 0,7 y 1,0 para barras lisas y corrugadas, respectivamente), y $k(x / r)$ es el ratio existente entre el coeficiente de fricción residual, para una determinada penetración de ataque x y un determinado radio de la armadura $r_{b}, \mathrm{y}$ el coeficiente de fricción inicial $\mu_{0}$. Como puede observarse en la Figura 2-40, Lundgren (2005) propone que para penetraciones de ataque bajas (hasta profundidades de hasta un 1\% del radio), la fricción mejore levemente (alrededor de un 5\%), mientras que superado ese umbral de corrosión, el valor del coeficiente de fricción comience a descender hasta alcanzar un valor residual constante, con una penetración de ataque del 7\% de la longitud del radio. Este coeficiente de fricción residual, cuyo valor es aproximadamente el $50 \%$ del valor original y que según el autor siempre debe ser mayor que 0,4 , se mantiene constante para mayores profundidades de ataque por corrosión. Cabe destacar que Ludgren, en trabajos anteriores (Lundgren, 2001), proponía que el coeficiente de fricción $\mu$ no se modificara con el aumento de los niveles de corrosión.

Al contrario que en los trabajos anteriores, Cairns et al. (2007) determinó que el coeficiente de fricción $\mu$ no variaba con la corrosión. Los autores llevaron a cabo una campaña experimental sobre probetas de hormigón prismáticas, de 50×100×130 mm, limitadas en las caras superior e inferior por dos placas metálicas de $50 \mathrm{~mm}$ de ancho y $20 \mathrm{~mm}$ de espesor (Figura 2-41). Estas placas fueron corroídas aceleradamente mediante corrientes de corrosión en el rango de $50-100 \mu \mathrm{A} / \mathrm{cm}^{2}$. Una vez alcanzado el nivel de corrosión deseado, se aplicaron fuerzas normales a la superficie de las placas, proporcionando tensiones normales $\sigma_{n}$ en la interfaz acero/hormigón de 3,4; 7,0 y $11,0 \mathrm{~N} / \mathrm{mm}^{2}$. Por último, se aplicó una fuerza horizontal sobre cada una de las probetas, provocando el deslizamiento relativo de las mismas con respecto a las placas.

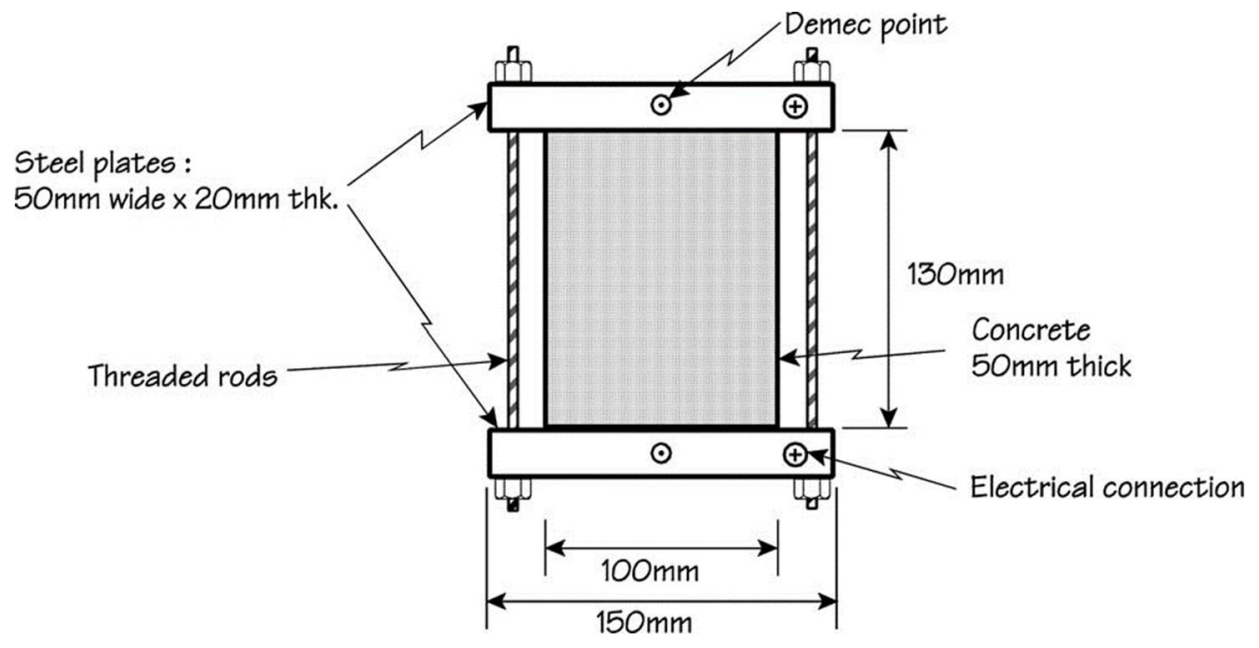

Figura 2-41 Esquema de ensayo de fricción hormigón/ acero para distintos grados de corrosión (Cairns, et al., 2007)

Los resultados obtenidos mostraron que la fricción entre las placas y el hormigón podía ser representada mediante una relación lineal, siguiendo la ley de fricción de Coulomb: $\tau_{b}=\tau_{b, a d h}+\mu \sigma_{n}$. El análisis de los datos para las probetas sin corrosión, mediante regresiones lineales, arrojó un 
coeficiente de fricción $\mu$ igual a 0,55 y una tensión de adherencia debida al mecanismo de adhesión $\tau_{b, a d b}$ igual a $0 \mathrm{~N} / \mathrm{mm}^{2}$. La Figura 242 muestra los resultados de fuerza lateral necesaria para deslizar las probetas de hormigón, en función de distintas fuerzas normales y grados de corrosión. Como puede apreciarse, para cada profundidad de ataque considerada, la pendiente de ajuste lineal de los resultados no se ve modificada, de lo que puede inferirse que los procesos de corrosión no modifican el coeficiente de fricción $\mu$. Por tanto, Cairns afirma que en estructuras reales corroídas, los cambios en la adherencia no son debidos a la modificación del coeficiente de fricción, sino a la pérdida de la capacidad de confinamiento del recubrimiento por la fisuración del hormigón. En consecuencia, el autor concluye que ignorar cualquier efecto de la corrosión sobre el coeficiente de fricción se encuentraría del lado de la seguridad.

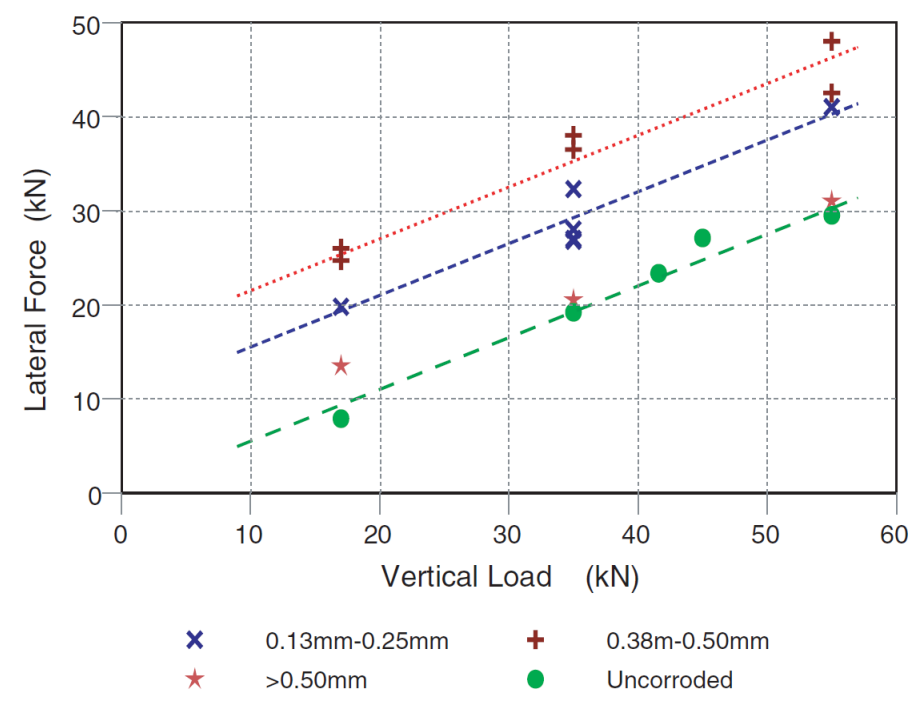

Figura 2-42 Fuerzas laterales necesarias para deslizar las probetas de hormigón en ensayo de fricción de Cairns (2007). Resultados para distintas fuerzas normales y grados de corrosión.

\subsubsection{Variables relativas a la corrosión que influyen el comportamiento adherente}

A la hora de modelizar la corrosión es necesario caracterizar una serie parámetros variables que definen el proceso de expansión de sus productos y que afectan, por un lado, al modo en el que se moviliza la capacidad de confinamiento del recubrimiento, y por otro, a la velocidad de avance del frente de fisuración. Estas variables determinan aspectos tales como el incremento de volumen de los óxidos con respecto al acero virgen (coeficiente de expansión de óxidos; $n$ ), la capacidad de deformación de la capa de óxidos que rodea el alambre sano (módulo de compresibilidad volumétrica; $K_{r}$ ), la difusión de parte de los productos de corrosión a través de la red de poros del hormigón que rodea el acero (espesor de la z̧ona porosa, $t_{p}$ ) y la penetración de óxidos en fisuras. Son parámetros que están íntimamente interconectados, con un efecto similar sobre la capacidad adherente y que, además, no cuentan con ensayos normalizados específicos para su caracterización, por lo que el rango de valores propuesto en la literatura científica es amplio. 


\subsubsection{Coeficiente de expansión de óxidos n.}

Cuando el acero embebido en el hormigón sufre un proceso de degradación por corrosión, se disuelve la capa pasiva del acero y se forman productos de oxidación. Al iniciarse este proceso, una capa de acero de profundidad $P_{x}$ se transforma en óxido, cuyo volumen específico es mayor que el del acero original, generándose tensiones en el hormigón circundante y propiciándose la aparición de fisuras y desprendimientos en el recubrimiento.

Definiendo $r_{m}$ como el ratio entre el peso molecular del acero y el del óxido, la cantidad de óxido producido $m_{r}$ viene dado por (Eq. 2-71):

$$
m_{r}=\frac{m_{s}}{r_{m}}
$$

donde:

$m_{s} \quad$ Pérdida total de masa, por unidad de longitud

El valor de $r_{m}$ depende de los productos de corrosión que se formen en el proceso ya que, por ejemplo, para el hidróxido ferroso, $\mathrm{Fe}(\mathrm{OH})_{2}$, toma un valor de 0,622, mientras que para el hidróxido férrico, $\mathrm{Fe}(\mathrm{OH})_{3}$, es de 0,523 .

Se denomina $n$ a la relación entre el volumen total de los productos de corrosión $\Delta V_{r}$ (sin comprimir) y el volumen de acero virgen consumido en el proceso $\Delta V_{s}^{\text {corr }}$ (Eq. 2-72):

$$
n=\frac{\Delta V_{r}}{\Delta V_{s}^{\text {corr }}}=\frac{m_{r} / \rho_{r}}{m_{s} / \rho_{s}}=\frac{\rho_{s}}{\rho_{r}} \cdot \frac{1}{r_{m}}
$$

donde:

$$
\begin{array}{ll}
\rho_{r} & \text { Densidad de los productos de corrosión del acero } \\
\rho_{s} & \text { Densidad del acero virgen }
\end{array}
$$

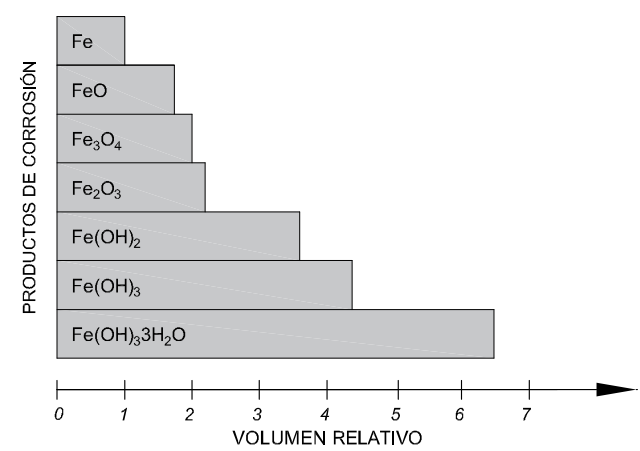

Figura 2-43 Coeficiente n entre el volumen de los productos de corrosión $\Delta V_{r}$ y el volumen de acero virgen consumido en el proceso $\Delta V_{s}^{c o r r}$. Figura basada en (Nielsen, 1976) 
En la Figura 2-43, basada en el trabajo de Nielsen (Nielsen, 1976) y en la Tabla 2-10 se muestran los incrementos de volumen con respecto al acero virgen de algunos de los productos de corrosión más habituales. De acuerdo con la figura, los óxidos del acero ocupan un volumen que varía entre 2 y 6,4 veces el volumen del acero original, en función del tipo de producto de corrosión que se haya generado, que es realmente el fenómeno que se desconoce. En ese sentido han apuntado varios trabajos (Liu \& Weyers, 1998) (Andrade, et al., 2011), concluyendo que la formación de uno u otro tipo de óxido depende de las distintas condiciones existentes durante el proceso, tales como la intensidad de corriente de corrosión, el pH de la fase acuosa del hormigón, el aporte de oxígeno y/o la cantidad de humedad.

Tabla 2-10 Ratio n entre el volumen de los productos de corrosión $\Delta V_{r}$ y el volumen de acero virgen consumido en el proceso $\Delta V_{s}^{\text {corr }}$

\begin{tabular}{cc}
\hline Producto de corrosión & Ratio n - Incremento de volumen \\
\hline $\mathrm{Fe}_{3} \mathrm{O}_{4}$ & 2,2 \\
\hline $\mathrm{Fe}(\mathrm{OH})_{2}$ & 3,8 \\
\hline $\mathrm{Fe}(\mathrm{OH})_{3}$ & 4,2 \\
\hline $\mathrm{Fe}(\mathrm{OH})_{3}, 3 \mathrm{H}_{2} \mathrm{O}$ & 6,4 \\
\hline
\end{tabular}

Algunos autores han intentado cuantificar la cantidad de productos de corrosión de cada tipo que se generan en el proceso. En ese contexto se encuadra el estudio de Suda et al. (1993), donde se propone un modelo que permite predecir el coeficiente de expansión de óxidos $n$ en función del tipo de óxidos formados y el porcentaje de cada uno de ellos. Los autores suponen que los productos de corrosión están conformados por componentes cristalinos [magnetita $\left(\mathrm{Fe}_{3} \mathrm{O}_{4}\right)$, goethita $(\alpha-\mathrm{FeO}(\mathrm{OH}))$ y lepidocrocita $(\gamma-\mathrm{FeO}(\mathrm{OH}))$ ], componentes amorfos [con la forma $\mathrm{FeO}_{\mathrm{x}}(\mathrm{OH})_{3-2 \mathrm{x}}$, con $\mathrm{x}$ igual a 0 o a 1], y otros componentes (por ejemplo, agua). Mediante análisis de Difracción de Rayos X (DRX) obtienen los porcentajes de los productos cristalinos y, en combinación con los datos obtenidos con Microsonda de Electrones (EPMA), obtienen el porcentaje de los componentes amorfos (cercanos al 65\%). Los coeficientes de expansión de los distintos componentes individuales que forman lo que globalmente se denomina productos de corrosión pueden ser estimados por consideraciones estequiométricas, mientras que las densidades pueden ser tomadas de la literatura. Por ejemplo, los coeficientes de expansión de la magnetita, goethita, lepidocrocita son 2,1; 2,9-3,8 y 3 , respectivamente, mientras que sus densidades son 5,2; 3,3-4,3 y 4,1 $\mathrm{g} / \mathrm{cm}^{3}$. Por su parte, los autores proponen que el coeficiente de expansión y la densidades relativa de los productos de corrosión amorfos tomen un valor de 3,0 y 4,0 g/ $\mathrm{cm}^{3}$ respectivamente. Por tanto, el coeficiente de expansión $n$ puede ser calculado como sigue:

$$
n=\frac{\frac{a}{d_{a}} a_{a}+\frac{b}{d_{b}} a_{b}+\frac{c}{d_{c}} a_{c}+\frac{x}{d_{x}} a_{x}}{\frac{a}{d_{a}}+\frac{b}{d_{b}}+\frac{c}{d_{c}}+\frac{x}{d_{x}}}
$$

Donde, $a, b, c \mathrm{y} \times$ son los porcentajes de magnetita, goethita, lepidocrocita y de los componentes amorfos en los productos de oxidación; y $a$ y $d$, con los subíndices $a, b, c$ y $x$, representan el coeficiente de expansión individual y las densidades relativas de cada uno de los componentes del óxido. Los autores, utilizando el modelo expuesto, obtienen un coeficiente $n$, ratio entre el volumen de los productos de corrosión $\Delta V_{r}$ y el volumen de acero virgen consumido en el proceso $\Delta V_{S}^{c o r r}$, con un 
valor en el rango 3-3,2, para barras de acero embebidas en hormigón. Posteriormente, Chernin et al. (Chernin, et al., 2010), basándose en estos resultados experimentales, concluyen que un valor de $n=3$ es el que mejor se adapta para su modelo numérico. Sanz (Sanz, 2014), en su estudio numérico y experimental, también opta por ese valor.

Desde que Andrade et al. (1993) y Molina (1993) llevaron a cabo un estudio sobre probetas sometidas a una corrosión acelerada de 10 y $100 \mu \mathrm{A} / \mathrm{cm}^{2}$, concluyendo que el valor del coeficiente de expansión $n$ que mejor reproducía los resultados experimentales era $n=2$, este es el valor más recurrente en la bibliografía. Este valor fue posteriormente utilizado por otros autores como Martin-Pérez (1999), Coronelli \& Gambarova (2000), Lundgren (2007) y Michel et al. (2011).

Aunque los valores del coeficiente de expansión de óxidos $n$ comprendidos entre 2 y 3 han sido los más utilizados, también es habitual el uso de valores superiores. Bhargava et al. (2006), basándose en los resultados experimentales del trabajo de Liu \& Weyers (1998), determinaron un valor de 3,39, mientras que Caré et al. (2008) utilizaron un $n=6,5$ para el análisis de su campaña experimental sobre probetas sometidas a corrosión acelerada con una densidad de corriente $i_{c o r r}=100 \mu \mathrm{A} / \mathrm{cm}^{2}$.

\subsubsection{Coeficiente de compresibilidad volumétrica $\mathrm{Kr}$}

El módulo de compresibilidad volumétrica $K_{r}$ contempla la capacidad de deformación de la capa de óxidos que rodea el alambre sano. En general, los resultados experimentales recogidos en la literatura científica en cuanto a las propiedades mecánicas de la capa de óxidos alrededor de la armadura son escasos. Habitualmente, a la hora de determinar el módulo $K_{l}$, existen dos enfoques: por un lado, considerar sus propiedades próximas a las del agua, al ser ésta mayoritaria en su composición, y por otro, considerar el comportamiento de los productos de corrosión como similar al de un material granular.

Entre los del primer enfoque, destaca el trabajo desarrollado por Molina, Alonso y Andrade (Molina, 1993), en el que se planteó por primera vez la posibilidad de asimilar las propiedades de los productos de corrosión a las del agua líquida, por ser ésta el componente mayoritario de los óxidos del acero. De esta manera, el módulo de compresibilidad $K_{r}$ adopta un valor igual a $2.0 \mathrm{GPa}$, mientras que el coeficiente de Poisson $u_{r}$ toma un valor de 0.5 (ligeramente inferior). El módulo elástico $\mathrm{E}_{\mathrm{r}}$ de los productos de corrosión es determinado usando la siguiente ecuación, obteniéndose valores bajos, pero no nulos (Eq. 2-74):

$$
E_{\text {rust }}=3(1-2 v) K_{r}
$$

Este modelo, junto a un modelo numérico basado en elementos finitos para la caracterización de la adherencia, fue usado en el estudio de la fisuración inducida por la corrosión y del comportamiento adherente en barras corroídas en ensayos de pull-out, obteniéndose ajustes razonablemente buenos con los resultados experimentales. A pesar de ello, Molina, Alonso y Andrade enfatizan la necesidad de profundizar en la determinación precisa de las propiedades mecánicas de los productos de oxidación. Posteriormente, otros autores han utilizado estos mismos valores (Martín-Pérez, 1999) 
(Sanz, et al., 2013), dando como válidos los postulados marcados en el trabajo original de Molina et al., y obteniendo buenos resultados.

Recientemente, Andrade et al. (2011) han profundizado en la morfología de los óxidos formados por los procesos de corrosión, corroborando cualitativamente las hipótesis planteadas en el trabajo publicado en el 1993 (Andrade, et al., 1993) (Molina, 1993) y reafirmándose, por tanto, en el valor del módulo de compresibilidad $K_{r}$ igual a $2 \mathrm{GPa}$.

Entre los del segundo grupo destaca el trabajo de Petre-Lazar \& Gerard (2000 ) que, utilizando la técnica de Difracción de Rayos X (DRX) para determinar qué productos se formaban durante el proceso de corrosión acelerada, concluyó que la capa de óxidos podía ser considerada como un ensamblaje sin cohesión de cristales incompresibles. Las conclusiones de este trabajo se quedaron en valoraciones cualitativas de las propiedades mecánicas de los óxidos, ya que no se aportaron valores numéricos.

Lundgren (2001) supone que la capa de óxidos se comporta como un material granular, cuya rigidez se incrementa con el nivel de tensión. De la combinación de resultados experimentales tomados de otros autores con un modelo numérico de elaboración propia, Lundgren determina la relación existente entre la tensión radial y la deformación por compresión en la capa de óxidos:

$$
p=K_{r} \varepsilon_{v}^{m}
$$

donde:

$\varepsilon_{v} \quad$ Deformación en la dirección axial dentro de la capa corroída

\section{m Parámetro variable de ajuste}

Lundgren (2001) determina que los valores que proporcionan un mejor ajuste con los resultados experimentales analizados son $K_{r}=7,0 \mathrm{GPa}$ y m=7. En trabajos posteriores (Lundgren, 2005), el valor del módulo de compresibilidad volumétrica $K_{r}$ es modificado por el autor hasta alcanzar un valor de $14 \mathrm{GPa}$, muy superior al propuesto por Molina (1993), con un enfoque distinto, y a otros investigadores que aceptan el mismo supuesto.

Retomando este enfoque, Ouglova et al (A. Ouglova, 2006) llevó a cabo una campaña experimental en la que midieron el módulo de elasticidad de óxidos del acero, obtenidos tanto de estructuras reales con más de 40 años de corrosión natural como de productos de corrosión generados en laboratorio. Los ensayos, realizados mediante ultrasonidos y procedimientos mecánicos, se llevaron a cabo sobre los óxidos desecados y reducidos a polvo. Los ensayos mostraron que los productos de corrosión del acero se comportaban de manera bastante similar a los materiales granulares, con comportamiento no lineal y una importante rama plástica. Los autores lograron cuantificaron el valor del módulo, señalando que era aproximadamente de $2 \mathrm{GPa}$, y era dependiente del grado de compactación y del grado de hidratación. 
Otros autores han optado por diferentes vías, basadas en distintas técnicas experimentales. Suda et al (1993), analizando los resultados experimentales de medidas de deformaciones expansivas en placas de acero con corrosión acelerada embebidas en probetas de mortero, obtenidos por Yoshioka (1982 ), concluyeron que el módulo de Young $E_{r}$ de la banda de óxidos oscilaba entre 0,1 y 0,5 GPa.

Por otro lado, Caré et al. (2008) llevaron a cabo una campaña experimental sobre barras embebidas en mortero, sometidas a corrosión acelerada. Para controlar los efectos mecánicos de la corrosión, el campo de desplazamientos fue monitorizado mediante la técnica de Correlación Digital de Imágenes (DIC), que combinaron con un modelo analítico elástico basado en la teoría del cilindro de pared gruesa sometido a presión interior, similar al expuesto en este capítulo, para calibrar el orden de magnitud de todas las variables que caracterizan las propiedades mecánicas de la capa de óxidos. Los autores concluyeron que el módulo de Young de los productos de corrosión dependía del espesor de la capa de óxidos, así como del radio inicial de la armadura. A modo de referencia, para profundidades de ataque entre 10 y $60 \mu \mathrm{m}$ los autores obtuvieron valores de módulo de elasticidad $E_{r}$ que variaban entre 0,04 y $0,26 \mathrm{GPa}$, por lo que considerando un coeficiente de Poisson $v_{r}=0,2-0,3$ y despejando de (Eq. 2-74), el valor del módulo de compresibilidad $K_{r}$ oscilaría entre los valores 0,02 y $0,22 \mathrm{GPa}$. Pease et al. (2012), utilizando la misma técnica experimental de Correlación Digital de Imágenes (DIC), concluyeron que un módulo de elasticidad $E_{r}$ con un valor comprendido entre 2,0 y 20,0 GPa proporcionaba los mejores ajustes con los resultados experimentales.

Konopka (2005) obtuvo muestras de óxido procedentes de limaduras de acero de barras de armar a las que sometió a un proceso de corrosión acelerado. Las escamas de acero corroído resultantes fueron desecadas y ensayadas en versiones a tamaño reducido del ensayo triaxial estándar de mecánica de suelos para suelos granulares sin cohesión y del ensayo edométrico. El rango de valores medido para el módulo de elasticidad $E_{r}$ estuvo en el rango 40-87 MPa, mientras que para el módulo de compresibilidad $K_{r}$ el rango fue 0,48-0,54 GPa.

Finalmente, es necesario resaltar que, tal y como afirma Andrade, los óxidos se comportan como geles hasta que comienza la fisuración, momento a partir del cual, y sólo si se alternan periodos de humedad-secado, precipitan y dan lugar a un material de naturaleza granular. Por tanto, cabe deducir, que los óxidos generados en los ensayos de corrosión acelerada deben ser considerados como geles, y sólo en hormigones reales ya envejecidos se podría aceptar la hipótesis del comportamiento granular y proponer módulos de compresibilidad que respondieran a tal comportamiento.

\subsubsection{Espesor de la zona porosa $t_{p}$}

Desde que fue sugerido por Andrade et al. (1993) y Molina et al. (1993), habitualmente se admite que parte de los productos de corrosión se difunden a través de la red de poros del hormigón que rodea el acero, así como a través de las microfisuras de nueva formación generadas por la propia presión interna de los óxidos, de tal manera que la expansión "efectiva" de los óxidos que generan tensiones es menor que la expansión "real" resultante en el caso de no existir esta zona porosa. Para tener en cuenta este efecto, que repercute en el retraso del inicio de la fisuración, se considera una región alrededor de la interfaz acero-hormigón en la que los óxidos pueden difundir sin ejercer ninguna presión en el hormigón circundante (región de porosidad infinita), y cuyo espesor aparente es equivalente a la suma del volumen de poros en los que presumiblemente se difundirían los productos de corrosión. Esta región, no siempre bien definida por los diversos autores, se denomina con 
frecuencia zona porosa (algunos autores la han denominado CAR: corrosión accommodation region, para evitar la ambigüedad de la denominación (Michel, et al., 2014)), y tiene un espesor equivalente aparente $t_{p}$. Por tanto, según esta concepción, los productos de corrosión sólo comienzan a ejercer presión sobre la pared interna del hormigón cuando se cumple la condición de que el espesor de la capa de óxidos en expansión libre supera a la suma de la penetración de ataque $P_{x}$ más el espesor de la zona porosa $t_{p}$. Esta región no sólo responde a una realidad observable en las campañas experimentales, es decir, el retraso de la fisuración del recubrimiento de hormigón con respecto a lo que predicen los modelos analíticos, sino que numerosos trabajos [ (Park \& Paulay, 1975) (Al Khalaf, 1979) (Scrivener, et al., 2004)] han demostrado que responde a una realidad física, la mayor porosidad de la matriz cementicia en la interfaz acero-hormigón. En cuanto a las variables que inciden en las propiedades de dicha región, existe disparidad de opiniones, siendo los factores más recurrentes la porosidad del hormigón y el ambiente de exposición, así como a otras variables relacionadas, tales como el acabado superficial del acero, el tamaño de árido o el grado de hidratación y de madurez del hormigón.

Se han llevado a cabo varios trabajos intentando cuantificar el espesor aparente equivalente $t_{p}$ de la zona porosa. En uno de los primeros, llevado a cabo por Liu \& Weyers (1998), se desarrolló un modelo para el estudio de la fisuración en el que se consideraron tres etapas, que a la postre son las mismas que plantearon Andrade et al. (1993) y Molina et al. (1993), a las que se definió de la siguiente manera:

1. Expansión: Fase en la que el volumen total de productos de corrosión $W_{T}$ es menor que el volumen total de poros $W_{P}$ de la zona porosa de espesor equivalente $t_{p}$, en la interfaz acerohormigón.

2. Inicio de la tensión radial: Etapa en la que el volumen total de productos de corrosión $W_{T}$ supera al volumen total de poros $W_{P}$, comenzando a ejercer presión en el hormigón circundante.

3. Fisuración: Fase en la que el volumen total de productos de corrosión $W_{T}$ supera el valor límite o crítico $W_{T}$, definido como el volumen de productos de corrosión necesarios para que el hormigón del recubrimiento supere su resistencia a tracción y comience a fisurarse.

Los autores establecieron el valor de $W_{p}$ mediante la siguiente expresión:

$$
W_{p}=\rho_{\text {rust }} V_{p} \approx \rho_{\text {rust }} \pi t_{p} 2 r_{p}
$$

donde:
$t_{p} \quad$ Espesor equivalente de la zona porosa
$r_{p} \quad$ Radio medio de la zona porosa, con origen en el centro de la sección del acero
$V_{p} \quad$ Volumen total de poros interconectados alrededor de la interfase acero-hormigón
$\rho_{\text {rust }}$ Densidad de los productos de corrosión 
Cómo puede observarse, el parámetro $V_{p}$ está relacionado con el diámetro de la armadura, con la densidad de los productos de corrosión y con las propiedades de la interfase acero-hormigón. Liu \& Weyers (1998) propusieron calibrar indirectamente el valor de $t_{p}$, ajustando los tiempos de iniciación de la fisuración predichos en su modelo analítico de fisuración inducida por corrosión con aquellos observados en sus ensayos. Esta metodología les permitió estimar un espesor equivalente $t_{p}$ de la región porosa de 12,5 $\mu \mathrm{m}$, valor que a partir de ese momento se convertirá en el más recurrente en la bibliografía, a pesar de que en rigor sólo sería aplicable a la campaña experimental con la que fue calibrado.

Por su parte, Petre-Lasar (2000) investigó la interfase acero-hormigón mediante el uso de un microscopio electrónico de barrido. De acuerdo con los resultados obtenidos, propuso una expresión relacionando el valor de $t_{p}$ con el espesor de la interfase observable acero-hormigón $t_{i n}$ (con un valor aproximado de $40 \mu \mathrm{m}$, según observaciones con el microscopio) y el grado de porosidad del mortero. La fórmula propuesta arroja valores de espesor equivalente $t_{p}$ que oscilan entre 2 y $8 \mu \mathrm{m}$.

El Maaddawy \& Soudki (2007) estiman, mediante el uso de ensayos para calibrar un modelo analítico basado en la teoría de cilindros huecos de pared gruesa, que el espesor de la capa porosa $t_{p}$ se encuentra típicamente en el rango entre 10 y $20 \mu \mathrm{m}$, utilizando dichos valores extremos para los límites inferior y superior de su modelo, correspondiéndose con el tiempo de inicio del ataque por corrosión y con el de la fisuración del recubrimiento. Los autores obtuvieron una buena concordancia entre los resultados analíticos y los ensayos sobre probetas con corrosión acelerada.

Chernin et al. (2010), por su parte, cambian el enfoque al abordar el problema y no realizan suposiciones previas acerca de la difusión de los productos de corrosión, es decir, los productos de corrosión pueden difundir tanto al comienzo del proceso de corrosión, hasta que rellenen la capa porosa, como hacerlo de manera continuada y constante a lo largo del tiempo. En este estudio, la cantidad de productos de corrosión que se difunden en el hormigón circundante queda representada por el espesor equivalente $t_{p}$, cuyo valor es estimado indirectamente, tal y como hicieron previamente Liu \& Weyers (1998), mediante el ajuste de los resultados experimentales con los obtenidos mediante su modelo analítico (Eq. 2-77):

$$
t_{p}=\delta_{c r, \exp }-\delta_{c r}
$$

Siendo $\delta_{c r, \exp }$ la expansión total supuesta de los productos de corrosión en los ensayos, en el momento de la fisuración y $\delta_{c r}$, el desplazamiento radial de la superficie interior del cilindro de pared gruesa que causa la fisuración, hallado analíticamente con datos procedentes de las probetas de ensayo.

La metodología seguida arroja valores de espesor equivalente de la capa porsosa $t_{p}$ muy dispersos (desde valores cercanos a 0 hasta valores cercanos a $120 \mu \mathrm{m}$, con un valor promedio de $28,7 \mu \mathrm{m}$ ), por lo que una vez obtenidos, Chermin et al. (2010) tratan de establecer correlaciones con la resistencia a compresión del hormigón $f_{c m}$ y con el tiempo para el inicio de la fisuración $t_{c r}$. En ambos casos realiza un ajuste mediante mínimos cuadrados (Figura 2-44), obteniendo una baja correlación $\left(R^{2}=0,3114\right)$ para la resistencia $f_{c}$, y un coeficiente de correlación $R^{2}$ suficientemente significativo $\left(R^{2}=0,8434\right)$ en el caso del tiempo $t_{c r}$ 
Tal y como explican los autores, la explicación más plausible para dicha circunstancia es que la hipótesis de que los productos de corrosión se difunden en el hormigón circundante únicamente hasta que logran rellenar la denominada "zona porosa" de espesor equivalente $t_{p}$ no es del todo precisa. Aunque la existencia de una zona de alta porosidad en la zona de contacto entre el acero y el hormigón se ha comprobado experimentalmente, los productos de corrosión siguen difundiéndose a lo largo del tiempo y no únicamente hasta rellenar dicha zona. Este hecho explicaría la gran correlación existente entre el espesor equivalente $t_{p}$ y el tiempo transcurrido para el inicio de la fisuración $t_{c}$, y vendría respaldado por las observaciones llevadas a cabo en campañas experimentales, donde fueron detectados productos de corrosión en poros del hormigón situados a varios milímetros, e incluso centímetros de la superficie del acero corroído (Andrade, et al., 1993).
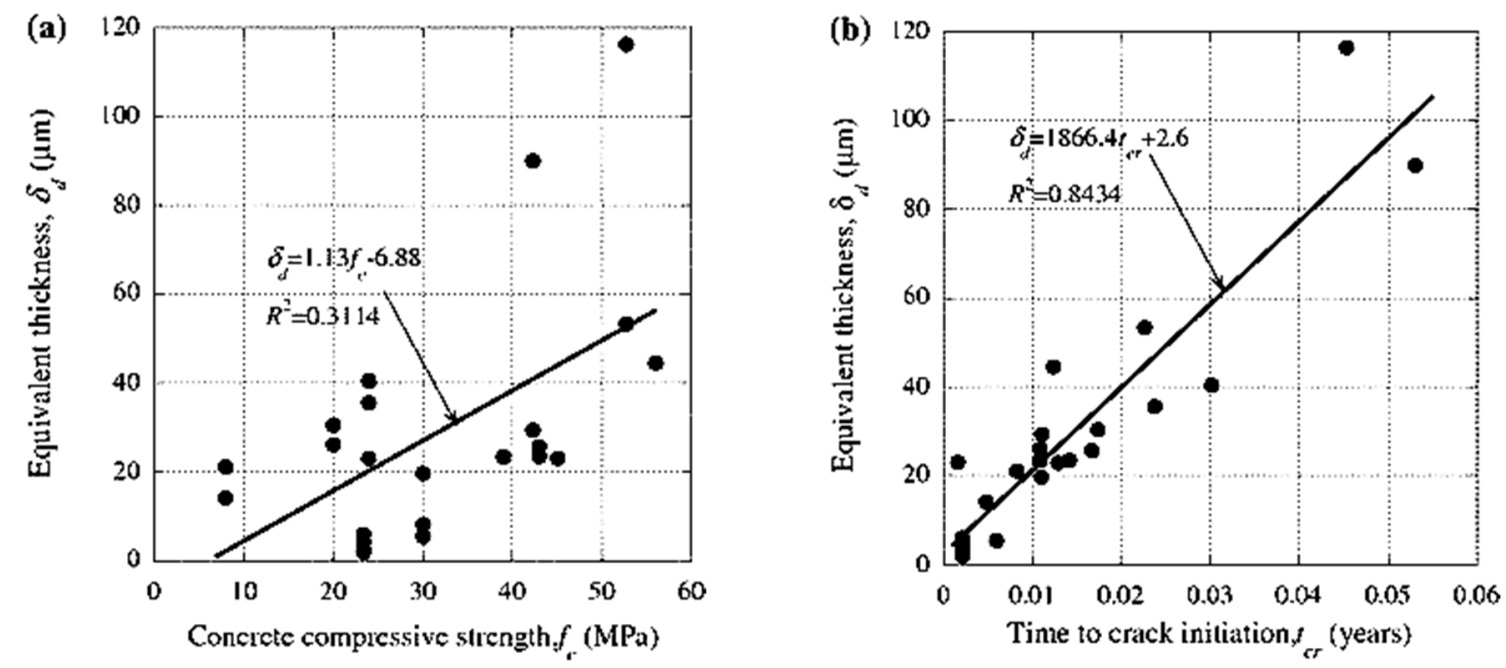

Figura 2-44 Espesor equivalente to de los productos de corrosión difundidos en función de: a) Resistencia a compresión del hormigón; y b) el tiempo para el inicio de la fisuración tor (Chernin, et al., 2010)

Por otro lado, Chernin et al. observaron que la relación entre $t_{p}$ y $\delta_{c r, \text { exp }}$, es decir, la cantidad de productos de corrosión que se difunden en el hormigón entre la cantidad total de óxidos formados en el momento de la fisuración, se mantenía constante en el tiempo. Basándose en este hecho, los autores proponen transformar dicho ratio en un coeficiente o "factor de eficacia" de valor constante, no dependiente del tiempo, al que denominan $\eta$. El valor que adopta $\eta$ oscila entre el 0,68 registrado en ensayos con corrosión acelerada y el 0,73 obtenido para probetas corroídas en condiciones naturales, por lo que proponen un valor promedio de $\eta=0,70$. En definitiva, dicho coeficiente indica que, independientemente del tiempo, únicamente el 30\% de los productos de corrosión generados durante el proceso presionan el hormigón circundante, mientras que el resto se difunde por la fase porosa del hormigón. Por tanto, con este cambio de enfoque llevado a cabo por Chermin et al. (2010), la cantidad de productos de corrosión que se difunden pasa a ser un valor dependiente de la producción total de óxidos y no un valor fijo relacionado con el espesor equivalente $t_{p}$ de la "zona porosa”. Este enfoque ya fue planteado originalmente por Andrade et al. (1993).

En cuanto a la distribución de los productos de corrosión a lo largo de la zona porosa, a pesar de que existen dificultades significativas en la toma de medidas en los ensayos, existe consenso en que la concentración de los óxidos decrece al alejarse de la superficie del acero, ya que se trata de un proceso 
de difusión. En ese sentido, en un reciente trabajo de Michel et al. (2014), se determinaron la penetración de óxidos y la concentración de estos a lo largo de la matriz cementicia que rodeaba el acero, hasta el comienzo de la fisuración, mediante medidas de atenuación de Rayos X. Las gráficas de la Figura 2-45 representan las concentraciones medias de productos de corrosión en distintas etapas previas al comienzo de la fisuración, para un mortero con relación agua/cemento $a / c=0,5$ e intensidad de corrosión $i_{\text {corr }}=10 \mu \mathrm{A} / \mathrm{cm}^{2}$, y otro con relación a $/ \mathrm{c}=0,3$ e intensidad de corrosión $i_{\text {corr }}=100 \mu \mathrm{A} / \mathrm{cm}^{2}$. Tal y como puede observarse, los ensayos permitieron detectar, por un lado, que los productos de corrosión lograron alcanzar zonas alejadas hasta $220 \mu \mathrm{m}$ de la interfaz acero/hormigón, y por otro, que la concentración de óxidos disminuye con el aumento de la distancia con respecto a la superficie del acero. Aunque los resultados no tienen trascendencia desde un punto de vista cuantitativo, ya que hormigones distintos arrojarían resultados diferentes, el descenso en la concentración de óxidos confirma cualitativamente el comportamiento esperable al tratarse de un proceso de difusión.
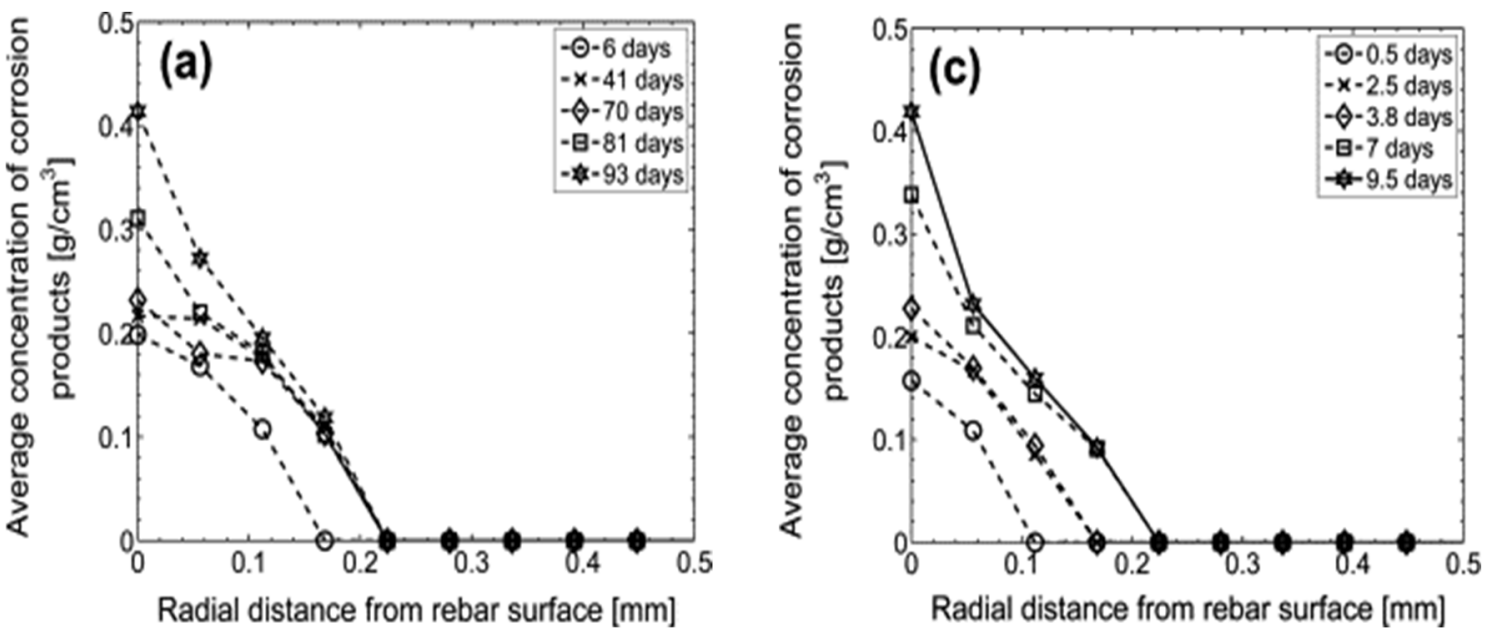

Figura 2-45 Concentración media de productos de corrosión en la matriz cementicia que rodea el acero para: (a) Mortero con relación a/c=0.5 e intensidad de corrosión $I_{\text {corr }}=10 \mu \mathrm{A} / \mathrm{cm}^{2}$; (b) Mortero con relación a $\mathrm{c}=0.3$ e intensidad de corrosión $I_{\text {corr }}=100 \mu \mathrm{A} / \mathrm{cm}^{2}$. $[$ Figura tomada de (Michel, et al., 2014)]

La porosidad es otro parámetro que juega un papel importante, tal y como afirmaron Alonso et al. (1998). Los autores determinaron que los poros alrededor del acero podían alojar los productos de corrosión tras el inicio de ésta, retrasando la transmisión de presiones al recubrimiento. Posteriormente, los óxidos podían difundir más allá de la interfaz acero/hormigón a través de la red de poros. En ese sentido, cabe destacar los trabajos de K.L. Scrivener et al. (1996) (Scrivener, et al., 2004) en la caracterización de la denominada "Zona de Transición Interfacial” (ITZ), región de mayor porosidad situada en la interfaz entre la pasta de cemento y los áridos. En estos estudios, los autores explican el origen de la ITZ mediante el denominado "efecto muro" ("Wall effect"), que causa una mayor compactación de gránulos anhidros de cemento de pequeño tamaño cerca de los áridos, lo que genera una mayor porosidad en la interfaz. El espesor de la ITZ depende fundamentalmente del grado de hidratación, y disminuye sus diferencias con el resto de la pasta de cemento con la madurez del hormigón, aun así, los autores lo cuantificaron en un rango comprendido entre las 15 y las $20 \mu \mathrm{m}$. Numerosos investigadores han trasladado las propiedades particulares de la región ITZ a la zona de contacto hormigón/acero. En ese contexto se enmarcan los experimentos llevados a cabo por Horne (2007) en los que mediante microscopía electrónica de barrido (SEM) se analizó la microestructura 
de la interfaz acero-hormigón, variando parámetros tales como la relación agua-cemento, el grado de hidratación o el acabado superficial del acero. Los resultados mostraron un descenso apreciable de la porosidad con el aumento de la distancia a la superficie del acero, tal y cómo puede observarse en la Figura 2-46.

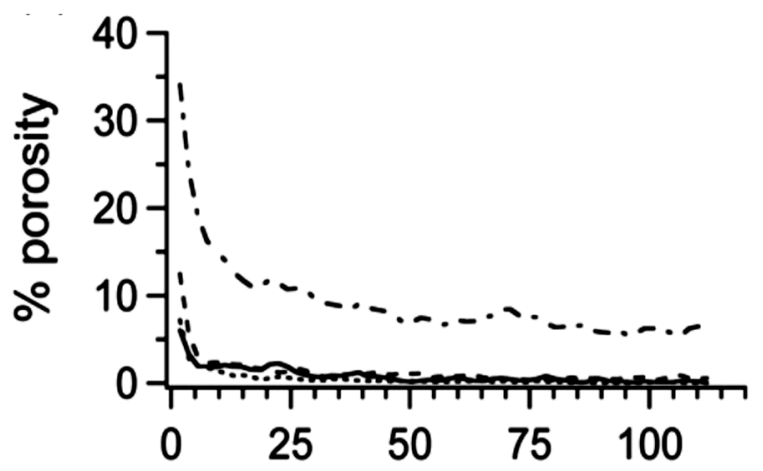

Figura 2-46 Gradientes de porosidad en la región de contacto entre pasta de cemento y acero para distintas edades del hormigón y una relación a/ $c=0,49$ (Horne, et al., 2007)

\subsubsection{Volumen de óxidos en fisuras}

Una vez que se ha iniciado la fisuración en el hormigón que circunda el alambre, los productos de corrosión pueden depositarse en el interior de las fisuras abiertas. Por tanto, este espacio adicional (equivalente al volumen liberado por las fisuras) para la difusión de los óxidos producirá, por una parte, un retraso en la fisuración del recubrimiento, por otra, un pico de tensión máxima de adherencia para un valor más elevado de corrosión, y por último, una tensión de adherencia residual superior para el mismo nivel de pérdida de sección.

Cuando no se tiene en cuenta la fisuración, el valor combinado de cambio de volumen del acero $\Delta V_{s}$ y del hormigón $\Delta V_{c}$ debe ser equivalente al volumen total comprimido de productos de corrosión $V_{r}$. En el caso de penetración de óxidos en las fisuras, se tendrá en cuenta un volumen adicional $\Delta V_{\text {crack }}$ correspondiente al espacio adicional liberado por la fisuración, de manera que se obtiene una relación de igualdad con la siguiente forma (Eq. 2-78):

$$
V_{r c}=\Delta V_{s}+\Delta V_{c}+\Delta V_{\text {crack }}
$$

El fenómeno del depósito de óxidos en el espacio liberado por las fisuras fue ya apuntado por Bazant (1979). Posteriormente, Andrade et al. (1993) señalaron que la velocidad de crecimiento del ancho de fisura $w$ disminuía una vez que la fisuración alcanzaba la superficie del recubrimiento de hormigón, atribuyendo esta ralentización al hecho de que parte de los productos de corrosión podían difundir fácilmente por las fisuras de nueva generación. Los autores apoyaban esta afirmación en el hecho de que aparecieran óxidos claramente observables en el exterior de las fisuras de las probetas de la campaña experimental que llevaron a cabo. Recientemente, en ese mismo sentido, Pedrosa et al. (2017), mediante ajustes empíricos han cuantificado y caracterizado las pendientes de las gráficas 
apertura de fisura $w$ - Penetración de ataque $P_{\rtimes}$ para distintas intensidades de corriente $I_{\text {corr }} \mathrm{y}$ distintos espesores del recubrimiento $c$, detectando pendientes más tendidas a partir de un determinado nivel de penetración de ataque $P_{x}$. En consecuencia, los autores proponen un modelo bilineal de evolución del ancho de fisura en función del nivel de corrosión., justificando el cambio de pendiente por el efecto combinado del ablandamiento del hormigón en tracción y la relajación de las tensiones radiales tras la fisuración.

Los aspectos que más controversia causan son, por un lado, la determinación del porcentaje de espacio liberado por las fisuras $\Delta V_{\text {crack }}$ que es ocupado por los productos de corrosión, incrementando el volumen disponible para la expansión de los óxidos $V_{r}$ y disminuyendo consecuentemente la presión $p$ que se ejerce sobre la pared interna del cilindro de hormigón, y por otro, cuáles son los parámetros que determinan dicho porcentaje. En vista de los trabajos analizados se puede deducir que existen tres parámetros fundamentales que determinan el valor de dicho porcentaje: el espesor de recubrimiento $c$, la magnitud de la fisuración y, por último, el valor de la densidad de corriente de corrosión $i_{\text {corr }}$.

En cuanto a la influencia de recubrimiento, Val et al. (2008), en su investigación numéricoexperimental, intentan establecer el porcentaje del espacio liberado por las fisuras que es ocupado por los productos de corrosión, en función del espesor de recubrimiento. Para ello, para distintos recubrimientos, comparan el ratio del volumen de productos de corrosión que han penetrado en las fisuras tras el comienzo de la fisuración entre el volumen total de fisuras, $\left(V_{r, c r}-V_{r, 0}\right) / V_{c r}$, donde $V_{r, c r}$ es la cantidad total de productos de corrosión que penetran en las fisuras, $V_{r, 0}$ es el volumen de óxidos que han penetrado en la "zona porosa" que rodea el alambre al comienzo de la fisuración, y $V_{c r}$ es el volumen total del espacio liberado por las fisuras inducidas por el proceso de corrosión. Los resultados obtenidos por los autores muestran que dicho ratio disminuye considerablemente con el incremento del espesor de recubrimiento $c$, dado que el volumen total de fisuras $V_{c r}$ también se incrementa (en recubrimientos de $50 \mathrm{~mm}$ se obtiene un ratio un $50 \%$ menor que en recubrimientos de $25 \mathrm{~mm})$.

Para Wang et al. (2017) el ancho de fisura $w$ es el parámetro controlante del proceso de ocupación de las fisuras por parte de los productos de corrosión. Para los autores, el porcentaje de volumen ocupado por los óxidos con respecto al volumen total liberado por la fisuración crece con el aumento del ancho de fisura, hasta alcanzar un valor máximo en el que se estabiliza. El máximo porcentaje indicado por Wang et al. es de aproximadamente un $85 \%$.

Por su parte, Lu et al. (2010) señalaron que la densidad de corriente de corrosión $i_{\text {corr }}$ tenía una influencia significativa en la cantidad de productos de corrosión que difundían a través de las fisuras. Para los autores, en el caso de procesos de corrosión natural, con densidades de corriente bajas $\left(i_{\text {corr }}<10 \mu \mathrm{A} / \mathrm{cm}^{2}\right.$ ), es inevitable que gran parte de las fisuras generadas sean ocupadas por los productos de corrosión, mientras que, para densidades de corrosión altas, características de los ensayos acelerados de laboratorio, el porcentaje de ocupación del espacio liberado por la fisuración es inversamente proporcional a la velocidad de corrosión. Lu et al. indican que, para procesos de corrosión natural, el porcentaje de volumen ocupado por los óxidos con respecto al volumen total liberado por la fisuración se encuentra en el rango 80-100\%, mientras que en el caso de corrosión 
TESIS DOCTORAL INFLUENCLA DE LA CORROSIÓN EN LA ADHERENCLA DE ALAMBRES EN ELEMENTOS PRETENS ADOS DE HORMIGÓN

acelerada desciende hasta el 15-30\%. Estas diferencias entre corrosión natural y acelerada concuerdan con lo señalado por Zhao et al. (2016). 
3. MODELO ANALÍTICO - ELEMENTOS PRETENSADOS DE HORMIGÓN CON PROCESOS DE DETERIORO POR CORROSIÓN

TESIS DOCTORAL 


\section{CAPÍTULO 3}

\section{Modelo analítico para evaluación de la adherencia en elementos pretensados de hormigón con procesos de deterioro por corrosión}

\subsection{Introducción}

El cálculo y diseño de elementos pretensados de hormigón con armaduras pretesas requiere una evaluación realista de la longitud de alambre necesaria para que las fuerzas de pretensado se transfieran completamente al hormigón. Esta longitud, que suele denominarse de transferencia o transmisión, depende en gran medida de la adherencia alambre-hormigón y puede verse afectada por varios factores, entre los que se encuentran los procesos de deterioro por corrosión. Las ecuaciones para caracterización de la longitud de transferencia existentes en los códigos estructurales [Eurocódigo 2 (2001); ACI 318-02 (2002); EHE-08 (2008); Model Code 2010 (2011)] suelen considerar únicamente el efecto de algunas variables, como el diámetro del alambre o la fuerza de pretensado inicial, omitiendo otros parámetros, como la resistencia del hormigón o el espesor de recubrimiento, cuya influencia ha sido demostrada en numerosos trabajos (Ver Capitulo 2). Además, en ningún caso, se cuantifica en qué medida afecta el ataque por corrosión a dicha longitud. Por tanto, es patente la necesidad de desarrollar un método racional que permita evaluar la adherencia, y consecuentemente la longitud de transferencia, en elementos pretensados de hormigón con distintas configuraciones geométricas y mecánicas.

En los siguientes apartados se desglosa la base teórica del modelo analítico desarrollado para esta tesis, implementado en Matlab, y que permite, una vez calibrado mediante ensayos básicos de adherencia, determinar la longitud de transferencia en elementos pretensados, así como su evolución con el aumento de la corrosión.

\subsubsection{Descripción del modelo analítico desarrollado}

En el Capitulo 2 se ha mostrado que los modelos que pretenden reproducir el comportamiento adherente de alambres pretensados pueden ser divididos en dos amplias categorías (den Ujil, 1998): aquellos que determinan la tensión de adherencia como función del deslizamiento y aquellos que determinan dicha tensión como función de la tensión de compresión radial sobre el acero. Un tercer grupo, que no llegaría a conformar una categoría propia, ya que siempre aparece combinado con las dos anteriores, sería el correspondiente a los datos experimentales extraídos de campañas experimentales, utilizados para la calibración de los modelos.

El modelo propuesto en esta tesis, calibrado mediante ensayos de adherencia tipo pull-out (o arrancamiento), permite la determinación de la longitud de transferencia mediante la definición de la tensión de adherencia a lo largo del alambre de pretensado, en función tanto del deslizamiento como 
de la tensión radial de compresión procedente del efecto Hoyer, de la expansión de los productos de corrosión y de la retracción. A la luz de las categorías enumeradas anteriormente, el modelo propuesto en esta tesis puede considerarse de naturaleza mixta, al conjugar elementos presentes en todas ellas y minimizar las limitaciones propias de cada uno.

Los modelos analíticos que simulan el estado tensional del recubrimiento de hormigón que rodea una barra o alambre que sufre un proceso de deterioro por corrosión se centran en la dirección transversal del elemento, mientras que aquellos que reproducen el comportamiento adherente a lo largo de un alambre de pretensado se centran en la dirección longitudinal, es decir, recogen la variación de las tensiones a lo largo de la longitud de transferencia y/o de anclaje (en función de si el elemento estructural se encuentra en servicio o no). En contraposición a estos modelos unidireccionales, el modelo analítico propuesto, que pretende conjugar pretensado y corrosión, es de carácter multidireccional. Para ello, el mecanismo adherente se desacopla en dos componentes diferenciadas:

- Una componente longitudinal $\tau_{b}$, que reproduce la variación de las tensiones a lo largo del alambre, transferidas gradualmente al hormigón circundante cuando la fuerza de pretensado es liberada tras el endurecimiento del hormigón. Esta parte del modelo es la que tiene en cuenta los fenómenos que tienen lugar en la dirección longitudinal del alambre, tales como la pérdida de adherencia y el deslizamiento.

- Una componente transversal $\sigma_{r}$ (o radial) que puede ser descompuesta en el sumatorio de las siguientes tensiones:

- Tensión derivada del efecto Hoyer, procedente de la transferencia del pretensado, $\sigma_{r, p}$.

- Tensión radial por la acumulación de productos de corrosión, $\sigma_{r, c o r r}$

- Tensión provocada por fuerzas de confinamiento exteriores, $\sigma_{\xi, \text { conf }}$.

- Tensión radial provocada por la retracción, $\sigma_{r, s h}$

Estas dos componentes del modelo, $\tau_{b}$ y $\sigma_{r}$, dejando a un lado la adhesión química $\tau_{\text {adb }}$ que suele considerarse constante y cuya acción desaparece para deslizamientos $s$ muy pequeños, están asociadas a través del coeficiente de fricción $\mu$ descrito por la Ley de rozamiento de Coulomb. Esta ley, por definición, establece que la máxima fuerza de rozamiento $F$ que puede existir entre dos cuerpos en contacto es directamente proporcional al valor de la fuerza normal $N$ a la superficie de contacto entre ellos, siendo la constante de proporcionalidad igual al coeficiente de fricción $\mu$ (Eq. 3-1):

$$
F=\mu N
$$

Si se toma un elemento diferencial $d S(d x \cdot d s)$ sobre la superficie cilíndrica de un alambre de radio $r_{b} \mathrm{y}$ longitud adherente $l_{\text {adb }}$, embebido en hormigón y sometido a una fuerza de arrancamiento $P$, puede suponerse que la fuerza reacción resultante, $d N$, que se opone a las tensiones radiales de compresión $\sigma_{r}$, es perpendicular a la superficie de contacto (Figura 3-1). Por tanto, en virtud de la Ley de fricción de Coulomb, se cumple la siguiente expresión (Eq. 3-2):

$$
d F=\mu \cdot d N
$$




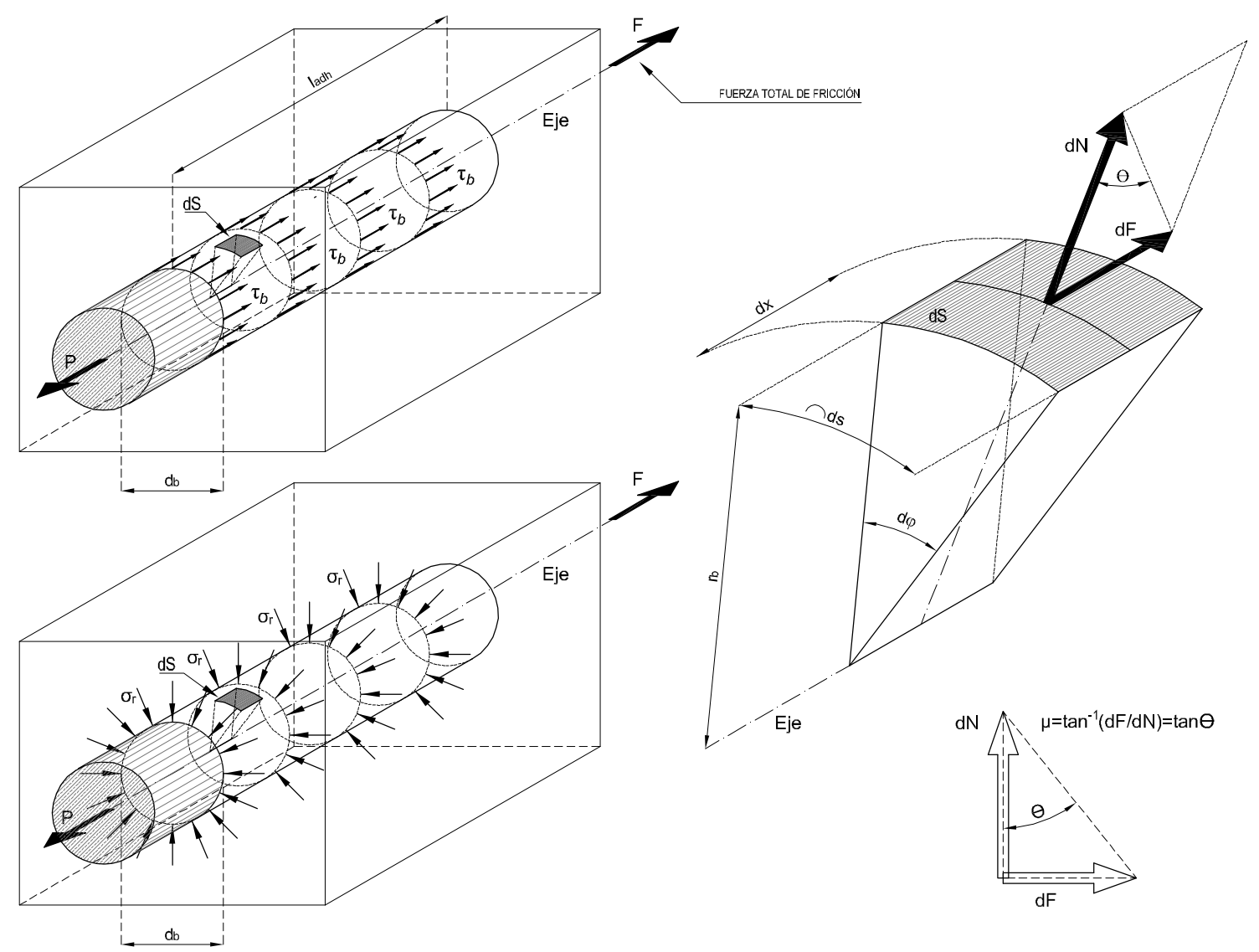

Figura 3-1 Tensiones tangenciales $\tau_{b}$ (izquierda-arriba) y radiales $\sigma_{r}$ (izquierda-abajo) a lo largo de la superficie cilindrica del alambre. Ley de fricción de Coulomb aplicada a un elemento difeencial de superficie dS.

El diferencial de la fuerza de rozamiento $d \mathrm{~F}$ es la resultante de la tensión de adherencia $\tau_{b}$ sobre el elemento diferencial de superficie $d S$, cuyos lados están definidos por la longitud diferencial $d x$, en la dirección del eje del alambre, y el diferencial del arco de circunferencia $d s$, en la dirección transversal. Por tanto, en coordenadas cilíndricas, se obtiene la expresión (Eq. 3-3):

$$
d F=\tau_{b} \cdot d S=\tau_{b} \cdot d s \cdot d x=\tau_{b} \cdot r_{b} \cdot d \varphi \cdot d x
$$

Por otro lado, el diferencial de la fuerza normal $d N$ sobre el elemento diferencial de superfice $d S$, en coordenadas cilíndricas, toma el siguiente valor (Eq. 3-4):

$$
d N=\sigma_{r} \cdot d s \cdot d x=\sigma_{r} \cdot r_{b} \cdot d \varphi \cdot d x
$$

Por tanto, la fuerza de rozamiento total $F$ es el resultado de la integración de $d F$ a lo largo de la superficie adherente del alambre (Eq. 3-5):

$$
F=\int_{0}^{l_{\text {adh }}} \int_{0}^{2 \pi} \tau_{b} \cdot r_{b} \cdot d \varphi \cdot d x=\tau_{b} \cdot r_{b} \cdot 2 \pi \cdot l_{a d h}
$$

De igual manera, la fuerza normal total $N$ se obtiene integrando el diferencial $d N$ a lo largo de la superficie del alambre en contacto con el hormigón (Eq. 3-6): 


$$
N=\int_{0}^{l_{a d h}} \int_{0}^{2 \pi} \sigma_{r} \cdot r_{b} \cdot d x \cdot d \varphi=\sigma_{r} \cdot r_{b} \cdot 2 \pi \cdot l_{a d h}
$$

Si se sustituye el valor total de la fuerza de rozamiento F (Eq. 3-5) y de la fuerza normal N (Eq. 3-6) en la ecuación que describe la Ley de Coulomb (Eq. 3-1), la tensión de adherencia $\tau_{b}$ puede despejarse como sigue (Eq. 3-7):

$$
F=\mu N \Rightarrow \tau_{b} \cdot r_{b} \cdot 2 \pi \cdot l_{a d h}=\mu \cdot \sigma_{r} \cdot r_{b} \cdot 2 \pi \cdot l_{a d h} \Rightarrow \tau_{b}=\mu \sigma_{r}
$$

Por último, sustituyendo la tensión radial total $\sigma_{r}$ por el conjunto de tensiones que la conforman, y añadiendo la tensión de adherencia debida al mecanismo de adhesión $\tau_{a d h}$, se obtiene la expresión que gobierna el comportamiento adherente de alambres embebidos en hormigón (Eq. 3-8):

$$
\tau_{b}=\mu\left[\sigma_{r, p}+\sigma_{r, c o r r}+\sigma_{r, s h}+\sigma_{r, \text { conf }}\right]+\tau_{a d h}
$$

En definitiva, la expresión anterior (Eq. 3-8) permite relacionar las tensiones radiales $\sigma_{r}$, obtenidas mediante el modelo analítico que se expone en este capítulo, con las tensiones de adherencia $\tau_{b}$ obtenidas en los ensayos de pull-out. Conocidas ambas tensiones para las distintas condiciones de ensayo contempladas, y suponiendo un determinado valor para la tensión de adhesión $\tau_{a d h}$, es fácilmente deducible el valor del coeficiente de ficción $\mu \mathrm{y}$, por tanto, su calibración.

En los siguientes apartados de este capítulo, tras exponer los modelos del material utilizados para describir el comportamiento del hormigón en compresión y tracción, se expone la base teórica que sustenta el modelo analítico desarrollado para esta tesis, que se estructura en las tres siguientes fases o etapas:

\section{- FASE I: DETERMINACIÓN DE TENSIONES RADIALES}

Esta primera etapa consiste en un análisis en dos dimensiones (2D) de la sección transversal del elemento de hormigón pretensado, basado, por un lado, en la teoría de cilindros huecos de pared gruesa (Timoshenko, 1956), y por otro, en un modelo de fisuración cohesiva para el hormigón. Esta fase permite determinar, por un lado, las tensiones radiales $\sigma_{r}$ a lo largo del recubrimiento, para unas condiciones concretas de nivel de pretensado y corrosión, y por otro, predecir la apertura de fisuras y el avance de éstas. El análisis depende tanto de parámetros conocidos, tales como las propiedades geométricas y mecánicas de los materiales, como de parámetros cuyo valor debe ser calibrado mediante la comparación de los resultados teóricos con los obtenidos en la campaña de ensayos tipo pull-out. Dentro de este último grupo se engloban, por un lado, el coeficiente de fricción $\mu \mathrm{y}$, por otro, los parámetros que definen el proceso de corrosión: el coeficiente de expansión de óxidos $n$, el módulo de deformabilidad volumétrica $K_{r}$, la penetración de ataque por corrosión $P_{x}$, el espesor de la capa porosa $t_{p}$ y el volumen de óxidos en las fisuras.

\section{- FASE II: SIMULACIÓN DEL ENSAYO DE ARRANCAMIENTO O PULL-OUT}


En esta fase se lleva a cabo un análisis en tres dimensiones (3D), en el que partiendo de las tensiones radiales $\sigma_{r}$ de la sección transversal halladas en la etapa anterior y reproduciendo las condiciones específicas del ensayo de pull-out, se analiza el comportamiento mecánico en la dirección longitudinal del elemento. Para ello, se recurre a los dos parámetros fundamentales que permiten el acople de ambas direcciones: el coeficiente de fricción $\mu$, calibrado en la fase anterior, y la ley de adherencia local-deslizamiento $\tau_{b}-s$. Por un lado, la tensión radial $\sigma_{r}$ (a la que debe sumarse en esta fase la tensión $\sigma_{r, c o n f}$ resultante de las fuerzas exteriores de confinamiento procedentes del propio ensayo), en combinación con el coeficiente de fricción $\mu$, permite hallar la tensión de adherencia máxima $\tau_{b, \max }$ que admite la sección. Por otro lado, partiendo de una ley de adherencia-deslizamiento genérica se implementan las expresiones que permiten relacionar los deslizamientos $S$ que provoca la fuerza de arrancamiento, con la distribución de la tensión de adherencia $\tau_{b}$ a lo largo de la longitud adherente del alambre $l_{a d h}$. Por último, mediante la comparación con las distribuciones de adherencia media-deslizamiento $\tau_{b, \max }-s$ obtenidas de los ensayos, se calibran las leyes genéricas de adherencia local - deslizamiento $\tau_{b}-s$, tanto de alambres lisos como indentados, obteniéndose el valor de los parámetros que las particularizan: el deslizamiento al final de la región elástica $s_{y}$, el deslizamiento al final de la región plástica $s_{u}$, el deslizamiento previo a la región de tensión residual $s_{r e s} \mathrm{y}$, por último, valor de la tensión residual de adherencia $\tau_{b, r e s}$.

\section{- FASE III: DETERMINACIÓN DE LA LONGITUD DE TRANSFERENCIA}

En esta última fase se realiza un análisis en la dirección longitudinal del elemento de pretensado, en el que en base a las tensiones radiales $\sigma_{r}$, el coeficiente de fricción $\mu$ y ley de adherencia local-deslizamiento $\tau_{b}-s$, determinados en las fases anteriores, se evalúa la distribución de tensiones y deformaciones en el hormigón y en el acero, así como los deslizamientos relativos acero-hormigón, a lo largo de toda la longitud del elemento. Con ello, queda definida tanto la longitud de transferencia $l_{t}$ como el deslizamiento $s$ en el extremo, parámetros que serán verificados mediante ensayos sobre vigas pretensadas reales.

\subsection{Modelo de comportamiento del material: hormigón}

Durante las últimas décadas se han desarrollado numerosos modelos constitutivos destinados a describir el complejo comportamiento del hormigón sometido a diversos campos de tensiones. Las campañas de ensayos efectuadas a tal efecto han demostrado que el hormigón a tracción presenta un comportamiento frágil y, tras el comienzo de la fisuración, desarrolla una fase de ablandamiento protagonizada por un descenso de la capacidad a tracción vinculada al aumento de la fisuración. Por su parte, el hormigón a compresión ha mostrado un comportamiento no-lineal muy pronunciado antes de alcanzar su máxima capacidad, seguido por una etapa de ablandamiento cuya fragilidad depende del tipo de hormigón utilizado.

El modelo del material utilizado en esta tesis, denominado de fisuración cohesiva, acepta la hipótesis de que el hormigón parcialmente deteriorado por la fisuración es aún capaz de transmitir ciertos esfuerzos de tracción. Por un lado, se supone que los planos de fisura coinciden con los planos de 
máxima deformación de tracción y que el hormigón fisurado se comporta como un material ortotrópico, con los ejes del material orientados a lo largo de la dirección de las tensiones principales. Por otro lado, al partirse de la suposición de axilsimetría en la analogía del cilindro de pared gruesa utilizada en el modelo analítico, se acepta que la dirección de las deformaciones principales coincide con la dirección de las tensiones principales, que a su vez se corresponden con las direcciones radial $r$ y circunferencial $\theta$ del cilindro. También se parte de la hipótesis de que las fisuras radiales están uniformemente distribuidas a través del recubrimiento de hormigón, por lo que las relaciones constitutivas del material están formuladas en términos de tensiones y deformaciones medias.

A continuación, se recogen las relaciones constitutivas del hormigón, tanto a compresión como a tracción, implementadas en el modelo analítico desarrollado para esta tesis.

\subsubsection{Hormigón en compresión}

Al igual que Pantazopoulou \& Papouli (Pantazopoulou \& Papoulia, 2001) y Martin-Pérez (MartínPérez, 2014), se ha supuesto que el comportamiento del hormigón en compresión sigue el modelo de Hognestad (Hognestad, et al., 1955). Dicho modelo, que relaciona el valor medio de las tensiones principales radiales y deformaciones principales radiales, $\sigma_{r}$ y $\varepsilon_{r}$, refleja el hecho de que, tras la fisuración, en estados de tensión biaxiales, la resistencia a compresión del hormigón $f_{c}$ se reduce debido a la aparición de deformaciones de tracción en la dirección circunferencial $\varepsilon_{\theta}$. Es uno de los modelos más ampliamente aceptados para hormigones no confinados y consta de una rama ascendente hasta alcanzar la resistencia máxima $f_{c}$, descrita por una parábola de segundo grado, seguida de una rama descendente simétrica a la anterior (Eq. 3-9):

$$
\sigma_{r}=\beta f_{c}^{\prime}\left[2\left(\frac{\varepsilon_{r}}{\varepsilon_{0}}\right)-\left(\frac{\varepsilon_{r}}{\varepsilon_{0}}\right)^{2}\right]
$$

donde:
$f_{c}^{\prime} \quad$ Resistencia máxima a compresión del hormigón, obtenida en ensayos de laboratorio.
$\varepsilon_{0} \quad$ Deformación asociada al pico de máxima resistencia a compresión del hormigón.
$\beta \quad$ Coeficiente que toma en cuenta el efecto de ablandamiento derivado de la presencia simultánea de la deformación de tracción $\varepsilon_{\theta}$.

Como se indicaba anteriormente, la tensión radial en el hormigón $\sigma_{r}$ no es sólo función de la deformación radial de compresión $\varepsilon_{r}$, sino tambien de la fisuración y, en consecuencia, de la deformación circunferencial de tracción $\varepsilon_{\theta}$. Por tanto, el hormigón fisurado sujeto a deformaciones de tracción en la dirección normal al esfuerzo de compresión es más debil y deformable que el hormigón de un ensayo estandar de compresión. Para recoger este fenómeno, Vecchio \& Collins (1986) definieron el valor de un coeficiente $\beta$ que responde a la siguiente expresión (Eq. 3-10):

$$
\beta=\frac{1}{0.8-0.34 \frac{\varepsilon_{\theta}}{\varepsilon_{0}}} \leq 1
$$


En la Figura 3-2 se representa la parábola de Hognestad, descrita por la expresión (Eq. 3-9) y cuya forma depende del nivel de deformaciones circunferenciales, así como la evolución del módulo de deformación en tracción del hormigón para cada estado tensional.

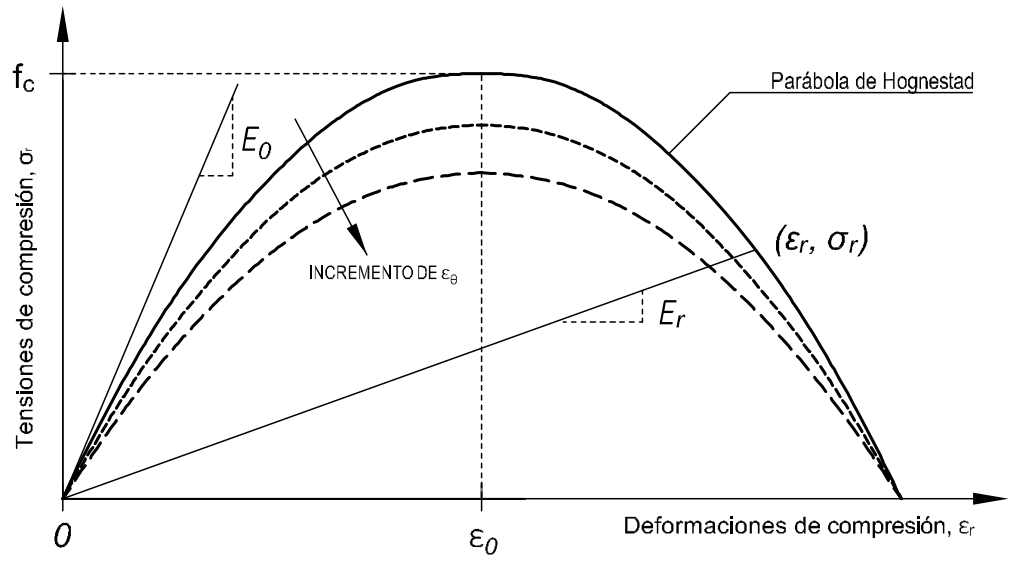

Figura 3-2 Modelo de Hognestad para comportamiento de hormigón en compresión

Por su parte, el módulo de elasticidad tangente inicial del hormigón $E_{o}$ se toma como (Eq. 3-11):

$$
E_{o}=2 \frac{f_{c}^{\prime}}{\varepsilon_{o}}
$$

\subsubsection{Hormigón en tracción}

El modelo supone que la relación existente entre la tensión principal de tracción $\sigma_{\theta}$ y la deformación principal de tracción $\varepsilon_{\theta}$, ambas en la direccion circunferencial $\theta$, es elástica y lineal para el hormigón sin fisurar, con una pendiente igual al módulo de elasticidad tangente inicial E. Cuando la tensión principal de tracción $\sigma_{\theta}$ supera el valor de la resistencia a tracción del hormigón $f_{t}^{\prime}$, para una deformación equivalente a $\varepsilon_{c r}$, se inicia la apertura de fisuras en el plano normal a la dirección principal de tracción, es decir, a lo largo de la dirección radial $r$. A partir de ese momento, el diagrama tensióndeformación evoluciona hacia una rama de ablandamiento lineal, debido a la progresiva fisuración,

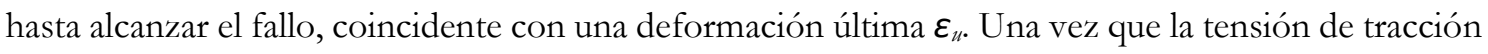
del hormigón $\sigma_{\theta}$ ha superado el valor de deformación $\varepsilon_{u}$, se supone que el material está plenamente fisurado y que la tensión de tracción es igual a cero (ver Figura 3-3).

Por tanto, el diagrama respuesta tensión-deformación del hormigón en tracción queda descrito mediante la siguiente función por tramos (Eq. 3-12):

$$
\begin{array}{cc}
\sigma_{\theta}=E_{o} \varepsilon & 0 \leq \varepsilon<\varepsilon_{c r} \\
\sigma_{\theta}=f_{t}^{\prime}-E_{t}\left(\varepsilon-\varepsilon_{c r}\right) & \varepsilon_{c r} \leq \varepsilon<\varepsilon_{u} \\
\sigma_{\theta}=0 & \varepsilon_{u}<\varepsilon
\end{array}
$$

donde $f_{t}{ }^{\prime}$ es la resistencia a tracción del hormigón, con un valor tomado de los ensayos experimentales (si se dispusiera de ellos) o, en su defecto, de la relación teórica $f_{t}{ }^{\prime}=0.33 \sqrt{f_{c}{ }^{\prime}}[\mathrm{Mpa}]$, 
y $\varepsilon_{c r}$ es la deformación crítica correspondiente a la tensión máxima del hormigón, es decir, $\varepsilon_{c r}=$ $f_{t}^{\prime} / E_{o}$.

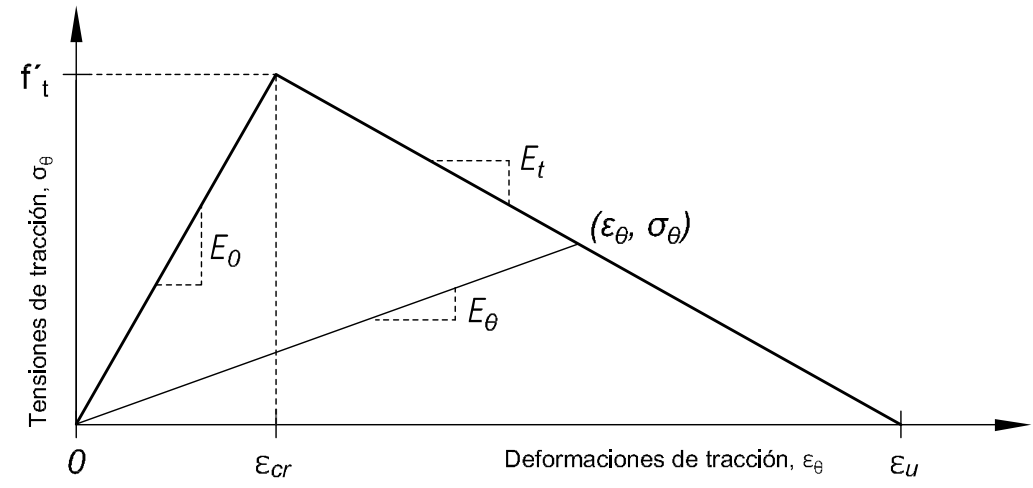

Figura 3-3 Modelo tensión-deformación bilineal para comportamiento de hormigón en tracción

Por su parte, el módulo de ablandamiento $E_{t}$ (ver Figura 3-3) y el valor de la deformación última de tracción $\varepsilon_{u}$ se evaluan mediante la energía de fractura $G_{f}$, que puede definirse como la disipación de energía que tiene lugar debido a la fisuración localizada por unidad de área, y es considerada una propiedad dependiente de la resistencia a compresión del hormigón. En ausencia de datos experimentales, según el Model Code 2010 (CEB-FIP, 2012), el valor de $G_{f}$, en N/m, puede ser estimado mediante la siguiente expresión (Eq. 3-13):

$$
G_{f}=73\left(f_{c}^{\prime}\right)^{0.18}
$$

donde $f_{c}^{\prime}$ es la resistencia a compresión del hormigón en MPa. Usando la energía de fractura $G_{f}$ como criterio para evaluar la fisuración, es necesario ajustar la relación tensión-deformación del hormigón en tracción para así asegurar la misma disipación de energía. Mediante este parámetro, que es equivalente al área bajo la curva "tensión uniaxial de tracción-apertura de fisura" según el estudio de Bazant (Bazant, 1986), se puede ajustar el valor de la deformación última de tracción $\varepsilon_{u}$, más allá de la cual la capacidad resistente a tracción del hormigón es nula (Eq. 3-14):

$$
\varepsilon_{u}=\frac{2 G_{f}}{f_{c}^{\prime} w_{c}}
$$

donde $w_{c}$ es el ancho característico de las fisuras, en la región microfisurada. De acuerdo con Bazant (1986) y Oh (Oh, et al., 2006), el valor de $w_{c}$ puede estimarse como $3 d_{a}$, es decir, tres veces el tamaño máximo del árido $d_{a}$ utilizado en la dosificación del hormigón. Una vez que la deformación última ha sido determinada, es posible obtener el módulo de ablandamiento $E_{t}$ mediante la siguiente expresión:

$$
E_{t}=\frac{f_{t}^{\prime}}{\varepsilon_{u}-\varepsilon_{c r}}
$$

Tal y como indican Planas \& Elices (1985), es importante señalar que este modelo del material, al partir de la hipótesis de que fuera de la zona de fisuración el hormigón se comporta en régimen elástico y lineal, está suponiendo que no existe disipación de energía en aquellas zonas donde no se ha alcanzado el valor de $f_{t}^{\prime}$. 


\section{FASE I: DETERMINACIÓN DE TENSIONES RADIALES}

Tal y como indica (Sánchez Gálvez, 1999), un tubo, por la simetría cilíndrica que le caracteriza, es uno de los escasas situaciones en la que es posible la obtención de soluciones analíticas para estados de carga simple, tales como presión interior o distribución estacionaria de temperaturas. Si el tubo tiene pequeño espesor, las tensiones pueden suponerse constantes, despreciando los efectos de borde, lo que simplifica el proceso de obtención de la solución. Para tubos gruesos, ya no puede mantenerse la hipótesis de tensión radial nula, por lo que la determinación de tensiones es más compleja, pero puede simplificarse si se adoptan leyes de comportamiento del material sencillas. En este modelo, el estado tensional provocado por la presión interna uniforme derivada del aumento de volumen de los productos de corrosión y/o por el efecto Hoyer ha sido establecido gracias a la solución del cilindro de pared gruesa bajo presión interna uniforme derivada de la teoría de la elasticidad lineal para deformaciones planas (Timoshenko, 1956). Las primeras aplicaciones de esta solución a modelos para la determinación de tensiones en el hormigón fueron llevadas a cabo por Tepfers (1973) y Bazant (1979), tratando de predecir la fisuración del hormigón en secciones con tensiones radiales conocidas.

Una limitación importante de los modelos basados en los cilindros de pared gruesa es su incapacidad para tener en cuenta el comportamiento no lineal del hormigón, que toma relevancia con el comienzo de la fisuración radial a nivel de la interfaz acero-hormigón, cuando la presión interna debida a la corrosión o al efecto Hoyer alcanza un determinado valor. Tepfers (1973) superó esta limitación dividiendo el cilindro en dos regiones: una interna fisurada, y una externa sin fisurar. En la solución de Tepfers, en la región fisurada, la resistencia a tracción del hormigón en la dirección normal a las fisuras (circunferencial) se considera nula, por lo que únicamente es capaz de transferir tensiones radiales. En esta tesis, como se ha mostrado en el apartado anterior, se ha utilizado un modelo de fisuración cohesiva para la caracterización de la región fisurada, en el que se describe el progresivo fallo del hormigón (Pantazopoulou \& Papoulia, 2001).

\subsection{Tensiones radiales debidas al pretensado $\left[\sigma_{r, p}\right]$}

\subsubsection{Introducción}

En elementos pretensados de hormigón, cuando el alambre es liberado, la fuerza de pretensado se transfiere gradualmente al hormigón. El acero de pretensado trata de acortar su longitud e incrementar su diámetro debido al efecto Poisson, trayendo consigo un incremento de la presión sobre el hormigón circundante. Esta tensión radial $\sigma_{r, p}$, que actúa contra el acortamiento del alambre de pretensado y mantiene la barra en tracción, comienza con valores altos en el extremo de la pieza y va decreciendo a lo largo de toda la longitud de transferencia hasta alcanzar una zona de estabilización tras la misma. Este fenómeno es conocido como Efecto Hoyer, y mejora enormemente la adherencia entre el acero pretensado y el hormigón que lo rodea. Como resultado de este efecto, la tensión en el acero aumenta gradualmente hasta alcanzar un valor constante más allá de la longitud de transferencia. La distribución de las tensiones de compresión en el hormigón sigue un patrón similar al del acero, con un efecto adicional de deformabilidad por cortante ("shear lag effect"). 
El modelo de Tepfers (1973) no es directamente trasladable a la determinación de tensiones en pretensado, ya que no toma en consideración el coeficiente de Poisson $v_{\mathrm{c}}$ ni el deslizamiento $s$ de los alambres ni la influencia de la tensión de compresión longitudinal $\sigma_{z}$, todos factores de gran importancia, especialmente en la región de transferencia. El presente modelo, estableciendo las condiciones de equilibrio y compatibilidad necesarias e imponiendo las condiciones de contorno adecuadas en cada sucesivo segmento de la dirección longitudinal de la viga (Ver 3.8 Determinación de la longitud de transferencia [lt]), permite la evaluación de las tensiones radiales $\sigma_{r}$ y tangenciales $\tau_{b}$ a lo largo del alambre, teniendo en cuenta tanto el coeficiente de Poisson $v_{\mathrm{c}}$ como los deslizamientos $s$ en toda su longitud y la influencia de la tensión longitudinal $\sigma_{z}$ en las tensiones transversales.

Numerosos autores, como Benitez et al. (2011) y Abdelatif et al. (2015) han supuesto un comportamiento elástico e isotrópico del material a lo largo de todo el recubrimiento, por considerar despreciable la posible fisuración del hormigón en la dirección radial debida a la presión ejercida por el acero tras la transferencia del pretensado. Otros autores, como Oh et al. (2006) y Han et al. (2016), han implementado un modelo del hormigón como material anisótropo, teniendo en cuenta la fisuración radial del recubrimiento. En esta tesis se han contemplado ambos modelos, exponiéndose a continuación el procedimiento seguido para el desarrollo, por un lado, de un modelo analítico isotrópico elástico para hormigón sin fisurar, y por otro, de un modelo analítico anisótropo para hormigón con fisuración radial. La comparación entre los resultados de ambos modelos permitirá evaluar la influencia de la fisuración en el comportamiento adherente de estructuras pretensadas.

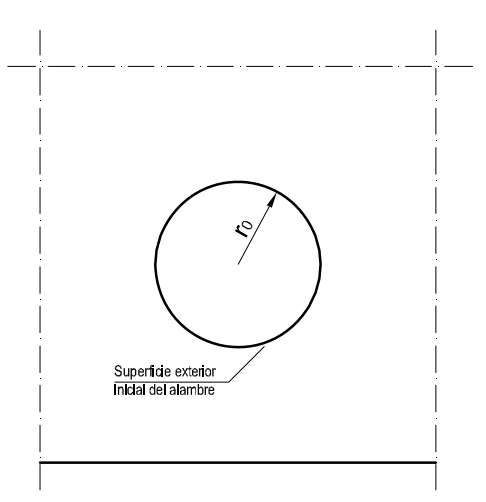

(a) Alambre previo al tesado, sin tensiones

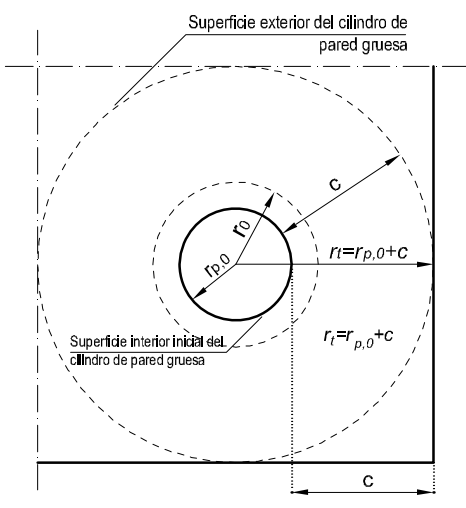

(b) Alambre tesado. Hormigón sin tensiones.

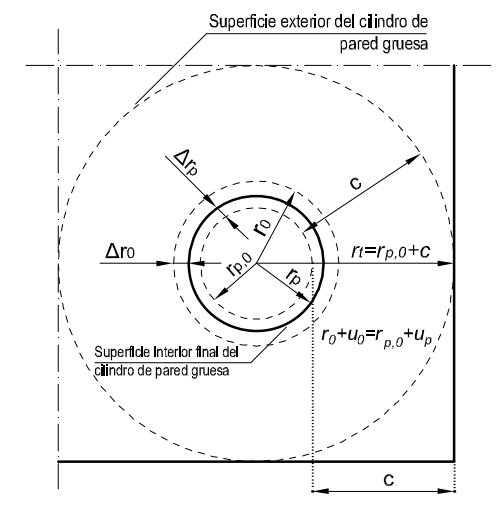

(c) Destesado. Situación de equilibrio

Figura 3-4 Descripción geométrica del problema. Radios iniciales y finales del acero y del cilindro de pared gruesa de hormigón

\subsubsection{Descripción geométrica del problema}

El acero se trata como a un cilindro sólido, cuyo radio original $r_{0}$ es igual al radio nominal del alambre no cargado (previo al pretensado) [Figura 3-4-a)]. Tras la aplicación de la fuerza de pretensado, el radio del acero disminuye hasta alcanzar un valor $r_{p, 0}$, que coincide con el radio de la pared interna del cilindro de hormigón, dado que el hormigón es vertido y endurece tras el tesado del alambre.

Considerando un espesor de recubrimiento geométrico del hormigón igual a $c$, el cilindro hueco de hormigón tiene un radio exterior igual a $r_{t}=r_{p, 0}+c$, medido desde el centro del alambre hasta el punto superficial más cercano del recubrimiento. Debido a la deformación transversal del alambre tesado, cuantificada mediante el coeficiente de Poisson $v_{s}, r_{p, 0}$ es siempre menor que $r_{0}$ [Figura 3-4 b)]. Una vez 
que se produce la transferencia del pretensado, tras el destesado, el acero se acorta, incrementando su sección transversal y ejerciendo una presión $p$ en la interfase acero-hormigón. El radio del acero resultante tras el destesado, que será menor que el nominal $r_{0}$ y mayor que el de el alambre tesado $r_{p, 0}$, se denomina $r_{p}$. El desplazamiento de la superficie del alambre de acero desde su situación original, con radio nominal $r_{0}$, hasta la situación de equilibrio tras el destesado, con radio $r_{p}$, es igual a $\Delta r_{0}$. Por su parte, el valor del desplazamiento de la cara interior del cilindro de hormigón, hasta alcanzar el equilibrio tras la liberación del alambre, es igual a $\Delta r_{p}$. Por lo tanto, debe cumplirse que $r_{p, 0}$ más $\Delta r_{p}$ es igual a $r_{0}$ menos $\Delta r_{0}[$ Figura $3-4$ c)].

\subsubsection{Modelo analítico isotrópico elástico para hormigón sin fisurar}

En este apartado se va a comprobar hasta qué punto es influyente el tipo de modelo del material seleccionado para la determinación del estado tensional del recubrimiento. Cómo se indicaba anteriormente, algunos de los autores que se han acercado a la modelización de las tensiones causadas en el recubrimiento de hormigón por el aumento de sección que experimenta el alambre tras su liberación, han decidido ignorar la posible fisuración derivada de las mismas, anteponiendo la manejabilidad del modelo a su precisión (Benitez et al. (2011) y Abdelatif et al. (2015)). Para ello, utilizan un modelo analítico isotrópico elástico para hormigón sin fisurar, en el que para determinar el estado tensional deben imponerse las condiciones de equilibrio y compatibilidad.

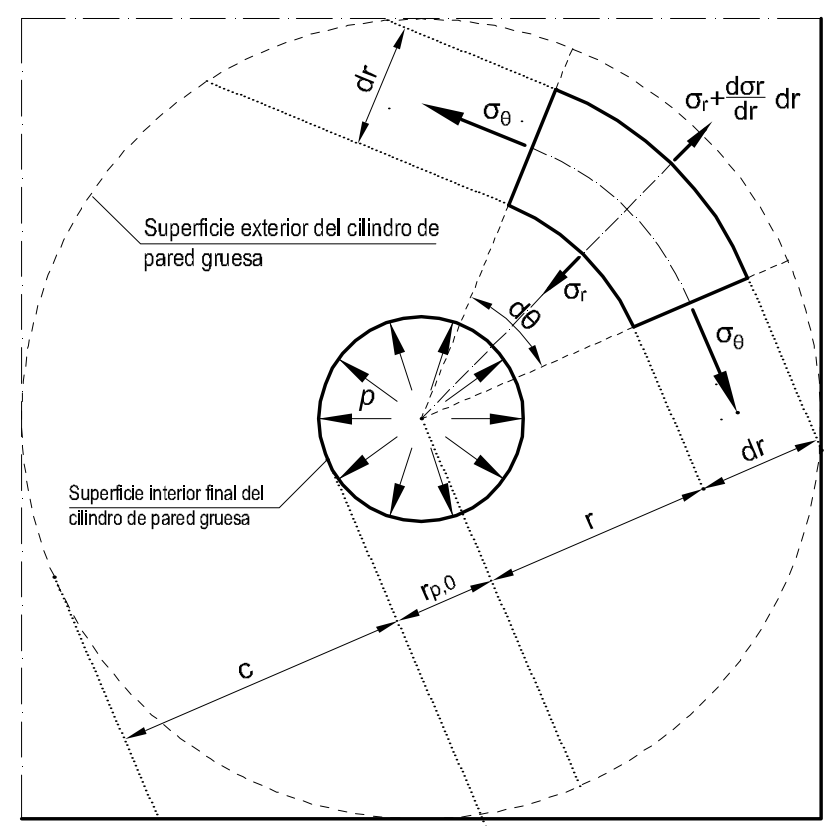

Figura 3-5 Elemento diferencial de espesor dry amplitud d $\theta$ en un cilindro de pared gruesa con presión interna $p$

\subsubsection{Ecuación de equilibrio}

Como se indicó anteriormente, en un cilindro hueco de pared gruesa las tensiones dejan de ser uniformes a lo largo del espesor, y su distribución, dada la simetría cilíndrica del problema, dependerá de la distancia $r$ del punto considerado al eje del cilindro. En un cilindro hueco de pared gruesa 
sometido a una presión interior $p$, las únicas tensiones no nulas serán la tensión radial $\sigma_{r}$, la tensión circunferencial $\sigma_{\theta}$ y la tensión longitudinal $\sigma_{z}$ (Figura 3-5).
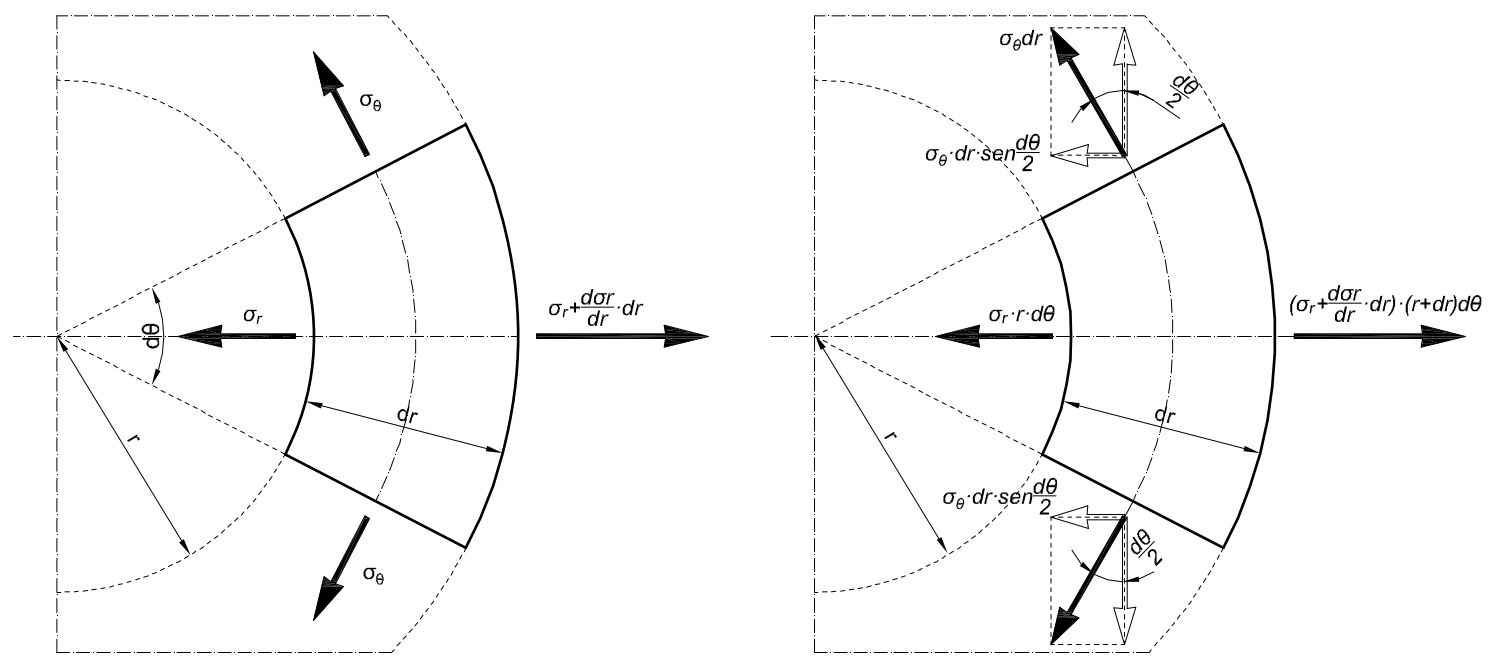

Figura 3-6 Equilibrio de fuerzas en elemento diferencial perteneciente a un cilindro de pared gruesa

Tomando un elemento diferencial $d r d \theta$ de una rebanada de espesor $d \%$, tal y como muestra la Figura 3-6, se impone el equilibrio de fuerzas en la dirección radial $r$ (Eq. 3-16):

$$
\sum F=0 \quad\left(\sigma_{r}+\frac{d \sigma_{r}}{d r} d r\right)(r+d r) d \theta d z-\sigma_{r} r d \theta d z-2 \sigma_{\theta} \operatorname{sen}\left(\frac{d \theta}{2}\right) d r d z=0
$$

Dado que $d \theta$ es muy pequeño, se puede aceptar la siguiente simplificación (Eq. 3-17):

$$
\operatorname{sen}\left(\frac{d \theta}{2}\right)=\frac{d \theta}{2}
$$

Y sustituyendo, la ecuación de equilibrio quedará como sigue (Eq. 3-18):

$$
\left(\sigma_{r} r+\frac{d \sigma_{r}}{d r} d r \cdot r+d r \sigma_{r}+d r \frac{d \sigma_{r}}{d r} d r\right) d \theta d z-\sigma_{r} r d \theta d z-\sigma_{\theta} d \theta d r d z=0
$$

A continuación, se saca factor común a $d \theta d z$ (Eq. 3-19):

$$
\left(\frac{d \sigma_{r}}{d r} d r \cdot r+d r \sigma_{r}+\frac{d \sigma_{r}}{d r} d r d r-\sigma_{\theta} d r\right) d \theta d z=0
$$

Y finalmente, se desprecian los infinitésimos de segundo orden y se opera hasta obtener la expresión del equilibrio de tensiones en la dirección radial $r$ (Eq. 3-20):

$$
\sigma_{r}+\frac{d \sigma_{r}}{d r} \cdot r-\sigma_{\theta}=0
$$


Cabe destacar que la relación anterior (Eq. 3-20), deducida a partir del equilibrio de fuerzas en la dirección $r$, es válida tanto si el cilindro se encuentra en régimen elástico como si se halla en régimen plástico. Sin embargo, para continuar con la resolución del problema y determinar la distribución de las tensiones radiales $\sigma_{r}$ y de las tensiones circunferenciales $\sigma_{\theta}$, es necesario recurrir a las ecuaciones constitutivas del material, que difieren en función del modelo del material por el que se haya optado.

\subsubsection{Ecuación de compatibilidad}

Una vez que se ha producido la transferencia del pretensado y se ha alcanzado la situación de equilibrio de fuerzas (Figura 3-6), debe imponerse la condición de compatibilidad de deformaciones en la superficie de contacto entre el hormigón y el acero, con lo que debe cumplirse que la deformación radial del radio exterior del alambre debe ser igual a la deformación radial del radio interior del hormigón (Eq. 3-21), tal y como puede apreciarse en la Figura 3-4:

$$
r_{0}-\Delta r_{0}=r_{p, 0}+\Delta r_{p}
$$

donde:
ro Radio inicial del acero, previo al pretensado
$\Delta r_{0} \quad$ Desplazamiento de radio exterior del alambre tras el destesado, con respecto a su radio inicial ro
$r_{p, 0} \quad$ Radio interno del hormigón, previo a la transferencia, equivalente al radio del acero pretensado.
$\Delta r_{p} \quad$ Desplazamiento de la pared interna del cilindro de hormigón tras la transferencia

\subsubsection{Obtención de las tensiones radiales y circunferenciales}

En la (Eq. 3-21) existen dos incógnitas, el desplazamiento de radio exterior del alambre tras el destesado $\Delta r_{0}$, con respecto a su radio inicial $r_{0}$, y el desplazamiento de la pared interna del cilindro de hormigón tras la transferencia $\Delta r_{p}$, por lo que es necesario plantear una ecuación adicional basada en las deformaciones para simplificar y posibilitar la resolución del problema. Para determinar las deformaciones radiales $\varepsilon_{r}$ y circunferenciales $\varepsilon_{\theta}$, se considera el vector de desplazamientos $u_{r}$ en la dirección radial $r$, donde el desplazamiento a nivel de la interfaz acero-hormigón es $u$, cuyo valor es equivalente a $\Delta r_{p}$.

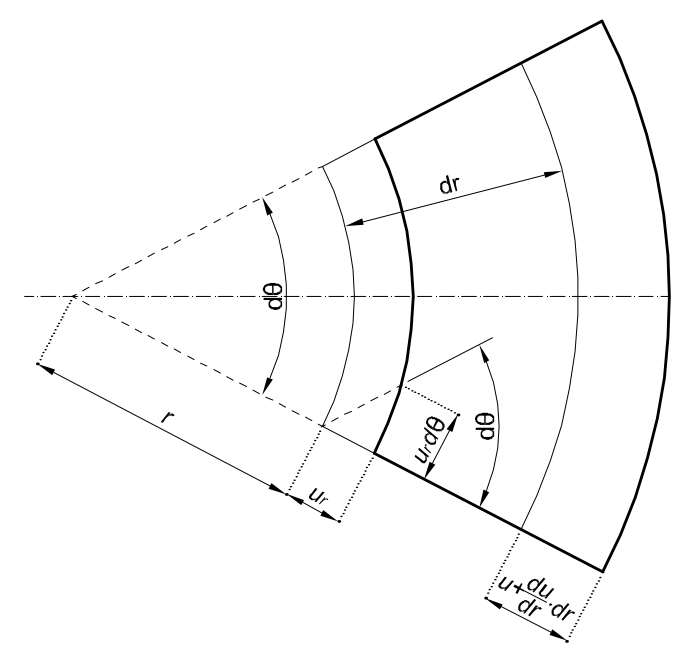

Figura 3-7 Deformaciones radiales y circunferenciales del elemento diferencial considerado 
De la interpretación de la Figura 3-7 se obtiene que la deformación en la dirección radial $\varepsilon_{r}$ vendrá expresada por (Eq. 3-22):

$$
\varepsilon_{r}=\frac{u+\frac{d u}{d r} d r-u}{d r}=\frac{d u}{d r}
$$

Mientras que la deformación en la dirección circunferencial $\varepsilon_{\theta}$ vendrá dada por (Eq.3-23):

$$
\varepsilon_{\theta}=\frac{u d \theta}{r d \theta}=\frac{u}{r}
$$

Por otro lado, y tal y como se indicó anteriormente, para la resolución del problema es necesario recurrir a las ecuaciones constitutivas del material. En este caso, se considerará un material isotrópico y homogéneo, en régimen elástico, por lo que son de aplicación las ecuaciones de la Ley de Hooke (Eq. 3-24):

$$
\left\{\begin{array}{c}
\varepsilon_{r} \\
\varepsilon_{\theta} \\
\varepsilon_{z}
\end{array}\right\}=\frac{1}{E_{c}}\left[\begin{array}{ccc}
1 & -v_{c} & -v_{c} \\
-v_{c} & 1 & -v_{c} \\
-v_{c} & -v_{c} & 1
\end{array}\right]\left\{\begin{array}{c}
\sigma_{r} \\
\sigma_{\theta} \\
\sigma_{z}
\end{array}\right\}
$$

donde:
$\sigma_{r, \theta, z} \quad$ Tensiones en las direcciones principales del elemento diferencial
$\varepsilon_{r, \theta, z} \quad$ Deformaciones en las direcciones principales del elemento diferencial
$E_{c} \quad$ Módulo de Young del hormigón sin fisurar, considerado como un material isótropo y homogéneo.
u. Coeficiente de Poisson del hormigón sin fisurar, considerado como un material isótropo y homogéneo.

Del sistema de ecuaciones tensión-deformación del elemento (Eq. 3-24) pueden despejarse las tensiones en la dirección radial $\sigma_{r}$ y circunferencial $\sigma_{\theta}$, obteniéndose las siguientes expresiones [(Eq. 3-25) y (Eq. 3-26)]:

$$
\begin{gathered}
\sigma_{r}=\frac{E}{1-v^{2}}\left(\varepsilon_{r}+v \varepsilon_{\theta}\right)+\frac{v(1+v) \sigma_{z}}{1-v^{2}} \\
\sigma_{\theta}=\frac{E}{1-v^{2}}\left(\varepsilon_{\theta}+v \varepsilon_{r}\right)+\frac{v(1+v) \sigma_{z}}{1-v^{2}}
\end{gathered}
$$

Sustituyendo estas ecuaciones en la expresión de equilibrio de tensiones establecida anteriormente (Eq. 3-20) y conociendo las relaciones desplazamiento-deformación $u-\varepsilon$, (Eq. 3-22) y (Eq. 3-23), se obtiene la siguiente ecuación equidimensional (Ecuación de Cauchy-Euler) en desplazamiento radial (Eq. 3-27):

$$
r \frac{d^{2} u}{d^{2}}+\frac{d u}{d r}-\frac{u}{r}=0
$$


Como puede observarse, el problema se ha simplificado considerablemente y la resolución de la ecuación diferencial permite determinar el desplazamiento $u$, y a través de éste, las deformaciones $\varepsilon$ y las tensiones $\sigma$ en el elemento. La solución general de la ecuación diferencial anterior (Eq. 3-27) se expresa como sigue (Eq. 3-28):

$$
u=c_{1} r+\frac{c_{2}}{r}
$$

donde $c_{1}$ y $c_{2}$ son constantes de integración que deben ser determinadas mediante las condiciones de contorno que se impongan. Sustituyendo la ecuación (Eq. 3-28) en las expresiones que relacionan desplazamientos $u$ y deformaciones $\varepsilon,(E q$. 3-22) y (Eq. 3-23), se obtienen las siguientes igualdades:

$$
\begin{gathered}
\varepsilon_{r}=\frac{d u}{d r}=c_{1}-\frac{c_{2}}{r^{2}} \\
\varepsilon_{\theta}=\frac{u}{r}=c_{1}+\frac{c_{2}}{r^{2}}
\end{gathered}
$$

Las tensiones radiales $\sigma_{r}$ y circunferenciales $\sigma_{\theta}[(E q$. 3-25) y (Eq. 3-26)], pueden ahora escribirse en función de las constantes de integración $c_{1}$ y $c_{2}$, quedando como sigue (Eq. 3-31) y (Eq. 3-32):

$$
\begin{gathered}
\sigma_{r}=E\left[\frac{c_{1}}{1-v}-\frac{c_{2}}{r^{2}(1+v)}\right]+\frac{v \sigma_{z}}{1-v} \\
\sigma_{\theta}=E\left[\frac{c_{1}}{1-v}+\frac{c_{2}}{r^{2}(1+v)}\right]+\frac{v \sigma_{z}}{1-v}
\end{gathered}
$$

Tal y como indican (Oh, et al., 2006), las constantes de integración $c_{1}$ y $c_{2}$ pueden ser determinadas usando las condiciones de contorno que describen, por un lado, el estado tensional del cilindro sólido de acero con el que se modeliza el alambre (Caso 1), y por otro, el estado tensional del cilindro hueco de hormigón con el que se modeliza el recubrimiento (Caso 2). Para cada uno de estos casos se han determinado las tensiones radiales $\sigma_{r}(r)$ y circunferenciales $\sigma_{\theta}(r)$, así como el desplazamiento $u(r)$ para cada distancia radial $r$, lo que a su vez permite conocer el valor de las dos incógnitas de la ecuación de compatibilidad de deformaciones (Eq. 3-21), es decir, el desplazamiento de radio exterior del alambre tras el destesado $\Delta r_{0}$, con respecto a su radio inicial $r_{0}$, y el desplazamiento de la pared interna del cilindro de hormigón $\Delta r_{p}$ tras la transferencia del pretensado.

\section{Caso 1: Cilindro sólido de acero}

Las condiciones de contorno para este caso son las siguientes: $u=0$ en $r=0$, es decir, el desplazamiento es nulo en el centro del cilindro sólido de acero. Como consecuencia de esta condición, la constante $c_{2}$, en la ecuación (Eq. 3-28), debe tener un valor nulo, por lo que las ecuaciones (Eq. 3-31) y (Eq. 3-32) adoptan un mismo valor, quedando simplificadas a la siguiente expresión (Eq.3-33): 


$$
\sigma_{r}(r)=\sigma_{\theta}(r)=\frac{\left(E_{s} c_{1}+v_{s} \sigma_{z}\right)}{\left(1-v_{s}\right)}
$$

Como puede observarse, esta ecuación es independiente de la distancia radial $r$. Por lo tanto, igualando $\sigma_{r}=\sigma_{\theta}=f_{r}$ en $r=\mathrm{R}$, donde $f_{r}$ es la tensión radial debida al pretensado y $\mathrm{R}$ es la distancia radial al extremo interior de la sección elástica sin fisurar, la ecuación (Eq. 3-28) es transformada al sustituir el valor de $c_{1}$, despejado de la expresión (Eq. 3-33). Como resultado, se obtiene la siguiente expresión del desplazamiento radial $u(r)$, en función de la posición radial $r$ del punto considerado (Eq. 3-34):

$$
u(r)=\left[\frac{f_{r}\left(1-v_{s}\right)-v_{s} \sigma_{z}}{E_{s}}\right] r
$$

Donde:

$\begin{array}{ll}u(r) & \text { Desplazamiento radial para la distancia radial r considerada } \\ f_{r} & \text { Tensiones en la dirección radial } \\ v_{S} & \text { Coeficiente de Poisson del acero } \\ E_{s} & \text { Modulo de elasticidad del acero } \\ \sigma_{z} & \text { Tensión normal en la dirección longitudinal del acero } \\ r & \text { Distancia radial al punto considerado }\end{array}$

Como puede deducirse, en el caso del modelo analítico isotrópico elástico para hormigón sin fisurar, $R$ será igual a $r_{0}$, es decir, el radio del acero previo al pretensado, $f_{r}$ será equivalente a la presión interna - $p$ debida a la expansión del alambre tras la transferencia de la fuerza de pretensado y $\sigma_{z}$ adoptará un valor $f_{p z}$, igual a la tensión normal del acero debida al pretensado, a una distancia $z$ del extremo libre. Por tanto, el valor del desplazamiento del radio exterior del alambre $\Delta r_{0}$ tras el destesado, con respecto a su radio inicial $r_{0}$, puede ser escrito de la siguiente forma (Eq. 3-35)(Figura 3-4):

$$
\Delta r_{0}=\left[\frac{-p\left(1-v_{s}\right)-v_{s} f_{p z}}{E_{s}}\right] r_{0}
$$

\section{Caso 2: Cilindro bueco de hormigón}

Las condiciones de contorno para el cilindro hueco de hormigón son las siguientes $\sigma_{r}=f_{r}$ en $r=\mathrm{R}$ (donde $f_{r}$ es la tensión radial debida al pretensado y $R$ es la distancia radial al extremo interior de la sección elástica sin fisurar) y $\sigma_{r}=0$ en $r=r_{t}$ (siendo $r_{t}$ el radio desde el centro del alambre hasta la cara exterior del hormigón). Imponiendo dichas condiciones en (Eq. 3-31) se despeja el valor de las constantes de integración $c_{1}$ y $c_{2}$ y sustituyendo en (Eq. 3-28), (Eq. 3-31), (Eq. 3-32) se obtienen las siguientes expresiones para las tensiones radiales $\sigma_{r}(r)\left(\mathrm{Eq}\right.$. 3-36) y circunferenciales $\sigma_{\theta}(r)$ (Eq. 3-37), así como para el desplazamiento $u(r)$ (Eq. 3-38), todas en función de la distancia radial $r$. 
TESIS DOCTORAL INFLUENCLA DE LA CORROSIÓN EN LA ADHERENCLA DE ALAMBRES EN ELEMENTOS PRETENSADOS DE HORMIGÓN

$$
\begin{gathered}
\sigma_{r}(r)=\frac{f_{r}\left(\frac{1}{r_{t}{ }^{2}}-\frac{1}{r^{2}}\right)}{\left(\frac{1}{r_{t}{ }^{2}}-\frac{1}{R^{2}}\right)} \\
\sigma_{\theta}(r)=\frac{f_{r}\left(\frac{1}{r_{t}^{2}}+\frac{1}{r^{2}}\right)}{\left(\frac{1}{r_{t}{ }^{2}}-\frac{1}{R^{2}}\right)} \\
u(r)=\frac{f_{r} r}{E_{s}\left(\frac{1}{r_{t}{ }^{2}}-\frac{1}{R^{2}}\right)}\left[\frac{(1-v)}{r_{t}{ }^{2}}+\frac{(1+v)}{r^{2}}\right]-\frac{v \sigma_{z} r}{E}
\end{gathered}
$$

Para el cilindro hueco de hormigón, el radio interior $r_{p, 0}$ viene determinado por el radio reducido del alambre de pretensado, previo al destesado, y puede ser calculado multiplicando la deformación longitudinal del alambre por su coeficiente de Poisson $u_{p}$, tal y como sigue (Eq. 3-39):

$$
r_{p, 0}=\left(1-\frac{\sigma_{p, 0}}{E_{p}} v_{p}\right) r_{0}
$$

donde:

$\sigma_{p, 0} \quad$ Tensión inicial del alambre, previa al destesado.

Por otra parte, el valor de la tensión longitudinal del hormigón $f_{c \text { c }}$ en un punto dado del elemento depende de la tensión longitudinal del alambre $f_{p z}$ en dicho punto, y puede calcularse como sigue (Eq. 3-40):

$$
f_{c Z}=f_{p z} A_{p}\left(\frac{1}{A_{c}}+\frac{e}{I_{c}} y\right)
$$

donde:
$A_{p} \quad$ Area de la sección transversal del alambre de pretensado
$A_{c} \quad$ Area bruta de la sección transversal de hormigón
Ic Momento de inercia de la sección bruta de hormigón
e $\quad$ Excentricidad del alambre de pretensado con respecto al centroide de la sección de hormigón.

Conocido el radio interior del cilindro de hormigón $r_{p, 0}$ y el valor de la tensión longitudinal en el hormigón $f_{c z}$ a una distancia $z$ del extremo libre, el desplazamiento en la superficie interior $\Delta r_{p}$, procedente de la ecuación (Eq. 3-38), viene dado por la siguiente expresión (Eq. 3-41): 


$$
\Delta r_{p}=\frac{-p r_{p, 0}}{E_{c}\left(\frac{1}{r_{t}{ }^{2}}-\frac{1}{r_{p, 0}{ }^{2}}\right)}\left[\frac{\left(1-v_{c}\right)}{r_{t}^{2}}+\frac{\left(1+v_{c}\right)}{r_{p, 0}{ }^{2}}\right]-\frac{v_{c} f_{c z} r_{p, 0}}{E_{c}}
$$

donde:

\section{$v_{c} \quad$ Coeficiente de Poisson del hormigón \\ $E_{c} \quad$ Módulo de elasticidad del hormigón}

Por tanto, conocido el valor de las dos incógnitas de la ecuación de compatibilidad de deformaciones (Eq. 3-21), es decir, el desplazamiento de radio exterior del alambre tras el destesado $\Delta r_{0}$, con respecto a su radio inicial $r_{0}$, y el desplazamiento de la pared interna del cilindro de hormigón $\Delta r_{p}$ tras la transferencia del pretensado, puede despejarse el valor de la presión $p$ ejercida en la interfase acerohormigón (Eq. 3-42):

$$
p=\frac{r_{0}\left(1-\frac{v_{p} f_{p z}}{E_{p}}\right)-r_{p, 0}\left(1-\frac{v_{c} f_{c z}}{E_{c}}\right)}{\left(1-v_{p}\right) \frac{r_{0}}{E_{p}}+\left[v_{c}-\frac{r_{p, 0}{ }^{2}+r_{t}^{2}}{r_{p, 0}^{2}-r_{t}^{2}}\right] \frac{r_{p, 0}}{E_{c}}}
$$

Finalmente, conocido el valor de la presión interna $p$, las tensiones radiales $\sigma_{r}$ y circunferenciales $\sigma_{\theta}$ a una distancia radial $r$, suponiendo un modelo isotrópico elástico para hormigón sin fisurar, pueden ser expresadas como sigue (Eq. 3-43) y (Eq. 3-44):

$$
\begin{gathered}
\sigma_{r}(r)=\frac{-p\left(\frac{1}{r_{t}{ }^{2}}-\frac{1}{r^{2}}\right)}{\left(\frac{1}{r_{t}{ }^{2}}-\frac{1}{r_{p, 0}{ }^{2}}\right)} \\
\sigma_{\theta}(r)=\frac{-p\left(\frac{1}{r_{t}{ }^{2}}+\frac{1}{r^{2}}\right)}{\left(\frac{1}{r_{t}{ }^{2}}-\frac{1}{r_{p, 0}{ }^{2}}\right)}
\end{gathered}
$$

En la Figura 3-8 se representan las tensiones radiales $\sigma_{r}(r)$ y circunferenciales $\sigma_{\theta}(r)$ calculadas en el extremo libre de una hipotética viga pretensada tras el destasado. El alambre, que ha sido tesado con una tensión inicial $f_{p, 0}$ de $1200 \mathrm{MPa}$, tiene un radio nominal $r_{0}$ de $2,5 \mathrm{~mm}$, mientras que el recubrimiento mecánico $r_{t}$ es igual a $20 \mathrm{~mm}$. Sin entrar en mayores consideraciones teóricas, para el caso de un hipotético hormigón cuya resistencia media a compresión $f_{\text {cm }}$ fuera $30 \mathrm{MPa}$ y su resistencia media a tracción $f_{c t, m}$ fuera de $3 \mathrm{MPa}$, en la Figura 3-8 se aprecia que para distancias radiales $\mathrm{r}$ menores a 9,5 $\mathrm{mm}$ la tensión circunferencial $\sigma_{\theta}$ supera el valor de $f_{c t, m}$ del hormigón, por lo que a partir de ese punto la sección se encontraría fisurada. Por otro lado, las tensiones radiales en las cercanías de la interfaz acero/hormigón alcanzan un valor que agotaría la capacidad resistente del hormigón, al superar su resistencia media a compresión $f_{c m}$. 


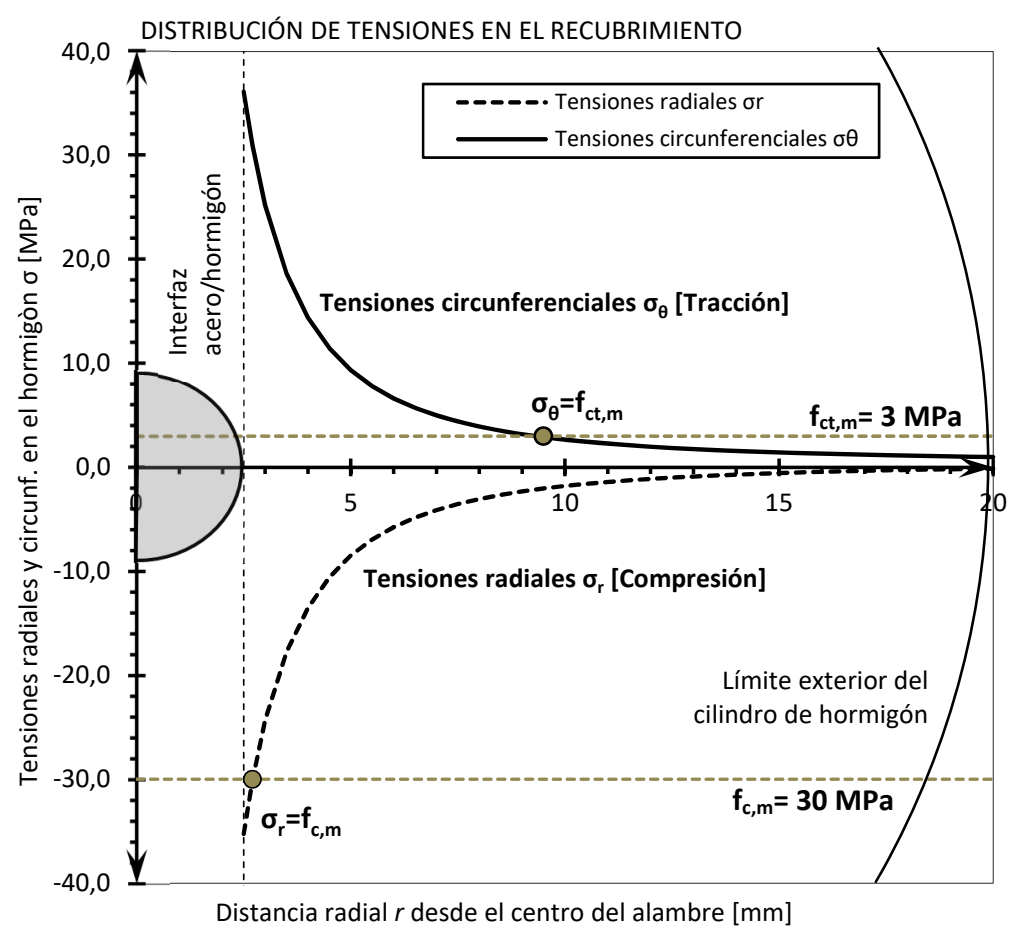

Figura 3-8 Tensiones radiales y circunferenciales en el cilindro de pared gruesa/ recubrimiento de hormigón. Comparación con las resistencias medias a tracción y compresión del hormigón.

Este simple ejercicio teórico refleja el principal problema del modelo elástico isotrópico, es decir, su incapacidad para tener en cuenta el comportamiento no lineal del hormigón, que tiene lugar cuando comienza la aparición de fisuras radiales en la superficie interior del cilindro. Por tanto, el modelo isotrópico elástico para hormigón nos permite conocer el estado tensional en recubrimientos no fisurados o en las regiones de éste que no han superado la resistencia a tracción, pero para una representación más ajustada del proceso real, en la que se recoja el cambio de rigidez del hormigón con el paulatino aumento de las tensiones, es necesario recurrir a un modelo anisótropo para hormigón con fisuración radial.

\subsubsection{Modelo analítico anisótropo para hormigón con fisuración radial}

Como se comentaba en el comienzo de este apartado (3.3 Tensiones radiales debidas al pretensado $\left[\boldsymbol{\sigma}_{\boldsymbol{r}, \boldsymbol{p}}\right]$ ), para considerar la posible fisuración del hormigón en la dirección radial debida a la presión ejercida por el acero tras la transferencia del pretensado, algunos autores, como Oh (Oh, et al., 2006) y (Han, et al., 2016) han implementado un modelo del hormigón como material anisótropo, teniendo en cuenta la fisuración radial del recubrimiento. En las siguientes páginas se expone el soporte teórico sobre el que se sustenta el modelo analítico para la determinación de tensiones derivadas del pretensado en un cilindro anisótropo de pared gruesa, con fisuración radial, en el que han aceptado las siguientes hipótesis:

- Aunque el problema real es tridimensional, en aras de la simplicidad y la eficiencia computacional, la determinación de tensiones radiales a lo largo de la viga se ha modelado 
como una sucesión de problemas bidimensional resueltos para cada sección considerada en la tercera dimensión.

- La fisuración en el recubrimiento del hormigón se ha considerado de carácter cohesivo, describiendo su progresivo fallo. Por tanto, el hormigón fisurado tendrá cierta capacidad resistente residual a pesar de haberse superado su resistencia media a tracción.

- Se impone la condición de axilsimetría, lo que implica que las fisuras se propagan en todas las direcciones hasta la misma distancia radial $\mathrm{r}$ y la fisuración se considera uniformemente repartida, por lo que la formulación está escrita en términos de tensiones y deformaciones medias.

- Las propiedades mecánicas del hormigón tales como su módulo de elasticidad o su resistencia a tracción se mantienen inalteradas por la edad de éste, considerándolo como un fenómeno independiente del tiempo. Por el contrario, la rigidez del hormigón varía gradualmente en función de las deformaciones radiales y circunferenciales.

- El desplazamiento $u_{p}$ del límite interior del cilindro de pared gruesa, obtenido en régimen elástico y que permite albergar la expansión del acero tras el destesado, se impone como condición previa de contorno. Con este acercamiento, la evolución de la presión interna $p$ en la interfase acero-hormigón pasa a ser una consecuencia de las condiciones impuestas, más que el parámetro controlante del proceso.

Tal y como se expuso en la descripción del modelo isótropo elástico, las relaciones deducidas a partir del equilibrio de fuerzas y de la compatibilidad de deformaciones son válidas independientemente del modelo del material utilizado, procediendo las diferencias de las ecuaciones constitutivas del material considerado.

\subsubsection{Formulación de la ecuación diferencial}

Para el análisis anisótropo del hormigón con fisuración radial, las ecuaciones constitutivas son diferentes a las vistas en 3.3.3 Modelo analítico isotrópico elástico para hormigón sin fisurar, incluso a pesar de que las ecuaciones de equilibrio y de compatibilidad deformación-desplazamiento son idénticas. Las relaciones constitutivas del hormigón, basadas en la Ley Generalizada de Hook para el caso de anisotropía cilíndrica, pueden ser escritas como sigue (Eq. 3-45):

$$
\left\{\begin{array}{c}
\varepsilon_{r} \\
\varepsilon_{\theta} \\
\varepsilon_{z}
\end{array}\right\}=\left[\begin{array}{ccc}
1 / E_{r} & -v_{\theta r} / E_{\theta} & -v_{z r} / E_{z} \\
-v_{r \theta} / E_{r} & 1 / E_{\theta} & -v_{z} / E_{z} \\
-v_{r z} / E_{r} & -v_{\theta z} / E_{\theta} & 1 / E_{z}
\end{array}\right]\left\{\begin{array}{c}
\sigma_{r} \\
\sigma_{\theta} \\
\sigma_{z}
\end{array}\right\}
$$

donde:

$$
\begin{array}{ll}
\varepsilon_{X}, \sigma_{X} & \text { Deformaciones y tensiones del cilindro en las coordenadas cilindricas } r, \theta y z \\
E_{X} & \text { Módulos de Young del hormigón en las coordenadas cilindricas } r, \theta y z \\
v_{X Y} & \text { Coeficientes de Poisson en las diferentes coordenadas cilindricas } r, \theta y z
\end{array}
$$


Por otro lado, para materiales con fisuración radial, y considerando que en la dirección z (la dirección longitudinal de la viga) el hormigón trabaja en la región elástica, las propiedades del material se reducen a las siguientes (Eq. 3-46) y (Eq. 3-47):

$$
\begin{gathered}
E_{z}=E_{c}, \quad E_{r}=g(r), \quad E_{\theta}=h(r) \\
v_{z \theta}=v_{z r}=v_{c} \\
E_{r} v_{\theta r}=E_{\theta} v_{r \theta} \quad E_{z} v_{\theta z}=E_{\theta} v_{z \theta}=E_{\theta} v_{c} \quad E_{z} v_{r z}=E_{r} v_{z r}=E_{r} v_{c}
\end{gathered}
$$

donde $E_{c}$ y $v_{c}$ son el módulo de elasticidad y el coeficiente de Poisson del hormigón en régimen elástico, respectivamente. Operando sobre el sistema, se obtienen las tensiones radiales $\sigma_{r} \mathrm{y}$ circunferenciales $\sigma_{\theta}$, en función de la tensión normal en la dirección longitudinal $\sigma_{z}$, quedando como sigue (Eq. 3-48) y (Eq. 349):

$$
\begin{gathered}
\sigma_{r}=\frac{1}{1-v_{r \theta} v_{\theta r}}\left(E_{r} \varepsilon_{r}+v_{r \theta} E_{\theta} \varepsilon_{\theta}\right)+\frac{v_{r \theta} v_{\theta z}+v_{r z}}{1-v_{r \theta} v_{\theta r}} \sigma_{z} \\
\sigma_{\theta}=\frac{1}{1-v_{r \theta} v_{\theta r}}\left(E_{\theta} \varepsilon_{\theta}+v_{\theta r} E_{r} \varepsilon_{r}\right)+\frac{v_{\theta r} v_{r z}+v_{\theta z}}{1-v_{r \theta} v_{\theta r}} \sigma_{z}
\end{gathered}
$$

Sustituyendo las ecuaciones (Eq. 3-22) y (Eq. 3-23) en las ecuaciones (Eq. 3-48) y (Eq. 3-49) se obtienen las siguientes ecuaciones, (Eq. 3-50) y (Eq. 3-51):

$$
\begin{aligned}
& \sigma_{r}=\frac{1}{1-v_{r \theta} v_{\theta r}}\left(E_{r} \frac{d u_{r}}{d r}+v_{r \theta} E_{\theta} \frac{u_{r}}{r}\right)+\frac{v_{r \theta} v_{\theta z}+v_{r z}}{1-v_{r \theta} v_{\theta r}} \sigma_{z} \\
& \sigma_{\theta}=\frac{1}{1-v_{r \theta} v_{\theta r}}\left(E_{\theta} \frac{u_{r}}{r}+v_{\theta r} E_{r} \frac{d u_{r}}{d r}\right)+\frac{v_{\theta r} v_{r z}+v_{\theta z}}{1-v_{r \theta} v_{\theta r}} \sigma_{z}
\end{aligned}
$$

Y teniendo en cuenta que en la dirección z el hormigón trabaja en la región elástica, (Eq. 3-46) y (Eq. 3-47), se obtiene las siguientes expresiones para describir la tensión radial (Eq. 3-52) y circunferencial (Eq. 3-53):

$$
\begin{aligned}
& \sigma_{r}=\frac{1}{1-v_{r \theta} v_{\theta r}}\left(E_{r} \frac{d u_{r}}{d r}+v_{r \theta} E_{\theta} \frac{u_{r}}{r}\right)+\frac{1}{1-v_{r \theta} v_{\theta r}}\left(E_{r}+v_{r \theta} E_{\theta}\right) \frac{v_{c}}{E_{c}} \sigma_{z} \\
& \sigma_{\theta}=\frac{1}{1-v_{r \theta} v_{\theta r}}\left(E_{\theta} \frac{u_{r}}{r}+v_{\theta r} E_{r} \frac{d u_{r}}{d r}\right)+\frac{1}{1-v_{r \theta} v_{\theta r}}\left(E_{\theta}+v_{\theta r} E_{r}\right) \frac{v_{c}}{E_{c}} \sigma_{z}
\end{aligned}
$$


donde $\sigma_{z}=0$ para el caso de tensión plana, $\sigma_{z}=v_{z r} \sigma_{r}+v_{z \theta} \sigma_{\theta}$ para el caso de deformación plana. La tensión longitudinal $\sigma_{z}$ puede ser conocida por las condiciones de carga del cilindro, caso habitual en los elementos pretensados. En el modelo, la tensión en la dirección longitudinal irá variando a lo largo de la longitud $₹$ dependiendo de factores tales como la tensión de pretensado inicial $\sigma_{p, 0}$ y el coeficiente de fricción $\mu$, incrementándose a lo largo de toda la longitud de transferencia $l_{t} \mathrm{y}$ estabilizándose una vez superada la misma.

Sustituyendo las ecuaciones anteriores (Eq. 3-52) y (Eq. 3-53) en la expresión del equilibrio de tensiones en la dirección $r$ (Eq. 3-20) se obtiene la siguiente ecuación diferencial no-lineal y nohomogénea que gobierna el problema (Eq. 3-54):

$$
\begin{aligned}
\frac{1}{1-v_{r \theta} v_{\theta r}}\left(E_{r} \frac{d u_{r}}{d r}\right. & \left.+v_{r \theta} E_{\theta} \frac{u_{r}}{r}\right)+\frac{1}{1-v_{r \theta} v_{\theta r}}\left(E_{r}+v_{r \theta} E_{\theta}\right) \frac{v_{c}}{E_{c}} \sigma_{z} \\
& +\frac{1}{1-v_{r \theta} v_{\theta r}}\left(E_{r} \frac{d^{2} u_{r}}{d r^{2}} r+v_{r \theta} E_{\theta} \frac{d u_{r}}{d r}-v_{r \theta} E_{\theta} \frac{u_{r}}{r}\right) \\
& -\frac{1}{1-v_{r \theta} v_{\theta r}}\left(E_{\theta} \frac{u_{r}}{r}+v_{\theta r} E_{r} \frac{d u_{r}}{d r}\right)-\frac{1}{1-v_{r \theta} v_{\theta r}}\left(E_{\theta}+v_{\theta r} E_{r}\right) \frac{v_{c}}{E_{c}} \sigma_{z}=0
\end{aligned}
$$

Y operando sobre la anterior expresión (Eq. 3-54), se simplifica hasta alcanzar la siguiente ecuación diferencial (Eq. 3-55):

$$
\frac{d^{2} u_{r}}{d r^{2}}+\frac{d u_{r}}{d r} \frac{1}{r}-\frac{E_{\theta}}{E_{r}} \frac{u_{r}}{r^{2}}+\frac{\left[E_{\theta}\left(v_{r \theta}-1\right)-E_{r}\left(v_{\theta r}-1\right)\right] v_{c}}{E_{c} E_{r}} \frac{1}{r} \sigma_{z}=0
$$

La ecuación (Eq. 3-55) es una ecuación diferencial lineal de segundo orden que describe el desplazamiento radial $u_{r}$ del recubrimiento de hormigón para cada distancia radial $r$. Las condiciones de contorno para el problema son las siguientes:

- El desplazamiento radial $u_{r}$ impuesto en el contorno interior del cilindro de hormigón de pared gruesa, $r=r_{p, 0}$, es igual a $r_{p}-r_{p, 0}=\Delta r_{p}$, calculado en régimen elástico (Eq. 3-56):

$$
\left.u\right|_{r=r_{p, 0}}=r_{p}-r_{p, 0}=\Delta r_{p}
$$

- La tensión radial $\sigma_{r}$ en la superficie exterior del cilindro de hormigón, $r=r_{t}=r_{p, 0}+c$, es nula (Eq. 3-57):

$$
\left.\sigma_{r}\right|_{r=r_{t}}=0
$$

Imponiendo la condición de contorno expresada en (Eq. 3-57) a la expresión que describe las tensiones radiales $\sigma_{r}$ (Eq. 3-52), se obtiene la siguiente igualdad (Eq. 3-58): 
TESIS DOCTORAL INFLUENCLA DE LA CORROSIÓN EN LA ADHERENCLA DE ALAMBRES EN ELEMENTOS PRETENSADOS DE HORMIGÓN

$$
\left.\sigma_{r}\right|_{r=r_{t}}=\frac{1}{1-v_{r \theta} v_{\theta r}}\left(E_{r} \frac{d u_{r}}{d r}+v_{r \theta} E_{\theta} \frac{u_{r}}{r}\right)+\frac{1}{1-v_{r \theta} v_{\theta r}}\left(E_{r}+v_{r \theta} E_{\theta}\right) \frac{v_{c}}{E_{c}} \sigma_{z}=0
$$

Y operando, la expresión se simplifica hasta obtener la siguiente ecuación:

$$
\left.\sigma_{r}\right|_{r=r_{t}}=\frac{d u_{r}}{d r}+v_{r \theta} \frac{E_{\theta}}{E_{r}} \frac{u_{r}}{r}+\frac{\left(v_{r \theta} E_{\theta}+E_{r}\right)}{E_{r}} \frac{v_{c}}{E_{c}} \sigma_{z}=0
$$

Para conocer el valor de las deformaciones y tensiones, así como del avance del frente de fisuración a lo largo del recubrimiento es necesario conocer la presión interna $p$ que generan los desplazamientos radiales $u_{r}$ debidos al aumento de sección transversal del alambre tras el destesado, para lo que a su vez debe resolverse el problema de contorno descrito por la ecuación (Eq. 3-55). Dada la complejidad de las ecuaciones constitutivas del material, el problema debe ser resuelto numéricamente. Para ello, se plantea un esquema de aproximación a la solución mediante diferencias finitas, dividiendo el recubrimiento de hormigón (se considerará la distancia mínima a la cara superficial del hormigón), en dirección radial, en $n+1$ puntos discretos $r_{0}, r_{1}, \ldots \ldots, r_{n}$, separados por una misma distancia de longitud h. El primer nodo, $i=0$, se encuentra ubicado en el límite interior del cilindro de pared gruesa (es decir, donde $\left.r=r_{p, 0}\right)$, y el último nodo, $i=n$, se encuentra en la superficie exterior del cilindro $\left(r=r_{t}\right)$. En la Figura 3-9 se esquematiza la discretización llevada a cabo en esta tesis para la resolución del problema mediante el método de diferencias finitas.

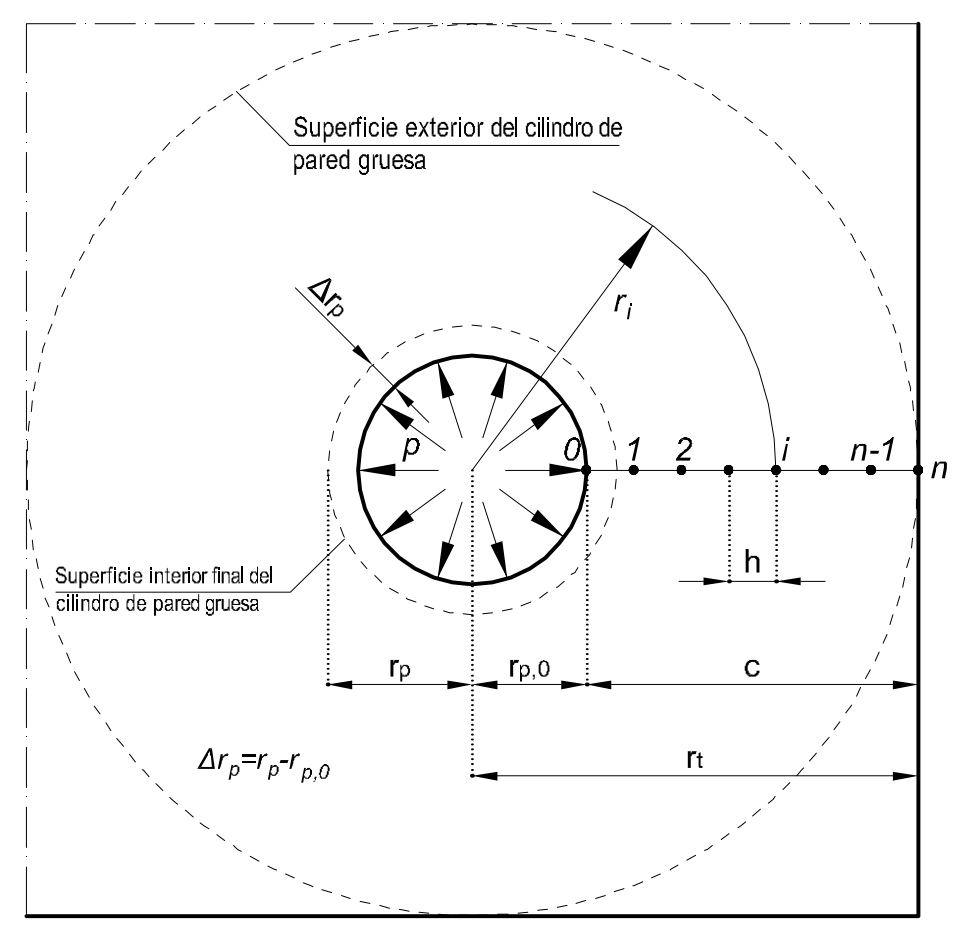

Figura 3-9 Discretización del cilindro de pared gruesa en la dirección radial para resolución del problema mediante diferencias finitas 
Los términos $d^{2} u / d r^{2}$ y $d u / d r$ de la ecuación (Eq. 3-55) pueden ser determinados mediante una aproximación de diferencias finitas centrales. Para ello, las derivadas en un punto $r=r_{i}$ (Figura 3-9) se asimilan a diferencias entre valores correspondientes a puntos discretos:

$$
\begin{gathered}
\frac{d^{2} u_{r}}{d r^{2}}=\frac{u_{i+1}-2 u_{i}+u_{i-1}}{h^{2}} \quad \text { para } i=0,1, \ldots . . n \\
\frac{d u_{r}}{d r}=\frac{u_{i+1}-u_{i-1}}{2 h} \quad \text { para } i=0,1, \ldots . . n
\end{gathered}
$$

Siendo $i$ el subíndice que indica la posición del punto discreto a lo largo del recubrimiento. Sustituyendo en la ecuación diferencial (Eq. 3-55), se obtiene (Eq. 3-62):

$$
\frac{u_{i+1}-2 u_{i}+u_{i-1}}{h^{2}}+\frac{u_{i+1}-u_{i-1}}{2 h} \frac{1}{r_{i}}-\frac{E_{\theta, i}}{E_{r, i}} \frac{u_{r}}{r_{i}{ }^{2}}+\frac{\left[E_{\theta, i}\left(v_{r \theta, i}-1\right)-E_{r, 1}\left(v_{\theta r, i}-1\right)\right]}{E_{r, i}} \frac{v_{c}}{E_{c}} \frac{1}{r_{i}} \sigma_{z}=0
$$

Y reordenando (Eq. 3-63):

$$
u_{i-1}\left(\frac{1}{h^{2}}-\frac{1}{2 h r_{i}}\right)-u_{i}\left(\frac{2}{h^{2}}+\frac{E_{\theta, i}}{E_{r i}} \frac{1}{r_{i}^{2}}\right)+u_{i+1}\left(\frac{1}{h^{2}}+\frac{1}{2 h r_{i}}\right)+\frac{\left[E_{\theta, i}\left(v_{r \theta, i}-1\right)-E_{r, i}\left(v_{\theta r i}-1\right)\right.}{E_{r, i}} \frac{v_{c}}{E_{c}} \frac{1}{r_{i}} \sigma_{z}=0 \quad \text { para } i=0,1 \ldots . . n
$$

Las condiciones de contorno (Eq. 3-56) y (Eq. 3-57) son impuestas en $i=0$ e $i=n$. Cuando $i=1$, la ecuación anterior (Eq. 3-63) pasa a ser la siguiente (Eq. 3-64):

$$
+u_{1}\left(\frac{2}{h^{2}}+\frac{E_{\theta, 1}}{E_{r, 1}} \frac{1}{r_{1}^{2}}\right)-u_{2}\left(\frac{1}{h^{2}}+\frac{1}{2 h r_{1}}\right)=u_{0}\left(\frac{1}{h^{2}}-\frac{1}{2 h r_{1}}\right)+\frac{\left[E_{\theta, 1}\left(v_{r \theta, 1}-1\right)-E_{r, 1}\left(v_{\theta r, 1}-1\right)\right]}{E_{r, 1}} \frac{v_{c}}{E_{c}} \frac{1}{r_{1}} \sigma_{z} \quad \text { para } i=1 \quad \text { (Eq.3-64) }
$$

donde $u_{0}$ es igual al desplazamiento de la pared interna del cilindro de hormigón $\Delta r_{p}$. Igualmente, usando la aproximación por diferencias finitas en la expresión que define la tensión radial $\sigma_{r}$ (Eq. 3-59) para $i=n$, resulta (Eq. 3-65):

$$
\left.\sigma_{r}\right|_{r=R_{j}+c}=\frac{u_{n+1}-u_{n-1}}{2 h}+v_{r \theta, n} \frac{E_{\theta, n}}{E_{r, n}} \frac{u_{n}}{r_{n}}+\frac{\left(v_{r \theta, n} E_{\theta, n}+E_{r, n}\right)}{E_{r, n}} \frac{v_{c}}{E_{c}} \sigma_{z}=0
$$

Y despejando (Eq. 3-66):

$$
u_{n+1}=u_{n-1}-2 h \cdot v_{r \theta, n} \frac{E_{\theta, n}}{E_{r, n}} \frac{u_{n}}{r_{n}}-2 h \cdot \frac{\left(v_{r \theta, n} E_{\theta, n}+E_{r, n}\right)}{E_{r, n}} \frac{v_{c}}{E_{c}} \sigma_{z}
$$

Sustituyendo la anterior expresión (Eq. 3-66) en (Eq. 3-63), para $i=n$, se obtiene (Eq. 3-67):

$$
\begin{aligned}
& u_{n-1}\left(\frac{2}{h^{2}}\right)-u_{n}\left[\frac{2}{h^{2}}+\frac{E_{\theta, n}}{E_{r, n}} \frac{1}{r_{n}^{2}}\left(1+v_{r \theta, n}\left(1+\frac{2}{h} r_{n}\right)\right)\right]-\left[\frac{2}{h}\left(v_{r \theta, n} E_{\theta, n}+E_{r, n}\right)+\frac{1}{r_{n}}\left(v_{\theta r, n} E_{r, n}+\right.\right. \\
& \left.\left.E_{\theta, n}\right)\right] \frac{1}{E_{r, n}} \frac{v_{c}}{E_{c}} \sigma_{z}=0 \quad \text { para } i=n
\end{aligned}
$$


TESIS DOCTORAL INFLUENCLA DE LA CORROSIÓN EN LA ADHERENCLA DE ALAMBRES EN ELEMENTOS PRETENSADOS DE HORMIGÓN

Para cada incremento en el desplazamiento radial del límite interior del cilindro de pared gruesa $\Delta r_{p}$, el vector de desplazamientos radiales desconocidos, $\left[u_{r}\right]^{T}=\left[\begin{array}{lllllll}u_{1} & u_{2} & u_{3} & u_{4} & \ldots \ldots & \ldots & u_{n}\end{array}\right]$, se obtiene de la solución del siguiente sistema tridiagonal de ecuaciones:

$$
[K]\left[u_{p}\right]=[F]
$$

Donde $[K]$ es la matriz de rigidez del problema (Eq. 3-69), compuesta por las ecuaciones expuestas anteriormente (Eq. 3-63)(Eq. 3-64) y (Eq. 3-67):

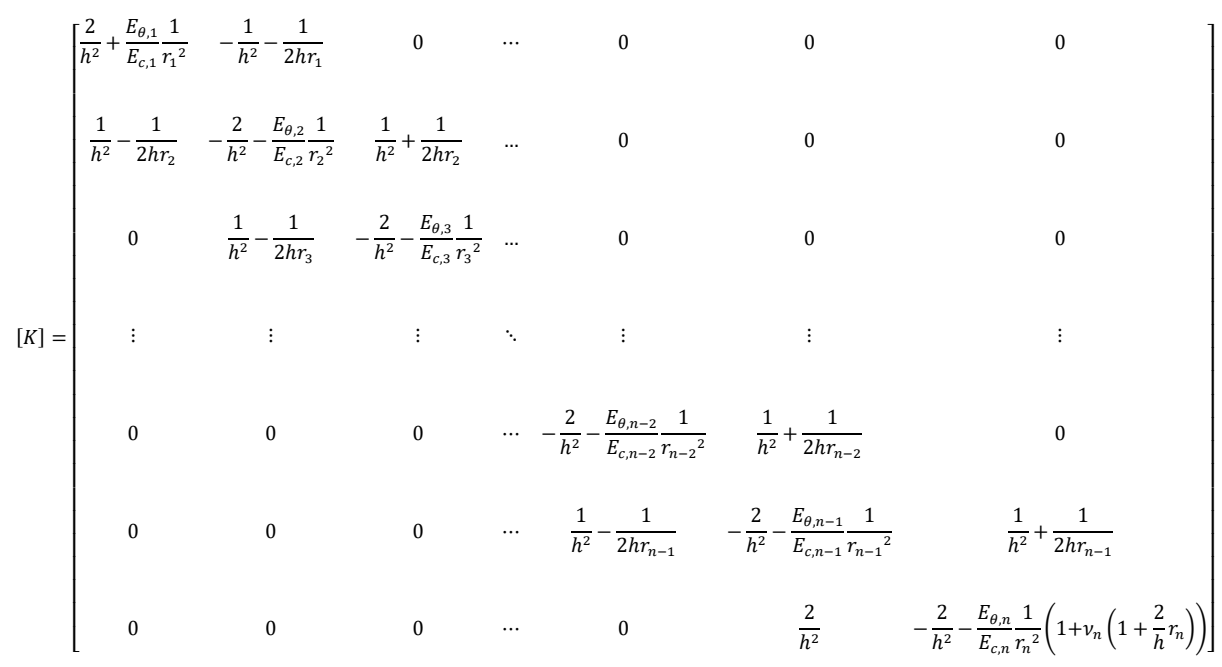

Siendo los vectores de términos no-homogéneos $\{F\}$ y de desplazamientos $\left\{u_{r}\right\}$ los que se recogen a continuación (Eq. 3-70):

$$
\{F\}=\left\{\begin{array}{c}
u_{0}\left(\frac{1}{h^{2}}-\frac{1}{2 h r_{1}}\right)+\frac{\left[E_{\theta, 1}\left(v_{r \theta, 1}-1\right)-E_{r, 1}\left(v_{\theta r, 1}-1\right)\right]}{E_{r, 1}} \frac{v_{c}}{E_{c}} \frac{1}{r_{1}} \sigma_{z} \\
-\frac{\left[E_{\theta, 2}\left(v_{r \theta, 2}-1\right)-E_{r, 2}\left(v_{\theta r, 2}-1\right)\right]}{E_{r, 2}} \frac{v_{c}}{E_{c}} \frac{1}{r_{2}} \sigma_{z} \\
-\frac{\left[E_{\theta, 3}\left(v_{r \theta, 3}-1\right)-E_{r, 3}\left(v_{\theta r, 3}-1\right)\right]}{E_{r, 3}} \frac{v_{c}}{E_{c}} \frac{1}{r_{3}} \sigma_{z} \\
\vdots \\
-\frac{\left[E_{\theta, n-2}\left(v_{r \theta, n-2}-1\right)-E_{r, n-2}\left(v_{\theta r, n-2}-1\right)\right]}{E_{r, n-2}} \frac{v_{c}}{E_{c}} \frac{1}{r_{n-2}} \sigma_{z} \\
-\frac{\left[E_{\theta, n-1}\left(v_{r \theta, n-1}-1\right)-E_{r, n-1}\left(v_{\theta r, n-1}-1\right)\right]}{E_{r, n-1}} \frac{v_{c}}{E_{c}} \frac{1}{r_{n-1}} \sigma_{z} \\
{\left[\frac{2}{h}\left(v_{r \theta, n} E_{\theta, n}+E_{r, n}\right)+\frac{1}{r_{n}}\left(v_{\theta r, n} E_{r, n}+E_{\theta, n}\right)\right] \frac{1}{E_{r, n}} \frac{v_{c}}{E_{c}} \sigma_{z}}
\end{array}\right\} \quad\left\{u_{r}\right\}=\left\{\begin{array}{c}
u_{1} \\
u_{2} \\
u_{3} \\
\vdots \\
u_{n-2} \\
u_{n-1} \\
u_{n}
\end{array}\right\} \quad \text { Eq.3-70) }
$$


Donde, tal y como indican Pantazopoulou \& Papoulia (Pantazopoulou \& Papoulia, 2001), los módulos de deformación $E_{\theta, i}$ y $E_{r, i}$ son variables dependientes de las correspondientes deformaciones principales a lo largo de los puntos o nodos $i$ de la malla radial.

Una vez determinado el valor del vector de desplazamientos $\left\{u_{r}\right\}$ tras la resolución del sistema de ecuaciones anterior (Eq. 3-68), las tensiones radiales $\sigma_{r}$ y circunferenciales $\sigma_{\theta}$ a lo largo del recubrimiento de hormigón, pueden determinarse sustituyendo las ecuaciones (Eq. 3-22), (Eq. 3-23), (Eq. 3-60) y (Eq. 3-61) en (Eq. 3-52) y (Eq. 3-53):

$$
\begin{aligned}
& \sigma_{r}=\frac{1}{1-v_{r \theta} v_{\theta r}}\left(E_{r} \frac{u_{i+1}-u_{i-1}}{2 h}+v_{r \theta} E_{\theta} \frac{u_{r}}{r}\right)+\frac{1}{1-v_{r \theta} v_{\theta r}}\left(E_{r}+v_{r \theta} E_{\theta}\right) \frac{v_{c}}{E_{c}} \sigma_{z} \\
& \sigma_{\theta}=\frac{1}{1-v_{r \theta} v_{\theta r}}\left(E_{\theta} \frac{u_{r}}{r}+v_{\theta r} E_{r} \frac{u_{i+1}-u_{i-1}}{2 h}\right)+\frac{1}{1-v_{r \theta} v_{\theta r}}\left(E_{\theta}+v_{\theta r} E_{r}\right) \frac{v_{c}}{E_{c}} \sigma_{z}
\end{aligned}
$$

Donde $u_{-1}$ y $u_{n+1}$ pueden obtenerse de la expresión (Eq. 3-63) para $r=r_{p, 0}(i=0)$ y $r=r_{p, 0}+c(i=n)$ :

$$
u_{-1}=\left(\frac{1}{h^{2}}-\frac{1}{2 h r_{p, 0}}\right)^{-1} \cdot\left[u_{p}\left(\frac{2}{h^{2}}+\frac{E_{\theta, 0}}{E_{c, 0}} \frac{1}{r_{p, 0}{ }^{2}}\right)-u_{1}\left(\frac{1}{h^{2}}+\frac{1}{2 h r_{p, 0}}\right)-\frac{\left[E_{\theta, 0}\left(v_{r \theta, 0}-1\right)-E_{r, 0}\left(v_{\theta r, 0}-1\right)\right]}{E_{r, 0}} \frac{v_{c}}{E_{c}} \frac{1}{r_{p, 0}} \sigma_{z}\right]
$$

$$
\text { para } i=0
$$

$$
\begin{aligned}
u_{n+1}= & \left(\frac{1}{h^{2}}+\frac{1}{2 h\left(r_{p, 0}+c\right)}\right)^{-1}\left[u_{n}\left(\frac{2}{h^{2}}+\frac{E_{\theta, n}}{E_{c, n}} \frac{1}{\left(r_{p, 0}+c\right)^{2}}\right)-u_{n-1}\left(\frac{1}{h^{2}}-\frac{1}{2 h\left(r_{p, 0}+c\right)}\right)-\right. \\
& \left.\frac{\left[E_{\theta, 0}\left(v_{r \theta, 0}-1\right)-E_{r, 0}\left(v_{\theta r, 0}-1\right)\right]}{E_{r, 0}} \frac{v_{c}}{E_{c}} \frac{1}{\left(r_{p, 0}+c\right)} \sigma_{z}\right] \quad \text { para } i=n
\end{aligned}
$$

Para evaluar adecuadamente la evolución de los módulos de elasticidad secantes, el desplazamiento total $\Delta r_{p}$, hallado en régimen elástico, es dividido en $m$ intervalos iguales de desplazamiento $\Delta r_{p} / m$, de manera que el primer nodo $j=0$, se corresponde con un desplazamiento nulo y por tanto describe la situación previa al destesado, mientras que el último nodo $j=m$ equivale a la situación de equilibrio posterior al destesado, en la que el acero ha trasmitido la tensión al hormigón y en la que el desplazamiento de la pared interna del cilindro de hormigón ha alcanzado un valor $\Delta r_{p}$ (Figura 3-10).

$$
\Delta r_{p, j}=\sum_{0}^{j} \Delta u_{p, j} \quad \operatorname{para} j=0,1, \ldots, m
$$

El análisis se lleva a cabo de manera incremental, de forma que para cada uno de los incrementos $m$ ésimos de desplazamiento radial, se calculan los desplazamientos nodales a lo largo del recubrimiento, así como las deformaciones y las tensiones asociadas. Para el siguiente incremento, $m+1$, los módulos de rigidez $E_{\theta}$ y $E_{r}$ son estimados a partir de las relaciones constitutivas del hormigón en tracción y 
compresión, respectivamente, usando para ello las deformaciones calculadas en el incremento $m$ anterior. Por tanto, para cada uno de los incrementos de desplazamiento radial $\Delta u_{p}$, el modelo actualiza los valores de los módulos de rigidez del hormigón, pasando a ser las condiciones iniciales del siguiente incremento de desplazamiento.

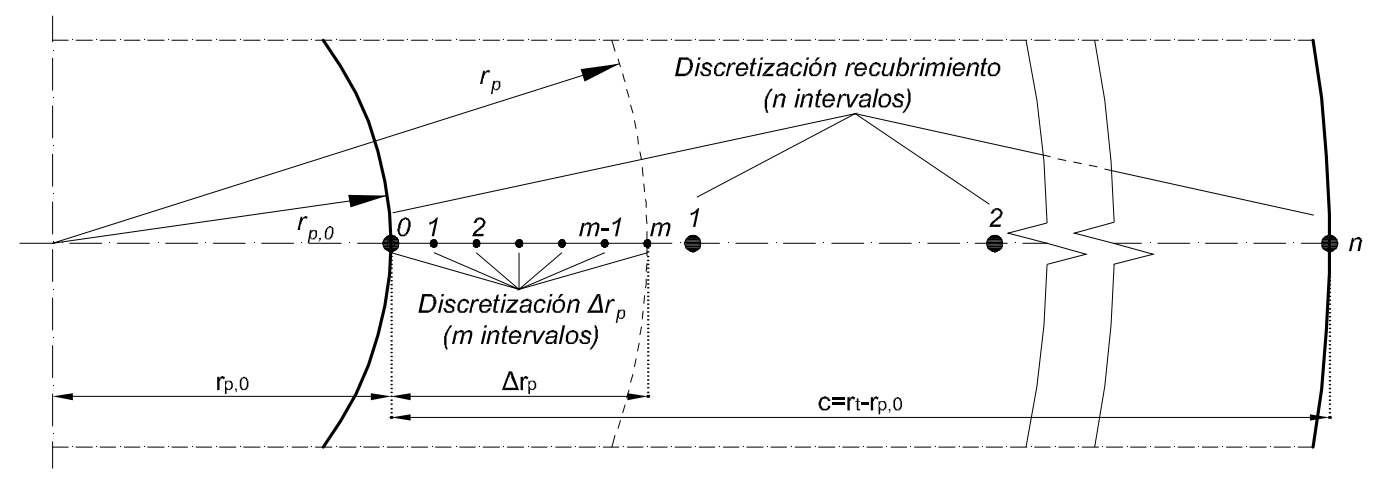

Figura 3-10 Discretización del desplazamiento radial $\Delta r_{p}$ para el análisis incremental del problema

Una vez que los valores finales de desplazamiento a lo largo del recubrimiento han sido determinados, y las correspondientes deformaciones y tensiones han sido calculadas, el modelo puede avanzar al siguiente paso, en el que se inicia el proceso de corrosión que se detalla en el siguiente apartado (Apartado 3.4).

\subsection{Tensiones radiales debidas a la expansión del acero por corrosión $\left[\sigma_{r, c o r r}\right]$}

\subsubsection{Introducción}

Tal y como se ha visto en el Capítulo 2 "Estado del conocimiento", la corrosión ha sido identificada como uno de los factores predominantes en el deterioro de estructuras de hormigón armado y pretensado. Los principales efectos de la corrosión en el comportamiento mecánico de elementos de hormigón son los siguientes (Andrade, et al., 1993) (Figura 3-11):

- Reducción de la sección de los alambres.

- Fragilización y reducción de la ductilidad del acero.

- Concentración de tensiones debidas a cambios en la geometría del acero, provocadas por procesos de corrosión no uniforme por picaduras.

- Fisuración del recubrimiento de hormigón y deterioro de la adherencia.

Este apartado se centra en este último efecto, el cual refleja el hecho de que, al igual que con el efecto Hoyer en el pretensado, la expansión de los productos de corrosión provoca el desarrollo de tensiones radiales $\sigma_{r}$ y circunferenciales $\sigma_{\theta}$ que pueden desembocar en la fisuración del recubrimiento y, por tanto, en la merma de las propiedades adherentes. 
Desde que Bazant (1979) utilizó por primera vez la teoría de cilindros de pared gruesa (Timoshenko, 1956) para el análisis del estado tensional del recubrimiento de hormigón debido a los procesos de corrosión, numerosos autores han abordado este problema desde ese enfoque (Martín-Pérez, 1999) (Pantazopoulou \& Papoulia, 2001) (Bhargava, et al., 2006) (Tastani \& Pantazopoulou, 2013). Tal y como indican Pantazopoulou \& Papoulia (2001), la utilización de estos modelos conduce a una fisuración del recubrimiento más temprana que la reflejada en observaciones experimentales. Para mitigar esta discrepancia, a lo largo de los últimos años los distintos autores han utilizado diferentes estrategias en el modelado, entre las que destacan, sin ser exhaustivo, las siguientes:

- Se ha considerado una región alrededor de la interfaz acero-hormigón en la que los óxidos pueden difundir sin ejercer ninguna presión en el hormigón circundante (región de porosidad infinita), y cuyo espesor aparente $t_{p}$ es equivalente a la suma del volumen de poros en los que presumiblemente se difundirían los productos de corrosión. (Andrade, et al., 1993) (Molina, 1993) (Liu \& Weyers, 1998) (Martín-Pérez, 1999)

- Se ha modificado la tasa de penetración de ataque constante que arroja la ley de Faraday (Liu \& Weyers, 1998) (Balafas \& Burgoyne, 2010a).

- Se ha admitido que el recubrimiento de hormigón conserva cierta resistencia residual tras haberse superado su capacidad a tracción $f_{c t}$ (Pantazopoulou \& Papoulia, 2001).

- Se ha considerado que, una vez iniciada la fisuración en el hormigón que circunda el alambre, un porcentaje de los productos de corrosión pueden depositarse en el interior de las fisuras abiertas (Bažant, 1979) (Andrade, et al., 1993) (Pantazopoulou \& Papoulia, 2001) (Coronelli, 2002)

Gran parte de las hipótesis de partida del presente modelo son comunes a las expuestas en el modelo para la determinación de tensiones radiales debidas al pretensado expuestas en el apartado 3.3. A continuación, en vista de lo expuesto anteriormente, se enumeran las hipótesis exclusivas relativas a la determinación de las tensiones en el recubrimiento de hormigón de alambres afectados por procesos de corrosión que se han contemplado:

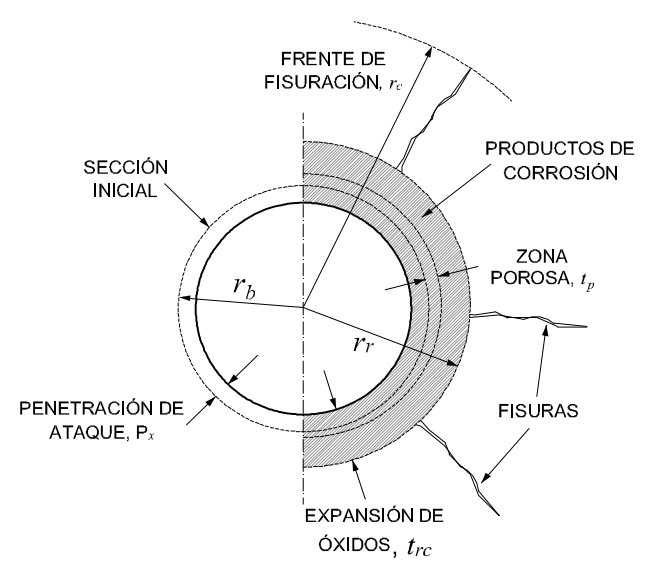

Figura 3-11 Sección transversal de un alambre corroído con óxidos expansivos (Andrade, et al., 1993) (Martín-Pérez, 2014) 
- Tanto el comienzo de la etapa de propagación de la corrosión como la velocidad de ésta son datos de partida.

- La corrosión se reparte uniformemente a lo largo de toda la superficie de la barra, de manera que la penetración de ataque $P_{x}$ es constante a lo largo de la misma, y con ella, la presión $p$ ejercida por los productos de corrosión sobre la pared interna del cilindro de hormigón con el que se modeliza el recubrimiento.

- Los parámetros relativos a la expansión de los óxidos ( $n$; Coeficiente de expansión de óxidos) y a las propiedades mecánicas de los productos de corrosión $\left(K_{n}\right.$; Coeficiente de deformabilidad volumétrica), son calibrados mediante los ensayos (Ver capítulo G).

- Se admite la existencia de una "zona porosa" de mayor porosidad en la interfaz acerohormigón, de espesor $t_{p}$, en las que los productos de corrosión difunden sin ejercer presión (o una presión menor que en áreas situadas fuera de dicha zona). El espesor equivalente de esta zona, que como se ha visto en el Capitulo 2 responde a una realidad física, así como la distribución de la porosidad a lo largo de la misma, se discute en el Capitulo 6.

- Se admite que una parte de los productos de corrosión generados puede depositarse en las fisuras radiales formadas alrededor del alambre.

A continuación, se expone el cuerpo teórico que sustenta el modelo analítico desarrollado para esta tesis.

\subsubsection{Expansión libre}

Una vez determinado el desplazamiento $u_{p}$ provocado en el cilindro hueco de hormigón debido a la presión ejercida por el alambre de pretensado tras el destesado (Apartado 3.3), el modelo analítico evalúa el desplazamiento radial provocado por la presión $p$ que ocasiona la corrosión de los alambres. El nuevo radio de partida, previo al comienzo del ataque, es igual a $r_{p}$.

Como se ha visto anteriormente, cuando el acero embebido en el hormigón sufre un proceso de degradación por corrosión, se disuelve la capa pasiva del acero y se forman productos de oxidación. $\mathrm{Al}$ iniciarse este proceso, una capa de acero de profundidad $P_{x}$ se transforma en óxido, cuyo volumen específico es mayor que el del acero original, generándose tensiones en el hormigón circundante y propiciándose la aparición de fisuras y desprendimientos en el recubrimiento.

La penetración de ataque $P_{x}$, que se supone uniforme en toda la superficie del alambre, depende del tiempo $t$ transcurrido desde el comienzo del periodo de propagación de la corrosión, así como de la densidad de corriente $i_{c o r r}$ a la que está sometido el acero. Aunque está universalmente admitido que el consumo de acero por el proceso de corrosión debe regirse por la Ley de Faraday (Andrade, et al., 1993), en los últimos años se han propuesto modelos alternativos, como el Modelo de Liu \& Weyers (Liu \& Weyers, 1998) y el de Balafas \& Burgoyne (Balafas \& Burgoyne, 2010a), cuyo objetivo es retrasar el inicio de la fisuración, para así acercarse a las observaciones experimentales (Ver Capítulo 2). Estos tres modelos han sido implementados en el programa desarrollado para la presente tesis, 
mientras que en el Capitulo 6 se ha discutido la conveniencia de su uso y el grado de adaptación a los resultados de los ensayos.

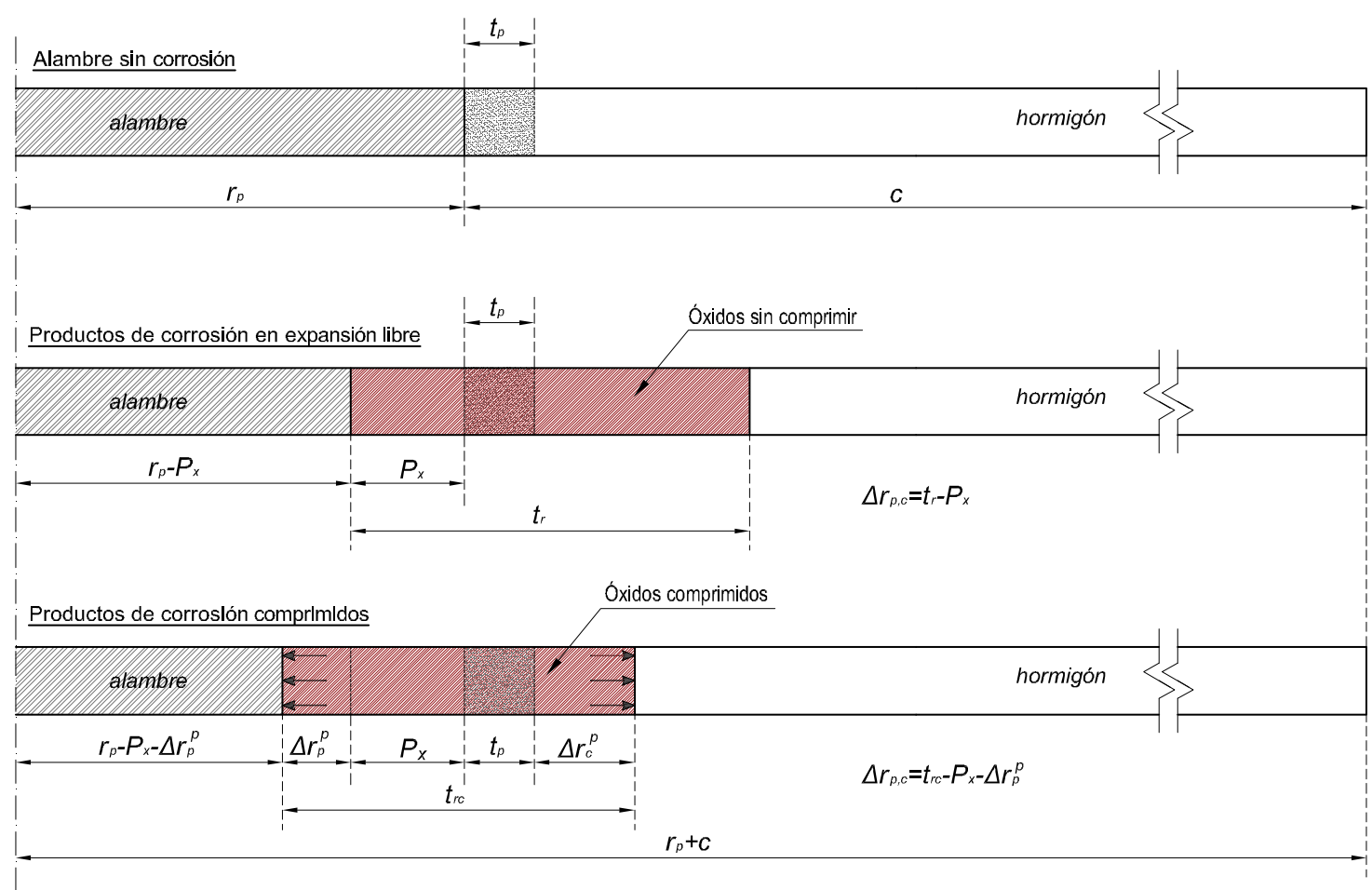

Figura 3-12 Expansión de los productos de corrosión a lo largo del recubrimiento de hormigón. Interpretación de figura contenida en (Balafas ఓ Burgoyne, 2011) y (Martin-Pérez, 2014)

Conocida la penetración de ataque $P_{x}$, el volumen de acero virgen corroído o consumido por el proceso de corrosión $\Delta V_{s}^{\text {corr }}$, por unidad de longitud del alambre, viene dado por (Eq. 3-76):

$$
\Delta V_{S}^{\text {corr }}=\pi r_{p}^{2}-\pi\left(r_{p}-P_{x}\right)^{2}=\pi P_{x}\left(2 r_{p}-P_{x}\right)
$$

Suponiendo una expansión libre de los productos de corrosión, de manera que se distribuyan uniformemente rodeando el alambre y formando una capa de espesor $t_{r}$, el volumen del óxido formado por unidad de longitud del alambre $V_{r}$ puede definirse como (Eq. 3-77):

$$
V_{r}=\pi\left(r_{p}-P_{x}+t_{r}\right)^{2}-\pi\left(r_{p}-P_{x}\right)^{2}=\pi t_{r}\left[2\left(r_{p}-P_{x}\right)+t_{r}\right]
$$

Por otro lado, como se ha visto en el Capitulo 2, el coeficiente de expansión de óxidos $n$ es igual al ratio entre el volumen de óxidos generados $V_{r}$ y el volumen de acero corroído $\Delta V_{s}^{\text {rorr }}$, de manera que se cumple (Eq. 3-78):

$$
V_{r}=n \Delta V_{s}^{c o r r}
$$

Y sustituyendo las ecuaciones (Eq. 3-76) y (Eq. 3-77) en (Eq. 3-78), se obtiene en una ecuación de segundo grado en función de $t_{r}$ (Eq. 3-79): 
TESIS DOCTORAL INFLUENCLA DE LA CORROSIÓN EN LA ADHERENCLA DE ALAMBRES EN ELEMENTOS PRETENSADOS DE HORMIGÓN

$$
\pi t_{r}\left[2\left(r_{p}-P_{x}\right)+t_{r}\right]=n \pi P_{x}\left(2 r_{p}-P_{x}\right) \Rightarrow t_{r}^{2}+2\left(r_{p}-P_{x}\right) t_{r}-n P_{x}\left(2 r_{p}-P_{x}\right)=0
$$

Por tanto, resolviendo la ecuación anterior (Eq.3-79), se determina que el espesor de la capa de óxido en expansión libre $t_{r}$ queda descrito por la siguiente expresión (Eq. 3-80)(Figura 3-12):

$$
\begin{aligned}
t_{r}=\frac{-2\left(r_{p}-P_{x}\right)+\sqrt{4 r_{p}^{2}-4 P_{x}^{2}(n-1)+8 r_{p} P_{x}(n-1)}}{2} \\
=-\left(r_{p}-P_{x}\right)+\sqrt{r_{p}^{2}-P_{x}^{2}(n-1)+2 r_{p} P_{x}(n-1)}
\end{aligned}
$$

\subsubsection{Presión debida a la expansión de los productos de corrosión}

Una vez definido el valor de la hipotética expansión libre de los productos corrosión, $V_{r}$, y definidos el coeficiente de expansión $n$ y la penetración de ataque $P_{x}$, el siguiente paso es el cálculo de espesor real $t_{r c}$ de los productos de corrosión, teniendo en cuenta que se encuentran confinados durante el proceso y que poseen un determinado grado de compresibilidad (Figura 3-12). El espesor real de la capa de productos de corrosión $t_{r c}$ viene definido por la siguiente expresión:

$$
t_{r c}=P_{x}+t_{p}+\Delta r_{p}^{p}+\Delta r_{c}^{p}
$$

Donde:
$\Delta r_{p}^{p} \quad$ Cambio del radio de la armadura debido a la presión $p$ derivada de la expansión de los productos de corrosión.
$\Delta r_{c}^{p} \quad$ Incremento del radio interior del cilindro bueco de hormigón debido a la presión $p$.
$t_{p} \quad$ Espesor equivalente de la zona porosa.

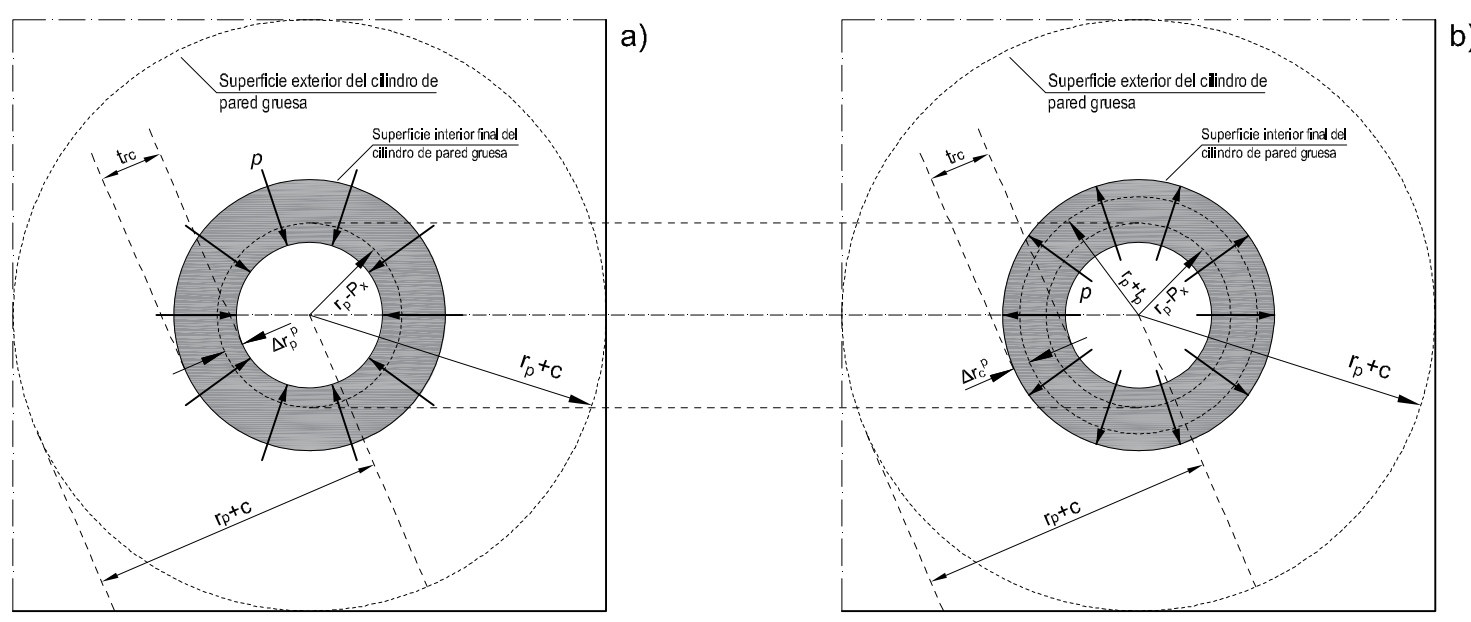

Figura 3-13 Cambio en a) el radio del alambre $\Delta r_{p}^{p}$ y b) en el radio interno del cilindro de hormigón $\Delta r_{c}^{p}$, debido a la presión $p$ ejercida por los productos de corrosión 
Como se adelantó en las hipótesis de partida del modelo referentes a la corrosión, la expresión (Eq. 3-82) incluye el término referente al espesor equivalente de la zona porosa $t_{p}$ en la que los óxidos pueden difundir sin ejercer presión sobre la cara interna del cilindro de hormigón.

Tal y como señalan Balafas \& Burgoyne (2011) y Martín-Pérez (2014), el cambio en la longitud del radio del alambre $\Delta r_{p}^{p}$ con respecto al radio original $r_{p}$ puede ser calculado asimilando la barra a un cilindro sólido de acero, con un comportamiento elástico y lineal, sometido a una presión $p$ (Timoshenko, 1956), según muestra la siguiente expresión (Eq. 3-82):

$$
\Delta r_{p}^{p}=\frac{1-v_{s}}{E_{s}} \cdot p \cdot\left(r_{p}-P_{x}\right)
$$

Por su parte, el incremento del radio interno del recubrimiento de hormigón $\Delta r_{c}^{p}$ puede ser calculado partiendo de la base de que el recubrimiento de hormigón se comporta como un cilindro hueco de pared gruesa, con un comportamiento elástico y lineal, sometido a una presión $p$ (Timoshenko, 1956), tal y como muestra la siguiente expresión (Eq. 3-83):

$$
\Delta r_{c}^{p}=\frac{\left(r_{p}+t_{p}\right)^{3} \cdot p}{E_{c} \cdot\left(c+t_{p}+2 r_{p}\right) \cdot\left(c-t_{p}\right)} \cdot\left[\left(1-v_{c}\right)+\left(1+v_{c}\right)\left(\frac{r_{p}+c}{r_{p}+t_{p}}\right)^{2}\right]
$$

Para determinar la presión $p$ que actúa sobre el las superficies de acero y hormigón, se establece una igualdad entre la suma del cambio de volumen del acero $\Delta V_{s}$ y del hormigón $\Delta V_{c}$, por un lado, y la cantidad total de productos de oxidación que se encuentran confinados y comprimidos $V_{r c}$, por el otro (Eq. 3-84):

$$
V_{r c}=\Delta V_{s}+\Delta V_{c}
$$

El cambio de volumen del acero $\Delta V_{S}$ es consecuencia de la reducción directa de sección transversal atribuible a la producción de óxidos $\Delta V_{s}^{\text {corr }}$ (Eq. 3-76), por un lado, y de la reducción de volumen derivada de las tensiones de compresión sobre la superficie del acero por la presión de los óxidos $\Delta V_{s}^{p}$, por otro (Eq. 3-85):

$$
\Delta V_{s}=\Delta V_{s}^{c o r r}+\Delta V_{s}^{p}
$$

El valor de la reducción de volumen en el alambre ocasionada por la presión $p, \Delta V_{s}^{p}$, viene definida por la siguiente expresión (Eq. 3-86):

$$
\Delta V_{s}^{p}=\pi\left(r_{p}-P_{x}\right)^{2}-\pi\left(r_{p}-P_{x}-\Delta r_{p}^{p}\right)^{2}=2 \pi \Delta r_{p}^{p}\left(r_{p}-P_{x}-\frac{\Delta r_{p}^{p}}{2}\right)
$$

Por lo que, sustituyendo las ecuaciones (Eq. 3-76) y (Eq. 3-86) en (Eq. 3-85), se obtiene el valor total de la reducción de volumen del acero $\Delta V_{S}$ (Eq. 3-87): 
TESIS DOCTORAL INFLUENCLA DE LA CORROSIÓN EN LA ADHERENCLA DE ALAMBRES EN ELEMENTOS PRETENSADOS DE HORMIGÓN

$$
\Delta V_{s}=\pi P_{x}\left(2 r_{p}-P_{x}\right)+\pi \Delta r_{p}^{p}\left(2 r_{p}-2 P_{x}-\Delta r_{p}^{p}\right)
$$

Sustituyendo el valor de reducción de longitud del radio de la barra con respecto al original $\Delta r_{p}^{p}$ (Eq. 3-82) en la expresión anterior se obtiene el cambio de volumen por unidad de longitud del alambre (Eq. 3-88):

$$
\begin{array}{r}
\Delta V_{s}=\pi P_{x}\left(2 r_{p}-P_{x}\right)+\pi \frac{1-v_{s}}{E_{s}} \cdot p \cdot\left(r_{p}-P_{x}\right)\left[2 r_{p}-2 P_{x}-\frac{1-v_{s}}{E_{s}} \cdot p \cdot\left(r_{p}-P_{x}\right)\right] \\
=\pi P_{x}\left(2 r_{p}-P_{x}\right)+\pi p \cdot \frac{1-v_{s}}{E_{s}} \cdot\left(r_{p}-P_{x}\right)^{2}\left[2-\frac{1-v_{s}}{E_{s}} \cdot p\right]
\end{array}
$$

Por su parte, el cambio de volumen por unidad de longitud del cilindro de hormigón $\Delta V_{c}$, debido a la presión $p$, viene dado por la siguiente expresión (Eq. 3-89):

$$
\Delta V_{c}=\pi\left(r_{p}+t_{p}+\Delta r_{c}^{p}\right)^{2}-\pi\left(r_{p}+t_{p}\right)^{2}=\pi \Delta r_{c}^{p}\left(2 r_{p}+2 t_{p}+\Delta r_{c}^{p}\right)
$$

Sustituyendo el valor del incremento del radio interno del recubrimiento de hormigón $\Delta r_{c}^{p}$ (Eq. 3-83) en la expresión anterior (Eq. 3-89), se obtiene el cambio de volumen por unidad de longitud del alambre (Eq. 3-90):

$$
\begin{gathered}
\Delta V_{c}=\frac{\left(r_{p}+t_{p}\right)^{4} p \pi}{E_{c}\left(c+t_{p}+2 r_{p}\right)\left(c-t_{p}\right)}\left[\left(1-v_{c}\right)+\left(1+v_{c}\right)\left(\frac{r_{p}+c}{r_{p}+t_{p}}\right)^{2}\right]\left\{2+\frac{\left(r_{p}+t_{p}\right)^{2} \cdot p}{E_{c}\left(c+t_{p}+2 r_{p}\right)\left(c-t_{p}\right)}\right. \\
\left.\cdot\left[\left(1-v_{c}\right)+\left(1+v_{c}\right)\left(\frac{r_{p}+c}{r_{p}+t_{p}}\right)^{2}\right]\right\}
\end{gathered}
$$

El volumen de productos de corrosión comprimidos por unidad de longitud del alambre $V_{r c}$, se calcula por definición a partir de la siguiente expresión (Eq. 3-91):

$$
V_{r c}=V_{r}\left(1-\varepsilon_{v}\right)
$$

donde:
$V_{r} \quad$ Volumen total de los productos de corrosión sin comprimir, por unidad de longitud de la barra
$\varepsilon_{v} \quad$ Deformación volumétrica experimentada por los productos de oxidación por la acción de $p$

La deformación volumétrica $\varepsilon_{v}$ puede expresarse en función de la presión $p$ y el módulo de deformación volumétrica $K_{r}$ (Eq. 3-92). Tal y como se indicó anteriormente, el módulo $K_{r}$ es calibrado en el Capítulo 6 en base a los resultados experimentales obtenidos en los ensayos de pullout.

$$
\varepsilon_{v}=\frac{p}{K_{r}}
$$


Por tanto, la presión $p$ provocada por la expansión de los productos de corrosión puede ser calculada sustituyendo las ecuaciones (Eq. 3-77), (Eq. 3-88), (Eq. 3-90) y (Eq. 3-92) en (Eq. 3-91), tal y como se recoge en la igualdad (Eq. 3-93):

$$
\begin{aligned}
\pi t_{r}\left[2\left(r_{p}-P_{x}\right)+t_{r}\right]\left(1-\frac{p}{K_{r}}\right) & \\
= & \left\{\pi P_{x}\left(2 r_{p}-P_{x}\right)+\pi p \cdot \frac{1-v_{s}}{E_{S}} \cdot\left(r_{p}-P_{x}\right)^{2}\left[2-\frac{1-v_{s}}{E_{S}} \cdot p\right]\right\} \\
& +\left\{\frac{\left(r_{p}+t_{p}\right)^{4} p \pi}{E_{c}\left(c+t_{p}+2 r_{p}\right)\left(c-t_{p}\right)}\left[\left(1-v_{c}\right)+\left(1+v_{c}\right)\left(\frac{r_{p}+c}{r_{p}+t_{p}}\right)^{2}\right]\right. \\
& \left.\cdot\left\{2+\frac{\left(r_{p}+t_{p}\right)^{2} \cdot p}{E_{c}\left(c+t_{p}+2 r_{p}\right)\left(c-t_{p}\right)} \cdot\left[\left(1-v_{c}\right)+\left(1+v_{c}\right)\left(\frac{r_{p}+c}{r_{p}+t_{p}}\right)^{2}\right]\right\}\right\}
\end{aligned}
$$

Para despejar el valor de la presión $p$ de la anterior ecuación, los términos que la componen se sustituyen por coeficientes, simplificándose como sigue (Eq. 3-94):

$$
F\left(1-\frac{p}{K_{r}}\right)=A+B p(2-C p)+D p(2+E p)
$$

Y operando, se obtiene la siguiente ecuación de $2^{\circ}$ grado, de la que es fácilmente deducible el valor de la presión $p$ (Eq. 3-95):

$$
(D E-B C) p^{2}+\left(2 B+2 D+\frac{F}{K_{r}}\right) p+(A-F)=0
$$

donde los coeficientes A, B, C, D, E y F, toman los siguientes valores:

$$
\begin{aligned}
& A=\pi P_{x}\left(2 r_{p}-P_{x}\right) \\
& B=\pi \frac{1-v_{s}}{E_{s}}\left(r_{p}-P_{x}\right)^{2} \\
& C=\frac{1-v_{s}}{E_{S}} \\
& D=\frac{\left(r_{p}+t_{p}\right)^{4} \pi}{E_{c}\left(c+t_{p}+2 r_{p}\right)\left(c-t_{p}\right)}\left[\left(1-v_{c}\right)+\left(1+v_{c}\right)\left(\frac{r_{p}+c}{r_{p}+t_{p}}\right)^{2}\right] \\
& E=\frac{\left(r_{p}+t_{p}\right)^{2}}{E_{c}\left(c+t_{p}+2 r_{p}\right)\left(c-t_{p}\right)}\left[\left(1-v_{c}\right)+\left(1+v_{c}\right)\left(\frac{r_{p}+c}{r_{p}+t_{p}}\right)^{2}\right] \\
& F=\pi t_{r}\left[2\left(r_{p}-P_{x}\right)+t_{r}\right]
\end{aligned}
$$


Una vez resuelta la ecuación y determinado el valor de $p$, puede hallarse el cambio en el radio de la barra $\Delta r_{p}^{p}$ con respecto al original (Eq. 3-82), así como el incremento del radio interno del recubrimiento de hormigón $\Delta r_{c}^{p}$ (Eq.3-83), con lo que queda establecido el espesor final de la capa comprimida de productos de corrosión $t_{r c}$ (Eq. 3-81), así como el desplazamiento final del radio interior del cilindro hueco de pared gruesa $\Delta r_{p, c}$, siguiendo la siguiente expresión (Eq. 3-97):

$$
\Delta r_{p, c}=t_{r c}-P_{x}-\Delta r_{p}^{p}=t_{p}+\Delta r_{c}^{p}
$$

\subsubsection{Formulación de la ecuación diferencial}

Una vez conocido el desplazamiento de la pared interna del cilindro de hormigón $\Delta r_{p, c}$ debido a la presión $p$ ejercida por el aumento de volumen de los productos de corrosión, es posible determinar los desplazamientos, deformaciones y tensiones a lo largo del recubrimiento.

Considerando las mismas relaciones constitutivas de anisotropía cilíndrica que para la modelización del estado tensional del pretensado (Eq. 3-45), (Eq. 3-46) y (Eq. 347), pero partiendo en esta ocasión de un estado de tensión plana $\left(\sigma_{z}=0\right)$, se puede determinar que las tensiones radiales y circunferenciales quedan como siguen:

$$
\begin{gathered}
\sigma_{r}=\frac{1}{1-v_{r \theta} v_{\theta r}}\left(E_{r} \varepsilon_{r}+v_{r \theta} E_{\theta} \varepsilon_{\theta}\right) \\
\sigma_{\theta}=\frac{1}{1-v_{r \theta} v_{\theta r}}\left(E_{\theta} \varepsilon_{\theta}+v_{\theta r} E_{r} \varepsilon_{r}\right)
\end{gathered}
$$

Sustituyendo las ecuaciones anteriores (Eq. 3-98) y (Eq. 3-99) en (Eq. 3-20) se obtiene la siguiente ecuación diferencial no-lineal y no-homogénea de desplazamientos radiales que gobierna el problema (Eq. 3-100):

$$
\frac{d^{2} u_{r}}{d r^{2}}+\frac{d u_{r}}{d r} \frac{1}{r}-\frac{E_{\theta}}{E_{r}} \frac{u_{r}}{r^{2}}=0
$$

donde las condiciones de contorno para la resolución del problema son las siguientes:

$$
\begin{gathered}
\left.u\right|_{r=r_{p}}=\Delta r_{p, c} \\
\left.\sigma_{r}\right|_{r=r_{c}}=0
\end{gathered}
$$

Siguiendo el mismo método de resolución de la ecuación mediante una aproximación de diferencias finitas centrales, para cada tiempo $t$, y dado el radio del frente de corrosión $r_{p}+\Delta r_{p, c}$, el vector de desplazamientos radiales desconocidos $\left[u_{p, c}\right]^{T}$ se obtiene de la solución del sistema de ecuaciones $[K]\left[u_{p, c}\right]=[F]$. Donde $[K]$ es la misma matriz de rigidez que en el problema anterior 
(Eq. 3-69), y los vectores de términos no-homogéneos $\{F\}$ y de desplazamientos $\left\{\mathrm{u}_{p, c}\right\}$ son los que se recogen a continuación (Eq. 3-103):

$$
\{F\}=\left\{\begin{array}{c}
u_{0}\left(\frac{1}{h^{2}}-\frac{1}{2 h r_{1}}\right) \\
0 \\
0 \\
\vdots \\
0 \\
0 \\
0
\end{array}\right\} \quad\left\{u_{p, c}\right\}=\left\{\begin{array}{c}
u_{1} \\
u_{2} \\
u_{3} \\
\vdots \\
u_{n-2} \\
u_{n-1} \\
u_{n}
\end{array}\right\}
$$

(Eq. 3-103)

Una vez determinado el valor del vector de desplazamientos $\left\{u_{p, c}\right\}$, obtenido mediante la resolución del sistema de ecuaciones anterior, las tensiones radiales y circunferenciales a lo largo del recubrimiento de hormigón, $\sigma_{r}$ y $\sigma_{\theta}$, pueden determinarse sustituyendo las ecuaciones (Eq. 3-22), (Eq. 3-23), (Eq. 3-60) y (Eq. 3-61) en (Eq. 3-98) y (Eq. 3-99):

$$
\begin{gathered}
\sigma_{r}=\frac{1}{1-v_{r \theta} v_{\theta r}}\left(E_{r} \frac{u_{i+1}-u_{i-1}}{2 h}+v_{r \theta} E_{\theta} \frac{u_{r}}{r}\right) \\
\sigma_{\theta}=\frac{1}{1-v_{r \theta} v_{\theta r}}\left(E_{\theta} \frac{u_{r}}{r}+v_{\theta r} E_{r} \frac{u_{i+1}-u_{i-1}}{2 h}\right)
\end{gathered}
$$

Donde los valores de $u_{-1}$ y $u_{n+1}$ pueden obtenerse de la expresión (Eq. 3-63) para $r=r_{p}(i=0)$ y $r=r_{p}+c$ $(i=n)$, quedando como sigue:

$$
\begin{gathered}
u_{-1}=\left(\frac{1}{h^{2}}-\frac{1}{2 h r_{p}}\right)^{-1} \cdot\left[u_{p}\left(\frac{2}{h^{2}}+\frac{E_{\theta, 0}}{E_{c, 0}} \frac{1}{r_{p}^{2}}\right)-u_{1}\left(\frac{1}{h^{2}}+\frac{1}{2 h r_{p}}\right)\right] \text { para } i=0 \\
u_{n+1}=\left(\frac{1}{h^{2}}+\frac{1}{2 h\left(r_{p}+c\right)}\right)^{-1}\left[u_{n}\left(\frac{2}{h^{2}}+\frac{E_{\theta, n}}{E_{c, n}} \frac{1}{\left(r_{p}+c\right)^{2}}\right)-u_{n-1}\left(\frac{1}{h^{2}}-\frac{1}{2 h\left(r_{p}+c\right)}\right)\right] \quad \text { para } i=n
\end{gathered}
$$

\subsubsection{Frente de fisuración $r_{c}$}

Conocida la ley tensión-deformación para el hormigón en tracción (Figura 3-3), y por tanto, siendo conocidos los valores de deformación crítica $\varepsilon_{c r}$ y deformación última $\varepsilon_{u}$, puede establecerse el nivel de fisuración de cada una de las regiones que conforman el recubrimiento de hormigón, así como el radio del frente de fisuración $r_{c}$. 
Inicialmente, para deformaciones pequeñas, se acepta que el hormigón de todo el recubrimiento se encuentra intacto, sin fisurar, y por tanto, en régimen elástico. Con el aumento de los desplazamientos en la cara interior del cilindro de pared gruesa, se produce un incremento de las deformaciones, tanto radiales en compresión $\varepsilon_{r}$, como circunferenciales en tracción $\varepsilon_{\theta}$. La fisuración no se considera un evento binario instantaneo, sino que se modela como un proceso de ablandamiento que comienza cuando, a nivel de la interfase, se supera la resistencia a tracción del hormigón $f_{t}{ }^{\prime}$, con una deformación $\varepsilon_{c r}$, y finaliza cuando la deformación circunferencial alcanza el valor $\varepsilon_{u}$, con tensiones residuales nulas. Este esquema nos permite establecer tres estados diferenciados del cilindro de pared gruesa en el proceso de fisuración (Figura 3-14):

- Cilindro sin fisurar [ $\left.\varepsilon_{\theta}<\varepsilon_{c t}\right]$ : se supone que el cilindro tiene un comportamiento elástico y lineal, al no superarse en ningún punto la resistencia a tracción del hormigón.

- Cilindro parcialmente fisurado: Una vez que la deformación circunferencial $\varepsilon_{\theta}$ alcanza su valor crítico $\varepsilon_{c r}$, el hormigón comienza a microfisurarse a nivel de la interfase. El cilindro se encuentra parcialmente fisurado, por lo que la respuesta a las presiones internas pasa a ser no lineal. Se establecen, por tanto, dos regiones: un anillo exterior de confinamiento con comportamiento elástico y lineal; y un anillo interior fisurado, en el que a su vez pueden diferenciarse otras dos zonas; aquella con deformaciones circunferenciales $\varepsilon_{\theta}$ menores a la deformación última $\varepsilon_{u}$, y por tanto con cierta capacidad residual a tracción, y aquella con resistencia a tracción nula, en la que las deformaciones han superado el valor de $\varepsilon_{u}$.

- Cilindro totalmente fisurado: Con el aumento de la presión interna (ya sea por productos de corrosión o por el efecto Hoyer), las fisuras se propagan en todas las direcciones a través del recubrimiento, hasta que una de ellas, situada en el lado más débil del elemento de hormigón, alcanza la superficie libre del mismo. Posteriores desplazamientos ocasionan que se alcance la deformación última en dicha superficie, y por tanto, la pérdida total de la capacidad de confinamiento del hormigón y el consiguiente fallo de la capacidad adherente.

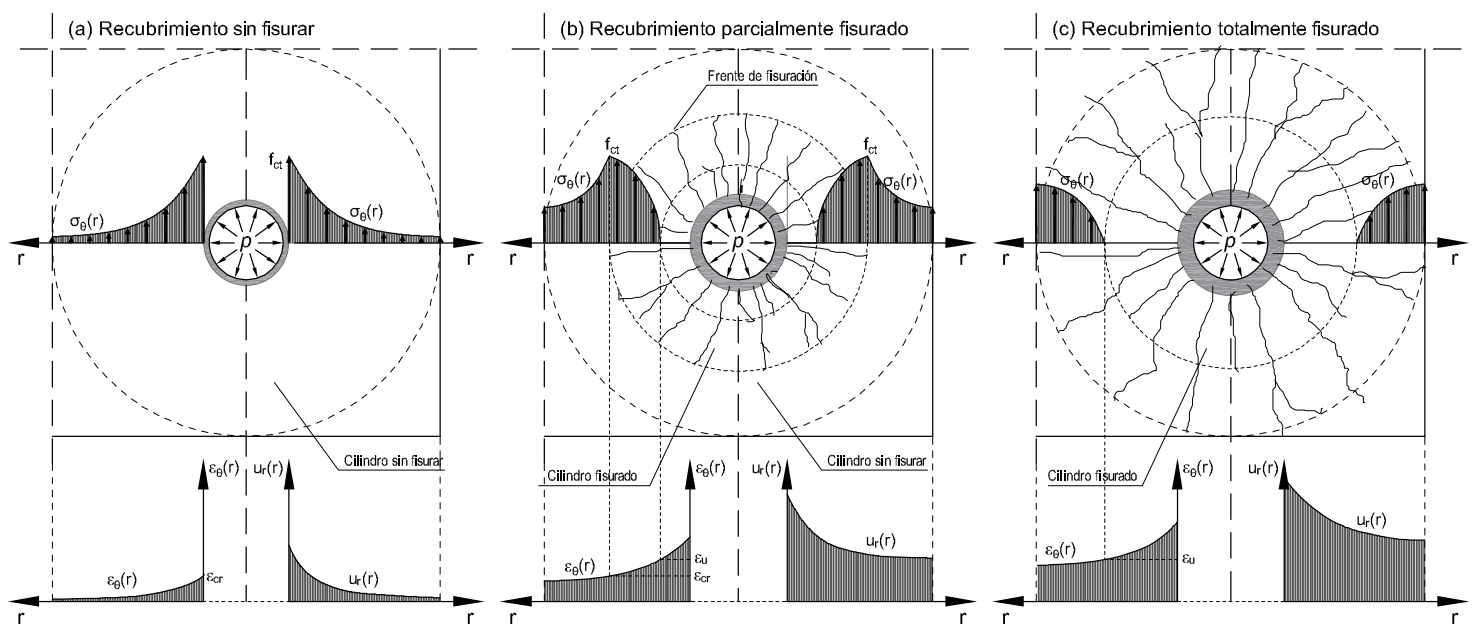

Figura 3-14 Diferentes estados de fisuración del recubrimiento de hormigón 


\subsubsection{Penetración de óxidos en fisuras}

Tal y como se ha indicado en las hipótesis de partida, el modelo analítico propuesto acepta que, una vez iniciada la fisuración en el hormigón que circunda el alambre, una parte de los productos de corrosión generados pueden depositarse en el interior de las fisuras abiertas. Por tanto, este espacio adicional para la difusión de los óxidos (equivalente a un porcentaje del volumen liberado por las fisuras) ocasionará, por una parte, que se retrase la fisuración del recubrimiento, por otra, que el pico de tensión máxima de adherencia $\tau_{b, \text { max }}$ tenga lugar para un valor más elevado de corrosión, y por último, que la tensión de adherencia residual $\tau_{b, r e s}$ sea mayor valor para el mismo nivel de pérdida de sección por corrosión. El porcentaje de productos de corrosión que se depositan en las fisuras se discute en el Capitulo 6 de la presente tesis.
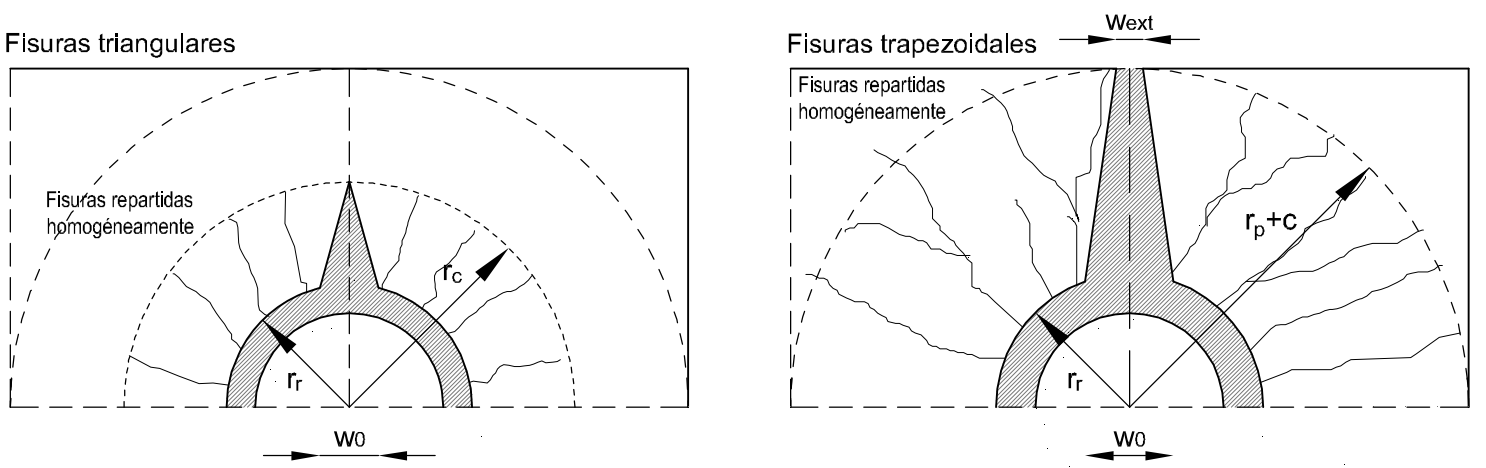

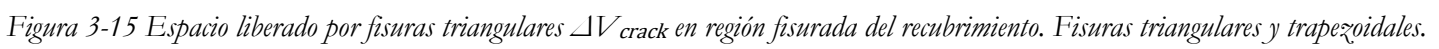

Cuando no se tiene en cuenta la fisuración, el valor combinado de cambio de volumen del acero $\Delta V$ s y del hormigón $\Delta V_{\text {, }}$ como se indicó anteriormente (Eq. 3-84), debe ser equivalente al volumen total comprimido de productos de corrosión $V_{r}$. En el caso de penetración de óxidos en las fisuras, se tendrá en cuenta un volumen adicional $\Delta V_{\text {crack }}$ correspondiente a un porcentaje del espacio adicional liberado por la fisuración, de manera que se obtiene una nueva relación de igualdad con la siguiente forma (Eq. 3-108):

$$
V_{r c}=\Delta V_{s}+\Delta V_{c}+\Delta V_{c r a c k}
$$

Tal y como se observa en la Figura 3-15, Pantazopoulou \& Papoulia (2001) modelizan las fisuras generadas con forma triangular, uniformemente distribuidas a lo largo de la región fisurada del recubrimiento, de manera que el volumen total por unidad de longitud disponible en las fisuras para el depósito de óxidos $\Delta V_{\text {crack }}$ es el siguiente (Eq. 3-109):

$$
\Delta V_{\text {crack }}=\sum w \frac{\left[r_{c}-r_{r}\right]}{2}=\sum w \frac{\left[r_{c}-\left(r_{b}-P_{x}+t_{r}\right)\right]}{2}=\sum w \frac{\left[r_{c}-r_{b}+P_{x}-t_{r}\right]}{2}
$$

Si el frente de fisuración $r_{c}$ alcanza la superficie del recubrimiento, de manera que el recubrimiento esté totalmente fisurado, las fisuras pasan a tener idealmente una forma trapezoidal, con lo que el volumen liberado por las mismas pasa a ser el siguiente (Eq. 3-110): 
TESIS DOCTORAL INFLUENCLA DE LA CORROSIÓN EN LA ADHERENCLA DE ALAMBRES EN ELEMENTOS PRETENSADOS DE HORMIGÓN

$$
\Delta V_{\text {crack }}=\sum \frac{\left(w+w_{\text {ext }}\right)}{2}\left[\left(r_{p}+c\right)-r_{r}\right]
$$

donde $w_{\text {ext }}$ es ancho de fisura en la superficie del recubrimiento. En el caso triangular habitual, sabiendo que $\sum w$ es el sumatorio del ancho de apertura de fisura a lo largo del perímetro del frente de avance de los óxidos, puede determinarse que (Eq. 3-111):

$$
\sum w=\varepsilon_{\theta} 2 \pi r_{b}=\frac{u_{0}}{r_{b}} 2 \pi r_{b}=u_{0} 2 \pi
$$

donde $\varepsilon_{\theta}$ es la deformación circunferencial en el frente de avance de los productos de oxidación. Sustituyendo (Eq. 3-111) en (Eq. 3-109) se obtiene que el volumen total de productos de corrosión que pueden depositarse en las fisuras (consideradas triangulares) es el siguiente (Eq. 3-112):

$$
\Delta V_{\text {crack }}=u_{0} 2 \pi \frac{\left[r_{c}-r_{r}\right]}{2}=u_{0} \pi\left[r_{c}-r_{r}\right]
$$

En el caso de que se consideraran fisuras rectangulares, se consideraría el siguiente valor de $V_{\text {crack }}$ :

$$
\Delta V_{\text {crack }}=u_{0} 2 \pi\left[r_{c}-r_{r}\right]=2 u_{0} \pi\left[r_{c}-r_{r}\right]
$$

Por tanto, la nueva presión $p$ provocada por la expansión de los productos de corrosión, teniendo en cuenta el espacio liberado por las fisuras para el depósito de óxidos, puede ser calculada sustituyendo las ecuaciones (Eq. 3-88), (Eq. 3-90) y (Eq. 3-111) en (Eq. 3-108), obteniéndose la siguiente ecuación (Eq. 3-114):

$$
\begin{aligned}
& \pi t_{r}\left[2\left(r_{p}-P_{x}\right)+t_{r}\right]\left(1-\frac{p}{K_{r}}\right)=\left\{\pi P_{x}\left(2 r_{p}-P_{x}\right)+\pi p \cdot \frac{1-v_{s}}{E_{s}} \cdot\left(r_{p}-P_{x}\right)^{2}\left[2-\frac{1-v_{s}}{E_{s}} \cdot p\right]\right\}+ \\
& \left\{\frac { ( r _ { p } + t _ { p } ) ^ { 4 } p \pi } { E _ { c } ( c + t _ { p } + 2 r _ { p } ) ( c - t _ { p } ) } [ ( 1 - v _ { c } ) + ( 1 + v _ { c } ) ( \frac { r _ { p } + c } { r _ { p } + t _ { p } } ) ^ { 2 } ] \cdot \left\{2+\frac{\left(r_{p}+t_{p}\right)^{2} \cdot p}{E_{c}\left(c+t_{p}+2 r_{p}\right)\left(c-t_{p}\right)} \cdot\left[\left(1-v_{c}\right)+(1+\right.\right.\right. \\
& \left.\left.\left.\left.v_{c}\right)\left(\frac{r_{p}+c}{r_{p}+t_{p}}\right)^{2}\right]\right\}\right\}+u_{0} \pi\left[r_{c}-r_{r}\right]
\end{aligned}
$$

Para despejar el valor de la presión $p$ de la anterior ecuación, se repite el proceso llevado a cabo en (Eq. 3-94), simplificándose a la siguiente forma (Eq. 3-115):

$$
F\left(1-\frac{p}{K_{r}}\right)=A+B p(2-C p)+D p(2+E p)+H
$$


Y operando, se obtiene la siguiente ecuación de $2^{\circ}$ grado, de donde se puede despejar fácilmente la presión interna provocada por los productos de corrosión $p$, en este caso teniendo en cuenta que una determinada cantidad de éstos se depositarán en las fisuras radiales alrededor del alambre (Eq. 3-116):

$$
(D E-B C) p^{2}+\left(2 B+2 D+\frac{F}{K_{r}}\right) p+(A-F+H)=0
$$

donde:

$$
\begin{aligned}
& A=\pi P_{x}\left(2 r_{p}-P_{x}\right) \\
& B=\pi \frac{1-v_{s}}{E_{s}}\left(r_{p}-P_{x}\right)^{2} \\
& C=\frac{1-v_{s}}{E_{S}} \\
& D=\frac{\left(r_{p}+t_{p}\right)^{4} \pi}{E_{c}\left(c+t_{p}+2 r_{p}\right)\left(c-t_{p}\right)}\left[\left(1-v_{c}\right)+\left(1+v_{c}\right)\left(\frac{r_{p}+c}{r_{p}+t_{p}}\right)^{2}\right] \\
& E=\frac{\left(r_{p}+t_{p}\right)^{2}}{E_{c}\left(c+t_{p}+2 r_{p}\right)\left(c-t_{p}\right)}\left[\left(1-v_{c}\right)+\left(1+v_{c}\right)\left(\frac{r_{p}+c}{r_{p}+t_{p}}\right)^{2}\right] \\
& F=\pi t_{r}\left[2\left(r_{p}-P_{x}\right)+t_{r}\right] \\
& H=u_{0} \pi\left[r_{c}-r_{r}\right]
\end{aligned}
$$

Una vez analizadas los efectos de la corrosión sobre el hormigón circundante, en el siguiente apartado se procede a describir la influencia de la retracción en el desarrollo de las tensiones en el recubrimiento.

\subsection{Modelado de la retracción $\left[\sigma_{r, s h}\right]$}

\subsubsection{Introducción}

En este apartado se modelan los efectos reológicos que afectan al comportamiento adherente en estructuras de hormigón, siendo estos principalmente la fluencia y la retracción. En ambos casos se trata de deformaciones dependientes del tiempo y, por tanto, no instantáneas. La primera se debe a la aplicación de una tensión constante a lo largo del tiempo, mientras que la segunda se debe a un gradiente de humedades entre el material y el medio en el que se encuentra. En esta tesis, el estudio de los efectos reológicos se centrará en la retracción, por tener una gran influencia en la capacidad del recubrimiento para generar confinamiento alrededor del alambre. Este efecto es particularmente significativo en el caso de alambres lisos sin corrosión y sin pretensar ya que, excluyendo la tensión de adherencia por el mecanismo de adhesión, es el único responsable de generar tensiones normales 
sobre la superficie del acero que, a la postre, posibilitan la aparición de tensiones tangenciales de adherencia en caso de que el alambre se encuentre solicitado.

\subsubsection{Retracción autógena y de secado}

Tal y como se apuntaba anteriormente, la retracción del hormigón consiste en una deformación volumétrica e isotrópica de contracción, cuya magnitud depende de las condiciones ambientales y de la duración de la exposición. Normalmente, se adopta la humedad relativa (HR) como variable de estado para definir este fenómeno. Debido a esta contracción, considerada como una deformación uniforme a lo largo de todo el volumen de hormigón, la presión interna necesaria para fisurar el hormigón, procedente tanto del aumento de volumen de los productos de corrosión como del efecto Hoyer del pretensado, se ve claramente incrementada. Es por ello que la retracción posibilita incrementos de la capacidad adherente, especialmente significativos para cantidades pequeñas de corrosión o niveles de pretensado moderados.

En la analogía del cilindro de pared gruesa, la retracción genera tensiones de compresión en la dirección radial $\sigma_{r, s h}$ mientras que el alambre embebido restringe el cambio de longitud del hormigón, actuando como un elemento rígido.

En este modelo analítico, para cuantificar el efecto de la retracción, se ha utilizado el modelo propuesto en el Model Code 2010 (CEB-FIP, 2012), que subdivide la retracción total en retracción autógena $\varepsilon_{c a s}$ y retracción por secado $\varepsilon_{c d s}$.

La retracción autógena $\varepsilon_{c a s}$ está asociada con la hidratación del cemento. Ocurre independientemente del ambiente, y consiste en la pérdida del agua de los poros capilares por causa de las reacciones químicas de hidratación del cemento. La retracción autógena se incrementa con la reducción de la relación agua/cemento a/c y la reducción del contenido de cemento.

La retracción por secado $\varepsilon_{c d s}$, por su parte, tiene lugar tras el fraguado, y se produce por la pérdida de humedad en la pasta cementicia del hormigón cuando está expuesto a un ambiente con humedad no saturada. Este fenómeno puede ocasionar en la pasta de cemento una reducción de volumen de hasta un 1\%. Al contrario de lo que ocurría con la retracción autógena, la retracción por secado disminuye con la reducción de la relación agua/cemento y la reducción del contenido de cemento. El Código Modelo 2010 (CEB-FIP, 2012), en vez de utilizar la cantidad total de cemento y la relación a/c, utiliza la resistencia a compresión del hormigón como parámetro sustitutivo, ya que normalmente es conocida en la etapa de diseño.

Por tanto, el procedimiento para determinar la retracción total del hormigón $\varepsilon_{s h}\left(t, t_{s}\right)$ en un determinado tiempo $t$, descrito por el Código Modelo 2010 y utilizado en esta tesis, es el siguiente (Eq. 3-118):

$$
\varepsilon_{s h}\left(t, t_{s}\right)=\varepsilon_{c a s}(t)+\varepsilon_{c d s}\left(t, t_{s}\right)
$$

Como se indicaba anteriormente, el Código Modelo 2010 subdivide la retracción total en retracción autógena $\varepsilon_{\text {cas }}(t)$ (Eq. 3-119): 


$$
\varepsilon_{\text {cas }}(t)=\varepsilon_{\text {cas } 0}\left(f_{c m}\right) \cdot \beta_{a s}(t)
$$

$Y$ en retracción por secado $\varepsilon_{c d s}\left(t, t_{s}\right)(E q .3-120)$ :

$$
\varepsilon_{c d s}\left(t, t_{s}\right)=\varepsilon_{c d s 0}\left(f_{c m}\right) \cdot \beta_{R H}(R H) \cdot \beta_{d s}\left(t-t_{s}\right)
$$

donde:
t Edad del hormigón, en días
$t_{s} \quad$ Edad del hormigón al comienzo del secado, en días
$\left(t, t_{s}\right) \quad$ Duración del periodo de saecado, en días

La componente de retracción autógena $\varepsilon_{c a s}(t)$ puede ser estimada a partir del coeficiente de retracción autógena $\varepsilon_{c a s 0}\left(f_{c m}\right)\left(E q\right.$. 3-121) y el coeficiente $\beta_{a s}(t)$ (Eq. 3-122) dependiente del tiempo:

$$
\begin{gathered}
\varepsilon_{c a s 0}\left(f_{c m}\right)=-\alpha_{a s}\left(\frac{f_{c m} / 10}{6+f_{c m} / 10}\right)^{2,5} \cdot 10^{-6} \\
\beta_{a s}(t)=1-e^{-0,2 \cdot \sqrt{t}}
\end{gathered}
$$

donde:

$$
\begin{aligned}
& f_{c m} \quad \text { Resistencia media a compresión del hormigón a la edad de } 28 \text { días, en } \mathrm{MPa} \\
& \alpha_{a s} \quad \text { Coeficiente dependiente del tipo de cemento, ver Tabla 3-1 }
\end{aligned}
$$

Tabla 3-1 Valores del coeficiente $\alpha_{i}$ en las ecuaciones (Eq. 3-121) y (Eq. 3-123)

\begin{tabular}{cccc}
\hline Clase de resistencia del cemento & $\alpha_{\text {as }}$ & $\alpha_{d s 1}$ & $\alpha_{d s 2}$ \\
\hline $32,5 \mathrm{~N}$ & 800 & 3 & 0,013 \\
\hline $32,5 \mathrm{R} ; 42,5 \mathrm{~N}$ & 700 & 4 & 0,012 \\
\hline $42,5 \mathrm{R} ; 52,5 \mathrm{~N} ; 52,5 \mathrm{R}$ & 600 & 6 & 0,012 \\
\hline
\end{tabular}

La retracción por secado $\varepsilon_{c d s}\left(t, t_{s}\right)$ es calculada a través del coeficiente teórico de retracción por secado $\varepsilon_{c d s 0}\left(f_{c m}\right)\left(E q\right.$. 3-123), el coeficiente $\beta_{R H}(R H)(E q$. 3-124), que toma en cuenta el efecto de la humedad relativa del ambiente, y de la función $\beta_{d s}\left(t-t_{s}\right)$ (Eq. 3-125), que describe su desarrollo en el tiempo:

$$
\varepsilon_{c d s 0}\left(f_{c m}\right)=\left[\left(220+110 \cdot \alpha_{d s 1}\right) \cdot e^{\left(-\alpha_{d s 2} \cdot f_{c m}\right)}\right] \cdot 10^{-6}
$$




$$
\begin{gathered}
\beta_{R H}=\left\{\begin{array}{c}
-1,55 \cdot\left[1-\left(\frac{R H}{100}\right)^{3}\right] ; \text { para } 40 \leq R H<99 \% \cdot \beta_{s 1} \\
0,25 \quad ; \text { para } R H \geq 99 \% \cdot \beta_{s 1}
\end{array}\right. \\
\beta_{d s}\left(t-t_{s}\right)=\left[\frac{\left(t-t_{s}\right)}{0,035 \cdot h^{2}+\left(t-t_{s}\right)}\right]^{0.5} \\
\beta_{s 1}=\left(\frac{35}{f_{c m}}\right)^{0,1} \leq 1,0
\end{gathered}
$$

donde:
$\alpha_{d s 1}, \alpha_{d s 2}$
Coeficientes dependientesdel tipo de cemento, ver Tabla 3-1.
$f_{c m}$ Resistencia media a compresión del hormigón a la edad de 28 días, obtenida de ensayos
$\mathrm{RH}$ Humedad relativa de la atmósfera, en \%.
$b$
$=2 A_{c} / u$, es el tamaño teórico del elemento, en mm, con $A_{c}$ igual a la sección transversal en $\mathrm{mm}^{2}$ y u igual al perímetro del elemnto en contacto con la atmósfera, en $\mathrm{mm}$
$t$
Edad total del hormigón, en días.
$t_{s}$
Edad del hormigón al comienzo del periodo de secado, en días.
$t-t_{s}$
Duración del periodo de secado del hormigón, en días.

La tensión radial debida a la retracción $\sigma_{r, s, b}$, determinada en este apartado a través de la deformación $\varepsilon_{s h}\left(t, t_{s}\right)$, junto con las tensiones radiales derivadas de la transferencia del pretensado $\sigma_{r, p}$ y de la corrosión $\sigma_{r, \text { corr }}$, configuran la tensión radial total $\sigma_{r}$ a la que está sometido el alambre antes del ensayo de arrancamiento.

\section{FASE II: SIMULACIÓN DE LOS ENSAYOS DE PULL-OUT}

En este apartado se expone la modelización de todas aquellas variables que permiten simular la tensión de adherencia $\tau_{b}$ que se obtiene en los ensayos de pull-out, partiendo de las tensiones radiales $\sigma_{r}$ obtenidas en los apartados anteriores, en virtud de la aplicación de la expresión (Eq. 3-8). Por tanto, a continuación se cuantifica la tensión radial de confinamiento $\sigma_{r, c o n f}$ (Apartado 3.6), derivada de la propia configuración del ensayo, y se analiza la relación existente entre la tensión de adherencia $\tau_{b} \mathrm{y}$ el deslizamiento $s$ (Apartado 3.7). 


\subsection{Modelado de fuerzas externas de confinamiento $\left[\sigma_{r, c o n f}\right]$}

Las fuerzas externas de compresión mejoran el comportamiento adherente de alambres embebidos en hormigón al incrementar la capacidad de confinamiento del recubrimiento, lo que posibilita que se alcancen mayores tensiones radiales $\sigma_{r}$ y se minimice la posibilidad de fallo por fisuración o splitting (Tastani \& Pantazopoulou, 2006). En la configuración habitual de los ensayos de pull-out, la fuerza de arrancamiento genera un campo de tensiones diagonales de compresión, desde la placa de reparto sobre la que se ejerce la fuerza hasta la superficie de la longitud adherente del alambre (Figura 3-10). $\mathrm{El}$ consiguiente aumento de las tensiones radiales alrededor del alambre mejora considerablemente sus prestaciones adherentes, por lo que el modelo analítico desarrollado, que pretende simular los ensayos de pull-out, debe tener en cuenta este efecto favorable para evitar sobreestimar las tensiones de adherencia procedentes exclusivamente del confinamiento proporcionado por el hormigón. Algunos autores (Malvar, 1995) han llegado a cuantificar en hasta un 100\% el incremento de la tensión de adherencia obtenida en los ensayos de arrancamiento respecto a los resultados arrojados por los ensayos de adherencia por flexión (ensayo de la viga), con las mismas características mecánicas y geométricas.

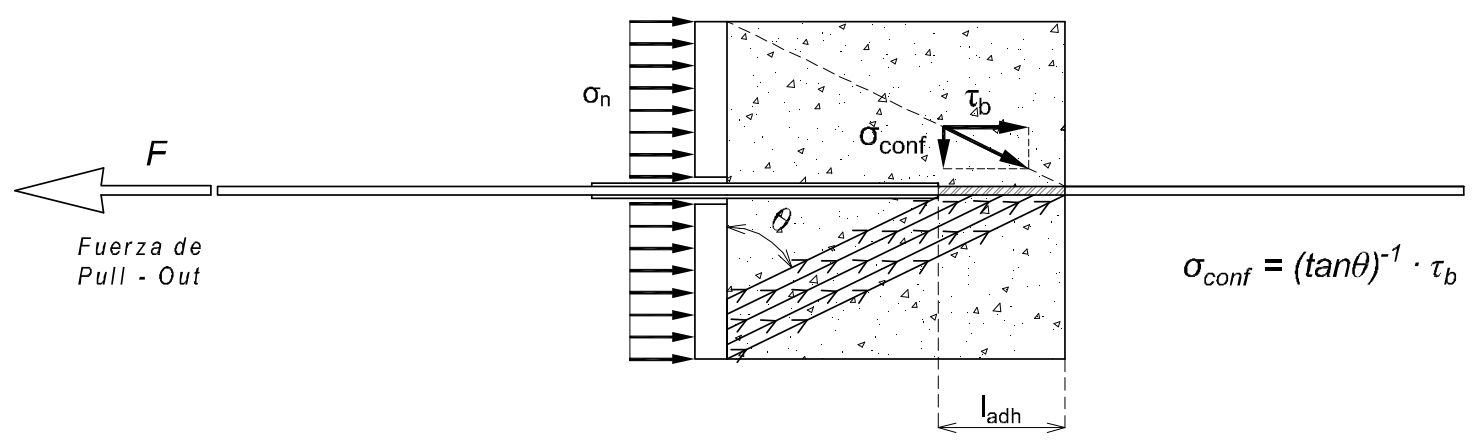

Figura 3-16 Tensiones radiales de confinamiento originadas por la configuración del ensayo de pull-out.

En definitiva, por equilibrio de fuerzas, tal y cómo se muestra en la Figura 3-16, se puede estimar que la tensión radial de confinamiento $\sigma_{\text {conf }}$ procedente de la fuerza de arrancamiento $F$ ejercida durante el ensayo de pull-out responde a la siguiente expresión (Eq. 3-127):

$$
\sigma_{\text {conf }}=(\tan \theta)^{-1} \tau_{b}
$$

donde:
$\tau_{b}$
Tensión de adherencia.
$\sigma_{\text {conf }}$
Tensión radial de confinamiento.
$\theta$
Ángulo entre la superficie normal a la fuerza de arrancamiento y la diagonal determinada por el semilado de la placa de reparto y la longitud embebida del alambre. 


\subsection{Relación adherencia-deslizamiento}

\subsubsection{Introducción}

El comportamiento adherente local está caracterizado por la relación existente entre la tensión de adherencia en la interfaz acero-hormigón y el deslizamiento local a lo largo de la longitud adherente (Rehm, 1961). Esta relación tensión de adherencia-deslizamiento depende de un considerable número de factores, incluyendo la geometría de la superficie del alambre (liso, indentado o corrugado), la resistencia del hormigón, la posición y orientación del alambre durante el hormigonado, el estado tensional del elemento, las condiciones de contorno y/o el espesor de recubrimiento.

\subsubsection{Formulación de las ecuaciones}

Las ecuaciones diferenciales que gobiernan el comportamiento adherente de un alambre de acero embebido en hormigón y sometido a una fuerza de arrancamiento se derivan, por una lado, del equilibrio de fuerzas aplicado a una rebanada transversal de longitud $d x$ y, por otro, de la compatibilidad entre el deslizamiento $s$ de la barra y las deformaciones del hormigón $\varepsilon_{c}$ y del acero $\varepsilon_{s}$ sobre dicha rebanada (Tassios \& Yannopoulos, 1981) (Filippou, et al., 1983) (Tastani \& Pantazopoulou, 2013).

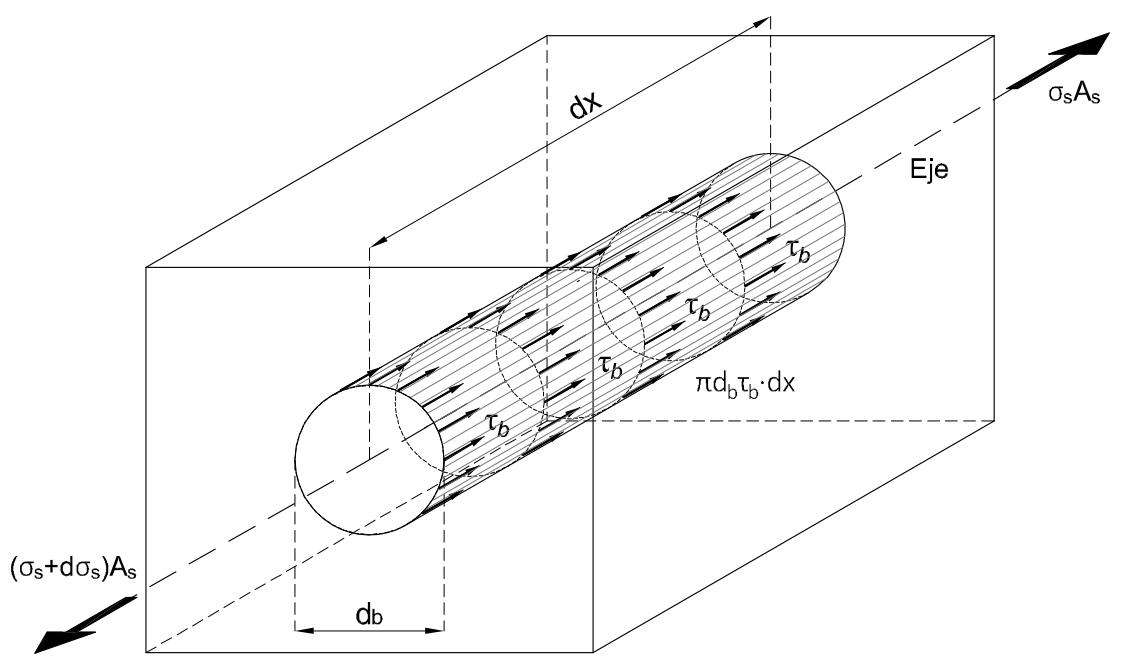

Figura 3-17 Tensiones de adherencia a lo largo de un alambre de acero embebido en hormigón (Martín-Pérez, 2014)

La tensión de adherencia a una distancia $x$ del extremo de la barra $\tau_{b}(x)$ está relacionada con el cambio en la tensión normal del acero a lo largo de la longitud del elemento diferencial $d x$, tal y como se muestra en la Figura 3-17, por lo que estableciendo el equilibrio de fuerzas sobre el elemento se extrae la siguiente relación (Eq. 3-128):

$$
\sum F_{x}=\left[\sigma_{s}(x)+d \sigma_{s}(x)\right] A_{s}-\sigma_{s}(x) A_{s}-\pi d_{b} \tau_{b}(x) d x=0
$$

Y operando (Eq. 3-129): 


$$
\tau_{b}(x)=-\frac{A_{s}}{\pi d_{b}} \frac{d \sigma_{s}(x)}{d x}=-\frac{d_{b}}{4} \frac{d \sigma_{s}(x)}{d x}
$$

donde $\sigma_{S}(x)$ es la tensión normal en el alambre y $A_{S}$ es el área de la sección transversal del acero.

Por otro lado, el incremento del deslizamiento local $s$ a lo largo de una longitud infinitesimal de alambre puede ser definido como la diferencia entre las deformaciones del acero $\varepsilon_{s}$ y del hormigón $\varepsilon_{i}$ :

$$
\frac{d s(x)}{d x}=-\left[\varepsilon_{s}(x)-\varepsilon_{c}(x)\right]
$$

Considerando que la contribución del hormigón al deslizamiento relativo $\varepsilon_{s} \cdot d x$ puede ser despreciada, al ser la deformación media del hormigón un orden de magnitud menor que la deformación media del alambre, la expresión (Eq. 3-130) puede simplificarse tomando la siguiente forma (Eq. 3-131):

$$
\frac{d s(x)}{d x} \approx-\varepsilon_{s}(x)
$$

Las ecuaciones anteriores (Eq. 3-129) y (Eq. 3-131) están relacionadas a través de la ley adherenciadeslizamiento, por un lado (Eq. 3-132):

$$
\tau_{b}(x)=f[s(x)]
$$

y por el otro, suponiendo un comportamiento elástico, por las relaciones de tensión-deformación del material (Eq. 3-133):

$$
\sigma_{s}(x)=E_{s} \varepsilon_{s}(x)
$$

Sustituyendo las ecuaciones (Eq. 3-131) y (Eq. 3-133) en (Eq. 3-129) se obtiene la ecuación diferencial de segundo orden que gobierna la relación tensión de adherencia-deslizamiento (Eq. 3-134):

$$
\tau_{b}(x)=\frac{d_{b} E_{s}}{4} \frac{d^{2} s(x)}{d x^{2}}
$$

\subsubsection{Ley de adherencia local-deslizamiento}

Para la resolución de dicha ecuación se requiere conocer las leyes constitutivas del acero (Eq. 3-133), así como la ley de adherencia local-deslizamiento para la interfase acero-hormigón. En el modelo analítico que nos ocupa, para la obtención de la distribución de las deformaciones longitudinales $\varepsilon_{s}$, de los deslizamientos del alambre $s$ y de la tensión de adherencia $\tau_{b}$ a lo largo de la longitud adherente, se ha optado por una ley adherencia local-deslizamiento no-lineal, perfectamente plástica, formada por una curva lineal por tramos que comprende cuatro segmentos diferenciados (Figura 3-18). Se ha seleccionado esta ley porque, sin pérdida de generalidad, su simplicidad permite una fácil resolución 
de la ecuación diferencial que rige el fenómeno, y además, en base a la revisión bibliográfica llevada a cabo, es la más utilizada en estudios anteriores al ser la que mejor reproduce los resultados experimentales (Eligehausen, et al., 1983) (Yankelevsky, 1985) (Eleftheriou, et al., 2013) (Melo, et al., 2014).

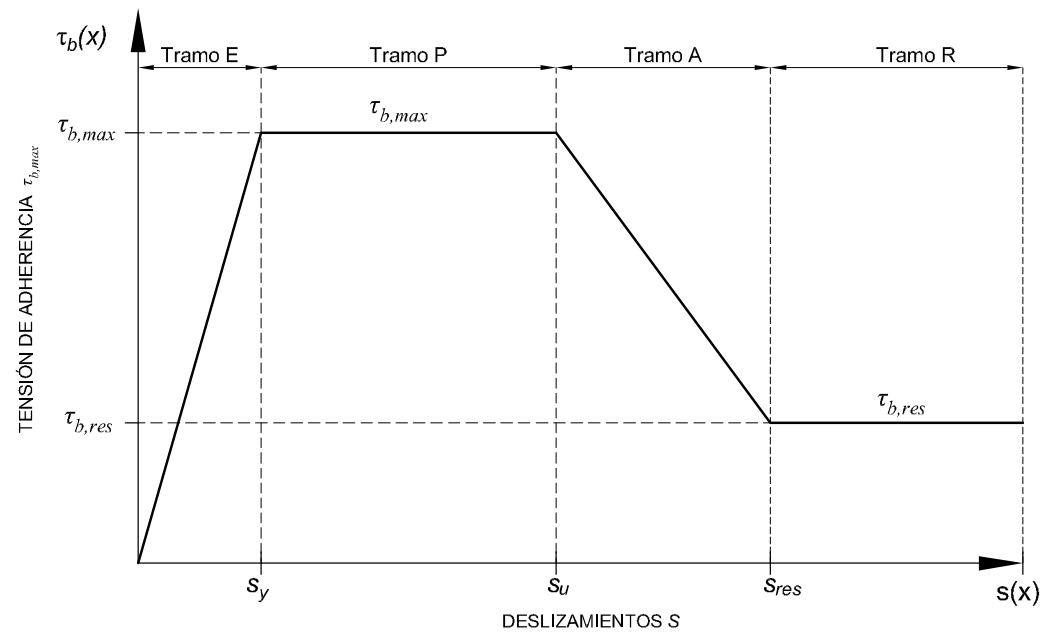

Figura 3-18 Ley de adherencia local-deslizamiento utilizada en el modelo

La ley de adherencia local-deslizamiento escogida permite reproducir los diferentes estados tensionales que experimenta el alambre de acero, a lo largo de su longitud, cuando es sometido a una fuerza de arrancamiento paralela a su directriz (Figura 3-18). El trazado de la curva por tramos que describe la ley viene definido por las siguientes ecuaciones:

\begin{tabular}{|c|c|c|c|}
\hline Tramo $\boldsymbol{E}$ - Elástico: & $\tau_{b, E}(s)=\frac{\tau_{b, \max }}{s_{y}} s$ & $; 0 \leq s<s_{y}$ & (Eq. 3-135) \\
\hline Tramo P - Plástico: & $\tau_{b, P}(s)=\tau_{b, \max }$ & $; s_{y} \leq s<s_{u}$ & (Eq. 3-136) \\
\hline Tramo A - Ablandamiento: & $\tau_{b, A}(s)=\tau_{b, \max }-\frac{\tau_{b, \max }-\tau_{b, r e s}}{s_{\text {res }}-s_{u}}\left(s-s_{u}\right)$ & $; s_{u} \leq s<s_{\text {res }}$ & (Eq.3-137) \\
\hline Tramo $\boldsymbol{R}$ - Tensión residual: & $\tau_{b, R}(s)=\tau_{b, \text { res }}$ & $; s \geq s_{\text {res }}$ & (Eq. 3-138) \\
\hline
\end{tabular}

donde:
$\tau_{b, \max } \quad$ Tensión máxima de adherencia
$\tau_{b, \text { res }} \quad$ Tensión residual de adherencia
sy Valor del deslizamiento relativo al final de la región elástica de adherencia
$s_{u} \quad$ Valor del deslizamiento relativo al final de la región plástica de adherencia
ses $\quad$ Valor del deslizamiento relativo previo a la región de tensión residual de adherencia 


\subsubsection{Resolución de las ecuaciones de adherencia a lo largo del alambre}

Sobre la base del estudio de Yankelesky (Yankelevsky, 1985) y las posteriores revisiones de Eleftheriou et al. (Eleftheriou, et al., 2013) y Tastani et al. (Tastani \& Pantazopoulou, 2013), se procederá a la resolución de las ecuaciones que rigen el comportamiento de un alambre embebido en hormigón y sometido a una fuerza de arrancamiento, lo que permitirá la simulación de ensayos de pull-out.

Con el aumento de la fuerza de arrancamiento, el alambre experimenta un paulatino aumento del deslizamiento relativo, de manera que cada punto a lo largo de la longitud adherente va recorriendo el rango de valores de deslizamiento de la ley de adherencia local-deslizamiento (Figura 3-18), experimentando la correspondiente tensión de adherencia y el consiguiente nivel de daño. Una vez que han sido establecidas las ecuaciones de cada uno de los cuatro tramos, éstas pueden combinarse con la ecuación diferencial general (Eq. 3-134), permitiendo determinar, a lo largo del proceso de carga, la distribución de las deformaciones longitudinales $\varepsilon_{s}$, de los deslizamientos del alambre $s$ y de la tensión de adherencia $\tau_{b}$ :

\section{TRAMO E: Comportamiento elástico: $0 \leq s(x)<s_{y}$}

La variación de la tensión de adherencia en este tramo, tal y como se ha visto anteriormente, es $\tau_{b}(x)=\frac{\tau_{b, \max }}{s_{y}} s(x)$, por lo que sustituyendo en la ecuación general (Eq. 3-134) se obtiene (Eq. 3-139):

$$
\frac{d^{2} s(x)}{d x^{2}}-\frac{4 \tau_{b, \max }}{d_{b} E_{s} s_{y}} s(x)=0
$$

Siendo su solución general la siguiente (Eq. 3-140):

$$
s_{E}(x)=C_{1} e^{-\omega_{1} x}+C_{2} e^{\omega_{1} x}
$$

De la que derivando se puede obtener la variación de deformaciones con respecto a la distancia $x$ (Eq. 3-141):

$$
\varepsilon_{E}(x)=\frac{d s(x)}{d x}=C_{1} \omega e^{-\omega_{1} x}-C_{2} \omega e^{\omega_{1} x}
$$

donde $\omega_{1}=\sqrt{\frac{4 \tau_{b, \max }}{d_{b} E_{s} s_{y}}}$ y $C_{1}, C_{2}$ son las constantes que han de determinarse por las condiciones de contorno.

\section{TRAMO P: Comportamiento perfectamente plástico: $s_{y} \leq s(x)<s_{u}$}

En este tramo la tensión de adherencia es constante e igual a la tensión máxima de adherencia $\tau_{b}(x)=\tau_{b, \max }$, con lo que al sustituir en (Eq. 3-134) se tiene la siguiente expresión (Eq. 3-142):

$$
\frac{d^{2} s(x)}{d x^{2}}-\frac{4 \tau_{b, \max }}{d_{b} E_{s}}=0
$$


TESIS DOCTORAL INFLUENCLA DE LA CORROSIÓN EN LA ADHERENCLA DE ALAMBRES EN ELEMENTOS PRETENSADOS DE HORMIGÓN

Cuya solución es (Eq. 3-143):

$$
S_{P}(x)=\frac{2 \tau_{b, \max }}{E_{S} d_{b}} x^{2}-C_{3} x+C_{4}
$$

donde $C_{3}, C_{4}$ son las constantes a determinar por las condiciones de contorno. Por su parte, la distribución de deformaciones atenderá a la siguiente expresión (Eq. 3-144):

$$
\varepsilon_{P}(x)=\frac{d s(x)}{d x}=-\frac{4 \tau_{b, \max }}{E_{s} d_{b}} x+C_{3}
$$

\section{TRAMO A: Ablandamiento: $s_{u} \leq s<s_{\text {res }}$}

La expresión de la tensión de adherencia en esta región es $\tau_{b}(x)=\tau_{b, \max }-k_{1}\left(s(x)-s_{u}\right)$ donde $k_{1}=\frac{\tau_{b, \text { max }}-\tau_{b, r e s}}{s_{\text {res }}-s_{u}}$, por lo que combinando con (Eq. 3-134) se obtiene:

$$
\frac{4}{d_{b} E_{s}}\left(k_{1} s_{u}+\tau_{b, \max }\right)=\frac{d^{2} s(x)}{d x^{2}}+\frac{4}{d_{b} E_{s}} k_{1} s(x)
$$

Cuya solución toma la siguiente forma (Eq. 3-146)(Eq. 3-147):

$$
\begin{gathered}
s_{A}(x)=C_{5} \operatorname{sen}\left(\omega_{2} x\right)+C_{6} \cos \left(\omega_{2} x\right)+\frac{k_{1} s_{u}+\tau_{b, \max }}{k_{1}} \\
\varepsilon_{A}(x)=-C_{5} \omega_{2} \cos \left(\omega_{2} x\right)+C_{6} \omega_{2} \operatorname{sen}\left(\omega_{2} x\right)
\end{gathered}
$$

donde $\omega_{2}=\sqrt{\frac{4 k_{1}}{d_{b} E_{s}}}$ y $C_{5}, C_{6}$ son las constantes que tienen que determinarse por las condiciones de contorno.

\section{TRAMO R: Tensión residual: $s \geq s_{\text {res }}$}

En esta región la tensión de adherencia es constante $\tau_{b}(x)=\tau_{b \text {,res }}$, tal y como ocurría en el tramo plástico, por lo que las expresiones de distribución de los deslizamientos y las deformaciones serán similares (Eq. 3-148)(Eq. 3-149):

$$
\begin{gathered}
s_{R}(x)=\frac{2 \tau_{b, r e s}}{E_{s} d_{b}} x^{2}-C_{7} x+C_{8} \\
\varepsilon_{R}(x)=\frac{d s(x)}{d x}=-\frac{4 \tau_{b, r e s}}{E_{s} d_{b}} x+C_{7}
\end{gathered}
$$

donde $C_{7}, C_{8}$ son las constantes que han de determinarse por las condiciones de contorno. 


\subsubsection{Distribución de deslizamientos, deformaciones y tensiones}

En general, según lo recogido en el apartado anterior, puede afirmarse que en problema existen 11 incógnitas: 8 constantes de integración $C_{1}-C_{8}$ y tres coordenadas $x_{y}, x_{u}$ y $x_{\text {res, }}$ correspondientes a las distancias $x$ desde el extremo cargado en las que los deslizamientos relativos son iguales a $s_{y}, s_{u}$ y $s_{r e s,}$ respectivamente. Para la determinación de éstas deben utilizarse las siguientes condiciones de contorno:

- Deben imponerse criterios de continuidad de las soluciones, tanto de deformaciones como de deslizamientos, en cada uno de los puntos de transición $\left(x_{y}, x_{\imath}\right.$ y $\left.x_{r e s}\right)$ entre las cuatro zonas descritas anteriormente.

- En $x=l_{b}$, la deformación longitudinal es conocida $\left[\varepsilon\left(x=l_{b}\right)=0\right]$.

- En $x=0$, las deformaciones o los deslizamientos, dependiendo del tipo de entrada de datos, son conocidos.

Dada la ley de adherencia-deslizamiento seleccionada, el paulatino incremento de carga configura cuatro etapas sucesivas, con distintas configuraciones tensionales, a través de las cuales irá pasando el alambre durante el ensayo. Son los siguientes:

\section{ETAPA I: Régimen elástico en toda la longitud adherente}

Si la deformación inicial en el extremo cargado $\varepsilon_{0}$ es baja, de manera que el deslizamiento $s(x)$ es menor a $s_{y}$ en la totalidad de la longitud adherente, la tensión de adherencia en la interfaz acerohormigón se mantiene en régimen elástico. Se supone, por tanto, que la variación de tensiones, deslizamientos y deformaciones siguen las expresiones deducidas para el Tramo E de la ley de adherencia local-deslizamiento (Eq. 3-140)(Eq. 3-141).
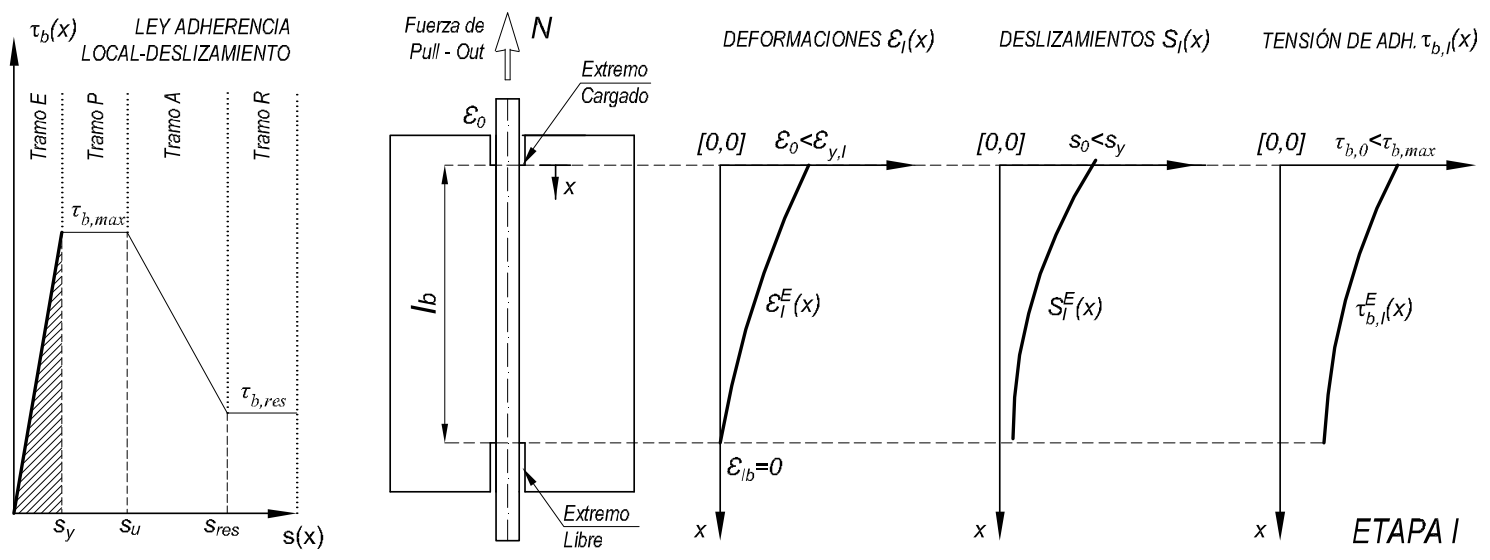

Figura 3-19 Deformaciones, deslizamientos y tensiones de adberencia a lo largo de un alambre de acero embebido en hormigón en la Etapa I

Suponiendo que el extremo cargado se encuentra en $x=0$ (por tanto, el extremo libre se encuentra en $\left.x=l_{b}\right)$, las condiciones de contorno son las siguientes (Eq. 3-150): 
TESIS DOCTORAL INFLUENCLA DE LA CORROSIÓN EN LA ADHERENCLA DE ALAMBRES EN ELEMENTOS PRETENSADOS DE HORMIGÓN

$$
\varepsilon_{I}^{E}(x=0)=\varepsilon_{0} \quad \varepsilon_{I}^{E}\left(x=l_{b}\right)=0
$$

Donde $\varepsilon_{0}$ es la deformación en el extremo cargado del alambre debida a la carga externa aplicada.

La aplicación de las condiciones de contorno determina el siguiente sistema de ecuaciones, cuya resolución permite determinar el valor de las constantes $C_{1}$ y $C_{2}$ (Eq. 3-151):

$$
\left.\begin{array}{l}
C_{1}=\frac{\varepsilon_{0}}{\omega_{1}} \frac{e^{2 \omega_{1} l_{b}}}{e^{2 \omega_{1} l_{b}}-1} \\
C_{2}=\frac{\varepsilon_{0}}{\omega_{1}} \frac{1}{e^{2 \omega_{1} l_{b}}-1}
\end{array}\right\}
$$

Las ecuaciones finales de la variación de las deformaciones, los deslizamientos y las tensiones en la Etapa I se obtienen con la sustitución de las constantes calculadas en las ecuaciones (Eq. 3-140) y (Eq. 3-141):

$$
\begin{array}{ll}
\varepsilon_{I}^{E}(x)=\frac{\varepsilon_{0}}{1-e^{2 \omega_{1} l_{b}}}\left(e^{\omega_{1} x}-e^{2 \omega_{1} l_{b}-\omega_{1} x}\right) \leq \varepsilon_{y, I} & 0 \leq x \leq l_{b} \\
s_{I}^{E}(x)=\frac{\varepsilon_{0}}{\omega_{1}\left(1-e^{2 \omega_{1} l_{b}}\right)}\left(-e^{\omega_{1} x}-e^{2 \omega_{1} l_{b}-\omega_{1} x}\right) \leq s_{y} & 0 \leq x \leq l_{b} \\
\tau_{b, I}^{E}(x)=\frac{\tau_{b, \max }}{s_{y}} s(x) & 0 \leq x \leq l_{b}
\end{array}
$$

donde $\varepsilon_{y, I}$ es el valor límite de deformación del alambre más allá del cual el mecanismo de adherencia entra en estado de plastificación (Tramo P), a pesar de que la barra permanezca en régimen elástico. La deformación límite $\varepsilon_{y, I}$ está íntimamente relacionada con el valor límite de deslizamiento $s_{y} \mathrm{y}$ puede determinarse igualando dicho valor al desplazamiento en el extremo cargado $\left[s_{I}^{E}(x=0)=\right.$ $s_{y}$ ] (Eq. 3-153), y sustituyendo $\varepsilon_{0}$ por $\varepsilon_{y, I}$, obteniéndose la siguiente expresión (Eq. 3-155):

$$
s_{I}^{E}(x=0)=s_{y} \quad ; \quad \varepsilon_{I}^{E}(x=0)=\varepsilon_{0}=\varepsilon_{y, I} \Rightarrow \quad \varepsilon_{y, I}=s_{y} \omega_{1} \frac{e^{2 \omega_{1} l_{b}}-1}{e^{2 \omega_{1} l_{b}}+1}
$$

Tal y como indica Tastani et al. (Tastani \& Pantazopoulou, 2013), si se analizan los deslizamientos en el extremo cargado del anclaje $\left(x=l_{b}\right)$ se puede comprobar que existen deslizamientos bajo cargas muy pequeñas, lo cual es consistente con los resultados experimentales recogidos en estudios anteriores.

Para esta etapa, la tensión de adherencia media $\tau_{b}^{\text {med }}$ se obtiene repartiendo uniformemente el sumatorio de tensiones de adherencia a lo largo de toda la longitud adherente, tal y como sigue

$$
\tau_{b, l}^{\text {med }}=\frac{1}{l_{b}} \int_{0}^{l_{b}} \tau_{b}(x) d x=\frac{1}{l_{b}} \int_{0}^{l_{b}} \frac{\tau_{b, \max }}{s_{y}} s(x) d x=\frac{\varepsilon_{0}}{l_{b} s_{y} \omega_{1}^{2}} \tau_{b, \max }
$$




\section{ETAPA II: Régimen elástico y plástico}

Una vez que la deformación en el extremo cargado del alambre ha superado el valor límite $\varepsilon_{y, I}$ (o lo que es equivalente, que se sobrepase el deslizamiento $s_{y}$ ), se alcanza la tensión máxima de adherencia $\tau_{b, \max }$ y el mecanismo de adherencia entra régimen plástico. La longitud del alambre donde se supera la deformación límite se denomina $l_{p}$, por lo que puede suponerse que, para el intervalo $0 \leq x \leq l_{p}$, el alambre se encuentra en el Tramo $P$ de la ley adherencia-deslizamiento (deslizamientos mayores a $s_{y}$ ), mientras que en el intervalo $l_{p} \leq x \leq l_{b}$ está localizado en la región de comportamiento elástico (Tramo E). Por tanto, las ecuaciones (Eq. 3-143) y (Eq. 3-144) describen la variación de desplazamientos y deformaciones para puntos situados en $l_{p}\left(x<l_{p}\right)$, mientras que las ecuaciones (Eq. 3-140) y (Eq. 3-141) lo hacen para puntos situados en la región $\mathrm{x} \geq l_{p}$ (Figura 3-20).
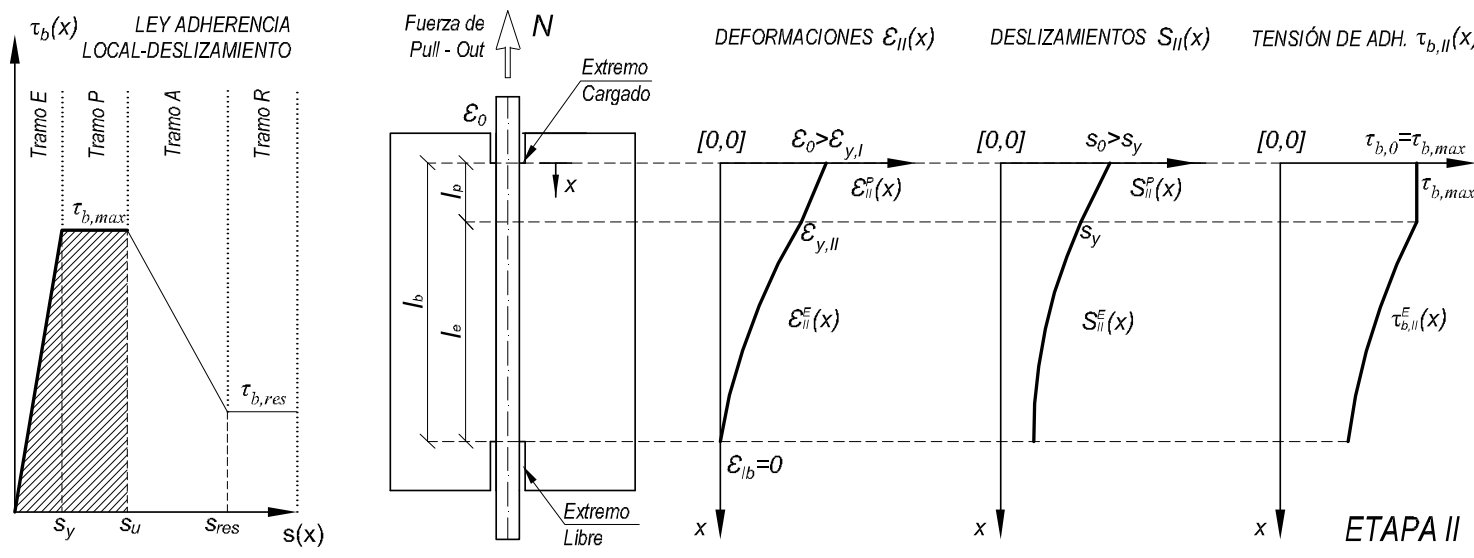

Figura 3-20 Deformaciones, deslizamientos y tensiones de adherencia a lo largo de un alambre de acero embebido en hormigón en la Etapa II

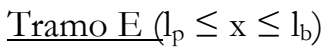

Las condiciones de contorno para este tramo son las siguientes (Eq. 3-157):

$$
\varepsilon_{I I}^{E}\left(x=l_{p}\right)=\varepsilon_{y, I I} \quad \varepsilon_{I I}^{E}\left(x=l_{b}\right)=0
$$

Donde $\varepsilon_{y, I I}$ es valor reducido de la deformación en la barra, comparado con $\varepsilon_{0}$ y $\varepsilon_{y, I}$, en el que se produce la plastificación del mecanismo de adherencia y que limita la longitud $l_{\mathrm{p}}$.

Aplicando estas condiciones de contorno nos permite deducir los valores de $C_{1}$ y $C_{2}$ (Eq. 3-158):

$$
\left.\begin{array}{rl}
C_{1} & =\frac{\varepsilon_{y, I I}}{\omega_{1}} \frac{e^{\omega_{1}\left(2 l_{b}-l_{p}\right)}}{e^{2 \omega_{1}\left(l_{b}-l_{p}\right)}-1} \\
C_{2} & =\frac{\varepsilon_{y, I I}}{\omega_{1}} \frac{e^{-\omega_{1} l_{p}}}{e^{2 \omega_{1}\left(l_{b}-l_{p}\right)}-1}
\end{array}\right\}
$$

y sustituyendolos en las ecuaciones (Eq. 3-140) y (Eq. 3-141), se obtienen la variación de las deformaciones, los deslizamientos y las tensiones en el intervalo $l_{p} \leq x \leq l_{b}$ : 
TESIS DOCTORAL INFLUENCLA DE LA CORROSIÓN EN LA ADHERENCLA DE ALAMBRES EN ELEMENTOS PRETENSADOS DE HORMIGÓN

$$
\begin{aligned}
& \varepsilon_{I I}^{E}(x)=\frac{\varepsilon_{y, I}}{1-e^{2 \omega_{1}\left(l_{b}-l_{p}\right)}}\left(e^{\omega_{1}\left(x-l_{p}\right)}-e^{2 \omega_{1}\left(l_{b}-l_{p}\right)-\omega_{1}\left(x-l_{p}\right)}\right) \leq \varepsilon_{y, I I} \quad l_{p} \leq x \leq l_{b} \\
& s_{I I}^{E}(x)=\frac{\varepsilon_{y, I I}}{\omega_{1}\left(1-e^{2 \omega_{1}\left(l_{b}-l_{p}\right)}\right)}\left(-e^{\omega_{1}\left(x-l_{p}\right)}-e^{2 \omega_{1}\left(l_{b}-l_{p}\right)-\omega_{1}\left(x-l_{p}\right)}\right) \leq s_{y} \quad l_{p} \leq x \leq l_{b} \quad \text { (Eq. 3-160) } \\
& \tau_{b, I I}^{E}(x)=\frac{\tau_{b, \max }}{s_{y}} s(x) \leq \tau_{b, \max } \quad l_{p} \leq x \leq l_{b} \quad \text { (Eq. 3-161) }
\end{aligned}
$$

$\left.\underline{\operatorname{Tramo} P(0} \leq \mathrm{x} \leq \mathrm{l}_{\mathrm{p}}\right)$

Las condiciones de contorno para este tramo son las siguientes (Eq. 3-162):

$$
\varepsilon_{I I}^{P}(x=0)=\varepsilon_{0} \quad s_{I I}^{P}\left(x=l_{p}\right)=s_{y} \quad \varepsilon_{I I}^{P}\left(x=l_{p}\right)=\varepsilon_{y, I I}
$$

Aplicando la primera condición a la ecuación (Eq. 3-144) se obtiene el valor de la constante $C_{3}$ (Eq. 3-163):

$$
\varepsilon_{I I}^{P}(x=0)=-\frac{4 \tau_{b, \max }}{E_{S} d_{b}} x+C_{3}=\varepsilon_{0} \Rightarrow C_{3}=\varepsilon_{0}
$$

Aplicando la segunda condición de contorno en la ecuación (Eq.3-143), en el intervalo $0 \leq x \leq l_{\text {p }}$, se logra despejar el valor de la constante $C_{4}$ (Eq. 3-164):

$$
s_{I I}^{P}\left(x=l_{p}\right)=s_{y} \Rightarrow \frac{2 \tau_{b, \max }}{E_{s} d_{b}} l_{p}{ }^{2}-\varepsilon_{0} l_{p}+C_{4}=s_{y} \Rightarrow C_{4}=-\frac{2 \tau_{b, \max }}{E_{S} d_{b}} l_{p}{ }^{2}+\varepsilon_{0} l_{p}+s_{y} \quad \text { (Eq. 3-164) }
$$

Por tanto, las ecuaciones generales para este tramo adoptarán la siguiente forma:

$$
\begin{array}{cc}
\varepsilon_{I I}^{P}(x)=\varepsilon_{0}-\frac{4 \tau_{b, \max }}{E_{s} d_{b}} x & 0 \leq x \leq l_{p} \\
s_{I I}^{P}(x)=\frac{2 \tau_{b, \max }}{E_{S} d_{b}}\left(x^{2}-l_{p}^{2}\right)-\varepsilon_{0}\left(x-l_{p}\right)+s_{y} & 0 \leq x \leq l_{p} \\
\tau_{b, I I}^{p}(x)=\tau_{b, \max } & 0 \leq x \leq l_{p}
\end{array}
$$

Por último, imponiendo criterios de continuidad de soluciones en ambos tramos, en el punto $x=l_{p}$, tanto de deformaciones $\left[\varepsilon_{I I}^{E}\left(l_{p}\right)=\varepsilon_{I I}^{P}\left(l_{p}\right)=\varepsilon_{y, I}\right]$ como de deslizamientos $\left[s_{I I}^{E}\left(l_{p}\right)=s_{I I}^{P}\left(l_{p}\right)=s_{y}\right]$, la longitud de plastificación $l_{p}$ puede ser despejada de la siguiente expresión (Eq. 3-168): 


$$
s_{y}=\frac{\varepsilon_{0}-\frac{4 \tau_{b, \max }}{E_{S} d_{b}} l_{p}}{\omega_{1}\left(1-e^{2 \omega_{1}\left(l_{b}-l_{p}\right)}\right)}\left(-1-e^{2 \omega_{1}\left(l_{b}-l_{p}\right)}\right)
$$

La expresión resultante es una ecuación trascendente, con una única incógnita $l_{p}$, y puede resolverse mediante técnicas numéricas comunes.

Integrando las funciones de distribución de la tensión de adherencia de ambos tramos y distribuyéndolas uniformemente a lo largo de la longitud adherente, se obtiene la tensión de adherencia media $\tau_{b, \text { med }}$ para la etapa II (Eq. 3-169):

$$
\tau_{b, \text { med }}=\frac{1}{l_{b}}\left[\int_{0}^{l_{p}} \tau_{b, \max } d x+\int_{l_{p}}^{l_{b}} \tau_{b, I}(x) d x\right]=\frac{\tau_{b, \max }}{l_{b}}\left(l_{p}+\frac{\varepsilon_{y, I I}}{s_{y} \omega_{1}^{2}}\right)
$$

Con el paulatino aumento de la carga, una vez que el extremo cargado desarrolla un deslizamiento $\mathrm{s}_{\mathrm{u}}$, se alcanza el punto de máxima tensión de adherencia que puede desarrollar la longitud de anclaje existente. A partir de ese momento, el alambre desliza con cargas menores a la máxima hasta llegar al fallo.

\section{ETAPA III: Régimen elástico, plástico y de ablandamiento}

Al alcanzar esta etapa, en la que la Ley de adherencia local-deslizamiento se ubica en el tramo de ablandamiento (Tramo A), la resolución del problema se lleva a cabo mediante control por desplazamiento, mediante sucesivos incrementos de desplazamiento en el extremo cargado del alambre, en oposición al control por carga con el que se solucionaron las etapas anteriores.
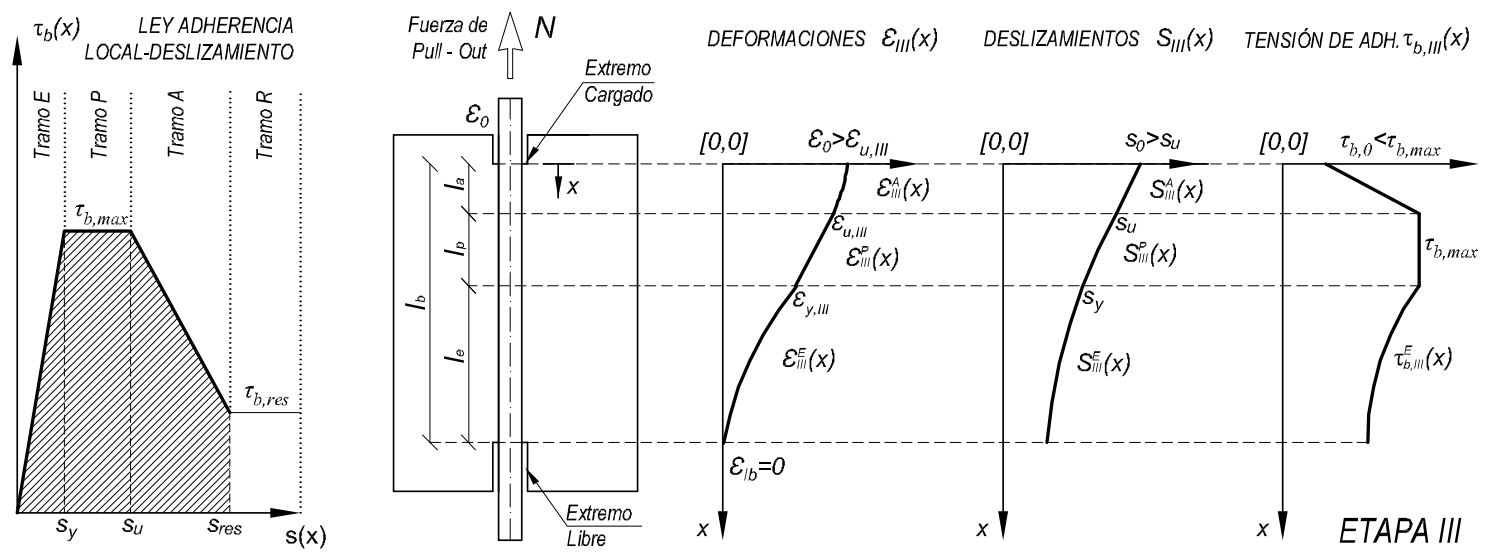

Figura 3-21 Deformaciones, deslizamientos y tensiones de adherencia a lo largo de un alambre de acero embebido en hormigón en la Etapa III 
Por tanto, el alambre, a lo largo de su longitud adherente, se encuentra en tres estados tensionales distintos:

- Tramo E: Régimen elástico; para longitudes superiores a $l_{p}+l_{s}\left(l_{p}+l_{s} \leq x \leq l_{b}\right)$, en las que los deslizamientos son menores a $s_{y}$, siendo $l_{s}$ la longitud correspondiente al tramo de ablandamiento.

- Tramo P: Régimen plástico; para longitudes mayores a $l_{s}$ y menores que $l_{p}+l_{s} \quad\left(l_{s} \leq x \leq l_{p}\right.$ $+l_{s}$ ), en las que los deslizamientos se encuentran comprendidos entre $s_{y}$ y $s_{u}$.

- Tramo A: Régimen de ablandamiento; para longitudes menores a $l_{s}\left(0 \leq x \leq l_{s}\right)$, en las que los deslizamientos son mayores a $s_{u}$.

$\underline{\text { Tramo E }}\left(l_{p}+l_{s} \leq x \leq l_{b}\right)$

Operando de forma similar que en las anteriores etapas, las condiciones de este tramo, mediante las cuales se pueden despejar las constantes de integración $C_{1}$ y $C_{2}$, son las siguientes (Eq. 3-170):

$$
\varepsilon_{I I I}^{E}\left(x=l_{p}+l_{s}\right)=\varepsilon_{y, I I I} \quad \varepsilon_{I I I}^{E}\left(x=l_{b}\right)=0
$$

Obtenido el valor de las constantes, mediante las ecuaciones (Eq. 3-140) y (Eq. 3-141) puede obtenerse la variación de las deformaciones, los deslizamientos y las tensiones en el intervalo $l_{p}+l_{s} \leq x \leq l_{b}$ :

$$
\begin{aligned}
& \varepsilon_{I I I}^{E}(x)=\frac{\varepsilon_{y, I I I}}{1-e^{2 \omega_{1}\left(l_{b}-l_{p}-l_{s}\right)}}\left(e^{\omega_{1}\left(x-l_{p}-l_{s}\right)}-e^{2 \omega_{1}\left(l_{b}-l_{p}-l_{s}\right)-\omega_{1}\left(x-l_{p}-l_{s}\right)}\right) \leq \varepsilon_{y, I I I} \quad l_{p}+l_{s} \leq x \leq l_{b} \quad \text { (Eq. 3-171) } \\
& \varepsilon_{I I I}^{E}(x)=\frac{\varepsilon_{y, I I I}}{\omega_{1}\left(1-e^{2 \omega_{1}\left(l_{b}-l_{p}-l_{s}\right)}\right)}\left(-e^{\omega_{1}\left(x-l_{p}-l_{s}\right)}\right. \\
& \left.-e^{2 \omega_{1}\left(l_{b}-l_{p}-l_{s}\right)-\omega_{1}\left(x-l_{p}-l_{s}\right)}\right) \\
& l_{p}+l_{s} \leq x \leq l_{b} \\
& \text { (Eq. 3-172) } \\
& \tau_{b, I I I}^{E}(x)=\frac{\tau_{b, \max }}{s_{y}} s(x) \leq \tau_{b, \max } \\
& l_{p}+l_{s} \leq x \leq l_{b}
\end{aligned}
$$

$\underline{\operatorname{Tramo} P}\left(1_{\mathrm{s}} \leq \mathrm{x} \leq 1_{\mathrm{p}}+1_{\mathrm{s}}\right)$

Las condiciones de contorno para este tramo son las siguientes (Eq. 3-174):

$$
\varepsilon_{I I I}^{P}\left(x=l_{p}+l_{s}\right)=\varepsilon_{y, I I I} \quad \varepsilon_{I I I}^{P}\left(x=l_{s}\right)=\varepsilon_{u} \quad s_{I I I}^{P}\left(x=l_{s}\right)=s_{u} \quad s_{I I I}^{P}\left(x=l_{p}+l_{s}\right)=s_{y}
$$

Donde $\varepsilon_{u}$ es la deformación del alambre que pone fin al tramo plastificado y marca el comienzo del tramo de ablandamiento, coincidiendo con el punto en el que es deslizamiento relativo es igual a $s_{u}$. 
Aplicando la primera condición a la ecuación (Eq. 3-144) se obtiene el valor de la constante $C_{3}$ :

$$
\varepsilon_{I I I}^{P}\left(x=l_{p}+l_{s}\right)=-\frac{4 \tau_{b, \max }}{E_{s} d_{b}}\left(l_{p}+l_{s}\right)+C_{3}=\varepsilon_{y, I I I} \Rightarrow C_{3}=\varepsilon_{y, I I I}+\frac{4 \tau_{b, \max }}{E_{S} d_{b}}\left(l_{p}+l_{s}\right)
$$

Aplicando la segunda condición de contorno en la ecuación (Eq. 3-143), en el intervalo $l_{p}+l_{s} \leq x \leq l_{s}$, se logra despejar el valor de la constante $C_{4}$ :

$$
\begin{aligned}
s_{I I I}^{P}\left(x=l_{p}+l_{s}\right)= & s_{y} \Rightarrow \frac{2 \tau_{b, \max }}{E_{s} d_{b}}\left(l_{p}+l_{s}\right)^{2}-\left[\varepsilon_{y, I I I}+\frac{4 \tau_{b, \max }}{E_{s} d_{b}}\left(l_{p}+l_{s}\right)\right]\left(l_{p}+l_{s}\right)+C_{4}=s_{y} \\
& \Rightarrow C_{4}=\frac{2 \tau_{b, \max }}{E_{s} d_{b}}\left(l_{p}+l_{s}\right)^{2}+\varepsilon_{y, I I I}\left(l_{p}+l_{s}\right)+s_{y}
\end{aligned}
$$

Por tanto, las ecuaciones generales para este tramo adoptarán la siguiente forma:

$$
\begin{array}{ll}
\varepsilon_{I I I}^{P}(x)=\frac{4 \tau_{b, \max }}{E_{s} d_{b}}\left(l_{s}+l_{p}-x\right)+\varepsilon_{y, I I I} & l_{s} \leq x \leq l_{p}+l_{s} \\
s_{I I I}^{P}(x)=\frac{2 \tau_{b, \max }}{E_{s} d_{b}}\left(l_{s}+l_{p}-x\right)^{2}+\varepsilon_{y, I I I}\left(l_{s}+l_{p}-x\right)+s_{y} & l_{s} \leq x \leq l_{p}+l_{s} \\
\tau_{b, I I I}^{p}(x)=\tau_{b, \max } & l_{s} \leq x \leq l_{p}+l_{s}
\end{array}
$$

Para el cálculo de la longitud de alambre $l_{p}$, donde la tensión de adherencia ha alcanzado el estado de plastificación, se imponen criterios de continuidad de soluciones en el punto de inflexión entre el Tramo $E$ y el $P$, en $x=l_{p}+l_{s}$, tanto de deformaciones $\left[\varepsilon_{I I I}^{E}\left(l_{p}+l_{s}\right)=\varepsilon_{I I I}^{P}\left(l_{p}+l_{s}\right)=\varepsilon_{y, I I I}\right]$ como de deslizamientos $\left[s_{I I I}^{E}\left(l_{p}+l_{s}\right)=s_{I I I}^{P}\left(l_{p}+l_{s}\right)=s_{y}\right]$. Previamente, es necesario determinar el valor de $\varepsilon_{y, I I I}$, despejándolo de la ecuación (Eq. 3-178), aplicada en el punto $x=l_{s}$, quedando como sigue:

$$
s_{I I I}^{P}\left(x=l_{s}\right)=s_{u} \Rightarrow \varepsilon_{y, I I I}=\frac{s_{u}-s_{y}}{l_{p}}-\frac{2 \tau_{b, \max }}{E_{s} d_{b}} l_{p}
$$

Por último, imponiendo $s_{I I I}^{P}\left(x=l_{p}+l_{s}\right)=s_{y}$, y sustituyendo el valor de $\varepsilon_{y, I I I}$ (Eq. 3-180), la longitud de plastificación puede ser estimada (Eq. 3-181):

$$
s_{y}=\frac{\frac{s_{u}-s_{y}}{l_{p}}-\frac{2 \tau_{b, \max }}{E_{s} d_{b}} l_{p}}{\omega_{1}\left(1-e^{2 \omega_{1}\left(l_{b}-l_{p}-l_{s}\right)}\right)}\left(-1-e^{2 \omega_{1}\left(l_{b}-l_{p}-l_{s}\right)}\right)
$$

Como en la anterior etapa, se obtiene una ecuación trascendente, con una única incógnita $l_{p}$, que se resuelve mediante técnicas numéricas comunes. 
TESIS DOCTORAL INFLUENCLA DE LA CORROSIÓN EN LA ADHERENCLA DE ALAMBRES EN ELEMENTOS PRETENSADOS DE HORMIGÓN

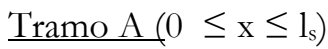

Las condiciones de contorno para este tramo son las siguientes:

$$
\varepsilon_{I I I}^{A}(x=0)=\varepsilon_{0} \quad s_{I I}^{A}\left(x=l_{s}\right)=s_{u} \quad \varepsilon_{I I I}^{A}\left(x=l_{s}\right)=\varepsilon_{u} \quad \text { (Eq. 3-182) }
$$

A continuación se aplican la segunda y tercera condiciones de contorno $\left[s_{I I I}^{A}\left(x=l_{s}\right)=s_{u} ; \varepsilon_{I I I}^{A}\left(x=l_{s}\right)=\right.$ $\varepsilon_{u}$ ] en las ecuaciones (Eq. 3-146) y (Eq. 3-147), correspondientes a las deformaciones y deslizamientos en el Tramo $A$, quedando el siguiente sistema de ecuaciones:

$$
\begin{array}{r}
\varepsilon_{I I I}^{A}\left(x=l_{s}\right)=\varepsilon_{u} \Rightarrow-C_{5} \omega_{2} \cos \left(\omega_{2} l_{s}\right)+C_{6} \omega_{2} \operatorname{sen}\left(\omega_{2} l_{s}\right)=\varepsilon_{u} \\
s_{I I I}^{A}\left(x=l_{s}\right)=s_{u} \Rightarrow C_{5} \operatorname{sen}\left(\omega_{2} l_{s}\right)+C_{6} \cos \left(\omega_{2} l_{s}\right)+\frac{k_{1} s_{u}+\tau_{b, \max }}{k_{1}}=s_{u}
\end{array}
$$

Y operando se obtiene el valor de las constantes $C_{5}$ y $C_{6}$ :

$$
\begin{aligned}
& C_{5}=\operatorname{sen}\left(\omega_{2} l_{s}\right)\left(s_{u}-\frac{k_{1} s_{u}+\tau_{b, \max }}{k_{1}}\right)-\frac{\varepsilon_{u}}{\omega_{2}} \cos \left(\omega_{2} l_{s}\right) \\
& C_{6}=\cos \left(\omega_{2} l_{s}\right)\left(s_{u}-\frac{k_{1} s_{u}+\tau_{b, \max }}{k_{1}}\right)+\frac{\varepsilon_{u}}{\omega_{2}} \operatorname{sen}\left(\omega_{2} l_{s}\right)
\end{aligned}
$$

Obtenido el valor de las constantes, mediante las ecuaciones (Eq. 3-146) y (Eq. 3-147) se obtiene la variación de las deformaciones, los deslizamientos y las tensiones en el Tramo $A$, región con régimen de ablandamiento:

$$
\begin{array}{ccc}
\begin{array}{c}
\varepsilon_{I I I}^{A}(x)=\omega_{2}\left(s_{u}-\frac{k_{1} s_{u}+\tau_{b, \max }}{k_{1}}\right)\left[\cos \left(\omega_{2} l_{s}\right) \operatorname{sen}\left(\omega_{2} x\right)-\operatorname{sen}\left(\omega_{2} l_{s}\right) \cos \left(\omega_{2} x\right)\right] \\
+\varepsilon_{u}\left[\operatorname{sen}\left(\omega_{2} l_{s}\right) \operatorname{sen}\left(\omega_{2} x\right)+\cos \left(\omega_{2} l_{s}\right) \cos \left(\omega_{2} x\right)\right]
\end{array} & 0 \leq x \leq l_{s} \quad \text { (Eq. 3-187) } \\
s_{I I I}^{A}(x)=\left(s_{u}-\frac{k_{1} s_{u}+\tau_{b, \max }}{k_{1}}\right)\left[\operatorname{sen}\left(\omega_{2} l_{s}\right) \operatorname{sen}\left(\omega_{2} x\right)+\cos \left(\omega_{2} l_{s}\right) \cos \left(\omega_{2} x\right)\right] & \\
+\frac{\varepsilon_{u}}{\omega_{2}}\left[\operatorname{sen}\left(\omega_{2} l_{s}\right) \cos \left(\omega_{2} x\right)-\cos \left(\omega_{2} l_{s}\right) \operatorname{sen}\left(\omega_{2} x\right)\right]+\frac{k_{1} s_{u}+\tau_{b, \max }}{k_{1}} & 0 \leq x \leq l_{s} \quad \text { (Eq.3-188) } \\
\tau_{b, I I I}^{A}(x)=\tau_{b, \text { max }}-\frac{\tau_{b, \text { max }}-\tau_{b, \text { res }}}{s_{\text {res }}-s_{u}}\left[s(x)-s_{u}\right] &
\end{array}
$$

Por otro lado, utilizando las ecuaciones anteriores, y teniendo en cuenta que la longitud $x$ del alambre hasta en punto en el que se alcanza el deslizamiento $s_{u}\left(x=l_{s}\right)$ es el nuevo parámetro de entrada en el 
problema, al estar controlado el proceso mediante control por desplazamiento, pueden hallarse los valores de deformación, desplazamiento y tensión de adherencia para $x=0$ (Eq. 3-190)(Eq. 3-191):

$$
\begin{array}{lll}
\varepsilon_{I I I}^{A}(x=0)=\varepsilon_{0} \Rightarrow \varepsilon_{0}=\omega_{2}\left(\frac{k_{1} s_{u}+\tau_{b, \max }}{k_{1}}-s_{u}\right) \operatorname{sen}\left(\omega_{2} l_{s}\right)+\varepsilon_{u} \cos \left(\omega_{2} l_{s}\right) & 0 \leq x \leq l_{s} & \text { (Eq. 3-190) } \\
s_{I I I}^{A}(x=0)=s_{0} \Rightarrow s_{0}=\left(s_{u}-\frac{k_{1} s_{u}+\tau_{b, \max }}{k_{1}}\right) \cos \left(\omega_{2} l_{s}\right)+\frac{\varepsilon_{u}}{\omega_{2}} \operatorname{sen}\left(\omega_{2} l_{s}\right)+\frac{k_{1} s_{u}+\tau_{b, \max }}{k_{1}} & 0 \leq x \leq l_{s} & \text { (Eq. 3-191) }
\end{array}
$$

Para la obtención de la tensión de adherencia media $\tau_{b, \text { med }}$ en esta etapa del proceso se integran las funciones de distribución de la tensión de adherencia en todos los tramos y se distribuyen uniformemente a lo largo de la longitud adherente (Eq. 3-192):

$$
\tau_{b, \text { med,III }}=\frac{1}{l_{b}}\left[\int_{0}^{l_{s}} \tau_{b, I I I}(x) d x+\int_{l_{s}}^{l_{p}+l_{s}} \tau_{b, \max } d x+\int_{l_{p}+l_{s}}^{l_{b}} \tau_{b, I}(x) d x\right]
$$

\section{ETAPA IV: Régimen elástico, plástico, de ablandamiento y residual}

Durante la aplicación de la carga, el deslizamiento relativo del alambre con respecto al hormigón circundante sigue aumentando hasta que se alcanza el valor $s_{r e s}$ en el extremo cargado, momento en el que se alcanza la Etapa IV, y la tensión en dicho extremo pasa a tomar un valor residual $\tau_{b, r e s}$ a lo largo de una longitud $l_{r}$ (Figura 3-22). Para la determinación de la distribución de las tensiones, los deslizamientos y las deformaciones, se llevará a cabo un control por desplazamiento del ensayo, similar al efectuado en la anterior etapa.
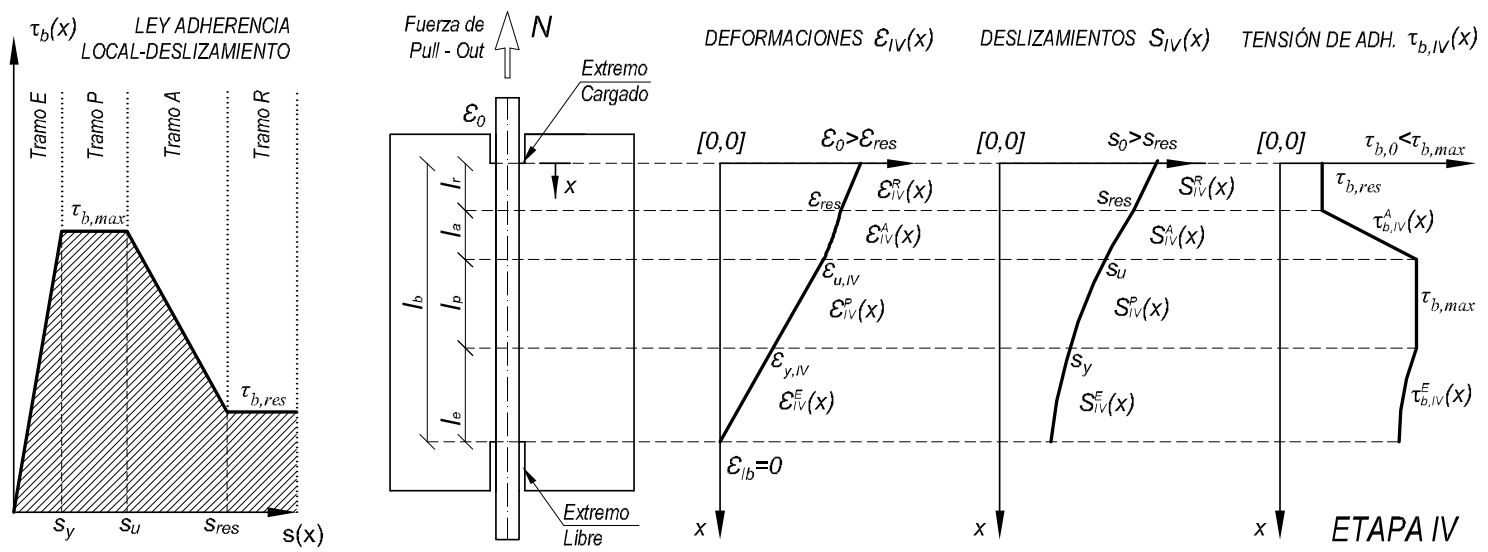

Figura 3-22 Deformaciones, deslizamientos y tensiones de adherencia a lo largo de un alambre de acero embebido en hormigón en la Etapa IV 
TESIS DOCTORAL INFLUENCLA DE LA CORROSIÓN EN LA ADHERENCLA DE ALAMBRES EN ELEMENTOS PRETENSADOS DE HORMIGÓN

$\underline{\text { Tramo E }}\left(l_{p}+l_{s}+l_{r} \leq x \leq l_{b}\right)$

Las condiciones de contorno en este tramo, mediante las cuales se despejan las constantes de integración $C_{1}$ y $C_{2}$, son las siguientes:

$$
\varepsilon_{I V}^{E}\left(x=l_{p}+l_{s}+l_{s}\right)=\varepsilon_{y, I V} \quad \varepsilon_{I V}^{E}\left(x=l_{b}\right)=0
$$

Obtenido el valor de las constantes, mediante las ecuaciones (Eq. 3-140) y (Eq. 3-141) puede obtenerse la variación de las deformaciones, los deslizamientos y las tensiones en el intervalo $l_{p}+l_{s}+l_{r} \leq x \leq$ $l_{b}$ :

$$
\begin{array}{ll}
\varepsilon_{I V}^{E}(x)=\frac{\varepsilon_{y, I V}}{1-e^{2 \omega_{1}\left(l_{b}-l_{p}-l_{s}-l_{r}\right)}}\left(e^{\omega_{1}\left(x-l_{p}-l_{s}-l_{r}\right)}-e^{2 \omega_{1}\left(l_{b}-l_{p}-l_{s}-l_{r}\right)-\omega_{1}\left(x-l_{p}-l_{s}-l_{r}\right)}\right) & l_{p}+l_{s}+l_{r} \leq x \leq l_{b} \quad \text { (Eq.3-194) } \\
s_{I V}^{E}(x)=\frac{\varepsilon_{y, I V}}{\omega_{1}\left(1-e^{2 \omega_{1}\left(l_{b}-l_{p}-l_{s}-l_{r}\right)}\right)}\left(-e^{\omega_{1}\left(x-l_{p}-l_{s}-l_{r}\right)}-e^{2 \omega_{1}\left(l_{b}-l_{p}-l_{s}-l_{r}\right)-\omega_{1}\left(x-l_{p}-l_{s}-l_{r}\right)}\right) & l_{p}+l_{s}+l_{r} \leq x \leq l_{b} \quad \text { Eq.3-195) } \\
\tau_{b, I V}^{E}(x)=\frac{\tau_{b, \max }}{s_{y}} S(x) \leq \tau_{b, \max } & l_{p}+l_{s}+l_{r} \leq x \leq l_{b} \text { (Eq.3-196) }
\end{array}
$$

$\underline{\operatorname{Tramo} \mathrm{P}\left(l_{s}+l_{r} \leq x \leq l_{p}+l_{s}+l_{r}\right)}$

Las condiciones de contorno para el tramo en el que la capacidad adherente ha plastificado, alcanzando su valor máximo a lo largo de una longitud $l_{p}$, son las siguientes:

$$
\varepsilon_{I V}^{P}\left(x=l_{p}+l_{s}+l_{r}\right)=\varepsilon_{y, I V} \quad \varepsilon_{I V}^{P}\left(x=l_{s}+l_{r}\right)=\varepsilon_{u} \quad s_{I V}^{P}\left(x=l_{s}+l_{r}\right)=s_{u} \quad s_{I V}^{P}\left(x=l_{p}+l_{s}+l_{r}\right)=s_{y}
$$

Aplicando la primera condición a la ecuación (Eq.3-144) se obtiene el valor de la constante $C_{3}$ :

$$
\varepsilon_{I V}^{P}\left(x=l_{p}+l_{s}+l_{r}\right)=-\frac{4 \tau_{b, \max }}{E_{s} d_{b}}\left(l_{p}+l_{s}+l_{r}\right)+C_{3}=\varepsilon_{y, I V} \Rightarrow C_{3}=\varepsilon_{y, I V}+\frac{4 \tau_{b, \max }}{E_{s} d_{b}}\left(l_{p}+l_{s}+l_{r}\right)
$$

Aplicando la última condición de contorno en la ecuación (Eq. 3-143) se despeja el valor de la constante $C_{4}$ :

$$
\begin{aligned}
s_{I V}^{P}\left(x=l_{p}+l_{s}+l_{r}\right) & =s_{y} \Rightarrow \frac{2 \tau_{b, \max }}{E_{s} d_{b}}\left(l_{p}+l_{s}+l_{r}\right)^{2}-\left[\varepsilon_{y, I V}+\frac{4 \tau_{b, \max }}{E_{s} d_{b}}\left(l_{p}+l_{s}+l_{r}\right)\right]\left(l_{p}+l_{s}+l_{r}\right)+C_{4} \\
& =s_{y} \Rightarrow C_{4}=\frac{2 \tau_{b, \max }}{E_{s} d_{b}}\left(l_{p}+l_{s}+l_{r}\right)^{2}+\varepsilon_{y, I V}\left(l_{p}+l_{s}+l_{r}\right)+s_{y}
\end{aligned}
$$

Por tanto, las ecuaciones generales de distribución de las deformaciones, los desplazamientos y las tensiones de adherencia para este tramo adoptarán la siguiente forma:

$$
\varepsilon_{I V}^{P}(x)=\frac{4 \tau_{b, \max }}{E_{s} d_{b}}\left(l_{p}+l_{s}+l_{r}-x\right)+\varepsilon_{y, I V} \quad l_{s}+l_{r} \leq x \leq l_{p}+l_{s}+l_{r}
$$




$$
\begin{array}{lll}
s_{I V}^{P}(x)=\frac{2 \tau_{b, \max }}{E_{s} d_{b}}\left(l_{p}+l_{s}+l_{r}-x\right)^{2}+\varepsilon_{y, I V}\left(l_{p}+l_{s}+l_{r}-x\right)+s_{y} & l_{s}+l_{r} \leq x \leq l_{p}+l_{s}+l_{r} & \text { (Eq. 3-201) } \\
\tau_{b, I V}^{P}(x)=\tau_{b, \max } & l_{s}+l_{r} \leq x \leq l_{p}+l_{s}+l_{r} & \text { (Eq. 3-202) }
\end{array}
$$

Donde $\varepsilon_{y, I V}$ es el valor reducido de la deformación del alambre, menor que sus equivalentes en las anteriores etapas: $\varepsilon_{y, I}, \varepsilon_{y, I I}$ y $\varepsilon_{y, I I I}$, y que provoca la plastificación de la capacidad adherente. Su valor puede ser despejado de la ecuación (Eq. 3-201), aplicada en el punto $x=l_{s}+l_{r}$, donde el deslizamiento relativo toma un valor equivalente a $s_{u}$ :

$$
s_{I V}^{P}\left(x=l_{s}+l_{r}\right)=s_{u} \Rightarrow \varepsilon_{y, I V}=\frac{s_{u}-s_{y}}{l_{p}}-\frac{2 \tau_{b, \max }}{E_{s} d_{b}} l_{p}
$$

Para el cálculo de la longitud de alambre $l_{p}$, se impone la continuidad de deslizamientos en el punto de inflexión entre el Tramo $E$ y el $P$, en $x=l_{p}+l_{s}+l_{r}$, obteniendo una ecuación trascendente cuya única incógnita es la longitud buscada (Eq. 3-204):

$$
s_{I V}^{P}\left(x=l_{p}+l_{s}+l_{r}\right)=s_{y} \Rightarrow s_{y}=\frac{\frac{s_{u}-s_{y}}{l_{p}}-\frac{2 \tau_{b, \max }}{E_{s} d_{b}} l_{p}}{\omega_{1}\left(1-e^{2 \omega_{1}\left(l_{b}-l_{p}-l_{s}-l_{r}\right)}\right)}\left(-1-e^{2 \omega_{1}\left(l_{b}-l_{p}-l_{s}-l_{r}\right)}\right)
$$

\section{$\underline{\text { Tramo A }}\left(l_{r} \leq x \leq l_{s}+l_{r}\right)$}

Las condiciones de contorno del tramo de ablandamiento para la Etapa IV son las siguientes:

$$
\varepsilon_{I V}^{A}\left(x=l_{r}\right)=\varepsilon_{r e s} \quad s_{I V}^{A}\left(x=l_{r}\right)=s_{r e s} \quad s_{I V}^{A}\left(x=l_{s}+l_{r}\right)=s_{u} \quad \varepsilon_{I V}^{A}\left(x=l_{s}+l_{r}\right)=\varepsilon_{u}
$$

A continuación se aplican la tercera y cuarta condiciones de contorno $\left[s_{I V}^{A}\left(x=l_{s}+l_{r}\right)=\right.$ $s_{u} ; \varepsilon_{I V}^{A}\left(x=l_{s}+l_{r}\right)=\varepsilon_{u}$ ] en las ecuaciones (Eq. 3-146) y (Eq. 3-147), correspondientes a las deformaciones y deslizamientos en el Tramo $A$, quedando un sistema de ecuaciones del que se obtiene el valor de las constantes $\mathrm{C}_{5}$ y $\mathrm{C}_{6}$ :

$$
\begin{aligned}
& C_{5}=\operatorname{sen}\left(\omega_{2}\left(l_{s}+l_{r}\right)\right)\left(s_{u}-\frac{k_{1} s_{u}+\tau_{b, \max }}{k_{1}}\right)-\frac{\varepsilon_{u}}{\omega_{2}} \cos \left(\omega_{2}\left(l_{s}+l_{r}\right)\right) \\
& C_{6}=\cos \left(\omega_{2}\left(l_{s}+l_{r}\right)\right)\left(s_{u}-\frac{k_{1} s_{u}+\tau_{b, \max }}{k_{1}}\right)+\frac{\varepsilon_{u}}{\omega_{2}} \operatorname{sen}\left(\omega_{2}\left(l_{s}+l_{r}\right)\right)
\end{aligned}
$$

Obtenido el valor de las constantes, mediante las ecuaciones (Eq. 3-146) y (Eq. 3-147) se obtiene la variación de las deformaciones, los deslizamientos y las tensiones en el Tramo III, región con régimen de ablandamiento: 
TESIS DOCTORAL INFLUENCLA DE LA CORROSIÓN EN LA ADHERENCLA DE ALAMBRES EN ELEMENTOS PRETENSADOS DE HORMIGÓN

$$
\begin{array}{cc}
\varepsilon_{I V}^{A}(x)=\omega_{2}\left(s_{u}-\frac{k_{1} s_{u}+\tau_{b, \max }}{k_{1}}\right)\left[\cos \left(\omega_{2}\left(l_{s}+l_{r}\right)\right) \operatorname{sen}\left(\omega_{2} x\right)-\operatorname{sen}\left(\omega_{2}\left(l_{s}+l_{r}\right)\right) \cos \left(\omega_{2} x\right)\right] & \\
+\varepsilon_{u}\left[\operatorname{sen}\left(\omega_{2}\left(l_{s}+l_{r}\right)\right) \operatorname{sen}\left(\omega_{2} x\right)+\cos \left(\omega_{2}\left(l_{s}+l_{r}\right)\right) \cos \left(\omega_{2} x\right)\right] \quad l_{s} \leq x \leq l_{s}+l_{r} \\
s_{I V}^{A}(x)=\left(s_{u}-\frac{k_{1} s_{u}+\tau_{b, \text { max }}}{k_{1}}\right)\left[\operatorname{sen}\left(\omega_{2}\left(l_{s}+l_{r}\right)\right) \operatorname{sen}\left(\omega_{2} x\right)+\cos \left(\omega_{2}\left(l_{s}+l_{r}\right)\right) \cos \left(\omega_{2} x\right)\right] \\
+\frac{\varepsilon_{u}}{\omega_{2}}\left[\operatorname{sen}\left(\omega_{2}\left(l_{s}+l_{r}\right)\right) \cos \left(\omega_{2} x\right)-\cos \left(\omega_{2}\left(l_{s}+l_{r}\right)\right) \operatorname{sen}\left(\omega_{2} x\right)\right]+\frac{k_{1} s_{u}+\tau_{b, \max }}{k_{1}} \\
\tau_{b, I V}^{A}(x)=\tau_{b, \text { max }}-\frac{\tau_{b, \text { max }}-\tau_{b, \text { res }}}{s_{\text {res }}-s_{u}}\left[s(x)-s_{u}\right] & l_{s} \leq x \leq l_{s}+l_{r}
\end{array}
$$

$\underline{\text { Tramo R }(0 \leq x \leq l)}$

El Tramo R de la Ley de tensión de adherencia local-deslizamiento actúa sobre la longitud del alambre $l_{r}$ en la que los deslizamientos relativos son mayores a $s_{\text {res. }}$ Las condiciones de contorno para este tramo serán las siguientes (Eq. 3-211):

$$
\varepsilon_{I V}^{R}(x=0)=\varepsilon_{0} \quad s_{I V}^{R}(x=0)=s_{0} \quad \varepsilon_{I V}^{R}\left(x=l_{r}\right)=\varepsilon_{r e s} \quad s_{I V}^{R}\left(x=l_{r}\right)=s_{\text {res }}
$$

(Eq. 3-211)

Aplicando las dos últimas condiciones de contorno $\left[\varepsilon_{I V}^{R}\left(x=l_{r}\right)=\varepsilon_{r e s} ; s_{I V}^{R}\left(x=l_{r}\right)=s_{r e s}\right]$ en las ecuaciones (Eq. 3-148) y (Eq. 3-149), correspondientes a las deformaciones y deslizamientos en el Tramo IV, se obtiene un sistema de ecuaciones del que se obtiene el valor de las constantes $C_{7}$ y $C_{8}$ :

$$
\begin{gathered}
s_{I V}^{R}\left(x=l_{r}\right)=s_{r e s} \Rightarrow \frac{2 \tau_{b, r e s}}{E_{s} d_{b}} l_{r}{ }^{2}-C_{7} l_{r}+C_{8}=s_{r e s} \\
\varepsilon_{I V}^{R}\left(x=l_{r}\right)=\varepsilon_{r e s} \Rightarrow \varepsilon(x)=-\frac{4 \tau_{b, r e s}}{E_{s} d_{b}} l_{r}+C_{7}=\varepsilon_{r e s}
\end{gathered}
$$

En esta región la tensión de adherencia es constante $\tau_{b}(x)=\tau_{b \text {,res }}$, tal y como ocurría en el tramo plástico, por lo que las expresiones de distribución de los deslizamientos y las deformaciones serán similares:

$$
\begin{array}{ll}
\varepsilon_{I V}^{R}(x)=\frac{4 \tau_{b, r e s}}{E_{s} d_{b}}\left(l_{r}-x\right)+\varepsilon_{r e s} & l_{s}+l_{r} \leq x \leq l_{p}+l_{s}+l_{r} \\
s_{I V}^{R}(x)=\frac{2 \tau_{b, r e s}}{E_{s} d_{b}}\left(l_{r}-x\right)^{2}+\varepsilon_{r e s}\left(l_{r}-x\right)+s_{r e s} & l_{s}+l_{r} \leq x \leq l_{p}+l_{s}+l_{r} \\
\tau_{b, I V}^{R}(x)=\tau_{b, r e s} & l_{s}+l_{r} \leq x \leq l_{p}+l_{s}+l_{r}
\end{array}
$$


La longitud $l_{r}$ se despeja de la ecuación de distribución de los deslizamientos del Tramo A (Eq. 3-209), que en el punto $x=l_{r}$ toma un valor conocido igual a $s_{\text {res }}$.

Como en los tramos anteriores, para la obtención de la tensión de adherencia media $\tau_{b, \text { med }}$ se integran las funciones de distribución de las tensiones de adherencia de todos los tramos y se distribuyen uniformemente a lo largo de la longitud adherente (Eq. 3-217):

$$
\tau_{b, \text { med,IV }}=\frac{1}{l_{b}}\left[\int_{0}^{l_{r}} \tau_{b, I V}(x) d x+\int_{l_{r}}^{l_{r}+l_{s}} \tau_{b, I I I}(x) d x+\int_{l_{r}+l_{s}}^{l_{r}+l_{s}+l_{p}} \tau_{b, \max } d x+\int_{l_{r}+l_{s}+l_{p}}^{l_{b}} \tau_{b, I}(x) d x\right]
$$

\section{FASE III: DETERMINACION DE LA LONGITUD DE TRANSFERENCIA}

\subsection{Determinación de la longitud de transferencia $\left[I_{t}\right]$}

Una vez determinada la tensión radial en la sección transversal procedente de la transferencia del pretensado, de la expansión de los productos de corrosión, de la retracción y de las fuerzas externas de confinamiento, y calibrados mediante ensayos el coeficiente de fricción y la ley de adherencia localdeslizamiento, los parámetros controlantes del proceso, es posible determinar la longitud de transferencia del pretensado para unas condiciones dadas tales como las características mecánicas del hormigón, el nivel de pretensado, la geometría de la sección o el nivel de corrosión.

Las ecuaciones de equilibrio han sido establecidas y resueltas para cada sucesivo segmento en la dirección longitudinal de la viga. Las longitudes de transferencia se han determinado gracias a los perfiles de deformación de los elementos pretensados.

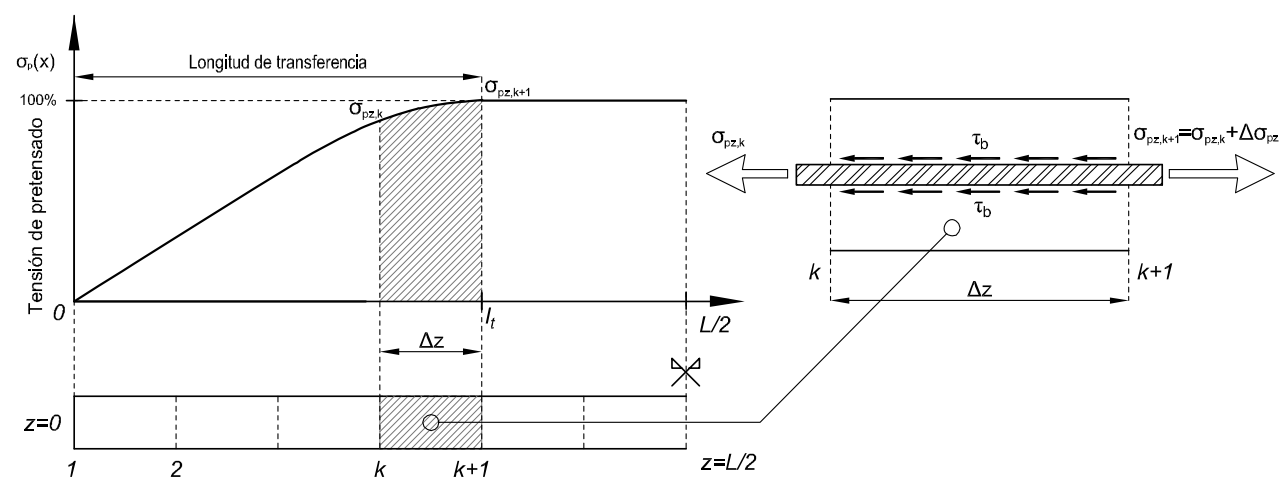

Figura 3-23 Diagrama del sólido libre aplicado a la barra pretensada entre los puntos de discretización iy i+1. Figura tomada de (Oh, et al., 2006) 
Como se indicaba al principio de este Capítulo, la longitud de transferencia $l_{t r}$ depende de la distribución de las tensiones de adherencia $\tau_{b}$ a lo largo del alambre, y ésta a su vez depende de la tensión radial $\sigma_{r, 0}$, del coeficiente de fricción $\mu$ y de la tensión debida al mecanismo de adhesión $f_{a d b}$ (Eq. 3-218):

$$
\tau_{b}=\mu \cdot \sigma_{r}+f_{a d h}
$$

Tal y como se muestra en la Figura 3-23, la longitud del elemento pretensado puede ser discretizada en $n$ elementos de longitud $\Delta z$. En cada uno de dichos elementos discretos, la tensión de adherencia $\tau_{b}$ es conocida, por lo que estableciéndose el equilibrio en su dirección longitudinal z puede deducirse el incremento de tensión normal $\Delta \sigma_{s z}$ que experimenta el alambre en la transferencia del pretensado (Eq. 3-219):

$$
\Delta \sigma_{s z}=\frac{\pi 2 r_{b} \Delta z \tau_{b}}{A_{s}}
$$

Por tanto, suponiendo que la tensión normal en el extremo del alambre de pretensado $(\mathrm{z}=0)$ es nula, el valor de dicha tensión en un elemento n-ésimo $\sigma_{s z, n}$ será equivalente al sumatorio de incrementos de tensión $\Delta \sigma_{s z}$ hasta dicho elemento, tal y como sigue (Eq. 3-220):

$$
\sigma_{s z, n}=\sum_{i=0}^{n} \Delta \sigma_{s z}
$$

$\mathrm{Al}$ mismo tiempo, la variación de la deformación del alambre $\Delta \varepsilon_{s z}$ con respecto a la deformación provocada por el pretensado inicial $\varepsilon_{s, 0}$ será máxima en el extremo del elemento, z $=0$, por lo que para cualquier elemento discreto n-ésimo de la viga pretensada se cumple que (Eq. 3-221):

$$
\Delta \varepsilon_{s z, n}=\varepsilon_{s, 0}-\frac{\sigma_{s z, n}}{E_{s}}
$$

Conocida la tensión del alambre en un determinado punto, la deformación del hormigón $\varepsilon_{c z, n}$ en el mismo puede deducirse de la ecuación (Eq. 3-40), obteniéndose la siguiente expresión (Eq. 3-222):

$$
\varepsilon_{c z, n}=\frac{\sigma_{s z, n} A_{p}}{E_{c}}\left(\frac{1}{A_{c}}+\frac{e}{I_{c}} y\right)
$$

Por tanto, la longitud de transferencia $l_{t r}$ puede ser determinada como la distancia desde el extremo del alambre hasta el punto en el que el cambio de deformación en el alambre de pretensado $\Delta \varepsilon_{s z, n}$, obtenido de la ecuación (Eq. 3-221), se iguala con la deformación del hormigón $\varepsilon_{c z, n}$, obtenido de la ecuación (Eq. 3-222), es decir, el punto en el que se cumple que $\Delta \varepsilon_{s z, n}=\varepsilon_{c z, n}$. 
3. MODELO ANALÍtico DE ESTRUCTURAS PRETENSADAS DE HORMIGÓN CON PROCESOS DE DETERIORO POR CORROSIÓN

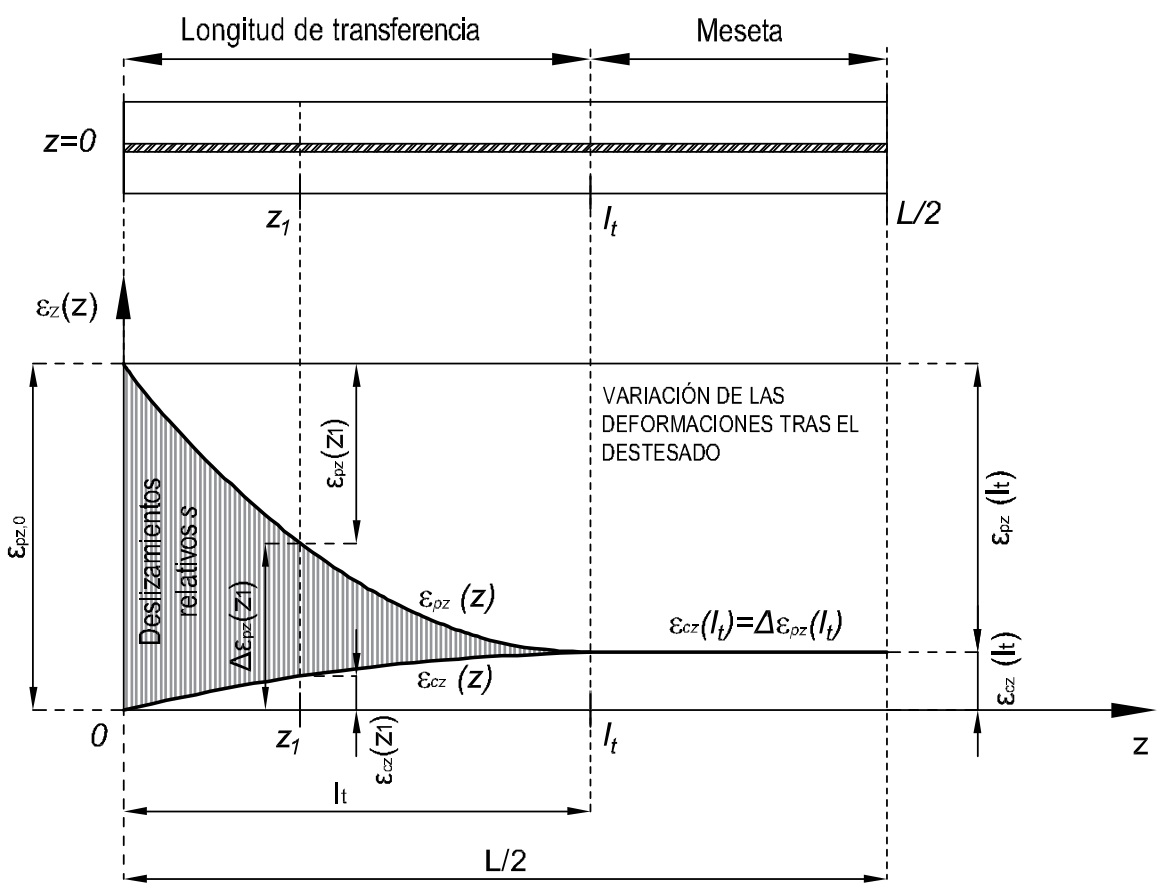

Figura 3-24 Variación de las deformaciones en el hormigón y en el acero a lo largo de la longitud de transferencia.

Por último, los deslizamientos relativos $s$ existentes entre el acero y el hormigón en cualquier punto $\mathrm{x}$ de la longitud de transferencia $l_{t}$ pueden estimarse mediante la integral de la diferencia entre la variación de la deformación del alambre $\Delta \varepsilon_{S Z}$ (con respecto a la deformación provocada por el pretensado inicial $\left.\varepsilon_{s, 0}\right)$ y la deformación del hormigón $\varepsilon_{c z}$, desde el comienzo de la longitud de transferencia $\left(\Delta \varepsilon_{s z, n}=\varepsilon_{c z, n}\right)$ hasta el punto considerado (Eq. 3-223). Se supone que más allá de del inicio de la longitud de transferencia, los deslizamientos entre el acero y el hormigón circundante son nulos.

$$
s(x)=\int_{0}^{x}\left(\Delta \varepsilon_{S Z}-\varepsilon_{C Z}\right) d x \quad 0<x \leq l_{t}
$$




\section{CAPÍTULO 4}

\section{Campaña experimental}

\subsection{Introducción}

En este capítulo se describe el plan de trabajo correspondiente a la campaña experimental realizada para la evaluación de la adherencia entre armaduras lisas e indentadas con el hormigón, cuyos resultados son expuestos en el Capitulo 5 y sirven de base para la calibración del modelo analítico desarrollado en esta tesis (Capitulo ๑). La campaña experimental para la verificación del modelo, basada en ensayos sobre elementos pretensados, se describe en el Capitulo 7.

El objetivo de la presente campaña de ensayos es, por tanto, estudiar cómo afectan las distintas variables consideradas, tanto geométricas y mecánicas como de deterioro, a las propiedades adherentes entre hormigón y acero, y posibilitar la calibración del modelo analítico. Para su realización, se parte de la configuración de ensayo de arrancamiento descrito en el Anexo D de la Norma EN 10080:2005 "Ensayo de adherencia para el acero corrugado o graficado para armaduras de hormigón armado. Ensayo de arrancamiento" (AENOR-AEN/CTN 36, 2006), que a su vez se basa en la Recomendación RILEM RC 6: "Ensayo de adherencia para el acero para armaduras de bormigón armado - 2. Ensayo de arrancamiento." (1983).

El ensayo de arrancamiento (pull-out) consiste en aplicar una carga de tracción a una barra o alambre embebido una longitud determinada en el interior de un prisma de hormigón, permaneciendo el otro extremo de la barra sin ningún tipo de tensión. La relación existente entre la fuerza de tracción aplicada y el deslizamiento producido (es decir, el desplazamiento relativo entre el acero y el hormigón) se mide hasta que se produce el fallo por arrancamiento de la barra (pull-out) o por fisuración longitudinal del hormigón del recubrimiento (splitting).

Existe una gran variedad de tipologías de ensayo para la caracterización y determinación de la adherencia entre las armaduras y el hormigón. La gran ventaja de los ensayos de arrancamiento reside en la facilidad del montaje, en su economía de medios y de tiempo, en su gran manejabilidad y en la posibilidad de controlar la carga aplicada y los deslizamientos relativos. Tal y como indica la Fib (CEB-FIB_Task Group 2.5, 2000), los ensayos de pull-out son útiles en estudios comparativos, en los que determinados parámetros (diámetro, recubrimiento, grado de corrosión, acabado superficial de la armadura, etc) son modificados, pero como contrapartida, la capacidad adherente encontrada con ellos tiene un valor limitado, dado que las condiciones de contorno en las probetas tienen poco que ver con las situaciones reales. No obstante, dado que el objetivo de la campaña es el análisis de la influencia relativa de las variables consideradas y la calibración del modelo analítico desarrollado, el ensayo de pull-out cumple sobradamente con este cometido.

A continuación, se exponen los elementos fundamentales de la campaña de ensayos, con la enumeración de las variables contempladas y la descripción del procedimiento experimental. 


\subsection{Descripción de las variables utilizadas}

La revisión bibliográfica ha permitido seleccionar una serie de variables experimentales, tanto procedimentales como geométricas y mecánicas, con relevancia en el comportamiento adherente de las armaduras embebidas en el hormigón sometidas a una fuerza de arrancamiento. La Tabla 4-1 resume las variables utilizadas y el rango de valores considerado en la campaña de ensayos de pullout de la presente tesis.

Tabla 4-1 Variables experimentales en la campaña de ensayos de Pull-Out

\begin{tabular}{|c|c|}
\hline Variables experimentales & Tipo y rango de las variables \\
\hline Tipo de ensayo & $\begin{array}{l}\text { - Pull-out centrado } \\
\text { - Pull.out excéntrico }\end{array}$ \\
\hline Acabado superficial de la barra & $\begin{array}{l}\text { Alambres lisos } \\
\text { - Alambres indentados }\end{array}$ \\
\hline Diámetro de la barra $[\phi]$ & - $5 \mathrm{~mm}$ \\
\hline Tipo de acero & - Y $1860 \mathrm{C}$ \\
\hline Límite elástico del acero & - $\mathrm{f}_{\mathrm{yk}}=1860 \mathrm{~N} / \mathrm{mm}^{2}$ \\
\hline Resistencia a compresión del hormigón & - $\mathrm{f}_{\mathrm{cm}}=43-68 \mathrm{~N} / \mathrm{mm}^{2}$ \\
\hline Longitud adherente $\left(l_{b}\right)$ & - $\mathrm{l}_{\mathrm{b}}=15 \phi$ en prolongación recta $(7,5 \mathrm{~cm})$ \\
\hline Armadura transversal & - Sin confinamiento por armadura transversal \\
\hline Recubrimiento mecánico [c] & $\begin{array}{l}\text { - } 100 \mathrm{~mm} \text { (probeta cúbica 200X200x200 mm) } \\
\text { - } 20 \mathrm{~mm} \text { (probeta prismática 100X100x200 mm) } \\
\text { - probeta prismática 100X100x200 mm) }\end{array}$ \\
\hline Ratio recubrimiento/diámetro $[\mathrm{c} / \phi]$ & $\begin{array}{ll} & \mathrm{c} / \phi=20 \\
: & \mathrm{c} / \phi=10 \\
-\mathrm{c} / \phi=4\end{array}$ \\
\hline Tipo de corrosión & $\begin{array}{ll}\text { - Sin corrosión } \\
\text { - Corrosión acelerada } \\
\end{array}$ \\
\hline Velocidad de corrosión acelerada & - $100 \mu \mathrm{A} / \mathrm{cm}^{2}$ \\
\hline Pérdida teórica de sección nominal por corrosión & $\begin{array}{l}: \quad 0 \% \\
: \quad 2 \% \\
: \quad 5 \% \\
: \quad 10 \% \\
:\end{array}$ \\
\hline
\end{tabular}

\subsection{Procedimiento experimental}

Tal y como se ha dicho anteriormente, para la configuración de los ensayos se ha seguido el Anexo D de la Norma EN 10080:2005 "Ensayo de adherencia para el acero corrugado o graficado para armaduras de hormigón armado. Ensayo de arrancamiento", que ha sido modificado en función de las necesidades concretas de la presente campaña. En total se han fabricado y sometido a ensayo de arrancamiento 109 probetas de pull-out, cuyas características se resumen en los siguientes apartados.

\subsubsection{Tipología de las probetas}

Se han utilizado dos moldes para la fabricación de las probetas: uno cúbico, de $200 \mathrm{~mm}$ de lado, y otro prismático, de dimensiones 100x100x200 mm, lo que ha permitido trabajar con tres tipos de recubrimientos mecánicos mínimos $c_{\text {min }}$ distintos en función de la colocación de la barra: $100 \mathrm{~mm}$ $(c / \phi=20), 50 \mathrm{~mm}(c / \phi=10)$ y $20 \mathrm{~mm}(c / \phi=4)$. Tal y como se aprecia en la Figura $4-1$, en los dos 
primeros casos la barra se ha colocado centrada en la sección transversal (series L20/I20 y L10/I10), mientras que en el último se ha situado excéntricamente, hacia una de las esquinas (Series L4/I4). Las dimensiones de la probeta cúbica son el fruto de la aplicación de las dimensiones mínimas sugeridas en la Norma EN 10080:2005 (AENOR-AEN/CTN 36, 2006), pero dado el diámetro de las barras utilizadas, la relación recubrimiento/diámetro resultante $(c / \phi=20)$ se aleja de los valores habituales en estructuras reales (Series L20/I20). Por ello, en las siguientes series de ensayos se ha optado por reducir la sección transversal de la probeta y/o por desplazar la barra del centro de la sección, logrando valores de recubrimiento/diámetro más usuales. La longitud de la probeta en la dirección de la barra se ha mantenido constante en todas las series de ensayos, con un valor de $200 \mathrm{~mm}$.

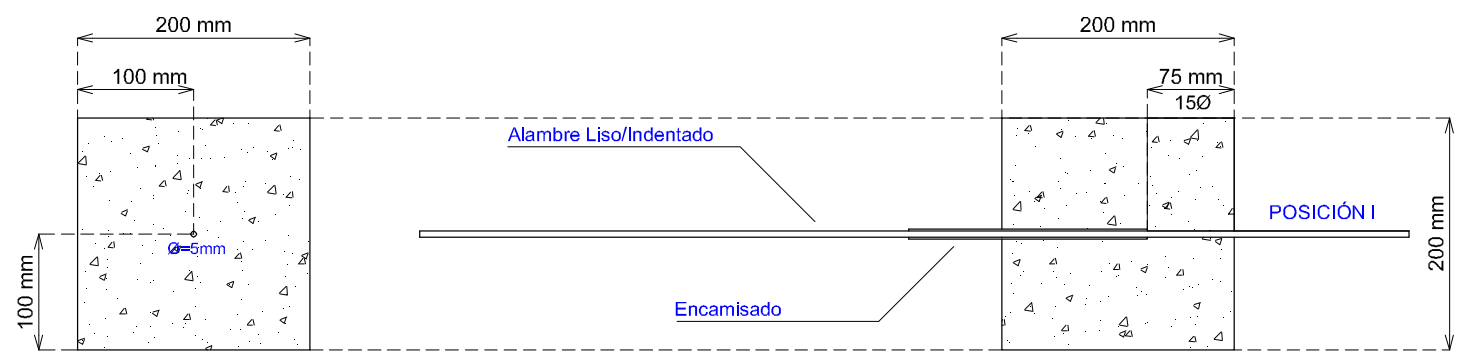

SERIES L20/I20

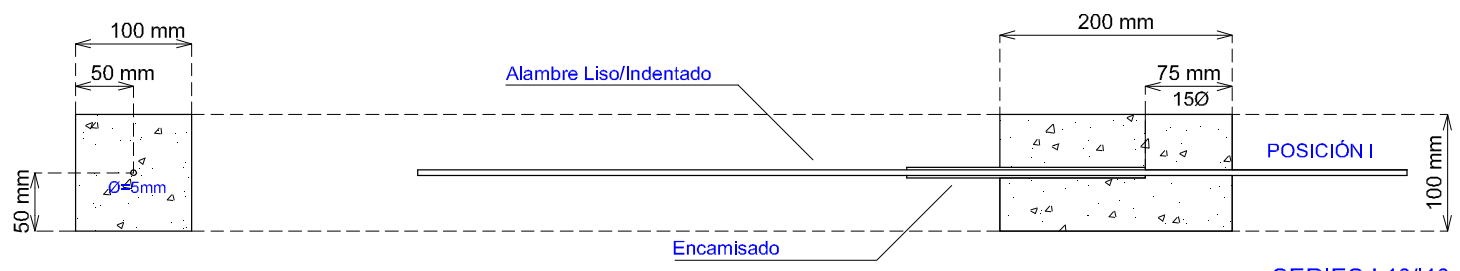

SERIES L10//10

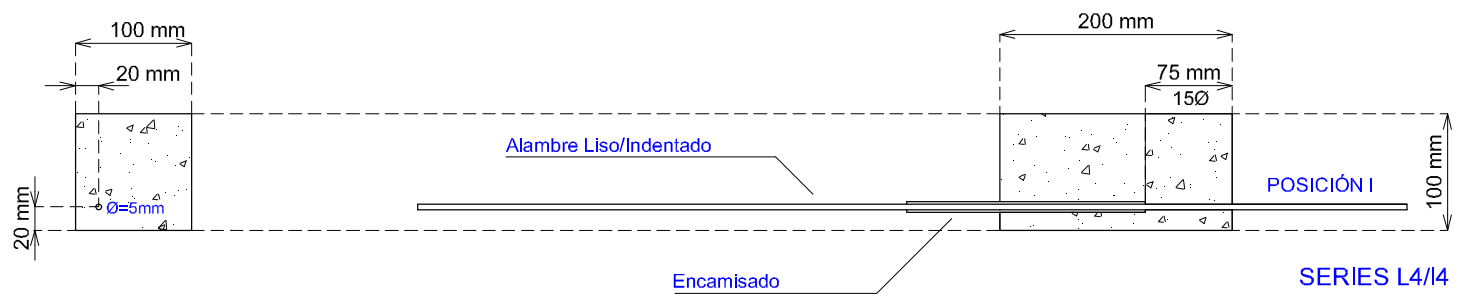

Figura 4-1 Seccion longitudinal y transversal de las distintas probetas: Series L20/I20; Series L10/I10 y Series L4/I4

Las barras utilizadas tienen dos tipos de acabado superficial, liso e indentado, y en todos los casos su diámetro nominal $\phi$ es de $5 \mathrm{~mm}$. Se ha utilizado una única longitud de adherencia $l_{\text {adb }}$ equivalente a 15 diámetros $(15 \phi=75 \mathrm{~mm})$, que es superior a la recomendada tanto en la Norma EN 10080:2005 como en la bibliografía consultada para la obtención de una tensión de adherencia constante a lo largo de dicha longitud. El valor de la longitud de adherencia utilizado es el resultado del compromiso entre un valor, por un lado, suficientemente grande como para permitir que la fuerza de arrancamiento adquiera una magnitud significativa, posibilitando una mejor apreciación de las diferencias existentes en la capacidad adherente al modificar las distintas variables contempladas, y por otro, suficientemente pequeño como para evitar la plastificación del acero durante el ensayo.

Como puede observarse en la Figura 4-1, la longitud de adherencia $l_{\text {adh }}$ utilizada es menor que la longitud total de las probetas en la dirección de la barra, por lo que se ha utilizado un «manguito» o 
«encamisado» de plástico termoretráctil para evitar el contacto adherente entre el hormigón y el acero a lo largo de las zonas que exceden la longitud designada. El manguito fue fijado al extremo de la longitud adherente mediante la aplicación de una temperatura elevada, lo que evitaba tanto la penetración de lechada en el interior del encamisado como el deslizamiento de la barra en su interior durante la fase de fabricación. Lógicamente, el diámetro interior del manguito es ligeramente mayor que el diámetro exterior de la barra.
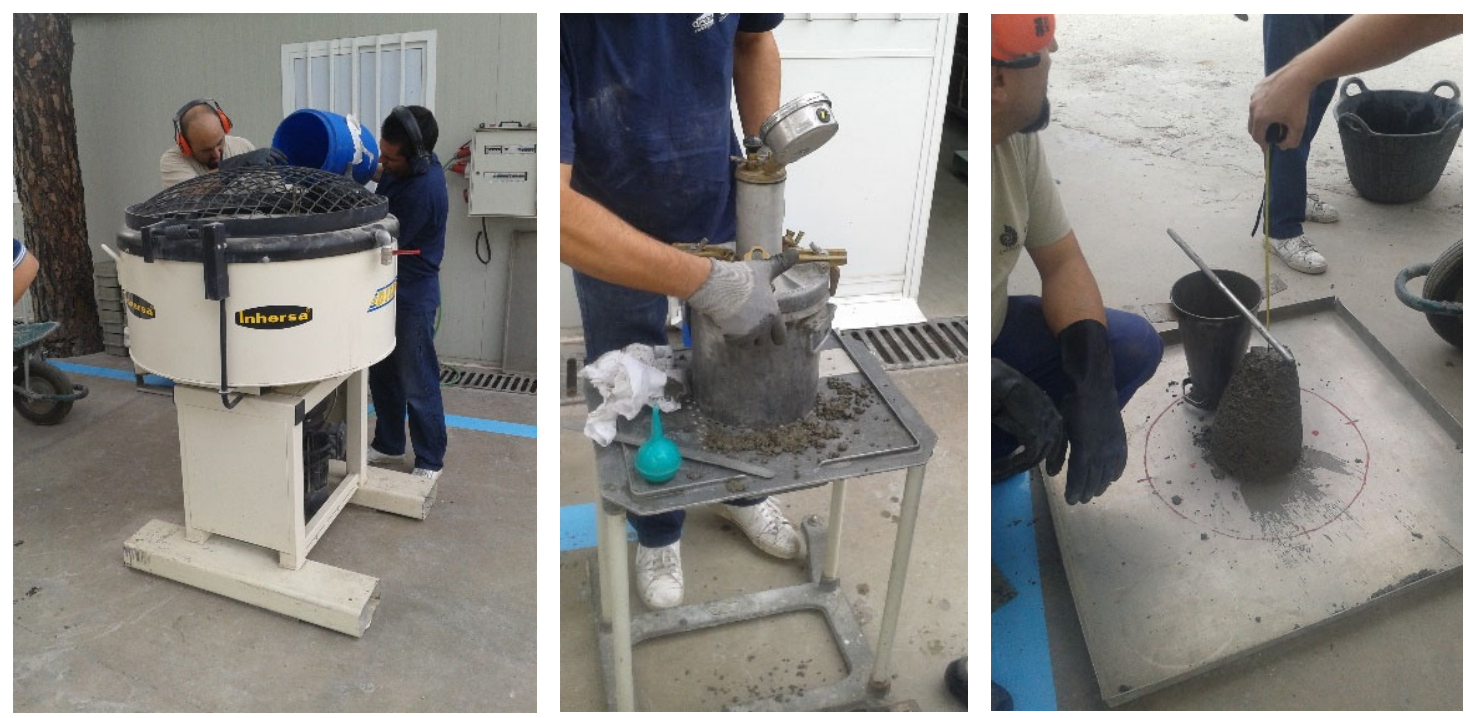

Figura 4-2 Proceso de fabricación del hormigón y ensayos de caracterización en estado fresco: densidad, aire ocluido y cono de Abrams

\subsubsection{Fabricación de las probetas}

El hormigón de las probetas fue elaborado en las instalaciones del Instituto de ciencias de la construcción Eduardo Torroja (IETcc) mediante hormigonera de 120 litros de capacidad. Como medida de control de calidad del hormigón, de cada una de las amasadas se llevaron a cabo ensayos de caracterización de las propiedades en estado fresco del hormigón: cono de Abrams, densidad y contenido de aire ocluido (Figura 4-2).
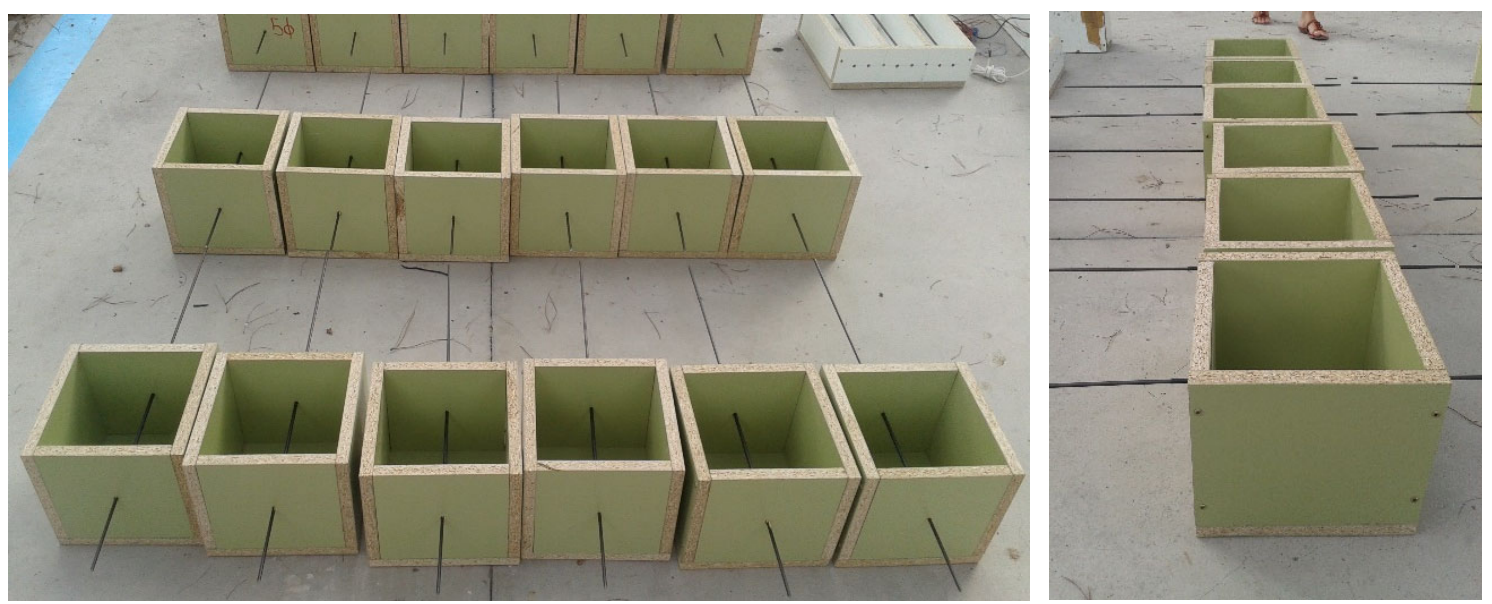

Figura 4-3 Encofrados de aglomerado de particulas, con barras de acero embebidas, listos para el vertido del hormigón. 
Las probetas se fabricaron mediante encofrados elaborados con tableros de aglomerado de partículas y revestimiento exterior de melanina, unidos mediante tornillos. Dos de los laterales situados en posiciones opuestas fueron perforados, permitiendo que las barras de acero fueran pasantes. El movimiento de las barras fue restringido exteriormente con el objetivo de evitar que, antes del fraguado, durante el vertido del hormigón y la posterior manipulación de las probetas, sufrieran cualquier tipo de deslizamiento (Figura 4-3).
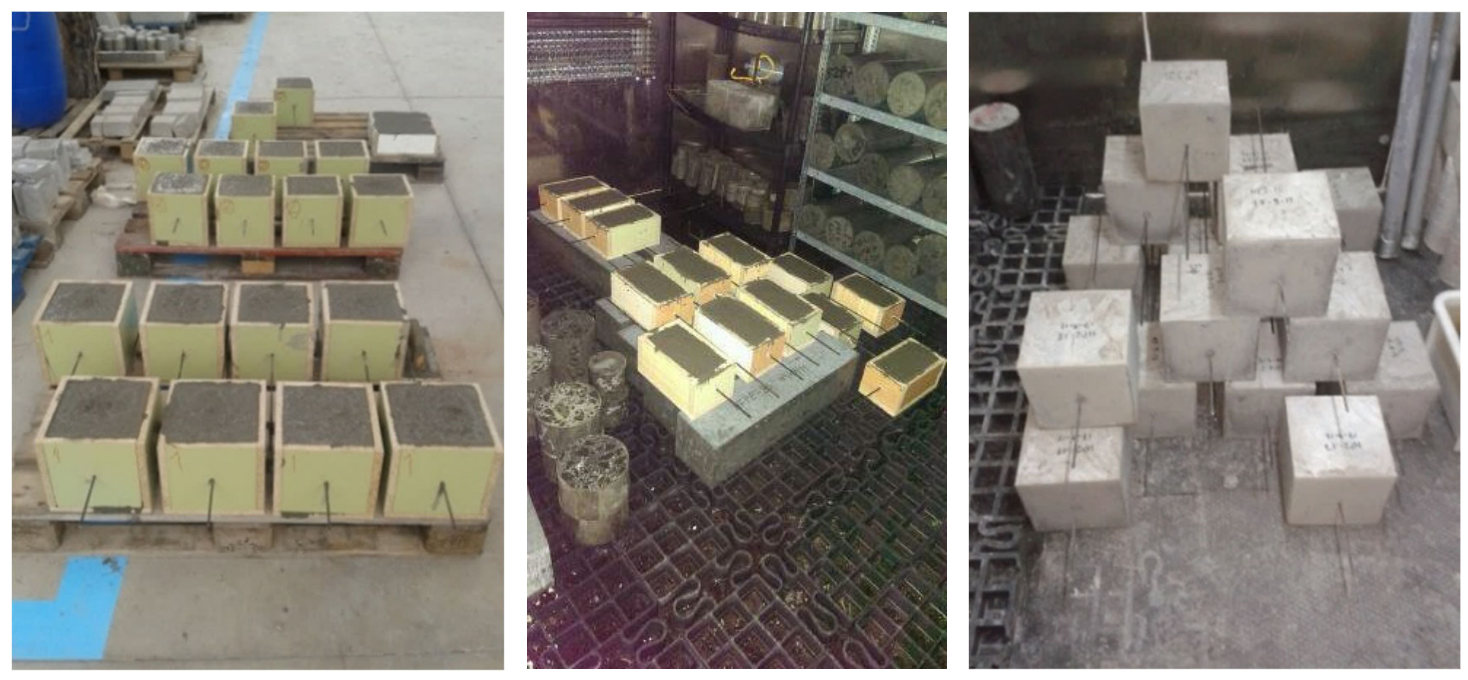

Figura 4-4 Vertido y curado de hormigón en cámara búmeda

Finalizado el hormigonado y allanado de la cara superior de las probetas, éstas permanecieron bajo una arpillera húmeda durante 24 horas, tiempo tras el cual se procedió al desencofrado. Después de esta operación, las probetas se trasladaron a una cámara húmeda, con $25^{\circ} \mathrm{C}$ de temperatura y $95 \%$ de humedad, donde se curaron hasta los 28 días, permitiendo que el hormigón alcanzara una resistencia suficiente antes del comienzo del procedimiento de corrosión acelerada (Figura 4-4). Posteriormente, las probetas se trasladaron al laboratorio, donde fueron corroídas hasta alcanzar el nivel teórico de pérdida de sección deseado, momento tras el cual fueron sometidas al ensayo de arrancamiento.

\subsubsection{Propiedades de los materiales}

\subsubsection{Hormigones}

Por razones operativas, de funcionamiento interno del Instituto Eduardo Torroja (disponibilidad de materiales, tiempos, capacidad de la amasadora, etc), y no tanto por razones derivadas de las necesidades de esta investigación, se han utilizado distintas dosificaciones de hormigón para las diferentes series de ensayos de las que se compone esta campaña experimental. En cuanto al hormigón, el único parámetro diferenciador que se ha tenido en cuenta a la hora de analizar los resultados obtenidos ha sido su resistencia, tanto a tracción como a compresión, obviando el resto de variables. Esta decisión es coherente con la revisión bibliográfica llevada a cabo, en la que la mayoría de estudios sólo tienen en cuenta las características mecánicas del hormigón a la hora de estudiar su influencia en el fenómeno de la adherencia. El amplio abanico de resistencias obtenidas ha permitido analizar cómo influye este parámetro en el comportamiento adherente. 
En la Tabla 4-2 se resumen las distintas dosificaciones utilizadas en cada una de las amasadas, así como la serie de ensayos en la que han sido utilizadas. Como puede apreciarse, se han empleado distintos cementos (CEM I-52,5 R y CEMI 42,5 R/SR), distintas relaciones agua/cemento (desde 0,42 hasta 0,53), diferentes fracciones de áridos y finos, tanto de naturaleza silícea como calcárea, y distintas cantidades de aditivo superflastificante/reductor de agua (MasterRheobuild ${ }^{\circledR}$ 1000, de BASF). En las dosificaciones se incluyó un $3 \%$ en peso de $\mathrm{NaCl}$, para favorecer la despasivación del acero.

Tabla 4-2. Dosificación de los hormigones empleados en los ensayos de pull-out

\begin{tabular}{|c|c|c|c|c|c|c|c|}
\hline \multirow[t]{2}{*}{ Componentes } & \multicolumn{6}{|c|}{ Peso SSS $\left[\mathrm{kg} / \mathrm{m}^{3}\right]$} & \multirow[b]{2}{*}{$\begin{array}{c}\text { Hormigón } \\
7\end{array}$} \\
\hline & $\begin{array}{c}\text { Hormigón } \\
1\end{array}$ & $\begin{array}{c}\text { Hormigón } \\
2\end{array}$ & $\begin{array}{c}\text { Hormigón } \\
3\end{array}$ & $\begin{array}{c}\text { Hormigón } \\
4\end{array}$ & $\begin{array}{c}\text { Hormigón } \\
5\end{array}$ & $\begin{array}{c}\text { Hormigón } \\
6\end{array}$ & \\
\hline Serie de ensayos & Serie L20(sc) & Serie L20(c) & $\begin{array}{l}\text { Serie } I 10 \\
\text { Serie } I 20\end{array}$ & $\begin{array}{l}\text { Serie I20 } \\
\text { Serie L10 }\end{array}$ & Serie 110 & Serie L4 & $\begin{array}{c}\text { Serie I4 } \\
\text { Serie I20 }\end{array}$ \\
\hline Cemento CEMI 52,5 R & 400 & 400 & 400 & 400 & - & - & - \\
\hline Cemento CEMI 42,5 R/SR & - & - & - & - & 400 & 400 & 400 \\
\hline Agua & 172 & 172 & 172 & 172 & 210 & 190 & 168 \\
\hline$a / c$ & 0,43 & 0,43 & 0,43 & 0,43 & 0,53 & 0,48 & 0,42 \\
\hline $\mathrm{NaCl}(3 \%$ peso cem $)$ & - & 19,78 & 19,78 & 19,78 & - & 19,78 & 19,78 \\
\hline Grava silícea (12/20) & 180 & 180 & 180 & 180 & - & - & - \\
\hline Grava silícea $(14 / 20)$ & - & - & - & - & - & - & 387 \\
\hline Grava silícea $(8 / 12)$ & 361 & 361 & 361 & 361 & - & - & - \\
\hline Grava caliza AG-6/12 & - & - & - & - & 790 & 790 & - \\
\hline Grava silícea (6/12) & - & - & - & - & - & - & 775 \\
\hline Grava silícea (4/8) & 180 & 180 & 180 & 180 & - & - & - \\
\hline Arena Caliza AF 0-4 & - & - & - & - & 483 & 483 & - \\
\hline Arena Silícea $(0 / 4)$ & 891 & 891 & 891 & 891 & - & - & 775 \\
\hline Arena Caliza AF-0/2 & - & - & - & - & 485 & 485 & - \\
\hline Arena Silícea $(0 / 1)$ & 201 & 201 & 201 & 201 & - & - & - \\
\hline Aditivo Rheobuild 1000 & 2 & 2 & 1 & 1,8 & 8 & 7,7 & 7 \\
\hline
\end{tabular}

En la Tabla 4-3 se recogen los resultados obtenidos en los ensayos sobre las propiedades en estado fresco del hormigón (cono de Abrams [cm], densidad $\left[\mathrm{g} / \mathrm{cm}^{3}\right]$ y contenido de aire [\%]), para cada una de las amasadas elaboradas. Como puede observarse, por diferentes motivos, de algunos de los hormigones no pudieron obtenerse estos datos.

Tabla 4-3. Propiedades en estado fresco de los hormigones utilizados en los ensayos de pull-out

\begin{tabular}{lccc}
\hline Amasada & Cono $[\mathrm{cm}]$ & Densidad en fresco $\left[\mathrm{g} / \mathrm{cm}^{3}\right]$ & Contenido en aire $[\%]$ \\
\hline Hormigón 1 & 6,2 & 2,37 & 2,6 \\
\hline Hormigón 2 & - & - & - \\
\hline Hormigón 3 & 8,5 & 2,283 & 5,1 \\
\hline Hormigón $\mathbf{1}$ & 8,5 & 2,3 & 4,3 \\
\hline Hormigón 5 & 12 & - & 2,9 \\
\hline Hormigón $\mathbf{6}$ & 10 & 2,27 & 4,5 \\
\hline Hormigón 7 & - & - & - \\
\hline
\end{tabular}


Por cada una de las amasadas, se hormigonaron también tres probetas cúbicas de 15x15x15 cm, para la caracterización de la resistencia a compresión del hormigón $f_{c m}$ y tres probetas cilíndricas de 10x20 $\mathrm{cm}$ (excepto en las dos primeras amasadas), con el objetivo de determinar la resistencia a tracción indirecta $f_{\text {ctm }}$. En la Tabla 4-4 se incluyen, para cada hormigón elaborado, los resultados medios de resistencia a compresión y tracción indirecta, así como su desviación estándar y su coeficiente de variación $(\mathrm{CoV})$.

Tabla 4-4 Resistencias a compresión y tracción de los hormigones empleados

\begin{tabular}{|c|c|c|c|c|c|c|c|}
\hline \multirow[b]{2}{*}{ Amasada } & \multirow[b]{2}{*}{ Serie de ensayos } & \multicolumn{3}{|c|}{$\begin{array}{c}\text { Resistencia a compresión } \\
f_{c}\left[\mathrm{~N} / \mathrm{mm}^{2}\right]\end{array}$} & \multicolumn{3}{|c|}{$\begin{array}{l}\text { Resistencia a tracción } \\
\text { fct }\left[\mathrm{N} / \mathrm{mm}^{2}\right]\end{array}$} \\
\hline & & Media & $\begin{array}{c}\text { Desviación } \\
\text { estándar }\end{array}$ & $\mathrm{CoV}$ & Media & $\begin{array}{c}\text { Desviación } \\
\text { estándar }\end{array}$ & $\mathrm{CoV}$ \\
\hline Hormigón 1 & Serie L20(sc) & 67,10 & 2,85 & 4,25 & - & - & - \\
\hline Hormigón 2 & Serie L20(c) & 51,98 & 2,82 & 5,42 & - & - & - \\
\hline Hormigón 3 & Serie I10 - Serie I20 & 48,40 & 2,05 & 4,24 & 3,52 & 0,13 & 3,82 \\
\hline Hormigón 4 & Serie I20 - Serie L10 & 43,72 & 1,58 & 3,61 & 3,16 & 0,25 & 7,82 \\
\hline Hormigón 5 & Serie I10 & 45,84 & 3,61 & 7,87 & 3,33 & 0,07 & 1,97 \\
\hline Hormigón 6 & Serie L4 & 32,43 & 2,44 & 7,52 & 3,79 & 0,23 & 5,97 \\
\hline Hormigón 7 & Serie I4 - Serie I20 & 51,67 & 1,55 & 3,00 & 4,13 & 0,03 & 0,84 \\
\hline
\end{tabular}

\subsubsection{Acero}

Se han utilizado alambres lisos e indentados de acero Y1860C, de $5 \mathrm{~mm}$ de diámetro nominal, con una carga última de rotura de $f_{p, u}=1860 \mathrm{~N} / \mathrm{mm}^{2}$ y un Módulo de elasticidad $E_{p}$ de $200000 \mathrm{~N} / \mathrm{mm}^{2}$. En la Tabla 4-5 se resumen las características mecánicas y geométricas comunes de los alambres utilizados.

En cuanto a las peculiaridades geométricas de los alambres indentados, la altura de las indentaciones $h_{r}$ oscila entre un mínimo de $60 \mu \mathrm{m}$ y un máximo de $130 \mu \mathrm{m}$, la longitud de éstas en la dirección del eje es de 2,5 $\mathrm{mm}$ y la longitud del paso de hélice $s_{r}$ es igual a $6,0 \mathrm{~mm}$.

Tabla 4-5 Propiedades geométricas y mecánicas de los alambres lisos e indentados

\begin{tabular}{|c|c|c|c|c|c|c|c|}
\hline $\begin{array}{c}\text { Diámetro } \\
\text { nominal } \\
{[\mathrm{mm}]}\end{array}$ & $\begin{array}{l}\text { Carga unit. } \\
\text { máxima } f_{p, u} \\
{\left[\mathrm{~N} / \mathrm{mm}^{2}\right]}\end{array}$ & $\begin{array}{l}\text { Masa } \\
{[\mathrm{g} / \mathrm{m}]}\end{array}$ & $\begin{array}{c}\text { Área } \\
\text { sección } \\
{\left[\mathrm{mm}^{2}\right]}\end{array}$ & $\begin{array}{l}\text { Módulo de } \\
\text { Young } \mathrm{E}_{\mathrm{p}} \\
{\left[\mathrm{N} / \mathrm{mm}^{2}\right]}\end{array}$ & $\begin{array}{c}\text { Carga mínima } \\
\text { de rotura } \\
{[\mathrm{kN}]}\end{array}$ & $\begin{array}{c}\text { Carga máxima } \\
\text { de rotura } \\
{[\mathrm{kN}]}\end{array}$ & $\begin{array}{c}\text { Fuerza en Límite } \\
\text { elático }\left(\varepsilon_{\mathrm{p}}=0,1 \%\right) \\
{[\mathrm{MPa}]}\end{array}$ \\
\hline 5 & 1860 & 153,1 & 19,6 & 200000 & 36,5 & 42,0 & 32,5 \\
\hline
\end{tabular}

\subsubsection{Procedimiento de corrosión acelerada}

Para el procedimiento de corrosión acelerada del acero embebido en las probetas se empleó el método galvanostático descrito, entre otros, en Andrade et al. (1993) y Rodriguez et al. (1994). Este método se basa en la aplicación de una corriente constante, generada mediante un intensiostato, a través de un circuito en el que los alambres de acero, que actúan como ánodos, se oxidan, y una malla de acero inoxidable situada perimetralmente, sobre la superficie del hormigón y en la proyección de la longitud adherente del acero, se reduce, actuando como contraelectrodo (Figura 4-5). Para asegurar la continuidad electrolítica del hormigón se colocó una esponja permanentemente humedecida entre su superficie y la malla de acero inoxidable. Las probetas se ubicaron en cubetas llenas de agua para asegurar el aporte continuo de humedad a las esponjas (ver Figura 4-๑). 
Se aplicó una densidad de corriente de $100 \mu \mathrm{A} / \mathrm{cm}^{2}$, unas diez veces superior a las máximas velocidades de corrosión medidas en estructuras reales sometidas a procesos de deterioro derivados de la carbonatación del hormigón, y similares a las máximas registradas en ambientes marinos. Esta corriente permitía unos tiempos razonables para la realización de los ensayos, mientras que aseguraba que la corrosión inducida se situara en un rango próximo a los valores "naturales" que pueden ser encontrados en la práctica. El intensiostato utilizado, diseño y fabricación del Dr. Fabiano Tavares, ingeniero mecánico del IETcc, permitió el control continuo y la regulación de las intensidades de corriente que circulaban por el circuito.

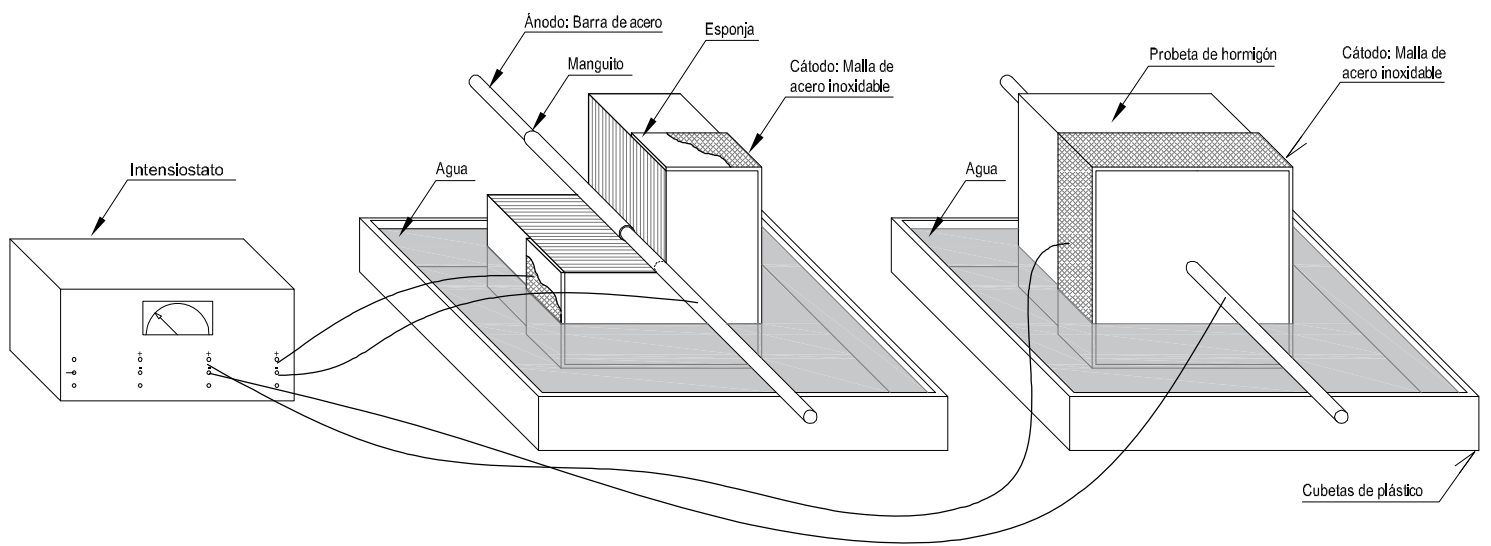

Figura 4-5 Esquema del procedimiento de corrosión acelerada de alambres, mediante procedimiento galvanoestático.

A efectos del análisis de la influencia de la corrosión en las propiedades adherentes, se establecieron distintos niveles de pérdida de sección teórica (en porcentaje): 0 (barras sanas), 2, 5, 10 y $20 \%$. En la Tabla 4-6 se incluye la penetración de ataque $P_{x}[\mu \mathrm{m}]$, el diámetro residual [mm] y el tiempo [días] a transcurrir para cada uno de los niveles de corrosión considerados.

Tabla 4-6 Niveles de pérdidas de sección teórica consideradas en los ensayos de corrosión acelerada

\begin{tabular}{|c|c|c|c|c|c|}
\hline $\begin{array}{l}\text { Perdida de } \\
\text { sección [\%] }\end{array}$ & $\mathbf{I}_{\text {corr }}\left[\boldsymbol{\mu} \mathrm{A} / \mathrm{cm}^{2}\right]$ & $\begin{array}{c}\text { Diámetro } \\
\text { nominal [mm] }\end{array}$ & $\begin{array}{l}\text { Penetración de } \\
\text { ataque } P_{x}[\mu \mathrm{m}]\end{array}$ & $\begin{array}{c}\text { Diámetro } \\
\text { residual [mm] }\end{array}$ & Tiempo [días] \\
\hline 0 & \multirow{5}{*}{100} & \multirow{5}{*}{5,00} & 0 & 5 & 0 \\
\hline 2 & & & 25,13 & 4,95 & 7,91 \\
\hline 5 & & & 63,30 & 4,87 & 19,92 \\
\hline 10 & & & 128,29 & 4,74 & 40,37 \\
\hline 20 & & & 263,93 & 4,47 & 83,05 \\
\hline
\end{tabular}

Cabe reseñar que la primera serie de probetas fabricadas, las denominadas L20, fue dividida en dos tandas: en una de ellas los cloruros fueron añadidos desde el primer momento, en el amasado del hormigón, mientras que en la otra se forzó la difusión de éstos tras su elaboración. El objetivo de esta diferencia metodológica fue determinar cómo influía la inclusión o no de cloruros en la masa de hormigón para el desarrollo de la corrosión, dado que en los ensayos sobre vigas pretensadas que se realizarían posteriormente (ver Capitulo 7), los cloruros habría que difundirlos una vez fabricados los elementos, permitiendo discernir claramente los efectos sobre la deformación de la viga atribuibles, por un lado, al pretensado y a los efectos dependientes del tiempo (retracción, relajación y fluencia), y por otro, al deterioro inducido por la corrosión. Por tanto, la penetración de cloruros desde la superficie del hormigón fue forzada (Andrade, 2013) basándose en el denominado "método integral" 
de la Norma UNE 83992-2:2012 EX "Durabilidad del hormigón. Métodos de ensayo. Ensayos de penetración de cloruros en el hormigón. Parte 2: Método integral acelerado." (CTN 83 - HORMIGÓN, 2012).
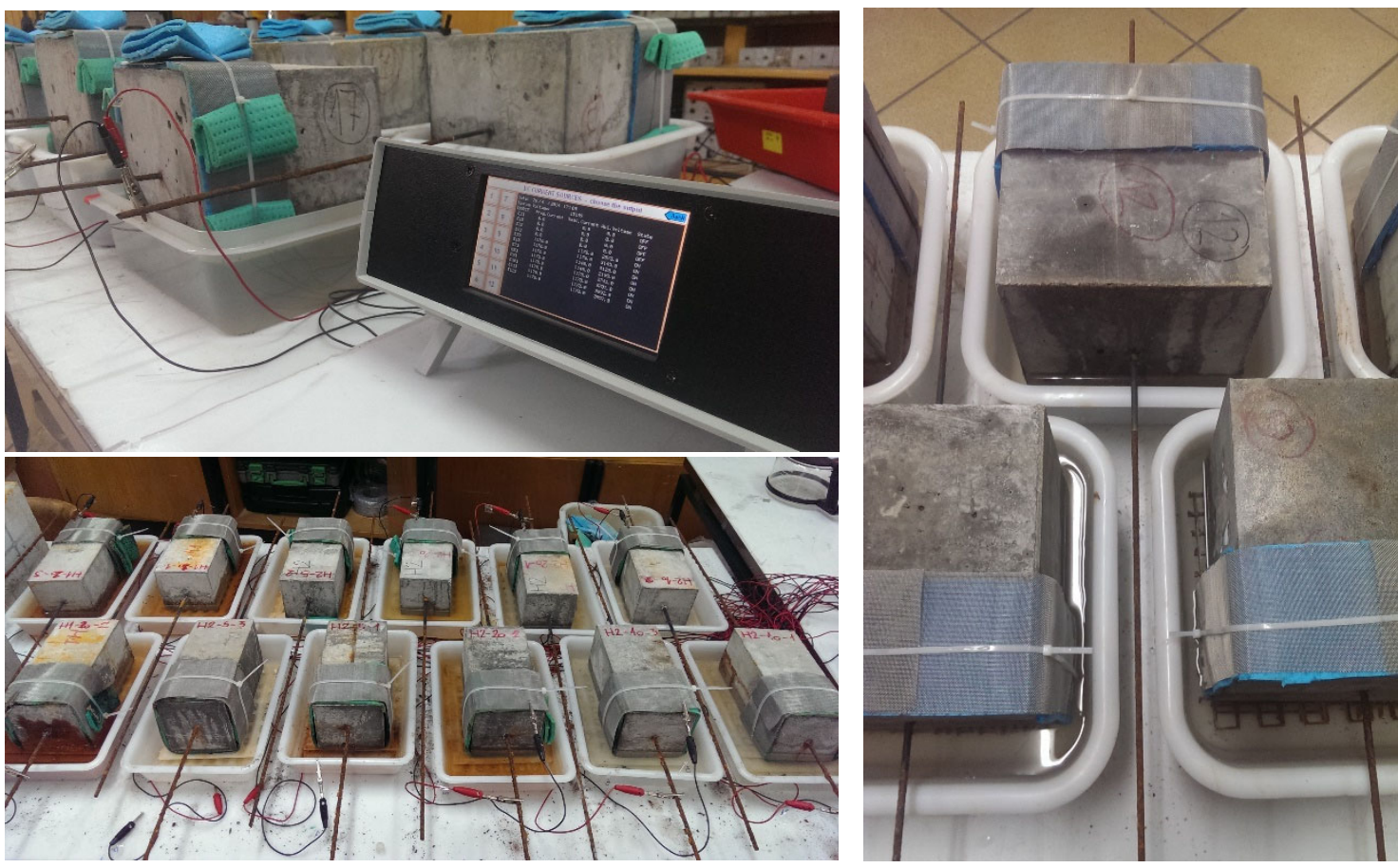

Figura 4-6 Configuración del procedimiento de corrosión acelerada sobre las probetas del ensayo de pull-out

\subsubsection{Método integral acelerado}

En términos generales, este ensayo consiste en exponer la probeta de hormigón, en la que se ha embebido transversalmente el alambre de acero, a un campo eléctrico aplicado mediante electrodos en los lados opuestos de la misma, de manera que se fuerce la penetración de los cloruros presentes en una disolución en contacto con el hormigón, hasta alcanzar la posición del alambre, posibilitando la despasivación del mismo.

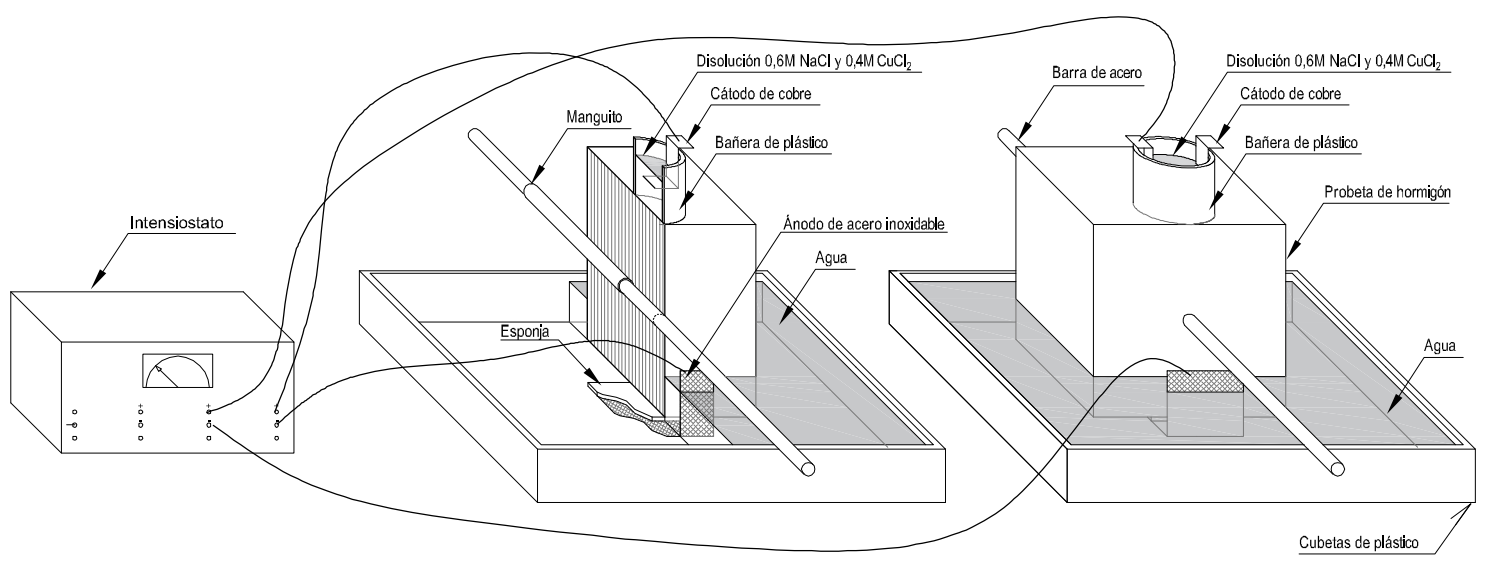

Figura 4-7 Esquema de configuración del método integral acelerado aplicado a las probetas del ensayo de pull-out 
Para asegurar un buen contacto entre la disolución con cloruros y la superficie de hormigón, y que la llegada de los cloruros al alambre fuera homogénea, fue necesaria adherir una bañera cilíndrica de plástico en la cara superior de las probetas, situada en la proyección vertical de la longitud adherente (Figura 4-7).

El método general incluido en la Norma UNE 83992-2:2012 EX (CTN 83 - HORMIGÓN, 2012) se modificó ligeramente para adaptarlo a las peculiaridades de las probetas. Se utilizó un cátodo de cobre, elaborado con chapa de dicho material, en contacto con una disolución de cloruro sódico y cúprico $\left(0,6 \mathrm{M} \mathrm{NaCl}\right.$ y $\left.0,4 \mathrm{M} \mathrm{CuCl}_{2}\right)$. En la cara opuesta, en la parte inferior de la probeta y en la proyección vertical de la longitud adherente, se situó una malla de acero inoxidable actuando como ánodo. Como en el procedimiento de corrosión acelerada expuesto anteriormente, la continuidad electrolítica se aseguró mediante una esponja permanentemente humedecida entre la superficie del hormigón y la malla de acero inoxidable. Con esta configuración, el cloruro cúprico permite que se reduzcan iones cúpricos sobre el electrodo de cobre, evitándose la hidrólisis del agua y, por tanto, la acidificación de la disolución. La intensidad de corriente $i_{\text {corr }}$ aplicada fue de $100 \mu \mathrm{A} / \mathrm{cm}^{2}$.

Una vez que se alcanzó la despasivación del acero de los alambres, lo que según el Metodo Integral Acelerado ocurre cuando se detecta un potencial de $-300 \mathrm{mV}$ o más negativo, se avanzó a la fase de corrosión acelerada. Para ello fue necesario retirar previamente las bañeras adheridas en la parte superior de las probetas.
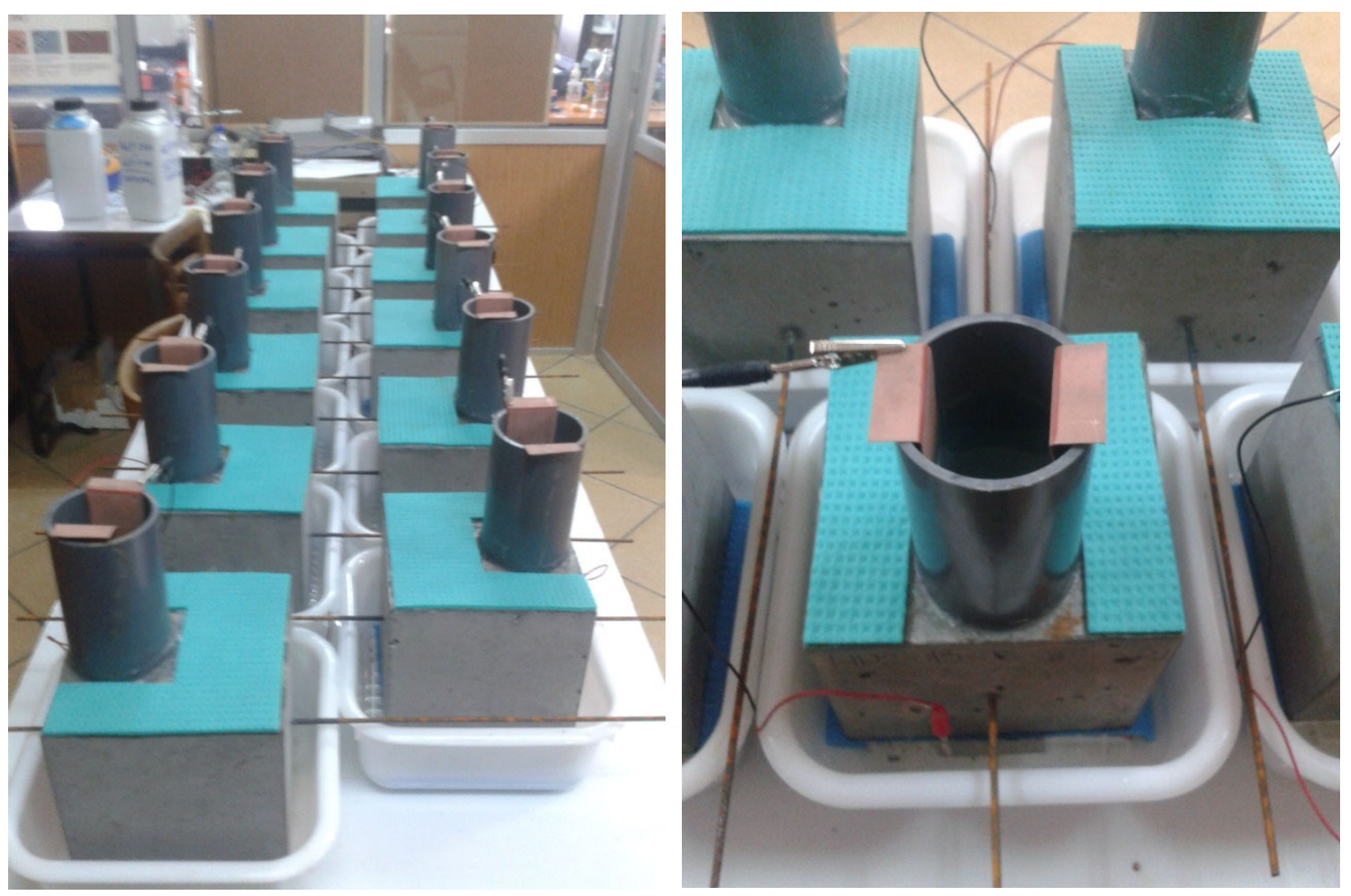

Figura 4-8 Imágenes de la configuración del método integral acelerado aplicado a las probetas del ensayo de pull-out, en el laboratorio de corrosión del IETcc 


\subsubsection{Dispositivo de ensayo y adquisición de datos}

Con el objeto de caracterizar de forma adecuada el comportamiento adherente durante los ensayos, se realizaron las siguientes mediciones (Figura 4-9):

- Deslizamiento relativo de la barra con respecto al hormigón. Para la medición se emplearon transductores lineales de desplazamiento (LVDT) en cada uno de los extremos de la probeta. En el extremo libre se situaron dos LVDT, uno con menor recorrido (Desplazamiento máximo: $10 \mathrm{~mm}$ ) y mayor precisión, y otro con más recorrido (Desplazamiento máximo: $40 \mathrm{~mm}$ ) y menor precisión y sensibilidad, que servía para validar los datos recogidos por el primero. En el lado cargado se ubicó un sensor de desplazamiento por hilo (Figura 4-10).

- Carga aplicada. Se utilizó un gato hidráulico de carga máxima igual a 156 kN. Mediante una célula de carga se controló la carga real que se estaba aplicando en cada momento (Figura 4-10).

El ensayo se ha realizó con control por carga, con un incremento constante de la tensión de adherencia. La Norma UNE-EN 10080:2006 recomienda una velocidad de incremento de carga igual a $v_{p}=0,56 \cdot d^{2}(\mathrm{~N} / \mathrm{sg})$, en el que $d$ es el diámetro nominal de la barra o alambre, en $\mathrm{mm}$. Teniendo en cuenta que el diámetro utilizado en todos los ensayos ha sido de $5 \mathrm{~mm}$, la velocidad recomendada por la norma sería $\mathrm{v}_{\mathrm{p}}=14 \mathrm{~N} / \mathrm{s}$. Por limitaciones del equipo utilizado, la velocidad real de aplicación de la carga ha sido $\mathrm{v}_{\mathrm{p}}=10 \mathrm{~N} / \mathrm{sg}$, cercana a la recomendada por la Norma. Esta velocidad se ha mantenido constante a lo largo de todos los ensayos de arrancamiento llevados a cabo.

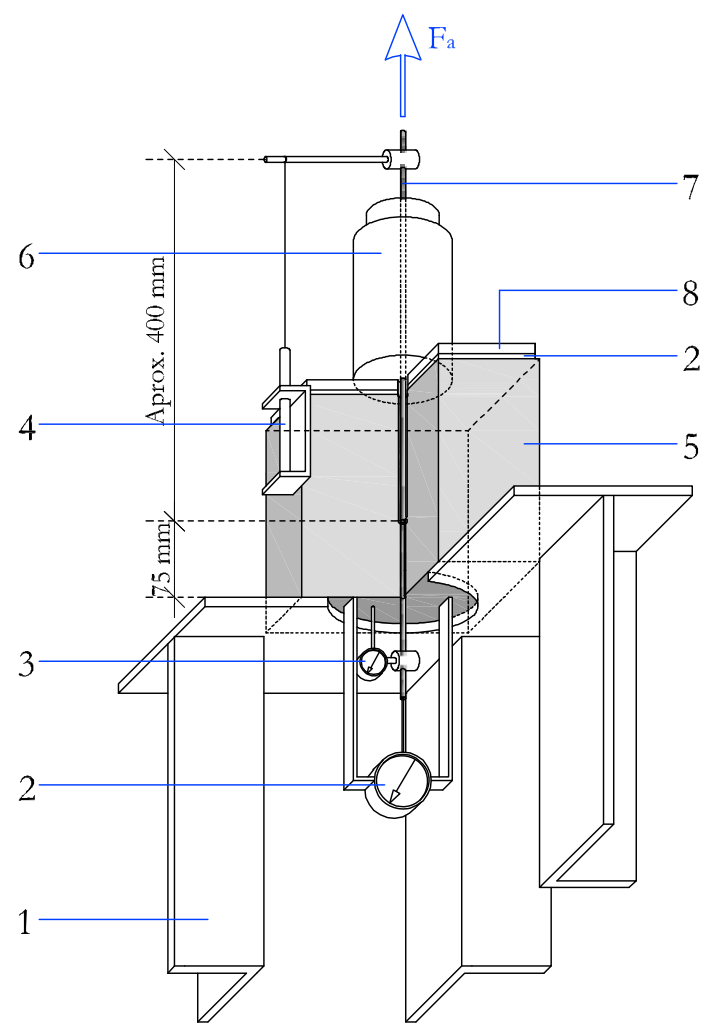

1. Soporte de acero para el ensayo

2. Captador de desplazamiento lineal. Desplazamiento máximo: $40 \mathrm{~mm}$. (Auxiliar 12 - Extremo libre)

3. Captador de desplazamiento lineal. Desplazamiento máximo: $10 \mathrm{~mm}$. (Auxiliar 10 - Extremo libre)

4. Sensor de desplazamiento por hilo. (Auxiliar 9 Extremo cargado)

5. Probeta prismática de hormigón $(100 \times 100 \times 200$ ó 200x200x200 mm)

6. Gato hidráulico. (Capacidad máxima 156 kN)

7. Barra de acero liso Y-1870. fpk $=1860 \mathrm{MPa}$. Diametro $\varnothing=5 \mathrm{~mm}$.

8. Placa metálica. Espesor e $=20 \mathrm{~mm}$

9. Lámina de neopreno. Espesor e=10mm

Figura 4-9 Esquema del dispositivo de ensayo y adquisición de datos en los ensayos de arrancamiento o pull-out 

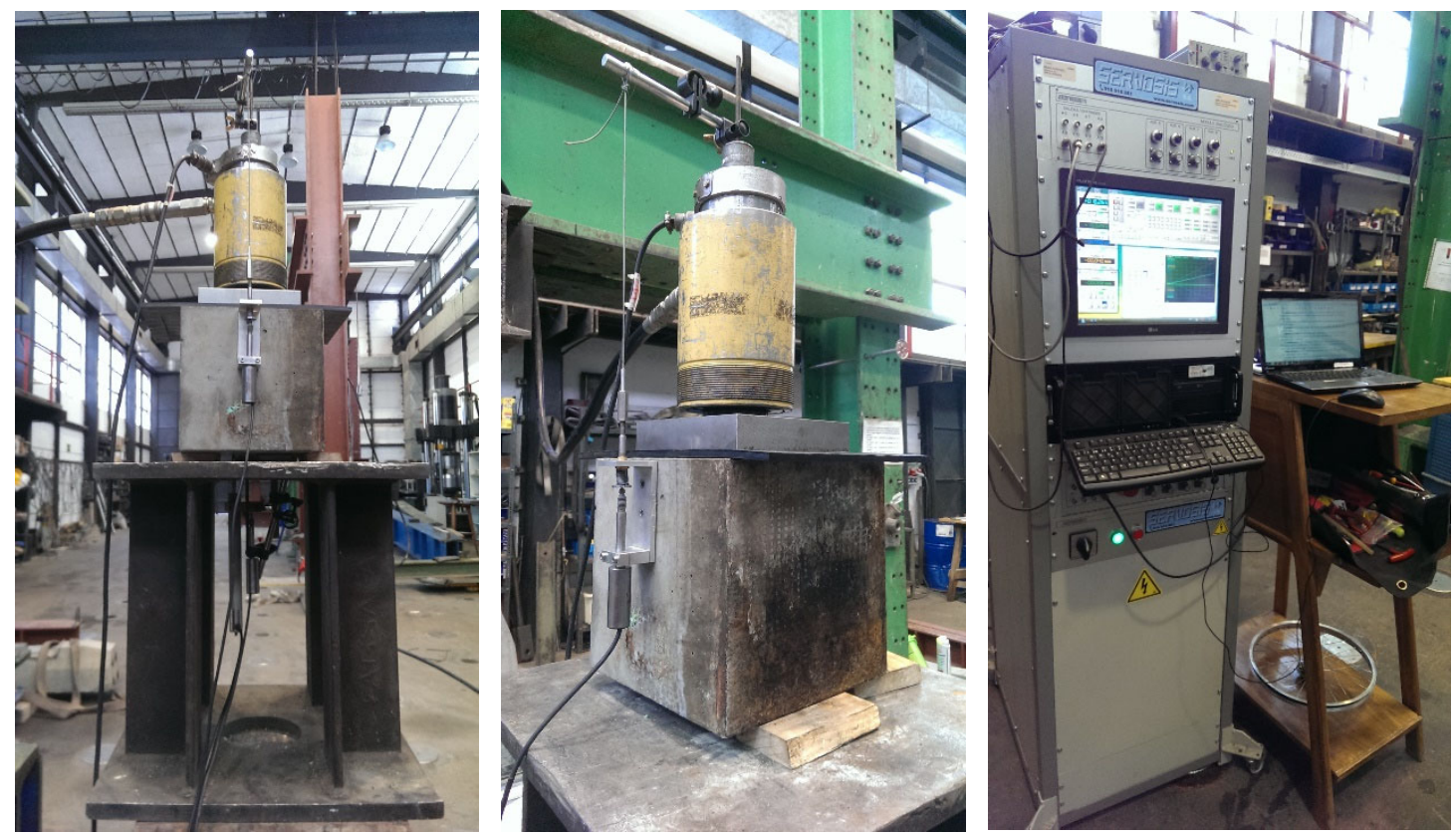

Figura 4-10 Instrumentación de las probetas durante el ensayo de pull-out.

\subsubsection{Gravimetría}

Una vez terminado el proceso de corrosión acelerada, y tras los ensayos de arrancamiento (pull-out), se obtuvieron las pérdidas gravimétricas generadas en el proceso. Para ello, las barras, que habían sido previamente pesadas, se extrajeron de las probetas de hormigón (Figura 4-12), se decaparon con un baño de ultrasonidos y una disolución de ácido clorhídrico 1:1 con 3\% de hexametilentetramina (urotropina), se limpiaron con un cepillo con cerdas de plástico. Finalmente, se lavaron con agua, se secaron con acetona y aire caliente, y se pesaron y midieron (Figura 4-11).
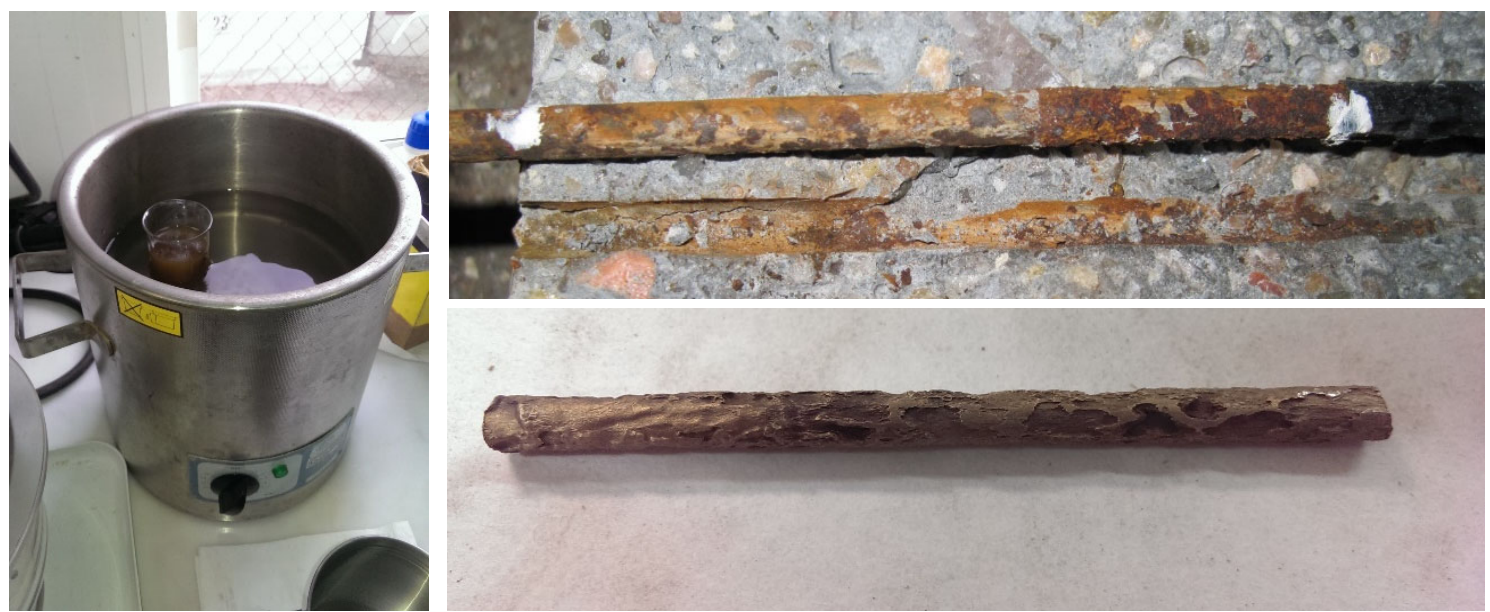

Figura 4-11 Proceso de decapado de alambres. Baño de ultrasonidos en disolución de ácido clorbídrico (irq.). Barra antes y después del decapado (Der.)

Mediante la diferencia de pesadas antes y después del proceso de corrosión se obtuvieron las pérdidas reales de material. A partir de las pérdidas gravimétricas se calculó la reducción de sección media y la 
profundidad media de ataque de cada barra. Estos valores fueron los que se usaron posteriormente para analizar los resultados.
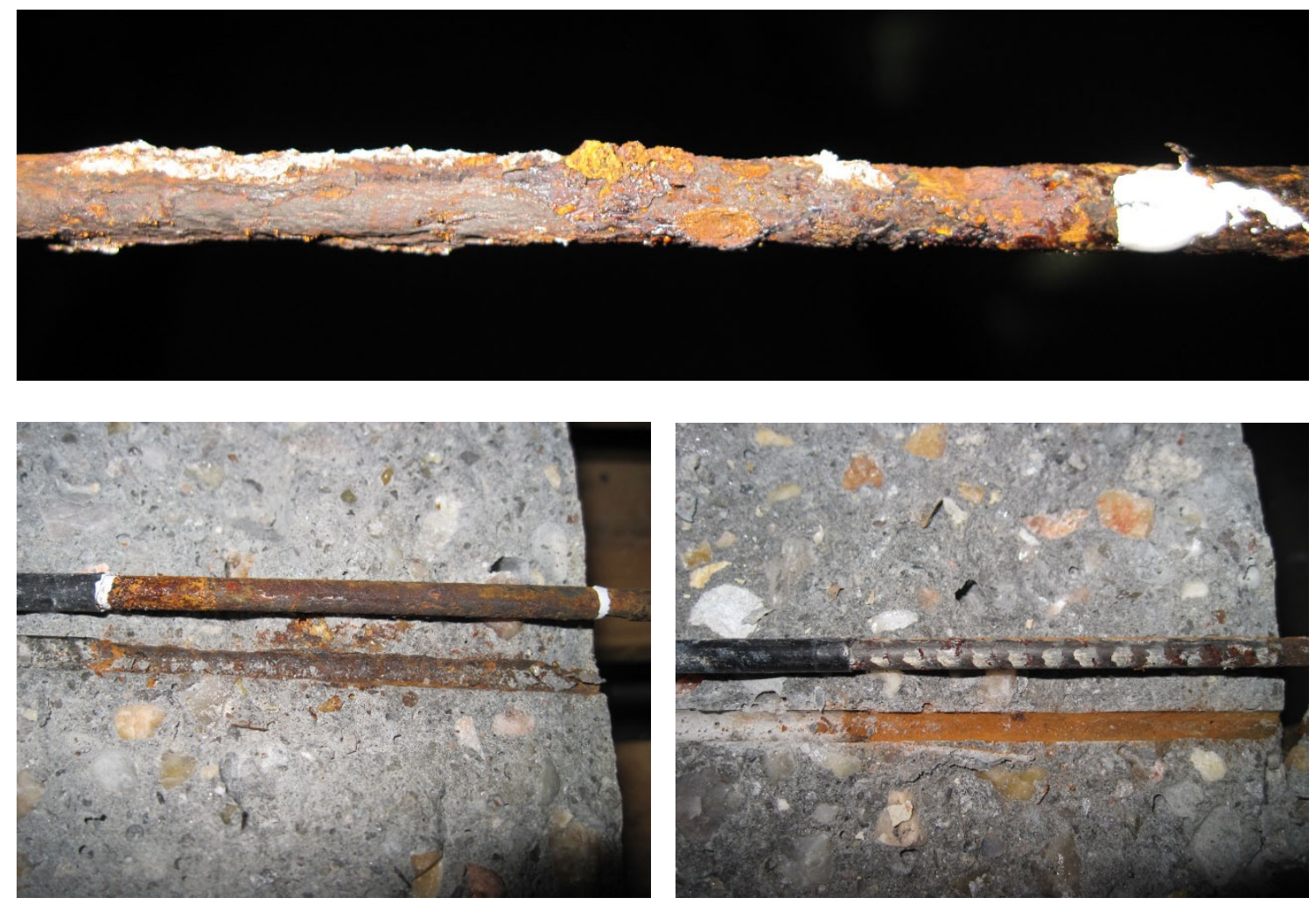

Figura 4-12 Extracción de las barras de las probetas de hormigón tras el ensayo de pull-out

\subsection{Series de ensayos}

La nomenclatura utilizada para designar las probetas informa del acabado superficial de las barras, de la relación recubrimiento/diámetro, del porcentaje de pérdida de sección teórica y del número de orden de la probeta dentro de la serie de ensayos. El esquema de designación es el siguiente:

$$
\operatorname{Sup} c / \phi-\% \operatorname{corr}-X
$$

donde:

Sup Acabado superficial del alambre. $I=$ alambre indentado; $L=$ alambre liso.

$c / \phi \quad$ Relación recubrimiento/ diámetro.

\%corr Porcentaje de pérdida teórica de sección transversal del alambre por proceso de corrosión.

X Número de orden de la probeta perteneciente a una serie de ensayos con las mismas características. 
Por ejemplo, la denominación I4-10-2 se corresponde con la segunda (2) probeta de la serie de ensayos sobre alambres indentados (I), con una relación recubrimiento/diámetro igual a 4 y un porcentaje de pérdida de sección equivalente a un $10 \%$.

A modo de resumen, la Tabla 4-7 recoge las principales características de cada una de las series de ensayos de pull-out de las que se compone la campaña experimental: acabado superficial, recubrimiento mecánico $c$, relación recubrimiento/diámetro $c / \phi$, tipo de hormigón utilizado, resistencia media a compresión del hormigón $f_{c m}$ y rango de pérdidas teóricas de sección transversal consideradas.

Tabla 4-7 Características de las diferentes series de ensayos de arrancamiento.

\begin{tabular}{|c|c|c|c|c|c|c|c|}
\hline & $\begin{array}{c}\text { Acabado } \\
\text { superficial }\end{array}$ & $\begin{array}{c}\mathrm{c} \\
{[\mathrm{mm}]}\end{array}$ & $\mathrm{c} / \phi$ & $\begin{array}{l}\text { Cloruros en } \\
\text { el amasado }\end{array}$ & Hormigón & $\begin{array}{c}f_{c m} \\
{[\mathrm{MPa}]}\end{array}$ & $\begin{array}{l}\text { Rango de pérdidas } \\
\text { de sección teóricas }\end{array}$ \\
\hline Serie L4 & Liso & \multirow{2}{*}{20} & \multirow{2}{*}{4} & $\mathrm{Si}$ & 6 & 32,43 & $0-20$ \\
\hline Serie I4 & Indentado & & & $\mathrm{Si}$ & 7 & 51,67 & $0-20$ \\
\hline Serie L10 & Liso & \multirow{2}{*}{50} & \multirow{2}{*}{10} & $\mathrm{Si}$ & 4 & 43,72 & $0-20$ \\
\hline Serie I10 & Indentado & & & $\mathrm{Si}$ & 3 y 5 & 48,$40 ; 45,84$ & $0-20$ \\
\hline \multirow{2}{*}{ Serie L20 } & \multirow{2}{*}{ Liso } & \multirow{3}{*}{100} & \multirow{3}{*}{20} & No & 1 & 67,10 & $0-10$ \\
\hline & & & & $\mathrm{Si}$ & 2 & 51,98 & $0-10$ \\
\hline Serie I20 & Indentado & & & $\mathrm{Si}$ & 3,4 y 7 & 48,$40 ; 43,72$ y 51,67 & $0-2$ \\
\hline
\end{tabular}




\section{CAPÍTULO 5}

\section{Resultados experimentales y discusión}

\subsection{Introducción}

En este capítulo se exponen, analizan y discuten los resultados obtenidos en la campaña experimental recogida en el Capítulo 4, consistente en 109 ensayos de pull-out. Los datos obtenidos han permitido conocer cómo afectan a la capacidad adherente las distintas variables contempladas: el acabado superficial del acero, la relación recubrimiento/diámetro, la resistencia a compresión y tracción del hormigón y el nivel de corrosión. La capacidad adherente del sistema acero/hormigón ha sido caracterizada mediante el máximo valor de la tensión media de adherencia $\tau_{b, \text { max }}^{\text {med }}$ a lo largo de la longitud adherente $l_{a d h}$ y mediante la ley de adherencia media-deslizamiento $\tau_{b, \text { med }}-s$.

Con carácter general, en el análisis de los ensayos de pull-out participan varios factores de cuyo grado de intervención van a depender los resultados obtenidos:

- Capacidad de confinamiento del recubrimiento de hormigón: Factor dependiente de valores geométricos (espesor de recubrimiento) y mecánicos (resistencias a compresión y tracción del hormigón, módulo de elasticidad, etc.).

- Capacidad del sistema acero-hormigón para movilizar la acción confinante del recubrimiento: el hormigón confina el alambre de acero únicamente si existe una tensión de compresión radial alrededor del alambre, y para que ésta aparezca debe producirse un desplazamiento de la pared interna del cilindro hueco de hormigón que circunda el acero. Este desplazamiento puede venir ocasionado por distintas razones, entre las que se encuentran los siguientes: la expansión de los productos de corrosión, la retracción asociada a la pérdida de humedad del hormigón o el deslizamiento de las indentaciones o corrugas del alambre.

- Forma en la que se lleva a cabo esta movilización: el gradiente de desplazamientos a lo largo del espesor de recubrimiento y sus deformaciones asociadas, difieren en función de la capacidad de confinamiento del hormigón. El aumento de esta capacidad puede conducir, a partir de un determinado nivel de confinamiento, a un incremento de deformaciones en la cercanía de la interfase acero-hormigón, al estar restringido el movimiento de las capas exteriores del recubrimiento. Si esta restricción alcanza cotas importantes, ya sea por el uso de hormigones de alta resistencia, de cuantías altas de armadura transversal o de recubrimientos de gran espesor, las deformaciones en la cara interior del cilindro de hormigón, y por tanto las tensiones, pueden alcanzar un grado tal que ocasionen el agotamiento de la capacidad resistente del mismo.

A continuación, se comparan las pérdidas de sección teórica por corrosión con las pérdidas reales obtenidas mediante gravimetría, se analiza la fisuración inducida por la corrosión observada en las probetas y, por último, se recopilan y discuten los resultados obtenidos en los ensayos de 
arrancamiento, utilizando para ello las leyes de tensión de adherencia media-deslizamiento $\tau_{b, m e d}-$ $s$.

\subsection{Pérdidas de sección por corrosión}

En este apartado se exponen y discuten los resultados de pérdida de sección obtenidos en las barras sometidas a corrosión acelerada. En primer lugar, se establecen los criterios seguidos para el cálculo de la pérdida de sección tanto teórica como real, considerando en ambos casos que la penetración de ataque por corrosión $P_{x}$ es uniforme en toda la superficie del alambre a lo largo de la longitud adherente $l_{\text {adb. }}$. Posteriormente, se comparan los resultados de pérdida de sección obtenidos mediante gravimetría con los estimados teóricamente mediante la Ley de Faraday, y se discute la capacidad predictiva de esta última en alambres tanto lisos como indentados. Finalmente, se analiza la fisuración derivada del proceso de corrosión.

\subsubsection{Generalidades}

El grado de corrosión real de las armaduras se determinó mediante gravimetría, siguiendo el procedimiento expuesto en el Capitulo 4. Dado que la Norma UNE-EN 10080 (Comité Técnico AEN/CTN 36,2006$)$ permite desviaciones con relación al valor nominal de la masa por metro de hasta $\pm 4,5 \%$ para diámetros nominales mayores que $8 \mathrm{~mm}$, y de hasta $\pm 6,0 \%$ para diámetros nominales menores o iguales que $8 \mathrm{~mm}$, los alambres se pesaron antes del hormigonado de las probetas, obteniéndose el peso real medio por unidad de longitud.

Tal y como indica el Manual CONTECVET (EC Innovation Program IN30902I, 2001), el porcentaje de pérdida de sección teórica por corrosión, así como la profundidad de ataque $P_{x}$, se han obtenido mediante la aplicación de la Ley de Faraday (Eq. 5-1), que permite convertir las unidades eléctricas en unidades de masa:

$$
\frac{I \cdot t}{F}=\frac{\Delta w}{W_{m} / z}
$$

donde:

$\begin{array}{ll}I & \text { Corriente electrica, en Amperios. }[A] \\ t & \text { Tiempo, en segundos. }[s] \\ F & \text { Constante de Faraday }=96500 \text { coulombios } \\ \Delta w & \text { Pérdida de masa en gramos. }[\mathrm{g}] \\ W_{m} & \text { Peso molecular del metal } \\ Z & \text { Valencia intercambiada }\end{array}$

Operando a partir de (Eq. 5-1) se obtiene que la equivalencia entre unidades eléctricas y unidades de masa es la siguiente (Eq. 5-2):

$$
1 \mu A / \mathrm{cm}^{2}<>11.6 \mu \mathrm{m} / a \tilde{\text { ño }}
$$


$\mathrm{Y}$, por tanto, la penetración de ataque por corrosión homogénea $P_{x}$, entendiéndose ésta como el parámetro que define la pérdida de radio de la armadura, puede obtenerse mediante la siguiente expresión (Eq. 5-3):

$$
P_{x}=0.0116 \cdot I_{\text {corr }}^{r e p} \cdot t_{p}
$$

donde:

$$
\begin{array}{ll}
I_{\text {corr }}^{\text {rep }} & \text { Intensidad de corrosión durante el periodo } t\left[\mu \mathrm{A} / \mathrm{cm}^{2}\right] \\
t_{p} & \text { Tiempo tras la despasivación de la armadura [años] }
\end{array}
$$

Conocida la profundidad de ataque teórica $P_{x}$ puede conocerse el diámetro residual de la barra afectada, a partir de la siguiente expresión (Eq. 5-4):

$$
\phi_{t}=\phi_{0}-\alpha \cdot P_{x}
$$

donde:
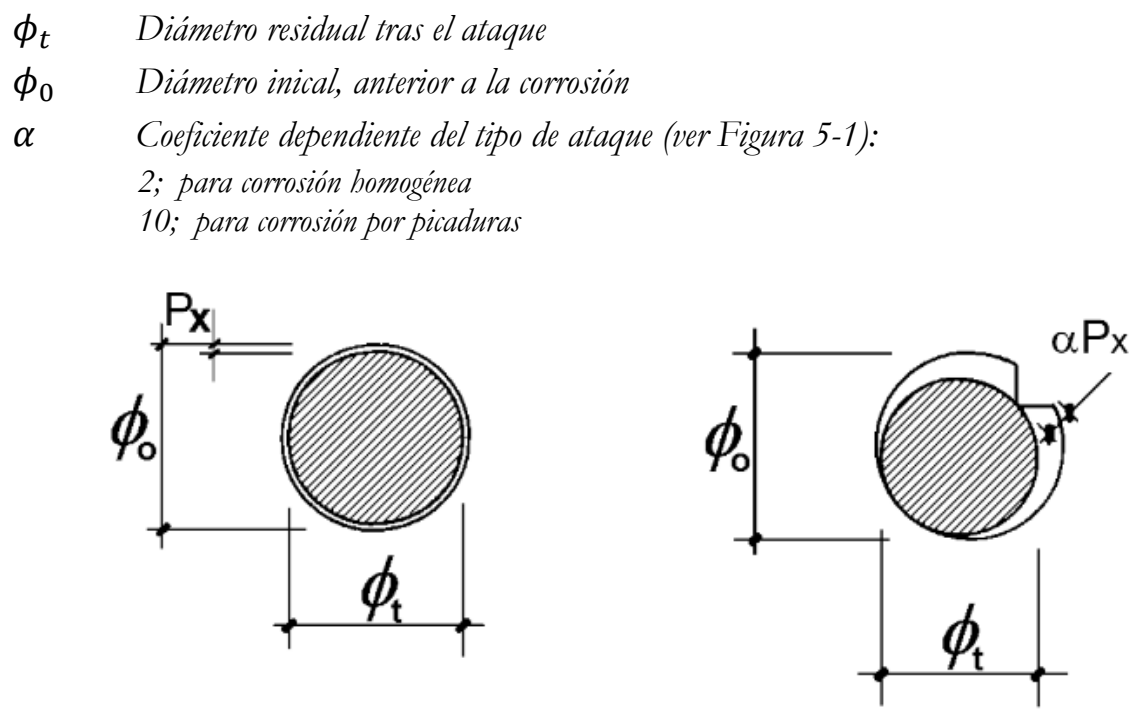

Figura 5-1 Profundidad de ataque Px, diámetro inicial de la armadura sana y diámetro residual de la armadura corroída. Manual CONTECVET (EC Innovation Program IN30902I, 2001)

Por tanto, el porcentaje de pérdida de sección teórica se ha calculado como sigue (Eq. 5-5):

$$
\% \operatorname{corr}_{\text {teorico }}=\frac{\phi_{0}{ }^{2}-\phi_{t}{ }^{2}}{\phi_{0}{ }^{2}} \cdot 100
$$

Por su parte, el porcentaje de pérdida de sección real se ha obtenido por diferencia de pesadas entre la armadura sana y la armadura corroída, tal y como se muestra en la siguiente expresión (Eq. 5-6):

donde:

$$
\% \operatorname{corr}_{\text {real }}=\frac{W_{\text {sana }}-W_{\text {corr }}}{W_{\text {sana }}} \cdot 100
$$

$$
\begin{array}{ll}
W_{\text {sana }} \text { Peso de la armadura sana } \\
W_{\text {corr }} \text { Peso de la armadura sana }
\end{array}
$$




\subsubsection{Pérdida de sección real vs teórica}

\subsubsection{Resultados experimentales}

En este apartado se comparan los resultados de pérdida de sección real, obtenida mediante gravimetría según el procedimiento expuesto en el Capitulo 4, frente a la pérdida teórica de sección por corrosión, siguiendo la Ley de Faraday. Para cada alambre ensayado se ha calculado la pérdida real de sección, así como la penetración equivalente de ataque $P_{x}$, considerando la corrosión uniforme a lo largo de toda la longitud adherente $l_{\text {adb }}$. Dentro de cada serie, para cada uno de los niveles teóricos de corrosión considerados $(2,5,10$ y 20\%), se ha obtenido la pérdida media de sección real de los alambres pertenecientes a dicho tramo, así como su desviación estándar y su coeficiente de variación ( CoV). Estos resultados se recogen en las siguientes tablas: Tabla 5-1 (Serie I4), Tabla 5-2 (Serie I10), Tabla 5-3 (Serie I20), Tabla 5-4 (Serie L4), Tabla 5-5 (Serie L10) y Tabla 5-6 (Serie L20).

Tabla 5-1 Perdidas de sección y profundidad de penetración de ataque por corrosión de la serie de ensayos I4, sobre alambres indentados con recubrimiento mecánico de $20 \mathrm{~mm}$ y distintos grados de corrosión.

\begin{tabular}{|c|c|c|c|c|c|c|c|}
\hline NOMBRE & $\begin{array}{c}\text { PERD. } \\
\text { SECC. } \\
\text { TEORIC [\%] } \\
\end{array}$ & $\begin{array}{c}\text { PERD. } \\
\text { SECC. REAL } \\
{[\%]} \\
\end{array}$ & DIFER [\%] & MEDIA & $\begin{array}{l}\text { DESV. } \\
\text { STAND }\end{array}$ & $\mathrm{CoV}[\%]$ & $\begin{array}{l}\text { Px }[\mu \mathrm{m}] \\
\text { (Teórica) }\end{array}$ \\
\hline I4-2-1 & \multirow{4}{*}{2} & 2.9528 & 47.6 & \multirow{4}{*}{3.366} & \multirow{4}{*}{0.418} & \multirow{4}{*}{12.415} & 37.19 \\
\hline I4-2-2 & & 3.9474 & 97.4 & & & & 49.84 \\
\hline I4-2-3 & & 3.3077 & 65.4 & & & & 41.69 \\
\hline I4-2-4 & & 3.2574 & 62.9 & & & & 41.05 \\
\hline I4-10-1 & \multirow{4}{*}{10} & 11.9295 & 19.3 & \multirow{4}{*}{11.842} & \multirow{4}{*}{0.227} & \multirow{4}{*}{1.915} & 153.85 \\
\hline I4-10-2 & & 12.0710 & 20.7 & & & & 155.74 \\
\hline I4-10-3 & & 11.5352 & 15.4 & & & & 148.61 \\
\hline I4-10-4 & & 11.8335 & 18.3 & & & & 152.57 \\
\hline I4-20-1 & \multirow{4}{*}{20} & 23.4304 & 17.2 & \multirow{4}{*}{23.255} & \multirow{4}{*}{2.441} & \multirow{4}{*}{10.497} & 312.40 \\
\hline I4-20-2 & & 26.0216 & 30.1 & & & & 349.73 \\
\hline I4-20-3 & & 23.4951 & 17.5 & & & & 313.32 \\
\hline I4-20-4 & & 20.0719 & 0.4 & & & & 264.94 \\
\hline
\end{tabular}

Tabla 5-2 Perdidas de sección y profundidad de penetración de ataque por corrosión de la serie de ensayos I10, sobre alambres indentadas con recubrimiento mecánico de $50 \mathrm{~mm}$ y distintos grados de corrosión.

\begin{tabular}{|c|c|c|c|c|c|c|c|}
\hline NOMBRE & $\begin{array}{c}\text { PERD. } \\
\text { SECC. } \\
\text { TEORIC [\%] }\end{array}$ & $\begin{array}{c}\text { PERD. } \\
\text { SECC. REAL } \\
{[\%]} \\
\end{array}$ & DIFER [\%] & MEDIA & $\begin{array}{l}\text { DESV. } \\
\text { STAND }\end{array}$ & $\mathrm{CoV}[\%]$ & $\begin{array}{l}\text { Px }[\mu \mathrm{m}] \\
\text { (Teórica) }\end{array}$ \\
\hline I10-2-1 & \multirow{5}{*}{2} & 3.7626 & 88.1 & \multirow{5}{*}{2.7988} & \multirow{5}{*}{0.8433} & \multirow{5}{*}{30.1321} & 47.48 \\
\hline I10-2-2 & & 1.5474 & -22.6 & & & & 19.42 \\
\hline I10-2-3 & & 2.4524 & 22.6 & & & & 30.85 \\
\hline I10-2-4 & & 2.9955 & 49.8 & & & & 37.73 \\
\hline I10-2-5 & & 3.2362 & 61.8 & & & & 40.79 \\
\hline I10-5-1 & \multirow{3}{*}{5} & 6.3637 & 27.3 & \multirow{3}{*}{5.7518} & \multirow{3}{*}{0.5494} & \multirow{3}{*}{9.5525} & 80.85 \\
\hline I10-5-2 & & 5.591 & 11.8 & & & & 70.89 \\
\hline I10-5-3 & & 5.3007 & 6.0 & & & & 67.16 \\
\hline I10-10-1 & \multirow{3}{*}{10} & 12.8974 & 29.0 & \multirow{3}{*}{12.8786} & \multirow{3}{*}{0.2516} & \multirow{3}{*}{1.9538} & 166.78 \\
\hline I10-10-2 & & 12.6181 & 26.2 & & & & 163.04 \\
\hline I10-10-3 & & 13.1203 & 31.2 & & & & 169.77 \\
\hline I10-20-1 & \multirow{3}{*}{20} & 17.1336 & -14.3 & \multirow{3}{*}{17.7090} & \multirow{3}{*}{0.5494} & \multirow{3}{*}{3.1026} & 224.23 \\
\hline I10-20-2 & & 19.5516 & -2.2 & & & & 257.67 \\
\hline I10-20-3 & & 16.4417 & -17.8 & & & & 214.74 \\
\hline
\end{tabular}


TESIS DOCTORAL INFLUENCLA DE LA CORROSIÓN EN LA ADHERENCLA DE ALAMBRES EN ELEMENTOS PRETENS ADOS DE HORMIGÓN

Tabla 5-3 Perdidas de sección y profundidad de penetración de ataque por corrosión de la serie de ensayos I20, sobre alambres indentados con recubrimiento mecánico de $100 \mathrm{~mm}$ y distintos grados de corrosión.

\begin{tabular}{|c|c|c|c|c|c|c|c|}
\hline NOMBRE & $\begin{array}{l}\text { PERD. } \\
\text { SECC. } \\
\text { TEORIC [\%] }\end{array}$ & $\begin{array}{c}\text { PERD. } \\
\text { SECC. REAL } \\
{[\%]}\end{array}$ & DIFER [\%] & MEDIA & $\begin{array}{l}\text { DESV. } \\
\text { STAND }\end{array}$ & $\mathrm{CoV}[\%]$ & $\begin{array}{l}\text { Px }[\mu \mathrm{m}] \\
\text { (Teórica) }\end{array}$ \\
\hline I20-2-1b & \multirow{2}{*}{2} & 3.5218 & 76.1 & \multirow{2}{*}{2.970} & \multirow{2}{*}{0.780} & \multirow{2}{*}{26.261} & 44.42 \\
\hline I $20-2-2 b$ & & 2.4187 & 20.9 & & & & 30.42 \\
\hline I20-2-1c & \multirow{3}{*}{2} & 2.3267 & 16.3 & \multirow{3}{*}{3.187} & \multirow{3}{*}{0.745} & \multirow{3}{*}{23.373} & 29.25 \\
\hline $\mathrm{I} 20-2-2 \mathrm{c}$ & & 3.6134 & 80.7 & & & & 45.58 \\
\hline I $20-2-3 c$ & & 3.6202 & 81.0 & & & & 45.67 \\
\hline
\end{tabular}

Tabla 5-4 Perdidas de sección y profundidad de penetración de ataque por corrosión de la serie de ensayos L4, sobre armaduras lisas con

\begin{tabular}{|c|c|c|c|c|c|c|c|}
\hline NOMBRE & $\begin{array}{c}\text { PERD. } \\
\text { SECC. } \\
\text { TEORIC [\%] }\end{array}$ & $\begin{array}{c}\text { PERD. } \\
\text { SECC. REAL } \\
{[\%]} \\
\end{array}$ & DIFER [\%] & MEDIA & $\begin{array}{l}\text { DESV. } \\
\text { STAND }\end{array}$ & $\mathrm{CoV}[\%]$ & $\begin{array}{l}\text { Px [um] } \\
\text { (Teórica) }\end{array}$ \\
\hline L4-2-1 & \multirow{4}{*}{2} & 2.3259 & 16.3 & \multirow{4}{*}{1.885} & \multirow{4}{*}{0.318} & \multirow{4}{*}{16.914} & 29.24 \\
\hline L4-2-2 & & 1.8768 & -6.2 & & & & 23.57 \\
\hline L4-2-3 & & 1.7632 & -11.8 & & & & 22.14 \\
\hline L4-2-4 & & 1.5755 & -21.2 & & & & 19.77 \\
\hline L4-5-1 & \multirow{4}{*}{5} & 5.9206 & 18.4 & \multirow{4}{*}{6.094} & \multirow{4}{*}{0.125} & \multirow{4}{*}{2.062} & 75.14 \\
\hline L4-5-2 & & 6.144 & 22.9 & & & & 78.02 \\
\hline L4-5-3 & & 6.2158 & 24.3 & & & & 78.94 \\
\hline L4-5-4 & & 6.0993 & 22.0 & & & & 77.44 \\
\hline L4-10-1 & \multirow{4}{*}{10} & 11.2885 & 12.9 & \multirow{4}{*}{11.791} & \multirow{4}{*}{0.420} & \multirow{4}{*}{3.567} & 145.33 \\
\hline L4-10-2 & & 11.8457 & 18.5 & & & & 152.74 \\
\hline L4-10-3 & & 11.7216 & 17.2 & & & & 151.09 \\
\hline L4-10-4 & & 12.3111 & 23.1 & & & & 158.94 \\
\hline L4-20-1 & \multirow{4}{*}{20} & 21.0834 & 5.4 & \multirow{4}{*}{20.504} & \multirow{4}{*}{0.668} & \multirow{4}{*}{3.262} & 279.12 \\
\hline L4-20-2 & & 19.8544 & -0.7 & & & & 261.90 \\
\hline L4-20-3 & & 21.0793 & 5.4 & & & & 279.07 \\
\hline L4-20-3 & & 20 & 0.0 & & & & 263.93 \\
\hline
\end{tabular}

Tabla 5-5 Perdidas de sección y profundidad de penetración de ataque por corrosión de la serie de ensayos L10, sobre armaduras lisas con

\begin{tabular}{|c|c|c|c|c|c|c|c|}
\hline NOMBRE & $\begin{array}{c}\text { PERD. } \\
\text { SECC. } \\
\text { TEORIC [\%] }\end{array}$ & $\begin{array}{c}\text { PERD. } \\
\text { SECC. REAL } \\
{[\%]} \\
\end{array}$ & DIFER [\%] & MEDIA & $\begin{array}{c}\text { DESV. } \\
\text { STAND }\end{array}$ & $\mathrm{CoV}[\%]$ & $\begin{array}{l}\text { Px }[\mu \mathrm{m}] \\
\text { (Teórica) }\end{array}$ \\
\hline L10-2-1 & & 1.6496 & -17.5 & & & & 20.7 \\
\hline L10-2-2 & 2 & 2 & --- & 2.155 & 0.408 & 18.914 & 25.1 \\
\hline L10-2-3 & & 2.4895 & 24.5 & & & & 31.3 \\
\hline L10-5-1 & & 8.2654 & 65.3 & & & & 105.5 \\
\hline L10-5-2 & 5 & 7.346 & 46.9 & 6.509 & 2.293 & 35.229 & 93.6 \\
\hline L10-5-3 & & 3.9148 & -21.7 & & & & 49.4 \\
\hline L10-10-1 & & 10 & 0 & & & & 128.30 \\
\hline L10-10-2 & 10 & 11.7363 & 17.4 & 11.390 & 0.490 & 4.304 & 151.3 \\
\hline L10-10-3 & & 11.0430 & 10.4 & & & & 142.1 \\
\hline L10-20-1 & & 21.6177 & 8.1 & & & & 286.7 \\
\hline L10-20-2 & 20 & 18.8108 & -5.9 & 21.961 & 3.335 & 15.184 & 247.4 \\
\hline L10-20-3 & & 25.4535 & 27.3 & & & & 341.5 \\
\hline
\end{tabular}


Tabla 5-6 Perdidas de sección y profundidad de penetración de ataque por corrosión de la serie de ensayos L20, sobre armaduras lisas con recubrimiento mecánico de $100 \mathrm{~mm}$ y distintos grados de corrosión.

\begin{tabular}{|c|c|c|c|c|c|c|c|}
\hline NOMBRE & $\begin{array}{c}\text { PERD. } \\
\text { SECC. } \\
\text { TEORIC [\%] }\end{array}$ & $\begin{array}{c}\text { PERD. } \\
\text { SECC. REAL } \\
{[\%]}\end{array}$ & DIFER [\%] & MEDIA & $\begin{array}{l}\text { DESV. } \\
\text { STAND }\end{array}$ & $\mathrm{CoV}[\%]$ & $\begin{array}{l}\text { Px }[\mu \mathrm{m}] \\
\text { (Teórica) }\end{array}$ \\
\hline L20-2-1b & \multirow{2}{*}{2} & 1.570 & -21.5 & \multirow{2}{*}{1.8508} & \multirow{2}{*}{0.397} & \multirow{2}{*}{21.468} & 19.70 \\
\hline L20-2-2b & & 2.132 & 6.6 & & & & 26.79 \\
\hline L20-5-1b & \multirow{2}{*}{5} & 6.234 & 24.7 & \multirow{2}{*}{6.5309} & \multirow{2}{*}{0.420} & \multirow{2}{*}{6.428} & 79.18 \\
\hline L20-5-2b & & 6.828 & 36.6 & & & & 86.86 \\
\hline L20-10-1b & \multirow{2}{*}{10} & 10.592 & 15.9 & \multirow{2}{*}{12.3664} & \multirow{2}{*}{1.8023} & \multirow{2}{*}{15.188} & 136.10 \\
\hline L20-10-2b & & 13.141 & 31.4 & & & & 170.04 \\
\hline
\end{tabular}

En las probetas sin cloruros añadidos durante el amasado, pertenecientes a una parte de la serie de ensayos L20, no se ha determinado la pérdida real de sección mediante gravimetría, por lo que se toma como valor de referencia la pérdida teórica. En la Tabla 5-6 se incluyen únicamente, por tanto, los resultados de la Serie L20 relativos a las probetas con cloruros.

\subsubsection{Interpretación de los resultados}

A la vista de los resultados expuestos en las tablas anteriores, y teniendo en cuenta siempre la naturaleza heterogénea del proceso de corrosión, se puede concluir que el cálculo teórico de pérdida de sección mediante la Ley de Faraday (Eq. 5-1) proporciona una aproximación razonablemente buena a la pérdida real, tal y como han corroborado anteriormente numerosos autores (Andrade, et al., 1993). Como era esperable, ya que los alambres fueron sometidos a la misma intensidad de corriente $\left(100 \mu \mathrm{A} / \mathrm{cm}^{2}\right)$, todas las series de ensayos tienen un comportamiento similar, observándose en todas ellas diferencias equiparables entre los valores teóricos y reales. Por tanto, bajo estas condiciones de ensayo, tanto el acabado superficial del alambre como el espesor o la resistencia del hormigón de recubrimiento tienen una influencia limitada en el proceso de corrosión.
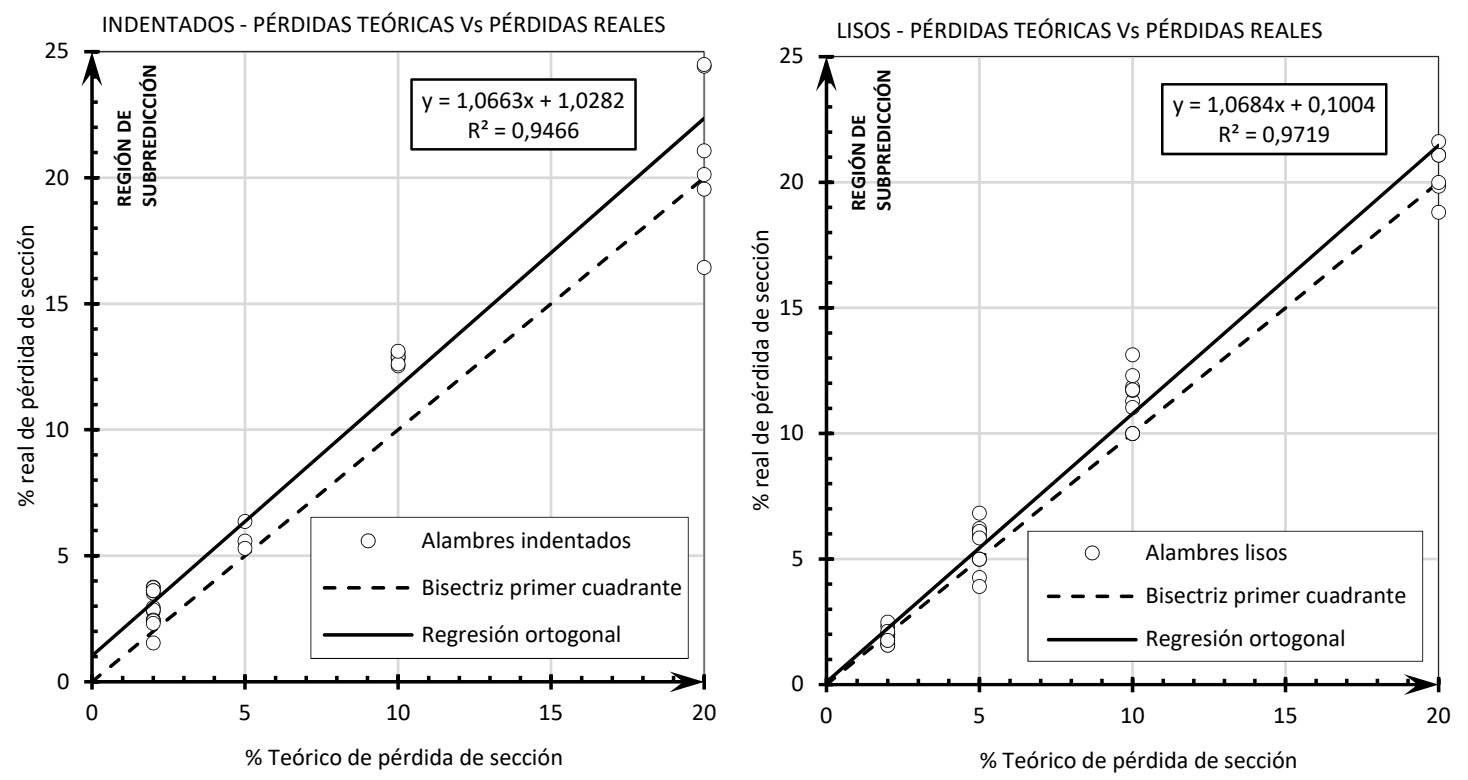

Figura 5-2 Diagramas predicción-realización de pérdidas de sección teórica frente a pérdidas de sección real para alambres indentados (irq.) y lisos (der.) 
Profundizando en el análisis, en la Figura 5-2 se representan los diagramas predicción-realización de la pérdida de sección por corrosión tanto para alambres indentados (irq.) como lisos (der.). La bisectriz de estos diagramas delimita dos regiones: la Zona de Subpredicción, aquella en la que la Ley de Faraday estima resultados por debajo de los observables (situada sobre la bisectriz); y la Zona de Sobrepredicción, en los que los resultados del modelo superan en valor a los observables (situada por debajo de la bisectriz). En estos diagramas, también se ha incluido el ajuste de los resultados mediante regresión lineal simple, obteniéndose tanto la ecuación que describe la recta como el coeficiente de determinación $R^{2}$. En el caso ideal, la recta de regresión simple debería de coincidir con la bisectriz del diagrama predicción-realización. Como puede observarse, la capacidad predictiva de la Ley de Faraday puede considerarse muy buena, al ser la pendiente de la recta de regresión próxima a 1 en ambos casos (1,066 para alambres indentados y 1,068 para alambres lisos) aunque con cierto sesgo a subestimar el valor real de la pérdida de sección. Este sesgo es ligeramente superior en las barras indentadas, donde la recta de regresión está más alejada de la bisectriz del diagrama. Por tanto, tal y como se dedujo de las tablas anteriores, la influencia del acabado superficial del acero no es significativa, aunque los diagramas permiten apreciar un mejor comportamiento predictivo de la Ley de Faraday en los alambres lisos.

Por último, la capacidad predictiva de la Ley de Faraday se ha evaluado mediante el denominado ratio $M$, que se obtiene dividiendo el valor experimental de la pérdida de sección (o su variable asociada $\left.P_{x, \text { exp }}\right)$, entre el valor predictivo, $P_{x, \text { ess: }}$

$$
M=\frac{P_{x, \text { exp }}}{P_{x, \text { est }}}
$$

En la Tabla 5-7 se muestran, para cada uno de los tipos de acabado superficial del acero considerados, el valor medio $\mu_{M}$ del ratio $M=P_{x, \exp } / P_{x, \text { est }}$, su desviación típica, $s_{M}$, su coeficiente de variación $C o V$, así como sus valores máximo y mínimo.

Tabla 5-7 Valores estadísticos vinculados al ratio $M$ para los distintos acabados superficiales del acero

\begin{tabular}{lccccc}
\hline Acabado superficial del acero & $\begin{array}{c}\text { Media } \\
\boldsymbol{\mu}_{\mathbf{M}}\end{array}$ & $\begin{array}{c}\text { Desviación } \\
\text { típica s }\end{array}$ & CoV [\%] & Máximo & Mínimo \\
\hline Indentado & 1.305 & 0.285 & 21.825 & 1.881 & 0.774 \\
\hline Liso & 1.079 & 0.166 & 15.382 & 1.366 & 0.783 \\
\hline
\end{tabular}

Como puede observarse, los datos experimentales en barras indentadas son, en promedio, un 30,5\% superiores a sus respectivas estimaciones, mientras que en barras lisas el promedio de los datos experimentales está un 7,9\% por encima de las predicciones teóricas. En estas últimas, los datos relativos al valor máximo y mínimo del ratio $M$ también se encuentran más próximos al valor medio $\mu_{M}$, con lo que se confirma que la capacidad predictiva de la Ley de Faraday es ligeramente mejor en el caso de barras lisas.

En definitiva, se puede concluir que, por un lado, la Ley de Faraday ofrece buenas estimaciones de la pérdida real de sección por corrosión, aunque con cierta tendencia a subestimar su valor, y por otro, que las diferencias observadas en su aplicación sobre barras lisas e indentadas, aunque significativas, no son concluyentes dada la heterogeneidad del proceso de corrosión. 


\subsubsection{Fisuración asociada al proceso de corrosión}

La fisuración asociada al proceso de corrosión acelerada no se ha monitorizado de manera sistemática, por no ser el objetivo principal de esta tesis, por lo que a continuación se aportan únicamente algunos datos cualitativos sobre su inicio y evolución.

El inicio de la fisuración en todas las probetas, sin distinción en cuanto al acabado superficial de las barras o al recubrimiento y resistencia del hormigón, se produce en el rango de entre el 2 y el $5 \%$ de pérdida de sección por corrosión, equivalente a un rango de profundidad de ataque $P_{x}$ de entre $25 \mathrm{y}$ $63 \mu \mathrm{m}$. En este proceso no se ha apreciado una influencia clara del acabado superficial de las barras ni de la resistencia a compresión del hormigón. Por el contrario, sí que se ha detectado cierta tendencia a que el inicio de la fisuración se anticipe ligeramente en las probetas con menor recubrimiento/diámetro.
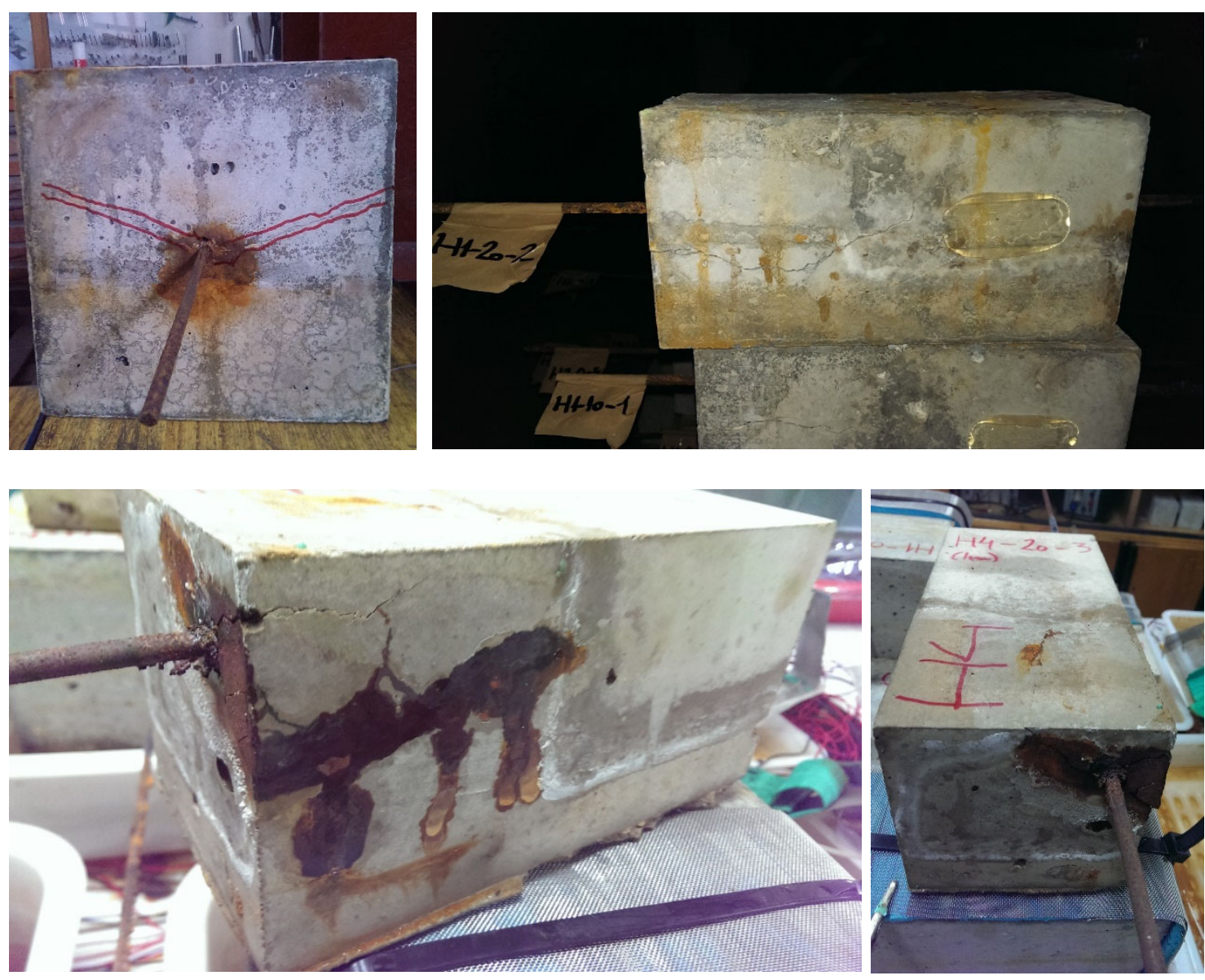

Figura 5-3 Fisuración de las probetas inducida por la corrosión, previa al ensayo de pull-out

Con carácter general, en las probetas con la barra centrada en la sección transversal (Series L20, I20, L10 e I10), las fisuras principales tienen un desarrollo diametral, con dos fisuras radiales enfrentadas dividiendo la sección en dos partes de similar área. Por el contrario, en las series L4 e I4, donde la barra se sitúa excéntricamente, las fisuras principales se desarrollan con una pendiente de $45^{\circ}$ con respecto a la horizontal, tal y como se muestra en la Figura 5-3. En cuanto a la dirección longitudinal, 
las fisuras en la superficie de la probeta tienen un trazado paralelo a la barra, con ramificaciones secundarias en diversas direcciones, y localizadas principalmente a lo largo de la proyección de la longitud adherente.

Tras el inicio de la fisuración, el aumento de los niveles de corrosión provoca un crecimiento paulatino del ancho de fisura observable y la aparición de óxidos de hierro en la superficie e la probeta. En ambos casos, el proceso es más acusado cuanto menor es la relación recubrimiento/diámetro de las probetas. En ninguna de las probetas se observó desprendimiento del recubrimiento (spalling) a causa de las tensiones derivadas de la acumulación de productos de corrosión.

\subsection{Ensayos de pull-out para evaluación de la adherencia}

En este apartado se exponen los resultados experimentales obtenidos de los ensayos de pull-out sobre las probetas descritas en el Capitulo 4. Se comienza exponiendo los criterios de interpretación de los datos arrojados por los ensayos: obtención de la tensión de adherencia media $\tau_{b \text {,med }}$, relación entre las leyes de tensión de adherencia local-deslizamiento $\tau_{b}$-s y tensión de adherencia media-deslizamiento $\tau_{b, \text { med }}-s$, y diferentes modos de fallo adherente; y se finaliza recopilando los resultados experimentales mediante tablas y gráficas.

\subsubsection{Criterios de interpretación de los resultados experimentales}

Tal y como se ha visto en el Capitulo 4, la instrumentación utilizada ha permitido obtener, de cada probeta ensayada, la fuerza aplicada $F$ y el deslizamiento $s$ de la barra en los extremos cargado y no cargado. Los datos han sido tratados de manera que, de todos los ensayos, se ha obtenido la tensión de adherencia media a lo largo del ensayo, los parámetros que definen la ley de tensión de adherencia media-deslizamiento y el modo de fallo.

\subsubsection{Tensión de adherencia media}

Para determinar la tensión de adherencia a la que se ha sometido la barra, se ha supuesto una distribución de tensiones tangenciales homogénea a lo largo de toda la longitud adherente de la barra. Por tanto, tal y como recoge la Norma UNE-EN 10080:2006 (Comité Técnico AEN/CTN 36 , 2006), la fuerza de tracción $F$ medida durante el ensayo se transforma en tensión de adherencia $\tau_{b, \text { med }}$ mediante la siguiente expresión (Eq. 5-8):

$$
\tau_{b, \text { med }}=\frac{F}{l_{b} \cdot \pi \cdot \phi}
$$

Donde:

$\begin{array}{ll}F & \text { Fuerza de tracción aplicada al alambre }[\mathrm{N}] \\ l_{b} & \text { Longitud adherente }[\mathrm{mm}] \\ \phi & \text { Diámetro del alambre }[\mathrm{mm}]\end{array}$


En el caso de los alambres que se han sometido a un proceso de corrosión, el diámetro empleado en la expresión (Eq. 5-8) es el diámetro inicial y no el diámetro residual tras descontar la penetración de ataque $P_{x}$.

\subsubsection{Ley de adherencia local-deslizamiento Vs Ley de adherencia media-deslizamiento}

El comportamiento adherente local está caracterizado por la relación existente entre la tensión de adherencia en la interfaz acero-hormigón y el deslizamiento local a lo largo de la longitud adherente (Rehm, 1961). Esta relación tensión de adherencia-deslizamiento depende de un considerable número de factores, incluyendo la geometría de la superficie del alambre (liso, indentado o corrugado), la resistencia del hormigón, la posición y orientación del alambre durante el hormigonado, el estado tensional del elemento, las condiciones de contorno y/o el espesor de recubrimiento.

Tal y como se ha expuesto en el Capitulo 3, en esta tesis se ha optado por modelar la ley adherencia local-deslizamiento con una relación no-lineal, perfectamente plástica, formada por una curva lineal por tramos que comprende cuatro segmentos diferenciados. Se ha escogido esta ley porque, sin pérdida de generalidad, su simplicidad permite una fácil resolución de la ecuación diferencial que rige el fenómeno, por un lado, y porque en base a la revisión bibliográfica llevada a cabo, es la más utilizada por estudios anteriores (Eligehausen, et al., 1983) (Yankelevsky, 1985) (Eleftheriou, et al., 2013) (Melo, et al., 2014) al ser la que mejor reproduce los resultados experimentales.

Uno de los ensayos más utilizados para la caracterización de esta ley, por su sencillez y economía de tiempo y medios, son los ensayos de pull-out. En este tipo de ensayos, si se utilizan longitudes adherentes cortas, de hasta 5 diámetros $\left(l_{a d b} / \phi<5\right)$, la tensión de adherencia se distribuye uniformemente a lo largo de toda la longitud, por lo que los resultados experimentales permiten determinar, sin análisis posteriores, los parámetros que configuran la ley de adherencia localdeslizamiento $\tau_{b}-s$, a saber: tensión máxima de adherencia $\tau_{b, \max }$ (proporcional a la máxima tensión radial $\sigma_{r, \max }$ y al coeficiente de fricción $\mu$ ), tensión residual de adherencia $\tau_{b \text {,res }}$, valor del deslizamiento al final de la región elástica $s_{y}$, valor del deslizamiento al final de la región plástica $s_{u}$ y valor del deslizamiento previo a la región de tensión residual $s_{\text {res }}$. Sin embargo, para longitudes adherentes mayores, al aumentar la longitud de contacto, disminuye la tensión adherente (Mathey \& Watstein, 1961) y se aprecian mayores diferencias entre la tensión máxima de adherencia local y la máxima tensión media de adherencia, obtenida de los ensayos (CIB, 1981). Tal y como se ha indicado en el Capitulo 4, en la presente tesis se ha optado por una longitud adherente equivalente a 15 diámetros (15 $\phi=75 \mathrm{~mm}$ ), ya que el proceso de corrosión, de naturaleza variable, requiere longitudes importantes para que las presumibles heterogeneidades en la penetración de ataque queden mitigadas al repartirse a lo largo de toda la longitud, considerándose una pérdida de sección uniforme. Como contrapartida, esta longitud se aleja sensiblemente de las recomendaciones, y los resultados obtenidos de los ensayos de pull-out no permiten la obtención directa de los parámetros que configuran la ley de adherencia local-deslizamiento $\tau_{b}-s$, sino sus "equivalentes" en términos de tensión de adherencia media, por lo que se hace necesario un análisis posterior mediante el modelo analítico expuesto en el Capitulo 3. En la Figura 5-4 se representa la relación existente entre los parámetros que definen la ley de adherencia local-deslizamiento y sus "equivalentes" en términos de tensión de adherencia media. 


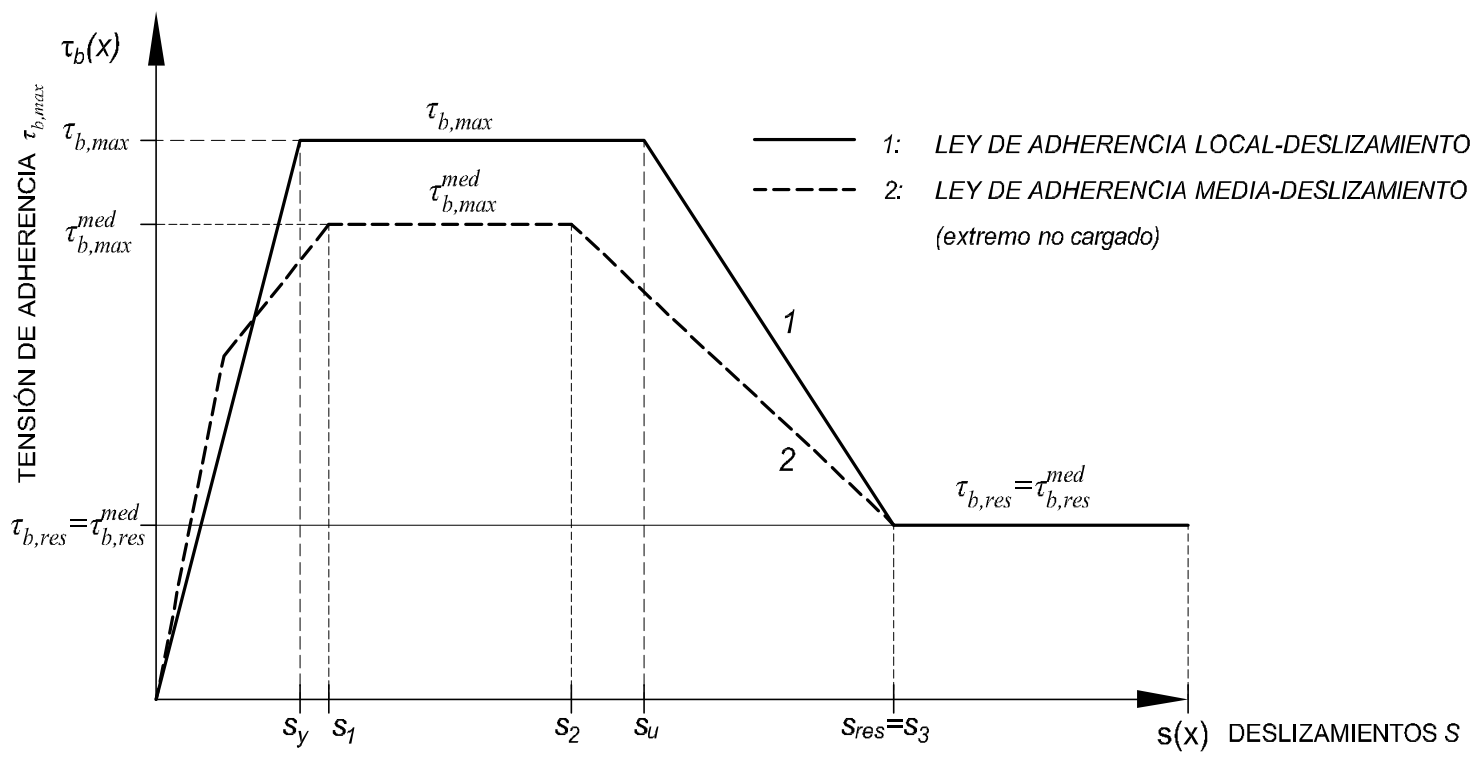

Figura 5-4 Comparación entre la ley de tensión de adherencia local-deslizamiento y la ley de tensión de adherencia media-deslizamiento procedente del ensayo.

De cada uno de los ensayos se han extraído los datos más significativos que, a la postre, han permitido la calibración del modelo analítico (Capitulo o) presentado en el Capitulo 3. Son los siguientes:

- $\tau_{b, \text { max }}^{\text {med }}$ : Valor medio de la tensión máxima de adherencia. Se acompaña de la media aritmética de los resultados experimentales de todas las probetas con condiciones de ensayo similares, así como del coeficiente de variación $(\mathrm{CoV})$ de los mismos para conocer el grado de fiabilidad del promedio.

- $\tau_{b, \text { res }}^{\text {med }}$ : Valor medio de la tensión residual de adherencia. Su valor en términos globales es el mismo que presenta en términos locales puesto que, en el fallo, toda la longitud adherente se encuentra en el tramo residual de la de la función tensión de adherencia local-deslizamiento. En las probetas cuyo fallo adherente ha sido tipo pull-out, con deslizamientos importantes en rotura, es fácilmente identificable el valor residual de la tensión de adherencia. Por el contrario, en las probetas en las que el fallo ha sido de tipo frágil, la tensión residual se ha considerado nula.

- $\boldsymbol{S}_{\boldsymbol{m a x}}$ : Deslizamiento en el extremo no cargado bajo carga máxima. Dicho deslizamiento se localiza en la meseta de tensión máxima de adherencia media de la gráfica adherencia-deslizamiento, y por tanto comprendido entre los valores de deslizamiento $s_{1}$ y $s_{2}$ que se definen a continuación.

- $\boldsymbol{s}_{\mathbf{1}}$ : Deslizamiento en el extremo no cargado al alcanzarse la tensión máxima de adherencia media. Separa los tramos elástico y plástico de la gráfica de tensión de adherencia media-deslizamiento $\tau_{b, m e d}-s \mathrm{y}$, dada la configuración del ensayo, presenta un valor próximo (aunque no igual) al deslizamiento con tensión de adherencia máxima $s_{y}$ en la función tensión de adherencia local-deslizamiento. En el análisis de los resultados experimentales, dado que los límites de la meseta con valor máximo de la tensión de adherencia media $\tau_{b, \max }^{\text {med }}$ son difusos, se ha considerado que el deslizamiento $s_{1}$ es alcanzado cuando la tensión de adherencia media es igual al 95\% del valor máximo. 
- $\boldsymbol{S}_{2}$ : Deslizamiento en el extremo no cargado al alcanzarse el final de la meseta, en la que la tensión máxima de adherencia media se mantiene más o menos constante, y previo al descenso de ésta. Separa los tramos plástico y de ablandamiento de la gráfica de tensión de adherencia media-deslizamiento $\tau_{b, \text { med }}-s$ y, tal y como se ha indicado en la definición del parámetro anterior, presenta un valor próximo al deslizamiento al final de la región plástica de adherencia $s_{u}$ de la función tensión de adherencia localdeslizamiento. Siguiendo el criterio establecido en el caso anterior, el deslizamiento $s_{2}$ queda determinado al alcanzarse el $95 \%$ del valor máximo de la tensión de adherencia en el tramo descendente de la gráfica, una vez superado el deslizamiento bajo carga máxima $s_{\max }$.

- $\boldsymbol{S}_{3}$ : Deslizamiento en el extremo no cargado previo al comienzo de la región con tensión residual de adherencia constante. Separa los tramos de ablandamiento y residual de la gráfica de tensión de adherencia mediadeslizamiento $\tau_{b, \text { med }}-s$ y presenta un valor próximo al deslizamiento $s_{r e s}$ de la función tensión de adherencia local-deslizamiento.

\subsubsection{Modo de fallo}

Tal y como indica den Uijl (den Uijl, 1996) cuando un alambre embebido en hormigón es sometido a una fuerza de arrancamiento se activa el mecanismo de adherencia, que consta de cuatro etapas diferencias, especialmente identificables en alambres con acabado superficial indentado: una primera etapa, donde la adherencia está asegurada principalmente por el mecanismo de adhesión; una segunda etapa, tras un pequeño deslizamiento relativo del alambre que conlleva la rotura del mecanismo de adhesión, en la que se manifiesta la adherencia por fricción y el acuñamiento de las indentaciones, provocando un aplastamiento local y las primeras microfisuras en la interfaz acero-hormigón (ver Figura 5-5); una tercera etapa en la que el aumento de las tensiones radiales, originadas por el acuñamiento de las indentaciones, provoca la generalización y propagación de las fisuras radiales, que dan lugar a dos posibles modos de fallo: fallo por splitting, si las fisuras se propagan hasta la superficie del recubrimiento, dando lugar a un fallo más o menos repentino, y fallo porpull-out, si el confinamiento para prevenir la fisuración es suficiente, de manera que el fallo se produce por deslizamiento del alambre; y una cuarta etapa caracterizada por el comportamiento residual tras el fallo adherente.

En cuanto a los modos de fallo adherente, tal y como indica la Fédération Internationale du Béton (CEB-FIP_Task Group 2.5, 2000), únicamente en ensayos en laboratorio, con longitudes adherentes cortas $\left(l_{a d b}<5 \phi\right)$, o en alambres con acabado superficial liso, bajo determinadas condiciones, puede obtenerse un fallo por pull-out "puro", sin estar precedido de fisuración previa en la interfaz. Por ello, en estructuras reales, con longitudes adherentes largas, es habitual detectar un modo de fallo adherente que combina los expuestos anteriormente, es decir, un fallo por pull-out inducido por fisuración (splitting) previa.

En definitiva, el parámetro clave que determina el modo de fallo adherente es la capacidad de confinamiento del recubrimiento, dando lugar a un fallo por splitting si el hormigón no se encuentra confinado, a un fallo por pull-out si el hormigón está suficientemente confinado o a un fallo por pullout inducido por fisuración para confinamientos medios. El confinamiento viene determinado por varios factores, incluyendo la cuantía de armadura transversal (si es que la hubiese), la distancia entre alambres, la resistencia del hormigón y el espesor de recubrimiento. En ese sentido, en el caso de alambres sanos sin procesos de corrosión, el Bulletin N 10 de la Fédération Internationale du Béton 
(Fib) «Bond of Renforcement in Concrete» (CEB-FIP_Task Group 2.5, 2000) señala que el hormigón se considera no confinado cuando el espesor de recubrimiento no supera el diámetro del alambre $(c \leq \phi)$ y el área total de los cercos (con dos ramas) sobre una longitud igual a la longitud de anclaje no supera un valor $A_{s, \text { min }}=0.25 \cdot n \cdot A_{s}$, donde $n$ es el número de alambres anclados rodeados por los cercos y $A_{s}$ es el área de uno de los alambres. Por el contrario, el hormigón puede considerarse "bien confinado" cuando el recubrimiento $c$ es mayor que 5 veces el diámetro del alambre $(\mathrm{c} \geq 5 \phi)$ y la distancia neta entre alambres $a$ es mayor a 10 veces el diámetro del alambre $(c \geq 10 \phi)$, cuando existe una considerable presión transversal exterior $p(\mathrm{p} \geq 7.5 \mathrm{MPa})$, o cuando la cuantía de armadura transversal $A_{s t}$ es elevada $\left(A_{s t} \geq 1.0 \cdot n \cdot A_{s}\right)$. Para situaciones intermedias entre la ausencia total (splitting) y el pleno confinamiento (pull-out), la Fib (CEB-FIP_Task Group 2.5, 2000), citando el Código Modelo 90 (FIB Special Activity Group 5, 2011), recomienda que se interpolen linealmente los valores que definen los diagramas de adherencia-deslizamiento de ambos tipos de fallo: $s_{y}, s_{u}, s_{r e s}, \tau_{\max }$ y $\tau_{\text {res. }}$

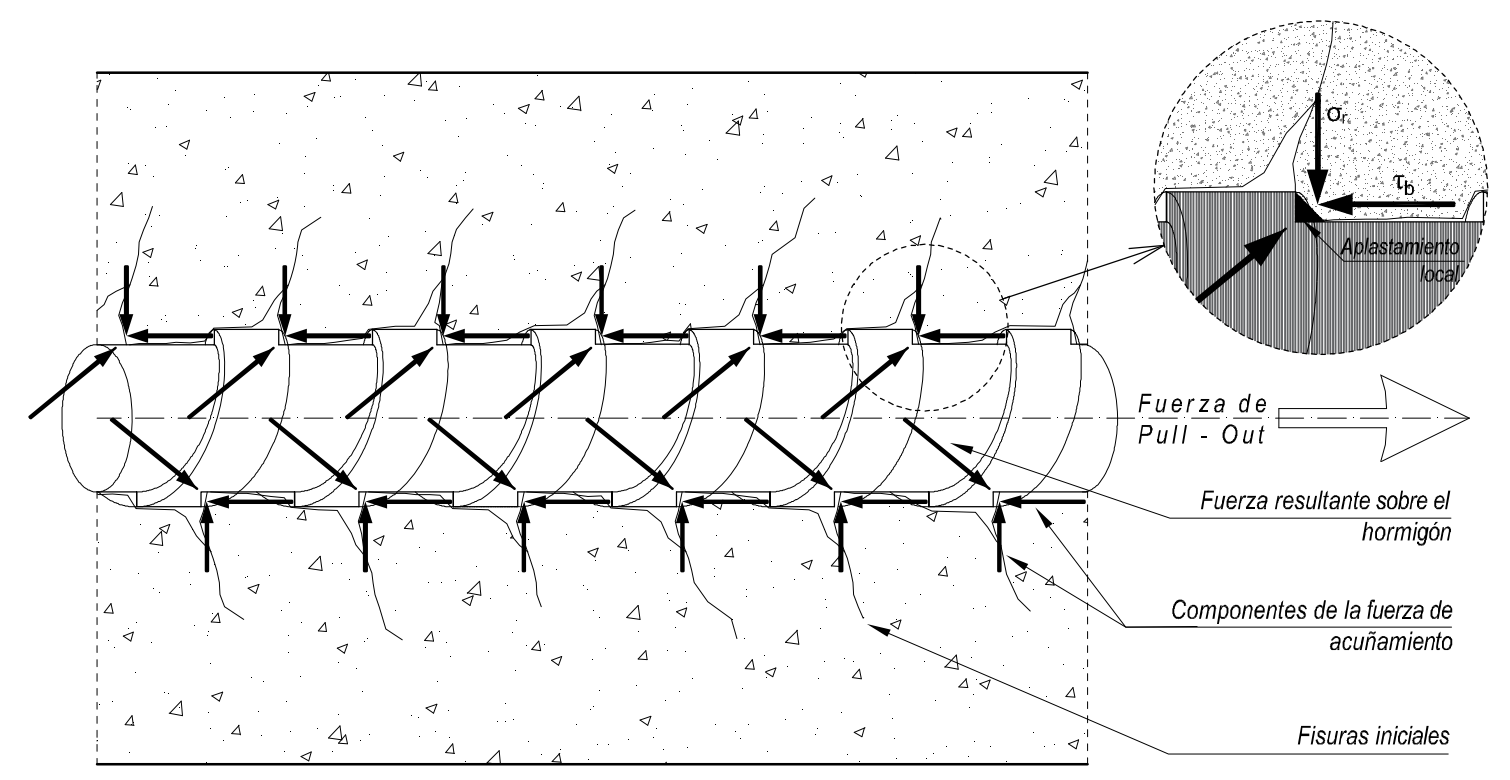

Figura 5-5 Fuerzas de acuñamiento y fisuración inicial en la interfaz acero-hormigón. Primeras etapas del proceso de arrancamiento.

\subsubsection{Resultados experimentales de los ensayos de pull-out}

A continuación, en base a los criterios expuestos en el apartado anterior, se recogen los resultados experimentales de todas las series de ensayos. Para cada una de ellas, se ha incluido una tabla con el máximo valor de la tensión de adherencia media a lo largo del ensayo $\tau_{b, \max }^{\text {med }}$, así como los parámetros que definen la ley de tensión de adherencia media-deslizamiento $\left(s_{1}, s_{2}, s_{3}\right.$ y $\left.s_{r e s}\right)$ y el modo de fallo predominante (pull-out o splitting). Los resultados se acompañan por las gráficas de tensión de adherencia media-deslizamiento, agrupadas por cada nivel teórico de pérdida de sección considerado.

\subsubsection{Alambres Indentados [Serie I]}

Se han llevado a cabo 55 ensayos de pull-out sobre alambres indentados, centrados y excéntricos, con recubrimientos mecánicos que han variado desde los $20 \mathrm{~mm}$ hasta los $100 \mathrm{~mm}$, con niveles de 
corrosión variables de hasta un $27,02 \%$ de pérdida de sección, y resistencias medias de compresión del hormigón de entre $43,72 \mathrm{~N} / \mathrm{mm}^{2}$ y $51,67 \mathrm{~N} / \mathrm{mm}^{2}$.

\subsection{Serie I4: Alambres indentados - Recubrimiento/diámetro $c / \phi=4$}

La serie de ensayos I4 está compuesta por un total de 16 probetas prismáticas, de 100x100x200 mm, con el alambre indentado situado excéntricamente, de manera que el recubrimiento mecánico mínimo resultante es de $20 \mathrm{~mm}$, con una relación recubrimiento/diámetro igual a 4 (Figura 5-๑). Como en todas las series de ensayos, la longitud adherente del alambre es de $75 \mathrm{~mm}(\approx 15 \phi)$. Para su fabricación se ha utilizado el Hormigón 7 (Tabla 4-4), cuya resistencia a compresión media es $f_{c m}=51,67 \mathrm{~N} / \mathrm{mm}^{2}$, y resistencia media a tracción es $f_{c t m}=4,13 \mathrm{~N} / \mathrm{mm}^{2}$. Cuatro de las probetas no han sido sometidas a corrosión acelerada, mientras que en el resto los alambres presentan distintos niveles de corrosión, alcanzándose pérdidas de sección transversal de hasta un 27,02\%. En la Tabla 5-8 se incluyen los parámetros más relevantes extraídos de la monitorización de los ensayos.

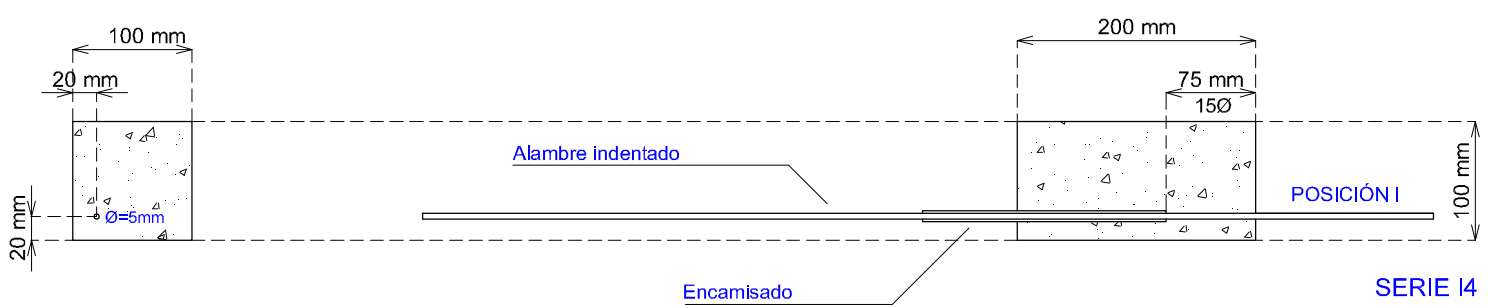

Figura 5-6 Configuración geométrica de las probetas 14 con alambres indentados y recubrimiento mecánico de $20 \mathrm{~mm}(\mathrm{c} / \phi=4)$

Tabla 5-8 Resumen de resultados de los ensayos sobre la serie de probetas I4

\begin{tabular}{|c|c|c|c|c|c|c|c|c|c|c|}
\hline \multirow{3}{*}{ PROB. } & \multicolumn{10}{|c|}{ Serie [I4] } \\
\hline & \multirow{2}{*}{$\begin{array}{c}\% \text { Corr, } \\
\text { real }\end{array}$} & \multirow{2}{*}{$\begin{array}{l}\mathrm{f}_{\mathrm{cm}}[\mathrm{MPa}] \\
\left(\mathrm{f}_{\mathrm{ct}}[\mathrm{MPa}]\right)\end{array}$} & \multirow{2}{*}{$\begin{array}{l}\tau_{b, \text { max }}^{\text {med }} \\
{[\mathrm{MPa}]}\end{array}$} & \multirow{2}{*}{$\begin{array}{c}\text { Med. } \tau_{b, \text { max }}^{\text {med }} \\
(\mathrm{CoV})\end{array}$} & \multirow[b]{2}{*}{$\tau_{\text {res }}[\mathrm{MPa}]$} & \multicolumn{4}{|c|}{ Deslizamientos [mm] } & \multirow{2}{*}{ Fallo } \\
\hline & & & & & & $s_{\max }$ & $s_{1}$ & $s_{2}$ & $s_{3}$ & \\
\hline I4-0-1 & 0 & \multirow{16}{*}{$\begin{array}{l}51,67 \\
(4,13)\end{array}$} & 12,763 & \multirow{4}{*}{$\begin{array}{c}\mathbf{1 3 , 7 9 1} \\
(8,39)\end{array}$} & 3,716 & 1,768 & 1,540 & 1,782 & 5,913 & Pull-out \\
\hline I4-0-2 & 0 & & 13,539 & & 5,369 & 2,513 & 1,799 & 2,905 & 5,507 & Pull-out \\
\hline I4-0-3 & 0 & & 15,450 & & 5,882 & 1,793 & 1,465 & 2,053 & 5,435 & Pull-out \\
\hline I4-0-4 & 0 & & 13,412 & & 5,774 & 2,625 & 1,973 & 3,099 & 6,086 & Pull-out \\
\hline I4-2-1 & 3,95 & & 15,764 & \multirow{4}{*}{$\begin{array}{c}\mathbf{1 6 , 9 9 5} \\
(6,36)\end{array}$} & 2,875 & 0,063 & 0,03 & 0,064 & 6,050 & Pull-out \\
\hline I4-2-2 & 4,95 & & 17,301 & & 0 & 0,055 & 0,025 & 0,068 & 2,419 & Frágil \\
\hline I4-2-3 & 4,31 & & 16,601 & & 0 & 0,030 & 0,013 & 0,043 & 0,484 & Frágil \\
\hline I4-2-4 & 4,26 & & 18,313 & & 0 & 0,044 & 0,016 & 0,055 & 0,891 & Frágil \\
\hline I4-10-1 & 12,93 & & 12,512 & \multirow{4}{*}{$\begin{array}{l}\mathbf{1 5}, \mathbf{4 1 9} \\
(13,70)\end{array}$} & 0 & 0,007 & 0,007 & 0,007 & 9,791 & Pull-out \\
\hline I4-10-2 & 13,07 & & 16,051 & & 0 & 0,038 & 0,017 & 0,049 & 9,699 & Pull-out \\
\hline I4-10-3 & 12,54 & & 17,545 & & 0 & 0,020 & 0,001 & 0,022 & 1,413 & Frágil \\
\hline I4-10-4 & 12,83 & & 15,569 & & 0 & 0,027 & 0,017 & 0,5 & 9,711 & Pull-out \\
\hline I4-20-1 & 24,43 & & 16,063 & \multirow{4}{*}{$\begin{array}{l}\mathbf{1 3 , 1 5 6} \\
(19,91)\end{array}$} & 0 & 0,021 & 0,011 & 0,336 & 2,235 & Frágil \\
\hline I4-20-2 & 27,02 & & 12,699 & & 0 & 0,026 & 0,018 & 0,027 & 8,468 & Pull-out \\
\hline I4-20-3 & 24,50 & & 9,820 & & 0 & 0,04 & 0,026 & 1,719 & 8,854 & Pull-out \\
\hline I4-20-4 & 21,07 & & 14,043 & & 0 & 0,194 & 0,178 & 0,752 & 7,490 & Pull-out \\
\hline
\end{tabular}


Las Figura 5-7 y Figura 5-8 muestran los diagramas tensión de adherencia media $\tau_{b}$ [MPa] - Deslizamiento en el extremo no cargado $[\mathrm{mm}]$ para distintos grados de corrosión teórica, obtenidos en los ensayos de pull-out sobre la serie de probetas I4.

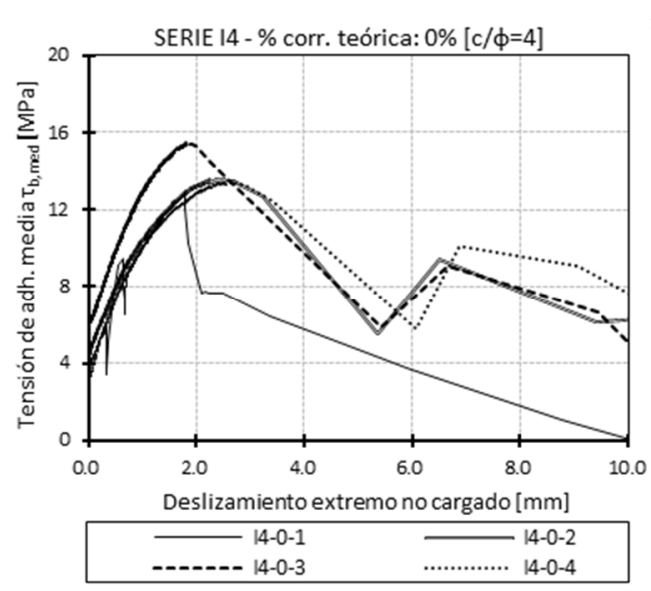

a)

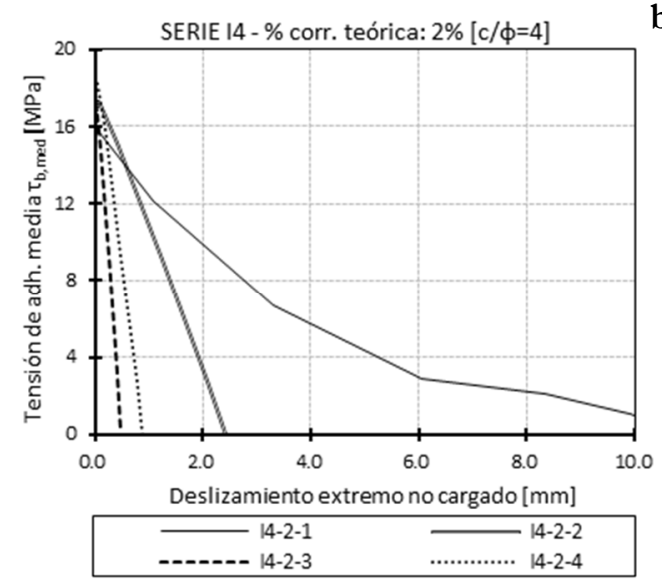

b)

Figura 5-7 Diagramas tensión de adherencia media-deslizamiento en extremo no cargado en probetas de la Serie I4: con alambres indentados, $20 \mathrm{~mm}$ de recubrimiento minimo y distintos grados de corrosión teórica [a) 0\% de pérdida de sección; a) 2\% de pérdida de sección]

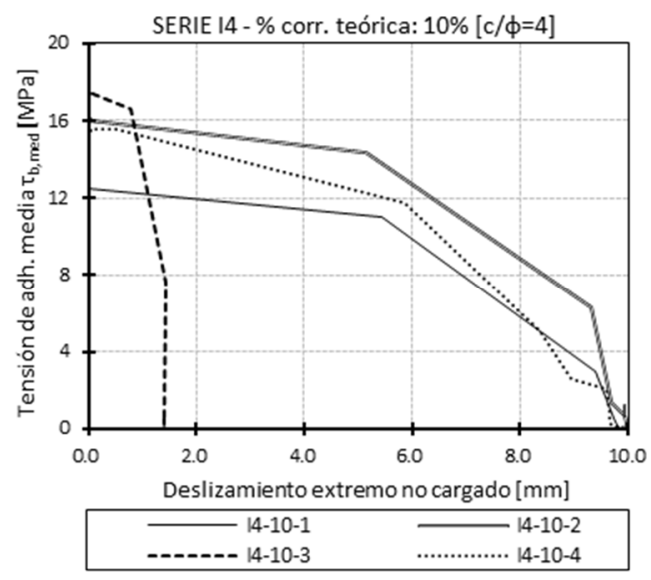

c)

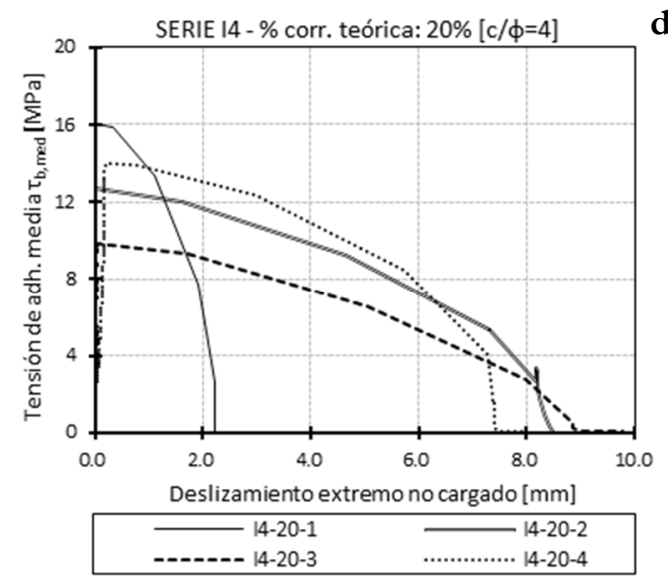

d)

Figura 5-8 Diagramas tensión de adherencia media-deslizamiento en extremo no cargado en probetas de la Serie I4: con alambres indentados, $20 \mathrm{~mm}$ de recubrimiento minimo y distintos grados de corrosión teórica [c) 10\% de pérdida de sección; d) 20\% de pérdida de sección]

\subsection{Serie I10: Alambres indentados - Recubrimiento/diámetro $\mathrm{c} / \phi=10$}

La serie de ensayos I10 está compuesta por un total de 23 probetas prismáticas, de 100x100x200 mm, con el alambre indentado situado en el centro de la sección, de manera que el recubrimiento mecánico mínimo resultante es de $50 \mathrm{~mm}$ (Figura 5-9), con una relación recubrimiento/diámetro igual a 10. La longitud adherente del alambre es de $75 \mathrm{~mm}(\approx 15 \phi)$. Con el objetivo de estudiar de manera aislada cómo afecta las características mecánicas del hormigón $\left(f_{c m}\right.$ y $\left.f_{c t m}\right)$ en la capacidad adherente, se han llevado a cabo 10 ensayos sobre armaduras sanas (sin procesos de corrosión) variando únicamente este parámetro. En cinco de ellas se ha utilizado el Hormigón 3 (Tabla 4-4), cuya resistencia media a compresión es $f_{c m}=48,40 \mathrm{~N} / \mathrm{mm}^{2}$ y resistencia media a tracción $f_{c t m}=3,33 \mathrm{~N} / \mathrm{mm}^{2}$, mientras que las otras cinco se han fabricado con el Hormigón 5 (Tabla 4-4), con $f_{c m}=45,84 \mathrm{~N} / \mathrm{mm}^{2}$ y $f_{\text {ctm }}=3,52 \mathrm{~N} / \mathrm{mm}^{2}$. 
Para las trece probetas restantes se ha utilizado el Hormigón 3, siendo sometidas a distintos niveles de corrosión y alcanzándose pérdidas reales de sección transversal en el alambre de hasta un 19,55\%. En la Tabla 5-9 se incluyen los parámetros más relevantes extraídos de las gráficas adherencia mediadeslizamiento obtenidas en los ensayos.

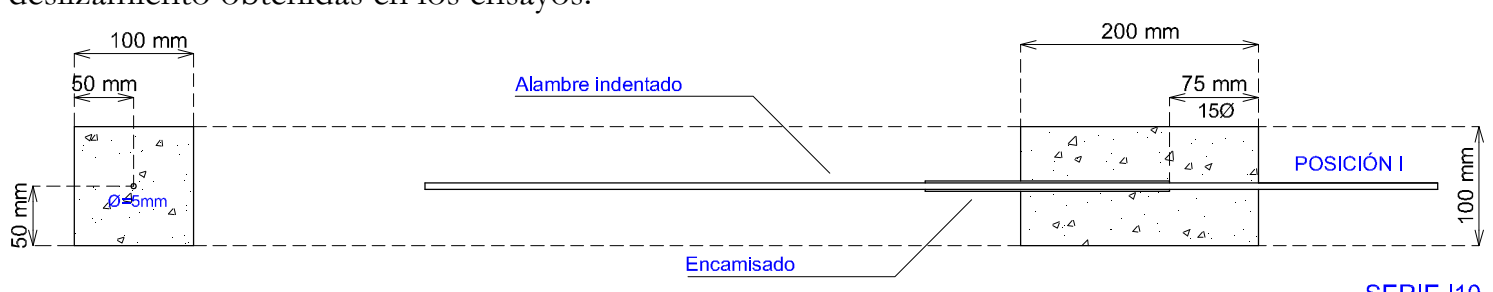

SERIE I10

Figura 5-9 Configuración geométrica de las probetas 110 con alambres indentados y recubrimiento mecánico de $50 \mathrm{~mm}(\mathrm{c} / \phi=10)$

Tabla 5-9 Resumen de resultados de los ensayos sobre la serie de probetas 110

\begin{tabular}{|c|c|c|c|c|c|c|c|c|c|c|}
\hline \multirow[b]{3}{*}{ PROB. } & \multicolumn{9}{|c|}{ Serie [I10] } & \multirow[b]{3}{*}{ Fallo } \\
\hline & \multirow{2}{*}{$\begin{array}{c}\% \\
\text { Corr, } \\
\text { real }\end{array}$} & \multirow{2}{*}{$\begin{array}{l}\mathrm{f}_{\mathrm{cm}}[\mathrm{MPa}] \\
\left(\mathrm{f}_{\mathrm{ct}}[\mathrm{MPa}]\right)\end{array}$} & \multirow{2}{*}{$\begin{array}{l}\tau_{b, \max }^{\operatorname{med}} \\
{[\mathrm{MPa}]}\end{array}$} & \multirow{2}{*}{$\begin{array}{c}\text { Med. } \tau_{b, \max }^{\text {med }} \\
(\mathrm{CoV})\end{array}$} & \multirow[b]{2}{*}{$\tau_{\text {res }}[\mathrm{MPa}]$} & \multicolumn{4}{|c|}{ Deslizamientos [mm] } & \\
\hline & & & & & & $s_{\max }$ & $s_{1}$ & $s_{2}$ & $s_{3}$ & \\
\hline I10-0-1 & 0 & \multirow{5}{*}{$\begin{array}{l}48,40 \\
(3,52)\end{array}$} & 12,289 & \multirow{5}{*}{$\begin{array}{l}12,254 \\
(13,35)\end{array}$} & 5,383 & 1,863 & 1,044 & 2,201 & 7,898 & Pull-out \\
\hline I10-0-2 & 0 & & 13,501 & & 5,471 & 2,011 & 1,138 & 2,572 & 6,485 & Pull-out \\
\hline I10-0-3 & 0 & & 14,187 & & 6,888 & 2,206 & 1,289 & 2,437 & 8,389 & Pull-out \\
\hline I10-0-4 & 0 & & 10,997 & & 6,996 & 2,591 & 1,722 & 3,142 & 7,624 & Pull-out \\
\hline I10-0-5 & 0 & & 10,295 & & 5,347 & 2,009 & 0,958 & 2,356 & 7,304 & Pull-out \\
\hline I10-0-1a & 0 & \multirow{5}{*}{$\begin{array}{l}45,84 \\
(3,33)\end{array}$} & 14,258 & \multirow{5}{*}{$\begin{array}{l}\mathbf{1 1 , 5 3 7} \\
(23,91)\end{array}$} & 7,572 & 2,497 & 2,069 & 3,163 & 5,609 & Pull-out \\
\hline I10-0-2a & 0 & & 13,501 & & 5,668 & 2,236 & 1,890 & 2,820 & 6,156 & Pull-out \\
\hline I10-0-3a & 0 & & 10,735 & & 6,066 & 2,968 & 2,472 & 3,295 & 6,399 & Pull-out \\
\hline I10-0-4a & 0 & & 11,940 & & 4,405 & 2,415 & 1,918 & 2,920 & 6,044 & Pull-out \\
\hline I10-0-5a & 0 & & 7,252 & & 4,279 & 2,617 & 2,148 & 3,278 & 5,690 & Pull-out \\
\hline I10-2-1 & 3.76 & \multirow{13}{*}{$\begin{array}{l}48,40 \\
(3,52)\end{array}$} & 25,646 & \multirow{4}{*}{$\begin{array}{c}27,491 \\
(6,32)\end{array}$} & 18,539 & 0,052 & 0,007 & 1,730 & 6,837 & Pull-out \\
\hline I10-2-2 & 1.55 & & 26,419 & & 9,786 & 0,036 & 0,004 & 1,551 & 4,227 & Pull-out \\
\hline I10-2-3 & 2.45 & & 28,601 & & 14,929 & 0,002 & 0,009 & 1,565 & 5,008 & Pull-out \\
\hline I10-2-4 & 2.99 & & 29,296 & & 24,317 & 0,205 & 0,192 & 1,640 & 3,910 & Pull-out** \\
\hline I10-5-1 & 6.36 & & 28,219 & \multirow{3}{*}{$\begin{array}{c}28,617 \\
(1,33)\end{array}$} & 9,808 & 0,013 & 0,002 & 0,408 & 3,003 & Pull-out \\
\hline I10-5-2 & 5.59 & & 28,651 & & 14,565 & 0,474 & 0,002 & 1,216 & 4,015 & Pull-out \\
\hline I10-5-3 & 5.30 & & 28,982 & & 2,889 & 0,987 & 0,003 & 1,492 & 4,976 & Pull-out \\
\hline I10-10-1 & 12.90 & & 25,794 & \multirow{3}{*}{$\begin{array}{c}24,447 \\
(6,96)\end{array}$} & 0 & 0,007 & 0,003 & 0,352 & 6,947 & Frágil \\
\hline I10-10-2 & 12.62 & & 25,010 & & 7,539 & 0,138 & 0,015 & 0,185 & $9,531 *$ & Pull-out \\
\hline I10-10-3 & 13.12 & & 22,536 & & 8,500 & 0,311 & 0,001 & 0,619 & $9,172^{*}$ & Pull-out \\
\hline I10-20-1 & 17.13 & & 16,437 & \multirow{3}{*}{$\begin{array}{l}\mathbf{1 9 , 9 8 2} \\
(15,88)\end{array}$} & 0 & 0,044 & 0,026 & 0,061 & 0,223 & Frágil \\
\hline I10-20-2 & 19.55 & & 20,951 & & 9,433 & 0,299 & 0,029 & 0,740 & $2,179 *$ & Pull-Out \\
\hline I10-20-3 & 16.44 & & 22,559 & & 8,783 & 0,059 & 0,002 & 0,099 & $7,352^{*}$ & Pull-Out \\
\hline
\end{tabular}

Las Figura 5-10, Figura 5-11 y Figura 5-12 muestran los diagramas tensión de adherencia media $\tau_{b}[\mathrm{MPa}]-$ Deslizamiento en el extremo no cargado [mm], agrupados en función de los distintos grados de corrosión teórica [a) $0 \%$, b) 2\%, c) 5\%, d) 10\% y e) 20\%], obtenidos en los ensayos de pull-out sobre las probetas de la Serie I10. 


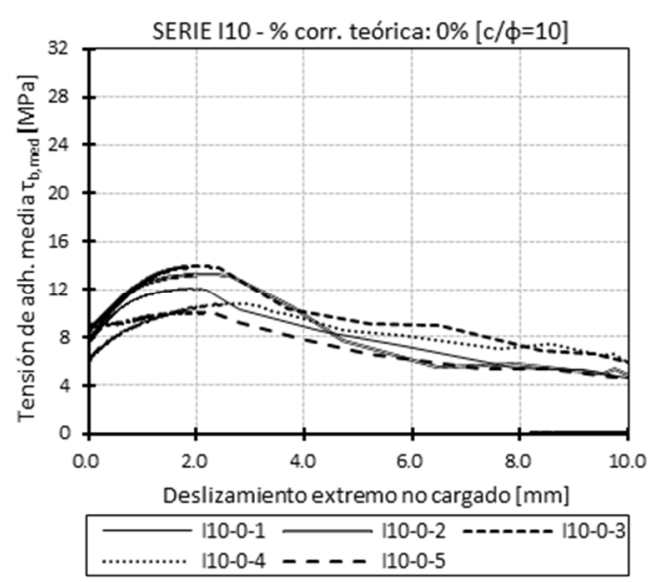

a)

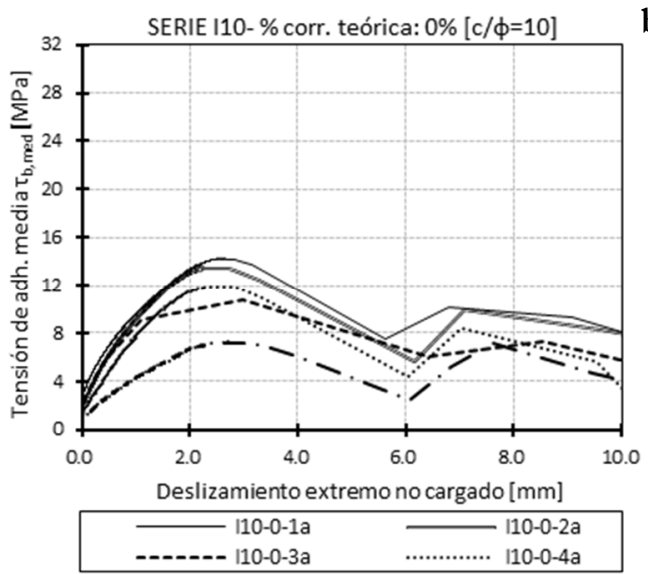

b)

Figura 5-10 Diagramas tensión de adherencia media-deslizamiento en extremo no cargado en probetas de la Serie I10: con alambres indentados, 50 mm de recubrimiento minimo y sin corrosión [a) Hormigón 3; a) Hormigón 5 ]

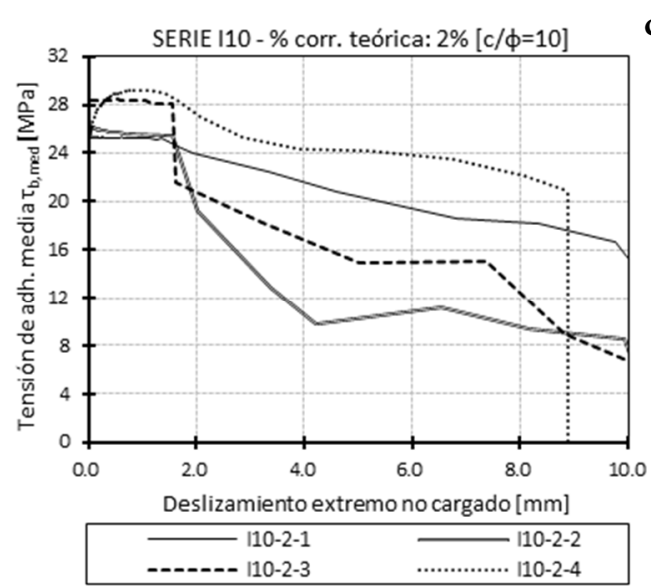

c)

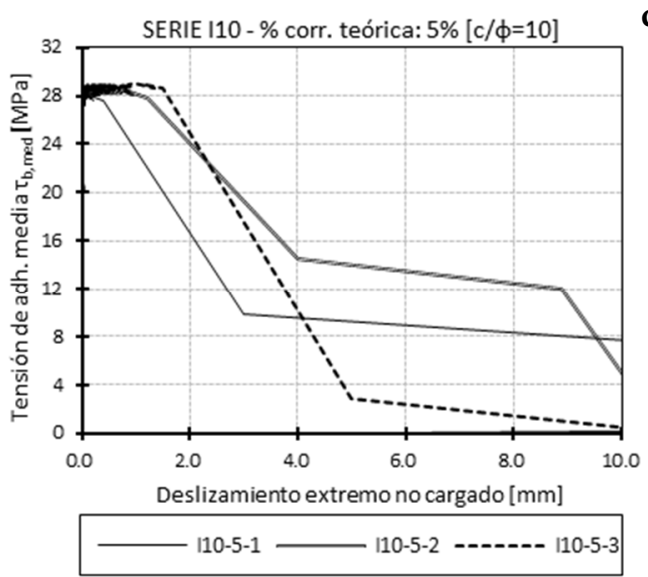

d)

Figura 5-11 Diagramas tensión de adherencia media-deslizamiento en extremo no cargado en probetas de la Serie I10: con alambres indentados, $50 \mathrm{~mm}$ de recubrimiento minimo y distintos grados de corrosión teórica [c) 2\% de pérdida de sección; d) $5 \%$ de pérdida de sección]

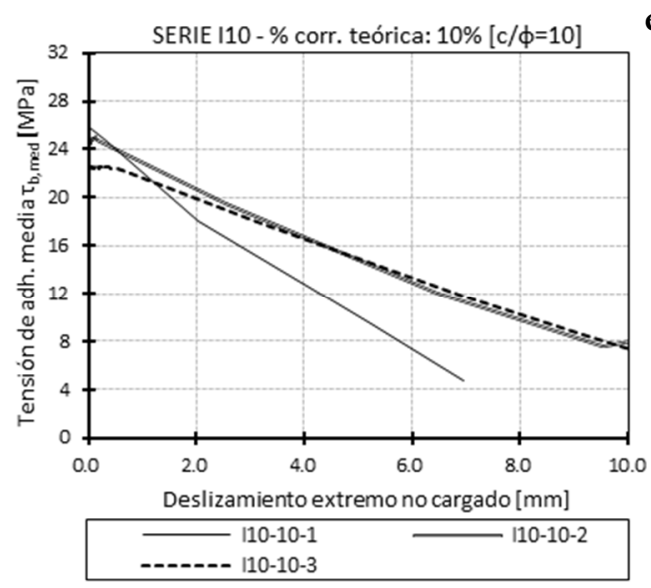

e)

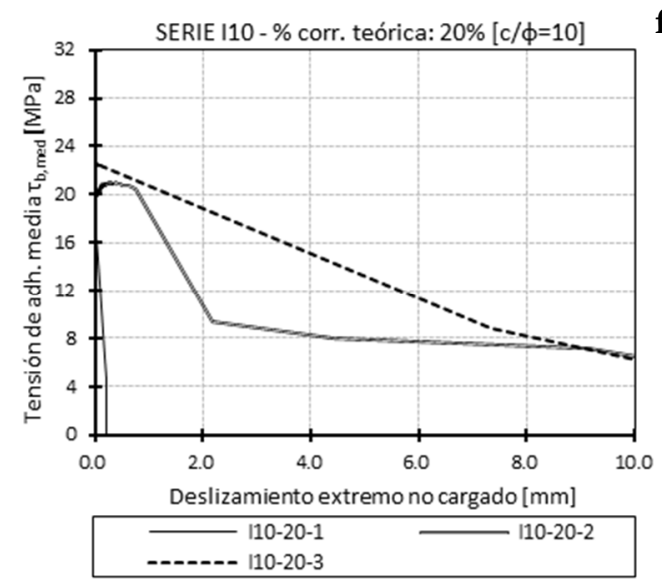

Figura 5-12 Diagramas tensión de adherencia media-deslizamiento en extremo no cargado en probetas de la Serie I10: con alambres indentados, $50 \mathrm{~mm}$ de recubrimiento mínimo y distintos grados de corrosión teórica (e) 10\% de pérdida de sección; f) $20 \%$ de pérdida de sección] 


\subsection{Serie I20: Alambres indentados - Recubrimiento/diámetro $\mathrm{c} / \phi=20$}

La serie de ensayos I20 está compuesta por un total de 15 probetas cúbicas, de 200x200x200 mm, con el alambre indentado situado concéntricamente en la sección transversal, de manera que el recubrimiento mecánico mínimo resultante es de $100 \mathrm{~mm}$ (Figura 5-13), con una relación recubrimiento/diámetro igual a 20. Como en los casos anteriores, la longitud adherente ha sido equivalente a $15 \phi(75 \mathrm{~mm})$. Tal y como muestra la Tabla 5-10, han sido utilizados hormigones con distintas características mecánicas: a) Hormigón 7: $f_{c m}=51,67 \mathrm{~N} / \mathrm{mm}^{2}$ y $f_{c t m}=4,13 \mathrm{~N} / \mathrm{mm}^{2}$; b) Hormigón 3: $f_{c m}=48,40 \mathrm{~N} / \mathrm{mm}^{2}$ y $f_{\mathrm{ctm}}=3,52 \mathrm{~N} / \mathrm{mm}^{2}$; y c) Hormigón 4: $f_{\mathrm{cm}}=43,72 \mathrm{~N} / \mathrm{mm}^{2}$ y $f_{\mathrm{ctm}}=3,16 \mathrm{~N} / \mathrm{mm}^{2}($ Ver Tabla 4-4). Se han ensayado 10 probetas con alambres sanos y el resto con alambres afectados por procesos de corrosión, alcanzándose pérdidas de sección transversal de hasta un 3,62\%. Cabe destacar que los ensayos de esta serie han sido usados como elemento de comparación y de control del resto de series, por lo que los hormigones utilizados son los mismos que en las anteriores, permitiendo un cruce de datos que facilita el análisis. Por esta misma razón, la penetración de ataque permitida en esta serie es significativamente menor que en las anteriores series. En la Tabla 5-10 se incluyen los parámetros más relevantes extraídos de los ensayos.

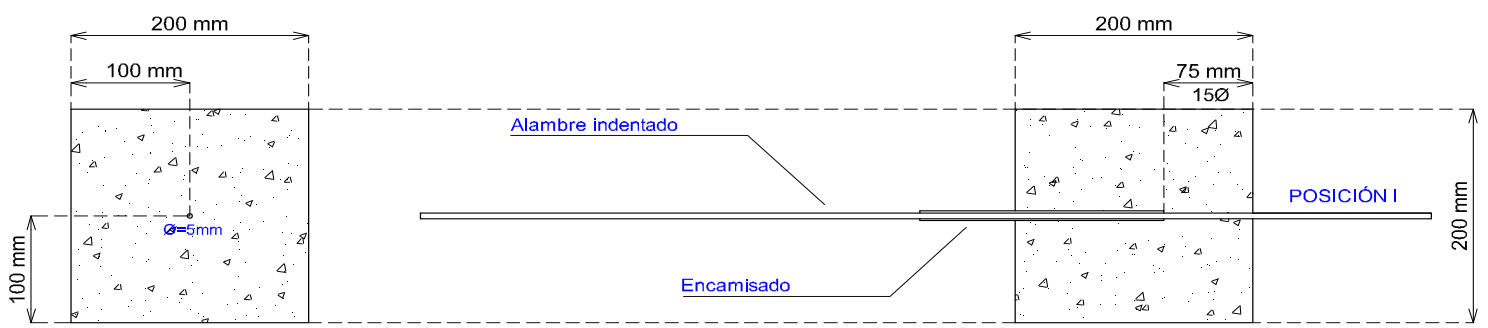

SERIE I20

Figura 5-13 Configuración geométrica de las probetas 120 con alambres indentados y recubrimiento mecánico de $100 \mathrm{~mm}(\mathrm{c} / \phi=20)$

Tabla 5-10 Resumen de resultados de los ensayos sobre la serie de probetas 120

\begin{tabular}{|c|c|c|c|c|c|c|c|c|c|c|}
\hline \multirow{3}{*}{ PROB. } & \multicolumn{10}{|c|}{ Serie [I20] } \\
\hline & \multirow{2}{*}{$\begin{array}{c}\% \text { Corr, } \\
\text { real }\end{array}$} & \multirow{2}{*}{$\begin{array}{l}\mathrm{f}_{\mathrm{cm}}[\mathrm{MPa}] \\
\left(\mathrm{f}_{\mathrm{ct}}[\mathrm{MPa}]\right)\end{array}$} & \multirow{2}{*}{$\begin{array}{l}\tau_{b, \text { max }}^{\text {med }} \\
{[\mathrm{MPa}]}\end{array}$} & \multirow{2}{*}{$\begin{array}{c}\text { Med. } \tau_{b, \max }^{\text {med }} \\
(\mathrm{CoV})\end{array}$} & \multirow{2}{*}{$\tau_{\text {res }}[\mathrm{MPa}]$} & \multicolumn{4}{|c|}{ Deslizamientos [mm] } & \multirow{2}{*}{ Fallo } \\
\hline & & & & & & $s_{\max }$ & $s_{1}$ & $s_{2}$ & $s_{3}$ & \\
\hline I20-0-1a & 0 & \multirow{5}{*}{$\begin{array}{l}51,67 \\
(4,13)\end{array}$} & 8,878 & \multirow{5}{*}{$\begin{array}{l}10,667 \\
(24,04)\end{array}$} & 3,469 & 2,537 & 2,002 & 3,060 & $6,348^{*}$ & Pull-out \\
\hline I20-0-2a & 0 & & 9,096 & & 3,589 & 2,530 & 1,986 & 3,119 & $5,847^{*}$ & Pull-out \\
\hline I20-0-3a & 0 & & 13,239 & & 5,672 & 2,684 & 1,969 & 3,134 & $4,655^{*}$ & Pull-out \\
\hline I20-0-4a & 0 & & 8,442 & & 3,365 & 2,503 & 1,955 & 2,785 & $5,337 *$ & Pull-out \\
\hline I20-0-5a & 0 & & 13,680 & & 5,612 & 2,194 & 1,698 & 2,740 & $4,817 *$ & Pull-out \\
\hline $\mathrm{I} 20-0-1 \mathrm{~b}$ & 0 & \multirow{3}{*}{$\begin{array}{l}48,40 \\
(3,52)\end{array}$} & 8,0274 & \multirow{3}{*}{$\begin{array}{l}11,664 \\
(30,02)\end{array}$} & 3,697 & 1,792 & 0,710 & 2,971 & $6,300 *$ & Pull-out \\
\hline I $20-0-2 b$ & 0 & & 15,014 & & 8,897 & 1,430 & 0,408 & 2,542 & $6,333 *$ & Pull-out \\
\hline I20-0-3b & 0 & & 11,951 & & 7,770 & 1,800 & 0,879 & 2,399 & $4,422 *$ & Pull-out \\
\hline I20-0-1c & 0 & \multirow{2}{*}{$\begin{array}{l}43,72 \\
(3,16)\end{array}$} & 10,786 & \multirow{2}{*}{$\begin{array}{c}11,332 \\
(6,81)\end{array}$} & 5,535 & 1,886 & 0,173 & 2,635 & $6,709 *$ & Pull-out \\
\hline I20-0-2c & 0 & & 11,878 & & 7,429 & 2,033 & 0,896 & 2,571 & $4,897 *$ & Pull-out \\
\hline I $20-2-1 b$ & 3,52 & \multirow{2}{*}{$\begin{array}{l}48,40 \\
(3,52)\end{array}$} & 19,264 & \multirow{2}{*}{$\begin{array}{l}\mathbf{1 6 , 8 7 8} \\
(19,99)\end{array}$} & 5,016 & 0,038 & 0,007 & 0,038 & $9,497 *$ & Pull-out \\
\hline I20-2-2b & 2,42 & & 14,492 & & 0 & 0,078 & 0,053 & 0,091 & 1,061 & Frágil \\
\hline I20-2-1c & 2,33 & \multirow{3}{*}{$\begin{array}{l}43,72 \\
(3,16)\end{array}$} & 12,955 & \multirow{3}{*}{$\begin{array}{l}\mathbf{1 4 , 7 6 9} \\
(11,34)\end{array}$} & 0 & 0,116 & 0,043 & 0,128 & 7,903 & Frágil \\
\hline I20-2-2c & 3,613 & & 16,255 & & 0 & 0,065 & 0,005 & 0,068 & 4,053 & Frágil \\
\hline I20-2-3c & 3,620 & & 15,098 & & 0 & 0,146 & 0,056 & 0,148 & 5,181 & Frágil \\
\hline
\end{tabular}


Las Figura 5-14 y Figura 5-15 muestran los diagramas tensión de adherencia media $\tau_{b}[\mathrm{MPa}]$ - Deslizamiento en el extremo no cargado $[\mathrm{mm}]$, agrupados en función de los distintos grados de corrosión teórica [a y b) $0 \%$, c) $2 \%$, obtenidos en los ensayos de pull-out sobre la serie de probetas I 20 .

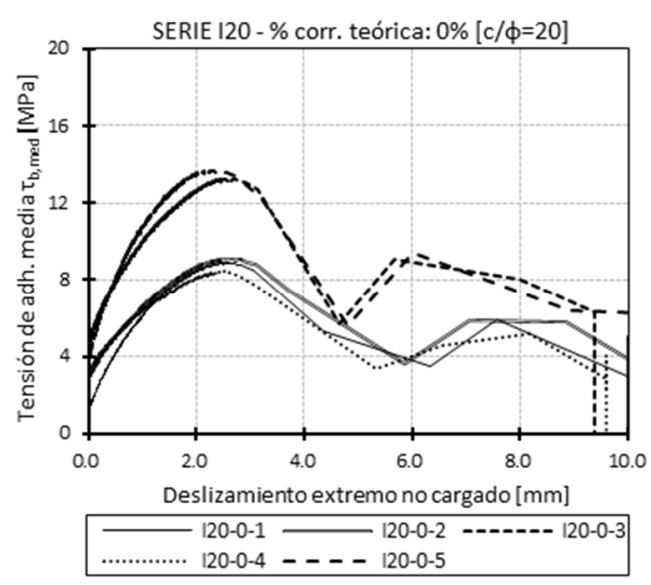

a)

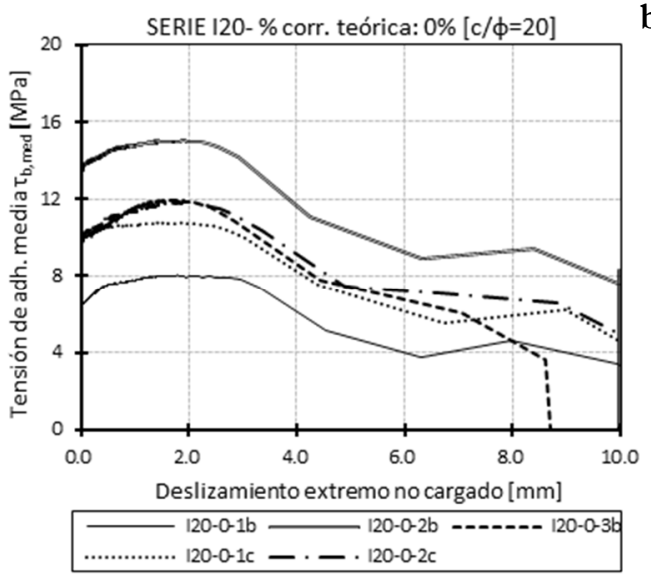

Figura 5-14 Diagramas tensión de adherencia media-deslizamiento en extremo no cargado en probetas de la Serie I20: con alambres indentados, $100 \mathrm{~mm}$ de recubrimiento minimo y sin corrosión [a) $f_{\mathrm{cm}}=51,67 \mathrm{MPa} ;$ a) $b: f_{\mathrm{cm}}=48,40 \mathrm{MPa}, c: f_{\mathrm{cm}}=43,72 \mathrm{MPa}$ ]

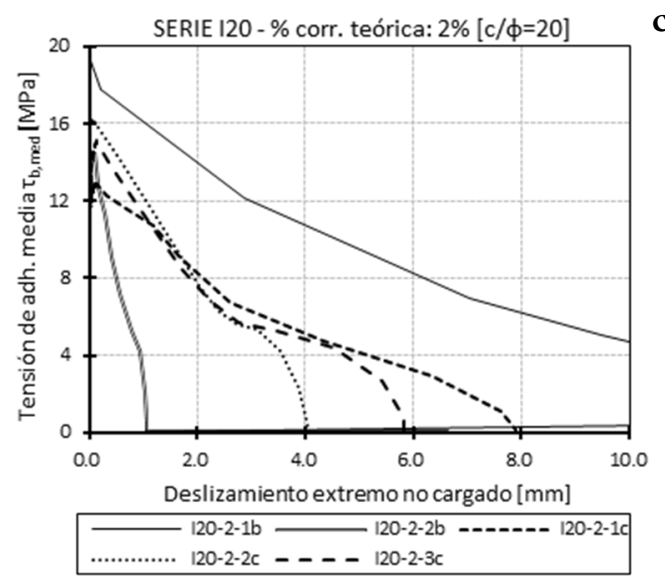

c)

Figura 5-15 Diagramas tensión de adherencia media-deslizamiento en extremo no cargado en probetas de la Serie I20: con alambres indentados, $100 \mathrm{~mm}$ de recubrimiento minimo y corrosión teórica de un 2\% de pérdida de sección [c) b: $f_{\mathrm{cm}}=48,40 \mathrm{MPa}, c: f_{\mathrm{cm}}=43,72 \mathrm{MPa}$ ]

\subsubsection{Alambres Lisos [Serie L]}

En esta tesis se han llevado a cabo 54 ensayos de pull-out sobre alambres lisos, centrados y excéntricos, con recubrimientos mecánicos que han variado desde los $20 \mathrm{~mm}$ hasta los $100 \mathrm{~mm}$, con niveles de corrosión variables de hasta un $25,45 \%$ de pérdida de sección, y resistencias medias de compresión del hormigón $f_{c m}$ que han oscilado entre $32,43 \mathrm{~N} / \mathrm{mm}^{2}$ y $51,67 \mathrm{~N} / \mathrm{mm}^{2}$.

\subsection{Serie L4: Alambres lisos - Recubrimiento/diámetro $\mathrm{c} / \phi=4$}

La serie de ensayos L4 está compuesta por un total de 20 probetas prismáticas, de 100x100x200 mm, con el alambre liso situado excéntricamente, de manera que el recubrimiento mecánico mínimo resultante es de $20 \mathrm{~mm}$ (Figura 5-19), con una relación recubrimiento/diámetro $(c / \phi)$ igual a 4 . La 


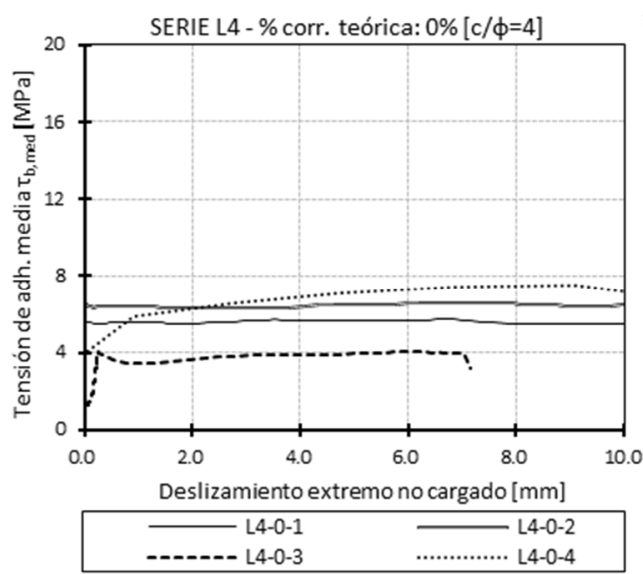

a)

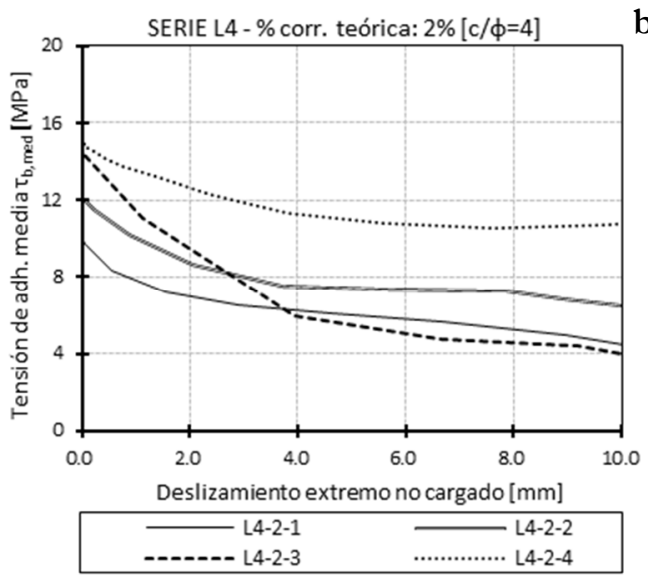

Figura 5-16 Diagramas tensión de adberencia media-deslizamiento en extremo no cargado en probetas de la Serie L4: con alambres lisos, 20 mm de recubrimiento mínimo y distintos grados de corrosión teórica [a) $0 \%$ de pérdida de sección; a) 2\% de pérdida de sección]

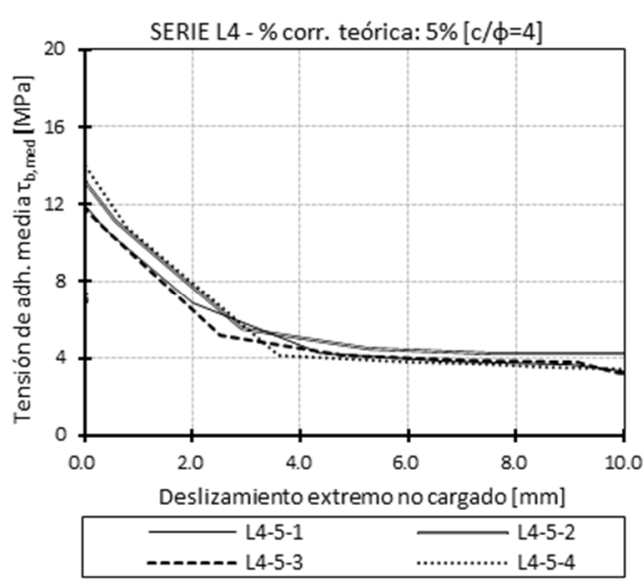

c)

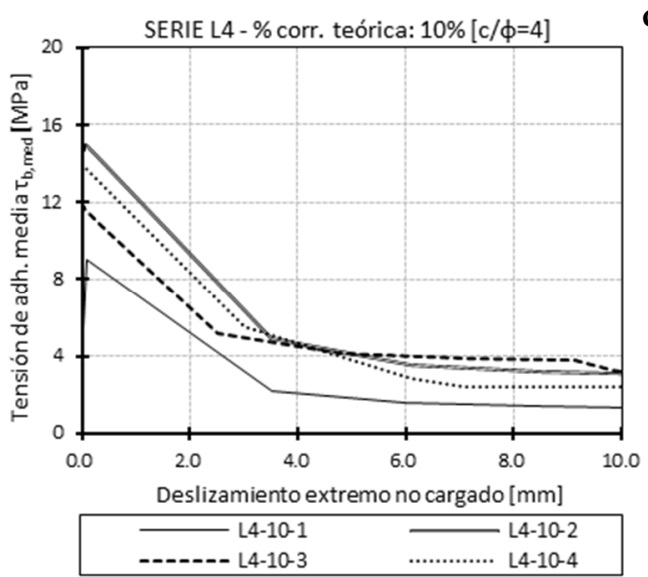

d)

Figura 5-17 Diagramas tensión de adherencia media-deslizamiento en extremo no cargado en probetas de la Serie L4: con alambres lisos, 20 mm de recubrimiento minimo y distintos grados de corrosión teórica [c) 5\% de pérdida de sección; d) 10\% de pérdida de sección]

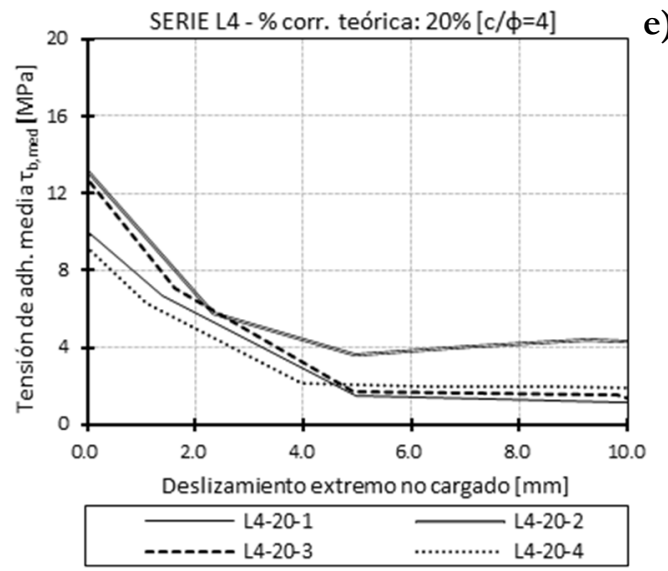

Figura 5-18 Diagramas tensión de adherencia media-deslizamiento en extremo no cargado en probetas de la Serie L4: con alambres lisos, 20 mm de recubrimiento minimo y $20 \%$ de pérdida de sección teórica 
longitud adherente del alambre es de $75 \mathrm{~mm}(\approx 15 \phi)$. Las probetas han sido fabricadas con el Hormigón 6 (Tabla 4-4), cuyas resistencias medias a compresión y tracción son $f_{\text {cm }}=32,43 \mathrm{~N} / \mathrm{mm}^{2}$ y $f_{\text {ctm }}=3,79$ $\mathrm{N} / \mathrm{mm}^{2}$, respectivamente. Se han ensayado cuatro probetas con alambres sanos, mientras que el resto se han ensayado con distintos niveles de corrosión, alcanzándose pérdidas de sección transversal de hasta un 21,08\%. En la Tabla 5-11 se incluyen los parámetros más relevantes extraídos de los ensayos.

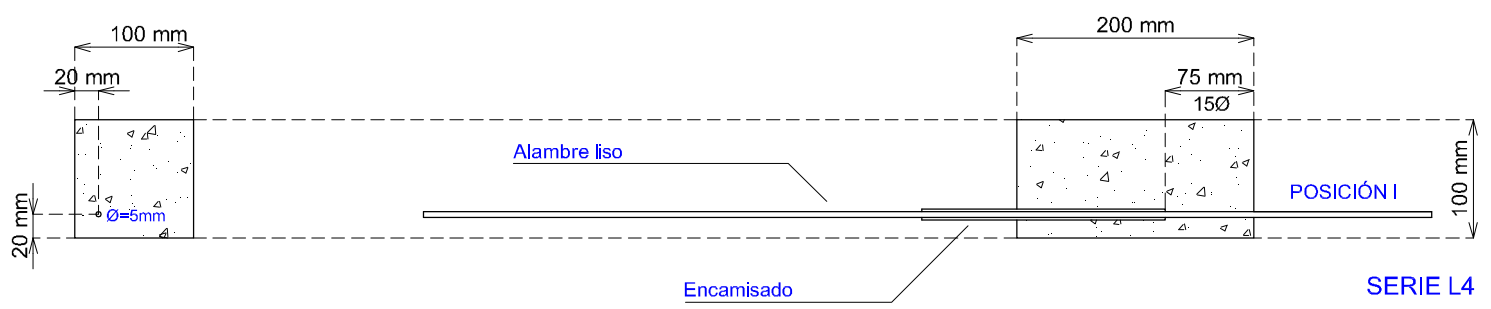

Figura 5-19 Configuración geométrica de las probetas L4 con alambres lisos y recubrimiento mecánico de $20 \mathrm{~mm}(\mathrm{c} / \phi=4)$

Tabla 5-11 Resumen de resultados de los ensayos sobre la serie de probetas LA

\begin{tabular}{|c|c|c|c|c|c|c|c|c|c|c|}
\hline \multirow{3}{*}{ PROB. } & \multicolumn{10}{|c|}{ Serie [L4] } \\
\hline & \multirow{2}{*}{$\begin{array}{c}\% \text { Corr, } \\
\text { real }\end{array}$} & \multirow{2}{*}{$\begin{array}{l}\mathrm{f}_{\mathrm{cm}}[\mathrm{MPa}] \\
\left(\mathrm{f}_{\mathrm{ct}}[\mathrm{MPa}]\right)\end{array}$} & \multirow{2}{*}{$\begin{array}{l}\tau_{b, \max }^{\operatorname{med}} \\
\text { [MPa] } \\
\end{array}$} & \multirow{2}{*}{$\begin{array}{l}\text { Med. } \tau_{b, \max }^{\text {med }} \\
(\mathrm{CoV})\end{array}$} & \multirow{2}{*}{$\tau_{\text {res }}[\mathrm{MPa}]$} & \multicolumn{4}{|c|}{ Deslizamientos [mm] } & \multirow{2}{*}{ Fallo } \\
\hline & & & & & & $s_{\max }$ & $s_{1}$ & $s_{2}$ & $s_{3}$ & \\
\hline L4-0-1 & 0 & \multirow{20}{*}{$\begin{array}{l}32,43 \\
(3,79)\end{array}$} & 5,714 & \multirow{4}{*}{$\begin{array}{c}5,967 \\
(24,99)\end{array}$} & 5,4181 & 6,845 & 0,011 & 10,42 & $10,421^{*}$ & Pull-Out \\
\hline L4-0-2 & 0 & & 6,582 & & 6,244 & 6,627 & 0,002 & 11,25 & $11,253^{*}$ & Pull-Out \\
\hline L4-0-3 & 0 & & 4,030 & & 3,8234 & 0,247 & 0,242 & 7,031 & $7,031 *$ & Pull-Out \\
\hline L4-0-4 & 0 & & 7,541 & & 7,541 & 8,990 & 0,002 & 9,113 & $9,113^{*}$ & Pull-Out \\
\hline L4-2-1 & 2,33 & & 9,891 & \multirow{4}{*}{$\begin{array}{l}12,829 \\
(18,16)\end{array}$} & 6,523 & 0,023 & 0,002 & 0,069 & $2,899 *$ & Pull-Out \\
\hline L4-2-2 & 1,88 & & 12,041 & & 7,548 & 0,015 & 0,005 & 0,230 & $3,723^{*}$ & Pull-Out \\
\hline L4-2-3 & 1,76 & & 14,469 & & 5,971 & 0,002 & 0,002 & 0,029 & $3,947^{*}$ & Pull-Out \\
\hline L4-2-4 & 1,58 & & 14,916 & & 10,744 & 0,038 & 0,007 & 0,418 & $3,806^{*}$ & Pull-Out \\
\hline L4-5-1 & 5,92 & & 11,878 & \multirow{4}{*}{$\begin{array}{c}12,695 \\
(8,50)\end{array}$} & 4,230 & 0,044 & 0,002 & 0,066 & $4,346^{*}$ & Pull-out \\
\hline L4-5-2 & 6,14 & & 13,138 & & 5,482 & 0,031 & 0,004 & 0,044 & $2,907 *$ & Pull-Out \\
\hline L4-5-3 & 6,22 & & 11,750 & & 4,088 & 0,033 & 0,010 & 0,041 & $4,807^{*}$ & Pull-Out \\
\hline L4-5-4 & 6,10 & & 14,012 & & 4,147 & 0,160 & 0,006 & 0,027 & $3,585^{*}$ & Pull-Out \\
\hline L4-10-1 & 11,29 & & 9,002 & \multirow{4}{*}{$\begin{array}{l}\mathbf{1 2 , 3 7 6} \\
(21,10)\end{array}$} & 2,147 & 0,105 & 0,105 & 0,105 & $3,532^{*}$ & Pull-Out \\
\hline L4-10-2 & 11,85 & & 14,960 & & 4,899 & 0,046 & 0,018 & 0,256 & $3,493^{*}$ & Pull-Out \\
\hline L4-10-3 & 11,72 & & 11,750 & & 5,160 & 0,033 & 0,010 & 0,041 & $2,520^{*}$ & Pull-Out \\
\hline L4-10-4 & 12,31 & & 13,792 & & 2,386 & 0,032 & 0,002 & 0,032 & $3,020^{*}$ & Pull-Out \\
\hline L4-20-1 & 21,08 & & 9,874 & \multirow{4}{*}{$\begin{array}{l}11,242 \\
(18,06)\end{array}$} & 1,469 & 0,045 & 0,026 & 0,610 & $4,987 *$ & Pull-Out \\
\hline L4-20-2 & 19,85 & & 13,153 & & 3,567 & 0,017 & 0,007 & 0,022 & $4,943^{*}$ & Pull-Out \\
\hline L4-20-3 & 21,08 & & 12,800 & & 1,672 & 0,008 & 0,002 & 0,010 & $4,913^{*}$ & Pull-Out \\
\hline L4-20-4 & 20,00 & & 9,140 & & 2,176 & 0,02 & 0,001 & 0,020 & $3,960^{*}$ & Pull-Out \\
\hline
\end{tabular}

Las Figura 5-16, Figura 5-17 y Figura 5-18 muestran los diagramas tensión de adherencia media $\tau_{b}[M P a]-$ Deslizamiento en el extremo no cargado [mm], agrupados en función de los distintos grados de corrosión teórica [a) $0 \%$; b) 2\%; c) $5 \%$; d) $10 \%$ y e) $20 \%$ ], obtenidos en los ensayos de pull-out sobre la serie de probetas L4. 


\subsection{Serie L10: Alambres lisos - Recubrimiento/diámetro $\mathrm{c} / \phi=10$}

La serie de ensayos L10 está compuesta por un total de 17 probetas prismáticas, de 100x100x200 $\mathrm{mm}$, con el alambre liso situado en el centro de la sección, de manera que el recubrimiento mecánico mínimo resultante es de $50 \mathrm{~mm}$ (Figura 5-20), con una relación recubrimiento/diámetro igual a 10. La longitud adherente del alambre es de $75 \mathrm{~mm}(\approx 15 \phi)$. Las probetas han sido fabricadas con el Hormigón 4 (Ver Tabla 4-4), cuyas resistencias medias a compresión y tracción son $f_{c m}=43,72 \mathrm{~N} / \mathrm{mm}^{2}$ y $f_{c t m}=3,16$ $\mathrm{N} / \mathrm{mm}^{2}$, respectivamente. Se han ensayado 5 probetas con alambres sanos, mientras que el resto presentaba alambres afectados por distintos niveles de corrosión, alcanzándose pérdidas de sección transversal de hasta un 21,62\%. En la Tabla 5-12 se incluyen los parámetros más relevantes extraídos de las gráficas de tensión de adherencia media-deslizamiento obtenidas en los ensayos. Cabe destacar que, por un fallo en el equipo informático, no se registraron datos durante el ensayo correspondiente a la probeta L10-10-1.

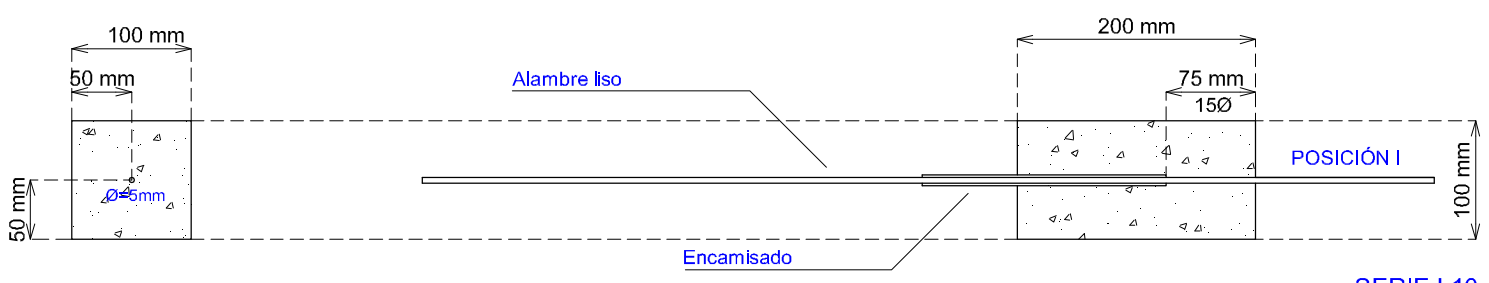

SERIE L10

Figura 5-20 Configuración geométrica de las probetas $L 10$ con alambres lisos y recubrimiento mecánico de $50 \mathrm{~mm}(\mathrm{c} / \phi=10)$

Tabla 5-12 Resumen de resultados de los ensayos sobre la serie de probetas L10

\begin{tabular}{|c|c|c|c|c|c|c|c|c|c|c|}
\hline \multirow[b]{3}{*}{ PROB, } & \multicolumn{10}{|c|}{ Serie [L10] } \\
\hline & \multirow{2}{*}{$\begin{array}{c}\% \\
\text { Corr, } \\
\text { real }\end{array}$} & \multirow{2}{*}{$\begin{array}{l}\mathrm{f}_{\mathrm{cm}}[\mathrm{MPa}] \\
\left(\mathrm{f}_{\mathrm{ct}}[\mathrm{MPa}]\right)\end{array}$} & \multirow{2}{*}{$\begin{array}{l}\tau_{b, \max }^{\text {med }} \\
{[\mathrm{MPa}]}\end{array}$} & \multirow{2}{*}{$\begin{array}{c}\text { Med, } \boldsymbol{\tau}_{b, \text { max }}^{\text {med }} \\
(\mathrm{CoV})\end{array}$} & \multirow[b]{2}{*}{$\tau_{\text {res }}[\mathrm{MPa}]$} & \multicolumn{4}{|c|}{ Deslizamientos [mm] } & \multirow[b]{2}{*}{ Fallo } \\
\hline & & & & & & $s_{\max }$ & $s_{1}$ & $s_{2}$ & $s_{3}$ & \\
\hline L10-0-1 & 0 & \multirow{17}{*}{$\begin{array}{l}43,72 \\
(3,16)\end{array}$} & 3,156 & \multirow{5}{*}{$\begin{array}{c}3,772 \\
(25,71)\end{array}$} & 2,060 & 0,041 & 0,021 & 9,999 & 9,999 & Pull-Out \\
\hline L10-0-2 & 0 & & 3,062 & & 2,896 & 0,076 & 0,008 & 7,843 & 9,999 & Pull-Out \\
\hline L10-0-3 & 0 & & 4,610 & & 3,911 & 1,956 & 0,041 & 4,441 & 8,858 & Pull-Out \\
\hline L10-0-4 & 0 & & 4,850 & & 3,571 & 0,023 & 0,012 & 1,640 & 5,323 & Pull-Out \\
\hline L10-0-5 & 0 & & 2,977 & & 2,030 & 0,020 & 0,008 & 9,999 & 9,999 & Pull-Out \\
\hline L10-2-1 & 1,65 & & 11,004 & \multirow{3}{*}{$\begin{array}{l}10,809 \\
(11,05)\end{array}$} & 5,744 & 1,527 & 1,493 & 4,059 & $10,078^{*}$ & Pull-Out \\
\hline L10-2-2 & 2,00 & & 11,894 & & 6,943 & 0,003 & 0,002 & 4,667 & $9,827^{*}$ & Pull-Out \\
\hline L10-2-3 & 2,49 & & 9,528 & & 8,472 & 5,205 & 0,402 & 7,254 & $9,765^{*}$ & Pull-Out \\
\hline L10-5-1 & 8,27 & & 20,652 & \multirow{3}{*}{$\begin{array}{l}22,171 \\
(23,50)\end{array}$} & 19,630 & 4,841 & 0,079 & 9,231 & $9,231 *$ & Pull-Out \\
\hline L10-5-2 & 7,35 & & 27,972 & & 10,558 & 0,870 & 0,028 & 1,608 & $5,296^{*}$ & Pull-Out \\
\hline L10-5-3 & 3,91 & & 17,888 & & 0 & 0,002 & 0,002 & 0,002 & $0,006^{* *}$ & Frágil \\
\hline L10-10-1 & --- & & --- & \multirow{3}{*}{$\begin{array}{c}25,372 \\
(4,87)\end{array}$} & --- & --- & --- & --- & $* * *$ & Sin datos \\
\hline L10-10-2 & 11,74 & & 26,245 & & 11,461 & 0,049 & 0,016 & 0,175 & $4,294^{*}$ & Pull-Out \\
\hline L10-10-3 & 11,04 & & 24,499 & & 0 & 0,037 & 0,029 & 0,037 & 0,037 & Frágil \\
\hline L10-20-1 & 21,62 & & 22,450 & \multirow{3}{*}{$\begin{array}{c}24,919 \\
(8,97)\end{array}$} & 8,673 & 0,074 & 0,028 & 0,099 & $3,509 *$ & Pull-Out \\
\hline L10-20-2 & 18,81 & & 25,502 & & 0 & 0,030 & 0,008 & 0,031 & 0,869 & Frágil \\
\hline L10-20-3 & 25,45 & & 26,806 & & 0 & 0,012 & 0,012 & 0,014 & 0,213 & Frágil \\
\hline
\end{tabular}


TESIS DOCTORAL INFLUENCLA DE LA CORROSIÓN EN LA ADHERENCLA DE ALAMBRES EN ELEMENTOS PRETENS ADOS DE HORMIGÓN

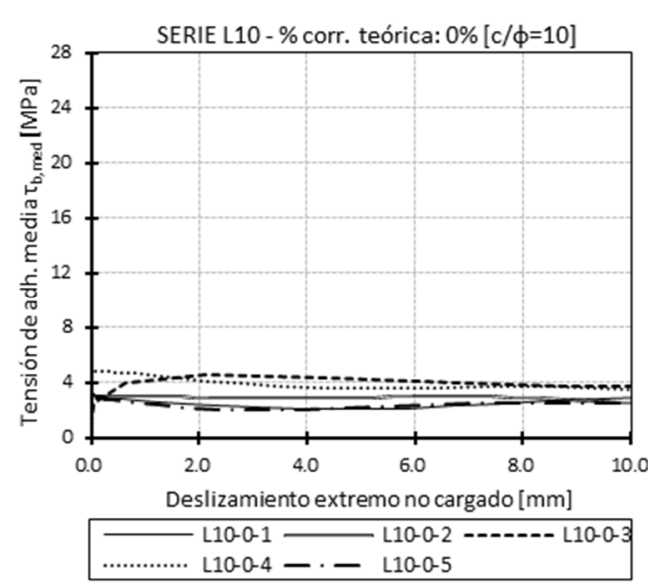

a)

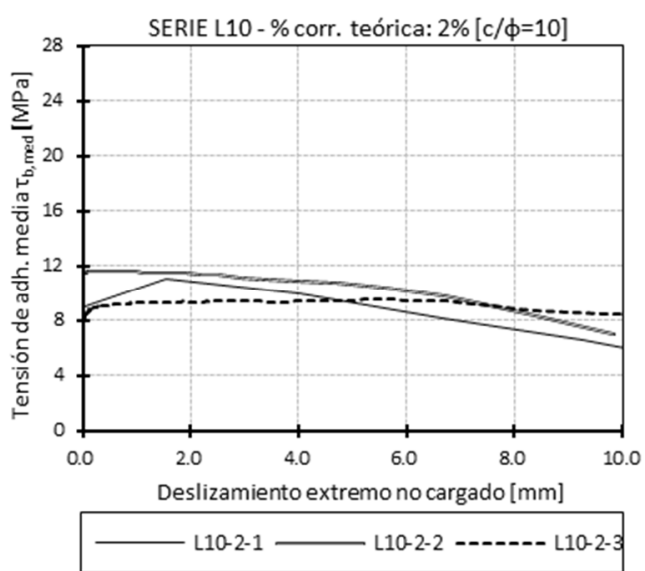

Figura 5-21 Diagramas tensión de adherencia media-deslizamiento en extremo no cargado en probetas de la Serie L10: con alambres lisos, 50 mm de recubrimiento mínimo y distintos grados de corrosión teórica [a) $0 \%$ de pérdida de sección; a) 2\% de pérdida de sección]

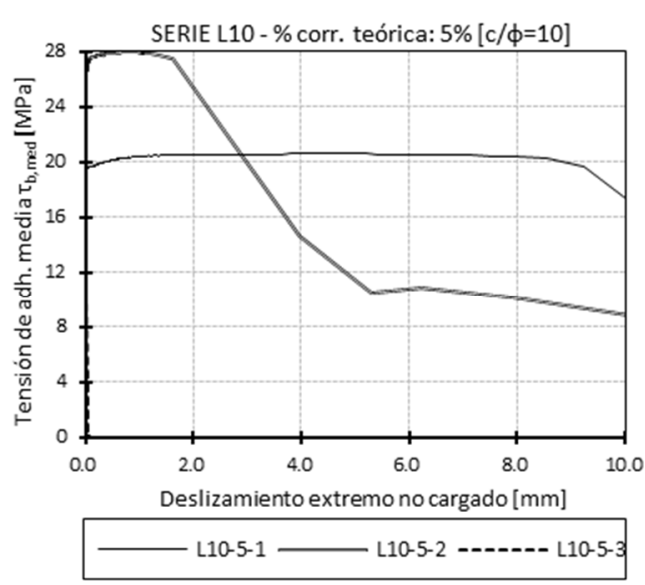

c)

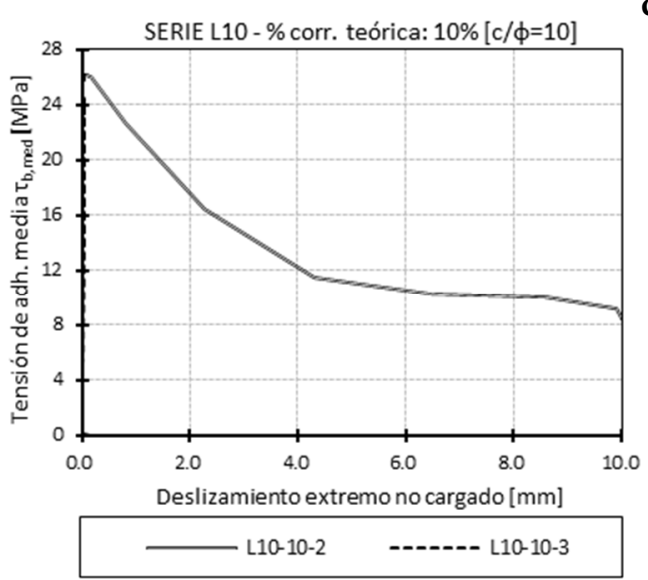

d)

Figura 5-22 Diagramas tensión de adherencia media-deslizamiento en extremo no cargado en probetas de la Serie L10: con alambres lisos, 50 mm de recubrimiento mínimo y distintos grados de corrosión teórica [c) 5\% de pérdida de sección; d) 10\% de pérdida de sección]

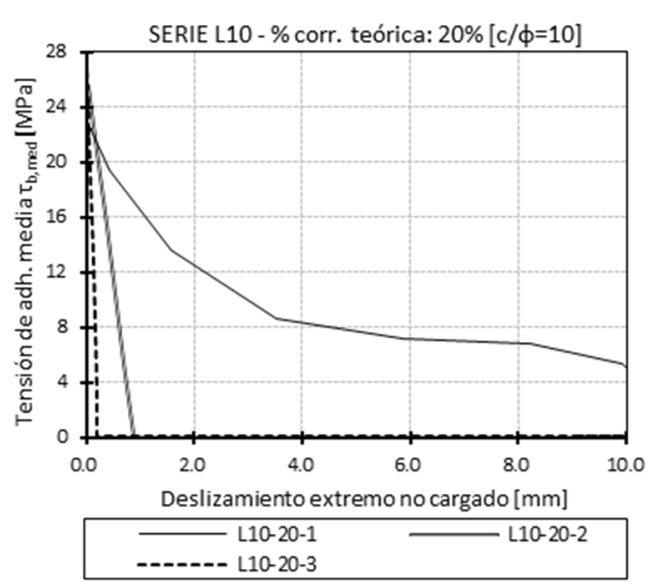

e)

Figura 5-23 Diagramas tensión de adberencia media-deslizamiento en extremo no cargado en probetas de la Serie L10: con alambres lisos, 50 mm de recubrimiento mínimo y $20 \%$ de pérdida de sección teórica 
Las Figura 5-21, Figura 5-22 y Figura 5-23 muestran los diagramas tensión de adherencia media $\tau_{b}$ [MPa] Deslizamiento en el extremo no cargado $[\mathrm{mm}]$, agrupados en función de los distintos grados de corrosión teórica [a) $0 \%$; b) 2\%; c) 5\%; d) $10 \%$ y e) $20 \%$ ], obtenidos en los ensayos de pull-out sobre la serie de probetas L10.

\subsection{Serie L20: Alambres lisos - Recubrimiento/diámetro $\mathrm{c} / \phi=20$}

La serie de ensayos L20 está compuesta por un total de 17 probetas prismáticas, de 200x200x200 $\mathrm{mm}$, con el alambre liso situado en el centro de la sección, de manera que el recubrimiento mecánico mínimo resultante es de $100 \mathrm{~mm}$ (Figura 5-24) y la relación recubrimiento/diámetro es igual a 20. Por su parte, la longitud adherente del alambre es de $75 \mathrm{~mm}(\approx 15 \phi)$. Para cada nivel de corrosión teórica $(0,2,5$ y $10 \%$ de pérdida de sección) se han utilizado dos hormigones distintos, cuyas resistencias medias a compresión han sido $f_{c m}=67,72 \mathrm{~N} / \mathrm{mm}^{2}$ (Hormigón 1) y $f_{c m}=51,98 \mathrm{~N} / \mathrm{mm}^{2}$ (Hormigón 2). Como ya se indicó en el capítulo anterior, al primero de ellos no se le incluyeron iones cloruros durante el hormigonado, por lo que se difundieron posteriormente, una vez fabricadas las probetas, con el método integral detallado en el Capitulo 4. El objetivo de esta diferencia metodológica era determinar cómo influía la inclusión o no de cloruros en la masa de hormigón para el desarrollo de la corrosión, dado que en los ensayos sobre vigas pretensadas que se realizarían posteriormente, los cloruros habría que difundirlos tras la fabricación, permitiendo delimitar perfectamente el efecto sobre la deformación de la viga atribuible exclusivamente al pretensado, por un lado, y a la corrosión, por otro. En cuanto a los niveles de corrosión alcanzados en esta serie, se han medido pérdidas reales de sección transversal de hasta un 13,14\%. En la Tabla 5-13 se incluyen los parámetros más relevantes extraídos de las gráficas de tensión de adherencia media-deslizamiento obtenidas en los ensayos.

Tabla 5-13 Resumen de resultados de los ensayos sobre la serie de probetas L2O

\begin{tabular}{|c|c|c|c|c|c|c|c|c|c|c|}
\hline \multirow{3}{*}{ PROB, } & \multicolumn{9}{|c|}{ Serie [L20] } & \multirow{3}{*}{ Fallo } \\
\hline & \multirow{2}{*}{$\begin{array}{c}\% \\
\text { Corr, } \\
\text { real }\end{array}$} & \multirow{2}{*}{$\begin{array}{l}\mathrm{f}_{\mathrm{cm}}[\mathrm{MPa}] \\
\left(\mathrm{f}_{\mathrm{ct}}[\mathrm{MPa}]\right)\end{array}$} & \multirow{2}{*}{$\begin{array}{l}\tau_{b, \max }^{\text {med }} \\
{[\mathrm{MPa}]}\end{array}$} & \multirow{2}{*}{$\begin{array}{c}\text { Med, } \tau_{b, \max }^{\text {med }} \\
(\mathrm{CoV})\end{array}$} & \multirow{2}{*}{$\tau_{\text {res }}[\mathrm{MPa}]$} & \multicolumn{4}{|c|}{ Deslizamientos [mm] } & \\
\hline & & & & & & $s_{\max }$ & $s_{1}$ & $s_{2}$ & $s_{3}$ & \\
\hline L20-0-1a & 0 & \multirow{3}{*}{67,10} & 3,811 & \multirow{3}{*}{$\begin{array}{c}3,399 \\
(10,55)\end{array}$} & 3,811 & 7,478 & 0,025 & 7,478 & $7,478^{*}$ & Pull-Out \\
\hline L20-0-2a & 0 & & 3,151 & & 3,081 & 1,117 & 0,003 & 11,40 & $11,402^{*}$ & Pull-Out \\
\hline L20-0-3a & 0 & & 3,237 & & 3,237 & 11,24 & 0,015 & 11,24 & $11,241^{*}$ & Pull-Out \\
\hline L20-0-1b & 0 & \multirow{2}{*}{51,98} & 2,203 & \multirow{2}{*}{$\begin{array}{c}2,704 \\
(26,22)\end{array}$} & 2,372 & 0,249 & 0,061 & 9,507 & $9,507^{*}$ & Pull-Out \\
\hline L20-0-2b & 0 & & 3,206 & & 2,676 & 0,015 & 0,007 & 2,691 & $8,039 *$ & Pull-out \\
\hline L20-2-1a & 2 & \multirow{2}{*}{67,10} & 13,134 & \multirow{2}{*}{$\begin{array}{c}12,574 \\
(6,30)\end{array}$} & 0 & 1,056 & 0,289 & 1,173 & 1,418 & Frágil \\
\hline L20-2-2a & 2 & & 12,013 & & 6,856 & 0,054 & 0,022 & 2,675 & $5,287^{*}$ & Pull-Out \\
\hline L20-2-1b & 1,57 & \multirow{2}{*}{51,98} & 9,711 & \multirow{2}{*}{$\begin{array}{l}\mathbf{1 1 , 2 7 2} \\
(19,58)\end{array}$} & 4,867 & 0,037 & 0,005 & 0,278 & $10,044^{*}$ & Pull-Out \\
\hline L20-2-2b & 2,13 & & 12,833 & & 6,607 & 0,036 & 0,011 & 0,118 & $9,690 *$ & Pull-Out \\
\hline L20-5-1a & 5 & \multirow{2}{*}{67,10} & 16,855 & \multirow{2}{*}{$\begin{array}{c}\mathbf{1 5 , 9 6 1} \\
(7,93)\end{array}$} & 0 & 1,163 & 0,052 & 2,094 & 5,153 & Frágil \\
\hline L20-5-2a & 5 & & 15,066 & & 10,362 & 7,856 & 4,850 & 8,889 & $9,883^{*}$ & Pull-Out \\
\hline L20-5-1b & 5 & \multirow{2}{*}{51,98} & 14,157 & \multirow{2}{*}{$\begin{array}{c}\mathbf{1 3 , 2 6 2} \\
(9,54)\end{array}$} & 12,094 & 8,947 & 7,562 & 9,751 & $10,442 *$ & Pull-Out \\
\hline L20-5-2b & 6,83 & & 12,367 & & 6,268 & 0,138 & 0,095 & 0,371 & $10,227^{*}$ & Pull-Out \\
\hline L20-10-1a & 10 & \multirow{2}{*}{67,10} & 23,716 & \multirow{2}{*}{$\begin{array}{l}21,168 \\
(17,02)\end{array}$} & 0 & 0,380 & 0,040 & 1,046 & 1,993 & Frágil \\
\hline L20-10-2a & 10 & & 18,619 & & 0 & 4,357 & 0,957 & 5,757 & 6,850 & Frágil \\
\hline L20-10-1b & 10 & \multirow{2}{*}{51,98} & 8,949 & \multirow{2}{*}{$\begin{array}{l}13,398 \\
(46,96)\end{array}$} & 7,716 & 6,297 & 4,047 & 7,913 & $9,769 *$ & Pull-Out \\
\hline L20-10-2b & 13,14 & & 17,847 & & 7,119 & 0,173 & 0,082 & 0,178 & $0,527^{*}$ & Pull-Out \\
\hline
\end{tabular}


TESIS DOCTORAL INFLUENCLA DE LA CORROSIÓN EN LA ADHERENCLA DE ALAMBRES EN ELEMENTOS PRETENSADOS DE HORMIGÓN

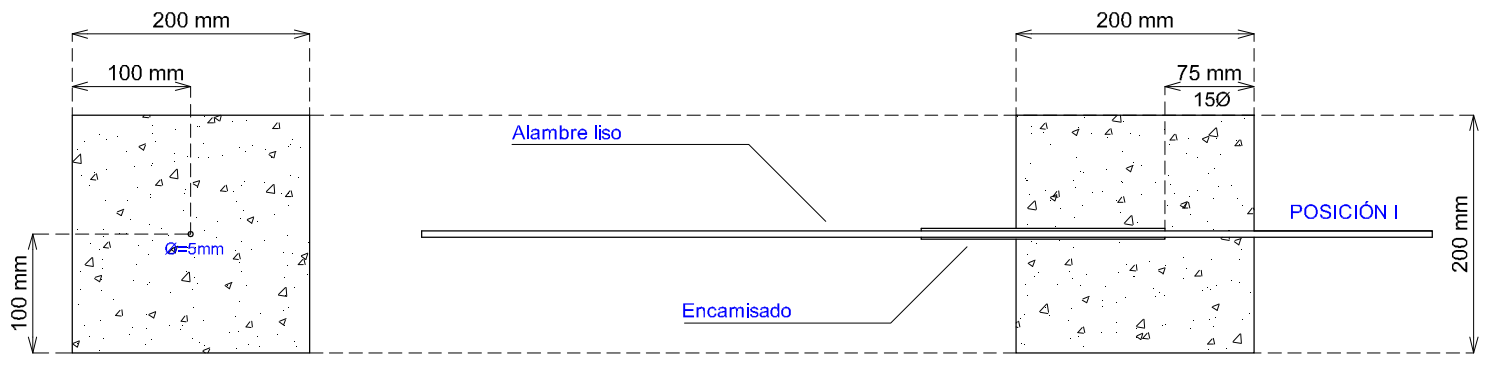

SERIE L20

Figura 5-24 Configuración geométrica de las probetas L20 con alambres lisos y recubrimiento mecánico de $100 \mathrm{~mm}(\mathrm{c} / \phi=20)$

Las Figura 5-25 y Figura 5-26 muestran los diagramas tensión de adherencia media $\tau_{b}$ [MPa] - Deslizamiento en el extremo no cargado [mm], agrupados en función de los distintos grados de corrosión teórica [a) $0 \%$; b) $2 \%$; c) $5 \%$ y d) $10 \%$, obtenidos en los ensayos de pull-out sobre la serie de probetas L20.

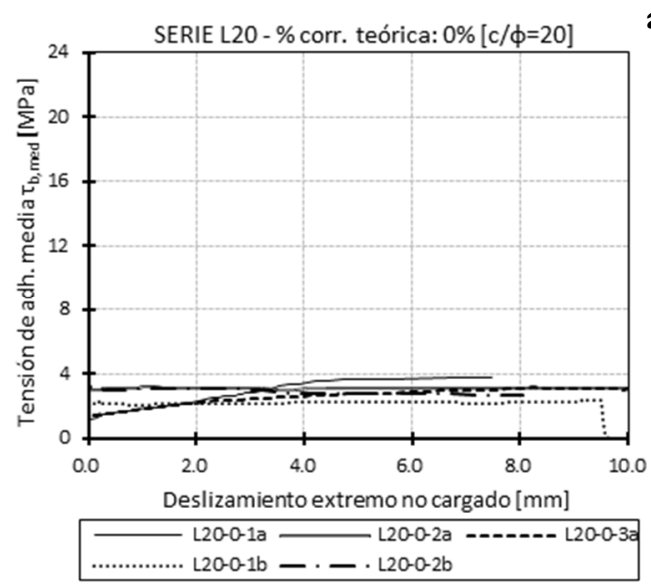

a)

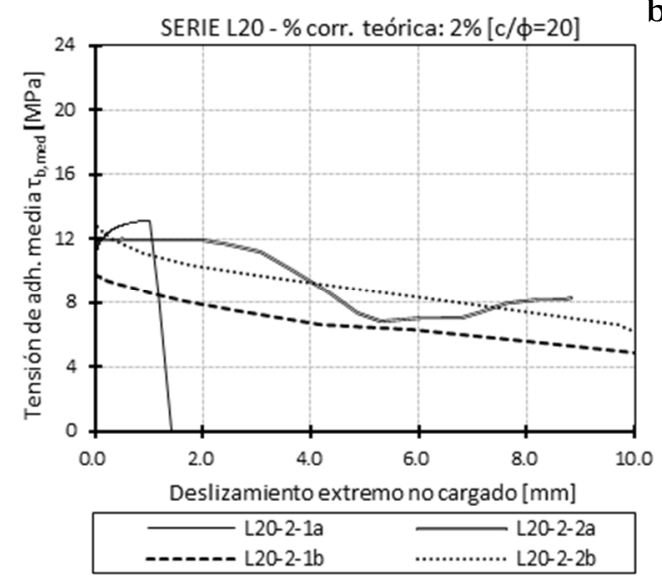

b)

Figura 5-25 Diagramas tensión de adherencia media-deslizamiento en extremo no cargado en probetas de la Serie L20: con alambres lisos, $100 \mathrm{~mm}$ de recubrimiento mínimo, distintos grados de corrosión teórica [a) 0\% de pérdida de sección; a) 2\% de pérdida de sección] y distintas resistencias medias a compresión (Sufijo -a: 67,10 MPa; Sufijo -b: 51,98 MPa)

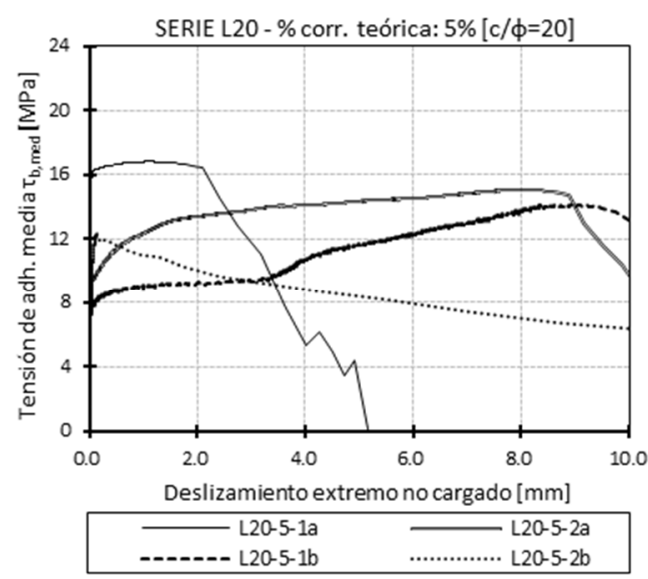

c)

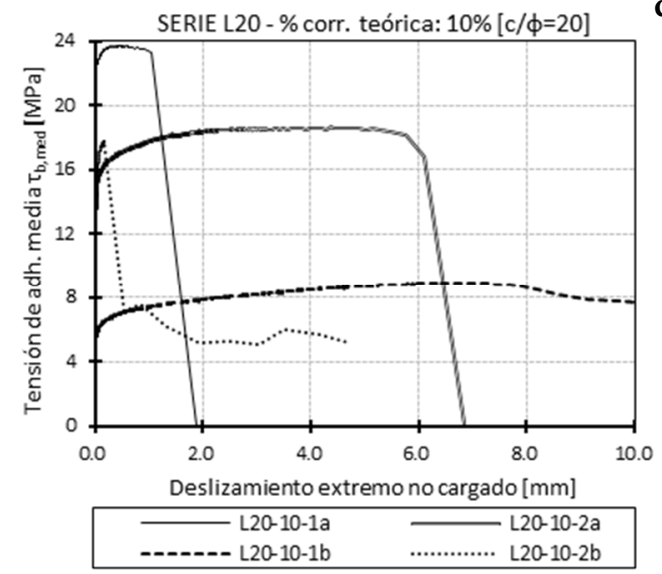

Figura 5-26 Diagramas tensión de adherencia media-deslizamiento en extremo no cargado en probetas de la Serie L20: con alambres lisos, $100 \mathrm{~mm}$ de recubrimiento mínimo, distintos grados de corrosión teórica [a) 5\% de pérdida de sección; a) 10\% de pérdida de sección] y distintas resistencias medias a compresión (Sufijo -a: 67,10 MPa; Sufijo -b: 51,98 MPa) 


\subsection{Discusión de los resultados de los ensayos de pull-out}

En este apartado se discuten los resultados experimentales de los ensayos de pull-out expuestos en el aparatado anterior (Apartado 5.3). Para ello, se utilizan dos elementos de análisis fundamentales: la variación de la tensión máxima de adherencia $\tau_{b, \max }$, que aporta información sobre la capacidad adherente del sistema acero/hormigón, y la variación de los parámetros que configuran las leyes de tensión de adherencia media-deslizamiento $\tau_{b, \text { med }}-s$ que, entre otros aspectos, describen el comportamiento frágil o dúctil del sistema durante el fallo. Hay que señalar que la discusión de los resultados de este capítulo se complementa con el contenido del siguiente capítulo (Capitulo G), en el que tras la calibración del modelo desarrollado en el Capitulo 3, se comparan los resultados analíticos y experimentales. Tal y como se verá posteriormente, el modelo no sólo permite predecir el comportamiento adherente de alambres sanos y corroídos, sino que además es una potente herramienta de análisis que permite una mejor comprensión de los mecanismos que intervienen en el fenómeno de la adherencia.

\subsubsection{Tensión de adherencia máxima $\tau_{b, \max }$}

En las tablas del Apartado 5.3 se han recopilado las tensiones de adherencia máximas $\tau_{b, m a x}$ registradas en los ensayos, calculadas según (Eq. 5-8). En los siguientes sub-apartados se discute la influencia del grado de corrosión, de la capacidad de confinamiento del recubrimiento (derivada de la resistencia del hormigón y de su espesor) y del acabado superficial del alambre, en la máxima capacidad adherente del sistema acero/hormigón. Salvo en el apartado relativo al estudio de la influencia de la resistencia del hormigón, la máxima tensión de adherencia se ha normalizado entre la resistencia media a tracción del hormigón $f_{\text {ctm }}$. Esta decisión se ha adoptado con la intención de limitar la influencia de esta última variable y permitir un análisis más preciso del resto de parámetros contemplados (acabado superficial del alambre, recubrimiento de hormigón y nivel de corrosión).

\subsubsection{Influencia de la corrosión}

Tal y como afirma el Bulletin 10 del CEB-FIB "Bond of reinforcement in concrete" (CEB-FIB (Task Group 2.5), 2000), el incremento del diámetro de la barra corroída provoca un aumento de la tension radial $\sigma_{r}$ entre la barra y el hormigón circundante y, por tanto, un incremento de la componente de fricción de la adherencia. Sin embargo, la presión ejercida por los productos de corrosión también supone un aumento de la tensión circunferencial $\sigma_{r}$ en el anillo de tracciones del hormigón que rodea el alambre. Cuando estas tracciones superan un determinado umbral (generalmente se considera que es la resistencia a tracción) comienza el desarrollo de la fisuración longitudinal (radial, en términos de sección transversal) que trae consigo una disminución de la resistencia del recubrimiento a las fuerzas de ruptura generadas por el fenómeno de la adherencia.

En la Figura 5-27 se incluye la evolución de las tensiones máximas de adherencia normalizadas $\tau_{b, \max } / f_{c t m}$ con el aumento de la corrosión (expresada en términos de pérdida de sección transversal), extraídas de los resultados experimentales sobre las probetas de las series I4, I10, L4 y L10, alambres lisos e indentados con relaciones recubrimiento/diámetro iguales $(c / \phi)$ a 4 y 10 . Las series con $c / \phi$ igual a 20 (I20 y L20), al ser menos completas, se reservan para los apartados relativos a la influencia 
del espesor de recubrimiento y de la resistencia a compresión. Los resultados mostrados en Figura 5-27 han sido ajustados mediante una regresión lineal por el método de los mínimos cuadrados, dividiendo cada serie de ensayos en los dos tramos lineales que mejor se ajustan a las tendencias generales observadas en la evolución de las tensiones de adherencia normalizadas con el aumento de la corrosión. La intersección entre los dos tramos lineales de ajuste de cada serie de ensayos configura un punto de inflexión (o pico), en el que se alcanza el máximo valor de la tensión de adherencia y que describe el nivel de pérdida de sección por corrosión a partir del cual la capacidad adherente comienza a descender. En la Tabla 5-14 se incluyen los resultados más relevantes extraídos de la Figura 5-27: tensión de adherencia normalizada para alambres sanos $\tau_{b, 0} / f_{\text {ctm }}[\mathrm{MPa} / \mathrm{MPa}]$, valor de la tensión de adherencia normalizada en el pico o punto de inflexión $\tau_{\text {, max }} / f_{\text {ctm }}[\mathrm{MPa} / \mathrm{MPa}]$, pérdida de sección [\%] y penetración de ataque por corrosión $P_{x}[\mu \mathrm{m}]$ en el punto de inflexión, y pendiente de la rama postpico.

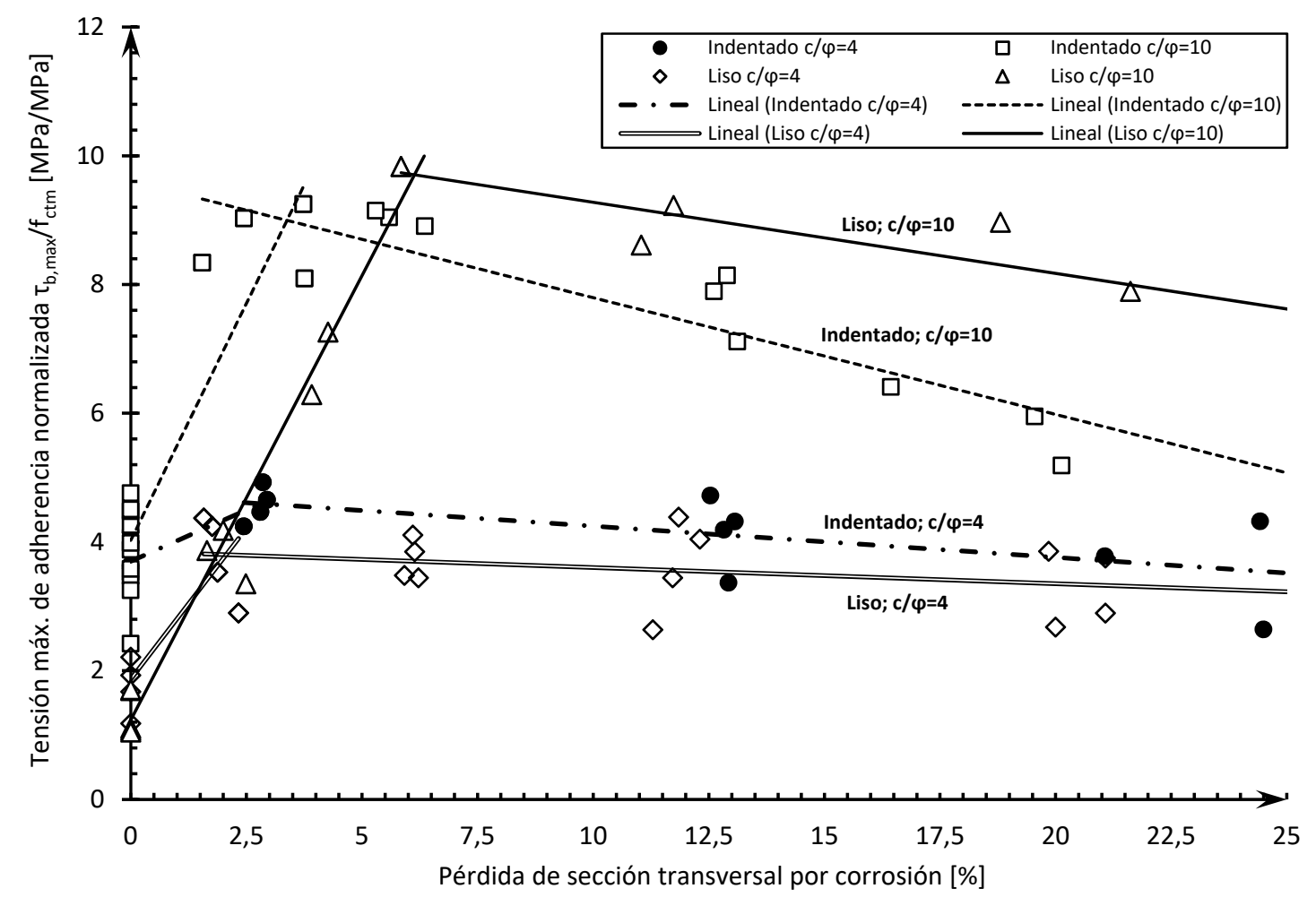

Figura 5-27 Comparativa de las tensiones máximas de adherencia normalizada para distintos niveles de corrosión obtenidas de las series de ensayos I4, I10, L4 y L10.

Como era esperable, las primeras etapas del proceso de corrosión están marcadas por un significativo aumento de la capacidad adherente. En el caso de las probetas con relación recubrimiento/diámetro igual a 4, el punto de inflexión de la gráfica para los alambres indentados (Serie I4) tiene lugar para una porcentaje de pérdida de sección transversal del 2,87\%, equivalente a una penetración de ataque uniforme por corrosión de $P_{x}=36,24 \mu \mathrm{m}$, y alcanzan una tensión máxima de adherencia normalizada $\tau_{b, \text { max }} / f_{\text {ctm }}$ igual a 4,61 MPa/MPa (la tensión máxima de adherencia en términos absolutos es igual a $\left.\tau_{b, \max }=17,16 \mathrm{MPa}\right)$. Por su parte, en la Serie L4, la tensión máxima normalizada alcanza un valor de 
$3,80 \mathrm{MPa} / \mathrm{MPa}\left(\tau_{b, \max }=12,97 \mathrm{MPa}\right)$ para una penetración de ataque $P_{x}=25,90 \mu \mathrm{m}$ (equivalente a un $2,06 \%$ de pérdida de sección transversal). En cuanto a las probetas con relación $c / \phi=10$, la tensión máxima de adherencia normalizada en alambres indentados (Serie I10) es $\tau_{b, \max } / f_{\mathrm{ctm}}=9,00 \mathrm{MPa} / \mathrm{MPa}$, $\left(\tau_{b, \max }=28,50 \mathrm{MPa}\right)$ y se alcanza para una pérdida de sección del 3,38\% (equivalente a $P_{x}=42,57 \mu \mathrm{m}$ ). En la Serie L10, el punto de inflexión de la gráfica se alcanza para una pérdida de sección del 6,18\% (equivalente a profundidad de ataque uniforme $P_{x}$ de $78,43 \mu \mathrm{m}$ ) y para un valor de tensión máxima normalizada $\tau_{b, \text { max }} / f_{\text {ctm }}=9,70 \mathrm{MPa} / \mathrm{MPa}\left(\tau_{b, \text { max }}=27,59 \mathrm{MPa}\right)$. La tensión máxima de adherencia está estrechamente vinculada con la capacidad de confinamiento del recubrimiento por lo que es razonable que, para espesores similares, independientemente del acabado superficial del acero y suponiendo que el incremento de volumen de los productos de corrosión logra movilizar la totalidad de la acción confinante del hormigón, se alcancen capacidades adherentes similares. Por otro lado, sería esperable que los alambres indentados alcanzasen la tensión máxima de adherencia para niveles de corrosión ligeramente más bajos, ya que al aumento de volumen de los óxidos habría que añadir el efecto del desplazamiento de la pared interna del cilindro de hormigón ocasionado por el deslizamiento de las indentaciones. Los resultados obtenidos en los ensayos muestran claramente este fenómeno en las probetas con relación $c / \phi=10$, mientras que para la relación recubrimiento/diámetro menor $(c / \phi=4)$ son las probetas con alambres lisos las que alcanzan el máximo para niveles ligeramente inferiores de corrosión.

Tabla 5-14 Datos relevantes en la evolución de la tensión de adberencia $\tau_{b}$ con el aumento de la corrosión

\begin{tabular}{|c|c|c|c|c|c|c|c|c|}
\hline Serie & $\begin{array}{c}\text { Acabado } \\
\text { superficial }\end{array}$ & $\mathrm{c} / \phi$ & $\begin{array}{c}\tau_{\mathrm{b}, 0} / \mathrm{f}_{\mathrm{ctm}} \\
{[\mathrm{MPa} / \mathrm{MPa}]}\end{array}$ & $\begin{array}{c}\tau_{\mathrm{b}, \max } / \mathrm{f}_{\mathrm{ctm}} \\
{[\mathrm{MPa} / \mathrm{MPa}]}\end{array}$ & $\begin{array}{c}\Delta_{\text {total }} \tau_{\mathbf{b}} \\
{[\%]}\end{array}$ & $\begin{array}{c}\% \text { Corr } \\
\tau_{\text {b,max }} / f_{\text {ctm }} \\
\end{array}$ & $\mathbf{P}_{\mathrm{x}}[\boldsymbol{\mu m}]$ & $\begin{array}{l}\text { Pendiente } \\
\text { Post-pico }\end{array}$ \\
\hline I4 & Indentado & 4 & 3,70 & 4,60 & 24 & 2,81 & 35,39 & $-0,0486$ \\
\hline L4 & Liso & 4 & 1,87 & 3,80 & 103 & 2,06 & 25,90 & $-0,0251$ \\
\hline $\mathrm{I} 10$ & Indentado & 10 & 4,03 & 9,00 & 123 & 3,38 & 42,47 & $-0,1813$ \\
\hline L10 & Liso & 10 & 1,24 & 9,70 & 684 & 6,18 & 78,43 & $-0,1105$ \\
\hline
\end{tabular}

Las tensiones máximas de adherencia normalizada $\tau_{b, \max } / f_{\text {ctm }}$, en el caso de alambres sanos (porcentaje de pérdida de sección nulo), son razonablemente similares entre aquellos con un mismo acabado superficial, independientemente del recubrimiento. Por el contrario, en los alambres indentados la tensión de adherencia es significativamente superior a la arrojada por los alambres lisos. Así, la media de la tensión máxima de adherencia normalizada en los alambres indentados alcanza un valor de $\tau_{b, \max } / f_{\text {ctm }}=3,70 \mathrm{MPa} / \mathrm{MPa}\left(\tau_{b, \max }=13,76 \mathrm{MPa}\right)$ en la Serie I4 y de $\tau_{b, \max } / f_{\text {ctm }}=4,03 \mathrm{MPa} / \mathrm{MPa}$ $\left(\tau_{b, \max }=12,76 \mathrm{MPa}\right)$ en la Serie I10, mientras que en los alambres lisos los valores son 1,87 y 1,24 $\mathrm{MPa} / \mathrm{MPa}\left(\tau_{b, \text { max }}=6,38 \mathrm{MPa}\right.$ y $\left.\tau_{b, \text { max }}=3,52 \mathrm{MPa}\right)$, en las Series L4 y L10 respectivamente. En ausencia de corrosión, el acero desliza antes de movilizar la totalidad de la capacidad de confinamiento del recubrimiento, por lo que no genera tensiones radiales significativas y el espesor de este pasa a tener un papel relativamente secundario, de ahí que las tensiones de adherencia sean similares para cada tipo de acabado superficial del alambre, independientemente del recubrimiento. Por otro lado, en las Series I4 e I10, el deslizamiento de las indentaciones durante el ensayo de arrancamiento desplaza la pared interna del cilindro de hormigón circundante, originando tensiones radiales de compresión que justifican las significativas diferencias existentes con los alambres de acabado liso.

Si se comparan los valores de tensión de adherencia normalizada sin corrosión con los máximos valores alcanzados en el punto de inflexión, el incremento en la capacidad adherente puede 
cuantificarse en un $24 \%$ en la Serie I4, en un $103 \%$ en la serie L4, en un $123 \%$ en la serie I10, y en un sorprendente $684 \%$ en la serie L10. Por tanto, el aumento de capacidad adherente es apreciablemente superior en las series de ensayos sobre alambres lisos que en sus series homólogas sobre alambres indentados. Como se ha expuesto anteriormente, la tensión de adherencia inicial es mayor en el caso de alambres indentados y, sin embargo, la tensión máxima de adherencia alcanzada es similar para cada espesor de recubrimiento, independientemente del acabado superficial del alambre. Por consiguiente, el margen hasta alcanzar el agotamiento de la capacidad de confinamiento del hormigón es mayor en el caso de alambres lisos. Por extensión, esta observación permite entender las diferencias existentes entre el comportamiento adherente en alambres lisos e indentados (con indentaciones de pequeña magnitud), objeto de esta tesis, y las armaduras corrugadas, sometidos ambos a procesos de corrosión. Para recubrimientos habituales y en ausencia de corrosión, el desplazamiento de la pared interna del cilindro de hormigón que provocan las corrugas en su deslizamiento, lleva al agotamiento de la capacidad de confinamiento del recubrimiento. Por tanto, el avance de la corrosión no conllevará una mejora de las prestaciones adherentes de las armaduras, o ésta será poco significativa para valores pequeños de penetración de ataque. Por el contrario, el deterioro de la interfaz acero-hormigón debido a la microfisuración del recubrimiento y la reducción de la altura de corruga traerá consigo un rápido deterioro de la capacidad adherente, tal y como ha sido apuntado por numerosos autores.

En cuanto al comportamiento residual post-pico, una vez superada la tensión máxima de adherencia, con el aumento de los niveles de corrosión, la capacidad adherente en todas las series disminuye lentamente y manera continua, siendo más acusado el descenso en el caso de las probetas con mayor espesor de recubrimiento ( $/ \phi=10$; Series $\mathrm{I} 10$ y L10) pero sin grandes diferencias de comportamiento entre los distintos acabados superficiales del acero. Las pendientes de la recta de regresión del tramo de adherencia post-pico son $\mathrm{m}=-0,049 \mathrm{y} \mathrm{m}=-0,025$, para las series I4 y L4, respectivamente, y $\mathrm{m}=-$ $0,235 \mathrm{y} \mathrm{m}=-0,111$, para las series I10 y L10. La altura de las indentaciones en los alambres utilizados fue como mínimo de $60 \mu \mathrm{m}$, tal y como se ha recogido en el Capitulo 4. Utilizando la ley de Faraday, el porcentaje de pérdida de sección transversal necesario para que la penetración de ataque uniforme $P_{x}$ alcance dicho valor es de un 4,75\%. Como se ha visto anteriormente, el pico de tensión máxima de adherencia se alcanza en un rango que oscila entre un 2 y un $6 \%$ de pérdida de sección, según las condiciones del ensayo, por lo que el comportamiento residual para niveles de corrosión altos apenas se ve influenciado por el perfil del acero.

Debe entenderse que los datos recopilados en la Tabla 5-14 son aproximados, fruto de la manipulación de las regresiones lineales por mínimos cuadrados que mejor se ajustan a las dos tendencias predominantes en las gráficas (comportamiento pre-pico y post-pico), y extraídas de una campaña experimental que, a pesar de ser completa y extensa, podría calificarse como modesta, por lo que los resultados deben tomarse con cautela. Pero sin lugar a duda, lo que sí que permiten es apreciar las tendencias más relevantes que rigen el comportamiento adherente de alambres con diferentes acabados superficiales y distintas relaciones $c / \phi$, sometidos a procesos de ataque por corrosión. Estas tendencias han sido recogidas en la Figura 5-28, y se pueden ser resumidas en los siguientes puntos:

- Para alambres lisos e indentados sanos, o con niveles de corrosión muy bajos $(\approx<1 \%)$, el parámetro controlante de la capacidad adherente alcanzada es el acabado superficial del acero, con cierta independencia del recubrimiento, puesto que la capacidad de confinamiento 
no llega a movilizarse por completo y el fallo se produce por deslizamiento. El comportamiento de las barras corrugadas difiere en este aspecto, ya que como se apuntó anteriormente, la mayor altura de corrugas permite movilizar la totalidad de la acción confinante del hormigón.

- Con el paulatino aumento de la corrosión, y la consiguiente aparición de tensiones radiales de importancia, el parámetro controlante pasa a ser la relación recubrimiento/diámetro, observándose tensiones de adherencia significativamente superiores en las probetas con mayor relación $c / \phi$, independientemente del acabado superficial del acero.

- La mayor capacidad de adherente se alcanza para valores de pérdida de sección de un 2-3\% en las probetas con relación $c / \phi=4$, y de un $5-6 \%$ en las probetas con relación $c / \phi=10$. Como se ha indicado anteriormente, sería esperable que las probetas con aceros indentados alcanzasen la tensión máxima de adherencia para valores de pérdida de sección inferiores, al superponerse el efecto de la corrosión con el de las indentaciones. Este fenómeno sólo ha sido verificado en las probetas con mayor relación recubrimiento/diámetro $(c / \phi=4)$.

- Una vez superada la tensión máxima de adherencia, el aumento de los niveles de corrosión conlleva, en todos los casos contemplados, un descenso lento y continuado de la capacidad adherente. Esta disminución es más acusada en el caso de las probetas con mayor espesor de recubrimiento, pero no se observan grandes diferencias de comportamiento entre los distintos acabados superficiales del acero.

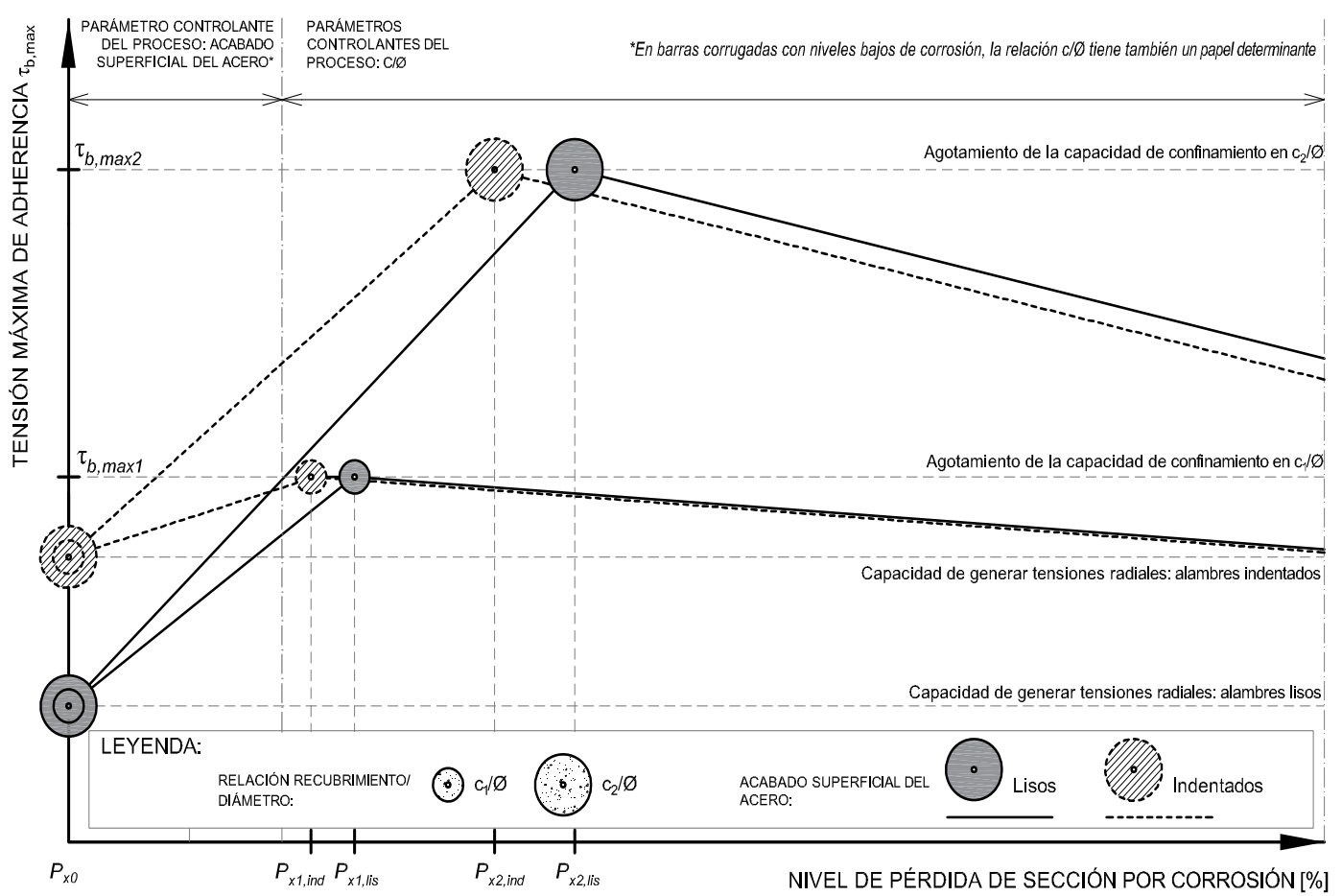

Figura 5-28 Esquema de la evolución de las tensiones máximas de adherencia con el aumento de la corrosión, para distintas relaciones $c / \phi y$ distintos acabados superficiales del acero (liso e indentado) 


\subsubsection{Influencia de la capacidad de confinamiento del hormigón}

Como se apuntaba al comienzo de este capítulo, y en línea con lo expuesto en la revisión bibliográfica del Capitulo 2, un factor fundamental en el fenómeno de la adherencia es la capacidad de confinamiento del recubrimiento de hormigón, que depende tanto de parámetros geométricos (espesor de recubrimiento, excentricidad del alambre, etc) como de parámetros mecánicos (resistencias a compresión y tracción del hormigón, módulo de elasticidad, cuantía de armadura transversal, etc). Este apartado se centra en la influencia del espesor de recubrimiento y de la resistencia del hormigón.

\subsection{Propiedades geométricas del hormigón: Espesor de recubrimiento}

Tal y como se ha discutido en el apartado anterior, el aumento de variable relativa al espesor del recubrimiento apenas tiene influencia en el comportamiento adherente de alambres sanos o con niveles de corrosión muy bajos $(\approx<1 \%)$, tanto lisos como indentados. Como se ha justificado, a pesar de que dicho incremento mejora la capacidad de confinamiento, la capacidad para movilizar dicha acción no se altera y es altamente improbable el fallo por fisuración del recubrimiento (splitting), haciendo que cualquier mejora en ese aspecto sea despreciable. En estas situaciones, el parámetro controlante del comportamiento adherente es el acabado superficial del acero, con cierta independencia del recubrimiento. Por el contrario, el paulatino aumento de la corrosión, y la consiguiente aparición de tensiones radiales y circunferenciales de importancia, hace que el parámetro controlante pase a ser la relación recubrimiento/diámetro, obteniéndose tensiones de adherencia significativamente superiores en las probetas con mayor relación $c / \phi$ y pasando el acabado superficial del alambre a un papel secundario. Estas conclusiones son coherentes con la revisión bibliográfica llevada a cabo en el Capitulo 2 "Estado del conocimiento" (Fang, et al., 2004) (Cairns, et al., 2006) (Lundgren, 2007).

Con el objetivo de caracterizar la influencia del recubrimiento en el fenómeno de la adherencia, en esta tesis se han llevado a cabo ensayos sobre probetas con tres espesores de recubrimiento distintos: $20 \mathrm{~mm}(c / \phi=4), 50 \mathrm{~mm}(c / \phi=10)$ y $100 \mathrm{~mm}(c / \phi=20)$. A continuación, se analiza cómo influye dicho espesor, tanto en alambres lisos como indentados, en función del nivel de deterioro por corrosión experimentado por los mismos:

\section{- Alambres sanos (0\% de pérdida de sección):}

En la Figura 5-29 se representan las tensiones máximas de adherencia, con y sin normalizar, $\tau_{b, \text { max }} / f_{\text {ctm }}$ $[\mathrm{MPa} / \mathrm{MPa}]$ (izquierda) y $\tau_{\text {, max }}[\mathrm{MPa}]($ derecha), en alambres lisos e indentados sin corroer, para los distintos recubrimientos contemplados en la campaña experimental. Los resultados han sido ajustados con regresiones lineales. Si se admite que la capacidad de confinamiento del recubrimiento no tiene una influencia directa sobre la capacidad adherente en alambres lisos e indentados sin corrosión, puede carecer de sentido el hecho de normalizar la tensión máxima de adherencia $\tau_{b \text {,max }}$ mediante la resistencia a tracción del hormigón $f_{c t m}$, de ahí que se haya optado por representar la evolución de las tensión de adherencia en ambos casos, normalizada y en valor absoluto. En la 
Tabla 5-15 se incluyen los valores medios, las desviaciones estándar y los coeficientes de variación (CoV) de dichas tensiones.
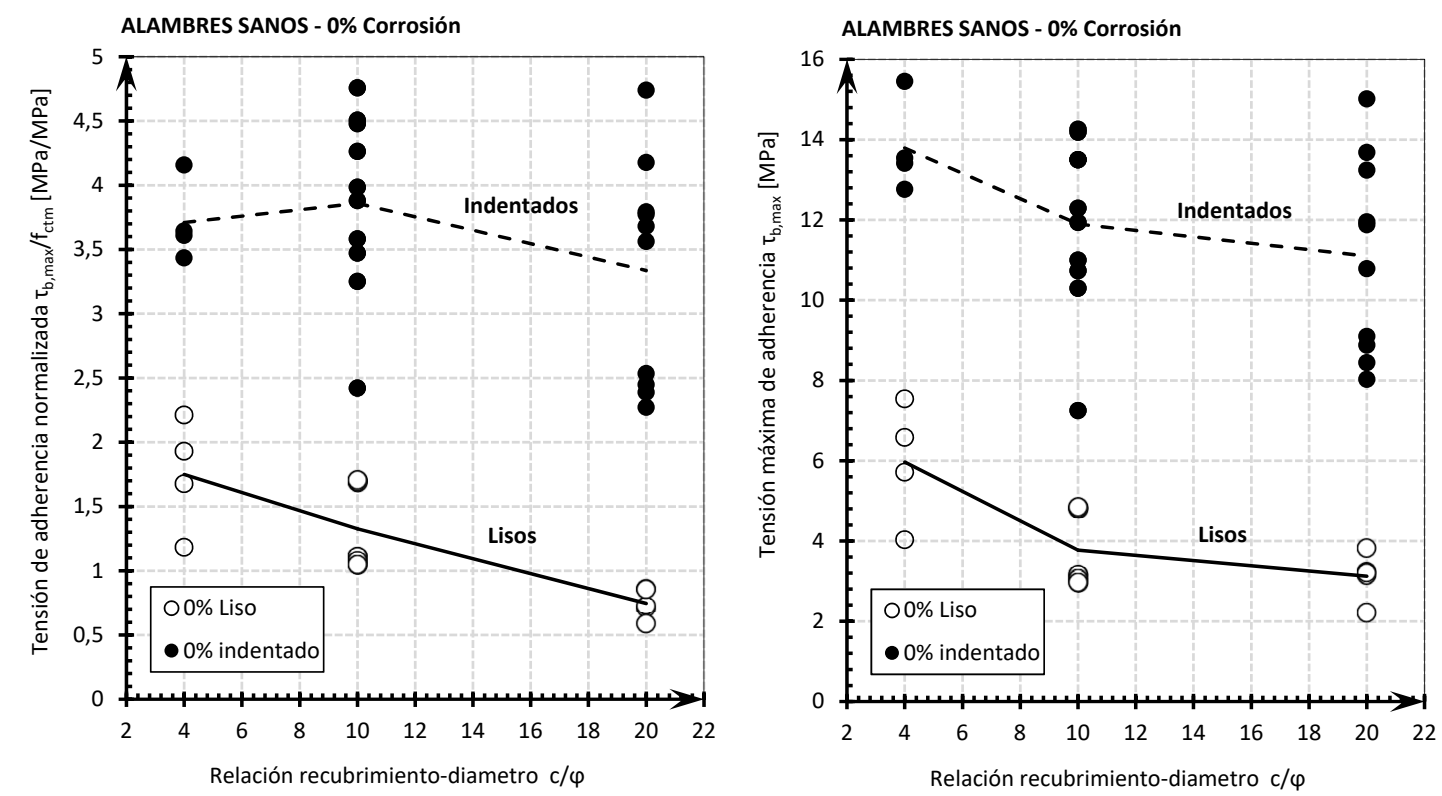

Figura 5-29 Tensión máxima de adherencia normalizada $\tau_{b, \max } / f_{c t m}[\mathrm{MPa} / \mathrm{MPa}]$ (izquierda) y Tensión máxima de adherencia $\tau_{b, \max }$

$[\mathrm{MPa}]($ derecha) en alambres lisos e indentados sin corroer, para distintos recubrimientos.

Tabla 5-15 Valor medio, desviación estandar, y coeficiente de variación $(\mathrm{CoV})$ de la tensión máxima de adherencia $\tau_{b, \max }[M P a]$ y de la tensión máxima de adherencia normalizada $\tau_{b, \max } / f_{\text {ctm }}[\mathrm{MPa} / \mathrm{MPa}]$, en los ensayos sobre alambres sanos.

\begin{tabular}{|c|c|c|c|c|c|c|c|c|c|}
\hline \multirow{2}{*}{ Serie } & \multirow{2}{*}{ Acabado } & \multirow{2}{*}{$c / \varphi$} & \multirow{2}{*}{$f_{c t, m}[M P a]$} & \multicolumn{3}{|c|}{$\tau_{b, \max }[M P a]$} & \multicolumn{3}{|c|}{$\tau_{b, \max } / f_{c t m}[\mathrm{MPa} / \mathrm{MPa}]$} \\
\hline & & & & Media & Desv. Stand & $\mathrm{CoV}$ & Media & Desv. Stand & $\mathrm{CoV}$ \\
\hline L4 & \multirow{3}{*}{ Liso } & 4 & 3,41 & 5,97 & 1,49 & 24,99 & 1,75 & 0,44 & 24,99 \\
\hline L10 & & 10 & 2,84 & 3,77 & 0,97 & 25,71 & 1,33 & 0,34 & 25,71 \\
\hline L20 & & 20 & $4,45-3,76$ & 3,12 & 0,58 & 18,54 & 0,75 & 0,11 & 15,12 \\
\hline I4 & \multirow{3}{*}{ Indentado } & 4 & 3,72 & 13,79 & 1,16 & 8,39 & 3,71 & 0,31 & 8,39 \\
\hline I10 & & 10 & $3,17-2,99$ & 11,90 & 2,17 & 18,25 & 3,86 & 0,70 & 18,23 \\
\hline I20 & & 20 & $3,72-3,17-2,84$ & 11,10 & 2,44 & 21,95 & 3,34 & 0,86 & 25,88 \\
\hline
\end{tabular}

En primer lugar, tal y como se puede apreciar en la Figura 5-29, cabe destacar la enorme dispersión de los resultados obtenidos, lo que dificulta su análisis y discusión. Los coeficientes de variación CoV son elevados en todos los casos, alcanzando hasta un $25 \%$ (

Tabla 5-15), sin encontrarse tendencias claras de cómo afecta el recubrimiento o el acabado superficial a dicha dispersión. Su procedencia puede deberse a dos posibles fenómenos:

- Por un lado, para tensiones radiales y circunferenciales bajas en las que no se agota la capacidad de confinamiento del recubrimiento, cualquier interacción o imperfección de carácter local entre el acero y el hormigón, o incluso ligeras excentricidades del alambre, pueden suponer una variación importante en el resultado final de tensión de adherencia obtenido. 
- Por otro lado, en alambres sanos no corrugados (lisos o indentados) la tensión radial que permite movilizar la acción confinante del recubrimiento procede casi exclusivamente de factores reológicos, como la retracción, y del engranamiento mecánico entre las microrugosidades de la superficie del acero y el hormigón. Estos factores, en contraposición con las tensiones generadas por las corrugas en su deslizamiento, son menos controlables y con mayor probabilidad de variación entre unas probetas y otras.

En las dos gráficas de la Figura 5-29 puede observarse que, al contrario de lo esperable y de lo que ocurre en las barras corrugadas, la tendencia de la tensión máxima de adherencia $\tau_{b \text {,max }}$, normalizada o no, es ligeramente decreciente con respecto al aumento del espesor de recubrimiento. El descenso es más acusado en el caso de alambres lisos. Este comportamiento, que se podría calificar de contraintuitivo, ha sido observado por otros autores (Ver Capitulo 2); Abrams (Abrams, 1913) detectó que la tensión máxima de adherencia $\tau_{b, \text { max }}$ en barras lisas mejoraba con el aumento de recubrimiento hasta alcanzar una relación $c / \phi=4$, y que a partir de ese punto cualquier aumento del espesor de hormigón suponía un leve descenso de dicha tensión. Por su parte, Feldman (Feldman, 2006) indicó que dicho comportamiento podría indicar un cambio en el modo de fallo adherente a partir de un determinado recubrimiento, fisuración longitudinal (splitting) para recubrimientos pequeños y fallo por deslizamiento del alambre (pull-out) para recubrimientos grandes.

Por otra parte, las gráficas de la Figura 5-29 muestran que los alambres indentados presentan, gracias al engranamiento mecánico entre las indentaciones y el hormigón, una capacidad adherente entre un 200-300 \% superior a la de los alambres lisos en todos los espesores de recubrimiento analizados. Esta observación es coherente con lo recogido por el Manual CONTECVET (EC Innovation Program IN30902I, 2001), en el que se propone, a la hora de evaluar estructuras con barras lisas, la reducción por un coeficiente reductor igual a 2,25 de la adherencia obtenida para barras corrugas (siguiendo el Eurocódigo 2).

La aparente independencia existente entre la capacidad adherente y el recubrimiento de hormigón en alambres sanos no corrugados (lisos o indentados), o incluso su influencia contraintuitiva, podría ser la razón por la cual, en la mayoría de los códigos estructurales, este parámetro no interviene en las formulaciones propuestas para el cálculo de la tensión de adherencia, en estructuras tanto de hormigón armado como pretensado.

\section{- Alambres con corrosión}

En las gráficas de la Figura 5-30 se representa la evolución de las tensiones máximas de adherencia normalizada $\tau_{b, \max } / f_{\text {ctm }}[\mathrm{MPa} / \mathrm{MPa}]$ en alambres lisos (izquierda) e indentados (derecha), para distintas pérdidas de sección por corrosión y distintos recubrimientos. En la Tabla 5-16 se incluyen los valores medios, las desviaciones estándar y los coeficientes de variación (CoV) de dichas tensiones.

En los alambres lisos, para el primer escalón de pérdida de sección considerado, 1,5-2,5\% (penetración de ataque $\mathrm{P}_{\mathrm{x}}=18,8-31,4 \mu \mathrm{m}$ ), la tensión de adherencia normalizada $\tau_{b, \max } / f_{\text {ctm }}$ se incrementa con respecto a la obtenida en alambres sin procesos de corrosión, pero sigue sin ser evidente la influencia del recubrimiento en el comportamiento adherente. Este fenómeno nos indica que, incluso para las relaciones $c / \phi$ más bajas $(c / \phi=4)$, el anillo de tracciones generado alrededor del alambre cuando éste es sometido a la fuerza de arrancamiento no llega a agotar la capacidad de 
confinamiento del recubrimiento, sobreviniendo el fallo por deslizamiento (pull-out). Sin embargo, en los alambres indentados, para ese mismo nivel de pérdida de sección, las tensiones radiales generadas por la combinación de la expansión de los productos de corrosión y del desplazamiento de la interfaz acero/hormigón provocado por el deslizamiento de las indentaciones, consiguen movilizar mayor capacidad de confinamiento, haciéndose evidente la mejora de las prestaciones adherentes con el aumento del espesor de recubrimiento, de $20 \mathrm{~mm}(c / \phi=4)$ a $50 \mathrm{~mm}(\mathrm{c} / \phi=10)$. En este caso, en términos medios, la mejora de la tensión de adherencia normalizada alcanza alrededor de un $200 \%$. En las probetas con mayor recubrimiento $(c / \phi=20)$ cabría esperar una mejora de las prestaciones adherentes, o al menos, que éstas se mantuvieran constantes, sin embargo, los resultados obtenidos muestran un descenso considerable de la tensión máxima de adherencia $\tau_{\text {b,max }}$ con respecto a la serie inmediatamente inferior $(c / \phi=10)$.
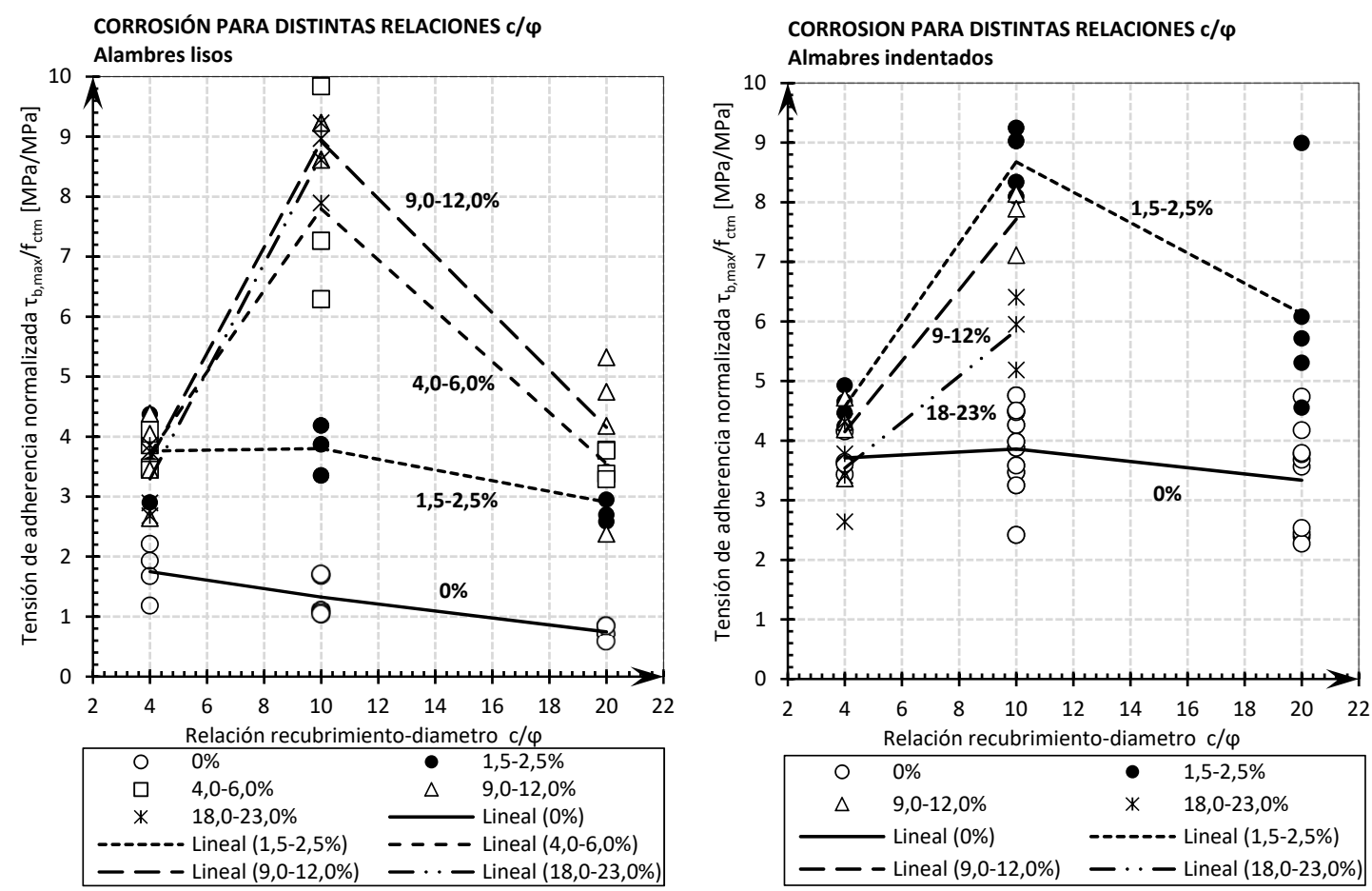

Figura 5-30 Tensiones máximas de adherencia normalizada $\tau_{b, \text { max }} / f_{\text {ctm }}[\mathrm{MPa} / \mathrm{MPa}]$ en alambres lisos (izquierda) e indentados (derecha), para distintas pérdidas de sección por corrosión y distintos recubrimientos

A partir del siguiente escalón de pérdida de sección, 4-6\% $\left(P_{x}=50,51-76,16 \mu \mathrm{m}\right)$, los alambres lisos comienzan a reproducir el mismo comportamiento que los indentados, es decir, un importante incremento de la tensión máxima de adherencia (200-250\%) para la relación recubrimiento/diámetro $c / \phi$ igual a 10 seguida de un descenso acusado para las probetas con $c / \phi$ igual a 20 , obteniéndose resultados similares a los arrojados por las probetas con un menor recubrimiento $(c / \phi=4)$. Por otra parte, a partir de este nivel de penetración de ataque por corrosión $P_{x}$, las diferencias de comportamiento entre alambres lisos e indentados se minimizan.

Para ambos acabados superficiales se observa que alcanzado un determinado nivel de pérdida de sección por corrosión, entre 4,0-6,0\% $\left(\mathrm{P}_{\mathrm{x}}=50,51-76,16 \mu \mathrm{m}\right)$ y $9,0-12,0 \% \quad\left(\mathrm{P}_{\mathrm{x}}=115,15-154,79 \mu \mathrm{m}\right)$ en alambres lisos y 1,5-2,5\% en alambres indentados, la tensión máxima de adherencia $\tau_{b, \max }$ para 
todas las relaciones recubrimiento/diámetro consideradas comienza a descender ligeramente con el aumento de la penetración de ataque, tal y como se ha discutido en el apartado relativo a la influencia de la corrosión.

Tabla 5-16 Valor medio, desviación estandar, y coeficiente de variación (CoV) de la tensión máxima de adberencia $\tau_{b, m a x}[M P a]$ y de la tensión máxima de adherencia normalizada $\tau_{b, \max } / f_{c t m}[\mathrm{MPa} / \mathrm{MPa}]$, en los ensayos sobre alambres lisos e indentados, para distintos niveles de

\begin{tabular}{|c|c|c|c|c|c|c|c|c|c|c|}
\hline \multirow[b]{2}{*}{ Serie } & \multirow[b]{2}{*}{ Acabado } & \multirow{2}{*}{$\begin{array}{c}\% \text { Corr } \\
\text { (Px) }\end{array}$} & \multirow[b]{2}{*}{$c / \varphi$} & \multirow{2}{*}{$\begin{array}{c}f_{c t, m} \\
{[M P a]}\end{array}$} & \multicolumn{3}{|c|}{$\tau_{b, \max }[\mathrm{MPa}]$} & \multicolumn{3}{|c|}{$\tau_{b, \max } / f_{c t m}[\mathrm{MPa} / \mathrm{MPa}]$} \\
\hline & & & & & Media & $\begin{array}{l}\text { Desv. } \\
\text { Stand }\end{array}$ & $\mathrm{CoV}$ & Media & $\begin{array}{l}\text { Desv. } \\
\text { Stand }\end{array}$ & $\mathrm{CoV}$ \\
\hline L4-2 & \multirow{3}{*}{ Liso } & \multirow{6}{*}{$\begin{array}{c}1,5-2,5 \% \\
\left(\mathrm{P}_{\mathrm{x}}=18,8-\right. \\
31,4 \mu \mathrm{m})\end{array}$} & 4 & 3,41 & 12,83 & 2,33 & 18,17 & 3,76 & 0,68 & 18,17 \\
\hline L10-2 & & & 10 & 2,84 & 10,81 & 1,20 & 11,06 & 3,80 & 0,42 & 11,06 \\
\hline L20-2 & & & 20 & $4,45-3,76$ & 11,92 & 1,55 & 12,99 & 2,91 & 0,37 & 12,67 \\
\hline I4-2 & \multirow{3}{*}{ Indent. } & & 4 & 3,72 & 16,99 & 1,08 & 6,36 & 4,57 & 0,29 & 6,36 \\
\hline I10-2 & & & 10 & 3,17 & 27,49 & 1,74 & 6,32 & 8,68 & 0,55 & 6,32 \\
\hline $\mathrm{I} 20-2$ & & & 20 & $3,17-2,84$ & 18,41 & 6,08 & 33,01 & 6,13 & 1,70 & 27,69 \\
\hline L4-5 & \multirow{3}{*}{ Liso } & \multirow{4}{*}{$\begin{array}{l}4,0-6,0 \% \\
\left(P_{x}=50,51-\right. \\
76,16 \mu \mathrm{m})\end{array}$} & 4 & 3,41 & 12,69 & 1,08 & 8,50 & 3,72 & 0,32 & 8,50 \\
\hline L10-5 & & & 10 & 2,84 & 22,17 & 5,21 & 23,50 & 7,80 & 1,83 & 23,50 \\
\hline L20-5 & & & 20 & $4,45-3,76$ & 14,61 & 1,87 & 12,79 & 3,55 & 0,26 & 7,20 \\
\hline I10-5 & Indent. & & 10 & 3,17 & 28,62 & 0,38 & 1,34 & 9,03 & 0,12 & 1,34 \\
\hline L4-10 & \multirow{3}{*}{ Liso } & \multirow{5}{*}{$\begin{array}{c}9,0-12,0 \% \\
\left(P_{x}=115,2-\right. \\
154,8 \mu \mathrm{m})\end{array}$} & 4 & 3,41 & 12,38 & 2,61 & 21,10 & 3,63 & 0,77 & 21,10 \\
\hline L10-10 & & & 10 & 2,84 & 25,37 & 1,23 & 4,87 & 8,92 & 0,43 & 4,87 \\
\hline L20-10 & & & 20 & $4,45-3,76$ & 17,28 & 6,14 & 35,50 & 4,16 & 1,27 & 30,62 \\
\hline I4-10 & \multirow{2}{*}{ Indent. } & & 4 & 3,72 & 15,42 & 2,11 & 13,70 & 4,15 & 0,57 & 13,70 \\
\hline I10-20 & & & 10 & 3,17 & 24,45 & 1,70 & 6,96 & 7,72 & 0,54 & 6,96 \\
\hline L4-20 & \multirow{2}{*}{ Liso } & \multirow{4}{*}{$18,0-23,0 \%$} & 4 & 3,41 & 11,24 & 2,03 & 18,06 & 3,30 & 0,60 & 18,06 \\
\hline L10-20 & & & 10 & 2,84 & 22,92 & 2,38 & 10,40 & 8,06 & 0,84 & 10,40 \\
\hline I4-20 & \multirow{2}{*}{ Indent. } & & 4 & 3,72 & 13,16 & 2,62 & 19,91 & 3,54 & 0,70 & 19,91 \\
\hline I10-20 & & & 10 & 3,17 & 19,98 & 3,17 & 15,88 & 6,31 & 1,00 & 15,88 \\
\hline
\end{tabular}

En definitiva, a pesar de que es indudable que el aumento del espesor de recubrimiento mejora la capacidad de confinamiento, los ensayos arrojan resultados contradictorios en cuanto su influencia en la capacidad adherente de alambres, tanto sanos como corroídos. Este aspecto se estudia en profundidad en el siguiente capítulo (Capitulo o) en el que, con el apoyo del modelo calibrado, se analizan los distintos fenómenos mecánicos que podrían justificar este comportamiento.

\subsection{Propiedades mecánicas del hormigón: Resistencia a compresión}

El otro parámetro fundamental a la hora de evaluar la capacidad de confinamiento del recubrimiento y su influencia en las capacidades adherentes de alambres embebidos en hormigón es la resistencia de este último, tanto a tracción $f_{\text {ctm }}$ como compresión $f_{\text {cmm }}$. Tal y como se ha visto en el Capitulo 2, en la 
mayor parte de códigos (FIB Special Activity Group 5, 2011) y modelos existentes, ya sean de carácter empírico (EC Innovation Program IN30902I, 2001) o analítico, la tensión de adherencia $\tau_{b}$ en estructuras de hormigón armado y pretensado es función de la resistencia media a compresión $f_{c m} \mathrm{O}$ a tracción $f_{\text {ctm }}$.

En las gráficas de la Figura 5-31 se representa la evolución de las tensiones máximas de adherencia $\tau_{b, \max }[\mathrm{MPa}]$ en alambres lisos (izquierda) e indentados (derecha) sin corrosión, para distintas resistencia a compresión del hormigón. Coherentemente con lo discutido en el apartado anterior, en el que se ha comprobado que el espesor de recubrimiento no tiene influencia en el comportamiento adherente de alambres sanos, en las gráficas se representan todos los resultados obtenidos, independientemente de la relación recubrimiento/diámetro $c / \phi$. En el caso de alambres lisos se aprecia cierta tendencia descendente, es decir, que el aumento de la resistencia a compresión $f_{c m}$ supone un leve descenso del valor máximo de la tensión de adherencia $\tau_{b, \max }$. En el caso de alambres indentados se invierte la tendencia, aumentando ligeramente la tensión de adherencia con el incremento de la resistencia del hormigón. En ambos casos, la dispersión de los resultados es alta, presentando coeficientes de correlación $\mathrm{R}^{2}$ bajos, y la pendiente de la recta de regresión es moderada, por lo que se puede deducir que para alambres sanos ( $0 \%$ de pérdida de sección por corrosión) la tensión de adherencia es prácticamente independiente de la resistencia a compresión del hormigón.
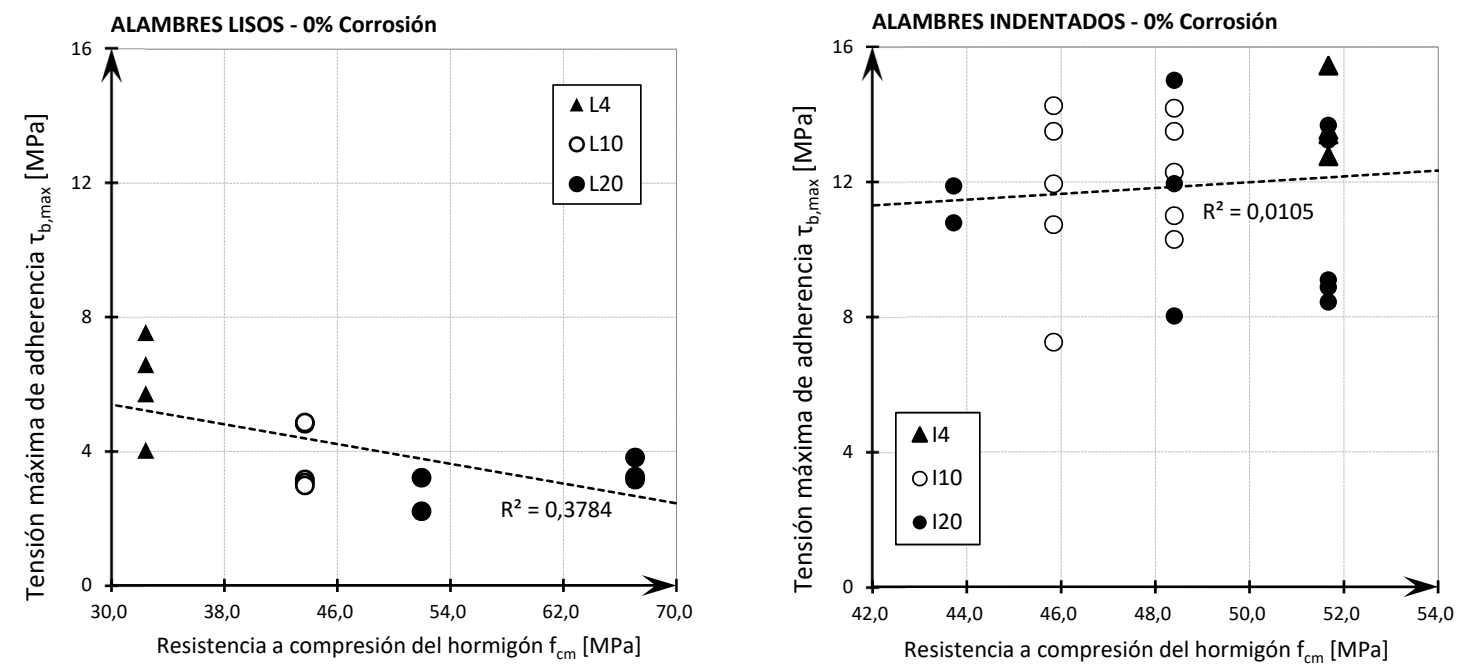

Figura 5-31 Influencia de la resistencia a compresión $f_{c m}$ en la tensión máxima de adherencia. Alambres lisos (irquierda) e indentados (derecha) sin corrosión.

En las gráficas de la Figura 5-32 se representa la evolución de las tensiones máximas de adherencia $\tau_{\text {b, max }}[\mathrm{MPa}$ ] en alambres lisos (irquierda) e indentados (derecha) con distintos niveles de corrosión, para distintas resistencias a compresión del hormigón $f_{c m}$. Las probetas utilizadas han sido las correspondientes a las series L20 e I20, con un recubrimiento de $100 \mathrm{~mm}(c / \phi=20)$. Como en el caso anterior, el número de resultados y su dispersión limitan la capacidad para extraer conclusiones categóricas. Aun así, puede apreciarse que el aumento de pérdida de sección, y por tanto de las tensiones radiales generadas por la expansión de los productos de corrosión, provoca un aumento de la influencia de la resistencia a compresión del hormigón. Esta apreciación es coherente con lo que se ha venido discutiendo a lo largo del presente capítulo, es decir, que la mejora de la capacidad de 
confinamiento del hormigón, ya sea por el aumento del espesor de recubrimiento $c$ o por el incremento de la resistencia a compresión $f_{c m}$ únicamente tiene trascendencia en la tensión de adherencia $\tau_{b, \text { max }}$ cuando existen una presión interna capaz de hacer trabajar a la totalidad del cilindro de hormigón que rodea el alambre.
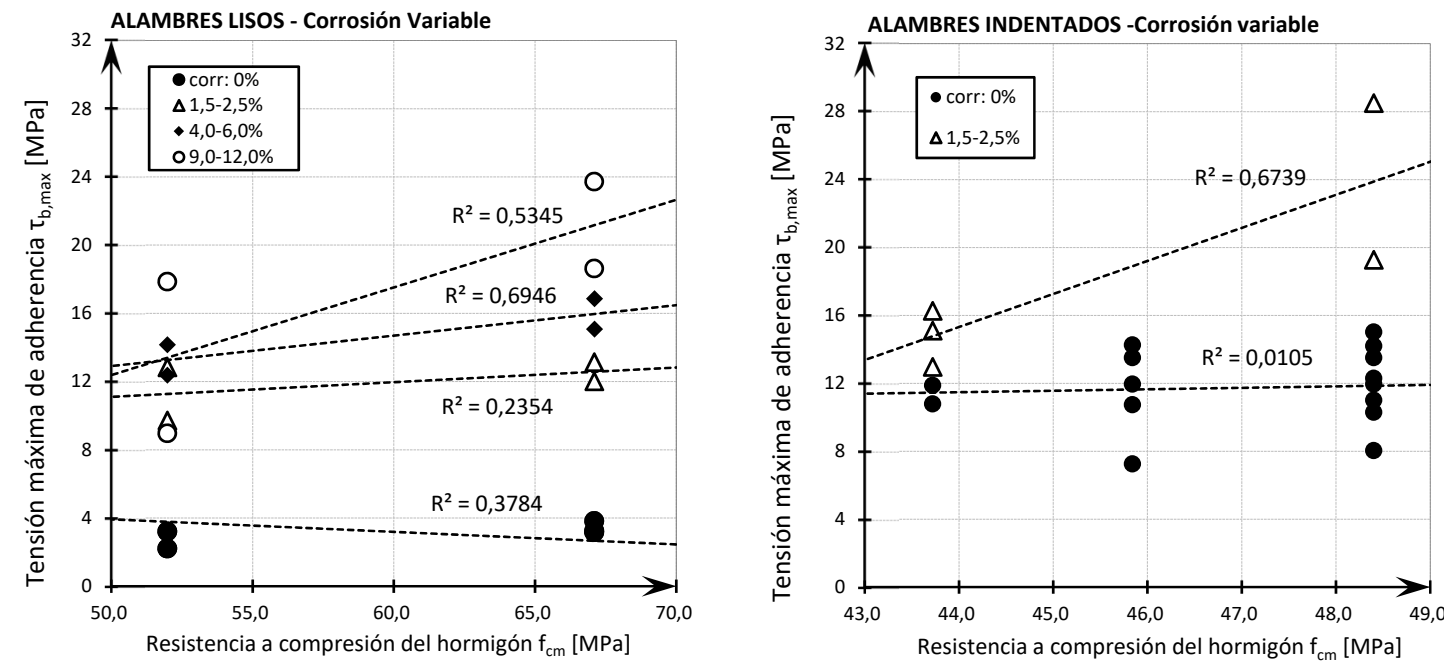

Figura 5-32 Influencia de la resistencia a compresión $f_{c m}$ en la tensión máxima de adherencia. Alambres lisos (izquierda) e indentados (derecha) con corrosión variable.

Como en el caso del espesor de recubrimiento, el análisis de la influencia de la resistencia del hormigón en la capacidad adherente de alambres lisos e indentados, tanto sanos como corroídos, se complementa con el contenido del Capitulo 6, donde los resultados experimentales se comparan con el modelo analítico calibrado.

\subsubsection{Leyes de tensión de adherencia media-deslizamiento $\tau_{b . \max }-\boldsymbol{S}$}

En los siguientes apartados se analizan las leyes de tensión de adherencia media-deslizamiento $\tau_{b}$-s obtenidas de los ensayos, para cada acabado superficial de los alambres (lisos e indentados) y para cada espesor de recubrimiento $(c / \phi=4, c / \phi=10 \mathrm{y} c / \phi=20)$, así como su evolución con el aumento de los niveles de corrosión. La discusión de este apartado se complementa con el contenido del Capitulo 6, donde se han calibrado los parámetros que definen las leyes de tensión de adherencia localdeslizamiento.

\subsubsection{Alambres indentados}

Los diagramas de tensión de adherencia media - deslizamiento $\tau_{b, \text { med }}-s$ obtenidos en cada uno de los ensayos sobre las series con alambres indentados han sido expuestas en el Apartado 5.3 "Ensayos de pull-out para evaluación de la adherencia": Serie I4 [Figura 5-7 y Figura 5-8], Serie I10 [Figura 5-9, Figura 5-11 y Figura 5-12] y Serie I20 [Figura 5-14 y Figura 5-15]. Los parámetros que determinan la forma de dichas leyes se encuentran recopilados en la Tabla 5-8 (Serie I4), en la Tabla 5-9(Serie 110) y en la Tabla 5-10(Serie I20). 


\subsection{Alambres indentados sanos}

En la Tabla 5-17 se incluye, a modo de resumen y para cada uno de los recubrimientos considerados, el promedio de los valores relativos a las leyes de tensión de adherencia media-deslizamiento $\tau_{b, \text { med }}-s$, obtenidos de los ensayos de pull-out:: $\tau_{b, \max }^{\text {med }}, \tau_{b, \text { res }}^{\text {med }}, s_{\max }, s_{1}, s_{2} y s_{3}$.

Las figuras del Apartado 5.3 muestran que las gráficas de tensión adherencia media-deslizamiento $\tau_{b, \text { med }}$ $-s$ de los alambres indentados sanos adoptan casi en la totalidad de los ensayos, de forma sistemática, forma de "ola" u "onda". Este fenómeno ha sido detectado por otros autores, como Bolmsvik \& Lundgren (2006). En todos los casos, la tensión media de adherencia $\tau_{b, \text { med }}$ crece linealmente hasta que se alcanza un deslizamiento $S_{1}$ emplazado, en términos medios, en el rango entre 1,26 y 1,69 $\mathrm{mm}$. A partir de ese momento, la pendiente de crecimiento de la tensión se atenúa, hasta alcanzar su valor máximo $\tau_{b, \text { max }}^{\text {med }}$ para un deslizamiento $s_{\max }$ situado en el rango entre 2,13 y 2,34 $\mathrm{mm}$. El promedio de $\tau_{b, \text { max }}^{\text {med }}$ para cada una de las series de ensayos oscila entre 11,09 y $13,79 \mathrm{MPa}$ (Tabla 5-17). A continuación, la tensión de adherencia comienza a descender lentamente, hasta llegar a un deslizamiento $S_{2}$ ubicado entre 2,45 y $2,81 \mathrm{~mm}$, que marca el final de la meseta plástica de tensiones máximas y el comienzo de la rama de ablandamiento, donde se acelera el descenso del valor medio de la tensión de adherencia. Éste continúa decreciendo hasta que el alambre alcanza un deslizamiento $s_{3}$, localizado entre 5,56 y $7,73 \mathrm{~mm}$, a partir del cual comienza la región de tensión de adherencia residual $\tau_{b, \text { res }}^{\text {med }}$, comprendida entre 5,18 y 5,80 MPa. Alcanzado ese punto de la ley de adherencia media-deslizamiento sería esperable que el alambre deslizara hasta el fallo manteniendo una tensión de adherencia más o menos constante. Sin embargo, en prácticamente todos los ensayos, independientemente del recubrimiento, se aprecia un repunte de la tensión de adherencia, alcanzando un máximo relativo para deslizamientos alrededor de $1,5 \mathrm{~mm}$ más allá de $s_{3}$. Dicho repunte, que en todos los casos es menor que la máxima tensión de adherencia $\tau_{b, \text { max }}^{\text {med }}$ obtenida anteriormente, es seguido por un descenso de la tensión hasta situarse en valores ligeramente inferiores a los de la tensión residual $\tau_{b, \text { res }}^{\text {med }}$, con deslizamientos situados entre 5 y $6 \mathrm{~mm}$ más allá de $s_{3}$.

Tabla 5-17 Valores medios de los parámetros que definen las leyes de adherencia media-deslizamiento $\tau_{b, m e d}-s$

\begin{tabular}{ccccccccc}
\hline SERIE & $\begin{array}{c}\boldsymbol{\tau}_{\boldsymbol{b}, \boldsymbol{m a x}}^{\text {med }} \\
{[\mathbf{M P a}]}\end{array}$ & $\begin{array}{c}\boldsymbol{\tau}_{\boldsymbol{b}, \boldsymbol{m a x}}^{\text {med }} / \boldsymbol{f}_{\boldsymbol{c t m}} \\
{[\mathbf{M P a}]}\end{array}$ & $\begin{array}{c}\boldsymbol{\tau}_{\boldsymbol{b}, \boldsymbol{r e s}}^{\text {med }} \\
{[\mathbf{M P a}]}\end{array}$ & $\begin{array}{c}\boldsymbol{\tau}_{\boldsymbol{b}, \boldsymbol{r e s}}^{\text {med }} / \boldsymbol{f}_{\boldsymbol{c t m}} \\
{[\mathbf{M P a}]}\end{array}$ & $\begin{array}{c}\boldsymbol{s}_{\boldsymbol{m a x}} \\
{[\mathbf{m m}]}\end{array}$ & $\begin{array}{c}\boldsymbol{s}_{\mathbf{1}} \\
{[\mathbf{m m}]}\end{array}$ & $\begin{array}{c}\boldsymbol{s}_{\mathbf{2}} \\
{[\mathbf{m m}]}\end{array}$ & $\begin{array}{c}\boldsymbol{s}_{\mathbf{3}} \\
{[\mathbf{m m}]}\end{array}$ \\
\hline Serie I4-0 & 13,79 & 3,71 & 5,18 & 1,40 & 2,17 & 1,69 & 2,45 \\
\hline Serie I10-0 & 11,89 & 3,86 & 5,80 & 1,88 & 2,34 & 1,66 & 2,81 \\
\hline Serie I20-0 & 11,09 & 3,34 & 5,50 & 1,68 & 2,13 & 1,26 & 2,79 \\
\hline
\end{tabular}

El patrón seguido puede explicarse a través de la geometría de los alambres indentados (Figura 5-33). En la situación inicial, previa al ensayo, la cara interna del hormigón ha adquirido, durante el fraguado, la forma negativa de la superficie del alambre, de manera que las indentaciones del acero coinciden con "canales" en el hormigón, mientras que el espacio entre indentaciones configura "resaltos" en la superficie del hormigón (Figura 5-33 (a)). El alambre, en su deslizamiento, hace que las indentaciones se sitúen paulatinamente frente a los resaltos del hormigón circundante, lo que a su vez provoca que gradualmente se alcance el máximo desplazamiento radial de la pared interna del recubrimiento. La relación existente entre la altura de las indentaciones y la capacidad de confinamiento del 
recubrimiento determina para que deslizamiento relativo del alambre se alcanza la tensión máxima de adherencia $\tau_{b, \text { max }}^{\text {med }}$ (Figura 5-33 (b)). A partir de ese momento, el deslizamiento posterior deteriora la interfaz acero-hormigón, lo que a su vez provoca un descenso de la tensión de adherencia (Figura 5-33 (c)). En su avance, las indentaciones alcanzan el siguiente "canal" sobre la superficie del hormigón, por lo que el alambre deja de ejercer empuje sobre la pared interna del recubrimiento, el desplazamiento radial vuelve a la situación inicial y la tensión de adherencia toma un valor residual $\tau_{b, \text { res }}^{\text {med }}$ (Figura 5-33 (d)). Si el deslizamiento relativo entre el alambre y el hormigón circundante continua, este fenómeno vuelve a repetirse, con sucesivas salidas y entradas de las indentaciones en los canales de la superficie del hormigón, haciendo que la gráfica tensión de adherencia-deslizamiento adquiera su característica forma de ola u onda. En cada ciclo, los valores máximos y residuales de la tensión descienden por el deterioro progresivo de la interfaz acero-hormigón.
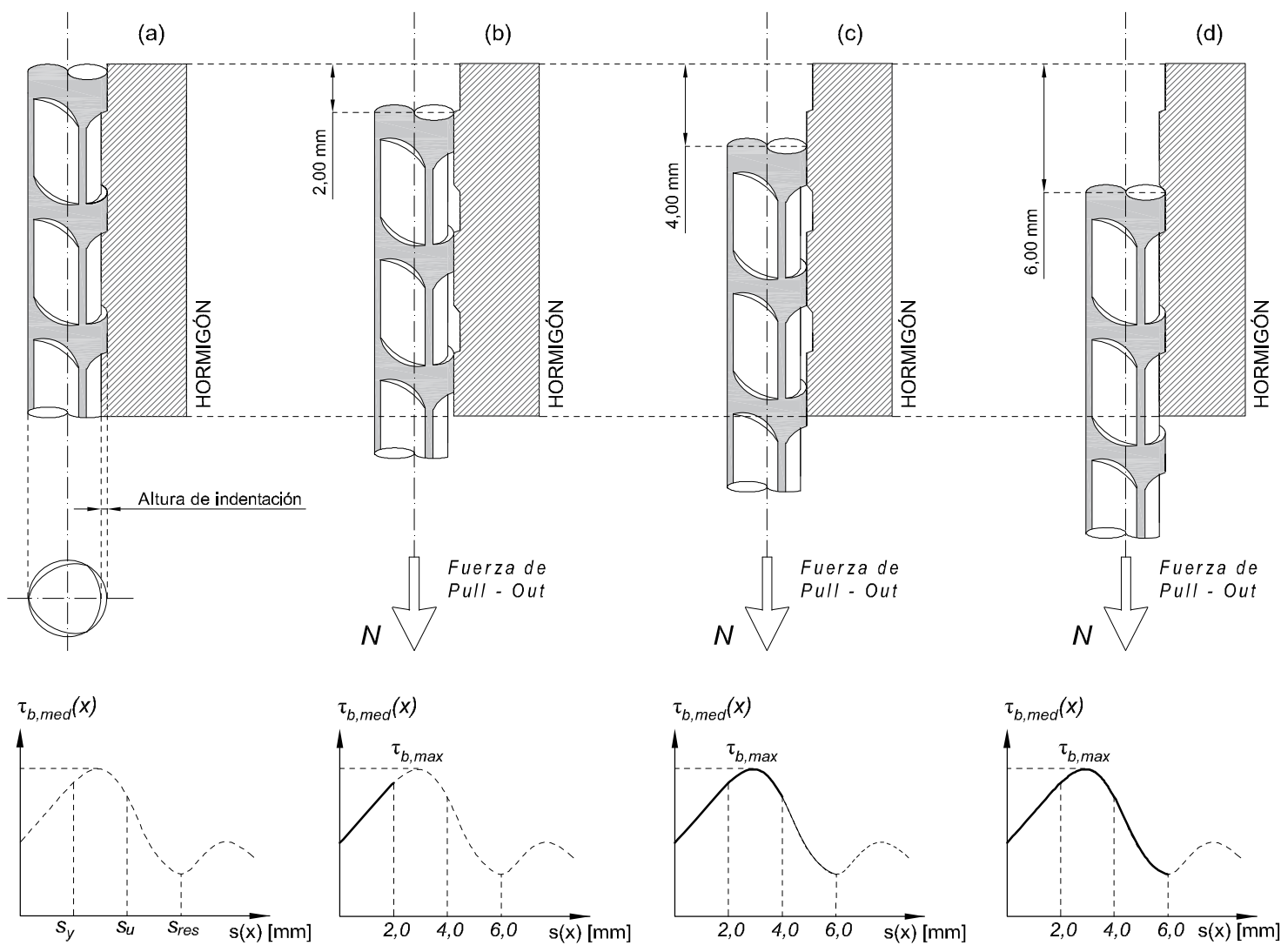

Figura 5-33 Relación entre la geometría superficial de los alambres indentados y las gráficas tensión de adherencia media-deslizamiento obtenidas en los ensayos de pull-out. Alambres sin corrosión.

En definitiva, puede establecerse una clara relación entre la geometría del alambre y su ley de adherencia-deslizamiento: el ancho de la indentación lind está vinculado al deslizamiento $s_{y}$, la distancia neta entre indentaciones $l_{w}$ se relaciona con el deslizamiento $s_{u}$ y el paso de hélice de las indentaciones $l_{\text {tot }}\left(l_{\text {tot }}=l_{\text {ind }}+l_{w}\right)$ determina el deslizamiento $s_{\text {res }}$. 


\subsection{Alambres indentados con corrosión}

Como se ha visto a lo largo de esta tesis, con el aumento de los niveles de corrosión aumenta el desplazamiento $u_{r}$ de la pared interna del cilindro de hormigón que rodea el alambre, debido al mayor volumen de los productos de corrosión con respecto al acero virgen. Esto implica que el diagrama de tensión de adherencia-deslizamiento se modifica a lo largo del proceso de corrosión: por un lado, aumenta la tensión de adherencia en el arranque del deslizamiento $\tau_{b, 0}$, debido a la mayor tensión radial inicial $\sigma_{r, 0}$, y por otro, hasta que la capacidad de confinamiento del recubrimiento se agota, se

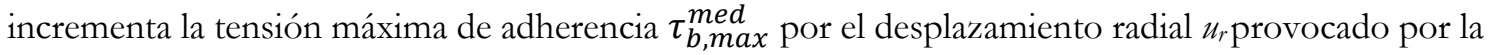
combinación de los efectos de la corrosión y del deslizamiento de las indentaciones.

En la Tabla 5-18 se incluye, a modo de resumen, el promedio de los valores relativos a las leyes de adherencia media-deslizamiento en extremo no cargado $\tau_{b \text {,med }}-s$ obtenidos de los ensayos de pull-out: $\tau_{b, \text { max }}^{\text {med }}, \tau_{b, \text { max }}^{\text {med }} / f_{c t m}, \tau_{b, \text { res }}^{\text {med }}, \tau_{b, \text { res }}^{\text {med }} / f_{c t m}, s_{\text {max }}, s_{1}, s_{2} y s_{3}$, para los distintos niveles de corrosión de la las probetas de la Serie I4, con relación recubrimiento/diámetro igual a 4:

Tabla 5-18 Valores medios de los parámetros que definen las leyes de adherencia media-deslizamiento $\tau_{b, \text { med }}-\mathbf{s}$ en los resultados de los ensayos sobre las probetas de la Serie I4

\begin{tabular}{|c|c|c|c|c|c|c|c|c|}
\hline SERIE & $\begin{array}{l}\tau_{b, \max }^{\text {med }} \\
{[\mathrm{MPa}]}\end{array}$ & $\begin{array}{c}\boldsymbol{\tau}_{\boldsymbol{b}, \max }^{\text {med }} / \boldsymbol{f}_{\boldsymbol{c t m}} \\
{[\mathrm{MPa}]}\end{array}$ & $\begin{array}{c}\tau_{b, r e s}^{\text {med }} \\
{[\mathrm{MPa}]}\end{array}$ & $\begin{array}{c}\tau_{b, r e s}^{\text {med }} / \boldsymbol{f}_{c t m} \\
{[\mathrm{MPa}]}\end{array}$ & $\begin{array}{c}s_{\max } \\
{[\mathrm{mm}]}\end{array}$ & $\begin{array}{c}s_{1} \\
{[\mathrm{~mm}]}\end{array}$ & $\begin{array}{c}s_{2} \\
{[\mathrm{~mm}]}\end{array}$ & $\begin{array}{c}s_{3} \\
{[\mathrm{~mm}]}\end{array}$ \\
\hline Serie I4-2 & 16,99 & 4,57 & 0,72 & 0,19 & 0,05 & 0,02 & 0,06 & 2,46 \\
\hline Serie I4-10 & 15,42 & 4,15 & 0,00 & 0,00 & 0,02 & 0,01 & 0,15 & 7,65 \\
\hline Serie I4-20 & 16,21 & 3,54 & 0,00 & 0,00 & 0,07 & 0,06 & 0,71 & 6,76 \\
\hline
\end{tabular}

En la Tabla 5-19 se incluyen los valores promedio $\tau_{b, \text { max }}^{\text {med }}, \tau_{b, \text { max }}^{\text {med }} / f_{c t m}, \tau_{b, r e s}^{\text {med }}, \tau_{b, r e s}^{\text {med }} / f_{c t m}, s_{\text {max }}$, $s_{1}, s_{2}$ y $s_{3}$ obtenidos de los ensayos de pull-out sobre las probetas de la Serie I10, con relación recubrimiento/diámetro igual a 10, para los distintos niveles de corrosión considerados:

Tabla 5-19 V alores medios de los parámetros que definen las leyes de adherencia media-deslizamiento $\tau_{b, m e d}-s$ en los resultados de los ensayos sobre las probetas de la Serie I10

\begin{tabular}{|c|c|c|c|c|c|c|c|c|}
\hline SERIE & $\begin{array}{l}\tau_{b, \max }^{\text {med }} \\
{[\mathrm{MPa}]}\end{array}$ & $\begin{array}{c}\boldsymbol{\tau}_{b, \max }^{\text {med }} / \boldsymbol{f}_{c t m} \\
{[\mathrm{MPa}]}\end{array}$ & $\begin{array}{c}\tau_{b, \text { res }}^{\text {med }} \\
{[\mathrm{MPa}]}\end{array}$ & $\begin{array}{c}\boldsymbol{\tau}_{b, r e s}^{\text {med }} / f_{c t m} \\
{[\mathrm{MPa}]}\end{array}$ & $\begin{array}{c}s_{\max } \\
{[\mathrm{mm}]}\end{array}$ & $\begin{array}{c}s_{1} \\
{[\mathrm{~mm}]}\end{array}$ & $\begin{array}{c}\boldsymbol{s}_{2} \\
{[\mathrm{~mm}]}\end{array}$ & $\begin{array}{c}S_{3} \\
{[\mathrm{~mm}]}\end{array}$ \\
\hline Serie I10-2 & 27,49 & 8,68 & 16,89 & 5,33 & 0,07 & 0,05 & 1,62 & 4,99 \\
\hline Serie I10-5 & 28,62 & 9,03 & 9,09 & 2,87 & 0,49 & 0,01 & 1,04 & 3,99 \\
\hline Serie I10-10 & 24,45 & 7,72 & 5,35 & 1,69 & 0,15 & 0,01 & 0,39 & 8,55 \\
\hline Serie I10-20 & 19,98 & 6,31 & 6,07 & 1,92 & 0,13 & 0,02 & 0,30 & 3,25 \\
\hline
\end{tabular}

Por último, en la Tabla 5-20 se incluyen los mismos valores que en las tablas anteriores obtenidos en los ensayos sobre las probetas de la Serie I20, con relación recubrimiento/diámetro igual a 20, para un $2 \%$ de porcentaje de pérdida de sección teórica: 
TESIS DOCTORAL INFLUENCLA DE LA CORROSIÓN EN LA ADHERENCLA DE ALAMBRES EN ELEMENTOS PRETENS ADOS DE HORMIGÓN

Tabla 5-20 Valores medios de los parámetros que definen las leyes de adherencia media-deslizamiento $\tau_{b, \text { med }}-s$ en los resultados de los ensayos

\begin{tabular}{|c|c|c|c|c|c|c|c|c|}
\hline SERIE & $\begin{array}{c}\tau_{b, \max }^{\text {med }} \\
{[\mathrm{MPa}]}\end{array}$ & $\begin{array}{c}\tau_{b, \max }^{\text {med }} / f_{\text {ctm }} \\
{[\mathrm{MPa}]}\end{array}$ & $\begin{array}{c}\tau_{b, r e s}^{\text {med }} \\
{[\mathrm{MPa}]}\end{array}$ & $\begin{array}{c}\tau_{b, r e s}^{\text {med }} / f_{c t m} \\
{[\mathrm{MPa}]}\end{array}$ & $\begin{array}{c}S_{\max } \\
{[\mathrm{mm}]}\end{array}$ & $\begin{array}{c}\boldsymbol{S}_{1} \\
{[\mathrm{~mm}]}\end{array}$ & $\begin{array}{c}\boldsymbol{S}_{2} \\
{[\mathrm{~mm}]}\end{array}$ & $\begin{array}{c}s_{3} \\
{[\mathrm{~mm}]}\end{array}$ \\
\hline Serie I10-2 & 15,613 & 6,13 & 1,003 & 0,32 & 0,09 & 0,04 & 0,09 & 4,55 \\
\hline
\end{tabular}

En todos los casos se aprecia, para niveles de corrosión bajos y medios (entre un 2 y un $5 \%$ de pérdida de sección), un incremento del máximo valor de la tensión de adherencia media $\tau_{b, \text { max }}^{\text {med }}$ con respecto a los valores obtenidos sobre alambres sanos, y un lento decrecimiento de dicho valor para niveles de corrosión superiores. La evolución de este valor, con el incremento de la corrosión, así como las razones de ésta, han sido discutidas en el Apartado 5.4.1.1.

En cuanto al valor medio de la tensión de adherencia residual $\tau_{b, r e s}^{\text {med }}$, se aprecian ciertos paralelismos con respecto a la evolución $\tau_{b, \max }^{\text {med }}$, aunque presenta algunas peculiaridades. En términos generales, mientras que en ambos casos los niveles bajos de corrosión (hasta un $2 \%$ de pérdida de sección) suponen un incremento de valor, el deterioro comienza antes y es más acusado en el caso de las tensiones residuales.

Otro de los aspectos significativos de la influencia de la corrosión en la ley de adherenciadeslizamiento es el cambio de fallo adherente. Mientras que en los ensayos con alambres sanos la totalidad de las probetas fallaron por pull-out, en alambres con procesos de corrosión se aprecia una clara tendencia a que el fallo frágil sea más recurrente cuanto mayor sea el deterioro (Ver Tabla 5-8, Tabla 5-9 y Tabla 5-10). En estos últimos, la fisuración del recubrimiento compromete parcialmente su capacidad de confinamiento, por lo que se minimiza la posibilidad de que se cree un nuevo plano de deslizamiento paralelo al eje del alambre, lo que implicaría un fallo por pull-out, y el fallo se produce de manera frágil. Este modo de fallo, que denominaremos por comodidad fallo por splitting, no responde fielmente a las características habituales de este tipo de fallo, ya que el recubrimiento no se fisura por las tensiones provocadas por deslizamiento del alambre, sino que se encuentra previamente fisurado debido a las tensiones provocadas por la acción expansiva de los productos de corrosión. En cualquier caso, en la mayor parte de los ensayos no se identifica un modo de fallo "puro", por pull-out o por splitting, sino un híbrido entre ambos que algunas autores han denominado como fallo por pull-out inducido por fisuración previa (CEB-FIP_Task Group 2.5, 2000).

Este fallo frágil sobreviene con pequeños deslizamientos relativos del alambre, en los que el desplazamiento radial del hormigón en contacto con el alambre que puede achacarse exclusivamente al movimiento de las indentaciones es reducido. La sección de hormigón se encuentra previamente muy solicitada por el aumento de volumen de los productos de corrosión, por lo que cualquier leve aumento de las tensiones provoca el fallo adherente. Por tanto, este fallo frágil, caracterizado por una caída brusca de la tensión de adherencia, tiene lugar para deslizamientos pequeños y sin apenas meseta plástica, de manera que los deslizamientos $s_{1}$, al final de la rama elástica, y $s_{2}$, al final de la rama plástica, se tornan prácticamente coincidentes en el diagrama tensión de adherencia media-deslizamiento (Figura 5-4). En las figuras y tablas recogidas en el Apartado 5.3.2.1 y en las tablas anteriores (Tabla 5-18, Tabla 5-19 y Tabla 5-20) puede observarse que los deslizamientos $s_{1}$, para todos los recubrimientos y niveles de corrosión considerados, sólo superan en casos excepcionales un valor de 0,1 mm, encontrándose habitualmente en el rango comprendido en el intervalo 0,05-0,005 mm. En 
cuanto a los deslizamientos $s_{2}$ se aprecia una mayor variabilidad, oscilando entre valores máximos cercanos a 2,0 mm y valores mínimos próximos a 0,1 mm. En la Figura 5-34 se incluyen los resultados de deslizamientos $s_{1}$ y $s_{2}$ obtenidos, con respecto al nivel de corrosión, en las probetas de la serie I10, así como su ajuste mediante una regresión polinómica de grado 2. Los coeficientes de correlación $R^{2}$, con valores de 0,68 para $s_{1}$ y 0,89 para $s_{2}$, muestran una dependencia no desdeñable entre la evolución de estos deslizamientos y el aumento de la pérdida de sección por corrosión.

Esta correlación no se aprecia de manera concluyente en el resto de las series ensayadas pero, en cualquier caso, a la vista de los resultados obtenidos, sí se puede afirmar que existe una relación clara entre el comienzo del proceso de corrosión y el cambio de modo de fallo adherente, de pull-out en alambres sanos a splitting en alambres con corrosión. Este cambio de modo de fallo viene acompañado, consecuentemente, de una reducción significativa de los deslizamientos $s_{1}$ y $s_{2}$.

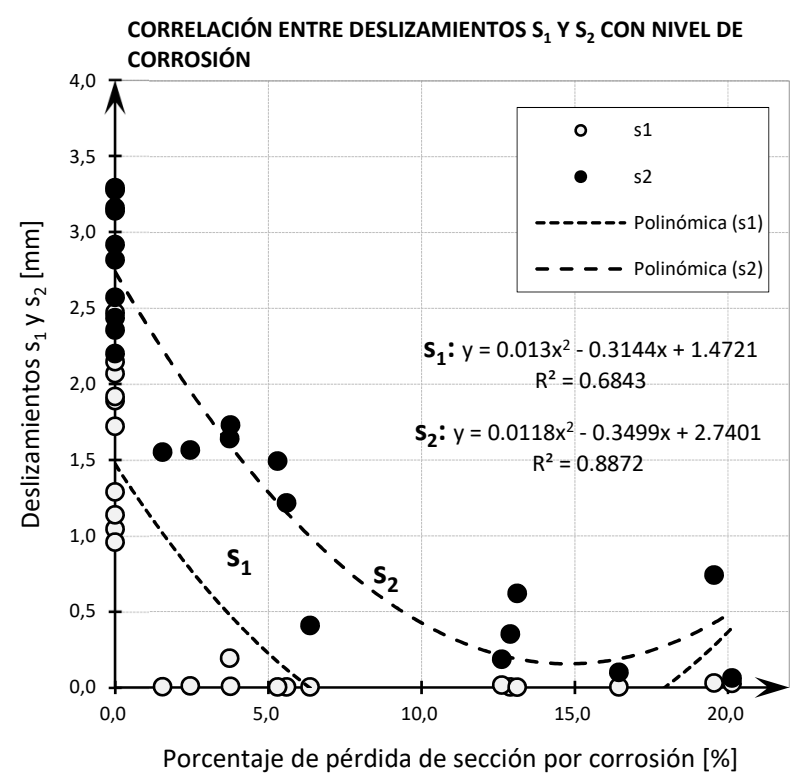

Figura 5-34 Correlación existente entre los deslizamientos $s_{1}$ y $s_{2}$ y el aumento de los niveles de corrosión. Serie de ensayos I10

Superado el valor máximo de la tensión de adherencia media $\tau_{b, \max }^{\text {med }}$ y el deslizamiento $s_{2}$, la gráfica de adherencia-deslizamiento comienza el tramo descendente. El desarrollo de las gráficas en este tramo puede calificarse de caótico, presentando gran variedad de configuraciones sin seguir ningún patrón claro en cuanto a su relación con el espesor de recubrimiento, con el grado de corrosión o con la fisuración previa. De esta manera, en ocasiones se produce un descenso acusado, alcanzando una tensión de adherencia nula $\left(\tau_{b, r e s}^{\text {med }}=0 \mathrm{MPa}\right)$ para deslizamientos $s_{3}$ ligeramente superiores a $s_{2}$, en otras, el descenso presenta pendientes moderadas, sin llegar a registrarse un tramo horizontal que pudiera identificarse como el correspondiente a la tensión residual de adherencia $\tau_{b, r e s}^{\text {med }}$ ni un deslizamiento $s_{3}$ que marcara el comienzo de éste, y en otras, el descenso conduce a tensiones residuales semejantes a las obtenidas en los ensayos sobre alambres sanos, al alcanzarse un deslizamiento $s_{3}$ cuyo valor se encuentra próximo al de la longitud del paso de hélice de las indentaciones $l_{\text {tot. }}$ En el primer caso, el fallo frágil indica que la capacidad de confinamiento del recubrimiento se encuentra totalmente agotada, siendo incapaz de generar tensiones radiales sobre el alambre; en los otros, el recubrimiento conserva cierta integridad, de manera que el alambre desliza bajo una cierta tensión de adherencia residual, que varía según los casos. 
Por último, es importante recordar que los ensayos se han llevado a cabo con control por fuerza, lo que implica que la precisión de los diagramas es menor tras superarse el pico de tensión de adherencia máxima, lo que en parte puede justificar los diferentes comportamientos registrados.

\subsubsection{Alambres lisos}

Los diagramas de tensión de adherencia media - deslizamiento $\tau_{b, \text { med }}-s$ obtenidas en cada uno de los ensayos sobre las series con alambres lisos han sido expuestas en el Apartado 5.3.2.2: Serie L4 [Figura 5-16, Figura 5-17 y Figura 5-18], Serie L10 [Figura 5-21, Figura 5-22 y Figura 5-23] y Serie L20 [Figura 5-25 y Figura 5-26]. Los parámetros que determinan la forma de dichas leyes se encuentran recopilados en la Tabla 5-11(Serie L4), en la Tabla 5-12 (Serie L10) y en la Tabla 5-13 (Serie L20).

\subsubsection{1 $\quad \underline{\text { Alambres lisos sanos }}$}

En la Tabla 5-21 se incluye, a modo de resumen y para cada uno de los recubrimientos considerados, el promedio de los valores relativos a las leyes de adherencia media-deslizamiento $\tau_{b \text {,med }}-s$ obtenidos de los ensayos de pull-out sobre alambres lisos sin procesos de corrosión: $\tau_{b, \text { max }}^{\text {med }}, \tau_{b, \text { max }}^{\text {med }} / f_{c t m}$, $\tau_{b, r e s}^{\text {med }}, \tau_{b, r e s}^{\text {med }} / f_{\text {ctm }}, s_{\text {max }}, s_{1}, s_{2}$ y $s_{3}$.

Tabla 5-21 Valores medios de los parámetros que definen las leyes de adherencia media-deslizamiento $\tau_{b, \text { med }}-s$ en alambres lisos sin corrosión

\begin{tabular}{|c|c|c|c|c|c|c|c|c|}
\hline SERIE & $\begin{array}{l}\tau_{b, \max }^{\text {med }} \\
{[\mathrm{MPa}]}\end{array}$ & $\begin{array}{c}\tau_{b, \max }^{\text {med }} / f_{c t m} \\
{[\mathrm{MPa}]}\end{array}$ & $\begin{array}{c}\tau_{b, r e s}^{\text {med }} \\
\text { [MPa] }\end{array}$ & $\begin{array}{c}\tau_{b, r e s}^{\text {med }} / f_{\text {ctm }} \\
{[\mathrm{MPa}]}\end{array}$ & $\begin{array}{c}S_{\max } \\
{[\mathrm{mm}]}\end{array}$ & $\begin{array}{c}\boldsymbol{s}_{1} \\
{[\mathrm{~mm}]}\end{array}$ & $\begin{array}{c}s_{2} \\
{[\mathrm{~mm}]}\end{array}$ & $\begin{array}{c}s_{3} \\
{[\mathrm{~mm}]}\end{array}$ \\
\hline Serie L4-0 & 5,97 & 1,75 & 5,76 & 1,69 & 5,68 & 0,06 & 9,45 & 9,46 \\
\hline Serie L10-0 & 3,77 & 1,33 & 2,89 & 1,02 & 0,42 & 0,01 & 6,78 & 8,84 \\
\hline Serie L20-0 & 3,12 & 0,75 & 3,04 & 0,72 & 4,02 & 0,02 & 8,46 & 9,53 \\
\hline
\end{tabular}

Como puede observarse en las figuras del Apartado 5.3.2.2, el fallo adherente predominante es el tipo pull-out. En cuanto al máximo valor de la tensión media de adherencia $\tau_{b, \text { max }}^{\text {med }}$, en concordancia con lo discutido ya en el Apartado 5.4.1.2.1, el aumento del espesor del recubrimiento no supone una mejora en el comportamiento adherente de alambres lisos sin corrosión, e incluso puede observarse cierta tendencia descendente (las probetas con relación $c / \phi=4$ llegan a alcanzar un valor máximo de tensión de adherencia que dobla el obtenido en las probetas con relación $c / \phi=10$ ). Como ya se ha justificado, a pesar de que el incremento de recubrimiento mejora la capacidad de confinamiento, la ausencia de productos de corrosión hace que dicha capacidad no se movilice, haciendo altamente improbable el fallo por fisuración del hormigón (splitting) y, por tanto, haciendo que cualquier mejora en el espesor sea despreciable. Dado el tipo de fallo adherente que acontece, el valor residual de la tensión media de adherencia $\tau_{b, \text { res }}^{\text {med }}$ es muy similar a su valor máximo, tal y como se puede apreciar en la Tabla 5-21.

En todos los casos, la rama elástica del diagrama de tensión de adherencia media-deslizamiento es prácticamente vertical, con un comportamiento rígido, de manera que el inicio de la rama plástica (el punto de inflexión en el que el diagrama cambia radicalmente de forma) se alcanza para deslizamientos muy pequeños $\left(s_{1}<0,1 \mathrm{~mm}\right.$ ) (Ver Tabla 5-21). En este segundo tramo del diagrama, donde la pendiente tiende a ser horizontal, aumenta la dispersión de los resultados obtenidos, ya que en algunas probetas la tensión media de adherencia $\tau_{b \text {,med }}$ mantiene su valor durante todo el 
deslizamiento, mientras que en otras probetas se aprecian ligeras tendencias ascendentes o decrecientes, según los casos. No se ha encontrado un patrón claro que permita justificar estas variaciones, pero una explicación plausible es que en alambres lisos sanos la tensión radial $\sigma_{r}$ que permite movilizar la acción confinante del recubrimiento procede de factores de gran variabilidad tales como la retracción o el micro-engranamiento mecánico entre las micro-rugosidades de la superficie del acero y el hormigón.

\subsection{Alambres lisos con corrosión}

En la Tabla 5-22 se incluye, a modo de resumen, el promedio de los valores relativos a las leyes de adherencia media-deslizamiento en extremo no cargado $\tau_{b \text {,med }}-s$ obtenidos de los ensayos de pull-out: $\tau_{b, \text { max }}^{\text {med }}, \tau_{b, \text { max }}^{\text {med }} / f_{\text {ctm }}, \tau_{b, \text { res }}^{\text {med }}, \tau_{b, \text { res }}^{\text {med }} / f_{c t m}, s_{\max }, s_{1}, s_{2} y s_{3}$, para los distintos niveles de corrosión de las probetas de la Serie L4, con relación recubrimiento/diámetro igual a 4.

Tabla 5-22 Valores medios de los parámetros que definen las leyes de adherencia media-deslizamiento $\tau_{b, m e d}-s$ en los resultados de los ensayos

\begin{tabular}{|c|c|c|c|c|c|c|c|c|}
\hline SERIE & $\begin{array}{l}\tau_{b, \max }^{\text {med }} \\
\text { [MPa] }\end{array}$ & $\begin{array}{c}\tau_{b, \max }^{\text {med }} / f_{c t m} \\
{[\mathrm{MPa}]}\end{array}$ & $\begin{array}{c}\tau_{b, r e s}^{\text {med }} \\
{[\mathrm{MPa}]}\end{array}$ & $\begin{array}{c}\boldsymbol{\tau}_{b, r e s}^{\text {med }} / \boldsymbol{f}_{\text {ctm }} \\
{[\mathrm{MPa}]}\end{array}$ & $\begin{array}{l}S_{\max } \\
{[\mathrm{mm}]}\end{array}$ & $\begin{array}{c}s_{1} \\
{[\mathrm{~mm}]}\end{array}$ & $\begin{array}{c}\boldsymbol{s}_{2} \\
{[\mathrm{~mm}]}\end{array}$ & $\begin{array}{c}s_{3} \\
{[\mathrm{~mm}]}\end{array}$ \\
\hline Serie L4-2 & 12,83 & 3,76 & 7,70 & 2,26 & 0,02 & 0,01 & 0,19 & 3,59 \\
\hline Serie L4-5 & 12,70 & 3,72 & 4,49 & 1,32 & 0,07 & 0,01 & 0,05 & 3,91 \\
\hline Serie L4-10 & 12,38 & 3,63 & 3,65 & 1,07 & 0,05 & 0,03 & 0,11 & 3,14 \\
\hline Serie L4-20 & 11,24 & 3,30 & 2,22 & 0,65 & 0,02 & 0,01 & 0,17 & 4,70 \\
\hline
\end{tabular}

En la Tabla 5-23 se incluyen los valores promedio $\tau_{b, \text { max }}^{\text {med }}, \tau_{b, \text { max }}^{\text {med }} / f_{c t m}, \tau_{b, \text { res }}^{\text {med }}, \tau_{b, r e s}^{\text {med }} / f_{c t m}, s_{\text {max }}$, $s_{1}, s_{2}$ y $s_{3}$, obtenidos de los ensayos de pull-out sobre las probetas de la Serie L10, con relación recubrimiento/diámetro igual a 10, para los distintos niveles de corrosión considerados.

Tabla 5-23 Valores medios de los parámetros que definen las leyes de adherencia media-deslizamiento $\tau_{b, \text { med }}-s$ en los resultados de los ensayos

\begin{tabular}{ccccccccc}
\hline SERIE & $\begin{array}{c}\boldsymbol{\tau}_{\boldsymbol{b}, \boldsymbol{m a x}}^{\text {med }} \\
{[\mathbf{M P a}]}\end{array}$ & $\begin{array}{c}\boldsymbol{\tau}_{\boldsymbol{b}, \boldsymbol{m a x}}^{\text {med }} / \boldsymbol{f}_{\boldsymbol{c t m}} \\
{[\mathbf{M P a}]}\end{array}$ & $\begin{array}{c}\boldsymbol{\tau}_{\boldsymbol{b}, \boldsymbol{r e s}}^{\text {med }} \\
{[\mathbf{M P a}]}\end{array}$ & $\begin{array}{c}\boldsymbol{\tau}_{\boldsymbol{b}, \boldsymbol{r e s}}^{\text {med }} / \boldsymbol{f}_{\boldsymbol{c t m}} \\
{[\mathbf{M P a}]}\end{array}$ & $\begin{array}{c}\boldsymbol{S}_{\boldsymbol{m a x}} \\
{[\mathbf{m m}]}\end{array}$ & $\begin{array}{c}\boldsymbol{s}_{\mathbf{1}} \\
{[\mathbf{m m}]}\end{array}$ & $\begin{array}{c}\boldsymbol{s}_{\mathbf{2}} \\
{[\mathbf{m m}]}\end{array}$ & $\begin{array}{c}\boldsymbol{s}_{\mathbf{3}} \\
{[\mathbf{m m}]}\end{array}$ \\
\hline Serie L10-2 & 10,81 & 3,80 & 7,05 & 2,48 & 2,25 & 0,63 & 5,33 & 9,89 \\
\hline Serie L10-5 & 22,17 & 7,80 & 10,06 & 3,54 & 1,90 & 0,04 & 3,61 & 4,84 \\
\hline Serie L10-10 & 25,37 & 8,92 & 5,73 & 2,01 & 0,04 & 0,02 & 0,11 & 2,17 \\
\hline Serie L10-20 & 24,92 & 8,43 & 2,89 & 1,02 & 0,04 & 0,01 & 0,05 & 1,53 \\
\hline
\end{tabular}

Por último, en la Tabla 5-24 se incluyen los mismos valores que en las tablas anteriores obtenidos en los ensayos sobre las probetas de la Serie L20, con relación recubrimiento/diámetro igual a 20, para los distintos niveles de corrosión considerados.

Tabla 5-24 Valores medios de los parámetros que definen las leyes de adherencia media-deslizamiento $\tau_{\text {,med }}-s$ en los resultados de los ensayos

\begin{tabular}{ccccccccc}
\hline SERIE & $\begin{array}{c}\boldsymbol{\tau}_{\boldsymbol{b}, \boldsymbol{m a x}}^{\text {med }} \\
{[\mathbf{M P a}]}\end{array}$ & $\begin{array}{c}\boldsymbol{\tau}_{\boldsymbol{b}, \boldsymbol{m a x}}^{\text {med }} / \boldsymbol{f}_{\boldsymbol{c t m}} \\
{[\mathbf{M P a}]}\end{array}$ & $\begin{array}{c}\boldsymbol{\tau}_{\boldsymbol{b}, \boldsymbol{\text { res }}}^{\text {mes }} \\
{[\mathbf{M P a}]}\end{array}$ & $\begin{array}{c}\boldsymbol{\tau}_{\boldsymbol{b}, \boldsymbol{r e s}}^{\text {med }} / \boldsymbol{f}_{\boldsymbol{c t m}} \\
{[\mathbf{M P a}]}\end{array}$ & $\begin{array}{c}\boldsymbol{s}_{\text {max }} \\
{[\mathrm{mm}]}\end{array}$ & $\begin{array}{c}\boldsymbol{s}_{\mathbf{1}} \\
{[\mathrm{mm}]}\end{array}$ & $\begin{array}{c}\boldsymbol{s}_{\mathbf{2}} \\
{[\mathrm{mm}]}\end{array}$ & $\begin{array}{c}\boldsymbol{s}_{\mathbf{3}} \\
{[\mathrm{mm}]}\end{array}$ \\
\hline Serie L20-2 & 11,92 & 2,91 & 4,58 & 1,15 & 0,27 & 0,08 & 1,06 & 6,61 \\
\hline Serie L20-5 & 14,61 & 3,55 & 7,18 & 1,80 & 4,53 & 3,14 & 5,28 & 8,93 \\
\hline Serie L20-10 & 17,28 & 4,16 & 3,71 & 0,99 & 2,80 & 1,28 & 3,72 & 4,79 \\
\hline
\end{tabular}


Como puede apreciarse en las figuras del Apartado 5.3.2.2, el diagrama tensión de adherencia localdeslizamiento se modifica a lo largo del proceso de corrosión, reproduciéndose las tendencias ya observadas para alambres indentados: por un lado, aumento del valor de la tensión de adherencia inicial $\tau_{b, 0}$, debido a la mayor tensión radial derivada de la presión ejercida por los productos de corrosión, y por otro, incremento paulatino del valor máximo de la tensión de adherencia $\tau_{b, \text { max }}^{\text {med }}$, hasta un determinado nivel de corrosión en el que se comienza a comprometer la capacidad de confinamiento del recubrimiento. En cuanto a la evolución del valor de $\tau_{b, \max }^{\text {med }}$, se observa que su tendencia ascendente se conserva hasta niveles de deterioro mayor que en el caso de los alambres indentados, debido a que los alambres lisos no cuentan con el desplazamiento radial adicional que provocan las indentaciones en su deslizamiento.

Al igual que ocurría con los alambres indentados, el aumento de los niveles de corrosión provoca adicionalmente un cambio en el modo de fallo adherente. Mientras que, en alambres sanos la totalidad de las probetas fallaron por pull-out, se observa que el inicio y el avance del deterioro por corrosión aumentan la probabilidad de que se produzca un fallo frágil (splitting). Este cambio en el modo de fallo se refleja en la evolución de los deslizamientos que definen la ley de tensión de adherencia mediadeslizamiento: $s_{1}, s_{2}$ y $s_{3}$. Con carácter general, el aumento de los niveles de corrosión provoca que estos deslizamientos desciendan de valor y converjan entre ellos (Ver Figura 5-33).

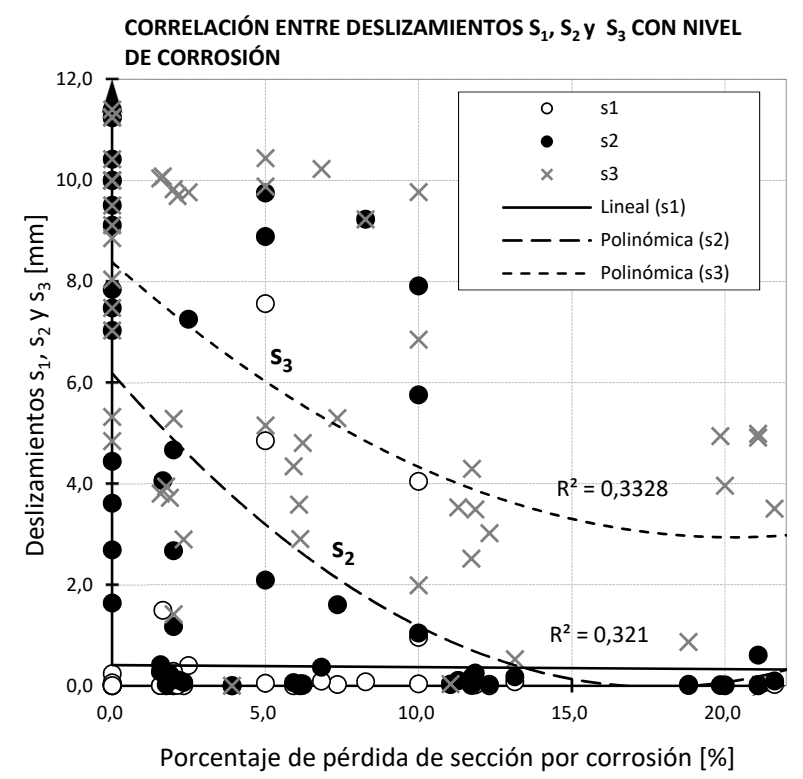

Figura 5-35 Correlación existente entre los desliz. $s_{1}, s_{2}$ y s 3 con el aumento de los niveles de corrosión en los ensayos sobre alambres lisos.

En la Figura $5-35$ se representan los deslizamientos $s_{1}, s_{2}$ y $s_{3}$ frente al porcentaje de pérdida de sección por corrosión en todas las series de ensayos sobre alambres lisos. Los valores de deslizamiento $s$, que delimitan la rama elástica de diagrama, continúan siendo muy bajos, al igual que en los alambres sanos, lo que denota un comportamiento rígido. Superado ese deslizamiento, el comportamiento de la tensión de adherencia pasa a ser muy heterogéneo, casi caótico, manteniéndose constante en ocasiones, experimentando ligeras tendencias ascendentes o descendentes en otras, o sufriendo caídas bruscas en la mayoría de los casos. Este decrecimiento abrupto, que puede relacionarse con el fallo 
por splitting, concurre más habitualmente cuanto menor es la relación recubrimiento/diámetro, de manera que, en la Serie $L 4 \operatorname{con} c / \phi=4$, aparece en la totalidad de los ensayos con corrosión. La menor capacidad de confinamiento del hormigón en estas probetas parece una explicación compatible con el fenómeno observado. En cuanto a los deslizamientos $s_{2}$, que limitan la rama plástica del diagrama, se aprecia una clara tendencia a que, a pesar de la gran dispersión de los resultados, converjan con el valor de los deslizamientos $s_{1}$ según aumenta la corrosión. Visto de otra manera, la meseta plástica del diagrama de adherencia-deslizamiento se va reduciendo con el avance del deterioro, de manera que el modo de fallo evoluciona paulatinamente de un fallo pull-out casi "puro" en alambres sanos a un fallo por splitting para alambres con niveles altos de corrosión. Aunque no ha sido habitual, el fallo por fisuración o splitting tanto en alambres sanos como indentados, ha venido acompañado en ocasiones por un estallamiento del recubrimiento de hormigón (“spalling"). Este tipo de fenómeno sólo se ha observado en las probetas con menor relación recubrimiento/diámetro y siempre para niveles altos de corrosión. En las fotografías de la Figura 5-36 se muestra el estado de la probeta L420-2 tras el ensayo de pull-out, en el que sufrió spalling del recubrimiento. Como puede observarse en la Tabla 5-11 y en la gráfica de la Figura 5-18, los valores de $s_{1}$ y $s_{2}$ en esta serie son prácticamente coincidentes $(0,002$ y $0,010 \mathrm{~mm})$, y tras superarse se produce una caída abrupta de la tensión de adherencia, coincidente con el fallo del hormigón, que conduce a valores residuales de la misma que pueden considerarse despreciables.

Por otro lado, cabe destacar que, con carácter general, los deslizamientos $s_{3}$ que dan comienzo a la rama de tensión de adherencia residual $\tau_{b, r e s}^{\text {med }}$, se comportan de manera similar a los deslizamientos $s_{1}$ y $s_{2}$, reduciendo su valor con el aumento de los niveles de corrosión (Figura 5-35).
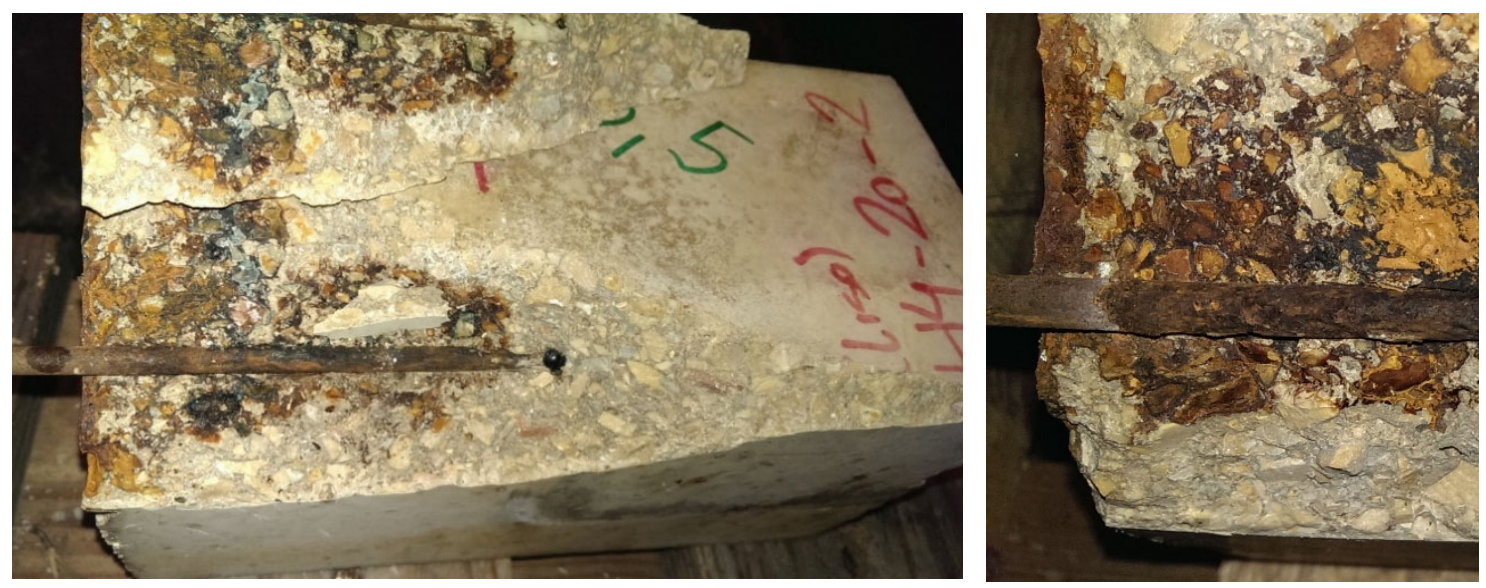

Figura 5-36 Estallamiento del recubrimiento de hormigón en la Probeta L4-20-2

Por último, en cuanto a la tensión residual, se observa que su valor en las probetas con alambres corroídos, cuando no es nulo, tiende a ser cercano al valor de la tensión de adherencia en la meseta plástica de los alambres lisos sanos, situada en el rango entre 4 y $8 \mathrm{MPa}$. Este fenómeno es especialmente evidente en los ensayos de la Serie L4 (Figura 5-16, Figura 5-17 y Figura 5-18). Además, debe señalarse que la tensión residual en los alambres indentados también se sitúa, con carácter general, en ese rango. 


\section{CAPÍTULO 6}

\section{Calibración del modelo analítico y comparación con los resultados experimentales}

\subsection{Introducción}

En este capítulo se procede a la calibración del modelo analítico desarrollado en el Capitulo 3 "Modelo analítico para evaluación de la adherencia en estructuras pretensadas de hormigón con procesos de deterioro por corrosión", mediante su comparación con los resultados experimentales recopilados y discutidos a lo largo del capítulo anterior (Capitulo 5).

Es importante señalar que, mientras que los ensayos se han llevado a cabo sobre elementos armados (probetas de pull-out convencionales), el modelo pretende simular el comportamiento de elementos pretensados. Según el desarrollo teórico expuesto en el Capítulo 3, el modelo parte de la hipótesis de que los efectos derivados de la corrosión y del pretensado son acoplables, es decir, que respetan el principio de superposición. Por tanto, partiendo de esa asunción, si al modelo íntegramente teórico para describir la adherencia en elementos pretensados se le incorporan las variables calibradas en este capítulo a partir de ensayos sobre elementos armados corroídos, se conseguirá, consecuentemente, un modelo calibrado para reproducir y evaluar el comportamiento adherente de alambres en estructuras pretensadas de hormigón con procesos de deterioro por corrosión. En definitiva, en este capítulo se pretende evaluar un fenómeno relativamente complejo mediante un procedimiento experimental simple, gracias a la intermediación de un modelo analítico. Esta hipótesis se verifica mediante la campaña experimental expuesta en el Capitulo 7.

Partiendo de esta base, el capítulo comienza con la calibración, por un lado, de las variables que describen la naturaleza y el comportamiento de los productos de corrosión, y que a la postre afectan al desarrollo de las tensiones y de la fisuración en el recubrimiento, y por otro, de las propiedades de fricción de los alambres (coeficiente de fricción $\mu$ ). Este estudio se hace a nivel de sección transversal, considerando de manera simplificada que el comportamiento tensional es idéntico a lo largo de toda la longitud del elemento.

Posteriormente, se procede a analizar la influencia de la capacidad de confinamiento, derivada tanto del espesor de recubrimiento como de su resistencia, en las propiedades adherentes de alambres lisos e indentados, complementando lo ya discutido en el Capitulo 5. Como se comentaba en ese capítulo, el modelo se convierte así en una potente herramienta de análisis que permite una mejor comprensión de cada uno de los mecanismos que intervienen en el fenómeno de la adherencia.

Finalmente, una vez calibrados los parámetros relacionados con la corrosión, se pasa al modelo tridimensional, en el que partiendo del estado tensional a nivel de sección transversal hallado en la etapa anterior, y reproduciendo las condiciones específicas del ensayo de pull-out, se acopla y analiza la dirección longitudinal del elemento. Mediante el ajuste del modelo a las gráficas de adherencia 
media-deslizamiento $\tau_{b, m e d}-s$ obtenidas de los ensayos se determina la ley de tensión de adherencia local-deslizamiento $\tau_{b}-s$, que es el elemento fundamental que permiten el acople de ambas direcciones.

\subsection{Influencia de la corrosión-Calibración de variables}

\subsubsection{Introducción}

Como se expuso en el Capitulo 2, en el modelado de la corrosión es necesario caracterizar una serie parámetros variables que definen el proceso de expansión de sus productos. En este apartado, mediante la comparación del modelo con los resultados experimentales, se calibra el incremento de volumen de los óxidos con respecto al acero virgen (coeficiente de expansión de óxidos; $n$ ), la capacidad de deformación de la capa de óxidos que rodea el alambre sano (módulo de compresibilidad volumétrica; $K_{r}$ ), la difusión de parte de los productos de corrosión a través de la red de poros del hormigón que rodea el acero (espesor de la zona porosa, $t_{p}$ ) y la penetración de óxidos en fisuras. Estas variables afectan, por un lado, al modo en el que se moviliza la capacidad de confinamiento del recubrimiento, y por otro, al avance del frente de fisuración, y permiten controlar el valor de penetración de ataque por corrosión (o su pérdida de sección equivalente) bajo el que se alcanza la máxima tensión de adherencia, así como la evolución de ésta una vez superado dicho pico. Son parámetros que están íntimamente interconectados, con un efecto similar sobre la capacidad adherente, por lo que, en ausencia de datos experimentales, se ha optado por escoger aquellos valores que mejor reproducen las tendencias extraídas de la campaña de ensayos de la presente tesis, enumeradas anteriormente, siempre dentro del rango universalmente aceptado en la bibliografía.

En este apartado también se discuten y comparan las distintas propuestas para la determinación de la relación existente entre corriente aplicada $i_{c o r r}$ y tasa de penetración de ataque $P_{x}$. Aunque existe consenso en la comunidad científica a la hora de usar la Ley de Faraday para este propósito (Andrade, et al., 1993), existen modelos alternativos, como el de Liu \& Weyers (1998) y el de Balafas \& Burgoyne (2011) que merecen ser analizados.

El proceso de calibración de cada uno de los parámetros enumerados anteriormente se ha descompuesto en dos partes diferenciadas: un estudio paramétrico, en el que se comprueba en qué forma y medida afecta al comportamiento adherente la fluctuación de la variable analizada, seguido de una comparación del modelo con los resultados de los ensayos de pull-out.

En el estudio paramétrico se ha modificado la magnitud del parámetro de estudio, manteniendo constantes el resto de las variables geométricas y mecánicas, dentro de un rango de valores probables o habituales, escogidos en virtud del análisis de la bibliografía. En la Tabla 6-1 se incluyen las variables mecánicas y geométricas de valor fijo utilizadas en el estudio paramétrico, mientras que en la Tabla 6-2 se muestra el rango de valores utilizado para cada parámetro analizado. En esta tabla, en negrita, se ha señalado el valor utilizado para cada parámetro cuando no ha sido el objeto de estudio, y que a la postre, ha sido el valor resultante tras la calibración. Las características mecánicas del hormigón utilizado han sido tomadas de las propuestas por el Código Modelo 2010 (FIB Special Activity Group $5,2011)$. El estudio se ha llevado a cabo a partir del análisis de la evolución, con el aumento de los niveles de corrosión (hasta un 20\% de pérdida de sección), de las siguientes gráficas: A) Tensión 
radial $\sigma_{r}$; B) Frente de fisuración; C) Deformaciones radiales $\varepsilon_{r}$ en la interfaz acero-hormigón; D) Deformaciones circunferenciales $\varepsilon_{\theta}$ en la interfaz acero-hormigón; E) Evolución de los módulos de elasticidad radial $E_{r}$ (compresión) y circunferencial $E_{\theta}$ (tracción) y F) Deformaciones circunferenciales $\varepsilon_{\theta} \mathrm{y}$ ancho de fisura $w$ en el perímetro del cilindro de hormigón.

Tabla 6-1 Parámetros mecánicos y geométricos con valor fijo utilizados en el estudio paramétrico

VARIABLES MECÁNICAS Y GEOMÉTRICAS CON VALOR FIJO UTILIZADAS EN EL ESTUDIO PARAMÉTRICO

\begin{tabular}{|c|c|c|c|}
\hline \multicolumn{4}{|c|}{ PARÁMETROS RELATIVOS AL HORMIGÓN } \\
\hline Parámetros Mecánicos & Notación & Unidades & Valor \\
\hline Resistencia media a compresión & $f_{c m}$ & $\mathrm{MPa}$ & 45 \\
\hline Resistencia media a tracción $\left[\boldsymbol{f}_{c t, m}=\mathbf{0 , 3} \cdot \boldsymbol{f}_{c m}{ }^{2 / 3}\right]$ & $f_{t, m}$ & $\mathrm{MPa}$ & 3,80 \\
\hline Módulo de elasticidad secante [Model Code (2010)] & $E_{0}$ & $\mathrm{GPa}$ & 34,5 \\
\hline Deformación máxima en régimen elástico & $\varepsilon_{0}$ & $\%$ & 2,5 \\
\hline Deformación última & $\varepsilon_{u}$ & $\%$ & 3,5 \\
\hline Coeficiente de Poisson & 0 & --- & 0,2 \\
\hline Tamaño máximo de árido & $d_{a}$ & $\mathrm{~mm}$ & 12 \\
\hline \multicolumn{4}{|l|}{ Parámetros Geométricos } \\
\hline Recubrimiento & $c$ & $\mathrm{~mm}$ & 50 \\
\hline \multicolumn{4}{|c|}{ PARÁMETROS RELATIVOS AL ACERO } \\
\hline Parámetros Mecánicos & Notación & Unidades & Valor \\
\hline Módulo de elasticidad & $E_{s}$ & GPa & 200 \\
\hline Coeficiente de Poisson & 0 & --- & 0,3 \\
\hline \multicolumn{4}{|l|}{ Parámetros Geométricos } \\
\hline Radio & $r b$ & $\mathrm{~mm}$ & 2,5 \\
\hline \multicolumn{4}{|c|}{ PARÁMETROS RELATIVOS AL PROCESO DE CORROSIÓN } \\
\hline Parámetros Mecánicos & Notación & Unidades & Valor \\
\hline Densidad de corriente & $i$ & $\mu \mathrm{A} / \mathrm{cm}^{2}$ & 100 \\
\hline
\end{tabular}

Tabla 6-2 Rango de valores de los parámetros relativos a la corrosión utilizados en el estudio paramétrico

\begin{tabular}{lcccccc}
\hline \multicolumn{5}{c}{ PARÁMETROS VARIABLES UTILIZADOS EN EL ESTUDIO PARAMÉTRICO } \\
\hline \multicolumn{1}{c}{ PARÁMETROS (O MODELOS) RELATIVOS AL PROCESO DE CORROSIÓN } \\
\hline Variable & Notación & Unidades & Opción 1 & Opción 2 & Opción 3 & Opción 4 \\
\hline Coeficiente de expansión de óxidos & $n$ & --- & 1,5 & $\mathbf{2}$ & 2,5 & 3 \\
\hline Módulo de compresibilidad & $K$ & $\mathrm{GPa}$ & $\mathbf{0 , 5}$ & $\mathbf{1}$ & 2 & 5 \\
\hline Penetración de óxidos en fisuras & -- & $\%$ & 10 & $\mathbf{2 5}$ & 50 & 100 \\
\hline Espesor de la capa porosa (constante ó variable) & $t_{p}$ & $\mu \mathrm{m}$ & 0 & $\mathbf{1 2 , 5}$ & $\mathbf{2 5}$ & 50 \\
\hline Modelo de tasa de penetración de ataque & -- & --- & $\begin{array}{c}\text { Faraday } \\
\text { (Andrade, et } \\
\text { al., 1993) }\end{array}$ & $\begin{array}{c}\text { Liu \& Weyers } \\
\text { (1998) }\end{array}$ & $\begin{array}{c}\text { Balafas et al. } \\
(2011)\end{array}$ \\
\hline
\end{tabular}

En cuanto a la calibración de las variables, ésta se ha llevado a cabo en virtud de la comparación del modelo con el máximo valor de la tensión de adherencia media $\tau_{b, \text { max }}^{\text {med }}$ alcanzado en los ensayos. Para ello se hace necesario que, a partir de la tensión radial derivada del proceso de corrosión $\sigma_{r, c o r r}$ arrojada por el modelo analítico (a la que debe sumarse la tensión radial resultante de las fuerzas exteriores de confinamiento procedentes del propio ensayo $\sigma_{r, c o n f}$ y la tensión radial provocada por la retracción $\sigma_{r, s h}$, así como la tensión de adherencia procedente del mecanismo de adhesión $\tau_{a d h}$ ) se 
obtenga la tensión tangencial de adherencia $\tau_{b}$, mediante la calibración del coeficiente de fricción $\mu$, gracias a la expresión que las relaciona (Eq. 6-1):

$$
\tau_{b}=\mu \cdot \sigma_{r}+\tau_{a d h}=\mu \cdot\left[\sigma_{r, c o r r}+\sigma_{r, s h}+\sigma_{r, \text { conf }}\right]+\tau_{a d h}
$$

donde:

$\begin{array}{ll}\mu & \text { Coeficiente de fricción } \\ \sigma_{r} & \text { Valor total de la tensión radial } \\ \tau_{a d h} & \text { Tensión de adherencia por adhesión química } \\ \sigma_{r, \text { corr }} & \text { Tensión radial por la acumulación de productos de corrosión } \\ \sigma_{r, \text { conf }} & \text { Tensión provocada por fuerzas de confinamiento exteriores } \\ \sigma_{r, s h} & \text { Tensión radial provocada por la retracción }\end{array}$

Los parámetros específicos para la determinación de la tensión de adherencia utilizados en el modelo se incluyen en la Tabla 6-3. En aras de la claridad, los valores reflejados en la tabla, tanto de la tensión de adherencia debida al mecanismo de adhesión $\tau_{a d h}$ como del coeficiente de fricción $\mu$, son aquellos que precisamente se han escogido tras la calibración, por reproducir de forma más precisa los resultados experimentales.

Tabla 6-3 Determinación de la tensión de adherencia: Valor de las variables utilizadas

\begin{tabular}{|c|c|c|c|}
\hline \multicolumn{4}{|c|}{ PARÁMETROS ESPECÍFICOS PARA LA DETERMINACIÓN DE LA TENSIÓN DE ADHERENCIA } \\
\hline \multicolumn{4}{|c|}{ PARÁMETROS RELATIVOS AL LA RETRACCIÓN } \\
\hline Variable & Notación & Unidades & Valor \\
\hline Edad del hormigón al comienzo del secado & $t_{s}$ & días & 28 \\
\hline Humedad relativa en el periodo de secado & $H R$ & $\%$ & 85 \\
\hline Coeficiente $\alpha_{\text {as }}[$ Model Code (2010)] & $\alpha_{\text {as }}$ & --- & 600 \\
\hline Coeficiente $\alpha_{\mathrm{ds} 1}[$ Model Code (2010)] & $\alpha_{\text {as }}$ & --- & 6 \\
\hline Coeficiente $\alpha_{\mathrm{ds} 2}$ [Model Code (2010)] & $\alpha_{\text {as }}$ & --- & 0,012 \\
\hline \multicolumn{4}{|c|}{ PARÁMETROS RELATIVOS A LA ADHERENCIA } \\
\hline Variable & Notación & Unidades & Valor \\
\hline Tensión de adherencia debida a la adhesión & $\tau_{\text {adb }}$ & $\mathrm{MPa}$ & 2 \\
\hline Coeficiente de fricción & $\mu$ & --- & 0,65 \\
\hline
\end{tabular}

Por último, cabe destacar que para la calibración de los parámetros que se analizan en este apartado se ha asimilado la tensión máxima de adherencia "media" $\tau_{b, \max }^{\text {med }}$, que es el dato que se obtiene de los ensayos de pull-out, con la tensión máxima de adherencia "local" $\tau_{b, \max }$ obtenida del modelo analítico a nivel de sección. De otra manera, se ha considerado que el sistema hormigón-acero es capaz de alcanzar la tensión máxima de adherencia $\tau_{b, \max }$ simultanemamente a lo largo de toda la longitud adherente $l_{a d b}$. En rigor, tal y como se ha visto en el Apartado 3.7 "Ley de Adherencia-Deslizamiento", esto no es estrictamente correcto, puesto que los deslizamientos que provoca la fuerza de arrancamiento $F$ deterioran las propiedades adherentes de la interfaz, de manera que para longitudes adherentes largas $(>5-10 \phi)$ las diferencias existentes entre los valores locales y medios pueden llegar a ser importantes. Como se ha visto en el Capitulo 4, en la campaña experimental de la presente tesis la longitud adherente es de $15 \phi(75 \mathrm{~mm})$, ligeramente mayor que el límite establecido. Sin embargo, se 
ha podido comprobar que las diferencias existentes entre el valor máximo local y el valor máximo medio pueden ser despreciadas para los objetivos de este apartado. En vista de este hecho, y con el objetivo de no introducir más variables que enturbien la interpretación de la influencia de los parámetros estudiados, se ha optado por asumir esta inexactitud y utilizar el modelo bidimensional (por otra parte, mucho menos exigente computacionalmente) para la calibración de los mismos.

Partiendo de los criterios expuestos anteriormente, a continuación se discute el modelo de tasa de penetración de ataque $d m_{s} / d t_{\text {corr }}$ que mejor reproduce los resultados experimentales, y se calibran el coeficiente de expansión de óxidos $n$, el módulo de compresibilidad volumétrica $K$, el espesor de la zona porosa t t y la penetración de óxidos en fisuras.

\subsubsection{Tasa de penetración de ataque $d m_{s} / d t_{c o r r}$}

El modelo de tasa penetración de ataque por corrosión $d m_{s} / d t_{c o r r}$ determina la pérdida de sección del alambre de acero para un periodo de tiempo $t_{c o r r} \mathrm{y}$ una densidad de corriente de corrosión $i_{\text {corr }}$ dadas. Es un importante parámetro en el análisis de la adherencia ya que, por un lado, determina la pérdida de sección del acero y, por otro, la evolución de la fisuración del recubrimiento derivada del incremento de volumen de los productos de corrosión. Habitualmente, el modelo con mayor consenso en la comunidad científica es el basado en la ley de Faraday (Capitulo 2), aplicado por Andrade en todos sus trabajos, el cual arroja una tasa teórica de penetración de ataque $P_{x}$ que predice con bastante precisión las pérdidas reales de sección medidas mediante gravimetría (Andrade, et al., 1993) (Alonso, et al., 1998). A la hora de modelar el estado tensional en el recubrimiento provocado por el fenómeno de la corrosión, cuando se utilizan modelos basados en la teoría de cilindros de pared gruesa, y siempre y cuando no se tomen medidas adicionales como las relativas al establecimiento de una "zona porosa" alrededor del acero (Ver Capitulo 2), la ley de Faraday arroja velocidades de penetración de ataque $P_{x}$ que generan un volumen de óxidos tal que provocarían una fisuración temprana (si se utilizan los valores de coeficiente de expansión $n$ habituales), ligeramente alejada de lo observado en la mayoría de las campañas experimentales recogidas en la bibliografía. Por ello, algunos autores, a la hora de modelar el fenómeno de la corrosión, han establecido diferentes estrategias para favorecer el retraso de la fisuración, siendo una de ellas la de modificar el modelo de penetración de ataque $P_{x}$ (o modelo de producción de óxidos, ambos estrechamente relacionados a través del coeficiente de expansión $n$ ). En ese contexto se enmarcan los modelos de Liu y Weyers (Liu \& Weyers, 1998) y de Balafas y Burgoyne (Balafas \& Burgoyne, 2011), ambos desarrollados en el Capitulo 2 e implementados en el modelo analítico de la presente tesis. En principio, cualquier modelo que viole el cumplimiento de la Ley de Faraday debería descartarse de antemano, pero para evitar planteamientos apriorísticos se ha decidido estudiar su comportamiento. A lo largo de este apartado, se compara el efecto que tiene el uso de los distintos modelos de tasa de penetración de ataque $d m_{s} / d t_{c o r r}$ sobre la evolución de las tensiones, las deformaciones y la fisuración en el recubrimiento de hormigón; se confrontan los resultados que arrojan en cuanto a la evolución de la tensión de adherencia $\tau_{b}$ con los obtenidos en la campaña experimental de la presente tesis, y por último, se contrastan los resultados teóricos de pérdida de sección con las pérdidas reales halladas mediante gravimetría. Estos análisis han permitido concluir que cualquier modelo de tasa de 
penetración de ataque alternativo al basado en la Ley de Faraday conduce a resultados no sólo erróneos sino también inseguros.

\subsubsection{Estudio de sensibilidad de la variable}

Tal y como se apuntaba en el Capitulo 2, mientras que la Ley de Faraday se basa en la consideración de que la tasa de penetración de ataque $P_{x}$ es constante y, por tanto, la pérdida de sección crece linealmente con el tiempo, el modelo de Liu y Weyers (1998), apoyado en sus resultados experimentales, se sustenta en la hipótesis de que la tasa de penetración de ataque $P_{x}$ decrece con el incremento del espesor de la capa de óxidos acumulados, ya que la distancia de difusión de los iones del acero aumenta. Posteriormente, Balafas y Burgoyne (2010) señalaron que ambos modelos presentaban inconvenientes apreciables: por un lado, la Ley de Faraday no tenía en cuenta el gradual engrosamiento de la capa de óxidos y la mayor dificultad para que difundieran los iones de acero, y por el otro, el modelo de Liu y Weyers arrojaba, para las etapas iniciales del proceso de corrosión, tasas de penetración de ataque muy elevadas y, por tanto, poco realistas. Para minimizar los inconvenientes que desde su punto de vista tenían ambos modelos, los autores propusieron un modelo alternativo que combinaba ambas distribuciones, ciñéndose a Ley de Faraday en fases tempranas de la corrosión, para posteriormente adaptarse al modelo propuesto por Liu y Weyers (Balafas \& Burgoyne, 2010).
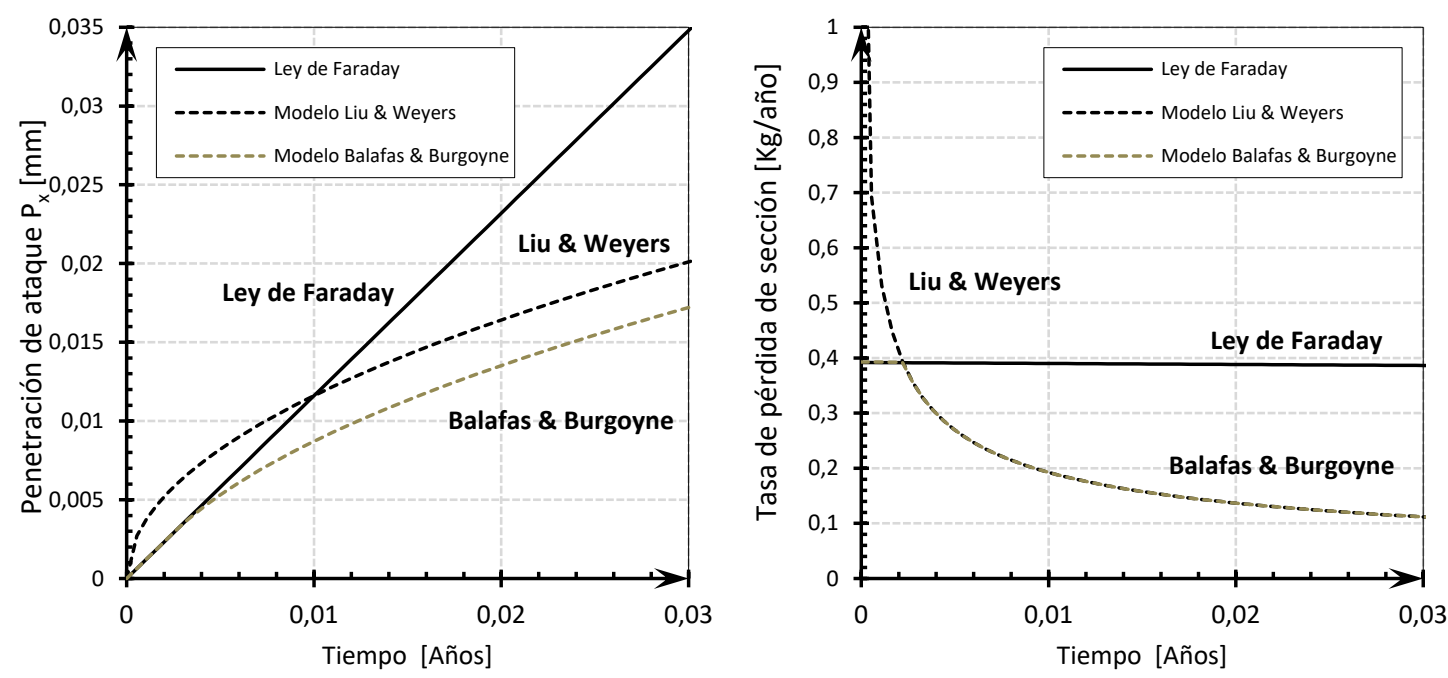

Figura 6-1 Comparación de la penetración de ataque por corrosión $P_{x}$ a lo largo del tiempo distintos modelos de tasa de producción de óxidos: Ley de Faraday; Modelo de Liu y Weyers; y Modelo de Balafas y Burgoyne.

En la Figura 6-1 se compara cómo evoluciona la penetración de ataque $P_{x}$ y la tasa o velocidad de pérdida de sección $d m_{s} / d t_{\text {corr }}$ a lo largo del tiempo para los distintos modelos considerados. Para una densidad de corriente $i_{c o r r}=100 \mu \mathrm{A} / \mathrm{cm}^{2}$ y las condiciones mecánicas y geométricas recogidas en la Tabla 6-1, el modelo de Liu y Weyers arroja una mayor penetración de ataque $P_{\mathrm{x}}$ hasta que se alcanza un tiempo $t_{c o r r}$ igual a 3,6 días (0,010 años) desde la despasivación del alambre. Por tanto, para ese tiempo $t_{\text {corr, }}$ la pérdida de masa de acero virgen $m_{s}$ es equivalente para los modelos de Faraday y de Liu-Weyers (Ver apartado 3.3.3). Ese tiempo equivaldría, para las condiciones establecidas, a aproximadamente un $1 \%$ de pérdida de sección con respecto al área original del acero. 

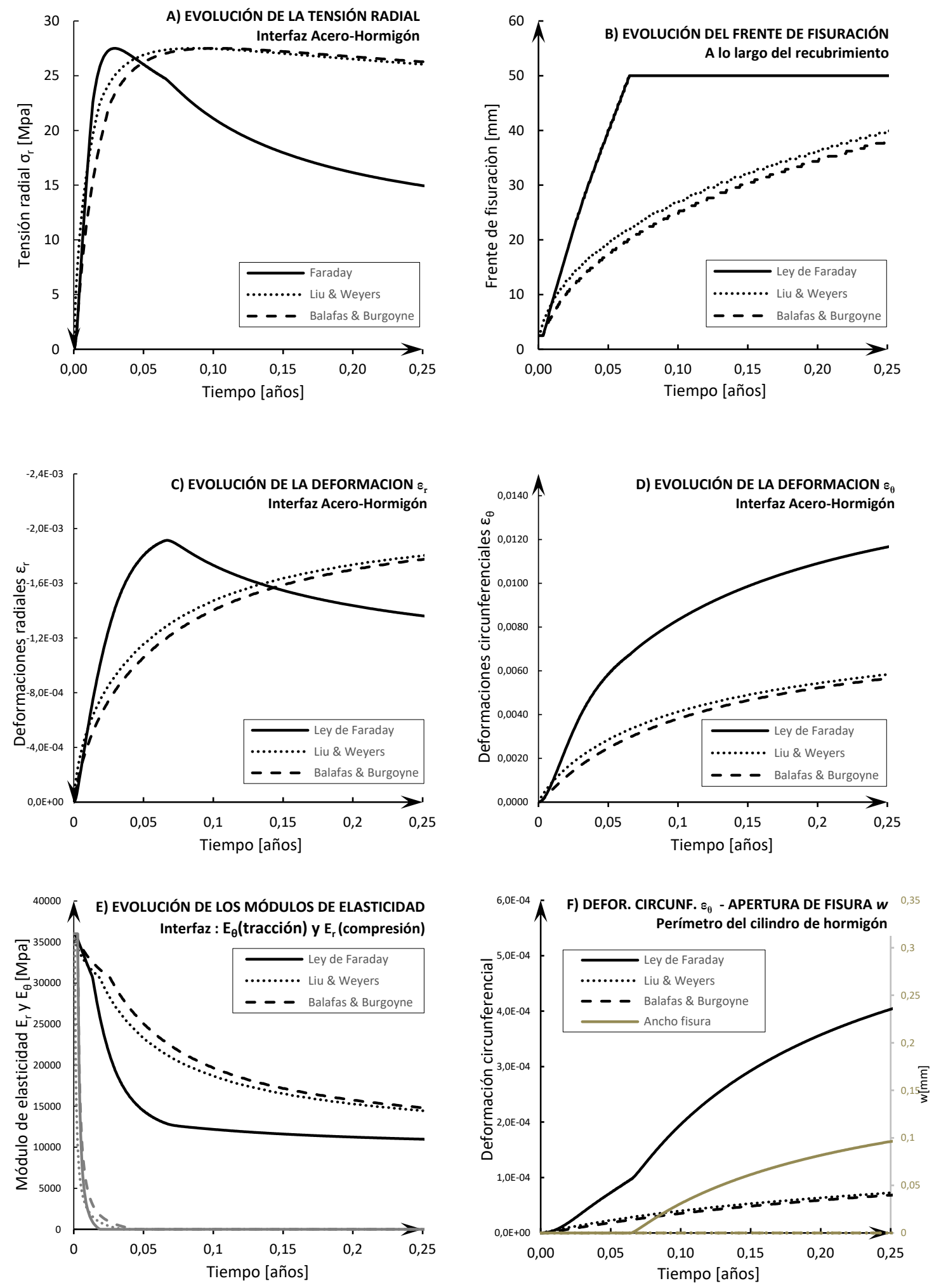

Figura 6-2 Influencia del modelo de tasa de penetr. de ataque en la evolución de distintos parámetros en relación con el aumento de la pérdida de sección por el proceso de corrosión: A) Tensión radial $\sigma_{n}$; B) Evolución del frente de fisuración; C) Deformaciones radiales $\varepsilon_{r}$ en la interfaz acero-hormigón; D) Deformaciones circunferenciales $\varepsilon_{\theta}$ en la interfaz acero-hormigón; E) Evolución de los módulos de elasticidad radial $E_{r}$ (compresión) y circunferencial $E_{\theta}$ (tracción) y F) Deformaciones circunferenciales $\varepsilon_{\theta}$ y ancho de fisura w en el perímetro del cilindro de hormigón. 
A continuación, se lleva a cabo un estudio paramétrico, analizando en qué forma y grado afecta la variación del modelo de tasa de pérdida de sección de acero a los resultados obtenidos mediante el modelo analítico propuesto en el Capitulo 3. Fijando el valor de los parámetros recogidos en la Tabla 6-1 (en negrita), en la Figura 6-2 se recoge como afecta la variación del modelo de tasa pérdida de sección de acero $d m_{s} / d t_{c o r r}$ a la evolución de los valores de: A) Tensión radial $\sigma_{r}$; B) Evolución del frente de fisuración; C) Deformaciones radiales $\varepsilon_{r}$ en la interfaz acero-hormigón; D) Deformaciones circunferenciales $\varepsilon_{\theta}$ en la interfaz acero-hormigón; E) Evolución de los módulos de elasticidad radial $E_{r}$ (compresión) y circunferencial $E_{\theta}$ (tracción) y F) Deformaciones circunferenciales $\varepsilon_{\theta}$ y ancho de fisura $w$ en el perímetro del cilindro de hormigón. Como era previsible, la tensión radial máxima $\sigma_{r, m a x}$ (Figura 6-2-A) que se alcanza en todos los casos es la misma, puesto que el modelo seleccionado no afecta a la capacidad de confinamiento del recubrimiento de hormigón. El mayor consumo de acero virgen determinado por el modelo de Liu y Weyers (1998) para etapas tempranas del proceso de corrosión (pedida de sección $\approx<1 \%$ para las condiciones consideradas) ocasiona el desarrollo de mayores tensiones y deformaciones, pero estas diferencias apenas son perceptible en las gráficas de la Figura 6-2. Superado ese límite, los modelos de Liu y Weyers y de Balafas y Burgoyne requieren un menor volumen disponible para alojar los productos de corrosión con respecto al modelo que sigue la Ley de Faraday, lo que hace que el desplazamiento radial de la cara interior del cilindro de hormigón sea menor y, por tanto, se produzca un retraso en el desarrollo de las tensiones y deformaciones, tanto radiales como circunferenciales, [Figura 6-2-A, $C, D$ y F], una menor pérdida de rigidez (Figura 6-2-E) y un menor avance del frente de fisuración (Figura 6-2-F). Este último factor es especialmente significativo, puesto que mientras el modelo que utiliza la ley de Faraday predice que la fisuración alcanza el perímetro exterior del recubrimiento de hormigón transcurridos 0,0652 años (23,8 días), los modelos alternativos no anticipan este hecho dentro de los 100 días analizados. Estos resultados difieren considerablemente de las observaciones realizadas en los ensayos de esta tesis, donde las probetas con una relación $c / \phi=10$ (equivalente a la utilizada en las gráficas de la Figura 6-2), fisuraron en un rango de tiempo comprendido entre los 20 y los 30 días desde la despasivación del acero $\left(i_{\text {corr }}=100 \mu \mathrm{A} / \mathrm{cm}^{2}\right)$.

\subsubsection{Selección del modelo de penetración de ataque}

En la Figura 6-3 se comparan los resultados experimentales con los obtenidos mediante el modelo analítico, representándose la evolución de las máximas tensiones de adherencia normalizadas $\tau_{b \text {,max }} / f_{c t \text { m }}$ $[\mathrm{MPa} / \mathrm{MPa}]$, con respecto al tiempo transcurrido desde la despasivación $t_{\text {corr }}$ para distintas relaciones $c / \varphi\left(4\right.$ y 10) y los distintos modelos contemplados de tasa de pérdida de sección de acero $d m_{s} / d t_{c o r r}$ [Faraday (Andrade), Liu\&Weyers y Balafas\&Bourgoyne].

Los datos más relevantes para la obtención de las gráficas analíticas se incluyen en la Tabla 6-4, mientras que el resto de parámetros utilizados pueden consultarse en la Tabla 6-1, para el cálculo de tensiones radiales $\sigma_{r}$ a nivel de sección, y en la Tabla 6-3, para la determinación de la tensión de adherencia $\tau_{b}$. En cuanto a las características mecánicas del hormigón, se han escogido las propiedades específicas de los hormigones correspondientes a la serie de alambres lisos (L4 y L10), aunque al normalizarse la tensión de adherencia mediante la resistencia a tracción del hormigón no existen grandes diferencias en el uso de un hormigón u otro. Cómo se justificó en la introducción del presente capítulo, el análisis en este apartado se hace a nivel de sección, sin tener en cuenta la influencia que la Ley de adherencia local-deslizamiento tendría sobre el desarrollo de la tensión de adherencia. 
El modelo bidimensional no tiene en cuenta las indentaciones, por lo que las mayores desviaciones entre los resultados experimentales y las predicciones del modelo aparecen en los casos de alambres sanos indentados, independientemente del recubrimiento. Tal y como se ha expuesto al comienzo de este capítulo, para el tramo que comprende niveles de corrosión muy bajos $(\approx<1 \%)$, el parámetro controlante de la capacidad adherente es el acabado superficial del acero, con relativa independencia del recubrimiento, puesto que la capacidad de confinamiento no llega a movilizarse por completo. Por tanto, es en este tramo donde se concentran las mayores diferencias ya que, con el paulatino aumento de la corrosión, el parámetro controlante pasa a ser la relación recubrimiento/diámetro, pasando el acabado superficial del acero a un segundo plano.

Tal y como había sido observado en el estudio de sensibilidad, la tensión de adherencia (estrechamente vinculada a las tensiones radiales) determinada a partir de la presión ejercida por los productos de corrosión que se forman a partir de la masa de acero consumida según la Ley de Faraday presenta un mejor ajuste a los resultados experimentales. Los modelos alternativos, cuyo desarrollo es prácticamente parejo entre sí, incrementan de manera considerable el tiempo necesario para alcanzar la tensión máxima de adherencia, y una vez superado el pico, la tensión residual apenas desciende.

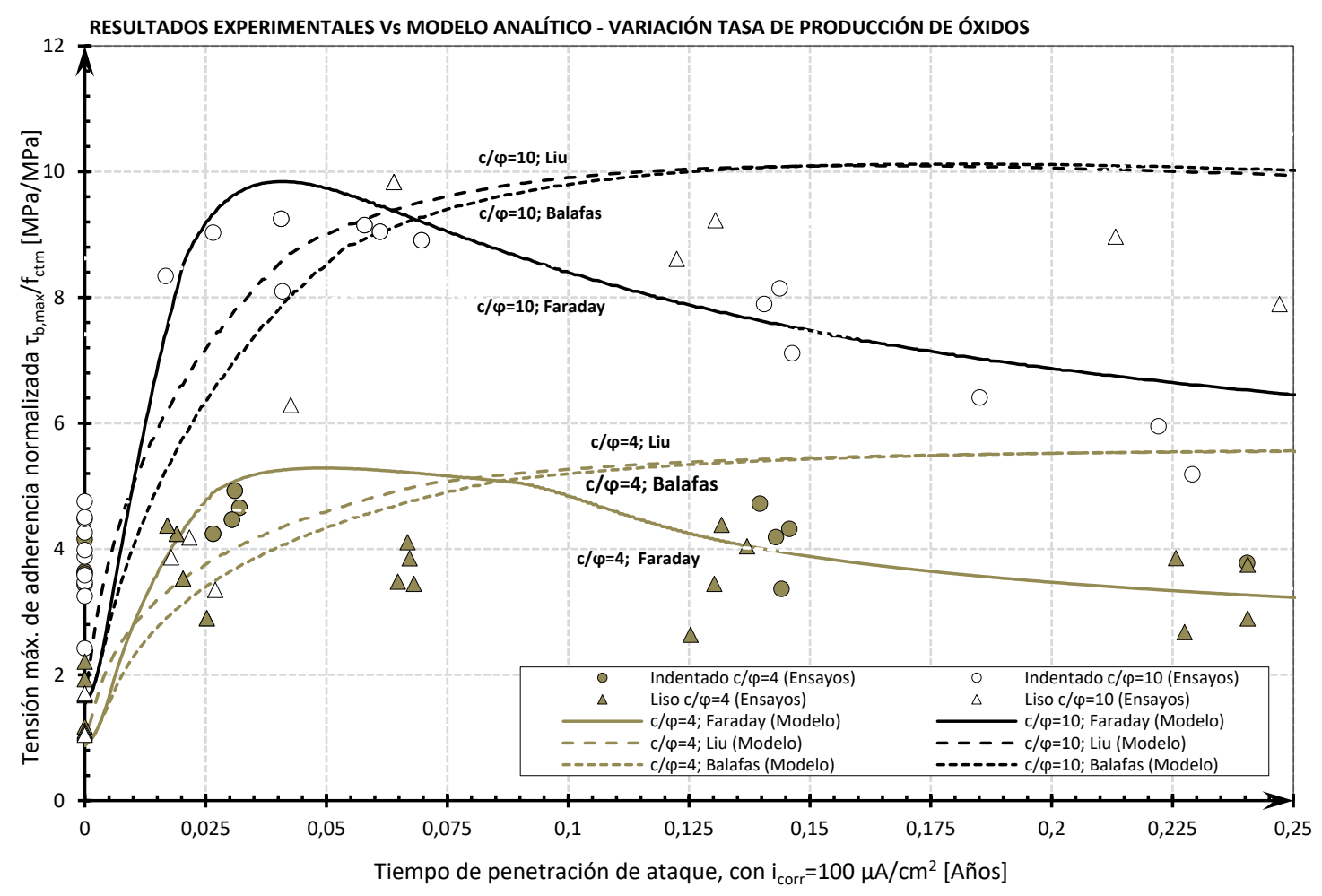

Figura 6-3 Comparación de la evolución en el tiempo de la tensión de adherencia normalizada $\tau_{b, \text { max }} / f_{\text {ctm }}[\mathrm{MPa} / \mathrm{MPa}]$, para distintos modelos de tasa de penetración de ataque, con respecto a los resultados experimentales.

Ahora bien, tal y como se ha visto a lo largo del presente capítulo, en la caracterización del proceso de corrosión intervienen una serie de parámetros a los que el modelo es muy sensible. Por lo que, con valores más restrictivos de espesor equivalente $t_{p}$ de la zona porosa o con valores más altos del módulo de compresibilidad $K$, por citar los vistos hasta ahora, se podría llegar a mejorar el ajuste de 
las gráficas basadas en los modelos de Liu y Weyers (Liu \& Weyers, 1998) y Balafas y Burgoyne (Balafas \& Burgoyne, 2011). Por tanto, con lo visto hasta ahora, sería complicado decantarse por uno u otro modelo. Afortunadamente, las pérdidas de sección real halladas mediante gravimetría, que se han recogido en el Capitulo 5 de la presente tesis, pueden ser utilizadas como el elemento de comparación definitivo para la selección del modelo de penetración de ataque.

Tabla 6-4 Valor de los parámetros de entrada en el modelo analítico para la obtención de las gráficas de la Figura 6-3

\begin{tabular}{|c|c|c|c|c|c|c|c|c|c|c|}
\hline \multirow[b]{2}{*}{ SERIE } & \multicolumn{2}{|c|}{$\begin{array}{l}\text { Parámetros } \\
\text { geométricos }\end{array}$} & \multicolumn{2}{|c|}{$\begin{array}{l}\text { Parámetros } \\
\text { mecánicos }\end{array}$} & \multicolumn{4}{|c|}{ Parámetros relativos a la corrosión } & \multicolumn{2}{|c|}{ Adherencia } \\
\hline & $C[\mathrm{~mm}]$ & $t_{p, c r i}[\mu m]$ & $\begin{array}{c}f_{c m} \\
{[\mathrm{MPa}]}\end{array}$ & $\begin{array}{c}f_{c t, m} \\
{[\mathrm{MPa}]}\end{array}$ & $\frac{d m_{s}}{d t_{c o r r}}$ & $n$ & $K_{r}$ & \% óx. fis. & $\begin{array}{c}\tau_{a d b} \\
{[\mathrm{MPa}]}\end{array}$ & $\mu$ \\
\hline $\mathrm{c} / \varphi=4$ & 17,5 & 75 (variable) & 32,43 & 3,79 & \multirow{2}{*}{$\begin{array}{c}\text { Faraday (Andrade) } \\
\text { Liu-Weyers } \\
\text { Balafas-Bourgoyne }\end{array}$} & \multirow{2}{*}{2,0} & 0,5 & $75 \%$ & \multirow{2}{*}{2,0} & \multirow{2}{*}{0,65} \\
\hline $\mathrm{c} / \varphi=10$ & 47,5 & 75 (variable) & 43,72 & 3,16 & & & 1,0 & $25 \%$ & & \\
\hline
\end{tabular}

Para analizar la bondad de los modelos se recurre a criterios estadísticos básicos, metodología tomada de la tesis de Prieto (Prieto Rábade, 2014), que a su vez se basa en las formulaciones de la Monografía 19 de ACHE “Modelos lineales aplicados al hormigón estructural” (ACHE, 2012) y de Peña (Peña, 2002). Por un lado, se han representado los diagramas predicción-realización de pérdida de sección del acero, para los tres modelos de tasa de penetración de ataque considerados: Ley de Faraday (Andrade et al, 1993), Modelo de Liu \& Weyers y Modelo de Balafas \& Burgoyne. En ellos se comparan los resultados experimentales de pérdida de sección real obtenidos mediante gravimetría, según la metodología expuesta en el Capitulo 4, frente a la pérdida de sección teórica. La bisectriz de estos diagramas delimita dos regiones: la Zona de Subpredicción, aquella en la que el modelo estima resultados por debajo de los observables (situada sobre la bisectriz); y la Zona de Sobrepredicción, en los que los resultados del modelo superan en valor a los observables (situada por debajo de la bisectriz). En estos diagramas, también se ha incluido el ajuste de los resultados mediante regresión lineal simple, obteniéndose tanto la ecuación que describe la recta como el coeficiente de determinación $R^{2}$. Como es bien sabido, la recta de regresión ortogonal es aquella que minimiza la suma de cuadrados de las distancias euclídeas entre los valores observados de la variable dependiente, en este caso la penetración de ataque por corrosión $P_{x}$ (o el porcentaje de pérdida de sección asociado), y los valores estimados de la misma, $\widehat{P}_{x}$. Es decir, se minimiza el siguiente sumatorio: $\sum\left(P_{x}-\widehat{P}_{x}\right)^{2}$. En el caso ideal, la recta de regresión simple debería de coincidir con la bisectriz del diagrama predicción-realización.

Otro aspecto importante para el análisis de los modelos es el punto de corte E de la recta de regresión con la bisectriz del primer cuadrante del diagrama predicción-realización, que aporta información de las zonas en la cuales, en promedio, el modelo está del lado de la seguridad o de la inseguridad, separando en regiones que en promedio son inseguras (subpredicción) de aquellas que en promedio son seguras (sobrepredicción).

Por último, la bondad de los modelos se ha evaluado también a través del ratio $M$ entre la pérdida de sección real (gravimetrías) y las predicciones obtenidas mediante los modelos planteados. El ratio $M$ para cada caso contemplado se obtiene dividiendo el valor experimental de la pérdida de sección (o su variable asociada $\left.P_{x, e x p}\right)$, entre el valor predictivo, $P_{x, e s t}$ : 
TESIS DOCTORAL INFLUENCLA DE LA CORROSIÓN EN LA ADHERENCLA DE ALAMBRES EN ELEMENTOS PRETENS ADOS DE HORMIGÓN

$$
M=\frac{P_{x, \text { exp }}}{P_{x, e s t}}
$$

En la Figura 6-4 se incluyen los diagramas predicción-realización de pérdida de sección del acero, para los tres modelos de tasa de penetración de ataque $P_{x}$ considerados: Ley de Faraday, Modelo de Liu \& Weyers y Modelo de Balafas \& Burgoyne. En ellos se ha representado la bisectriz del primer cuadrante, la recta de regresión ortogonal y el punto de corte E. En la Tabla 6-5 se muestran, para los modelos analizados, el valor medio $\mu_{M}$ del ratio $M=P_{x, \text { exp }} / P_{x, e s t}$, su desviación típica, $s_{M}$, su coeficiente de variación $C o V$, así como sus valores máximo y mínimo.
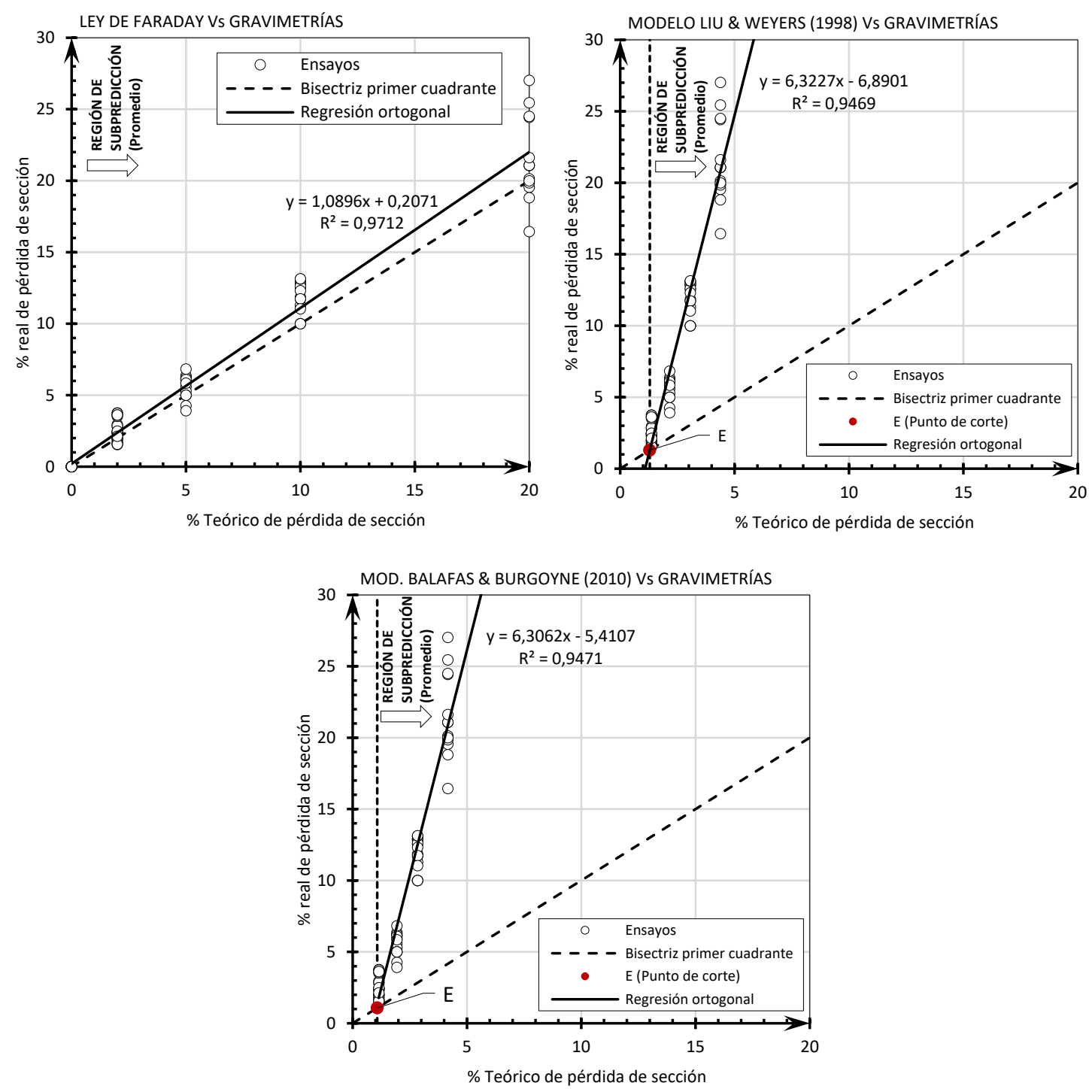

Figura 6-4 Diagramas predicción-realización de la pérdida de sección del acero, para los tres modelos de tasa de penetración de ataque considerados: Ley de Faraday, Modelo de Lin \& Weyers y Modelo de Balafas \& Burgoyne.

Como puede observarse en la Figura 6-4, las estimaciones del modelo utilizando la Ley de Faraday pueden considerarse muy buenas, aunque con cierto sesgo a subestimar el valor real de la pérdida de 
sección. El punto de corte E se encuentra en el tercer cuadrante del diagrama (no representado), por lo que en promedio todo el modelo se encuentra en la región de inseguridad o de subpredicción. Este hecho se ve claramente reflejado en el valor de la media $\mu$ del ratio $M$, recogido en la Tabla 6-5, que señala que los datos experimentales son, en promedio, un 16,8\% superiores a sus respectivas estimaciones. Por otro lado, el modelo basado en la Ley de Faraday ofrece un coeficiente de variación $\mathrm{CoV}$ igual a 0,213 , un valor razonable que nos señala que la dispersión del ratio $M$ está controlada.

Tabla 6-5 Valores estadísticos vinculados al ratio $M$, para los distintos modelos analizados

\begin{tabular}{lccccc}
\hline Modelo & $\begin{array}{c}\text { Media } \\
\boldsymbol{\mu}_{\mathbf{M}}\end{array}$ & $\begin{array}{c}\text { Desviación } \\
\text { típica sM }\end{array}$ & CoV & Máximo & Mínimo \\
\hline Ley de Faraday (Andrade el al, 1993) & 1,168 & 0,249 & 0,213 & 1,881 & 0,774 \\
\hline Liu \& Weyers (1998) & 3,105 & 1,312 & 0,423 & 6,170 & 1,129 \\
\hline Balafas \& Burgoyne (2011) & 3,424 & 1,305 & 0,381 & 6,498 \\
\hline
\end{tabular}

En cuanto a los otros dos modelos, los diagramas predicción-realización nos muestran que las estimaciones se encuentran totalmente alejadas de la bisectriz del primer cuadrante, en la zona de subpredicción y, por tanto, no son capaces de predecir el valor de pérdida de sección por procesos de corrosión obtenido en los ensayos. En el Modelo de Liu \& Weyers, el punto de corte E entre la bisectriz y la recta de regresión ortogonal se da para un valor de 1,29\% de pérdida de sección, mientras que para el modelo de Balafas \& Burgoyne tiene lugar para un 1,07\%. Por tanto, una vez superados esos niveles de corrosión, las predicciones de ambos modelos se encuentran, en promedio, en la zona de inseguridad o subpredicción. La media $\mu$ del ratio $M$ de ambos modelos es especialmente significativa (Tabla 6-5), ya que muestra que los valores experimentales son en promedio un $210 \%$ superiores a sus respectivas estimaciones, para el modelo de Liu \& Weyers, y un $242 \%$ superiores en el caso del Modelo de Balafas \& Burgoyne.

La evidente falta de capacidad predictiva que presenta el modelo de Liu \& Weyers y su versión modificada por parte de Balafas \& Burgoyne, pone de manifiesto un problema de base en la formulación de ambos, es decir, su falta de adecuación a las Ley de la electrólisis de Faraday. En esta última, la masa de acero consumida $m_{s}$ es directamente proporcional a la densidad de corriente de corrosión $i_{\text {corr }}$ y al tiempo transcurrido desde la despasivación del acero tcorr (Eq. 6-6). En el modelo de Liu-Weyers, tal y como se refleja en el Capitulo 2 de la presente tesis, la penetración de ataque es directamente proporcional a la raíz cuadrada del producto de $i_{\text {corr }}$ por $t_{\text {corr }}\left(m_{r}=\sqrt{2 k_{p} t_{\text {corr }}}\right)$. Por tanto, para el mismo tiempo de exposición a la corrosión, la hipótesis del modelo Liu-Weyers conduce a subestimar la cantidad de acero virgen consumido en comparación con la contrastada Ley de Faraday, lo que a su vez conduce, a igualdad de otros parámetros como el coeficiente de expansión de óxidos o el coeficiente de compresibilidad $K_{t}$, a sobreestimar el tiempo hasta la fisuración.

La inconsistencia del Modelo Liu-Weyers con la ley de Faraday queda patente en el siguiente desarrollo. En el Capitulo 2 de la presente tesis se ha visto que el Modelo de Liu-Weyers supone que la tasa de producción de óxidos $d m_{r} / d t_{c o r r}$ no es constante, sino que es inversamente proporcional a la cantidad de productos de corrosión $m_{r} y$, consecuentemente, decrece con el tiempo torr (Eq. 6-3):

$$
\frac{d m_{r}}{d t_{\text {corr }}}=\frac{k_{p}}{m_{r}}
$$


Hallado el valor de la cantidad de productos de corrosión generados $m_{l}$, mediante la solución de la ecuación diferencial anterior, se sustituye en la expresión en (Eq. 6-3), obteniéndose una expresión (Eq. 6-4) en la que se aprecia claramente que la tasa de producción de óxidos es inversamente proporcional a la raíz cuadrada del tiempo transcurrido desde la despasivación del acero $t_{c o r r}$ :

$$
\frac{d m_{r}}{d t_{\text {corr }}}=\sqrt{\frac{k_{p}}{2 t_{\text {corr }}}}
$$

Por la ley de Faraday de la electrólisis se sabe que la tasa de pérdida de acero virgen $d m_{r} / d t_{\text {corr }}$ es la siguiente (Eq. 6-5):

$$
\frac{d m_{s}}{d t_{\text {corr }}}=\frac{M}{z F} \cdot \pi \cdot d_{b} \cdot i_{c o r r}
$$

$\mathrm{Y}$, por tanto, conociendo el ratio entre el peso molecular del acero y el del óxido $r_{m}$, la tasa de producción de óxidos puede expresarse cómo sigue (Eq. 6-6):

$$
\frac{d m_{r}}{d t_{c o r r}}=\frac{M}{z F} \frac{1}{r_{m}} \cdot \pi \cdot d_{b} \cdot i_{c o r r}
$$

La última expresión muestra que la densidad de corriente $i_{c o r r}$ es directamente proporcional a la tasa de producción de óxidos, y si se acepta la premisa de la que parte el modelo de Liu \& Weyers (Eq. 6-4), también será inversamente proporcional a la raíz cuadrada del tiempo $t_{c o r r}$.

Como se vio en el Capitulo 3, en el modelo de Liu-Weyers, $k_{p}$ es un valor constante que puede expresarse en función de la densidad de corriente $i_{c o r r}$, tal y como sigue (Eq. 6-7):

$$
k_{p}=0,098 \cdot\left(\frac{1}{r_{m}}\right) \pi d_{b} i_{c o r r}
$$

Por lo expuesto anteriormente, $k_{p}$ no podría ser un valor constante, ya que es directamente proporcional a la densidad de corriente $i_{c o r r}$ y ésta es inversamente proporcional a la raíz cuadrada del tiempo. Por tanto, la formulación propuesta por Liu \& Weyers (1998) en su modelo de tasa de producción de óxidos no es consistente.

Esta incongruencia ha sido detectada por otros autores, tales como Guzmán et al (2012), Chermin y Val (2010) y El Maaddawy y Soudki (2007). Guzmán et al. (2012) desarrollan un modelo de elementos finitos para el análisis de la fisuración derivada de procesos de corrosión. En su trabajo justifican el uso de la Ley de Faraday como modelo para la tasa penetración de ataque, de carácter constante, frente a aquellos estudios en los que dicha tasa es inversamente proporcional a la cantidad de óxidos acumulados y, por tanto, dependiente del tiempo. Guzmán et al. (2012) señala que estos últimos, basados en el parámetro constante $k_{p}$ calibrado mediante ensayos experimentales y cuyo valor difiere hasta un orden de magnitud en función del trabajo que se consulte, arrojan resultados que subestiman la tasa de producción de óxidos. Por su parte, El Maaddawy and Soudki (2007) señalan que la hipótesis en la que se basa el modelo de Liu-Weyers conduce a subestimar la tasa de penetración de ataque, en especial, si lo que se está analizando son ensayos de corrosión acelerada en laboratorio, donde la intensidad de corriente es constante, y por tanto, se espera que la tasa de penetración de ataque también lo sea. Chermin y Val (2010), siguiendo el razonamiento que se ha recogido en esta tesis 
anteriormente, exponen la inconsistencia que supone la utilización de un parámetro $k_{p}$ constante en función de una densidad de corriente de corrosión $i_{\text {corr }}$ que debe ser variable si se acepta que la tasa de producción de óxidos $d m_{r} / d t_{c o r r}$ (proporcional a la tasa de penetración de ataque) también lo es. Chermin y Val (2010) llegan incluso a señalar cual pudo ser la fuente del error en el modelo.

En definitiva, el modelo de Liu-Weyers (1998), que intenta retrasar las fisuraciones tempranas a las que conduce la aplicación de la Ley de Faraday y que difieren de las observaciones experimentales, no respeta la ley de la electrólisis de Faraday y, por tanto, no debe ser utilizado, ya que su uso conduce a subestimar la pérdida de sección del acero y la fisuración del hormigón, situándose del lado de la inseguridad. Es significativo que uno de los artículos de referencia en el modelado de la corrosión, que ha sido citado en múltiples ocasiones y del que parten muchos otros trabajos, arranque de premisas erróneas, y pone de manifiesto las escasas certidumbres que existen en el análisis del fenómeno de la corrosión, siendo indudablemente el cumplimiento de Ley de Faraday una de ellas.

A la vista de la revisión bibliográfica, del estudio de sensibilidad, y de la comparación entre los resultados del modelo analítico y los obtenidos en la campaña experimental, en esta tesis se utiliza la ley de Faraday para determinar la tasa de penetración de ataque.

\subsubsection{Coeficiente de expansión de óxidos $n$.}

Como se expuso en los Capítulos 2, cuando el acero embebido en el hormigón sufre un proceso de degradación por corrosión, se disuelve la capa pasiva del acero y se forman productos de oxidación. $\mathrm{Al}$ iniciarse este proceso, una capa de acero virgen de profundidad $P_{x}$ se transforma en óxido, cuyo volumen específico es mayor que el del acero original, generándose tensiones en el hormigón circundante y propiciándose la aparición de fisuras y desprendimientos en el recubrimiento. El coeficiente de expansión de óxidos $n$ determina la relación existente entre el volumen específico del acero virgen y el de los productos de corrosión.

\subsubsection{Estudio de sensibilidad de la variable}

Como se vio en el Capitulo 3, se denomina $n$ al ratio entre el volumen total de los productos de corrosión $\Delta V_{r}$ (sin comprimir) y el volumen de acero virgen consumido en el proceso $\Delta V_{s}^{\text {corr }}$ (Eq. 6-8):

$$
n=\frac{V_{r}}{\Delta V_{s}^{\text {corr }}}
$$

El coeficiente de expansión de óxidos $n$ es un importante parámetro del modelo, ya que los resultados de deformaciones, tensiones y fisuración son muy sensibles al valor que se tome para el mismo. Para un mismo tiempo desde la despasivación $t_{\text {corr }}$ y una misma densidad de corriente $i_{\text {corr }}$, valores bajos de $n$ suponen un menor volumen de productos de oxidación $V_{r}$, lo que a su vez repercute en un menor desplazamiento radial de la cara interior del cilindro de hormigón que confina el alambre, ya que el 
espacio que debe liberarse entre el acero y el recubrimiento para alojar la expansión de los óxidos disminuye. Un menor desplazamiento radial del hormigón en contacto con el acero trae consigo menores deformaciones y tensiones, así como un menor avance del frente de fisuración. Este hecho puede apreciarse con claridad en la Figura 6-5, donde se compara cómo evoluciona el desplazamiento radial de la cara interna del cilindro de hormigón con el aumento de la penetración de ataque $P_{x}$, para distintos coeficientes $n$ de expansión de óxidos.

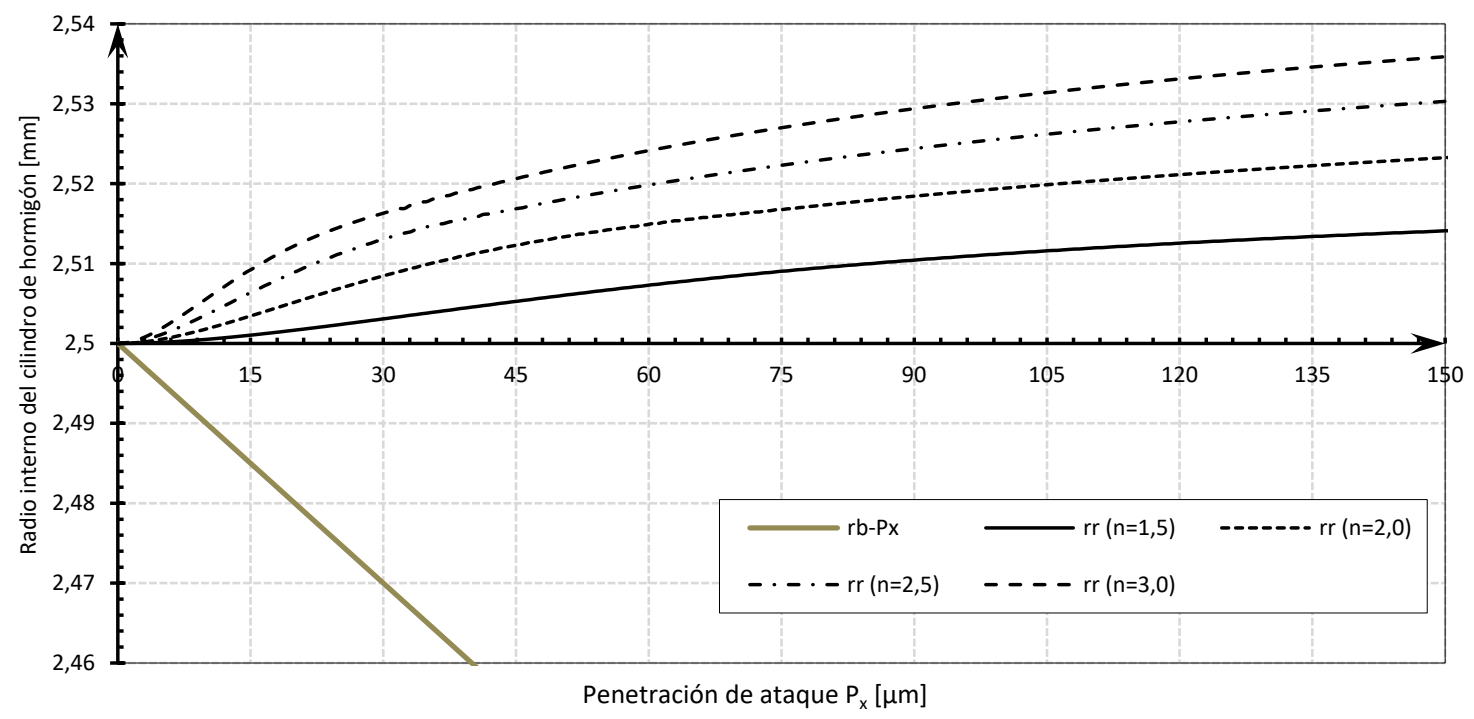

Figura 6-5 Comparación del radio interno del cilindro de hormigón, con respecto a la penetración de ataque $P_{x}$ para distintos coeficientes de expansión de óxidos $n$

En las gráficas de la Figura 6-6 se representan la influencia del coeficiente $n$ en la evolución de distintas variables mecánicas con el avance del proceso de corrosión: A) Tensión radial $\sigma_{i}$; B) Evolución del frente de fisuración; C) Deformaciones radiales $\varepsilon_{r}$ en la interfaz acero-hormigón; D) Deformaciones circunferenciales $\varepsilon_{\theta}$ en la interfaz acero-hormigón; E) Evolución de los módulos de elasticidad radial $E_{r}$ (compresión) y circunferencial $E_{\theta}$ (tracción) y F) Deformaciones circunferenciales $\varepsilon_{\theta}$ y ancho de fisura $w$ en el perímetro del cilindro de hormigón. Para la obtención de las gráficas, los datos de entrada utilizados para el modelo analítico han sido los señalados en negrita en la Tabla 6-1, variándose la magnitud coeficiente de expansión $n$, dentro del rango de valores más habitual extraído de la revisión bibliográfica $(1.5,2.0,2.5$ y 3.0$)$.

Dado que el coeficiente de expansión de óxidos $n$ no modifica las características mecánicas del recubrimiento de hormigón, la tensión radial máxima $\sigma_{r}$ que se logra es igual en todos los casos, aproximadamente 27,50 MPa [(Figura 6-6 A)], pero el grado de pérdida de sección por corrosión necesario para alcanzar dicho valor disminuye con el aumento del coeficiente $n$, siendo: $6,40 \%$ para $\mathrm{n}=1,5\left(P_{x}=70,1 \mu \mathrm{m}\right) ; 2,73 \%$ para $\mathrm{n}=2,0\left(P_{x}=29,5 \mu \mathrm{m}\right) ; 1,72 \%$ para $\mathrm{n}=2,5\left(P_{x}=18,6 \mu \mathrm{m}\right) ; \mathrm{y} 1,27 \%$ para $\mathrm{n}=3,0\left(P_{x}=13,7 \mu \mathrm{m}\right)$.

En la Figura 6-7 se han incluido las gráficas de penetración de ataque $P_{x}$ necesaria para alcanzar la tensión radial máxima $\sigma_{\mathrm{r}, \max }$ (izqierda), y de tensión máxima radial normalizada $\sigma_{\mathrm{r}, \max } / \mathrm{f}_{\mathrm{ctm}}($ derecha) en función del coeficiente de expansión de óxidos $n$, para distintas relaciones recubrimiento/diámetro $c / \phi$. 

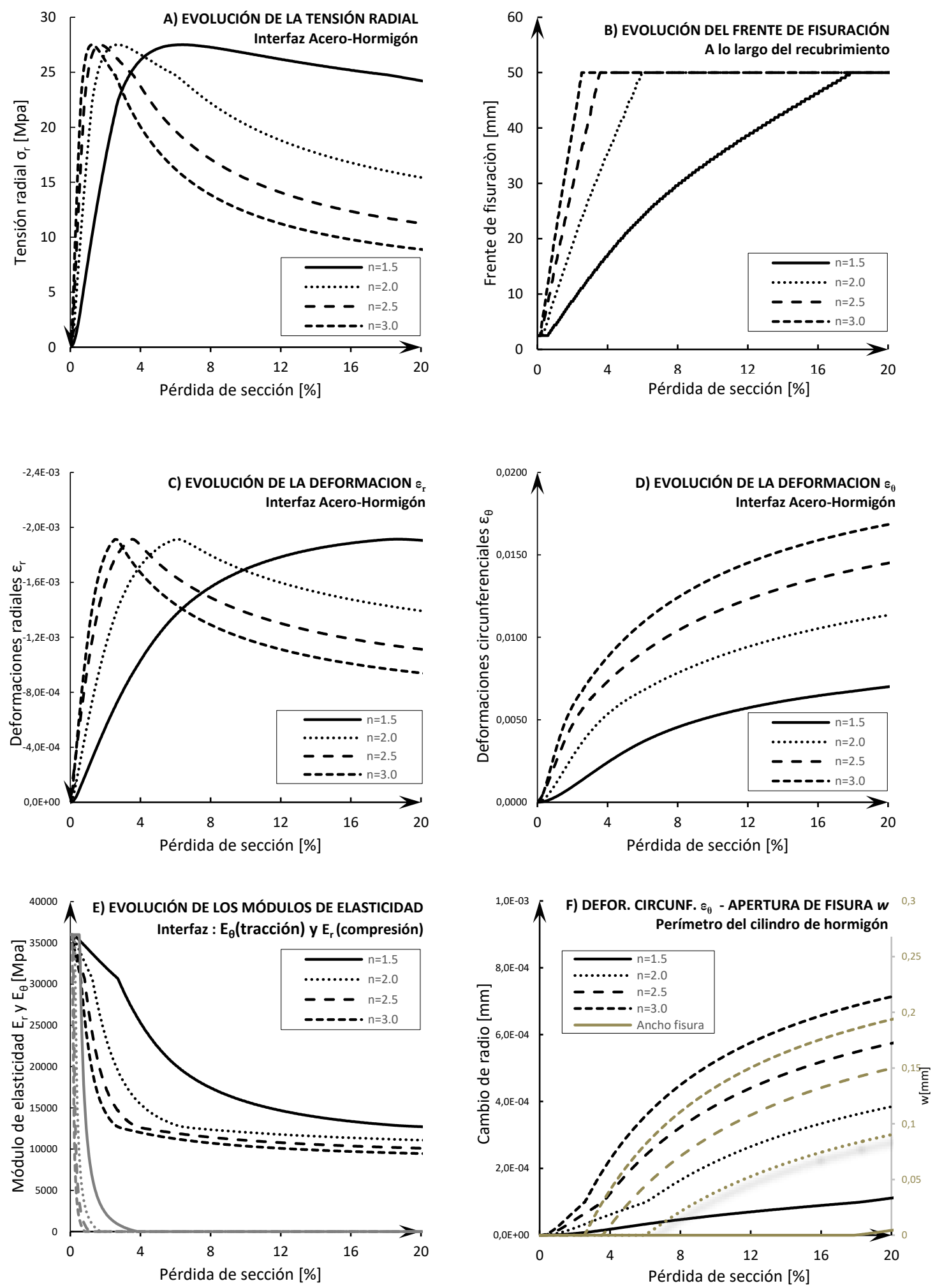

Figura 6-6 Influencia del coef. de expansión de óxidos n en la evolución de distintos parámetros en relación con el aumento de la pérdida de sección por el proceso de corrosión: A) Tensión radial $\left.\sigma_{i} ; B\right)$ Evolución del frente de fisuración; C) Deformaciones radiales $\varepsilon_{r}$ en la interfaz. acero-hormigón; D) Deformaciones circunferenciales $\varepsilon_{\theta}$ en la interfaz acero-hormigón; E) Evolución de los módulos de elasticidad radial $E_{r}$ (compresión) y circunferencial $E_{\theta}$ (tracción) y F) Deformaciones circunferenciales $\varepsilon_{\theta}$ y ancho de fisura w en el perímetro del cilindro de hormigón. 
La Figura 6-7 muestra claramente que para cada una de las relaciones $c / \phi$ analizadas, el coeficiente de expansión de óxidos $n$ no influye en la máxima tensión radial $\sigma_{\mathrm{r}, \text { max }}$ alcanzada, manteniéndose constante cualquiera que sea el valor seleccionado (las pequeñas variaciones se deben a imprecisiones por la discretización utilizada). Por el contrario, el modelo es muy sensible al valor del coeficiente de expansión de óxidos a la hora de predecir la penetración de ataque bajo la cual se alcanza dicha tensión máxima. Para valores de $n$ menores a 2, los niveles de corrosión necesarios se disparan, siendo más acusada la diferencia en el caso de relaciones $c / \phi$ elevadas. Cuando el valor de $n$ es mayor que 2 , las diferencias se atenúan, y cualquier aumento del coeficiente supone un leve descenso de la penetración de ataque necesaria. En cuanto al comportamiento post-pico, tras superarse la tensión radial máxima, menores valores de $n$ aseguran una caída más atenuada de las tensiones residuales.
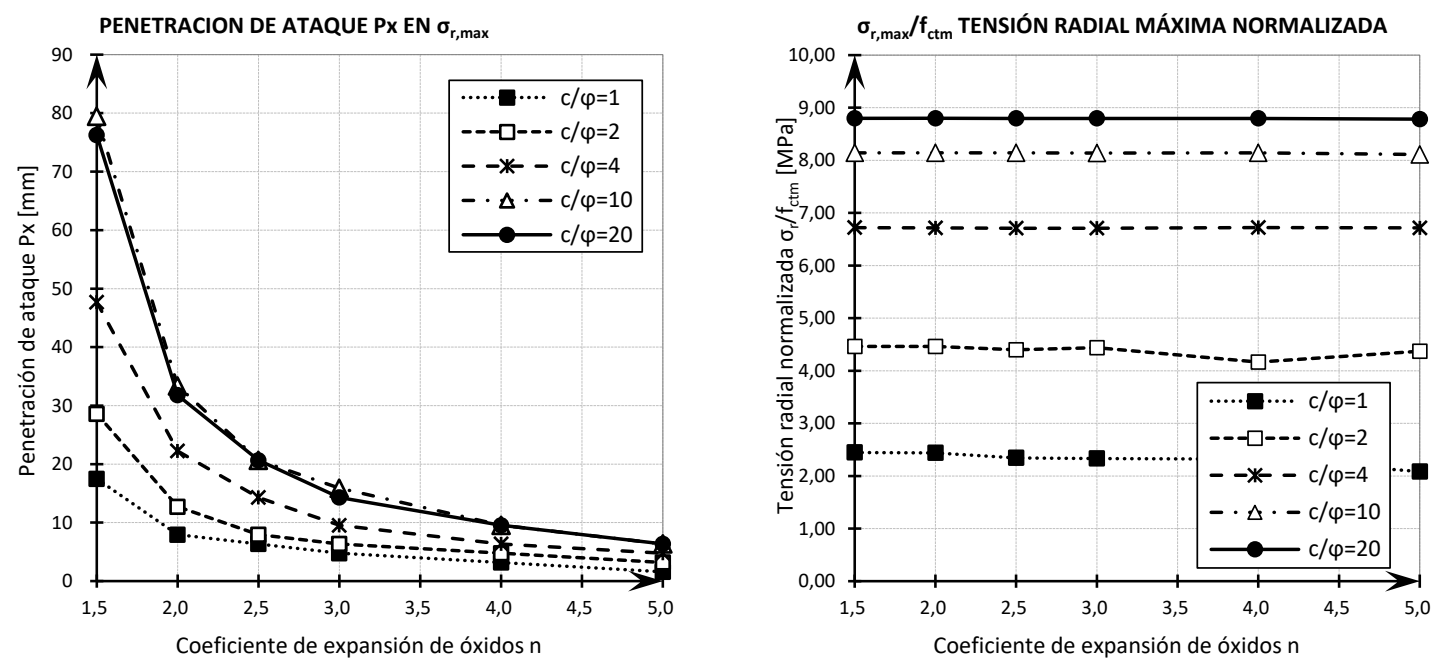

Figura 6-7 Penetración de ataque $P_{x}$ necesaria para alcanzar la tensión radial máxima $\sigma_{r, m a x}$ (izq.) y tensión máxima radial normalizada $\sigma_{r, m a x} / f_{\text {ctm }}$ (der.) en función del coeficiente de expansión de óxidos $n$, para distintas relaciones $c / \phi$.

Por otro lado, el menor desplazamiento radial de la pared interna del cilindro de hormigón aparejado a valores bajos del coeficiente $n$ provoca menores deformaciones circunferenciales $\varepsilon_{\vartheta}$ [Figura 6-6 D)], por lo que el avance del frente de fisuración se ralentiza [Figura 6-6 B)], al igual que la apertura de fisura $w$ [Figura 6-6 F]. Las fisuras se hacen visibles con los siguientes valores de pérdida de sección por corrosión: $17,83 \%$ para $n=1,5\left(P_{x}=201,1 \mu \mathrm{m}\right) ; 5,95 \%$ para $n=2,0\left(P_{x}=64,65 \mu \mathrm{m}\right) ; 3,58 \%$ para $n=2,5\left(P_{x}=38,9 \mu \mathrm{m}\right) ; \mathrm{y} 2,53 \%$ para $n=3,0\left(P_{x}=27,4 \mu \mathrm{m}\right)$. En las series de ensayos L10 e I10, con una relación recubrimiento/diámetro igual a la utilizada en el estudio de sensibilidad $(c / \phi=10)$, las primeras fisuras se detectaron en el rango que oscila entre el 4 y el $6 \%$ de pérdida de sección $(\mathrm{Px}=43,5-65,7 \mu \mathrm{m})$, por lo que coeficientes de expansión de óxidos ubicados en el rango 2,0-2,5 son los que mejor predicen este fenómeno. En la gráfica de la Figura 6-8 se representa la penetración de ataque $P_{x}$ necesaria para fisurar el recubrimiento en función del coeficiente de expansión de óxidos $n$, para distintas relaciones $c / \phi$. Tal y como ocurría con la penetración de ataque $P_{x}$ necesaria para alcanzar la máxima tensión radial, para valores por encima de $n=2$, las diferencias de pérdida de sección se encuentran muy atenuadas. 


\subsubsection{Calibración del coeficiente de expansión de óxidos}

A la vista de lo expuesto en el apartado anterior, los resultados de deformaciones y tensiones, obtenidos mediante el modelo analítico desarrollado para esta tesis, no son excesivamente sensibles a valores del coeficiente de expansión de óxidos $n$ comprendidos en su rango más habitual, que como se vio en el Capitulo 2 "Estado del conocimiento" oscila entre 2 y 3. Aun así se ha comprobado que el mayor grado de adaptación se obtiene para valores comprendidos entre 2 y 2,5, ya que para valores menores la fisuración se retrasa con respecto a lo observado en los ensayos, y valores mayores conducen a fisuraciones que se adelantan a las observaciones.

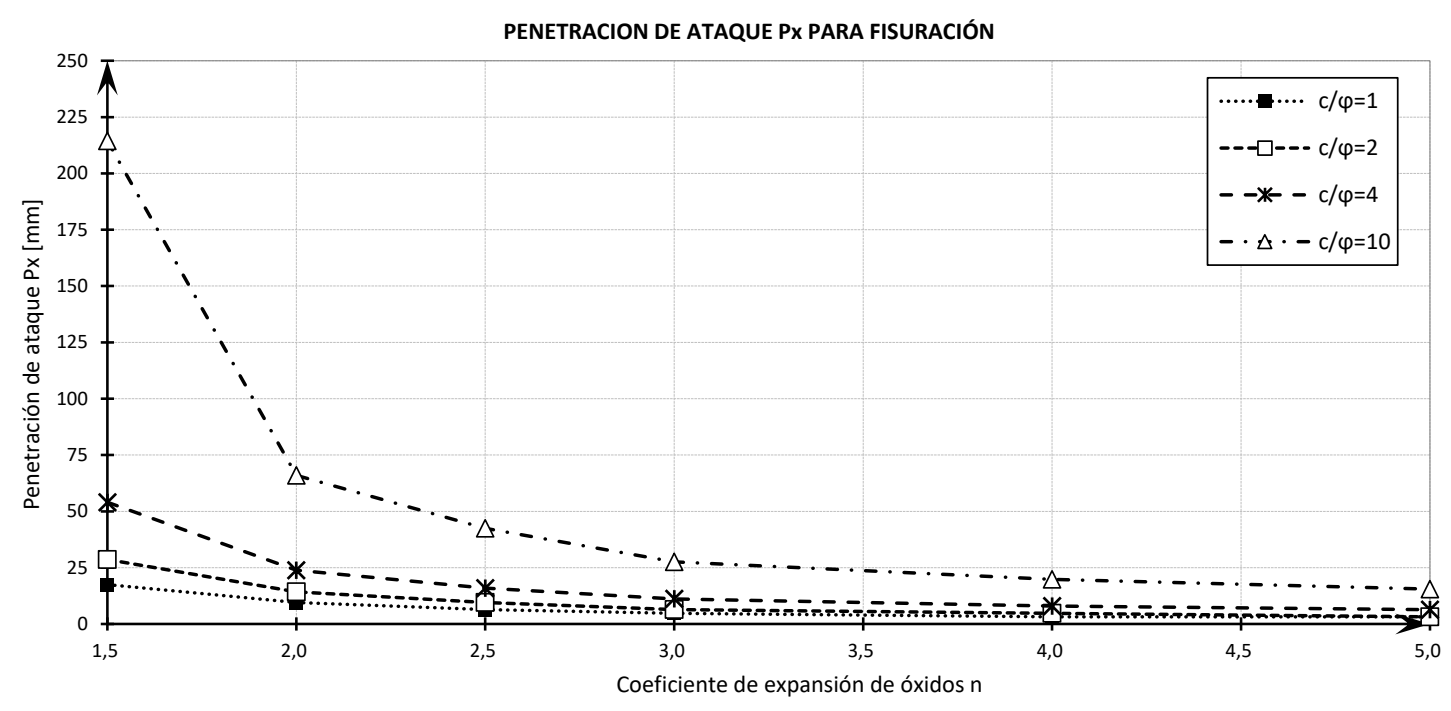

Figura 6-8 Penetración de ataque $P_{x}$ necesaria para fisurar el recubrimiento en función del coeficiente de expansión de óxidos n, para distintas relaciones $c / \phi$

En la Figura 6-9 se comparan los resultados experimentales con los obtenidos mediante el modelo analítico, representándose la evolución de las máximas tensiones de adherencia normalizadas $\tau_{b \text {,max }} / f_{c t \text { m }}$ $[\mathrm{MPa} / \mathrm{MPa}]$, con respecto a la a la pérdida de sección por corrosión [\%], para distintas relaciones $c / \varphi$ (4 y 10) y distintos coeficientes de expansión de óxidos $n$ (2 y 2,5).

$\mathrm{Al}$ igual que en el apartado anterior, los datos más relevantes para la obtención de las gráficas analíticas se incluyen en la Tabla 6-6, mientras que el resto de parámetros utilizados pueden consultarse en la Tabla 6-1, para el cálculo de tensiones radiales $\sigma_{r}$ a nivel de sección, y en la Tabla 6-3, para la determinación de la tensión de adherencia $\tau_{b}$.

Tabla 6-6 Valor de los parámetros de entrada en el modelo analítico para la obtención de las gráficas de la Figura 6-9

\begin{tabular}{|c|c|c|c|c|c|c|c|c|c|c|}
\hline \multirow[b]{2}{*}{ SERIE } & \multicolumn{2}{|c|}{$\begin{array}{l}\text { Parámetros } \\
\text { geométricos }\end{array}$} & \multicolumn{2}{|c|}{$\begin{array}{l}\text { Parámetros } \\
\text { mecánicos }\end{array}$} & \multicolumn{4}{|c|}{ Parámetros relativos a la corrosión } & \multicolumn{2}{|c|}{ Adherencia } \\
\hline & $C[\mathrm{~mm}]$ & $t_{p, c i r}[\mu m]$ & $f_{c m}[\mathrm{MPa}]$ & $f_{c, m}[\mathrm{MPa}]$ & $\frac{d m_{s}}{d t_{\text {corr }}}$ & $n$ & $K_{r}$ & $\% o ́ x$. fis. & $\begin{array}{c}\tau_{\text {adh }} \\
{[\mathrm{MPa}]}\end{array}$ & $\mu$ \\
\hline $\mathrm{c} / \varphi=4$ & 17,5 & 75 (variable) & 32,43 & 3,79 & \multirow{2}{*}{ Faraday } & \multirow{2}{*}{$2-2,5$} & 0,5 & $75 \%$ & \multirow{2}{*}{2,0} & \multirow{2}{*}{0,65} \\
\hline$c / \varphi=10$ & 47,5 & 75 (variable) & 43,72 & 3,16 & & & 1,0 & $25 \%$ & & \\
\hline
\end{tabular}


Los resultados obtenidos con el uso de coeficientes de expansión de óxidos $n$ igual a 2 y 2,5 son razonablemente similares. Como se había anticipado en el estudio de sensibilidad, el valor $n=2,5$, por un lado, adelanta ligeramente la pérdida de sección para la que se alcanza la tensión máxima de adherencia $\tau_{\text {b, max, }}$ y la completa fisuración del recubrimiento, y por otro, conlleva un descenso más acusado de la tensión de adherencia residual post-pico.

Una vez superada la tensión de adherencia máxima, el coeficiente de expansión de óxidos $n=2$ predice con precisión los valores medios de la tensión de adherencia $\tau_{b, \max }$, mientras que el coeficiente $n=2,5$ actúa como un límite inferior de la distribución.

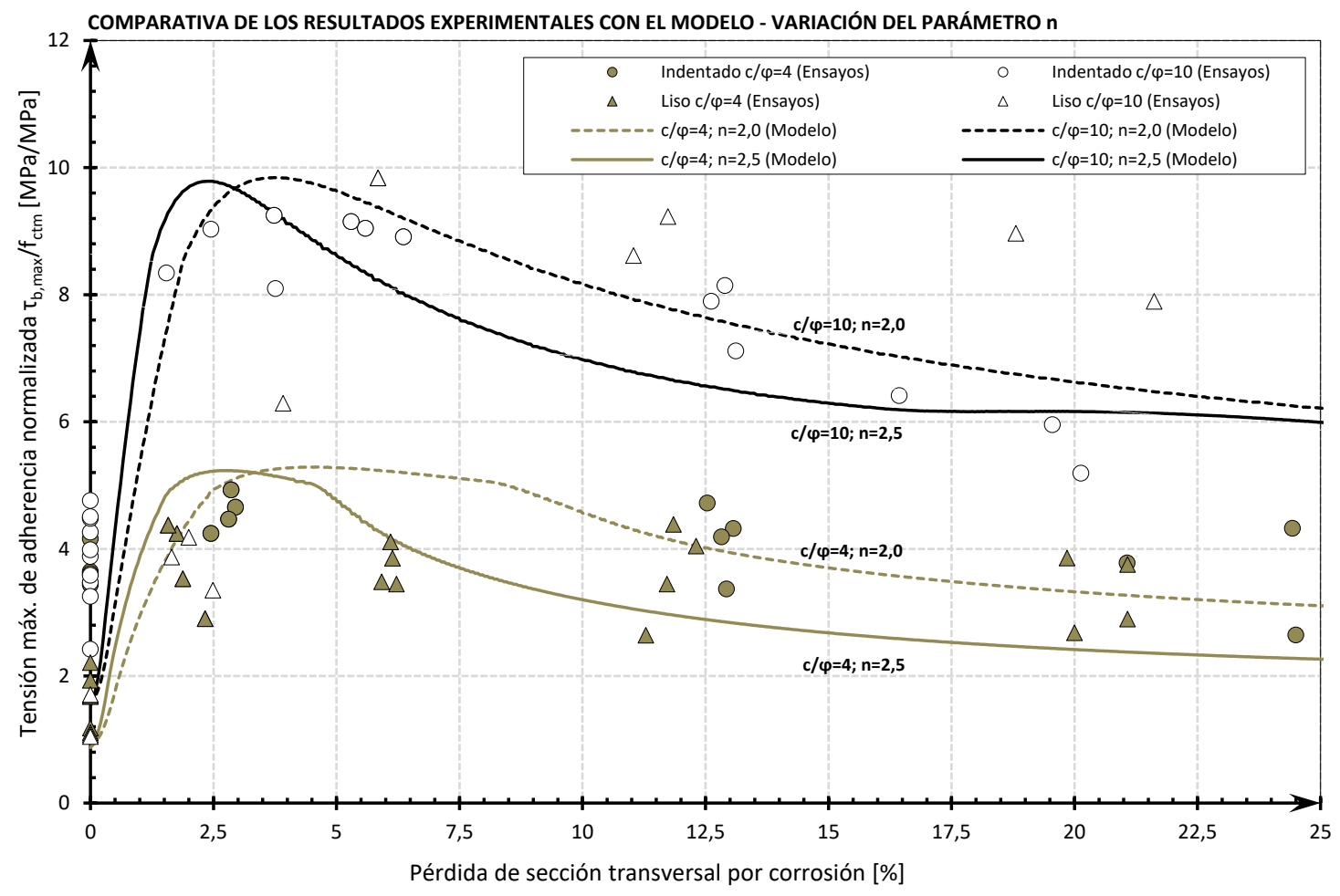

Figura 6-9 Comparación de los resultados experimentales con los obtenidos mediante el modelo analitico. Evolución de las máximas tensiones de adherencia normalizadas $\tau_{b, \max } / f_{c t m}[\mathrm{MPa} / \mathrm{MPa}]$, con respecto a la a la pérdida de sección por corrosión [\%], para distintas relaciones $c / \varphi$ $y$ distintos coeficientes de expansión de óxidos $n$.

En la Figura 6-10 se representan los diagramas predicción-realización de las tensiones de adherencia normalizadas $\tau_{\text {b, max }} / f_{\text {ctm }}[\mathrm{MPa} / \mathrm{MPa}]$, para coeficientes de expansión de óxidos $n$ con valor 2,0 y 2,5. Como puede apreciarse, la recta de la regresión ortogonal para los resultados que arroja el coeficiente $n=2$ no sólo tiene un menor coeficiente de determinación $\mathrm{R}^{2}$ sino que además presenta un pendiente más cercana a 1 , es decir, una mayor proximidad a la bisectriz del primer cuadrante. Con ello, se puede concluir que $n=2$ permite predecir unos resultados más ajustados a los obtenidos experimentalmente. Por otra parte, el diagrama permite comprobar, mediante la intersección de las rectas de regresión con la bisectriz del $1^{\text {er }}$ cuadrante, que para valores bajos de la tensión de adherencia normalizada, correspondientes con los ensayos sobre armaduras sanas, el modelo subpredice ligeramente los resultados, mientras que para valores intermedios-altos de tensión, correspondientes a la mayor parte de los ensayos en los que el proceso de corrosión ya se había iniciado, el modelo 
predice valores ligeramente superiores a los realmente obtenidos (siempre hablando en términos medios). Por último, es también destacable que el comportamiento de la relación recubrimiento/diámetro menor $(c / \varphi=4)$ es mejor tanto en dispersión como en grado de ajuste entre los resultados teóricos y experimentales.

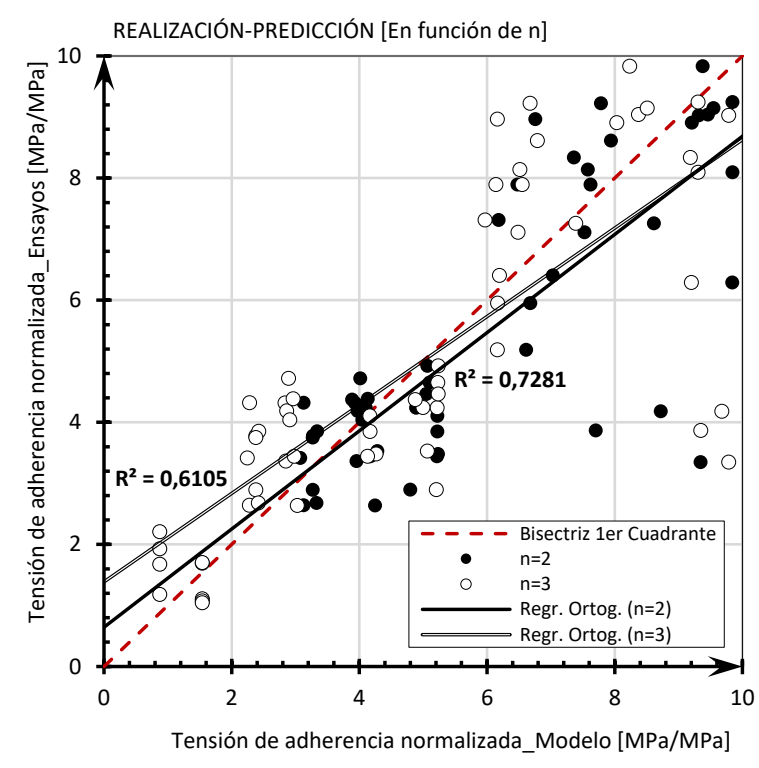

Figura 6-10 Diagrama predicción-realización de las tensiones de adherencia normalizadas $\tau_{b, \max } / f_{c t m}[M P a / M P a]$, para coeficientes de expansión de óxidos $n$ con valor 2,0 y 2,5

A la vista del estudio de sensibilidad realizado y del grado de ajuste del modelo a los resultados experimentales, en esta tesis se utiliza preferentemente un ratio $n$ entre el volumen de acero sano y el volumen del óxido igual a 2 .

\subsubsection{Coeficiente de compresibilidad volumétrica $\mathrm{K}_{\mathrm{r}}$}

El módulo de compresibilidad volumétrica $K_{r}$ contempla la capacidad de deformación de la capa de óxidos que rodea el alambre sano. En el Apartado 2.3.6.2 se ha llevado a cabo una revisión bibliográfica de los trabajos anteriores que han intentado caracterizar este módulo.

\subsubsection{Estudio de sensibilidad de la variable}

El análisis de la bibliografía ha permitido comprobar la enorme dispersión de resultados existentes en la caracterización de las propiedades del módulo de compresibilidad $K_{t}$, observándose resultados que distan varios órdenes de magnitud, oscilando entre un límite inferior de 0,02 GPa (Pease, et al., 2012) y uno superior de $14 \mathrm{GPa}$ (Lundgren, 2005).

Tal y como se vio en el Capitulo 3, el volumen de productos de corrosión comprimidos por unidad de longitud del alambre $V_{r c}$ se calcula a partir de la siguiente expresión $V_{r c}=V_{r}\left(1-\varepsilon_{v}\right)$, donde $V_{r}$ es el volumen total de los productos de corrosión sin comprimir, por unidad de longitud del alambre, y $\varepsilon_{v}$ es la deformación volumétrica experimentada por los productos de corrosión por la acción de la 
presión $p$, pudiéndose expresar como $\varepsilon_{v}=p / K_{r}$. De manera que, para un mismo nivel de corrosión, el volumen necesario para alojar los productos de corrosión es menor en el caso de módulos de compresibilidad bajos y, por tanto, el desplazamiento de la cara interior del cilindro de hormigón en estos casos es también menor, generando tensiones radiales de menor cuantía.

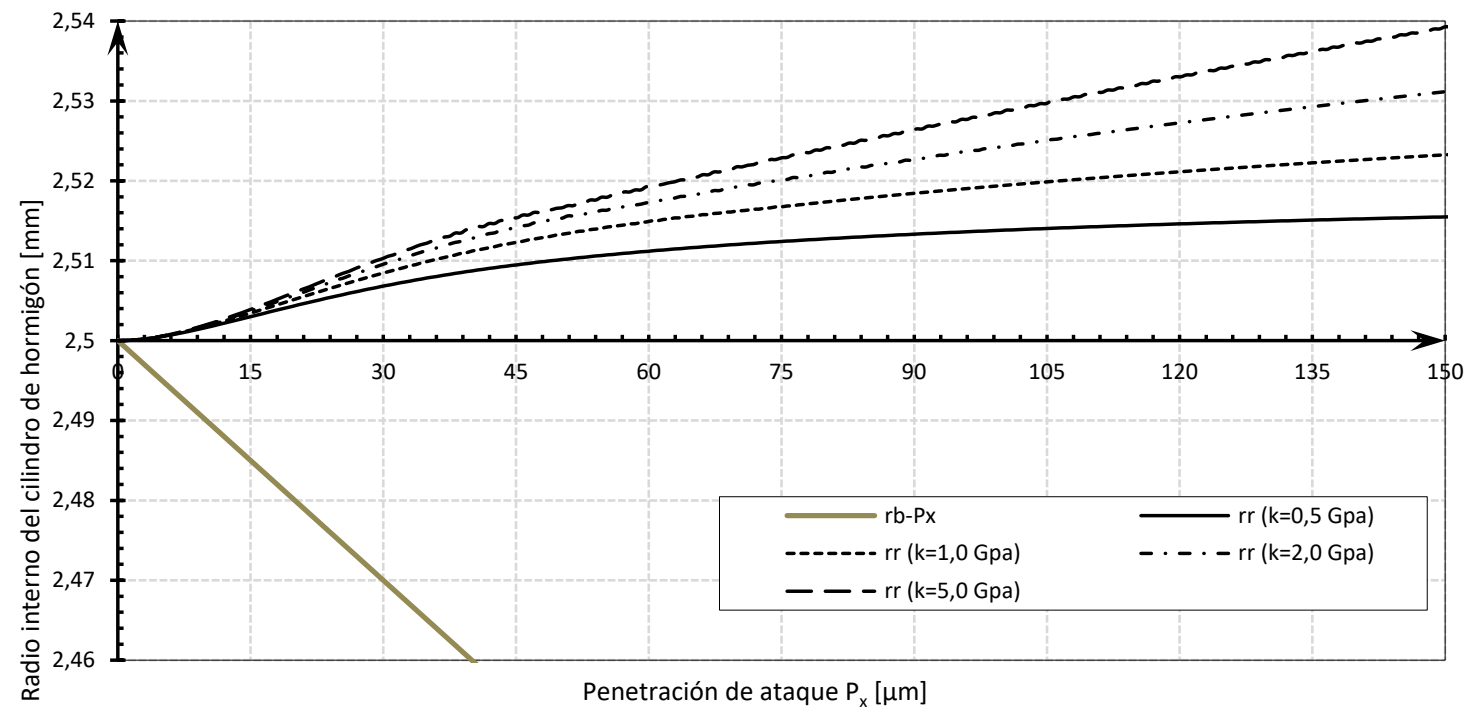

Figura 6-11 Comparación del radio interno del cilindro de hormigón, con respecto a la penetración de ataque $P_{x}$ para distintos $K_{r}$

Este hecho puede observarse con claridad en la Figura 6-11, en la que se ha representado la evolución frente a la penetración de ataque $P_{x}$ del radio $r_{r}$ de la pared interna del cilindro de hormigón que rodea el alambre y el radio residual $r_{b}-x$ del acero, para distintos módulos de compresibilidad volumétrica $K_{r}$. Para un mismo nivel de corrosión, el desplazamiento de la pared interna del recubrimiento frente a su posición inicial depende claramente del parámetro $K_{t}$, de manera que cuanto mayor es el módulo de deformabilidad mayor es el desplazamiento necesario para alojar el volumen de óxidos. Si se confrontan la Figura 6-11 con la Figura 6-5, en la que se compara la evolución de los desplazamientos radiales para distintos coeficientes de expansión de óxidos $n$, se comprueba que ambas gráficas presentan grandes semejanzas. Este hecho no es sorprendente, ya que ambos parámetros $\left(K_{r}\right.$ y $\left.n\right)$ se encuentran relacionados a través de la expresión (Eq. 6-9) que determina el volumen de productos de corrosión comprimidos $V_{r c}$ :

$$
V_{r c}=n \Delta V_{s}^{\operatorname{corr}}\left(1-p / K_{r}\right)
$$

Como puede apreciarse, aplicando coeficientes de expansión $n$ con un valor elevado junto con módulos $K_{r}$ de valores reducidos se puede llegar a determinar un volumen de óxidos comprimidos $V_{r}$ similar al que se lograría si se utilizasen coeficientes de expansión bajos junto con módulos de compresibilidad altos. En definitiva, para las mismas condiciones, existen múltiples duplas de los parámetros $n-K_{r}$ que pueden arrojar resultados de tensiones y deformaciones similares.

En la Figura 6-12, se recogen las gráficas de evolución de las deformaciones, las tensiones y la fisuración para distintos valores del módulo de compresibilidad volumétrica $K_{r}$. Para la obtención de las mismas, los datos de entrada utilizados para el modelo analítico han sido los señalados en negrita en la Tabla 6-1, variándose la magnitud del módulo $K_{r}$ dentro del rango de valores más habitual extraído de la revisión bibliográfica $(0,5 ; 1,0 ; 2,0$ y 5,0 GPa). 

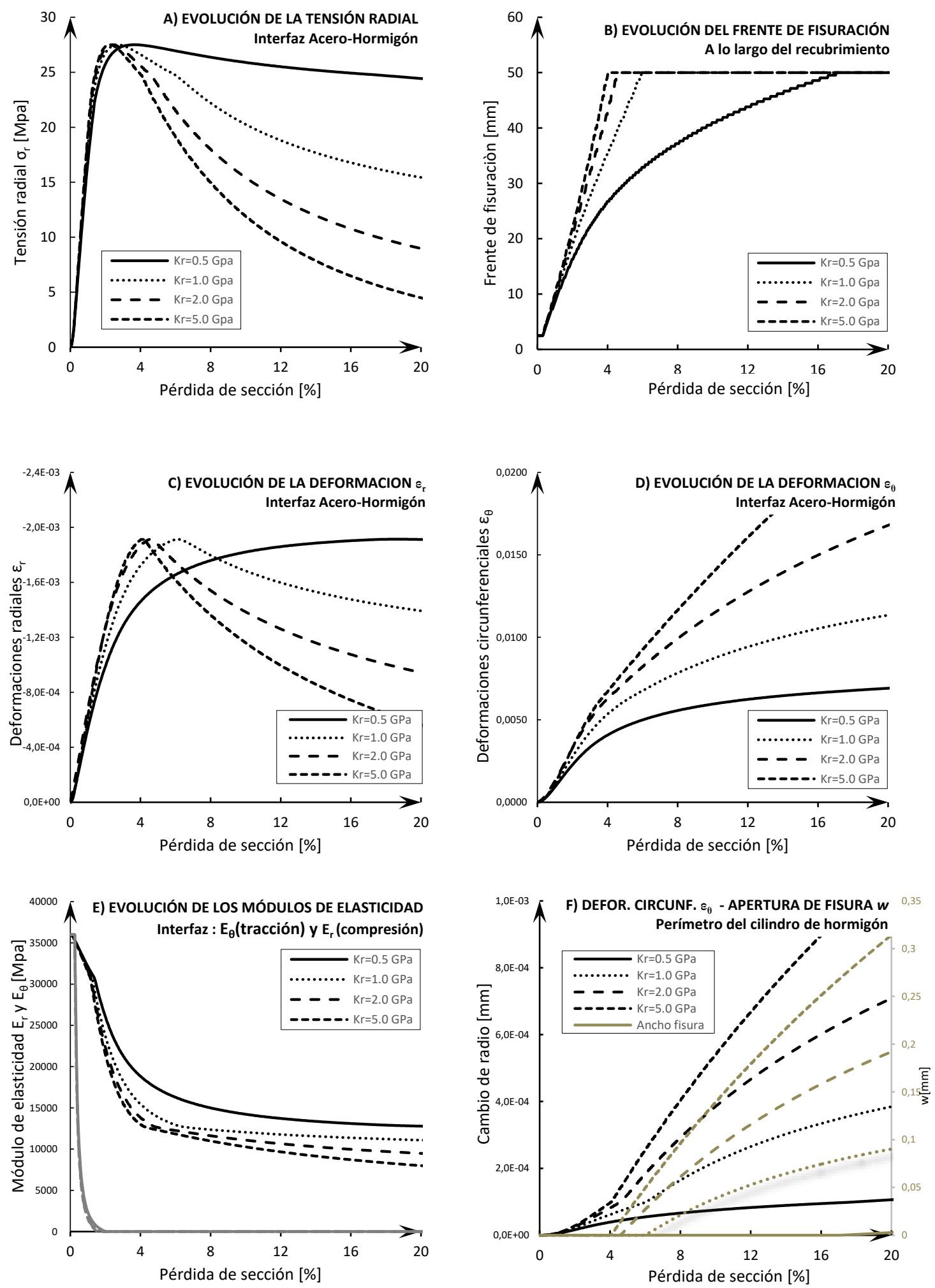

Figura 6-12 Influencia del módulo de deformabilidad $K_{r}$ en la evolución de distintos parámetros en relación con el aumento de la pérdida de sección por el proceso de corrosión: A) Tensión radial $\sigma_{n}$; B) Evolución del frente de fisuración; C) Deformaciones radiales $\varepsilon_{r}$ en la interfaz. acero-hormigón; D) Deformaciones circunferenciales $\varepsilon_{\theta}$ en la interfaz acero-hormigón; E) Evolución de los módulos de elasticidad radial $E_{r}$ (compresión) y circunferencial $E_{\theta}$ (tracción) y F) Deformaciones circunferenciales $\varepsilon_{\theta}$ y ancho de fisura w en el perímetro del cilindro de hormigón. 
Tal y como puede observarse en la Figura 6-12 A), el módulo de compresibilidad volumétrica de los productos de corrosión no tiene una influencia trascendental en las primeras fases del proceso de corrosión, evolucionando la tensión radial $\sigma_{r}$ con una pendiente similar en todos los casos analizados. Las diferencias empiezan a ser significativas en cuanto al nivel de corrosión necesario para alcanzarse la tensión radial máxima $\sigma_{r}$,max, que es la misma en todos los casos $(27,51 \mathrm{MPa})$, ya que el parámetro $K_{r}$ no modifica la capacidad de confinamiento del recubrimiento. La tensión máxima se alcanza para los siguientes valores de penetración de ataque: $P_{x(k r=0,5)}=40,0 \mu \mathrm{m}(3,68 \%), P_{x(k r=1,0)}=29,5 \mu \mathrm{m}(2,73 \%)$, $P_{x(k r=2,0)}=26,3 \mu \mathrm{m}(2,43 \%)$ y $P_{x(k r=5,0)}=24,66 \mu \mathrm{m}(2,28 \%)$.

Cabe resaltar que, mientras que las tensiones radiales $\sigma_{r}$ [Figura 6-12 A)], comienzan a decrecer sobrepasado el nivel de corrosión señalado, las deformaciones radiales $\boldsymbol{\varepsilon}_{r}$ [Figura 6-12 B)] continúan aumentando hasta que el frente de fisuración alcanza la superficie del recubrimiento. Desde el momento en el que los productos de corrosión empiezan a formarse, aparecen desplazamientos $u_{o}$ en la pared interior del cilindro de hormigón que rodea el alambre, provocando la aparición de deformaciones radiales $\varepsilon_{r}$, y circunferenciales $\varepsilon_{\vartheta}$ [(Figura 6-12 C) y D)]., A su vez, este aumento de deformaciones provoca la paulatina pérdida de rigidez del recubrimiento [(Figura 6-12 E)], al disminuir la pendiente de la tangente a la Parábola de Hognestad (Capitulo 3). El óptimo en la interacción entre las deformaciones crecientes y los módulos de elasticidad decrecientes $\left(E_{r} y E_{\vartheta}\right)$ determina el nivel de corrosión para el que se alcanza el máximo de tensión radial $\sigma_{r}$, a partir del cual comenzará a descender. Dependiendo del espesor de recubrimiento $c$, una vez alcanzado dicho máximo, las deformaciones radiales $\varepsilon_{r}$ pueden seguir aumentando, ya que el hormigón conserva gran parte de su capacidad de confinamiento. Pero una vez que el frente de fisuración alcanza la superficie, el recubrimiento no es capaz de confinar el aumento de los desplazamientos $u_{0}$ en la pared interior del cilindro de hormigón, provocando un descenso significativo en las deformaciones radiales en la interfaz acero/hormigón y un aumento de la pendiente de crecimiento de las deformaciones circunferenciales $\varepsilon_{\vartheta}$ en la pared exterior del cilindro (acompañado del correspondiente aumento del ancho de fisura w) [Figura 6-12; F)]. Para cada uno de los casos contemplados, los niveles de corrosión en el que las fisuras aparecen en el perímetro exterior del recubrimiento de hormigón, que cómo se ha justificado coinciden con el momento en el que se alcanzan las máximas deformaciones radiales $\boldsymbol{\varepsilon}_{r}$ en la interfaz acero-hormigón, son los siguientes: $17,05 \%\left(K_{r}=0,5\right) ; 5,96 \%\left(K_{r}=1,0\right) ; 4,57 \%\left(K_{r}=2,0\right)$ y $4,02 \%\left(K_{r}=5,0\right)$.

Como consecuencia de esto, es en el comportamiento post-pico, tras alcanzarse la tensión radial máxima, donde el módulo de deformabilidad volumétrica $k_{r}$ tiene una influencia más clara. La mayor capacidad de deformación de los productos de corrosión con valores bajos de $k_{r}$ provoca que el frente de fisuración, vinculado estrechamente a las tensiones circunferenciales, evolucione más lentamente, con lo que el recubrimiento conserva su capacidad para confinar y permite que las tensiones radiales residuales se mantengan en valores más elevados con respecto a aquellos con valores altos de $K_{r}$.

\subsubsection{Calibración del parámetro $K_{r}$}

En la Figura 6-13 se compara la tensión máxima de adherencia $\tau_{b, \max }$ obtenida de los ensayos sobre probetas con relaciones recubrimiento/diámetro iguales a 4 y 10 , con los resultados del modelo utilizando valores de $K_{r}$ iguales a 0,5 y 1,0 GPa. Como se vio en el subapartado anterior (Figura 6-12 A), para valores más altos del módulo de compresibilidad volumétrica, la tensión de adherencia sufre 
descensos pronunciados tras superarse el pico de tensión máxima, fenómeno que se aleja de lo observado en los ensayos de esta tesis. Los datos más relevantes para la obtención de las gráficas analíticas se incluyen en la Tabla 6-7, mientras que el resto de parámetros utilizados pueden consultarse en la Tabla 6-1, para el cálculo de tensiones radiales $\sigma_{r}$ a nivel de sección, y en la Tabla 6-3, para la determinación de la tensión de adherencia $\tau_{b}$.

Tabla 6-7 Valor de los parámetros de entrada en el modelo analítico para la obtención de las gráficas de la Figura 6-13

\begin{tabular}{|c|c|c|c|c|c|c|c|c|c|c|}
\hline \multirow[b]{2}{*}{ SERIE } & \multicolumn{2}{|c|}{$\begin{array}{l}\text { Parámetros } \\
\text { geométricos }\end{array}$} & \multicolumn{2}{|c|}{$\begin{array}{l}\text { Parámetros } \\
\text { mecánicos }\end{array}$} & \multicolumn{4}{|c|}{ Parámetros relativos a la corrosión } & \multicolumn{2}{|c|}{ Adherencia } \\
\hline & $C[\mathrm{~mm}]$ & $t_{p, c r i}[\mu m]$ & $f_{c m}[M P a]$ & $f_{c t, m}[M P a]$ & $\frac{d m_{s}}{d t_{\text {corr }}}$ & $n$ & $\boldsymbol{K}_{r}$ & $\% o ́ x . f i s$. & $\begin{array}{c}\tau_{a d b} \\
{[\mathrm{MPa}]}\end{array}$ & $\mu$ \\
\hline$c / \varphi=4$ & 17,5 & 75 (variable) & 32,43 & 3,79 & \multirow{2}{*}{ Faraday } & \multirow{2}{*}{2} & \multirow{2}{*}{$0,5-1,0$} & $75 \%$ & \multirow{2}{*}{2,0} & \multirow{2}{*}{0,65} \\
\hline $\mathrm{c} / \varphi=10$ & 47,5 & 75 (variable) & 43,72 & 3,16 & & & & $25 \%$ & & \\
\hline
\end{tabular}

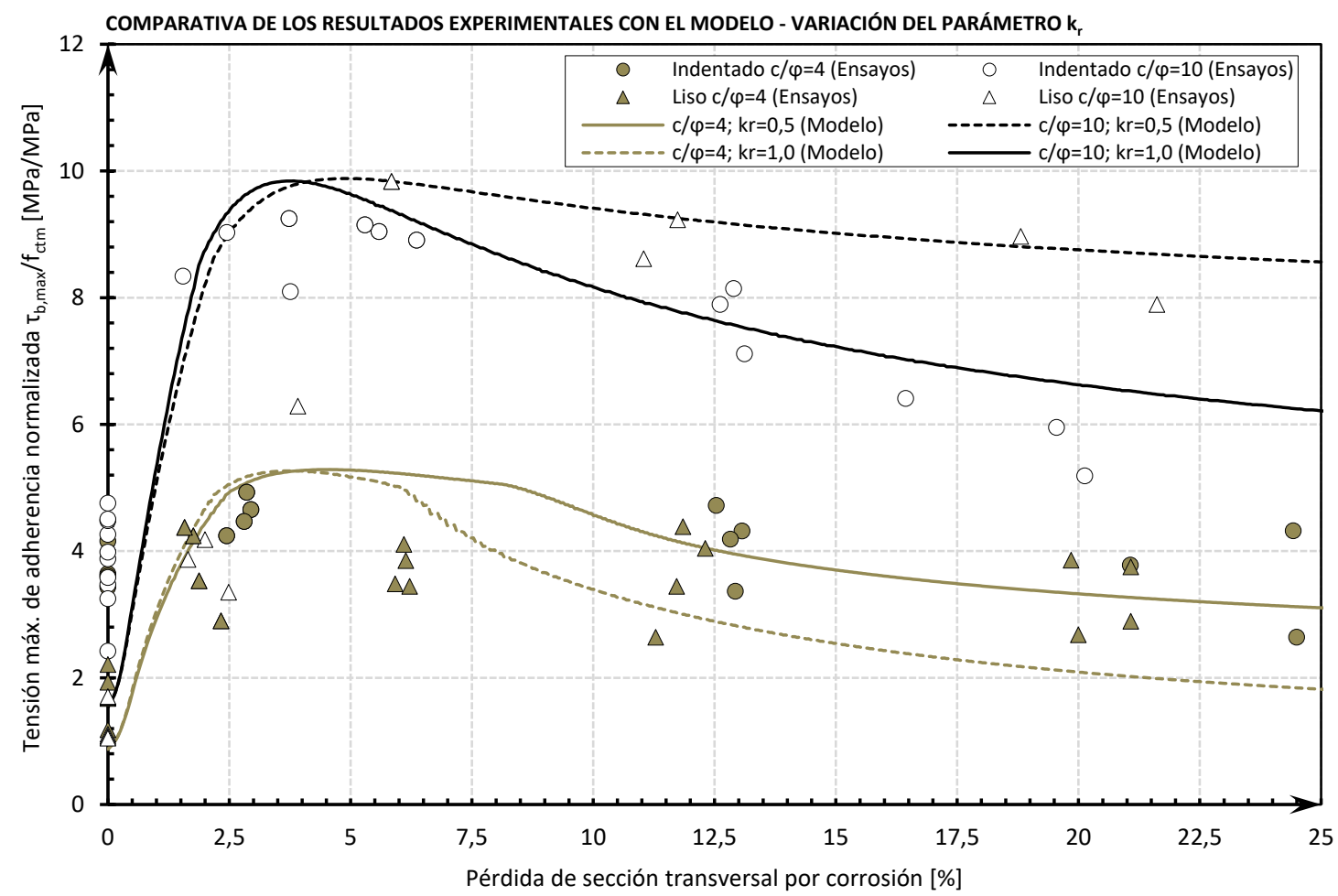

Figura 6-13 Comparación de la evolución de la tensión de adherencia normalizada $\tau_{b, m a x} / f_{c t m}[M P a / M P a]$, con respecto a la pérdida de sección transversal $[\%]$ debida a la corrosión, para distintos valores del parámetro $K_{r}$.

En el modelo aplicado a probetas con $c / \phi$ igual a 10 , la utilización de $K_{r}=1,0 \mathrm{GPa}$ arroja una curva con un alto grado de ajuste a los resultados obtenidos sobre alambres indentados, mientras que el uso de $K_{r}=0,5 \mathrm{GPa}$ determina una curva que predice con precisión la evolución de la tensión de adherencia en alambres lisos. A la vista de la Figura 6-13, en el caso de relaciones $c / \varphi$ igual a 10, los valores de $K_{r}$ utilizados $(0,5$ y 1,0 GPa) establecen con bastante precisión un límite superior e inferior de la evolución de la tensión máxima de adherencia $\tau_{b, \max }$.

En cuanto a las probetas $\operatorname{con} c / \varphi=4$, el comportamiento del modelo analítico es similar al del caso anterior, aunque su grado de ajuste es algo menor. Con un módulo de compresibilidad igual a 1,0 
GPa, se determina una curva de evolución de la tensión de adherencia que funciona bien como límite inferior de los resultados experimentales obtenidos. Mientras que un $K_{r}=0,5 \mathrm{GPa}$ predice razonablemente bien los valores medios de tensión de adherencia, tanto en alambres lisos como indentados, pero presenta algunas dificultades para predecir los valores más altos de tensión postpico. Por supuesto, valores por debajo de $0,5 \mathrm{GPa}$ permitirían que el descenso de la curva de evolución fuera menor, mejorando el grado de ajuste a los resultados experimentales, pero como contrapartida, la velocidad de avance del frente de fisuración se ralentizaría de manera significativa, alejándose excesivamente de lo observado en los ensayos.

En la Figura 6-14 se representan los diagramas predicción-realización de las tensiones de adherencia normalizadas $\tau_{b, \text { max }} / f_{\text {ctm }}[\mathrm{MPa} / \mathrm{MPa}]$, para módulos de compresibilidad volumétrica de óxidos $K_{r}$ con valores de 0,5 y 1,0 GPa. Como puede apreciarse, las rectas de regresión ortogonal para los resultados derivados del uso de ambos módulos presentan una pendiente similar, más tendida que la bisectriz del $1^{\text {er }}$ cuadrante, subestimando ligeramente el resultado obtenido en los ensayos para valores bajos de tensión normalizada $\tau_{b \text {, max }} / f_{c t m}$, correspondientes con los ensayos sobre alambres sanos, y sobrestimando el resultado para valores de tensión medios y altos El uso de un módulo de compresibilidad volumétrica $K_{r}=0,5 \mathrm{GPa}$ arroja resultados con una menor dispersión (coeficiente de determinación $\left.R^{2}=0,794>0,704\right)$ y un mejor comportamiento para relaciones recubrimiento/diámetro bajas $(c / \varphi=4)$, mientras que la utilización de $K_{r}=1 \mathrm{GPa}$ permite un mayor grado de adaptación a los resultados obtenidos en los ensayos sobre probetas con relación $c / \varphi=10$.

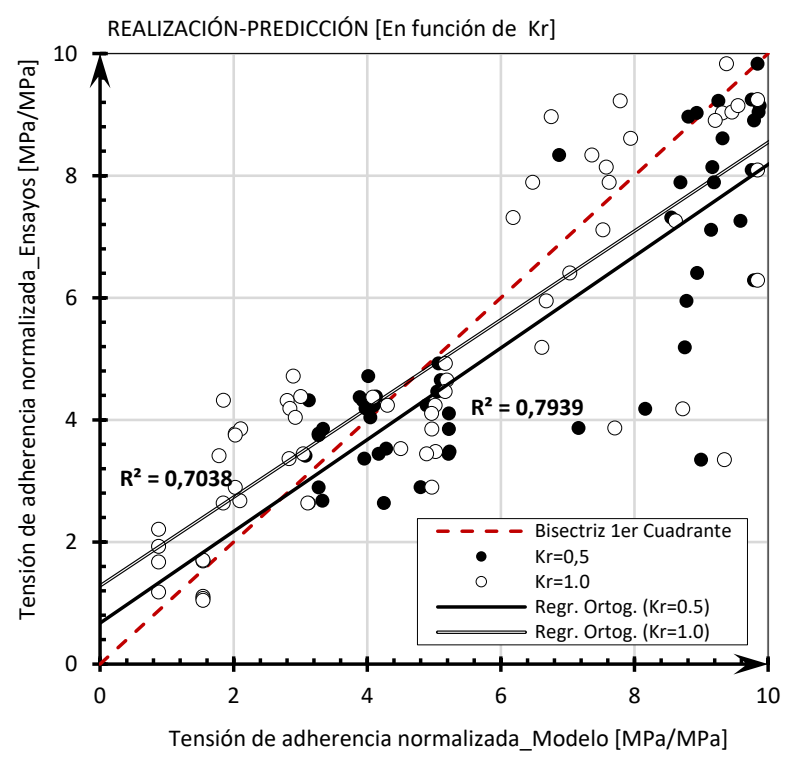

Figura 6-14 Diagrama predicción-realización de las tensiones de adherencia normalizadas $\tau_{b, \max } / f_{c t m}[M P a / M P a]$, para modulos de compresibilidad volumétrica de los óxidos $\mathrm{Kr}$ con valor 0,5 GPa y 1,0 GPa.

A la vista de lo expuesto en este apartado, el rango de valores asignado en esta tesis para el módulo de compresibilidad volumétrica $K_{n}$, que permite un mayor grado de adaptación a los resultados obtenidos en la campaña experimental, se encuentra comprendido en el rango 0,5-1,0 GPa. 


\subsubsection{Espesor de la zona porosa $t_{p}$}

Tal y como se vio en el Capitulo 2, desde que fue sugerido por Andrade et al. (1993) y Molina et al. (1993), habitualmente se admite que parte de los productos de corrosión difunden a través de la red de poros del hormigón que rodea el acero, de tal manera que la expansión "efectiva" de los óxidos que generan tensiones es menor que la expansión "real" resultante en el caso de no existir esta zona porosa. Para tener en cuenta este efecto, que repercute en el retraso del inicio de la fisuración, habitualmente se considera una región alrededor de la interfaz acero-hormigón en la que los óxidos pueden difundir sin ejercer ninguna presión en el hormigón circundante (región de porosidad infinita), y cuyo espesor aparente es equivalente a la suma del volumen de poros en los que presumiblemente se difundirían los productos de corrosión. Tal y como se discutió anteriormente, este parámetro tiene importancia en los modelos analíticos que intentan reproducir el fenómeno de la corrosión, basados en la distribución de tensiones sobre un cilindro de pared gruesa y que caracterizan la pérdida de masa de acero virgen $m_{s}$ mediante la Ley de Faraday, puesto que retrasa la fisuración que de otro modo tendría lugar en fases anteriores a lo observado en la mayoría de campañas experimentales.

\subsubsection{Influencia de la variable " $t_{p}$ "}

En este apartado se realiza un estudio paramétrico, analizando en qué forma y grado afecta la variación del espesor equivalente de la zona porosa $t_{p}$ a los resultados obtenidos mediante el modelo analítico propuesto en el Capítulo 3. Fijando el valor de los parámetros recogidos en la Tabla 6-1, se ha variado la magnitud del parámetro $t_{p}$, dentro del rango de valores más habitual extraído del análisis bibliográfico, de manera que se analizan espesores de la capa porosa de 0, 12,5, 25 y $50 \mu \mathrm{m}$. En la Figura 6-15 se recoge como afecta la variación de este parámetro, con el aumento de la corrosión (hasta un 20\% de pérdida de sección transversal), a los valores de: A) Tensión radial $\sigma_{r}$; B) Evolución del frente de fisuración; C) Deformaciones radiales $\varepsilon_{r}$ en la interfaz acero-hormigón; D) Deformaciones circunferenciales $\varepsilon_{\theta}$ en la interfaz acero-hormigón; E) Evolución de los módulos de elasticidad radial $E_{r}$ (compresión) y circunferencial $E_{\theta}$ (tracción) y F) Deformaciones circunferenciales $\varepsilon_{\theta} \mathrm{y}$ ancho de fisura $w$ en el perímetro del cilindro de hormigón.

Por la propia concepción del parámetro $t_{p}$ como el espesor de una región o zona en la que los óxido pueden difundir sin generar tensiones, la variación del espesor de dicha región no tiene consecuencias en la evolución de las tensiones y deformaciones derivadas de la corrosión, sino que únicamente influye en el momento en que los productos de corrosión empiezan a ejercer presión en la pared interna del cilindro de hormigón que rodea el acero. Por tanto, su efecto es el de decalar en el tiempo los diagramas de tensiones y deformaciones derivados de la presión ejercida por los óxidos.

Aplicando la Ley de Faraday (1993), y sabiendo que el coeficiente de expansión de óxidos $n$ utilizado en las gráficas de la Figura 6-15 es igual a 2, puede deducirse que cada micra que aumenta el espesor de la banda porosa $t_{p}$ se retrasa la aparición de tensiones en el recubrimiento el equivalente a un $0,08 \%$ de pérdida de sección transversal (para alambres de $5 \mathrm{~mm}$ de diámetro). De esta manera, mientras que, para el caso en el que no se contempla la zona porosa, la máxima tensión radial $\sigma_{r}$ se alcanza con un valor de pérdida de sección del 1,8\%, para las regiones porosas de espesores equivalentes 12,5, 25 

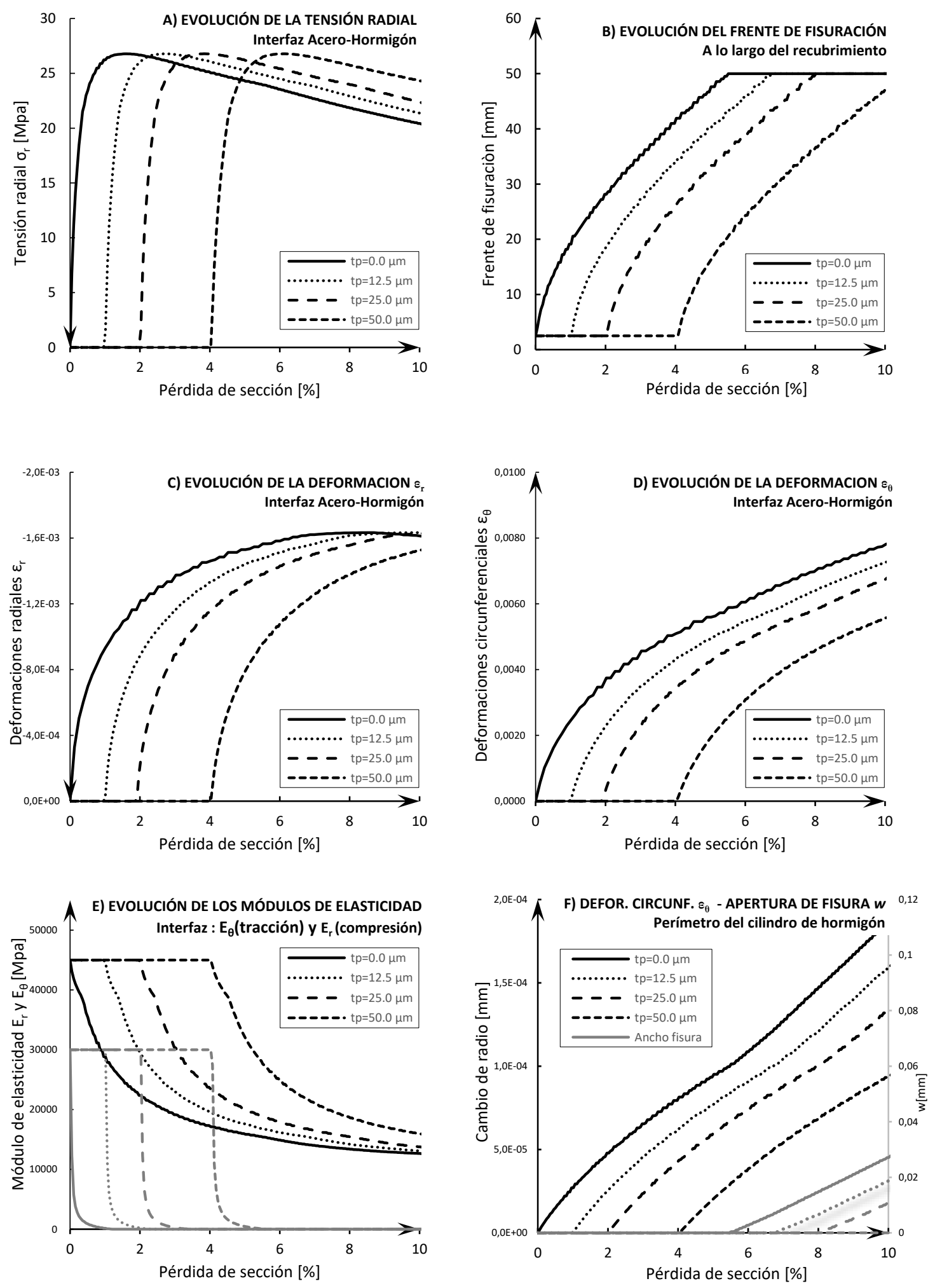

Figura 6-15 Influencia del espesor de la banda porosa tp en la evolución de distintos parámetros en relación con el aumento de la pérdida de sección por el proceso de corrosión: A) Tensión radial $\sigma_{r}$. B) Evolución del frente de fisuración; C) Deformaciones radiales $\varepsilon_{r}$ en la interfaz. acero-hormigón; D) Deformaciones circunferenciales $\varepsilon_{\theta}$ en la interfaz acero-hormigón; E) Evolución de los módulos de elasticidad radial E ${ }_{r}$ (compresión) y circunferencial $\mathrm{E}_{\theta}$ (tracción) y F) Deformaciones circunferenciales $\varepsilon_{\theta}$ y ancho de fisura w en el perímetro del cilindro de hormigón. 
y $50 \mu \mathrm{m}$ se alcanza con pérdidas del 2,8, 3,8 y 5,8\%, respectivamente. Por otro lado, como era esperable, la máxima tensión radial $\sigma_{r}$ es independiente del espesor equivalente $t_{p}$ de la zona porosa, ya que este parámetro no afecta a la capacidad de confinamiento del recubrimiento, alcanzándose en todos los casos el mismo valor.

\subsubsection{Calibración del parámetro $t_{p}$}

En base a los resultados experimentales obtenidos, a la revisión bibliográfica realizada y al modelo analítico desarrollado se opta por implementar una ley que reproduzca la denominada zona porosa siguiendo los siguientes criterios:

- El fenómeno de la difusión de los productos de corrosión por la matriz de cemento puede considerarse como un fenómeno de transporte, por lo que la formulación para determinar el porcentaje de óxidos que generan presiones radiales en cada punto de la interfaz acerohormigón puede apoyarse en una interpretación de las leyes de difusión de Fick.

- Su espesor equivalente tendría que ocupar una región mayor a la habitualmente considerada desde que Liu \& Weyers (Liu \& Weyers, 1998) fijaron su valor en 12,5 $\mu \mathrm{m}$. En base a los últimos trabajos publicados (Michel, et al., 2014), los productos de corrosión son capaces de difundir hasta distancias que exceden ampliamente este límite.

- El valor de pérdida de sección bajo el que se alcanza el máximo valor de la tensión radial $\sigma_{r}$ debería incrementarse hasta un rango que oscilase entre el 3 y el 5\%, en base a los resultados experimentales de la presente tesis. Según el modelo analítico, para un espesor equivalente nulo de zona porosa $t_{p}$, la máxima tensión se alcanzaría para una pérdida de sección de entre el 1,5 y $2 \%$, por lo que para obtener el máximo en el rango buscado sería necesario un espesor equivalente $t_{p}$ de entre 20 y $30 \mu \mathrm{m}$.

- Debería reproducir con mayor precisión la realidad física de la región, estableciendo un gradiente de porosidad que, partiendo desde la superficie del acero, disminuyera la capacidad de difusión de óxidos a lo largo de la capa porosa.

- Su espesor tendría que ser independiente de la resistencia a compresión del hormigón $f_{c k}$ y, por tanto, de su variable asociada, la relación agua/cemento $a / c$. Aunque generalmente se acepta que el aumento de porosidad vinculado al aumento de la relación $a / c$ supone un retraso en la aparición de la fisuración (Alonso, et al., 1998), los trabajos analizados centrados en las propiedades de la interfaz no muestran con claridad esta tendencia, mostrando consenso en que este parámetro no tiene trascendencia, o ésta es muy limitada.

Con estas premisas, y a falta de resultados experimentales, se elabora una ley sencilla, en la que el porcentaje de difusión de óxidos \%dif es función de la distancia $x$ existente desde la interfaz, donde alcanza el 100\%, y decrece hasta alcanzar el límite exterior de la banda de porosidad variable que se denominará $t_{p, r r i}$ La ley para la definición de la región de porosidad variable responde a la siguiente expresión (Eq. 6-10)(Figura 6-17-izquierda): 


$$
\% \text { dif }=\left(1-\frac{x}{t_{p, c r i}}\right)^{2} \cdot 100
$$

La expresión puede referirse también al porcentaje de productos de corrosión \%ox que ejercen presión en el recubrimiento de hormigón sobre el total de óxidos generados (lógicamente, descontando aquellos que se alojan en el espacio liberado por la penetración de ataque $P_{x}$ ), adoptando la siguiente forma (Eq. 6-11)(Figura 6-17-derecha):

$$
\% o x=\left(\frac{x}{t_{p, c r i}}\right)^{2} \cdot 100 \quad \% o x=\frac{x}{t_{p, c r i}}\left(2-\frac{x}{t_{p, c r i}}\right) \cdot 100
$$

De las anteriores expresiones puede deducirse que el porcentaje de óxidos que generan presión es directamente proporcional al cuadrado de la distancia desde la interfaz hasta el punto considerado. En la Figura 6-16 se comparan el porcentaje de difusión de óxidos a través de la interfaz \%dif (izquierda) y el porcentaje de productos de corrosión que ejercen presión en el recubrimiento \%ox (derecha), con respecto a la distancia a la superficie original del acero, para distintas leyes de distribución: una ley de distribución constante, basada en el modelo de Liu (Liu \& Weyers, 1998), en la que los productos de corrosión no ejercen ninguna presión hasta que superan el espesor de la capa porosa $t_{p}$; una ley de distribución de carácter lineal, en la que los óxidos ejercen presión en la pared interna del recubrimiento de hormigón desde el comienzo del proceso de corrosión; y una ley de distribución parabólica, propuesta de esta tesis e inspirada en las leyes de difusión de Fick, en la que los óxidos ejercen presión desde el primer momento, como en el caso anterior, y el porcentaje de los mismos que actúan sobre el recubrimiento se incrementa hasta alcanzar el máximo a una distancia $t_{p, c r i}$ de la interfaz (Figura 6-17).
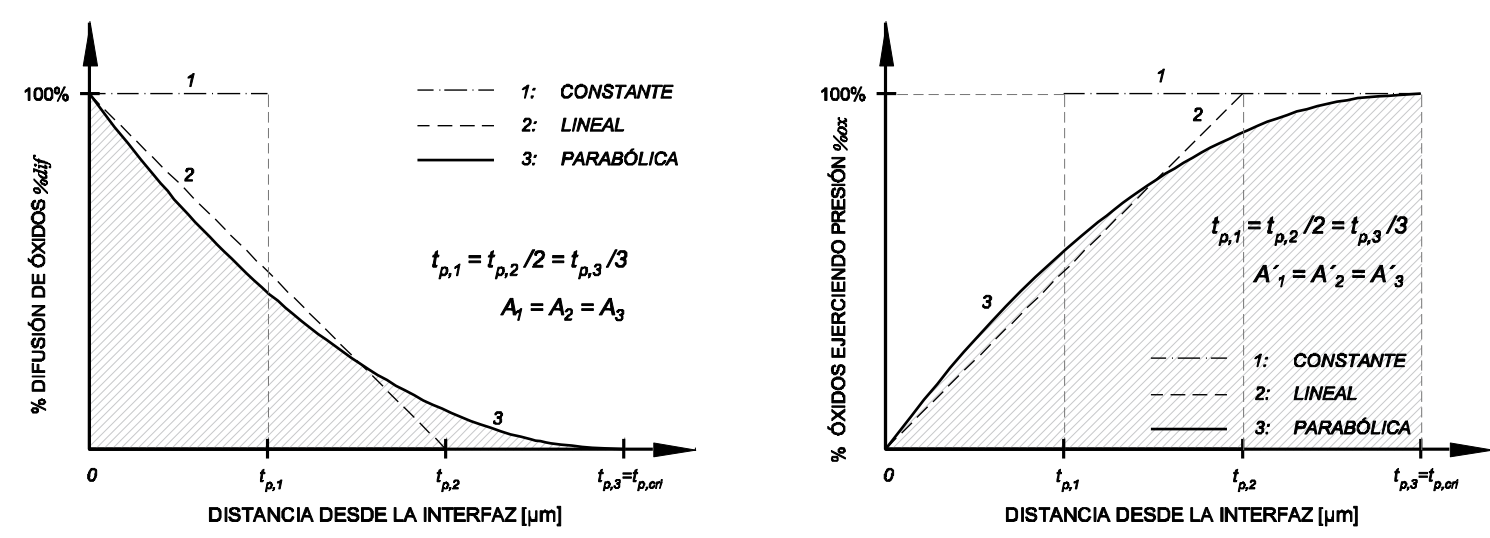

Figura 6-16 Comparación del porcentaje de difusión de óxidos a través de la interfaz. (izquierda) y del porcentaje de productos de corrosión que ejercen presión en el recubrimiento (derecha), con respecto a la distancia a la superficie del acero, para distintas leyes: Constante (Liu \& $W$ eyers, 1998), Lineal y Parabólica (propuesta de esta tesis).

Como puede observarse en la Figura 6-16, el área contenido baja las tres funciones consideradas es equivalente, es decir, los tres modelos permiten que una misma cantidad de productos de corrosión difundan en la matriz de cemento del hormigón. Sin embargo, los modelos lineal y parabólico reproducen de manera más fidedigna la realidad física de la interfaz acero/homigón, en la que tiene lugar un gradiente descendente de porosidad que conlleva un paulatino aumento del porcentaje de óxidos que es capaz de ejercer presión sobre el hormigón ((Horne, et al., 2007) (Michel, et al., 2014)). 

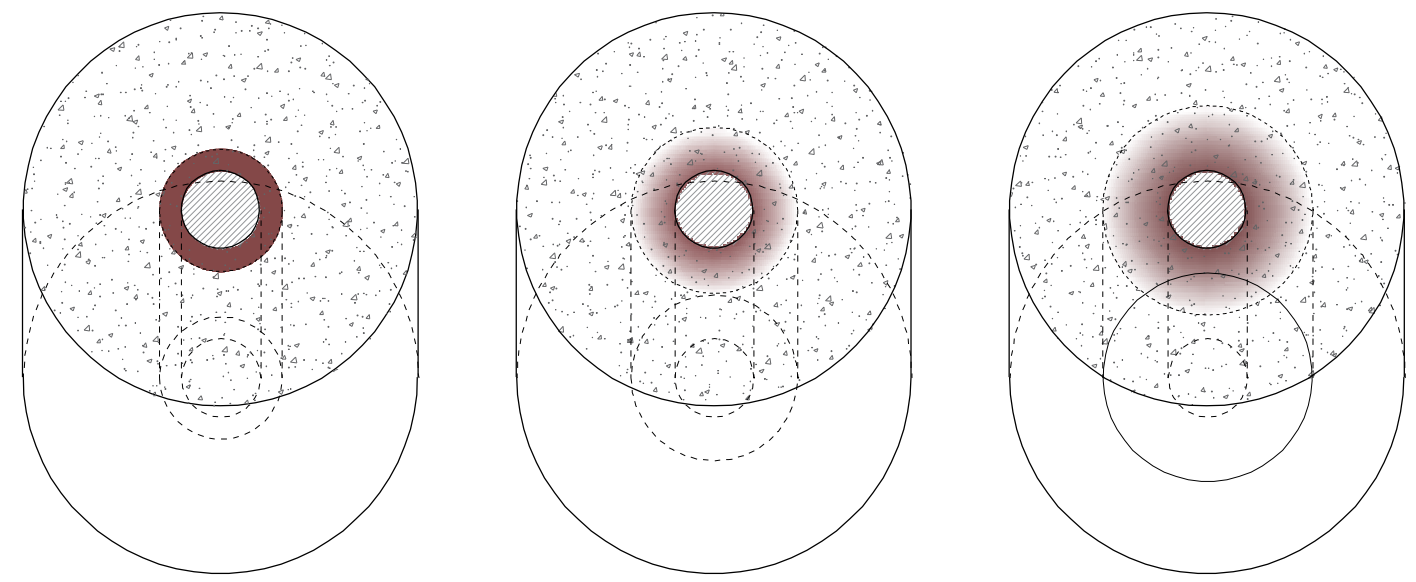

Figura 6-17 Representación de los distintos modelos analizados en esta: Constante (Liu \& Weyers, 1998), a la izquierda, Lineal, en el centro, y Parabólica (propuesta de esta tesis), a la derecha.

Por otro lado, el uso de la ley parabólica permite justificar la aparición de óxidos que han difundido hasta puntos alejados de la interfaz, como ha sido observado en varios trabajos, sin que esto suponga un retraso adicional en la evolución de la fisuración con respecto al modelo de distribución constante propuesto por Liu (Liu \& Weyers, 1998). Tal y como aparece en la Figura 6-17, el modelo parabólico predice distancias de difusión de óxidos hasta tres veces superiores que el modelo de distribución constante $\left(t_{p, r i}=3 \cdot t_{p, t e t}\right)$, sin un aumento del volumen de óxidos difundido. Para cada distancia $x$ desde la interfaz, la relación existente entre el espesor $t_{p, r i}$ de la banda de porosidad variable del modelo parabólico y su espesor equivalente $t_{p, c t e}$ en el modelo de difusión constante, es la siguiente (Eq. 6-12):

$$
t_{p, c t e}=x-\frac{t_{p, c r i} \cdot x^{2}-\frac{x^{3}}{3}}{t_{p, c r i}{ }^{2}}
$$

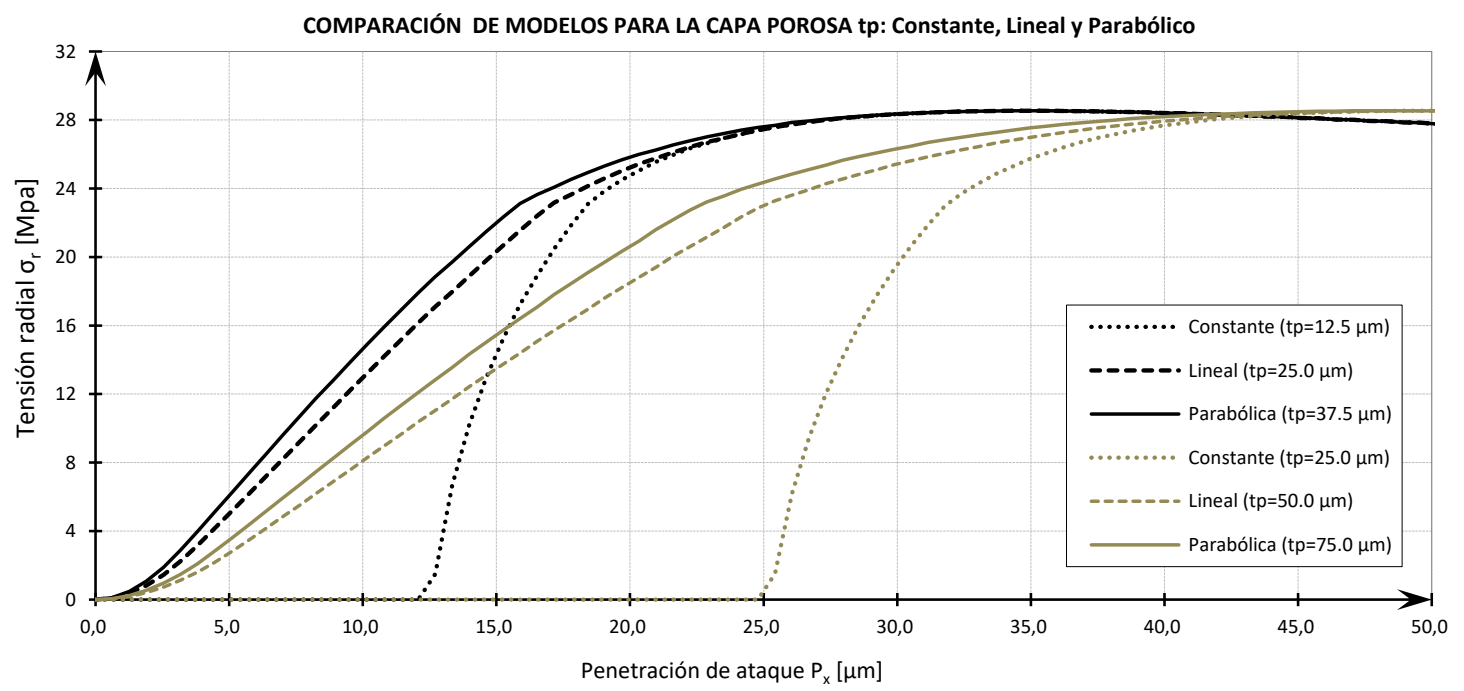

Figura 6-18 Comparación de la evolución de las tensiones radiales, con respecto a la penetración de ataque $P_{x}$ para distintos modelos de capa porosa: Constante (Liu \& Weyers, 1998), Lineal y Parabólico (propuesta de esta tesis). 
En la Figura 6-18 se muestra cómo afecta a la evolución de las tensiones radiales el uso de cada uno de los modelos de capa porosa analizados. Se han considerado dos espesores constantes de capa porosa $(12,5$ y $25,0 \mu \mathrm{m})$ y sus equivalentes en los modelos lineal y parabólico (Lineal: $t_{p, r i}=25,0$ y 50,0 $\mu \mathrm{m}$; Parabólico: $t_{p, r i}=37,5$ y $\left.75 \mu \mathrm{m}\right)$. Como se expuso anteriormente y se observa en la figura, mientras que el modelo constante no genera tensiones radiales hasta que los óxidos del acero rellenan la capa porosa, los modelos variables predicen la existencia de presiones desde que se desencadena el proceso de corrosión. Los distintos modelos no repercuten en la máxima tensión radial desarrollada $\left(\sigma_{r, m a x}=28,54 \mathrm{MPa}\right)$ ni en la penetración de ataque $P_{x}$ necesaria para alcanzarla $(34,95 \mu \mathrm{m}$ y 47,45 $\mu \mathrm{m})$, pero sí en la manera en la que se desarrollan las tensiones radiales en las fases tempranas de la corrosión.

En la Figura 6-19 se compara la evolución de las tensiones máximas de adherencia normalizada $\tau_{\text {b.max }} / f_{\text {ctm }}$ frente al avance de la corrosión (\% de pérdida de sección), obtenidas mediante el modelo analítico, con los resultados experimentales de los ensayos de arrancamiento, para las relaciones $c / \phi$ iguales a 4 y 10. Los datos más relevantes para la obtención de las gráficas analíticas se incluyen en la Tabla 6-8, mientras que el resto de parámetros utilizados pueden consultarse en la Tabla 6-1 y en la Tabla 6-3 del presente capítulo.

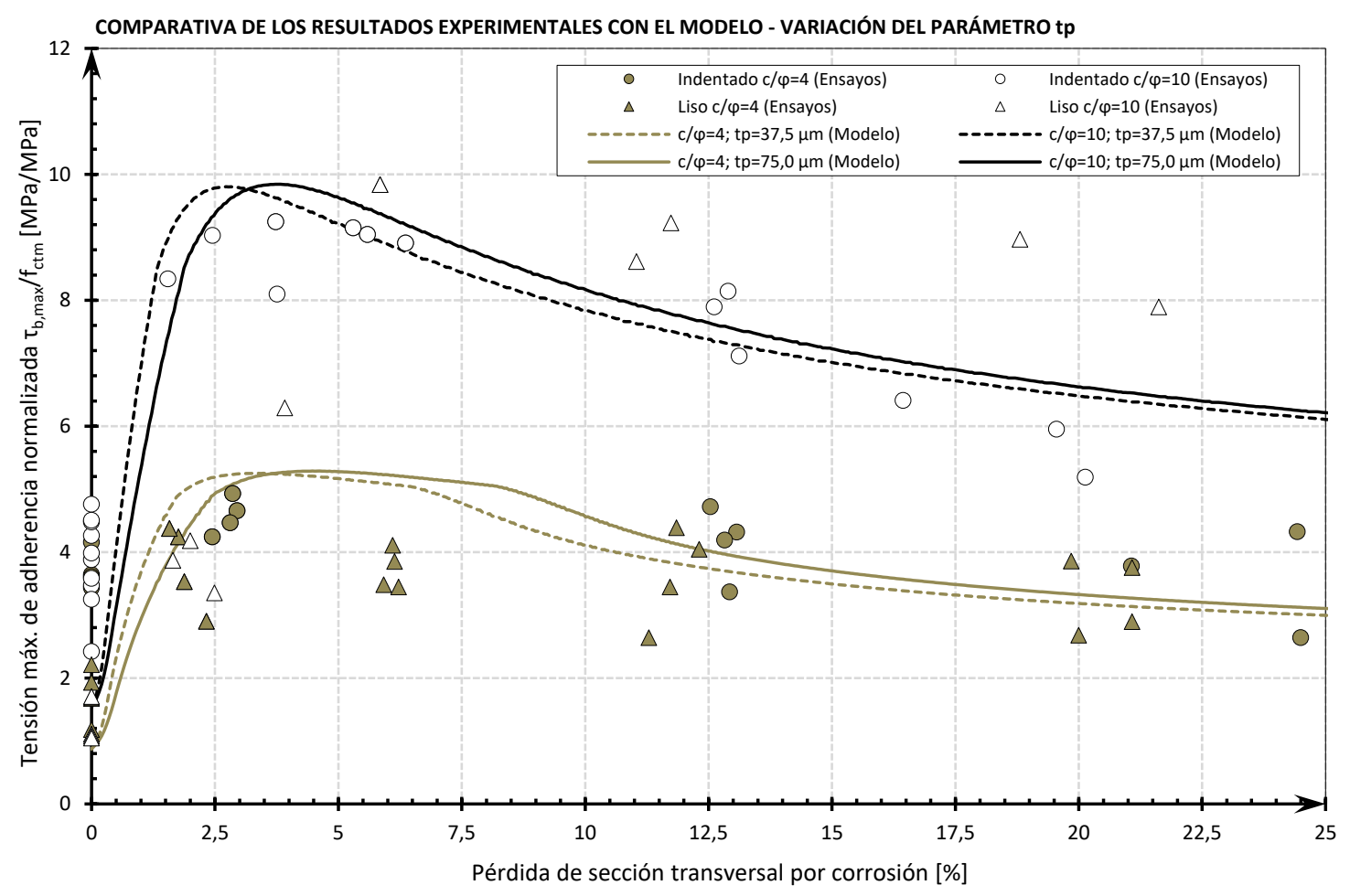

Figura 6-19 Comparación de la evolución de la tensión de adherencia normalizada $\tau_{b, \max } / f_{c t m}[M P a / M P a]$, con respecto a la pérdida de sección transversal [\%] debida a la corrosión, para distintos valores de espesor equivalente de capa porosa.

Para la caracterización de la capa porosa se ha optado por el modelo parabólico, estableciéndose un rango caracterizado por un límite inferior con un espesor $t_{p, c r i}$ de $37,5 \mu \mathrm{m}$ (equivalente a un espesor constante de 12,5 $\mu \mathrm{m}$ ) y un límite superior de 75,0 $\mu \mathrm{m}$ (equivalente a un espesor constante de 25,0 $\mu \mathrm{m})$. 
Tabla 6-8 Valor de los parámetros de entrada en el modelo analítico para la obtención de las gráficas de la Figura 6-19

\begin{tabular}{|c|c|c|c|c|c|c|c|c|c|c|}
\hline \multirow[b]{2}{*}{ SERIE } & \multicolumn{2}{|c|}{$\begin{array}{l}\text { Parámetros } \\
\text { geométricos }\end{array}$} & \multicolumn{2}{|c|}{$\begin{array}{l}\text { Parámetros } \\
\text { mecánicos }\end{array}$} & \multicolumn{4}{|c|}{ Parámetros relativos a la corrosión } & \multicolumn{2}{|c|}{ Adherencia } \\
\hline & $C[\mathrm{~mm}]$ & $t_{p, c r i}[\mu \mathrm{m}]$ & $f_{c m}[M P a]$ & $f_{c t, m}[\mathrm{MPa}]$ & $\frac{d m_{s}}{d t_{\text {corr }}}$ & $n$ & $K_{r}$ & \% óx. fis. & $\begin{array}{c}\tau_{a d h} \\
{[\mathrm{MPa}]}\end{array}$ & $\mu$ \\
\hline $\mathrm{c} / \varphi=4$ & 17,5 & \multirow{2}{*}{$\begin{array}{c}37,5-75 \\
\text { (variable) }\end{array}$} & 32,43 & 3,79 & \multirow{2}{*}{ Faraday } & \multirow{2}{*}{2} & 0,5 & $75 \%$ & \multirow{2}{*}{2,0} & \multirow{2}{*}{0,65} \\
\hline $\mathrm{c} / \varphi=10$ & 47,5 & & 43,72 & 3,16 & & & 1,0 & $25 \%$ & & \\
\hline
\end{tabular}

A pesar de la alta dispersión de los resultados experimentales, el modelo ofrece un ajuste razonablemente bueno y es capaz de reproducir todas las tendencias observadas en los ensayos. A efectos de la influencia del parámetro $t_{p}$, objeto de este apartado, tanto el límite inferior como el límite superior propuestos proporcionan resultados aceptables. La tensión máxima de adherencia $\tau_{b \text {,max }}$ se alcanza para perdidas de sección de entre un 3 y un 4,5\%, y existe cierta independencia entre el recubrimiento y el nivel de corrosión bajo el que se alcanza dicha tensión.

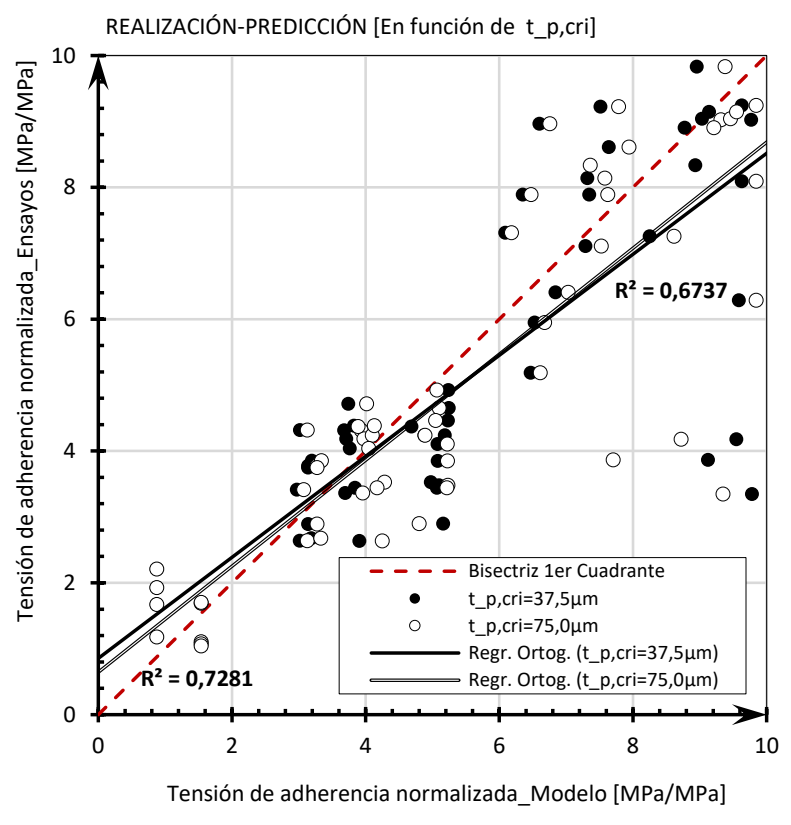

Figura 6-20 Diagrama predicción-realización de las tensiones de adberencia normalizadas $\tau_{b, \max } / f_{\text {ctm }}[\mathrm{MPa} / \mathrm{MPa}]$, para espesores equivalentes de "zona porosa" tp,cri iguales a 37,5 y $75 \mu \mathrm{m}$, con distribución parabólica..

En la Figura 6-20 se representan los diagramas predicción-realización de las tensiones de adherencia normalizadas $\tau_{b, \max } / f_{\text {ctm }}[\mathrm{MPa} / \mathrm{MPa}]$, para espesores equivalentes de "zona porosa" $t_{\text {p,ri }}$ con valores de 37,5 y 75,0 $\mu \mathrm{m}$, modelados con una distribución parabólica. Las rectas de regresión ortogonal para los resultados derivados del uso de ambos espesores son prácticamente coincidentes, más tendidas que la bisectriz del $1{ }^{\text {er }}$ cuadrante, subestimando ligeramente el resultado obtenido en los ensayos para valores bajos de tensión normalizada $\tau_{b \text {,max }} / f_{\text {ctm }}$, correspondientes con los ensayos sobre alambres sanos, y sobrestimando el resultado para valores de tensión medios y altos El uso de un espesor equivalente de "zona porosa" igual $75 \mu \mathrm{m}$ proporciona resultados con una menor dispersión (coeficiente de determinación $R^{2}=0,728>0,674$ ) y una pendiente ligeramente más próxima a la de los $45^{\circ}$ de la bisectriz. 
A la vista del análisis llevado a cabo en este apartado, el modelo analítico desarrollado para esta tesis utiliza preferentemente, para la caracterización del parámetro $t_{p, c r i}$ en el modelo parabólico, un espesor límite $t_{p, r i}$ igual a $75 \mu \mathrm{m}$.

\subsubsection{Volumen de óxidos en fisuras}

Como se ha visto en el Capitulo 2, una vez que se ha iniciado la fisuración en el hormigón que circunda el alambre, los productos de corrosión pueden depositarse en el interior de las fisuras abiertas (Bažant, 1979) (Andrade, et al., 1993). Este espacio adicional para la difusión de los óxidos (equivalente a un porcentaje del volumen total liberado por las fisuras) conllevará, por una parte, un retraso en la fisuración del recubrimiento, por otra, un pico de tensión máxima de adherencia para un valor más elevado de corrosión y, por último, una tensión de adherencia residual superior para el mismo nivel de pérdida de sección.

Cuando no se contempla la fisuración como espacio de expansión para los óxidos, como se desarrolló en el Capitulo 3, el valor combinado de cambio de volumen del acero $\Delta V_{s}$ y del hormigón $\Delta V_{c}$ debe ser equivalente al volumen total comprimido de productos de corrosión $V_{r}$. En el caso de tener en cuenta la penetración de óxidos en las fisuras, se tendrá en cuenta un volumen adicional $\Delta V_{\text {crack }}$ correspondiente al espacio adicional liberado por la fisuración, de manera que se obtiene una nueva relación de igualdad con la siguiente forma (Eq. 6-13):

$$
V_{r c}=\Delta V_{s}+\Delta V_{c}+\Delta V_{\text {crack }}
$$

La revisión bibliográfica ha permitido comprobar que los aspectos relativos a este fenómeno que conllevan más controversia son, por un lado, la determinación del porcentaje de espacio liberado por las fisuras $\Delta V_{\text {crack }}$ que es ocupado por los productos de corrosión, incrementando el volumen disponible para la expansión de los óxidos $V_{r}$ y disminuyendo consecuentemente la presión $p$ que se ejerce sobre la pared interna del cilindro de hormigón, y por otro, cuáles son los parámetros que determinan dicho porcentaje. En vista de los trabajos analizados se puede deducir que existen tres parámetros fundamentales que determinan el valor de dicho porcentaje: el espesor de recubrimiento c (Val, et al., 2008), la extensión de la fisuración (Wang, et al., 2017), y por último, el valor de la densidad de corriente de corrosión $i_{\text {corr }}(\mathrm{Lu}$, et al., 2010).

\subsubsection{Estudio de sensibilidad de la variable}

Como se ha hecho en apartados anteriores, en este apartado se lleva a cabo un estudio paramétrico, analizando en qué forma y grado afecta a los resultados obtenidos mediante el modelo analítico propuesto en el Capítulo 3 la variación del porcentaje de volumen de óxidos que difunden por las fisuras con respecto al volumen total liberado por las mismas. Fijando el valor de los parámetros recogidos en la Tabla 6-1, se ha variado la magnitud del porcentaje de óxidos depositados, dentro del rango de valores más habitual extraído del análisis bibliográfico: 0, 10, 25, 50 \%. En la Figura 6-21 se recoge como afecta la variación de este parámetro, con el aumento de la corrosión (hasta un $20 \%$ de pérdida de sección transversal), a los valores de: A) Tensión radial $\sigma_{r} ;$ B) Evolución del frente de fisuración; C) Deformaciones radiales $\varepsilon_{r}$ en la interfaz acero-hormigón; D) Deformaciones circunfe- 

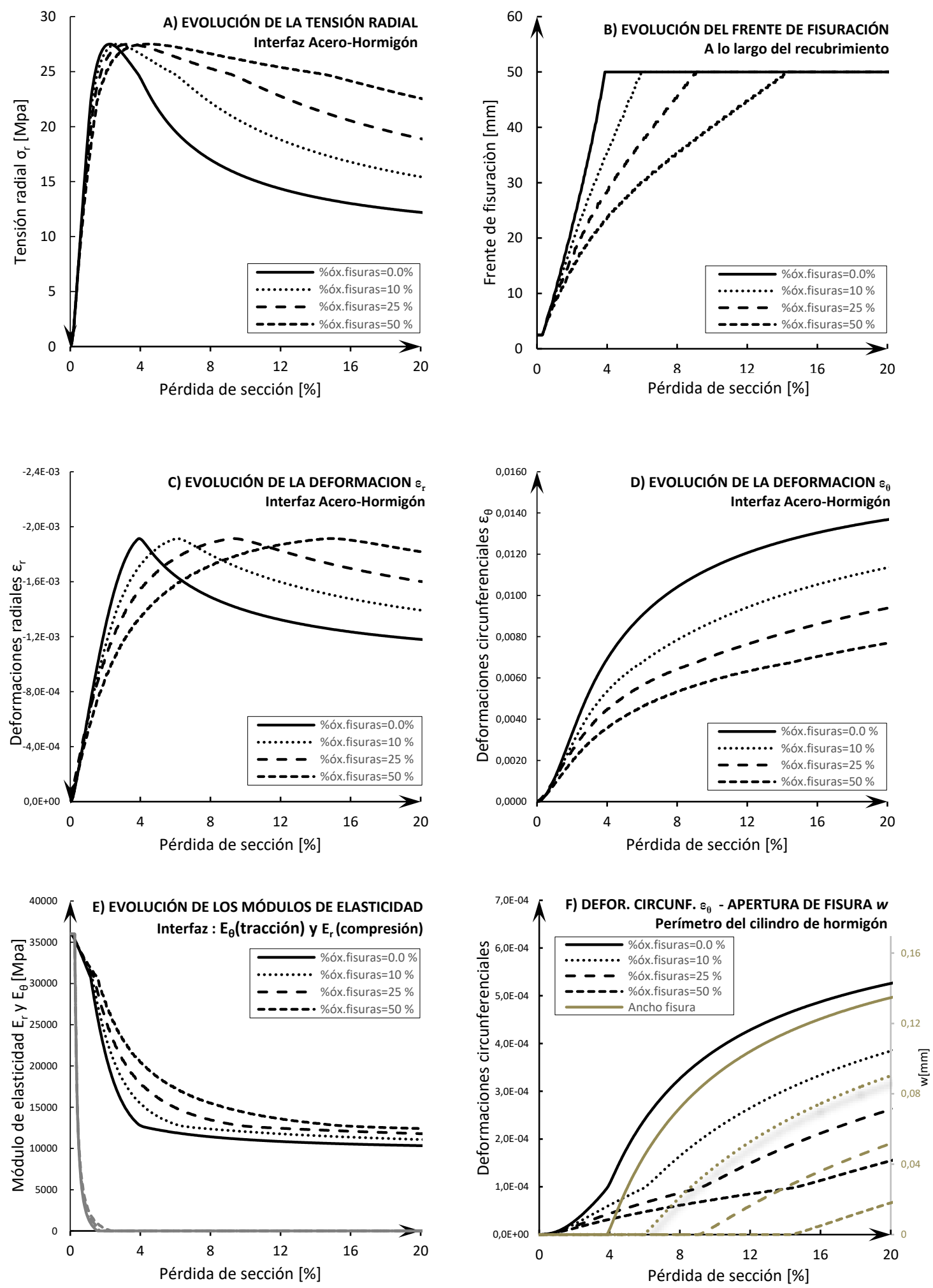

Figura 6-21 Influencia del volumen de óxidos en fisuras, en la evolución de distintos parámetros, en relación con el aumento de la pérdida de sección por el proceso de corrosión: A) Tensión radial $\sigma_{r}$; B) Evolución del frente de fisuración; C) Deformaciones radiales $\varepsilon_{r}$ en la interfaz. acero-hormigón; D) Deformaciones circunferenciales $\varepsilon_{\theta}$ en la interfaz acero-hormigón; E) Evolución de los módulos de elasticidad radial $E_{r}$ (compresión) y circunferencial $E_{\theta}$ (tracción) y F) Deformaciones circunferenciales $\varepsilon_{\theta}$ y ancho de fisura w en el perímetro del cilindro de hormigón. 
renciales $\varepsilon_{\theta}$ en la interfaz acero-hormigón; E) Evolución de los módulos de elasticidad radial $E_{r}$ (compresión) y circunferencial $E_{\theta}$ (tracción) y F) Deformaciones circunferenciales $\varepsilon_{\theta}$ y ancho de fisura $w$ en el perímetro del cilindro de hormigón.
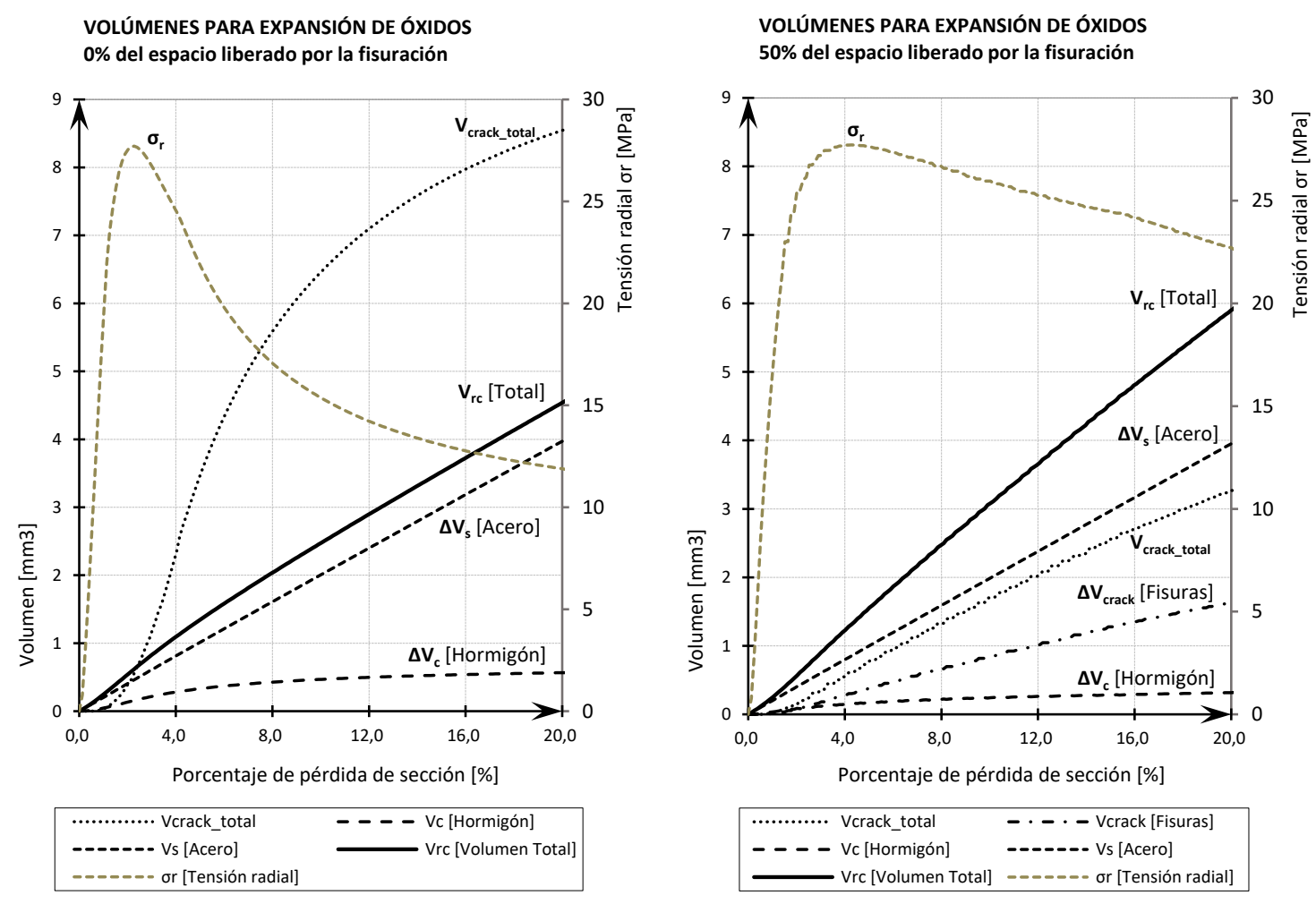

Figura 6-22 Comparación de volumenes disponibles para la expansión de óxidos en función del nivel de pérdida de sección por corrosión, para distintos porcentajes de óxidos depositados en el espacio liberado por la fisuración

Dado que el porcentaje de óxidos que se depositan en las fisuras no afecta a la capacidad de confinamiento del recubrimiento, la tensión radial $\sigma_{r}$ alcanzada es la misma en todos los casos (Figura 6-21 A). Sin embargo, el aumento de este porcentaje supone un retraso en la evolución de las tensiones (Figura 6-21 A), de las deformaciones (Figura 6-21 C, D y F), del frente de fisuración (Figura 6-21 B) y de la apertura de fisura (Figura 6-21 F), así como una atenuación del descenso de la tensión radial $\sigma_{r}$ post-pico. Una vez que comienza la fisuración y para un mismo nivel de pérdida de sección por corrosión, un mayor porcentaje de óxidos depositados en las fisuras de nueva creación $\Delta V_{\text {crack }}$ supone un aumento del volumen $V_{r}$ disponible para la expansión de los mismos y, por tanto, un menor desplazamiento radial $u_{r}$ de la pared interna del cilindro de hormigón que confina el alambre. Esto puede apreciarse con claridad en la Figura 6-22, donde se han representado las gráficas de evolución de los volúmenes disponibles para la expansión de óxidos en función del nivel de pérdida de sección por corrosión, para un $0 \%$ (izquierda) y un 50\% (derecha) de óxidos depositados en el espacio liberado por la fisuración. El aumento de volumen total $V_{r}$ proporcionado por el volumen adicional procedente de las fisuras $\Delta V_{\text {crack, }}$ permite que el volumen $\Delta V_{c}$ necesario, cuyo origen es el desplazamiento de la cara interna del recubrimiento de hormigón, sea menor, disminuyendo por tanto el desplazamiento radial $u$. 


\subsubsection{Calibración del porcentaje de óxidos en fisuras}

Como primera aproximación al problema, y a falta de una campaña experimental diseñada al efecto, se decide que el volumen de óxidos que penetren en las fisuras $\Delta V_{\text {crack, }}$, para el mismo nivel de pérdida de sección por corrosión y una misma intensidad de corriente $i_{\text {corr, }}$ sea igual en términos absolutos para todos los recubrimientos considerados, con lo que, dado que el volumen total de fisuras $V_{\text {crack, total }}$ crece con el recubrimiento, el porcentaje de volumen ocupado decrece con el aumento del mismo. Este planteamiento es coherente con los escasos estudios existentes al respecto (Val, et al., 2008).

En la Figura 6-23, para una relación recubrimiento/diámetro $c / \phi$ igual a 4 (izquierda) y a 10 (derecha), y un nivel de corrosión dado ( $20 \%$ de pérdida de sección), se representan las gráficas de evolución del volumen total de óxidos comprimidos $V_{r}$, del volumen total de fisuras $V_{\text {crack_total }}$ y del volumen de óxidos en fisuras $\Delta V_{\text {crack, }}$ para distintos porcentajes de $\Delta V_{\text {crack }}$ con respecto $V_{\text {crack_total. }}$ Como puede observarse en las gráficas, el aumento del porcentaje trae consigo un descenso del volumen total de fisuras $V_{\text {crack_total }}$ y un aumento del volumen disponible para la expansión de los óxidos $V_{r}$. Siguiendo el criterio expuesto anteriormente, para los recubrimientos considerados se determinan duplas de porcentajes en los que el volumen de óxidos en fisuras $\Delta V_{\text {crack }}$ es aproximadamente igual, obteniéndose las siguientes parejas de valores: 40-10\%, 80-20\%, 100-30\% (donde el primer término se corresponde con $c / \phi=4$ y el segundo término $\operatorname{con} c / \phi=10)$.
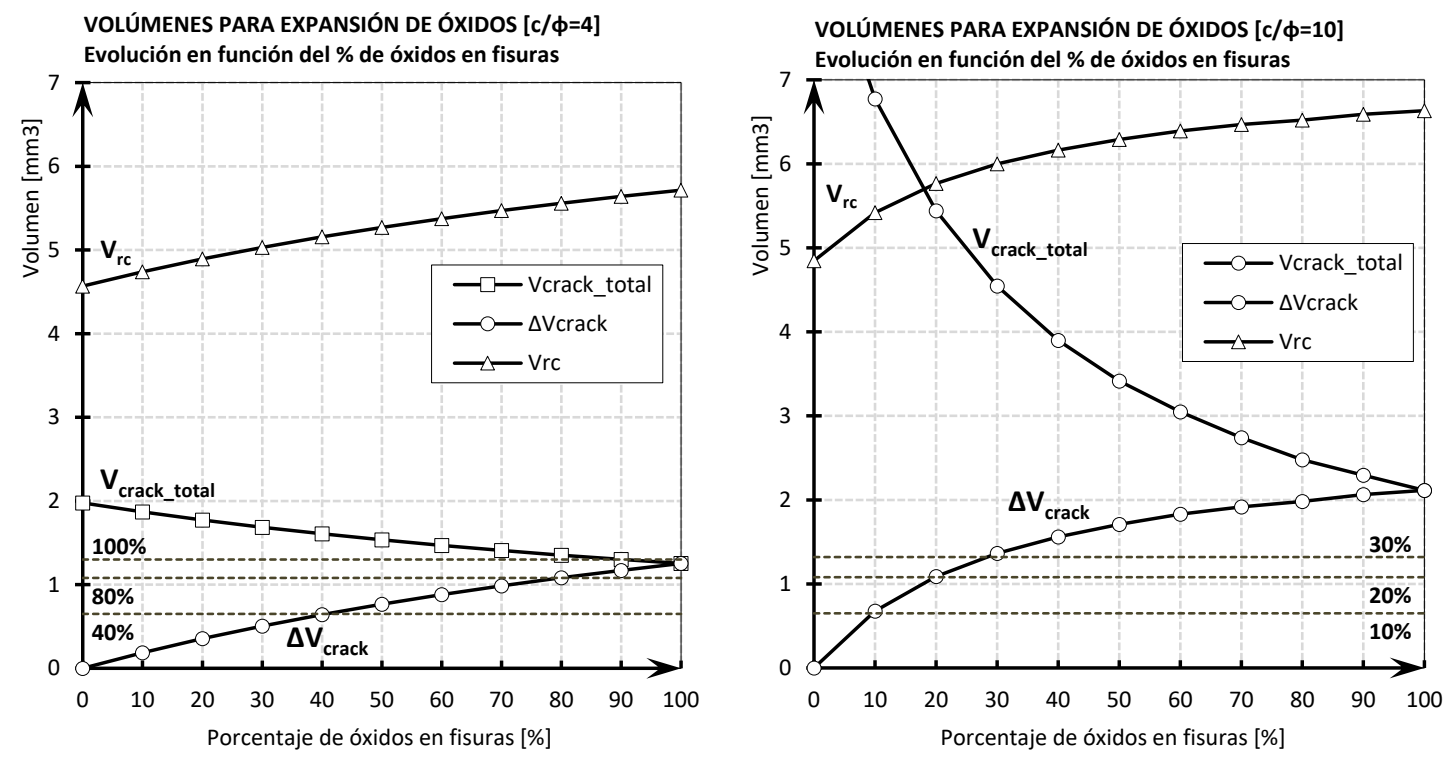

Figura 6-23 Evolución del volumen total de óxidos comprimidos $V_{r}$, del volumen total de fisuras $V_{\text {crack_total }} y$ del volumen de óxidos en fisuras

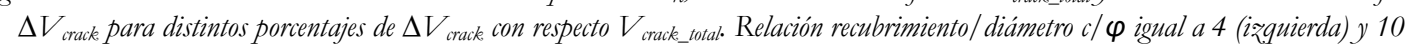
(derecha).

En la Figura 6-24 se compara la tensión máxima de adherencia normalizada $\tau_{b, \max } / f_{\text {ctm }}$ obtenida de los ensayos sobre probetas con relaciones recubrimiento/diámetro iguales a 4 y 10 , con los resultados del modelo para las duplas de porcentajes de volumen de óxido en fisuras $\Delta V_{\text {crack }}$ con respecto al volumen total de las mismas $V_{\text {crack_total }}$ obtenidas anteriormente: 40-10\%, 80-20\%, 100-30\%. Los datos de entrada más relevantes para la obtención de las gráficas analíticas se incluyen En la Tabla 6-9 se 
incluyen los datos más relevantes para la obtención de las gráficas analíticas, mientras que el resto de parámetros utilizados pueden consultarse en la Tabla 6-1 y en la Tabla 6-3 del presente capítulo.

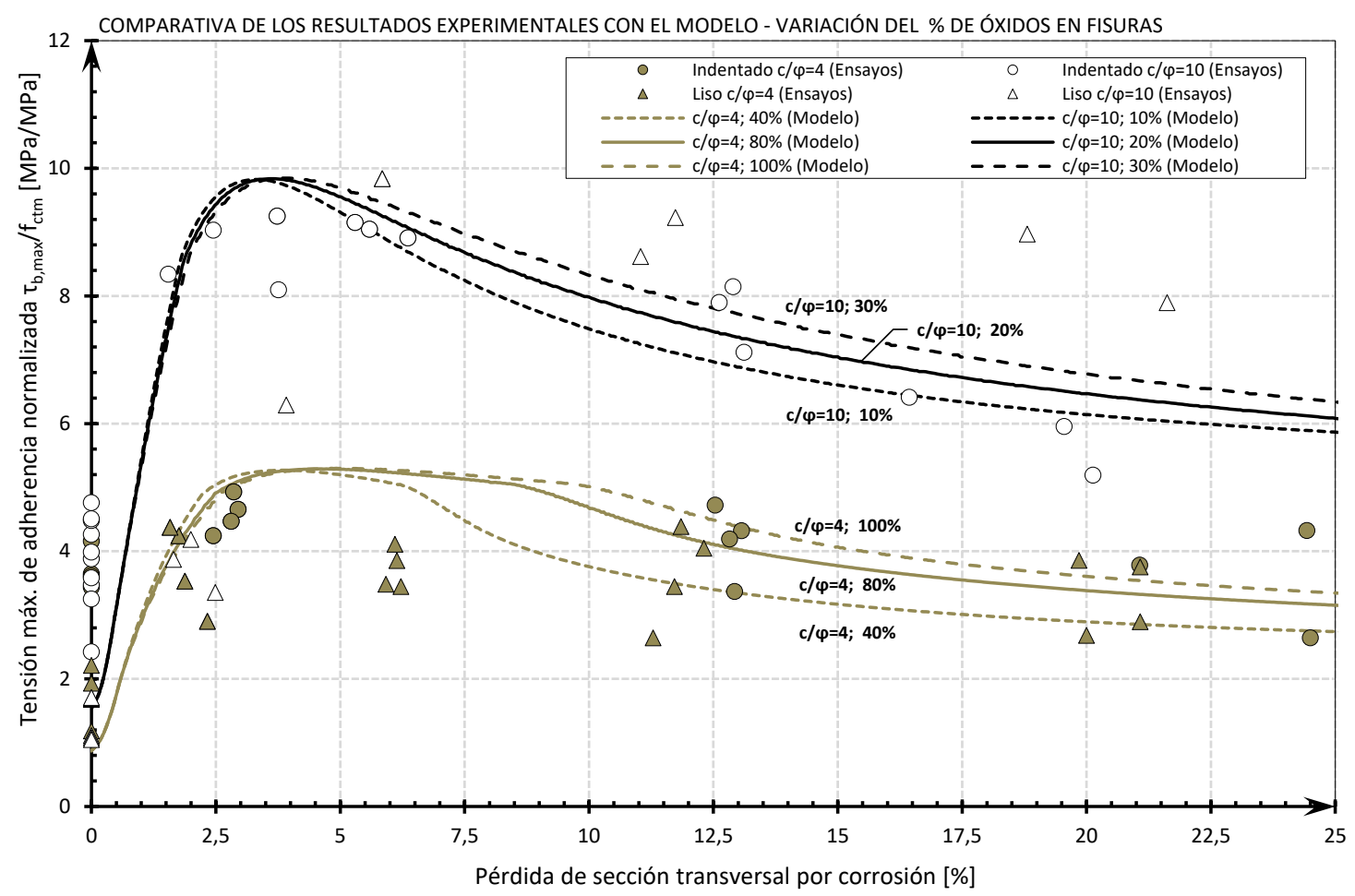

Figura 6-24 Comparación de la evolución de la tensión de adherencia normalizada $\tau_{b, \text { max }} / f_{c t m}[M P a / M P a]$, con respecto a la pérdida de sección transversal [\%] debida a la corrosión, para distintos porcentajes de volumen de óxidos en fisuras.

Tabla 6-9 V alor de los parámetros de entrada en el modelo analitico para la obtención de las gráficas de la Figura 6-24

\begin{tabular}{|c|c|c|c|c|c|c|c|c|c|c|}
\hline \multirow[b]{2}{*}{ SERIE } & \multicolumn{2}{|c|}{$\begin{array}{l}\text { Parámetros } \\
\text { geométricos }\end{array}$} & \multicolumn{2}{|c|}{$\begin{array}{l}\text { Parámetros } \\
\text { mecánicos }\end{array}$} & \multicolumn{4}{|c|}{ Parámetros relativos a la corrosión } & \multicolumn{2}{|c|}{ Adherencia } \\
\hline & $C[\mathrm{~mm}]$ & $t_{p, c r i}[\boldsymbol{\mu} \mathrm{m}]$ & $f_{c m}[M P a]$ & $f_{c t, m}[\mathrm{MPa}]$ & $\frac{d m_{s}}{d t_{\text {corr }}}$ & n & $K_{r}$ & $\%$ óx. fis. & $\tau_{\text {adb }}[\mathrm{MPa}]$ & $\mu$ \\
\hline$c / \varphi=4$ & 17,5 & \multirow{2}{*}{75 (variable) } & 32,43 & 3,79 & \multirow{2}{*}{ Faraday } & \multirow{2}{*}{2} & 0,5 & $40-80-100 \%$ & \multirow{2}{*}{2,0} & \multirow{2}{*}{1,0} \\
\hline$c / \varphi=10$ & 47,5 & & 43,72 & 3,16 & & & 1,0 & $10-20-30 \%$ & & \\
\hline
\end{tabular}

Las diferentes duplas de porcentaje de óxidos en fisuras arrojan resultados similares, especialmente en las fases previas a la tensión máxima de adherencia normalizada $\tau_{b, \text { max }} / f_{c t m}$, donde la fisuración no ha adquirido aún una importancia significativa. Para las probetas con relación recubrimiento/diámetro $c / \phi$ igual a 4 , el modelo determina que la tensión máxima de adherencia normalizada $\left(\tau_{b, \max } / f_{\text {ctm }}=5,268 \mathrm{MPa} / \mathrm{MPa}\right)$ se alcanza para perdidas de sección de: 3,83\% $(48,34 \mu \mathrm{m})$ para un $40 \%$ de ocupación del volumen total de fisuras $V_{\text {crack_total }}, 5,46 \%(69,21 \mu \mathrm{m})$ para un $80 \%$; y $5,02 \%(63,55 \mu \mathrm{m})$ para un $100 \%$. Es destacable el hecho de que los mayores porcentajes permiten que la tensión de adherencia se mantenga durante mayor tiempo en valores cercanos al máximo antes de comenzar a decaer. En cuanto a las probetas con relación recubrimiento/diámetro $c / \phi$ igual a 10 , la tensión máxima de adherencia normalizada $\left(\tau_{b, \max } / f_{\mathrm{ctm}}=9,825 \mathrm{MPa} / \mathrm{MPa}\right)$ se alcanza para pérdidas de sección de: $3,33 \%(41,98 \mu \mathrm{m})$ para un 10\% de ocupación de las fisuras; 3,68\% $(46,43 \mu \mathrm{m})$ para un $20 \%$; y $3,85 \%(48,60 \mu \mathrm{m})$ para un $30 \%$. 
Es en el comportamiento post-pico donde crecen las diferencias (aunque en todo caso moderadas), produciéndose para ambos recubrimientos caídas más pronunciadas en la tensión de adherencia con la reducción del porcentaje de óxidos que difunden en las fisuras. Este resultado confirma lo observado en el estudio de sensibilidad, es decir, que menores porcentajes de penetración de óxidos ocasionan mayores desplazamientos radiales de la pared interna del cilindro de hormigón y, como consecuencia, adelantan el agotamiento de la sección. A pesar de ello, y de la alta dispersión de los resultados experimentales, el modelo ofrece para los dos recubrimientos considerados y las distintas duplas de porcentajes analizadas, un ajuste razonablemente bueno y es capaz de reproducir todas las tendencias observadas en los ensayos.

En la Figura 6-25 se representan los diagramas predicción-realización de las tensiones de adherencia normalizadas $\tau_{b \text {, max }} / f_{\text {ctm }}[\mathrm{MPa} / \mathrm{MPa}$, para las duplas de porcentajes $40-10 \%$ y $80-20 \%$ (primer valor, $c / \phi=4$; segundo valor $c / \phi=10$ ), referidas al volumen de óxido en fisuras $\Delta V_{\text {crack }}$ con respecto al volumen total de las mismas $V_{\text {crack_total. }}$ A pesar de que la dupla $100-30 \%$ ha arrojado un buen ajuste con respecto a los resultados experimentales, se opta por no utilizarlos, ya que como se vio en el Capítulo 2, la plena ocupación de las fisuras debería estar reservada únicamente para procesos de corrosión natural, es decir, para densidades de corriente bajas $<10 \mu \mathrm{A} / \mathrm{cm}^{2}$.

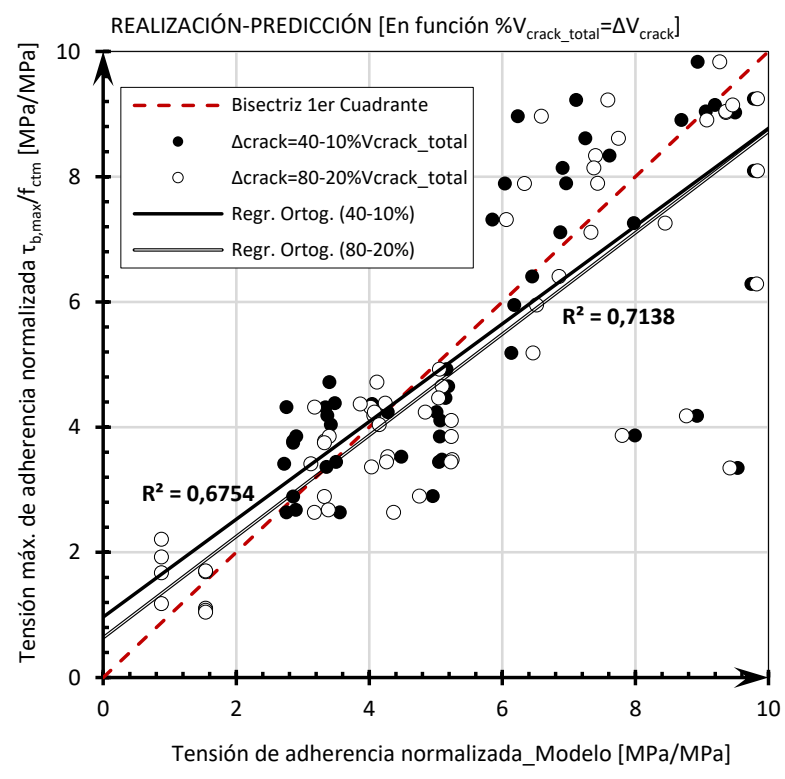

Figura 6-25 Diagrama predicción-realización de las tensiones de adherencia normalizadas $\tau_{b, \max } / f_{c t m}[M P a / M P a]$, para diferentes porcentajes de volumen de óxidos en fisuras con respecto al volumen total de éstas.

Como puede apreciarse en la Figura 6-25, las rectas de regresión ortogonal para los resultados derivados del uso de ambos duplas presentan pendientes similares, más tendidas que la bisectriz del primer cuadrante, y puntos de corte con dicha bisectriz razonablemente cercanos. Al igual que se ha observado al analizar otros parámetros, la gráfica muestra que el modelo subpredice ligeramente el resultado para valores bajos de tensión normalizada $\tau_{b, \max } / f_{\mathrm{ctm}, \text { }}$ correspondientes con los ensayos sobre alambres sanos, y sobrestima el resultado para valores de tensión medios y altos. El uso de la dupla $80-20 \%$ arroja resultados con una menor dispersión (coeficiente de determinación $R^{2}=0,714>0,675$ ) y la pendiente de su recta de regresión está ligeramente más próxima a 1 (0,81 frente a 0,78$)$. 
Por tanto, por un lado, siguiendo el criterio adoptado según el cual el volumen de óxidos que penetra en las fisuras $\Delta V_{\text {crack }}$ es igual para la misma densidad de corriente $i_{\text {corr }}$ e independiente del espesor $c$ de recubrimiento (Figura 6-23), y por otro, a la vista del estudio de sensibilidad realizado (Figura 6-21), del grado de ajuste del modelo a los resultados experimentales (Figura 6-24) y del diagrama realizaciónpredicción (Figura 6-25), en esta tesis se considera que en las probetas con relación recubrimiento/diámetro igual a 4 un $80 \%$ del volumen liberado por la fisuración es ocupado por los productos de corrosión, siendo de un $20 \%$ para las probetas con relación recubrimiento/diámetro igual a 10.

\subsubsection{Coeficiente de fricción $\mu$}

El modelo analítico desarrollado en esta tesis, basado en el modelo de fricción de Coulomb, desacopla el mecanismo adherente en dos componentes diferenciadas: Una componente longitudinal $\tau_{b}$, que reproduce la variación de las tensiones a lo largo del alambre, transferidas gradualmente al hormigón circundante cuando el pretensado es liberado tras el endurecimiento del hormigón, y una componente transversal o radial $\sigma_{r, 0}$ asociada al desplazamiento radial $u_{r}$, procedente del efecto Hoyer derivado de la transferencia del pretensado $\sigma_{r ; p}$, de la acumulación de productos de corrosión $\sigma_{r, \text { rorr }}$ y/o de la retracción, $\sigma_{r, s b}$.

Como se ha visto en el Capitulo 3, estas dos componentes del modelo, dejando a un lado la adhesión química $\tau_{\text {adb }}$ que suele considerarse constante y cuya acción desaparece para deslizamientos $s$ muy pequeños, están asociadas a través del coeficiente de fricción $\mu$ descrito por la Ley de rozamiento de Coulomb. Por definición, esta ley establece que la fuerza de rozamiento máxima $F$ que puede existir entre dos cuerpos en contacto es directamente proporcional al valor de la fuerza normal $\mathrm{N}$ a la superficie de contacto entre ellos, siendo la constante de proporcionalidad igual al coeficiente de fricción $\mu$ (Eq. 6-14).

$$
F=\mu N \Rightarrow \tau_{b}=\mu \sigma_{r}
$$

En esta tesis se parte de la hipótesis de que dicho coeficiente es una propiedad intrínseca del contacto entre dos materiales determinados, por lo que su valor es independiente del contorno o forma externa de los mismos. En consecuencia, se supone que el coeficiente de fricción es el mismo para los alambres lisos e indentados utilizados en los ensayos de pull-out. La mayor capacidad adherente de los alambres sanos con indentaciones se debe al engranamiento mecánico de estas últimas con el hormigón circundante, y no a un mayor valor del coeficiente en cuestión.

Por otra parte, también se parte de la base de que la corrosión no afecta al valor del coeficiente de fricción $\mu$. Este aspecto genera controversia en la comunidad científica, estando aún alejada la posibilidad de alcanzarse un consenso (Ver Capitulo 2). Mientras que algunos autores defienden que el coeficiente de fricción se modifica en paralelo al avance del proceso de corrosión de los alambres, aumentando de valor para niveles bajos de deterioro [ (Al-Sulaimani, et al., 1990), (Lundgren, 2005) (Lundgren, 2007)] y descendiendo posteriormente con mayores penetraciones de ataque (Jin \& Zhao, 2001), otros autores, como Cairns (2007), han demostrado que su valor se mantiene constante sea cual sea el nivel de corrosión alcanzado. En la revisión bibliográfica se ha podido comprobar que en aquellos trabajos en los que el coeficiente modifica su valor, la evolución responde más a ajustes 
empíricos que a certezas experimentales, de manera que el coeficiente absorbe la influencia de aquellos fenómenos con repercusión en la adherencia que no han sido contemplados explícitamente en el modelo. Valga como ejemplo como algunos autores (Lundgren, 2005) justifican las subidas de tensión de adherencia $\tau_{b}$ provocadas por niveles bajos de corrosión con la mejora del valor del coeficiente de fricción $\mu$, favorecida por el aumento rugosidad superficial del acero, cuando la causa probable es el aumento de tensión radial $\sigma_{r}$ previo a la fisuración del recubrimiento, procedente del incremento de volumen de los productos de corrosión. En cualquier caso, es un campo que merece ser explorado con campañas experimentales diseñadas al efecto, ya que aún quedan muchas incertidumbres y existen pocas certezas.

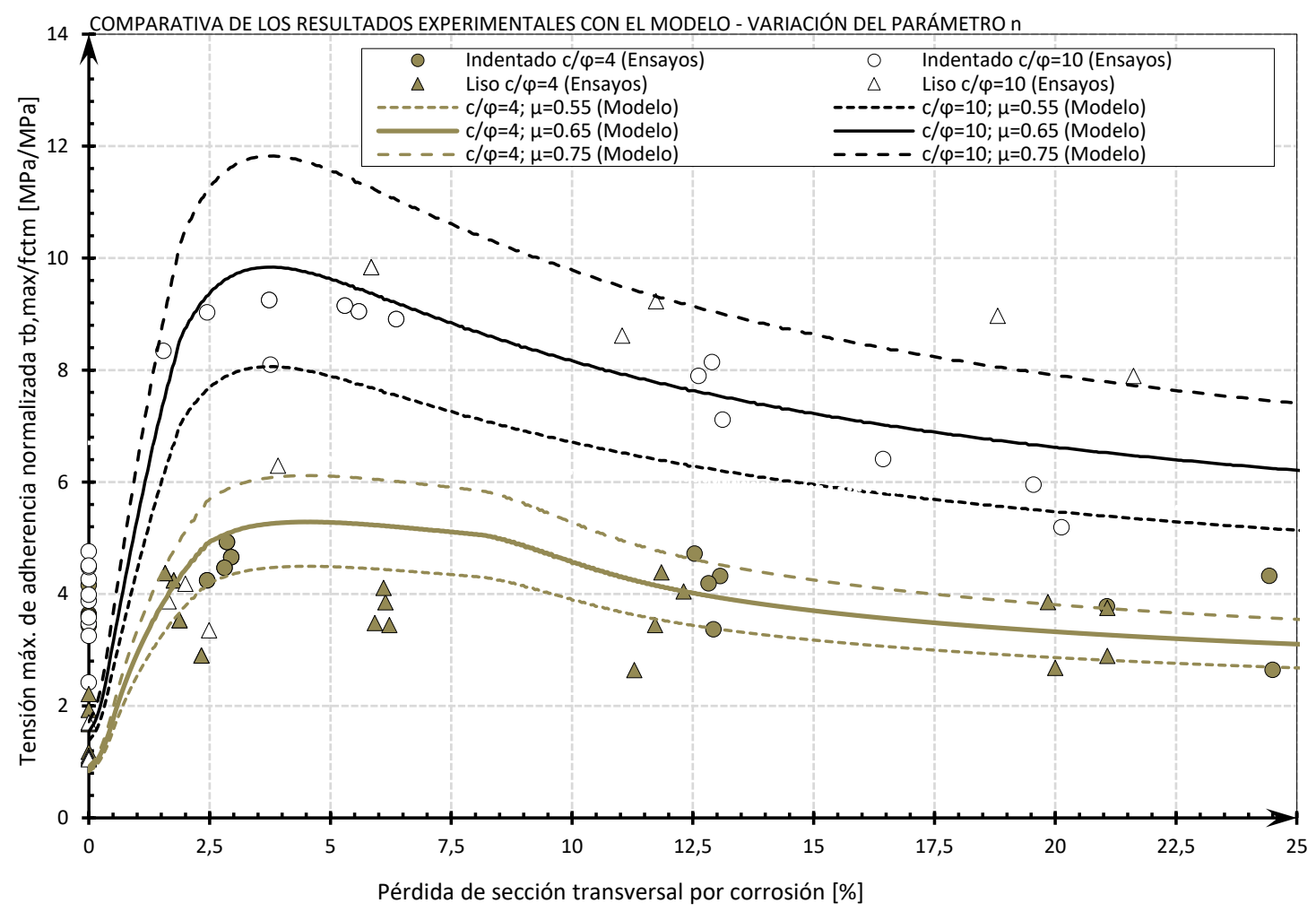

Figura 6-26 Comparación de la evolución de la tensión de adherencia normalizada $\tau_{b, \max } / f_{c t m}[M P a / M P a]$, con respecto a la pérdida de sección transversal $[\%]$ debida a la corrosión, para distintos coeficientes de fricción $\mu$.

Por tanto, partiendo de la hipótesis de que el coeficiente de fricción no se modifica por la forma de la superficie del alambre (lisa o indentada) ni con el aumento de los niveles de corrosión, en la Figura 6-26 se compara la tensión máxima de adherencia normalizada $\tau_{b, \max } / f_{\text {ctm }}$ obtenida de los ensayos, con los resultados arrojados por el modelo usando coeficientes de fricción igual a 0,55, 0,65 y 0,75. Aparentemente, para las dos relaciones recubrimiento/diámetro consideradas, $\mu=0,55$ tiende a subestimar los resultados, mientras que $\mu=0,75$ los sobrestima claramente, obteniéndose el mejor ajuste con el valor intermedio $\mu=0,65$.

Para corroborar las tendencias observadas en la figura anterior, en la Tabla 6-10 se muestra, para cada coeficiente de fricción considerado, el valor medio del ratio $M$ (que se obtiene dividiendo el valor experimental entre el valor predictivo), su desviación típica, $s M$, su coeficiente de variación $C o V$, así como sus valores máximo y mínimo. 
TESIS DOCTORAL INFLUENCLA DE LA CORROSIÓN EN LA ADHERENCLA DE ALAMBRES EN ELEMENTOS PRETENSADOS DE HORMIGÓN

Tabla 6-10 Valores estadisticos vinculados al ratio $M$ para los distintos coeficientes de fricción considerados

\begin{tabular}{cccccc}
\hline Coeficiente de fricción & Media & Desv. típica $\mathbf{S}_{\mathbf{M}}$ & $\mathbf{C o V}[\%]$ & Máximo & Mínimo \\
\hline$\mu=0,55$ & 1,139 & 0,301 & 26,452 & 2,067 & 0,437 \\
\hline$\mu=0,65$ & 0,975 & 0,280 & 28,742 & 1,953 & 0,359 \\
\hline$\mu=0,75$ & 0,846 & 0,267 & 31,514 & 1,846 & 0,299 \\
\hline
\end{tabular}

Como puede observarse, tanto el coeficiente de variación CoV, por encima del $25 \%$ en todos los casos, como los valores máximo y mínimo del ratio $\mathrm{M}$, reflejan la alta dispersión de los resultados obtenidos. A pesar de este hecho, la media del ratio $\mathrm{M}$ obtenido para el coeficiente de fricción $\mu=0.65$, muy cercana a la unidad (0.975), corrobora que es el que proporciona un mejor ajuste con los resultados experimentales.

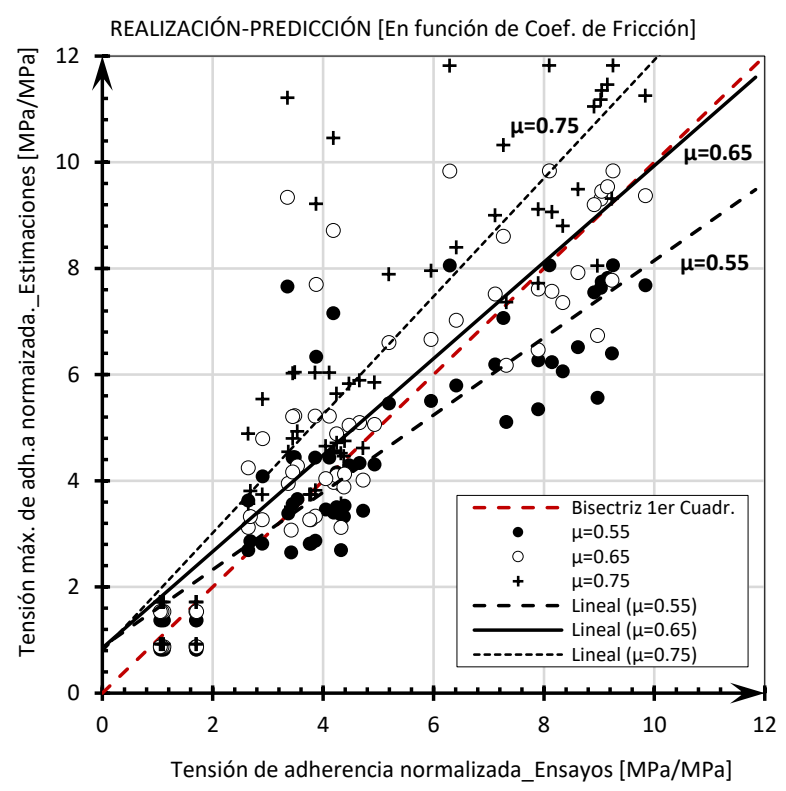

Figura 6-27 Diagrama predicción-realización de las tensiones de adherencia normalizadas $\tau_{b, \max } / f_{c t m}[M P a / M P a]$, para diferentes coeficientes de fricción $\mu$

Por último, en la Figura 6-27 se representan los diagramas predicción-realización de las tensiones de adherencia normalizadas $\tau_{b, \text { max }} / f_{\text {ctm }}$ para los diferentes coeficientes de fricción considerados. La cercanía del trazado de la recta de regresión correspondiente al coeficiente de fricción $\mu=0.65$ con respecto a la bisectriz del primer cuadrante termina por confirmar que dicho valor es el que permite una mayor capacidad predictiva al modelo. A pesar de ello, la alta dispersión de los resultados no permite ser categórico, por lo que coeficientes en el rango entre 0,6 y 0,7 podrían considerarse igualmente válidos.

Si se compara el coeficiente de fricción obtenido con los propuestos por otros autores se puede afirmar que se encuentra en el rango de valores habituales. Así, en el Capitulo 2 se ha visto como Rabat $\&$ Russell (1985) obtuvieron valores entre 0,57 y 0,70, recomendando un $\mu=0,65$ para el coeficiente estático de fricción entre hormigón y placas metálicas con la interfaz húmeda. Posteriormente, 
Olofsson \& Holmgren (1994) desarrollaron un método de ensayo para estimar el coeficiente de fricción, determinando que su valor variaba entre 0,51 y 0,66 , con un valor medio igual a 0,59 . En cuanto a los códigos estructurales, el código ACI-318 (ACI Comittee 318, 2002) recomienda un coeficiente de fricción igual a 0,7 para hormigones no ligeros anclados a perfiles laminados o barras de acero y el Código Modelo 2010 (CEB-FIP, 2012) afirma que el coeficiente entre el hormigón y el acero puede variar desde valores prácticamente despreciables, cercanos al cero, hasta valores cercanos al 0,6 para superficies libres de impurezas.

En este apartado se ha calibrado el valor máximo del coeficiente de fricción, previo al deterioro derivado del deslizamiento del alambre. Este coeficiente, que según los tratamientos más habituales de la problemática de la ficción suele denominarse coeficiente de fricción estático $\mu_{s}$ (Hibbeler, 2010), comienza a descender de valor al alcanzarse un determinado deslizamiento, correspondiente con la carga máxima de arrancamiento, a partir del cual el alambre desliza sin poder asumir nuevos incrementos de carga. El valor del coeficiente disminuye hasta un límite inferior, vinculado a la tensión de adherencia residual y que suele denominarse coeficiente de fricción dinámico $\mu_{k}$. El valor de este coeficiente se trata en el Apartado 6.4, en el que se estudia y calibra la ley de adherencia localdeslizamiento.

\subsubsection{Conclusiones parciales sobre la calibración de parámetros relativos a la corrosión}

A lo largo de los apartados anteriores se ha desarrollado una metodología para la calibración de los parámetros relativos al proceso de corrosión que influyen en el comportamiento adherente de alambres de acero, basada en la combinación y comparación de los resultados experimentales con los analíticos. Este procedimiento ha permitido la obtención de valores fundamentados, coherentes con la bibliografía consultada, y que proporcionan un buen ajuste entre los resultados experimentales y los arrojados por el modelo analítico desarrollado para esta tesis.

El resultado numérico obtenido para estos parámetros no es estrictamente extrapolable a otras situaciones, ya que se requeriría una campaña experimental más ambiciosa y de mayor especificidad para generalizar dichos valores, pero sí que lo son gran parte de las conclusiones extraídas acerca de su influencia en el fenómeno de la adherencia de alambres de acero, así como la metodología seguida para su determinación.

En la Tabla 6-11 se presentan, a modo de recopilación, los valores de los parámetros relativos a la corrosión y el coeficiente de fricción calibrados para el modelo analítico de la presente tesis.

Tabla 6-11 Valor de los parámetros relativos a la corrosión calibrados para el modelo analitico de la presente tesis

\begin{tabular}{|c|c|c|c|c|c|}
\hline $\begin{array}{c}\text { Relación } \\
\text { recubrimiento/ } \\
\text { diámetro }\end{array}$ & $\begin{array}{c}\text { Tasa de penetración } \\
\text { de ataque }\end{array}$ & $\begin{array}{l}\text { Coeficiente de } \\
\text { expansión de } \\
\text { óxidos }\end{array}$ & $\begin{array}{c}\text { Módulo de } \\
\text { compresibilidad } \\
\text { volumétrica }\end{array}$ & $\begin{array}{c}\text { Espesor } \\
\text { equivalente de la } \\
\text { capa porosa }\end{array}$ & $\begin{array}{c}\text { Porcentaje de } \\
\text { óxidos en fisuras }\end{array}$ \\
\hline$c / \varphi$ & $d m_{s} / d t$ & $n$ & $\mathrm{Kr}[\mathrm{GPa}]$ & $t_{p, c r i}[\mu m]$ & $V_{\text {crack }}[\%]$ \\
\hline 4 & \multirow{2}{*}{$\begin{array}{l}\text { Ley de Faraday } \\
\text { (Andrade) }\end{array}$} & \multirow{2}{*}{2} & 0,5 & \multirow{2}{*}{$\begin{array}{c}75 \\
\text { (Ley variable) }\end{array}$} & 80 \\
\hline 10 & & & 1,0 & & 20 \\
\hline
\end{tabular}




\subsection{Influencia de la capacidad de confinamiento del hormigón}

Como se ha expuesto en el Capitulo 2, a través de la revisión bibliográfica, y en el Capitulo 5, a partir de la discusión de los resultado experimentales, un factor fundamental en el fenómeno de la adherencia es la capacidad de confinamiento del recubrimiento de hormigón, que depende de parámetros geométricos como el espesor de recubrimiento y la excentricidad del alambre, y de parámetros mecánicos como las resistencias a compresión y tracción del hormigón, su módulo de elasticidad y/o la cuantía de armadura transversal. En este apartado, utilizando el modelo desarrollado como herramienta de análisis, se justifican desde un punto de vista mecánico la influencia del espesor de recubrimiento y de la resistencia del hormigón, complementando la discusión de los resultados efectuada en el Capítulo 5.

Tal y como se hizo en el apartado anterior, el análisis de la influencia de las variables contempladas se ha descompuesto en dos partes diferenciadas: un estudio paramétrico, en el que se comprueba en qué forma y medida afecta al comportamiento adherente la fluctuación de la variable analizada, seguido de una comparación del modelo con los resultados de los ensayos de pull-out. En el estudio paramétrico se ha modificado la magnitud del parámetro de estudio, manteniendo constantes el resto de las variables geométricas y mecánicas (Tabla 6-1). En cuanto a los parámetros relativos a la corrosión, se han utilizado los valores calibrados en el apartado anterior (Tabla 6-11).

\subsubsection{Propiedades geométricas del hormigón: Espesor de recubrimiento}

En la Figura 6-28 se incluyen las gráficas de evolución de las tensiones, deformaciones y fisuraciones en el recubrimiento con el aumento de la corrosión, obtenidas mediante el modelo analítico, para distintas relaciones recubrimiento/diámetro. Fijando el valor de los parámetros recogidos en la Tabla 6-1, incluyendo el diámetro del alambre, se ha variado la magnitud del recubrimiento $c$, de manera que se analizan relaciones $c / \phi$ iguales a $2(c=10 \mathrm{~mm}), 4(c=20 \mathrm{~mm}), 10(c=50 \mathrm{~mm})$ y $20(c=100 \mathrm{~mm})$, obteniéndose los valores de: A) Tensión radial $\sigma_{r}$; B) Evolución del frente de fisuración; C) Deformaciones radiales $\varepsilon_{r}$ en la interfaz acero-hormigón; D) Deformaciones circunferenciales $\varepsilon_{\theta}$ en la interfaz acero-hormigón; E) Evolución de los módulos de elasticidad radial $E_{r}$ (compresión) y circunferencial $E_{\theta}$ (tracción) y F) Deformaciones circunferenciales $\varepsilon_{\theta}$ y ancho de fisura $w$ en el perímetro del cilindro de hormigón.

En el Capitulo 5 se había concluido que, para niveles bajos de corrosión (hasta $\approx 1 \%$ de pérdida de sección), el parámetro controlante de la capacidad adherente era el acabado superficial del acero, con cierta independencia del recubrimiento, puesto que la capacidad de confinamiento no llegaba a movilizarse por completo y el fallo se producía por deslizamiento, mientras que para niveles mediosaltos de corrosión, el parámetro controlante pasaba a ser precisamente la relación recubrimiento/diámetro, observándose tensiones de adherencia significativamente superiores en las probetas con mayor relación $c / \phi$, independientemente del acabado liso o indentado del acero. En efecto, en las gráficas de la Figura 6-28 se observa que el comportamiento en etapas tempranas del proceso de corrosión es prácticamente idéntico en todos los casos, independientemente del espesor de recubrimiento. El avance de la corrosión, con el incremento de las tensiones radiales $\sigma_{r}$ (Figura 6-28-A) y circunferenciales $\sigma_{\theta}$ (Figura 6-28-D) va agotando sucesivamente la capacidad de confinamiento de las secciones con menor relación recubrimiento/diámetro, permaneciendo el resto 

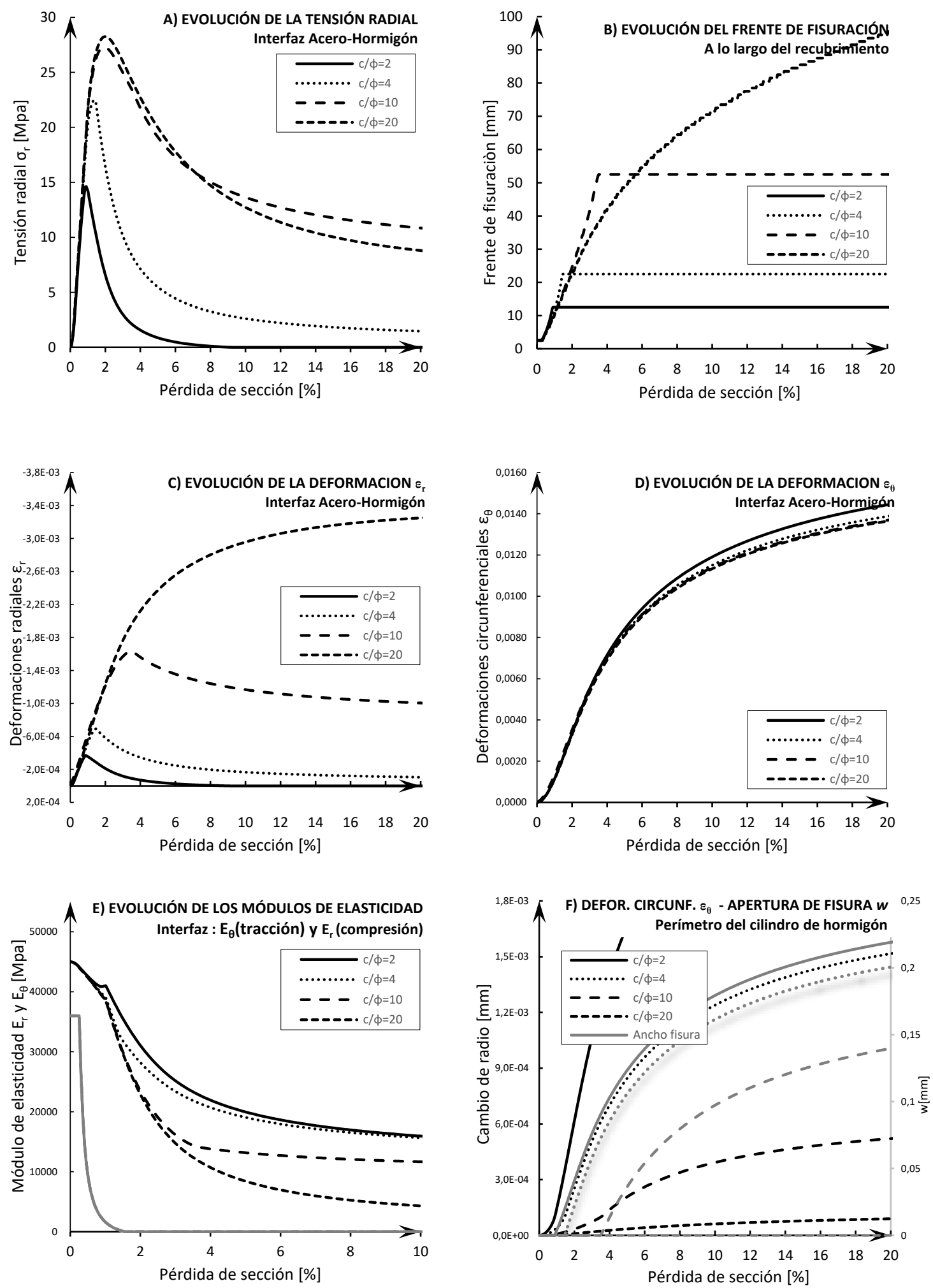

Figura 6-28 Influencia de la relación recubrimiento/ diámetro y del aumento de la pérdida de sección por el proceso de corrosión en la evolución de: A) Tensión radial $\sigma_{n}$. B) Evolución del frente de fisuración; C) Deformaciones radiales $\varepsilon_{r}$ en la interfaz acero-hormigón; D) Deformaciones circunferenciales $\varepsilon_{\theta}$ en la interfaz acero-bormigón; E) Evolución de los módulos de elasticidad radial $E_{r}$ (compresión) y circunferencial $E_{\theta}$ (tracción) y F) Deformaciones circunferenciales $\varepsilon_{\theta}$ y ancho de fisura w en el perimetro del cilindro de hormigón. 
con comportamientos similares. Por tanto, el incremento del espesor de recubrimiento retrasa el momento en el que la corrosión comienza a mermar el confinamiento del hormigón, principalmente por la fisuración del recubrimiento (Figura 6-28-B). De esta manera, el pico de tensión radial máxima $\sigma_{r, m a x}$, a partir del cual comienza a descender de valor, se alcanza para una pérdida de sección por corrosión del 1,01\% en las secciones con $c / \phi=2$, del 1,37\% en las secciones con $c / \phi=4$, del 1,92\% en las secciones con $c / \phi=10$ y del $1,97 \%$ en las secciones con $c / \phi=20$. La fisuración superficial también se ve retrasada con el aumento del recubrimiento (Figura 6-28-B), tal y como han comprobado otros autores [Andrade (1995) y Rodríguez et al. (1994)], alcanzándose para una pérdida de sección por corrosión del $0,91 \%$ en las secciones con $c / \phi=2$, del 1,47\% en las secciones con $c / \phi=4$ y del 3,53\% en las secciones con $c / \phi=10$. En las secciones con $c / \phi=20$, el modelo demora la aparición de la primera fisura superficial hasta el momento en el que se alcanza una pérdida de sección del 24,56\%, lo cual se aleja bastante de las observaciones experimentales, donde se ha comprobado que las probetas con esta relación fisuraban con pérdidas de sección cercanas al 5\%. Esto demuestra que el modelo analítico desarrollado comienza a fallar más allá de las relaciones recubrimiento/diámetro habituales, al menos a la hora de predecir la fisuración, y sus resultados deben ser tomados con cautela en las relaciones $c / \phi$ extremas.

Por otra parte, los resultados obtenidos con el modelo muestran que las máximas tensiones radiales $\sigma_{r, \text { max }}$ crecen con el aumento del espesor de recubrimiento (Figura 6-28-A), aunque este incremento se va atenuando hasta alcanzar una relación $c / \phi$ a partir de la cual apenas existen mejoras. El incremento de tensión radial máxima entre el recubrimiento de $50 \mathrm{~mm}(c / \phi=10)$ y el de $100 \mathrm{~mm}(c / \phi=20)$ es de apenas un 3,5\% (27,30 frente a 28,25 MPa). En esta figura se pone de manifiesto que el modelo analítico desarrollado no es capaz de reproducir con precisión el descenso de tensión máxima de adherencia $\tau_{b, \text { max }}$ detectado en la campaña experimental para los probetas con una mayor relación recubrimiento/diámetro $(c / \phi=20)$, que ha sido discutido en el Capitulo 5. Sin embargo, el modelo nos aporta pistas del fenómeno que podría estar aconteciendo y que justificaría ese comportamiento "contraintuitivo" o "anómalo".

Tal y como puede observarse en la gráfica de la Figura 6-28- $A$, el deterioro de la tensión radial $\sigma_{r}$ postpico es más acusado para la máxima relación recubrimiento/diámetro considerada $(c / \phi=20$, $c=100 \mathrm{~mm})$ que para la inmediatamente inferior, de manera que a partir de una determinada penetración de ataque $P_{x}=79,45 \mu \mathrm{m}(7,24 \%$ de pérdida de sección), las tensiones radiales para la relación $c / \phi=10(c=50 \mathrm{~mm})$ son mayores. Al mismo tiempo, en la Figura 6-28-C puede apreciarse que, para la mayor relación recubrimiento/diámetro, la deformación radial $\varepsilon_{r}$ a nivel de la interfaz crece de manera monótona durante todo el proceso de pérdida de sección considerado, mientras que en el resto ésta disminuye coincidiendo con la fisuración del recubrimiento. Ya que las deformaciones circunferenciales $\varepsilon_{\theta}$ a nivel de interfaz son iguales en todos los casos (Figura 6-28-D), el deterioro de la rigidez en la dirección radial $E_{r}$ (Figura 6-28-E) es más acusado para el caso del recubrimiento de mayor espesor, en virtud del modelo del material utilizado (parábola de Hognestad; Capitulo 3). Por otro lado, mientras que los desplazamientos radiales $u$, proporcionales a las deformaciones circunferenciales $\varepsilon_{\theta}$, son iguales a nivel de intefaz, en la superficie del cilindro de hormigón los desplazamientos radiales son menores con el aumento del recubrimiento $c$ (Figura 6-28-F). Por tanto, la mayor capacidad de confinamiento que proporciona el aumento de recubrimiento restringe los desplazamientos radiales a lo largo del espesor de éste, y dado que el desplazamiento inicial $u_{0}$ 
provocado por el aumento de volumen de los productos de corrosión es el mismo, se produce un incremento del gradiente de desplazamientos en las inmediaciones del alambre. Este incremento ocasiona un aumento de las deformaciones radiales $\varepsilon_{r}$ que, si alcanzan una determinada cuantía, conducen a la pérdida de rigidez del material y al agotamiento de la sección.

En definitiva, el comportamiento "anómalo" detectado en los ensayos por el cual, a partir de una determinada relación $c / \phi$, la capacidad adherente no sólo no mejora sino que puede llegar a empeorar, y que ha sido recogido previamente por otros autores, puede atribuirse al hecho de que la mejora de confinamiento que proporciona el aumento de espesor $c$ de recubrimiento ocasiona un incremento del gradiente de desplazamientos radiales $u_{r}$ en las inmediaciones de la interfaz alambre/hormigón. Este incremento del gradiente de desplazamientos provoca a su vez un mayor crecimiento de las deformaciones radiales $\varepsilon_{r}$ y una reducción más acusada de la rigidez radial $E_{r}$, provocando el fallo adherente para tensiones más bajas. En cualquier caso, es necesario señalar que este fenómeno es muy sensible al tipo de modelo del material utilizado y a las variables mecánicas del hormigón que se utilicen, pero que aun así aporta una respuesta razonable a un fenómeno observado por otros autores [Abrams (1913), Feldman (2006)] pero por ahora sin una justificación clara.
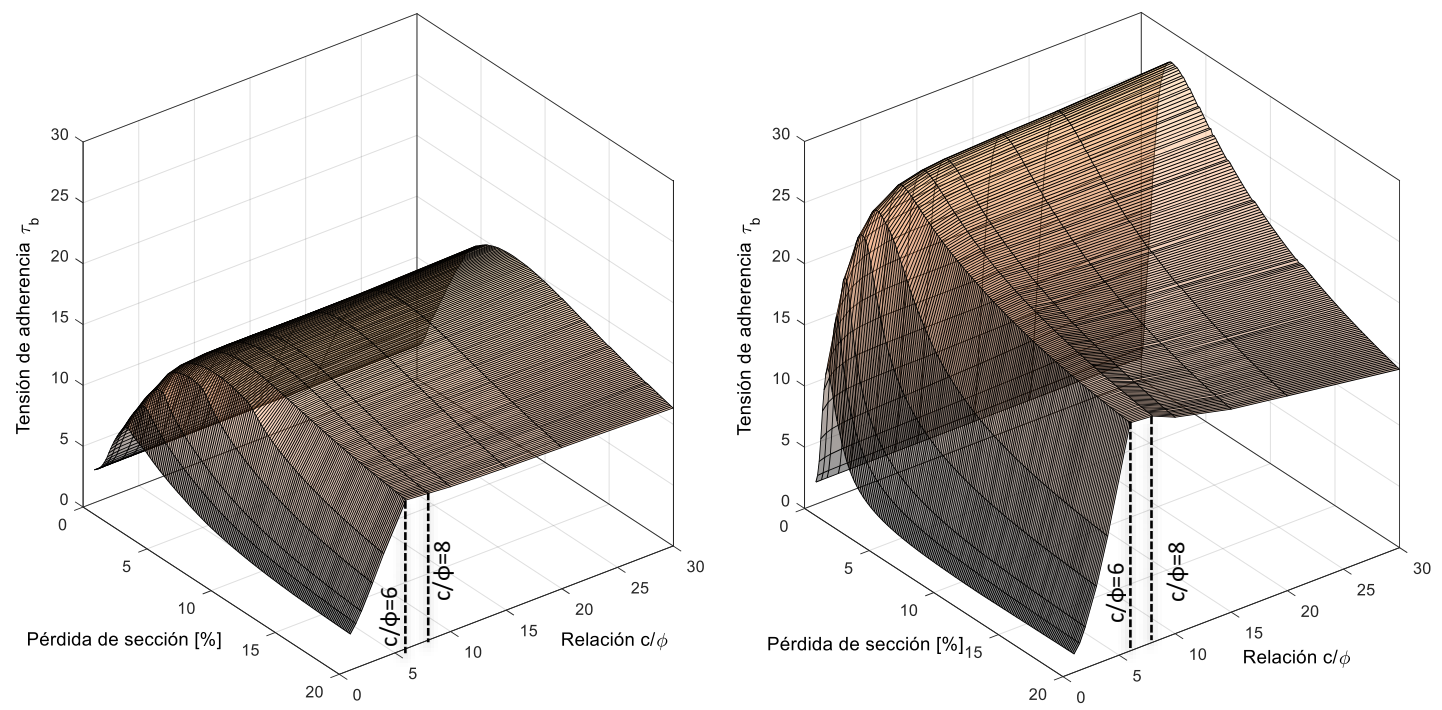

Figura 6-29 Influencia de la relación recubrimiento/diámetro y del aumento de la pérdida de sección por el proceso de corrosión en la evolución de las tensiones de adherencia $\tau_{b}$

A la vista de esta conclusión, es deseable determinar la relación recubrimiento/diámetro a partir de la cual, bajo determinadas condiciones de presión interna, el comportamiento adherente se mantiene constante o puede llegar a empeorar. En la Figura 6-29 se representa la evolución de las tensiones de adherencia frente a la relación recubrimiento/diámetro $c / \phi$ y a la pérdida de sección por el proceso de corrosión, para una resistencia a compresión $f_{c m}$ de $25 \mathrm{MPa}$ (izquierda) y de $45 \mathrm{MPa}$ (derecha). En ambos casos puede apreciarse que la tensión máxima de adherencia $\tau_{b, \text { max }} \mathrm{y}$ la tensión residual de adherencia incrementan su valor hasta alcanzar una relación $c / \phi$ situada en el rango entre 6 y 8 . A partir de dicha relación, cualquier incremento en el recubrimiento $c$ conduce a mejoras prácticamente inapreciables en la tensión máxima de adherencia $\tau_{b \text {,max }}$ y a leves descensos en el valor de la tensión residual. Estos descensos son más acusados para la mayor resistencia a compresión, presumiblemente por su mayor capacidad de confinamiento, con lo que se refuerza la hipótesis expuesta anteriormente. 


\subsubsection{Propiedades mecánicas del hormigón: Resistencia a compresión}

El otro parámetro fundamental a la hora de evaluar la capacidad de confinamiento del recubrimiento para la determinación de las capacidades adherentes de alambres embebidos en hormigón es la resistencia a compresión $f_{c m}$ de este último. Tal y como se ha visto en el Capitulo 2, en la mayor parte de códigos (FIB Special Activity Group 5, 2011) y modelos existentes, ya sean de carácter empírico (EC Innovation Program IN30902I, 2001) o analítico, la tensión de adherencia $\tau_{b}$ en estructuras de hormigón es función de la resistencia media a compresión $f_{c m} \mathrm{o}$ a tracción $f_{c t m}$.

En las gráficas de la Figura 6-30 se lleva a cabo un estudio paramétrico para determinar la influencia de la resistencia a compresión $f_{\mathrm{cm}}$ del hormigón en la evolución de distintas variables mecánicas con el avance del proceso de corrosión: A) Tensión radial $\sigma_{r} ;$ B) Evolución del frente de fisuración; C) Deformaciones radiales $\varepsilon_{r}$ en la interfaz acero-hormigón; D) Deformaciones circunferenciales $\varepsilon_{\theta}$ en la interfaz acero-hormigón; E) Evolución de los módulos de elasticidad radial $E_{r}$ (compresión) y circunferencial $E_{\theta}$ (tracción) y F) Deformaciones circunferenciales $\varepsilon_{\theta}$ y ancho de fisura $w$ en el perímetro del cilindro de hormigón. Para la obtención de las gráficas, los datos de entrada utilizados han sido los recogidos en la Tabla 6-1, variándose la magnitud de la resistencia de compresión $f_{c m}$, así como sus valores mecánicos dependientes, y el valor calibrado en los apartados anteriores de las variables relativas al proceso de corrosión. Para la determinación de la resistencia a tracción $f_{\mathrm{ctm}}$, del módulo de elasticidad $E_{\mathrm{o}}$ y de la deformación máxima en régimen elástico $\varepsilon_{0}$, a partir de una resistencia a compresión dada, se han seguido las recomendaciones recogidas en el Código Modelo 2010 (Tabla 6-12).

Tabla 6-12 Propiedades mecánicas del hormigón segín el Model Code 2010

\begin{tabular}{|c|c|c|c|c|c|c|}
\hline \multicolumn{7}{|c|}{ Parámetros Mecánicos } \\
\hline Resistencia media a compresión & $f_{c m}$ & $\mathrm{MPa}$ & 25 & 35 & 45 & 55 \\
\hline Resistencia media a tracción $\left[\boldsymbol{f}_{c t, \boldsymbol{m}}=\mathbf{0 , 3} \cdot \boldsymbol{f}_{c m}{ }^{2 / 3}\right]$ & $f_{c t, m}$ & $\mathrm{MPa}$ & 2,56 & 3,21 & 3,80 & 4,34 \\
\hline Módulo de elasticidad secante [Model Code (2010)] & $E_{0}$ & $\mathrm{GPa}$ & 28 & 31,4 & 34,5 & 37,5 \\
\hline Deformación máxima en régimen elástico & $\varepsilon_{0}$ & $\%$ & 2,2 & 2,3 & 2,5 & 2,6 \\
\hline
\end{tabular}

A pesar de la gran dispersión de los resultados, en el Capitulo 5 se ha podido comprobar que la influencia de la resistencia a compresión del hormigón $f_{c}$ en el comportamiento adherente, siendo prácticamente inexistente para alambres sanos, aumenta paulatinamente con el incremento de los niveles de corrosión. Esto es coherente con lo registrado en las gráficas de la Figura 6-30, donde se aprecia, para todas las resistencia a compresión del hormigón consideradas, una gran similitud de comportamiento en las etapas tempranas del proceso de corrosión, que va dejando paso a diferencias, significativas en algunos casos, con el aumento de la pérdida de sección.

En las etapas iniciales, en las que ninguna sección ha alcanzado el agotamiento, los desplazamientos impuestos por los productos de corrosión provocan deformaciones radiales $\boldsymbol{\varepsilon}_{r}$ y circunferenciales $\boldsymbol{\varepsilon}_{\vartheta}$ similares en todos los casos analizados, aunque se aprecia cierta tendencia a que las deformaciones sean ligeramente mayores en los hormigones con menor resistencia a compresión, dada su menor rigidez a la hora confinar los desplazamientos impuestos por el aumento de volumen de los productos de corrosión (Figura 6-30-C-D). Su mayor módulo de Young $E_{c}$ hace que los hormigones con mayor resistencia, a pesar de experimentar deformaciones radiales ligeramente inferiores, alcancen mayores 

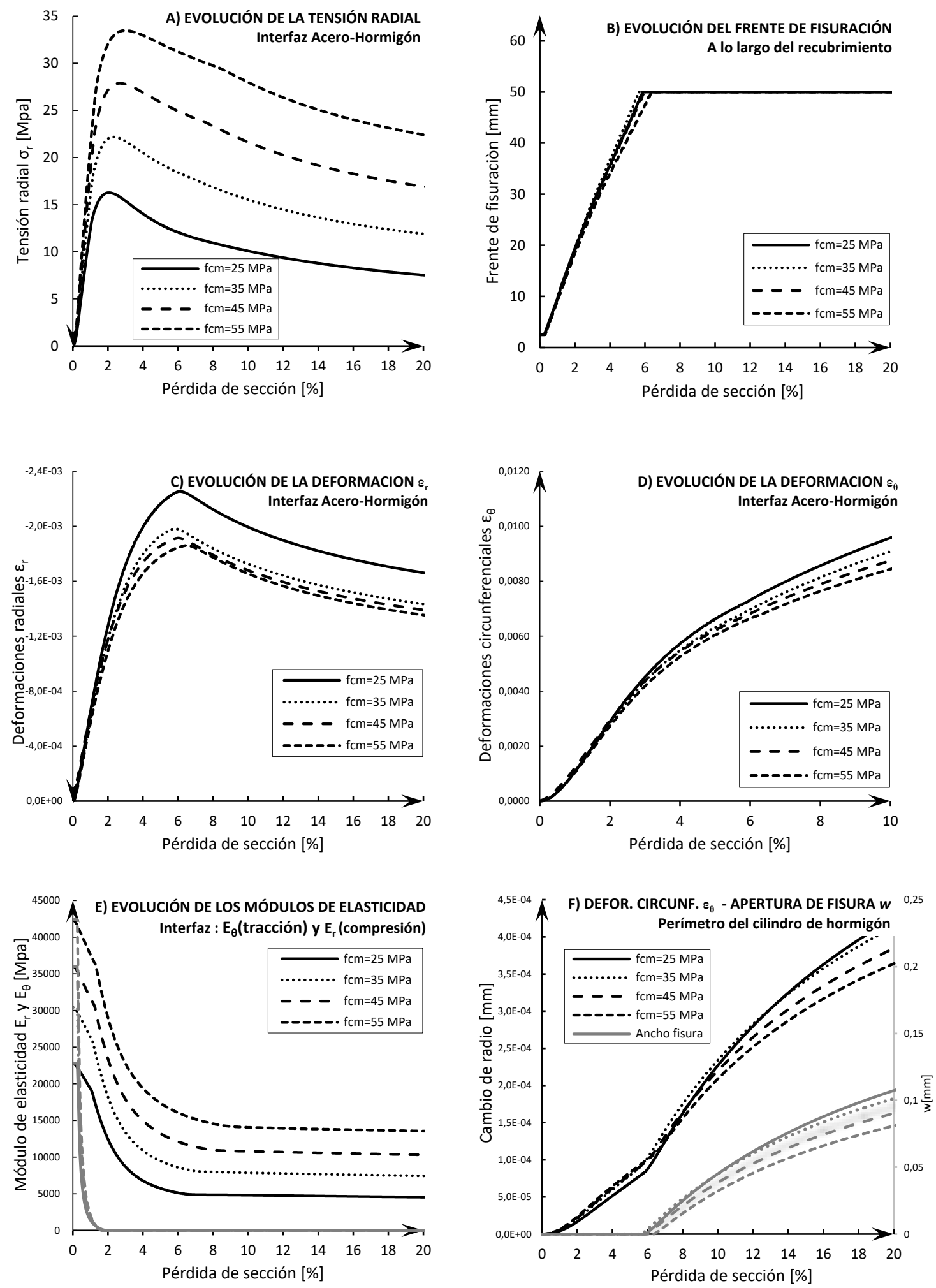

Figura 6-30 Influencia de la resistencia a compresión del hormigón $f_{\text {cm }}$ y del aumento de la pérdida de sección por el proceso de corrosión en la evolución de: A) Tensión radial $\sigma_{r}$; B) Evolución del frente de fisuración; C) Deformaciones radiales $\varepsilon_{r}$ en la interfaz acero-bormigón; D) Deformaciones circunferenciales $\varepsilon_{\theta}$ en la interfaz acero-hormigón; E) Evolución de los módulos de elasticidad radial $E_{r}$ (compresión) y circunferencial $E_{\theta}$ (tracción) y F) Deformaciones circunferenciales $\varepsilon_{\theta}$ y ancho de fisura w en el perímetro del cilindro de hormigón. 
tensiones radiales $\sigma_{r}$. De esta manera, los hormigones con resistencia a compresión $f_{c}$ de $25 \mathrm{MPa}$ logran una tensión radial máxima $\sigma_{r ; \text { max }}$ de $16,52 \mathrm{MPa}$; los de $35 \mathrm{MPa}, \sigma_{r, \text { max }}=22,09 \mathrm{MPa}$; los de 45 $\mathrm{MPa}, \sigma_{r, \text { max }}=27,50 \mathrm{MPa}$; y los de $55 \mathrm{MPa}, \sigma_{r, \text { max }}=32,78 \mathrm{MPa}$ (Figura 6-30-A). Los resultados muestran que, para el caso concreto analizado en este estudio paramétrico, la tensión radial máxima es directamente proporcional a la resistencia a compresión del hormigón elevada a 5/6, y por tanto, a un valor intermedio entre la resistencia a tracción (2/3) y la resistencia a compresión (1).

En el gráfico tridimensional de la Figura 6-31 se representa la evolución de las tensiones máximas de adherencia (considerándolas proporcionales a las tensiones radiales $\sigma_{r}$ ) frente a la resistencia a compresión del hormigón y a la pérdida de sección por el proceso de corrosión, para una relación recubrimiento/diámetro $c / \phi$ igual a 10 . Se aprecia claramente como la resistencia a compresión del hormigón va ganando influencia en el comportamiento adherente con el incremento paulatino del nivel de corrosión. Mientras que para alambres sanos la influencia es prácticamente inexistente, en el pico de tensión radial máxima alcanza su mayor influencia (para pérdidas de sección en el rango del 5,5-6,5\%). En las etapas residuales del fenómeno de la adherencia, una vez superado el pico de máxima tensión, la influencia de la resistencia a compresión se mantiene prácticamente constante. Por último, al contrario de lo que ocurre con el incremento del espesor de recubrimiento, no se observa que la influencia de la resistencia del hormigón se atenúe para valores altos de la misma.

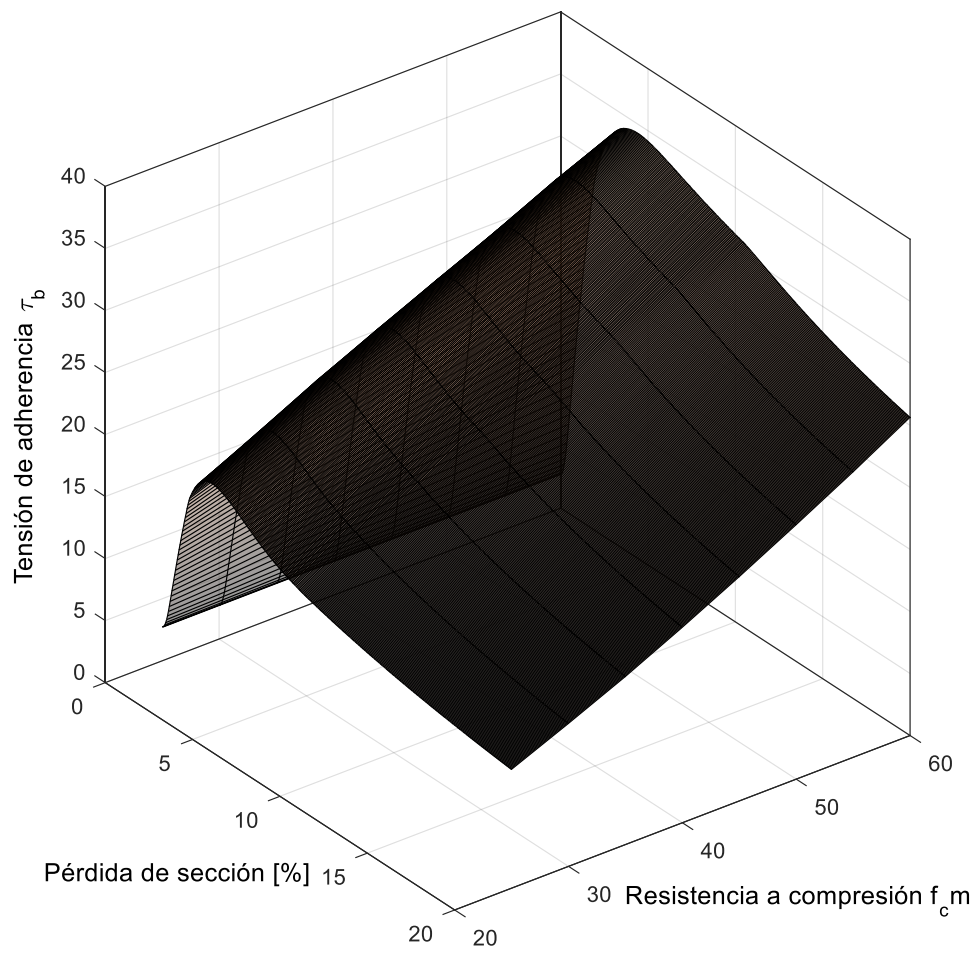

Figura 6-31 Influencia de la resistencia a compresión $f_{c m}$ y del aumento de la pérdida de sección por el proceso de corrosión en la evolución de la tensión de adherencia $\tau_{b}$

En cuanto a la fisuración, las gráficas obtenidas no permiten concluir que la resistencia del hormigón tenga una influencia decisiva en su inicio (Figura 6-30-B) y evolución (Figura 6-30-F). El rápido deterioro del módulo de elasticidad en tracción con pequeñas deformaciones circunferenciales (Figura 
6-30-E), independientemente del valor inicial de dicho módulo, hace que el desarrollo de la fisuración sea similar en todos los casos. El frente de fisuración alcanza la superficie del hormigón para una pérdida de sección del 5,81\% en los hormigones con $f_{c}=25 \mathrm{MPa}$; para 5,66\% con $f_{c}=35 \mathrm{MPa}$; para $5,96 \%$ con $f_{c}=45 \mathrm{MPa}$; y para $6,35 \%$ con $f_{c}=55 \mathrm{MPa}$. Por otro lado, debe destacarse que el modelo analítico desarrollado no ha tenido en cuenta el incremento de porosidad asociado al incremento de la relación agua/cemento del hormigón y, por tanto, al descenso de su resistencia a compresión. Para algunos autores, como Andrade (1995) y Rodríguez et al. (1994), esta relación entre porosidad y resistencia del hormigón hace que los hormigones con menores resistencias tengan mayor capacidad para absorber el incremento de volumen de los productos de corrosión, lo que retrasa la aparición y la apertura de fisuras.

En definitiva, el aumento de la resistencia a compresión del hormigón tiene una influencia decisiva en el crecimiento de las tensiones radiales máximas alcanzadas y, por ende, en la capacidad adherente. Sin embargo, su influencia en la aparición de la fisuración superficial y en su posterior apertura es muy limitada. Estas tendencias, muy claras en el modelo y ligeramente apuntadas por los resultados obtenidos en la campaña experimental, no pueden considerarse corroboradas, ya que el número de ensayos llevados a cabo para analizar exclusivamente la influencia de la resistencia a compresión ha sido limitado. Aun así, añadiendo a la interpretación la información recogida en la revisión bibliográfica, puede considerarse que las tendencias señaladas por el modelo son razonables y cercanas al comportamiento real.

Por tanto, el aumento del espesor de recubrimiento $c$ supone una clara mejora en el comportamiento adherente, tanto en la aparición y evolución de las fisuras como en las máximas tensiones de adherencia alcanzadas. En este último caso, la capacidad adherente mejora hasta alcanzarse una relación recubrimiento/diámetro límite a partir de la cual cualquier incremento de espesor de recubrimiento no se traduce en un aumento de la adherencia. En el caso estudiado, la relación recubrimiento/diámetro límite se sitúa aproximadamente en el rango entre 6 y 8 . Por otro lado, el aumento de resistencia a compresión $f_{c}$ es aproximadamente proporcional al incremento de la máxima tensión radial que puede desarrollarse en la sección $\left(f_{c}^{5 / 6} \propto \sigma_{r, \text { max }}\right)$, sin que se observe ninguna tendencia a que esta influencia se atenúe con el aumento de la resistencia. Por el contrario, la influencia de la resistencia del hormigón en el desarrollo de la fisuración es muy limitada. En alambres sanos, la influencia de ambos parámetros, espesor de recubrimiento $c$ y resistencia a compresión del homigón $f_{c}$, no es significativa, y solo es apreciable cuando se superan las etapas tempranas del proceso de corrosión. En conclusión, el aumento de espesor de recubrimiento aumenta la capacidad de confinamiento y el tiempo que la misma tarda en verse comprometida por la fisuración, mientras que la resistencia del hormigón influye de una manera decisiva en el nivel de confinamiento y no tanto en el tiempo que ésta tarda en movilizarse y deteriorarse.

\subsection{Ley de adherencia local-deslizamiento}

Tal y como se ha visto en los Capitulos 3 y 5 , la adherencia de alambres embebidos en hormigón está condicionada por la relación existente entre la tensión de adherencia en la interfaz acero-hormigón y el deslizamiento local a lo largo de la longitud adherente (Rehm, 1961). La ley de adherencia localdeslizamiento depende de numerosas variables, incluyendo la geometría superficial del alambre, la resistencia del hormigón, la posición y orientación del alambre durante el hormigonado, el estado 
tensional del elemento, las condiciones de contorno y/o el espesor de recubrimiento. Tal y como se ha expuesto en el Capitulo 3, en esta tesis se ha optado por modelar la relación entre la adherencia local y el deslizamiento con una ley no-lineal, perfectamente plástica, formada por una función por tramos que comprende cuatro segmentos diferenciados (Ver Figura 5-4). En este apartado, en base a las leyes de tensión de adherencia "media"-deslizamiento $\tau_{b, m e d}-s$ obtenidas de los ensayos (Capitulos 4 y 5), y con el apoyo analítico brindado por el modelo, se calibran los parámetros que definen la ley de tensión de adherencia "local"-deslizamiento $\tau_{b}-s$. En el Capitulo 5 se ha establecido la relación existente entre los parámetros que definen ambas leyes (local y media).

\subsubsection{Introducción}

Cuando un alambre embebido en hormigón es sometido a una fuerza de arrancamiento se activa el mecanismo de adherencia, que consta de cuatro etapas diferencias (den Uijl, 1996): una primera etapa, donde la adherencia está asegurada principalmente por el mecanismo de adhesión; una segunda etapa, en la que tras la rotura del mecanismo de adhesión se activan los mecanismos de adherencia por fricción y por el acuñamiento de las indentaciones (si las hubiera); una tercera etapa; protagonizada por el modo de fallo: por splitting o por pull-out (Ver Capitulo 5); y una cuarta etapa caracterizada por el comportamiento residual tras el fallo adherente.

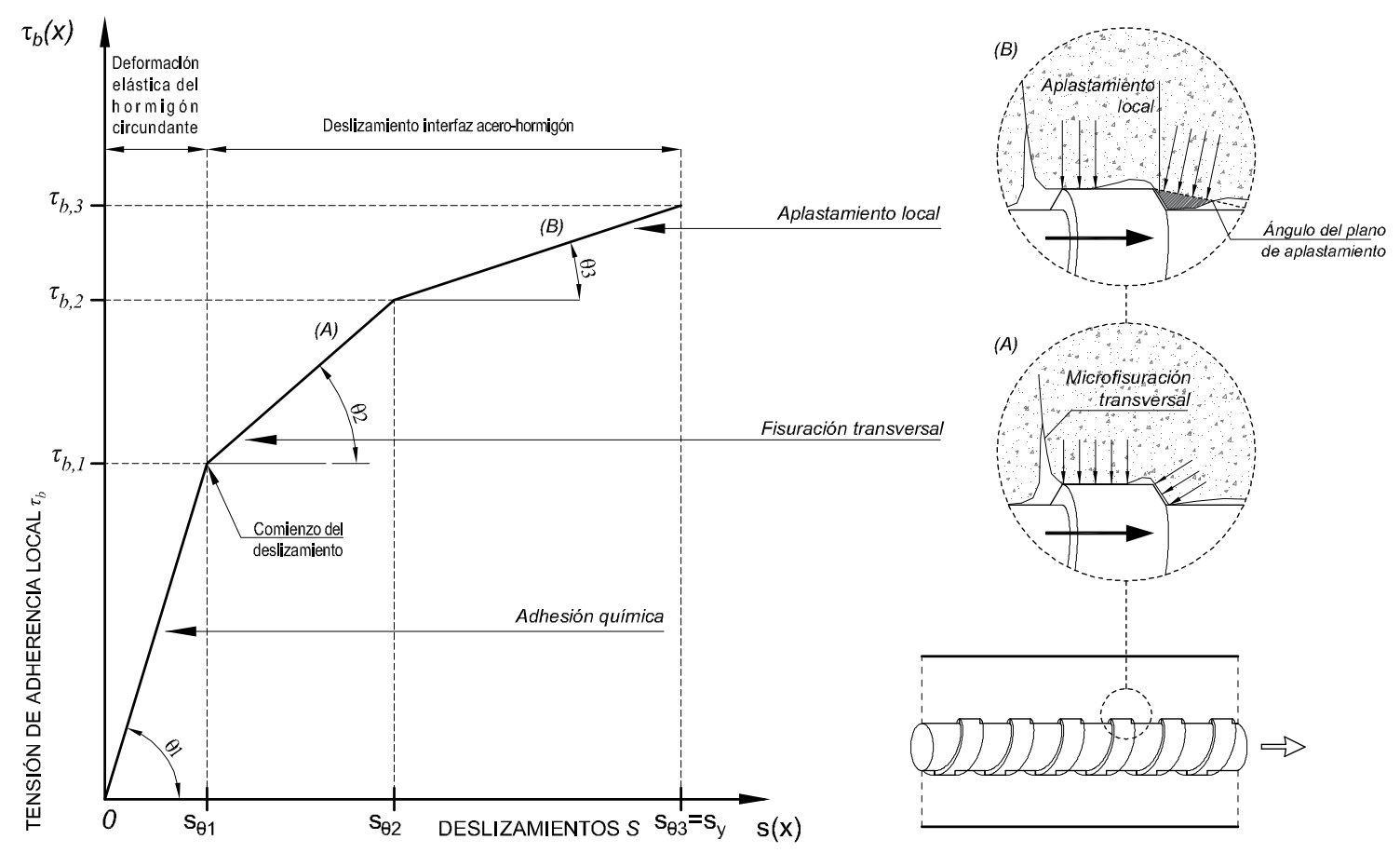

Figura 6-32 Diagrama tensión de adherencia local-deslizamiento en las primeras etapas del proceso de arrancamiento.

En la primera etapa, la correspondiente al mecanismo de adhesión, los deslizamientos detectados con respecto al hormigón inalterado no proceden de movimientos diferenciales en la interfaz entre el acero y el hormigón, sino principalmente de la deformación elástica por cortante del hormigón que circunda al alambre. Por tanto, incluso si no existe deslizamiento relativo entre el alambre y el hormigón puede medirse un cierto deslizamiento debido a las deformaciones tangenciales localizadas cerca de la interfaz (Figura 6-32). Una vez superado el valor de la tensión de adhesión $\tau_{\text {adh__primera }}$ 
etapa), el alambre se adentra en la segunda etapa, en la que la adherencia está gobernada principalmente por el acuñamiento de las indentaciones en el hormigón circundante. Las fuerzas de acuñamiento, concentradas en el frente de las indentaciones, causan la formación de fisuras en forma de cono, que comienzan en el extremo de la meseta superior de las indentaciones y delimitan los "voladizos" de hormigón que equilibran la fuerza de arrancamiento del alambre. Las fuerzas de acuñamiento, inclinadas con respecto al eje de la barra, puedan ser descompuestas en las direcciones paralela y perpendicular a dicho eje. La componente longitudinal, paralela al eje, equivale a la fuerza de adherencia $\tau_{b}$, mientras que la componente perpendicular induce la aparición de tensiones de compresión en la dirección radial $\sigma_{\mathrm{r}} \mathrm{y}$ de tracción en la dirección circunferencial $\sigma_{\theta}$ (Figura 6-33). Si estas últimas superan la resistencia a tracción del hormigón $f_{c t}$ comienza la formación de fisuras radiales.

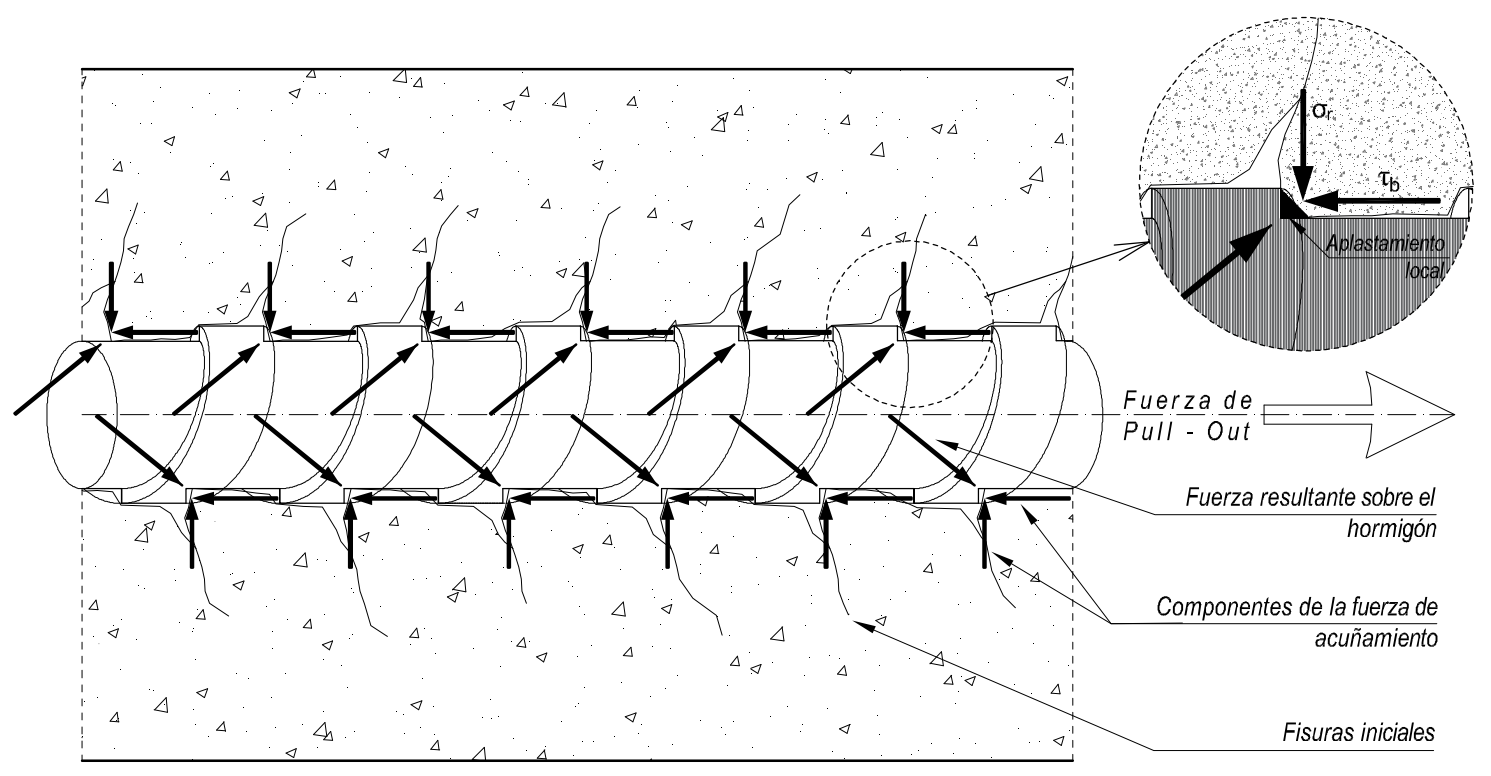

Figura 6-33 Fuerzas de acuñamiento y fisuración inicial en la interfaz acero-bormigón. Primeras etapas del proceso de arrancamiento.

En la segunda etapa, el deslizamiento relativo del alambre con respecto al hormigón circundante es debido, en primer término, a la flexión de los "voladizos" de hormigón formados entre fisuras consecutivas (Figura 6-32 (A)), y en segundo término, al aplastamiento del hormigón en contacto con el frente de las indentaciones (Figura 6-32 (B)). Este aplastamiento local genera un nuevo plano de deslizamiento, que parte del vértice superior de la indentación y está inclinado con respecto al eje del alambre, sobre el que actúan perpendicularmente las tensiones radiales. Como puede apreciarse en la Figura 6-32, el aumento de la fisuración deteriora la rigidez del hormigón, lo que provoca que la pendiente del diagrama de tensión de adherencia local-deslizamiento vaya reduciéndose con el aumento del deslizamiento $\left(\boldsymbol{\vartheta}_{1}>\boldsymbol{\vartheta}_{2}>\boldsymbol{\vartheta}_{3}\right)$. Los deslizamientos en esta etapa, $s_{\vartheta 2}$ y $s_{\vartheta}$, así como las tensiones de adherencia asociadas, $\tau_{b 2}$ y $\tau_{b 3}$, van a depender de la capacidad de confinamiento del recubrimiento, así como de la geometría del alambre. En este aspecto, es importante recordar que, tal y como se comentó en el Capitulo 2, debido a la ausencia de indentaciones, en los alambres lisos esta etapa es prácticamente despreciable, alcanzándose la máxima tensión de adherencia para deslizamientos muy pequeños y gracias al mecanismo de adhesión, tanto química como física, y a la 
interacción micromecánica ("microinterlocking") entre las partículas cementicias y la rugosidad microscópica de la superficie del acero.

La tercera etapa está protagonizada por el modo de fallo adherente predominante. Si la fisuración radial se propaga a lo largo de todo el recubrimiento, hasta alcanzar la superficie, se produce un fallo frágil sin apenas deslizamiento, denominado fallo por splitting. Por tanto, la máxima tensión de adherencia es fruto de la máxima tensión radial que es capaz de soportar el hormigón circundante. En este caso, la cuarta etapa del proceso adherente comienza con la llegada de la fisuración a la superficie exterior del recubrimiento, y viene acompañada de un descenso acusado de la tensión radial y la consiguiente caída brusca de la tensión de adherencia. Por tanto, no existe meseta plástica, y los deslizamientos $s_{y}$, al final de la rama elástica, y $s_{u}$, al comienzo de la rama plástica, se tornan coincidentes en el diagrama tensión de adherencia local-deslizamiento.

Sin embargo, cuando el confinamiento es suficiente para prevenir el fallo por splitting del recubrimiento de hormigón, el fallo adherente es protagonizado por el arrancamiento del alambre (fallo por pull-out). En este caso, según den Uijl (den Uijl, 1996), se origina un nuevo plano de deslizamiento alrededor del alambre (paralelo a la directriz del alambre) y el mecanismo de transferencia de la fuerza de arrancamiento cambia del acuñamiento de las indentaciones al mecanismo de fricción (Figura 6-34). Este cambio en el mecanismo de transferencia posibilita la aparición de una meseta en el diagrama de adherencia-deslizamiento en la que el valor de la tensión de adherencia se mantiene aproximadamente constante con el aumento del deslizamiento. El nuevo plano de deslizamiento es fruto del aplastamiento local de la matriz cementicia próxima a las indentaciones y del fallo por cortante de los "voladizos" formados entre fisuras consecutivas. En alambres lisos, donde el propio acabado superficial del acero delimita un plano de deslizamiento paralelo al eje, el fallo adherente predominante es el de pull-out.

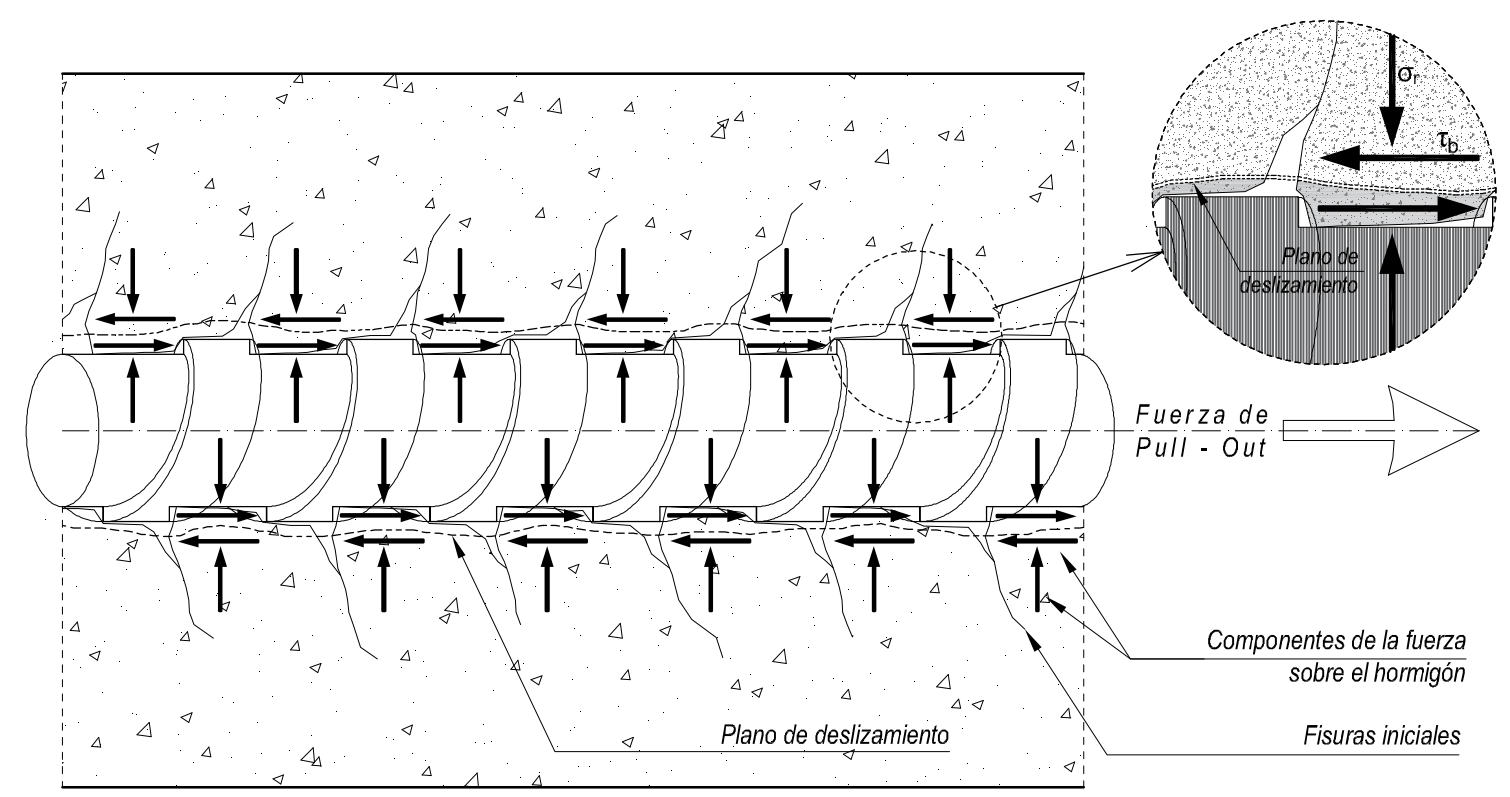

Figura 6-34 Fallo por Pull-out inducido por fisuración. Distribución de fuerzas y plano de deslizamiento. 


\subsubsection{Influencia del deslizamiento en el coeficiente de fricción}

En el Apartado 6.2.7, partiendo de la hipótesis de que el coeficiente de fricción $\mu$ es una propiedad intrínseca del contacto entre dos materiales determinados, se ha determinado que su valor es independiente del contorno o forma externa de los alambres y que la corrosión no afecta a su valor. Por otro lado, se ha comprobado que un coeficiente de fricción igual a 0,65 reproduce con suficiente precisión las tensiones máximas alcanzadas en los ensayos.

Habitualmente, los tratamientos más sencillos de la problemática de la fricción introducen dos coeficientes de fricción: el coeficiente estático $\mu_{s}$ y dinámico $\mu_{k}$. De acuerdo con este enfoque, el comportamiento adherente de cualquier par de materiales en contacto puede ser descrito por dichos coeficientes, sabiendo que el coeficiente de fricción estático es siempre mayor que el dinámico $\mu_{s}>$ $\mu_{k}$.

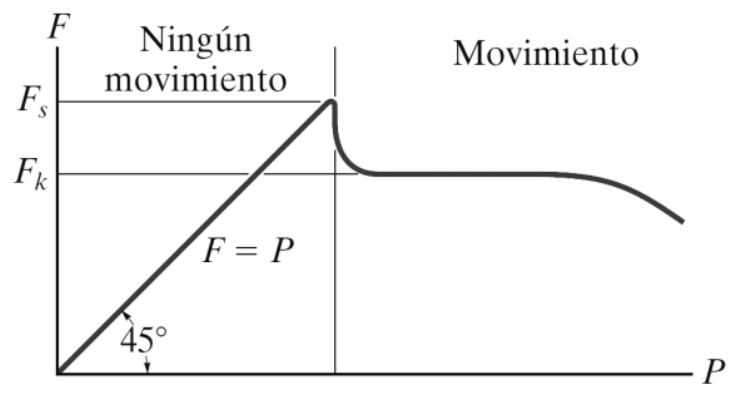

Figura 6-35 Relación existente entre la carga aplicada P y la fuerza de fricción F, según Hibbeler (2010)

La Figura 6-35 resume el comportamiento adherente de dos superficies en contacto mediante la variación de la fuerza de fricción F contra la carga aplicada P. Según Hibbeler (2010), la fuerza de fricción $F$ puede tomar los siguientes valores en función de la magnitud de $P$ :

- $F$ es una fuerza de fricción estática si se mantiene el equilibrio $(F=P)$.

- F es una fuerza de fricción estática limitante $F_{s}$, cuando alcanza un valor máximo en equilibrio con la carga aplicada $P$. En ese punto, el deslizamiento está a punto de ocurrir, y la fuerza de fricción máxima es proporcional a la fuerza normal $N$ (integral de las tensiones radiales $\sigma_{r}$ a lo largo de la superficie del alambre), de manera que $F_{s}=\mu_{s} \cdot N$ y, por tanto, $\tau_{b}=\mu_{s} \cdot \sigma_{r}$

- F es una fuerza de fricción cinética $F_{k}$, cuando comienza el deslizamiento sobre la superficie de contacto. La fuerza de fricción cinética es proporcional a la fuerza normal $\mathrm{N}$, de manera que $F_{k}=\mu_{k} \cdot N y \tau_{b}=\mu_{k} \cdot \sigma_{r}$

Tal y como se ha visto a lo largo de esta tesis, la fricción pasa a ser el mecanismo adherente predominante una vez superadas las etapas dependientes de la tensión de adhesión, del microengranamiento mecánico y el acuñamiento de las indentaciones (en alambres lisos, solo las dos primeras). El deslizamiento relativo asociado a ese punto de inflexión es igual a $s_{u}$ en el diagrama de tensión de adherencia local-deslizamiento, por lo que es razonable considerar que el deterioro del coeficiente de fricción $\mu$ comienza tras superarse dicho deslizamiento, tomando su mínimo valor al alcanzarse un deslizamiento $s_{r e s}$. Por tanto, a pesar de existir deslizamientos previos, puede 
considerarse que el coeficiente de fricción para deslizamientos menores a $s_{u}$ permanece inalterado y está vinculado al coeficiente de fricción estática $\mu_{s}$, mientras que la tensión residual de adherencia $\tau_{b, r e s,}$ que se alcanza tras superar el deslizamiento $s_{r e s}$, está vinculada al coeficiente de fricción dinámica $\mu_{k}$. Por otro lado, el valor máximo de la fuerza de fricción $F_{\max }$, reacción a la fuerza de arrancamiento $P_{\max }$, alcanza su máximo para un deslizamiento $s_{u}$ (al menos en alambres sanos). Superado ese umbral, el plano de deslizamiento no es capaz de generar las tensiones de adherencia $\tau_{b}$ necesarias para equilibrar la fuerza de arrancamiento $P$, por lo que se produce una aceleración del deslizamiento s del alambre, junto con un descenso de la fuerza de fricción $F$, y con ello, de la tensión de adherencia $\tau_{b}$.

Planteamientos similares al anterior han sido adoptados por numerosos autores, tales como Lundgren \& Gylltoft (2000), Amleh \& Gosh (2006) y Tastani \& Pantazopoulou (2010). Estos últimos proponen un modelo de deterioro del coeficiente de fricción idéntico al planteado anteriormente, aunque cambian la denominación, de manera que los coeficientes de fricción estático y dinámico pasan a ser denominados máximo y residual.

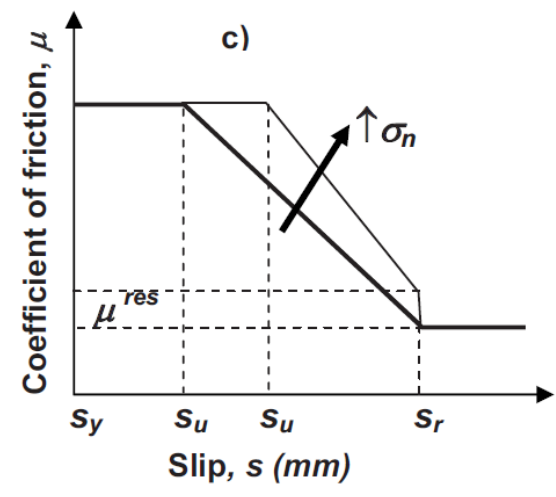

Figura 6-36 Modelo de deterioro del coeficiente de fricción con el deslizamiento. Coeficientes de fricción estático $\mu_{s}$ (o máximo $\mu_{\max }$ ) y dinámico $\mu_{k}$ (o residual $\left.\mu_{r e s}\right)$. Figura tomada de Tastani \& Pantazopoulou (2010)

Por tanto, en base a la teoría de los coeficientes de fricción dinámicos y estáticos, se plantea una ley de debilitamiento del coeficiente de fricción $\mu$ con el aumento del deslizamiento $s$, en tres tramos diferenciados (Eq. 6-15):

$$
\begin{aligned}
& \tau_{b} / \sigma_{r} \leq \mu_{s} \quad \text { si } s<s_{u} \\
& \tau_{b} / \sigma_{r}=\mu_{s}-\left(\mu_{s}-\mu_{k}\right) \frac{s}{s_{u}} \quad \text { si } s_{u} \leq s<s_{r e s} \quad\left(\begin{array}{c}
\text { Eq. } \\
6-15)
\end{array}\right. \\
& \tau_{b, r e s} / \sigma_{r}=\mu_{k} \quad \text { si } s \geq s_{r e s}
\end{aligned}
$$

Mientras que el coeficiente de fricción estático $\mu_{s}$ ha podido ser calibrado en el Apartado 6.2.7 $\left(\mu_{s}=0,65\right)$, la alta dispersión de los resultados obtenidos en las etapas residuales del diagrama de adherencia-deslizamiento ha imposibilitado llevar a cabo un análisis similar para determinar el valor del coeficiente de fricción dinámico $\mu_{k}$. No obstante, como se ha visto en el Capitulo 5 , se ha detectado cierta tendencia a que la tensión de adherencia residual, tanto en alambres lisos como indentados, se sitúe en el rango entre 4 y $8 \mathrm{MPa}$. Por tanto, se decide, de forma en cierta manera arbitraria, forzar al 
modelo para que, superado el deslizamiento $s_{u}$ que limita la rama plástica del diagrama de adherenciadeslizamiento, la tensión de adherencia disminuya hasta alcanzar un valor igual a $6 \mathrm{MPa}$. Ya que esta evolución del modelo se impone, y no es fruto del descenso de la tensión radial calculada (que en el modelo existe, pero no es tan acusada), la disminución de la tensión de adherencia debe entenderse como el resultado de la degradación del coeficiente de fricción hasta alcanzar su valor dinámico $\mu_{k}$. Esta aproximación es válida para los propósitos de esta tesis, ya que los deslizamientos relativos para los que se alcanza la tensión de adherencia residual no tienen excesiva trascendencia en el análisis de elementos pretensados, pero aun así sería deseable obtener una mayor precisión. En definitiva, queda pendiente para trabajos futuros una determinación menos grosera de la tensión de adherencia residual y de su coeficiente de fricción dinámico asociado, probablemente mediante una campaña experimental de ensayos de pull-out cuya fuerza de arrancamiento sea controlada por deslizamiento, y no por carga como en la presente tesis.

\subsubsection{Calibración de la ley de adherencia local-deslizamiento}

Una vez establecidas las bases del análisis, a continuación, se calibran los parámetros que definen la ley de adherencia local-deslizamiento para cada uno de los casos estudiados, así como su evolución con el aumento de los niveles de deterioro por corrosión. La calibración se centra fundamentalmente en los alambres indentados, puesto que su comportamiento es más complejo por la interacción de la geometría superficial del acero con el hormigón circundante y en la actualidad es el tipo de alambre más habitual en elementos pretensados. Aun así, se incluyen algunas consideraciones acerca de las leyes de adherencia-deslizamiento en alambres lisos.

\subsubsection{Alambres indentados sanos}

Tal y como se vio en el Capitulo 3, el mecanismo adherente de alambres embebidos en hormigón puede desacoplarse en dos componentes diferenciadas: una componente longitudinal $\tau_{b}$, que reproduce la variación de las tensiones a lo largo del alambre, y una componente transversal $\sigma_{r}$ (o radial) asociada al desplazamiento radial $u_{r}$. Ambas componentes están asociadas a través de las propiedades de fricción descritas por la Ley de Coulomb, que relaciona las tensiones tangenciales de adherencia $\tau_{b}$ a lo largo de la interfaz entre el alambre y el hormigón circundante con la tensión radial de confinamiento $\sigma_{r}$ ejercida por el recubrimiento (Tastani \& Pantazopoulou, 2007). A esta relación, de carácter mecánico, hay que añadir una relación de compatibilidad de carácter geométrico que permita relacionar el deslizamiento longitudinal $s$ del alambre con el desplazamiento radial $u_{r}$ de la cara interior del cilindro de hormigón y, por tanto, con la tensión de adherencia $\tau_{b}$. A continuación se exponen los dos enfoques que se han desarrollado en esta tesis para reproducir dicha compatibilidad geométrica, procediendo las diferencias entre ambos en la manera en que los deslizamientos $s$ del alambre se convierten en desplazamientos radiales $u_{r} \mathrm{y}$, a la postre, en tensiones radiales $\sigma_{r} \mathrm{y}$ de adherencia $\tau_{b}$. en el 1 er enfoque se establece que el alambre, en su deslizamiento, provoca un desplazamiento radial $u_{r}$ equivalente a la altura total de las indentaciones en aquellos puntos en los que éstas coinciden con los resaltos del hormigón, haciendo que se alcance localmente la tensión máxima de adherencia $\tau_{\text {b,max }}$, mientras que el resto del hormigón mantiene la situación tensional existente antes de la aplicación de la carga de arrancamiento. En el $2^{\circ}$ enfoque se establece un plano de deslizamiento definido por la geometría del alambre, que determina incrementos paulatinos del desplazamiento radial en función del deslizamiento existente en cada punto de la longitud adherente. Es importante manifestar que ambos enfoques, aun basándose en el comportamiento mecánico real expuesto anteriormente, no 
pretenden reproducir con exactitud la distribución local de tensiones del sistema hormigón-acero, puesto que esto se aleja del objetivo y las posibilidades del modelo analítico propuesto, sino que pretende simular o predecir el comportamiento adherente general del sistema. Por tanto, para hacer abordable el problema, se han adoptado las siguientes hipótesis de partida:

- En base al modelo analítico para la distribución de tensiones en la dirección longitudinal del alambre, expuesto en el Apartado 3.8 de la presente tesis, la fuerza de arrancamiento $F$ aplicada en un extremo del alambre induce, por un lado, la aparición de deformaciones longitudinales en el hormigón y en el acero, y por otro, deslizamientos relativos $s$ en cada punto de la interfaz acero-hormigón. En virtud de los distintos modelos/enfoques que se exponen a continuación, se establece la relación existente entre dicho deslizamiento $s$ y el desplazamiento radial $u_{r}$ en el hormigón. Establecido el valor de los desplazamientos radiales $u$, se obtienen las tensiones radiales $\sigma_{r}$ a lo largo del recubrimiento, mediante el modelo basado en la teoría del cilindro hueco de pared gruesa expuesto en el Capitulo 3.

- Se acepta que el mecanismo adherente se basa en la ley de fricción de Coulomb, por lo que admitiendo que la tensión de adhesión $\tau_{\text {adh }}$ influye únicamente en deslizamientos pequeños $(s<0,01 \mathrm{~mm})$, la tensión de adherencia $\tau_{b}$ es directamente proporcional a la tensión radial de compresión $\sigma_{r}$ a través del coeficiente de fricción $\mu$. Este coeficiente puede entenderse como la cotangente del ángulo $\theta$, siendo este ángulo el existente entre la fuerza de acuñamiento y el plano de deslizamiento (Ver Figura 6-37). Como se ha indicado anteriormente, la componente longitudinal de la fuerza de acuñamiento equivale a la fuerza de adherencia $\tau_{b}$, mientras que la componente perpendicular es igual a la tensión de compresión radial $\sigma_{r}$.
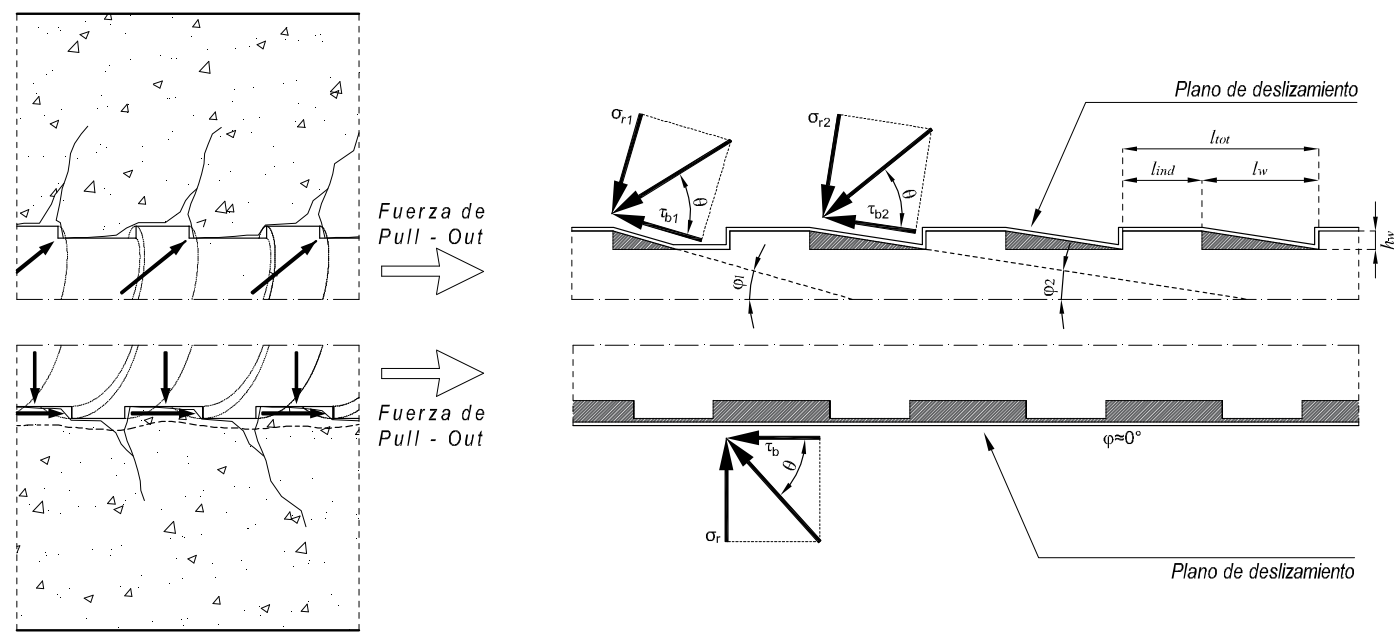

Figura 6-37 Planos de deslizamiento en ensayo de arrancamiento. Geometría de los alambres indentados.

- En alambres con acabado superficial liso, el plano de deslizamiento siempre es paralelo al eje de estos. En alambres indentados, por el contrario, el plano de deslizamiento puede adoptar distintas configuraciones: paralelo al eje del alambre si el confinamiento es suficiente y el fallo sobreviene por rotura a esfuerzo cortante de los "voladizos" formados entre fisuras consecutivas (fallo porpull-out); o con un determinado ángulo $\varphi$ por el aplastamiento de la matriz cementicia ubicada delante del frente de la indentación, tras la formación de las fisuras iniciales 
en el hormigón que circunda el alambre (splitting inicial). La pendiente del plano determina la relación existente entre el deslizamiento $s$ y el desplazamiento radial $u_{r}$ (Ver Figura 6-37).

- La distribución en espiral de las indentaciones a lo largo de la superficie de los alambres hace que el perfil de cada una de las secciones transversales consideradas sea irregular, por lo que para la eficacia del modelo se opta por repartir homogéneamente la altura $h_{w}$ de la indentación a lo largo de todo el perímetro del alambre.

- A pesar de que el diámetro del alambre no es constante a lo largo de la longitud adherente, por la presencia de las indentaciones, se propone la existencia de una "capa límite", coincidente con la superficie cilíndrica determinada por el diámetro nominal del acero, en la que se concentran todas las tensiones y los desplazamientos radiales que actúan en la interfaz.

- Las tensiones radiales previas a la puesta en carga del alambre, debidas a los procesos de corrosión, a la retracción o al efecto Hoyer, se reparten homogéneamente a lo largo de toda la superficie adherente.

- Los procesos de pérdida de sección por corrosión afectan de igual manera a toda la superficie del alambre, por lo que la altura de las indentaciones con respecto a la superficie del alambre permanece constante a lo largo de todo el proceso.

\subsection{Relación deslizamiento-desplazamiento radial en alambres indentados sanos: $1^{\text {er }}$ Enfoque}

Este enfoque es fruto de la aplicación directa del modelo de adherencia-deslizamiento expuesto en el Apartado 3.8 de la presente tesis, alimentado con las conclusiones extraídas del análisis de los resultados experimentales.

Tal y cómo se ha mostrado en el Capitulo 5, los resultados experimentales han mostrado una clara relación entre la geometría del alambre y su ley de adherencia-deslizamiento: el ancho de la indentación $l_{\text {ind }}$ está vinculado al deslizamiento $s_{y}$ en el que se alcanza la tensión máxima de adherencia $\tau_{b, \text { max }}$ la distancia neta entre indentaciones $l_{w}$ se relaciona con el deslizamiento $s_{u}$, que limita la meseta de tensiones de adherencia máximas, y el paso de hélice de las indentaciones $l_{t o t}\left(l_{t o t}=l_{i n d}+l_{w}\right)$ determina el deslizamiento $s_{r e s}$, a partir del cual la tensión de adherencia toma su valor residual $\tau_{b, r e s .}$.

La realidad física subyacente bajo esta observación experimental es que el alambre, en su deslizamiento, provoca el aplastamiento de la matriz cementicia situada en la proyección del frente de avance de la indentación, generándose un nuevo plano de deslizamiento con un ángulo $\varphi$, cuya tangente queda definida por el cociente entre la altura $h_{w}$ y la anchura $l_{i n d}$ de la indentación (Figura 6-37). Esto implica que, para deslizamientos $s$ comprendidos en el rango $0 \leq s \leq s_{y}$, el desplazamiento radial $u_{r}$ es igual a $s \cdot \operatorname{tg} \varphi$, y alcanza un valor igual a $h_{w}$ cuando el deslizamiento $s$ es igual a $s_{j}$. En otras palabras, el desplazamiento radial tiene un crecimiento lineal hasta que la totalidad de la indentación coincide con el resalto de hormigón, lo que ocurre para un deslizamiento $s_{y}=l_{\text {ind }}$.

Sin embargo, este desplazamiento radial $u_{r}$ no es igual a lo largo de toda la longitud adherente, puesto que las indentaciones se reparten a lo largo de la superficie del alambre a intervalos regulares. Si se observan los diagramas de tensión de adherencia media - deslizamiento $\tau_{b \text {,med }}$-s de los ensayos sobre 
alambres indentados, que se recogen en el Capitulo 5 "Resultados experimentales", se puede apreciar que la tensión máxima de adherencia $\tau_{b \text {,max }}$ que alcanzan los alambres indentados sin corrosión (Figura 5.8 a); Figura 5.11 a) y b); Figura 5.15 a) y b)) es considerablemente menor a la obtenida para alambres y recubrimientos con las mismas características pero con procesos de corrosión iniciados. Esto no sería reseñable salvo por el hecho de que la altura de las indentaciones $h_{w}$ es tal que, teóricamente, induciría un desplazamiento de la pared interna del hormigón $u_{r}$ que movilizaría la totalidad de la capacidad confinante del recubrimiento, provocando la aparición de tensiones radiales $\sigma_{r}$ de una magnitud similar a las producidas por un proceso de corrosión cuyos productos generasen un desplazamiento radial $u_{r}$ equivalente. Por tanto, sería esperable que las tensiones de adherencia $\tau_{b}$ arrojadas por los ensayos sobre alambres sanos fueran similares a las obtenidas sobre alambres con corrosión. Sin embargo, el valor máximo de la tensión de adherencia media $\tau_{b, \text { max }}^{\text {med }}$ en alambres sanos es entre un 35 y $50 \%$ menor que las obtenidas sobre alambres corroídos.

Una explicación compatible con los resultados obtenidos es que el desplazamiento radial $u_{r}$, provocado por el deslizamiento del alambre, sólo tiene lugar en aquellas zonas del recubrimiento en las que la indentaciones coinciden con el resalto del hormigón (Figura 6-38). Bajo este enfoque, la pared interna del recubrimiento va alcanzando máximos de desplazamiento, y por tanto de tensión radial $\sigma_{r}$, en diversas regiones locales a lo largo de la longitud adherente, mientras que el resto permanece con una tensión radial $\sigma_{r, 0}$ igual al estado tensional existente al comienzo del ensayo (Figura 6-38 a)). Estos valores locales máximos sobre las indentaciones serán iguales al valor máximo que puede alcanzar el recubrimiento por su capacidad de confinamiento, es decir, por sus condiciones geométricas y mecánicas (o algo menor si el desplazamiento de la pared interna $u_{r}$ es tal que provoca pérdidas significativas de rigidez por fisuración). Por tanto, puede afirmarse que existen dos relaciones tensión de adherencia local-deslizamiento cohabitando a lo largo del alambre: una de ellas, cuyo origen es la tensión de adhesión y la tensión radial procedente tanto del aumento de volumen de los productos de corrosión como de la retracción, y que se encuentra repartida homogéneamente, y otra debida al desplazamiento de la pared interna por el paulatino deslizamiento de las indentaciones. El valor "medio" de tensión de adherencia obtenido en el ensayo será igual al reparto homogéneo de las distintas tensiones de adherencia a lo largo de la longitud adherente. Por tanto, de manera simplificada, en alambres indentados sanos, el valor local máximo de la tensión de adherencia $\tau_{b, \text { max }}^{\text {med }}$, repartida homogéneamente en una longitud igual al paso de hélice de las indentaciones $l_{\text {tot }}$ (donde puede considerarse que todos los deslizamientos son iguales), respondería a la siguiente expresión (Eq. 6-16):

$$
\tau_{b, \max }^{\text {med }}=\tau_{b, \max } \cdot \frac{l_{\text {ind }}}{l_{\text {tot }}}+\tau_{b, 0} \frac{l_{w}}{l_{\text {tot }}}
$$

donde $\tau_{b, \max }$ es la máxima tensión de adherencia local, provocada por el desplazamiento radial $u_{r}=h_{w}, \tau_{b, 0}$ es la tensión de adherencia generada por la tensión radial $\sigma_{r, 0}$ previa al ensayo, $l_{\text {ind }}$ es la distancia neta entre indentaciones, $l_{w}$ es el ancho de las indentaciones y $l_{t o t}$ es el paso de hélice $\left(l_{\text {tot }}=l_{\text {ind }}+l_{w}\right)$. Hay que destacar que este valor local "medio" de la tensión de adherencia $\tau_{b, \text { max }}^{\text {med }}$ se refiere al promedio de las diferentes tensiones de adherencia existentes en una longitud pequeña igual al paso de hélice, donde puede suponerse que todos los deslizamientos $s$ son iguales. Si el ensayo se lleva a cabo sobre una longitud adherente larga $l_{a d b}>5 \phi$, este valor local medio irá variando a lo largo de dicha longitud, proporcional a los deslizamientos en cada punto del alambre. 


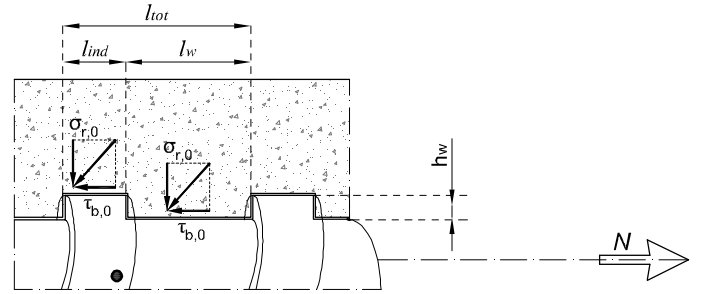

Situación inicial $\mathrm{s}_{0}=0$

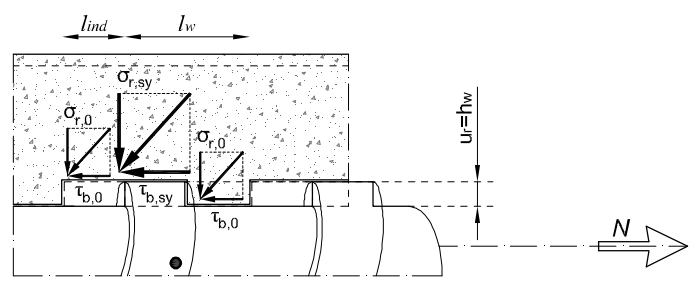

Deslizamiento $\mathrm{s}_{\mathrm{y}}$

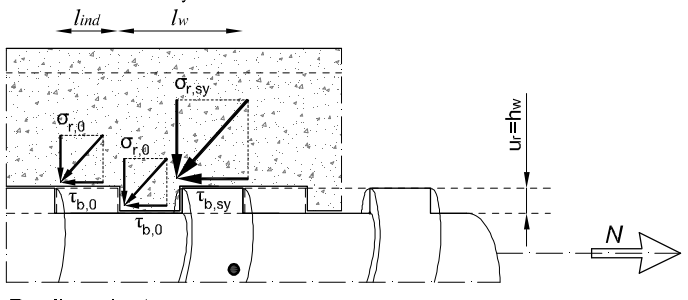

Deslizamiento $s_{\bullet}$

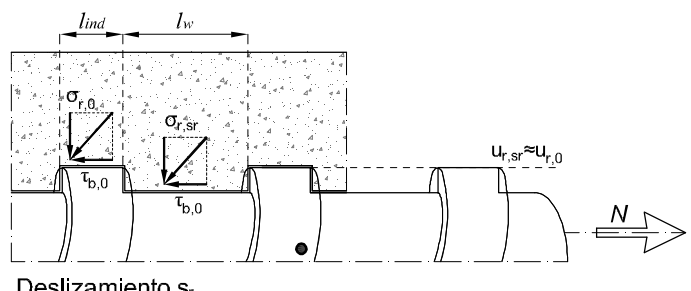

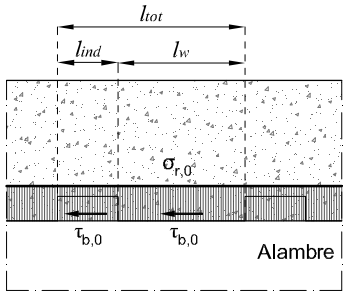
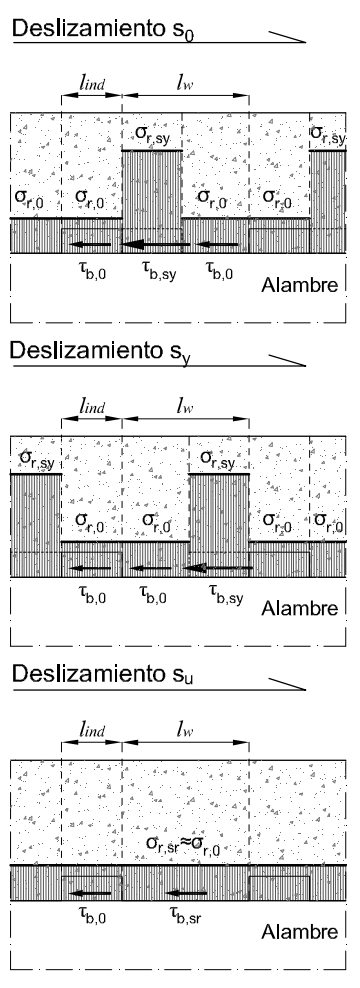

Deslizamiento $\mathrm{s}_{\mathrm{r}}$
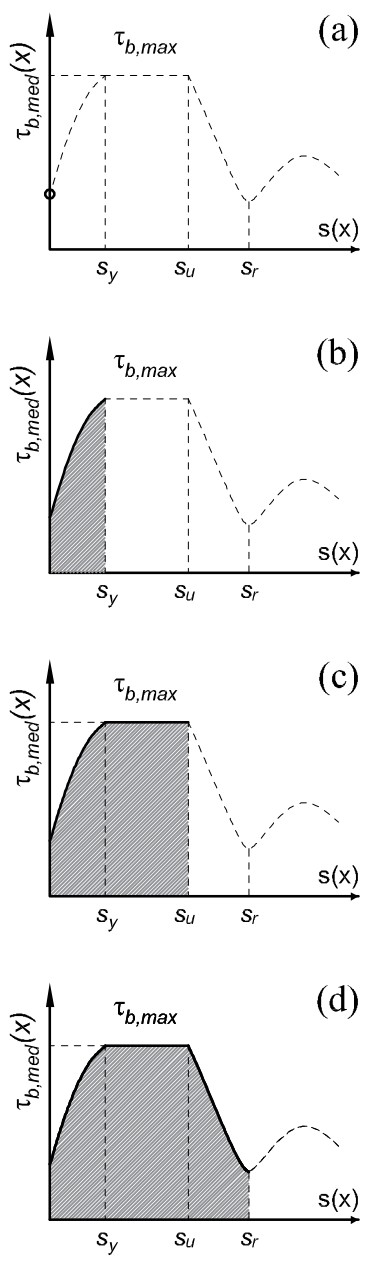

Figura 6-38 1er Enfoque: Evolución del estado tensional de un alambre indentado sin corrosión durante el ensayo de arrancamiento. Ley de adherencia local-deslizamiento.

Determinados tanto el valor máximo de la tensión de adherencia como el deslizamiento $s_{y}$ para el que se alcanza dicho valor, queda definido el tramo elástico de la ley de tensión de adherencia localdeslizamiento (Figura 6-38 b)). Tras alcanzar dicho valor, comienza la meseta plástica, en la que la tensión de adherencia se mantiene constante hasta que se alcanza un deslizamiento $s_{u}$, que es coincidente con la distancia neta entre indentaciones $l_{w}$ (Figura 6-38 c)). Una interpretación física compatible con tal comportamiento es que, tras la fisuración inicial producida en la fase elástica del proceso, si el confinamiento es suficiente para prevenir el fallo por splitting del recubrimiento de hormigón, el fallo adherente es protagonizado por el arrancamiento del alambre (fallo por pull-out). En este caso, se origina un nuevo plano de deslizamiento alrededor del alambre (paralelo a la directriz del alambre) y el mecanismo de transferencia de la fuerza de arrancamiento cambia del acuñamiento de las indentaciones al mecanismo de fricción. Este cambio en el mecanismo de transferencia es el que posibilita la aparición de la meseta plástica en el diagrama de adherencia-deslizamiento. Tal y como se ha comentado anteriormente, el nuevo plano de deslizamiento es fruto del aplastamiento local de la matriz cementicia próxima a las indentaciones y del fallo por cortante de los "voladizos" formados entre fisuras consecutivas (Figura 6-34). 
Una vez sobrepasado el deslizamiento $s_{u}$, la indentación comienza a abandonar el resalto de hormigón y a ocupar un nuevo "canal" en el hormigón, correspondiente a la indentación precedente, por lo que la tensión radial $\sigma_{r}$, y con ello la tensión de adherencia $\tau_{b}$, comienza a descender hasta que toma un valor residual $\tau_{b, r e s}$, similar a la tensión de adherencia generada por la tensión radial $\sigma_{r, 0}$ previa al comienzo del ensayo. Este proceso define la rama de ablandamiento del diagrama de adherencia localdeslizamiento (Figura 6-38d)). Por su parte, la tensión de adherencia residual $\tau_{b, r e s}^{\text {med }}$ se alcanza para un deslizamiento $s_{r e s}$, igual a la longitud del paso de hélice $l_{t o t}$, en la que la indentación ocupa completamente el canal de la indentación precedente, y que marca el comienzo de la etapa residual del diagrama de adherencia local-deslizamiento (Figura 6-38 d)).

Las implicaciones de lo expuesto anteriormente son significativas, ya que este enfoque permite deducir por completo la ley de tensión de adherencia local-deslizamiento $\tau_{b}-s$ si se conoce, por un lado, la capacidad de confinamiento del recubrimiento (mediante el modelo analítico basado en la teoría del cilindro de pared gruesa expuesto en el Capitulo 3), y por otro, la geometría del alambre.

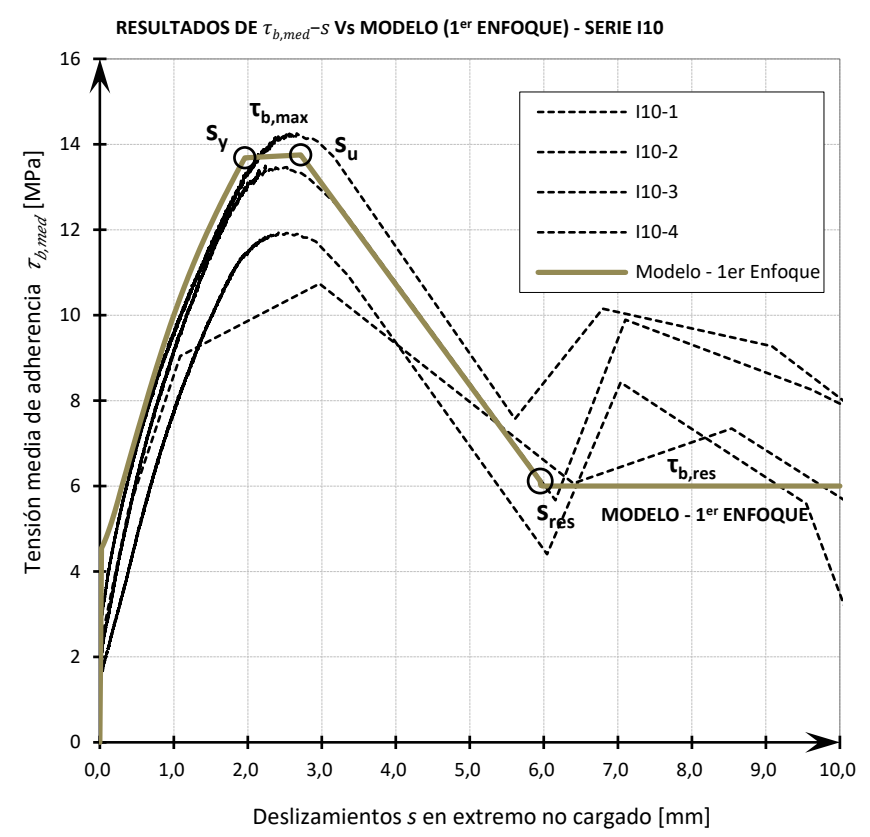

Figura 6-39 Diagrama de adberencia-deslizamiento en extremo no cargado en ensayos sobre alambres indentados, serie I10. Comparación con el modelo propuesto (1er enfoque)

\subsection{Verificación del modelo: 1er enfoque}

En la Figura 6-39 se comparan las gráficas de tensión media de adherencia-deslizamiento en extremo no cargado $\tau_{b, \text { med }}-s$, obtenidas en los ensayos experimentales sobre alambres indentados sin corrosión de la Serie I10 (c/ $\phi=10)$, frente a la predicción teórica arrojada por el modelo siguiendo la formulación recogida en el apartado 3.7 de la presente Tesis y el primer enfoque de compatibilidad expuesto en este apartado. El coeficiente de fricción utilizado $\mu=0,65$ es el mismo que en la calibración de los parámetros relativos a la corrosión. 
Como puede apreciarse, a pesar de la alta dispersión de los resultados experimentales, el grado de adaptación del modelo es significativamente bueno. En el modelo, el tramo correspondiente a la etapa elástica arroja una pendiente y desarrollo similares a las obtenidas en los ensayos, mientras que, en la etapa plástica, en la que se localiza el máximo valor de la tensión de adherencia media $\tau_{b, \text { max }}^{\text {med }}$, se obtienen resultados cercanos al límite superior del rango de valores obtenidos experimentalmente. Para deslizamientos superiores a $s_{u}$, el modelo ofrece una buena adaptación, lo que no es sorprendente ya que en esos tramos el modelo se encuentra muy pautado y la forma del diagrama se deriva principalmente de la geometría del alambre, impuesta como condición de partida. El repunte de la tensión de adherencia $\tau_{b, \text { med }}$ que tiene lugar para deslizamientos mayores que $s_{\text {res }}$ no se ha implementado en el modelo, puesto que carece de interés para el comportamiento adherente global del elemento.

\subsection{Relación deslizamiento-desplazamiento radial en alambres indentados sanos: $2^{\circ}$ Enfoque}

Este enfoque es similar en su concepción al anterior, pero presenta algunas diferencias significativas que se desglosan a continuación. Tal y como ocurría anteriormente, en este enfoque, para relacionar los deslizamientos relativos del alambre $s$ con los desplazamientos radiales $u_{r}$ del hormigón circundante, la geometría del alambre se idealiza, a lo largo de su longitud adherente, como una sucesión de troncos de cono cuyas superficies generan planos de deslizamiento (Figura 6-37). La formación de estos nuevos planos se debe el aplastamiento de la matriz cementicia situada en la proyección del frente de avance de la indentación, y su geometría queda definida por troncos de cono conformados por los siguientes elementos: la generatriz, que coincide con el eje del alambre; la directriz, que está definida por la recta que une el vértice superior de la indentación con el vértice en la base de la siguiente, formando un ángulo $\varphi^{\prime}$ con la generatriz; la altura, que es igual a la distancia neta entre indentaciones $l_{m}$; la base menor, que es equivalente a la sección nominal del alambre, de radio $r_{b}$; y la base mayor, que se corresponde con el círculo cuyo radio es igual al nominal del alambre $r_{b}$ más la altura de la indentación repartida uniformemente $h_{w}$. Por tanto, se supone que la relación existente entre deslizamiento $s$ y el desplazamiento radial $u_{r}$ viene dada por el ángulo $\varphi^{\prime}$, delimitado por la generatriz y la directriz de cada uno de estos troncos de cono, cuya tangente es equivalente al cociente de la altura homogeneizada de las indentaciones $h_{w}$ entre la distancia neta entre indentaciones $l_{w}$. Por otro lado, en el análisis de los resultados experimentales se ha podido comprobar que el deslizamiento $s_{u}$, que limita la zona plástica del diagrama de tensión de adherencia local-deslizamiento, es igual a la distancia $l_{w}$, por lo que se puede deducir que para deslizamientos $s$ comprendidos en el rango $0 \leq_{s} \leq s_{u}$, el desplazamiento radial $u_{r}$ es igual a $s \cdot \operatorname{tg}^{\prime} \varphi^{\prime}$, alcanzando un valor igual a $h_{w}$ cuando el deslizamiento $s$ es igual a $s_{\|}$

Las diferencias más significativas con respecto al primer enfoque se encuentran en la pendiente $\left(\operatorname{tg} \varphi^{\prime}\right.$ $<\operatorname{tg} \varphi$ ) y en la proyección horizontal del plano de deslizamiento $\left(1_{\mathrm{w}}>\mathrm{l}_{\text {ind }}\right)$ (Ver Figura 6-37). En este enfoque, al igual que en el anterior, el alambre está sometido a una tensión radial inicial $\sigma_{r, 0}$ previa al comienzo del ensayo, procedente de los fenómenos higrotérmicos (retracción) y del aumento de volumen de los productos de corrosión (si es que los hubiera) (ver Figura 6-40 a)). Con la aplicación de la fuerza de arrancamiento $F$, el alambre comienza a deslizar, provocando un desplazamiento radial $u_{r}$ en la pared interna del recubrimiento, en una longitud $l_{w}$ coincidente con el resalto de hormigón ubicado originalmente entre indentaciones. Por su parte, la región del recubrimiento situada al comienzo del ensayo sobre las indentaciones conserva la tensión radial inicial $\sigma_{r, 0}$. El crecimiento lineal 
de la tensión de adherencia $\tau_{b}$ continúa hasta que el desplazamiento radial $u_{\text {r }}$, provocado por el deslizamiento $s$, alcanza un valor tal que propicia el desarrollo de la fisuración del recubrimiento y una reducción acentuada de la pendiente del diagrama adherencia-deslizamiento, poniendo fin al primer tramo del mismo (ver Figura 6-40 b)). En este nuevo enfoque no se impone que el deslizamiento $s_{y}$, que delimita el tramo elástico de la gráfica, sea igual al ancho de la indentación lind, sino que es consecuencia del paulatino agotamiento de la sección por el desplazamiento radial $u_{r}$. Desde este punto de vista $s_{y}$ no es una condición de partida, sino el resultado de la relación existente entre la geometría del alambre y la capacidad de confinamiento del recubrimiento.

Sobrepasado el deslizamiento $s_{y}$, la tensión de adherencia crece ligeramente hasta lograr la tensión de adherencia máxima $\tau_{\text {b,max }}$, para luego mantener ese valor o comenzar un ligero descenso hasta alcanzar un deslizamiento $s_{u}$, igual a la distancia entre indentaciones $l_{w}$ (Ver Figura 6-40 cl). La tasa de decrecimiento es más o menos acusada en función del grado de degradación del recubrimiento provocado por el desplazamiento radial $u_{r}$.
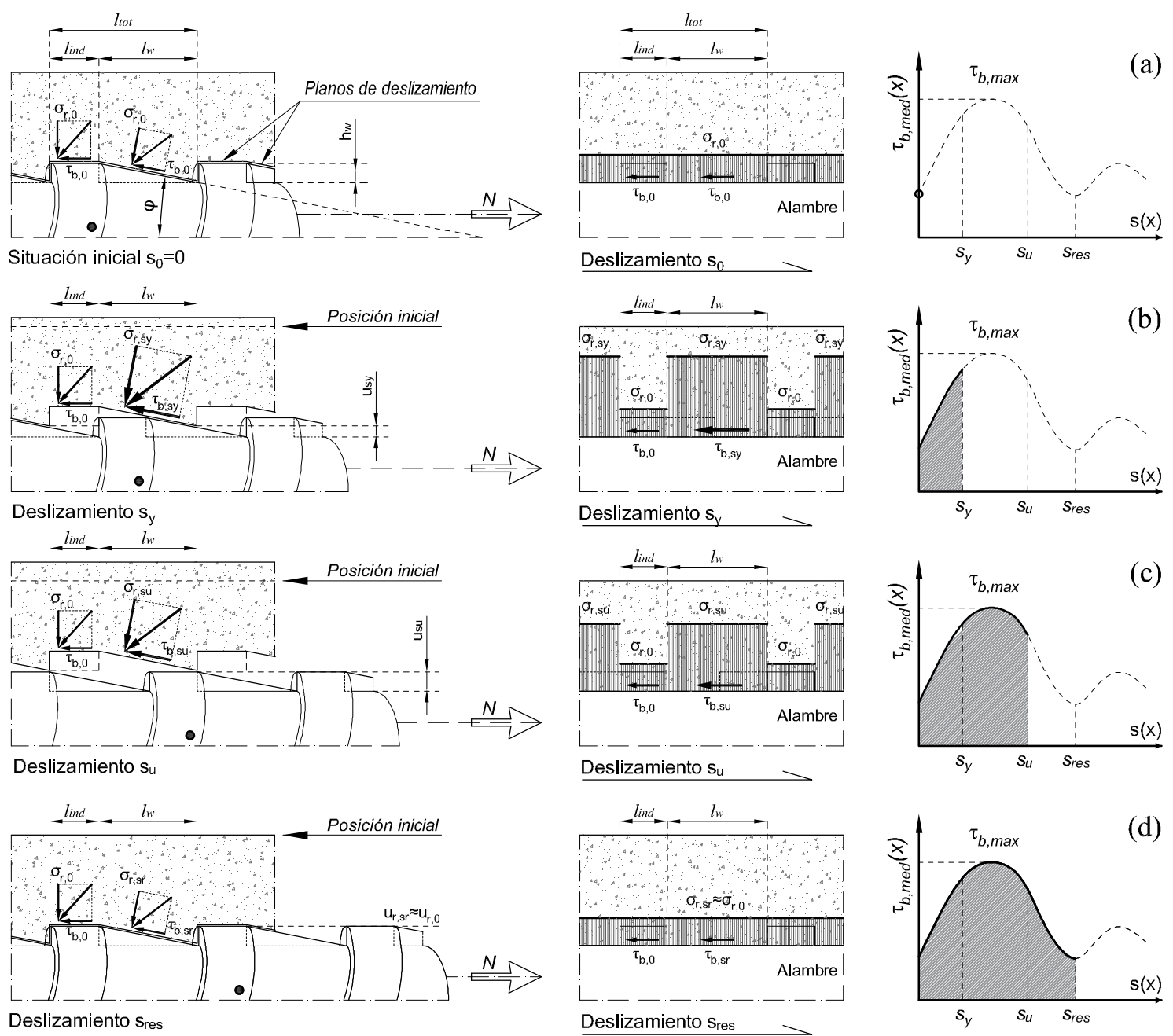

Figura 6-40 20 Enfoque: Evolución del estado tensional de un alambre indentado sin corrosión durante el ensayo de arrancamiento. Ley de adherencia local-deslizamiento. 
Por último, una vez superado el deslizamiento $s_{u}$, el diagrama adherencia-deslizamiento se adentra en la rama de ablandamiento, reproduciendo el comportamiento expuesto en el anterior enfoque. La indentación comienza a abandonar el plano de deslizamiento de ángulo $\varphi$ ' y a ocupar el "canal" de hormigón de la indentación precedente, provocando un paulatino descenso la tensión de adherencia $\tau_{b}$. Cuando el deslizamiento alcanza un valor $s_{\text {res }}$, igual al paso de hélice de la indentación $l_{t o t}$, la indentación ocupa completamente el canal de la indentación precedente y el valor de la tensión de adherencia toma un valor residual $\tau_{b, r e s}($ Ver Figura 6-40 d)). En el modelo, deslizamientos superiores $a_{\text {sres }}$ viene acompañados de un valor constante de la tensión residual $\tau_{b, \text { res }}$ ya que no se reproduce el repunte de tensión de adherencia $\tau_{b}$ observado en los ensayos experimentales.

Al igual que en el caso anterior, el valor local "medio" de la tensión de adherencia es igual al promedio de las diferentes tensiones de adherencia existentes en una longitud pequeña igual al paso de hélice, donde puede suponerse que todos los deslizamientos $s$ son iguales.

\subsection{Verificación del modelo analítico: $2^{\circ}$ enfoque}

En la Figura 6-41 se comparan las gráficas de tensión media de adherencia-deslizamiento en extremo no cargado $\tau_{b, \text { med }}-s$, obtenidas en los ensayos experimentales sobre alambres indentados sin corrosión de la serie I10 (c/ $\phi=10)$, frente a la predicción teórica arrojada por el modelo siguiendo la formulación recogida en el apartado 3.7 de la presente Tesis y el segundo enfoque de compatibilidad expuesto en este apartado. El coeficiente de fricción utilizado $\mu=1.0$ es el mismo que en la calibración de los parámetros relativos a la corrosión.

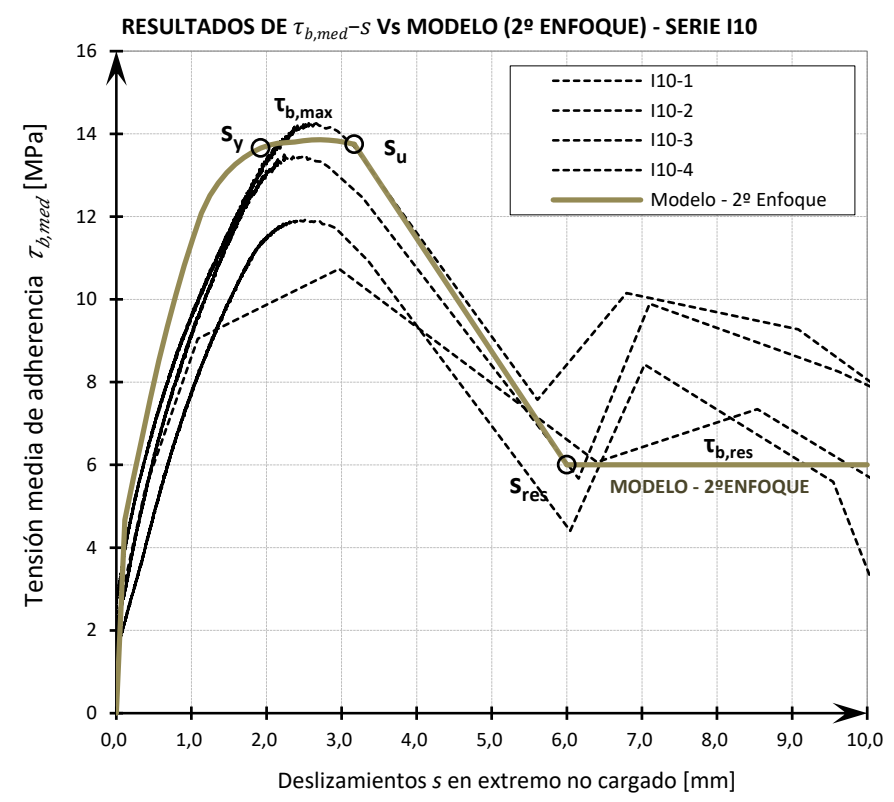

Figura 6-41 Diagrama de adherencia-deslizamiento en extremo no cargado en ensayos sobre alambres indentados, serie I10. Comparación con el modelo propuesto ( $2^{\circ}$ enfoque)

Como puede apreciarse, en este enfoque el primer tramo del diagrama tensión de adherencia media $\tau_{b, m e d}-$ deslizamiento en extremo no cargado $s$ muestra una pendiente más acusada que la resultante 
de la aplicación del primer enfoque y que la obtenida en los ensayos. Aunque el ángulo $\varphi^{\prime}$ que define la pendiente del plano de deslizamiento es menor que el ángulo $\varphi$ del primer caso, lo que implica que a igual deslizamiento $s$ se produce un menor desplazamiento radial $u_{r}$ y por tanto una menor tensión de adherencia $\tau_{b}$, el plano de deslizamiento tiene un mayor desarrollo, ya que su proyección horizontal es igual a la separación entre indentaciones, por lo que el desplazamiento radial se produce en una mayor superficie que en el primer caso. Como resultado de estos dos factores, se necesitan menores deslizamientos s para obtener las mismas tensiones de adherencia que en el primer enfoque. Por el mismo motivo, el máximo valor de la tensión de adherencia media $\tau_{b, \max }^{\text {med }}$ es también mayor que en el primer caso, estableciendo un límite superior de los resultados obtenidos en los ensayos realizados. Como se ha indicado en el desarrollo teórico, en este enfoque el deslizamiento $s_{y}$ para el que se alcanza el tramo plástico de la gráfica adherencia-deslizamiento no es una condición inicial de contorno sino la consecuencia del agotamiento de la capacidad de confinamiento del recubrimiento por los desplazamientos radiales $u_{r}$ que ocasionan las indentaciones en su deslizamiento. Por ello, la definición del punto exacto en el que comienza dicho tramo es más difusa que en el primer enfoque, pero a pesar de ello, muestra un comportamiento significativamente similar al recogido en los ensayos.

Como en el enfoque anterior, para deslizamientos superiores a $s_{u}$, el desarrollo del modelo se encuentra muy pautado por la geometría del alambre, por ello ofrece un alto grado de adaptación a los resultados experimentales.

\subsubsection{Alambres indentados con procesos de corrosión}

Como se ha visto a lo largo de esta tesis, con el aumento de los niveles de corrosión aumenta el desplazamiento $u_{r}$ de la pared interna del cilindro de hormigón que rodea el alambre, debido al mayor volumen de los productos de corrosión generados. Esto implica que el diagrama tensión de adherencia local-deslizamiento se modifica a lo largo del proceso de corrosión: por un lado, aumenta la tensión de adherencia $\tau_{\mathrm{b}}$ en el arranque del deslizamiento, debido a la mayor tensión radial inicial $\sigma_{r, 0}, \mathrm{y}$ por otro, hasta que la capacidad de confinamiento del recubrimiento se agota, se incrementa la tensión máxima de adherencia $\tau_{b, \max }^{\text {med }}$, por la combinación de los efectos de la corrosión y del desplazamiento radial $u_{r}$ generado por las indentaciones.

Como se ha indicado al enumerar las hipótesis de partida comunes a los dos enfoques para simular el estado tensional generado por el deslizamiento de los alambres indentados, se considera que los procesos de pérdida de sección por corrosión afectan de igual manera a toda la superficie del alambre, por lo que la altura de las indentaciones con respecto a la superficie del alambre permanece constante a lo largo de todo el proceso (ver Figura 6-42). Esta hipótesis simplificadora no se ajusta fielmente a la realidad, ya que la altura relativa de las indentaciones se reduciría paulatinamente con el aumento de la corrosión, pero en aras de la claridad y simplicidad del modelo se ha optado por utilizarla.

Mediante el modelo de determinación de tensiones radiales $\sigma_{r}$ basado en la teoría de cilindros de pared gruesa, expuesto en el Capítulo 3, se determina el estado tensional del alambre al comienzo del ensayo. Como se ha visto a lo largo de este capítulo, la tensión radial se incrementa con el aumento de la corrosión hasta alcanzar niveles de pérdida de sección comprendidos en el rango entre 3-5\%, dependiendo de las condiciones geométricas y mecánicas del recubrimiento, momento en el que el 
frente de fisuración radial alcanza la superficie exterior del hormigón y la tensión radial comienza a decrecer. Por tanto, la corrosión genera una tensión radial inicial $\sigma_{r, 0}$ mayor que la existente en alambres sanos (ver Figura 6-42).

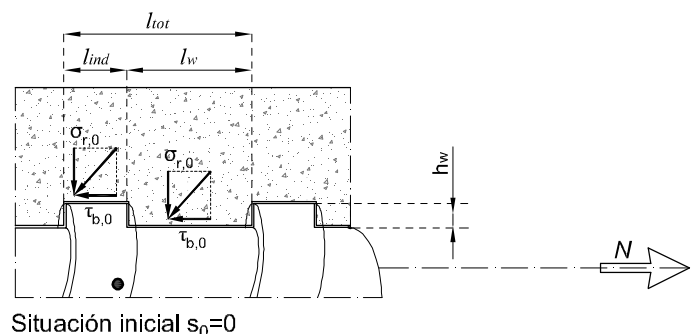

Situación inicial $\mathrm{s}_{0}=0$

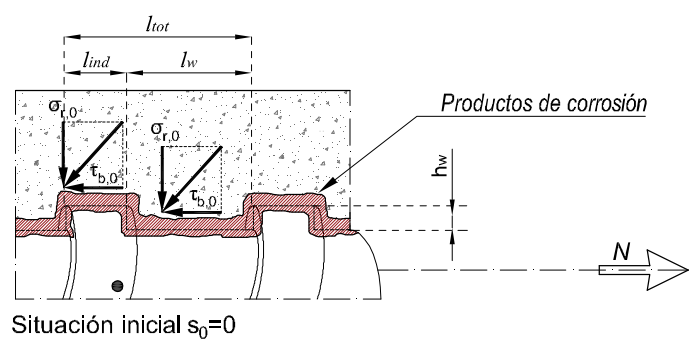

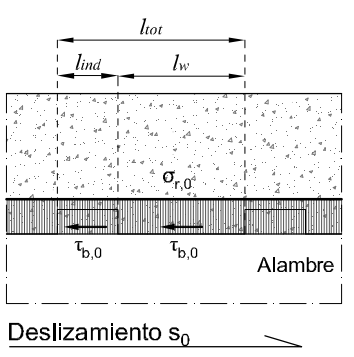
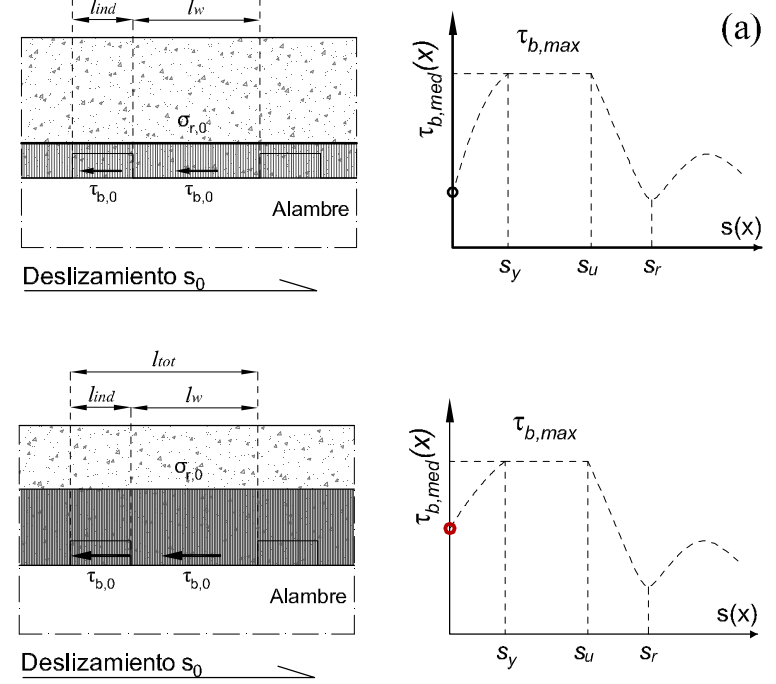

Figura 6-42 Comparación del estado tensional de un alambre indentado sano (arriba) y corroído (abajo) previo al comien zo del ensayo de arrancamiento.

Continuando con la metodología seguida para el análisis de alambres sanos, se han estudiado dos posibles enfoques para abordar el problema.

\subsection{Relación deslizamiento-desplazamiento radial con corrosión: $1^{\text {er Enfoque }}$}

Tal y como se ha expuesto al analizar el comportamiento de alambres sanos, este enfoque se basa en la determinación de los deslizamientos que definen el diagrama de adherencia local-deslizamiento $\left(s_{y}\right.$, $s_{u}$ y $\left.s_{r e s}\right)$ mediante la geometría del alambre indentado, de manera que el deslizamiento al final del tramo elástico $s_{y}$ es igual al ancho de la indentación $l_{\text {ind }}$, el deslizamiento $s_{u}$ que delimita la meseta plástica es igual a la distancia neta entre indentaciones $l_{w}$ y el deslizamiento $s_{r e s}$ con el que comienza el tramo con tensión de adherencia residual es igual a la longitud del paso de hélice $l_{\text {tor }}$
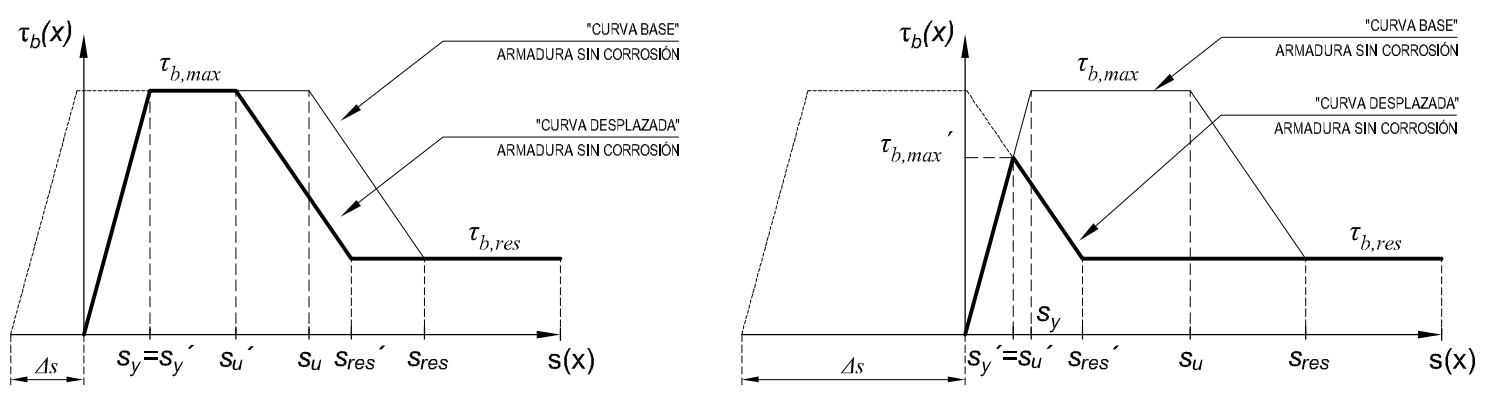

Figura 6-43 Evolución de los diagramas de tensión de adherencia local-deslizamiento con el aumento del nivel de corrosión, según Lundgren (Lundgren, et al., 2012) y Schlune (Schlune, 2006) 
Este enfoque ofrece un buen ajuste cuando se aplica sobre alambres sanos, pero su aplicación sobre alambres corroídos presenta algunos problemas. Es capaz de predecir con precisión el incremento de tensión de adherencia al comienzo del diagrama, así como el valor máximo de la misma, pero el esquema rígido en el que se basa es incapaz de reproducir la reducción de los deslizamientos $s_{y}$ y $s_{u}$ observada en los ensayos sobre probetas con corrosión, así como el cambio en el modo de fallo adherente.

A la vista de los resultados experimentales, se puede concluir que el incremento del nivel de corrosión no solo modifica el valor de la tensión máxima de adherencia, sino que además provoca un paulatino desplazamiento de la ley de adherencia local-deslizamiento sobre alambres sanos hacia la "izquierda" del eje de deslizamientos (abcisas). Lundgren et al. (2012) y Schlune (2006), basándose en los resultados experimentales de otros autores sobre armaduras corrugadas, exploraron esta hipótesis y propusieron un modelo analítico en el que, partiendo del "diagrama base" que definía la ley de adherencia local-deslizamiento sobre armaduras sanas, ajustaban los deslizamientos en función del nivel de corrosión. Para los autores, este comportamiento se justifica en base al agotamiento de la capacidad de confinamiento del recubrimiento por la fisuración inducida por la corrosión, que en último término tiene un efecto similar a la producida por una fuerza de arrancamiento sobre el acero. En base a ello, los autores proponen modificar la formulación del modelo de adherenciadeslizamiento del CEB-FIP en base a un desplazamiento $\Delta s$ del "diagrama base" (Eq. 6-17):

$$
\Delta s=a \cdot x
$$

Donde $x$ es igual a la penetración de ataque por corrosión y $a$ es un parámetro constante que depende de las condiciones del ensayo. Por otra parte, los autores consideran que la pendiente de la rama elástica se mantiene constante, por lo que la ley de adherencia local-deslizamiento para armaduras con corrosión es el resultado de la intersección entre la rama elástica del "diagrama base", procedente de las armaduras sanas, con el "diagrama desplazado" una distancia $\Delta s$ hacia la izquierda sobre el eje de deslizamientos, tal y como se muestra en la Figura 6-43.

Hay que tener en cuenta que el modelo propuesto por Lundgren (2012) y Schlune (2006) se basa en resultados experimentales sobre armaduras corrugadas, donde debido a la mayor altura de las corrugas el deslizamiento de la una barra sana ya agota de hecho la capacidad de confinamiento del recubrimiento en todas las secciones, por lo que, al contrario de lo observado en los ensayos sobre alambres indentados, el inicio del proceso de corrosión no produce un considerable aumento en las prestaciones adherentes. Por el mismo motivo, en la campaña de ensayos de la presente tesis se observa un acusado aumento de la pendiente de la rama elástica para niveles bajos de corrosión, lo que se opone a la propuesta de Lundgren

Siguiendo un procedimiento similar, pero atendiendo a las consideraciones anteriores, se propone que el desplazamiento $\Delta s$ hacia la izquierda del eje de deslizamientos, en el diagrama adherenciadeslizamiento, siga la siguiente expresión:

$$
\Delta s=\frac{\tau_{b, 0}^{\prime}}{\tau_{b, \max }{ }^{\prime}} \cdot s_{y} \leq s_{y}
$$


donde:

Deslizamiento hacia la izquierda del "diagrama base" de adherencia-deslizamiento (alambre sin corrosión)

$\tau_{b, 0}{ }^{\prime} \quad$ Tensión de adherencia inicial debida a la tensión radial ocasionada por la corrosión, previa al ensayo

$\tau_{b, \max }{ }^{\prime}$ Máxima tensión de adherencia derivada de las condiciones mecánicas y geométricas de la probeta

$S_{y} \quad$ Deslizamiento límite de la rama elástica en el "diagrama base" (alambre sin corrosión)

Como puede verse en la Figura 6-44 y en la expresión (Eq. 6-18), el "diagrama base" de adherenciadeslizamiento, que describe el comportamiento de alambres sanos, se desplaza una distancia $\Delta s$ en función de la relación existente entre la tensión de adherencia inicial $\tau_{b, 0}{ }^{\prime}$, derivada del estado tensional previo al ensayo por las condiciones de corrosión y retracción existentes, y el valor de la tensión máxima de adherencia $\tau_{b, \text { max }}$ que puede alcanzarse por las condiciones mecánicas y geométricas de la probeta (y que también depende del nivel de corrosión). De esta manera, el deslizamiento $s_{y}{ }^{\prime}$, bajo el cual se alcanza la tensión máxima de adherencia, va disminuyendo hasta alcanzar el punto en el que la expansión de los productos de corrosión es tal que llega a agotar la capacidad de confinamiento del recubrimiento y, por tanto, $\tau_{b, 0}{ }^{\prime}$ y $\tau_{b, \max }{ }^{\prime}$ son prácticamente iguales. En ese momento, la proyección horizontal de la rama elástica es prácticamente cero, y para deslizamientos muy pequeños se alcanza el valor máximo de la tensión de adherencia $\tau_{b, \text { max }}$. Este valor, siendo coherente con el primer enfoque expuesto para alambres sanos, se mantiene hasta alcanzar un deslizamiento $s_{u}{ }^{\prime}$, también desplazado solidariamente una distancia $\Delta s$ con respecto al "diagrama base". A partir de ese momento, cualquier aumento en el nivel de corrosión supone una disminución de la máxima tensión de adherencia, aunque los deslizamientos $s_{y}{ }^{\prime}$ y $s_{u}$ ' no se modifican. Por último, en base a los resultados experimentales, se decide que el valor de deslizamiento $s_{\text {res }}$, que da paso a la rama residual, permanezca inamovible durante todo el proceso de corrosión y, por tanto, sea igual a la longitud del paso de hélice $l_{t o t}$
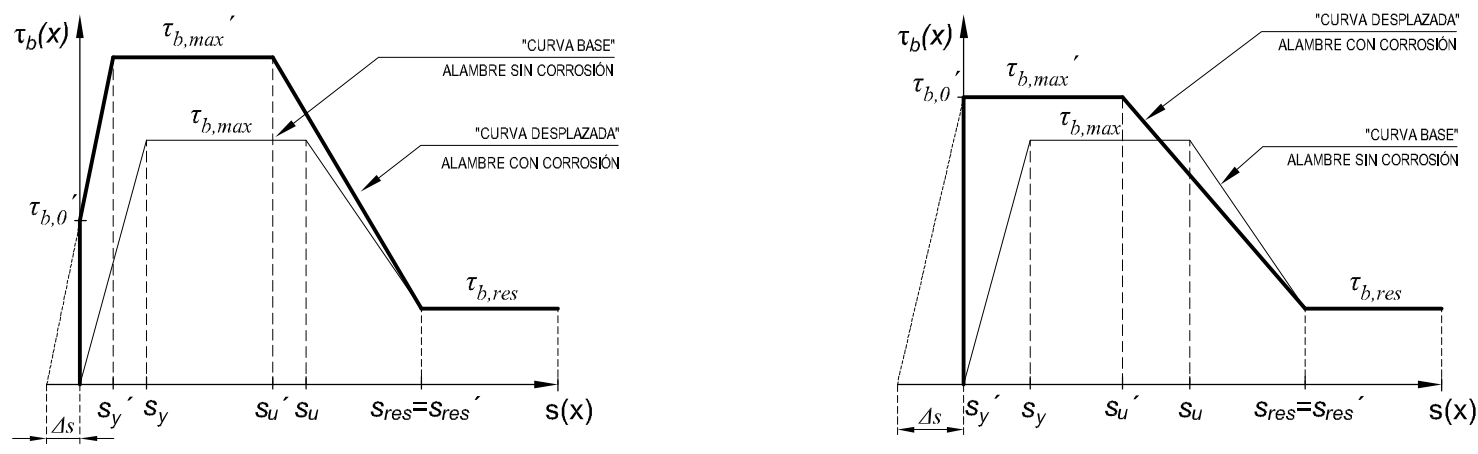

Figura 6-44 Evolución de los diagramas de tensión de adherencia local-deslizamiento con el aumento del nivel de corrosión (1er enfoque)

En la Figura 6-45 se representa la evolución de los diagramas de tensión de adherencia mediadeslizamiento en extremo no cargado $\tau_{b},-s$ para distintos grados de corrosión, obtenidos mediante la aplicación del $1^{\text {er }}$ enfoque a las condiciones mecánicas y geométricas de la serie de ensayos I10. La comparación con los resultados experimentales de la misma serie [Figura 5-11, Figura 5-12 y Figura 513] permite extraer las siguientes conclusiones: 
- Debido a que los parámetros relativos a la corrosión que influyen en el desarrollo de las tensiones radiales han sido calibrados previamente, los valores de las tensiones máximas de adherencia alcanzadas para cada nivel de pérdida de sección se obtienen con márgenes de error razonables.

-En cuanto a la forma de los diagramas de adherencia-deslizamiento, el incremento del nivel de corrosión aleja los resultados del modelo analítico de los resultados experimentales. Los buenos resultados predictivos obtenidos por este enfoque en su aplicación sobre alambres sanos no se ven reflejados en alambres con procesos de corrosión iniciados.

- El "artificio" por el cual se desplaza el diagrama de adherencia-deslizamiento sobre el eje de deslizamientos con el aumento de la corrosión permite reproducir razonablemente bien el comportamiento para niveles bajos de pérdida de sección, pero comienza a fallar en el momento en el que las condiciones tensionales de la probeta conducen a un cambio en el modo de fallo adherente.

- Por tanto, la principal limitación de este enfoque es su imposibilidad para predecir tanto la reducción de los deslizamientos $s_{y}$ y $s_{u}$, como el cambio en el modo de fallo.

Los problemas detectados en este enfoque se intentan subsanar en el siguiente apartado, donde se aplica a alambres indentados con corrosión el $2^{\circ}$ enfoque desarrollado en esta tesis para establecer la relación entre deslizamientos y desplazamientos radiales.

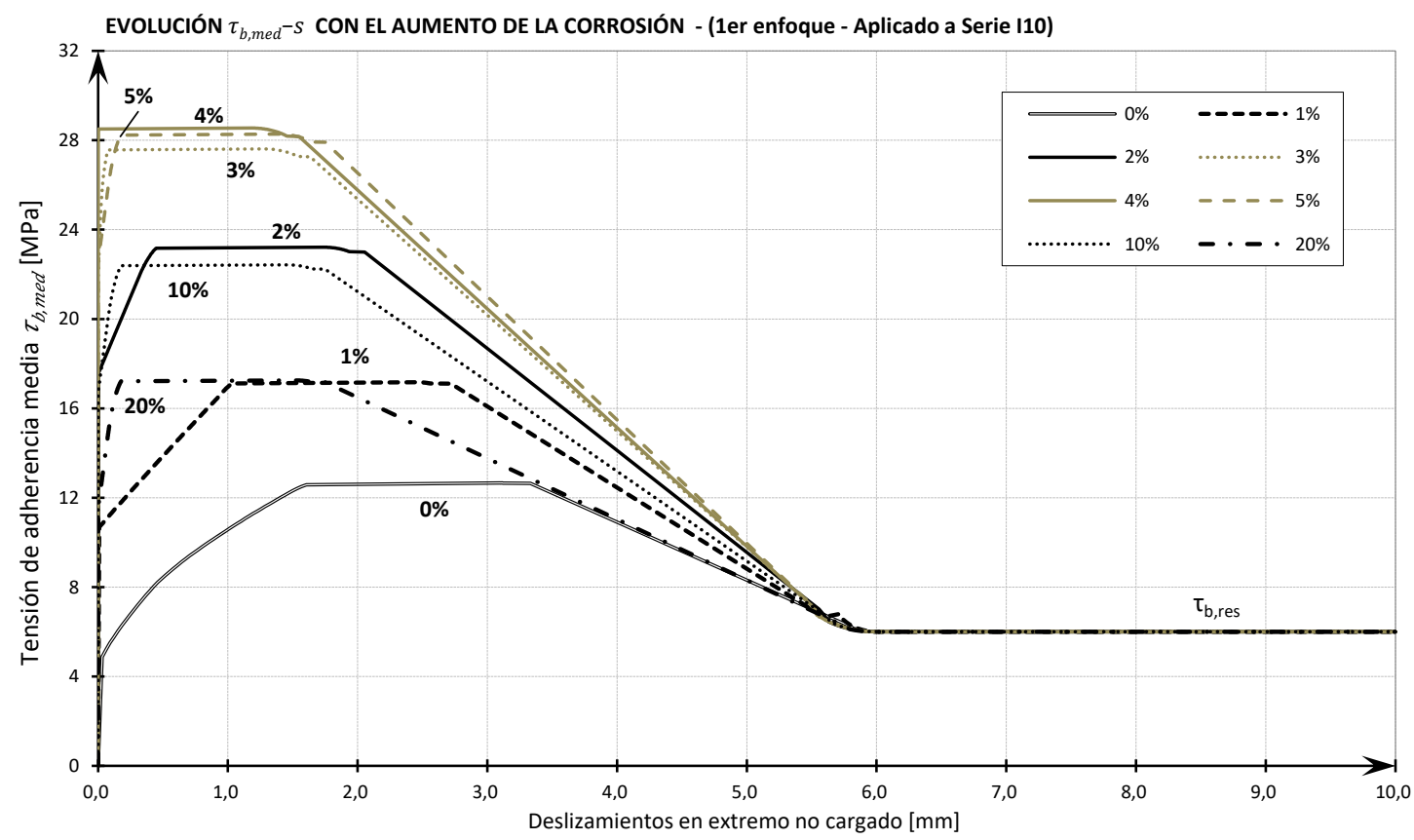

Figura 6-45 Evolución de los diagramas de adberencia-deslizamiento en extremo no cargado según el modelo desarrollado (1 ${ }^{\circ}$ enfoque). Propiedades mecánicas y geométricas equivalentes a las de las probetas de la serie I10. 


\subsection{Relación deslizamiento-desplazamiento radial con corrosión: $2^{\circ}$ Enfoque}

Como se ha visto anteriormente, este enfoque se encuentra menos "pautado" que el anterior, de manera que no se impone que el deslizamiento $s_{y}$, que delimita el tramo elástico de la gráfica, sea igual al ancho de la indentación $l_{\text {ind }}$, sino que es consecuencia del paulatino agotamiento de la sección por el desplazamiento radial $u_{n}$ originado por la retracción, la corrosión y las indentaciones.

En este enfoque la geometría del alambre se idealiza como una sucesión de troncos de cono cuyas superficies generan planos de deslizamiento de ángulo $\varphi^{\prime}$ (Figura 6-37), cuya tangente es equivalente al cociente de la altura homogeneizada de las indentaciones $h_{w}$ entre la distancia neta entre indentaciones $l_{m}$. Ya que se ha considerado como hipótesis de partida que la corrosión afecta de igual manera a toda la superficie del alambre, la pendiente de dicho plano no se ve afectada por la pérdida de sección y, por tanto, para deslizamientos $s$ comprendidos en el rango $0 \leq s \leq s_{u}$, los desplazamientos radiales $u_{r}$ continúan siendo iguales a $s \cdot \operatorname{tg} \varphi$ '.

La principal diferencia con respecto a los alambres sanos es que la tensión radial inicial $\sigma_{r, 0}$ previa al comienzo del ensayo, procedente de los fenómenos higrotérmicos (retracción) y del aumento de volumen de los productos de corrosión, adquiere un mayor valor, lo que posibilita que se alcance la tensión máxima de adherencia para menores deslizamientos.

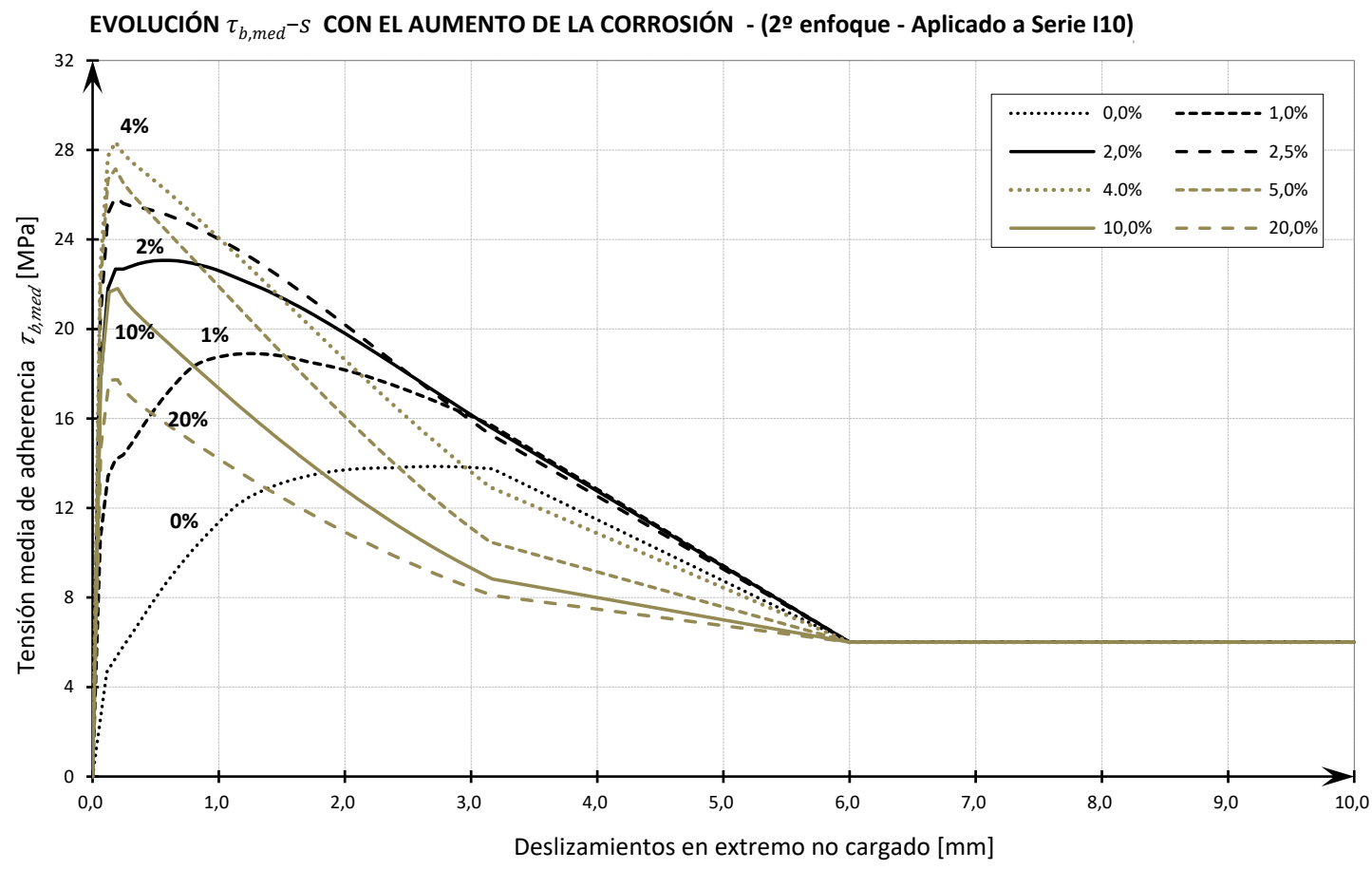

Figura 6-46 Evolución de los diagramas de adherencia-deslizamiento en extremo no cargado según el modelo desarrollado (2ºnfoque). Propiedades mecánicas y geométricas equivalentes a las de las probetas de la serie 110.

En la Figura 6-46 se representa la evolución de los diagramas de tensión de adherencia mediadeslizamiento en extremo no cargado $\tau_{b},-s$ para distintos grados de corrosión, obtenidos mediante la aplicación del $2^{\circ}$ enfoque a las condiciones mecánicas y geométricas de la serie de ensayos I10. Como puede observarse, con respecto a la situación inicial, el paulatino incremento del nivel de 
corrosión provoca, por un lado, un incremento de la tensión inicial de adherencia $\tau_{b, 0}$, por otro, un aumento de la pendiente de la rama elástica del diagrama adherencia-deslizamiento, y por último, una importante mejora del valor máximo de la tensión de adherencia $\tau_{b \text {,max }} \mathrm{y}$ una considerable disminución del deslizamiento $s_{y}$ para el que se alcanza dicho valor.
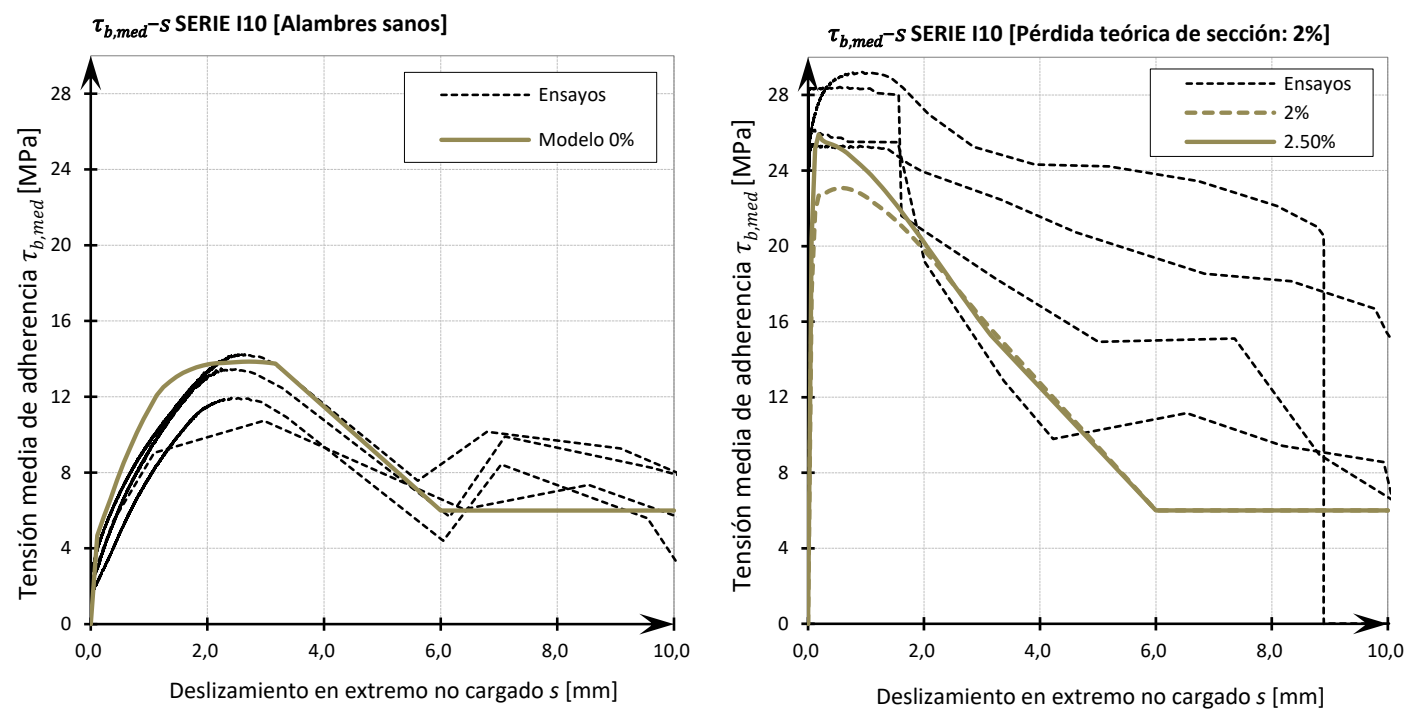

Figura 6-47 Comparación de los diagramas de adherencia-deslizamiento en extremo no cargado según el modelo desarrollado (2 ${ }^{\circ}$ enfoque) con los obtenidos en los ensayos sobre las probetas de la serie I10. Iqquierda: 0\% de pérdida teórica de sección. Derecha: 2\% de pérdida teórica de sección.
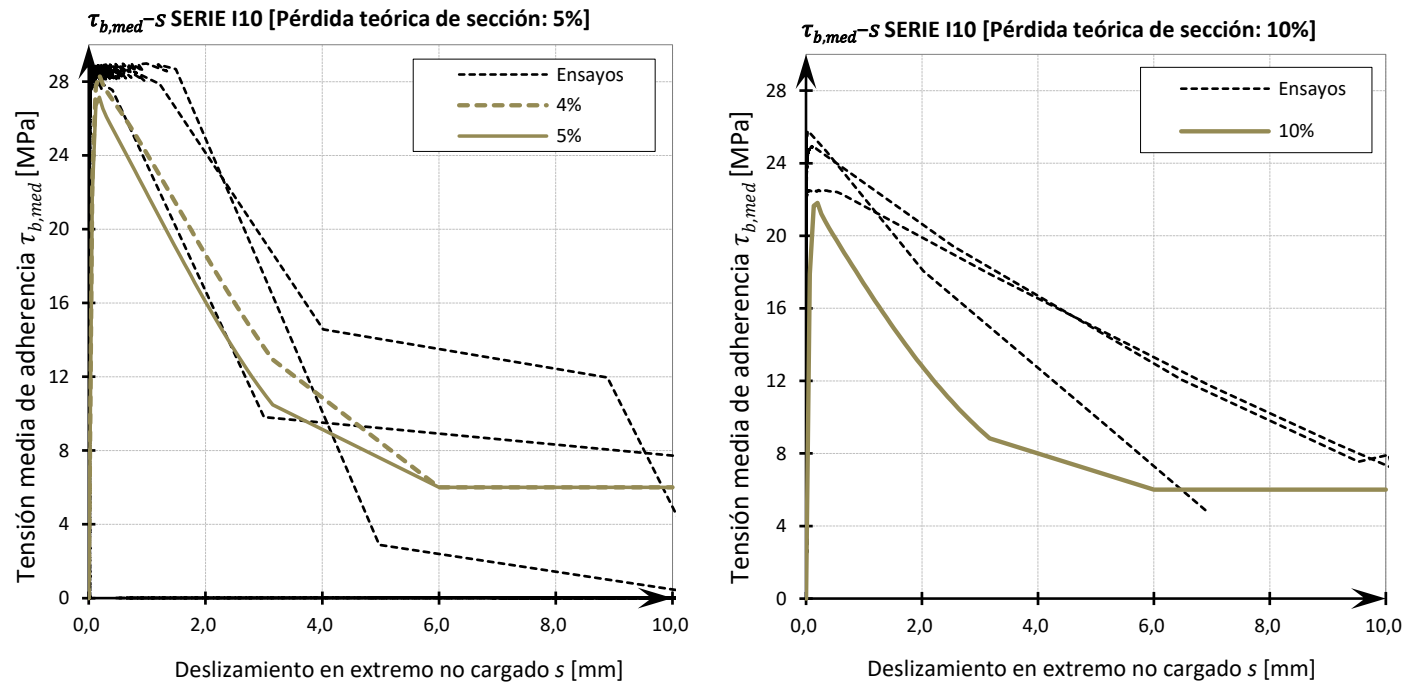

Figura 6-48 Comparación de los diagramas de adherencia-deslizamiento en extremo no cargado según el modelo desarrollado (2enfoque) con los obtenidos en los ensayos sobre las. probetas de la serie 110. Izquierda: 5\% de pérdida teórica de sección. Derecha: 10\% de pérdida teórica de sección.

Dado que se acepta que la pendiente del plano de deslizamiento no se modifica $\left[\tan \left(\varphi^{\prime}\right)=c t e\right]$, puede deducirse que el aumento del nivel de corrosión provoca que la tensión máxima de adherencia $\tau_{b \text {,max }}$ y el posterior fallo adherente se alcanza para menores desplazamientos radiales $u_{r}$ procedentes exclusivamente del deslizamiento del alambre. Esta situación se va agravando hasta que, debido a la 
fisuración del hormigón, la capacidad de confinamiento se agota y el recubrimiento no es capaz de asumir ningún desplazamiento radial $u_{r}$ adicional procedente de las indentaciones. Este comportamiento nos indica que se está produciendo un cambio en el modo de fallo, desde el fallo por deslizamiento o pull-out inicial, hasta el fallo por fisuración o splitting. Como se vio al comienzo de este apartado, si el recubrimiento es capaz de confinar las tensiones procedentes de los desplazamientos radiales $u_{r}$ en la interfaz acero-hormigón, puede formarse un nuevo plano de deslizamiento, paralelo al eje del alambre, y el fallo se produce por pull-out. El aumento de volumen de los productos de corrosión va solicitando el recubrimiento, provocando que la fisuración radial se propague a lo largo del mismo, hasta alcanzar la superficie y provocando un fallo frágil por splitting sin apenas deslizamiento. Tal y como se puede ver en la Figura 6-46, este enfoque predice un cambio paulatino en el modo de fallo adherente, desde el pull-out puro para alambres sanos $(0 \%$ de pérdida de sección), pasando por situaciones intermedias en las que el recubrimiento fisurado aún es capaz de confinar las tensiones radiales (pérdidas menores al 4\%), hasta llegar al punto de inflexión en el que la máxima tensión de adherencia se alcanza para deslizamientos muy pequeños y cualquier desplazamiento radial posterior derivado del deslizamiento del alambre provoca un descenso en las prestaciones adherentes (fallo por splitting). Para las condiciones de las probetas de la serie I10, el modelo predice que el punto de inflexión se encuentra en un rango comprendido entre un 2,5 y un $4,0 \%$ de pérdida de sección por corrosión. Pérdidas de sección posteriores provocan un descenso paulatino en el valor máximo de la tensión de adherencia $\tau_{b, \max } \mathrm{y}$ descensos bruscos superado dicho valor. Al igual que en el anterior enfoque, y en ausencia de resultados experimentales más precisos, se ha optado por conservar el valor del deslizamiento $s_{r e s}$ utilizado para alambres sanos, valor que es igual a la longitud del paso de hélice de la indentaciones $l_{t o t}$ Para la tensión residual de adherencia $\tau_{b, r e s}$ se ha utilizado un valor de $6 \mathrm{~N} / \mathrm{mm}^{2}$, ya que, en virtud de los resultados obtenidos en los ensayos, puede considerarse un límite inferior de las gráficas adherencia-deslizamiento.

En las Figura 6-47 y Figura 6-48 se comparan los diagramas de adherencia-deslizamiento en extremo no cargado, según $2^{\circ}$ enfoque del modelo desarrollado, con los obtenidos en los ensayos sobre las probetas de la serie I10. Como puede observarse, el modelo basado en este enfoque no sólo predice con precisión la tensión máxima alcanzada para cada nivel de corrosión considerado, sino que es capaz de reproducir con bastante precisión el cambio en el modo de fallo adherente y la evolución de la forma de los diagramas de tensión de adherencia-deslizamiento.

\subsection{Conclusiones parciales}

En el apartado anterior se han desarrollado dos enfoques para simular el comportamiento adherente de alambres indentados embebidos en hormigón y sometidos a una fuerza de arrancamiento. Dada su complejidad, los enfoques propuestos no intentan representar fielmente la realidad del proceso, sino predecir, con cierto apoyo en los fenómenos mecánicos que realmente tienen lugar, las leyes de adherencia-deslizamiento que controlan el proceso, así como su evolución con el avance de la corrosión.

A la vista de lo expuesto, se puede concluir que las leyes de adherencia-deslizamiento vienen determinadas por los siguientes factores: la geometría del alambre (diámetro, separación de indentaciones, ancho y altura de éstas, etc), la capacidad de confinamiento del recubrimiento derivada de sus propiedades mecánicas y geométricas, y el coeficiente de fricción existente entre el acero y el 
hormigón. Por otro lado, la presión interna procedente de la retracción, la corrosión o el efecto Hoyer origina modificaciones en la ley de adherencia local-deslizamiento original, pudiendo incluso modificar el mecanismo de fallo por adherencia, de un fallo dúctil por pull-out a otro de naturaleza frágil por fisuración o splitting.

El primer enfoque expuesto permite deducir por completo la ley de tensión de adherencia localdeslizamiento si se conoce, por un lado, la capacidad de confinamiento del recubrimiento, y por otro, la geometría del alambre. Este enfoque tiene un buen comportamiento a la hora de simular el comportamiento de alambres sanos, reproduciendo con razonable precisión la magnitud y pendiente de los distintos tramos que comprenden el diagrama de adherencia-deslizamiento, pero el esquema rígido en el que se basa no es capaz de predecir su evolución con el aumento de la corrosión ni, por tanto, el cambio en el modo de fallo adherente.

El segundo enfoque es similar al anterior, pero la ley de adherencia-deslizamiento se encuentra menos pautada por la geometría del alambre, de manera que al contrario que en el primer caso, no se impone que el deslizamiento $s_{y}$, que delimita el tramo elástico de la gráfica, sea igual al ancho de la indentación $l_{\text {ind, }}$ sino que es consecuencia del paulatino agotamiento de la sección de hormigón por el desplazamiento radial $u_{r}$ que generan las indentaciones en su deslizamiento. De esta manera, $s_{y}$ no es una condición de partida, sino el resultado de la relación existente entre la geometría del alambre y la capacidad de confinamiento del recubrimiento. Esta pequeña modificación hace que su aplicación sobre alambres sanos conduzca a gráficas con una mayor desviación con respecto a los resultados experimentales, pero reproduce con precisión la evolución del diagrama adherencia-deslizamiento que provoca el aumento de la corrosión, así como el cambio en el modo de fallo adherente. Por tanto, a la vista de estas conclusiones, se opta por aplicar este segundo enfoque en el análisis de las gráficas de adherencia-deslizamiento de alambres indentados.

\subsubsection{Alambres lisos sanos y con corrosión}

La CEB-FIP (Fédération internationale du béton / International Federation for Structural Concrete) propone en distintos documentos, tales como el Bulletin d'Information N. 217 (CEB, 2000) y el Model Code 2010 (CEB-FIP, 2012), una curva idealizada para la relación adherencia localdeslizamiento $\tau_{b}-S$ en barras lisas que depende de la rugosidad de la superficie del acero (acero estirado en frío o laminado en caliente), de las condiciones adherentes derivadas de la posición del acero durante el hormigonado (buenas o malas) y de las condiciones mecánicas del recubrimiento (resistencia media a compresión del hormigón $f_{c m}$ ). El modelo propuesto por la CEB-FIP se divide en dos intervalos diferenciados: una rama inicial no lineal hasta alcanzar la tensión máxima de adherencia $\tau_{b, \max }$ en $s_{y}$, seguida de una rama horizontal de pendiente nula (constante) en la que la tensión máxima de adherencia $\tau_{b, \max }$ se mantiene constante. En este modelo, los deslizamientos $s_{y}, s_{u} \mathrm{y}$ $s_{r e s}$ son coincidentes $\left(s_{1}=s_{2}=s_{3}=0,01 \mathrm{~mm}\right.$ para acero estirado en frío), así como el valor máximo de la tensión de adherencia $\tau_{b, \text { max }}$ y el valor residual de la misma $\tau_{b, \text { res. }}$

El modelo propuesto por CEB-FIP contempla únicamente la posibilidad de fallo por deslizamiento o pull-out en alambres lisos sanos, lo que coincide con los resultados obtenidos en la campaña experimental recogida en el Capitulo 5, donde se ha deducido que el confinamiento proporcionado por el recubrimiento de hormigón, en todos los espesores ensayados, es suficiente para prevenir el 
fallo por splitting, de manera que el fallo adherente es protagonizado por el arrancamiento del alambre (fallo por pull-out), y la transferencia de la fuerza se basa en el mecanismo de fricción. El plano de deslizamiento entre el acero y el hormigón está configurado, en este caso, por la superficie de contacto entre el hormigón y el acero, y por tanto es paralelo a la directriz del alambre (Figura 6-34). Por otro lado, en el Capitulo 5 también se ha comprobado que la rama elástica del diagrama de tensión de adherencia media-deslizamiento es prácticamente vertical en todos los casos, de manera que para deslizamientos muy pequeños $\left(s_{1}<0,1 \mathrm{~mm}\right)$ se alcanza el máximo valor de la tensión media de adherencia $\tau_{b, \text { max }}^{\text {med }}$ o al menos, el punto de inflexión en el que el diagrama cambia radicalmente de forma, adquiriendo una pendiente prácticamente horizontal. En este segundo tramo aumenta notablemente la dispersión la evolución del valor de la tensión de adherencia, obteniéndose tendencias ascendentes, descendentes o constantes, sin un patrón que lo justifique.

Por tanto, en base a los resultados experimentales obtenidos y a la curva idealizada propuesta por Código Modelo 2010 (CEB-FIP, 2012), en esta tesis se propone un diagrama de adherencia localdeslizamiento también en dos tramos: una rama lineal definida por el deslizamiento $s_{y}$ y el valor máximo de la tensión de adherencia $\tau_{b, \max }$, y una rama horizontal en la que dicho valor se mantiene constante (Ver Figura 6-49). Se supone, por otro lado, que el diagrama de tensión de adherencia localdeslizamiento $\tau_{b-s}$ es muy similar al diagrama de tensión de adherencia media-deslizamiento $\tau_{b, \text { med }}-s$ obtenido de los ensayos, por lo que el valor del deslizamiento $s_{y}$ local será prácticamente igual al $s_{1}$ en extremo no cargado. En definitiva, en virtud de los resultados obtenidos en los ensayos, el deslizamiento $s_{y}$, coincidente con los deslizamientos $s_{u}$ y $s_{r e s}$, toma un valor de $0,1 \mathrm{~mm}$, mientras que el valor de la tensión máxima de adherencia $\tau_{b, \max }$ es el resultado de la tensión radial inicial, fruto de la retracción, y de la tensión de adhesión $\tau_{a d b}$.

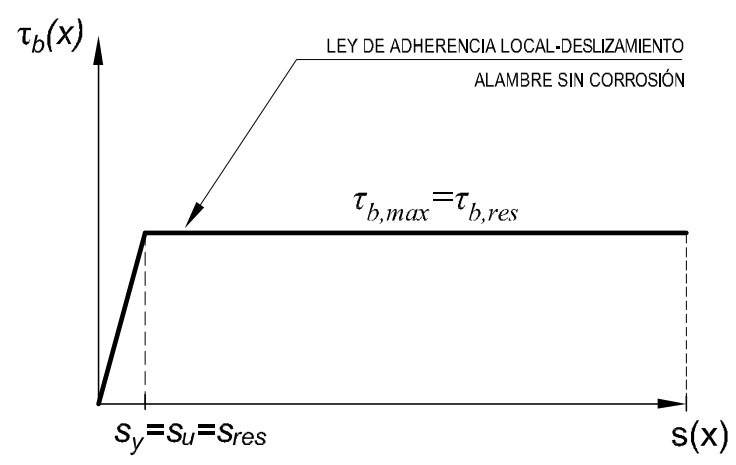

Figura 6-49 Diagramas de tensión de adherencia local-deslizamiento para alambres lisos sin corrosión.

Tal y como se indicó en el Apartado 3.4 "Modelado de la retracción", el comportamiento adherente de los alambres lisos sanos es especialmente sensible a la deformación volumétrica e isotrópica de contracción derivada de la retracción, al ser ésta, en ausencia de procesos de corrosión, las principal responsable de la aparición de tensiones radiales $\sigma_{r}$ sobre la superficie del acero, que a la postre, junto con la tensión de adherencia por el mecanismo de adhesión $\tau_{\text {adh }}$, posibilitan la aparición de tensiones tangenciales de adherencia $\tau_{b}$ cuando el alambre se encuentra solicitado. Es por ello que, sin entrar en otras consideraciones, la retracción posibilita incrementos de la capacidad adherente, especialmente significativos para cantidades pequeñas de corrosión o niveles de pretensado moderados. Para tener en cuenta este efecto, en esta tesis se ha utilizado el modelo propuesto en el Model Code 2010 (CEB- 
FIP, 2012), que subdivide la retracción total $\varepsilon_{s h}\left(t, t_{s}\right)$ en retracción autógena $\varepsilon_{c a s}(t)$, asociada con la hidratación del cemento, y retracción por secado $\varepsilon_{c d s}\left(t, t_{s}\right)$, que tiene lugar tras el fraguado, y se produce por la pérdida de humedad en la pasta cementicia del hormigón cuando está expuesto a un ambiente con humedad relativa (HR) no saturada.

.En la Figura 6-50 se comparan las gráficas de tensión media de adherencia-deslizamiento en extremo no cargado $\tau_{b \text {,med }}-s$, obtenidas en los ensayos experimentales sobre alambres lisos sin corrosión de la serie L10 (c/ $\phi=10)$, frente a la predicción teórica arrojada por el modelo analítico para distintos niveles de retracción. Para su obtención se ha seguido la formulación recogida en el apartado 3.7 de la presente tesis y la ley de adherencia local-deslizamiento propuesta anteriormente. El coeficiente de fricción utilizado $\mu=0.65$ es el mismo que el utilizado para alambres indentados. Por otro lado, como norma general, los ensayos de pull-out se llevaron a cabo justo después del periodo de curado de las probetas en la cámara húmeda, pero en ocasiones, por necesidades del servicio en la Nave de Ensayos del IETcc, se realizaron transcurridos unos días, en las que las condiciones atmosféricas presentaron distintos grados de humedad, en función de la estación del año y/o del tiempo atmosférico. Por ello, se han representado los siguientes niveles de retracción:

- Únicamente retracción autógena: $\varepsilon_{s h}\left(t, t_{s}\right)=\varepsilon_{c a s}(t)$ : El ensayo se lleva a cabo tras 28 días de curado en la cámara húmeda, con una humedad relativa (HR) del $98 \%$, en la que sólo se ha producido una pérdida volumétrica por la retracción autógena $\varepsilon_{c a s}(t)$ asociada a la hidratación del cemento.

- Retracción tras un periodo de secado $\left(t-t_{s}\right): \varepsilon_{s h}\left(t, t_{s}\right)=\varepsilon_{c a s}(t)+\varepsilon_{c d s}\left(t, t_{s}\right)$. El ensayo se realiza tras el curado de las probetas en cámara húmeda ( $t_{s}=28$ días) y un periodo de secado $t-t_{s}$ de 7 días en un ambiente con una con una determinada humedad relativa HR, por lo que la retracción total es fruto de la retracción autógena durante 35 días $\varepsilon_{c a s}(t=35)$ y la retracción por secado durante 7 días $\varepsilon_{c d s}\left(t=35, t_{s}=28\right)$. Se han considerado tres ambientes de secado: secado en cámara húmeda ( $\mathrm{HR}=98 \%)$, secado en condiciones atmosféricas húmedas ( $\mathrm{HR}=80 \%$, exteriores) y secado en condiciones atmosféricas secas ( $\mathrm{HR}=50 \%$, interiores).

A la vista de la Figura 6-50, la tensión de adherencia $\tau_{b}$ derivada únicamente de la retracción autógena, asociada a una deformación volumétrica total $\varepsilon_{s h}\left(t, t_{s}\right)=\varepsilon_{c a s}(t)=-5,27 \cdot 10^{-5}$, marca el límite inferior de los resultados experimentales obtenidos. En este caso, el valor máximo de la tensión media de adherencia, $\tau_{b, \max }^{\text {med }}=2,984 \mathrm{MPa}$, es muy similar al obtenido en los ensayos sobre las probetas L10-0-1, L10-0-2 y L10-0-5 (3,156, 3,062 y 2,977 MPa, respectivamente). Por otro lado, el valor máximo de la tensión media de adherencia $\tau_{b, \text { max }}^{\text {med }}$ obtenido en las probetas restantes, $L 10-0-3: \tau_{b, \text { max }}^{\text {med }}=4,610 \mathrm{MPa} \mathrm{y}$ L10-0-4: $\tau_{b, \max }^{\text {med }}=4,850 \mathrm{MPa}$, se encuentra muy próximo al arrojado por el modelo para un periodo de secado de 7 días al $80 \%$ de humedad relativa, asociado a una deformación volumétrica de compresión con un valor $\varepsilon_{s h}\left(t, t_{s}\right)=\varepsilon_{s h}\left(t, t_{s}\right)=\varepsilon_{c a s}(t)+\varepsilon_{c d s}\left(t, t_{s}\right)=-5,60 \cdot 10^{-5}-4,81 \cdot 10^{-5}=$ $-1,04 \cdot 10^{-4}$.

En todos las gráficas de tensión media de adherencia-deslizamiento $\tau_{b \text {,med }}-s$ obtenidas en los ensayos experimentales se observa un ligero descenso de la curva una vez alcanzado el pico de su máximo valor. Este comportamiento, que no ha sido tenido en cuenta en el modelo propuesto, puede deberse 
a un paulatino deterioro de las propiedades de fricción de la interfaz acero-hormigón durante el progresivo deslizamiento relativo del alambre.

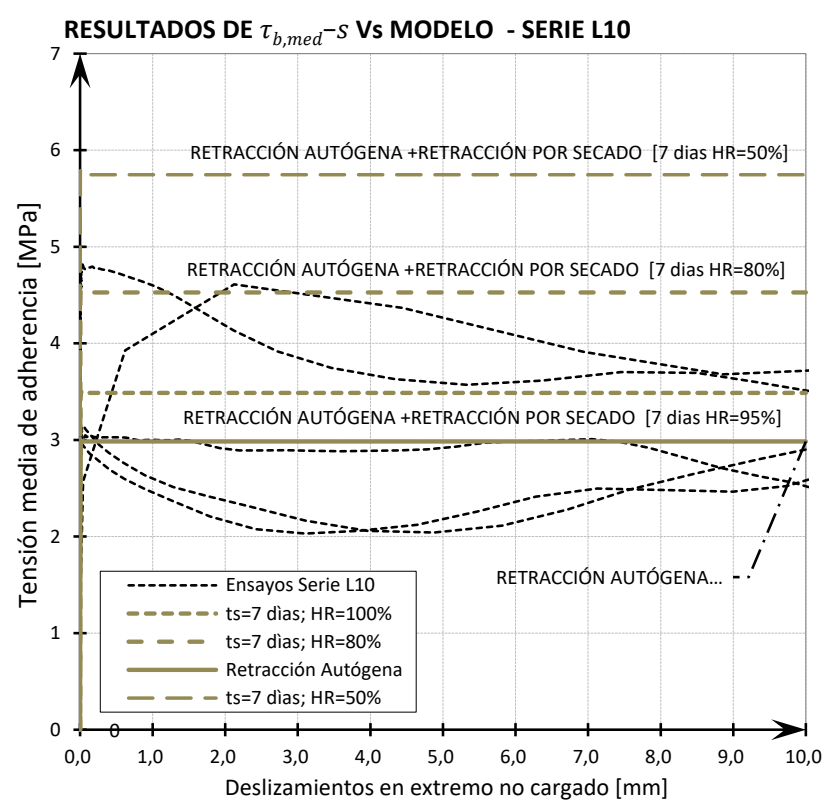

Figura 6-50 Diagrama de adherencia-deslizamiento en extremo no cargado en ensayos sobre alambres lisos sin corrosión, serie L10. Comparación con el modelo propuesto, para distintos niveles de retracción.

En definitiva, el modelo analítico propuesto reproduce con bastante precisión el comportamiento adherente de alambres lisos sin procesos de corrosión y, además, consigue justificar la considerable dispersión de resultados obtenidos en base a leves diferencias en el tiempo de curado y en las condiciones atmosféricas durante el secado de las probetas.

En cuanto a los alambres con corrosión, en el Capitulo 5 se ha discutido cómo reproducen las tendencias ya observadas para alambres indentados. Por un lado, tiene lugar un aumento del valor de la tensión de adherencia tanto inicial como máxima hasta un determinado nivel de corrosión en el que se comienza a comprometer la capacidad de confinamiento del recubrimiento. Por otro, se produce un paulatino cambio en el modo de fallo, de pull-out a splitting, que se ve reflejado en la reducción de los deslizamientos $s_{1}, s_{2}$ y $s_{3}$. Mientras que los deslizamientos que limitan la rama elástica del diagrama $s_{1}$ se mantienen esencialmente constantes con el aumento de la corrosión, los deslizamientos $s_{2}$ y $s_{3}$, que respectivamente limitan la rama plástica y la de ablandamiento del diagrama, aun teniendo en general una tendencia descendente, muestran una gran dispersión (Ver Figura 5-35). Esta dispersión procede probablemente de la combinación del proceso de corrosión, de naturaleza heterogénea, y de la propia configuración del ensayo, ya que los deslizamientos obtenidos en un ensayo por control por fuerza son menos fiables una vez superado el pico de fuerza máxima. Si bien es cierto que ambos factores están presentes también en los alambres indentados, éstos cuentan con el elemento homogeneizador que supone la geometría superficial del acero, que cómo se ha visto anteriormente influye de manera decisiva en la relación entre adherencia y deslizamiento. En definitiva, el estudio de los diagramas de tensión de adherencia local-deslizamiento en alambres lisos con corrosión necesita de campañas específicas diseñadas a tal efecto y, por tanto, se reserva para trabajos futuros. 


\section{CAPÍTULO 7}

\section{Validación del Modelo Analítico de Adherencia de Alambres Pretensados con Corrosión}

\subsection{Introducción}

El objetivo de este capítulo es, por un lado, llevar a cabo la verificación experimental del modelo teórico propuesto en el Capitulo 3, y cuyas variables han sido calibradas en el Capitulo 6. Para ello, se han comparado los resultados experimentales obtenidos en una campaña de ensayos diseñada al efecto, con los resultados teóricos obtenidos mediante la aplicación del modelo analítico, simulando las condiciones mecánicas y geométricas de los ensayos de laboratorio. La campaña de ensayos ha constado de dos etapas diferenciadas: la primera de ellas se ha diseñado siguiendo la Norma UNE 7436-82 "Método de ensayo para la determinación de las características de adherencia de las armaduras de pretensado" (Instituto Nacional de Racionalización y Normalización - IRANOR, 1982) y su objetivo ha sido el de determinar las longitudes de transferencia $l_{t}$ en vigas pretensadas de hormigón sin procesos de corrosión; la segunda, partiendo de las vigas anteriores, ha analizado la influencia de la corrosión en las propiedades adherentes. Para ello se han monitorizado las deformaciones longitudinales en el hormigón $\boldsymbol{\varepsilon}_{\imath}$, los deslizamientos de los alambres en los extremos $\delta_{c}$ y la evolución de la fisuración.

Una vez validado el modelo, se ha estudiado la influencia que tienen las principales variables geométricas y mecánicas que intervienen en el pretensado, en conjunción con la corrosión, en el comportamiento adherente de elementos pretensados de hormigón.

\subsection{Procedimiento experimental}

Para la realización de los ensayos se ha seguido la Norma UNE 7-436-82 "Método de ensayo para la determinación de las características de adherencia de las armaduras de pretensado". Se han llevado a cabo una tanda de ensayos con dos etapas diferenciadas, separadas en el tiempo. En la primera etapa se ha permitido que los efectos reológicos tras el destesado se desarrollen durante 365 días, mientras que, en la segunda, las probetas han sido sometidas a un proceso de corrosión acelerada para estudiar el efecto de ésta sobre la longitud de transferencia.

\subsubsection{Tipología de las probetas}

\subsubsection{Geometría y denominación}

Se han fabricado 4 probetas prismáticas de hormigón pretensado de sección rectangular, mediante moldes metálicos, que han sido pretensadas mediante 4 alambres indentados de $5 \mathrm{~mm}$ de diámetro $\phi$ situados en cada una de las esquinas de la viga. Las dimensiones de las probetas son las siguientes: 
a) Longitud L: $1976 \mathrm{~mm}$. Esta longitud se encuentra dentro de los límites de la norma UNE 7-436-82 (Instituto Nacional de Racionalización y Normalización - IRANOR, 1982), que recomienda usar una longitud L igual a $200 \phi+500 \mathrm{~mm}$ como mínimo (siendo $\phi$ el diámetro de las armaduras utilizadas), y nunca inferior a $1800 \mathrm{~mm}$ ni a $2 l_{t}+300 \mathrm{~cm}$.

b) Sección transversal: Sección rectangular de $80 \mathrm{x} 90 \mathrm{~mm}^{2}$. Las recomendaciones de la Norma indican que para armaduras activas cuyo diámetro $\phi$ sea mayor o igual a $5 \mathrm{~mm}$ se deben utilizar probetas con lados no menores a $80 \mathrm{~mm}$.

c) Recubrimiento mecánico: $20 \mathrm{~mm}$.

Las vigas fueron denominadas mediante números cardinales (Viga 1, Viga 2, Viga 3 y Viga 4), situándose la Viga 1 en el extremo de la bancada de pretensado próximo al estribo pasivo de anclaje y la Viga 4 en el extremo opuesto, próximo al estribo activo de anclaje.
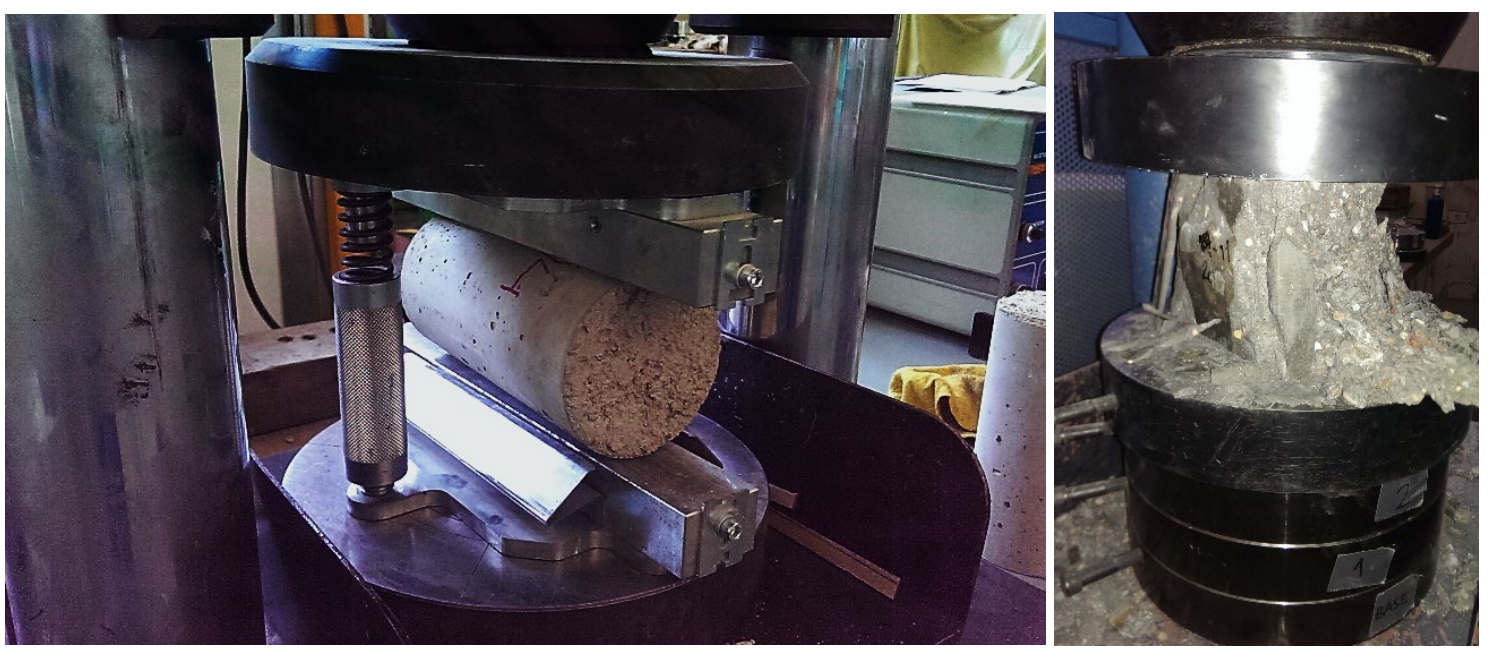

Figura 7-1 Fotografías del ensayo de tracción indirecta del hormigón sobre probeta cilindrica $10 \times 20 \mathrm{~cm}$ y de compresión sobre probeta cúbica $15 \times 15 \times 15 \mathrm{~cm}$

\subsubsection{Materiales}

\subsection{Hormigón}

La dosificación del hormigón utilizado para la fabricación de las probetas, con cemento CEMI 52,5R, relación agua cemento a/c $=0,5$ y áridos silíceos de $12 \mathrm{~mm}$ de tamaño máximo, se resume en la Tabla 7-1.

Tabla 7-1 Dosificación del hormigón utilizado para la fabricación de las vigas pretensadas

\begin{tabular}{cccccccc}
\hline Componentes & $\begin{array}{c}\text { Cemento } \\
\text { CEMI 52,5 R }\end{array}$ & Agua & a/c & $\begin{array}{c}\text { Grava silicea } \\
(\mathbf{8} / \mathbf{1 2})\end{array}$ & $\begin{array}{c}\text { Grava silicea } \\
\mathbf{( 4 / 8 )}\end{array}$ & $\begin{array}{c}\text { Arena silicea } \\
\mathbf{( 0 / 4 )}\end{array}$ & $\begin{array}{c}\text { Arena silicea } \\
\mathbf{( 0 / 1 )}\end{array}$ \\
\hline Peso SSS $\left[\mathrm{kg} / \mathrm{m}^{3}\right]$ & 400 & 180 & 0,45 & 400 & 180 & 890 & 200 \\
\hline
\end{tabular}

Debido a la capacidad limitada de la amasadora disponible en la Nave de Ensayos del IETcc, el hormigonado de las vigas se hizo en dos amasadas. En cada una de las amasadas se hormigonaron dos de las vigas pretensadas, así como 9 probetas cúbicas de $15 \mathrm{~cm}$ de lado y 3 probetas cilíndricas de 10x20 cm, para la caracterización del hormigón. Las probetas cilíndricas permitieron obtener la 
resistencia a tracción indirecta $f_{c t i}$, mientras que las probetas cúbicas permitieron determinar la resistencia media a compresión del hormigón $f_{c m}$ y el módulo de elasticidad $E_{c}$, en distintos periodos de tiempo tras el hormigonado (21 días, 60 y 90 días). La Tabla 7-2 resume los resultados de caracterización mecánica del hormigón.

Tabla 7-2 Resistencia media a compresión, resitencia a tracción directa e indirecta y Módulo de Young del hormigón utilizado en los ensayos

\begin{tabular}{ccccc}
\hline Etapa & $\mathbf{f}_{\mathrm{cm}}[\mathbf{M P a}]$ & $\mathbf{E}_{\mathrm{c}}[\mathbf{M p a}]$ & $\mathbf{f}_{\mathrm{ct}, \mathrm{i}}[\mathbf{M P a}]$ & $\mathbf{f}_{\mathrm{ct}}[\mathbf{M P a}]$ \\
\hline 21 días & 30 & 27000 & 2,82 & 2,54 \\
\hline $\mathbf{6 0}$ días & 32 & 28500 & --- & --- \\
\hline $\mathbf{9 0}$ días & 35 & 29700 & --- & --- \\
\hline
\end{tabular}

La resistencia a tracción directa $f_{c t, m}$ se ha obtenido mediante la resistencia a tracción indirecta $f_{c t i}$ hallada en los ensayos, siguiendo la siguiente expresión $f_{c t, m}=0,9 \cdot f_{c i}$ recogida EN 1992-1-1 (2004) y en la EHE-08 (Fomento, 2008).
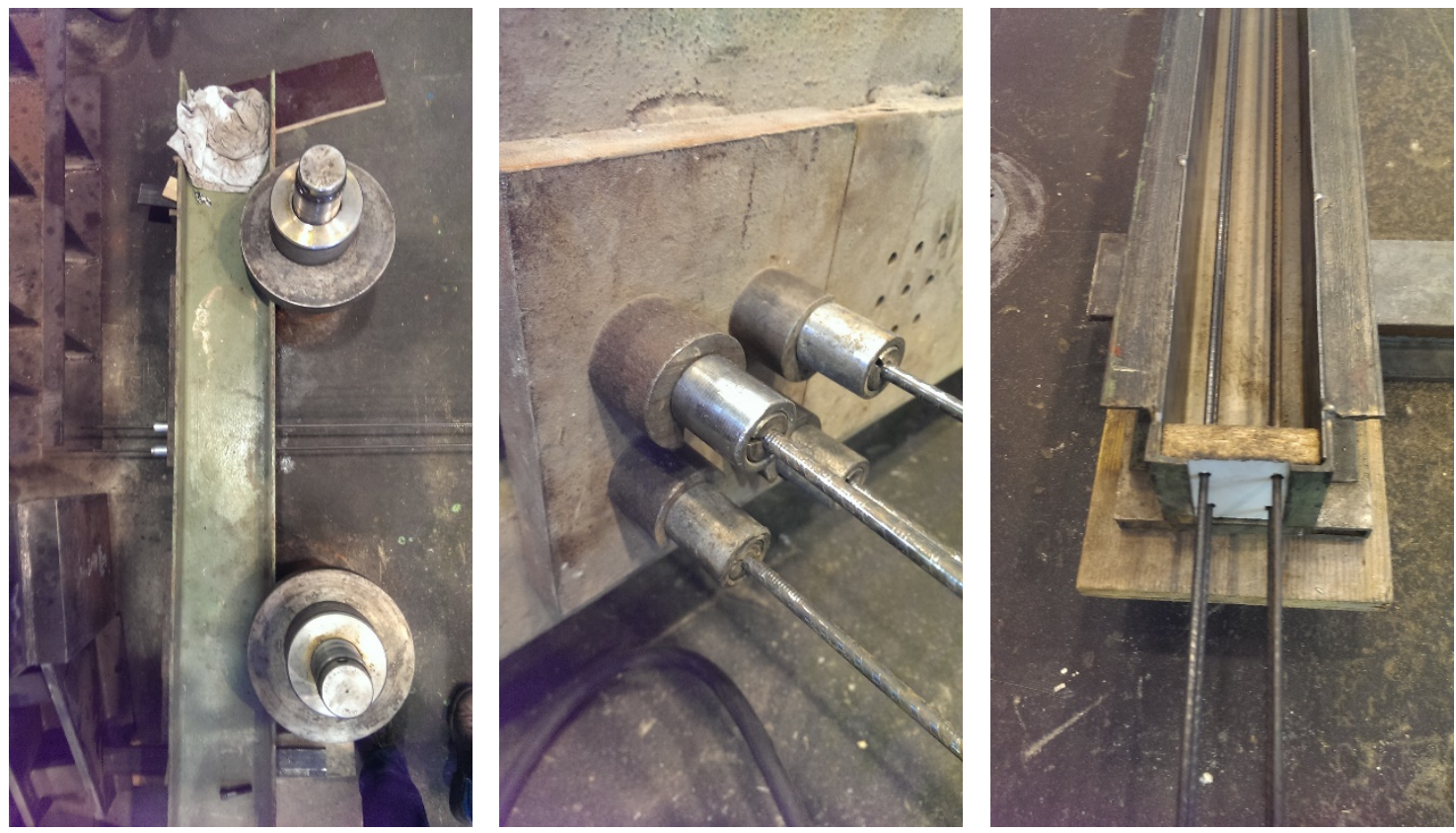

Figura 7-2 Configuración de ensayos sobre vigas pretensadas: a) Estribo pasivo de anclaje, b) Detalle de las cuñas de anclaje en el estribo pasivo, $y$ c) Enfilado de cables en el interior de las vigas mediante desviadores.

\subsubsection{2 $\underline{\text { Acero }}$}

Se han utilizado alambres indentado de acero Y1860C, de $5 \mathrm{~mm}$ de diámetro, con una carga última de rotura de $\mathrm{f}_{\mathrm{p}, \mathrm{u}}=1860 \mathrm{~N} / \mathrm{mm}^{2}$ y un Módulo de elasticidad $E_{p}$ de $200000 \mathrm{~N} / \mathrm{mm}^{2}$. En la Tabla 7-3 se resumen las características mecánicas de los alambres utilizados.

Tabla 7-3 Propiedades geométricas y mecánicas de los alambres de pretensado

\begin{tabular}{cccccccc}
\hline $\begin{array}{c}\text { Diámetro } \\
\text { nominal } \\
{[\mathrm{mm}]}\end{array}$ & $\begin{array}{c}\text { Carga unit. } \\
\text { máxima } f_{p, u} \\
{\left[\mathbf{N} / \mathrm{mm}^{2}\right]}\end{array}$ & $\begin{array}{c}\text { Masa } \\
{[\mathrm{g} / \mathrm{m}]}\end{array}$ & $\begin{array}{c}\text { Área } \\
\text { sección } \\
{\left[\mathrm{mm}^{2}\right]}\end{array}$ & $\begin{array}{c}\text { Módulo de } \\
\text { Young } \mathbf{E}_{\mathrm{p}} \\
{\left[\mathbf{N} / \mathbf{m m}^{2}\right]}\end{array}$ & $\begin{array}{c}\text { Carga mínima } \\
\text { de rotura } \\
{[\mathrm{kN}]}\end{array}$ & $\begin{array}{c}\text { Carga mínima } \\
\text { de rotura } \\
{[\mathrm{kN}]}\end{array}$ & $\begin{array}{c}\text { Fuerza en Límite } \\
\text { elático }\left(\boldsymbol{\varepsilon}_{\mathrm{p}}=\mathbf{0 , 1}\right) \\
{[\mathbf{M P a})}\end{array}$ \\
\hline 5 & 1860 & 153,1 & 19,6 & 200000 & 36,5 & 42,0 & 32,5 \\
\hline
\end{tabular}


La altura de las indentaciones $h_{r}$ oscila entre un mínimo de $60 \mu \mathrm{m}$ y un máximo de $130 \mu \mathrm{m}$, la longitud de las mismas en la dirección del eje es de 2,5 mm y la longitud del paso de hélice $s_{r}$ es igual a 6,0 mm.

\subsubsection{Proceso de fabricación}

\subsubsection{Tesado y hormigonado}

La bancada de pretensado, ubicada en la Nave de Ensayos Mecánicos del IETcc y de 12 metros de longitud, estaba limitada en cada extremo por estribos de anclaje construidos a tal efecto, actuando uno como anclaje activo y el ubicado en el extremo opuesto como anclaje pasivo. Una vez colocados en posición los moldes metálicos, se procedió al enfilado de los alambres, cuya correcta ubicación dentro de las vigas fue asegurada mediante desviadores de aglomerado de partículas situados en los extremos de los moldes. Tras asegurar la posición de los alambres en el estribo pasivo de la bancada con cuñas de anclaje, éstos se tesaron mediante gato hidráulico contra el estribo activo (Figura 7-2).

Los alambres se tesaron inicialmente hasta alcanzar su límite elástico, en este caso limitado a $0.85 f p, u$. Tras las pérdidas por penetración de cuñas, se recuperó carga mediante un sistema de tuercas, hasta lorar la fuerza P deseada de $26,5 \mathrm{kN}$ por alambre, equivalente a una tensión de $1350 \mathrm{~N} / \mathrm{mm}^{2}$. Esta tensión supone hacer trabajar al alambre de forma permanente a un 72,5\% de la carga unitaria máxima fp, $u$, menor al 75\% marcado por la la EHE-08 (Fomento, 2008). El control del tesado se efectuó mediante un flexímetro y una célula de carga ubicados en el estribo de anclaje activo, y mediante galgas adheridas en los alambres de pretensado (Ver Figura 7-3).
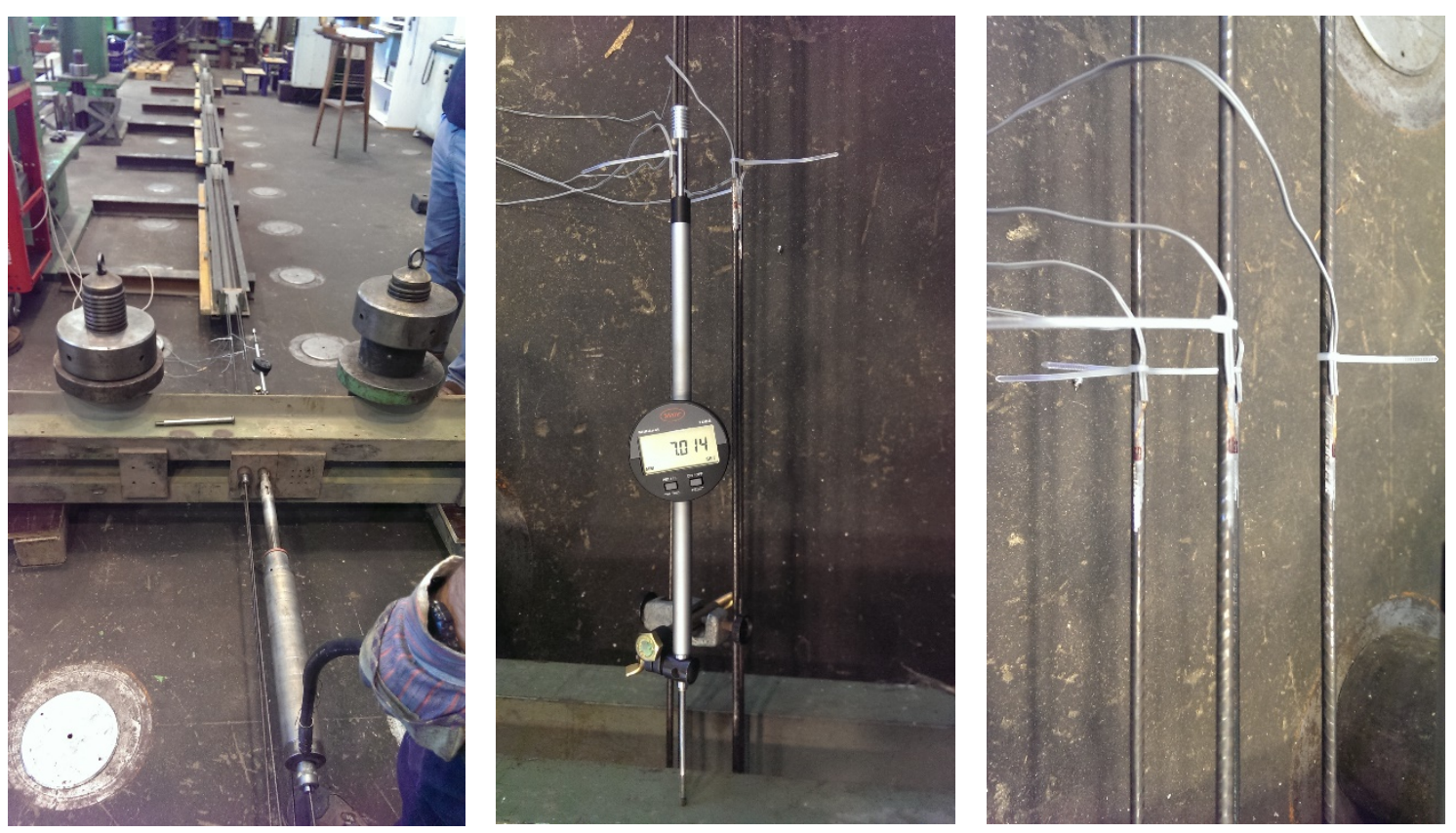

Figura 7-3 Configuración de ensayos sobre vigas pretensadas: a) Tesado de alambres mediante gato hidraúlico, b) Fleximetro en estribode anclaje activo y c) Galgas extensiométricas adheridas a los alambres de pretensado. 


\subsubsection{Hormigonado, curado y transferencia del pretensado}

Una vez comprobado el correcto trazado de los alambres respecto a la sección del prisma, se procedió al hormigonado de las probetas. El compactado del hormigón se llevó a cabo con vibrador de aguja de $25 \mathrm{~mm}$ de diámetro y la superficie superior de las probetas fue alisada manualmente mediante llana de hormigón. Paralelamente se confeccionaron las probetas de acompañamiento para la caracterización de las propiedades mecánicas del hormigón, que se compactaron de la misma manera.

Tras la fabricación, las probetas permanecieron 24 horas en los moldes, con un elevado porcentaje de humedad. Una vez desmoldadas, tanto vigas como probetas se mantuvieron durante 7 días en condiciones de alta humedad (cubiertas con arpillera húmeda).

Hasta el destesado de los alambres, a los 21 días tras el hormigonado, vigas y probetas permanecieron en el banco de pretensado en ambiente de laboratorio.

La transferencia del pretensado se llevó a cabo de forma súbita, ya que por problemas técnicos no se pudo hacerse de manera gradual. Tras el destesado, vigas y probetas fueron trasladas desde la bancada de pretensado a una estancia interior de la Nave de Ensayos, donde permanecieron almacenadas en condiciones de temperatura y de humedad ambiente, hasta la finalización de los ensayos. Las vigas se colocaron sobre apoyos deslizantes, que permitían la libre deformación axial del elemento y que minimizaban las posibles deformaciones derivadas de la flexión bajo peso propio.
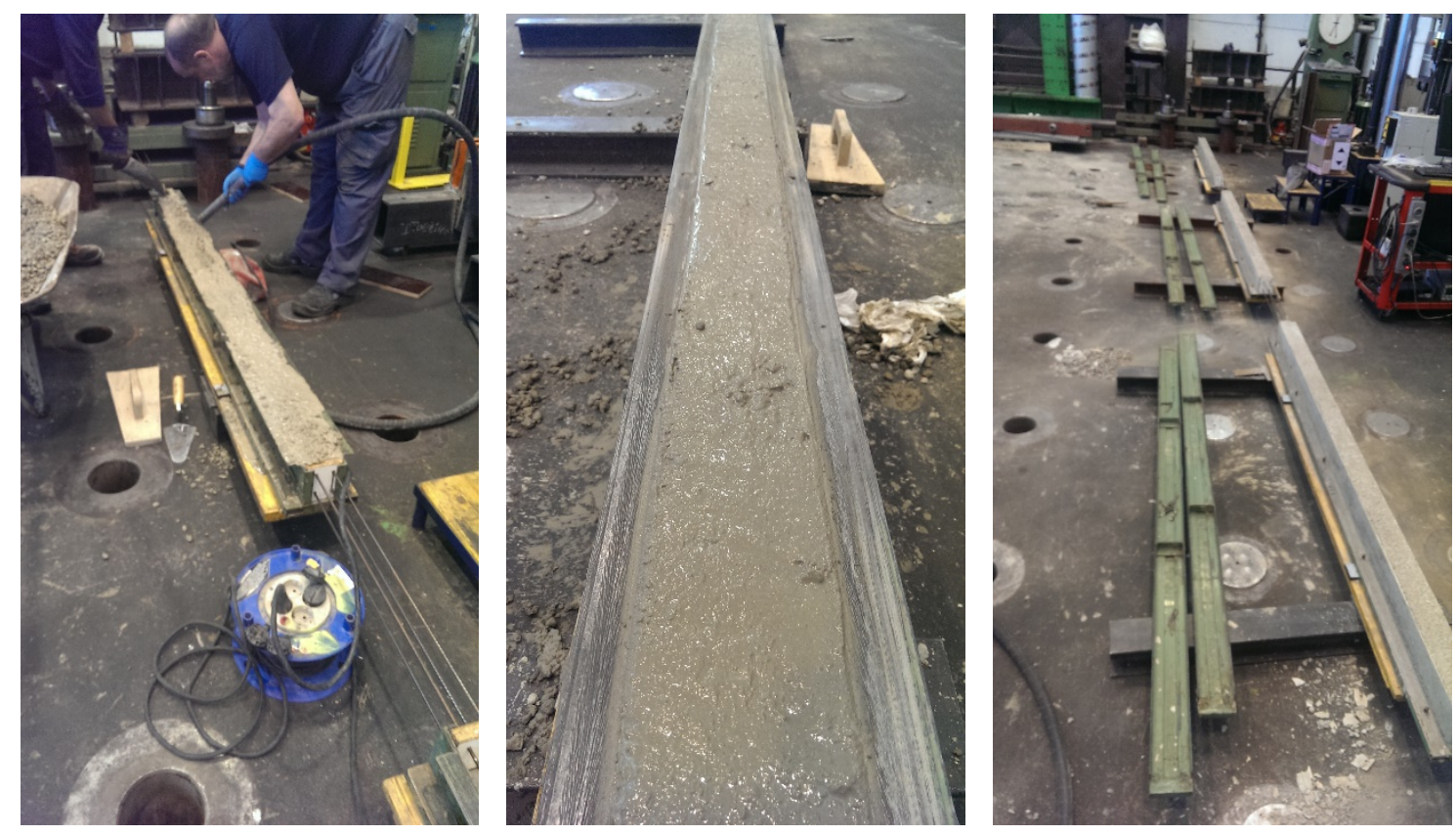

Figura 7-4 Configuración de ensayos sobre vigas pretensadas: a) Hormigonado y vibrado de las probetas, b) Superficie superior de las probetas tras llaneado y c) Probetas desmoldadas.

\subsubsection{Instrumentación de las vigas pretensadas}

Tras el desmoldado y antes de la transferencia del pretensado, las vigas fueron instrumentadas. La determinación de la longitud de transferencia del pretensado se llevó a cabo mediante dos métodos 
complementarios, basados en el empleo de instrumentación no invasora: por un lado, flexímetros para el cálculo de los deslizamientos de los alambres en los extremos de las vigas pretensadas $\delta_{d}$, y por otro, galgas extensiométricas y puntos de medida para extensiometría manual para la determinación de las deformaciones longitudinales $\boldsymbol{\varepsilon}_{c}$ en la superficie del hormigón:

- Deslizamientos: La variación de los deslizamientos de los alambres en los extremos de viga fue determinada mediante relojes comparadores analógicos (flexímetros), unidos a cada uno de los cuatro alambres, en ambos extremos, siguiendo las prescripciones de la norma del ensayo de adherencia de armaduras activas (Instituto Nacional de Racionalización y Normalización - IRANOR, 1982). La precisión de los flexímetros utilizados era de una centésima de milímetro (Ver Figura 7-5). El registro de las medidas no estaba automatizado, dado el carácter analógico de los comparadores, por lo que éstas se tomaron manualmente en los periodos de tiempo considerados.

- Deformaciones longitudinales: Se han utilizado dos sistemas distintos para el seguimiento de las deformaciones longitudinales a lo largo de la viga, galgas extensiométricas y puntos de medida para extensometría manual.
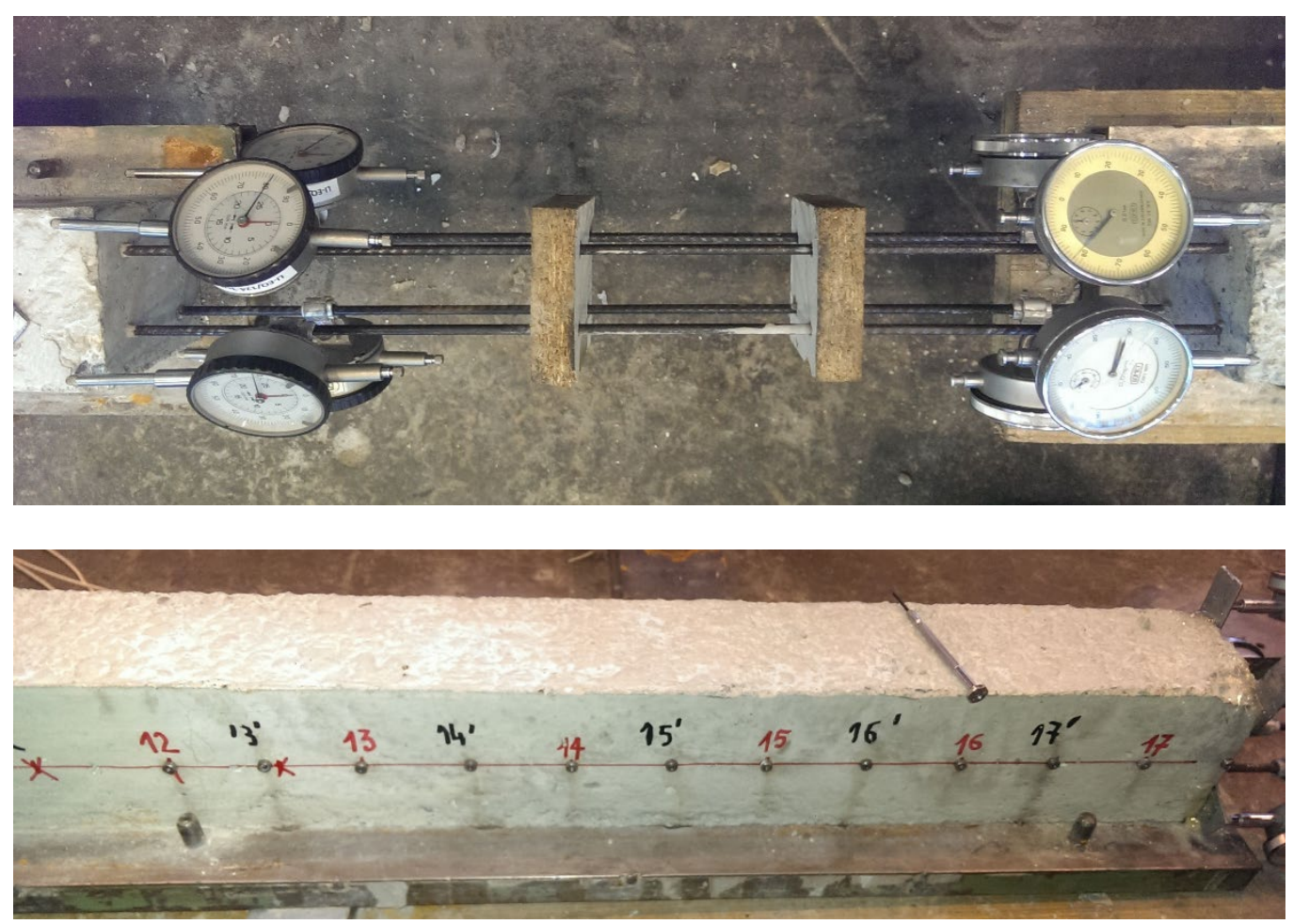

Figura 7-5 Instrumentación de las vigas pretensadas: a) Fleximetros (relojes comparadores analógicos) ubicados en cada uno de los alambre de las vigas, en ambos extremos, para control de los deslizamientos; y b) Ubicación de las bases de medida para extensometría manual en Viga 3

- Galgas extensiométricas: Uno de los métodos utilizados para la determinación del perfil de deformaciones longitudinales fue el de galgas extensiométricas adheridas a la superficie de hormigón de uno de los laterales de las vigas elaboradas (denominado Cara G). Las galgas utilizadas eran de la marca TML PL-90, de $90 \mathrm{~mm}$ de longitud. El adhesivo utilizado para su fijación fue cianocrilato. La fuente de alimentación de las galgas suministraba un voltaje 
medio de 5 voltios. La forma de conexión de las galgas extensométricas fue en cuarto de puente de Wheatstone, mediante tres hilos, con el fin de compensar las pérdidas producidas por los cables de conexión. La longitud máxima de los cables no superó los 6 metros.

Las medidas arrojadas por las galgas dejan de ser válidas cuando se separan de la superficie que están midiendo, lo que puede suceder cuando el hormigón del recubrimiento se fisura. Como contrapartida, las medidas exigen menos esfuerzo, ya que el sistema está automatizado, y son más precisas.

- Puntos para extensometría manual: El otro método utilizado se basó en la colocación de bases de medida (discos de acero inoxidable), en el otro lateral de las vigas (denominado Cara E). Las deformaciones fueron determinadas mediante un deformímetro digital, que constaba de un cuerpo metálico extensible y un comparador situado en la parte central, que captaba las variaciones de longitud.

El sistema manual no se ve afectado por la fisuración derivada de la corrosión o del efecto Hoyer, pero exige una importante dedicación a la hora de tomar medidas. La deformaciones pequeñas, aunque el comparador cuenta teóricamente con una precisión de $0.01 \mathrm{~mm}$, están muy influidas por errores debidos al operador.

A pesar de que estrictamente sólo sería necesario la determinación de las deformaciones longitudinales en uno de los paramentos verticales de la viga, se ubicaron en ambo laterales, con el fin de compensar posibles excentricidades de los esfuerzos de pretensado, más que probables una vez iniciado el proceso de corrosión, y minimizar así posibles errores. Para ello, sobre los ejes de cada una de las caras verticales de la viga, se ubicaron las galgas extensiométricas y las bases de medida, a intervalos regulares de longitud. Siguiendo la recomendación de la Norma UNE 7-436-82 (Instituto Nacional de Racionalización y Normalización - IRANOR, 1982), en los extremos de las vigas, los puntos de medida se dispusieron de forma que se pudieran obtener como mínimo 5 lecturas sobre la previsible longitud de transferencia $l_{t}$ del pretensado. En el centro de la viga, donde la fuerza de pretensado estaría plenamente transferida, se aumentó la longitud de los intervalos, quedando la distribución de los mismos como se aprecia en la Figura 7-6:

A) $200 \mathrm{~cm}$

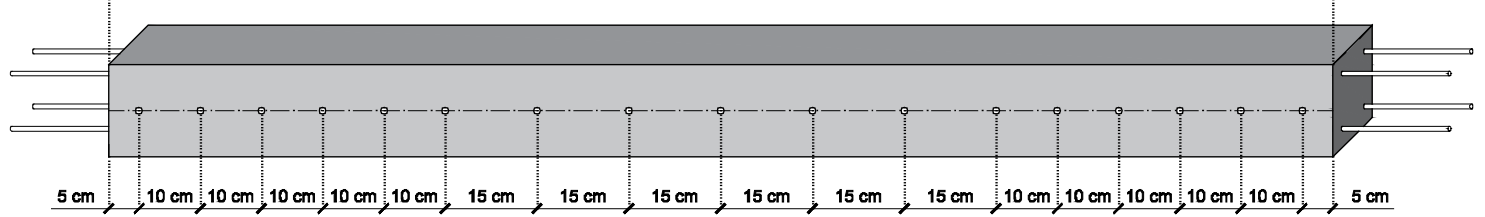

B) $200 \mathrm{~cm}$

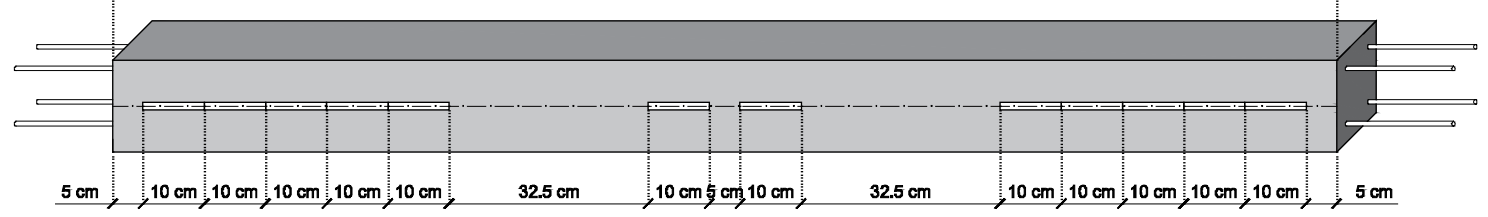

Figura 7-6 Vigas A: A) Ubicación de los puntos de medida para extensiometría manual (Cara E) y B) Distribución de las galgas extensiométricas (Cara G) 
Cabe destacar que la separación de las bases de medida en los extremos de la cara E, en la Viga 3, se redujo a $5 \mathrm{~cm}$, la mitad que en el resto de vigas, para comprobar si este cambio aumentaba la precisión de las medidas obtenidas mediante extensometría manual.

\subsubsection{Registro de medidas}

Para todas las vigas se han tomado medidas de las deformaciones de compresión en el hormigón $\boldsymbol{\varepsilon}_{c} \mathrm{y}$ de deslizamiento de los alambres en el extremo $\boldsymbol{\delta}_{d}$ durante un tiempo $t$ igual a 90 días, de manera continuada mediante las galgas extensiométricas y a intervalos regulares de tiempo mediante los puntos de extensiométría manual y los flexímetros. El registro continuo de datos procedente de las galgas extensiométricas se llevó a cabo mediante DataLogger.

La toma de datos antes y tras dos horas desde la transferencia del pretensado permitió la determinación de las deformaciones y deslizamientos instantáneos. Los datos posteriores, tomados de forma periódica, permitieron caracterizar la influencia de los fenómenos reológicos de retracción y fluencia.

\subsubsection{Proceso de corrosión}

Trascurrido un año desde la transferencia del pretensado, los alambres embebidos en las vigas fueron sometidos a un proceso de corrosión acelerada. Como se ha señalado en el apartado 7.2.1.2.1, el hormigón utilizado para la elaboración de las vigas no contaba con cloruros incorporados por lo que, para facilitar el proceso de corrosión acelerada, se optó por forzar la penetración de cloruros desde la superficie del hormigón (Andrade, 2013), basándose en el denominado "método integral" de la Norma UNE 83992-2:2012 EX “Durabilidad del hormigón. Métodos de ensayo. Ensayos de penetración de cloruros en el hormigón. Parte 2: Método integral acelerado.” (CTN 83 HORMIGÓN, 2012).

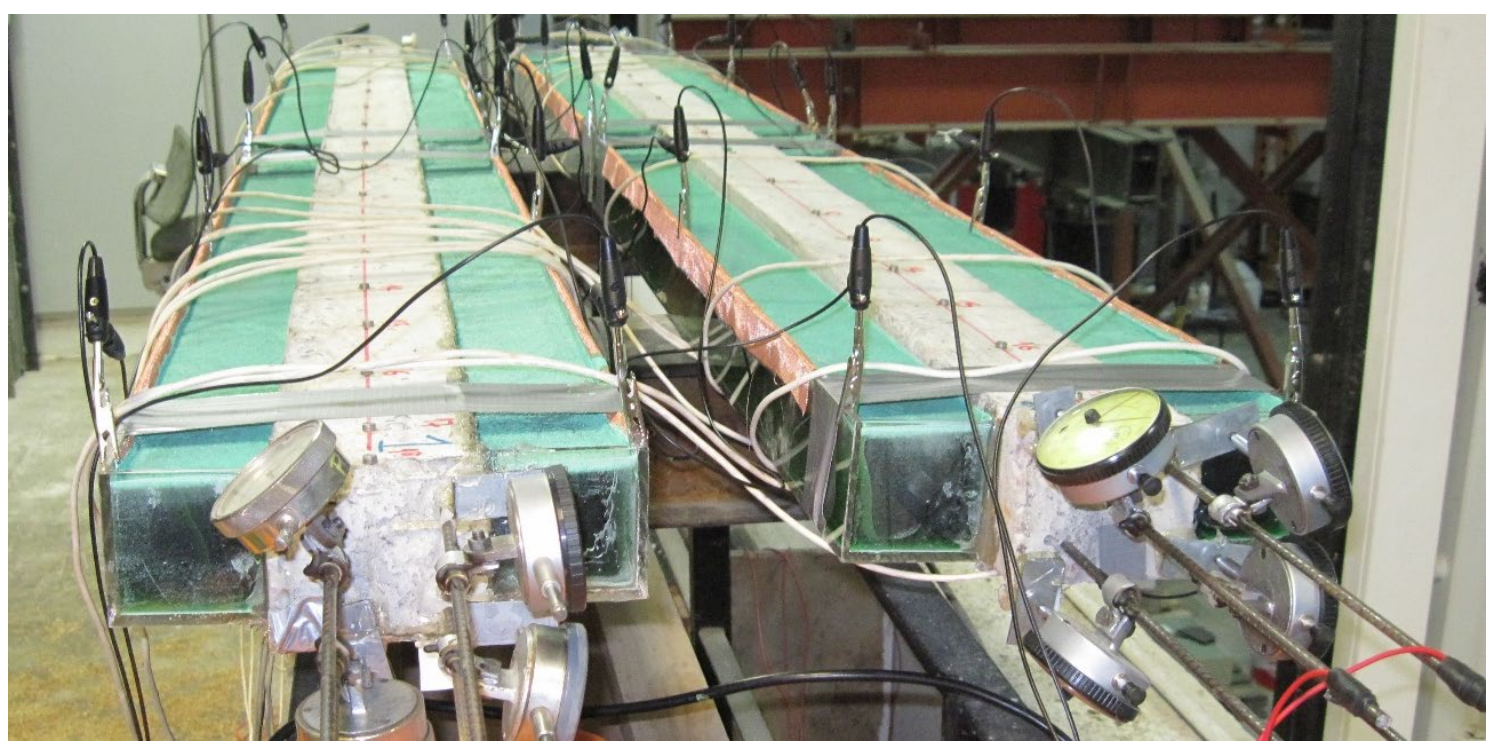

Figura 7-7 Bañeras de metacrilato con disolución de cloruro sódico y cúprico a ambos lados de las vigas 


\subsubsection{Método integral acelerado}

En términos generales, este ensayo consiste en exponer a la viga de hormigón, en la que se han embebido transversalmente los alambres pretensados de acero, a un campo eléctrico aplicado mediante electrodos en sus lados opuestos, de manera que se fuerce la penetración de los cloruros presentes en una disolución en contacto con el hormigón, hasta alcanzar la posición de los alambres, posibilitando la despasivación de los mismos.

Para asegurar un buen contacto entre la disolución con cloruros y la superficie de hormigón, y que la llegada de los cloruros a los alambres fuera homogénea, fue necesaria la fabricación de piscinas de metacrilato que se adhirieron a ambos lados de cada una de las vigas (Figura 7-8).

Dada la disponibilidad de materiales, la migración de los cloruros se llevó a cabo en dos tandas diferenciadas, de dos vigas cada una. El método general incluido en la Norma UNE 83992-2:2012 EX (CTN 83 - HORMIGÓN, 2012) se modificó ligeramente para adaptarlo a las peculiaridades de las vigas, de manera que la configuración final de cada uno de los ensayos fue la siguiente:

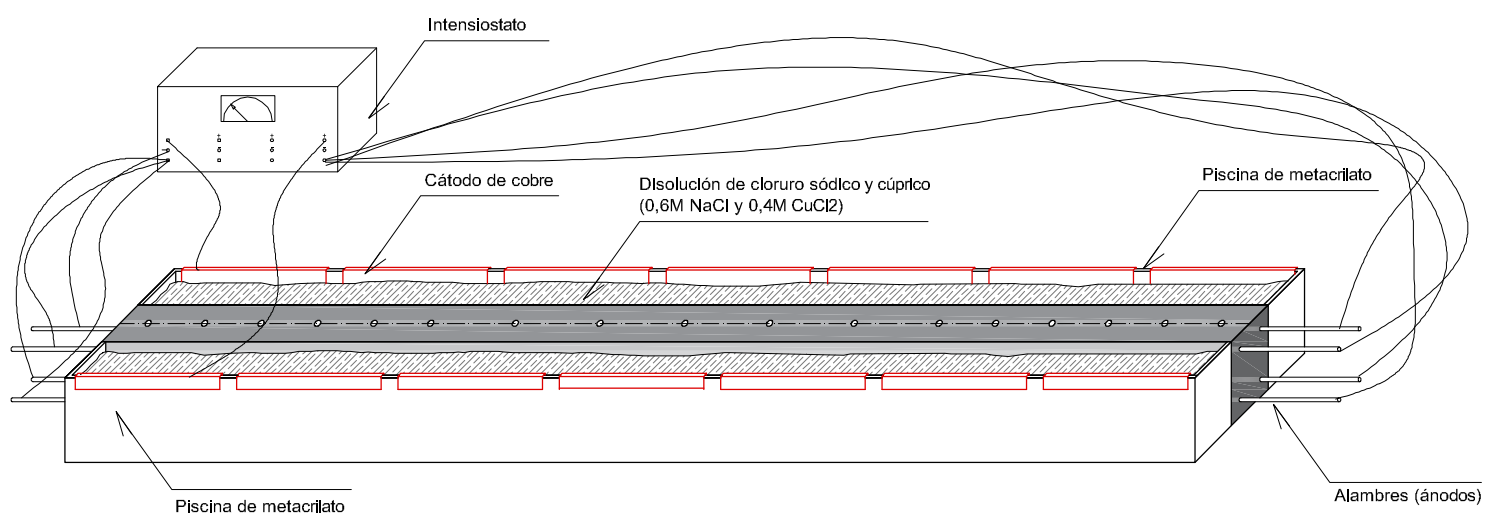

Figura 7-8 Configuración del método integral acelerado aplicado a las vigas pretensadas.

- $1^{a}$ Tanda: Se utilizó un cátodo de cobre, elaborado con malla de dicho material, en contacto con una disolución de cloruro sódico y cúprico $(0,6 \mathrm{M} \mathrm{NaCl}$ y $0,4 \mathrm{M} \mathrm{CuCl} 2)$. Los alambres funcionaron como ánodos. La intensidad de corriente $i_{c o r r}$ aplicada fue de $100 \mu \mathrm{A} / \mathrm{cm}^{2}$.

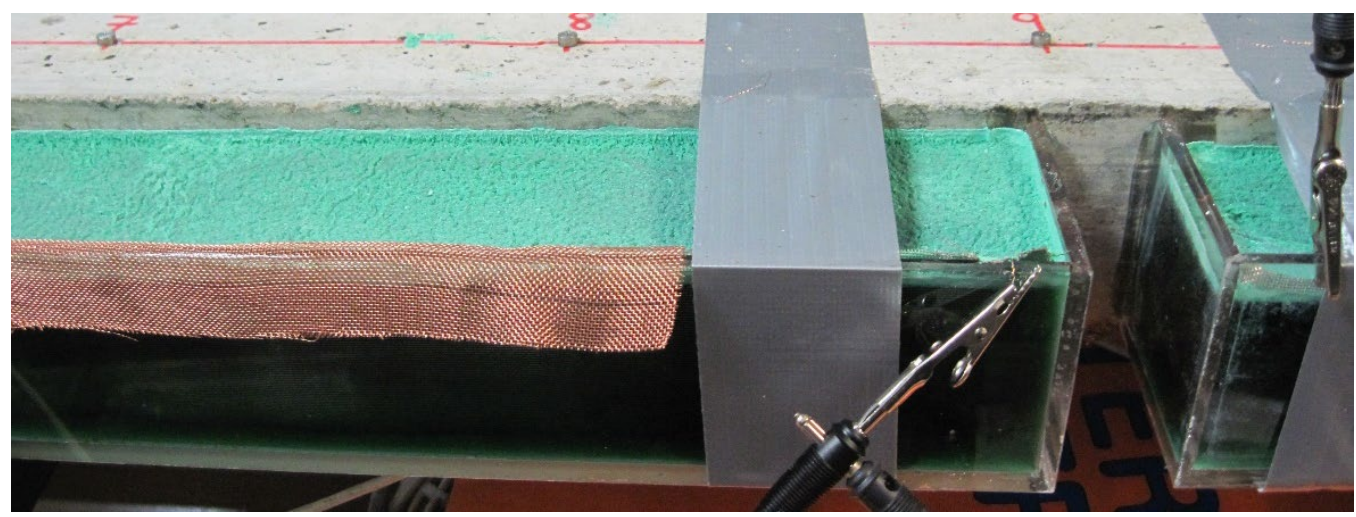

Figura 7-9 Cardenillo en suspensión sobre la disolución de cloruro sódico y cúprico. 
Teóricamente, con esta configuración, el cloruro cúprico permite que se reduzcan iones cúpricos sobre el electrodo de cobre, evitándose la hidrólisis del agua, y por tanto, la acidificación de la disolución. Sin embargo, durante el ensayo se comenzó a generar cardenillo, un acetato de cobre de gran toxicidad, lo que dificultó las operaciones alrededor de las vigas. En la Figura 7-9 se observa con claridad el cardenillo en suspensión, de color verdoso, sobre la disolución de las piscinas. Dada esta situación, se decidió cambiar la configuración del ensayo para la siguiente tanda.

- $2^{a}$ Tanda: Se utilizó un cátodo de acero inoxidable, elaborado con malla de dicho material, en contacto con una solución de cloruro de sodio $0,5 \mathrm{M}(30 \mathrm{~g} / \mathrm{l})$, equivalente a concentración de cloruros presente en el agua de mar. Como en la tanda anterior, los alambres funcionaron como ánodos. La intensidad de corriente $i_{\text {corr }}$ aplicada fue de $100 \mu \mathrm{A} / \mathrm{cm}^{2}$.

En ambas tandas, una vez que se alcanzó la despasivación del acero de los alambres, lo que según el Metodo Integral Acelerado ocurre cuando se detecta un potencial de $-300 \mathrm{mV}$ o más negativo, se pasó a la fase de corrosión acelerada. Para ello fue necesario retirar previamente las piscinas adheridas a los laterales de las vigas.

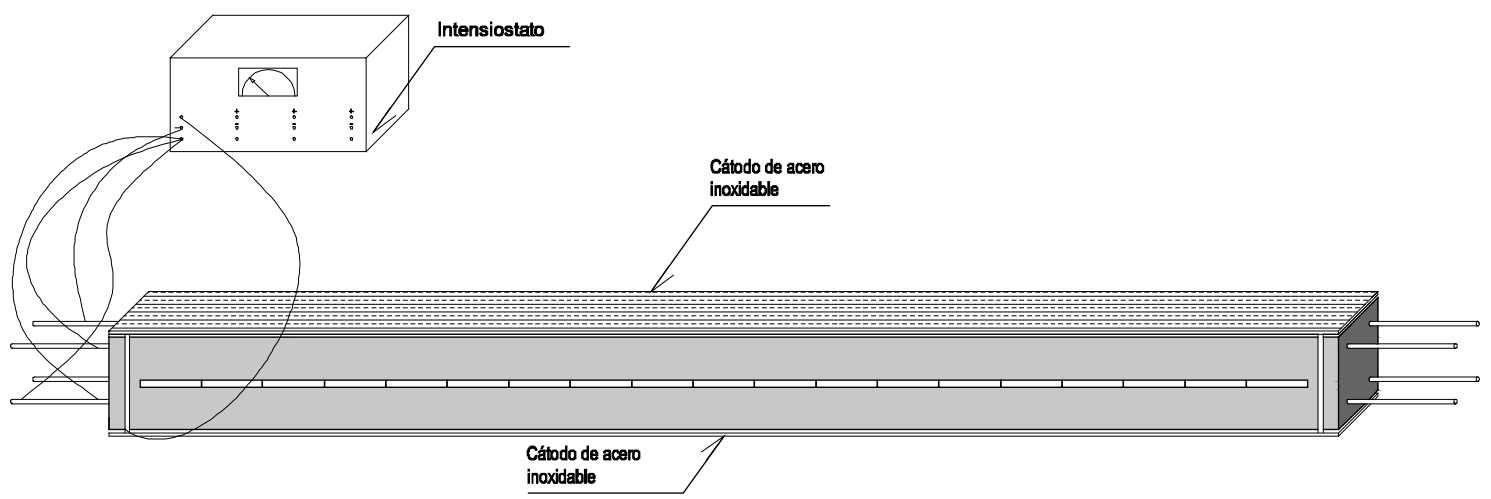

Figura 7-10 Esquema de funcionamiento del procedimiento de corrosión acelerada

\subsubsection{Proceso de corrosión acelerada}

Para el procedimiento de corrosión acelerada se empleó un método galvanostático descrito, entre otros, en Rodriguez et al. (1994). Este método (Figura 7-10) consiste en aplicar una corriente constante, generada mediante un intensiostato, a través de un circuito en el que los alambres de acero, que actúan como ánodos, se oxidan. Los iones metálicos liberados en el proceso circulan a través del hormigón hacia una malla de acero inoxidable situada en la superficie superior e inferior del hormigón y que actúa como cátodo o contraelectrodo. Para asegurar que exista continuidad electrolítica en el hormigón se coloca una esponja permanentemente humedecida entre la superficie del mismo y la malla de acero inoxidable. Se ha aplicado una densidad de corriente de $100 \mu \mathrm{A} / \mathrm{cm}^{2}$.

El proceso de corrosión acelerada se controlaba de forma periódica midiendo las intensidades circulantes por el circuito. En la Figura 7-11 puede observarse una fotografía de la vista general de las vigas pretensadas durante el proceso de corrosión acelerada, en el interior de la Nave de Ensayos del IETcc. 


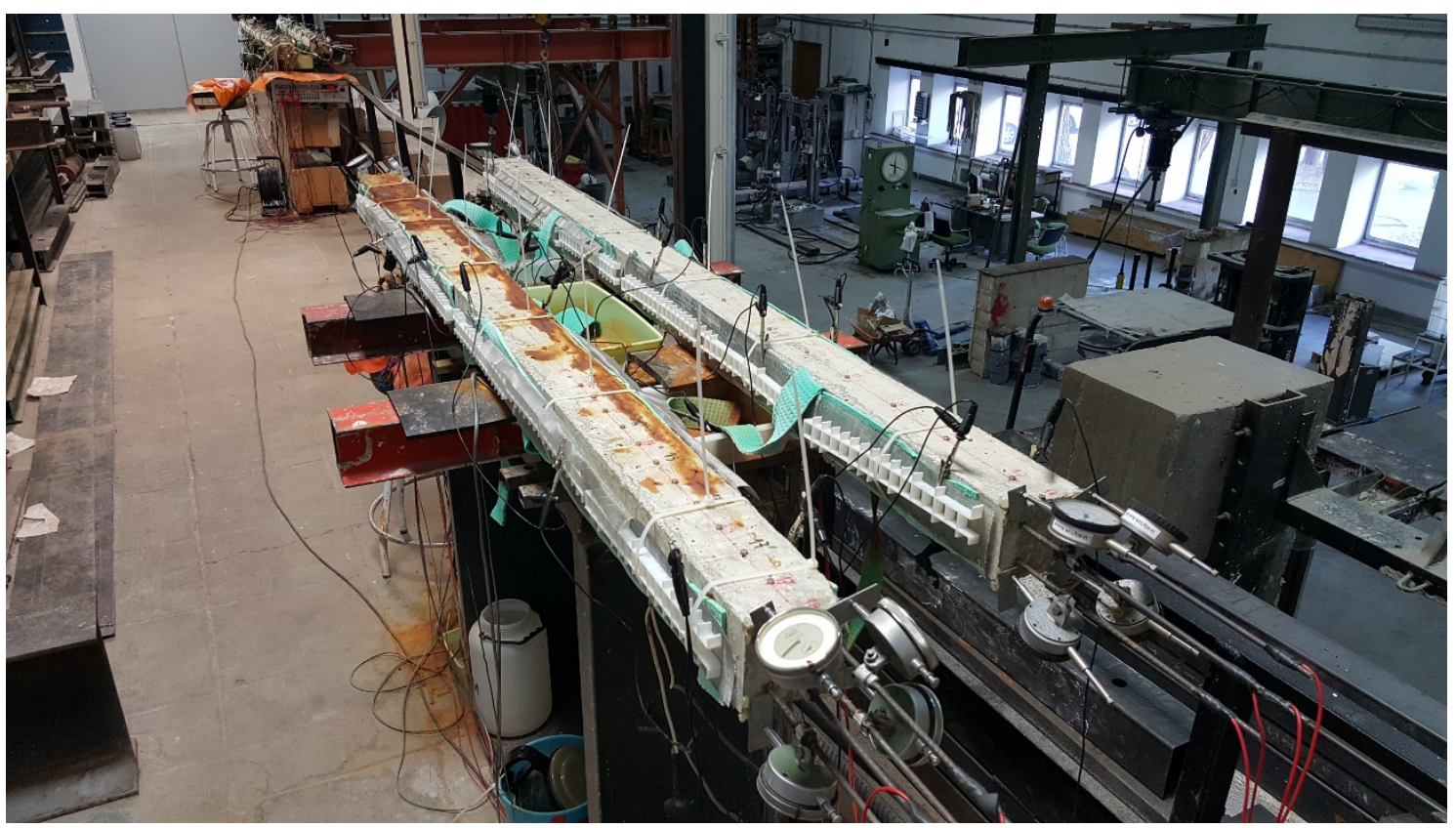

Figura 7-11 Fotografía de las vigas pretensadas durante el proceso de corrosión acelerada

\subsubsection{Instrumentación y toma de datos en vigas pretensadas con corrosión}

La instrumentación no invasora utilizada en las vigas pretensadas con corrosión fue la misma que en las vigas con alambres sanos, es decir: por un lado, flexímetros para el cálculo de los deslizamientos de los alambres en los extremos de las vigas pretensadas $\delta_{d}$, y por otro, galgas extensiométricas y puntos de medida para extensiometría manual para el control de la evolución de las deformaciones longitudinales $\boldsymbol{\varepsilon}_{c}$ en la superficie del hormigón.

Como se ha descrito en los apartados anteriores, la deformación de las vigas se monitorizó únicamente durante los tres primeros meses y no hasta el comienzo de los ensayos de corrosión. Por ello, las deformaciones que se obtienen una vez iniciado el proceso de corrosión son con respecto a la viga ya deformada por la transferencia del pretensado y por los efectos reológicos (retracción y fluencia), y no con respecto a la situación previa al destesado.

Para todas las vigas, se han tomado medidas de las deformaciones de compresión en el hormigón durante 84 días, de manera continuada mediante las galgas extensiométricas y a intervalos regulares de tiempo mediante los puntos de extensiometría manual. Por problemas técnicos en el DataLogger utilizado para el registro de datos, sólo se conservan datos de los 63 primeros días en las Vigas 1 y 2, y de los primeros 45 días en las Vigas 3 y 4 . Con la densidad de corriente de corrosión $\mathrm{i}_{\text {corr }}$ utilizada $\left(100 \mu \mathrm{A} / \mathrm{cm}^{2}\right)$, esto equivale a que se tienen registro de aproximadamente hasta un $15 \%$ de pérdida teórica de sección en las vigas 1 y 2 y de hasta un 10\% de pérdida teórica de sección en las Vigas 3 y 4.

En la Tabla 7-4 se incluyen, a modo de resumen y de forma aproximada, las distintas etapas de las que ha constado la campaña experimental relativa a las vigas pretensadas, junto con el tiempo trascurrido desde el hormigonado y el registro de datos llevado a cabo. 
Tabla 7-4 Campaña experimental sobre vigas pretensadas: Procesos, tiempos trasncurridos desde el hormigonado y registro de datos

\begin{tabular}{lccc}
\hline Procesos & Dias & Registro de datos \\
\hline Hormigonado & 0 & \\
\hline Desencofrado & 1 & Previa al destesado \\
\hline Instrumentación & & $1-21$ & $\begin{array}{c}\text { 2 horas tras el destesado } \\
\text { 24 horas tras el destesado }\end{array}$ \\
\hline Destesado & 21 & Cada 7 días \\
\hline \multirow{2}{*}{ Efectos reologicos } & & $21-111$ & --- \\
\hline Migración de cloruros & & $111-365$ & --- \\
\hline \multirow{2}{*}{ Corrosión } & Corrosion $\mathbf{0} \%$ & $365-380$ & $\begin{array}{c}\text { Antes de iniciar corr } \\
\text { Cada } 0,5 \% \text { (2días) }\end{array}$ \\
\cline { 2 - 4 } & Corrosion $\mathbf{2} \%$ & 380 & Cada $1 \%$ (4 días) \\
\cline { 2 - 4 } & Corrosion $\mathbf{5} \%$ & 388 & Cada 2\% (7 días) \\
\cline { 2 - 4 } & Corrosion $\mathbf{2 0} \%$ & 400 & Al acabar el proceso. \\
\hline
\end{tabular}

\subsubsection{Fisuración}

Durante el proceso de corrosión acelerada, se ha llevado a cabo un control de la fisuración de las vigas, únicamente desde un punto de vista cualitativo. Aunque en términos generales la fisuración detectada puede calificarse como heterogénea, con distintos grados de incidencia en diferentes zonas
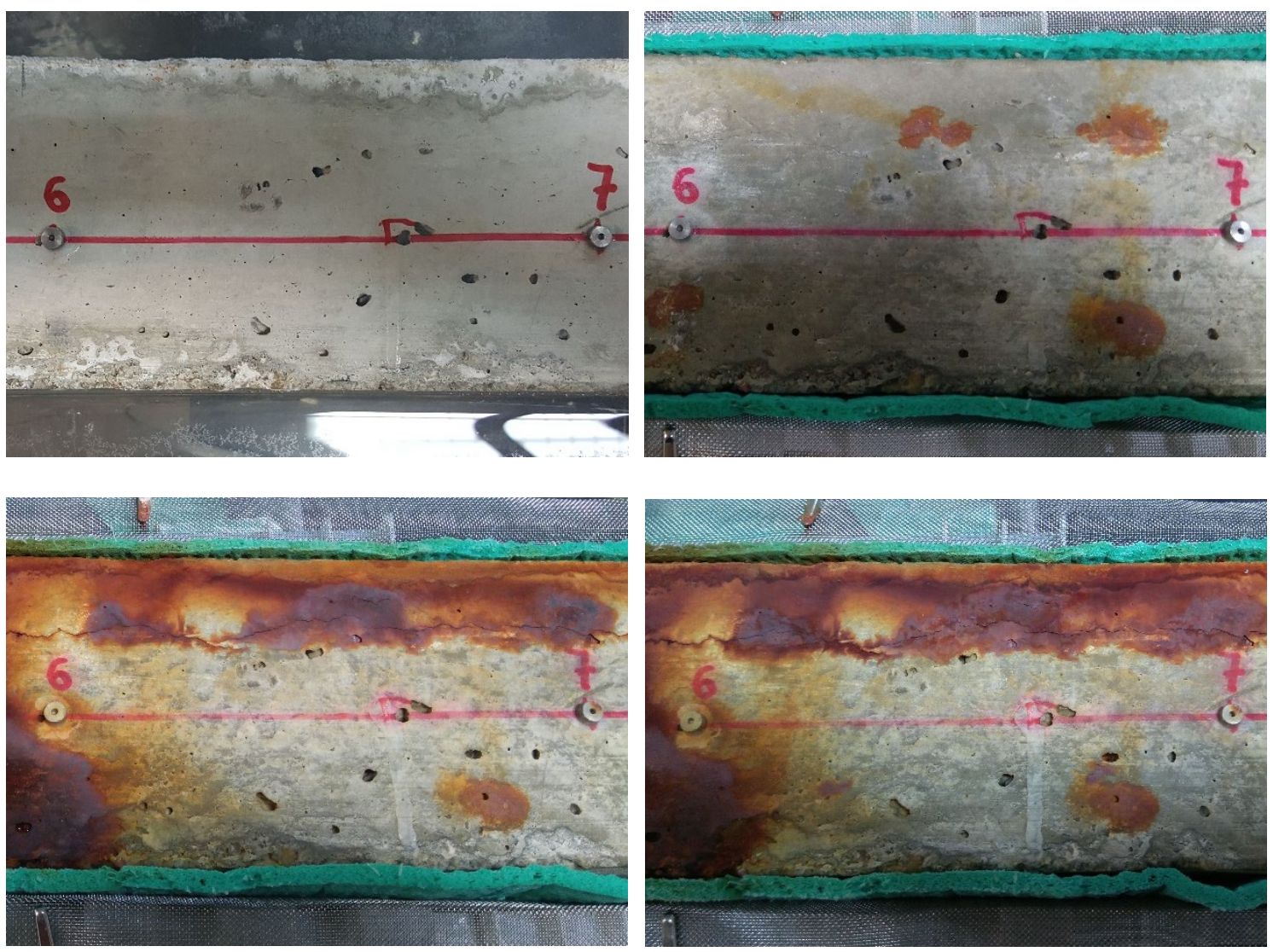

Figura 7-12 Evolución de la fisuración en la Viga 3 para distintas etapas del proceso de corrosión: antes del ensayo; y tras un 5\%, un 10\% y un $20 \%$ de pérdida de sección teórica por corrosión. 
de las vigas, sin un patrón claro, sí que han podido apreciarse algunas tendencias comunes. Se ha observado que a partir de pérdidas teóricas de sección de un $2 \%$ comenzaban a aparecer las primeras fisuras, siendo habituales a partir de una pérdida del $5 \%$ y con una presencia generalizada a partir de pérdidas teóricas del 10\%. Como era esperable, en todos los casos las fisuras han sido paralelas al trazado de los alambres, sin embargo, no se ha observado una mayor incidencia en los extremos de la viga, donde presumiblemente el recubrimiento se encontraba más solicitado, por lo acción conjunta del efecto Hoyer y de la corrosión.

En la Figura 7-12, a modo de ejemplo, se incluyen fotografías de la misma zona de la Viga 3 para distintas etapas del proceso de corrosión: antes del ensayo; y tras un 5\%, un $10 \%$ y un $20 \%$ de pérdida de sección teórica por corrosión. En ellas puede apreciarse el incremento paulatino de la fisuración, acompañada por la aparición de manchas causadas por los óxidos.

\subsection{Resultados experimentales}

\subsubsection{Introducción}

Habitualmente se consideran tres métodos para medir la longitud de transferencia: tensiones en el alambre, deformaciones del hormigón y deslizamientos relativos del alambre. El primer método obtiene las deformaciones de los alambres pretensados mediante galgas extensiométricas adheridas a la superficie de los mismos. Teóricamente, este método proporcionaría los datos más precisos y directos de las deformaciones en los alambres, y por tanto, su estado tensional. Sin embargo, las galgas extensiométricas se dañan fácilmente durante la colocación de los alambres y el posterior hormigonado, por lo que no es habitual su utilización. El segundo método mide las deformaciones en la superficie del recubrimiento de hormigón, ya sea mediante sistemas manuales (puntos de medida para extensometría manual) o automatizados (galgas extensiométricas), de manera que la longitud de transferencia es determinada por el perfil de deformaciones del hormigón. El tercer método mide el deslizamiento de los alambres en el extremo, en el momento del destesado, de forma que la longitud de transferencia se determina de manera indirecta mediante la ecuación propuesta por Guyon (Guyon, 1953). En esta tesis se han utilizado los dos últimos métodos, aplicados tanto en alambres sanos como en alambres con procesos de corrosión, que pasan a detallarse a continuación.

\subsubsection{Determinación de la longitud de transferencia mediante el perfil de deformaciones}

Las longitudes de transferencia de cada viga han sido determinadas mediante los perfiles de deformación obtenidos en los ensayos, tanto sobre vigas con alambres sanos como sobre las vigas con procesos de deterioro por corrosión. En estos perfiles se representan las deformaciones obtenidas sobre la superficie del hormigón (mediante galgas eléctricas y puntos para medición por extensometría mecánica) frente a la longitud de la viga ensayada. 
El método utilizado es el denominado "Método del 95\% de la deformación máxima media"("95\% Average Maximun Strain Method (AMS)"), inspirado parcialmente en la Norma UNE 7-436-82 "Método de ensayo para la determinación de las características de adherencia de las armaduras de pretensado" (Instituto Nacional de Racionalización y Normalización - IRANOR, 1982). Este método, cuya precisión para vigas de sección rectangular ha sido demostrada por numerosos investigadores [ (Russell \& Burns, 1993), (Martinez-Abella \& Vazquez-Herrero, 2002), (Zhao, et al., 2013)] consta de las siguientes etapas (Martí, et al., 2002):

1. Las deformaciones obtenidas se representan en un gráfico deformación-distancia al extremo del elemento. En el caso de que se haya producido una transmisión del pretensado completa, la curva resultante presenta tres partes: un primer tramo ascendente (deformaciones de compresión positivas), con deformaciones crecientes al aumentar la distancia al extremo del elemento, un segundo tramo sensiblemente horizontal (meseta) definido por las máximas deformaciones alcanzadas, y un tercer tramo descendente, correspondiente a la zona de transferencia o transmisión del pretensado en el extremo opuesto del elemento.

2. Se calcula la media de las máximas deformaciones alcanzadas (AMS), esto es, la media de las deformaciones en el tramo de meseta, cuya extensión debe determinarse mediante estimación por inspección visual.

3. Se representa en el gráfico una recta horizontal de valor $\alpha$ AMS, asignando a $\alpha$ un valor comprendido entre 0.85 y 1 (la mayoría de autores adopta $\alpha=0.95$ ).

4. Se obtienen los puntos de intersección de la recta anterior con los tramos ascendente y descendente de la curva. En esta tesis se ha llevado a cabo un ajuste mediante regresión lineal de los puntos situados en la zona de transferencia. Algunos autores han propuesto un ajuste exponencial para determinar la forma de estos tramos (Martinez-Abella \& Vazquez-Herrero, 2002).

5. La longitud de transmisión se determina, en cada extremo del elemento, como la distancia existente desde el extremo del elemento hasta el punto intersectado.

Este procedimiento arroja valores razonables para la longitud de transferencia y evita la interpretación arbitraria de los resultados experimentales.

\subsubsection{Determinación de la longitud de transferencia mediante el deslizamiento de los alambres en el extremo}

Por otra parte, tal y como se ha comentado anteriormente, también se han controlado las variaciones del deslizamiento de los extremos de los alambres, mediante flexímetros unidos a cada una de las barras, en ambos extremos, siguiendo las prescripciones de la norma del ensayo de adherencia de armaduras activas (Instituto Nacional de Racionalización y Normalización - IRANOR, 1982). La variación entre la medida inicial, previa al destesado, y las siguientes, determina el acortamiento elástico de los alambres que tiene lugar a lo largo de la longitud de transferencia. 
En el ensayo, para la determinación del valor del deslizamiento $\delta_{d}$ en el extremo de la viga, las medidas obtenidas mediante los flexímetros $l_{m}$ deben corregirse para tener en cuenta el acortamiento elástico $\Delta l_{a}$ del alambre en la longitud $l_{a}$ comprendida entre el punto de fijación del comparador (o flexímetro) y el extremo de la viga, en el momento de la transferencia del pretensado (Figura 7-14). Por tanto, el deslizamiento $\delta_{d}$ que debe utilizarse para la determinación de la longitud de transferencia $l_{t}$ responde a la siguiente expresión (Eq. 7-6):

$$
\delta=l_{m}-\Delta l_{a}
$$

En la serie de ensayos llevados a cabo, la longitud $l_{a}$ entre la pinza de fijación del flexímetro y el extremo de la viga fue de $100 \mathrm{~mm}$.

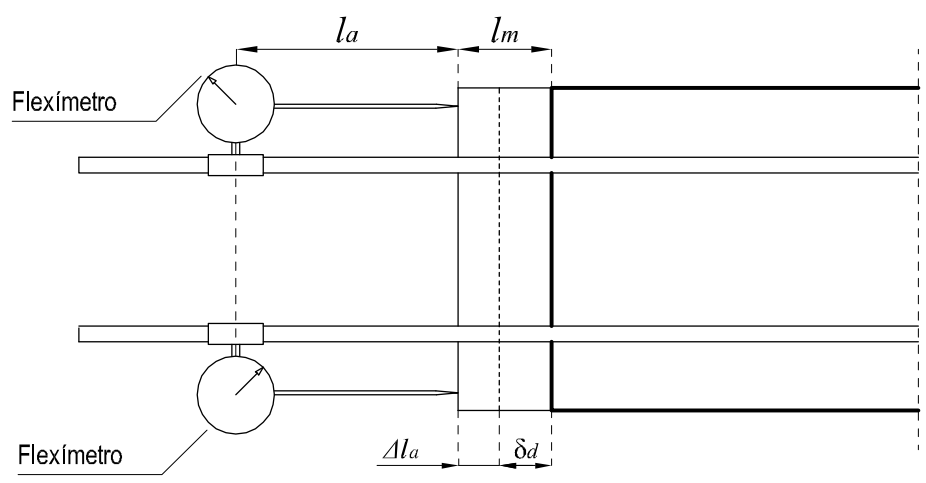

Figura 7-13 Corrección de los deslizamientos medidos por los fleximetros

\subsubsection{Vigas pretensadas con alambres sanos}

Para todas las vigas, se han tomado medidas de las deformaciones de compresión en el hormigón durante 90 días, de manera continuada mediante las galgas extensiométricas y a intervalos regulares de tiempo mediante los puntos de extensiométría manual. En las figuras siguientes se presentan los diagramas de deformación longitudinal, obtenidos mediante los dos sistemas de medida especificados y elaborados según el procedimiento descrito anteriormente ("Método del 95\% de la deformación máxima media"), en distintos momentos tras el destesado de los alambres: momento de la transferencia (0 días), 7 días, 28 días, 60 días y 90 días.

\subsubsection{Viga 1}

\section{Perfil de deformaciones longitudinales}

En la Figura 7-15 se recoge el perfil de deformaciones longitudinales $\varepsilon$ del hormigón a lo largo de la longitud de la Viga 1, medido mediante extensometría manual tras la transferencia del pretensado y en las edades de medida posteriores (7 días, 28 días, 60 días y 90 días). Por su parte, en la Figura 7-16 se recoge el perfil de deformaciones longitudinales $\varepsilon$ de la Viga 1, medido mediante instrumentación electrónica (galgas extensiométricas), en los mismos periodos de tiempo. En ambas perfiles de 
deformación se ha supuesto un comportamiento lineal a lo largo de la longitud de transferencia $l_{t}$, ajustado mediante regresiones lineales, y una ley constante a lo largo de la meseta central, equivalente al $95 \%$ del valor medio de deformación $\boldsymbol{\varepsilon}_{\max }$ de los puntos de medida de la meseta central. Las longitudes de transferencia en ambos extremos (Extremo A y B) han sido determinadas por la intersección entre ambas leyes.

En la Tabla 7-7 se incluyen, para la Viga 1 y para los distintos periodos de tiempo considerados, los parámetros derivados de las medidas tomadas mediante extensometría manual que determinan el perfil de deformaciones: el valor de deformación media $\varepsilon_{\max }$ en la meseta central, donde el pretensado está plenamente desarrollado; el valor del $95 \%$ de dicha deformación media ( $\left.95 \% \boldsymbol{\varepsilon}_{\max }\right)$; las leyes de ajuste lineal en la zona de transferencia, así como su coeficiente de determinación $\mathrm{R}^{2}$; y las longitudes de transferencia en los extremos A y B.

Tabla 7-5 Parámetros numéricos de los perfiles de deformación en la Viga 1. Deformaciones medidas con extensiometría manual [Cara E]

\begin{tabular}{|c|c|c|c|c|c|c|c|c|}
\hline \multirow{2}{*}{$\begin{array}{c}\text { Tiempo } \\
\text { [días] }\end{array}$} & \multicolumn{2}{|c|}{ Meseta Central } & \multicolumn{3}{|c|}{ Extremo A } & \multicolumn{3}{|c|}{ Extremo B } \\
\hline & $\begin{array}{c}\varepsilon_{\max } \\
{[\mu \mathrm{m} / \mathrm{m}]}\end{array}$ & $\begin{array}{l}95 \% \varepsilon_{\max } \\
{[\mu \mathrm{m} / \mathrm{m}]}\end{array}$ & Ajuste lineal & $\mathbf{R}^{2}$ & $\begin{array}{c}1_{\mathrm{t}, \mathrm{A}} \\
{[\mathrm{mm}]}\end{array}$ & Ajuste lineal & $\mathbf{R}^{2}$ & $\begin{array}{c}\mathrm{l}_{\mathrm{t}, \mathrm{B}} \\
{[\mathrm{mm}]}\end{array}$ \\
\hline $\mathrm{t}=0$ & -542.58 & -515.45 & $y=-0.9495 x-17.636$ & 0.88 & 524.29 & $y=1.1912 x-1681.9$ & 0.96 & 441.34 \\
\hline $\mathrm{t}=7$ & -901.02 & -855.97 & $y=-1.5501 x-35.19$ & 0.95 & 529.50 & $y=1.7897 x-3519.2$ & 0.92 & 486.87 \\
\hline $\mathrm{t}=28$ & -1109.68 & -1054.20 & $y=-1.9002 x-64.812$ & 0.94 & 520.18 & $y=2.1755 x-4326.3$ & 0.95 & 470.89 \\
\hline $\mathrm{t}=60$ & -1304.63 & -1239.40 & $y=-2.0507 x-73.609$ & 0.97 & 568.49 & $y=2.5289 x-4984.3$ & 0.97 & 494.12 \\
\hline $\mathrm{t}=90$ & -1492.60 & -1417.97 & $y=-2.2991 x-60.245$ & 0.97 & 590.54 & $y=2.8761 x-5646.8$ & 0.98 & 504.62 \\
\hline
\end{tabular}

VIGA 1. DEFORMACIONES MEDIDAS CON EXTENSOMETRÍA MANUAL - CARA E

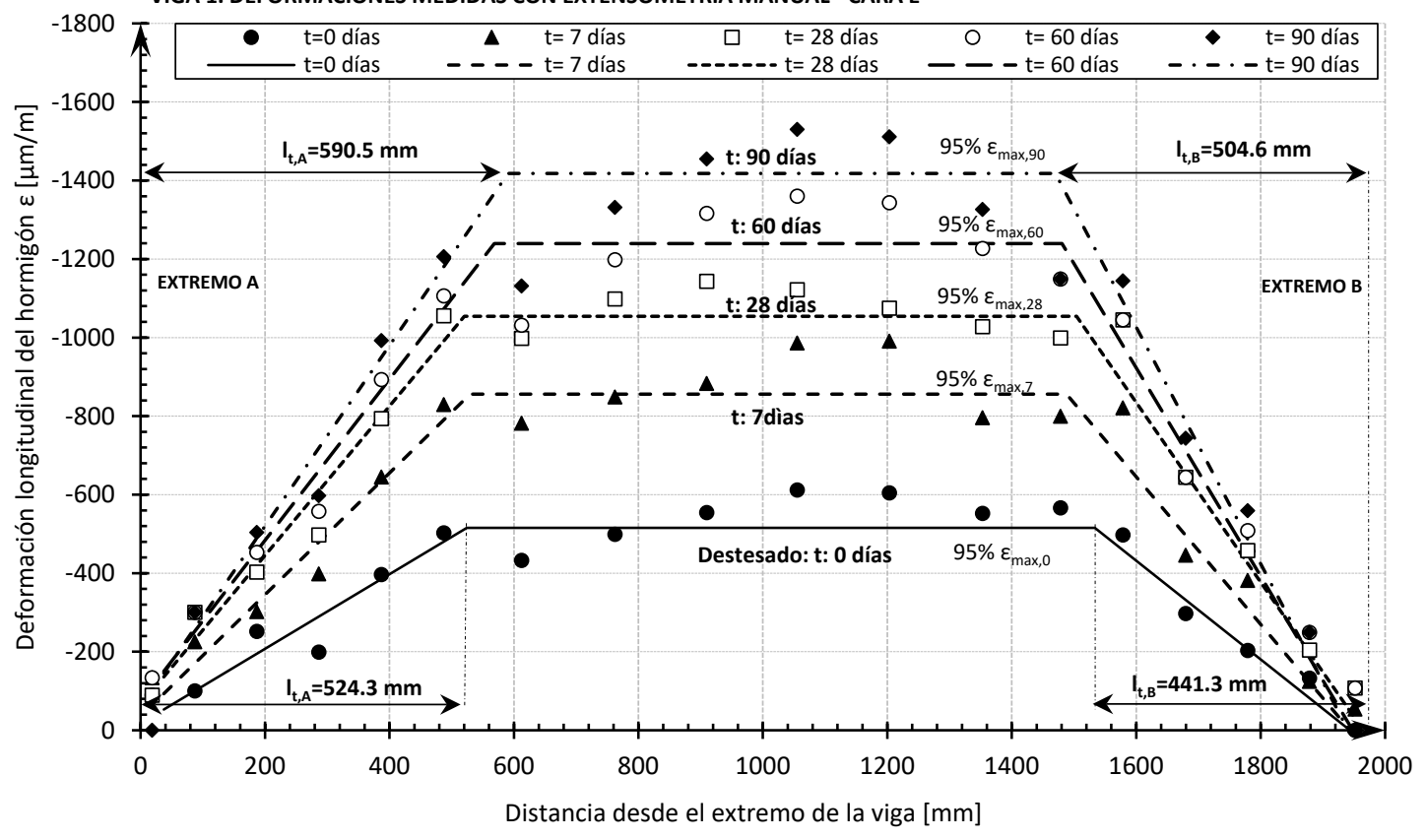

Figura 7-14 Evolución de la longitud de transferencia lt y de las deformaciones longitudinales $\varepsilon$ en la Viga 1, tras el destesado. Alambres sin corrosión. Deformaciones medidas con extensiometría manual. 


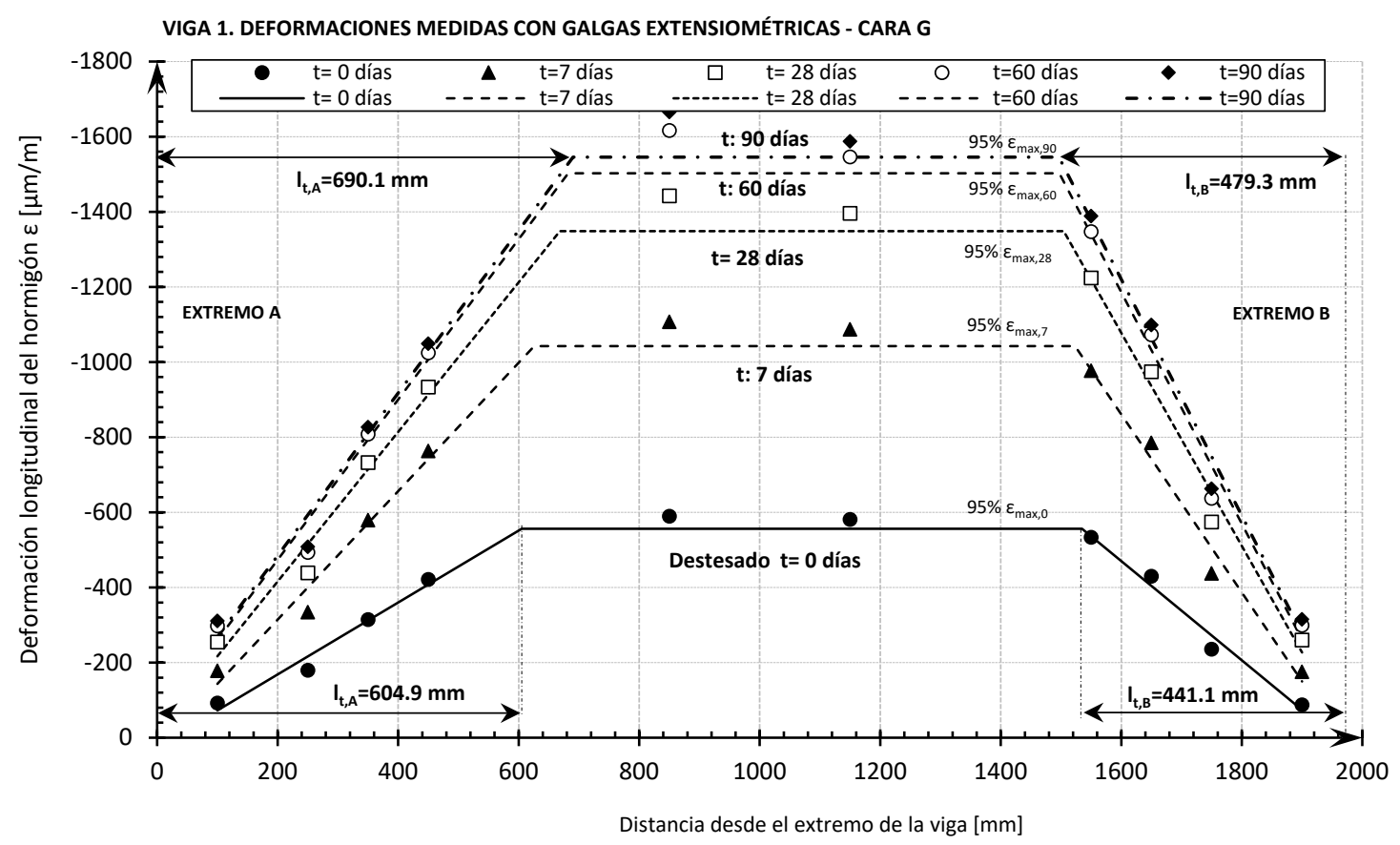

Figura 7-15 Evolución de la longitud de transferencia lt y de las deformaciones longitudinales $\varepsilon$ en la Viga 1, tras el destesado. Alambres sin corrosión. Deformaciones medidas con galgas extensiométricas.

Por su parte, en la Tabla 7-6 se incluyen los parámetros que definen los perfiles de deformación, obtenidos mediante el análisis de los resultados experimentales arrojados por la instrumentación electrónica.

Tabla 7-6 Parámetros numéricos de los perfiles de deformación en la Viga 1. Deformaciones medidas con galgas extensiométricas.

\begin{tabular}{ccccccccc}
\hline \multirow{2}{*}{$\begin{array}{c}\text { Tiempo } \\
{[\mathrm{días}]}\end{array}$} & \multicolumn{2}{c}{ Meseta Central } & \multicolumn{2}{c}{ Extremo A } & \multicolumn{3}{c}{ Extremo B } \\
\cline { 2 - 8 } & $\begin{array}{c}\boldsymbol{\varepsilon}_{\max } \\
\boldsymbol{\mu} / \mathrm{m}]\end{array}$ & $\begin{array}{c}\mathbf{9 5 \%} \boldsymbol{\varepsilon}_{\max } \\
{[\boldsymbol{\mu} \mathbf{m} / \mathbf{m}]}\end{array}$ & Ajuste lineal & $\mathbf{R}^{2}$ & $\begin{array}{c}\mathbf{1}_{\mathrm{t}, \mathrm{A}} \\
{[\mathrm{mm}]}\end{array}$ & Ajuste lineal & $\mathbf{R}^{2}$ & $\begin{array}{c}\mathbf{1}_{\mathrm{t}, \mathrm{B}} \\
{[\mathrm{mm}]}\end{array}$ \\
\hline $\mathrm{t}=0$ & -585.49 & -556.21 & $\mathrm{y}=-0.9576 \mathrm{x}+23.111$ & 0.97 & 604.97 & $\mathrm{y}=1.3203 \mathrm{x}-2582.8$ & 0.98 & 441.05 \\
\hline $\mathrm{t}=7$ & -1097.30 & -1042.44 & $\mathrm{y}=-1.7096 \mathrm{x}+27.629$ & 0.97 & 625.91 & $\mathrm{y}=2.3704 \mathrm{x}-4653.3$ & 0.98 & 452.69 \\
\hline $\mathrm{t}=28$ & -1419.40 & -1348.43 & $\mathrm{y}=-1.9917 \mathrm{x}-17.525$ & 0.97 & 668.23 & $\mathrm{y}=2.8338 \mathrm{x}-5611.4$ & 0.98 & 471.67 \\
\hline $\mathrm{t}=60$ & -1581.60 & -1502.52 & $\mathrm{y}=-2.1338 \mathrm{x}-46.635$ & 0.97 & 682.30 & $\mathrm{y}=3.0810 \mathrm{x}-6115.4$ & 0.98 & 478.80 \\
\hline $\mathrm{t}=90$ & -1626.80 & -1545.46 & $\mathrm{y}=-2.1644 \mathrm{x}-51.739$ & 0.97 & 690.13 & $\mathrm{y}=3.1466 \mathrm{x}-6255.0$ & 0.99 & 479.29 \\
\hline
\end{tabular}

Tal y como se ha visto en el Capítulo 2 "Estado del conocimiento", las deformaciones de compresión en el hormigón pretensado se encuentran fuertemente influenciadas por los procesos reológicos, en concreto, la retracción y la fluencia. En la Tabla 7-7 se incluyen los incrementos relativos, medidos con extensiometría manual, que experimenta la deformación por compresión en la meseta central $\left(\Delta 0.95 \cdot \varepsilon_{\max }\right)$, así como los incrementos en las longitudes de transferencia $\Delta l_{t, A}$ y $\Delta l_{t, B}$ en los extremos, con respecto a la situación de partida tras el destesado. 
7. VALIDACIÓN DEL MODELO ANALÍTICO DE ADHERENCIA DE ALAMBRES PRETENSADOS CON CORROSIÓN

Tabla 7-7 Incrementos de deformación a lo largo del tiempo en Viga 1. Deformaciones medidas con extensiometría manual.

\begin{tabular}{|c|c|c|c|c|c|c|}
\hline \multirow{2}{*}{ t [días] } & \multicolumn{2}{|c|}{ Meseta Central } & \multicolumn{2}{|c|}{ Extremo A } & \multicolumn{2}{|c|}{ Extremo B } \\
\hline & $0.95 \cdot \varepsilon_{\max }[\mu \mathrm{m} / \mathrm{m}]$ & $\Delta 0.95 \cdot \varepsilon_{\max }[\%]$ & $\mathbf{l}_{t, \mathrm{~A}}[\mathrm{~mm}]$ & $\Delta \mathbf{l}_{\mathrm{t}, \mathrm{A}}[\%]$ & $\mathbf{l}_{\mathrm{t}, \mathrm{B}}[\mathrm{mm}]$ & $\Delta \mathbf{l}_{\mathrm{t}, \mathrm{B}}[\%]$ \\
\hline 0 & -515.45 & 0.00 & 524.29 & 0.00 & 441.34 & 0.00 \\
\hline 7 & -855.97 & 66.06 & 529.50 & 0.99 & 486.87 & 10.32 \\
\hline 28 & -1054.20 & 104.52 & 520.18 & -0.78 & 470.89 & 6.70 \\
\hline 60 & -1239.40 & 140.45 & 568.49 & 8.43 & 494.12 & 11.96 \\
\hline 90 & -1417.97 & 175.09 & 590.54 & 12.64 & 504.62 & 14.34 \\
\hline
\end{tabular}

En la Tabla 7-8, al igual que en la anterior, se incluyen los incrementos relativos, medidos con galgas extensiométricas, que experimenta la deformación por compresión en la meseta central $\left(\Delta 0.95 \cdot \varepsilon_{\max }\right)$, así como los incrementos en las longitudes de transferencia $\Delta l_{t, A}$ y $\Delta l_{t, B}$ en los extremos A y B.

Tabla 7-8 Incrementos de deformación a lo largo del tiempo en Viga 1. Deformaciones medidas con galgas extensiométricas.

\begin{tabular}{|c|c|c|c|c|c|c|}
\hline \multirow{2}{*}{ t [días] } & \multicolumn{2}{|c|}{ Meseta Central } & \multicolumn{2}{|c|}{ Extremo A } & \multicolumn{2}{|c|}{ Extremo B } \\
\hline & $0.95 \cdot \varepsilon_{\max }[\mu \mathrm{m} / \mathrm{m}]$ & $\Delta 0.95 \cdot \varepsilon_{\max }[\%]$ & $1_{\mathrm{t}, \mathrm{A}}[\mathrm{mm}]$ & $\Delta 1_{t, \mathrm{~A}}[\%]$ & $1_{\mathrm{t}, \mathrm{B}}[\mathrm{mm}]$ & $\Delta 1_{t, \mathrm{~B}}[\%]$ \\
\hline 0 & -556.21 & 0.00 & 604.97 & 0.00 & 441.05 & 0.00 \\
\hline 7 & -1042.44 & 87.42 & 625.91 & 3.46 & 452.69 & 2.64 \\
\hline 28 & -1348.43 & 142.43 & 668.23 & 10.46 & 471.67 & 6.94 \\
\hline 60 & -1502.52 & 170.13 & 682.30 & 12.78 & 478.80 & 8.56 \\
\hline 90 & -1545.46 & 177.85 & 690.13 & 14.08 & 479.29 & 8.67 \\
\hline
\end{tabular}

Se observa claramente que la longitud de transferencia, así como su incremento porcentual, es considerablemente mayor en el extremo de la viga más cercano a la zona de corte de los alambres. Este comportamiento ha sido observado por otros autores (Oh, et al., 2001).

\section{Deslizamiento en los extremos}

En las gráficas de la Figura 7-17 se recogen los deslizamientos en los extremos A y B de la Viga 1, registrados mediante los flexímetros ubicados en cada uno de los alambres. Los flexímetros $F_{1}$ y $F_{2}$ estaban ubicados en la cara superior de la viga, mientras que los flexímetros $\mathrm{F}_{3}$ y $\mathrm{F}_{4}$ registraban los deslizamientos de los alambres situados en la cara inferior.

En la Tabla 7-9 se incluyen los deslizamientos en cada extremo de la viga, $F_{A}$ y $F_{B}$, cuyo valor es el resultado de la media de los registros de los cuatro flexímetros ubicados en dicho extremo. Además, se incluyen los siguientes parámetros: el incremento relativo con respecto al valor registrado tras el destesado $\Delta \mathrm{F}_{\mathrm{A}}$, y el valor del coeficiente $\alpha$ resultante de la aplicación de la expresión de Guyon (Guyon, 1953) sobre la longitud de transferencia $l_{t, m e d i a}$ en cada extremo, media de las longitudes obtenidas mediante la extensiometría manual y mediante las galgas extensiométricas. 

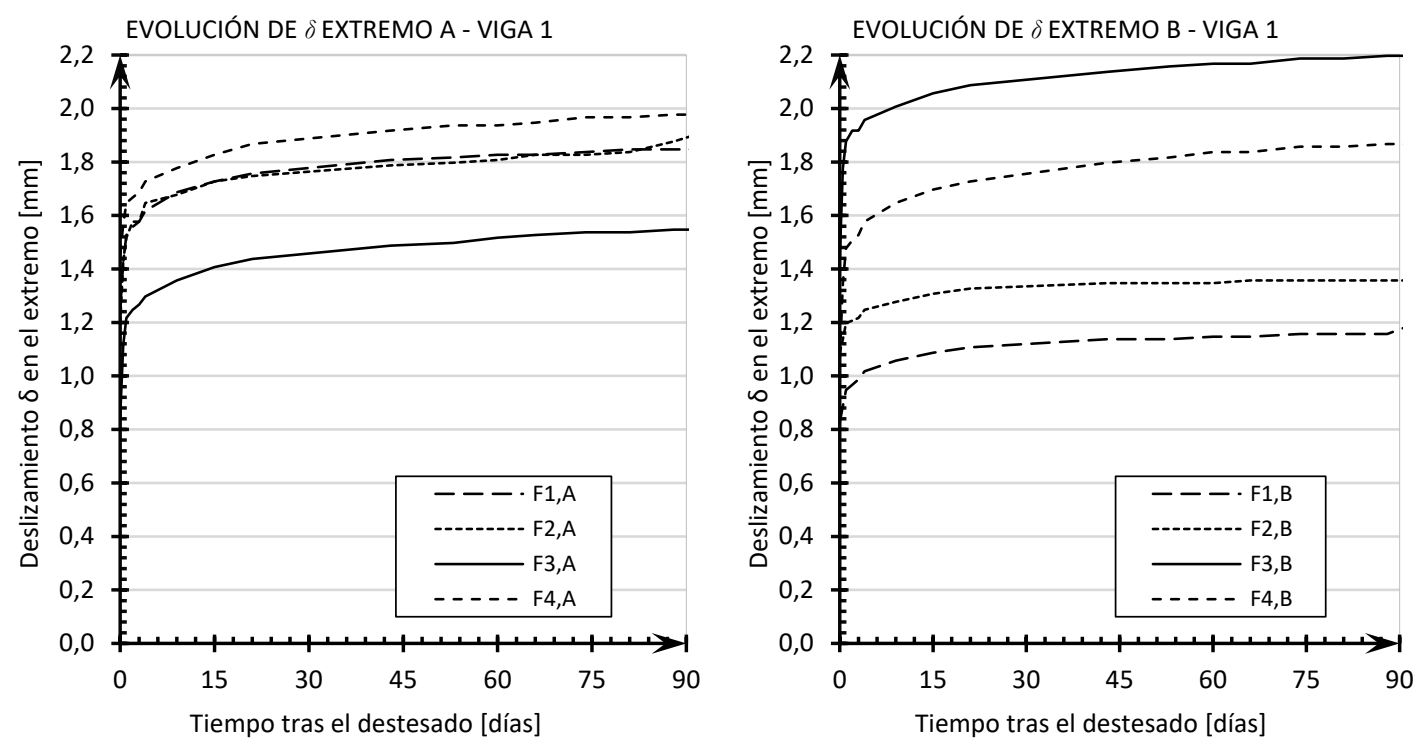

Figura 7-16 Evolución de los deslizamientos de los alambres en los extremos A (izq.) y B (der.) de la Viga 1, tras el destesado. Alambres sin corrosión. Deslizamientos medidos con fleximetros.

Tabla 7-9 Deslizamientos en los extremos registrados por los fleximetros de la Viga 1

\begin{tabular}{ccccccccc}
\hline \multirow{2}{*}{ Tiempo } & \multicolumn{3}{c}{ Extremo A (Extremo de corte) } & \multicolumn{4}{c}{ Extremo B (Extremo muerto) } \\
\cline { 2 - 8 } & $\mathbf{F}_{\mathbf{A}}[\mathbf{m m}]$ & $\Delta \mathbf{F}_{\mathbf{A}}[\mathbf{\%}]$ & $\mathbf{1}_{\mathrm{t}, \mathrm{A}-\mathrm{media}}[\mathbf{m m}]$ & $\boldsymbol{\alpha}$ & $\mathbf{F}_{\mathbf{B}}[\mathbf{m m}]$ & $\Delta \mathbf{F}_{\mathbf{B}}[\mathbf{0}]$ & $\mathbf{L}_{\mathrm{t}, \mathrm{B}-\mathrm{media}}[\mathbf{m m}]$ & $\boldsymbol{\alpha}$ \\
\hline $\mathrm{t}=0$ días & 1.19 & 0.00 & 564.63 & $\mathbf{3 . 0 6}$ & 1.10 & 0.00 & 441.20 & $\mathbf{2 . 5 7}$ \\
\hline $\mathrm{t}=7$ días & 1.60 & 34.64 & 577.71 & $\mathbf{2 . 3 2}$ & 1.47 & 33.38 & $\mathbf{2 . 0 5}$ \\
\hline $\mathrm{t}=28$ días & 1.73 & 45.38 & 594.20 & $\mathbf{2 . 2 1}$ & 1.58 & 43.34 & 471.28 \\
\hline $\mathrm{t}=60$ días & 1.77 & 49.28 & 625.39 & $\mathbf{2 . 2 7}$ & 1.62 & 46.85 & 486.46 & $\mathbf{1 . 9 3}$ \\
\hline
\end{tabular}

\section{Valoración de los resultados experimentales obtenidos en la Viga 1}

La máxima deformación instantánea media del hormigón $\boldsymbol{\varepsilon}_{\max }$, tras la transferencia del pretensado, en la meseta central de la viga es de $-542,58 \mu \mathrm{m} / \mathrm{m}$ en la cara $\mathrm{E}$ (cara en la que las mediciones se han llevado a cabo mediante Extensiometría manual) y de $-585,49 \mu \mathrm{m} / \mathrm{m}$ en la cara $\mathrm{G}$ (cara en la que las mediciones se han llevado a cabo mediante Galgas extensiométricas). Por tanto, la máxima deformación media $\varepsilon_{\max }$ entre ambas caras es de -564,03 $\mu \mathrm{m} / \mathrm{m}$ (Tabla 7-10). Las pequeñas diferencias de valor registradas entre cada una de las caras pueden deberse a una ligera excentricidad del centro de gravedad de los alambres, a heterogeneidades del hormigón, o simplemente, a márgenes de error derivados de la sensibilidad del método de medida. 

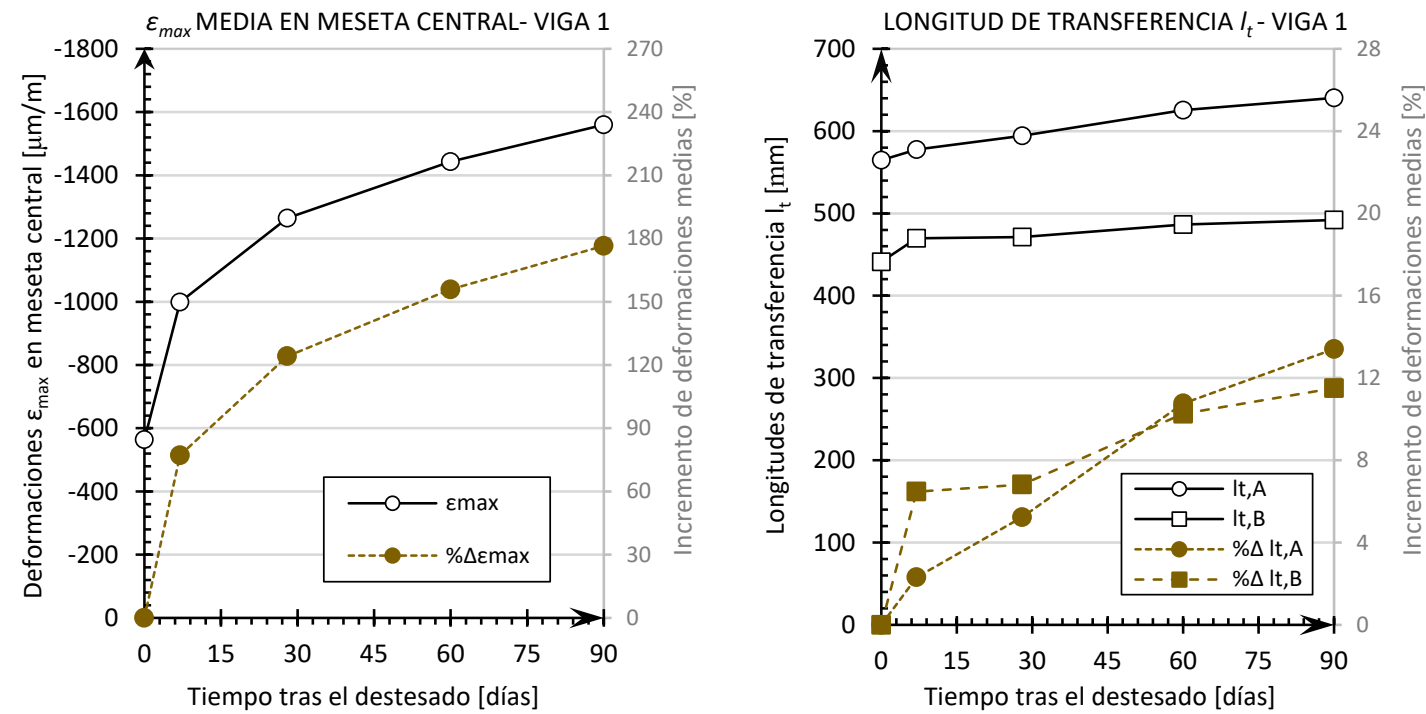

Figura 7-17 Evolución de los valores medios de deformación $\varepsilon_{\max }$ en meseta central (izquierda) y de longitud de transferencia lt (derecha) en la Viga 1, tras el destesado. Alambres sin corrosión. V alores promedio de ambas caras.

Tabla 7-10 Incrementos de deformación a lo largo del tiempo en Viga 1. Deformaciones medidas con galgas extensiométricas.

\begin{tabular}{|c|c|c|c|c|c|c|}
\hline \multirow{2}{*}{ t [días] } & \multicolumn{2}{|c|}{ Meseta Central [Media caras E y G] } & \multicolumn{2}{|c|}{ Extremo A [Media caras E y G] } & \multicolumn{2}{|c|}{ Extremo B [Media caras E y G] } \\
\hline & $\varepsilon_{\max }[\mu \mathrm{m} / \mathrm{m}]$ & $\Delta \varepsilon_{\max }[\%]$ & $\mathbf{1}_{\mathrm{t}, \mathrm{A}}[\mathrm{mm}]$ & $\Delta 1_{t, \mathrm{~A}}[\%]$ & $1_{\mathrm{t}, \mathrm{B}}[\mathrm{mm}]$ & $\Delta \mathbf{l}_{\mathrm{t}, \mathrm{B}}[\%]$ \\
\hline 0 & -564.03 & 0.00 & 564.63 & 0.00 & 441.20 & 0.00 \\
\hline 7 & -999.16 & 77.15 & 577.71 & 2.32 & 469.78 & 6.48 \\
\hline 28 & -1264.54 & 124.20 & 594.20 & 5.24 & 471.28 & 6.82 \\
\hline 60 & -1443.12 & 155.86 & 625.39 & 10.76 & 486.46 & 10.26 \\
\hline 90 & -1559.70 & 176.53 & 640.34 & 13.41 & 491.96 & 11.51 \\
\hline
\end{tabular}

Durante los primeros 7 días se observa un aumento importante de la deformación máxima $\boldsymbol{\varepsilon}_{\max }$ (Tabla 7-5, Tabla 7-6), que en términos medios supone un aumento del $77 \%$ con respecto al valor inicial. A partir de esa edad, las deformaciones de compresión a lo largo de la viga siguen creciendo, debido al efecto de los procesos reológicos dependientes del tiempo que afectan a la viga (fundamentalmente la retracción), pero la tasa de crecimiento se va atenuando. Transcurridos 90 días desde el destesado, la meseta central presenta una deformación máxima de $-1492,60 \mu \mathrm{m} / \mathrm{m}$ en la cara $\mathrm{E}$ (Tabla 7-5) y de $-1626,80 \mu \mathrm{m} / \mathrm{m}$ en la cara $\mathrm{G}$ (Tabla 7-6), lo que se traduce una deformación media de $-1559.70 \mu \mathrm{m} / \mathrm{m}$ y un incremento del 176,53\% con respecto a la situación inicial (Figura 7-18)(Tabla 7-10).

Los ajustes lineales de los resultados puntuales registrados en los extremos de la viga, para la determinación de los tramos ascendente y descendente del perfil de deformaciones, arrojan buenos coeficientes de determinación $\mathrm{R}^{2}$ para ambos métodos de medición (Tabla 7-5, Tabla 7-6). El límite inferior de los coeficientes hallados es 0,88 y el máximo 0,99 .

En cuanto a las longitudes de transferencia $l_{\text {, }}$ destaca la diferencia existente entre el extremo A y el B en el momento de la transferencia ( $t=0$ días). Mientras que en el extremo $B$, la longitud de transferencia media $1_{t, B}$ en el momento del destesado es de 441,20 mm, en el extremo A el valor de longitud $1_{t, A}$ alcanza los 564,63 mm (Figura 7-18)(Tabla 7-10). Hay que tener en cuenta que el extremo 
A de la Viga 1 se encontraba en uno de los límites de la pista de pretensado, lo que unido a que se ha detectado un comportamiento similar en el extremo A de la Viga 4, situado en el límite opuesto de la pista, parece indicar que la transferencia del pretensado se ve influida por la ubicación de las vigas en el momento del destesado. Por otro lado, al igual que ocurre con las deformaciones de compresión en el tramo central $\varepsilon_{\max }$, las longitudes de transferencia $l_{t}$ experimentan un crecimiento desde el momento del destesado, atenuado con el tiempo, alcanzando a los 90 días un valor promedio $1_{t, A}=640,34 \mathrm{~mm}$ en el extremo $A$, lo que supone un incremento del $13,41 \%$ con respecto al valor inicial, y de $\mathrm{l}_{\mathrm{t}, \mathrm{B}}=491,96 \mathrm{~mm}$ en el extremo B $\left(\Delta \mathrm{l}_{\mathrm{t}, \mathrm{B}}=11,51 \%\right)$ (Figura 7-18)(Tabla 7-10).

Los incrementos rápidos de longitud de transferencia en periodos cortos de tiempo que se observan en ocasiones pueden ser debidos a imprecisiones en la medición o interpretación de los resultados, o a la aparición de fisuras en el recubrimiento debidas a las tensiones radiales $\sigma_{r}$ derivadas del efecto Hoyer. Esta fisuración reduce la capacidad de confinamiento del hormigón y, como se ha visto a lo largo de esta tesis, la tensión de adherencia $\tau_{b}$ disminuye, provocando una redistribución de los esfuerzos derivados del pretensado y, como consecuencia, un aumento de la longitud de transferencia $l_{t}$ y una reducción de la longitud de la meseta central de deformaciones de compresión constante.

En cuanto a los deslizamientos $\delta$ en extremo de vigas, como puede observarse en la Figura 7-17 y en la Tabla 7-9, la dispersión de los resultados obtenidos es alta, especialmente en el extremo B. En el momento del destesado, el coeficiente $\alpha$ obtenido en el extremo A es igual a 3,06, lo que según el esquema teórico que acompaña a la expresión de Guyon (1953), sería equivalente a suponerque la variación de la tensión de adherencia $\tau_{b}$ a lo largo de la longitud de transferencia $l_{t}$ es lineal, y como consecuencia, la distribuciones tanto de la deformación longitudinal de acero $\varepsilon_{p}$ como la del hormigón $\varepsilon_{c}$ son parabólicas. Por otro lado, el coeficiente $\alpha$ obtenido en el extremo B es igual a 2,57, lo que equivaldría a suponer una distribución de las deformaciones en el hormigón intermedia entre una ley lineal $(\alpha=2)$ y otra parabólica $(\alpha=3)$.

Con el paso del tiempo se observa, en ambos extremos, que el coeficiente $\alpha$ tiende a converger hacia un valor igual a 2. Este valor, utilizado por muchos investigadores [ (Guyon, 1953), (Russell \& Burns, 1997), (Logan, 1997)] para la determinación de la longitud de transferencia a partir de los deslizamientos en el extremo de las vigas, supone aceptar una distribución constante de la tensión de adherencia $\tau_{b}$, dando como resultado una variación lineal de las deformaciones en el alambre y en el hormigón.

\subsubsection{Viga 2}

\section{Perfil de deformaciones longitudinales}

En la Figura 7-19 se recoge el perfil de deformaciones longitudinales $\varepsilon$ del hormigón a lo largo de la longitud de la Viga 2, medido mediante extensometría manual tras la transferencia del pretensado y en las edades de medida posteriores (7 días, 28 días, 60 días y 90 días). Por otro lado, en la Figura 7-20 se incluye el perfil de deformaciones longitudinales $\varepsilon$ de la Viga 2, medido mediante instrumentación electrónica (galgas extensiométricas), en los mismos periodos de tiempo. Para la determinación de las longitudes de transferencia se ha seguido el "Método del 95\% de la deformación máxima media", expuesto anteriormente. 
En la Tabla 7-11 se incluyen, para la Viga 2 y para los distintos periodos de tiempo considerados, los parámetros derivados de las medidas tomadas mediante extensometría manual que determinan el perfil de deformaciones: el valor de deformación media $\boldsymbol{\varepsilon}_{\max }$ en la meseta central, donde el pretensado está plenamente desarrollado; el valor del $95 \%$ de dicha deformación media ( $95 \% \boldsymbol{\varepsilon}_{\text {max }}$ ); las leyes de ajuste lineal en la zona de transferencia, así como su coeficiente de determinación R²; y las longitudes de transferencia en los extremos A y B, resultantes de la intersección de ambas leyes.

Tabla 7-11 Parámetros numéricos de los perfiles de deformación en la Viga 2. Deformaciones medidas con extensiometría manual.

\begin{tabular}{|c|c|c|c|c|c|c|c|c|}
\hline \multirow{2}{*}{$\begin{array}{c}\text { Tiempo } \\
\text { [días] }\end{array}$} & \multicolumn{2}{|c|}{ Meseta Central } & \multicolumn{3}{|c|}{ Extremo A } & \multicolumn{3}{|c|}{ Extremo B } \\
\hline & $\begin{array}{c}\varepsilon_{\max } \\
{[\mu \mathrm{m} / \mathrm{m}]}\end{array}$ & $\begin{array}{l}95 \% \varepsilon_{\max } \\
{[\mu \mathrm{m} / \mathrm{m}]}\end{array}$ & Ajuste lineal & $\mathbf{R}^{2}$ & $\begin{array}{c}1_{\mathrm{t}, \mathrm{A}} \\
{[\mathrm{mm}]}\end{array}$ & Ajuste lineal & $\mathbf{R}^{2}$ & $\begin{array}{c}1_{t, \mathrm{~B}} \\
{[\mathrm{~mm}]}\end{array}$ \\
\hline $\mathrm{t}=0$ & -678.36 & -644.45 & $y=-1.6892 x-4.2956$ & 0.94 & 378.97 & $y=1.6615 x-3314.3$ & 0.68 & 368.07 \\
\hline $\mathrm{t}=7$ & -1008.59 & -958.16 & $y=-2.2112 x+51.135$ & 0.97 & 456.45 & $y=2.1499 x-4368.4$ & 0.69 & 388.73 \\
\hline $\mathrm{t}=28$ & -1305.63 & -1240.34 & $y=-2.7810 x+29.867$ & 0.99 & 456.75 & $y=2.8434 x-5717.5$ & 0.69 & 400.38 \\
\hline $\mathrm{t}=60$ & -1434.65 & -1362.92 & $y=-2.9312 x+63.091$ & 0.99 & 486.49 & $y=2.8625 x-5773.0$ & 0.68 & 434.32 \\
\hline $\mathrm{t}=90$ & -1616.16 & -1535.36 & $y=-3.2785 x-60.245$ & 0.99 & 478.36 & $y=3.1402 x-6285.3$ & 0.78 & 462.34 \\
\hline
\end{tabular}

Por su parte, en la Tabla 7-12 se incluyen los parámetros que definen los perfiles de deformación, obtenidos mediante el análisis de los resultados experimentales arrojados por la instrumentación electrónica.

Tabla 7-12 Parámetros numéricos de los perfiles de deformación en la Viga 2. Deformaciones medidas con galgas extensiométricas.

\begin{tabular}{|c|c|c|c|c|c|c|c|c|}
\hline \multirow{2}{*}{$\begin{array}{c}\text { Tiempo } \\
\text { [días] }\end{array}$} & \multicolumn{2}{|c|}{ Meseta Central } & \multicolumn{3}{|c|}{ Extremo A } & \multicolumn{3}{|c|}{ Extremo B } \\
\hline & $\begin{array}{c}\varepsilon_{\max } \\
{[\mu \mathrm{m} / \mathrm{m}]}\end{array}$ & $\begin{array}{l}95 \% \varepsilon_{\max } \\
{[\mu \mathrm{m} / \mathrm{m}]}\end{array}$ & Ajuste lineal & $\mathbf{R}^{2}$ & $\begin{array}{c}\mathbf{l}_{\mathrm{t}, \mathrm{A}} \\
{[\mathrm{mm}]}\end{array}$ & Ajuste lineal & $\mathbf{R}^{2}$ & $\begin{array}{c}1_{t, \mathrm{~B}} \\
{[\mathrm{~mm}]}\end{array}$ \\
\hline $\mathrm{t}=0$ & -555.85 & -528.06 & $y=-1.0399-33.791$ & 0.99 & 475.30 & $y=1.1794 x-2351.1$ & 0.98 & 430.26 \\
\hline $\mathrm{t}=7$ & -1046.75 & -994.41 & $y=-1.8838 x-77.155$ & 0.98 & 486.92 & $y=2.1654 x-4328.1$ & 0.98 & 436.48 \\
\hline $\mathrm{t}=28$ & -1375.42 & -1306.65 & $y=-2.2903 x-139.64$ & 0.98 & 509.55 & $y=2.7028 x-5443.5$ & 0.98 & 445.42 \\
\hline $\mathrm{t}=60$ & -1534.75 & -1458.01 & $y=-2.4963 x-163.84$ & 0.98 & 518.44 & $y=2.9589 x-5977.4$ & 0.97 & 448.61 \\
\hline $\mathrm{t}=90$ & -1578.15 & -1499.24 & $y=-2.470 x-208.25$ & 0.98 & 522.67 & $y=3.0386 x-6143.3$ & 0.98 & 447.65 \\
\hline
\end{tabular}




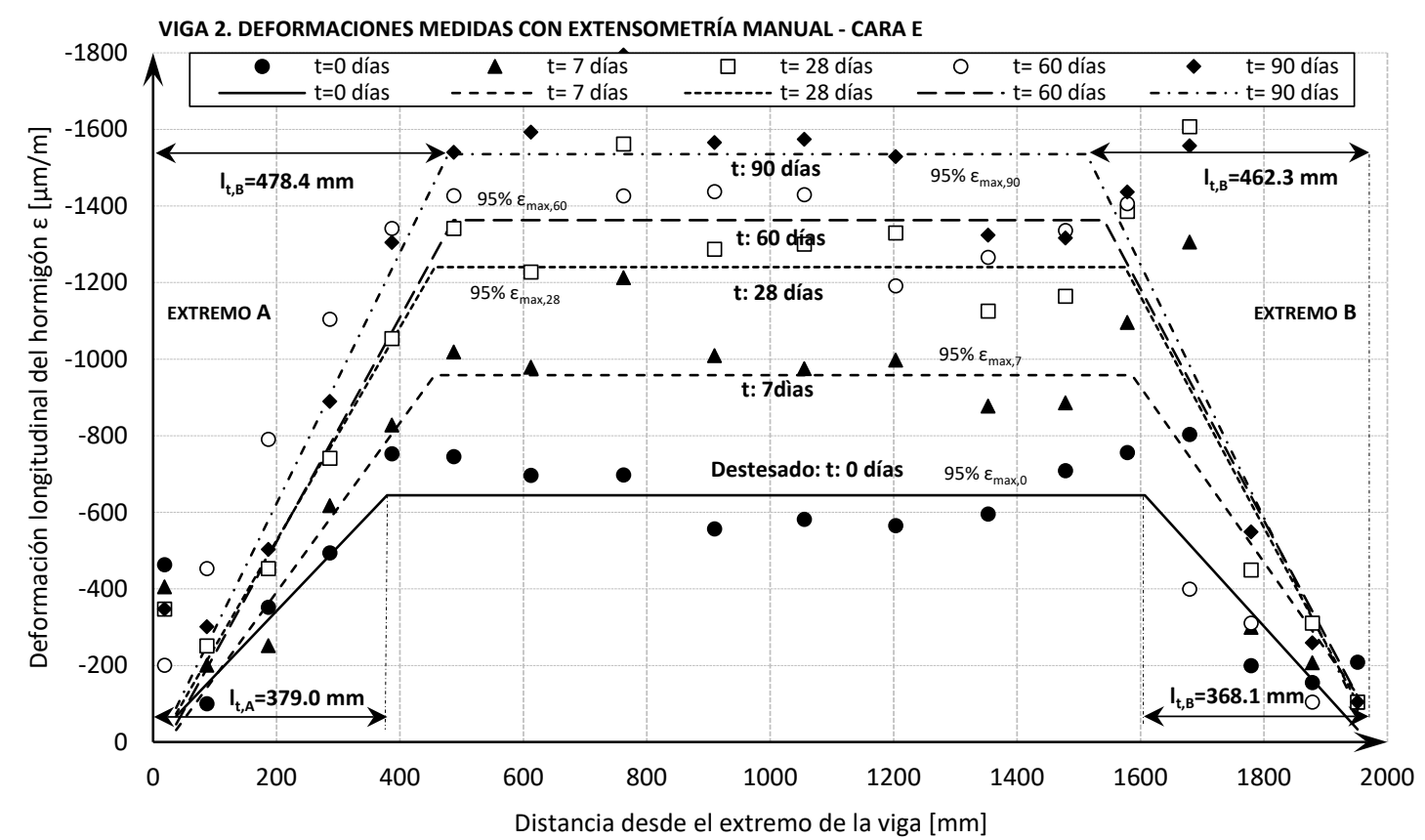

Figura 7-18 Evolución de la longitud de transferencia lt y de las deformaciones longitudinales $\boldsymbol{\varepsilon}$ en la Viga 2, tras el destesado. Alambres sin corrosión. Deformaciones medidas con extensiometría manual.

VIGA 2. DEFORMACIONES MEDIDAS CON GALGAS EXTENSIOMÉTRICAS - CARA G

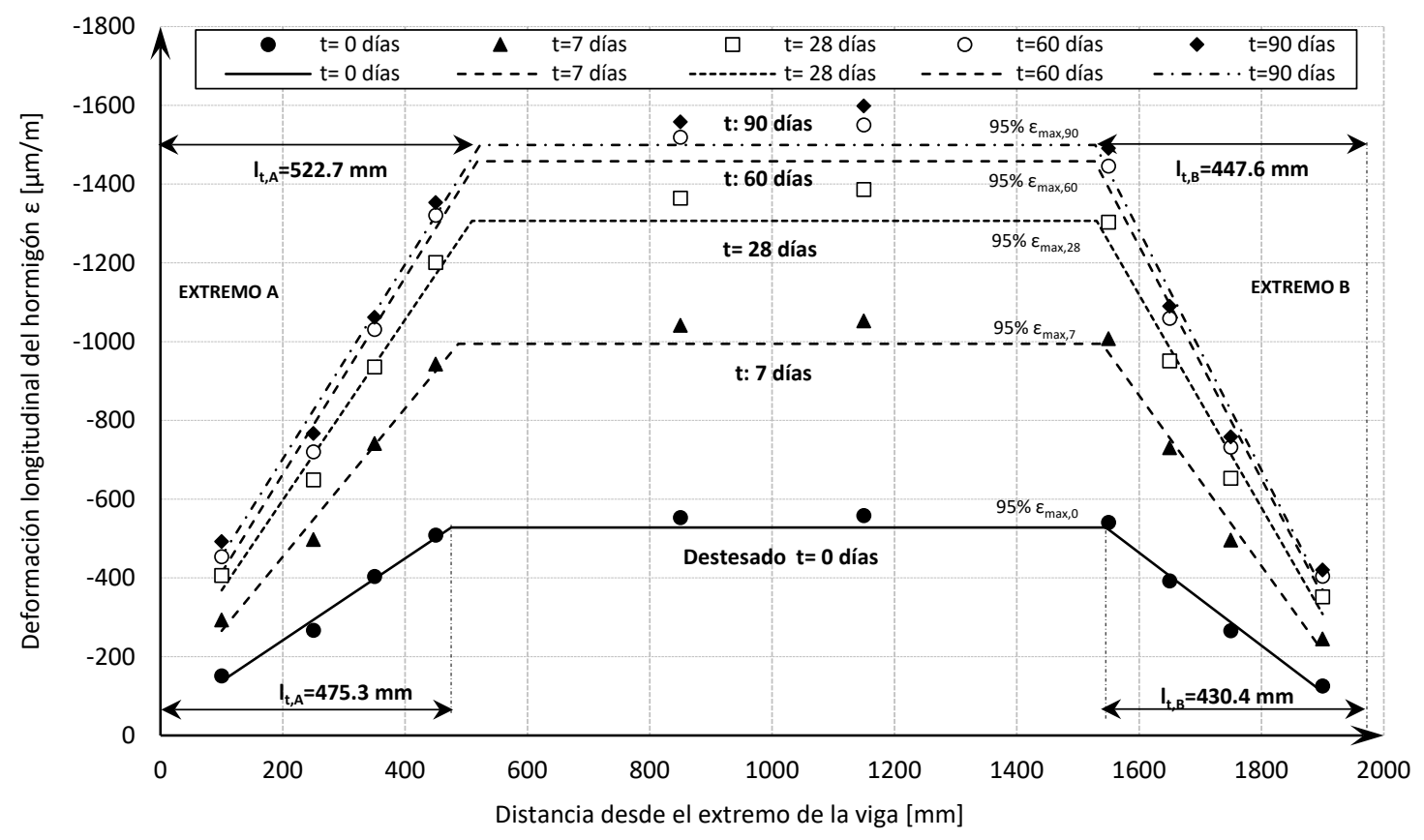

Figura 7-19 Evolución de la longitud de transferencia lty de las deformaciones longitudinales $\varepsilon$ en la Viga 2, tras el destesado. Alambres sin corrosión. Deformaciones medidas con galgas extensiométricas. 
En la Tabla 7-13 se incluyen los incrementos relativos, medidos con extensiometría manual, que experimenta la deformación por compresión en la meseta central $\left(\Delta 0.95 \cdot \varepsilon_{\max }\right)$, así como los incrementos en las longitudes de transferencia $\Delta l_{b, A}$ y $\Delta l_{t, B}$ en los extremos.

Tabla 7-13 Incrementos de deformación a lo largo del tiempo en Viga 2. Deformaciones medidas con extensiometría manual.

\begin{tabular}{|c|c|c|c|c|c|c|}
\hline \multirow{2}{*}{ t [días] } & \multicolumn{2}{|c|}{ Meseta Central } & \multicolumn{2}{|c|}{ Extremo A } & \multicolumn{2}{|c|}{ Extremo B } \\
\hline & $0.95 \cdot \varepsilon_{\max }[\mu \mathrm{m} / \mathrm{m}]$ & $\Delta 0.95 \cdot \varepsilon_{\max }[\%]$ & $\mathbf{1}_{\mathrm{t}, \mathrm{A}}[\mathrm{mm}]$ & $\Delta 1_{t, \mathrm{~A}}[\%]$ & $\mathbf{l}_{\mathrm{t}, \mathrm{B}}[\mathrm{mm}]$ & $\Delta \mathbf{l}_{\mathrm{t}, \mathrm{B}}[\%]$ \\
\hline $\mathrm{t}=0$ & -644.45 & 0.00 & 378.97 & 0.00 & 368.07 & 0.00 \\
\hline $\mathrm{t}=7$ & -958.16 & 48.68 & 456.45 & 20.45 & 388.73 & 5.61 \\
\hline $\mathrm{t}=28$ & -1240.34 & 92.47 & 456.75 & 20.52 & 400.38 & 8.78 \\
\hline $\mathrm{t}=60$ & -1362.92 & 111.49 & 486.49 & 28.37 & 434.32 & 18.00 \\
\hline $\mathrm{t}=90$ & -1535.36 & 138.24 & 478.36 & 26.23 & 462.34 & 25.61 \\
\hline
\end{tabular}

En la Tabla 7-14, al igual que en la anterior, se incluyen los incrementos relativos, medidos con galgas extensiométricas, que experimenta la deformación por compresión en la meseta central $\left(\Delta 0.95 \cdot \varepsilon_{\max }\right)$, así como los incrementos en las longitudes de transferencia $\Delta l_{t, A}$ y $\Delta l_{t, B}$ en los extremos A y B.

Tabla 7-14 Incrementos de deformación a lo largo del tiempo en Viga 2. Deformaciones medidas con galgas extensiométricas.

\begin{tabular}{|c|c|c|c|c|c|c|}
\hline \multirow{2}{*}{ t [días] } & \multicolumn{2}{|c|}{ Meseta Central } & \multicolumn{2}{|c|}{ Extremo A } & \multicolumn{2}{|c|}{ Extremo B } \\
\hline & $0.95 \cdot \varepsilon_{\max }[\mu \mathrm{m} / \mathrm{m}]$ & $\Delta 0.95 \cdot \varepsilon_{\max }[\%]$ & $\mathbf{1}_{\mathrm{t}, \mathrm{A}}[\mathrm{mm}]$ & $\Delta 1_{t, \mathrm{~A}}[\%]$ & $1_{\mathrm{t}, \mathrm{B}}[\mathrm{mm}]$ & $\Delta 1_{t, \mathrm{~B}}[\%]$ \\
\hline $\mathrm{t}=0$ & -528.06 & 0.00 & 475.30 & 0.00 & 430.26 & 0.00 \\
\hline $\mathrm{t}=7$ & -994.41 & 88.32 & 486.92 & 2.44 & 436.48 & 1.44 \\
\hline $\mathrm{t}=28$ & -1306.65 & 147.45 & 509.55 & 7.20 & 445.42 & 3.52 \\
\hline $\mathrm{t}=60$ & -1458.01 & 176.11 & 518.44 & 9.08 & 448.61 & 4.26 \\
\hline $\mathrm{t}=90$ & -1499.24 & 183.92 & 522.67 & 9.97 & 447.65 & 4.04 \\
\hline
\end{tabular}

\section{Deslizamiento en los extremos}

En las gráficas de la Figura 7-21 se recogen los deslizamientos en los extremos A y B de la Viga 2, registrados mediante los flexímetros ubicados en cada uno de los alambres. Los flexímetros $F_{1}$ y $F_{2}$ estaban ubicados en la cara superior de la viga, mientras que los flexímetros $\mathrm{F}_{3}$ y $\mathrm{F}_{4}$ registraban los deslizamientos de los alambres situados en la cara inferior.

Tabla 7-15 Deslizamientos en los extremos A y B de la Viga 2, registrados por los fleximetros

\begin{tabular}{|c|c|c|c|c|c|c|c|c|}
\hline \multirow{2}{*}{ Tiempo } & \multicolumn{4}{|c|}{ Extremo A (Extremo de corte) } & \multicolumn{4}{|c|}{ Extremo B (Extremo muerto) } \\
\hline & $\mathrm{F}_{\mathrm{A}}[\mathrm{mm}]$ & $\Delta \mathrm{F}_{\mathrm{A}}[\%]$ & $\mathbf{1}_{\mathrm{t}, \mathrm{A}-\mathrm{media}}[\mathrm{mm}]$ & $\alpha$ & $\mathrm{F}_{\text {в }}[\mathrm{mm}]$ & $\Delta \mathrm{F}_{\mathrm{B}}[\%]$ & $\mathbf{L}_{\mathrm{t}, \mathrm{B} \text {-media }}[\mathrm{mm}]$ & $\alpha$ \\
\hline $\mathrm{t}=0$ días & 0.96 & 0.00 & 427.13 & 2.87 & 0.96 & 0.00 & 399.16 & 2.66 \\
\hline $\mathrm{t}=7$ días & 1.19 & 24.81 & 471.68 & 2.54 & 1.32 & 36.80 & 412.60 & 2.01 \\
\hline $\mathrm{t}=28$ días & 1.32 & 37.74 & 483.15 & 2.36 & 1.46 & 51.18 & 422.90 & 1.86 \\
\hline $\mathrm{t}=60$ días & 1.36 & 41.62 & 502.46 & 2.38 & 1.52 & 57.45 & 441.47 & 1.87 \\
\hline $\mathrm{t}=90$ días & 1.39 & 45.45 & 500.51 & 2.31 & 1.55 & 61.03 & 454.99 & 1.88 \\
\hline
\end{tabular}


En la Evolución de los deslizamientos de los alambres en los extremos A (irq.) y B (der.) de la Viga 2, tras el destesado. Alambres sin corrosión. Deslizamientos medidos con fleximetros.

se incluyen los deslizamientos en cada extremo de la viga $2, F_{A}$ y $F_{B}$, cuyo valor es el resultado de la media de los registros de los cuatro flexímetros ubicados en dicho extremo. Además, se incluyen los siguientes parámetros: el incremento relativo con respecto al valor registrado tras el destesado $\Delta \mathrm{F}_{\mathrm{A}}$, y el valor del coeficiente $\alpha$ resultante de la aplicación de la expresión de Guyon (Guyon, 1953) sobre la longitud de transferencia $l_{\text {, media }}$ en cada extremo, media de las longitudes obtenidas en las caras E y $\mathrm{G}$ mediante extensiometría manual y mediante galgas extensiométricas, respectivamente.

EVOLUCIÓN DE $\delta$ EXTREMO A - VIGA 2

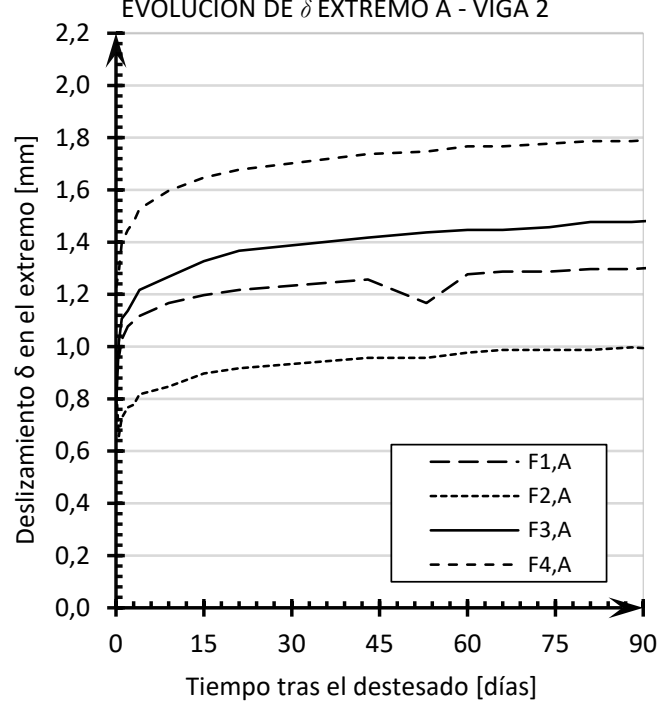

EVOLUCIÓN DE $\delta$ EXTREMO B - VIGA 2

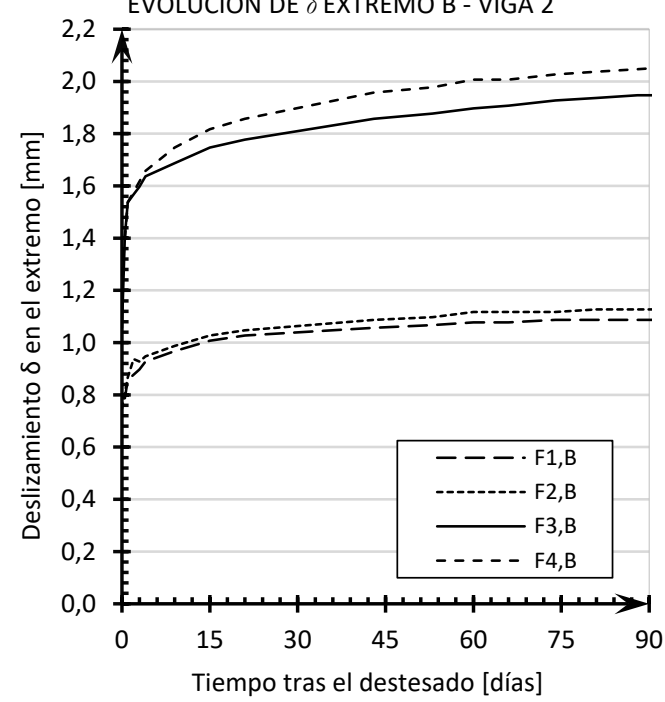

Figura 7-20 Evolución de los deslizamientos de los alambres en los extremos A (izq.) y B (der.) de la Viga 2, tras el destesado. Alambres sin corrosión. Deslizamientos medidos con fleximetros.

\section{Valoración de los resultados experimentales obtenidos en la Viga 2}

La máxima deformación instantánea media del hormigón $\boldsymbol{\varepsilon}_{\max }$, tras la transferencia del pretensado, en la meseta central de la viga es de $-678,36 \mu \mathrm{m} / \mathrm{m}$ en la cara $\mathrm{E}$ (Tabla $7-11$ ) y de $-555,85 \mu \mathrm{m} / \mathrm{m}$ en la cara G (Tabla 7-12). Por tanto, la máxima deformación $\varepsilon_{\max }$ promedio de ambas caras es -617,11 $\mu \mathrm{m} / \mathrm{m}$ (Tabla 7-16). Las diferencias de valor registradas entre cada una de las caras y, por tanto, entre cada uno de los métodos de medida utilizados, son considerables. Como se comentó anteriormente, pueden deberse a una ligera excentricidad del centro de gravedad de los alambres, a heterogeneidades del hormigón, o simplemente, a márgenes de error derivados de la sensibilidad del método de medida. Sin embargo, tal y como puede apreciarse en las Tabla 7-11 y Tabla 7-12, estas diferencias van atenuándose hasta ser prácticamente inexistentes.

Como puede apreciarse en la Figura 7-22 (izq.), durante los primera semana se observa un aumento importante de la deformación máxima $\boldsymbol{\varepsilon}_{\max }$ (Tabla 7-11; Tabla 7-12), alcanzando un valor promedio $1027,67 \mu \mathrm{m} / \mathrm{m}$ y un incremento porcentual del 63,5\% con respecto al valor inicial (Tabla 7-10). Como ocurría en el caso anterior, a partir de ese momento las deformaciones de compresión a lo largo de la viga siguen creciendo, debido fundamentalmente a la retracción, pero la tasa de crecimiento se va 
atenuando. Transcurridos 90 días desde el destesado, la meseta central presenta una deformación máxima de -1616,16 $\mu \mathrm{m} / \mathrm{m}$ en la cara $\mathrm{E}$ (Tabla 7-11) y de -1578,15 $\mu \mathrm{m} / \mathrm{m}$ en la cara $\mathrm{G}$ (Tabla 7-12), lo que se traduce una deformación media de $-1597,16 \mu \mathrm{m} / \mathrm{m}$ y un incremento del $158,81 \%$ con respecto a la situación inicial (Tabla 7-16; Figura 7-22).

Tabla 7-16 Incrementos de deformación a lo largo del tiempo en Viga 2. Deformaciones medidas con galgas extensiométricas.

\begin{tabular}{|c|c|c|c|c|c|c|}
\hline \multirow{2}{*}{ t [días] } & \multicolumn{2}{|c|}{ Meseta Central [Media caras E y G] } & \multicolumn{2}{|c|}{ Extremo A [Media caras E y G] } & \multicolumn{2}{|c|}{ Extremo B [Media caras E y G] } \\
\hline & $\varepsilon_{\max }[\mu \mathrm{m} / \mathrm{m}]$ & $\Delta \varepsilon_{\max }[\%]$ & $\mathbf{l}_{\mathrm{t}, \mathrm{A}}[\mathrm{mm}]$ & $\Delta 1_{t, \mathrm{~A}}[\%]$ & $\mathbf{l}_{\mathrm{t}, \mathrm{B}}[\mathrm{mm}]$ & $\Delta \mathbf{l}_{\mathrm{t}, \mathrm{B}}[\%]$ \\
\hline $\mathrm{t}=0$ & -617.11 & 0.00 & 427.13 & 0.00 & 399.16 & 0.00 \\
\hline $\mathrm{t}=7$ & -1027.67 & 66.53 & 471.68 & 10.43 & 412.60 & 3.37 \\
\hline $\mathrm{t}=28$ & -1340.52 & 117.23 & 483.15 & 13.11 & 422.90 & 5.95 \\
\hline $\mathrm{t}=60$ & -1484.70 & 140.59 & 502.46 & 17.64 & 441.47 & 10.60 \\
\hline $\mathrm{t}=90$ & -1597.16 & 158.81 & 500.51 & 17.18 & 454.99 & 13.99 \\
\hline
\end{tabular}
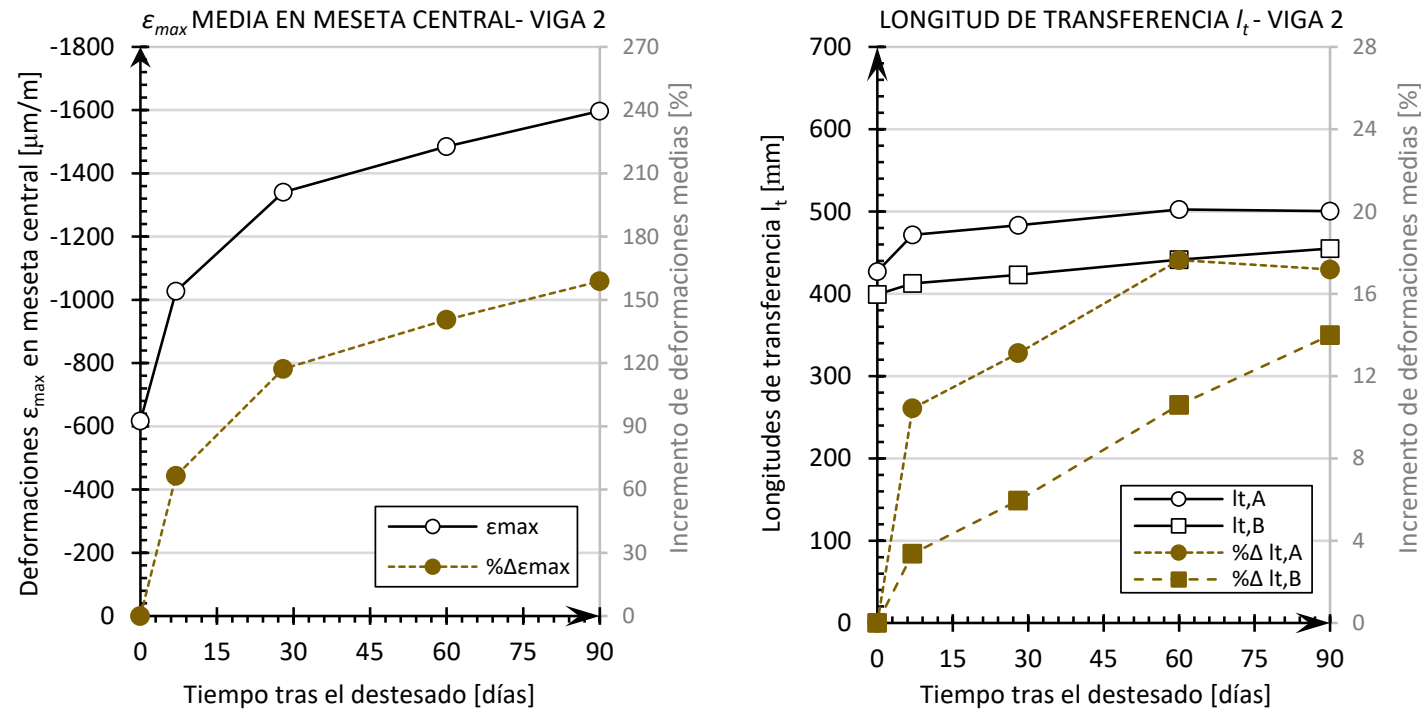

Figura 7-21 Evolución de los valores medios de deformación $\varepsilon_{\text {max }}$ en meseta central (izquierda) y de longitud de transferencia lt (derecha) en la Viga 2, tras el destesado. Alambres sin corrosión. Valores promedio de ambas caras.

Los ajustes lineales de los resultados experimentales registrados en los extremos de la viga, para la determinación de los tramos ascendente y descendente del perfil de deformaciones, arrojan muy buenos coeficientes de determinación $\mathrm{R}^{2}$, situándose por encima del 0,94 excepto en el extremo $\mathrm{B}$ de la Cara $\mathrm{E}$ (medidos mediante extensometría manual), donde el coeficiente desciende hasta 0,68 (Tabla 7-11, Tabla 7-12). Por otro lado, las pendientes de los tramos ascendente y descendente aumentan rápidamente los primeros días tras el destesado, pero se aprecia cierta tendencia hacia la estabilización a partir de los 28-60 días (Tabla 7-11; Tabla 7-12).

En cuanto a las longitudes de transferencia $l_{t}$, los resultados en ambos extremos de la viga son similares en cada cara de la viga, pero su valor difiere entre las mismas, y por tanto, entre cada método de medición (Tabla 7-13; Tabla 7-14). Estas diferencias se minimizan con el paso del tiempo, cuando las deformaciones por compresión aumentan a lo largo de toda la viga. Por otra parte, este comportamiento ha sido observado de forma general en todas las vigas, por lo que es achacable a la 
falta de precisión de la extensometría manual para deformaciones bajas y no tanto a un diferente comportamiento entre caras.

En el extremo A, el valor promedio entre caras de la longitud de transferencia $l_{\hbar,}$, en el momento de la transferencia ( $\mathrm{t}=0$ días), es igual $427,12 \mathrm{~mm}$, mientras que en el extremo $\mathrm{B}$ es igual a $l_{t, \mathrm{~B}}=399,16$ $\mathrm{mm}$. Por otro lado, al igual que ocurre con las deformaciones de compresión en el tramo central $\boldsymbol{\varepsilon}_{\max }$, las longitudes de transferencia $l_{t}$ experimentan un crecimiento desde el momento del destesado, atenuado con el tiempo, alcanzando a los 90 días un valor promedio $l_{h A}=500,51 \mathrm{~mm}$ en el extremo A, lo que supone un incremento del $17,18 \%$ con respecto al valor inicial, y de $l_{6 B}=454,99 \mathrm{~mm}$ en el extremo $\mathrm{B}\left(\Delta \mathrm{l}_{\mathrm{t}, \mathrm{B}}=13,99 \%\right)$ (Figura 7-22)(Tabla 7-16). Se observa un incremento rápido en la longitud de transferencia del extremo A a lo largo de la primera semana $\left(\Delta \mathrm{l}_{\mathrm{t}, \mathrm{B}}=10,43 \%\right)$ que, como se apuntó anteriormente, puede deberse a pérdidas puntuales de confinamiento por fisuración del recubrimiento.

En cuanto los deslizamientos relativos del alambre $\delta$ en los extremos de las vigas, tal y como ocurría en la Viga 1 y como puede observarse en la Figura 7-21, la dispersión es alta, especialmente en el extremo B. En este extremo se observa que los extensómetros situados en la parte superior de la viga $\operatorname{arrojan}$ deslizamientos $\delta$ que prácticamente doblan los obtenidos en la parte inferior.

En el momento del destesado, el coeficiente $\alpha$ obtenido en el extremo A es igual a 2,86, lo que sería equivalente a suponer que la variación de la tensión de adherencia $\tau_{b}$ a lo largo de la longitud de transferencia $l_{t}$ fuera prácticamente lineal, y como consecuencia, la distribuciones tanto de la deformación longitudinal de acero $\varepsilon_{p}$ como la del hormigón $\varepsilon_{c}$ fueran parabólicas. Por otro lado, el coeficiente $\alpha$ obtenido en el extremo B es igual a 2,66, lo que equivaldría a suponer una distribución de las deformaciones en el hormigón intermedia entre una ley lineal $(\alpha=2)$ y otra parabólica $(\alpha=3)$.

Como en la Viga 1, en ambos extremos de la Viga 2 se observa que, con el paso del tiempo, el coeficiente $\alpha$ va descendiendo y tiende a converger hacia un valor cercano a 2. Según la expresión de Guyon (1953), este valor supone que la tensión de adherencia $\tau_{b}$ tiene una distribución aproximadamente constante, dando como resultado una variación lineal de las deformaciones en el alambre y en el hormigón.

\subsubsection{Viga 3}

\section{Perfil de deformaciones longitudinales}

En la Figura 7-23 se recoge el perfil de deformaciones longitudinales $\varepsilon$ del hormigón a lo largo de la longitud de la Viga 3, medido mediante extensometría manual tras la transferencia del pretensado y en las edades de medida posteriores ( 7 días, 28 días, 60 días y 90 días). Por otro lado, en la Figura 7-24 se incluye el perfil de deformaciones longitudinales $\varepsilon$ de la Viga 3, medido mediante instrumentación electrónica (galgas extensiométricas), en los mismos periodos de tiempo. Para la determinación de las longitudes de transferencia se ha seguido el "Método del 95\% de la deformación máxima media", expuesto anteriormente. 
VIGA 3. DEFORMACIONES MEDIDAS CON EXTENSOMETRÍA MANUAL

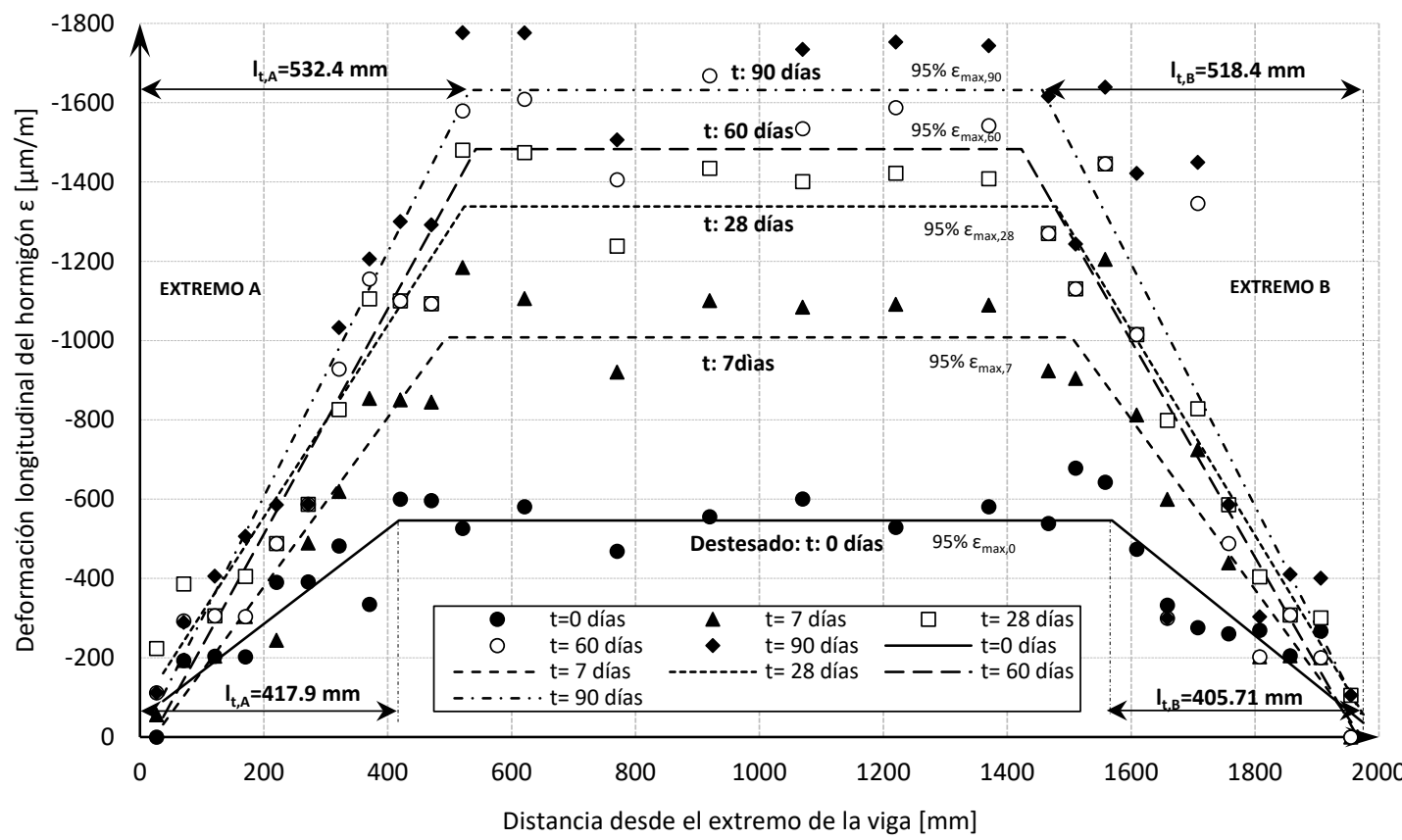

Figura 7-22 Evolución de la longitud de transferencia lt y de las deformaciones longitudinales $\varepsilon$ en la Viga 3, tras el destesado. Alambres sin corrosión. Deformaciones medidas con extensiometría manual.

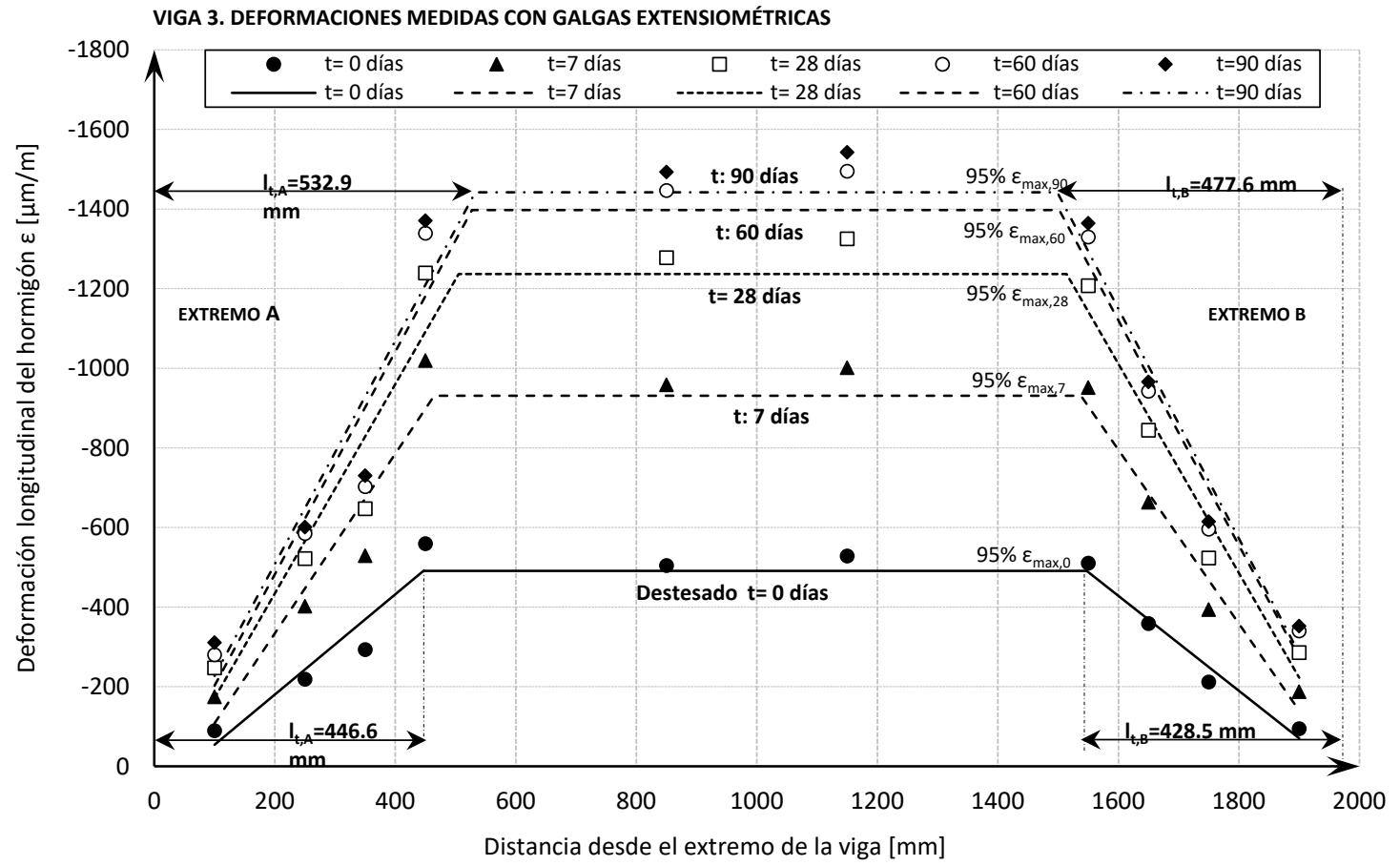

Figura 7-23 Evolución de la longitud de transferencia lt y de las deformaciones longitudinales $\varepsilon$ en la Viga 3, tras el destesado. Alambres sin corrosión. Deformaciones medidas con galgas extensiométricas. 
En la Tabla 7-17 se incluyen, para la Viga 3 y para los distintos periodos de tiempo considerados, los parámetros derivados de las medidas tomadas mediante extensometría manual que determinan el perfil de deformaciones: el valor de deformación media $\boldsymbol{\varepsilon}_{\max }$ en la meseta central, donde el pretensado está plenamente desarrollado; el valor del $95 \%$ de dicha deformación media ( $\left.95 \% \boldsymbol{\varepsilon}_{\max }\right)$; las leyes de ajuste lineal en la zona de transferencia, así como su coeficiente de determinación $\mathrm{R}^{2}$; y las longitudes de transferencia en los extremos A y B, resultantes de la intersección de ambas leyes.

abla 7-17 Parámetros numéricos de los perfiles de deformación en la Viga 3. Deformaciones medidas con extensiometría manual.

\begin{tabular}{|c|c|c|c|c|c|c|c|c|}
\hline \multirow{2}{*}{$\begin{array}{c}\text { Tiempo } \\
\text { [días] }\end{array}$} & \multicolumn{2}{|c|}{ Meseta Central } & \multicolumn{3}{|c|}{ Extremo A } & \multicolumn{3}{|c|}{ Extremo B } \\
\hline & $\begin{array}{c}\varepsilon_{\max } \\
{[\mu \mathrm{m} / \mathrm{m}]}\end{array}$ & $\begin{array}{l}95 \% \varepsilon_{\max } \\
{[\mu \mathrm{m} / \mathrm{m}]}\end{array}$ & Ajuste lineal & $\mathbf{R}^{2}$ & $\begin{array}{c}1_{\mathrm{t}, \mathrm{A}} \\
{[\mathrm{mm}]}\end{array}$ & Ajuste lineal & $\mathbf{R}^{2}$ & $\begin{array}{c}1_{\mathrm{t}, \mathrm{B}} \\
{[\mathrm{mm}]}\end{array}$ \\
\hline $\mathrm{t}=0$ & -574.97 & -546.23 & $y=-1.1973 x-45.846$ & 0.81 & 417.92 & $y=1.2581 x-2520.5$ & 0.85 & 405.71 \\
\hline $\mathrm{t}=7$ & -1061.13 & -1008.07 & $y=-2.1336 x+47.643$ & 0.93 & 494.80 & $y=2.1511 x-4243.9$ & 0.83 & 470.69 \\
\hline $\mathrm{t}=28$ & -1408.64 & -1338.21 & $y=-2.4213 x-70.540$ & 0.93 & 523.55 & $y=2.5569 x-5225.1$ & 0.66 & 495.89 \\
\hline $\mathrm{t}=60$ & -1561.02 & -1482.97 & $y=-2.8383 x+55.987$ & 0.92 & 542.21 & $y=2.7323 x-5371.4$ & 0.63 & 551.83 \\
\hline $\mathrm{t}=90$ & -1717.85 & -1631.95 & $y=-3.0835 x+9.7929$ & 0.99 & 532.43 & $y=3.1402 x-6285.3$ & 0.62 & 518.38 \\
\hline
\end{tabular}

Por su parte, en la Tabla 7-18 se incluyen los parámetros que definen los perfiles de deformación de la Viga 3, obtenidos mediante el análisis de los resultados experimentales arrojados por la instrumentación electrónica (galgas extensiométricas).

Tabla 7-18 Parámetros numéricos de los perfiles de deformación en la Viga 2. Deformaciones medidas con galgas extensiométricas.

\begin{tabular}{|c|c|c|c|c|c|c|c|c|}
\hline \multirow{2}{*}{$\begin{array}{c}\text { Tiempo } \\
\text { [días] }\end{array}$} & \multicolumn{2}{|c|}{ Meseta Central } & \multicolumn{3}{|c|}{ Extremo A } & \multicolumn{3}{|c|}{ Extremo B } \\
\hline & $\begin{array}{c}\varepsilon_{\max } \\
{[\mu \mathrm{m} / \mathrm{m}]}\end{array}$ & $\begin{array}{l}95 \% \varepsilon_{\max } \\
{[\mu \mathrm{m} / \mathrm{m}]}\end{array}$ & Ajuste lineal & $\mathbf{R}^{2}$ & $\begin{array}{c}\mathbf{l}_{\mathrm{t}, \mathrm{A}} \\
{[\mathrm{mm}]}\end{array}$ & Ajuste lineal & $\mathbf{R}^{2}$ & $\begin{array}{c}1_{\mathrm{t}, \mathrm{B}} \\
{[\mathrm{mm}]}\end{array}$ \\
\hline $\mathrm{t}=0$ & -516.82 & -490.98 & $y=-1.2601+71.839$ & 0.90 & 446.64 & $y=1.1928 x-2336.8$ & 0.98 & 428.53 \\
\hline$t=7$ & -979.97 & -930.97 & $y=-2.2573 x+117.66$ & 0.89 & 464.55 & $y=2.1841 x-4289.4$ & 0.97 & 438.33 \\
\hline $\mathrm{t}=28$ & -1301.80 & -1236.71 & $y=-2.6304 x+91.973$ & 0.88 & 505.13 & $y=2.6277 x-5215.4$ & 0.96 & 461.87 \\
\hline $\mathrm{t}=60$ & -1471.00 & -1397.45 & $y=-2.7975 x+77.236$ & 0.88 & 527.14 & $y=2.8249 x-5639.9$ & 0.96 & 474.19 \\
\hline $\mathrm{t}=90$ & -1518.00 & -1442.10 & $y=-2.8064 x+53.487$ & 0.88 & 532.92 & $y=2.8850 x-5765.1$ & 0.96 & 477.56 \\
\hline
\end{tabular}

En la Tabla 7-19 se incluyen los incrementos relativos, medidos con extensiometría manual, que experimenta la deformación por compresión en la meseta central $\left(\Delta 0.95 \cdot \varepsilon_{\max }\right)$ de la Viga 3 , así como los incrementos en las longitudes de transferencia $\Delta l_{t, A}$ y $\Delta l_{t, B}$ en los extremos, con respecto a la situación de partida tras el destesado.

Tabla 7-19 Incremento de las deformaciones a lo largo del tiempo en Viga 3. Deformaciones medidas con extensiometría manual.

\begin{tabular}{|c|c|c|c|c|c|c|}
\hline \multirow{2}{*}{ t [días] } & \multicolumn{2}{|c|}{ Meseta Central } & \multicolumn{2}{|c|}{ Extremo A } & \multicolumn{2}{|c|}{ Extremo B } \\
\hline & $0.95 \cdot \varepsilon_{\max }[\mu \mathrm{m} / \mathrm{m}]$ & $\Delta 0.95 \cdot \varepsilon_{\max }[\%]$ & $\mathbf{l}_{\mathrm{t}, \mathrm{A}}[\mathrm{mm}]$ & $\Delta \mathbf{l}_{\mathrm{t}, \mathrm{A}}[\%]$ & $1_{\mathrm{t}, \mathrm{B}}[\mathrm{mm}]$ & $\Delta \mathbf{l}_{t, \mathrm{~B}}[\%]$ \\
\hline $\mathrm{t}=0$ & -546.23 & 0.00 & 417.92 & 0.00 & 405.71 & 0.00 \\
\hline $\mathrm{t}=7$ & -1008.07 & 84.55 & 494.80 & 18.40 & 470.69 & 16.02 \\
\hline $\mathrm{t}=28$ & -1338.21 & 144.99 & 523.55 & 25.27 & 495.89 & 22.23 \\
\hline $\mathrm{t}=60$ & -1482.97 & 171.49 & 542.21 & 29.74 & 551.83 & 36.01 \\
\hline $\mathrm{t}=90$ & -1631.95 & 198.77 & 532.43 & 27.40 & 518.38 & 27.77 \\
\hline
\end{tabular}


En la Tabla 7-20, al igual que en la anterior, se incluyen los incrementos relativos, medidos con galgas extensiométricas, que experimenta la deformación por compresión en la meseta central $\left(\Delta 0.95 \cdot \varepsilon_{\max }\right)$ de la Viga 3, así como los incrementos en las longitudes de transferencia $\Delta l_{t, A}$ y $\Delta l_{t, B}$ en los extremos A y B.

Tabla 7-20 Incrementos de deformación a lo largo del tiempo en Viga 3. Deformaciones medidas con galgas extensiométricas.

\begin{tabular}{ccccccc}
\hline \multirow{2}{*}{$\mathrm{t}$ [días] } & \multicolumn{2}{c}{ Meseta Central } & \multicolumn{2}{c}{ Extremo A } & \multicolumn{2}{c}{ Extremo B } \\
\cline { 2 - 7 } & $\mathbf{0 . 9 5} \cdot \varepsilon_{\max }[\boldsymbol{\mu m} / \mathrm{m}]$ & $\Delta \mathbf{0 . 9 5} \cdot \varepsilon_{\max }[\%]$ & $\mathbf{1}_{\mathrm{t}, \mathrm{A}}[\mathrm{mm}]$ & $\Delta \mathbf{1}_{\mathrm{t}, \mathrm{A}}[\%]$ & $\mathbf{1}_{\mathrm{t}, \mathrm{B}}[\mathrm{mm}]$ & $\Delta \mathbf{1}_{\mathrm{t}, \mathrm{B}}[\%]$ \\
\hline $\mathrm{t}=0$ & $\mathbf{- 4 9 0 . 9 8}$ & 0.00 & $\mathbf{4 4 6 . 6 4}$ & 0.00 & $\mathbf{4 2 8 . 5 3}$ & 0.00 \\
\hline $\mathrm{t}=7$ & $\mathbf{- 9 3 0 . 9 7}$ & 89.62 & $\mathbf{4 6 4 . 5 5}$ & 4.01 & $\mathbf{4 3 8 . 3 3}$ & 2.29 \\
\hline $\mathrm{t}=28$ & $\mathbf{- 1 2 3 6 . 7 1}$ & 151.89 & $\mathbf{5 0 5 . 1 3}$ & 13.09 & $\mathbf{4 6 1 . 8 7}$ & 7.78 \\
\hline $\mathrm{t}=60$ & $\mathbf{- 1 3 9 7 . 4 5}$ & 184.63 & $\mathbf{5 2 7 . 1 4}$ & 18.02 & $\mathbf{4 7 4 . 1 9}$ & 10.66 \\
\hline $\mathrm{t}=90$ & $\mathbf{- 1 4 4 2 . 1 0}$ & 193.72 & $\mathbf{5 3 2 . 9 2}$ & 19.32 & $\mathbf{4 7 7 . 5 6}$ & 11.44 \\
\hline
\end{tabular}

\section{Deslizamiento en los extremos}

En las gráficas de la Figura 7-25 se recogen los deslizamientos en los extremos A y B de la Viga 3, registrados mediante los flexímetros ubicados en cada uno de los alambres. Los flexímetros $F_{1}$ y $F_{2}$ estaban ubicados en la cara superior de la viga, mientras que los flexímetros $\mathrm{F}_{3}$ y $\mathrm{F}_{4}$ registraban los deslizamientos de los alambres situados en la cara inferior.
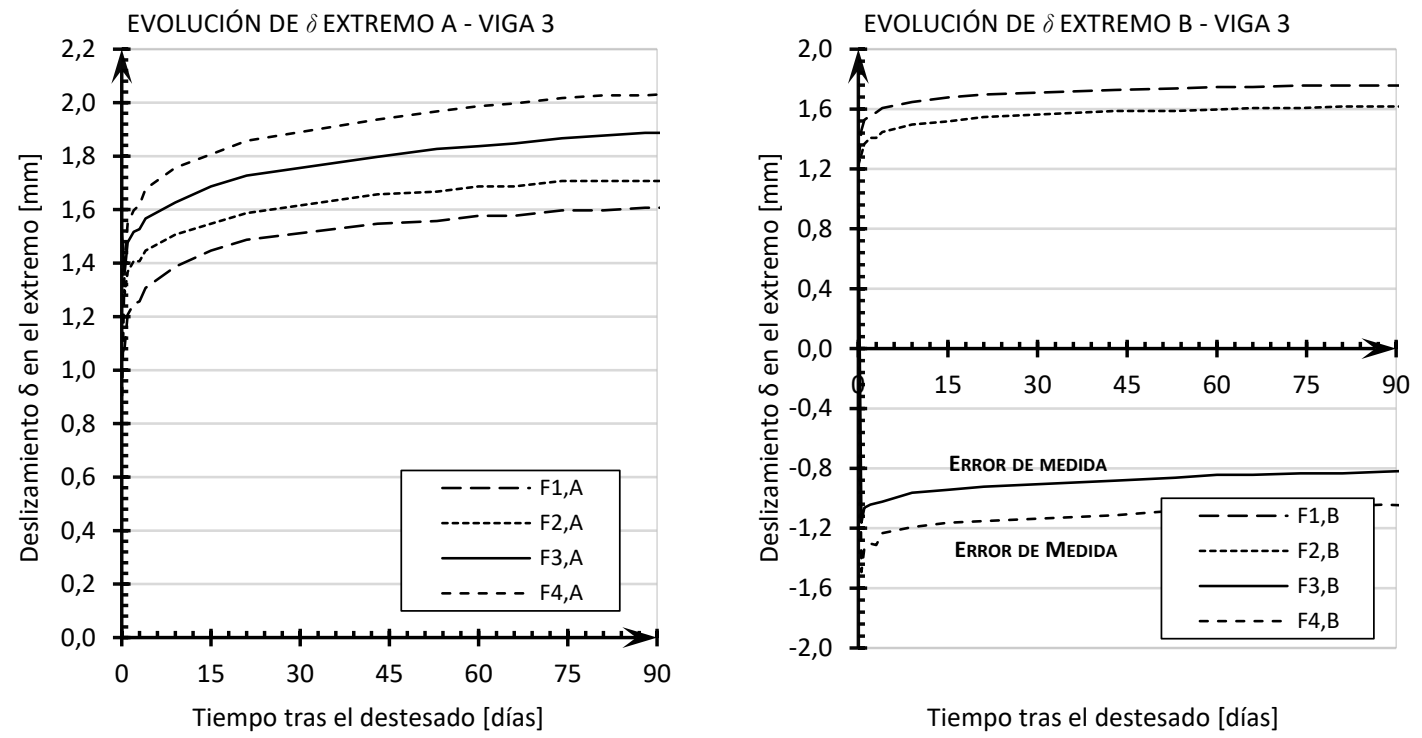

Figura 7-24 Evolución de los deslizamientos de los alambres en los extremos A (izq.) y B (der.) de la Viga 3, tras el destesado. Alambres sin corrosión. Deslizamientos medidos con fleximetros.

En la Tabla 7-21 se incluyen los deslizamientos en cada extremo de la Viga $3, F_{A}$ y $F_{B}$, cuyo valor es el resultado de la media de los registros de los cuatro flexímetros ubicados en dicho extremo. Además, 
se incluyen los siguientes parámetros: el incremento relativo con respecto al valor registrado tras el destesado $\Delta \mathrm{F}$, el valor del coeficiente $\alpha$ y la longitud de transferencia $l_{\text {t,media }}$ en cada extremo.

Tabla 7-21 Deslizamientos en los extremos A y B de la Viga 3, registrados por los fleximetros

\begin{tabular}{ccccccccc}
\hline \multirow{2}{*}{ Tiempo } & \multicolumn{3}{c}{ Extremo A (Extremo de corte) } & \multicolumn{3}{c}{ Extremo B (Extremo muerto) } \\
\cline { 2 - 9 } & $\mathbf{F}_{\mathbf{A}}[\mathbf{m m}]$ & $\Delta \mathbf{F}_{\mathbf{A}}[\%]$ & $\mathbf{1}_{\mathrm{t}, \mathrm{A}-\mathrm{media}}[\mathrm{mm}]$ & $\alpha$ & $\mathbf{F}_{\mathbf{B}}[\mathbf{m m}]$ & $\Delta \mathbf{F}_{\mathbf{B}}[\%]$ & $\mathbf{L}_{\mathrm{t}, \mathrm{B}-\mathrm{media}}[\mathrm{mm}]$ & $\alpha$ \\
\hline $\mathrm{t}=0$ días & 1.20 & 0.00 & 432.28 & 2.32 & 1.23 & 0.00 & 417.12 & 2.18 \\
\hline $\mathrm{t}=7$ días & 1.53 & 28.19 & 479.68 & 2.01 & 1.55 & 25.77 & 454.51 & 1.89 \\
\hline $\mathrm{t}=28$ días & 1.70 & 41.97 & 514.34 & 1.95 & 1.64 & 33.07 & 478.88 & 1.88 \\
\hline $\mathrm{t}=60$ días & 1.77 & 47.68 & 534.68 & 1.94 & 1.67 & 35.57 & 513.01 & 1.97 \\
\hline $\mathrm{t}=90$ días & 1.81 & 51.06 & 532.67 & 1.89 & 1.69 & 36.93 & 497.97 & 1.90 \\
\hline
\end{tabular}

\section{Valoración de los resultados experimentales obtenidos en la Viga 3}

La máxima deformación instantánea media del hormigón $\boldsymbol{\varepsilon}_{\max }$, tras la transferencia del pretensado, en la meseta central de la Viga 3 es de $-574,97 \mu \mathrm{m} / \mathrm{m}$ en la cara E (Tabla $7-17$ ) y de $-516,82 \mu \mathrm{m} / \mathrm{m}$ en la cara G (Tabla 7-18). Por tanto, la máxima deformación $\varepsilon_{\max }$ promedio de ambas caras es $-545,90$ $\mu \mathrm{m} / \mathrm{m}$ (Tabla 7-22). Como se ha comentado en la valoración de los resultados obtenidos en las vigas anteriores, las pequeñas diferencias de valor registradas entre cada una de las caras pueden deberse a una ligera excentricidad del centro de gravedad de los alambres, a heterogeneidades del hormigón, o simplemente, a márgenes de error derivados de la sensibilidad del método de medida.

\begin{tabular}{|c|c|c|c|c|c|c|}
\hline \multirow{2}{*}{ t [días] } & \multicolumn{2}{|c|}{ Meseta Central [Media caras E y G] } & \multicolumn{2}{|c|}{ Extremo A [Media caras E y G] } & \multicolumn{2}{|c|}{ Extremo B [Media caras E y G] } \\
\hline & $\varepsilon_{\max }[\mu \mathrm{m} / \mathrm{m}]$ & $\Delta \varepsilon_{\max }[\%]$ & $\mathbf{1}_{\mathrm{t}, \mathrm{A}}[\mathrm{mm}]$ & $\Delta \mathbf{1}_{\mathrm{t}, \mathrm{A}}[\%]$ & $1_{t, B}[\mathrm{~mm}]$ & $\Delta \mathbf{l}_{\mathrm{t}, \mathrm{B}}[\%]$ \\
\hline $\mathrm{t}=0$ & -545.90 & 0.00 & 432.28 & 0.00 & 417.12 & 0.00 \\
\hline $\mathrm{t}=7$ & -1020.55 & 86.95 & 479.68 & 10.96 & 454.51 & 8.96 \\
\hline $\mathrm{t}=28$ & -1355.22 & 148.26 & 514.34 & 18.98 & 478.88 & 14.81 \\
\hline $\mathrm{t}=60$ & -1516.01 & 177.71 & 534.68 & 23.69 & 513.01 & 22.99 \\
\hline $\mathrm{t}=90$ & -1617.92 & 196.38 & 532.67 & 23.22 & 497.97 & 19.38 \\
\hline
\end{tabular}

Como puede apreciarse en la Figura 7-26 (irq.), durante los primera semana se observa un aumento considerable de la deformación máxima de compresión $\boldsymbol{\varepsilon}_{\max }$ (Tabla 7-17; Tabla 7-18), alcanzando un valor promedio $-1020,67 \mu \mathrm{m} / \mathrm{m}$ y un incremento porcentual del $86,95 \%$ con respecto al valor inicial (Tabla 7-22). Como ocurría en los casos anteriores, a partir de ese momento las deformaciones a lo largo de la viga siguen creciendo, debido fundamentalmente a la retracción, pero la tasa de crecimiento se va atenuando, de manera que a los 28 días, en la meseta central, la deformación promedio es igual a $-1355,22 \mu \mathrm{m} / \mathrm{m}\left(\Delta \varepsilon_{\max , 28}=148,26 \%\right)$, a los 60 días es $-1516,01 \mu \mathrm{m} / \mathrm{m}\left(\Delta \varepsilon_{\max , 00}=177,71 \%\right), y$ transcurridos 90 días es igual -1617,92 $\mu \mathrm{m} / \mathrm{m}\left(\Delta \varepsilon_{\max , 90}=196,38 \%\right.$ ) (Tabla 7-22; Figura 7-26).

Los ajustes lineales para la determinación de los tramos ascendente y descendente del perfil de deformaciones arrojan coeficientes de determinación $\mathrm{R}^{2}$ razonablemente buenos, situándose por encima del 0,80 excepto en el extremo B de la Cara E (medidos mediante extensometría manual), 
donde el coeficiente desciende hasta 0,62 (Tabla 7-17, Tabla 7-18). La mayor dispersión de los resultados localizada en dicho extremo es debida a que uno de los tramos de medición situado en el mismo arrojaba resultados muy alejados del resto. Por otro lado, como en los casos anteriores, las pendientes de los tramos ascendente y descendente del perfil de deformaciones aumentan rápidamente los primeros días tras el destesado, pero se aprecia cierta tendencia hacia la estabilización a partir de los 60 días (Tabla 7-17; Tabla 7-18).

En cuanto a las longitudes de transferencia $l_{t}$, los resultados en ambos extremos y en ambas caras de la viga son similares, así como su evolución con el paso del tiempo (Tabla 7-19; Tabla 7-20). Valga como ejemplo que justo tras la transferencia del pretensado ( $\mathrm{t}=0$ días), las longitudes de transferencia obtenidas han sido: en el extremo A, 417,92 mm (Cara E) y 446,64 mm (Cara G); en el extremo B, $405,71 \mathrm{~mm}$ (Cara E) y 428,53 mm (Cara G). En el extremo A, el valor promedio entre caras de la longitud de transferencia $l_{t, A}$, en el momento de la transferencia ( $\mathrm{t}=0$ días), es igual 432,28 mm, mientras que en el extremo B es igual a $l_{h \mathrm{~B}}=417,12 \mathrm{~mm}$. Por otro lado, al igual que ocurre con las deformaciones de compresión en el tramo central $\boldsymbol{\varepsilon}_{\text {max }}$, las longitudes de transferencia $l_{t}$ experimentan un crecimiento desde el momento del destesado, atenuado con el tiempo, alcanzando a los 90 días un valor promedio $l_{h A}=532,67 \mathrm{~mm}$ en el extremo $A$, lo que supone un incremento del $23,22 \%$ con respecto al valor inicial, y de $l_{b B}=497,97 \mathrm{~mm}$ en el extremo $\mathrm{B}\left(\Delta \mathrm{l}_{\mathrm{t}, \mathrm{B}}=19,38 \%\right.$ ) (Figura 7-26(der);Tabla 7-22). En el extremo B, en el tramo comprendido entre los 60 y los 90 días se observa una reducción de la longitud de transferencia $l_{t}$ (de 513,01 a 497,97 mm), cuyo origen es más probable que se encuentre en errores de medida o de interpretación de los resultados que en un fenómeno real de redistribución de esfuerzos de difícil explicación.
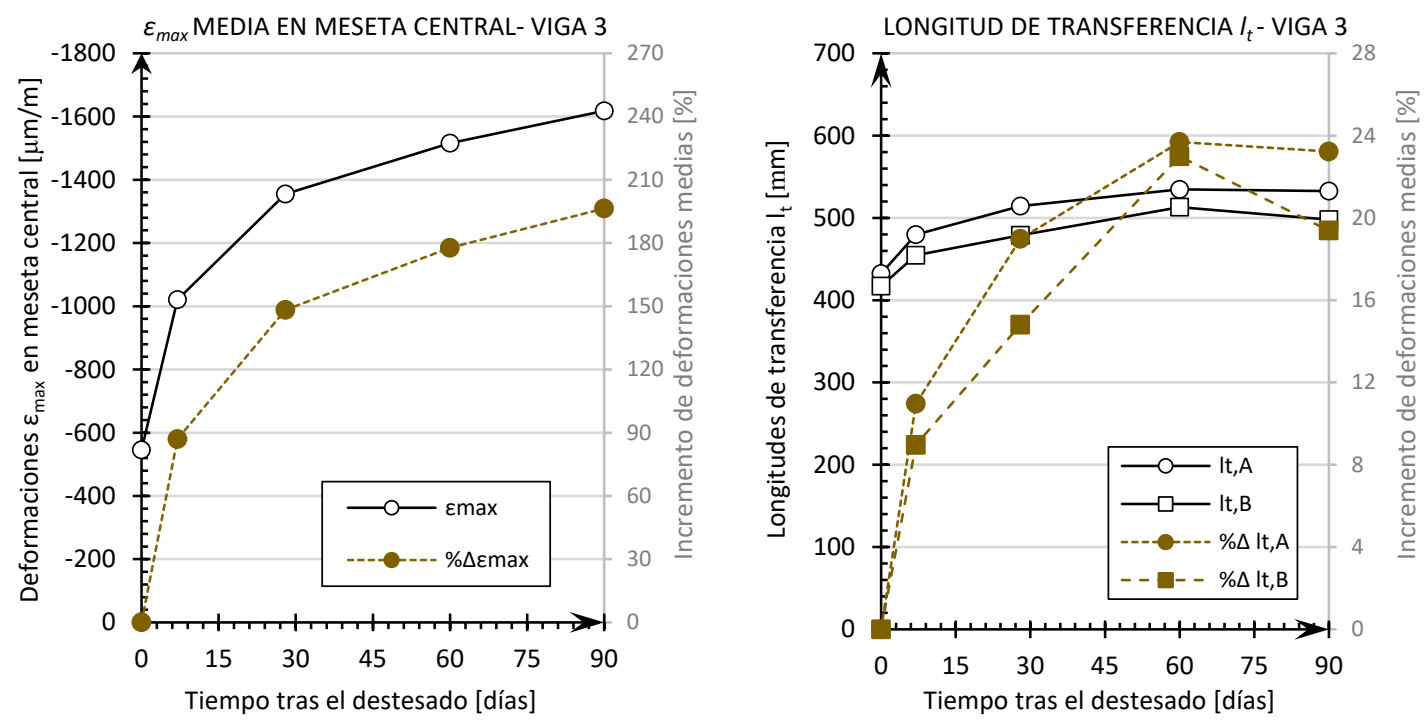

Figura 7-25 Evolución de los valores medios de deformación $\varepsilon_{\text {max }}$ en meseta central (izquierda) y de longitud de transferencia lt (derecha) en la Viga 3, tras el destesado. Alambres sin corrosión. Valores promedio de ambas caras.

Tal y como puede observarse en la Figura 7-21, la dispersión de los deslizamientos relativos del alambre $\delta$ en extremo de vigas es menor que en los casos anteriores, sin embargo, los flexímetros $\mathrm{F}_{3}$ y $\mathrm{F}_{4}$ del extremo $\mathrm{B}$ fallaron en sus lecturas iniciales, aunque su evolución posterior parece coherente con el resto de los resultados. A efectos de la determinación del deslizamiento medio en el extremo 
$\mathrm{B}$, los datos registrados en dichos flexímetros no se han tenido en cuenta en el análisis, por considerarse atípicos.

En el momento del destesado ( $\mathrm{t}=0$ días), el coeficiente $\alpha$ obtenido en el extremo A es igual a 2,32, mientras que en el extremo B es igual a 2,18. En ambos casos, los valores son inferiores a los registrados en las vigas anteriores, por lo que siguiendo el esquema teórico de la expresión de Guyon (Guyon, 1953), la distribución de la tensión de adherencia $\tau_{b}$ sería prácticamente constante, dando como resultado una variación lineal de las deformaciones en el alambre y en el hormigón. Por otro lado, como en los casos anteriores, se observa que, con el paso del tiempo, el coeficiente $\alpha$ va descendiendo y tiende a converger hacia un valor cercano a 2 .

\subsubsection{Viga 4}

\section{Perfil de deformaciones longitudinales}

En la Figura 7-27 se recoge el perfil de deformaciones longitudinales $\varepsilon$ del hormigón a lo largo de la longitud de la Viga 4, medido mediante extensometría manual tras la transferencia del pretensado y en las edades de medida posteriores (7 días, 28 días, 60 días y 90 días). Por otro lado, en la Figura 7-28 se incluye el perfil de deformaciones longitudinales $\varepsilon$ de la Viga 3, medido mediante instrumentación electrónica (galgas extensiométricas), en los mismos periodos de tiempo. Para la determinación de las longitudes de transferencia se ha seguido el "Método del 95\% de la deformación máxima media", expuesto anteriormente. Por otro lado, en la Tabla 7-23 se incluyen, para la Viga 4 y para los distintos periodos de tiempo considerados, los parámetros derivados de las medidas tomadas mediante extensometría manual que determinan el perfil de deformaciones: el valor de deformación media $\boldsymbol{\varepsilon}_{\max }$ en la meseta central, donde el pretensado está plenamente desarrollado; el valor del $95 \%$ de dicha deformación media $\left(95 \% \boldsymbol{\varepsilon}_{\max }\right)$; las leyes de ajuste lineal en la zona de transferencia, así como su coeficiente de determinación $\mathrm{R}^{2}$; y las longitudes de transferencia en los extremos A y B, resultantes de la intersección de ambas leyes.

Tabla 7-23 Parámetros numéricos de los perfiles de deformación en la Viga 3. Deformaciones medidas con extensiometría manual.

\begin{tabular}{|c|c|c|c|c|c|c|c|c|}
\hline \multirow{2}{*}{$\begin{array}{c}\text { Tiempo } \\
\text { [días] }\end{array}$} & \multicolumn{2}{|c|}{ Meseta Central } & \multicolumn{3}{|c|}{ Extremo A } & \multicolumn{3}{|c|}{ Extremo B } \\
\hline & $\begin{array}{c}\varepsilon_{\max } \\
{[\mu \mathrm{m} / \mathrm{m}]}\end{array}$ & $\begin{array}{l}95 \% \varepsilon_{\max } \\
{[\mu \mathrm{m} / \mathrm{m}]}\end{array}$ & Ajuste lineal & $\mathbf{R}^{2}$ & $\begin{array}{c}1_{\mathrm{t}, \mathrm{A}} \\
{[\mathrm{mm}]}\end{array}$ & Ajuste lineal & $\mathbf{R}^{2}$ & $\begin{array}{c}\mathrm{l}_{\mathrm{t}, \mathrm{B}} \\
{[\mathrm{mm}]}\end{array}$ \\
\hline $\mathrm{t}=0$ & -634.02 & -602.32 & $y=-0.9867 x-46.247$ & 0.87 & 563.57 & $y=1.4178 x-2807.5$ & 0.83 & 419.61 \\
\hline $\mathrm{t}=7$ & -885.25 & -840.99 & $y=-1.2437 x-39.992$ & 0.98 & 644.05 & $y=1.9295 x-3790.4$ & 0.90 & 446.37 \\
\hline $\mathrm{t}=28$ & -1204.10 & -1143.89 & $y=-1.7860 x-31.852$ & 0.97 & 650.85 & $y=2.7193 x-5288.7$ & 0.93 & 450.74 \\
\hline $\mathrm{t}=60$ & -1398.96 & -1329.01 & $y=-1.8598 x-11.069$ & 0.98 & 708.65 & $y=2.8203 x-5506.3$ & 0.91 & 493.81 \\
\hline $\mathrm{t}=90$ & -1569.43 & -1490.96 & $y=-2.0868 x-52.974$ & 0.98 & 689.09 & $y=3.1332 x-6146.8$ & 0.94 & 488.99 \\
\hline
\end{tabular}

Por su parte, en la Tabla 7-24 se incluyen los parámetros que definen los perfiles de deformación de la Viga 4, obtenidos mediante el análisis de los resultados experimentales arrojados por la instrumentación electrónica (galgas extensiométricas). 
VIGA 4. DEFORMACIONES MEDIDAS CON EXTENSOMETRÍA MANUAL - CARA E

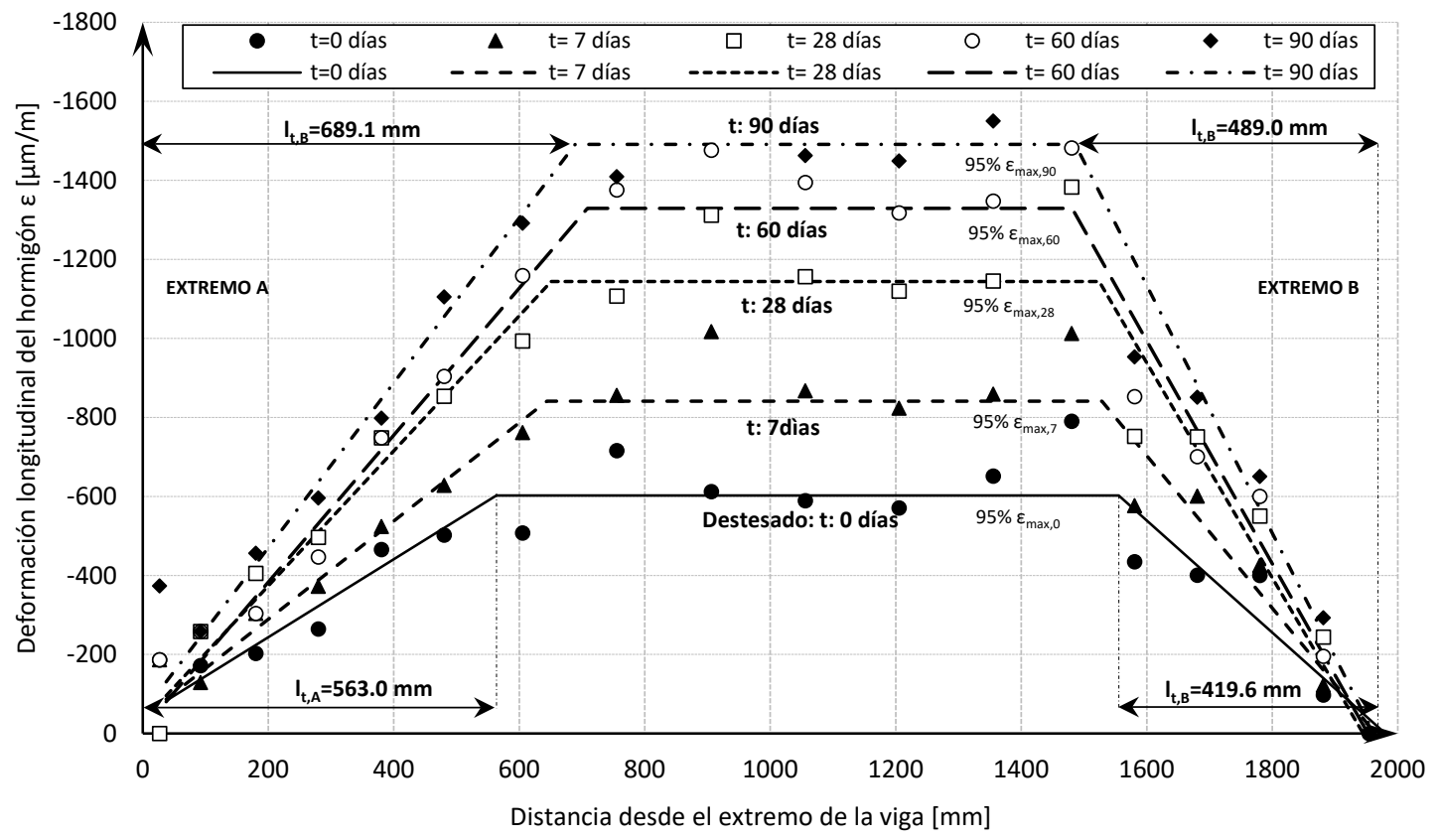

Figura 7-26 Evolución de la longitud de transferencia l y de las deformaciones longitudinales $\boldsymbol{\varepsilon}$ en la Viga 4, tras el destesado. Alambres sin corrosión. Deformaciones medidas con extensiometría manual.

VIGA 4. DEFORMACIONES MEDIDAS CON GALGAS EXTENSIOMÉTRICAS - CARA G

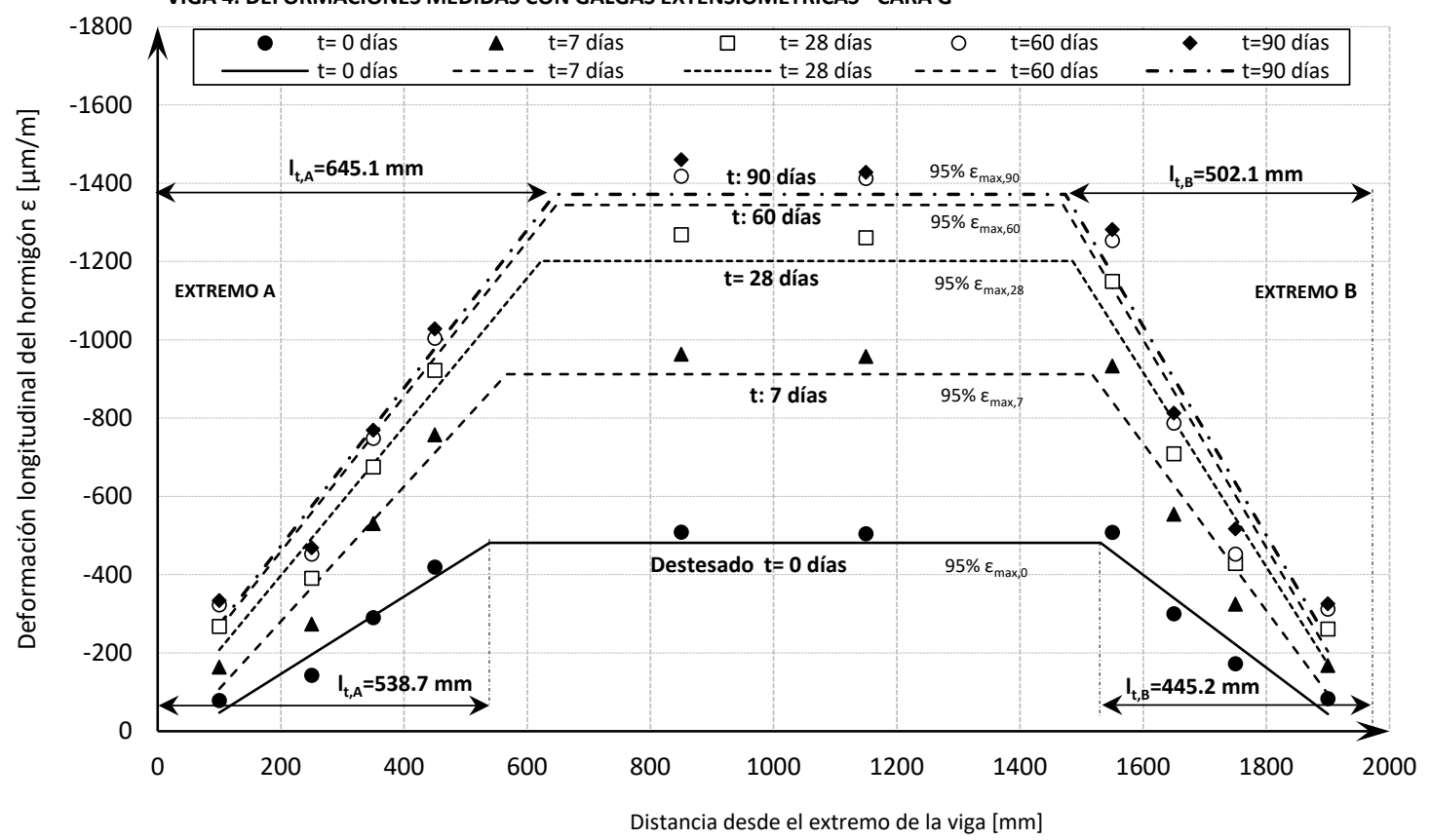

Figura 7-27 Evolución de la longitud de transferencia lty de las deformaciones longitudinales $\varepsilon$ en la Viga 4, tras el destesado. Alambres sin corrosión. Deformaciones medidas con galgas extensiométricas. 
TESIS DOCTORAL INFLUENCLA DE LA CORROSIÓN EN LA ADHERENCIA DE ALAMBRES EN ELEMENTOS PRETENSADOS DE HORMIGÓN

Tabla 7-24 Parámetros numéricos de los perfiles de deformación en la Viga 2. Deformaciones medidas con galgas extensiométricas.

\begin{tabular}{|c|c|c|c|c|c|c|c|c|}
\hline \multirow{2}{*}{$\begin{array}{c}\text { Tiempo } \\
\text { [días] }\end{array}$} & \multicolumn{2}{|c|}{ Meseta Central } & \multicolumn{3}{|c|}{ Extremo A } & \multicolumn{3}{|c|}{ Extremo B } \\
\hline & $\begin{array}{c}\varepsilon_{\max } \\
{[\mu \mathrm{m} / \mathrm{m}]}\end{array}$ & $\begin{array}{l}95 \% \varepsilon_{\max } \\
{[\mu \mathrm{m} / \mathrm{m}]}\end{array}$ & Ajuste lineal & $\mathbf{R}^{2}$ & $\begin{array}{c}1_{\mathrm{t}, \mathrm{A}} \\
{[\mathrm{mm}]}\end{array}$ & Ajuste lineal & $\mathbf{R}^{2}$ & $\begin{array}{c}\mathbf{l}_{\mathrm{t}, \mathrm{B}} \\
{[\mathrm{mm}]}\end{array}$ \\
\hline $\mathrm{t}=0$ & -506.64 & -481.31 & $y=-0.9893+51.640$ & 0.94 & 538.72 & $y=1.1849 x-2295.2$ & 0.92 & 445.16 \\
\hline $\mathrm{t}=7$ & -960.18 & -912.17 & $y=-1.7233 x+64.228$ & 0.93 & 566.58 & $y=2.1335 x-4148.5$ & 0.92 & 459.09 \\
\hline $\mathrm{t}=28$ & -1264.60 & -1201.37 & $y=-1.8998 x-17.809$ & 0.94 & 622.99 & $y=2.4834 x-4889.8$ & 0.91 & 490.77 \\
\hline $\mathrm{t}=60$ & -1415.15 & -1344.39 & $y=-1.9791 x-63.074$ & 0.94 & 647.42 & $y=2.6529 x-5244.2$ & 0.90 & 505.98 \\
\hline $\mathrm{t}=90$ & -1443.75 & -1371.56 & $y=-2.0184 x-69.571$ & 0.94 & 645.06 & $y=2.6716 x-5309.3$ & 0.92 & 502.08 \\
\hline
\end{tabular}

En la Tabla 7-25 se incluyen los incrementos relativos, medidos con extensiometría manual, que experimenta la deformación por compresión en la meseta central $\left(\Delta 0.95 \cdot \varepsilon_{\max }\right)$ de la Viga 4 , así como los incrementos en las longitudes de transferencia $\Delta l_{t, A}$ y $\Delta l_{t, B}$ en los extremos, con respecto a la situación de partida tras el destesado.

\begin{tabular}{|c|c|c|c|c|c|c|}
\hline \multirow{2}{*}{ t [días] } & \multicolumn{2}{|c|}{ Meseta Central } & \multicolumn{2}{|c|}{ Extremo A } & \multicolumn{2}{|c|}{ Extremo B } \\
\hline & $0.95 \cdot \varepsilon_{\max }[\mu \mathrm{m} / \mathrm{m}]$ & $\Delta 0.95 \cdot \varepsilon_{\max }[\%]$ & $\mathbf{l}_{\mathrm{t}, \mathrm{A}}[\mathrm{mm}]$ & $\Delta 1_{t, A}[\%]$ & $\mathbf{l}_{t, \mathrm{~B}}[\mathrm{~mm}]$ & $\Delta \mathbf{l}_{\mathrm{t}, \mathrm{B}}[\%]$ \\
\hline $\mathrm{t}=0$ & -602.32 & 0.00 & 563.57 & 0.00 & 419.61 & 0.00 \\
\hline $\mathrm{t}=7$ & -840.99 & 39.62 & 644.05 & 14.28 & 446.37 & 6.38 \\
\hline $\mathrm{t}=28$ & -1143.89 & 89.91 & 650.85 & 15.49 & 450.74 & 7.42 \\
\hline $\mathrm{t}=60$ & -1329.01 & 120.65 & 708.65 & 25.74 & 493.81 & 17.68 \\
\hline $\mathrm{t}=90$ & -1490.96 & 147.54 & 689.09 & 22.27 & 488.99 & 16.53 \\
\hline
\end{tabular}

En la Tabla 7-26, al igual que en la anterior, se incluyen los incrementos relativos, medidos con galgas extensiométricas, que experimenta la deformación por compresión en la meseta central $\left(\Delta 0.95 \cdot \varepsilon_{\max }\right)$ de la Viga 4, así como los incrementos en las longitudes de transferencia $\Delta l_{t, A}$ y $\Delta l_{t, B}$ en los extremos A y B.

Tabla 7-26 Incrementos de deformación a lo largo del tiempo en Viga 4. Deformaciones medidas con galgas extensiométricas.

\begin{tabular}{ccccccc}
\hline \multirow{2}{*}{ [días] } & \multicolumn{2}{c}{ Meseta Central } & \multicolumn{2}{c}{ Extremo $\mathbf{A}$} & \multicolumn{2}{c}{ Extremo $\mathbf{B}$} \\
\cline { 2 - 7 } & $\mathbf{0 . 9 5} \cdot \boldsymbol{\varepsilon}_{\max }[\boldsymbol{\mu \mathrm { m } / \mathrm { m } ]}$ & $\Delta \mathbf{0 . 9 5} \cdot \boldsymbol{\varepsilon}_{\max }[\mathbf{\%}]$ & $\mathbf{1}_{\mathrm{t}, \mathrm{A}}[\mathbf{m m}]$ & $\Delta \mathbf{1}_{\mathrm{t}, \mathrm{A}}[\mathbf{\%}]$ & $\mathbf{1}_{\mathrm{t}, \mathrm{B}}[\mathbf{m m}]$ & $\Delta \mathbf{1}_{\mathrm{t}, \mathrm{B}}[\mathbf{\%}]$ \\
\hline $\mathrm{t}=0$ & -481.31 & 0.00 & 538.72 & 0.00 & 445.16 & 0.00 \\
\hline $\mathrm{t}=7$ & -912.17 & 89.52 & 566.58 & 5.17 & 459.09 & 3.13 \\
\hline $\mathrm{t}=28$ & -1201.37 & 149.60 & 622.99 & 15.64 & 490.77 & 10.24 \\
\hline $\mathrm{t}=60$ & -1344.39 & 179.32 & 647.42 & 20.18 & 505.98 & 13.66 \\
\hline $\mathrm{t}=90$ & -1371.56 & 184.96 & 645.06 & 19.74 & 502.08 & 12.78 \\
\hline
\end{tabular}

\section{Deslizamiento en los extremos}

En las gráficas de la Figura 7-29 se recogen los deslizamientos en los extremos A (extremo de corte de alambres) y B (extremo "muerto") de la Viga 4, registrados mediante los flexímetros ubicados en cada uno de los alambres. Los flexímetros $\mathrm{F}_{1}$ y $\mathrm{F}_{2}$ estaban ubicados en la cara superior de la viga, 
mientras que los flexímetros $\mathrm{F}_{3}$ y $\mathrm{F}_{4}$ registraban los deslizamientos de los alambres situados en la cara inferior.
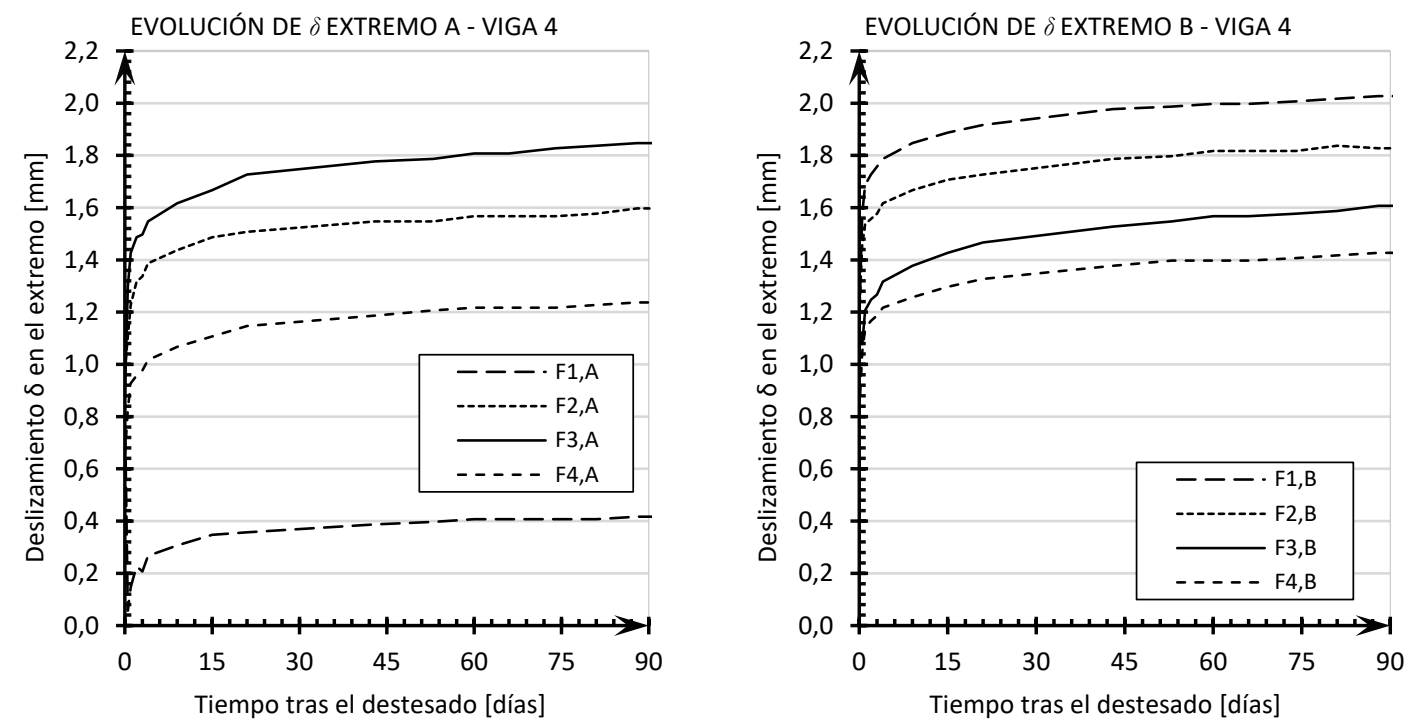

Figura 7-28 Evolución de la longitud de transferencia l ty de las deformaciones longitudinales $\boldsymbol{\varepsilon}$ en la Viga 4, tras el destesado. Alambres sin corrosion. Deformaciones medidas con galgas extensiométricas.

En la Tabla 7-27 se incluyen los deslizamientos en cada extremo de la viga $4, F_{A}$ y $F_{B}$, cuyo valor es el resultado de la media de los registros de los cuatro flexímetros ubicados en dicho extremo. Además, se incluyen los siguientes parámetros: el incremento relativo con respecto al valor registrado tras el destesado $\Delta \mathrm{F}_{\mathrm{A}}$, y el valor del coeficiente $\alpha$ resultante de la aplicación de la expresión de Guyon (Guyon, 1953) sobre la longitud de transferencia $l_{t, \text { media }}$ en cada extremo, media de las longitudes obtenidas mediante la extensiometría manual y mediante las galgas extensiométricas.

Tabla 7-27 Deslizamientos en los extremos A y B de la Viga 4, registrados por los fleximetros

\begin{tabular}{ccccccccc}
\hline \multirow{2}{*}{ Tiempo } & \multicolumn{3}{c}{ Extremo A (Extremo de corte) } & \multicolumn{5}{c}{ Extremo B (Extremo muerto) } \\
\cline { 2 - 9 } & $\mathbf{F}_{\mathrm{A}}[\mathrm{mm}]$ & $\Delta \mathbf{F}_{\mathrm{A}}[\%]$ & $\mathbf{1}_{\mathrm{t}, \mathrm{A}-\mathrm{media}}[\mathrm{mm}]$ & $\boldsymbol{\alpha}$ & $\mathbf{F}_{\mathrm{A}}[\mathrm{mm}]$ & $\Delta \mathbf{F}_{\mathrm{A}}[\%]$ & $\mathbf{L}_{\mathrm{t}, \mathrm{A}-\mathrm{media}}[\mathrm{mm}]$ & $\alpha$ \\
\hline $\mathrm{t}=0$ días & 0.93 & 0.00 & 551.14 & 3.81 & 1.08 & 0.00 & 432.39 & 2.58 \\
\hline $\mathrm{t}=7$ días & 1.35 & 44.73 & 605.31 & 2.89 & 1.51 & 40.27 & 452.73 & 1.93 \\
\hline $\mathrm{t}=28$ días & 1.48 & 59.43 & 636.92 & 2.76 & 1.64 & 52.11 & 470.75 & 1.85 \\
\hline $\mathrm{t}=60$ días & 1.52 & 64.03 & 678.04 & 2.86 & 1.69 & 56.94 & 499.90 & 1.90 \\
\hline $\mathrm{t}=90$ días & 1.56 & 67.86 & 667.07 & 2.75 & 1.72 & 59.88 & 495.53 & 1.85 \\
\hline
\end{tabular}

\section{Valoración de los resultados experimentales obtenidos en la Viga 4}

La máxima deformación instantánea media del hormigón $\boldsymbol{\varepsilon}_{\max }$, tras la transferencia del pretensado, en la meseta central de la Viga 4 es de $-634,02 \mu \mathrm{m} / \mathrm{m}$ en la cara $\mathrm{E}($ Tabla $7-23)$ y de $-506,64 \mu \mathrm{m} / \mathrm{m}$ en la cara G (Tabla 7-24). Por tanto, la máxima deformación $\varepsilon_{\max }$ promedio de ambas caras es $-570,33$ 
$\mu \mathrm{m} / \mathrm{m}$ (Tabla 7-28). En esta viga vuelven a apreciarse diferencias considerables entre los datos de deformación registrados en ambas caras, siendo la causa probable los márgenes de error derivados de la sensibilidad de cada método de medida.

Como puede apreciarse en la Figura 7-30(izq.), y al igual que en las anteriores vigas, durante los primera semana se observa un aumento considerable de la deformación máxima de compresión $\boldsymbol{\varepsilon}_{\max }$ (Tabla 7-23; Tabla 7-24), alcanzando un valor promedio de $-922,71 \mu \mathrm{m} / \mathrm{m}$ y un incremento porcentual del $61,79 \%$ con respecto al valor inicial (Tabla 7-28). Como ocurría en los casos anteriores, a partir de ese momento las deformaciones a lo largo de la viga siguen creciendo debido a los efectos reológicos, fundamentalmente a la retracción, pero la tasa de crecimiento se atenua, de manera que a los 28 días, en la meseta central, la deformación promedio es igual a $-1234,35 \mu \mathrm{m} / \mathrm{m}\left(\Delta \varepsilon_{\max , 28}=116,43 \%\right)$, a los 60 días es $-1407,05 \mu \mathrm{m} / \mathrm{m}\left(\Delta \varepsilon_{\max , 60}=146,71 \%\right)$, y transcurridos 90 días es igual $-1506,59 \mu \mathrm{m} / \mathrm{m}(\Delta$ $\left.\varepsilon_{\max , 90}=164,16 \%\right)$ (Tabla 7-22; Figura 7-26).

Tabla 7-28 Incrementos de deformación a lo largo del tiempo en Viga 4. Deformaciones medidas con galgas extensiométricas.

\begin{tabular}{|c|c|c|c|c|c|c|}
\hline \multirow{2}{*}{ t [días] } & \multicolumn{2}{|c|}{ Meseta Central [Media caras E y G] } & \multicolumn{2}{|c|}{ Extremo A [Media caras E y G] } & \multicolumn{2}{|c|}{ Extremo B [Media caras E y G] } \\
\hline & $\varepsilon_{\max }[\mu \mathrm{m} / \mathrm{m}]$ & $\Delta \varepsilon_{\max }[\%]$ & $\mathbf{l}_{\mathrm{t}, \mathrm{A}}[\mathrm{mm}]$ & $\Delta \mathbf{l}_{\mathrm{t}, \mathrm{A}}[\%]$ & $\mathbf{1}_{\mathrm{t}, \mathrm{B}}[\mathrm{mm}]$ & $\Delta \mathbf{1}_{\mathrm{t}, \mathrm{B}}[\%]$ \\
\hline $\mathrm{t}=0$ & -570.33 & 0.00 & 551.14 & 0.00 & 432.39 & 0.00 \\
\hline $\mathrm{t}=7$ & -922.71 & 61.79 & 605.31 & 9.83 & 452.73 & 4.71 \\
\hline $\mathrm{t}=28$ & -1234.35 & 116.43 & 636.92 & 15.56 & 470.75 & 8.87 \\
\hline $\mathrm{t}=60$ & -1407.05 & 146.71 & 678.04 & 23.02 & 499.90 & 15.61 \\
\hline $\mathrm{t}=90$ & -1506.59 & 164.16 & 667.07 & 21.03 & 495.53 & 14.60 \\
\hline
\end{tabular}
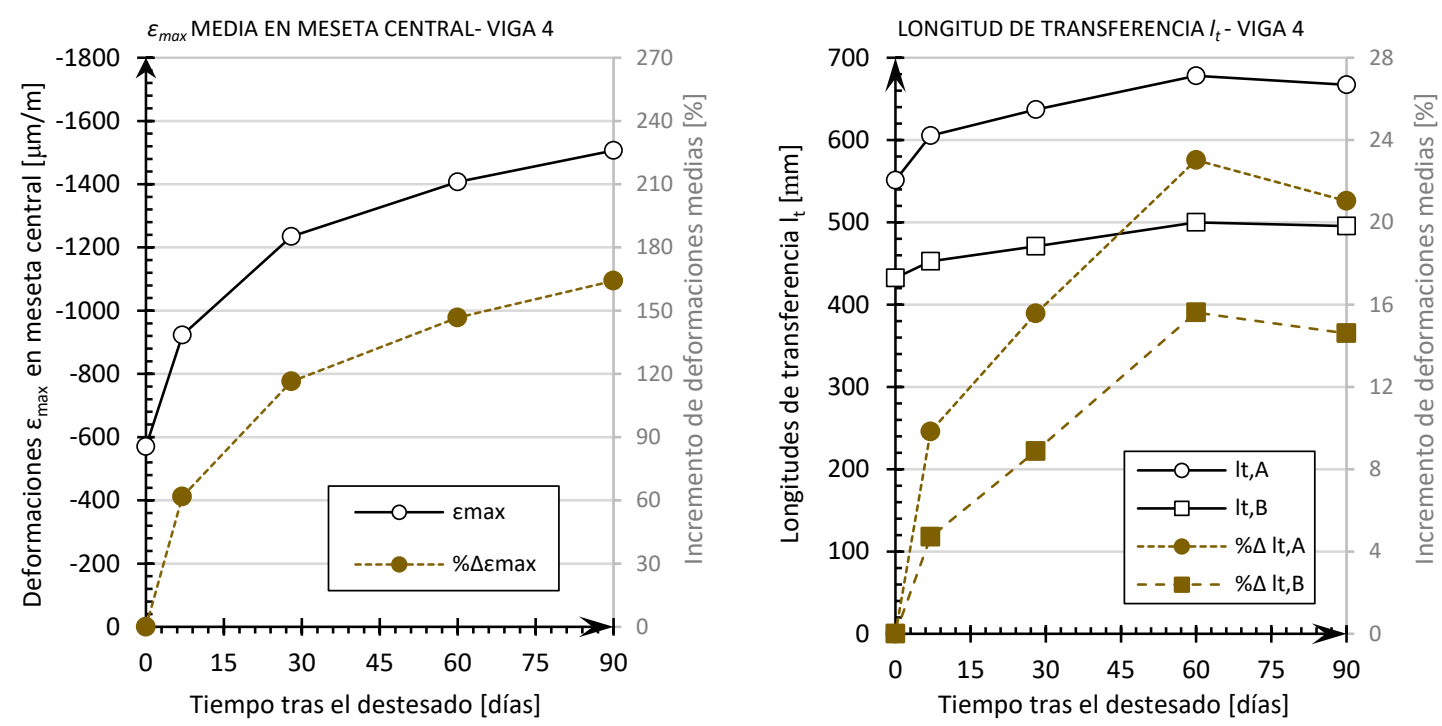

Figura 7-29 Evolución de los valores medios de deformación $\boldsymbol{\varepsilon}_{\max }$ en meseta central (izquierda) y de longitud de transferencia lt (derecha) en la Viga 3, tras el destesado. Alambres sin corrosión. Valores promedio de ambas caras.

Los ajustes lineales para la determinación de los tramos ascendente y descendente del perfil de deformaciones arrojan coeficientes de determinación $\mathrm{R}^{2}$ razonablemente buenos, situándose por encima del 0,83 en todos los casos, y alcanzando valores de hasta 0,98 (Tabla 7-23, Tabla 7-24). 
En cuanto a las longitudes de transferencia $l_{t}$, al igual que ocurría en la Viga 1, destaca la diferencia existente entre el extremo A y el B en el momento de la transferencia ( $\mathrm{t}=0$ días). Mientras que en el extremo B, la longitud de transferencia media $\mathrm{l}_{\mathrm{t}, \mathrm{B}}$ en el momento del destesado es de 432,29 mm, en el extremo A el valor de la longitud $1_{t, A}$ alcanza los 551,14 mm (Figura 7-30)(Tabla 7-28). El hecho de este patrón se repita en los extremos de las vigas más cercanos a los límites de la pista de pretensado parece confirmar que la transferencia se ve afectada por la ubicación de las vigas en el momento del destesado. Por otro lado, al igual que ocurre con las deformaciones de compresión en el tramo central $\boldsymbol{\varepsilon}_{\max }$, las longitudes de transferencia $l_{t}$ se incrementa desde el momento del destesado, alcanzando a los 90 días un valor promedio $1_{t, A}=667,07 \mathrm{~mm}$ en el extremo $A$, lo que supone un incremento del $21,03 \%$ con respecto al valor inicial, y de $\mathrm{l}_{\mathrm{t}, \mathrm{B}}=495,53 \mathrm{~mm}$ en el extremo $\mathrm{B}\left(\Delta \mathrm{l}_{\mathrm{t}, \mathrm{B}}=14,60 \%\right)$ (Figura 7-30; Tabla 7-28). También cabe destacar que en ambos extremos, y al igual que ocurría en la Viga 3 , en el tramo de tiempo comprendido entre los 60 y los 90 días se observa una pequeña reducción de la longitud de transferencia $l_{t}$ (Extremo A: de 678,04 a 667,07 mm; Extremo B: de 499,90 a 495,53), cuyo origen es más probable que se encuentre en errores de medida o de interpretación de los resultados que en un fenómeno real de redistribución de esfuerzos de difícil explicación.

Por último, el diferente comportamiento existente entre los extremos A y B de la Viga 4 también se ve reflejado en la pendiente de los tramos ascendente y descendente del perfil de deformaciones, siendo las pendientes del extremo A mucho más tendidas que las del extremo contrario (Figura 7-27; Figura 7-28).

En cuanto a los deslizamientos relativos del alambre $\delta$ en extremo de vigas, como puede observarse en la Figura 7-29, el flexímetro $\mathrm{F}_{4}$ del extremo A arrojó una lectura inicial muy baja, aunque su evolución posterior parece coherente con el resto de los resultados. A efectos de la determinación del deslizamiento medio en el extremo A, los datos registrados en dicho flexímetro se han excluido del análisis, por considerarse un valor atípico.

Como puede observarse en la Figura 7-17 y en la Tabla 7-9, y como ha ocurrido con el resto de vigas analizadas, la dispersión de los deslizamientos relativos del alambre $\delta$ en extremo de vigas es alta. En el momento del destesado, el coeficiente $\alpha$ obtenido en el extremo A es igual a 3,81, por encima del valor $\alpha=3$ que según la expresión de Guyon (1953) sería equivalente a suponer que las distribuciones tanto de la deformación longitudinal de acero $\varepsilon_{p}$ como la del hormigón $\varepsilon_{c}$ son parabólicas. Por tanto, el comportamiento atípico detectado en este extremo en cuanto a su longitud de transferencia $l_{t}$ también se ve reflejado en la medición del deslizamiento $\delta$, arrojando resultados poco habituales. Por otro lado, el coeficiente $\alpha$ obtenido en el extremo B es igual a 2,58, lo que equivaldría a suponer una distribución de las deformaciones en el hormigón intermedia entre una ley lineal $(\alpha=2)$ y otra parabólica $(\alpha=3)$.

Con el paso del tiempo se observa, en ambos extremos, que el coeficiente $\alpha$ desciende de valor, convergiendo hacia un valor cercano a 2 en el extremo B, como en la mayoría de los casos analizados en esta tesis, y manteniéndose en niveles altos, cercanos a 3, en el extremo A.

\subsubsection{Discusión de los resultados obtenidos sobre vigas pretensadas sin corrosión}

Tal y como indica la Norma UNE 7-436-82 "Método de ensayo para la determinación de las características de adherencia de las armaduras de pretensado" (Instituto Nacional de Racionalización 
y Normalización - IRANOR, 1982), dada la presumible heterogeneidad y el número de incertidumbres de los resultados obtenidos mediante este ensayo, éstos deben analizarse como el promedio de los obtenidos en al menos tres vigas, y no tanto de manera individualizada. A partir del análisis de los resultados experimentales expuestos en los apartados anteriores, pueden extraerse las siguientes conclusiones de los ensayos sobre las cuatro vigas sin corrosión:

- La deformación máxima $\boldsymbol{\varepsilon}_{\max }$ en la meseta central, donde la fuerza de pretensado ha sido plenamente transferida, es el resultado del efecto acumulado de tres fenómenos: la deformación instantánea tras el pretensado $\left(\boldsymbol{\varepsilon}_{\max , 0}\right.$ para $\mathrm{t}=0$ días); la deformación $\boldsymbol{\varepsilon}_{s b r}$ debida a la retracción del hormigón, que es constante a lo largo de toda la viga pretensada; y la deformación por fluencia $\boldsymbol{\varepsilon}_{\text {creep }}$ originada por la fuerza de compresión actuante en cada sección de la viga, causada por el pretensado. Una vez que se ha producido la deformación instantánea de la viga $\boldsymbol{\varepsilon}_{\max , 0}$, tras la transferencia del pretensado, tiene lugar un incremento rápido de las deformaciones por compresión, especialmente significativo la primera semana, debido a los fenómenos de retracción y fluencia. Este incremento se va ralentizando y comienza a estabilizarse a partir de los $28-60$ primeros días. Para los periodos de tiempo considerados, el valor promedio del $95 \%$ de la deformación máxima $\boldsymbol{\varepsilon}_{\max }$ en la meseta central de las 4 vigas analizadas ha sido el siguiente:

- Deformación instantánea, $\varepsilon_{\max , 0}=-545.63 \mu \mathrm{m} / \mathrm{m}$;

- A los 7 días, $\varepsilon_{\max , 7}=-942.90 \mu \mathrm{m} / \mathrm{m}\left(\Delta \varepsilon_{\max , 7}=72,81 \%\right)$;

- A los 28 días, $\varepsilon_{\max , 28}=-1233.73 \mu \mathrm{m} / \mathrm{m}\left(\Delta \varepsilon_{\max , 28}=126,11 \%\right)$;

- A los 60 días, $\varepsilon_{\max , 60}=-1389.58 \mu \mathrm{m} / \mathrm{m}\left(\Delta \varepsilon_{\max , 60}=154,68 \%\right)$;

- A los 90 días, $\varepsilon_{\max , 90}=-1491.83 \mu \mathrm{m} / \mathrm{m}\left(\Delta \varepsilon_{\max , 90}=173,42 \%\right)$;

Como puede apreciarse, a los 90 días las deformaciones totales habían prácticamente triplicado $\left(\Delta \varepsilon_{\max , 90}=173,42 \%\right)$ la deformación instantánea tras el destesado $\left(\varepsilon_{\max , 0}=-545.63\right.$ $\mu \mathrm{m} / \mathrm{m}$ ), debido a la contribución de las deformaciones por retracción y fluencia. Este incremento es coherente con lo obtenido por otros autores (Oh, et al., 2001) (VázquezHerrero, et al., 2013). Aunque el crecimiento de la deformación se va atenuando, a la vista de los resultados obtenidos (Figura 7-31) se puede afirmar que la influencia de los efectos reológicos no se había detenido en el momento en el que se dejaron de registrar datos, 90 días tras el destesado.

En la Tabla 7-29 se incluyen, para los distintos periodos de tiempo considerados, el valor promedio del $95 \%$ de la deformación máxima $\varepsilon_{\max }$ en la meseta central de las vigas, así como la longitud de transferencia media en los extremos; además, para cada una de estas variables, se incluye su desviación estandard, su coeficiente de variación y el incremento porcentual con respecto el valor inicial tras el destesado. Por último, se incluye la pendiente $m$ de la recta ascendente del perfil de deformaciones. Los coeficientes de variación CV obtenidos para las deformaciones en la meseta central (Tabla 7-29) son relativamente bajos, alcanzando su máximo $(10,14 \%)$ en los resultados de deformación instantánea ( $\mathrm{t}=0$-destesado) y disminuyendo paulatinamente hasta el 5,48\% obtenido para los resultados de deformación a una edad de 90 días. La causa probable para este descenso es que la falta de sensibilidad en 
la obtención de deformaciones mediante extensometría manual se minimiza con el aumento de las mismas.

- En todos los periodos de tiempo considerados, las longitudes de transferencia $l_{t}$ obtenidas en los extremos de las vigas ubicados en los límites de la pista de pretensado (Extremo A en Vigas 1 y 4) han sido similares entre sí (564,63 mm y 551,14 mm, tras el destesado) y significativamente superiores al resto de longitudes obtenidas (como promedio, un 31,3\% superiores). Este hecho, observado por otros autores (Oh, et al., 2001), confirma que la transmisión del pretensado no depende únicamente de factores mecánicos o geométricos, sino que la velocidad de puesta en carga y la ubicación de la viga con respecto a la zona de corte de alambres (extremo activo o pasivo) influye en los valores de longitud de transferencia obtenidos.

Por tanto, a efectos de la determinación de la longitud de transferencia media, los datos registrados en el Extremo A de las Vigas 1 y 4 se han excluido del análisis, por considerarse valores atípicos.
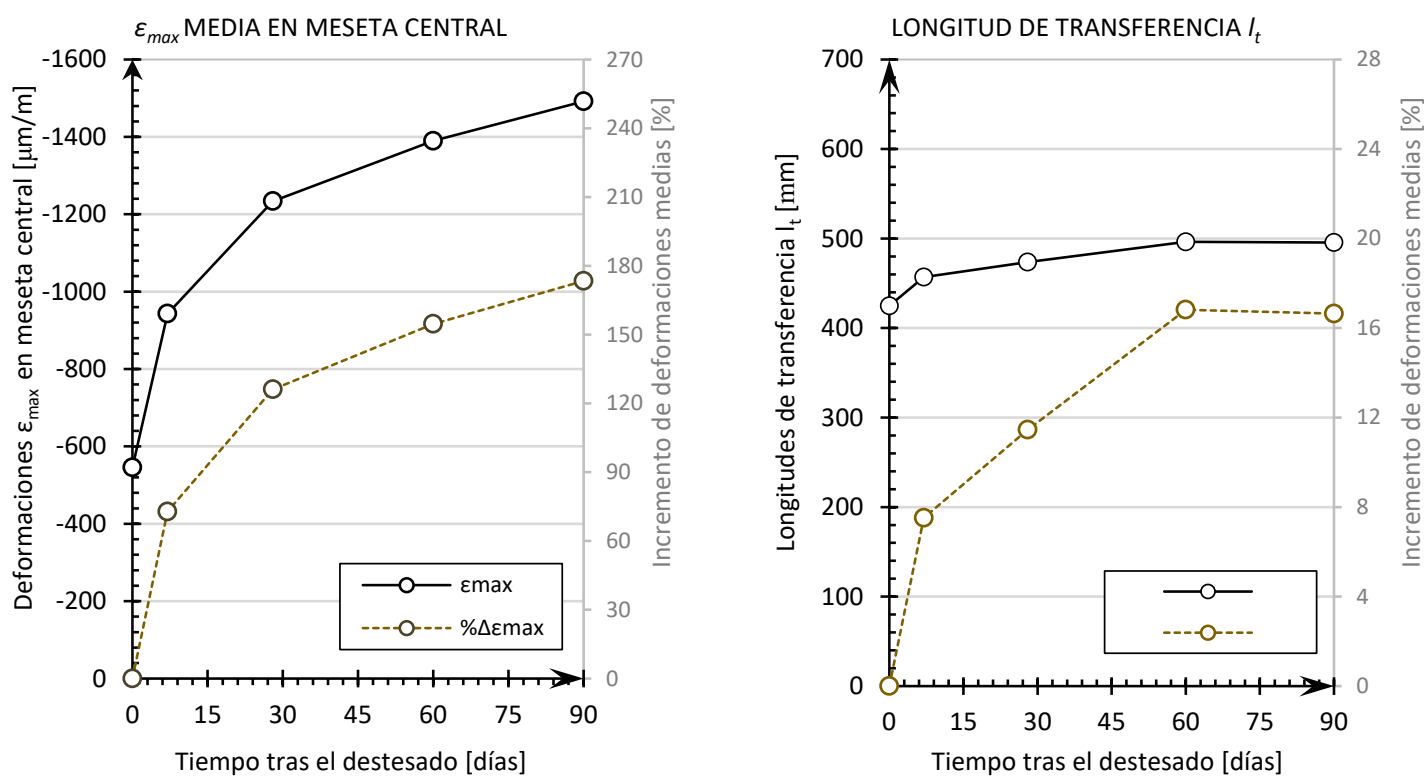

Figura 7-30 Evolución de los valores medios de deformación $\boldsymbol{\varepsilon}_{\text {max }}$ en meseta central (irquierda) y de longitud de transferencia lt (derecha) en las vigas ensayadas, tras el destesado. Alambres sin corrosión.

- Las deformaciones de compresión derivadas de los efectos reológicos, $\boldsymbol{\varepsilon}_{s h}$ y $\boldsymbol{\varepsilon}_{\text {creepp }}$, no sólo elevan el perfil de deformaciones de las vigas, sino que también influyen en la longitud de transferencia $l_{t}$. Al igual que ocurría con las deformaciones por compresión en la meseta central, las longitudes de transferencia crecen rápidamente los primeros días tras el destesado. La tasa de crecimiento de atenúa con el paso del tiempo, hasta llegar a estabilizarse a partir de los 60 días. Para los periodos de tiempo considerados, la longitud de transferencia calculada a partir de los perfiles de deformación de las 4 vigas analizadas ha sido la siguiente: 
- En el momento de la transferencia del pretensado, $1_{\mathrm{t}, 0}=424.88 \mathrm{~mm}$;

- A los 7 días, $l_{6,7}=456.83 \mathrm{~mm}\left(\Delta l_{6,7}=7,52 \%\right)$;

- A los 28 días, $l_{t, 28}=473.55 \mathrm{~mm}\left(\Delta l_{t, 28}=11,45 \%\right)$;

- A los 60 días, $l_{t, 60}=496.33 \mathrm{~mm}\left(\Delta l_{t, 60}=16,82 \%\right)$;

- A los 90 días, $l_{t, 90}=495.61 \mathrm{~mm}\left(\Delta l_{t, 90}=16,65 \%\right)$;

Como puede observarse (Figura 7-31), a los 7 días la longitud de transferencia se ha incrementado un $7,52 \%$ con respecto a la longitud inicial $l_{t, 0}$ derivada de las deformaciones instantáneas, y partir de los 60 días tras el destesado se registran incrementos estables superiores al $15 \%\left(\Delta l_{6,60}=16,82 \%\right)$.

La revisión bibliográfica ha permitido comprobar que existe una enorme disparidad de resultados a este respecto. Evans (1951) registró que la longitud de transferencia de alambres de $2 \mathrm{~mm}$ de diámetro prácticamente se doblaba a los 2 años y medio. Por su parte, Base (1957), detectó incrementos de hasta un 10\% en los primeros 4 meses, aunque la mayor parte de los cambios se concentraban en los primeros 10 o 20 días. Base también registró, en sus ensayos sobre alambres de $2 \mathrm{~mm}$ de diámetro, que la longitud de transferencia se incrementaba hasta $76 \mathrm{~mm}$ en los 10 primeros días tras la transferencia, para posteriormente permanecer estable. Kaar et al. (1963) encontraron incrementos de hasta un $20 \%$ en probetas pretensadas con cable de 7 alambres, aunque la media obtenida fue de un $6 \%$ durante el primer año. Oh et al. (2001), en su campaña experimental sobre cables pretensados de 12,7 y 15,2 mm de diámetro, registraron incrementos del 2-3\% en la longitud de transferencia a la edad de 7 días, y de hasta un 5\% a los 90 días. Por su parte, Barnes et al. (2003) detectaron, por un lado, incrementos medios de entre el 10 y el 20\%, llegando algunos de ellos hasta un $50 \%$, y por otro, que la mayor parte de los mismos se producían los 28 primeros días. En el extremo opuesto, Vazquez-Herrero et al. (2013) apreciaron que las longitudes de transferencia permanecían con valores relativamente constantes durante el primer año tras el destesado. A la vista de lo expuesto, la causa probable que justifica esta disparidad de resultados es la considerable diferencia existente entre las variables (secciones, resistencias, fuerzas de pretensado, etc) de los procedimientos experimentales utilizados por los diferentes autores.

Por último, los coeficientes de variación CV obtenidos muestran una baja dispersión de los resultados, al encontrarse ubicados en el rango 3,5-6,5\% (Tabla 7-29).

\begin{tabular}{|c|c|c|c|c|c|c|c|c|c|}
\hline \multirow{2}{*}{$\begin{array}{r}\text { Tiem } \\
\text { po } \\
\text { [días] }\end{array}$} & \multicolumn{4}{|c|}{ Meseta Central - $95 \% \varepsilon_{\max }$} & \multicolumn{4}{|c|}{ Extremos - Longitud de transferencia } & \multirow{2}{*}{$\frac{\text { Pendiente }}{m}$} \\
\hline & $\begin{array}{c}\text { Media } \\
{[\mu \mathrm{m} / \mathrm{m}]}\end{array}$ & $\begin{array}{c}\text { Desv. } \\
\text { estándar }\end{array}$ & Coef.Var. & $\begin{array}{c}\Delta 0.95 \varepsilon_{\max } \\
{[\%]}\end{array}$ & $\begin{array}{c}\text { Media } \\
{[\mathrm{mm}]}\end{array}$ & $\begin{array}{c}\text { Desv. } \\
\text { estándar }\end{array}$ & Coef.Var. & $\Delta I_{t}[\%]$ & \\
\hline $\mathrm{t}=0$ & -545.63 & 55.34 & 10.14 & 0.00 & 424.88 & 14.86 & 3.50 & 0.00 & -1.28 \\
\hline$t=7$ & -942.90 & 71.78 & 7.61 & 72.81 & 456.83 & 24.04 & 5.26 & 7.52 & -2.08 \\
\hline $\mathrm{t}=28$ & -1233.73 & 100.56 & 8.15 & 126.11 & 473.55 & 29.54 & 6.24 & 11.45 & -2.54 \\
\hline$t=60$ & -1389.58 & 88.80 & 6.39 & 154.68 & 496.33 & 31.33 & 6.31 & 16.82 & -2.76 \\
\hline $\mathrm{t}=90$ & -1491.83 & 81.81 & 5.48 & 173.42 & 495.61 & 24.77 & 5.00 & 16.65 & -2.93 \\
\hline
\end{tabular}


- La pendiente de los tramos ascendente y descendente del perfil de deformaciones aumenta rápidamente los primeros días tras el destesado $\mathrm{y}$, al igual que ocurre con las deformaciones y las longitudes de transferencia, comienza a estabilizarse a partir de los 28-60 días (Tabla 7-29).
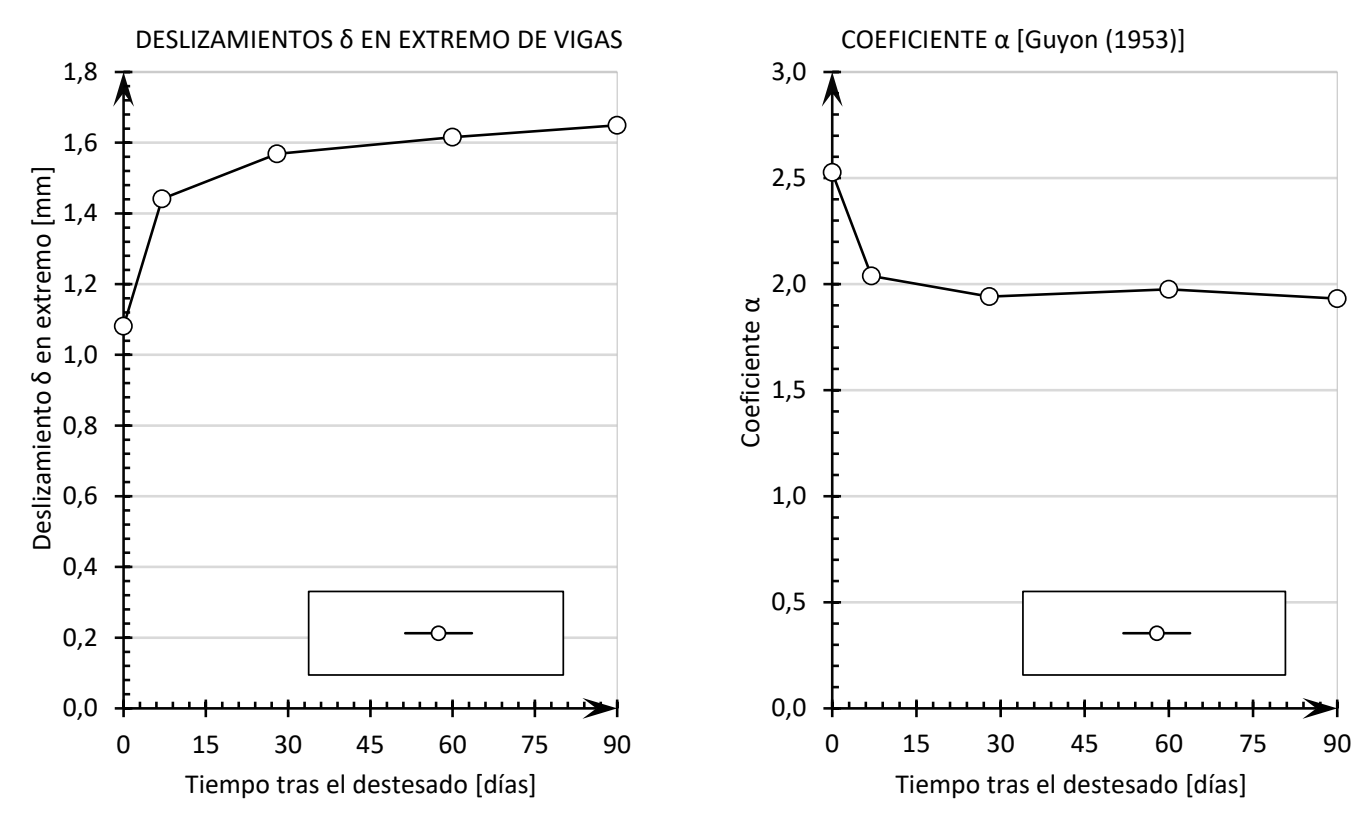

Figura 7-31 Evolución de los valores medios de deslizamiento $\delta$ y del coeficiente a en las vigas ensayadas, tras el destesado.

- En cuanto los deslizamientos relativos del alambre $\delta$ en los extremos de las vigas se ha observado una alta dispersión de los registros obtenidos, sin identificar un patrón claro que justifique tales variaciones. Excluyendo los resultados obtenidos en los flexímetros situados en los extremos de la pista de pretensado, por las razones expuestas anteriormente, así como como aquellos que claramente han ofrecido una lectura errónea, el promedio del coeficiente $\alpha$ obtenido en el momento del destesado es igual a 2,53 (Figura 7-32). Este valor, según la justificación teórica que acompaña a la expresión de Guyon (1953), equivale a suponer una distribución de las deformaciones longitudinales, tanto del de acero $\varepsilon_{p}$ como la del hormigón $\varepsilon_{c}$, intermedia entre una ley lineal $(\alpha=2)$ y otra parabólica $(\alpha=3)$. A partir de la primera semana tras el destesado se observa una tendencia general a que el coeficiente $\alpha$ vaya descendiendo y tienda a converger hacia un valor cercano a 2. Según la expresión de Guyon (Guyon, 1953), este valor implica una distribución constante de la tensión de adherencia $\tau_{b}$, dando como resultado una variación lineal de las deformaciones en el alambre $\varepsilon_{p}$ y en el hormigón $\varepsilon_{c}$. Un coeficiente $\alpha$ igual a 2 ha sido utilizado anteriormente utilizado por muchos investigadores [ (Guyon, 1953), (Russell \& Burns, 1997), (Logan, 1997)]. Para los periodos de tiempo considerados, los promedios de deslizamientos relativos del alambre $\delta$ y sus correspondientes coeficientes $\alpha$, han sido los siguientes (Figura 7-32):

- En el momento de la transferencia del pretensado, $\delta_{0}=1,08 \mathrm{~mm}\left(\alpha_{0}=2,53\right)$;

- $\quad$ A los 7 días, $\delta_{7}=1.44 \mathrm{~mm}\left(\alpha_{7}=2,04\right)$;

- $\quad$ A los 28 días, $\delta_{28}=1.57 \mathrm{~mm}\left(\alpha_{28}=1,94\right)$; 
- A los 60 días, $\delta_{60}=1.62 \mathrm{~mm}\left(\alpha_{60}=1,98\right)$;

- A los 90 días, $\delta_{90}=1.65 \mathrm{~mm}\left(\alpha_{90}=1.93\right)$;

Por tanto, en virtud de lo expuesto anteriormente, puede calcularse un perfil de deformaciones promedio derivado de las condiciones geométricas, mecánicas y de puesta en carga de las vigas pretensadas ensayadas, así como su evolución con el tiempo. En la Figura 7-33 se recogen los perfiles promedio de deformaciones longitudinales $\varepsilon_{c}$ del hormigón a lo largo de la longitud de las vigas ensayadas, en los periodos de tiempo considerados (tras la transferencia del pretensado, 7 días, 28 días, 60 días y 90 días). Para su obtención se ha supuesto un comportamiento lineal de la ley de deformaciones a lo largo de la longitud de transferencia $l_{t}$, y una ley constante a lo largo de la meseta central, equivalente al 95\% del valor medio de deformación $\boldsymbol{\varepsilon}_{\max }$ obtenido en los ensayos.

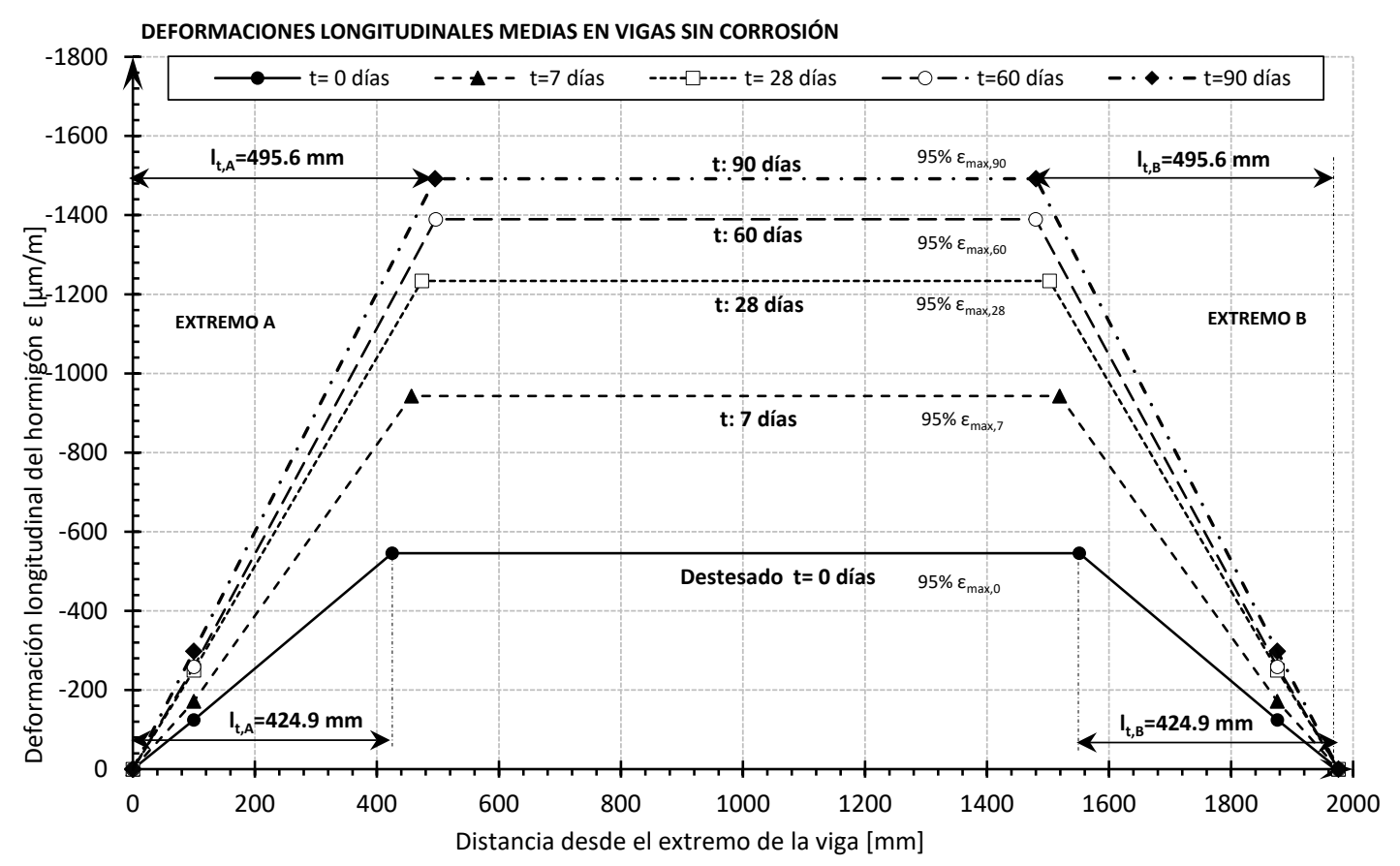

Figura 7-32 Evolución media de la longitud de transferencia lt y de las deformaciones longitudinales $\varepsilon$ en todas las vigas ensayadas, tras el destesado. Alambres sin corrosión. Deformaciones medidas con galgas extensiométricas y extensometría manual.

La deformación instantánea ( $\mathrm{t}=0$ días) de la Figura 7-33 sirve de base para la comprobación del grado de precisión del modelo analítico desarrollado en esta tesis, que se realiza a continuación.

\subsubsection{Comparacion de los resultados experimentales con el modelo analítico}

En este apartado se realiza la comparación de los resultados obtenidos mediante el modelo analítico expuesto en Capítulo 3 de la presente tesis con los resultados experimentales registrados en las vigas pretensadas expuestos en el apartado anterior. El análisis de la bondad del modelo se basa en su capacidad de predicción del perfil de deformaciones en el hormigón $\boldsymbol{\varepsilon}_{\mathfrak{l}}$, de la longitud de transferencia $l_{t}$ y del deslizamiento $\delta$ en el extremo. 
Como se indicó en la descripción de los ensayos, al comienzo de este capítulo, por problemas técnicos la transferencia del pretensado no se llevó a cabo de manera gradual, sino súbita. A este respecto, Kaar et al. (1963) observaron, en sus ensayos sobre piezas pretensadas con cables de 7 alambres, que la longitud de transferencia $l_{t}$ se incrementaba hasta un $20 \%$ cuando el proceso de destesado se llevaba a cabo de manera súbita, sin escalones de descarga, con respecto a la que se obtenía con una transferencia gradual del pretensado. Muchos códigos estructurales recogen consideraciones similares. Por ejemplo, la expresión empírica para la obtención de longitudes de transferencia que aporta el Model Code 2010 (CEB-FIP, 2012), y que ha sido recogida en el Capítulo 2 "Estado del conocimiento", incluye un factor que recoge la influencia de la velocidad de puesta en carga del pretensado, de manera que para destesados súbitos se obtienen longitudes de transferencia un $25 \%$ superiores a las obtenidas con un destesado gradual. Este incremento coincide con el propuesto por el Eurocódigo 2 (2004) y por la Instrucción Española de Hormigón Estructural EHE-08 (Fomento, 2008). Para tener en cuenta este fenómeno y coherentemente con lo expuesto anteriormente, el modelo analítico desarrollado en esta tesis incluye un factor de minoración $Y=1.25$ que, operando sobre el valor del coeficiente de fricción $\mu$ en aquellos casos en los que el destesado se lleva a cabo de manera súbita, consigue aumentar la longitud de transferencia $l_{t}$ en un porcentaje similar al propuesto por los códigos. Este enfoque parece razonable, ya que el efecto probable de una transferencia repentina sería el mayor deterioro de la interfaz acero/hormigón, y las propiedades adherentes de esta superficie de contacto están fundamentalmente recogidas en el coeficiente de fricción $\mu$.

El modelo se ha alimentado con los datos geométricos y mecánicos correspondientes a los ensayos sobre vigas pretensadas expuestos al principio de este capítulo, y con el coeficiente de fricción y la ley de tensión de adherencia-deslizamiento calibrados en el Capitulo 6. La Tabla 7-30 resume el valor de las variables más relevantes que se han introducido en el modelo.

Tabla 7-30 Valor de las principales variables introducidas en el modelo analitico

\begin{tabular}{ccccccccccc}
\hline VIGA & \multicolumn{4}{c}{ ACERO } & \multicolumn{3}{c}{ HORMIGÓN } & & ADHERENCIA \\
\hline $\begin{array}{c}\mathbf{L} \\
{[\mathbf{m m}]}\end{array}$ & $\begin{array}{c}\mathbf{r}_{\mathbf{b}} \\
{[\mathbf{m m}]}\end{array}$ & $\begin{array}{c}\mathbf{h}_{\mathbf{r}} \\
{[\mathbf{m m}]}\end{array}$ & $\begin{array}{c}\mathbf{E}_{\mathbf{s}} \\
{[\mathbf{G P a}]}\end{array}$ & $\begin{array}{c}\mathbf{f}_{\mathrm{pz}} \\
{[\mathbf{M P a}]}\end{array}$ & $\begin{array}{c}\mathbf{c} \\
{[\mathbf{m m}]}\end{array}$ & $\begin{array}{c}\mathbf{f}_{\mathrm{cm}} \\
{[\mathbf{M P a}]}\end{array}$ & $\begin{array}{c}\mathbf{f}_{\mathrm{ctm}} \\
{[\mathbf{M P a}]}\end{array}$ & $\begin{array}{c}\mathbf{E}_{\mathbf{c}} \\
{[\mathbf{G P a}]}\end{array}$ & $\boldsymbol{\mu}$ & $\mathbf{r}$ \\
\hline 1976 & 2,5 & 0,025 & 210 & 1350 & 17,5 & 30 & 2,89 & 27 & 0,625 & 1,25 \\
\hline
\end{tabular}

En cuanto a las limitaciones del modelo, no se han cuantificado las pérdidas de pretensado ni se han tenido en cuenta los efectos reológicos (retracción y fluencia) en el cálculo del perfil de deformaciones, por lo que el modelo es únicamente capaz de determinar las deformaciones instantáneas tras el destesado ( $\mathrm{t}=0$ días).

En vista a estas consideraciones, en la Figura 7-34 se compara el perfil de deformaciones obtenido mediante el modelo analítico, con el ajuste trilineal (rama lineal ascendente, meseta central de valor constante y rama lineal descendente) mediante el "Método del 95\% de la deformación máxima media" ("95\% Average Maximun Strain Method (AMS)") así como con los resultados puntuales obtenidos, tanto mediante medios electrónicos (galgas extensiométricas) como manuales (extensiometría manual). También se indican las longitudes de transferencia $l_{t}$ obtenidas mediante el análisis AMS de los ensayos y mediante el modelo analítico. En este último caso, y para ser coherente con el análisis de los resultados experimentales, se ha considerado que la longitud de transferencia $l_{t}$ es equivalente 
a la distancia desde el extremo de la viga hasta el punto en el que se alcanza el 95\% de la deformación máxima de compresión en la meseta central de ésta.

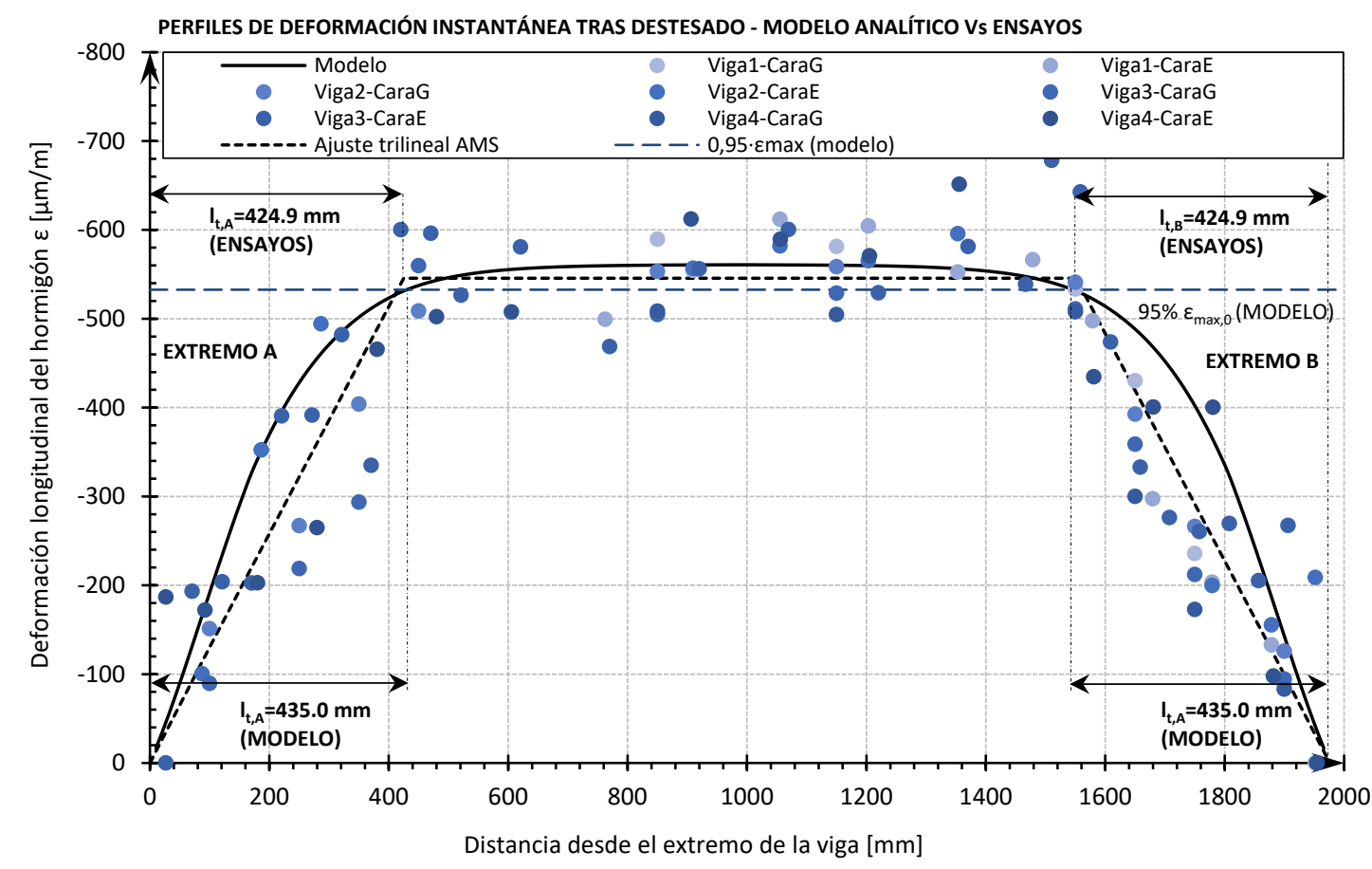

Figura 7-33 Comparación del perfil de deformaciones instantáneas tras el destesado ( $t=0$ días) y de las longitudes de transferencia ly obtenidos en los ensayos con los resultados arrojados por el modelo analitico. Alambres sin corrosión.

Tal y como se aprecia en la Figura 7-34, la deformación máxima instantánea en la meseta central $\boldsymbol{\varepsilon}_{\max }$, que se obtiene de los resultados experimentales ajustados con el Método AMS es estimada correctamente por el modelo analítico. Los resultados experimentales indican que la deformación media instantánea ( $\mathrm{t}=0$ días) en el tramo central de las vigas, donde el pretensado ha sido transferido completamente al hormigón circundante, es de $-570,33 \mu \mathrm{m} / \mathrm{m}$, mientras que el modelo predice una deformación de $-560,78 \mu \mathrm{m} / \mathrm{m}$, lo que supone que el valor predictivo es un 1,69\% menor que el valor real obtenido de los ensayos.

En cuanto a la longitud de transferencia $l$, el modelo analítico predice que es necesaria una longitud de 435,04 mm para que la fuerza de pretensado se transmita completamente al hormigón, mientras que los resultados experimentales arrojan un valor $424,9 \mathrm{~mm}$. Esto supone que para el caso estudiado, el modelo predice un valor de longitud de transferencia un 2,39\% superior al obtenido mediante el análisis de los ensayos.

Las mayores diferencias entre el modelo analítico y los ensayos se aprecian en la pendiente de los tramos ascendente y descendente del perfil de deformaciones. La pendiente de estos tramos es menor en los ensayos, lo que implica que el modelo sobreestima la capacidad de generar tensiones radiales $\sigma_{r}$ debidas a la capacidad de confinamiento del recubrimiento de hormigón en los extremos de la viga. Como consecuencia, el modelo predice en estas zonas mayores tensiones de adherencia $\tau_{b}$, que 
provocan una mayor tasa de transferencia del pretensado al hormigón circundante y, por tanto, una mayor tasa de crecimiento de las deformaciones por compresión en el hormigón.

Esta diferencia no es sorprendente, ya que no hay que olvidar que el Método AMS es una simplificación cuya utilización supone, al partir de un desarrollo lineal de las deformaciones tanto en el hormigón como en el acero, que el valor de la tensión de adherencia es constante a lo largo de toda la longitud de transferencia. Como se ha visto a lo largo de esta tesis, el efecto Hoyer provoca, desde el extremo y a lo largo de la longitud de transferencia, un gradiente descendente de los desplazamientos radiales $u_{r}$ de la pared interna del cilindro de hormigón que rodea el alambre, y por tanto, una variación de las tensiones radiales $\sigma_{r}$ y de la tensión de adherencia $\tau_{b}$. A pesar de estas consideraciones, y en base al análisis de los resultados puntuales de los ensayos que pueden observarse en detalle en la Figura 7-35 y en la Figura 7-36, es evidente que el modelo analítico marca un límite superior de los mismos en la zona de transferencia, por lo que puede deducirse que sobreestima ligeramente la capacidad de confinamiento del recubrimiento y, por tanto, predice una menor fisuración derivada de las tensiones circunferenciales $\sigma_{\vartheta}$ generadas por la acción conjunta del efecto Hoyer y del deslizamiento $s$ de las indentaciones.

A este respecto, es interesante observar cómo evoluciona teóricamente la tensión tangencial $\tau_{b}$, tanto en el ajuste trilineal AMS de los resultados experimentales como en el modelo analítico. En la Figura 7-37 se representan ambas tensiones, junto con el avance teórico del frente de fisuración que arroja el modelo.

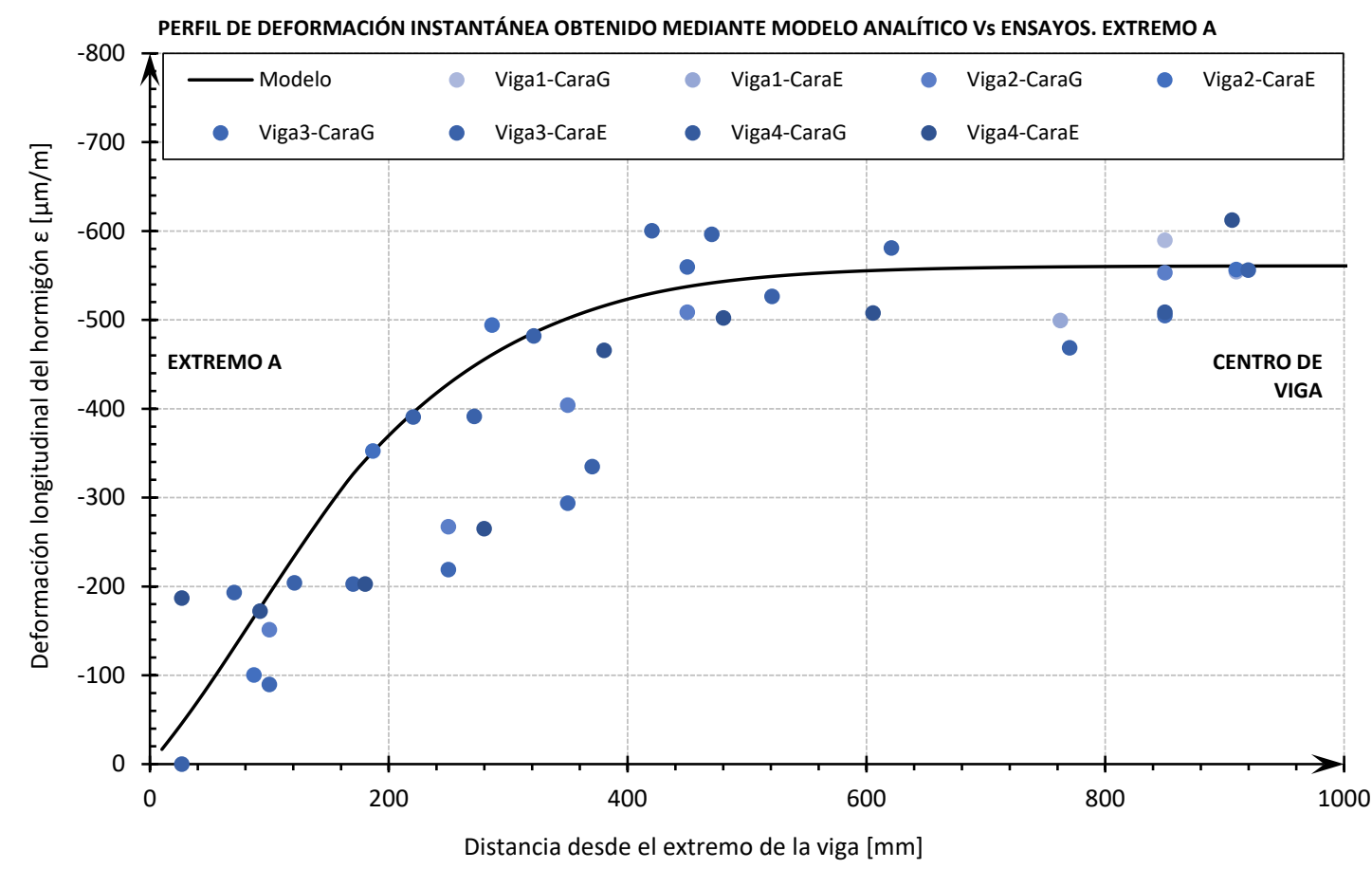

Figura 7-34 Comparación de los resultados experimentales con el perfil de deformaciones instantáneas tras el destesado ( $t=0$ días) obtenido mediante el modelo analítico, en el Extremo A. Alambres sin corrosión. 


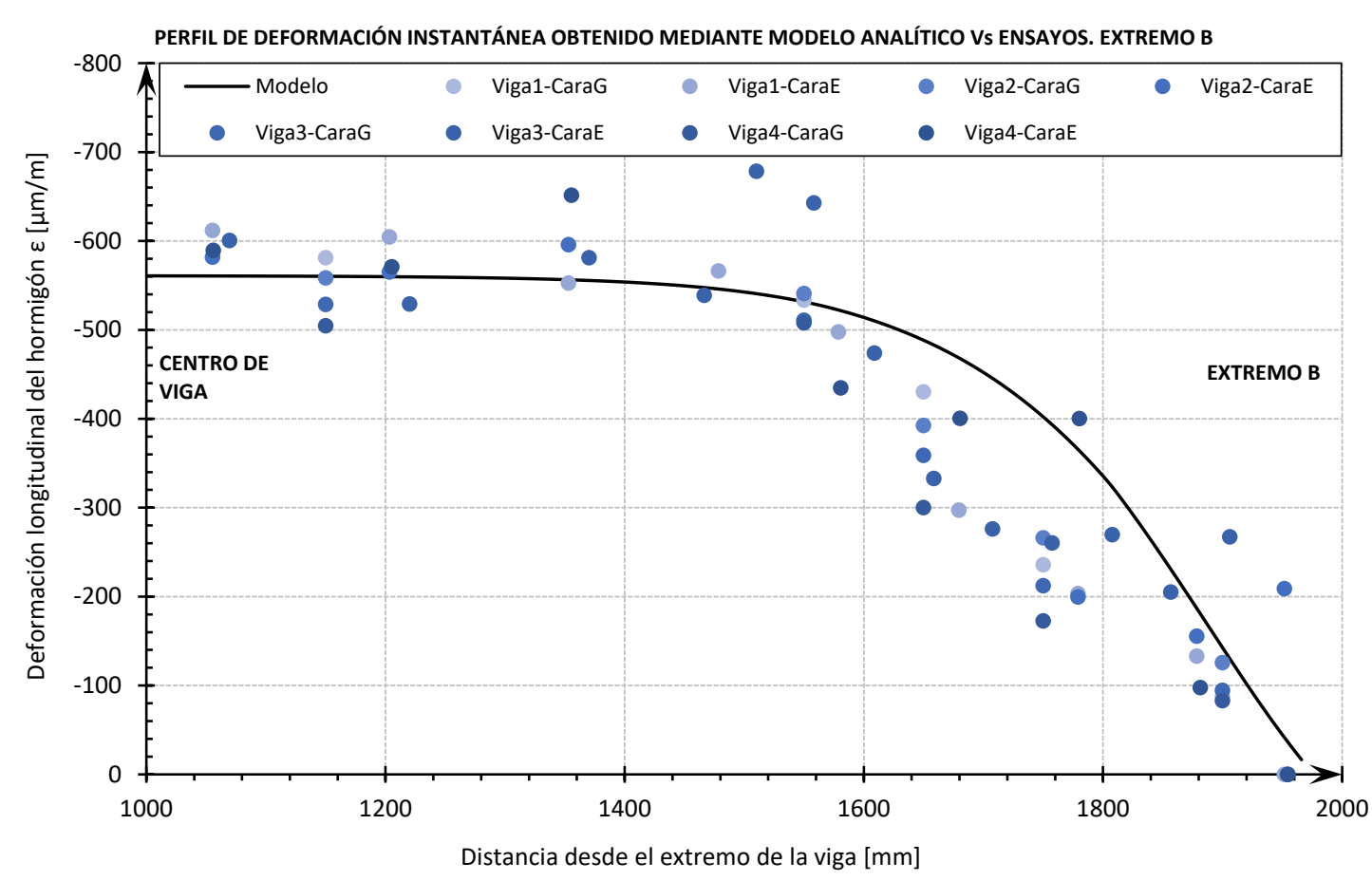

Figura 7-35 Comparación de los resultados experimentales con el perfil de deformaciones instantáneas tras el destesado (t=0 dias) obtenido mediante el modelo analítico, en el Extremo B. Alambres sin corrosión.

Como puede observarse (Figura 7-37), según el ajuste trilineal (AMS) la tensión tangencial $\tau_{b}$ a lo largo de la longitud de transferencia $\left(l_{t}=424,88 \mathrm{~mm}\right)$, toma un valor constante igual a 3,971 MPa. Superada dicha longitud, la tensión de adherencia pasa a ser nula. Por el contrario, según el modelo analítico, la tensión de adherencia $\tau_{b}$ a lo largo de la longitud de transferencia $l_{t}$ pasa por varias etapas. En el caso concreto que nos ocupa, en la primera etapa, los primeros $70 \mathrm{~mm}$ desde el extremo, el recubrimiento está completamente fisurado, debido a las tensiones circunferenciales $\sigma_{\vartheta}$ generadas por la acción conjunta del efecto Hoyer y de las indentaciones en su deslizamiento, pero debido al modelo de fisuración cohesiva que se ha utilizado el hormigón es aún capaz de generar tensiones radiales $\sigma_{r}$ considerables. En la segunda etapa, desde el final de la primera hasta una distancia de 400 $\mathrm{mm}$ desde el extremo de la viga, el recubrimiento se encuentra parcialmente fisurado. El frente de fisuración se reduce con la distancia al extremo, debido a la disminución del desplazamiento radial generado por el efecto Hoyer y al menor deslizamiento de las indentaciones. En esta etapa se alcanza la mayor tensión de adherencia $\left(\tau_{\mathrm{b}, \max }=6,43 \mathrm{MPa}\right)$ a una distancia aproximada de $90 \mathrm{~mm}$ desde el extremo, y comienza a descender hasta alcanzar un valor de 1,17 MPa a una distancia de $390 \mathrm{~mm}$ desde el extremo, donde comienza la tercera etapa. En esta etapa el recubrimiento no ha comenzado a fisurarse, por lo que se encuentra en régimen elástico. La tensión de adherencia $\tau_{b}$ continúa descendiendo de forma muy atenuada, hasta alcanzar la longitud de transferencia en la que se ha desarrollado el $95 \%$ de las deformaciones por compresión del hormigón $\left(l_{l}=435,04 \mathrm{~mm}\right)$. A partir de ese punto, y aunque ya no se tenga en cuenta a la hora de determinar la longitud de transferencia, la tensión de adherencia $\tau_{b}$ residual, generada por pequeños desplazamientos radiales debidos al efecto Hoyer y a las indentaciones, permite alcanzar la transmisión plena de la fuerza de pretensado. 
Lógicamente, la integral de la ley de la tensión de adherencia a lo largo de la superficie del alambre en sus respectivas longitudes de transferencia debe ser igual en ambos casos, pero su diferente distribución justifica las diferencias obtenidas en el perfil de deformaciones del hormigón.

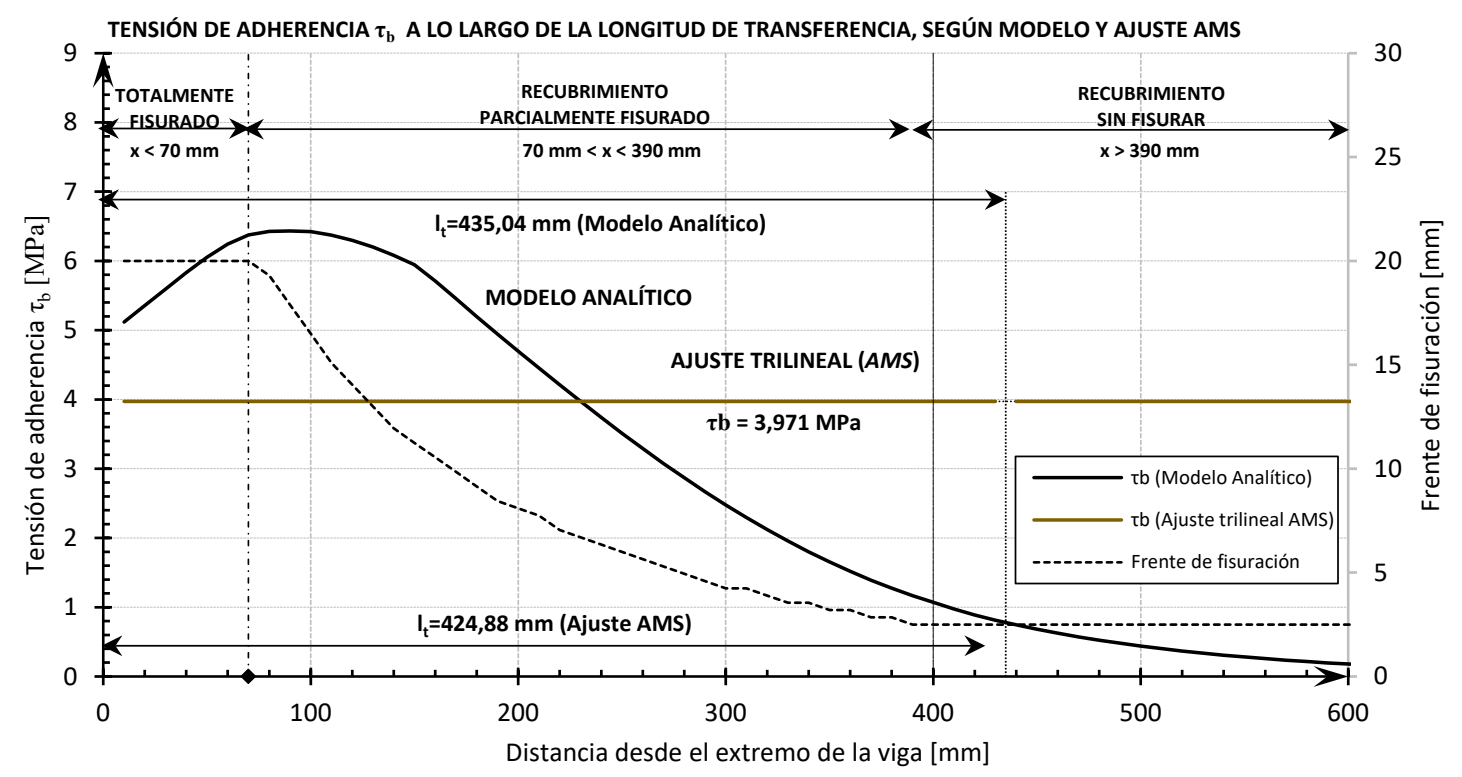

Figura 7-36 Comparación de las leyes de tensión de adherencia a lo largo de la viga según el modelo analitico y el ajuste trilineal AMS de los resultados experimentales. Alambres sin corrosión.

La Figura 7-38 incluye la gráfica la evolución de los deslizamientos relativos del alambre a lo largo de la longitud de transferencia, calculada mediante el modelo analítico. Además, se incluye el perfil de deformaciones del hormigón correspondiente a tales deslizamientos, también calculado con el modelo, y los resultados medios de los deslizamientos en extremo de viga en cada uno de los extremos de las cuatro vigas ensayadas, así como el promedio total de los mismos.

Como se vio anteriormente (Eq. 7-1), los deslizamientos relativos $\delta$, a lo largo de la longitud de transferencia $l_{t}$, son el resultado de la diferencia entre el acortamiento elástico del alambre tras el destesado $\left(\varepsilon_{p, 0}-\varepsilon_{p}\right)$ y la deformación por compresión del hormigón $\varepsilon_{c}$ debida a la fuerza de pretensado transferida. Por tanto, a una distancia $\mathrm{x}=l_{t}$ del extremo de la viga, el deslizamiento relativo es nulo $(\boldsymbol{\delta}=0)$. Según nos desplazamos hacia el extremo de la viga, los deslizamientos crecen exponencialmente hasta alcanzar su máximo en el extremo. El valor medio de los deslizamientos $\delta_{0}$ en el extremo de las vigas, obtenidos mediante flexímetros, ha sido de $1,081 \mathrm{~mm}$, mientras que el modelo arroja un resultado de $1,047 \mathrm{~mm}$, lo que supone una diferencia del -3,14\%.

En definitiva, en este apartado se han comparado los resultados obtenidos en la campaña experimental con los resultados arrojados por el modelo analítico desarrollado para esta tesis y, a pesar de las salvedades expuestas, la capacidad predictiva del modelo analítico, basado en la teoría del cilindro hueco de pared gruesa, puede considerarse como muy buena. Este hecho nos permitirá analizar, en los próximos apartados, cómo influyen distintas variables geométricas y mecánicas en el desarrollo de la longitud de transferencia. 


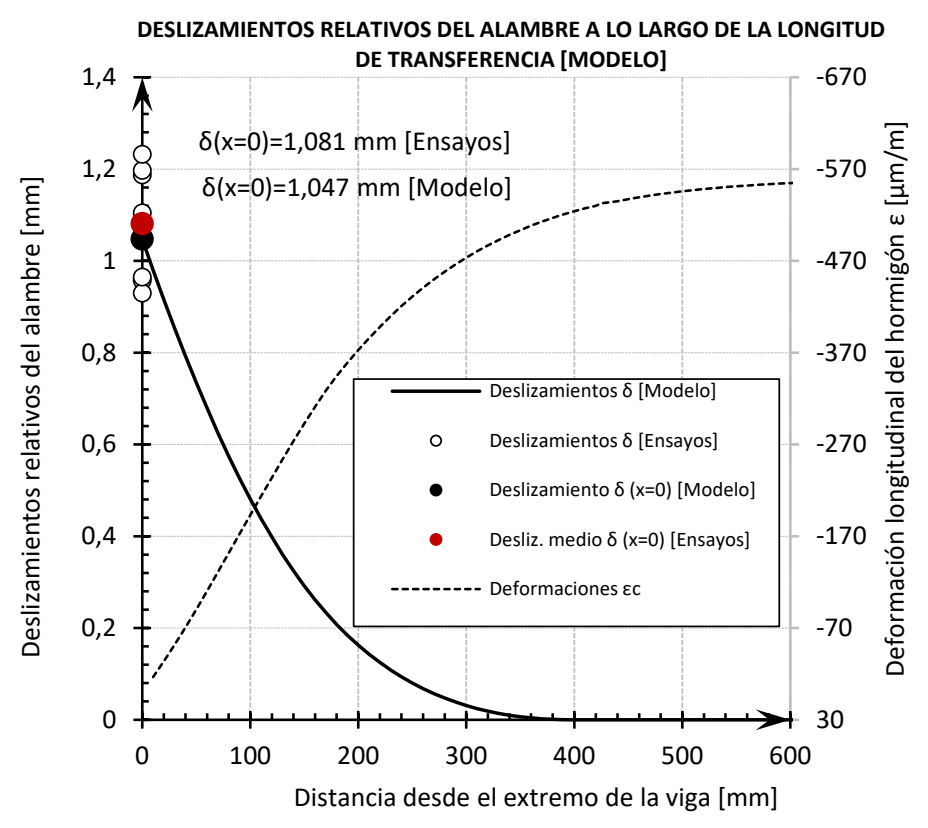

Figura 7-37 Comparación de las leyes de tensión de adherencia a lo largo de la viga según el modelo analitico y el ajuste trilineal AMS de los resultados experimentales. Alambres sin corrosión.

\subsubsection{Vigas pretensadas con alambres corroídos}

Las vigas anteriores fueron sometidas a un proceso de corrosión acelerada que comenzó un año después de la transferencia del pretensado. Como se ha descrito en los apartados anteriores, la deformación de las vigas se monitorizó únicamente durante los tres primeros meses y no hasta el comienzo de los ensayos de corrosión. Por ello, las deformaciones que se obtienen una vez iniciado el proceso de corrosión son con respecto a la viga ya deformada por la transferencia del pretensado y por los efectos reológicos (retracción y fluencia), y no con respecto a la situación previa al destesado.

Para todas las vigas, se han tomado medidas de las deformaciones de compresión en el hormigón durante 84 días, de manera continuada mediante las galgas extensiométricas y a intervalos regulares de tiempo mediante los puntos de extensiometría manual. Por problemas técnicos en el DataLogger utilizado para el registro de datos, sólo se conservan datos de los 63 primeros días en las Vigas 1 y 2, y de los primeros 45 días en las Vigas 3 y 4 . Con la densidad de corriente de corrosión $\mathrm{i}_{\text {corr }}$ utilizada $\left(100 \mu \mathrm{A} / \mathrm{cm}^{2}\right)$, esto equivale a que se tienen registro de hasta un $15 \%$ de pérdida teórica de sección en las vigas 1 y 2 y de hasta un $10 \%$ de pérdida teórica de sección en las Vigas 3 y 4.

Como se ha comentado en los apartados anteriores, las medidas tomadas con extensometría manual adolecen de falta de precisión en el caso de deformaciones pequeñas. Este hecho es especialmente significativo en los incrementos de deformación del hormigón, derivados del proceso de corrosión, al obtenerse valores bajos en los que los márgenes de error superan las propias medidas obtenidas. Por ello, los resultados obtenidos mediante extensometría manual se han obviado en el análisis, al aportar más confusión al ya de por sí caótico y heterogéneo fenómeno de la corrosión. 
En cuanto a las medidas tomadas con galgas extensiométricas, si bien no tienen tan acentuado el problema de la falta de sensibilidad como en los medios manuales, comienzan a fallar si la fisuración del recubrimiento interfiere con ellas. Por ello, en ocasiones las deformaciones registradas por las mismas crecen exponencialmente, haciendo inviable su interpretación. Por ello, los puntos de medida que sufren este problema se han obviado en el análísis.

Por tanto, a la vista de lo expuesto anteriormente, y unido al hecho de que la corrosión es un fenómeno de naturaleza caótica y que la campaña de ensayos es reducida, el análisis de los resultados se enfocará más desde un punto de vista cualitativo que cuantitativo, ya que no se pueden considerar totalmente representativos. Aun así, señalan tendencias que permiten validar el modelo analítico propuesto.

En la Tabla 7-31 se presentan los resultados medios de deformación del hormigón $\varepsilon_{c}$ obtenidos de las galgas extensiométricas de las cuatro vigas ensayadas, excluyendo los valores atípicos arrojados por las mismas, fruto de la interacción con fisuras en el recubrimiento o de fallos en el registro, para los periodos de tiempo considerados.

Tabla 7-31 Promedio de la evolución de las deformaciones en el hormigón, obtenidas de los ensayos, para vigas con procesos de corrosión.

\begin{tabular}{|c|c|c|c|c|c|}
\hline & $\begin{array}{c}\varepsilon_{c}(x=150-1826) \\
{[\mu \mathrm{m} / \mathrm{m}]}\end{array}$ & $\begin{array}{c}\varepsilon_{c}(x=250-1726) \\
{[\mu \mathrm{m} / \mathrm{m}]}\end{array}$ & $\begin{array}{c}\varepsilon_{\mathrm{c}}(\mathrm{x}=350-1626) \\
{[\mu \mathrm{m} / \mathrm{m}]}\end{array}$ & $\begin{array}{c}\varepsilon_{\mathrm{c}}(\mathrm{x}=450-1526) \\
{[\mu \mathrm{m} / \mathrm{m}]}\end{array}$ & $\begin{array}{c}\varepsilon_{\mathrm{c}}(\mathrm{x}=850-1150) \\
{[\mu \mathrm{m} / \mathrm{m}]}\end{array}$ \\
\hline $0 \%$ pérdida de sección & 0.00 & 0.00 & 0.00 & 0.00 & 0.00 \\
\hline $1 \%$ pérdida de sección & 47.41 & 41.00 & 26.08 & 13.28 & 11.63 \\
\hline $2,5 \%$ pérdida de sección & 74.90 & 56.33 & 19.24 & 7.11 & -2.46 \\
\hline $5 \%$ pérdida de sección & 80.82 & 45.88 & 6.71 & -18.03 & -34.06 \\
\hline $7.5 \%$ pérdida de sección & 103.79 & 63.14 & 25.51 & -2.70 & -64.95 \\
\hline $10 \%$ pérdida de sección & 111.05 & 56.91 & 9.23 & -11.64 & -99.07 \\
\hline
\end{tabular}

En la Figura 7-38 se presentan gráficamente los datos de la Tabla 7-31, pudiéndose apreciar con claridad las dos principales tendencias observadas en los ensayos:

- Se observa que el mayor deterioro de las propiedades adherentes y, por tanto, la mayor reducción de las deformaciones por compresión del hormigón $\boldsymbol{\varepsilon}_{c}$, se concentra en los extremos de las vigas. Además, dicho deterioro se va atenuando con el aumento de la distancia desde dichos extremos. Este comportamiento es el esperable, ya que las secciones más extremas son las más solicitadas antes del comienzo de ensayo por corrosión, desde el punto de vista de tensiones radiales $\sigma_{r}$ y circunferenciales $\sigma_{\theta}$. En estas secciones el desplazamiento radial $u_{r}$ de la pared interna del cilindro de hormigón que rodea el alambre es mayor por la acción conjunta del efecto Hoyer y el deslizamiento $s$ las indentaciones. Teóricamente, la corrosión genera un desplazamiento radial $u_{r}$ homogéneo a lo largo de toda la superficie del alambre, de manera que al superarse un determinado umbral provoca que el frente de fisuración alcance la cara externa del recubrimiento, y con ello, que comience el deterioro de las tensiones radiales $\sigma_{r}$ y de la tensión de adherencia $\tau_{b}$.

- En cuanto a la evolución de las deformaciones del hormigón $\boldsymbol{\varepsilon}_{c}$ en el centro de la viga, se aprecia que para valores bajos de corrosión (1,0-2,5\%) permanecen prácticamente inalteradas. Superados esos niveles de corrosión se observa que cuanto mayor es el deterioro 
en los extremos (relajación de las deformaciones de compresión), mayor es la deformación de compresión $\boldsymbol{\varepsilon}_{c}$ en el centro de vano. Este incremento de las deformaciones de compresión no puede deberse en ningún caso al incremento de la fuerza de pretensado, ya que esta fue transmitida previamente, por lo que es achacable únicamente a la acción de los fenómenos reológicos de retracción y fluencia. Sin ser taxativos en este aspecto, ya que no se han monitorizado estos fenómenos, y dado que el efecto de la retracción tendía a estabilizarse tras los tres primeros meses, parece que la fluencia tiene un papel determinante en este fenómeno.

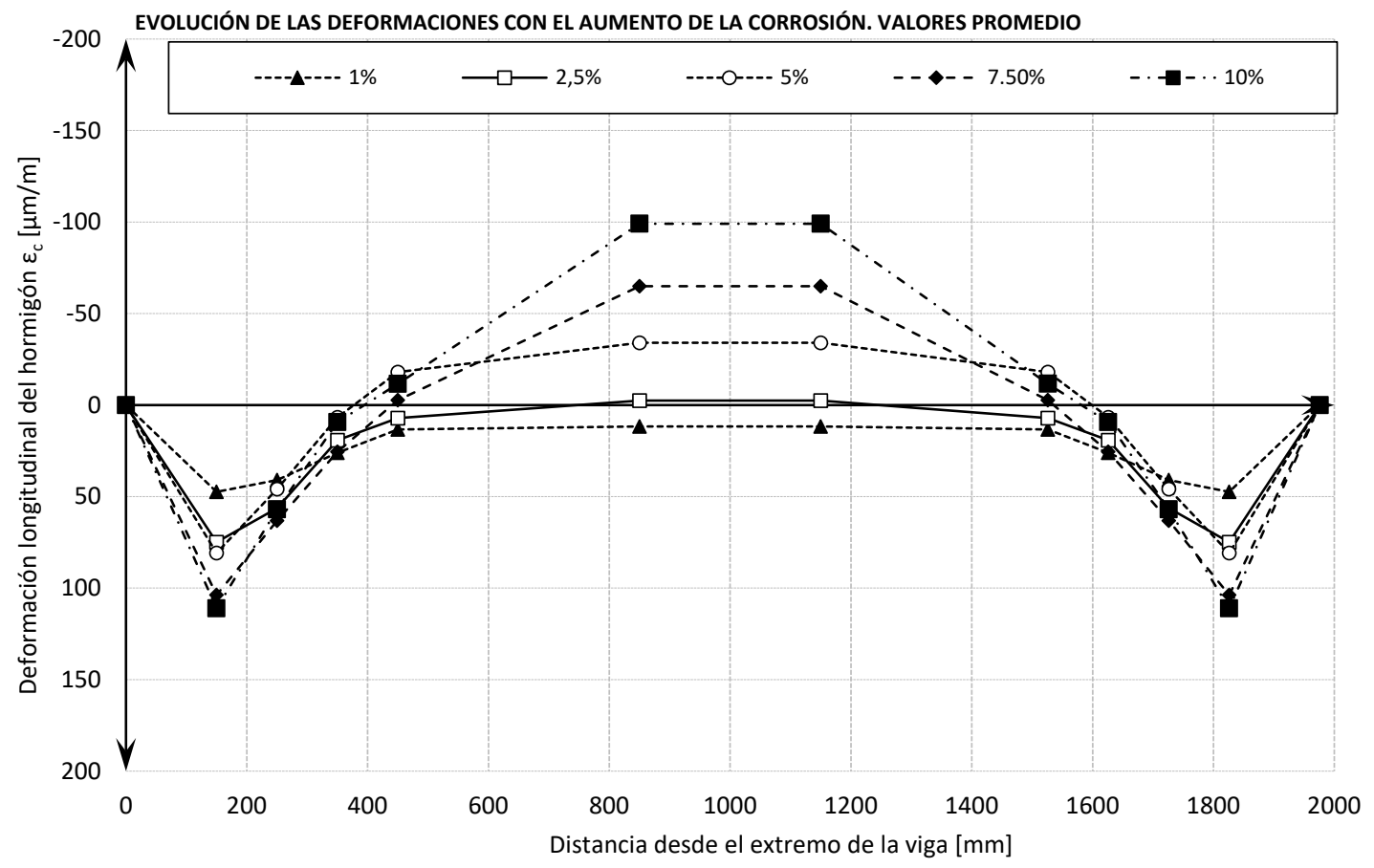

Figura 7-38 Promedio de la evolución de las deformaciones longitudinales $\varepsilon_{c}$ del hormigón, para distintas pérdidas de sección teórica por corrosión. Medidas obtenidas con galgas extensiométricas.

Los incrementos de deformación del hormigón con respecto a las de la viga sin corroer que se presentan en la Figura 7-38 sirven de base para la comprobación de la capacidad predictiva del modelo analítico desarrollado en esta tesis, que se realiza a continuación.

\subsubsection{Comparacion de los resultados experimentales en vigas pretensadas con corrosión con el modelo analítico}

En este apartado se lleva a cabo la comparación de los resultados obtenidos mediante el modelo analítico expuesto en Capítulo 3 de la presente tesis con los resultados experimentales registrados en las vigas pretensadas con procesos de corrosión, expuestos en el apartado anterior. El análisis de la bondad del modelo se basa en su capacidad de predicción de la variación de las deformaciones en el hormigón $\varepsilon_{c}$ a lo largo de la longitud de las vigas, así como del deslizamiento $\delta$ en el extremo de las mismas. 
7. VALIDACIÓN DEL MODELO ANALÍTICO DE ADHERENCIA DE ALAMBRES PRETENSADOS CON CORROSIÓN

Tabla 7-32 Valor de los parámetros relativos a la corrosión calibrados para el modelo analitico de la presente tesis

\begin{tabular}{cccccc}
\hline $\begin{array}{c}\text { Relación } \\
\text { tecubrimiento/ } \\
\text { diámetro }\end{array}$ & $\begin{array}{c}\text { Tasa de penetración } \\
\text { de ataque }\end{array}$ & $\begin{array}{c}\text { Coeficiente de } \\
\text { expansión de } \\
\text { óxidos }\end{array}$ & $\begin{array}{c}\text { Módulo de } \\
\text { compresibilidad } \\
\text { volumétrica }\end{array}$ & $\begin{array}{c}\text { Espesor } \\
\text { equivalente de la } \\
\text { capa porosa }\end{array}$ & $\begin{array}{c}\text { Porcentaje de } \\
\text { óxidos en fisuras }\end{array}$ \\
\hline$c / \varphi$ & $d m_{s} / d t$ & $n$ & $K r[G P a]$ & $t_{p, r i z}[\mu m]$ & $V_{\text {crack }}[\%]$ \\
\hline 4 & $\begin{array}{c}\text { Ley de Faraday } \\
\text { (Andrade) }\end{array}$ & 2 & 0,5 & 75 & 80 \\
\hline
\end{tabular}

En el Capítulo 6 se desarrolló una metodología para la calibración de los parámetros relativos al proceso de corrosión que influían en el comportamiento adherente de alambres de acero, basada en la combinación y comparación de resultados experimentales y analíticos. Este procedimiento permitió la obtención de valores fundamentados, coherentes con la bibliografía consultada, y que proporcionaban un buen ajuste entre los resultados experimentales de los ensayos de pull-out y los arrojados por el modelo analítico desarrollado para esta tesis. En este apartado se recuperan dichos valores, que se resumen en la Tabla 7-32, y junto con las variables geométricas y mecánicas de los ensayos que se han resumido en la Tabla 7-30, se tienen todos los datos necesarios para la obtención de la evolución de las deformaciones del hormigón mediante el modelo analítico.

$\mathrm{Al}$ igual que ocurría con las vigas sin corrosión, no se han cuantificado las pérdidas de pretensado ni se han tenido en cuenta los efectos reológicos (retracción y fluencia) en el cálculo de la evolución de las deformaciones, por lo que el modelo es únicamente capaz de determinar la influencia que tiene en las mismas el proceso de corrosión.

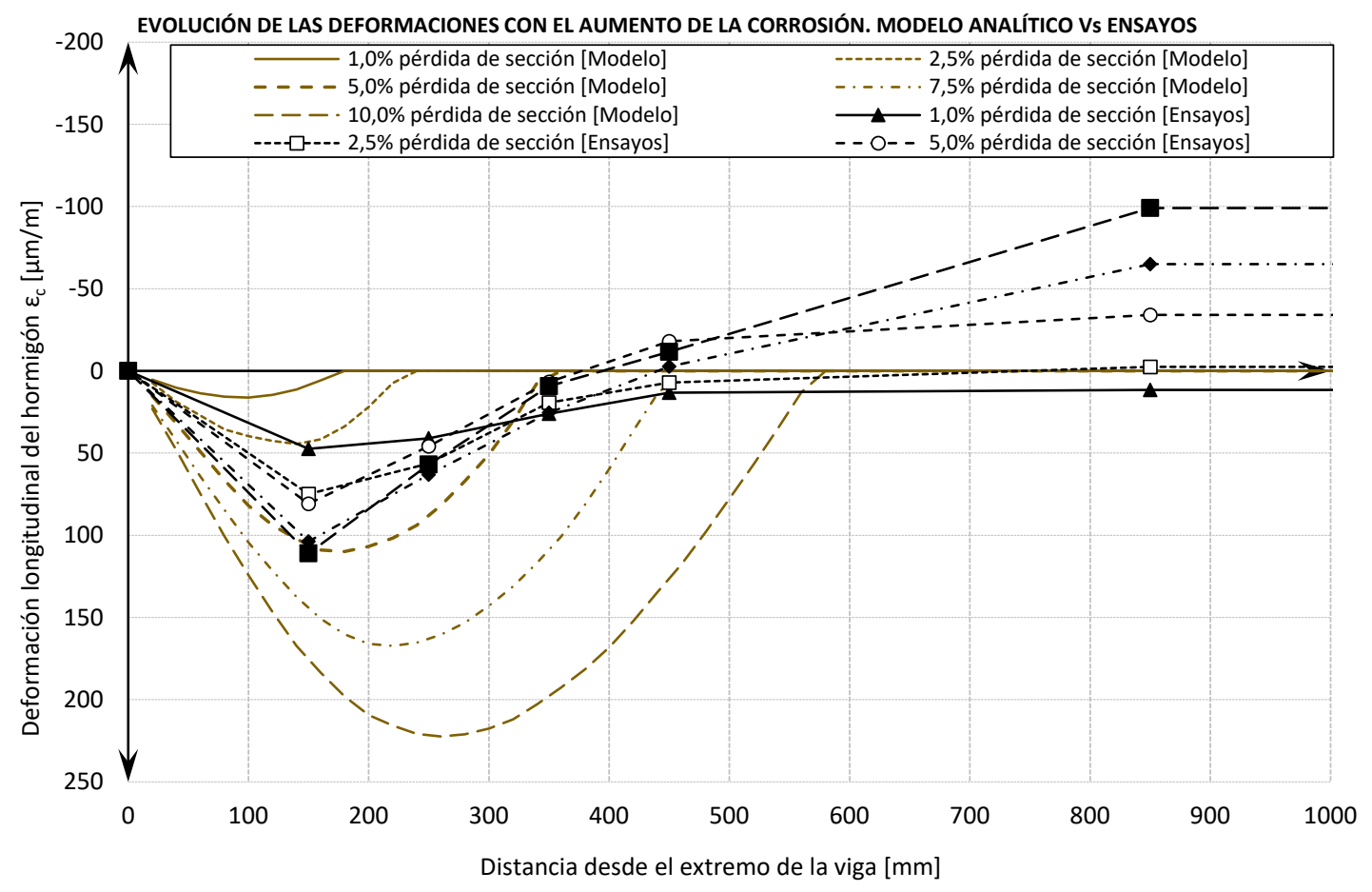

Figura 7-39 Comparación de la evolución de las deformaciones en el hormigón obtenidas en los ensayos con los resultados arrojados por el modelo analítico. Alambres con corrosión. 
En vista de estas consideraciones, en la Figura 7-39 se compara la evolución de las deformaciones en el hormigón $\boldsymbol{\varepsilon}_{c}$ obtenidas en los ensayos de vigas pretensadas con corrosión, con los resultados arrojados por el modelo analítico.

Como puede comprobarse, las diferencias existentes entre los resultados experimentales y el modelo son considerables, de manera que para niveles bajos de corrosión (hasta pérdidas de sección del $2,5 \%$ ), el modelo arroja resultados significativamente más bajos que los obtenidos en los ensayos $(16,2 \mu \mathrm{m} / \mathrm{m}$ frente a $47,4 \mu \mathrm{m} / \mathrm{m}$, para un $1 \%$ de pérdida de sección), mientras que para niveles medios y altos de pérdida de sección, el modelo predice una relajación en las deformaciones de compresión del hormigón que llega a doblar el resultado experimental $(222,4 \mu \mathrm{m} / \mathrm{m}$ frente a 111,1 $\mu \mathrm{m} / \mathrm{m}$ para un $10 \%$ de pérdida de sección teórica). Por otra parte, los resultados experimentales detectan un incremento considerable de las deformaciones por compresión en el hormigón en la zona central de la viga, que aumenta con el avance de la corrosión, hasta alcanzar un valor de $-99,1 \mu \mathrm{m} / \mathrm{m}$ para una pérdida de sección teórica del 10\%. Como se comentó en la discusión de los resultados, este aumento de las deformaciones de compresión solo puede deberse a los efectos reológicos, y en ningún caso a un aumento de la fuerza de pretensado. Por tanto, a la vista de estos resultados, pueden hacerse las siguientes consideraciones:

- En primer lugar, dada la heterogeneidad del proceso de corrosión, por un lado, y el volumen de asunciones y de simplificaciones en las que se basa el modelo analítico, por el otro, hacen que el hecho de que el este último sea capaz de detectar las principales tendencias observadas en los ensayos (deterioro concentrado en los extremos, reducción del deterioro hacia el centro de la viga, etc) y arroje resultados que capten el orden de magnitud del fenómeno, no sea en absoluto desdeñable.

- En segundo lugar, la variación de las deformaciones en el proceso de corrosión es fruto de la intervención de dos factores diferenciados, por un lado, la relajación o reducción provocada por el deterioro de la capacidad adherente que induce el proceso de corrosión, y por otro, el incremento de las deformaciones de compresión que provocan la retracción y la fluencia. Como se ha comentado a lo largo de este capítulo, el modelo no contempla los procesos reológicos, por lo que era esperable que se detectasen diferencias significativas con los resultados experimentales.

Partiendo de esta última consideración, si en los ensayos se lograse aislar el efecto atribuible a la corrosión en la variación de las deformaciones por compresión del hormigón, teóricamente se obtendrían resultados más cercanos a los obtenidos en el modelo. Para ello, si se da por cierto que todas las deformaciones que aparecen en el centro de la viga tienen su origen exclusivamente en los fenómenos reológicos y suponiendo de manera simplificadora que éstos se reparten homogéneamente a lo largo de la longitud de la viga, obtendremos que para cada periodo de tiempo considerado la variación de las deformaciones de compresión atribuibles únicamente al fenómeno de la corrosión, es igual a la diferencia entre el resultado obtenido en los ensayos y el valor de deformación registrado en el centro del vano. En las gráficas de variación de deformaciones en el hormigón, esto sería equivalente a desplazar el eje de abscisas hasta hacer que la deformación en el tramo central de la viga fuera nula. Este ejercicio teórico tiene utilidad porque nos aporta información sobre lo que podría considerarse un límite superior de la variación de deformaciones atribuible a la 
corrosión, pero en ningún caso pretende ser un reflejo fiel de la realidad, ya que se están suponiendo como ciertas hipótesis alejadas del comportamiento real. Por ejemplo, mientras que es razonable suponer que la retracción provoca una deformación homogénea a lo largo de toda la viga, no lo es hacerlo con la fluencia, ya que ésta depende del estado tensional de cada sección.

Con todas las salvedades expuestas anteriormente, en la Figura 7-40 se comparan las gráficas de evolución de los incrementos de deformación del hormigón, obtenidas del análisis de los ensayos y modificadas para mostrar las deformaciones atribuibles exclusivamente a la corrosión, con los resultados arrojados por el modelo. Por otro lado, en la Tabla 7-33 se presentan, para las pérdidas de sección consideradas, los resultados medios de deformación del hormigón $\varepsilon_{c}$ obtenidos de las galgas extensiométricas de las cuatro vigas ensayadas, tratados para mostrar las deformaciones atribuibles exclusivamente a la corrosión.

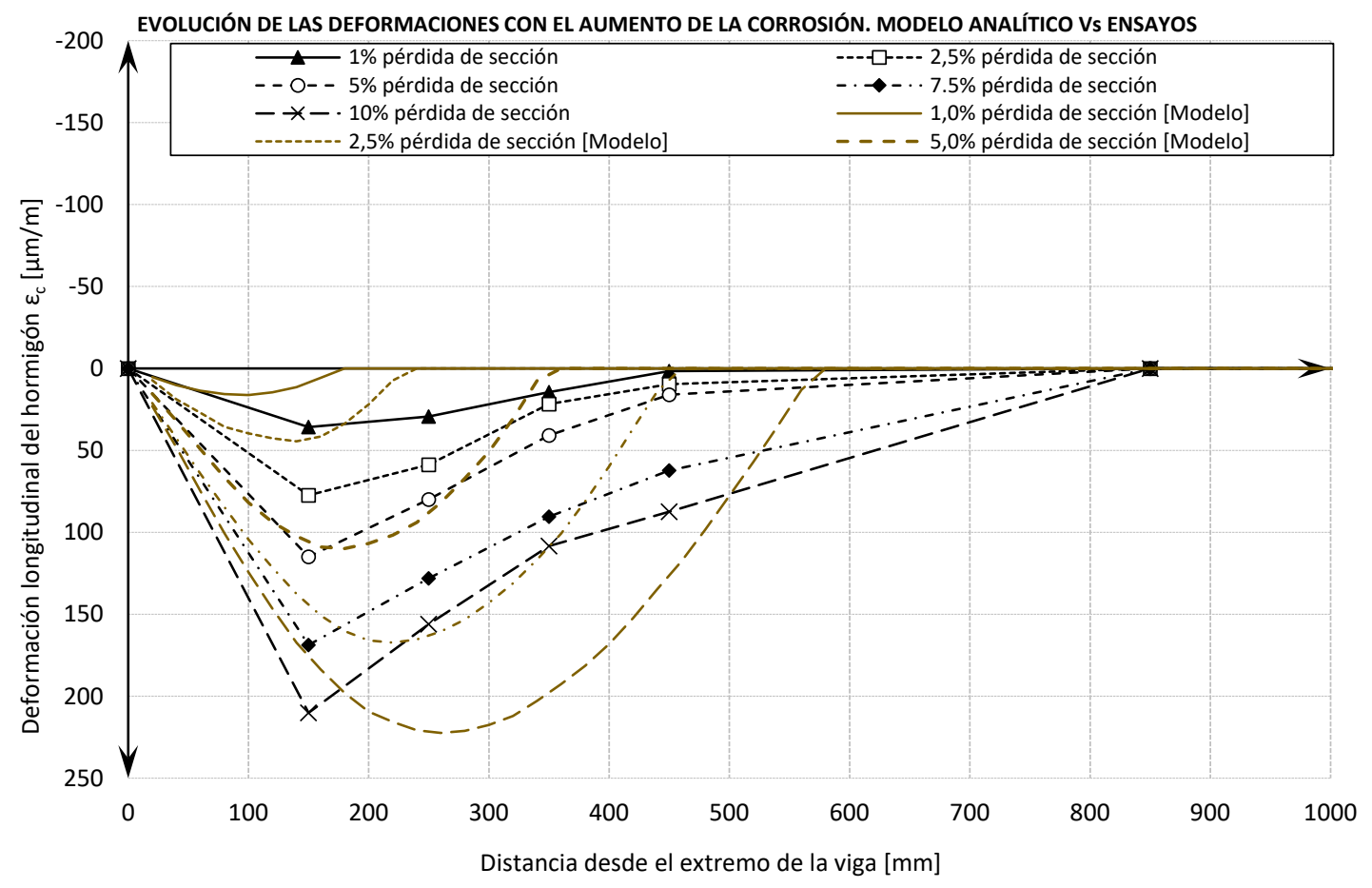

Figura 7-40 Comparación de la evolución de las deformaciones en el hormigón, obtenidas en los ensayos y modificadas para mostrar las atribuibles exclusivamente a la corrosión, con los resultados arrojados por el modelo analítico. Alambres con corrosión.

Tabla 7-33 Deformaciones en el hormigón, obtenidas en los ensayos y modificadas para mostrar las atribuibles exclusivamente a la corrosión.

\begin{tabular}{|c|c|c|c|c|c|}
\hline & $\begin{array}{c}\varepsilon_{\mathrm{c}}(\mathrm{x}=150-1826) \\
{[\mu \mathrm{m} / \mathrm{m}]}\end{array}$ & $\begin{array}{c}\varepsilon_{\mathrm{c}}(\mathrm{x}=250-1726) \\
{[\mu \mathrm{m} / \mathrm{m}]}\end{array}$ & $\begin{array}{c}\varepsilon_{\mathrm{c}}(\mathrm{x}=350-1626) \\
{[\mu \mathrm{m} / \mathrm{m}]}\end{array}$ & $\begin{array}{c}\varepsilon_{\mathrm{c}}(\mathrm{x}=450-1526) \\
{[\mu \mathrm{m} / \mathrm{m}]}\end{array}$ & $\begin{array}{c}\varepsilon_{\mathrm{c}}(\mathrm{x}=850-1150) \\
{[\mu \mathrm{m} / \mathrm{m}]}\end{array}$ \\
\hline $0 \%$ pérdida de sección & 0.00 & 0.00 & 0.00 & 0.00 & 0.00 \\
\hline $1 \%$ pérdida de sección & 35.79 & 29.38 & 14.46 & 1.65 & 0.00 \\
\hline $2,5 \%$ pérdida de sección & 77.37 & 58.79 & 21.71 & 9.57 & 0.00 \\
\hline $5 \%$ pérdida de sección & 114.88 & 79.94 & 40.77 & 16.03 & 0.00 \\
\hline $7.5 \%$ pérdida de sección & 168.74 & 128.09 & 90.46 & 62.25 & 0.00 \\
\hline $10 \%$ pérdida de sección & 210.12 & 155.98 & 108.30 & 87.42 & 0.00 \\
\hline
\end{tabular}


La Figura 7-40 muestra que el modelo tiene una buena capacidad predictiva de la evolución de las deformaciones atribuibles exclusivamente a la corrosión. Para valores medios y altos de pérdida de sección (5-10 \%) los máximos arrojados por el modelo son muy similares a los obtenidos en los ensayos, mientras que se observa una desviación mayor para valores bajos de corrosión (1-2.5\% de pérdida de sección). Para valores bajos de corrosión el modelo es muy sensible a pequeñas variaciones en parámetros como el espesor equivalente de la capa porosa $t_{p, r i r}$ o el módulo de compresibilidad volumétrica $K_{l}$, por lo que no es sorprendente que las mayores diferencias se localicen en etapas tempranas del proceso de corrosión.

En definitiva, en este apartado se han comparado los resultados obtenidos en la campaña experimental sobre vigas pretensadas con alambres corroidos con los resultados arrojados por el modelo analítico desarrollado para esta tesis $\mathrm{y}$, a pesar de las salvedades expuestas, puede concluirse que la capacidad predictiva del modelo analítico es razonablemente buena. Este hecho nos permitirá analizar, en el próximo apartado, cómo influye la corrosión en la evolución de la longitud de transferencia del pretensado.

\subsection{Influencia de las distintas variables en la longitud de transferencia}

\subsubsection{Introducción}

Con las salvedades expuestas en los apartados anteriores, una vez comprobada la validez del modelo analítico como herramienta para la predicción y el análisis de las propiedades adherentes en alambres pretensados, así como su evolución con el avance de los procesos de corrosión, en este apartado se estudiará la influencia cualitativa de los principales parámetros geométricos y mecánicos que intervienen en el fenómeno: resistencia a compresión del hormigón $f_{c}$, recubrimiento de hormigón $c$, diámetro del alambre $\phi$, tensión inicial de pretensado $f_{p, 0}$, velocidad del destesado, rugosidad superficial del alambre, altura de indentaciones $h_{r}$ y pérdida de sección por corrosión. Todos estos parámetros, excepto el último, se estudian conjuntamente con el avance del fenómeno de la corrosión.

Para este análisis, se parte de una configuración tipo basada en un alambre pretensado centrado en un cilindro de hormigón, en la que se van variando los parámetros de estudio. Esta configuración tipo consiste en un alambre de $5 \mathrm{~mm}$ de diámetro $\phi$ y una altura homogéneamente repartida de indentaciones $h_{r}$ igual a $0,025 \mathrm{~mm}$, con una carga unitaria máxima $f_{p}$, max igual a $1860 \mathrm{MPa}$ y una tensión inicial de pretensado $f_{p, 0}$ de $1350 \mathrm{Mpa}$. La rugosidad superficial del alambre viene caracterizada por un coeficiente de fricción $\mu$ igual a 0,6. La relación recubrimiento/diámetro es igual a 4, por lo que el recubrimiento mecánico $c$ tiene un espesor de $20 \mathrm{~mm}$, y la resistencia a compresión del hormigón $f_{c}$ es de $30 \mathrm{MPa}$, con una resistencia a tracción $f_{c t}$ de 2,90 MPa y un módulo de elasticidad $E_{c}$ de $29700 \mathrm{MPa}$. Por último, se ha supuesto una puesta en carga del pretensado gradual, no súbita. No se ha fijado una longitud $L$ de la viga, sino que se ha adaptado en función de las necesidades para el cálculo de la transferencia total del pretensado. En la Tabla 7-34 se han incluido, a modo de resumen, algunas de las variables utilizadas en la configuración tipo. 
Tabla 7-34 Valor de las variables de la configuración tipo introducidas en el modelo analítico

\begin{tabular}{ccccccccccc}
\hline VIGA & \multicolumn{4}{c}{ ACERO } & \multicolumn{3}{c}{ HORMIGÓN } & \multicolumn{2}{c}{ ADHERENCIA } \\
\hline $\mathbf{L}$ & $\mathbf{r}_{\mathbf{b}}$ & $\mathbf{h}_{\mathbf{r}}$ & $\mathbf{E}_{\mathbf{s}}$ & $\mathbf{f}_{\mathbf{p}, \mathbf{0}}$ & $\mathbf{c}$ & $\mathbf{f}_{\mathbf{c m}}$ & $\mathbf{f}_{\mathbf{c t m}}$ & $\mathbf{E}_{\mathbf{c}}$ & $\boldsymbol{\mu}$ \\
{$[\mathbf{m m}]$} & {$[\mathbf{m m}]$} & {$[\mathbf{m m}]$} & {$[\mathbf{G P a}]$} & {$[\mathbf{M P a}]$} & {$[\mathbf{m m}]$} & {$[\mathbf{M P a}]$} & {$[\mathbf{M P a}]$} & {$[\mathbf{G P a}]$} & $\mathbf{Y}$ \\
\hline Variable & 2,5 & 0,025 & 210 & 1350 & 17,5 & 30 & 2,89 & 27 & 0,6 & 1 \\
\hline
\end{tabular}

La evolución de las propiedades adherentes, en función de cada uno de los parámetros de estudio, se ha estudiado mediante los cambios que experimentan la longitud de transferencia $l_{t}$, el deslizamiento en el extremo $\delta_{d}$ y el coeficiente $\alpha$ (Guyon, 1953), así como mediante el perfil de deformaciones en el hormigón $\boldsymbol{\varepsilon}_{c}$ y la tensión de adherencia $\tau_{b}$ a lo largo de la longitud de la viga. Para cada una de estas variables se han incluido gráficas en las que se muestran los resultados obtenidos.

\subsubsection{Influencia del diámetro del alambre $\phi$ en la longitud de transferencia}

En la Tabla $7-35$ se incluyen las longitudes de transferencia $l_{t}$ y los desplazamientos $\delta_{d}$ en el extremo de viga que se obtienen mediante el modelo analítico, para distintos diámetros $\phi$ del alambre de pretensado y distintas pérdidas de sección por corrosión. Se ha fijado la relación recubrimiento/diámetro (c/ $\phi=4)$, por lo que el cambio en el diámetro del alambre ha venido acompañado por cambios en el recubrimiento del hormigón $c$, en el área transversal $\mathrm{A}_{\mathrm{c}} \mathrm{y}$ en el porcentaje de óxidos generados que penetran en el espacio liberado por las fisuras radiales ( $V e r$ Capitulo o).

Tabla 7-35 Longitudes de transferencia l y deslizamientos en el extremo $\delta_{d}$ para distintos diámetros del alambre de pretensado $\phi$ y distintos niveles de corrosión

\begin{tabular}{|c|c|c|c|c|c|c|c|c|c|}
\hline$\phi[\mathrm{mm}]$ & 4 & 5 & 6 & 7 & 8 & $\begin{array}{c}\left(3 / 8^{\prime \prime}\right) \\
9.53\end{array}$ & $\begin{array}{c}\text { (7/16") } \\
11.11\end{array}$ & $\begin{array}{c}(1 / 2 ") \\
12.70\end{array}$ & $\begin{array}{l}(0,6 ") \\
15.24\end{array}$ \\
\hline$c / \phi$ & & & & & 4 & & & & \\
\hline c & 16 & 20 & 24 & 28 & 32 & 38.12 & 44.44 & 50.8 & 60.96 \\
\hline $\mathbf{A}_{\mathrm{c}}\left[\mathrm{mm}^{2}\right]$ & 804.25 & 1256.64 & 1809.65 & 2463.00 & 3216.99 & 4656.16 & 6204.37 & 8107.32 & 11674.54 \\
\hline \multirow[t]{2}{*}{$\%$ ox.fis } & 87 & 80 & 73 & 66 & 59 & 49 & 38 & 27 & 10 \\
\hline & \multicolumn{9}{|c|}{$0 \%$ de pérdida de sección } \\
\hline $1_{t}[\mathrm{~mm}]$ & 266.48 & 335.34 & 403.87 & 471.37 & 536.68 & 628.15 & 755.55 & 863.86 & 1032.2 \\
\hline \multirow[t]{2}{*}{$\delta_{\mathrm{d}}[\mathrm{mm}]$} & 0.5787 & 0.7185 & 0.8583 & 0.9977 & 1.1371 & 1.3501 & 1.5702 & 1.7916 & 2.1451 \\
\hline & \multicolumn{9}{|c|}{$5 \%$ de pérdida de sección } \\
\hline $\mathbf{l}_{\mathrm{t}}[\mathrm{mm}]$ & 266.48 & 335.34 & 403.87 & 471.37 & 536.68 & 628.15 & 755.55 & 863.86 & 1032.2 \\
\hline \multirow[t]{2}{*}{$\delta_{\mathbf{d}}[\mathrm{mm}]$} & 0.7534 & 0.8888 & 1.0228 & 1.1614 & 1.3207 & 1.5496 & 1.8196 & 2.0986 & 2.7095 \\
\hline & \multicolumn{9}{|c|}{$10 \%$ de pérdida de sección } \\
\hline $\mathbf{l}_{\mathrm{t}}[\mathrm{mm}]$ & 330.48 & 383.62 & 437.36 & 491.03 & 549.91 & 644.82 & 766.45 & 909.83 & 1282.1 \\
\hline \multirow[t]{2}{*}{$\delta_{\mathbf{d}}[\mathrm{mm}]$} & 1.1306 & 1.3085 & 1.4882 & 1.6720 & 1.8722 & 2.1918 & 2.5970 & 3.0897 & 4.3762 \\
\hline & \multicolumn{9}{|c|}{$15 \%$ de pérdida de sección } \\
\hline $\mathbf{l}_{\mathbf{t}}[\mathrm{mm}]$ & 441.19 & 505.93 & 573.57 & 642.34 & 716.88 & 837.57 & 1000.5 & 1206.6 & 1748.0 \\
\hline \multirow[t]{2}{*}{$\delta_{\mathrm{d}}[\mathrm{mm}]$} & 1.5019 & 1.7182 & 1.9449 & 2.1751 & 2.4270 & 2.8431 & 3.3806 & 4.0800 & 5.9309 \\
\hline & \multicolumn{9}{|c|}{$20 \%$ de pérdida de sección } \\
\hline $\mathbf{l}_{\mathbf{t}}[\mathrm{mm}]$ & 546.88 & 627.36 & 710.96 & 797.54 & 889.52 & 1044.6 & 1244.6 & 1508.7 & 2203.6 \\
\hline$\delta_{\mathrm{d}}[\mathrm{mm}]$ & 1.8565 & 2.1245 & 2.4038 & 2.6943 & 3.0056 & 3.5220 & 4.1963 & 5.0913 & 7.4586 \\
\hline
\end{tabular}



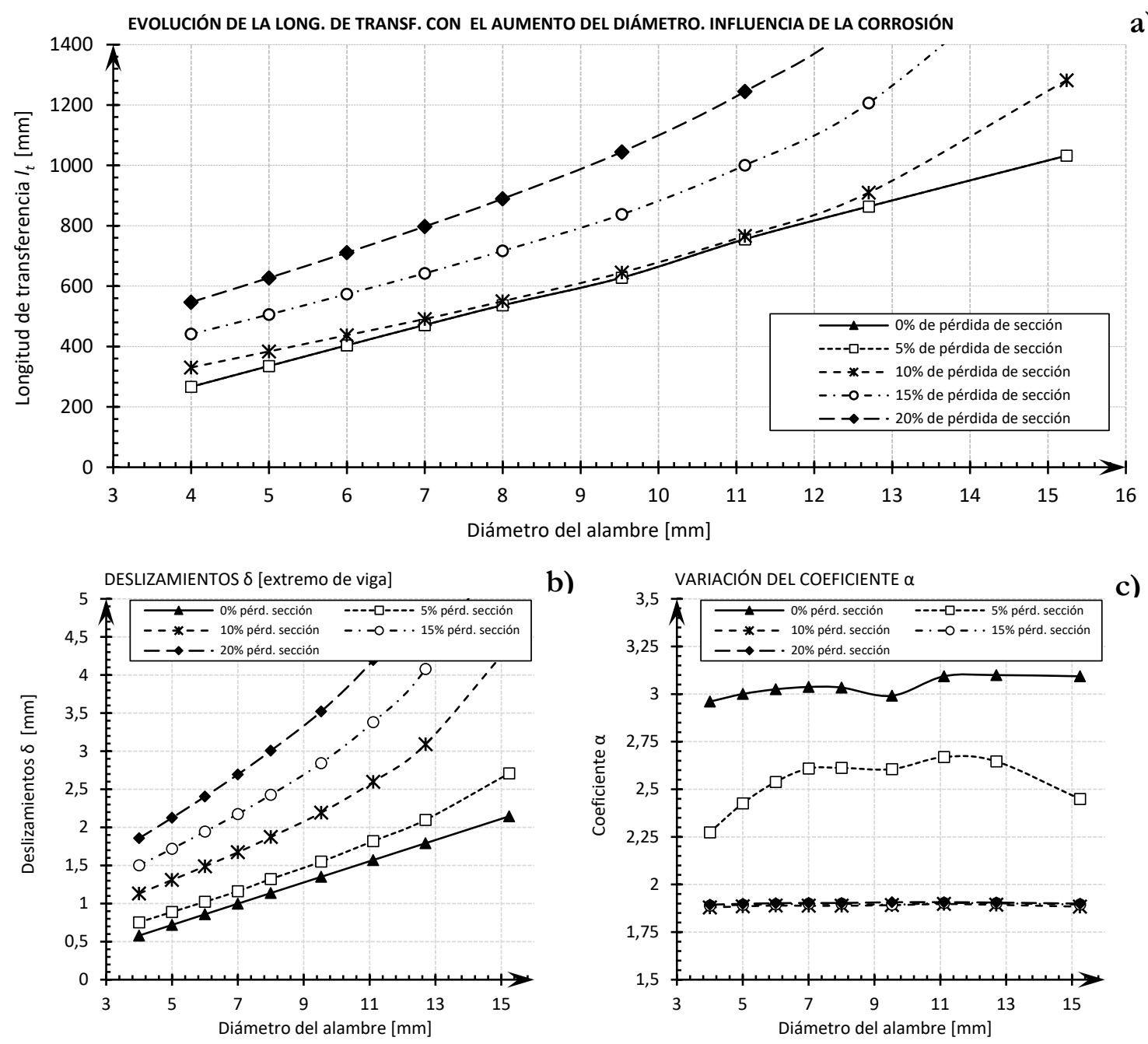

b)

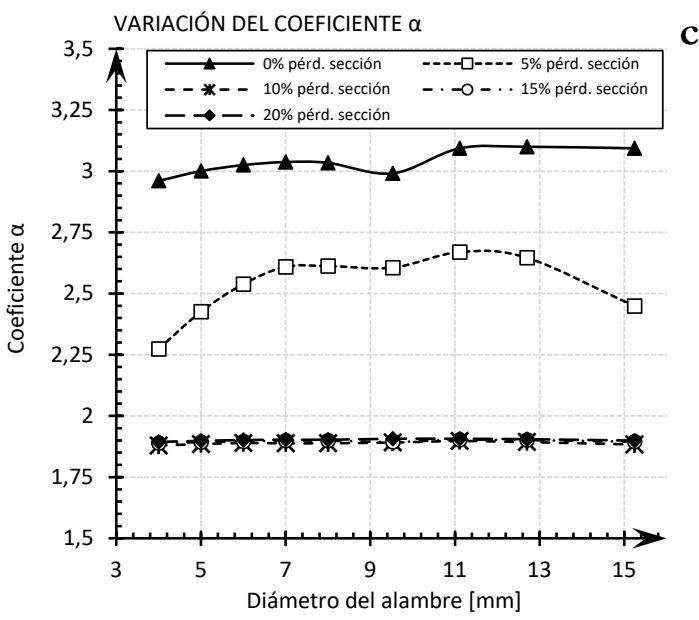

PERFILES DE DEFORMACIÓN DEL HORMIGÓN

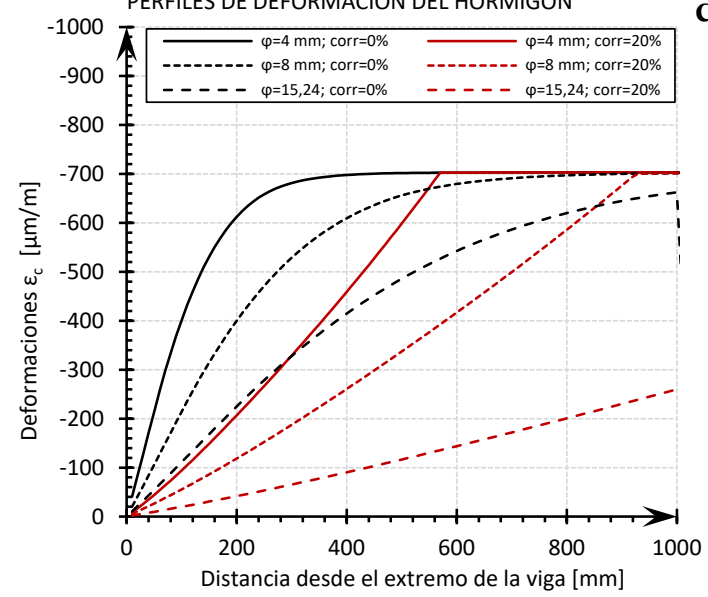

d)

TENSIONES DE ADHERENCIA $\tau_{b}$

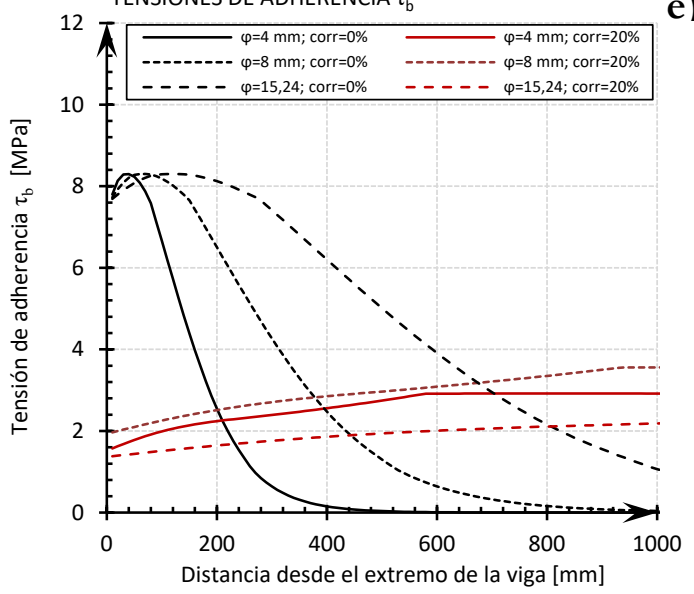

c)

e)

Figura 7-41 Evolución de $l_{t}(a)$, de los deslizamientos en el extremo $\delta_{d}(b)$, del coeficiente a (c), del perfil de deformaciones en el hormigón $\boldsymbol{\varepsilon}_{c}(d)$ $y$ de las tensiones de adherencia tb (e) para distintos diámetros del alambre $\phi$ y distintos niveles de corrosión en el hormigón. Resultados arrojados por el modelo analítico. 
Tal y como puede apreciarse en la Figura 7-41-(a.), en ausencia de corrosión, la longitud de transferencia crece linealmente con el aumento del diámetro del alambre de pretensado. El crecimiento relativo no es sólo lineal, sino que también es directamente proporcional. Por ejemplo: a un alambre de $4 \mathrm{~mm}$ de diámetro, para las condiciones consideradas, le corresponde una longitud de transferencia de 266,48 $\mathrm{mm}$ (Ver Tabla 7-35), mientras que a un alambre con el doble de diámetro (8 $\mathrm{mm}$ ) le corresponde una longitud de transferencia próxima al doble de la anterior $(536,68 \mathrm{~mm})$. Esta proporcionalidad puede observarse en la Figura 7-42, donde se han representado la evolución relativa de las longitudes de transferencia $\left(1_{t, 2} / 1_{t, 1}\right)$ frente a los crecimientos relativos del diámetro del alambre $\left(\phi_{2} / \phi_{1}\right)$. Por tanto, gracias a que se cumple $l_{t, 1} \cdot \phi_{2}=l_{t, 2} \cdot \phi_{1}$, puede deducirse que la longitud de transferencia $l_{t}$ es directamente proporcional al diámetro del alambre $\phi\left(l_{t} \propto \phi\right)$, o de forma parecida, a una función potencial del diámetro con exponente $1\left(l_{t} \propto a_{0} \phi^{\beta} ; \operatorname{con} \beta=1\right.$ y $\left.a_{0}=1\right)$. Esta transformación, aparentemente innecesaria, cobrará importancia a la hora de construir la expresión simplificada para determinar la longitud de transferencia en alambres sanos. Un comportamiento proporcional similar aparece en los deslizamientos en el extremo de viga $\delta_{d}$ (Figura 7-41-b).

Una vez que comienza el proceso de corrosión, la longitud de transferencia $l_{t}$ tiende a aumentar. Este incremento no se produce hasta que se supera un determinado umbral de productos de corrosión, que en el caso analizado se ubicaría en los producidos para una pérdida de sección de entre un 5 y un $10 \%$. Superado este umbral, la longitud de transferencia comienza a crecer para todos los diámetros considerados (Figura 7-41-(a) y Figura 7-42(der)). Es destacable que el deterioro relativo es mayor en los alambres de las series con diámetros menores, y tiende a tomar un valor constante en los alambres de las series intermedias y altas. Este comportamiento puede ser debido, por un lado, a un efecto de escala motivado por el cambio del espesor de recubrimiento $c$, y por otro, a la variación del porcentaje de volumen de fisuras ocupado por los productos de corrosión, que como se ha visto, es un parámetro de entrada del modelo.
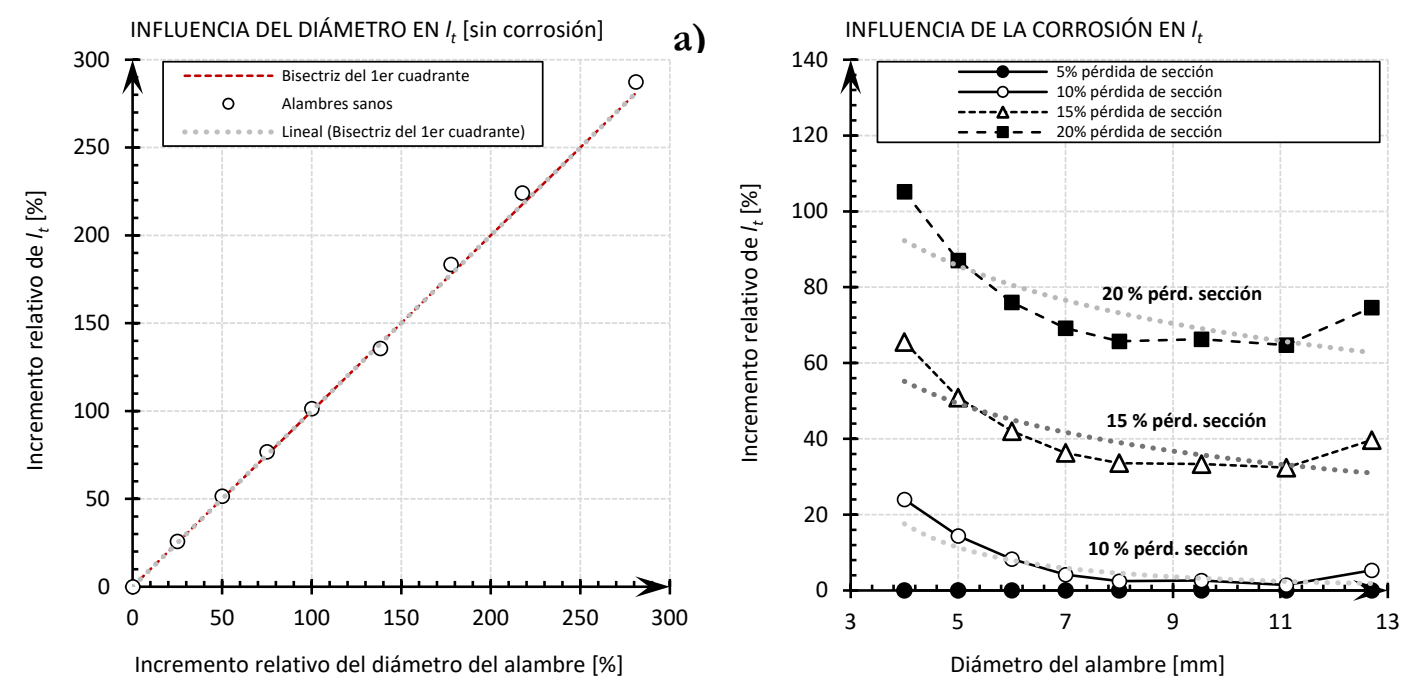

b)

Figura 7-42 Incrementos relativos de la longitud de transferencia l frente a incrementos relativos (a) y cambios absolutos (b) del diámetro del alambre de pretensado $\phi$

Por otro lado, los deslizamientos relativos en extremo de vigas $\delta_{d}$, al contrario de lo que ocurre con las longitudes de transferencia $l_{\text {, }}$ comienzan a crecer ya desde etapas tempranas del proceso de 
corrosión (Figura 7-41-b), presentando incrementos significativos desde pérdidas de sección de un $5 \%$, para todos los diámetros considerados.

Estos deslizamientos $\delta_{d}$ vienen acompañados por una variación importante del coeficiente $\alpha$ que, como se ha visto anteriormente, relaciona éstos con las longitudes de transferencia $l_{t}$. El coeficiente $\alpha$ pasa de valores cercanos a 3 para alambres sanos, a valores entre 2,27 y 2,67 para una pérdida de sección del 5\%, y finalmente a valores cercanos a 2 a partir de pérdidas de un 10\% (Figura 7-41-c). Esto implica, según la expresión de Guyon (1953), que la ley de distribución de la tensión de adherencia $\tau_{b}$, a lo largo de la longitud de transferencia $l_{t}$, va modificándose con el aumento de los niveles de corrosión, pasando de una distribución lineal $(\alpha=3)$ a una constante $(\alpha=2)$. Lógicamente, el perfil de deformaciones en el hormigón también se ve afectado, evolucionando de una distribución parabólica a otra de carácter lineal.

La evolución de las deformaciones de compresión en el hormigón $\boldsymbol{\varepsilon}_{c}$ y de las tensiones de adherencia $\tau_{b}$, con el aumento del diámetro de pretensado y de la corrosión pueden observarse en la Figura 7-41$d$ y en la Figura 7-41-e, respectivamente. Como puede apreciarse, la deformación máxima que se alcanza no varía con el diámetro $\phi$ ya que, aunque aumenta la fuerza de pretensado, también lo hace de forma proporcional el área de hormigón que rodea el alambre. De la misma manera, la tensión de adherencia máxima $\tau_{b \text {,max }}$ tampoco se ve afectada. En ambos casos, la forma de las gráficas obtenidas en el supuesto de alambres con procesos de corrosión confirma explícitamente lo expuesto anteriormente para la evolución del coeficiente $\alpha$.

\subsubsection{Influencia de la resistencia a compresión del hormigón en la longitud de transferencia}

En la Tabla $7-36$ se incluyen las longitudes de transferencia $l_{t}$ y los desplazamientos $\delta_{d}$ en el extremo de viga que se obtienen mediante el modelo analítico, para distintas resistencias a compresión del hormigón $f_{c}$ y distintas pérdidas de sección por corrosión. El cambio en la resistencia a compresión ha venido acompañado por modificaciones en la resistencia a tracción del hormigón $f_{c t}$, en el módulo de rigidez $E_{c}$ y en la deformación en el límite elástico $\varepsilon_{\sigma}$.

Las gráficas de la Figura 7-43 recogen gráficamente los datos incluidos en la Tabla 7-36. Como puede observarse, el incremento de la resistencia a compresión $f_{c}$ reduce de manera apreciable la longitud de transferencia $l_{t}$. Este cambio es más significativo para resistencia bajas del hormigón $\left(\mathrm{f}_{\mathrm{c}}<35-40 \mathrm{MPa}\right)$, y se va atenuando con el aumento de la resistencia. Como se vio en el Capítulo 3 y en la discusión de resultados en este capítulo, el hormigón que rodea al alambre a lo largo de su longitud de transferencia $l_{t}$ puede ser dividido en dos zonas diferenciadas según su comportamiento mecánico. Una primera zona, con comportamiento elástico, en la que las tensiones derivadas del pretensado (efecto Hoyer, indentaciones, etc) son relativamente pequeñas, de manera que la tensión radial $\sigma_{r}$ de compresión y la tensión de adherencia $\tau_{b}$ resultante son directamente proporcionales al desplazamiento radial del acero y al módulo de rigidez del hormigón $E_{c}$. Y una segunda zona, con comportamiento inelástico, en la que la tensión circunferencial derivada de la expansión radial del acero fisura el recubrimiento, de manera que se produce un ablandamiento en la respuesta del hormigón. El aumento de la resistencia a tracción $f_{c t}$ y del módulo de rigidez $E_{c}$ permite la disminución de dicha fisuración, aumentando la capacidad de confinamiento del recubrimiento, lo que posibilita que se puedan generar 


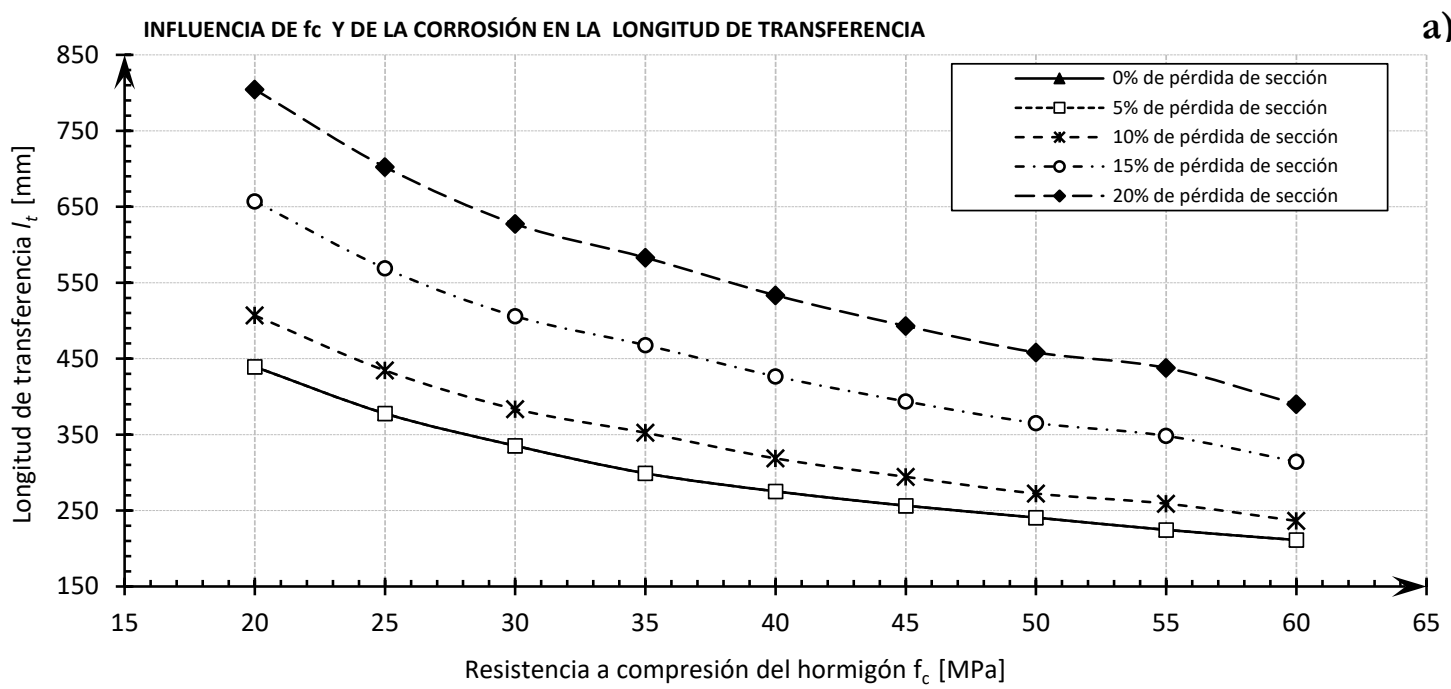

DESLIZAMIENTOS $\delta$ [extremo de viga]

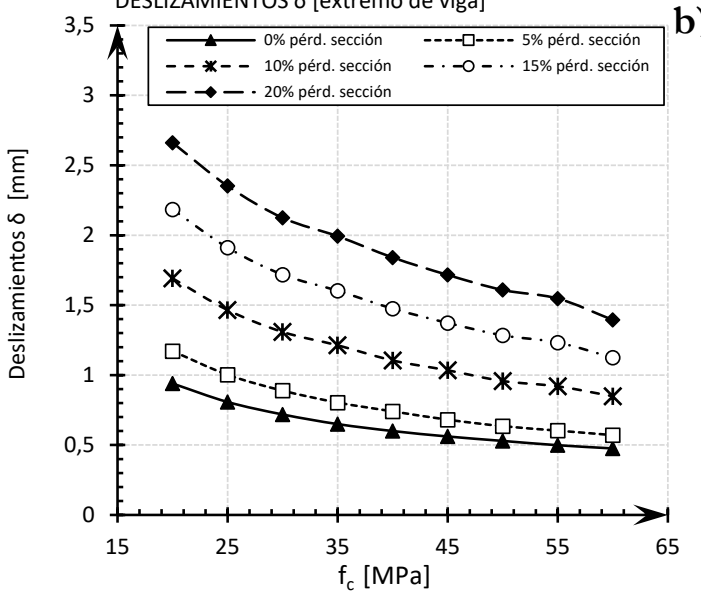

PERFILES DE DEFORMACIÓN DEL HORMIGÓN

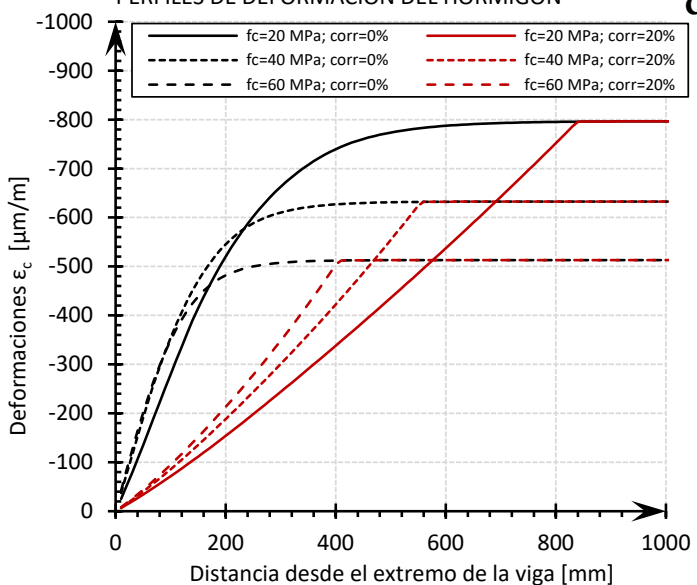

VARIACIÓN DEL COEFICIENTE $\alpha$

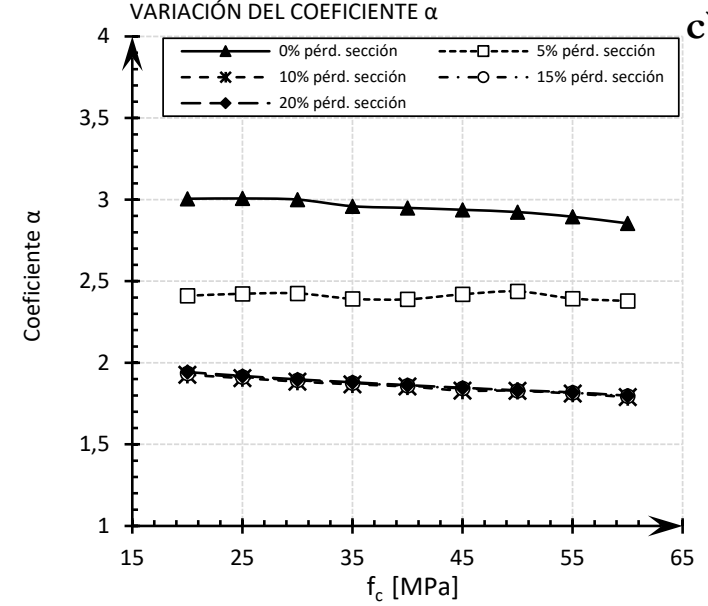

d)

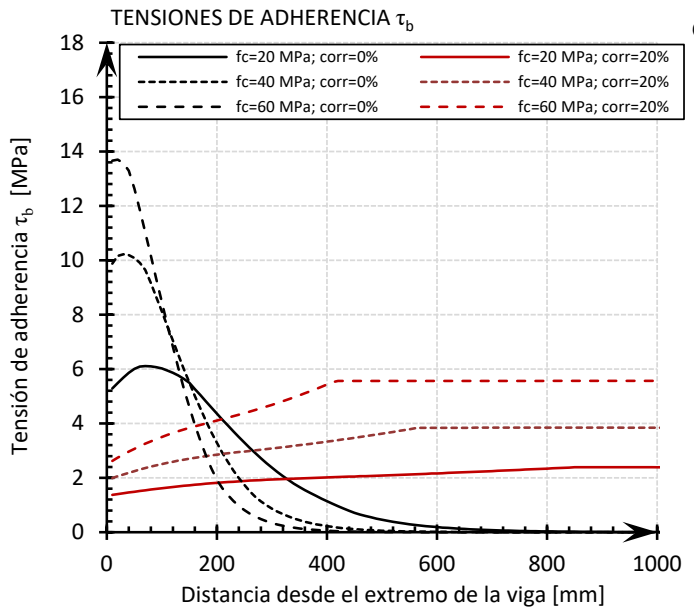

e)

Figura 7-43 Evolución de $l_{t}(a)$, de los deslizamientos en el extremo $\delta_{d}(b)$, del coeficiente a $(c)$, del perfil de deformaciones en el hormigón $\boldsymbol{\varepsilon}_{c}(d)$ $y$ de las tensiones de adherencia $\tau b$ (e) para distintas resistencia a compresión del hormigón y diferentes niveles de corrosión en el hormigón. 
mayores tensiones radiales $\sigma_{r}$ alrededor del alambre, lo que a su vez provoca un aumento de la tensión de adherencia $\tau_{b}$. El incremento de esta tensión hace que la transmisión de la fuerza de pretensado pueda llevarse a cabo en un menor longitud. Como se vio en el Capitulo 6, la mejora relativa de la capacidad de confinamiento del recubrimiento con el aumento de la resistencia a compresión $f_{c}$ se modera para resistencias altas, lo que justifica el comportamiento observado en la gráfica de la Figura $7-43-a$.

Tabla 7-36 Longitudes de transferencia lty de los desplazamientos en el extremo para distintas resistencias del hormigón fc y distintos niveles

\begin{tabular}{|c|c|c|c|c|c|c|c|c|c|}
\hline$f_{c m}$ & 20 & 25 & 30 & 35 & 40 & 45 & 50 & 55 & 60 \\
\hline$f_{c t m}$ & 2,21 & 2,56 & 2,90 & 3,21 & 3,51 & 3,80 & 4,07 & 4,34 & 4,60 \\
\hline$E_{c}$ & 26,2 & 28.0 & 29.7 & 31,4 & 33.0 & 34,5 & 36,0 & 37,5 & 40,7 \\
\hline \multirow[t]{2}{*}{$\varepsilon_{o}$} & 2,1 & 2,2 & 2,3 & 2,3 & 2,4 & 2,5 & 2,6 & 2,6 & 2,7 \\
\hline & \multicolumn{9}{|c|}{$0 \%$ de pérdida de sección } \\
\hline $\mathrm{l}_{\mathrm{t}}[\mathrm{mm}]$ & 439.31 & 377.80 & 335.34 & 299.06 & 275.26 & 256.36 & 240.73 & 224.55 & 211.19 \\
\hline \multirow[t]{2}{*}{$\delta_{\mathrm{d}}[\mathrm{mm}]$} & 0.9397 & 0.8077 & 0.7185 & 0.6496 & 0.6000 & 0.5610 & 0.5293 & 0.4986 & 0.4756 \\
\hline & \multicolumn{9}{|c|}{$5 \%$ de pérdida de sección } \\
\hline $\mathbf{1}_{\mathbf{t}}[\mathrm{mm}]$ & 439.31 & 377.80 & 335.34 & 299.06 & 275.26 & 256.36 & 240.73 & 224.55 & 211.19 \\
\hline \multirow[t]{2}{*}{$\delta_{\mathrm{d}}[\mathrm{mm}]$} & 1.1714 & 1.0023 & 0.8888 & 0.8037 & 0.7407 & 0.6811 & 0.6349 & 0.6030 & 0.5707 \\
\hline & \multicolumn{9}{|c|}{$10 \%$ de pérdida de sección } \\
\hline $1_{\mathrm{t}}[\mathrm{mm}]$ & 506.88 & 434.46 & 383.62 & 352.42 & 318.64 & 294.37 & 272.35 & 259.04 & 236.35 \\
\hline \multirow[t]{2}{*}{$\delta_{\mathrm{d}}[\mathrm{mm}]$} & 1.6919 & 1.4654 & 1.3085 & 1.2129 & 1.1045 & 1.0342 & 0.9575 & 0.9194 & 0.8489 \\
\hline & \multicolumn{9}{|c|}{$15 \%$ de pérdida de sección } \\
\hline $\mathbf{1}_{\mathbf{t}}[\mathrm{mm}]$ & 657.19 & 568.96 & 505.93 & 467.87 & 426.68 & 393.65 & 365.25 & 348.28 & 314.27 \\
\hline \multirow[t]{2}{*}{$\delta_{\mathrm{d}}[\mathrm{mm}]$} & 2.1842 & 1.9117 & 1.7182 & 1.6032 & 1.4751 & 1.3728 & 1.2840 & 1.2327 & 1.1249 \\
\hline & \multicolumn{9}{|c|}{$20 \%$ de pérdida de sección } \\
\hline $\mathbf{1}_{\mathrm{t}}[\mathrm{mm}]$ & 804.53 & 702.35 & 627.36 & 582.99 & 533.45 & 493.02 & 458.20 & 437.73 & 389.99 \\
\hline$\delta_{\mathrm{d}}[\mathrm{mm}]$ & 2.6616 & 2.3523 & 2.1245 & 1.9929 & 1.8408 & 1.7161 & 1.6084 & 1.5471 & 1.3942 \\
\hline
\end{tabular}

En la Figura 7-44-a) se ha representado, obtenidos para alambres sanos, la evolución relativa de la longitud de transferencia $\left(l_{t, 2} / l_{t, 1}\right)$ frente a la relación inversa de las resistencias a compresión $\left(f_{c, 1} / f_{c, 2}\right)$ y a tracción $\left(f_{c t, 1} / f_{c t, 2}\right)$ del hormigón. Como puede observarse, los resultados obtenidos para las resistencias a tracción $f_{c t}$ prácticamente se superponen a la línea de proporcionalidad inversa perfecta (línea discontinua roja), de lo que puede deducirse que la longitud de transferencia $l_{t}$ es inversamente proporcional a la resistencia a tracción del hormigón ; $l_{t, 1} \cdot f_{c t, 1}=l_{t, 2} \cdot f_{c t, 2}\left(l t \propto 1 / f_{c t}\right)$. Por otro lado, entre la longitud de transferencia $l_{t}$ y la resistencia a compresión del hormigón $f_{c}$ existe una relación de carácter potencial, con exponente igual a $2 / 3$, que coincide con la relación existente en el modelo analítico entre las resistencia a compresión y a tracción del hormigón. Por tanto, se cumple que $l t \propto$ $a_{0} f_{c}{ }^{\beta} ; \operatorname{con} \beta=2 / 3$. 


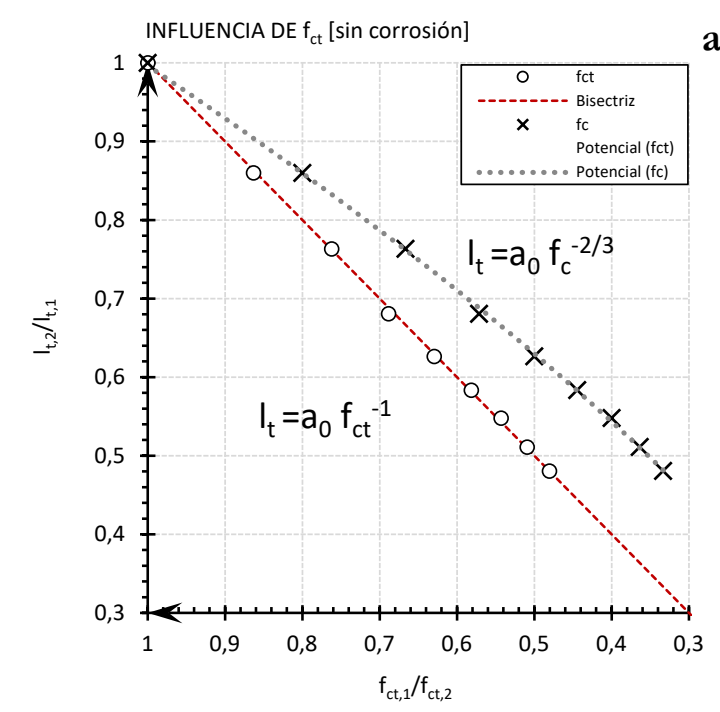

a)

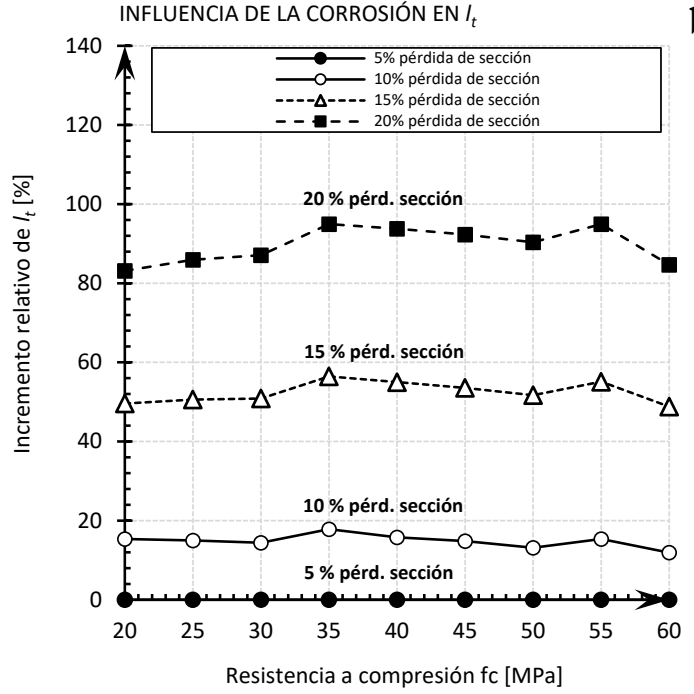

b)

Figura 7-44 Incrementos relativos de la longitud de transferencia $l_{t}$ frente a incrementos relativos (a) y cambios absolutos (b) de la resistencia del bormigón

Con el inicio del proceso de corrosión, como era esperable, la longitud de transferencia inicial del pretensado $l_{t, 0}$ va aumentando, al deteriorarse la capacidad de confinamiento del recubrimiento. Este aumento sólo es apreciable para pérdidas de sección del alambre superiores al 5\% (Figura 7-43-a). Por otro lado, a la vista de la gráfica b) de la Figura 7-44, los aumentos relativos de la longitud de transferencia con respecto al aumento del nivel de corrosión son independientes de la resistencia a compresión. De esta manera, independientemente del hormigón utilizado, se obtiene un aumento medio del 14,8\% para pérdidas de sección de un 10\%, del 52,4\% para pérdidas del 15\% y del 89,7\% para pérdidas del $20 \%$.

De manera similar a lo que ocurría para el diámetro $\phi$ del alambre, el coeficiente $\alpha$ para alambres sanos toma un valor próximo a 3 (distribución lineal de la tensión de adherencia $\tau_{b}$ ), independientemente de la resistencia a compresión del hormigón (Figura 7-43-c). El aumento del nivel de corrosión provoca que descienda de valor, hasta que para niveles de pérdida de sección del 10\% y superiores toma un valor ligeramente inferior al 2 (distribución constante de la tensión de adherencia $\left.\tau_{b}\right)$.

Tal y como se puede ver en la Figura 7-44-d, el aumento de la resistencia a compresión del hormigón $f_{c}$ trae consigo un descenso en el valor máximo del perfil de deformaciones, debido al incremento de rigidez del material. También se aprecia un aumento la pendiente de dicho perfil, debido a que el aumento de la capacidad de confinamiento posibilita la aparición de mayores tensiones de adherencia (Figura 7-44-e). Por otra parte, la corrosión provoca que el perfil de deformaciones a lo largo de la longitud de transferencia evolucione desde una distribución aproximadamente parabólica a una prácticamente lineal. 


\subsubsection{Influencia del recubrimiento $(c / \phi)$ en la longitud de transferencia}

En la Tabla 7-37 se incluyen las longitudes de transferencia $l_{t}$ y los desplazamientos $\delta_{d}$ en el extremo de viga que se obtienen mediante el modelo analítico, para distintas relaciones recubrimiento/diámetro $c / \phi$ y distintos niveles de corrosión. El cambio en el espesor de recubrimiento ha venido acompañado por modificaciones en el área transversal $A_{c} y$ en el porcentaje de óxidos generados que penetran en el espacio liberado por las fisuras radiales.

Tabla 7-37 Longitudes de transferencia lt y desplazamientos en el extremo de vigas $\delta_{d}$ para distintas relaciones recubrimiento/diámetro c/ $\phi y$

\begin{tabular}{|c|c|c|c|c|c|c|c|c|c|}
\hline$c / \phi$ & $c / \phi=1.5$ & $c / \phi=2$ & $c / \phi=2.5$ & $c / \phi=3$ & $c / \phi=3.5$ & $c / \phi=4$ & $c / \phi=4.5$ & $c / \phi=5$ & $c / \phi=7.5$ \\
\hline$\phi$ & \multicolumn{9}{|c|}{5} \\
\hline c & 7.5 & 10 & 12.5 & 15 & 17.5 & 20 & 22.5 & 25 & 37.5 \\
\hline $\mathbf{A}_{c}$ & 176.71 & 314.16 & 490.87 & 706.86 & 962.11 & 1256.64 & 1590.43 & 1963.50 & 4417.87 \\
\hline \multirow[t]{2}{*}{$\begin{array}{c}\% \\
\text { fisuras }\end{array}$} & 96.66 & 93.33 & 90 & 86.66 & 83.33 & 80.0 & 76.25 & 72.5 & 45 \\
\hline & \multicolumn{9}{|c|}{$0 \%$ de pérdida de sección } \\
\hline $1_{\mathrm{t}}[\mathrm{mm}]$ & 699.63 & 490.58 & 407.75 & 363.74 & 345.33 & 335.34 & 329.29 & 324.94 & 311.56 \\
\hline \multirow[t]{2}{*}{$\delta_{\mathrm{d}}[\mathrm{mm}]$} & 1.8462 & 1.1799 & 0.9172 & 0.7885 & 0.7332 & 0.7185 & 0.7213 & 0.7271 & 0.7507 \\
\hline & \multicolumn{9}{|c|}{$5 \%$ de pérdida de sección } \\
\hline $\mathbf{1}_{\mathbf{t}}[\mathrm{mm}]$ & --- & 1104.3 & 595.84 & 401.06 & 345.33 & 335.34 & 329.29 & 324.94 & 311.56 \\
\hline \multirow[t]{2}{*}{$\delta_{\mathrm{d}}[\mathrm{mm}]$} & --- & 3.2151 & 1.8609 & 1.3085 & 1.0385 & 0.8888 & 0.8029 & 0.7628 & 0.7530 \\
\hline & \multicolumn{9}{|c|}{$10 \%$ de pérdida de sección } \\
\hline $\mathbf{l}_{\mathrm{t}}[\mathrm{mm}]$ & --- & --- & 1364.3 & 749.99 & 507.96 & 383.62 & 329.29 & 324.94 & 311.56 \\
\hline \multirow[t]{2}{*}{$\delta_{\mathrm{d}}[\mathrm{mm}]$} & --- & --- & 4.2494 & 2.4254 & 1.6940 & 1.3085 & 1.0764 & 0.9376 & 0.7754 \\
\hline & \multicolumn{9}{|c|}{$15 \%$ de pérdida de sección } \\
\hline $\mathbf{l}_{\mathrm{t}}[\mathrm{mm}]$ & --- & --- & --- & 1137.1 & 705.94 & 505.93 & 394.84 & 328.87 & 311.56 \\
\hline \multirow[t]{2}{*}{$\delta_{\mathrm{d}}[\mathrm{mm}]$} & --- & --- & --- & 3.6792 & 2.3452 & 1.7182 & 1.3629 & 1.1413 & 0.8118 \\
\hline & \multicolumn{9}{|c|}{$20 \%$ de pérdida de sección } \\
\hline $\mathbf{1}_{\mathrm{t}}[\mathrm{mm}]$ & --- & --- & --- & 1583.6 & 914.09 & 627.36 & 476.21 & 384.85 & 311.56 \\
\hline$\delta_{\mathrm{d}}[\mathrm{mm}]$ & --- & --- & --- & 5.1416 & 3.0336 & 2.1245 & 1.6392 & 1.3415 & 0.8558 \\
\hline
\end{tabular}

Las gráficas de la Figura 7-45 muestran gráficamente los datos de la Tabla 7-37. A la vista de los resultados obtenidos, puede deducirse que el incremento de la relación recubrimiento/diámetro $c / \phi$ mejora considerablemente el comportamiento adherente de los alambres pretensados. Esta mejora se produce hasta que se alcanza una determinada relación $c / \phi$, a partir de la cual cualquier aumento del recubrimiento conduce a reducciones mucho más atenuadas de la longitud de transferencia $l_{\text {t }}$ Para alambres sanos, en el caso de estudio que nos ocupa, esta relación se encuentra en el rango entre $c / \phi=3,0-3,5$. Este umbral viene marcado por la relación existente entre la capacidad de confinamiento del recubrimiento, determinada por la resistencia a compresión del hormigón $f_{c}$ y la relación recubrimiento/diámetro, y la solicitación a la que es sometido por los desplazamientos radiales que provoca tanto el efecto Hoyer, como las indentaciones en su deslizamiento. Por tanto, fijando el resto de las variables, para resistencias menores del hormigón, el incremento de la relación 

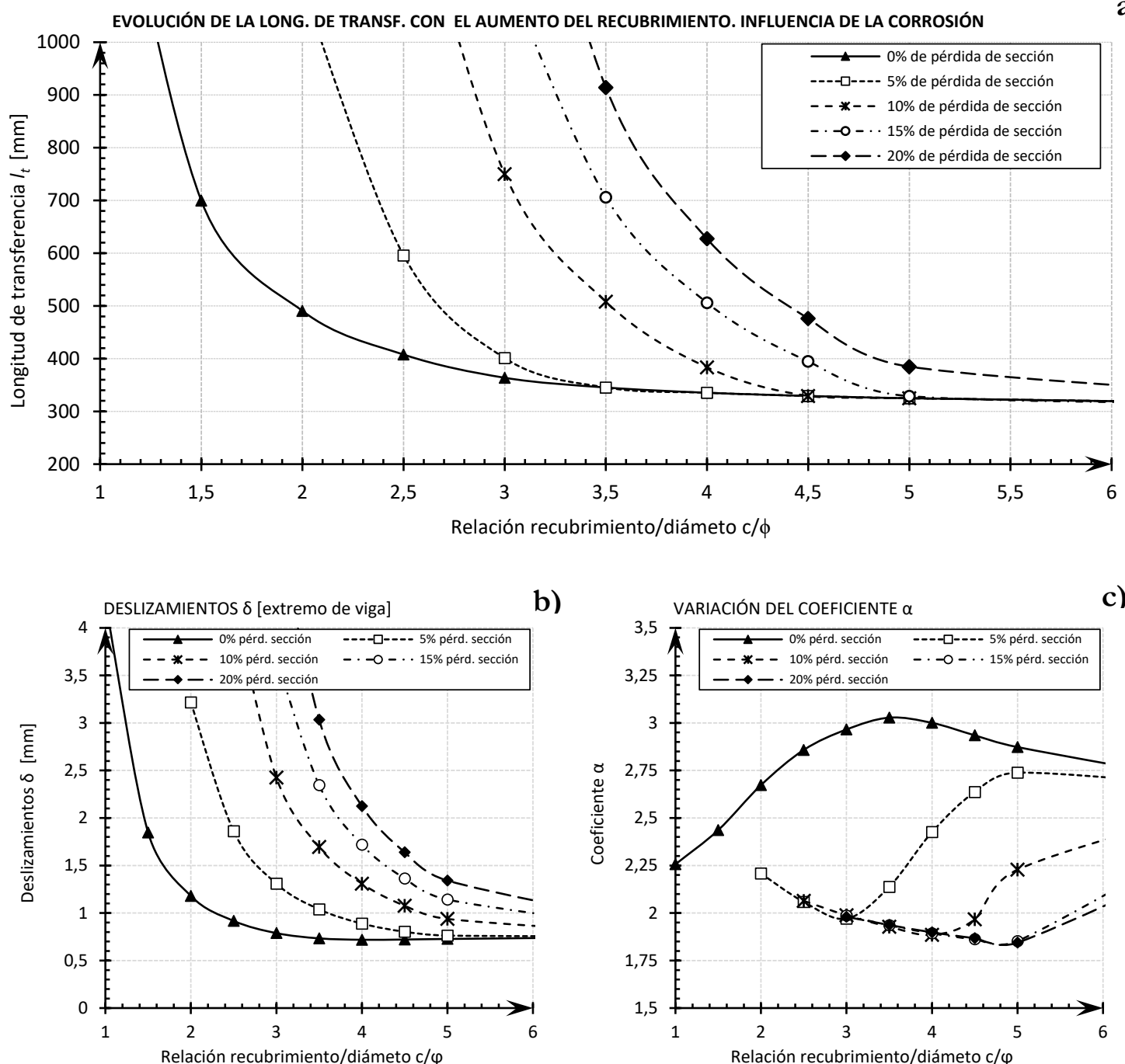

b)
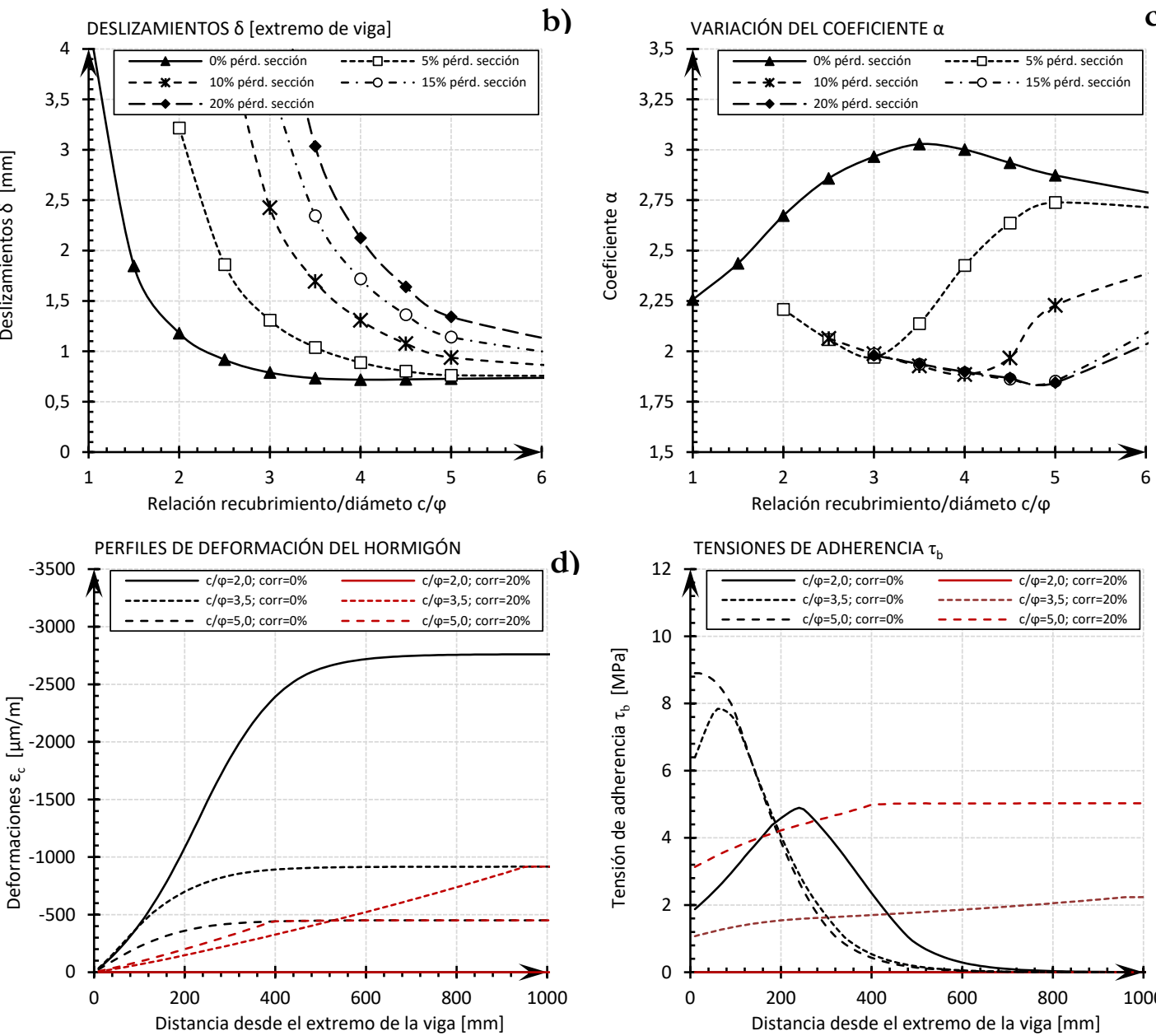

d)

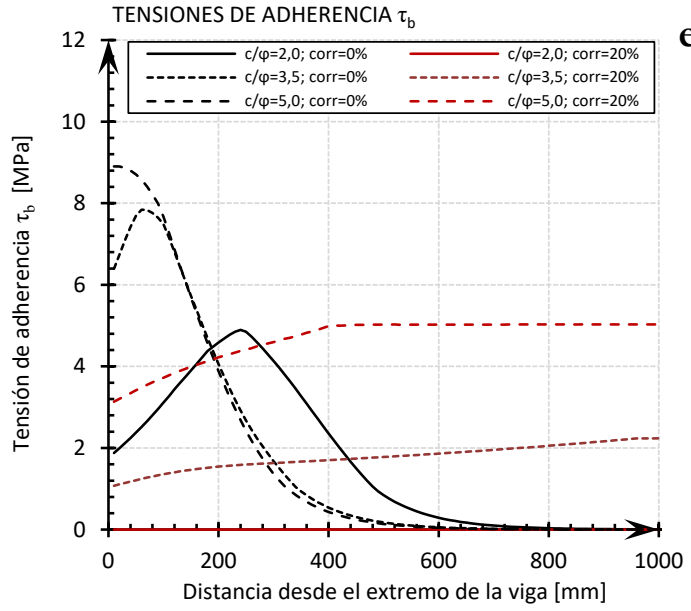

Figura 7-45 Evolución de $l_{t}(a)$, de los deslizamientos en el extremo $\delta_{d}(b)$, del coeficiente a (c), del perfil de deformaciones en el hormigón $\boldsymbol{\varepsilon}_{c}(d)$ $y$ de las tensiones de adherencia $\tau b$ (e) para distintas relaciones recubrimiento/ diámetro $c / \phi$ y diferentes niveles de corrosión. Resultados arrojados por el modelo analítico. 
recubrimiento/diámetro permitiría disminuciones significativas de la longitud de transferencia más allá del límite 3,5-4. Del mismo modo, un aumento de la fuerza de pretensado inicial provocaría una mayor solicitación del recubrimiento en la zona de transferencia, por lo que las propiedades adherentes serían sensibles a un aumento del recubrimiento por encima del límite hallado para el caso de estudio.

Por otro lado, la acumulación de productos de corrosión en la interfaz acero-hormigón es otro factor que puede incrementar las solicitaciones a las que está sometido el recubrimiento. Por tanto, cualquier aumento en el grado de corrosión provoca que el sistema sea más sensible al aumento de la relación recubrimiento/diámetro. De esta manera, en la gráfica Figura 7-45-a puede observarse que el umbral o límite en el que un aumento de la relación recubrimiento-diámetro no supone una mejora sustancial de las propiedades adherentes se desplaza hasta $c / \phi=3,5$ para un $5 \%$ de pérdida de sección, hasta $c / \phi=4,5$ para un $10 \%$, hasta $c / \phi=5,0$ para un $10 \%$, y a valores superiores a $c / \phi=6,0$ para pérdidas de un $20 \%$ de sección.

Por tanto, puede afirmarse que existe una relación de proporcionalidad inversa entre la longitud de transferencia $l_{t}$ y la relación recubrimiento/diámetro $c / \phi$. En la Figura 7-46-a) se estudia esta proporcionalidad, ajustando los resultados obtenidos para alambres sanos en el rango de relaciones $c / \phi$ más habituales (entre 2,0 y 4,5$)$ mediante una regresión potencial del tipo $a_{0}(c / \phi)^{\beta}$. Como puede observarse, se obtienen buenos grados de ajuste, por lo que se puede concluir que que $l t \propto$ $a_{0}(c / \phi)^{\beta}$.
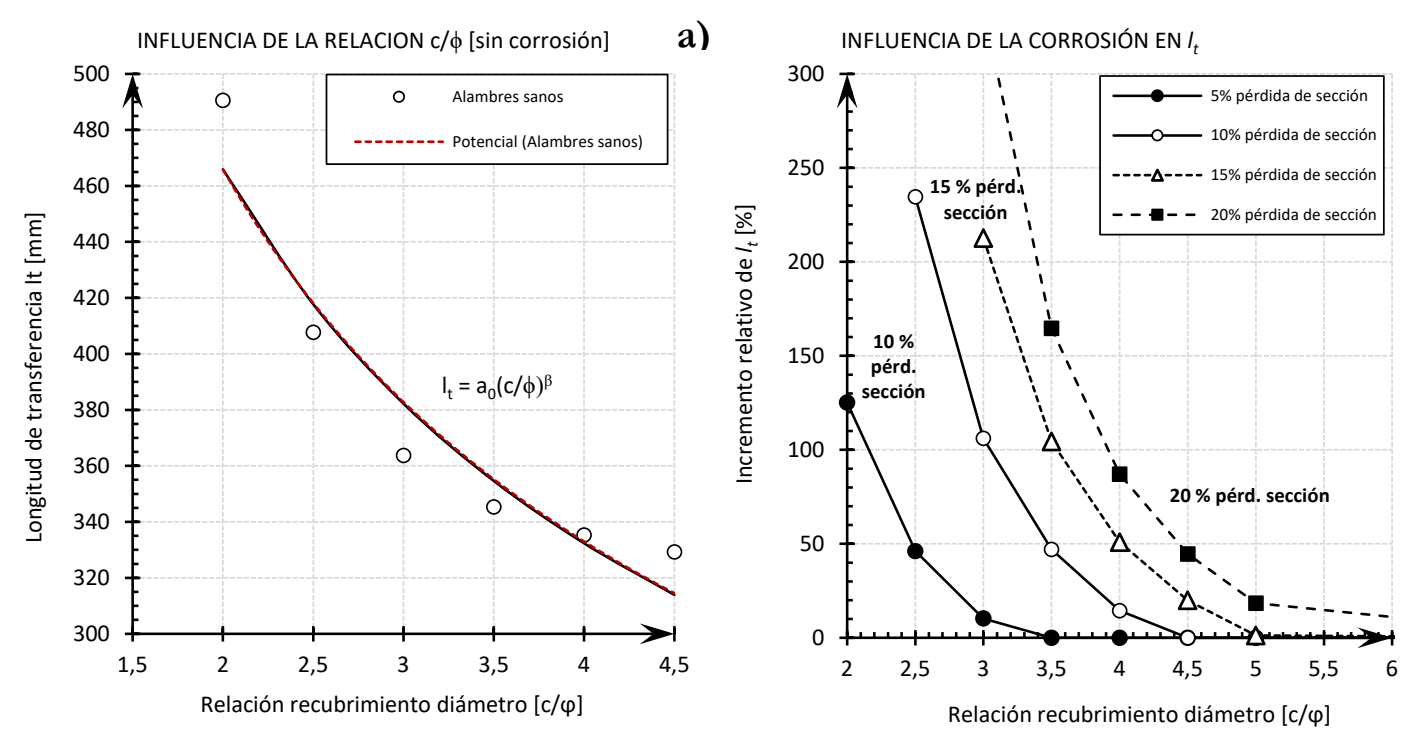

b)

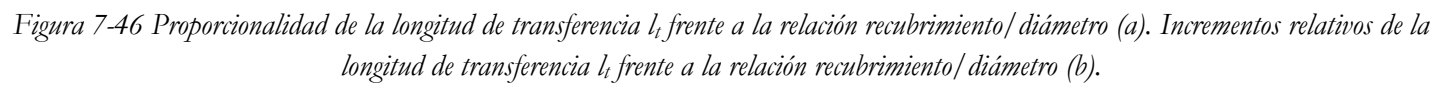

En cuanto a los deslizamientos en extremo de vigas $\delta_{d}$ (Figura 7-45-b), los resultados ofrecen un comportamiento similar al obtenido en las longitudes de transferencia $l_{t}$ al aumentar las relaciones recubrimiento/diámetro, es decir, un descenso de los mismos bastante acusado para relaciones $c / \phi$ bajas, y un estancamiento de los mismos superado una determinada relación límite o umbral, que en 
este caso es igual a $c / \phi=3,0-3,5$. Este comportamiento también se ve reflejado en el coeficiente $\alpha$ donde, para alambres sanos, el coeficiente evoluciona desde valores cercanos a 2 para relaciones $c / \phi$ bajas, a un valor por encima de 3 en límite indicado anteriormente. Esto nos indica que para valores por debajo de este umbral, la capacidad de confinamiento del recubrimiento no es capaz de ofrecer una respuesta completa a las solicitaciones procedentes del efecto Hoyer y del deslizamiento de las indentaciones, encontrándose completamente fisurado en zonas cercanas a los extremos. Esto también es observable en la Figura 7-45-e), donde se ve que para un alambre sano, con una relación recubrimiento/diámetro baja $(c / \phi=2)$, la tensión de adherencia $\tau_{b}$ no alcanza su máximo hasta haberse alejado una distancia considerable unos $(250 \mathrm{~mm})$ del extremo de la viga, lo que indica que en esa zona la degradación de la capacidad de confinamiento debida a la fisuración es significativa. El aumento de la relación recubrimiento/diámetro provoca no sólo que la tensión de adherencia máxima $\tau_{b, \text { max }}$ sea mayor, sino que también desplaza el punto en el que se alcanza hacia zonas cercanas al extremo de la viga.

$\mathrm{Al}$ igual que ocurría en los casos anteriores, el aumento del nivel de corrosión acerca el coeficiente $\alpha$ a valores cercanos a 2 (Figura 7-45-c), lo que implica que, a lo largo de la longitud de transferencia $l_{\text {t, }}$ la ley de tensión de adherencia $\tau_{b}$ se aproxima a una distribución constante y el perfil de deformaciones en el hormigón $\varepsilon_{c}$ a una distribución lineal.

\subsubsection{Influencia de la fuerza de pretensado inicial en la longitud de transferencia}

En la Tabla 7-38 se incluyen las longitudes de transferencia $l_{t}$ y los desplazamientos $\delta_{d}$ en el extremo de viga que se obtienen mediante el modelo analítico para distintas fuerzas de pretensado inicial $\sigma_{p, 0}$, en función de su relación con la carga unitaria máxima $f_{p, u}$, y distintos niveles de corrosión.

Tabla 7-38 Longitudes de transferencia lt y desplazamientos en el extremo de vigas $\delta_{d}$ para distintas fuerza de pretensado inicial $f_{p, o} y$ distintos niveles de corrosión

\begin{tabular}{|c|c|c|c|c|c|c|c|c|c|}
\hline$f_{p, 0}$ & $0,5 \cdot f_{\mathrm{pu}}$ & $0,55 \cdot f_{\mathrm{pu}}$ & $\mathbf{0 , 6 0} \cdot \mathrm{f}_{\mathrm{pu}}$ & $0,65 \cdot f_{p u}$ & $0,70 \cdot f_{\mathrm{pu}}$ & $0,75 \cdot f_{\mathrm{pu}}$ & $0,80 \cdot f_{\mathrm{pu}}$ & $0,85 \cdot f_{\mathrm{pu}}$ & $0,90 \cdot f_{\mathrm{pu}}$ \\
\hline $\mathrm{f}_{\mathrm{p}, 0}[\mathrm{MPa}]$ & 930 & 1023 & 1116 & 1209 & 1302 & 1395 & 1488 & 1581 & 1674 \\
\hline & \multicolumn{9}{|c|}{$0 \%$ de pérdida de sección } \\
\hline $1_{\mathrm{t}}[\mathrm{mm}]$ & 296.54 & 304.48 & 312.74 & 321.29 & 330.38 & 339.92 & 350.35 & 361.75 & 374.18 \\
\hline \multirow[t]{2}{*}{$\delta_{\mathrm{d}}[\mathrm{mm}]$} & 0.4026 & 0.4628 & 0.5280 & 0.5985 & 0.6756 & 0.7615 & 0.8589 & 0.9706 & 1.0988 \\
\hline & \multicolumn{9}{|c|}{$5 \%$ de pérdida de sección } \\
\hline $\mathbf{1}_{\mathrm{t}}[\mathrm{mm}]$ & 296.54 & 304.48 & 312.74 & 321.29 & 330.38 & 339.92 & 350.35 & 361.75 & 374.18 \\
\hline \multirow[t]{2}{*}{$\delta_{\mathrm{d}}[\mathrm{mm}]$} & 0.4244 & 0.5076 & 0.5961 & 0.6956 & 0.8202 & 0.9581 & 1.0943 & 1.2522 & 1.4454 \\
\hline & \multicolumn{9}{|c|}{$10 \%$ de pérdida de sección } \\
\hline $\mathbf{l}_{\mathbf{t}}[\mathrm{mm}]$ & 296.54 & 304.48 & 312.74 & 336.99 & 366.37 & 399.42 & 431.42 & 467.82 & 502.25 \\
\hline \multirow[t]{2}{*}{$\delta_{\mathrm{d}}[\mathrm{mm}]$} & 0.5759 & 0.7058 & 0.8583 & 1.0215 & 1.2021 & 1.4077 & 1.6311 & 1.8895 & 2.1585 \\
\hline & \multicolumn{9}{|c|}{$15 \%$ de pérdida de sección } \\
\hline $\mathbf{1}_{\mathrm{t}}[\mathrm{mm}]$ & 326.14 & 364.24 & 402.74 & 442.97 & 483.95 & 527.12 & 570.04 & 615.69 & 662.89 \\
\hline \multirow[t]{2}{*}{$\delta_{\mathrm{d}}[\mathrm{mm}]$} & 0.7513 & 0.9251 & 1.1199 & 1.3384 & 1.5807 & 1.8527 & 2.1469 & 2.4769 & 2.8382 \\
\hline & \multicolumn{9}{|c|}{$20 \%$ de pérdida de sección } \\
\hline $\mathbf{1}_{\mathrm{t}}[\mathrm{mm}]$ & 403.82 & 450.79 & 499.14 & 548.93 & 600.26 & 653.20 & 707.91 & 764.50 & 823.13 \\
\hline$\delta_{\mathrm{d}}[\mathrm{mm}]$ & 0.9260 & 1.1406 & 1.3826 & 1.6539 & 1.9559 & 2.2907 & 2.6611 & 3.0694 & 3.5187 \\
\hline
\end{tabular}



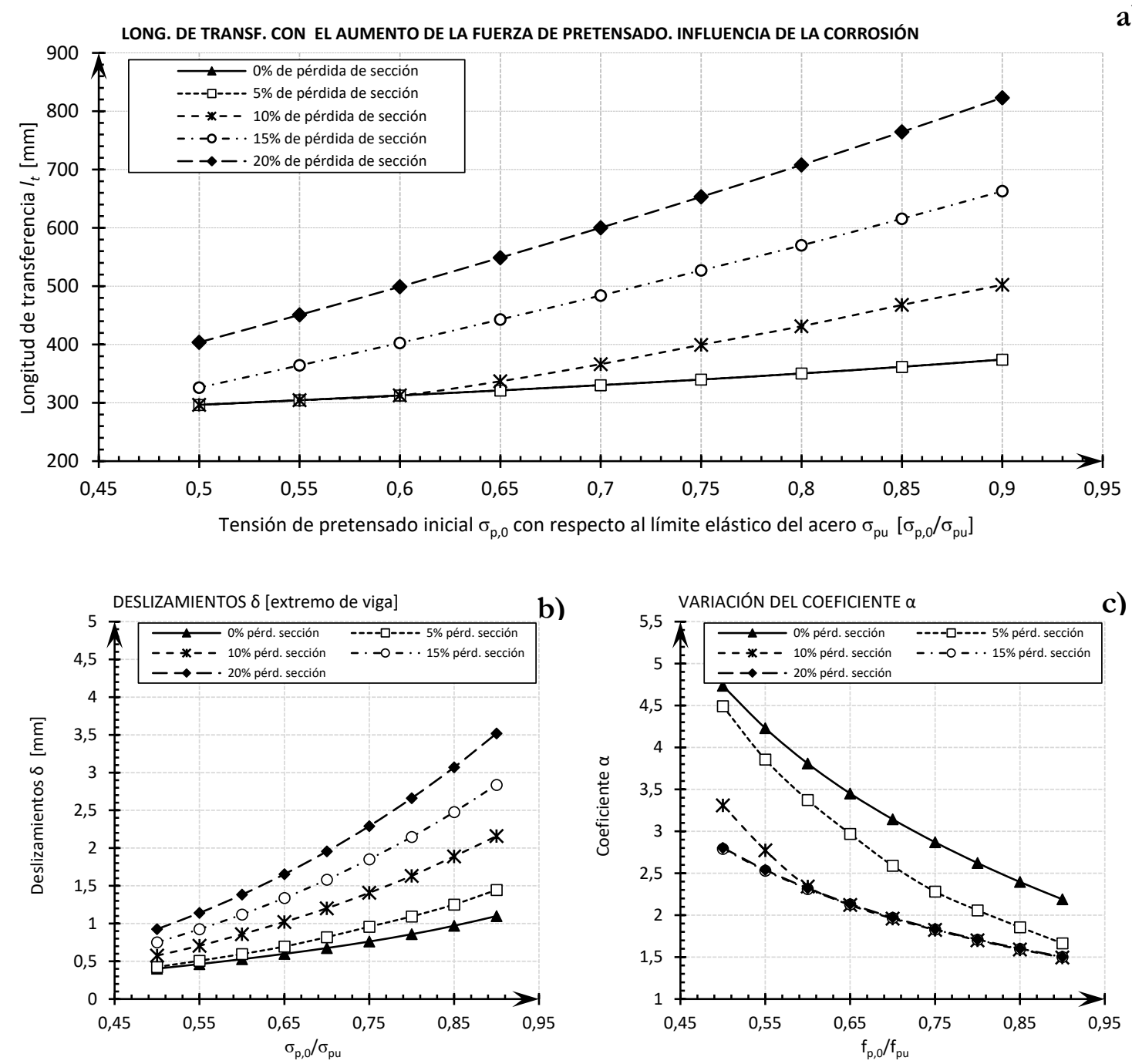

b)

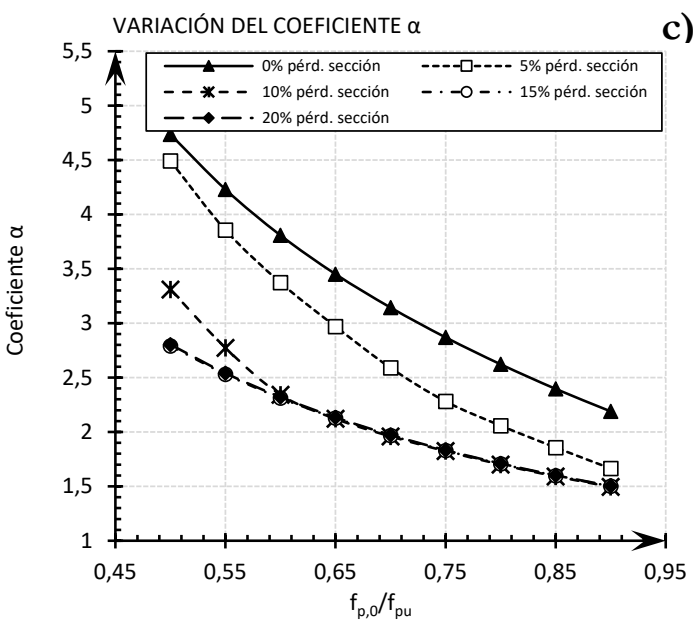

PERFILES DE DEFORMACIÓN DEL HORMIGÓN

d)
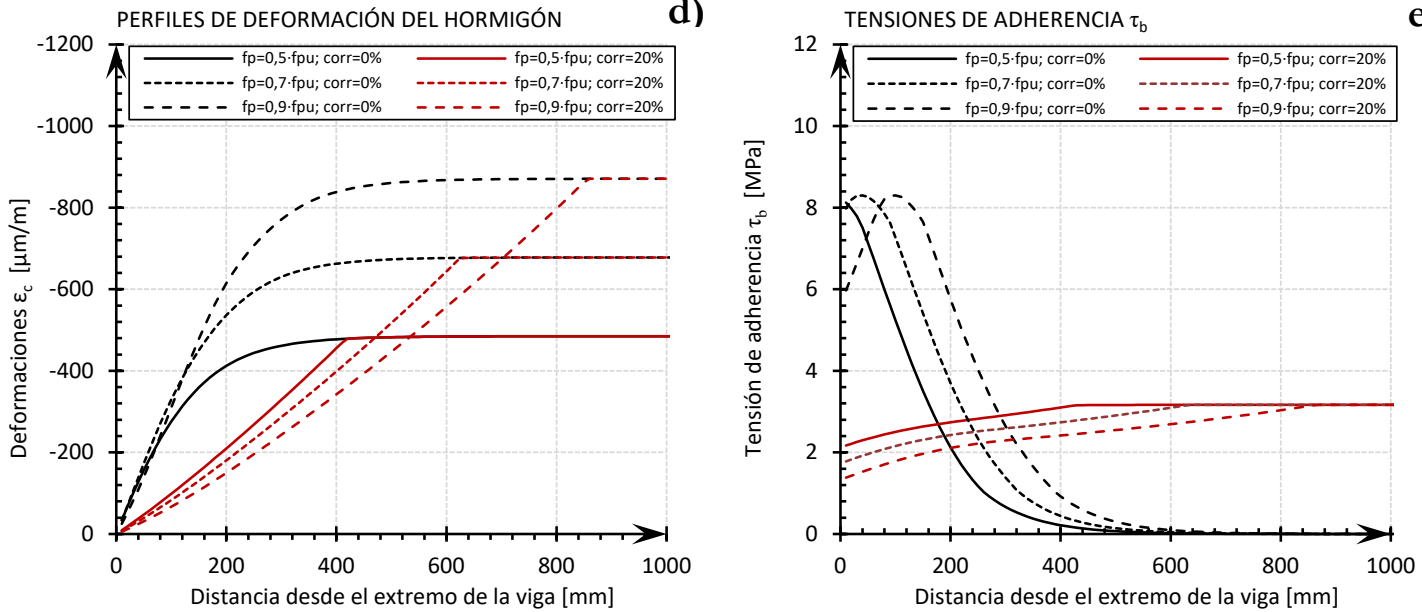

e)

Figura 7-47 Evolución de $l_{t}(a)$, de los deslizamientos en el extremo $\delta_{d}(b)$, del coeficiente a (c), del perfil de deformaciones en el hormigón $\varepsilon_{c}(d)$ $y$ de las tensiones de adherencia tb (e) para distintas fuerzas de pretensado inicial $f_{p, 0}$ y diferentes niveles de corrosión. Resultados arrojados por el modelo analítico. 
En las gráficas de la Figura 7-47 se muestran gráficamente los datos de la Tabla 7-38. A la vista de los resultados obtenidos (Figura 7-47-a), puede deducirse que el incremento de la fuerza inicial de pretensado $\sigma_{p, 0}$ trae consigo un aumento de la longitud de transferencia $l_{t}$. Este aumento no es sólo debido a que sea necesario transferir una mayor fuerza entre el alambre y el acero, sino al hecho de que ésta también viene acompañada de un mayor deterioro del recubrimiento en los extremos. Este deterioro, derivado de una mayor fisuración, es debido a un incremento en el desplazamiento radial $u_{r}$ de la pared interna del cilindro que rodea el alambre, ya que la diferencia en el radio del mismo antes y después de la transferencia es mayor, así como el deslizamiento de las indentaciones (Figura 7-47-b). Paralelamente, el coeficiente $\alpha$ para alambres sanos disminuye de manera significativa desde un valor de 4.73 para una tensión de pretensado del 50\% con respecto a la carga unitaria máxima $f_{p u}$ $\left(930 \mathrm{MPa}\right.$ ), hasta un valor $\alpha=2.18$ para una tensión inicial del $90 \%$ de $f_{p u}$, equivalente a $1674 \mathrm{MPa}$ (Figura 7-47-c).

En la Figura 7-48-a) se analiza la proporcionalidad existente entre la longitud de transferencia $l_{t}$ y la fuerza de pretensado inicial $\sigma_{p, 0}$. Los datos obtenidos se han ajustado mediante una regresión potencial, obteniéndose un buen ajuste, por lo que puede afirmarse que $l_{t, 0} \propto a_{0} \sigma_{p, 0} \beta$.

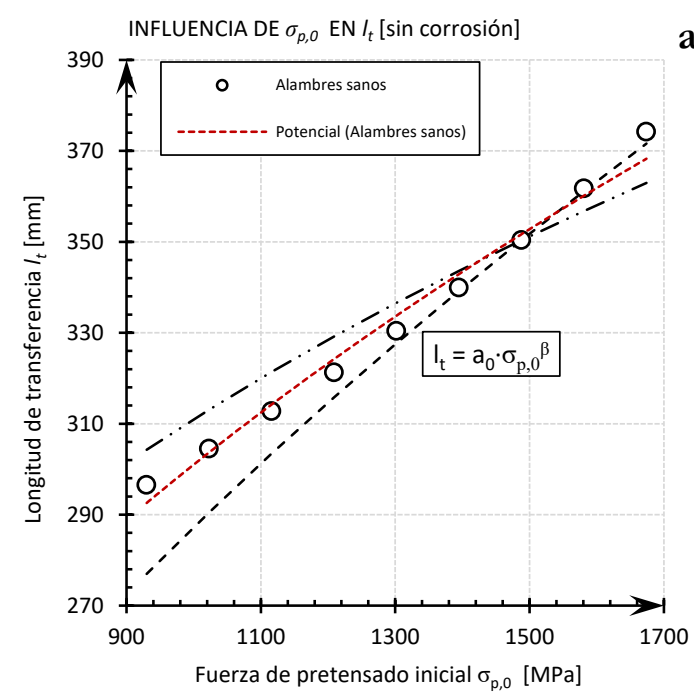

a)

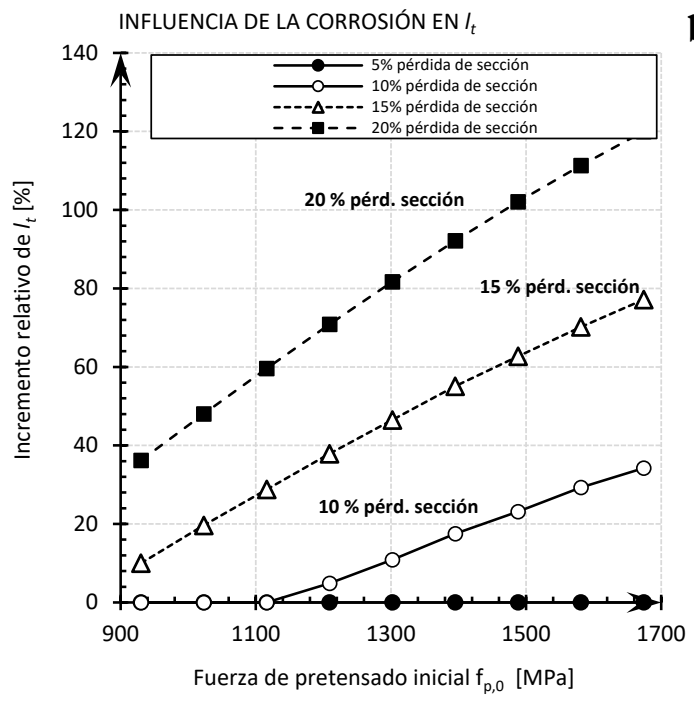

b)

Figura 7-48 Proporcionalidad de la longitud de transferencia l frente a tensión de pretensado inicial $\sigma_{p, 0}($ a). Incrementos relativos de la longitud de transferencia $l_{t}$ frente a tensión de pretensado inicial $\sigma_{p, 0}(b)$.

En cuanto a la corrosión, con fuerzas de pretensado bajas el recubrimiento en los extremos tiene mayor capacidad de absorber desplazamientos radiales derivados de la acumulación de productos de corrosión en la interfaz. Una vez que el deterioro de hace palpable y comienza a aumentar la longitud de transferencia, esta evoluciona de forma similar en todos los casos. Es decir, la fuerza de pretensado modifica el grado de corrosión en el que se empieza a deteriorar las propiedades adherentes pero no incide excesivamente en la velocidad de avance de dicho deterioro (Figura 7-48-b)). 


\subsubsection{Influencia de la velocidad de destesado en la longitud de transferencia}

La velocidad de destesado influye de manera significativa en la longitud de transferencia. Generalmente es aceptado que puestas en carga súbitas (mediante corte de los alambres, por ejemplo) traen consigo longitudes de transferencia mayores que si el destesado se hace de manera gradual, a una velocidad controlada. Este efecto es debido a un aumento de la fisuración del recubrimiento, derivada del choque dinámico del alambre con el hormigón. Este incremento en la longitud de transferencia es especialmente significativo en el extremo activo de la viga, el más cercano a la zona de corte de los alambres, y se encuentra mitigado en el extremo pasivo de ésta, donde suelen medirse longitudes de transferencia similares a las derivadas de un destesado gradual.

Numerosos investigadores han estudiado y cuantificado la influencia de la velocidad de destesado en la longitud de transferencia. Russell \& Burns (1997) midieron diferencias de hasta un 34\% entre el extremo activo y pasivo de vigas pretensadas con cordones de $12,7 \mathrm{~mm}(0,5 \mathrm{in}$.) de diámetro. Oh \& Kim (2000) determinaron, de media, incrementos de un $16 \%$ en vigas pretensadas con cordones de $12,7 \mathrm{~mm}$ (0,5 in.), y de un $13 \%$ en vigas pretensadas con cordones de $15.2 \mathrm{~mm}$ (0.6 in.) de diámetro.

Coherentemente con estas observaciones, muchos de los Códigos estructurales de uso más extendido también recogen este efecto. El Código Modelo 2010 (FIB Special Activity Group 5, 2011), el Eurocódigo 2 (CEN, 2004) y la EHE-08 (Fomento, 2008) incluyen un coeficiente $a_{p 1}$ que tiene en cuenta la velocidad de la transferencia del pretensado, con un valor igual a 1 para destesado graduales e igual a 1,25 para destesados súbitos (Ver Capitulo 2). En consecuencia, los Códigos incrementan la longitud de transferencia en un $25 \%$ en el caso de destesados súbitos.

En la Figura 7-49 se han representado las gráficas de evolución de la longitud de transferencia $l_{t}$ para distintos coeficientes $a_{p 1}$ y distintos grados de corrosión. Lógicamente, la longitud de transferencia $l_{t}$ es directamente proporcional al coeficiente $a_{p} 1$.

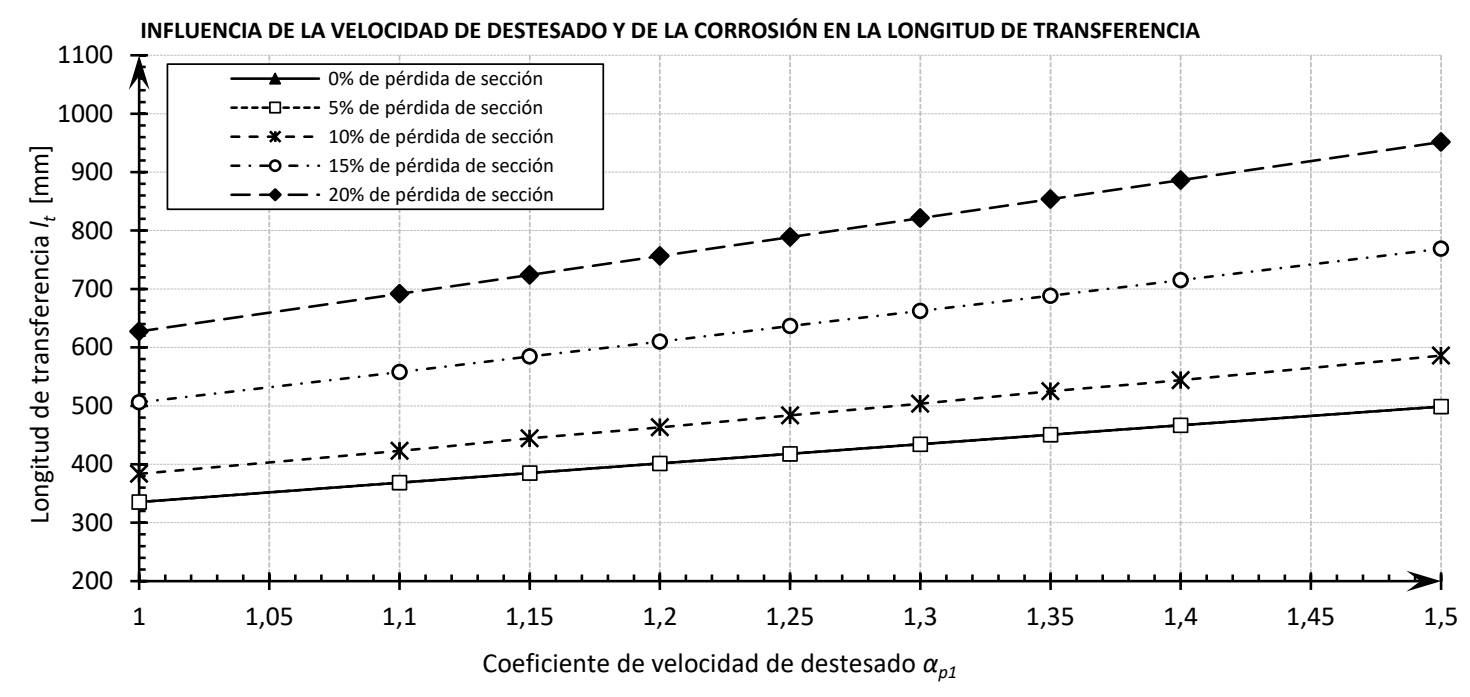

Figura 7-49 Evolución de l para distintos niveles de corrosión y diferentes coeficientes de velocidad de destesado ap1. Resultados arrojados por el modelo analítico. 


\subsubsection{Influencia de la rugosidad superficial del alambre (coeficiente de fricción) en la longitud de transferencia}

Está universalmente aceptado que el aumento de rugosidad de la superficie del alambre de pretensado mejora la adherencia entre el hormigón y el acero. Esta rugosidad, que suele quedar caracterizada mediante el coeficiente de fricción $\mu$, puede proceder del propio acabado superficial del alambre o de la formación de óxidos superficiales antes de la puesta en obra del acero.

Los numerosos estudios que se han centrado en estudiar la influencia del óxido superficial en el acero han obtenido conclusiones variadas. Mientras que Base (1958) y Logan (1997) no apreciaron diferencias significativas por esta razón; Ban et al. (1960) obtuvieron longitudes de transferencia entre $1 / 2$ y $2 / 3$ menores en cordones con óxido superficial. De manera similar, Janney (1963) obtuvo longitudes de transferencia un 33\% menores en cordones óxidados, frente al 30\% obtenido por Hanson (1969) y el 40\% obtenido por Holmberg \& Lindgren (1970).

En cuanto al coeficiente de fricción $\mu$, existe gran heterogeneidad en los resultados de los estudios que han intentado cuantificar su valor tanto en armaduras pasivas como en alambres o cordones de pretensado. Los valores más recurrentes se encuentran en el rango comprendido entre 0,3 y 0,7 (ver Capitulo 2). En el análisis de los ensayos de pull-out llevados a cabo para la presente tesis (Capitulo o), se ha concluido que un valor de coeficiente de fricción $\mu$ igual a 0,6 permitía una buena predicción de los resultados obtenidos. Como se ha visto en este capítulo (7.3.2.6 Comparacion de los resultados experimentales con el modelo analítico), la aplicación de este coeficiente a los ensayos sobre vigas pretensadas ha permitido también predecir con razonable exactitud las longitudes de transferencia medidas.

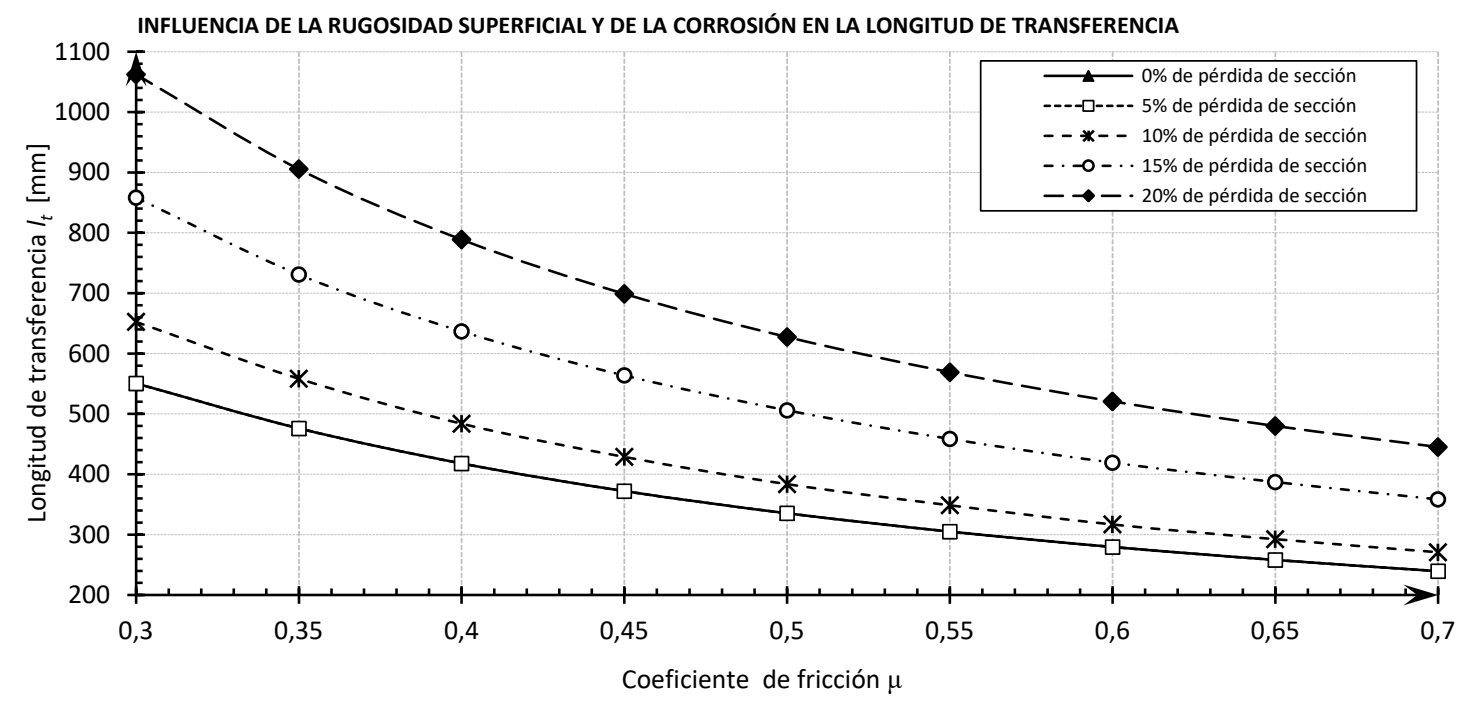

Figura 7-50 Evolución de lt para distintos niveles de corrosión y diferentes coeficientes de fricción $\mu$. Resultados arrojados por el modelo analítico.

En la Figura 7-50 se representa la evolución de la longitud de transferencia $l_{t}$ para distintos coeficientes de fricción $\mu$, en su rango más habitual (0.3-0.7), y para distintos niveles de corrosión (de 0 a $20 \%$ de 
pérdida de sección). Como se ha visto a lo largo de esta tesis, obviando la influencia de la tensión de adherencia debida al mecanismo de adhesión $\tau_{b, a d h}$, la tensión de adherencia es directamente proporcional al coeficiente de fricción $\mu$ y a la tensión radial $\sigma_{r}$ existente en la interfaz acero hormigón. A su vez, la longitud de transferencia $l_{t}$ es inversamente proporcional a la tensión de adherencia $\tau_{b}$, y por tanto, también lo es al coeficiente de fricción $\mu$. Esta relación de proporcionalidad inversa se observa claramente en la Figura 7-50.

Sin embargo, tal y como se aprecia en la figura, la relación entre longitud de transferencia y coeficiente de fricción no es perfectamente lineal. Esto es debido a que un menor coeficiente de fricción $\mu$ implica mayores deslizamientos del alambre, y por tanto, mayores desplazamientos radiales causados por las indentaciones, lo que puede llevar a la fisuración del recubrimiento y a la reducción de las tensiones radiales $\sigma_{r}$

\subsubsection{Influencia de la altura de las indentaciones en la longitud de transferencia}

No existen demasiados trabajos que estudien la influencia de la altura de las indentaciones $h_{r}$ en las propiedades adherentes de los alambres de pretensado. En los pocos encontrados (Benítez \& Gálvez, 2011) (Bodapati, et al., 2013) concluyen que el aumento de la profundidad de las indentaciones mejora sustancialmente la tensión de adherencia $\tau_{b}$, y por tanto, acorta las longitudes de transferencia $l_{t}$.

En la Figura $7-51$ se representa la evolución de la longitud de transferencia $l_{t}$ para distintas alturas de indentación $h_{r}$, desde $0 \mathrm{~mm}$ (alambres lisos) hasta $0.13 \mathrm{~mm}$, y distintos niveles de corrosión. Se ha considerado que la separación entre indentaciones y el paso de hélice es constante en todos los casos, 3,5 y $6 \mathrm{~mm}$, respectivamente. El perfil de las indentaciones no es constante a lo largo de toda la sección transversal del alambre, sin embargo el modelo analítico desarrollado es axilsimétrico, por lo que es necesario que la altura $h_{r}$ sea la resultante de repartir homogéneamente la profundidad real de la indentación alrededor de todo el perímetro del alambre. Dada la complejidad geométrica de las indentaciones y la dificultad para medir con precisión su perfil, no es sencillo hacer este reparto homogéneo. A modo de aproximación, para los alambres indentados utilizados en la tesis (Tipo I, profundidad indentaciones: $0.04-0.06 \mathrm{~mm}$ ), se ha utilizado una altura $h_{r}$ equivalente de $0.025 \mathrm{~mm}$, es decir, un $50 \%$ de la profundidad media real.

A la vista de las gráficas de la Figura 7-51, la longitud de transferencia $l_{t}$ en alambres sin procesos de corrosión disminuye con el aumento de la altura de indentaciones hasta alcanzar un punto óptimo en $h_{r}=0.055 \mathrm{~mm}$. La longitud de transferencia en alambres lisos $\left(h_{\mathrm{r}}=0.00 \mathrm{~mm}\right), \mathrm{l}_{\mathrm{t}}=355,1 \mathrm{~mm}$, es aproximadamente un $10 \%$ superior a la obtenida en el punto óptimo, $1_{\mathrm{t}}=331,2 \mathrm{~mm}$. A partir de ese punto, incrementos de la altura de la indentación $h_{r}$ suponen un ligero aumento de la longitud de transferencia.

La mayor altura de las indentaciones provoca que los alambres de pretensado, en su deslizamiento, ocasionen un mayor desplazamiento radial en la cara interna del recubrimiento, lo que a su vez se traduce en un aumento de las tensiones radiales $\sigma_{r}$ y circunferenciales $\sigma_{\theta}$ en el mismo. El aumento de las tensiones radiales mejora la tensión de adherencia $\tau_{b}$, pero si la tensión circunferencial alcanzada es tal que fisura el hormigón circundante, la capacidad de confinamiento del recubrimiento queda 
debilitada y se empeoran las propiedades adherentes. En definitiva, el aumento de la altura de las indentaciones supondrá un beneficio hasta que el desplazamiento radial que provocan suponga el agotamiento de la capacidad de confinamiento del recubrimiento, y por tanto, la altura óptima variará en función de la relación recubrimiento diámetro y de la resistencia del hormigón.

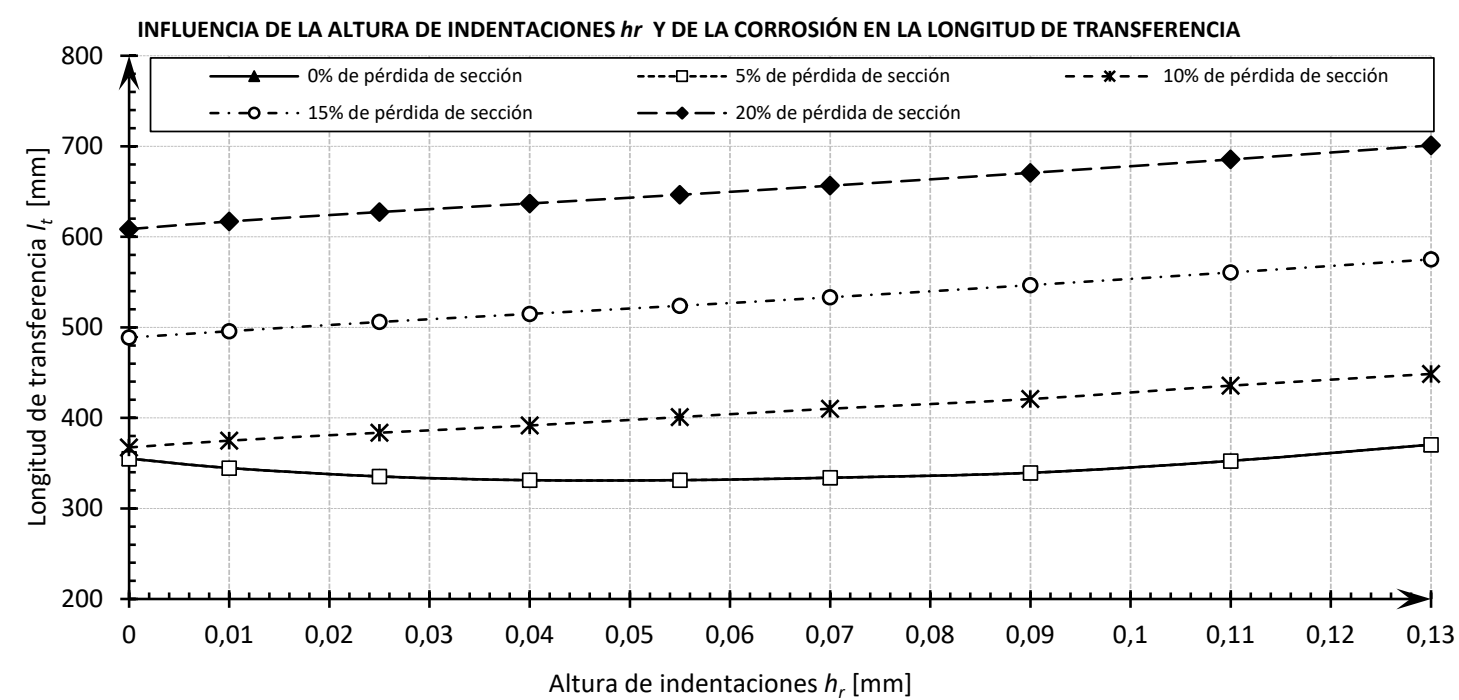

Figura 7-51 Evolución de lt para distintas niveles de corrosión y diferentes alturas de indentación $h_{r}$. Resultados arrojados por el modelo analítico.

En cuanto a la corrosión, pérdidas de sección de hasta un 5\% no suponen una alteración apreciable en el comportamiento adherente de los alambres, sin embargo, a partir de pérdidas de un 10\% el recubrimiento está al límite de su capacidad, por lo que cualquier incremento en la altura de las indentaciones supone un aumento de la longitud de transferencia.

Hay que señalar que las diferencias entre alambres lisos e indentados arrojadas por el modelo son menores que las registradas en la campaña experimental consultada (Bodapati, et al., 2013), en la que se llegan a registrar diferencias de hasta el 100\%, por lo que serían necesarios estudios posteriores para refinar el modelado de este fenómeno.

\subsubsection{Influencia de la corrosión en la longitud de transferencia}

En los apartados anteriores se ha analizado cómo influye el fenómeno de la corrosión, en combinación con diferentes variables mecánicas y geométricas, a la longitud de transferencia del pretensado. Desde un punto de vista cualitativo, se han apreciado dos tendencias fundamentales:

1) La longitud de transferencia $l_{t}$ se mantiene inalterada hasta que es superado un determinado umbral de pérdida de sección por corrosión. Este límite o umbral será denominado en esta tesis $X_{\text {lim }}$ 
2) Una vez superado dicho umbral, la longitud de transferencia $l_{t}$ crece paralelamente al deterioro de la adherencia hormigón-acero, motivada por la paulatina pérdida de la capacidad de confinamiento del recubrimiento de hormigón. La tasa o velocidad de incremento de la longitud de transferencia con el aumento de la pérdida de sección por corrosión será denominada en esta tesis $V_{\text {det }}$
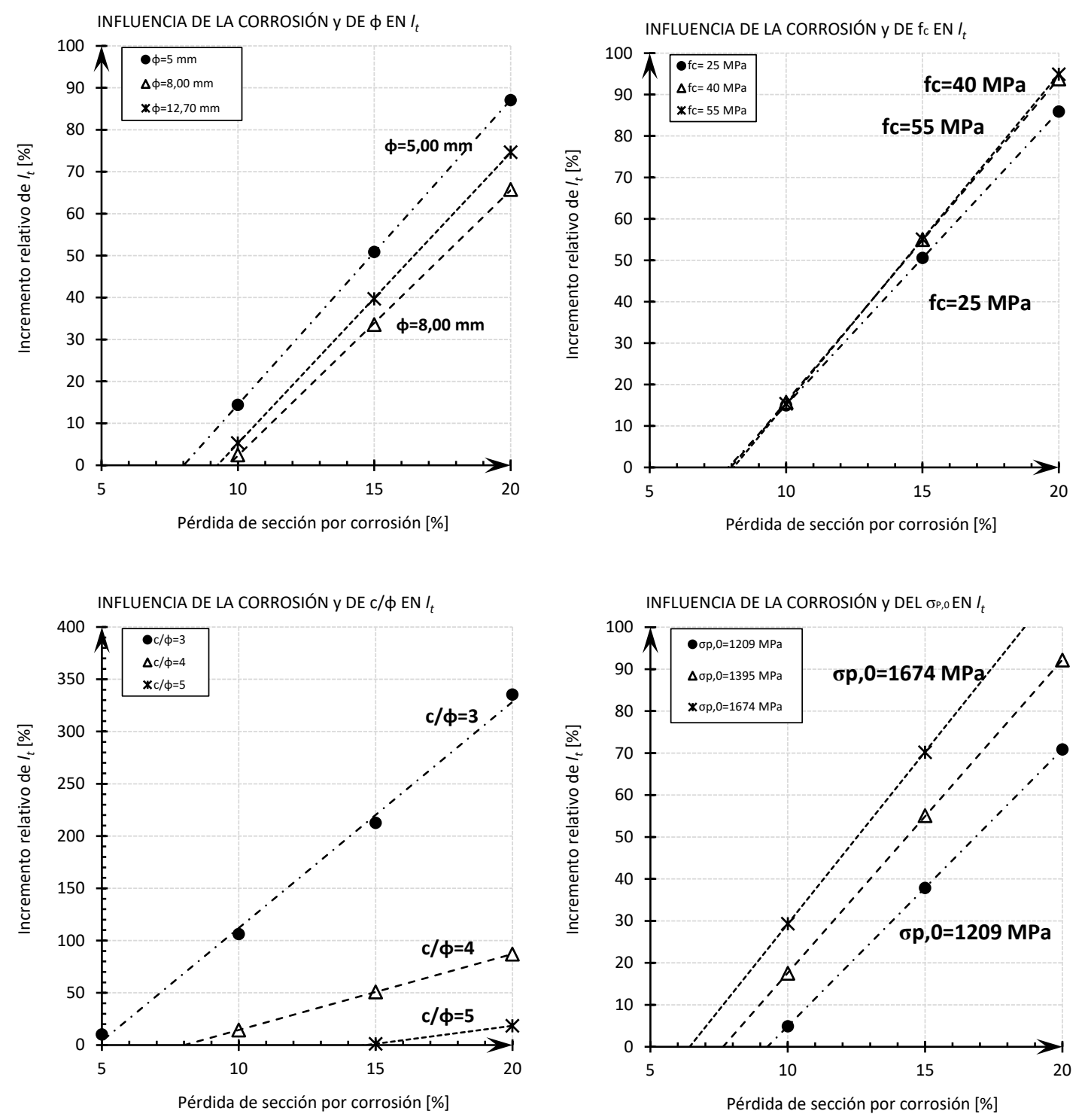

Figura 7-52 Porcentaje de incremento relativo de la longitud de transferencia frente a la pérdida de sección por corrosión para distintos valores de diámetros de alambre $\phi$, de resistencias a compresión del hormigón $f_{c}$, de relaciones $c / \phi$ y de fuerza inicial de pretensado $\sigma_{p, 0}$.

En las gráficas de la Figura 7-52 se ha representado la evolución de la longitud de transferencia, en porcentaje con respecto a la correspondiente a alambres sanos, frente al avance de la pérdida de sección por corrosión, en porcentaje con respecto a la sección original del acero, para distintos valores de las variables contempladas. Del análisis estas gráficas, unido a lo visto en los apartados anteriores, se pueden extraer dos conclusiones importantes: 


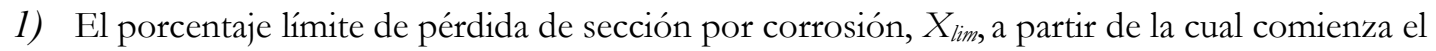
deterioro de la longitud de transferencia $l_{t}$, está condicionada en gran medida por la relación $c / \phi$, y en menor proporción por la tensión de pretensado inicial $f_{p, 0}$ y por el diámetro del alambre $\phi$. Por tanto $X_{\text {lim }}$ es función de $c / \phi$, $f_{p, 0}$ y $\phi\left[X_{\text {lim }} \sim f\left(c / \phi, f_{p, 0}, \phi\right)\right]$.

2) La tasa o velocidad de deterioro de la longitud de transferencia, $V_{\text {det }}$, que viene dada por la pendiente de la gráfica de incremento relativo de dicha longitud con respecto al porcentaje de pérdida de sección por corrosión, se mantiene constante a lo largo del proceso. Esta velocidad de deterioro depende en gran medida de la relación recubrimiento/diámetro, una vez que se ha superado el umbral $X_{\text {lim }}$. La modificación del resto de parámetros contemplados $\left(\phi, f_{c} y f_{p, o}\right)$, modifica o matiza ligeramente dicha velocidad. Por tanto $V_{\text {det }}$ es función de $c / \phi, \phi, f_{c} y f_{p, 0}\left[V_{d e t} \sim f\left(c / \phi, \phi, f_{c} y f_{p, o}\right)\right]$.

Por tanto, el modelo de deterioro de la longitud de transferencia procesos de corrosión se puede representar gráficamente como sigue (Figura 7-53):

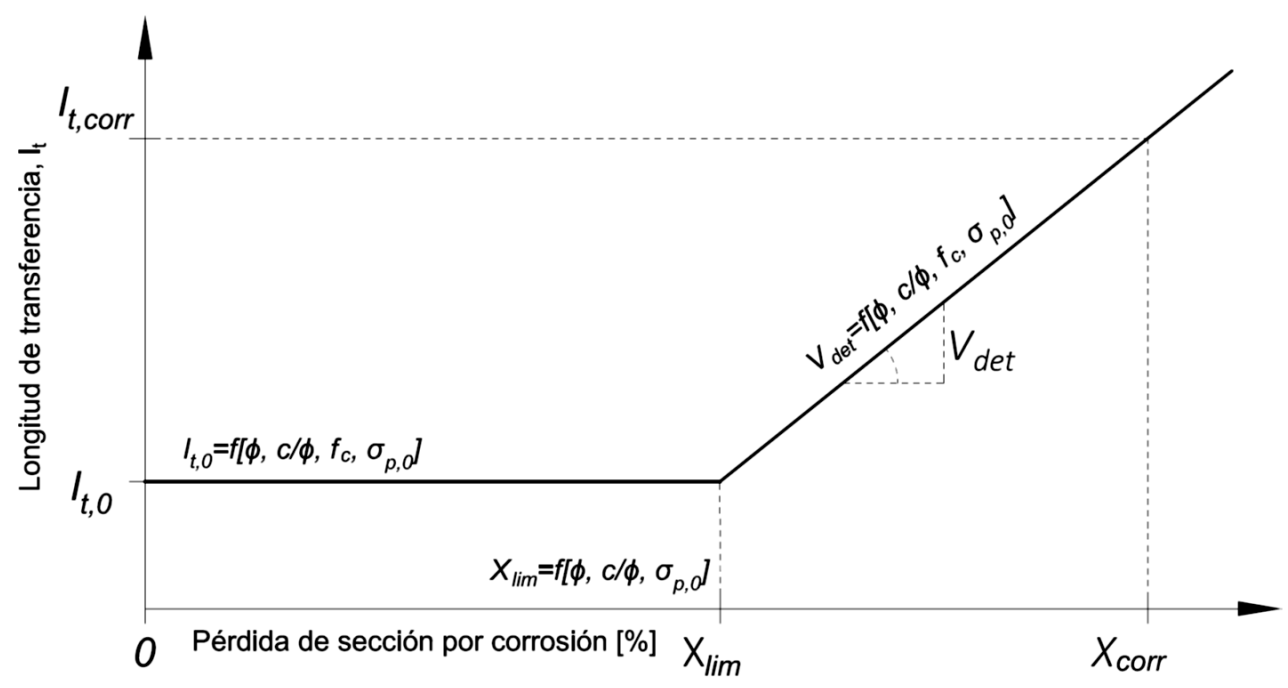

Figura 7-53 Modelo de deterioro de la longitud de transferencia por procesos de deterioro por corrosión en alambres pretensados. Parámetros $X_{\text {lim }}$ V $V_{\text {det }}$

Una vez identificados los factores $X_{\text {lim }} \mathrm{y} V_{\text {det }}$ que definen las gráficas de deterioro de la longitud de transferencia por el proceso de corrosión de los alambres de pretensado, en los próximos apartados se analiza cualitativamente como se ven afectados por los distintos parámetros contemplados. Para apoyar este análisis se ha estudiado cómo evoluciona la longitud de transferencia $l_{t}$ para distintos grados de pérdida de sección por corrosión (hasta un $20 \%$ de pérdida de sección) y para distintas relaciones recubrimiento/diámetro $\mathrm{c} / \phi(2.5,3,4$ y 5$)$. En la Tabla $7-39$ y en las gráficas de la Figura 7-54 se recogen los resultados obtenidos mediante el modelo analítico. 
TESIS DOCTORAL INFLUENCLA DE LA CORROSIÓN EN LA ADHERENCLA DE ALAMBRES EN ELEMENTOS PRETENS ADOS DE HORMIGÓN

Tabla 7-39 Longitudes de transferencia lty desplazamientos en el extremo de vigas $\delta_{d}$ para distintas fuerza de pretensado inicial $f_{p, 0} y$ distintos niveles de corrosión

\begin{tabular}{|c|c|c|c|c|c|c|c|c|c|c|c|c|}
\hline $\begin{array}{l}\text { \% pérdida } \\
\text { de sección }\end{array}$ & 0 & 2.5 & 3.75 & 5 & 6.25 & 7.5 & 8.75 & 10 & 11.25 & 12.5 & 15 & 20 \\
\hline & \multicolumn{12}{|c|}{$\mathrm{c} / \phi=2.5$} \\
\hline $1_{t}[\mathrm{~mm}]$ & 407.75 & 407.75 & 428.45 & 595.84 & 742.36 & 920.29 & 1107.4 & 1364.3 & 1543.0 & 1784.8 & ---- & ---- \\
\hline \multirow[t]{2}{*}{$\delta_{\mathrm{d}}[\mathrm{mm}]$} & 0.9172 & 1.0363 & 1.3729 & 1.8609 & 2.3375 & 2.8641 & 3.4813 & 4.2494 & 4.8689 & 5.6280 & ---- & ---- \\
\hline & \multicolumn{12}{|c|}{$c / \phi=3$} \\
\hline $\mathrm{l}_{\mathrm{t}}[\mathrm{mm}]$ & 363.74 & 363.74 & 363.74 & 401.06 & 478.97 & 563.82 & 654.65 & 749.99 & 816.49 & 904.61 & 1137.1 & 1583.6 \\
\hline \multirow[t]{2}{*}{$\delta_{\mathrm{d}}[\mathrm{mm}]$} & 0.7885 & 0.8542 & 1.0547 & 1.3085 & 1.5534 & 1.8272 & 2.0958 & 2.4254 & 2.6384 & 2.9285 & 3.6792 & 5.1416 \\
\hline & \multicolumn{12}{|c|}{$\mathrm{c} / \phi=4$} \\
\hline $\mathbf{l}_{\mathrm{t}}[\mathrm{mm}]$ & 335.34 & 335.34 & 335.34 & 335.34 & 335.34 & 335.34 & 354.38 & 383.62 & 407.21 & 445.33 & 505.93 & 627.36 \\
\hline \multirow[t]{2}{*}{$\delta_{\mathrm{d}}[\mathrm{mm}]$} & 0.7185 & 0.7427 & 0.8056 & 0.8888 & 0.9815 & 1.0656 & 1.2076 & 1.3085 & 1.3838 & 1.5087 & 1.7182 & 2.1245 \\
\hline & \multicolumn{12}{|c|}{$\mathrm{c} / \phi=5$} \\
\hline $\mathbf{l}_{\mathbf{t}}[\mathrm{mm}]$ & 324.94 & 324.94 & 324.94 & 324.94 & 324.94 & 324.94 & 324.94 & 324.94 & 324.94 & 324.94 & 328.87 & 384.85 \\
\hline $\boldsymbol{\delta}_{\mathbf{d}}[\mathrm{mm}]$ & 0.7271 & 0.7303 & 0.7389 & 0.7628 & 0.8133 & 0.8494 & 0.8896 & 0.9376 & 0.9676 & 1.0274 & 1.1413 & 1.3415 \\
\hline
\end{tabular}

\subsubsection{Porcentaje límite de pérdida de sección por corrosión $X_{\text {lim }}$}

El incremento de volumen que experimentan los productos de corrosión con respecto al acero virgen de los alambres de pretensado genera tensiones radiales $\sigma_{r}$ y circunferenciales $\sigma_{\vartheta}$ adicionales a las producidas por el efecto Hoyer. Por tanto, considerando una corrosión uniforme a lo largo de los alambres, el aumento del nivel de ataque provoca el fallo paulatino de las zonas más solicitadas por el efecto Hoyer, localizadas en los extremos del elemento pretensado. Cuando éstos pierden parcialmente la capacidad de transferir la fuerza de pretensado al hormigón circundante, ceden esta responsabilidad a las sucesivas secciones de la viga que todavía no han alcanzado el fallo, situadas hacia el centro del elemento. En estas secciones, la tensión radial $\sigma_{r}$ crece debido a que, por un lado, la tensión normal del alambre es menor, provocando un mayor desplazamiento radial $u_{r}$ de la pared interna del recubrimiento de hormigón, y por otro, el volumen de los productos de corrosión se ha incrementado. Este aumento de la tensión radial $\sigma_{r}$ genera consecuente un aumento de la tensión de

adherencia $\tau_{b}$ (Figura 7-54-e), con lo que el alambre es capaz de transmitir al hormigón circundante una mayor fuerza de pretensado en una misma longitud. Por ello, en el perfil de deformaciones longitudinales del hormigón $\boldsymbol{\varepsilon}_{c}$ puede observarse una disminución de la pendiente en las secciones situadas en el extremo del elemento seguida de un aumento de ésta en determinadas secciones de la longitud de transferencia (Figura 7-54- ¿). La consecuencia última de este fenómeno es que la longitud de transferencia $l_{t}$ de los alambres no se ve modificada de manera apreciable para niveles bajos y medios de pérdida de sección por corrosión, a pesar de que la capacidad adherente de los extremos se encuentre muy dañada. Sin embargo, al alcanzarse un determinado valor de pérdida de sección por corrosión, el elemento pretensado no es capaz de compensar la pérdida de tensión de 


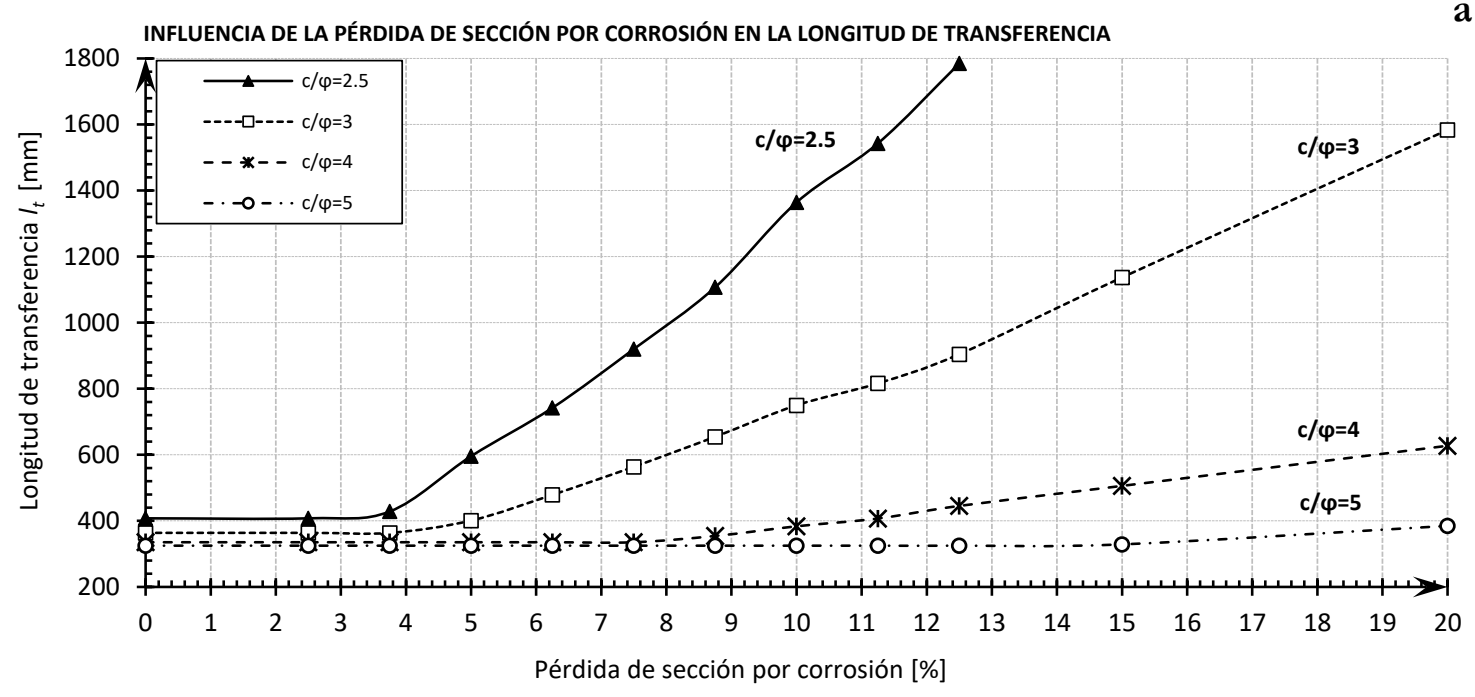

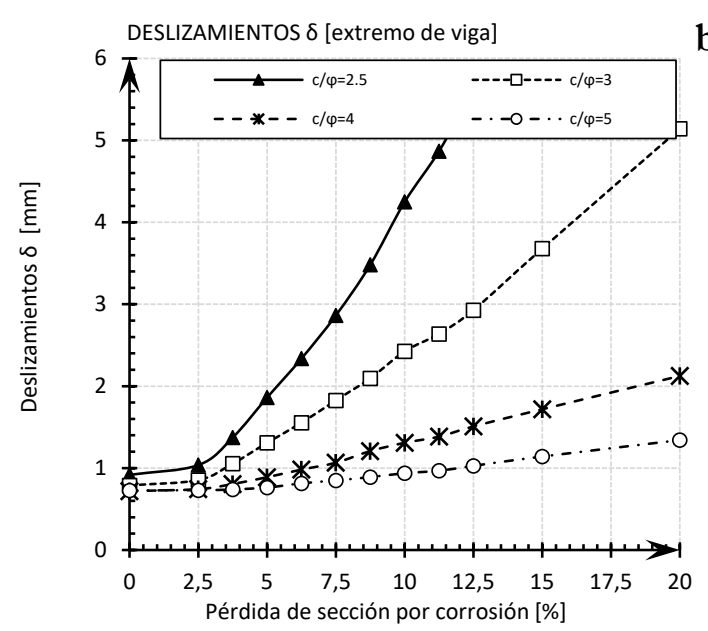

b)

d)

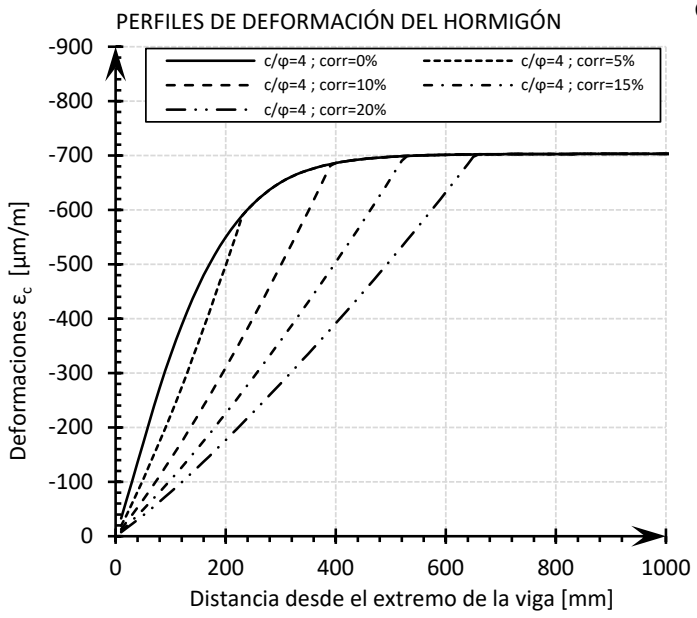

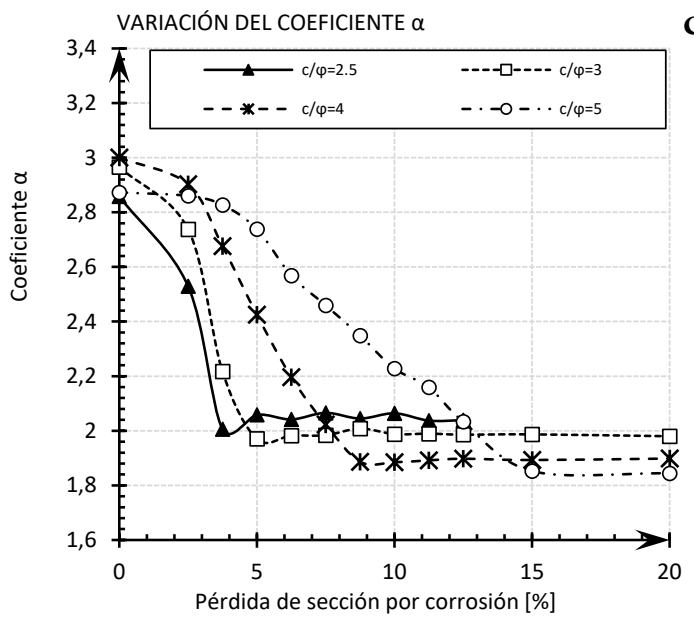

c)

e)

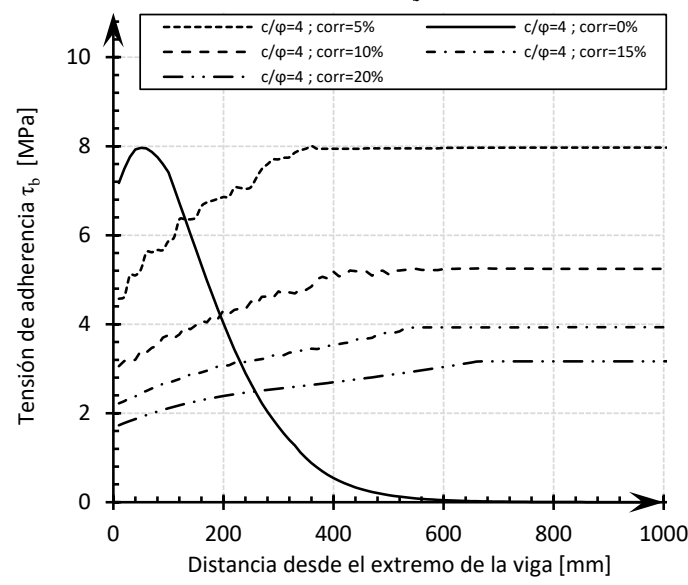

Figura 7-54 Evolución de $l_{t}(a)$, de los deslizamientos en el extremo $\delta_{d}(b)$, del coeficiente a (c), del perfil de deformaciones en el hormigón $\boldsymbol{\varepsilon}_{c}(d)$ $y$ de las tensiones de adherencia $\tau b$ (e) para distintas niveles de corrosión en vigas con alambres de $5 \mathrm{~mm}$ de diámetro y relación $\mathrm{c} / \phi=4$. 
adherencia en sus extremos, por lo que la longitud de transferencia comienza a incrementarse. Como se ha introducido anteriormente, a este valor límite de corrosión se le denomina $X_{\text {lim. }}$.

En las gráficas de la Figura 7-52 se ha comprobado que $X_{\text {lim }}$ es función de la relación recubrimientodiámetro $c / \phi$, de la tensión inicial de pretensado $f_{p, 0}$ y del diámetro del alambre $\phi\left[X_{\text {lim }} \sim f\left(c / \phi, \sigma_{p, 0}\right.\right.$, $\phi)$ ], siendo el primer parámetro el que tiene una mayor influencia en su valor.

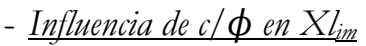

El ajuste lineal de las gráficas de evolución de la longitud de transferencia de la Figura 7-54-a, para cada relación recubrimiento/diámetro considerada, y la determinación de su intersección con el valor de la longitud de transferencia inicial $l_{t, 0}$ permite calcular con precisión para qué nivel de corrosión comienza el aumento de la longitud de transferencia, $X_{\text {lim }}($ Tabla $7-40)$.

Tabla 7-40 Parámetros que definen la evolución de la longitud de transferencia con el aumento de la corrosión para distintas relaciones recubrimiento/diámetro

\begin{tabular}{|c|c|c|c|c|}
\hline Relación c/ $\phi$ & $\mathrm{l}_{\mathrm{t}, 0}[\mathrm{~mm}]$ & Ajuste lineal & $\mathrm{R}^{2}$ & $\mathrm{X}_{\lim }[\%]$ \\
\hline$c / \phi=2.5$ & 407.75 & $y=155.08 x-199.2$ & 0.99 & 3.91 \\
\hline$c / \phi=3$ & 363.74 & $y=78.197 x-26.242$ & 0.99 & 4.99 \\
\hline $\mathrm{c} / \phi=4$ & 335.34 & $y=24.457 x+138.06$ & 0.99 & 8.07 \\
\hline$c / \phi=5$ & 324.94 & $y=11.196 x+160.93$ & 1 & 14.65 \\
\hline
\end{tabular}

De esta manera, para $c / \phi=2.5$, el deterioro comienza con una pérdida de sección del 3.91\%; para c/ $\phi=3, X_{\text {lim }}$ es igual a $4.99 \%$; para c $/ \phi=4, X_{\text {lim }}$ es igual a $8.07 \%$; y para $c / \phi=5, X_{\text {lim }}$ es igual a $14.65 \%$. En la Figura 7-55 se representa la porcentaje de pérdida de sección por corrosión necesario para el inicio del deterioro de la longitud de transferencia $\left[X_{\text {lim }}\right]$ en función de la relación recubrimiento/diámetro $c / \phi$. Como puede observarse, $X_{\text {lim }}$ establece una relación de carácter potencial con $c / \phi$ (en este caso, el mejor ajuste se obtiene para una potencia próxima a 2 ). Por tanto, $X_{\text {lim }} \propto a_{0}(c / \phi)^{\beta}$.
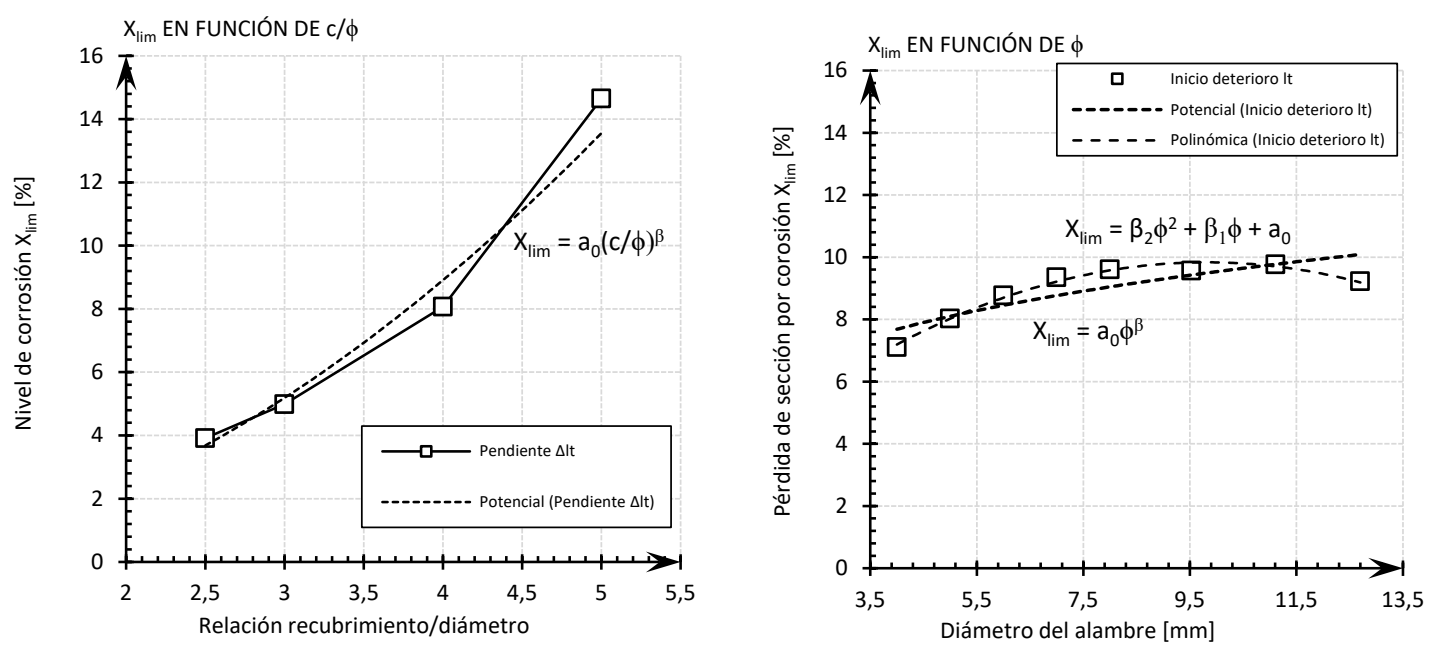

Figura 7-55 Evolución del porcentaje de pérdida de sección por corrosión necesario para el inicio del deterioro de la longitud de transferencia $\left[X_{\text {lim] }}\right.$ en función de la relación recubrimiento/ diámetro $c / \phi$ (izq.) y del diámetro $\phi$ (der.) 
Aunque la relación recubrimiento/diámetro es el factor determinante en la caracterización de $X_{\text {lim }}$, existen otros factores, como el diámetro del alambre $\phi$ y la tensión de pretensado inicial $\sigma_{p, \theta}$, que modulan este comportamiento.

\section{- Influencia de $\phi$ en $X_{\text {lim }}$}

En el Apartado 7.4.2 (Figura 7-42-b) se ha mostrado cómo el diámetro del alambre $\phi$ influye de manera apreciable en el grado de corrosión necesario para que dé comienzo el deterioro de la longitud de transferencia, $X_{\text {lim, }}$ acelerándose el proceso en los aceros de de menor diámetro. Partiendo de la hipótesis de que la pendiente de deterioro por corrosión es constante, para cada diámetro considerado puede calcularse de forma aproximada el valor de $X_{\text {lim }}$ (Tabla 7-41). Estos datos se representan en la gráfica de la Figura 7-55 (der.), donde se han sido ajustados mediante una regresión polinómica $\left(X_{\text {lim }}\right.$ $\left.=\beta_{2} \phi^{2}+\beta_{1} \phi+a_{0}\right)$ y otra potencial $\left(X_{\text {lim }}=a_{0} \phi^{\natural}\right)$. Aunque en este caso concreto, el mejor ajuste se obtiene para la regresión polinómica, se opta por seleccionar el ajuste potencial, puesto que facilitará la regresión multiple que se realizará en el Apartado 7.5.2 para la obtención de la expresión simplificada de cálculo de la longitud de transferencia con alambres corroídos. Por tanto, aceptando estas reservas, se puede afirmar que $X_{\text {lim }}$ está relacionada con $\phi$ mediante una función potencial de la forma $a_{0}(\phi)^{\beta}$.

Tabla 7-41 Porcentaje de pérdida de sección por corrosión necesaria para que se inicie el proceso de aumento de la longitud de transferencia

\begin{tabular}{ccccccccc}
\hline $\boldsymbol{\phi}[\mathrm{mm}]$ & \multirow{2}{*}{$\mathbf{4}$} & $\mathbf{5}$ & $\mathbf{6}$ & $\mathbf{7}$ & $\mathbf{8}$ & $\begin{array}{c}\mathbf{( 3 / 8 ” )} \\
\mathbf{9 . 5 3}\end{array}$ & $\begin{array}{c}\mathbf{( 7 / 1 6 ” )} \\
\mathbf{1 1 . 1 1}\end{array}$ & $\begin{array}{c}\mathbf{( 1 / 2 ” )} \\
\mathbf{1 2 . 7 0}\end{array}$ \\
\hline $\mathrm{X}_{\lim }$ & 7.11 & 8.07 & 8.77 & 9.35 & 9.60 & 9.57 & 9.77 & 9.23 \\
\hline
\end{tabular}

\section{- Influencia de $\sigma_{p, 0}$ en $X_{\text {lim }}$}

En el Apartado 7.4.5 (Figura 7-48-b) se ha se ha observado que la tensión inicial de pretensado $\sigma_{p, 0}$ influye en el grado de corrosión necesario para que dé comienzo el deterioro de la longitud de transferencia, $X_{\text {lim, }}$, siendo necesarias pérdidas de sección menores cuanto mayor es $\sigma_{p, 0}$. Esto es debido a que, con fuerzas de pretensado bajas, el recubrimiento en los extremos tiene mayor capacidad de absorber desplazamientos radiales derivados de la acumulación de productos de corrosión en la interfaz. Partiendo de los datos de ese apartado, se ha estimado el $X_{\text {lim }}$ para cada tensión de pretensado inicial, obteniéndose los datos recogidos en la Tabla 7-42.

Tabla 7-42 $X_{\text {lim }}$ para distintas tensiones iniciales de pretensado

\begin{tabular}{cccccccccc}
\hline $\boldsymbol{\sigma}_{\mathbf{p}, \mathbf{0}}\left[\mathbf{N} / \mathbf{m m}^{2}\right]$ & $\mathbf{9 3 0}$ & $\mathbf{1 0 2 3}$ & $\mathbf{1 1 1 6}$ & $\mathbf{1 2 0 9}$ & $\mathbf{1 3 0 2}$ & $\mathbf{1 3 9 5}$ & $\mathbf{1 4 8 8}$ & $\mathbf{1 5 8 1}$ & $\mathbf{1 6 7 4}$ \\
\hline $\mathrm{X}_{\lim }[\%]$ & 13,09 & 11,55 & 10,33 & 9,26 & 8,45 & 7,64 & 7,06 & 6,43 & 6,01 \\
\hline
\end{tabular}

La representación gráfica de estos datos (Figura 7-50) posibilita deducir que el nivel de corrosión para el que comienza el deterioro de la longitud de transferencia $X_{\text {lim }}$ mantiene una relación de carácter potencial con la tensión de pretensado inicial $\sigma_{p, 0}$. Por tanto, $X_{l i m} \propto a_{0} \sigma_{p, 0}{ }^{\beta}$. 


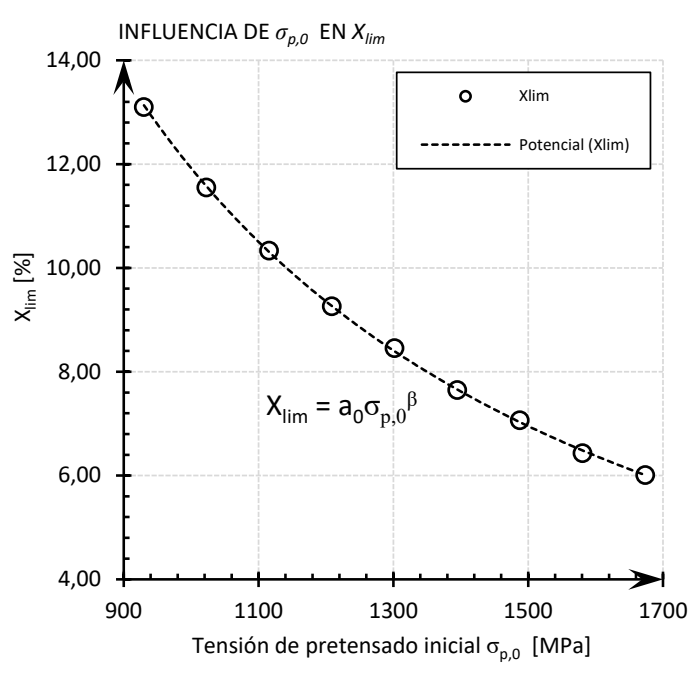

Figura 7-56 Evolución del inicio del deterioro de la longitud de transferencia $X_{\text {lim }}$ en función de $\sigma_{p, 0}$

\subsubsection{Velocidad de deterioro de la longitud de transferencia $V_{\text {det }}$}

Al superarse el valor $X_{\text {lim }}$ de pérdida de sección por corrosión, el elemento pretensado no es capaz de compensar la pérdida de tensión de adherencia en sus extremos mediante el aumento de tensión radial en sus secciones intermedias, por lo que la longitud de transferencia $l_{t}$ comienza a crecer. Este crecimiento, denominado tasa o velocidad de deterioro de la longitud de transferencia, $V_{d e t}$, se mantiene constante a lo largo del proceso de corrosión. Tal y como se vió en la Figura 7-52, este parámetro depende en gran medida de la relación recubrimiento/diámetro $c / \phi$, y la variación del resto de parámetros mecánicos y geométricos $\left(\phi, f_{c}\right.$ y $\left.\sigma_{p, 0}\right)$, modifica ligeramente su valor.

Dado un elemento de hormigón pretensado con procesos de corrosión, cuya longitud de transferencia $l_{\text {t,corr }}$ se ha alcanzado tras la pérdida de sección por corrosión $X_{\text {corr }}$ sufrida por sus alambres, la velocidad de deterioro $V_{\text {det }}$ se entiende como el incremento relativo (en tanto por uno) de la longitud de transferencia inicial $l_{t, 0}$ con respecto al incremento porcentual de la pérdida de sección por corrosión, una vez superado el valor límite $X_{\text {limm. }}$ Por tanto se tiene que $V_{\text {det }}$ es igual $a$ (Eq. 7-2):

$$
V_{\text {det }}=\frac{\frac{\Delta l_{t, 0}}{l_{t, 0}}}{X_{\text {corr }}-X_{\text {lim }}}=\frac{\frac{l_{t, \text { corr }}-l_{t, 0}}{l_{t, 0}}}{X_{\text {corr }}-X_{\text {lim }}}=\frac{\frac{l_{t, \text { corr }}}{l_{t, 0}}-1}{X_{\text {corr }}-X_{\text {lim }}}
$$

En las gráficas de la Figura 7-57 se representa como evoluciona la velocidad de deterioro $V_{\text {det }}$ con respecto a la variación del diámetro del alambre de pretensado $\phi$ (Tabla 7-43), la relación recubrimiento/diámetro $c / \phi$ (Tabla 7-44), la tensión inicial de pretensado $\sigma_{p, 0}$ (Tabla 7-45) y la resistencia a compresión del hormigón $f_{c}$ (Tabla 7-46). 

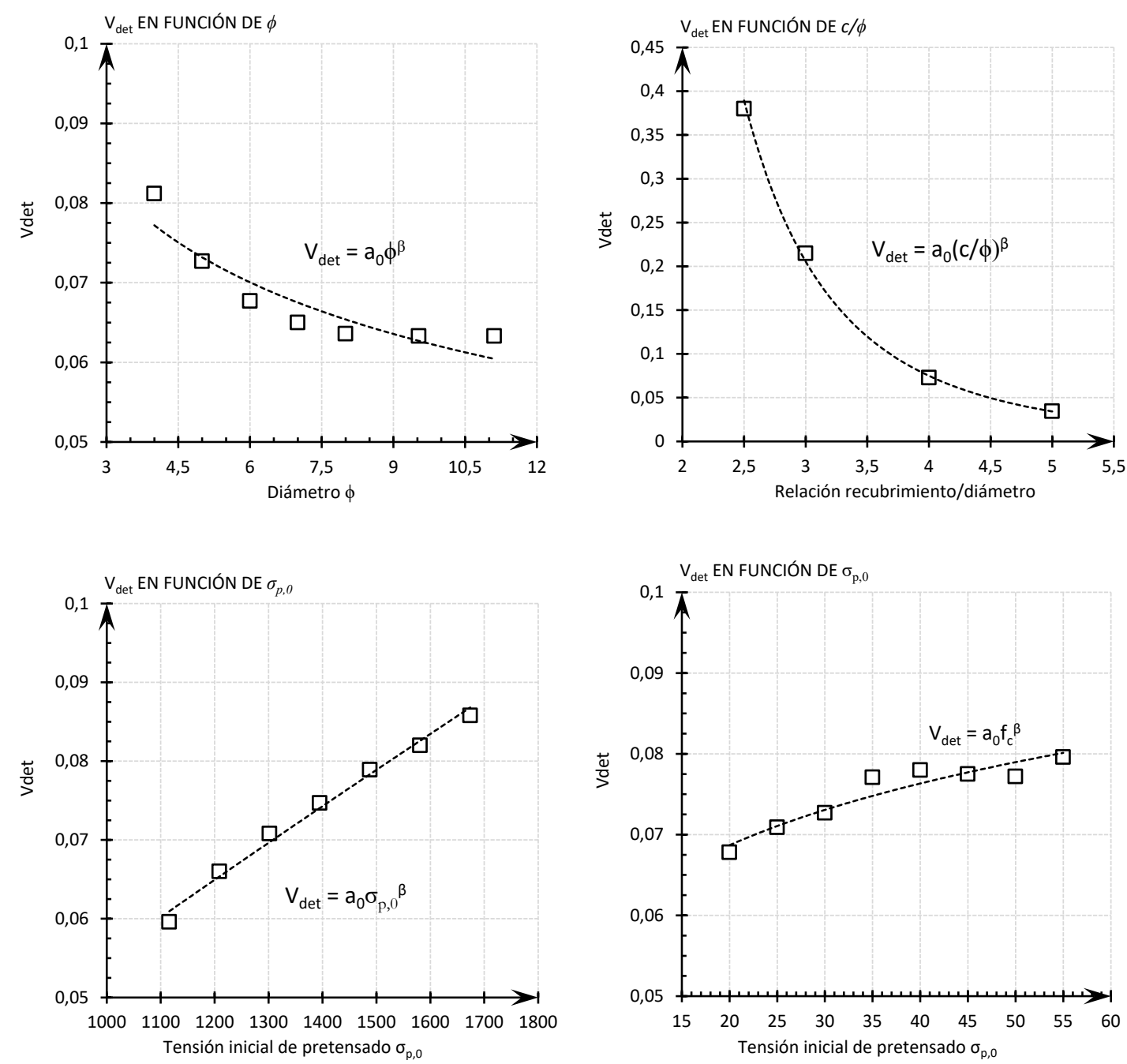

Figura 7-57 Evolución de $V_{\text {det }}$ con respecto a distintos parámetros geométricos y mecánicos

En general, se aprecia que $V_{\text {det }}$ disminuye con el aumento del diámetro y de la relación recubrimiento/diámetro, mientras que aumenta con el incremento de la tensión inicial de pretensado y de la resistencia a compresión del hormigón. Como se había afirmado previamente, el parámetro más influyente es $c / \phi$, cuyas variaciones, que inciden directamente en la capacidad de confinamiento del recubrimiento, traen consigo significativos cambios en la velocidad de deterioro $V_{\text {det }}$ La influencia del resto de parámetros es mucho más limitada.

El comportamiento más atípico es el relacionado con la resistencia a compresión del hormigón ya que, por un lado, su aumento trae consigo un incremento de $V_{\text {det }}$ (lo que es en cierta manera contraintuitivo), y por otro, aparecen "saltos" poco justificables en su evolución. El comportamiento contraintuitivo ya ha sido ampliamente discutido en esta tesis, mientras que los saltos pueden proceder de las propiedades mecánicas del hormigón introducidas en el modelo $\left(\varepsilon_{0}\right.$ y E). Estas propiedades proceden de los datos tabulados en el Código Modelo 2010 (CEB-FIP, 2012) y pueden presentar pequeñas faltas de continuidad que justifiquen parte de las variaciones detectadas. A pesar 
de todo, su impacto en el valor final de la velocidad de deterioro es limitado, por lo que se dan por buenos los resultados obtenidos.

Por último, los datos de las gráficas de la Figura 7-57 han sido ajustados mediante curvas de carácter potencial, del tipo $a_{0} \sigma_{p, 0}{ }^{\beta}$, mostrando un aceptable grado de correlación.

\begin{tabular}{|c|c|c|c|c|c|c|c|c|}
\hline$\phi$ & 4 & 5 & 6 & & 7 & 8 & 9,53 & 11,11 \\
\hline$V_{\text {det }}$ & 0,0812 & 0,0727 & 0,0677 & & 0,065 & 0,0636 & 0,0633 & 0,0633 \\
\hline \multicolumn{9}{|c|}{ Tabla 7-44 $V_{\text {det }}$ para distintas relaciones recubrimiento/diámetro $c / \phi$} \\
\hline $\mathbf{c} / \phi$ & \multicolumn{2}{|c|}{2,5} & \multicolumn{2}{|c|}{3} & \multicolumn{2}{|r|}{4} & \multicolumn{2}{|c|}{5} \\
\hline $\mathrm{V}_{\text {det }}$ & \multicolumn{2}{|c|}{0,38} & \multicolumn{2}{|l|}{0,215} & \multicolumn{2}{|c|}{0,0729} & \multicolumn{2}{|c|}{0,0345} \\
\hline \multicolumn{9}{|c|}{ Tabla 7-45 $V_{\text {det }}$ para distintos diámetros tensiones iniciales de pretensado $\sigma_{p, 0}$} \\
\hline$\sigma_{\mathrm{p}, 0}$ & 1116 & 1209 & 1302 & & 1395 & 1488 & 1581 & 1674 \\
\hline $\mathrm{V}_{\text {det }}$ & 0,0596 & 0,066 & 0,0708 & & 0,0747 & 0,0789 & 0,082 & 0,0858 \\
\hline \multicolumn{9}{|c|}{ Tabla 7-46 $V_{\text {det }}$ para distintos resistencias a compresión del hormigón $f_{c}$} \\
\hline $\mathbf{f}_{\mathrm{c}}$ & 20 & 25 & 30 & 35 & 40 & 45 & 50 & 55 \\
\hline $\mathrm{V}_{\mathrm{det}}$ & 0,0678 & 0,0700 & 0,0727 & 0,0771 & 0,078 & 0,0775 & 0,0772 & 0,0796 \\
\hline
\end{tabular}

\subsection{Expresión simplificada para el cálculo de longitudes de transferencia en elementos pretensados}

Una vez realizado el análisis cualitativo de la influencia de cada uno de los factores que intervienen en el fenómeno de la adherencia en elementos pretensados de hormigón, en este apartado se cuantifica dicha influencia, permitiendo la elaboración de expresiones simplificadas que posibiliten el cálculo o predicción de longitudes de transferencia, así como su evolución al experimentar procesos de deterioro por corrosión. Para ello, se lleva a cabo un análisis estadístico de los resultados obtenidos mediante el modelo analítico, para una combinación de los principales parámetros que intervienen en el fenómeno, identificados en el apartado anterior.

Se han contemplado cinco variables independientes (resistencia del hormigón, diámetro, recubrimiento, tensión inicial de pretensado y pérdida de sección por corrosión) de cuyas múltiples combinaciones surgen los resultados que permiten analizar su influencia en la longitud de transferencia (variable dependiente). Se han estudiado los siguientes rangos de valores:

- Resistencia a compresión del hormigón $f_{c}$ (y a tracción $\left.f_{c t}\right): 20(2,21), 30(2,97), 40$ (3,51), 50 $(4,07)$ y $60(4,60) \mathrm{N} / \mathrm{mm}^{2}$.

- Diámetro $\phi: 5,0-8,0-11,11-12,7 \mathrm{~mm}$

- Recubrimiento $c$ : Relaciones c/ $\phi$ 2,5 - 3,0 - 3,5 - 4,0 - 4,5 
- Tensión inicial de pretensado $\sigma_{\mathrm{p}, 0}: 50 \% f_{p u}(930 \mathrm{Mpa}), 70 \% f_{p u}(1302 \mathrm{Mpa})$ y $90 \% f_{p u}(1674$ Mpa).

- Porcentaje de pérdida de sección por corrosión: 0-30\%

Se han obtenido un total de 168 resultados, que se recogen el Anexo XXX. Para el estudio de los datos obtenidos se utiliza el programa de análisis estadístico R.

\subsubsection{Longitud de transferencia en alambres sanos}

Como se ha visto a lo largo de esta tesis, por definición, la longitud de transferencia $l_{t}$ es aquella necesaria para que la totalidad de la fuerza de pretensado $F_{p}$ introducida en un alambre se transfiera por adherencia al hormigón. Esta longitud abarca la distancia existente desde el extremo libre del elemento pretensado hasta la sección a partir de la cual la tensión en el alambre es constante y de valor igual a la tensión inicial de pretensado $\sigma_{p, o}$. Por tanto, la fuerza de pretensado en un alambre de diámetro $\phi$ debe ser equivalente a la integral de la ley de distribución de la tensión de adherencia $\tau_{b}(x)$ que actúa sobre la superficie del alambre a lo largo de la longitud de transferencia $l_{t}$ (Eq. 7-3).

$$
F_{p}=\sigma_{p, 0} \cdot \frac{\pi \phi^{2}}{4}=\int_{0}^{l_{t}} \pi \phi \tau_{b}(x) d x
$$

En los casos más habituales, de la igualdad anterior (Eq. 7-3) se conocen todos los datos excepto la longitud de transferencia $l_{t}$ y la ley de distribución de la tensión de adherencia a lo largo de ésta $\tau_{b}(x)$. En la mayor parte de los códigos [Código Modelo (FIB Special Activity Group 5, 2011), Eurocódigo 2 (CEN, 2004), EHE-08 (Fomento, 2008)] se opta por considerar esta ley como constante y dependiente de la resistencia del hormigón a tracción $f_{c t}$, del tipo de alambre y de la posición del mismo durante el hormigonado (Ver Capitulo 2). Sin embargo, en los apartados anteriores se ha comprobado que esta ley dista de tener un valor constante a lo largo de la longitud de transferencia y que además depende de otros factores, tales como el diámetro del alambre $\phi$, la relación recubrimiento/diámetro $c / \phi$ y la tensión de pretensado inicial $\sigma_{p, 0}$. Conocer con exactitud la ley de distribución de la tensión de adherencia para cada caso estudiado es un proceso complejo, únicamente viable mediante modelos como el desarrollado en el Capitulo 3 de esta tesis, y además se aleja de los objetivos de una expresión simplificada. Por el contrario, considerar que la integral de la tensión de adherencia $\tau_{b}(x)$ es equivalente a una tensión media $\tau_{b \text {,med }}$ distribuida uniformemente a lo largo de la longitud de transferencia $l_{t}$, simplifica de manera considerable el problema. A la vista de estas consideraciones, la igualdad anterior (Eq. 7-3) puede reescribirse como sigue (Eq. 7-4):

$$
F_{p}=\sigma_{p, 0} \cdot \frac{\pi \phi^{2}}{4}=l_{t} \pi \phi \tau_{b, \text { med }}
$$

$\mathrm{Y}$ de (Eq. 7-4) se despeja fácilmente la longitud de transferencia $l_{t}(E q .7-5)$ :

$$
l_{t}=\sigma_{p, 0} \frac{\phi}{4} \cdot \frac{1}{\tau_{b, \text { med }}}
$$


Como puede comprobarse, la expresión (Eq. 7-5) es similar a la recogida en los códigos estructurales citados anteriormente.

\subsubsection{Análisis de regresión múltiple}

Siguiendo con el razonamiento, en el apartado anterior se ha llevado a cabo un estudio paramétrico que ha permitido analizar la influencia de distintas variables geométricas y mecánicas en la longitud de transferencia $l_{t}$. Las principales conclusiones que se han extraído son las siguientes:

- La longitud de transferencia $l_{t}$ crece proporcionalmente al aumento del diámetro del alambre de pretensado $\phi$, estableciéndose una relación de carácter potencial, casi lineal (Eq. 7-6).

$$
l_{t} \propto a_{0}(\phi)^{\beta}
$$

- La resistencia a tracción (y a compresión) del hormigón $f_{c t}$ es inversamente proporcional a la longitud de transferencia $l$, existiendo una relación de carácter potencial entre ambas $(E q$. 7-7).

$$
l_{t} \propto a_{0}\left(f_{c t}\right)^{\beta}
$$

- La longitud de transferencia $l_{t}$ disminuye con el incremento del ratio recubrimiento/diámetro $c / \phi$, estableciéndose unamn relación entre ambas variables de carácter potencial (Eq. 7-8).

$$
l_{t} \propto a_{0}(c / \phi)^{\beta}
$$

- La relación existente entre la longitud de transferencia $l_{t}$ y la tensión de pretensado inicial $\sigma_{p, 0}$ es aproximadamente potencial (Eq. 7-9).

$$
l_{t} \propto a_{0}\left(\sigma_{p, 0}\right)^{\beta}
$$

El modelo de regresión múltiple establece la relación existente entre una variable dependiente o respuesta y dos o mas variables independientes o explicativas. El modelo más habitual de regresión múltiple es el lineal, cuya forma general es la siguiente (Eq. 7-10):

$$
y_{i}=a_{0}+\beta_{1} x_{1 i}+\beta_{2} x_{2 i}+\cdots+\beta_{k} x_{k i}+u_{i}
$$

Donde $y$ es la variable dependiente; $x_{i}$ son las variables independientes; $\beta$ los coeficientes parciales de regresión entre cada $x$ e $y$, es decir, el efecto promedio que tiene el incremento en una unidad de cada variable independiente $x_{i}$ sobre la variable dependiente $y$, manteniéndose constantes el resto de variables, y $u$ es el residuo o error, es decir, la diferencia entre el valor observado y el estimado por el modelo. Los coeficientes $\beta$ son aquellos que minimizan la suma de cuadrados entre los valores observados y los pronosticados, es decir, que minimizan la varianza residual. 
El modelo lineal exige que la relación entre variable dependiente y variables independientes sea lineal. Sin embargo, en el análisis paramétrico llevado a cabo en el apartado anterior, se ha comprobado que la relación existente entre la variable respuesta y las variables explicativas es de carácter potencial $\left[y=a_{0} x^{\beta}\right]$. Por ello, mediante la utilización de logaritmos, se procede a linealizar dichas relaciones (Eq. 7-11):

$$
y=a_{0} x^{\beta} \Rightarrow \log (y)=\log \left(a_{0}\right)+\beta \log (x)
$$

Por lo que el modelo lineal resultante adopta la siguiente forma (Eq. 7-12):

$$
\log \left(y_{i}\right)=\log \left(a_{0}\right)+\beta_{1} \log \left(x_{1 i}\right)+\beta_{2} \log \left(x_{2 i}\right) \ldots \beta_{k} \log \left(x_{k i}\right)+u
$$

Al singularizar la expresión general anterior para el análisis de la longitud de transferencia con alambres sanos se obtiene la siguiente expresión para el modelo de regresión múltiple linealizado (Eq. 7-13):

$$
\log \left(l_{t, 0}\right)=\log \left(a_{0}\right)+\beta_{1} \log (\phi)+\beta_{2} \log (c / \phi)+\beta_{3} \log \left(f_{c}\right)+\beta_{4} \log \left(\sigma_{p, 0}\right)+u
$$

Mediante el programa de análisis estadístico $R$ se obtiene la bondad del ajuste del modelo propuesto, obteniéndose un coeficiente de determinación múltiple $R^{2}$ igual a 0,9894 ( $R^{2}$ corregido igual a 0,9891$)$, es decir, que las cuatro variables independientes contempladas en el análisis justifican un 98,9\% de la varianza de la variable respuesta.

Tabla 7-47 Coeficientes de determinación $\mathrm{R}^{2}$. Error estándar. Estadístico F.

\begin{tabular}{ccccc} 
& Coef. Determ. $\mathbf{R}^{2}$ & $\mathbf{R}^{2}$ (corregido) & Error estándar & Estadístico F \\
\hline Regresión $\mathrm{X}_{\lim }$ & 0,9894 & 0,9891 & 0,0693 & 3804 \\
\hline
\end{tabular}

El estadístico F, procedente del análisis de la varianza (ANOVA), contrasta la hipótesis nula de que el valor poblacional de $\mathrm{R}$ es cero $\mathrm{y}$, por tanto, permite determinar si existe una relación lineal significativa entre la variable dependiente y el conjunto de las variables independientes. En el modelo analizado, F toma un valor igual a 3804, y el p-valor (<2e-16) está muy por debajo del nivel de significancia $(0,05)$ lo que permite rechazar la Hipótesis Nula. Es decir, el modelo seleccionado es explicativo, y al menos una de las variables independientes contempladas $\left(\phi, c / \phi, f_{c} \mathrm{y} \sigma_{p, 0}\right)$ influye en la longitud de transferencia $l_{t, 0}$.

La Tabla 7-48 incluye todos los valores que permiten construir la ecuación de regresión que define el modelo. El Valor ty su nivel de significación ( $\not$-valor) sirven para determinar si se cumple la hipótesis nula, es decir, que el coeficiente de regresión vale cero en la población. Generalmente, p-valores pequeños (por debajo del 0,05) indican que se debe rechazar la hipótesis nula. Por el contrario, valores $\mathrm{t}$ alejados de 0 informan de que la variable independiente analizada es relevante en la ecuación de regresión. Los valores de t obtenidos para todas las variables están alejados significativamente de 0 y su p-valor es $<2 \mathrm{e}-16$, por lo que se puede concluir que contribuyen de manera determinante a explicar el valor adoptado por la variable dependiente. 
TESIS DOCTORAL INFLUENCLA DE LA CORROSIÓN EN LA ADHERENCLA DE ALAMBRES EN ELEMENTOS PRETENS ADOS DE HORMIGÓN

Tabla 7-48 Coeficientes de regresión parcial estandarizados y no estandarizados. Error estándar. P-valores. Intervalos de confianza.

\begin{tabular}{cccccccc}
\hline & $\begin{array}{c}\text { Coef. } \boldsymbol{\beta} \\
\text { No estand. }\end{array}$ & $\begin{array}{c}\text { Coef. } \boldsymbol{\beta}^{\prime} \\
\text { estandarizados }\end{array}$ & $\begin{array}{c}\text { Error } \\
\text { estándar }\end{array}$ & Valor t & $\operatorname{Pr}(>|\mathbf{t}|)$ & \multicolumn{2}{c}{ Intervalo de conf. 95\% } \\
\hline $\log \left(\mathrm{a}_{0}\right)$ & 3,30857 & 0 & 0,11822 & 27,99 & $<2 \mathrm{e}-16$ & 3,0751 & 3,5420 \\
\hline $\log (\phi)$ & 1,01216 & 0,8147 & 0,01002 & 101,03 & $<2 \mathrm{e}-16$ & 0,9924 & 1,0319 \\
\hline $\log (\mathrm{c} / \phi)$ & $-0,36751$ & $-0,1541$ & 0,01924 & $-19,1$ & $<2 \mathrm{e}-16$ & $-0,4055$ & $-0,3295$ \\
\hline $\log \left(\mathrm{f}_{\mathrm{c}}\right)$ & $-0,65281$ & $-0,4737$ & 0,01112 & $-58,73$ & $<2 \mathrm{e}-16$ & $-0,6748$ & $-0,6309$ \\
\hline $\log \left(\sigma_{\mathrm{p}, 0}\right)$ & 0,50594 & 0,2728 & 0,01495 & 33,84 & $<2 \mathrm{e}-16$ & 0,4764 & 0,5355 \\
\hline
\end{tabular}

Los coeficientes estandarizados $\beta^{\prime}$ recogidos en la Tabla 7-48 permiten determinar la contribución individual de cada variable independiente en la explicación de la variable dependiente. Como puede apreciarse, el diámetro del alambre $\phi$ es el parámetro con una mayor influencia relativa en el valor adoptado por la longitud de transferencia $\left(\beta^{\prime}=0,8147\right)$, seguido por la resistencia a compresión del hormigón $f_{c}\left(\beta^{\prime}=-0,4737\right)$, la tensión inicial de pretensado $\sigma_{p, 0}\left(\beta^{\prime}=0,2728\right)$ y, por último, la relación recubrimiento/diámetro $c / \phi\left(\beta^{\prime}=-0,1541\right)$. El signo de los coeficientes $\beta^{\prime}$ informa de la forma en que influyen las variables independientes en la variable respuesta, de tal manera que si $\beta^{\prime}$ es positivo cualquier aumento de la variable independiente ocasiona un crecimiento de la variable independiente, por el contrario, si $\beta^{\prime}$ es negativo, el aumento de la variable explicativa disminuye el valor de la variable dependiente.

Finalmente, los coeficientes $\beta$ (no estandarizados) permiten definir la ecuación de regresión. Para ello, se sustituyen dichos coeficientes en la expresión (Eq. 7-13):

$$
\log \left(l_{t, 0}\right)=3,30857+1,01216 \log (\phi)-0,36751 \log (c / \phi)+-0,65281 \log \left(f_{c}\right)+0,50594 \log \left(\sigma_{p, 0}\right) \quad(E q .7-14)
$$

$\mathrm{Y}$ operando, se obtiene que la longitud de transferencia en alambres de pretensado sanos es igual a (Eq. 7-15):

$$
l_{t, 0}=27,35 \frac{\phi^{1,01216} \sigma_{p, 0}{ }^{0,50594}}{(c / \phi)^{0,36751} \cdot f_{c}^{0,65281}}
$$

En virtud de la sencillez de utilización y de su manejabilidad, se propone simplificar la expresión anterior. Para ello, para minimizar la influencia sobre los resultados obtenidos, los nuevos valores para los coeficientes se encuentran incluidos dentro de su intervalo de confianza del 95\% (Tabla 7-48). Mediante este proceso de simplificación, la expresión (Eq. 7-15) se reduce a la siguiente (Eq. 7-16):

$$
l_{t, 0}=30 \frac{\phi \cdot \sigma_{p, 0}{ }^{1 / 2}}{(c / \phi)^{1 / 3} \cdot f_{c}^{2 / 3}}
$$

En la Figura 7-58 se comparan los diagramas de realización-predicción para las expresiones (Eq. 7-15) y (Eq. 7-16), observándose que los resultados son prácticamente idénticos. Sin embargo, la expresión (Eq. 7-16) gana en legibilidad y permite apreciar con claridad las tendencias halladas en el apartado anterior y el fenómeno físico subyacente. En ambos diagramas se observa que la dispersión de los 
resultados aumenta cuanto mayor es la longitud de transferencia, correspondiéndose con aquellas situaciones en las que confluyen una alta tensión inicial de pretensado y un alambre de pretensado de diámetro considerable con bajas relaciones recubrimiento/diámetro y bajas resistencias a compresión del hormigón.
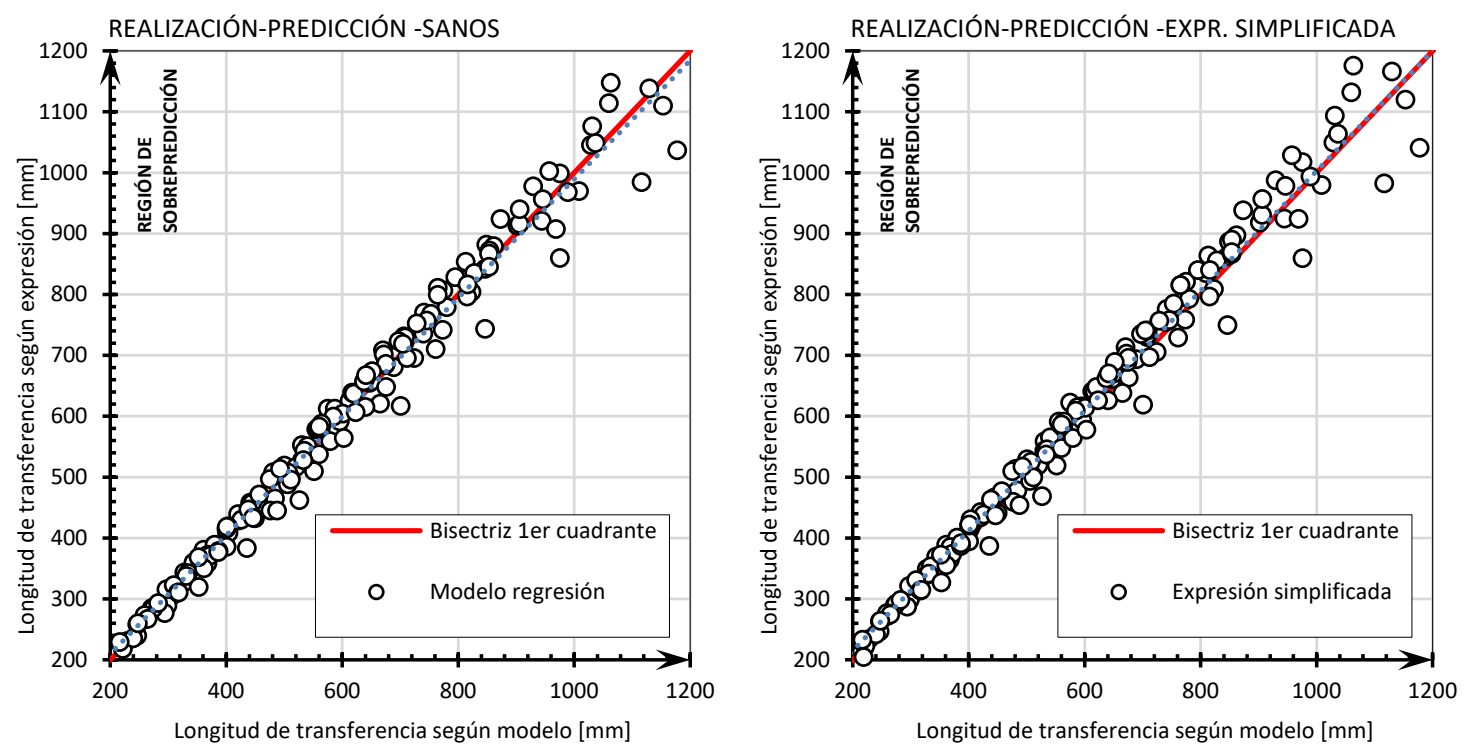

Figura 7-58 Diagramas predicción-realización para las longitudes de transferencia calculadas con la ecuación de la regresión múltiple frente a las arrojadas por la expresión tras su simplificación.

Cabe señalar que el modelo resultante es multiplicativo, mientras que el modelo general de regresión lineal múltiple es de carácter aditivo. En muchas ocasiones, las variables muestran una correlación de forma individual pero también cambian su grado de influencia en función del valor de una tercera variable, en un proceso denominado interacción. En estos casos, el modelo aditivo presenta problemas y debe recurrirse a uno de carácter multiplicativo En el caso que nos ocupa, es evidente que existen variables independientes que interactúan, de manera que, por ejemplo, la resistencia a compresión del hormigón disminuye su influencia cuando la relación recubrimiento diámetro crece, y viceversa.

Una vez validada la expresión simplificada para la determinación de la longitud de transferencia, extraída del modelo, puede igualarse con la expresión analítica general que define la longitud de transferencia $l_{t}$, Eq. 7-5), tal y como sigue (Eq. 7-17).

$$
l_{t, 0}=\sigma_{p, 0} \frac{\phi}{4} \cdot \frac{1}{\tau_{b, \text { med }}}=30 \frac{\phi \cdot \sigma_{p, 0}{ }^{1 / 2}}{(c / \phi)^{1 / 3} \cdot f_{c}^{2 / 3}}
$$

De la igualdad (Eq. 7-17) puede despejarse la tensión de adherencia media a lo largo de la longitud de transferencia $l_{t, 0}$, obteniéndose la siguiente expresión (Eq. 7-18):

$$
\tau_{b, \text { med }}=\frac{1}{4 \cdot 30} f_{c}^{2 / 3} \sigma_{p, 0}{ }^{1 / 2}\left(\frac{c}{\phi}\right)^{1 / 3}=\frac{f_{c}^{2 / 3} \sigma_{p, 0}{ }^{1 / 2}}{120}\left(\frac{c}{\phi}\right)^{1 / 3}
$$


La ecuación (Eq. 7-18) confirma que, como fue discutido ampliamente en el Capítulo 6, la tensión de adherencia media $\tau_{b, \text { med }}$ depende de la relación existente entre la capacidad de confinamiento del recubrimiento y la capacidad del sistema acero-hormigón para movilizar la acción confinante del mismo. La capacidad de confinamiento del recubrimiento de hormigón viene determinada por factores geométricos (relación recubrimiento/diámetro $c / \phi$ ) y mecánicos (resistencias a tracción del hormigón $f_{c t}$ ), mientras que el grado de movilización de dicha capacidad depende de la tensión inicial de pretensado $\sigma_{p, 0}$, a través del desplazamiento radial de la pare interna del recubrimiento de hormigón que provoca el efecto Hoyer.

La expresión (Eq. 7-5) es válida únicamente para alambres lisos e indentados, con sección circular, en la que la relación existente entre el área transversal $A_{p}$ y el perímetro es igual a $\phi / 4$. Su adaptación a cordones requiere tener en cuenta la relación existente entre estos dos parámetros en este tipo de armadura. Según el Código Modelo 2010 (FIB Special Activity Group 5, 2011), dicha relación es igual a $\phi \cdot 7 / 36$, por lo que la expresión para definir la longitud de transferencia $l_{t}$ en cordones de pretensado, sin entrar en análisis más profundos, quedaría de la siguiente manera (Eq. 7-19):

$$
l_{t}=\sigma_{p, 0} \frac{7 \phi}{36} \cdot \frac{1}{\tau_{b, \text { med }}}
$$

La expresión anterior toma esta forma siempre y cuando la tensión de adherencia media $\tau_{b, m e d}$ se considere repartida homogéneamente a lo largo del perímetro de una circunferencia de radio $\phi$, y no alrededor del contorno real del cordón de pretensado, cuyo valor es $P_{\text {ral }}=4 / 3 \pi \phi$.

\subsubsection{Longitud de transferencia en alambres corroídos}

Una vez determinada la longitud de transferencia en alambres y cordones sanos, en este apartado se desarrolla un método simplificado para su cálculo en elementos pretensados de hormigón con procesos de deterioro derivados de la corrosión. Para ello se parte de la hipótesis de que la corrosión modifica la tensión de adherencia media $\tau_{b, \text { med }}$ a lo largo de la longitud de transferencia, tomando un nuevo valor denominado $\tau_{b, c o r r}$. Por tanto, la longitud de transferencia de un alambre con procesos de degradación por corrosión $l_{t, c o r r}$ vendría determinada por la siguiente expresión (Eq. 7-20):

$$
l_{t, \mathrm{corr}}=\sigma_{p, 0} \frac{\phi}{4} \cdot \frac{1}{\tau_{b, \mathrm{corr}}}
$$

donde $\tau_{b, c o r r}$ es igual a la tensión de adherencia media en alambres sanos $\tau_{b, \text { med }}$ (Eq. 7-18) minorada por un coeficiente $\alpha_{\text {corr }}$ (Eq. 7-21):

$$
\tau_{b, \text { corr }}=\frac{\tau_{b, \text { med }}}{\alpha_{\text {corr }}}
$$

Sustituyendo (Eq. 7-21) en (Eq. 7-20) se determina que la longitud de transferencia de un alambre de pretensado con procesos de corrosión $l_{t, c o r r}$ depende de su longitud de transferencia previa a la corrosión $l_{t, 0}$ y del coeficiente de degradación $\alpha_{\text {corr }}$ (Eq. 7-22): 


$$
l_{t, \mathrm{corr}}=l_{t, 0} \cdot \alpha_{\mathrm{corr}}
$$

En virtud del estudio de la influencia de la corrosión en la longitud de transferencia que se ha llevado a cabo en el Apartado 7.4.9, es fácil deducir que el valor del coeficiente de deterioro $\alpha_{\text {corr }}$ viene determinado por el porcentaje de pérdida de sección en el momento de la evaluación $X_{\text {corr }}$, por el porcentaje de pérdida de sección que provoca el inicio del deterioro de la longitud de transferencia $X_{\text {lim }}$ y por la velocidad de deterioro de dicha longitud $V_{\text {det }}$. Por tanto, el coeficiente $\alpha_{\text {corr }}$ queda definido por la siguiente expresión (Eq. 7-23)(Figura 7-59):

$$
\alpha_{\text {corr }}=1+\left(X_{\text {corr }}-X_{\text {lim }}\right) \cdot V_{\text {det }} \geq 1
$$

A continuación, al igual que se ha hecho con alambres sanos, se lleva a cabo un análisis estadístico de los resultados relativos a $X_{\text {lim }}$ y a $V_{\text {det }}$, obtenidos mediante el modelo analítico, para una combinación de los principales parámetros que intervienen en el proceso de deterioro por corrosión, identificados en el Apartado 7.4.9.

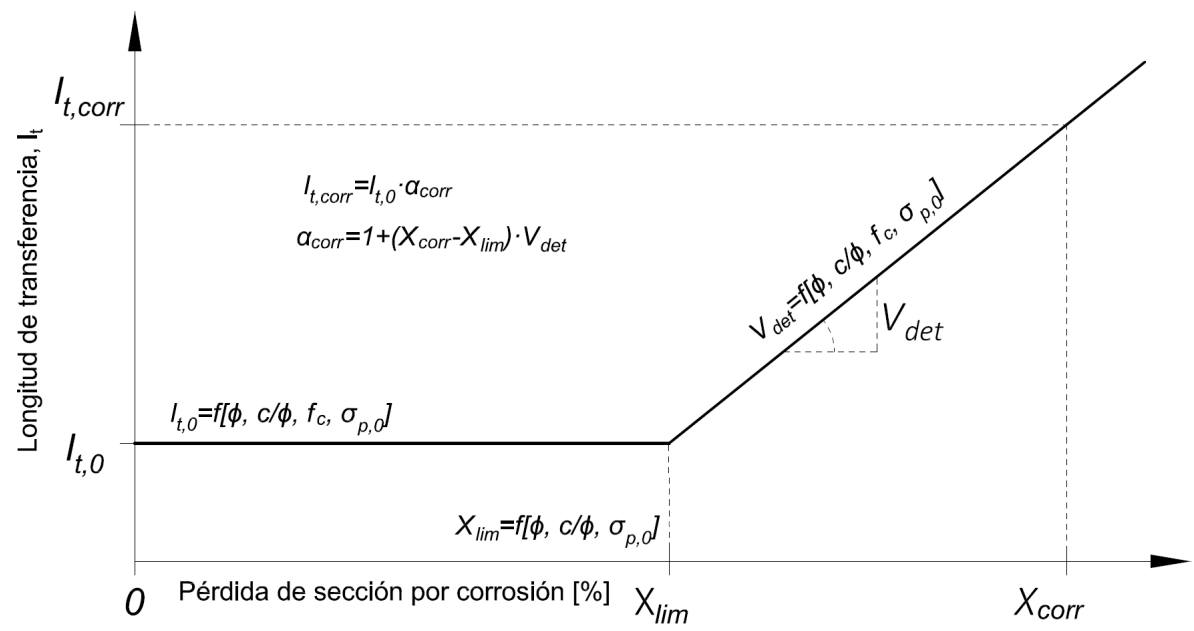

Figura 7-59 Modelo de deterioro de la longitud de transferencia y expresiones simplificadas para su caracterización.

\subsubsection{Análisis de regresión múltiple para la determinación de $X_{\text {lim }}$}

El Apartado 7.4.9 ha permitido analizar cualitativamente la influencia que las distintas variables geométricas y mecánicas tienen el porcentaje de pérdida de sección que provoca el inicio del deterioro de la longitud de transferencia $X_{\text {lim }}$. Las principales conclusiones que se han extraído son las siguientes:

- La pérdida de sección $X_{\text {lim }}$ es proporcional a la relación recubrimiento/diámetro $c / \phi$, existiendo una relación de carácter potencial entre ambas variables (Eq. 7-24).

$$
X_{\text {lim }} \propto a_{0}(c / \phi)^{\beta}
$$

- El umbral $X_{\text {lim }}$ aumenta con el incremento del diámetro del alambre $\phi$, observándose una relación de carácter potencial entre ambas variables (Eq. 7-25). 
TESIS DOCTORAL INFLUENCLA DE LA CORROSIÓN EN LA ADHERENCLA DE ALAMBRES EN ELEMENTOS PRETENS ADOS DE HORMIGÓN

$$
X_{\text {lim }} \propto a_{0}(\phi)^{\beta}
$$

- El porcentaje de pérdida de sección necesaria para que comience el deterioro de la longitud de transferencia $X_{\text {lim }}$ disminuye con el aumento de la tensión de pretensado inicial $\sigma_{p, \theta}$, mediante una ley potencial (Eq. 7-26).

$$
X_{\text {lim }} \propto a_{0}\left(\sigma_{p, 0}\right)^{\beta}
$$

- La resistencia a compresión del hormigón fc no influye en la pérdida de sección por corrosión necesaria para que se inicie el aumento de la longitud de transferencia.

Dado que las relaciones encontradas entre la variable independiente $\left(X_{\text {lim }}\right)$ y las variables siguen leyes potenciales, y por tanto linealizables mediante transformaciones logarítmicas (Eq. 7-11), se utiliza el mismo procedimiento utilizado para la determinación de la longitud de transferencia en alambres sanos (Eq. 7-13). Aunque se ha observado que la resistencia del hormigón $f_{c}$ no tiene una influencia directa en el valor de $X_{\text {lim }}$, se opta por introducirla como variable independiente para comprobar si el análisis estadístico corrobora dicha observación, obteniéndose la siguiente expresión para el modelo de regresión múltiple linealizado (Eq. 7-27):

$$
\log \left(X_{\text {lim }}\right)=\log \left(a_{0}\right)+\beta_{1} \log (\phi)+\beta_{2} \log (c / \phi)+\beta_{3} \log \left(\sigma_{p, 0}\right)+\beta_{4} \log \left(f_{c}\right)+u
$$

Utilizando el programa de análisis estadístico $R$ se comprueba el grado de ajuste del modelo propuesto, obteniéndose un coeficiente de determinación múltiple $\mathrm{R}^{2}$ igual a 0,9748 ( $\mathrm{R}^{2}$ corregido igual a 0,9742), es decir, que las cuatro variables independientes contempladas en el análisis justifican aproximadamente un $97,4 \%$ de la varianza de la variable respuesta $\left(X_{\text {lim }}\right)$.

Tabla 7-49 Coeficientes de regresión parcial estandarizados y no estandarizados. Error estándar. P-valores. Intervalos de confianza.

\begin{tabular}{cccccccc}
\hline & Coef. $\beta$ & Coef. $\boldsymbol{\beta}^{\prime}$ & Error & Valor t & P- & \multicolumn{2}{c}{ Intervalo de conf. 95\% } \\
\cline { 7 - 9 } & No estand. & estandarizados & estándar & & valor $>|\mathbf{t}|)$ & Cuantil 2,5\% & Cuantil 97,5\% \\
\hline $\log (\mathrm{a} 0)$ & 7,69619 & $-9,55 \mathrm{E}-17$ & 0,18108 & 42,501 & $<2 \mathrm{e}-16$ & 7,3383 & 8,0541 \\
\hline $\log (\phi)$ & 0,35909 & 0,304 & 0,01543 & 23,265 & $<2 \mathrm{e}-16$ & 0,3286 & 0,3896 \\
\hline $\log (\mathrm{c} / \phi)$ & 1,97811 & 0,803 & 0,03308 & 59,795 & $<2 \mathrm{e}-16$ & 1,9127 & 2,0435 \\
\hline $\log (\sigma \mathrm{p}, 0)$ & $-1,26716$ & $-0,701$ & 0,02429 & $-52,174$ & $<2 \mathrm{e}-16$ & $-1,3152$ & $-1,2192$ \\
\hline $\log (\mathrm{fc})$ & 0,03717 & 0,0292 & 0,01665 & 2,232 & 0,0271 & 0,0043 & 0,0701 \\
\hline
\end{tabular}

Como puede observarse en la Tabla 7-49, el p-valor de la variable vinculada a la resistencia a compresión del hormigón ( $\mathrm{p}$-valor $=0,0271)$ está en el límite usualmente admitido del nivel de significancia $(<$ $0,05)$, y su coeficiente $\beta^{\prime}$ estandarizado $(0,0292)$ nos informa de su baja influencia relativa en la determinación de la variable respuesta. Por tanto, el análisis estadístico corrobora las observaciones realizadas y se opta por excluir la variable $f_{c}$ del modelo de regresión, quedando la siguiente expresión:

$$
\log \left(X_{\text {lim }}\right)=\log \left(a_{0}\right)+\beta_{1} \log (\phi)+\beta_{2} \log (c / \phi)+\beta_{3} \log \left(\sigma_{p, 0}\right)+u
$$

El nuevo modelo de regresión múltiple arroja un coeficiente de determinación $\mathrm{R}^{2}$ igual a 0,974 (Tabla 7-50), muy similar al obtenido en el modelo anterior, a pesar de haberse suprimido la variable relativa a la resistencia a compresión del hormigón. 
Tabla 7-50 Coeficientes de determinación $\mathrm{R}^{2}$. Error estándar. Estadístico F.

\begin{tabular}{cccccc}
\hline & Coef. Det. $\mathbf{R}^{2}$ & $\mathbf{R}^{2}$ (corregido) & Error estándar & Estadístico $\mathbf{F}$ & p-valor \\
\hline Regresión $\mathrm{X}_{\lim }$ & 0,974 & 0,9735 & 0,0693 & 1848 & $<2 \mathrm{e}-16$ \\
\hline
\end{tabular}

El estadístico F toma un valor igual a 1848, y el p-valor $(<2,2 \mathrm{e}-16)$ está muy por debajo del nivel de significancia $(0,05)$ lo que permite rechazar la hipótesis nula. Es decir, el modelo seleccionado es explicativo, y al menos una de las variables independientes contempladas $\left(\phi, c / \phi\right.$ y $\left.\sigma_{p, 0}\right)$ influye en la el porcentaje de pérdida de sección límite por corrosión que marca el comienzo del aumento de la longitud de transferencia $\left(X_{\text {lim }}\right)$.

En la Tabla 7-51 se pormenoriza la influencia de cada una de las variables. Los valores de t obtenidos para todas las variables están alejados significativamente de 0 y su p-valor es prácticamente nulo $(<2$ e16), por lo que se puede concluir que contribuyen de manera determinante a explicar el valor adoptado por la variable dependiente. Por su parte, los coeficientes estandarizados $\beta^{\prime}$ permiten determinar que la relación recubrimiento/diámetro $c / \phi$ es el parámetro con una mayor influencia relativa en el valor adoptado por $X_{\text {lim }}\left(\beta^{\prime}=0,8025\right)$, seguido por la tensión inicial de pretensado $\sigma_{p, 0}$ $\left(\beta^{\prime}=-0,6999\right)$ y por el diámetro del alambre $\phi\left(\beta^{\prime}=0,3043\right)$.

Tabla 7-51 Coeficientes de regresión parcial estandarizados y no estandarizados. Error estándar. P-valores. Intervalos de confianza.

\begin{tabular}{cccccccc}
\hline & $\begin{array}{c}\text { Coef. } \boldsymbol{\beta} \\
\text { No estand. }\end{array}$ & $\begin{array}{c}\text { Coef. } \boldsymbol{\beta}^{\prime} \\
\text { estandarizados }\end{array}$ & $\begin{array}{c}\text { Error } \\
\text { estándar }\end{array}$ & Valor t & $\begin{array}{c}\text { p- } \\
\text { valor }(>|\mathbf{t}|)\end{array}$ & \multicolumn{2}{c}{ Intervalo de conf. 95\% } \\
\hline $\log (\mathrm{a} 0)$ & 7,81992 & 0 & 0,17469 & 44,76 & $<2 \mathrm{e}-16$ & 7,4747 & 8,1651 \\
\hline $\log (\phi)$ & 0,35909 & 0,3043 & 0,01564 & 22,96 & $<2 \mathrm{e}-16$ & 0,3282 & 0,3900 \\
\hline $\log (\mathrm{c} / \phi)$ & 1,97742 & 0,8025 & 0,03352 & 58,99 & $<2 \mathrm{e}-16$ & 1,9112 & 2,0437 \\
\hline $\log \left(\sigma_{\mathrm{p}, 0}\right)$ & $-1,26584$ & $-0,6999$ & 0,0246 & $-51,45$ & $<2 \mathrm{e}-16$ & $-1,3145$ & $-1,2172$ \\
\hline
\end{tabular}

Finalmente, los coeficientes $\beta$ (no estandarizados) permiten definir la ecuación de regresión para la determinación de $X_{\text {lim. }}$ Para ello, se sustituyen dichos coeficientes en la expresión (Eq. 7-28):

$$
\log \left(X_{\text {lim }}\right)=\log (7,81992)+0,35909 \log (\phi)+1,97742 \log (c / \phi)-1,26584 \log \left(\sigma_{p, 0}\right) \quad \text { (Eq. 7-29) }
$$

Operando, se obtiene que el porcentaje límite de pérdida de sección por procesos de corrosión a partir del cual se comienza a deteriorar la longitud de transferencia, $X_{\text {lim }}$, es igual a (Eq. 7-30):

$$
X_{\text {lim }}=2489,7 \frac{\phi^{0,35909}(c / \phi)^{1,97742}}{\sigma_{p, 0} 1,26584}
$$

Tal y como se hizo actúo con la expresión para la determinación de la longitud de transferencia en alambres de pretensado sanos, la expresión anterior (Eq. 7-30) se simplifica para aumentar su manejabilidad, reduciéndose a la siguiente expresión (Eq. 7-31):

$$
X_{\text {lim }}=2250 \frac{\phi^{1 / 3}(c / \phi)^{2}}{\sigma_{p, 0} 5 / 4}
$$



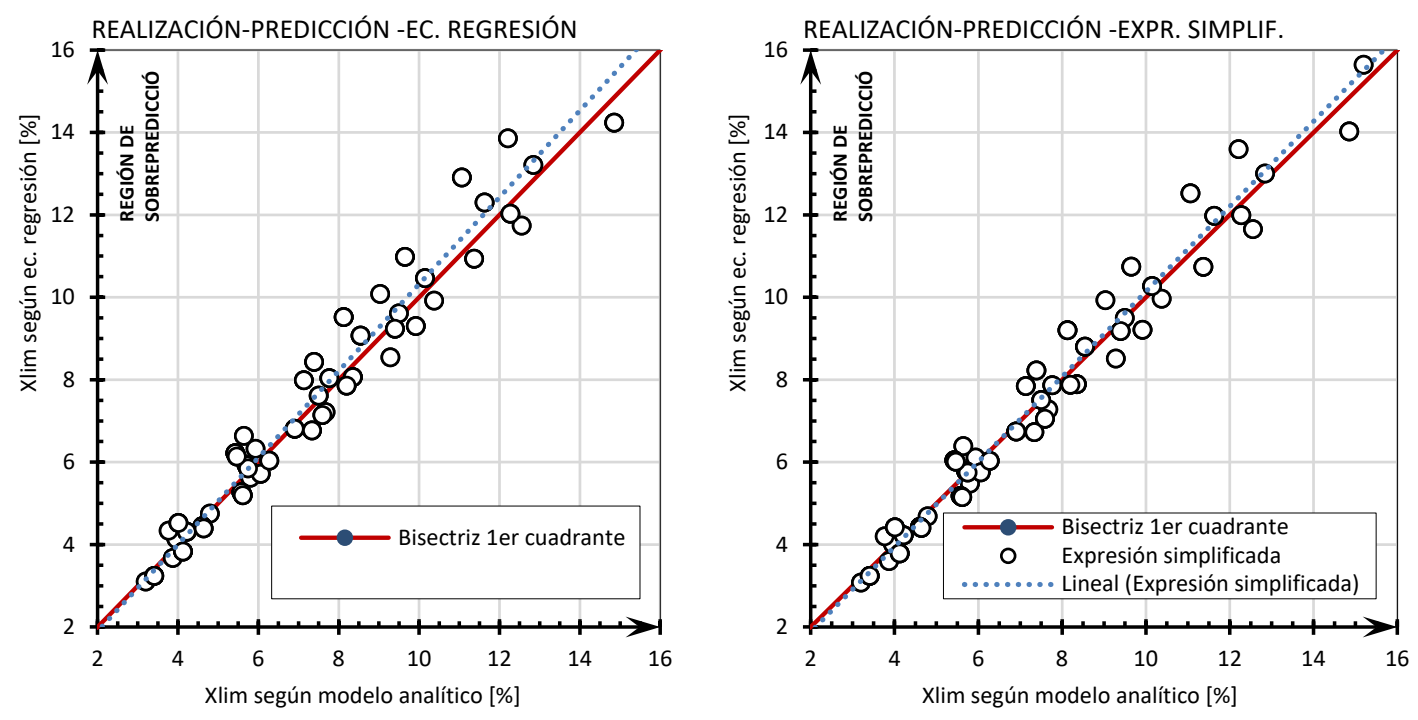

Figura 7-60 Diagramas predicción-realización para $X_{\text {lim }}$ calculadas con la ecuación de la regresión múltiple frente a las arrojadas por la expresión tras su simplificación.

En la Figura 7-60 se comparan los diagramas de realización-predicción para la ecuación obtenida de la regresión (Eq. 7-30) y para su versión simplificada (Eq. 7-31), observándose que los resultados son prácticamente idénticos. Por tanto, puede validarse la simplificación llevada a cabo sobre la expresión para la determinación del porcentaje límite de pérdida de sección por procesos de corrosión a partir del cual se comienza a deteriorar la longitud de transferencia, $X_{\text {lim. }}$.

\subsubsection{Análisis de regresión múltiple para la determinación de $V_{\text {det }}$}

El Apartado 7.4.9.2 ha permitido analizar cualitativamente la influencia que tienen distintas variables geométricas y mecánicas en la velocidad de deterioro de la longitud de transferencia $V_{\text {det }}$, entendida ésta como el incremento relativo de dicha longitud con respecto al aumento de los niveles de pérdida de sección por corrosión. Este análisis ha permitido comprobar que las relaciones que es establecen entre las variables independientes y la velocidad de deterioro de la longitud de transferencia $V_{\text {det }}$ son de carácter potencial $V_{\text {det }} \propto a_{0}\left(\sigma_{p, 0}\right)^{\beta}$, y que la variable explicativa más determinante es la relación recubrimiento/diámetro $c / \phi$ (Figura 7-57).

Dado que las relaciones encontradas entre la variable dependiente $\left(V_{d e t}\right)$ y las variables independientes siguen leyes potenciales, y por tanto linealizables mediante transformaciones logarítmicas (Eq. 7-11), se utiliza el mismo procedimiento que en los apartados anteriores. Por lo tanto, se obtiene la siguiente expresión para el modelo de regresión múltiple linealizado (Eq. 7-32):

$$
\log \left(V_{\text {det }}\right)=\log \left(a_{0}\right)+\beta_{1} \log (\phi)+\beta_{2} \log (c / \phi)+\beta_{3} \log \left(\sigma_{p, 0}\right)+\beta_{4} \log \left(f_{c}\right)+u
$$

Utilizando el programa de análisis estadístico $R$ se obtiene un coeficiente de determinación múltiple $\mathrm{R}^{2}$ igual a 0,9507 ( $\mathrm{R}^{2}$ corregido igual a 0,9493), es decir, que las cuatro variables independientes contempladas en el análisis justifican aproximadamente un $95 \%$ de la varianza de $V_{\text {det }}$ (Tabla $7-52$ ). El 
estadístico F toma un valor igual a 646,3, y el p-valor $(<2,2 \mathrm{e}-16)$ está muy por debajo del nivel de significancia $(0,05)$ lo que permite rechazar la hipótesis nula. Es decir, el modelo seleccionado es explicativo, y al menos una de las variables independientes contempladas $\left(\phi, c / \phi, \sigma_{p, 0}\right.$ y $\left.f_{c}\right)$ influye en la velocidad de deterioro de la longitud de transferencia $\left(V_{\text {det }}\right)$.

Tabla 7-52 Coeficientes de determinación $\mathrm{R}^{2}$. Error estándar. Estadístico $F$.

\begin{tabular}{cccccc}
\hline & Coef. Det. $\mathbf{R}^{\mathbf{2}}$ & $\mathbf{R}^{\mathbf{2}}$ (corregido) & Error estándar & Estadístico $\mathbf{F}$ & p-valor \\
\hline Regresión $\mathrm{X}_{\lim }$ & 0,9507 & 0,9493 & 0,0693 & 646,3 & $<2,2 \mathrm{e}-16$ \\
\hline
\end{tabular}

En la Tabla 7-53 se recoge la influencia de cada una de las variables independientes en el modelo. Los valores de t obtenidos para todas las variables están alejados significativamente de 0 y su p-valor es prácticamente nulo $(<2 \mathrm{e}-16)$, por lo que se puede concluir que todas ellas contribuyen de manera determinante a explicar el valor adoptado por la variable dependiente $V_{\text {det }}$. Por su parte, los coeficientes estandarizados $\beta^{\prime}$ permiten determinar que la relación recubrimiento/diámetro $c / \phi$ es el parámetro con una mayor influencia relativa en el valor adoptado por $V_{\operatorname{det}}\left(\beta^{\prime}=-0,9614\right)$, seguido por la tensión inicial de pretensado $\sigma_{p, 0}\left(\beta^{\prime}=0,4174\right)$, por el diámetro del alambre $\phi\left(\beta^{\prime}=-0,1812\right)$ y, por último, la resistencia a compresión del hormigón $\left(\beta^{\prime}=0,07537\right)$. Los coeficientes estandarizados confirman, por tanto, las tendencias encontradas en el Apartado 7.4.9.2.

Tabla 7-53 Coeficientes de regresión parcial estandarizados y no estandarizados. Error estándar. P-valores. Intervalos de confianza.

\begin{tabular}{cccccccc}
\hline & Coef. $\boldsymbol{\beta}$ & Coef. $\boldsymbol{\beta}^{\prime}$ & Error & Valor t & p- & \multicolumn{2}{c}{ Intervalo de conf. 95\% } \\
\cline { 7 - 10 } & No estand. & estandarizados & estándar & & valor( $>|\mathbf{t}|)$ & Cuantil 2,5\% & Cuantil 97,5\% \\
\hline $\log (\mathrm{a} 0)$ & $-4,95469$ & 0 & 0,32577 & $-15,209$ & $<2 \mathrm{e}-16$ & $-5,59900$ & $-4,31038$ \\
\hline $\log (\phi)$ & $-0,28611$ & $-0,1812$ & 0,0306 & $-9,35$ & $2,63 \mathrm{e}-16$ & $-0,34662$ & $-0,22559$ \\
\hline $\log (\mathrm{c} / \phi)$ & $-3,20077$ & $-0,9614$ & 0,06559 & $-48,8$ & $<2 \mathrm{e}-16$ & $-3,33049$ & $-3,07105$ \\
\hline $\log \left(\sigma_{\mathrm{p}, 0}\right)$ & 0,92767 & 0,4174 & 0,04342 & 21,364 & $<2 \mathrm{e}-16$ & 0,84179 & 1,01355 \\
\hline $\log \left(\mathrm{f}_{\mathrm{c}}\right)$ & 0,12131 & 0,07537 & 0,03094 & 3,921 & 0,00014 & 0,06011 & 0,18250 \\
\hline
\end{tabular}

Por último, los coeficientes $\beta$ (no estandarizados) permiten definir la ecuación de regresión para la determinación de $V_{\text {det. }}$ Para ello, se sustituyen dichos coeficientes en la expresión (Eq. 7-33):

$$
\begin{gathered}
\log \left(V_{\text {det }}\right)=\log (-4,95469)-0,28611 \log (\phi)-3,20077 \log \left(\frac{c}{\phi}\right)+0,92767 \log \left(\sigma_{p, 0}\right) \\
+0,12131 \log \left(f_{c}\right)
\end{gathered}
$$

Deshaciendo la transformación logarítmica, se obtiene que la velocidad de deterioro, $V_{\text {det }}$, responde a la siguiente expresión (Eq. 7-30):

$$
V_{\text {det }}=0,007 \frac{\sigma_{p, 0}^{0,92767} f_{c}^{0,12131}}{\phi^{0,28611}(c / \phi)^{3,20077}}
$$

$\mathrm{Al}$ igual que anteriormente, se propone simplificar la expresión anterior para aumentar su manejabilidad. Los nuevos valores para los coeficientes que afectan a las variables se encuentran incluidos dentro de su intervalo de confianza del 95\% (Tabla 7-53) de manera que se obtiene la siguiente expresión (Eq. 7-35) : 


$$
V_{\text {det }}=0,004 \frac{\sigma_{p, 0} \cdot f_{c}^{1 / 9}}{\phi^{1 / 3}(c / \phi)^{3}}
$$

En la Figura 7-61 se comparan los diagramas de realización-predicción para la ecuación obtenida de la regresión (Eq. 7-34) y para su versión simplificada (Eq. 7-35), observándose que los resultados son prácticamente idénticos. Por tanto, puede validarse la simplificación llevada a cabo sobre la expresión para la determinación de la velocidad de deterioro de la longitud de transferencia debida a procesos de corrosión, $V_{\text {det }}$.
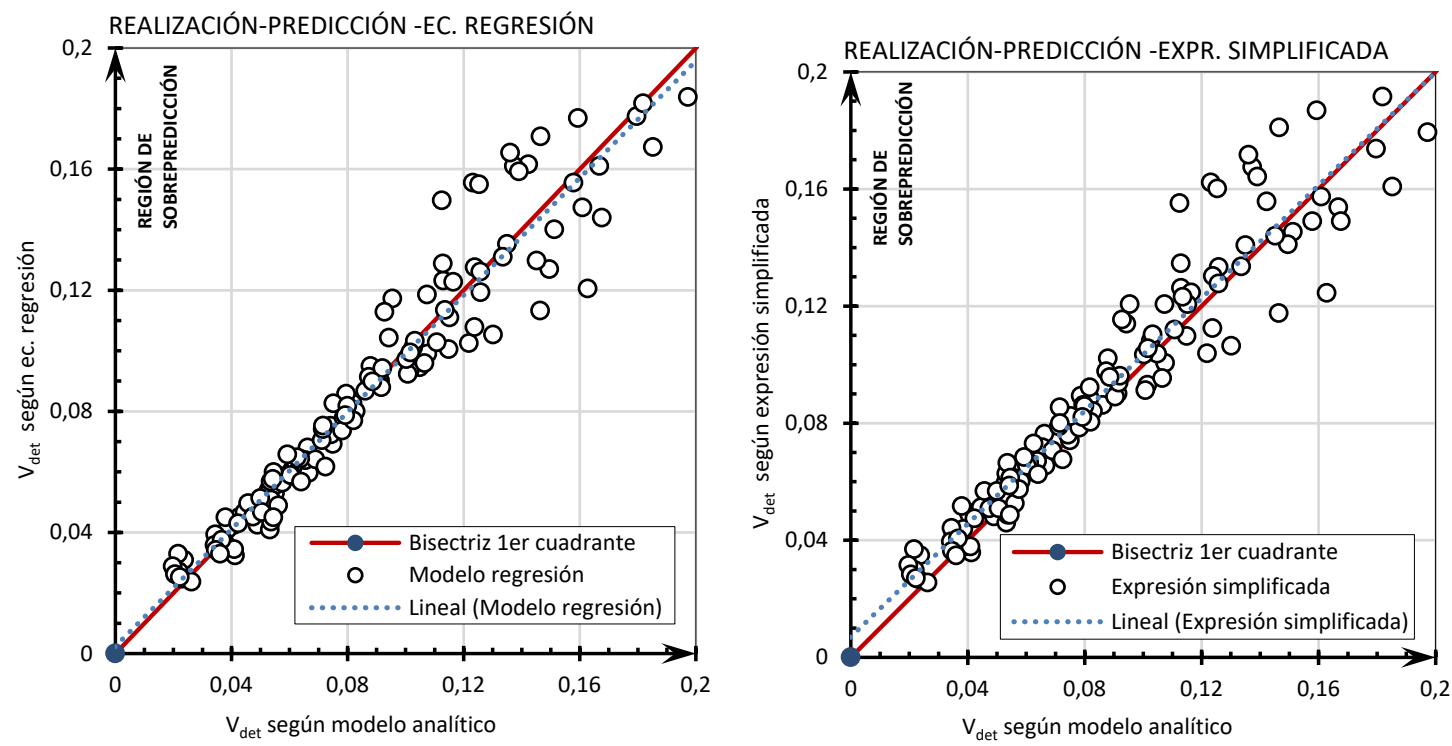

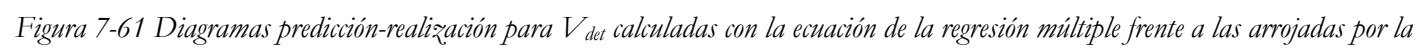
expresión tras su simplificación.

Como puede observarse, la expresión simplificada consigue reproducir con suficiente precisión el modelo de regresión, pero ambas gráficas muestran un aumento significativo de la dispersión para velocidades de deterioro $V_{\text {det }}$ medias y altas, correspondientes con elementos con bajas relaciones recubrimiento/diámetro y/o altas tensiones iniciales de pretensado. Esta imprecisión del modelo deberá ser investigada en futuros estudios.

En la Figura 7-62 se han representado los diagramas predicción-realización de las longitudes de transferencia para alambres corroídos $l_{\text {t,corr }}$ calculadas con la expresión simplificada frente a las arrojadas por el modelo analítico, para un $5 \%$, un $10 \%$, un $15 \%$ y un $20 \%$ de pérdida de sección por corrosión. Para todos los niveles de corrosión representados, el ajuste entre los resultados analíticos y los procedentes de las expresiones simplificadas es destacable. Estos buenos resultados indican únicamente que las expresiones simplificadas propuestas son capaces de reproducir con fiabilidad el funcionamiento del modelo analítico desarrollado en esta tesis, contemplando todas las variables determinantes en el proceso, y otorgándolas un grado de influencia adecuado. Sin embargo, al no existir campañas experimentales extensas que estudien la influencia de la corrosión en la longitud de transferencia, la expresión simplificada no puede darse por totalmente validada, siendo necesarios estudios posteriores que demuestren su capacidad de predicción. Por tanto, las expresiones 
propuestas pueden considerarse un buen punto de partida para el desarrollo de una expresión que permita la evaluación de longitudes de transferencia en elementos pretensados corroídos.
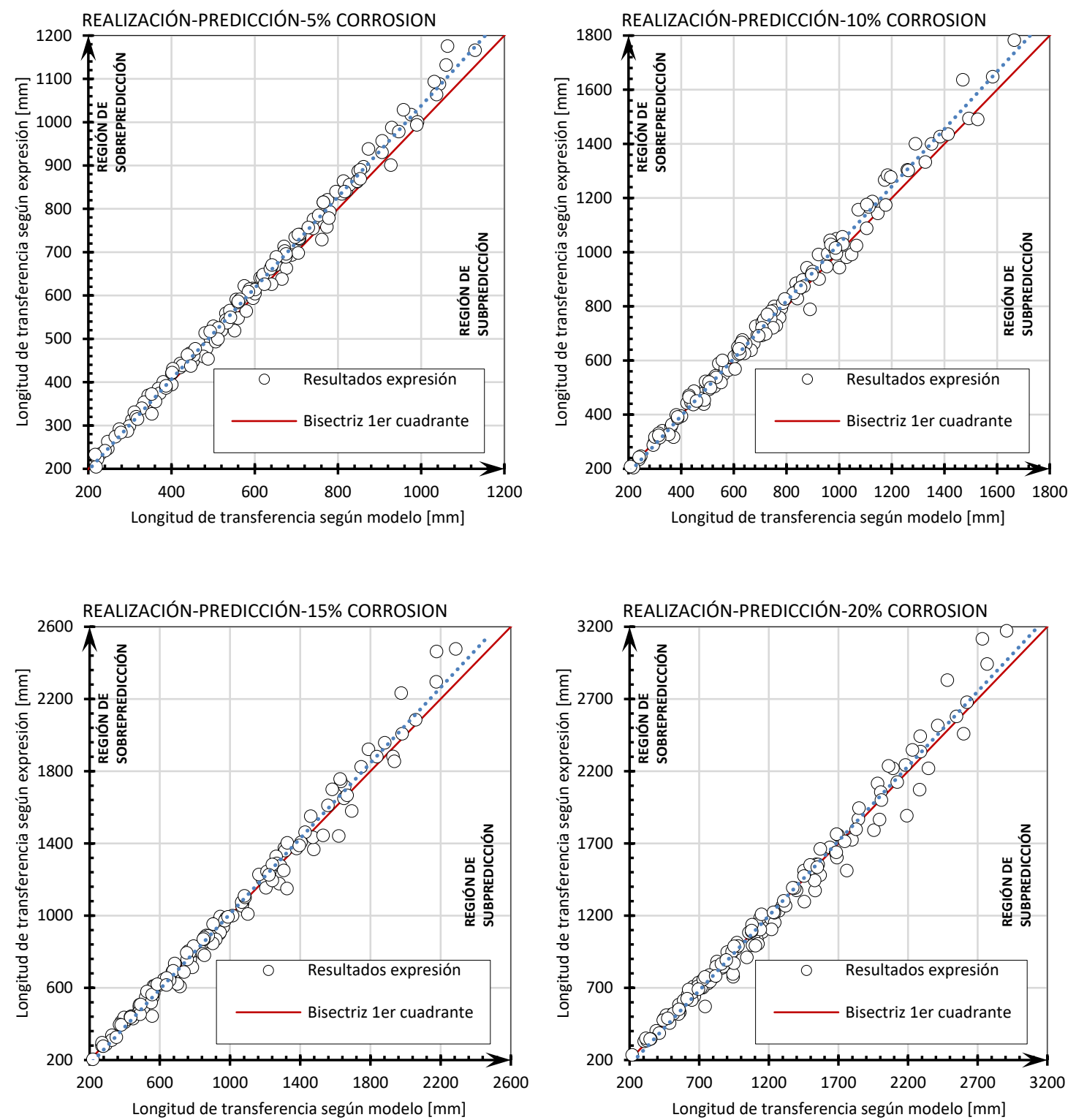

Figura 7-62 Diagramas predicción-realización para las longitudes de transferencia en alambres corroídos calculadas con la expresión simplificada frente a las arrojadas por el modelo analítico., para varios niveles de pérdida de sección por corrosión

\subsubsection{Comparación con campañas experimentales de otros investigadores}

En este apartado se comprueba la capacidad de predicción de la expresión simplificada propuesta a través de su comparación con los resultados experimentales en ensayos para la determinación de longitudes de transferencia en elementos pretensados sin corrosión, recogidos de la bibliografía consultada. No se han encontrado datos fiables relativos a la longitud de transferencia en alambres indentados, por lo que la verificación se ha llevado a cabo con datos obtenidos de ensayos sobre 
cordones de pretensado. Para ello se han recopilado los resultados obtenidos en dos de las campañas experimentales más completas, por número de probetas y por variables contempladas, y más recurrentes en la bibliografía, las llevadas a cabo por Mitchell et al. (1993) y por Oh \& Kim (2000). La primera consistió en 22 vigas pretensadas, fabricadas con cordones de 9.5 (3/8”), 12.7 (1/2”) y 15.7 (0.62") $\mathrm{mm}$ de diámetro, con resistencias a compresión del hormigón en el momento del destesado que oscilaron entre 21 y $50 \mathrm{MPa}$, con recubrimientos mecánicos entre 50 y $100 \mathrm{~mm}$ y con tensiones de pretensado entre 871 y $1374 \mathrm{MPa}$. La segunda constaba de 36 vigas pretensadas de 3000 $\mathrm{mm}$ de longitud, 24 de ellas tesadas con un solo cordón y el resto con dos cordones. En esta comparación se han tomado las 24 primeras, compuestas por 12 series de dos vigas, en las que se utilizaron 2 diámetros de cordones $\phi(12.7$ y $15.2 \mathrm{~mm}), 2$ resistencias del hormigón $f_{c}$ (35 y $45 \mathrm{MPa}$ ) y 3 recubrimientos geométricos (c- $\phi / 2)$ distintos $(20,30$ y $50 \mathrm{~mm})$.

En ambas campañas experimentales la sección transversal de las vigas era rectangular, con el cordón desplazado hacia la parte inferior de las mismas, por lo que no estaban cargadas concéntricamente y existía una cierta excentricidad. La expresión simplificada se ha utilizado despreciando los efectos de dicha excentricidad y considerando que el recubrimiento mecánico es equivalente al menor existente en las vigas.

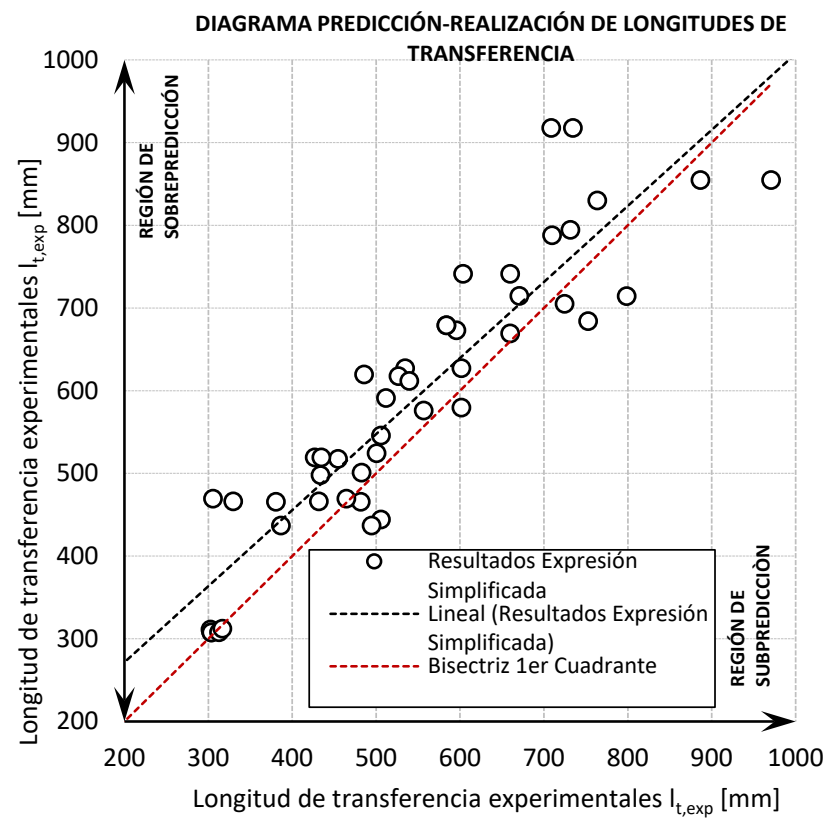

Figura 7-63 Diagramas predicción-realización para las longitudes de transferencia obtenidas de los ensayos recogidos de la bibliografía frente a las arrojadas por la expresión simplificada.

En la Tabla 7-54 se resumen los principales parámetros mecánicos y geométricos que definen las campañas de ensayos analizadas y se comparan las longitudes de transferencia obtenidas en los ensayos, $l_{t, e x p}$, con las determinadas por la expresión simplificada propuesta, $l_{t, c a l}$. Por otro lado, en la Figura 7-63 se incluye el diagrama predicción- realización para las longitudes de transferencia calculadas mediante la expresión simplificada frente a los resultados experimentales de las campañas seleccionadas. 
Tabla 7-54 Parámetros geométricos y mecánicos de las campañas experimentales de referencia [Mitchell et al. (1993) y Ob \& Kim (2000)]. Comparación entre resultados experimentales y resultados obtenidos mediante la expresión simplificada.

\begin{tabular}{|c|c|c|c|c|c|c|c|c|}
\hline $\begin{array}{c}\text { Denominació } \\
\mathrm{n}\end{array}$ & $\begin{array}{c}\mathrm{f}_{\mathrm{cm}} \\
{[\mathrm{MPa}]}\end{array}$ & $\begin{array}{c}\mathrm{f}_{\mathrm{ct}, \mathrm{m}} \\
{[\mathrm{MPa}]}\end{array}$ & $\begin{array}{c}\Phi \\
{[\mathrm{mm}]}\end{array}$ & $\begin{array}{c}\mathrm{c} \\
{[\mathrm{mm}]}\end{array}$ & $\begin{array}{c}\sigma_{\mathrm{p}, 0} \\
{[\mathrm{MPa}]}\end{array}$ & $\begin{array}{c}l_{t, \exp } \\
{[\mathrm{mm}]}\end{array}$ & $\begin{array}{c}l_{t, \mathrm{cal}} \\
{[\mathrm{mm}]}\end{array}$ & $\begin{array}{c}\Delta \\
{[\%]}\end{array}$ \\
\hline \multicolumn{9}{|c|}{ Mitchell et al. (1993) } \\
\hline $9.5 / 31-1200$ & 21.0 & 2.51 & 9.5 & 50.0 & 1219.0 & 506.0 & 545,6 & 7,8 \\
\hline $9.5 / 43-1350$ & 27.0 & 2.97 & 9.5 & 50.0 & 1240.0 & 482.0 & 465,4 & $-3,5$ \\
\hline $9.5 / 43-1350$ & 27.0 & 2.97 & 9.5 & 50.0 & 1240.0 & 381.0 & 465,4 & 22,1 \\
\hline $9.5 / 65-800$ & 48.0 & 4.36 & 9.5 & 50.0 & 1192.0 & 303.0 & 310,9 & 2,6 \\
\hline $9.5 / 75-950$ & 50.0 & 4.48 & 9.5 & 50.0 & 1230.0 & 304.0 & 307,3 & 1,1 \\
\hline $9.5 / 75-700$ & 50.0 & 4.48 & 9.5 & 50.0 & 1230.0 & 304.0 & 307,3 & 1,1 \\
\hline $9.5 / 89-825$ & 50.0 & 4.48 & 9.5 & 50.0 & 1234.0 & 313.0 & 307,8 & $-1,6$ \\
\hline $9.5 / 89-575$ & 50.0 & 4.48 & 9.5 & 50.0 & 1267.0 & 317.0 & 311,9 & $-1,6$ \\
\hline $13 / 31-1200$ & 21.0 & 2.51 & 12.7 & 63.5 & 1374.0 & 710.0 & 787,7 & 10,9 \\
\hline $13 / 43-1600$ & 27.0 & 2.97 & 12.7 & 50.0 & 1217.0 & 584.0 & 678,9 & 16,3 \\
\hline $13 / 43-1250$ & 27.0 & 2.97 & 12.7 & 50.0 & 1217.0 & 584.0 & 678,9 & 16,3 \\
\hline $13 / 65-850$ & 48.0 & 4.36 & 12.7 & 63.5 & 1315.0 & 506.0 & 444,1 & $-12,2$ \\
\hline $13 / 75-1100$ & 50.0 & 4.48 & 12.7 & 50.0 & 1303.0 & 432.0 & 465,9 & 7,8 \\
\hline $13 / 75-950$ & 50.0 & 4.48 & 12.7 & 50.0 & 1303.0 & 330.0 & 465,9 & 41,2 \\
\hline $13 / 89-950$ & 50.0 & 4.48 & 12.7 & 62.5 & 1329.0 & 387.0 & 436,8 & 12,9 \\
\hline $13 / 89-650$ & 50.0 & 4.48 & 12.7 & 62.5 & 1329.0 & 495.0 & 436,8 & $-11,8$ \\
\hline $16 / 31-1865$ & 21.0 & 2.51 & 15.7 & 78.5 & 1220.0 & 735.0 & 917,5 & 24,8 \\
\hline $16 / 31-1500$ & 21.0 & 2.51 & 15.7 & 78.5 & 1220.0 & 709.0 & 917,5 & 29,4 \\
\hline $16 / 65-1150$ & 48.0 & 4.36 & 15.7 & 78.5 & 1176.0 & 427.0 & 519,2 & 21,6 \\
\hline $16 / 65-725$ & 48.0 & 4.36 & 15.7 & 78.5 & 1176.0 & 435.0 & 519,2 & 19,3 \\
\hline $16 / 31-975$ & 50.0 & 4.48 & 15.7 & 62.5 & 871.0 & 306.0 & 469,1 & 53,3 \\
\hline $16 / 31-675$ & 50.0 & 4.48 & 15.7 & 62.5 & 871.0 & 465.0 & 469,1 & 0,9 \\
\hline \multicolumn{9}{|c|}{ Oh \& Kim (2000) } \\
\hline M12-N-C3-1 & 34.7 & 3.51 & 12.7 & 36.4 & 1395.0 & 753.0 & 683,9 & $-9,2$ \\
\hline M12-N-C3-2 & 32.5 & 3.36 & 12.7 & 36.4 & 1395.0 & 671.0 & 714,4 & 6,5 \\
\hline M12-N-C4-1 & 35.0 & 3.53 & 12.7 & 46.4 & 1395.0 & 535.0 & 627,1 & 17,2 \\
\hline M12-N-C4-2 & 35.0 & 3.53 & 12.7 & 46.4 & 1395.0 & 602.0 & 627,1 & 4,2 \\
\hline M12-N-C5-1 & 34.7 & 3.51 & 12.7 & 56.4 & 1395.0 & 512.0 & 590,9 & 15,4 \\
\hline M12-N-C5-2 & 32.5 & 3.36 & 12.7 & 56.4 & 1395.0 & 527.0 & 617,3 & 17,1 \\
\hline M12-H-C3-1 & 44.9 & 4.17 & 12.7 & 36.4 & 1395.0 & 557.0 & 575,9 & 3,4 \\
\hline M12-H-C3-2 & 44.5 & 4.14 & 12.7 & 36.4 & 1395.0 & 602.0 & 579,4 & $-3,8$ \\
\hline M12-H-C4-1 & 46.7 & 4.28 & 12.7 & 46.4 & 1395.0 & 455.0 & 517,4 & 13,7 \\
\hline M12-H-C4-2 & 45.8 & 4.22 & 12.7 & 46.4 & 1395.0 & 501.0 & 524,1 & 4,6 \\
\hline M12-H-C5-1 & 44.9 & 4.17 & 12.7 & 56.4 & 1395.0 & 434.0 & 497,6 & 14,7 \\
\hline M12-H-C5-2 & 44.5 & 4.14 & 12.7 & 56.4 & 1395.0 & 483.0 & 500,6 & 3,6 \\
\hline M15-N-C3-1 & 35.0 & 3.53 & 15.2 & 37.6 & 1395.0 & 971.0 & 854,4 & $-12,0$ \\
\hline M15-N-C3-2 & 35.0 & 3.53 & 15.2 & 37.6 & 1395.0 & 887.0 & 854,4 & $-3,7$ \\
\hline M15-N-C4-1 & 34.7 & 3.51 & 15.2 & 47.6 & 1395.0 & 732.0 & 794,3 & 8,5 \\
\hline M15-N-C4-2 & 32.5 & 3.36 & 15.2 & 47.6 & 1395.0 & 764.0 & 829,8 & 8,6 \\
\hline M15-N-C5-1 & 35.0 & 3.53 & 15.2 & 57.6 & 1395.0 & 660.0 & 741,1 & 12,3 \\
\hline M15-N-C5-2 & 35.0 & 3.53 & 15.2 & 57.6 & 1395.0 & 604.0 & 741,1 & 22,7 \\
\hline M15-H-C3-1 & 46.7 & 4.28 & 15.2 & 37.6 & 1395.0 & 725.0 & 704,9 & $-2,8$ \\
\hline M15-H-C3-2 & 45.8 & 4.22 & 15.2 & 37.6 & 1395.0 & 799.0 & 714,1 & $-10,6$ \\
\hline M15-H-C4-1 & 44.9 & 4.17 & 15.2 & 47.6 & 1395.0 & 660.0 & 668,9 & 1,4 \\
\hline M15-H-C4-2 & 44.5 & 4.14 & 15.2 & 47.6 & 1395.0 & 596.0 & 673,0 & 12,9 \\
\hline M15-H-C5-1 & 46.7 & 4.28 & 15.2 & 57.6 & 1395.0 & 540.0 & 611,5 & 13,2 \\
\hline M15-H-C5-2 & 45.8 & 4.22 & 15.2 & 57.6 & 1395.0 & 486.0 & 619,5 & 27,5 \\
\hline
\end{tabular}


El diagrama de realización predicción muestra un excelente ajuste entre los resultados experimentales y los calculados mediante la expresión, de manera que la regresión lineal prácticamente se superpone a la bisectriz del primer cuadrante. Este excelente ajuste, aunque aporta buenas señales, debe tomarse como circunstancial, ya que hay que tener en cuenta que se está utilizando expresión simplificada procedente de una calibración de resultados analíticos sobre alambres indentados, no sobre cordones de pretensado. Todos los códigos estructurales consultados diferencian entre la tensión de adherencia de cálculo que es capaz de desarrollar un alambre indentado frente a la desarrollada por un cordón. Esta diferencia varía entre códigos, de manera que la tensión de adherencia en alambres indentados es un $16.7 \%$ mayor en el Código Modelo y alrededor de un 15\% en la EHE- 08 , mientras que en el Eurocódigo-2 la diferencia es a favor de la tensión de adherencia en cordones de 3 ó 7 alambres, cuantificada en un 18,5\%. Sin embargo, a pesar de esta salvedad, lo que sí es realmente relevante es que la pendiente de la recta de ajuste de los resultados sea prácticamente de $45^{\circ}$, igual que la de la bisectriz, lo que permite deducir que se están reproduciendo adecuadamente todas las tendencias presentes en el fenómeno. El amplio rango de valores tanto de las variables utilizadas en los ensayos como de las longitudes de transferencia observadas permite concluir que la expresión simplificada propuesta no sólo está teniendo en cuenta todos los factores determinantes en el fenómeno, sino que también está cuantificando adecuadamente el peso o influencia de cada uno en el mismo.

A pesar del buen ajuste encontrado, es evidente que la formulación simplificada propuesta tiende a sobreestimar la longitud de transferencia. Esta desviación es más significativa cuanto menor es la longitud de transferencia experimental $l_{\text {texp }}$, coincidiendo con aquellos ensayos en los que la tensión inicial de pretensado $\sigma_{p, 0}$ es baja, y/o la capacidad de confinamiento del recubrimiento es alta (confluencia de relaciones recubrimiento/diámetro elevadas con altas resistencias a compresión del hormigón). Aunque las desviaciones son asumibles, sobre todo teniendo en cuenta que el pretensado es un fenómeno complejo en el que intervienen numerosos factores, merecen ser estudiadas en profundidad en investigaciones futuras por si aportaran pistas para mejorar la capacidad de predicción del modelo analítico desarrollado.

\subsubsection{Comparación con códigos estructurales existentes}

A continuación se comparan los resultados experimentales de las campañas de ensayos seleccionadas con las longitudes de transferencia que predicen algunos de los códigos estructurales cuyo uso está más extendido (Ver Capitulo 2): Código Modelo 2010 (FIB Special Activity Group 5, 2011), Eurocódigo 2 (CEN, 2004), ACI-318 (ACI Comittee 318, 2002) y EHE-08 (Fomento, 2008). En todos los casos se ha considerado que los cordones de pretensado se encuentran en posición favorable para la adherencia y que la puesta en carga ha sido gradual. Por otro lado, para que los resultados fueran comparables con los obtenidos tanto mediante los experimentos como mediante la expresión simplificada, se ha utilizado el valor medio de la resistencia a tracción $f_{c t, m}$, en lugar del valor de cálculo $f_{c t, m}$ que aparece en las expresiones. En el caso de la EHE-08, los valores de tensión de adherencia de cálculo $f_{b p d}$ que aparecen en la Tabla 70.2.3 de la Instrucción se han mayorado por el coeficiente de seguridad del material. El coeficiente de seguridad utilizado ha sido $r_{c}=1,40$, el indicado por la Instrucción para elementos prefabricados de hormigón sin Distintivo Oficialmente Reconocido. En cuanto a la tensión de pretensado, todas las expresiones utilizan el valor inicial, $\sigma_{p, 0}$, excepto el Código ACI 318 que utiliza el valor de ésta tras las pérdidas. Para este caso, se ha supuesto un $15 \%$ de pérdidas de pretensado con respecto al valor inicial. 
En la Figura 7-64 se incluyen los diagramas predicción-realización para las longitudes de transferencia recogidas de los ensayos consultados en la bibliografía frente a las arrojadas por las expresiones de los diferentes códigos analizados y la desarrollada en esta tesis. En la Tabla 7-55 se recogen la ecuación de la recta de regresión lineal, el coeficiente de determinación $R^{2}$, la desviación estándar y coeficiente de variación de los resultados arrojados por las expresiones de los códigos analizados y de la expresión simplificada propuesta.

Tabla 7-55 Ecuación de la recta de regresión lineal, coeficiente de determinación, desviación estándar y coeficiente de variación de los resultados arrojados por las expresiones de los códigos analizados

\begin{tabular}{ccccc}
\hline & Ajuste lineal & $\mathbf{R}^{\mathbf{2}}$ & Desv. Estándar [mm] & CoV \\
\hline Código Modelo 2010 & $\mathrm{y}=0,500 \mathrm{x}+96,172$ & 0,6801 & 201,5 & 31.1 \\
\hline Eurocódigo 2_EN 1992-1-1:2004 & $\mathrm{y}=0,375 \mathrm{x}+72,129$ & 0,6801 & 289,7 & 307,0 \\
\hline EHE-08 & $\mathrm{y}=1,1194 \mathrm{x}+215,3$ & 0,6801 & 191,0 & 34.3 \\
\hline ACI-318 & $\mathrm{y}=0,5878 \mathrm{x}+379,31$ & 0,5226 & 81,6 \\
\hline Modelo propuesto (Tesis) & $\mathrm{y}=0,9197 \mathrm{x}+87,704$ & 0,8278 & 12,4 \\
\hline
\end{tabular}

En primer lugar, sorprende la gran heterogeneidad de resultados obtenidos. Mientras que el ajuste lineal de los resultados obtenidos a través de las expresiones del Código Modelo 2010 y del Eurocódigo 2 se sitúa claramente en la zona de subpredicción, los ajustes derivados del Código ACI318 y de la EHE-08 sobreestiman los resultados, situándose en la zona de sobrepredicción.

Los resultados obtenidos mediante el Códico ACI-318 son el reflejo del tipo de expresión utilizada por el mismo. Como se vio en el Capitulo 2, la formulación propuesta por el código estadounidense depende únicamente del diámetro del alambre $\phi$ y de la tensión de pretensado inicial $\sigma_{p, 0}$. Dicha expresión es el resultado de ajustes empíricos sobre una campaña experimental llevada a cabo en los últimos años de la década de los 50 y los primeros de la década de los 60, y es fruto de considerar un valor constante de la tensión de adherencia igual a 2,76 $\mathrm{MPa}$ : al aplicar equilibrio con dicho valor, particularizando a cordones de $1720 \mathrm{MPa}$, se llega a la Ecuación que aparece en el Código. Como resultado de este hecho, cualquier elemento con características geométricas o mecánicas que se alejen de las condiciones de las que se derivó la ecuación recogida en ACI-318 presentará longitudes de transferencia alejadas de las predecidas. El hecho de obviar variables que se han demostrado influyentes a lo largo de esta tesis, tales como la relación recubrimiento/diámetro y la resistencia a tracción del hormigón, queda reflejado en la baja correlación existente $\left(\mathrm{R}^{2}=0.52\right)$ entre las longitudes de transferencia medidas y las calculadas.

El Código Modelo 2010, el Eurocódigo 2 y la EHE-08 utilizan, con pequeñas diferencias (Ver Capitulo 2), un mismo método para la determinación de las longitudes de transferencia, contemplando las mismas variables y con un mismo grado de influencia en el resultado final. Los tres códigos tienen en cuenta la tensión de pretensado inicial $\sigma_{p, 0}$, el diámetro del alambre $\phi$ y la resistencia a tracción del hormigón $f_{c \text {, }}$ pero dejan de lado la relación recubrimiento/diámetro c/ $\phi$. Por ello, el coeficiente de determinación $\mathrm{R}^{2}$ de los ajustes lineales procedentes de los resultados arrojados por cada uno de estos códigos es identico $\left(\mathrm{R}^{2}=068\right)$. Las diferencias existentes entre los mismos proceden del valor que se le otorga a la tensión de adherencia de cálculo a lo largo de la longitud de transferencia $\left(f_{b p d}\right.$ en la notación de los códigos; $\tau_{b, \text { med }}$ en la notación de esta tesis). Mientras que la EHE-08 propone valores bajos, recogidos en la Tabla 70.2.3 de la Instrucción, el Código Modelo y el Eurocódigo 2 
DIAGRAMA PREDICCIÓN-REALIZACIÓN. LONGITUDES DE TRANSFERENCIA EN DIFERENTES CÓDIGOS

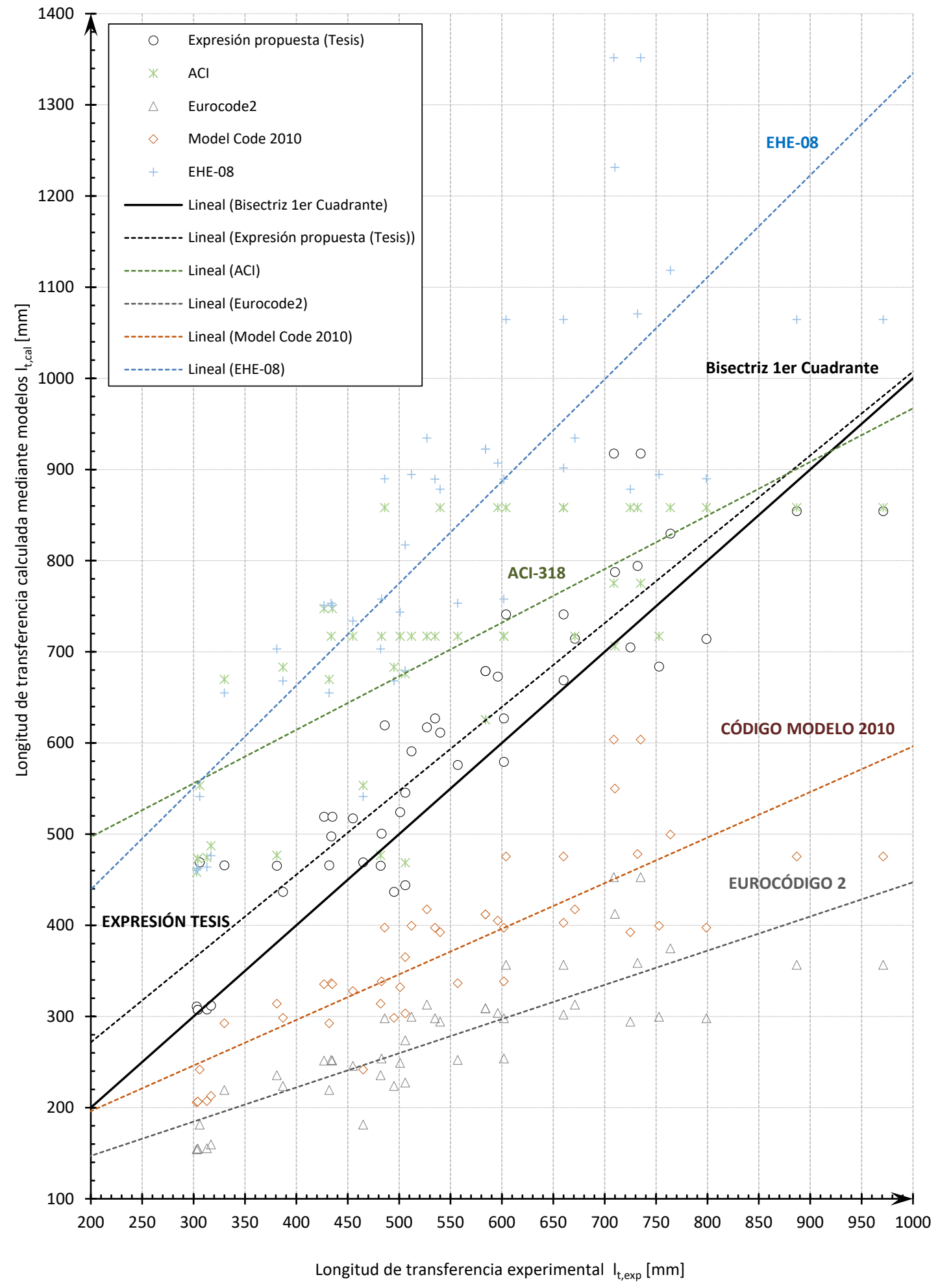

Figura 7-64 Diagramas predicción-realización para las longitudes de transferencia obtenidas de los ensayos recogidos de la bibliografia frente a las arrojadas por las expresiones de los diferentes códigos analizados y la desarrollada en esta tesis. 
(especialmente este último) proponen valores muy altos. Como resultado de este hecho, la Instrucción Española predice valores siempre del lado de la seguridad, pero excesivamente conservadores, mientras que el Código Modelo y el Eurocódigo 2 se sitúan claramente del lado de la inseguridad.

Por último, la expresión propuesta en esta tesis contempla todas las variables que influyen de manera determinante en la transferencia del pretensado, a saber: tensión de pretensado inicial $\sigma_{p, 0}$, diámetro del alambre $\phi$, resistencia a tracción del hormigón $f_{c t}$ y relación recubrimiento/diámetro $\mathrm{c} / \phi$. Esto permite obtener muy buena correlación entre las longitudes de transferencia medidas en los ensayos y las calculadas mediante la expresión simplificada $\left(\mathrm{R}^{2}=0,83\right)$. La bondad de la expresión propuesta queda refrendada con el hecho de que la pendiente del ajuste lineal de la muestra sea próxima a 1 $(0,92)$, con que la desviación estándar sea de aproximadamente $81,6 \mathrm{~mm}$ y con que el coeficiente de variación $\mathrm{CoV}$ tenga un valor reducido $(\mathrm{CoV}=12,4)$, especialmente si se compara con los obtenidos para el resto de las expresiones. $\mathrm{Si}$ a estos factores estadísticos se les suma que la expresión propuesta es de fácil utilización, que requiere datos siempre disponibles durante el desarrollo del proyecto y que, además, es respetuosa con la metodología seguida por los códigos, matizando únicamente el valor de la tensión de adherencia media a lo largo de la longitud de transferencia, se puede concluir que es una alternativa recomendable a las recogidas actualmente por los Códigos estructurales cuyo uso está más extendido. 


\section{CAPÍTULO 8}

\section{Conclusiones, Contribuciones y Líneas Futuras de Investigación}

\subsection{Conclusiones}

\subsubsection{Conclusiones generales}

En esta tesis se han investigado los procesos de degradación de la adherencia motivados por la corrosión en alambres lisos e indentados y se ha analizado su influencia en el comportamiento de elementos pretensados de hormigón. Para ello, se ha desarrollado un modelo analítico cuyas variables han sido calibradas mediante ensayos de arrancamiento sobre alambres no tesados y cuyos resultados teóricos han sido verificados gracias a su comparación con los datos extraídos de una campaña experimental sobre elementos pretensados tipo viga.

El modelo validado ha permitido estudiar la influencia que tienen en el comportamiento adherente las principales variables geométricas y mecánicas que intervienen en el pretensado, lo que a su vez ha posibilitado el desarrollo de expresiones simplificadas para el cálculo de longitudes de transferencia en elementos pretensados de hormigón tanto con alambres sanos como corroídos. Los resultados arrojados por la expresión propuesta para alambres sanos han sido comparados con los obtenidos en campañas experimentales de otros autores, mostrando una mejor capacidad predictiva que las expresiones recogidas en los códigos estructurales cuyo uso está más extendido.

La metodología seguida, que puede calificarse como teórico-experimental y consistente en varias etapas diferenciadas, se ha mostrado como un procedimiento eficaz para identificar, analizar y cuantificar las principales variables mecánicas y geométricas que intervienen en el fenómeno de la corrosión en elementos pretensados. Las etapas de las que ha constado esta investigación son las siguientes:

- Desarrollo de un modelo analítico bidimensional para la determinación de las tensiones radiales a nivel de sección derivadas de los procesos de corrosión en estructuras de hormigón armado;

- Realización de campaña de ensayos de arrancamiento para la calibración de los parámetros que definen la expansión de los productos de corrosión y las propiedades adherentes entre el hormigón y el acero;

- Extensión del modelo a la dirección longitudinal del elemento (tres dimensiones) para la determinación de las leyes que rigen la relación entre adherencia y deslizamiento, en alambres sanos y corroídos, mediante su comparación con la campaña experimental anterior. 
- Elaboración de un modelo analítico integral para la determinación de la longitud de transferencia en estructuras pretensadas sanas y corroídas, acoplando los efectos del pretensado al modelo analítico tridimensional sobre elementos de hormigón armado con corrosión.

- Verificación del modelo integral mediante su comparación con ensayos sobre elementos pretensados con procesos de degradación por corrosión.

- Desarrollo de expresiones simplificadas, basadas en el modelo analítico verificado, para el cálculo de longitudes de transferencia en elementos pretensados de hormigón tanto con alambres sanos como corroídos, comparando los resultados obtenidos con campañas experimentales de otros investigadores y con los códigos estructurales cuyo uso está más extendido.

\subsubsection{Conclusiones relativas al modelo analítico para la determinación de tensiones radiales en secciones de hormigón armado con procesos de corrosión}

- El modelo analítico, bidimensional y anisótropo, desarrollado en esta tesis para la determinación de las tensiones radiales derivadas de los procesos de corrosión en estructuras de hormigón armado, basado en la teoría de cilindros huecos de pared gruesa y en un modelo de fisuración cohesiva para el hormigón, ha demostrado ser una herramienta eficaz para predecir y evaluar el estado tensional en secciones de hormigón sometidas a este fenómeno de degradación.

- El modelo, junto con los ensayos de arrancamiento, ha permitido concluir que la tensión de adherencia $\tau_{b}$, la ley de tensión de adherencia -deslizamiento $\tau_{b}$-s y los diferentes modos de fallo adherente, así como su evolución debida a la corrosión, dependen de la interacción de dos factores fundamentales:

- La capacidad de confinamiento del recubrimiento de hormigón: Factor dependiente de valores geométricos (espesor de recubrimiento $c$ ) y mecánicos (resistencias a compresión $f_{c}$ y tracción del hormigón $f_{c t}$ módulo de elasticidad $E$, etc).

- La capacidad del sistema acero-hormigón para movilizar la acción confinante del recubrimiento: el hormigón confina el alambre de acero únicamente si existe una tensión de compresión radial $\sigma_{r}$ alrededor del alambre, que puede venir ocasionada por distintas razones, entre las que se encuentran la expansión de los productos de corrosión, el efecto Hoyer (en el caso de elementos pretensados), la retracción asociada a la pérdida de humedad del hormigón o el deslizamiento de las indentaciones o corrugas del alambre.

- Se ha concluido que el incremento de volumen de los óxidos siempre aumenta las solicitaciones en el recubrimiento, de manera que, si éste es capaz de soportar dichos esfuerzos, la tensión de adherencia $\tau_{b}$ aumenta, mientras que, si las tensiones radiales $\sigma_{r} \mathrm{y}$ 
circunferenciales $\sigma_{\theta}$ generadas conducen a la fisuración y agotamiento del hormigón, la tensión de adherencia $\tau_{b}$ disminuye.

- Se ha constatado que, en alambres sanos, la influencia del espesor de recubrimiento $c$ y resistencia a compresión del hormigón $f_{c}$ no es significativa, y solo es apreciable cuando se superan las etapas tempranas del proceso de corrosión, al incrementar su capacidad para movilizar el confinamiento del recubrimiento.

- Se ha comprobado que el aumento de la resistencia a compresión del hormigón tiene una influencia decisiva en el crecimiento de las tensiones radiales máximas alcanzadas, al mejorarse la capacidad de confinamiento del recubrimiento. Sin embargo, su influencia en la aparición de la fisuración superficial y en su posterior apertura es muy limitada. Se ha determinado que el aumento de resistencia a compresión $f_{c}$ es aproximadamente proporcional al incremento de la máxima tensión radial que puede desarrollarse en la sección $f_{c}^{5 / 6} \propto$ $\left.\sigma_{r, \max }\right)$, sin que se observe ninguna tendencia a que esta influencia se atenúe con el aumento de la resistencia del hormigón.

- Se ha comprobado que el aumento del espesor de recubrimiento $c$ supone una clara mejora en el comportamiento adherente, tanto en la aparición y evolución de las fisuras como en las máximas tensiones de adherencia alcanzadas. En este último caso, la capacidad adherente mejora hasta alcanzarse una relación recubrimiento/diámetro límite a partir de la cual cualquier incremento de espesor de recubrimiento no se traduce en un aumento de la adherencia.

\subsubsection{Conclusiones relativas a los ensayos de arrancamiento}

- Se ha constatado que los ensayos de arrancamiento, siguiendo la Norma UNE-EN 10080:2006, son adecuados para medir el máximo valor de la tensión de adherencia media $\tau_{b, \text { med }}^{\max }$, para determinar los parámetros que definen la ley de tensión de adherencia mediadeslizamiento $\tau_{b, \text { med }}-s$ y para definir el modo de fallo adherente de cada una de las probetas ensayadas.

- Las principales conclusiones relativas a la máxima tensión de adherencia $\tau_{b \text {,max }}$, extraídas de los resultados obtenidos de los ensayos de arrancamiento, son las siguientes:

- Se ha observado que, para alambres lisos e indentados sanos, o con niveles de corrosión muy bajos $(\approx<1 \%)$, el parámetro controlante de la tensión máxima de adherencia alcanzada $\tau_{\text {b, max }}$ es el acabado superficial del acero, con cierta independencia de la relación recubrimiento/diámetro $\phi / c$ y de la resistencia a compresión del hormigón, puesto que la capacidad de confinamiento no llega a movilizarse por completo.

- Se ha constatado que, en ausencia de corrosión, el máximo valor de la tensión de adherencia en alambres indentados es entre un 200-300\% superior al de los 
alambres lisos, en todos los espesores de recubrimiento analizados, gracias al engranamiento mecánico entre las indentaciones y el hormigón.

- Se ha determinado que, con el paulatino aumento de la corrosión, y la consiguiente aparición de tensiones radiales de importancia, el parámetro controlante pasa a ser la relación recubrimiento/diámetro $\phi / c$ y su capacidad de confinamiento asociada, observándose tensiones de adherencia significativamente superiores en las probetas con mayor relación $c / \phi$, independientemente del acabado superficial del acero.

- Se ha observado que la mayor tensión de adherencia $\tau_{b, \max }$ se alcanza para valores de pérdida de sección de un 2-3\% en las probetas con relación $c / \phi=4$, y de un 5-6\% en las probetas con relación $\mathrm{c} / \phi=10$, independientemente del acabado superficial del acero.

- Una vez superada la tensión máxima de adherencia $\tau_{b \text {,max }}$, el aumento de los niveles de corrosión conlleva, en todos los casos contemplados, un descenso lento y continuado de la capacidad adherente. Esta disminución es más acusada en el caso de las probetas con mayor espesor de recubrimiento, pero no se observan grandes diferencias de comportamiento entre los distintos acabados superficiales del acero.

- Las principales conclusiones relativas a la ley de tensión de adherencia media-deslizamiento $\tau_{\text {b,met }}-\mathrm{s}$ y al modo de fallo adherente de cada una de las probetas ensayadas, extraídas de los resultados obtenidos de los ensayos de arrancamiento, son las siguientes:

- Se ha observado que, en alambres lisos e indentados, el aumento de volumen de los productos de corrosión aumenta la tensión de adherencia en el arranque del deslizamiento $\tau_{b, 0}$. Debido a la mayor tensión radial inicial $\sigma_{r, 0}$, y hasta que la capacidad de confinamiento del recubrimiento se agota, se incrementa la tensión

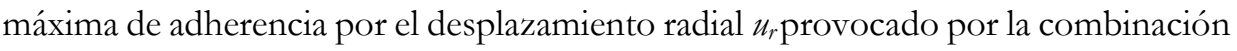
de los efectos de la corrosión y del deslizamiento de las indentaciones (en su caso).

- Se ha determinado que, independientemente del acabado superficial del alambre, el aumento de la corrosión provoca una reducción de los deslizamientos $s_{1}$, al final de la rama elástica, y $s_{2}$, al final de la rama plástica, así como una paulatina tendencia a confluir, de manera que, para niveles altos de corrosión, ambos deslizamientos se tornan prácticamente coincidentes.

- Se ha constatado que la corrosión modifica el modo de fallo adherente. Mientras que en los ensayos con alambres sanos la totalidad de las probetas fallaron por pullout, en alambres con procesos de corrosión se aprecia una clara tendencia a que el fallo frágil sea más recurrente cuanto mayor sea el deterioro. En cualquier caso, en la mayor parte de los ensayos no se identifica un modo de fallo adherente "puro", por pull-out o por splitting, sino un híbrido que se suele denominar pull-out inducido por fisuración previa. 


\subsubsection{Conclusiones relativas a la calibración de parámetros del modelo analítico}

- Se ha desarrollado una metodología para la calibración de los parámetros relativos al proceso de corrosión que influyen en el comportamiento adherente de alambres de acero, basada en un estudio paramétrico, en el que se comprueba en qué forma y medida afecta al comportamiento adherente la fluctuación de la variable analizada, seguido de una comparación de los resultados arrojados por el modelo analítico con los obtenidos en los ensayos de arrancamiento. Esta misma metodología se ha utilizado para la calibración del coeficiente de fricción $\mu$ y para la selección del modelo de penetración de ataque por corrosión.

- Se ha comprobado que para el correcto modelado de la corrosión, los parámetros que han de ser calibrados son los siguientes: el incremento de volumen de los óxidos con respecto al acero virgen (coeficiente de expansión de óxidos; $n$ ), la capacidad de deformación de la capa de óxidos que rodea el alambre sano (módulo de compresibilidad volumétrica; $K_{r}$ ), la difusión de parte de los productos de corrosión a través de la red de poros del hormigón que rodea el acero (espesor de la zona porosa, $t_{\text {p }}$ ) y la penetración de óxidos en fisuras.

- Se ha obtenido que un coeficiente de expansión de los óxidos $n$ igual 2 reproduce adecuadamente los resultados experimentales. Se ha constatado que el coeficiente $n$ no influye en la máxima tensión radial $\sigma_{r, \text { max }}$ alcanzada, manteniéndose constante cualquiera que sea el valor seleccionado.

- Se ha determinado que el rango de valores del módulo de compresibilidad volumétrica $K_{\mathrm{r}}$ que permite un mayor grado de adaptación a los resultados obtenidos en la campaña experimental, se encuentra comprendido entre 0,5-1,0 GPa. Se ha comprobado que es en el comportamiento post-pico, tras alcanzarse la tensión radial máxima, donde el módulo de deformabilidad volumétrica $k_{r}$ tiene una influencia más clara. La mayor capacidad de deformación de los productos de corrosión con valores bajos de $K_{r}$ provoca que el frente de fisuración, vinculado estrechamente a las tensiones circunferenciales, evolucione más lentamente, con lo que el recubrimiento conserva su capacidad para confinar y permite que las tensiones radiales residuales se mantengan en valores más elevados con respecto a aquellos con valores altos de $K_{r}$

- Se ha constatado que el volumen de productos de corrosión comprimidos $V_{r c}$ es función del coeficiente de expansión de óxidos $n$ y del módulo de compresibilidad volumétrica $K_{\text {r, }}$, de manera que aplicando coeficientes de expansión $n$ con un valor elevado junto con módulos $K_{r}$ de valores reducidos se puede llegar a determinar un volumen de óxidos comprimidos $V_{r}$ similar al que se lograría si se utilizasen coeficientes de expansión bajos junto con módulos de compresibilidad altos. En conclusión, para las mismas condiciones, existen múltiples duplas de los parámetros $n-K_{r}$ que pueden arrojar resultados de tensiones y deformaciones similares en el hormigón que circunda el alambre. 
- Se ha admitido la existencia de una zona porosa $t_{p}$ alrededor del alambre en la que parte de los productos de corrosión generados difunden a través de la red de poros del hormigón, sin ejercer presión en el recubrimiento. Se ha comprobado que la variación del espesor de dicha región no tiene consecuencias en la evolución de las tensiones y deformaciones derivadas de la corrosión, sino que únicamente influye en el momento en que los productos de corrosión empiezan a ejercer presión en la pared interna del cilindro de hormigón que rodea el acero. En conclusión, su efecto es el de decalar en el tiempo las tensiones y deformaciones (y por tanto la fisuración) en el recubrimiento de hormigón, derivadas de la presión ejercida por los óxidos.

- Se ha desarrollado, partiendo de la hipótesis de que la difusión de óxidos en el hormigón es un fenómeno de transporte, un modelo para definir la capa porosa $t_{p}$, basado en una ley de distribución parabólica inspirada en las leyes de difusión de Fick, en la que los óxidos generados ejercen presión desde el primer momento, y el porcentaje de los mismos que actúan sobre el recubrimiento se incrementa hasta alcanzar el máximo a una distancia $t_{p, c r i}$ de la interfaz acero-hormigón. El procedimiento de calibración ha permitido determinar que un espesor equivalente $t_{p, \text { cri }}$ comprendido en el rango entre 37,5 y $75 \mu \mathrm{m}$ ofrece un aceptable ajuste con los resultados experimentales obtenidos.

- Se ha admitido que, una vez que se ha iniciado la fisuración en el hormigón que circunda el alambre, un porcentaje de los productos de corrosión generados pueden depositarse en el interior de las fisuras abiertas. Se ha comprobado que este espacio adicional para la difusión de los óxidos (equivalente a un porcentaje del volumen total liberado por las fisuras) conlleva, por una parte, un retraso en la fisuración del recubrimiento $c$, por otra, un pico de tensión máxima de adherencia para un valor más elevado de corrosión y, por último, una tensión de adherencia residual superior para el mismo nivel de pérdida de sección.

- Se ha propuesto un criterio para definir el volumen de fisuras susceptible de ser ocupado por los productos de corrosión, según el cual el volumen de óxidos que penetra en las fisuras $\Delta V_{\text {crack }}$ es igual para la misma densidad de corriente $i_{c o r r}$ e independiente del espesor $c$ de recubrimiento. Según este criterio, y a la vista del estudio de sensibilidad realizado y del grado de ajuste del modelo a los resultados experimentales, en esta tesis se ha considerado que en las probetas con relación recubrimiento/diámetro igual a 4 un $80 \%$ del volumen liberado por la fisuración es ocupado por los productos de corrosión, siendo de un $20 \%$ para las probetas con relación recubrimiento/diámetro igual a 10.

- Se ha determinado que un coeficiente de fricción $\mu$ igual a 0,65 , independientemente de la forma del alambre (liso o indentado) y del nivel de corrosión, permite una buena predicción de los resultados experimentales mediante el modelo analítico.

- Se ha admitido la hipótesis de que el coeficiente de fricción $\mu$ es una propiedad intrínseca del contacto entre dos materiales determinados, por lo que su valor es independiente del contorno o forma externa de los mismos. En consecuencia, se ha supuesto que el coeficiente de fricción es el mismo para los alambres lisos e indentados y que mayor capacidad adherente 
de los alambres sanos con indentaciones se debe al engranamiento mecánico de estas últimas con el hormigón circundante, y no a un mayor valor del coeficiente en cuestión.

- Se ha supuesto que la corrosión no afecta al valor del coeficiente de fricción $\mu$. Este aspecto genera controversia en la comunidad científica, estando aún alejada la posibilidad de alcanzarse un consenso. En la revisión bibliográfica se ha podido comprobar que en aquellos trabajos en los que el coeficiente $\mu$ modifica su valor, la evolución responde más a ajustes empíricos que a certezas experimentales, de manera que el coeficiente de fricción $\mu$ absorbe la influencia de aquellos fenómenos con repercusión en la adherencia que no han sido contemplados explícitamente en el modelo.

- Se ha demostrado que los modelos de penetración de ataque por corrosión distintos a la Ley de Faraday no sólo carecen de sentido físico, sino que proporcionan resultados alejados de los resultados experimentales. Se ha comprobado que la ley de Faraday proporciona una ajustada predicción de las pérdidas de sección por corrosión medidas mediante análisis gravimétrico en la campaña experimental.

\subsubsection{Conclusiones relativas a la adherencia de alambres sanos y corroídos en hormigón pretensado}

- Se ha desarrollado un modelo analítico integral para la determinación de la longitud de transferencia en estructuras pretensadas sanas y corroídas, superponiendo los efectos del pretensado al modelo analítico tridimensional sobre elementos de hormigón armado con corrosión.

- Se ha llevado a cabo una campaña experimental, diseñada siguiendo la Norma UNE 7-43682 "Método de ensayo para la determinación de las características de adherencia de las armaduras de pretensado" (Instituto Nacional de Racionalización y Normalización IRANOR, 1982) para la verificación experimental del modelo integral.

- Se han fabricado 4 probetas prismáticas de hormigón pretensado de sección rectangular, mediante moldes metálicos, que han sido pretensadas mediante 4 alambres indentados de 5 $\mathrm{mm}$ de diámetro $\phi$ situados en cada una de las esquinas de la viga. Las vigas tenían una longitud de $1976 \mathrm{~mm}$, y una sección transversal de $80 \times 90 \mathrm{~mm}^{2}$, con un recubrimiento de 20 $\mathrm{mm}$.

- Se ha determinado la longitud de transferencia del pretensado mediante dos métodos complementarios, basados en el empleo de instrumentación no invasora: por un lado, flexímetros para el cálculo de los deslizamientos de los alambres en los extremos de las vigas pretensadas $\delta_{d}$, y por otro, galgas extensiométricas y puntos de medida para extensiometría manual para la determinación de las deformaciones longitudinales $\boldsymbol{\varepsilon}_{c}$ en la superficie del hormigón.

- Se han comparado los resultados experimentales con los resultados teóricos obtenidos mediante la aplicación del modelo analítico integral, simulando las condiciones mecánicas y 
geométricas de los ensayos de laboratorio. La campaña de ensayos ha constado de dos etapas diferenciadas: en la primera de ellas se han determinado las longitudes de transferencia $l_{t, 0}$ en vigas pretensadas de hormigón sin procesos de corrosión; en la segunda, partiendo de las vigas anteriores, se ha analizado la influencia de la corrosión en las propiedades adherentes (pérdidas de sección de entre un 10 y un $15 \%$ ). Para ello se han monitorizado las deformaciones longitudinales en el hormigón $\varepsilon_{\mathrm{c}}$, los deslizamientos de los alambres en los extremos $\delta_{\mathrm{c}}$ y la evolución de la fisuración.

- En la primera etapa, a partir del análisis de los resultados experimentales, se han extraído las siguientes conclusiones de los ensayos sobre vigas pretensadas sin corrosión:

- Se ha supuesto que la deformación máxima $\boldsymbol{\varepsilon}_{\max }$ en la meseta central, donde la fuerza de pretensado ha sido plenamente transferida, es el resultado del efecto acumulado de tres fenómenos: la deformación instantánea tras el pretensado $\left(\boldsymbol{\varepsilon}_{\max , 0}\right.$ para $\mathrm{t}=0$ días); la deformación $\boldsymbol{\varepsilon}_{s b r}$ debida a la retracción del hormigón, que es constante a lo largo de toda la viga pretensada; y la deformación por fluencia $\boldsymbol{\varepsilon}_{\text {creep }}$ originada por la fuerza de compresión actuante en cada sección de la viga, causada por el pretensado.

- Se ha observado que una vez que se ha producido la deformación instantánea de la viga $\boldsymbol{\varepsilon}_{\text {max }, 0}$, tras la transferencia del pretensado, tiene lugar un incremento rápido de las deformaciones por compresión, especialmente significativo la primera semana, debido a los fenómenos de retracción y fluencia. Este incremento se va ralentizando y comienza a estabilizarse a partir de los 28-60 primeros días.

- Se ha constatado que a los 90 días las deformaciones totales aproximadamente se han triplicado, debido a la contribución de las deformaciones por retracción y fluencia. Aunque el incremento de la deformación se va atenuando, a la vista de los resultados obtenidos se puede afirmar que la influencia de los efectos reológicos no se había detenido completamente en el momento en que se dejaron de registrar datos, 90 días tras el destesado.

- Se ha comprobado que las deformaciones de compresión derivadas de los efectos reológicos, $\boldsymbol{\varepsilon}_{s h}$ y $\boldsymbol{\varepsilon}_{\text {creep }}$, no sólo elevan el perfil de deformaciones de las vigas, sino que también influyen en la longitud de transferencia $l_{\text {. }}$ Al igual que ocurría con las deformaciones por compresión en la meseta central, las longitudes de transferencia crecen rápidamente los primeros días tras el destesado, atenuándose a con el paso del tiempo, hasta llegar a estabilizarse a partir de los 60 días con un incremento medio de aproximadamente un $16 \%$.

- Se ha observado que la pendiente de los tramos ascendente y descendente del perfil de deformaciones aumenta rápidamente los primeros días tras el destesado y, al igual que ocurre con las deformaciones y las longitudes de transferencia, comienza a estabilizarse a partir de los 28-60 días. 
- Se ha calculado que, en el momento del destesado, los deslizamientos relativos del alambre $\delta$ en los extremos de las vigas arrojan un coeficiente $\alpha$ promedio igual a 2,53. Este valor equivale a suponer una distribución de las deformaciones longitudinales, tanto del de acero $\varepsilon_{p}$ como la del hormigón $\varepsilon_{c}$, intermedia entre una ley lineal $(\alpha=2)$ y otra parabólica $(\alpha=3)$. A partir de la primera semana tras el destesado se observa una tendencia general a que el coeficiente $\alpha$ vaya descendiendo y tienda a converger hacia un valor cercano a 2 (1,93 a los 90 días tras el destesado).

- Finalmente, se han comparado los resultados obtenidos en la campaña experimental con los resultados arrojados por el modelo analítico integral, mostrándose que la capacidad predictiva del modelo analítico desarrollado puede considerarse como muy buena.

- En la segunda etapa, a partir del análisis de los resultados experimentales, se han extraído las siguientes conclusiones de los ensayos sobre vigas pretensadas con corrosión:

- Se ha observado que el mayor deterioro de las propiedades adherentes y, por tanto, la mayor reducción de las deformaciones por compresión del hormigón $\varepsilon_{\mathfrak{c}}$, se concentra en los extremos de las vigas. Además, dicho deterioro se va atenuando con el aumento de la distancia desde dichos extremos. Este comportamiento es el esperable, ya que las secciones más extremas son las más solicitadas antes del comienzo de ensayo por corrosión, desde el punto de vista de tensiones radiales $\sigma_{r} \mathrm{y}$ circunferenciales $\sigma_{\theta}$, debido al efecto Hoyer.

- Se ha constatado que las deformaciones del hormigón $\boldsymbol{\varepsilon}_{c}$ en el centro de la viga permanecen prácticamente inalteradas para valores bajos de corrosión (1,0-2,5\%). Superados esos niveles de corrosión se observa que cuanto mayor es el deterioro en los extremos (relajación de las deformaciones de compresión), mayor es la deformación de compresión $\boldsymbol{\varepsilon}_{c}$ en el centro de vano. Este incremento de las deformaciones de compresión no puede deberse en ningún caso al incremento de la fuerza de pretensado, ya que esta fue transmitida previamente, ni al efecto de la corrosión, por lo que es achacable únicamente a la acción de los fenómenos reológicos de retracción y fluencia.

- Finalmente, se han comparado los resultados obtenidos en la campaña experimental con los resultados arrojados por el modelo analítico integral, observándose que el modelo es capaz de captar la reducción de las deformaciones por compresión del hormigón $\varepsilon_{c}$, concentrada en los extremos de la viga, pero presenta limitaciones a la hora reproducir el aumento de deformación de compresión $\varepsilon_{c}$ en su centro de vano. A pesar de esta salvedad, puede concluirse que la capacidad predictiva del modelo analítico es razonablemente buena. 


\subsubsection{Conclusiones relativas al modelo para la determinación de la longitud de transferencia en elementos pretensados de hormigón}

- Se han identificado los principales parámetros geométricos y mecánicos que intervienen en la adherencia de elementos pretensados con corrosión: resistencia a compresión del hormigón $f_{c}$, recubrimiento de hormigón $c$, diámetro del alambre $\phi$, tensión inicial de pretensado $\sigma_{p, 0}$; y pérdida de sección por corrosión.

- Se ha desarrollado un análisis estadístico, basado en un modelo de regresión múltiple, de los resultados arrojados por el modelo analítico para una combinación de los principales parámetros que intervienen en el fenómeno del pretensado. Se han contemplado cinco variables independientes (resistencia del hormigón, diámetro, recubrimiento, tensión inicial de pretensado y pérdida de sección por corrosión) de cuyas múltiples combinaciones se han obtenido los resultados que han permitido analizar su influencia en la longitud de transferencia (variable dependiente).

- El estudio paramétrico, junto con el modelo de regresión múltiple, ha permitido obtener las siguientes conclusiones relativas a la longitud de transferencia en elementos de hormigón pretensado con alambres sanos:

- Se ha determinado que la longitud de transferencia $l_{t}$ es directamente proporcional al diámetro del alambre $\phi\left(l_{t} \propto \phi\right)$, siendo este parámetro el que tiene una mayor influencia relativa en el valor de dicha longitud.

- Se ha cuantificado que la resistencia a tracción del hormigón $f_{c t}$ es inversamente proporcional a la longitud de transferencia $l_{t}\left(l t \propto 1 / f_{c t}\right)$, debido a la mejora en la capacidad de confinamiento del recubrimiento que supone el incremento de esta resistencia. En consecuencia, entre la longitud de transferencia $l_{t}$ y la resistencia a compresión del hormigón $f_{c}$ existe una relación de proporcionalidad inversa, de carácter potencial con exponente igual a $-2 / 3\left[l t \propto a_{0} f_{c}{ }^{\beta} ; \operatorname{con} \beta=-2 / 3\right.$.]

- Se ha establecido que la longitud de transferencia $l_{t}$ disminuye con el incremento del ratio recubrimiento/diámetro $c / \phi$, estableciéndose una relación entre ambas variables de carácter potencial, con exponente igual a $-1 / 3\left(l t \propto a_{0}(c / \phi)^{\beta}\right.$; $\operatorname{con} \beta=-$ $1 / 3)$

- Se ha determinado que, de forma aproximada, la longitud de transferencia $l_{t}$ es directamente proporcional a la raíz cuadrada la tensión de pretensado inicial $\sigma_{p, 0}(l t \propto$ $\left.a_{0} \sqrt{\sigma_{p, 0}}\right)$

- El estudio paramétrico, junto con el modelo de regresión múltiple, ha permitido obtener las siguientes conclusiones relativas a la longitud de transferencia en elementos de hormigón pretensado con procesos de deterioro por corrosión: 
- Se ha desarrollado un modelo de deterioro de la longitud de transferencia en elementos pretensados con procesos de corrosión basado en los parámetros $X_{\text {lim }} \mathrm{y}$ $V_{d e t}$

- Se ha determinado que la longitud de transferencia $l_{t}$ se mantiene inalterada hasta que es superado un determinado umbral de pérdida de sección por corrosión, que ha sido denominado en esta tesis $X_{\text {lim. }}$

- Se ha constatado que el valor de $X_{\text {lim }}$, depende en gran medida de la relación $c / \phi, \mathrm{y}$ en menor proporción por la tensión de pretensado inicial $\sigma_{p, 0}$ y por el diámetro del alambre $\phi$. La resistencia del hormigón no influye en el valor de este parámetro.

- Se ha comprobado que el valor de $X_{\text {lim }}$ aumenta (y por tanto retrasa el comienzo del deterioro de la longitud de transferencia) con el aumento de la relación recubrimiento/diámetro $c / \phi\left(X_{\text {lim }} \propto a_{0}(c / \phi)^{2}\right)$, con el incremento del diámetro del alambre $\phi\left(X_{\text {lim }} \propto a_{0}(\phi)^{1 / 3}\right)$ y con la disminución de la tensión inicial de pretensado $\sigma_{p, 0}\left(X_{\text {lim }} \propto a_{0}\left(\sigma_{p, 0}\right)^{-5 / 4}\right)$

- Se ha determinado que una vez superado $X_{\text {limm }}$ la longitud de transferencia $l_{t}$ crece paralelamente al deterioro de la adherencia hormigón-acero, motivada por la paulatina pérdida de la capacidad de confinamiento del recubrimiento de hormigón. La tasa o velocidad de aumento de la longitud de transferencia con el aumento de pérdida de sección por corrosión se ha denominado en esta tesis $V_{d e t}$

- Se ha constatado que la tasa o velocidad de deterioro de la longitud de transferencia, $V_{\text {det, }}$ que viene dada por la pendiente de la gráfica de incremento relativo de dicha longitud con respecto al porcentaje de pérdida de sección por corrosión, se mantiene constante a lo largo del proceso de deterioro por corrosión. Además, se ha determinado que esta velocidad de deterioro depende en gran medida de la relación recubrimiento/diámetro $c / \phi$, y que la modificación del resto de parámetros contemplados $\left(\phi, f_{c} y \sigma_{p, 0}\right)$, únicamente matiza ligeramente su valor.

- Se ha comprobado que el valor de $V_{\text {det }}$ aumenta, con la disminución de la relación recubrimiento/diámetro $c / \phi\left(V_{\text {det }} \propto a_{0}(c / \phi)^{-3}\right)$ y del diámetro del alambre $\phi\left(V_{\text {det }} \propto\right.$ $\left.a_{0}(\phi)^{-1 / 3}\right)$ y con el incremento de la tensión inicial de pretensado $\sigma_{p, 0}\left(V_{\text {det }} \propto a_{0} \sigma_{p, 0}\right)$ y de la resistencia a compresión del hormigón $f_{c}\left(V_{\text {det }} \propto a_{0}\left(f_{c}\right)^{1 / 9}\right)$.

\subsubsection{Conclusiones relativas a las expresiones simplificadas para la determinación de la longitud de transferencia}

- A partir del modelo analítico desarrollado, junto con un estudio paramétrico y un análisis estadístico, se ha desarrollado una expresión simplificada que permite el cálculo de longitudes de transferencia en elementos pretensados con alambres sanos: 


$$
l_{t, 0}=30 \frac{\phi \cdot \sigma_{p, 0}{ }^{1 / 2}}{(c / \phi)^{1 / 3} \cdot f_{c}^{2 / 3}}
$$

- Se ha desarrollado una expresión para predecir el deterioro de la longitud de transferencia debida a procesos de corrosión, basada en el coeficiente de deterioro $\alpha_{c o r r}$, que determina el incremento relativo de dicha longitud con respecto a la correspondiente a alambres sanos:

$$
l_{t, c o r r}=l_{t, 0} \cdot \alpha_{c o r r}
$$

- Se ha determinado que el coeficiente de deterioro $\alpha_{c o r r}$ está definido por el porcentaje de pérdida de sección en el momento de la evaluación $X_{c o r r}$, por el porcentaje de pérdida de sección que provoca el inicio del deterioro de la longitud de transferencia $X_{\text {lim }}$ y por la velocidad de deterioro de dicha longitud $V_{d e t}$.

$$
\alpha_{\text {corr }}=1+\left(X_{\text {corr }}-X_{\text {lim }}\right) \cdot V_{\text {det }} \geq 1
$$

- A partir del modelo analítico desarrollado, junto con un estudio paramétrico y un análisis estadístico, se ha desarrollado una expresión simplificada que determina el porcentaje límite de pérdida de sección por procesos de corrosión a partir del cual se comienza a deteriorar la longitud de transferencia, $X_{\text {lim }}$.

$$
X_{\text {lim }}=2250 \frac{\phi^{1 / 3}(c / \phi)^{2}}{\sigma_{p, 0}{ }^{5 / 4}}
$$

- Se ha desarrollado una expresión simplificada para la determinación de la velocidad de deterioro de la longitud de transferencia debida a procesos de corrosión, $V_{d e t}$.

$$
V_{\text {det }}=0,004 \frac{\sigma_{p, 0} \cdot f_{c}^{1 / 9}}{\phi^{1 / 3}(c / \phi)^{3}}
$$

- Se han comparado los resultados arrojados por el modelo analítico integral con los obtenidos mediante las expresiones simplificadas, obteniéndose excelentes grados de ajuste.

- Se ha comprobado la capacidad de predicción de la expresión el cálculo de longitudes de transferencia en elementos pretensados con alambres sanos mediante su comparación con los resultados obtenidos en campañas experimentales de otros autores, obteniéndose excelentes resultados. Esta comprobación no ha podido llevarse a cabo para elementos pretensados deteriorados por corrosión, al no existir en la bibliografía campañas experimentales que atiendan a este fenómeno. 
- Se ha comparado la expresión propuesta para el cálculo de longitudes de transferencia en elementos pretensados con alambres sanos con las contempladas en los códigos estructurales cuyo uso está más extendido: Código Modelo 2010, Eurocódigo 2, ACI-318 y EHE-08. Los resultados obtenidos muestran que la expresión propuesta ofrece una capacidad predictiva muy superior a la mostrada por los códigos.

\subsection{Contribuciones de la tesis}

Las principales contribuciones de esta tesis han sido las siguientes:

- Se ha propuesto por primera vez un modelo analítico para el estudio de la influencia del fenómeno de la corrosión en la adherencia de elementos pretensados de hormigón.

- Se ha desarrollado una metodología para la calibración de los parámetros relativos al proceso de corrosión que influyen en el comportamiento adherente de alambres de acero, basada en estudios paramétricos y en la comparación de resultados analíticos y experimentales.

- Se ha desarrollado un modelo para definir la capa porosa $t_{p}$, basado en una ley de distribución parabólica inspirada en las leyes de difusión de Fick, en la que los óxidos generados ejercen presión desde el primer momento, y el porcentaje de éstos que actúan sobre el recubrimiento se incrementa hasta alcanzar el máximo a determinada distancia de la interfaz acerohormigón.

- Se ha propuesto un criterio para definir el volumen de fisuras susceptible de ser ocupado por los productos de corrosión, según el cual el volumen de óxidos que penetra en las fisuras es igual para la misma densidad de corriente e independiente del espesor de recubrimiento.

- Se han propuesto expresiones simplificadas que permite el cálculo de longitudes de transferencia en elementos pretensados con alambres sanos, así como su evolución al experimentar procesos de deterioro por corrosión.

\subsection{Líneas futuras de investigación}

Las líneas futuras de investigación que se derivan del trabajo realizado en esta tesis se enumeran a continuación:

- Ampliar la campaña experimental de ensayos de arrancamiento sobre alambres sanos y corroídos, utilizando relaciones recubrimiento/diámetro $c / \phi$ más comunes e incluyendo explícitamente la resistencia a compresión $f_{c}$, como una de las variables fundamentales de estudio.

- Estudiar en profundidad la influencia de la relación recubrimiento/diámetro $c / \phi$ y de la resistencia del hormigón $f_{c}$, en la adherencia de alambres, para aclarar el origen de algunos de 
los comportamientos anómalos detectados tanto en la campaña experimental de esta tesis como en la literatura científica.

- Verificar la capacidad predictiva del modelo en cuanto a la fisuración provocada por procesos de deterioro por corrosión en estructuras de hormigón armado, mediante su comparación con los numerosos ensayos recogidos en la literatura científica.

- Realizar ensayos para determinar el coeficiente de fricción $\mu$, así como su evolución con el incremento de la corrosión.

- Profundizar en los conceptos de capa porosa alrededor del alambre y de volumen de óxidos en fisuras para mejorar y ampliar los modelos propuestos en esta tesis.

- Diseñar ensayos específicos para mejorar los modelos propuestos tanto de caracterización de la capa porosa alrededor de los alambres como del volumen de fisuras que es ocupado por los productos de corrosión, en función del espesor de recubrimiento $c$ y de la velocidad de corrosión $i_{c o r r}$.

- Estudiar e implementar en el modelo analítico cómo influyen los efectos dependientes del tiempo, como la retracción y la fluencia, en el aumento tanto de las deformaciones de compresión como de la longitud de transferencia. Ambos fenómenos han sido detectados tanto en la revisión bibliográfica como en la campaña experimental realizada.

- Analizar e implementar en el modelo analítico la interacción entre alambres de pretensado y cómo afecta la separación de estos en el desarrollo de las tensiones en el recubrimiento, comparando los resultados con las separaciones mínimas recomendadas en la normativa.

- Extender el modelo analítico desarrollado de manera que pueda ser capaz de predecir longitudes de anclaje en elementos de hormigón armado y su evolución al sufrir procesos de deterioro por corrosión.

- Ampliar la campaña experimental sobre elementos pretensados de hormigón sometidos a procesos de corrosión, mejorando el procedimiento de toma de datos de las deformaciones longitudinales a lo largo de los mismos, para verificar o mejorar las expresiones simplificadas propuestas para evaluar su longitud de transferencia $l_{t}$.

- Profundizar en el análisis del deterioro por corrosión del anclaje de alambres en los extremos de elementos de hormigón pretensado y su incidencia en la verificación del Estado Límite Último de agotamiento por esfuerzo cortante. 


\section{CHAPTER 8}

\section{Conclusions, Contributions and Future Research Lines}

\subsection{Conclusions}

\subsubsection{General conclusions}

In this $\mathrm{PhD}$ thesis, the processes of bond degradation due to the corrosion of both indented and smooth wires have been studied, and its influence in the behavior of prestressed concrete members has been analyzed. To that end, it has been developed an analytical model whose variables have been calibrated through pull-out test on non-stressed wires, and whose theoretical results have been verified thanks to its comparison with the data derived from an experimental campaign on prestressed beams.

The validated model has allowed to study the influence on bond behavior of the main geometric and mechanical variables involved in the prestressing, which has also allowed the development of simplified expressions to calculate the transfer length in prestressed concrete elements with noncorroded and corroded wires. The results given by the proposed expression for non-corroded wires have been compared with those obtained in previous experimental works from other authors, and it shows a better predictive capacity than other expressions included on the structural codes which are more frequently used.

The methodology followed, which may be described as both theoretical and experimental, and consisting in several distinct stages, has been shown as an efficient procedure to identify, analyse, and measure the main geometric and mechanical variables involved in the phenomenon of the corrosion of prestressed elements. The stages in which this research has consisted are the following:

- Development of a bi-dimensional analytical model for the determination of the tensile radial stresses derived from corrosion at the cross-section level in reinforced concrete structures.

- Conduction of a pull-out test campaign to calibrate the parameters defining the expansion of corrosion products and the bond properties between concrete and steel.

- Extension of the analytical model to the longitudinal direction of the element (three dimensions) to determine the laws governing the relation between bond and slip, in both non-corroded and corroded wires, through its comparison with the previous experimental campaign.

- Development of an integral analytical model to determine the transfer length in noncorroded and corroded prestressed structures, coupling the effects of prestress to the three- 
dimensional analytical model regarding corroded reinforced concrete elements. Some novel features of this model are the treatment of the porous layer around the prestressing wires and the volume of cracks occupied by corrosion products to determine the confinement capacity of the concrete cover as well as the incorporation of prestressing along the longitudinal direction.

- Verification of the integral analytical model by comparing it with test on prestressed beams with corrosion degradation mechanisms.

- Development of simplified expressions, based on the verified analytical model, for the assessment of transfer lengths in prestressed concrete members with both non-corroded and corroded wires. The results obtained by the expression proposed for non-corroded wires have been compared with those found in governing concrete design standards as well as with experimental results reported by others.

\subsubsection{Conclusions derived from the analytical model for the determination of radial stresses in reinforced concrete cross-sections with corrosion}

- The two-dimensional anisotropic analytical model, developed in this $\mathrm{PhD}$ thesis for the determination of radial stresses derived from corrosion processes in reinforced concrete structures, based on both the theory of thick-walled hollow cylinder and a model of cohesive cracking for the concrete, has proven to be an effective tool for predicting the stress state in concrete cross-sections subjected to this degradation phenomenon.

- The model, along with the pull-out tests, allowed to conclude that the bond stress $\tau_{b}$, the bond-slip law $\tau_{b}-s$, and the different modes of bond failure, as well as their evolution due to corrosion, depend on the interaction of two fundamental factors:

- The confinement capacity of the concrete cover: factor depending on geometrical (cover thickness, $c$ ) and mechanical (compressive strength, $f_{c}$, and tensile strength, $f_{c t}$, Young's modulus E, etc.) values.

- The steel-concrete system capacity to mobilize the confinement action of the cover: concrete confines the steel wire only if there is a radial compressive stress $\sigma_{r}$ around the wire, which may be caused by different reasons, among which are the expansion of the corrosion products, the Hoyer effect (in the case of prestressed elements), the shrinkage associated with the moisture loss in concrete or the slip of indentations of the wire.

- It has been concluded that the increase of oxides volume always increases the concrete cover displacement. If cover can bear these stresses, the bond stress $\tau_{b}$ increases, while if the radial $\sigma_{r}$ and circumferential stresses $\sigma_{\theta}$ lead to the concrete cracking and failure, the bond stress $\tau_{b}$ decreases. 
- It has been found that, in non-corroded wires, the influence of the cover thickness $c$ and the concrete compressive strength $f_{c}$ is not relevant. This influence is only remarkable beyond the early stages of the corrosion process, when oxides begin to mobilize the confinement capacity of the concrete cover.

- It has been observed that the increasing in the concrete compressive strength has a decisive influence on the growth of the maximum radial stresses reached, by improving of the confinement capacity of the cover. However, its influence on the appearance of surface cracking and its subsequent opening is very limited. It has been determined that the growth of compressive strength $f_{c}$ is approximately proportional to the increase in the maximum radial stress that can be developed in the concrete cross-section $\left(f_{c}^{5 / 6} \propto \sigma_{r, \max }\right)$. It was not observed any pattern regarding the attenuation of this influence with the growth of the concrete strength.

- It has been noted that the increase of the concrete cover thickness $c$ leads to a clear improvement in the bond behavior, both in the appearance and evolution of the cracks and in the maximum bond stresses achieved. In the latter case, the bond capacity improves until a limit cover/diameter ratio is reached, from which any increase in cover thickness does not result in an increase in bond capacity.

\subsubsection{Conclusions derived from pull-out tests}

- It has been verified that the pull-out tests, following the UNE-EN 10080:2006 Standard, are appropriate to measure the maximum value of the average bond stress $\tau_{b, \text { med }}^{\max }$, to determine the parameters that define the bond-slip law $\tau_{b, m e d}-s$ and to observe the bond failure mode of the tested samples.

- The main conclusions about the maximum bond stress $\tau_{b, \text { max }}$ derived from the results obtained from the pull-out tests, are the following:

- It has been observed that, for smooth and indented wires, or with very low levels of corrosion $(\approx<1 \%)$, the controlling parameter of the maximum bond stress reached $\tau_{b, \max }$ is the surface geometry of the steel, with a certain independence of the cover/diameter ratio $\phi / c$ and of the concrete compressive strength, since the confinement capacity does not fully mobilize.

- It has been noted that, in healthy wires, the maximum bond stress value in indented wires is in the range of 200 and $300 \%$ higher than that of smooth wires, in all cover thicknesses analyzed, thanks to the mechanical interlocking between indentations and concrete.

- It has been determined that, with the gradual increase in corrosion attack, and the consequent appearance of high radial stresses, the controlling parameter becomes the cover/diameter ratio $\phi / c$ and its associated confinement capacity, observing 
significantly higher bond stresses in the test samples with the highest cover/diameter ratio $c / \phi$, regardless of the surface geometry of the steel.

- It has been observed that the highest bond stress $\tau_{b, \text { max }}$ is reached for values of wire section loss of $2-3 \%$ in the test samples with ratio $c / \phi=4$, and of $5-6 \%$ in the test samples with ratio $c / \phi=10$, regardless of the surface geometry of the steel.

- Once the maximum bond stress $\tau_{b, \max }$, has been overcome, the increase in corrosion levels leads to, in all the considered cases, a slow and continuous decrease in the bond capacity. This decrease is more pronounced in the case of test samples with greater cover thickness, but no large differences in behavior are observed between the different surface geometries of the steel.

- The main conclusions about the law of average bond-slip $\tau_{b, \text { med }}-s$ and the bond failure mode of each of the test samples, derived from the results obtained from the pull-out tests, are the following:

- It has been observed that, in smooth and indented wires, the growth in corrosion products volume increases the bond stress at the start of the slip $\tau_{b, 0}$. Due to the higher initial radial stress $\sigma_{r, 0}$, and until the cover confinement capacity fails, the maximum bond stress is increased by the radial displacement $u_{r}$ caused by the combination of the corrosion effects and the slip of the wire (only in indented wires).

- It has been noted that, regardless of the surface geometry of the steel, the increase in corrosion causes a reduction of the slip $s 1$, at the end of the elastic branch, and slip $s_{2}$, at the end of the plastic branch, as well as a gradual tendency to converge for high levels of corrosion, so that both slips become practically coincident.

- It has been found that corrosion modifies the bond failure mode. While in the tests with non-corroded wires all the test samples failed by pull-out, brittle failure is more frequent the greater is the corrosion attack in wires with corrosion processes. In any case, most of the tests do not show a pure bond failure, by pull-out or by splitting, but a hybrid that is usually called splitting-induced pull-out.

\subsubsection{Conclusions derived from the calibration of parameters of the analytical model}

- A methodology has been developed for the calibration of the parameters related to the corrosion process that influence the bond behavior of steel wires, based on a parametric study, in which it is verified in what way and how the variation of the analyzed variable affects the bond behavior, followed by a comparison of the results obtained by the analytical model with those obtained in the pull-out tests. This same methodology has been used for the calibration of the friction coefficient $\mu$ and for the selection of the model of corrosion attack. 
- It has been proven that for the correct modeling of corrosion, the parameters that must be calibrated are the following: the oxides volume increase respect to the virgin steel (expansion coefficient of rust; $n$ ), the strain capacity of the oxide layer surrounding the wire (rust bulk modulus; $K r)$, the concrete pore network around the wire (porous layer thickness, $t_{p}$ ) and the volume of cracks occupied by corrosion products.

- It has been obtained that an expansion coefficient of rust $n$ equivalent to 2 reproduces properly the experimental results. It has been found that the coefficient $n$ does not influence the maximum radial stress $\sigma_{5}$,max reached, remaining constant regardless of the selected value.

- It has been noted that the range of values of rust bulk modulus $K_{\mathrm{r}}$ that allows more adaptation to the experimental results is between 0,5-1,0 GPa. It has been found that it is in the post-peak behavior, after reaching the maximum radial tension, where the rust bulk modulus $K_{r}$ has a clearer influence. The higher deformation capacity of corrosion products with low values of $K_{r}$ causes the cracking front, closely linked to circumferential stresses, to grow more slowly. Therefore, concrete cover keeps its capacity to confine, allowing higher residual radial stresses values than those with high values of $K_{r}$.

- It has been noted that the volume of compressed corrosion products $V_{r}$ is a function of both the expansion coefficient of rust $n$ and the rust bulk modulus $K_{r}$. Therefore, by applying coefficients of expansion $n$ with a high value along with reduced values of $K_{r}$ it can be determined a volume of compressed oxides $V_{r c}$ similar to that which would reach if low expansion coefficients were used along with high rust bulk modulus. In conclusion, for the same conditions, there are multiple pairs of $n-K_{r}$ parameters that can give similar stresses and strains in the concrete cover around the wire.

- The existence of a porous layer around the wire has been assumed. In this layer the corrosion products can diffuse through the pore network of the concrete, without exerting pressure on the cover. It has been verified that the variation of the porous layer thickness has no consequences on the evolution of the strains and stresses induced by corrosion, but only influences the moment in which corrosion products begin to exert pressure on the inner wall of the cylinder of concrete around the steel. In conclusion, its effect is to displace in time the stresses and strain s (and therefore the cracking) in the concrete cover, derived from the rust pressure.

- It has been developed, based on the hypothesis that the oxides diffusion in concrete is a transport phenomenon, a model to define the porous layer $t_{p}$, based on a parabolic distribution law inspired by the Fick diffusion laws. In this model, the corrosion products exert pressure from the first moment, and the percentage of them acting on the cover increases until reaching the maximum at a distance $t_{p, c r i}$ from the steel-concrete interface. Thanks to the calibration methodology, it has been found that a thickness $t_{p, r i}$ in the range between 37,5 and $75 \mu \mathrm{m}$ accurately reproduces the experimental results.

- It has been admitted that, once cracking has begun in the concrete around the wire, a percentage of the corrosion products can be deposited inside the open cracks. It has been 
found that this additional space for the diffusion of the oxides (equivalent to a percentage of the total volume released in cracks) entails, on the one hand, a delay in the cover cracking, on the other hand, a maximum bond stress peak for a higher value of corrosion, and finally, a higher residual bond stress for the same level of section loss.

- A new criterion has been proposed to calculate the volume of cracks that can be occupied by corrosion products, according to which the volume of oxides deposited into the cracks $\Delta V_{\text {crack }}$ is the same for the same corrosion current density $i_{c o r r}$ and independent of the cover thickness $c$. According to this criterion, and on the basis of the sensitivity analysis carried out and the fit of the analytical model to the experimental results, in this research has been considered that in the test samples with a cover/diameter ratio equals to 4 , the $80 \%$ of the volume released by cracking is occupied by corrosion products, being the $20 \%$ for the test samples with a cover/diameter ratio equals to 10 .

- It has been determined that a friction coefficient $\mu$ equivalent to 0,65 , regardless of the geometry surface of the wire (smooth or indented) and the level of corrosion, allows a good prediction of the experimental results through the analytical model.

- The hypothesis that the friction coefficient $\mu$ is an intrinsic property of the contact between two materials has been admitted. Therefore, its value is independent of the contour or external shape of said materials. Consequently, it has been assumed that the friction coefficient is the same for smooth and indented wires. The higher bond capacity of the noncorroded indented wires is due to the mechanical interlocking of the indentations with the surrounding concrete, and not to a higher value of the friction coefficient.

- It has been assumed that corrosion does not affect the value of the friction coefficient $\mu$. This aspect generates controversy among scientists, and the possibility of reaching a consensus is still far away. In the literature review it has been noted that in those works in which the $\mu$ coefficient modifies its value, the change responds more to empirical fits than to experimental certainties, so that friction coefficient $\mu$ absorbs the influence of those phenomena with influence on bond that have not been explicitly contemplated in the model.

- It has been demonstrated that corrosion attack models other than Faraday's Law not only lack physical sense but provide results far from the experimental ones. It has been shown that Faraday's law provides an accurate prediction of corrosion section losses measured by gravimetric analysis in the experimental tests.

\subsubsection{Conclusions about bond of non-corroded and corroded wires in prestressed concrete}

- An integral analytical model for the determination of the transfer length in non-corroded and corroded prestressed members has been developed, superimposing the effects of the prestress to the three-dimensional analytical model on reinforced concrete elements with corrosion. 
- An experimental campaign has been carried out, following the UNE 7-436-82 Standard "Test method for the determination of the bond characteristics of prestressing reinforcements" (Instituto Nacional para Racionalización y Normalización - IRANOR, 1982) for the experimental verification of the integral model.

- Four prismatic prestressed concrete beams with rectangular cross-section have been manufactured by means of metal formworks. Beams have been prestressed with 4 indented wires of $5 \mathrm{~mm}$ diameter $\phi$ located in the beam corners. Beams had a length of $1976 \mathrm{~mm}$, a $80 \times 90 \mathrm{~mm}^{2}$ cross-section, and a concrete cover of $20 \mathrm{~mm}$.

- The transfer length of prestress is determined by two complementary methods based on the use of non-invasive instrumentation: first, fleximeters for measure slip of wires at the ends of the prestressed beams $\delta_{d}$, and on the other, strain-gauges and manual extensometer for the determination of longitudinal strains $\boldsymbol{\varepsilon}_{c}$ on the concrete surface.

- The experimental results were compared with the theoretical results obtained by applying the integral analytical model, simulating the mechanical and geometric conditions of the laboratory tests. The testing campaign consisted of two different stages: in the first, the transfer lengths $l_{t, 0}$ were determined in prestressed concrete beams without corrosion; in the second, starting from the previous beams, the influence of corrosion on bond properties has been analyzed (section losses between 10 and $15 \%$ ). To this end, the longitudinal strains in concrete $\varepsilon_{\mathrm{c}}$, the slip of wires at the ends $\delta_{\mathrm{c}}$ and the evolution of the cracking have been monitored.

- In the first stage, from the analysis of the experimental results, the following conclusions have been derived from the tests on prestressed beams without corrosion:

- It is assumed that the maximum compressive strain $\varepsilon_{\max }$ in the central zone, where the prestressing force has been fully transferred, is the result of the cumulative effect of three phenomena: instantaneous strain after the prestressing release operation ( $\boldsymbol{\varepsilon}_{\text {max }, 0}$ for $\mathrm{t}=0$ days); the strain $\boldsymbol{\varepsilon}_{s b r}$ due to the concrete shrinkage, which is constant along the entire prestressed beam; and creep strain $\boldsymbol{\varepsilon}_{\text {creep }}$ caused by the compression force acting on each section of the beam, caused by prestress.

0 It has been noted that once the instantaneous strain $\boldsymbol{\varepsilon}_{\text {max }, 0}$ is produced, after the transfer of the prestress, a quick increase of strains caused by compression takes place, especially significant in the first week, due to shrinkage and creep phenomena. This increase slows down and begins to stabilize after the first 28-60 days.

- It has been found that after 90 days, the total compressive strains have approximately tripled its value, due to the contribution of the retraction and creep strains. Although the increase in strain is attenuated, in view of the results obtained, it can be stated that the influence of the rheological effects had not completely stopped at the time when data were no longer recorded, 90 days after the prestressing release operation. 
- It has been found that the compression strains derived from the rheological effects, $\boldsymbol{\varepsilon}_{s b}$ and $\boldsymbol{\varepsilon}_{\text {creep }}$, not only raise the strain profile of the beams, but also influence the

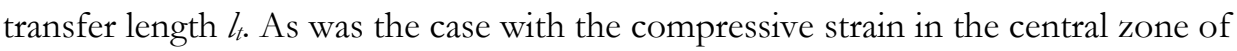
the beams, the transfer lengths rapidly grow the first days after the prestressing release, attenuating over time, up to stabilize from 60 days with an average increase of approximately $16 \%$.

- It has been observed that the slope of the ascending and descending branchs of the strain profile rapidly increase during the first days after the prestressing release and, as with the compressive strains and the transfer lengths, it begins to stabilize after 28-60 days.

- It has been measured that, at the moment of the prestressing force release, the relative slips of the wire $\delta$ at the beams ends give an average coefficient $\alpha$ equal to 2,53. This value is equivalent to assume a distribution of the longitudinal strains, both of the steel $\varepsilon_{p}$ and that of the concrete $\varepsilon_{c}$, intermediate between a linear law $(\alpha=2)$ and another parabolic one $(\alpha=3)$. From the first week after the prestressing release, is observed a general tendency for that the coefficient $\alpha$ decreases and tends to converge towards a value close to 2 (1,93 at 90 days after the release).

- At the end, it has been compared the results obtained in the experimental campaign with the results thrown by the integral analytical model, showing that the predictive capacity of the model can be considered very good.

- In the second stage, based on the analysis of the experimental results, the following conclusions have been drawn from the tests on prestressed beams with corrosion:

- It has been observed that the greater bond deterioration and, therefore, the greater reduction of the concrete compressive strains $\boldsymbol{\varepsilon}_{\mathfrak{c}}$, is concentrated at the ends of the beams. In addition, such deterioration is attenuated with the increase of the distance from those ends. This behavior is expected, since the end sections are the most stressed ones before the beginning of the accelerated corrosion test, from the point of view of radial stress $\sigma_{r}$ and circumferential stress $\sigma_{\theta}$, due to the Hoyer effect.

0 It has been found that the concrete strains $\varepsilon_{c}$ in the center of the beam remain practically unchanged for low values of corrosion $(1,0-2,5 \%)$. Once these corrosion levels have been exceeded, it is observed that the greater deterioration is in the ends (relaxation of the compression strains), the greater is the compression strain $\varepsilon_{c}$ in the center of the span. This increase in compression strains cannot be due in any case to the increase of the prestressing force, since this was previously transmitted, nor to the effect of corrosion. Therefore, it is only attributable to the action of the time-dependent effects, shrinkage and creep.

- Finally, the results obtained in the experimental campaign have been compared with the results obtained by the integral analytical model, observing that the model 
reproduce the reduction of concrete compressive strains $\varepsilon_{\mathfrak{c}}$, concentrated at the ends of the beam, but it has limitations when reproducing the increase in compressive strains $\boldsymbol{\varepsilon}_{c}$ at center of span. Despite this exception, it can be concluded that the predictive capacity of the analytical model is reasonably good.

\subsubsection{Conclusions derived from the model for the determination of the transfer length in prestressed concrete elements}

- The main geometrical and mechanical parameters that intervene in the bond of prestressed members with corrosion have been identified as the following: concrete compressive strength $f_{c}$, concrete cover $c$, wire diameter $\phi$, initial stress of prestress $\sigma_{p, \theta}$; and loss of section due to corrosion.

- Based on a multiple regression model, a statistical analysis has been developed from the results thrown by the analytical model, for a combination of the main parameters involved in the prestress phenomenon. Five independent variables have been considered (concrete strength, diameter, cover, initial stress of prestress and loss of section by corrosion). Multiple combinations of these variables have allowed to analyze their influence on transfer length (dependent variable).

- The parametric study, along with the multiple regression model, has made it possible to obtain the following conclusions about the transfer length in prestressed concrete elements with non-corroded wires:

- It has been determined that transfer length $l_{t}$ is directly proportional to the wire diameter $\phi\left(l_{t} \propto \phi\right)$. This parameter has the greatest relative influence on the value of transfer length.

- It has been quantified that the tensile strength of concrete $f_{c t}$ is inversely proportional to the transfer length $l_{t}\left(l t \propto 1 / f_{c t}\right)$, due to the improvement in the confinement capacity of the cover that implies the increase of this strength. Consequently, between the transfer length $l_{t}$ and the compressive strength of the concrete $f_{c}$ exists an inverse proportional relation, of potential character with an exponent equivalent to $-2 / 3\left[l t \propto a_{0} f_{c}^{\beta}\right.$; with $\left.\beta=-2 / 3\right]$.

- It has been established that the transfer length $l_{t}$ decreases with the increase in the cover/diameter ratio $c / \phi$, establishing a relation of potential character, with an exponent equivalent to $-1 / 3\left(l t \propto a_{0}(c / \phi)^{\beta}\right.$; with $\left.\beta=-1 / 3\right)$.

- It has been determined that, approximately, the transfer length $l_{t}$ is directly proportional to the square root of the initial prestressing stress $\sigma_{p, 0}\left(l t \propto a_{0} \sqrt{\sigma_{p, 0}}\right)$.

- The parametric study, along with the multiple regression model, has allowed reaching the following conclusions about the transfer length in prestressed concrete members with corrosion deterioration processes: 
- It has been developed a deterioration model of the transfer length in prestressed concrete elements with corrosion, based on $X_{l i m}$ and $V_{d e t}$. parameters.

- It has been determined that transfer length $l_{t}$ remains unchanged until a certain threshold of corrosion section loss is exceeded. This threshold has been denominated in this $\mathrm{PhD}$ thesis $X_{\text {lim, }}$

- It has been found that the value of $X_{\text {lim }}$, depends to a large extent on the relation $c / \phi$, and to a lesser extent on the initial prestressing stress $\sigma_{p, 0}$ and on the wire diameter $\phi$. Concrete strength does not affect the value of this parameter.

- It has been found that the value of $X_{\text {lim }}$ increases (and therefore delays the beginning of the deterioration of the transfer length) with the increase in the cover/diameter ratio $c / \phi\left(X_{\text {lim }} \propto a_{0}(c / \phi)^{2}\right)$, with the increase of the wire diameter $\phi\left(X_{\text {lim }} \propto a_{0}(\phi)^{1 / 3}\right)$ and with the decrease in the initial stress of prestress $\sigma_{p, 0}\left(X_{\text {lim }} \propto a_{0}\left(\sigma_{p, 0}\right)^{-5 / 4}\right)$

- It has been determined that once $X_{\lim }$ is exceeded, the transfer length $l_{t}$ increases with the concrete-steel bond deterioration, caused by the gradual loss of the confinement capacity of the concrete cover. In this research, the rate of growth of the transfer length with the growth of corrosion section loss has been denominated $V_{d e t}$

- It has been found that the rate of the transfer length deterioration, $V_{\text {det }}$ which is given by the slope of the graph of relative increase of transfer length with respect to the percentage of section loss by corrosion, remains constant throughout of the corrosion deterioration process. Furthermore, it has been determined that this deterioration rate depends to a large extent on the cover/diameter relation $c / \phi$, and that the modification of the rest of the parameters contemplated $\left(\phi, f_{c}\right.$ and $\left.\sigma_{p, 0}\right)$, only slightly modifies its value.

- It has been found that the value of $V_{\text {det }}$ increases, with the decrease in the cover/diameter ratio $c / \phi\left(V_{\text {det }} \propto a_{0}(c / \phi)^{-3}\right)$ and the wire diameter $\phi\left(V_{\text {det }} \propto\right.$ $\left.a_{0}(\phi)^{-1 / 3}\right)$, and with the increase of the initial prestressing stress $\sigma_{p, 0}\left(V_{d e t} \propto a_{0} \sigma_{p, 0}\right)$ and the compressive strength of the concrete $f_{c}\left(V_{\text {det }} \propto a_{0}\left(f_{c}\right)^{1 / 9}\right)$.

\subsubsection{Conclusions derived from the simplified expressions for the determination of the transfer length}

- From the developed analytical model, along with a parametric study and a statistical analysis, a simplified expression has been developed that allows to calculate transfer lengths in prestressed concrete members with non-corroded wires:

$$
l_{t, 0}=30 \frac{\phi \cdot \sigma_{p, 0}{ }^{1 / 2}}{(c / \phi)^{1 / 3} \cdot f_{c}^{2 / 3}}
$$


- An expression has been developed to predict the transfer length deterioration due to corrosion attack, based on the deterioration coefficient $\alpha_{\text {corr }}$, which determines the relative increase of the transfer length with respect to that corresponding to non-corroded wires:

$$
l_{t, \mathrm{corr}}=l_{t, 0} \cdot \alpha_{\text {corr }}
$$

- It has been determined that the deterioration coefficient $\alpha_{c o r r}$ is defined by the percentage of corrosion section loss at the assessment time $X_{\text {corr }}$, by the percentage of section loss which cause the beginning of the transfer length deterioration $X_{\text {lim }}$ and transfer length deterioration rate $V_{\text {det }}$

$$
\alpha_{\text {corr }}=1+\left(X_{\text {corr }}-X_{\text {lim }}\right) \cdot V_{\text {det }} \geq 1
$$

- From the analytical model, along with a parametric study and a statistical analysis, a simplified expression has been developed to calculate the percentage limit of corrosion section loss from which the transfer length begins to deteriorate, $X_{\text {lim }}$.

$$
X_{\text {lim }}=2250 \frac{\phi^{1 / 3}(c / \phi)^{2}}{\sigma_{p, 0}{ }^{5 / 4}}
$$

- A simplified expression has been developed for the determination of the transfer length deterioration rate due to corrosion processes, $V_{\text {det }}$

$$
V_{\text {det }}=0,004 \frac{\sigma_{p, 0} \cdot f_{c}{ }^{1 / 9}}{\phi^{1 / 3}(c / \phi)^{3}}
$$

- The results obtained by the integral analytical model have been compared with those obtained through the simplified expressions, with excellent fit degrees.

- Results from the expression to calculate the transfer lengths in prestressed members with non-corroded wires has been compared with the results obtained in experimental campaigns of other authors, with excellent results. This verification could not be carried out for prestressed elements with corrosion damaged, since there are no experimental works in literature that respond to this phenomenon.

- The proposed expression to calculate transfer lengths in prestressed elements with noncorroded wires has been compared with those included in main design concrete standards: Code Model 2010, Eurocode 2, ACI-318 and EHE-08. The results obtained show that the proposed expression offers a predictive capacity far superior to that shown by the codes. 


\subsection{Main work contributions}

The main contributions of this $\mathrm{PhD}$ thesis have been the following:

- For the first time, an analytical model for the study of the influence of corrosion on the bond of prestressed concrete elements has been proposed.

- A methodology to calibrate the main model parameters that affect the bonding behavior of prestressing wires affected by corrosion through comparison of analytical and experimental results has been developed.

- A model to define the porous layer $t_{p}$ has been developed, based on a parabolic distribution law inspired by the Fick diffusion laws. In this model, the corrosion products exert pressure from the first moment, and the percentage of them acting on the cover increases until reaching the maximum at a distance $t_{p, c r i}$ from the steel-concrete interface.

- A criterion to define the volume of cracks that can be occupied by corrosion products has been proposed, according to which the volume of oxides entering the cracks is equal for the same corrosion current density and independent of the cover thickness.

- Simplified expressions to calculate the transfer length in prestressed concrete elements with both healthy and corrosion-affected wires have been proposed.

\subsection{Future research lines}

Future research lines deriving from the work carried out in this research are listed below:

- Expand the experimental campaign of pull-out tests on non-corroded and corroded wires, using the most common cover/diameter ratio $c / \phi$ and explicitly including the compressive strength $f_{c}$, as one of the fundamental variables of the study.

- In-depth analysis of the influence of both the cover/diameter ratio and the concrete strength on bond of wires, to clarify the origin of some anomalous behaviors detected in both the experimental tests of this research and the scientific literature.

- Verification of the capacity of the analytical model to predict the appearance and evolution of the corrosion-induced cracking in reinforced concrete structures, by comparing with test results collected from the scientific literature.

- Conduct specific tests to determine the friction coefficient $\mu$, as well as its evolution with the increase of corrosion attack.

- Develop tests to characterize the porous layer around the wires and quantify the volume of corrosion products that diffuse through it. 
- In-depth analysis of the porous layer around the prestressing wires and the volume of cracks occupied by corrosion products to improve and extend the models proposed in this research.

- Develop specific tests to quantify both the porous layer and the volume of cracks that are occupied by corrosion products, depending on the cover thickness $c$ and the corrosion rate $i_{\text {corr }}$

- Analyze and implement in the analytical model how affect the time-dependent effects, shrinkage and creep, in the increase of both the compressive strains and the transfer length in prestressed concrete members.

- Extend the analytical model to predict anchorage lengths in reinforced concrete elements and their evolution with corrosion damage.

- Expand the experimental campaign about prestressed concrete elements subjected to corrosion processes, improving the procedure of data collection of longitudinal strains, to verify or improve the proposed simplified expressions to evaluate their transfer length $l_{t}$.

- In-depth analysis of the corrosion damage of the anchorage of wires at the ends of prestressed concrete elements and its influence in the calculation of the shear Ultimate Limit State. 
BIBLIOGRAFÍA

TESIS DOCTORAL 
TESIS DOCTORAL INFLUENCLA DE LA CORROSIÓN EN LA ADHERENCLA DE ALAMBRES EN ELEMENTOS PRETENS ADOS DE HORMIGÓN

\section{BIBLIOGRAFÍA}

A. Ouglova, 2006. Mechanical properties of an iron oxide formed by corrosion in reinforced concrete structures. Corrosion Science, 48(12), p. 3988-4000.

Abdelatif, A., Owen, J. \& Hussein, M., 2015. Modelling the prestress transfer in pre-tensioned concrete elements. Finite Elements in Analysis and Design, Issue 94, pp. 47-63.

Abrams, D., 1913. Test of bond between concrete and steel. s.l.:University of Illinois. Bulletin $\mathrm{N}^{\circ} 71$.

Abrishami, H. \& Mitchell, D., 1993. Bond Characteristics of Pretensioned Strand. ACI Materials Journal, 90(3), pp. 228-235.

ACHE, 2012. Monografia M-19: Modelos lineales aplicados al hormigón estructural. Madrid: Asociación Cientifico-Técnica del Hormigón Estructural.

ACI Comittee 318, 2002. Building Code Requirements for Structural Concrete (ACI 318-2) and Commentary (318R-02). Farmington Hills: American Concrete Institute.

AENOR-AEN/CTN 36, 2006. UNE-EN 10080:2006 "Acero para el armado del hormigón. Acero soldable para armaduras de hormigón armado. generalidades, s.l.: AENOR.

Al Khalaf, M., 1979. Steel/mortar interfaces: Microstructural features and mode of failure. Cement and Concrete Research, 9(2), pp. 197-207.

Almusallam, A., Al-Gahtani, A., Abdur, R. \& Rasheeduzzafar, 1996. Effect of reinforcement corrosion on bond strength. Construction Building Material, 10(2), pp. 123-129.

Alonso, C., Andrade, C., Rodriguez, J. \& Díez, J., 1998. Factors controlling cracking of concrete affected by reinforcement corrosion. Materials and Structures, Volumen 31, pp. 435-441.

Al-Sulaimani, G. J., Kaleemullah, M., Basunbul, I. A. \& Rasheeduzzafar, 1990. Influence of Corrosion and Cracking on Bond Behavior and Strength of Reinforced Concrete Members. ACI Structural Journal, 87(2).

Andrade, C., 1982. Corrosión y protección de armaduras. Informes de la construcción, 33(339), pp. 33-41.

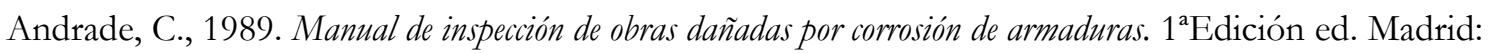
Consejo Superior de Investigaciones Científicas.

Andrade, C., 2007. Corrosion of steel reinforcement. En: Transactions on State of the Art in Science and Engineering. s.l.:WIT Press, pp. 185-216.

Andrade, C., Alonso, C. \& Molina, F., 1993. Cover cracking as a function of bar corrosion: Part I Experimental test. Materials and Structures, Volumen 26, pp. 453-464. 
Andrade, C. y otros, 1995. Relation between corrosion and concrete cracking, s.l.: Internal report of Brite/Euram project BE-4062. DG XII, C.E.C..

Andrade, C., Tavares, F., Toro, L. \& Fullea, J., 2011. Observations on the morphology of oxide formation due to reinforcement corrosion. Modelling of Corroding Concrete Structures. RILEM, pp. 179193.

BAEL-91, 2000. Règles BAEL 91, modifiées 99 : règles techniques de conception et de calcul des ouvrages et constructions en béton armé suivant la méthode des états limites. Paris: Eyrolles.

Balafas, I. \& Burgoyne, C., 2010a. Environmental effects on cover cracking due to corrosion. Cement and Concrete Research, 40(9), p. 1429-1440.

Balafas, I. \& Burgoyne, C. J., 2011. Modeling the Structural Effects of Rust in Concrete Cover. Journal of Engineering Mechanics, 137(3).

Balazs, G., 1992. Transfer control of prestressing strands. PCI Journal, 37(6), pp. 60-71.

Balazs, G. L., 1993. Transfer Length of Prestressing Strand as a Function of Draw-In and Initial Prestress. PCI Journal, 38(2), pp. 86-93.

Baldwin, M. J. \& Clark, L. A., 1995. The assessment of reinforcing bars with inadequate anchorage. Magazine of Concrete Research, 47(171), pp. 95-102.

Baltay, P. \& Gjelsvik, A., 1990. Coefficient of Friction for Steel on Concrete at High Normal Stress. Journal of Materials in Civil Engineering, 2(1), p. 46-49.

Barnes, R. W., Grove, J. W. \& Burns, N. H., 2003. Experimental Assessment of Factors Affecting Transfer Length. ACI Structural Journal, 100(6).

Base, G. D., 1957. Some Tests on the Effect of Time on Transmission Length in Pretensioned Concrete. Magazine of Concrete Research, 9(26), pp. 73-82.

Bažant, Z., 1979. Physical model for steel corrosion in concrete sea structures-theory. ASCE Journal of the Structural Division, 105(6), p. 1137-1153.

Bažant, Z., 1979. Physical model for steel corrosion in concrete sea structures-theory. ACI Structure Journal, 105(6), p. 1137-1153.

Benítez, J. M. \& Gálvez, J. C., 2011. Bond modelling of prestressed concrete during the prestressing force release. Materials and Structures, Issue 44, pp. 263-278.

Bhargava, K., Ghosh, A., Mori, Y. \& Ramanujam, S., 2006. Model for cover cracking due to rebar corrosion in RC structures. Engineering Structures, Volumen 28, p. 1093-1109.

Bhargava, K., Gosh, A. K., Mori, Y. \& Ramanujan, S., 2006. Model for cover cracking due to rebar corrosion in rc structures. Engineering Structures, 28(8), pp. 1093-1109. 
TESIS DOCTORAL INFLUENCLA DE LA CORROSIÓN EN LA ADHERENCLA DE ALAMBRES EN ELEMENTOS PRETENS ADOS DE HORMIGÓN

Bruggeling, A., 1991. Structural concrete. Theory and its application. s.l.:A. A. BALKEMA.

Byung Hwan Oh, Eui Sung Kim \& Young Cheol Choi, 2006. Theoretical Analysis of Transfer Lengths in Pretensioned Prestressed Concrete Members. Journal of Engineering Mechanics, 132(10).

Cabrera, J. \& Ghodussi, P., 1992. Effect of reinforcement corrosion on the strength of steel concrete bond. p. 10.11-10.24.

Cairns, J., 2004. Influence of cover on bond of plain round reinforcement, s.l.: Unpublished report. See: http:// fibtg45.dii.unile.it/presentations.htm.

Cairns, J., Du, Y. \& Law, D., 2006. Residual bond strength of corroded plain round bars. Magazine of Concrete Research, 58(4), pp. 221-231.

Cairns, J., Du, Y. \& Law, D., 2007. Influence of corrosion on the friction characteristics of the steel/concrete interface. Construction and Building Materials, Volumen 21, p. 190-197.

Caré, S., Nguyen, Q., L’Hostis, V. \& Berthaud, Y., 2008. Mechanical properties of the rust layer induced by impressed current method in reinforced mortar. Cement and Concrete Research, Volumen 38, p. 1079-1091.

Caro Forero, L. A., 2012. Comportamiento adherente diferido de armaduras pretesas en hormigón (Tesis doctoral). Valencia: Universidad Politécnica de Valencia (UPV).

CEB, 1982. Bond action and bond behaviour of reinforcement - State of the Art Report. Bulletin dinformation N. 151, s.l.: Comité Euro-International du Béton.

CEB-FIB (Task Group 2.5), 2000. Bond of Reinforcement in Concrete. s.l.:International Federation for Structural Concrete (fib).

CEB-FIP, 2000. Bulletin d'Information N. 217- Selected justification notes, s.l.: Comité Euro-International du Béton.

CEB-FIP, 2012. Model Code 2010. Bulletin 65-66, Lausanne: International Federation for Structural Concrete.

CEN, 2004. Eurocode 2 [2004] "EN 1992-1-11: Eurocode 2: Design of concrete structures - Part 1-1: General rules and rules for buildings.. Brussels, Belgium: CEN.

Chana, P. S., 1990. A test method to establish realistic bond stresses. Magazine of Concrete research, 40(151), pp. 83-90.

Chermin, L. \& Val, D., 2009. Numerical modelling of bond between concrete and corroded reinforcement. Haifa, Israel, Conference: 2nd International RILEM Workshop on Concrete Durability and Service Life Planning (ConcreteLife'09). 
Chernin, L. \& Val, D. V., 2010. Prediction of corrosion-induced cover cracking in reinforced concrete structures. Construction and Building Materials, Volumen 25, p. 1854.1869.

Chernin, L., Val, D. V. \& Volokh, K. Y., 2010. Analytical modelling of concrete cover cracking caused by corrosion of reinforcement. Materials and Structures, 43(4), p. 543-556.

Clark, L. \& Saifullah, M., 1993. Effect of corrosion on reinforcement bond strength. s.l., Proceedings of the Conference on Structural Faults \& Repair, p. 113-119.

Clark, L. \& Saifullah, M., 1994. Effect of corrosion rate on the bond strength of corroded reinforcement. s.l., s.n., p. 591-602.

Cleland, D. \& Basheer, P., 2005. Bond loss due to prestressing corrosion. Kielce, Institute of Terootechnology - NRI, Radom, Poland, pp. 98-100.

Cleland, D. y otros, 2001. Influence of Reinforcement Anchorage on the Bending and Shear Capacity of Bridge Decks. The Structural Engineer, 79(16), pp. 24-31.

Committee-408, A., 2003. ACI 408R-03 Bond and Development of Straight Reinforcing Bars in Tension, Farmington Hills, Mich: American Concrete Institute.

CONTECVET , 2001. A validated Users Manual for assessing the residual service life of concrete structures, s.1.: EC Innovation Program IN30902I.

Coronelli, C., 2002. Corrosion cracking and bond strength modeling for corroded bars in reinforced concrete. ACI Structural Journal, 99(3), pp. 267-276.

Coronelli, D., 1997. Bond of corroded bars in confined concrete: test results and mechanical modelling. Studi E Richerche, Volumen 18, pp. 137-211.

Coronelli, D., Castel, A., François, R. \& Cleland, D., 2009. Modelling the response of prestressed beams with corroded reinforcement. European Journal of Environmental and Civil Engineering, 13(6), pp. 653-669.

Coronelli, D. \& Gambarova, P., 2004. Structural assessment of corroding R/C beams: modelling guidelines. ASCE Journal of Structural Engineering, Volumen 130, pp. 1214-1224.

Cousins, T. E., Johnston, D. W. \& Zia, P., 1990. Transfer and development Length for Pretensioned Concrete Members. PCI Journal, 35(4), pp. 92-103.

Dai, L., Wang, L., Zhang, J. \& Zhang, X., 2016. A global model for corrosion-induced cracking in prestressed concrete structures. Engineering Failure Analysis, Volumen 62, pp. 263-275.

Dai, L., Wang, L., Zhang, J. \& Zhang, X., 2016. A global model for corrosion-induced cracking in prestressed concrete structures. Engineering Failure Analysis, Volumen 62, pp. 263-275. 
TESIS DOCTORAL INFLUENCLA DE LA CORROSIÓN EN LA ADHERENCLA DE ALAMBRES EN ELEMENTOS PRETENS ADOS DE HORMIGÓN

Dang, C. N., Murray, C. D., Floyd, R. W. \& Hale, W. M., 2014. A correlation of transfer length and strand end slip. Quebec (Canada), 10th International PhD Symposium in Civil Engineering.

den Uijl, J., 1992. Bond and splitting action of prestressing strand.. Riga, International Conference Bond in Concrete.

den Uijl, J., 1995. Part 3: Transmission length of prestressing strand. En: High Perfonmance concrete in the prefab industry. Delft: TU Delft, Stevin report 25.5-95-3, p. 65.

Den Uijl, J., 1995. Transfer Length of Prestrssing Strand in HPC. Progress in Concrete Research, Volumen 4, pp. 75-90.

den Ujil, J. A., 1998. Bond Modelling of Prestressing Strand. Special Publication, Volumen 180, pp. 145170.

EC Innovation Program IN30902I, 2001. CONTECVET A validated Users Manual for assessing the residual service life of concrete structures, s.l.: s.n.

El Maaddawy, T. \& Soudki, K., 2007. A model for prediction of time from corrosion initiation to corrosion cracking. Cement and Concrete Composites, 29(3), p. 168-175.

Eleftheriou, T. E., Tastani, S. P. \& Pantazopoulou, S. J., 2013. Bond of Reinforcing Bars Embedded in Concrete. Chania, Crete, Greece, 10th HSTAM International Congress on Mechanics.

Eligehausen, R., Popov, E. \& Bertero, V., 1983. Local bond stress-slip relationships of deformed bars under generalized excitations. Report no. UCB/EERC 83-23, s.l.: EERC University of California, Berkeley. .

European Committee for Standardization., 2001. Eurocode 2 1992-1-1:Design of concrete structures- Part 1: General rules and rules for buildings., Brussels: CEN.

Evans, R., 1951. Research and Developments in Prestressing. Journal of the Institution of Civil Engineers, 35(4), pp. 231-261.

Fang, C., Lundgren, K., Chen, L. \& Zhu, C., 2004. Corrosion influence on bond in reinforced concrete. Cement and Concrete Research, Volumen 34, pp. 2159-2167.

Feldman, L. R., 2006. Thesis "Bond of Plain Steel Reinforcement". London, Ontario: Faculty of Graduate Studies. The University of Western Ontario.

Feldman, L. R. \& Barlett, F. M., 2005. Bond strength variability in pullout specimens with plain reinforcement. ACI Structural Journal, 102(6).

FIB Special Activity Group 5, 2011. Model Code 2010, s.l.: CEB-FIB.

Filippou, F. C., Popov, E. P. \& Bertero, V. V., 1983. Modeling of R/C Joints under Cyclic Excitations. Journal of Structural Engineer. ASCE, 109(11). 
Fomento, M. d., 2008. Instrucción Española de Hormigón Estructural (EHE-08), s.l.: s.n.

Goto, Y., 1971. Cracks formed in concrete around deformed tension bars. ACI Journa, 68(4), pp. 244251.

Guo, Z., 2014. Principles of Reinforced Concrete. s.l.:Butterworth-Heinemann.

Guyon, Y., 1953. Pretensioned concrete: Theoretical and experimental study, Paris: Contractors Record and Municipal Engineering.

Guzmán, S., Jaime C., G. \& José M., S., 2012. Modelling of corrosion-induced cover cracking in reinforced concrete by an embedded cohesive crack finite element. Engineering Fracture Mechanics, Volumen 93, pp. 92-107.

Hanson, N. \& Kaar, P., 1959. Flexural Bond Tests of Pretensioned Prestressed Beams. ACI Journal, 55(7), pp. 783-803.

Hognestad, E., Hanson, N. W. \& McHenry, D., 1955. Concrete Stress Distribution in Ultimate Strength Design. ACI Journal Proceedings, 52(12), pp. 455-480.

Horne, A. T., Richardson, I. G. \& Brydson, R. M. D., 2007. Quantitative analysis of the microstructure of interfaces in steel reinforced concrete. Cement and Concrete Research, Volumen 37, pp. 1613-1623.

Hoyer, E. \& Friedrich, E., 1939. Beitrag zur Frage der Haftspannung in Eisenbetonbauteilen. (Contribution to the question of bond in concrete elements). Beton und Eisen, pp. 107-110.

Instituto Nacional de Racionalización y Normalización - IRANOR, 1982. UNE 7-436-82vMétodo de ensayo para la determinación de las características de adherencia de las armaduras de pretensado. Madrid: IRANOR.

Iverson, P., 1996. Strand Bond Assurance. Urgent Action Required. 2nd Alert, s.l.: Informe Stresscon Corporation, Precast/Prestressed Concrete Institute.

Jin, W.-1. \& Zhao, Y.-x., 2001. Effect of corrosion on bond behaviour and bending strenght of reinforced concrete beams. Journal of Zhejiang University (Science), 2(3), pp. 298-308.

Kaar, P., LaFraugh, R. \& Mass, M., 1963. Influence of Concrete Strength on Strand Transfer Length. PCI Journal,, 8(5), pp. 47-67.

Keuning, R., Sozen, M. \& Siess, C., 1962. A study of anchorage Bond in Prestressed concrete, s.l.: University of Illinois. Structural Research Series NO. 251.

Kommer, B., 2004. Bond Anchorage Behaviour of Pretensioned Tendons in High Performance Concrete. Delft (Netherland), 5th International Phd Symposium in Civil Engineering.

Konopka, P., 2005. Structural properties of rust, Cambridge, UK: Univ. of Cambridge, Cambridge. 4thyear undergraduate project. 
TESIS DOCTORAL INFLUENCLA DE LA CORROSIÓN EN LA ADHERENCLA DE ALAMBRES EN ELEMENTOS PRETENS ADOS DE HORMIGÓN

Leonhardt, F., 1988. Estructuras de Hormigón Armado (Tomo I): Bases para el dimensionado de estructuras de hormigón armado. Buenos Aires: El Ateneo.

Li, F., Yuan, Y. \& Li, C.-Q., 2011. Corrosion propagation of prestressing steel strands in concrete subject to chloride attack. Construction and Building Materials, Volumen 25, p. 3878-3885.

Liu, T. \& Weyers, R., 1998. Modeling the time-to-corrosion cracking in chloride contaminated concrete structures. ACI Materials Journal, 95(6).

Logan, D. R., 1997. Acceptance Criteria for Bond Quality of Strand for Pretensioned Prestressed Concrete Aplications. PCI Journal, Issue 42, pp. 52-90.

Lu, C., Liu, R. \& Jin, W., 2010. A model for predicting time to corrosion-induced cover cracking in reinforced concrete structures. Korea Concrete Institute, Seoul., Fracture Mechanics of Concrete and Concrete Structures - Assessment, Durability, Monitoring and Retrofitting of Concrete Structures.

Lundgren, K., 2001. Modelling bond between corroded reinforcement and concrete. Fracture Mechanics of Concrete Structures, pp. 247-254.

Lundgren, K., 2005. Bond between ribbed bars and concrete. Part 2: The effect of corrosion. Magazine of Concrete Research, 57(7), p. 383-395.

Lundgren, K., 2007. Effect of corrosion on the bond between steel and concrete: an overview. Magazine of Concrete Research, 59(6), pp. 447-461.

Lutz, L. A. \& Gergely, P., 1967. Mechanics of Bond and Slip of Deformed Bars in Concrete. Journal Proceedings, 64(11), pp. 711-721.

Malvar, L., 1991. Bond of Reinforcement under controlled Confinement, California: Naval Civil Engineering Laboratory Port Hueneme.

Martinez-Abella, F. \& Vazquez-Herrero, C., 2002. Transfer length of high performance pretensioned concrete elements. En: . C. A. B. (. W. P. de Wilde (Editor), ed. High Performance Structures and Composites. Southampton (UK): WIT Press, p. 672.

Martin, H., 1973. Zusammenhang zwischen Oberflä̈chenbeschaffenheit, Verbund und Sprengwirkung von Bewehrungsstäblen unter Kurzzeitbelastung, s.l.: Deutscher Ausschuss für Stahlbeton, Heft 228.

Martín-Pérez, B., 1999. Service life modelling of RC highway structures exposed to chlorides., Toronto: Univ. of Toronto. Ph.D. thesis.

Martín-Pérez, B., 2014. Bond Modelling of Corroding Plain Bars, Madrid: IETcc-Sabbatical project (20132014).

Martí-Vargas, J. y otros, 2007. Analytical model for transfer length prediction of $13 \mathrm{~mm}$ prestressing strand. Structural Engineering and Mechanics, 26(2), pp. 211-229. 
Martí-Vargas, J., Caro, L., García-Taengua, E. \& Serna, P., 2012. Test method to characterize bond creep in pretensioned concrete. Brescia, Bond in concrete: Bond, Anchorage, Detailing. Fourth International Symposium.

Martí-Vargas, J. R., 2002. Estudio experimental de la adherencia de cordones pretesos en hormigones de altas prestaciones iniciales. Tesis Doctoral, s.l.: Universidad Politécnica de Valencia.

Martí-Vargas, J., Serna, P., Fernández, M. \& Miguel, P., 2002. Determinación de la longitud de transmisión del pretensado a partir de las deformaciones longitudinales del hormigón. Gandía, VIII Congreso Nacional de Propiedades Mecánicas de Sólidos.

Martí-Vargas, J., Serna-Ros, P., Fernández-Prada, M. A. \& Miguel-Sosa, P., 2003. Ensayo ECADA para la caracterización de la adherencia de armaduras de pretensado. Hormigón y Acero, Issue 230, pp. $57-69$.

Martí-Vargas, J., Serna-Ros, P., Fernández-Prada, M. \& Miguel-Sosa, P., 2006. Test method for determination of the transmission and anchorage lengths in prestressed reinforcement. Magarine of Concrete Research, 58(1), pp. 21-29.

Melchers, R., 2003. Mathematical modelling of the diffusion controlled phase in marine immersion corrosion of mild steel. Corrosion Science, 45(5), pp. 923-940.

Melo, J., Rossetto, T. \& Varum, H., 2014. Experimental study of bond-slip in RC structural elements with plain bars. Materials and structures, 48(8).

Michel, A. y otros, 2011. Monitoring reinforcement corrosion and corrosion-induced cracking using non-destructive x-ray attenuation measurements. Cement and Concrete Research, 41(11), pp. 1085-1094.

Michel, A. y otros, 2014. Penetration of corrosion products and corrosion-induced cracking in reinforced cementitious materials: Experimental investigations and numerical simulations. Cement and Concrete Composites, Volumen 47, pp. 75-86.

Miguel, P., Martí, J., Serna, P. \& Fernández, M., 2002. La adherencia en elementos prefabricados pretensados de hormigón. Problemática y tendencias actuales. Gandía, VIII Congreso Nacional de Propiedades Mecánicas de Sólidos.

Mitchell, D., Cook, W. \& Khan, A., 1993. Influence of High Strength Concrete on Transfer and Development Length of Pretensioning Strand. PCI Journal, 38(3), pp. 52-66.

Molina, F. A. C. \&. A. C., 1993. Cover cracking as a function of rebar corrosion: Part 2-Numerical model. Materials and Structures, 253(26).

Moustafa, S., 1974. Pull-out strength of strand and lifting loops, Chicago: Concrete Technology Associates Technical Bulletin, 74-B5.

Nielsen, A., 1976. Hvid grön og sort rust ("Óxido blanco, verde y negro"). Nordisk Betong, 2(76). 
TESIS DOCTORAL INFLUENCLA DE LA CORROSIÓN EN LA ADHERENCLA DE ALAMBRES EN ELEMENTOS PRETENS ADOS DE HORMIGÓN

Noakowski, P., 1978. Die Bewehrung von Stablbetonbauteilenbei Zwangsbeanspruchung infolge Temperatur, s.l.: Deutscher Ausschuss für Stahlbeton, Heft 296 (144 pp).

Oh, . B. H. \& Kim, E. S., 2000. Realistic Evaluation of Transfer Lengths in Pretensioned, Prestressed Concrete Members. Structural Journal, 97(6), pp. 821-830.

Oh, B. H., Kim, E. S. \& Choi, Y. C., October 2006. Theorical Analysis of Transfer Lengths in Pretensioned Prestressed Concrete Members. Journal of Engineering Mechanics, 132(10).

Oh, B. H., Kim, E. S. \& Kim, K. S., 2001. Correct Prediction of Transfer Lengths in Pretensioned Prestressed Concrete Structures. Washington DC, SMiRT 16 Conference.

Oh, B. H., Lim, S. N., Lee, M. K. \& Yoo, S. W., 2014. Analysis and Prediction of Transfer Length in Pretensioned, Prestressed Concrete Members. ACI Structural Journal, 111(3).

Oh, B. \& Kim, E., 2000. Realistic evaluation of transfer lengths in pretensioned prestressed concrete members. ACI Structural Journal, 97(6), pp. 821-830.

Olesniewicz, A., 1975. Statistical evaluation of transmission length of strand. Varsovia, BISTYP.

Olofsson, U. \& Holmgren, M., 1994. Friction measurement at low sliding speed using a servohydraulic tension-torsion machine. Experimental Mechanics, 34(3), pp. 202-207.

Pantazopoulou, S. J. \& Papoulia, K. D., 2001. Modeling Cover-Cracking due to Reinforcement Corrosion in RC Strucrtures. Journal of Engineering Mechanics, 127(4), pp. 342-351.

Park, R. \& Paulay, T., 1975. Reinforced concrete structures. New York (USA): John Willey and Sons.

PCI, 2003. Interim Guidelines for the Use of Self-Consolidating Concrete in Precast/Prestressed Concrete Institute Member Plants, Chicago: Precast/Prestressed Concrete Institute.

Pease, B., Michel, A., Thybo, A. \& Stang, H., 2012. Estimation of elastic modulus of reinforcement corrosion products using inverse analysis of digital image correlation measurements for input in corrosion-induced cracking model.. Lago Como, Italy, 6th International conference on bridge maintenance, safety and.

Pedrosa, F. \& Andrade, C., 2017. Corrosion induced cracking: Effect of different corrosion rates on crack width evolution. Construction and Building Materials, Issue 133, p. 525-533.

Peña, D., 2002. Regresión y diseño de experimentos. Madrid: Ciencias Sociales Alianza Editorial.

Petre-Lazar, I., 2000. Aging assessment of concrete structures submitted to steel corrosion. PhD Thesis, Quebec (Canada): Laval University.

Petre-Lazar, I. G. B., 2000 . Mechanical behaviour of corrosion products formed at the steel concrete interface. Testing and modelling. Austin (Texas), ASCE. Proceedings EM2000, Fourteenth Engineering Mechanics Conference. 
Prieto Rábade, M., 2014. Estudio de la adherencia de armaduras corroídas y su influencia en la capacidad resistente de elementos de hormigón armado (Tesis), Madrid: Universidad Politécnica de Madrid (UPM).

Públicas, M. d. O., 1939. Instrucción para el proyecto y ejecución de obras de hormigón. Burgos: Publicaciones del Ministerio de Obras Públicas.

Rabbat, B. G. \& Russell, H. G., 1985. Friction Coefficient of Steel on Concrete or Grout. Journal of Structural Engineering, Issue 111(3), p. 505-515.

Ratz, E., Holmjanski, M. \& Kolner, V., 1958. The Transmission of Prestress to Concrete by Bond. s.l., Paper No. 10, Session III, Proceedings of the Third Congress of FIP, V.1..

Rinaldi, Z., Imperatore, S. \& Valente, C., 2010. Experimental evaluation of the flexural behavior of corroded P/C beams. Construction and Building Materials, Volumen 24, p. 2267-2278.

Rodríguez, J., Andrade, C., Izquierdo, D. \& Tanner, P., 2014. El Eurocódigo 2 y la evaluación de estructuras de hormigón armado con armaduras corroídas. Hormigón y Acero, 65(272), pp. 123-132.

Rodríguez, J., Ortega, L. \& Aragoncillo, J., 1999. Corrosion rate and structural perfonmance. En: C. Andrade, C. Alonso \& J. Fullea, edits. Measurement and interpretation of the n-site Corrosion Rate. Madrid: International workshop MESINA. RILEM publications S.A.R.L, pp. 191-213.

Rodríguez, J., Ortega, L. \& Casal, J., 1994-b. Corrosion of reinforcing bars and service life of reinforced concrete structures: Corrosion and bond deterioration. Odense, Denmark, s.n., pp. 315-326.

Rodríguez, J., Ortega, L., Casal, J. \& Díez, J., 1996. Corrosion of reinforcement and service life of concrete structures. London, Proceedings of the Seventh International Conference on Durability of Building Materials and Components. pp. 117-126..

Rodríguez, J., Ortega, L. M. \& García, A. M., 1994-a. Assessment of structural elements with corroded reinforcement. Corrosion and Corrosion Protection of Steel in Concrete. Sheffield Academic Press, p. 171-185.

Rose, D. \& Russell, B., 1997. Investigation of Standardized Tests to Measure the Bond Performance of Prestressing Strand. PCI Journal, 42(4), pp. 56-80.

Rueda Contreras, J. \& González Valle, E., 2014. Modelos de transferencia del pretensado: análisis comparativo. Hormigón y Acero, 65(272), pp. 97-111.

Rüsch, H. \& Rehm, G., 1963. "Versuchezur Bestimmung der über Tragungslänge von Spannstählen ("Tests for Determining the Transmission Length of Prestressing Wires") (En alemán; traducción al inglés disponible en British Cement Association). Deutscher Ausschuss für Stablbeton, Volumen 147, pp. $1-38$.

Russell, B. \& Burns, N., 1993. Design guide lines for transfer,development and debonding of large diameter seven wire strands in pretensioned concrete ginders, Austin, Texas: Research Report 1210-5F, Center for Transportation Research. University of Texas at Austin. 
Russell, B. \& Burns, N., 1993. Design Guidelines for Transfer, Development and Debonding of Large Diameter Seven Wire Strands in Pretensioned Concrete Girders, Austin, TX: Center for Transportation Research, University of Texas at Austin.

Russell, B. \& Burns, N., 1997. Measurement of transfer lengths on pretensioned concrete elements. Journal of Structural Engineering, 123(5), pp. 541-549.

Russell, B. W. \& Burns, N. H., 1996. Measured Transfer Lengths of 0.5 and 0.6 in. Strands in Pretensioned Concrete. PCI Journal, pp. 44-65.

Sánchez Gálvez, V., 1999. Curso de Comportamiento Plástico de Materiales. Madrid: Escuela Técnica Superior de Ingenieros de caminos, Canales y Puertos.

Sanz Merino, B., Planas Roselló, J., Fathy Abdelaziz, A. M. \& Sancho Aznal, J. M., 2008. Modelización con elementos finitos de la fisuración en el hormigón causada por la corrosión de las armaduras. Anales de Mecánica de la Fractura, 25(102), pp. 623-628.

Sanz, B., 2014. Experimental and numerical study of cracking of concrete due to reinforcement corrosion (Tesis doctoral), Madrid: UPM.

Sanz, B., Planas, J. \& Sancho, J. M., 2013. Study of concrete cracking during accelerated corrosion tests in reinforced concrete. s.l., VIII International Conference on Fracture Mechanics of Concrete and Concrete Structures FraMCoS-8.

Schenkel, M. \& Vogel, T., 1997. Versuche zum Verbundverbalten von Bewehrung bei mangelhafter Betondeckung. Zürich, ETHZ.

Scrivener, K. L., Crumbie, A. K. \& Laugesen, P., 2004. The Interfacial Transition Zone (ITZ) Between Cement Paste and Aggregate in Concrete. Interface Science, Volumen 12, pp. 411-421.

Scrivener, K. L. \& Nemati, K. M., 1996. The Percolation of Pore Space in the Cement Paste/Aggregate Interfacial Zone of Concrete. Cement and Concrete Research, 26(1), pp. 35-40.

Southworth, G., 1997. Discussion of "Acceptance Criteria for Bond Quality of Strand for Pretensioned Prestressed Concrete Applications” de D. Logan. PCI Journal, 42(5), pp. 98-100.

Stanish, K., 1997. Corrosion effects on bond strength in reinforcement in concrete (tesis doctoral), Toronto: Department of Civil Engineering. Universidad de Toronto.

Stoker, M. \& Sozen, M., 1970. Investigation of presstressed reinforced concrete for highway bridges. Part V: Bond characteristics of presstressing strands, s.l.: University of Illinois at Urbana Champaign, College of Engineering. Engineering Experiment Station..

Suda, K., Misra, S. \& Motohashi, K., 1993. Corrosion products of reinforcing bars embedded in concrete. Corrosion Science, 35(5-8), pp. 1543-1549. 
Tabatabai, H. \& Dickson, T., 1995. The history of the prestressing strand development length equation, Skokie, IL: Construction Technology Laboratories, Inc..

Tassi, G., Balázs, G. \& Bodi, I., 1988. Bond Properties of Prestressing Strands. Jeruzalem, Proc. of FIP Symposium.

Tassi, G. \& Erdélyi, L., 1984. The time-dependant change of the transmission length in prestressed pretensioned members. Budapest, Rilem symposium on long-term observation of concrete structures.

Tassios, T., 1979. Properties of bond between concrete and steel under load cycles idealizing seismic actions, Paris: Comté Euro-International du Béton.

Tassios, T. \& Yannopoulos, P., 1981. Analytical Studies on Reinforced Concrete Members Under Cyclic Loading Based on Bond Stress-Slip Relationships. Journal Proceedings, 78(3), pp. 206-216.

Tastani, S. P. \& Pantazopoulou, S. J., 2007. Behavior of corroded bar anchorages. ACI Structural Journal, Issue Title No. 104-S72.

Tastani, S. P. \& Pantazopoulou, S. J., 2010. Direct Tensión Pullout Bond Test: Experimental Result. Journal of Structural Engineering. ASCE, 136(6), pp. 731-743.

Tastani, S. P. \& Pantazopoulou, S. J., 2013. Reinforcement and Concrete Bond: State Determination along the Development Length. Journal of Structural Engineering. CASCE, 139(9).

Technical Committee B/514, 2004. BS 5975:1996 Code of practice for falsework, s.l.: British Standard.

Tepfers, R., 1973. A theory of bond applied to overlapped tensile reinforcement splices for deformed bars. 2nd edn ed. Goteborg, Sweden: Chalmers University of Technology.

Thang, A. L., Maurel, O. \& Buyle-Bodin, F., 2007. Numerical assessment of the structural behavior of prestressed concrete beams damaged by corrosion. Revue Européenne de Génie Civil, 11(1-2), pp. 213231.

Thorsen, N., 1954. Use of Large Tendons in Pre-tensioned Concrete. Journal of the American Concrete Institute, 27(6), pp. 649-659.

Timoshenko, S., 1956. Strength of Materials. Part II: Advanced Theory and Problems. Tercera Edición ed. Princeton, New Jersey: D.Van Nostrand Company Inc.

Tuutti, K., 1982. Corrosion of steel in concrete, Stockholm: Swedish Cement and Concrete Research Institute.

UPC-IETcc-DRAGADOS, 2012. Predicción de los efectos estructurales del deterioro y refuerzo en puentes. Entregable 1.3.3., s.l.: Proyecto I+D INNPACTO REHABCAR. 
Val, D. V., Chernin, L. \& Stewart, M. G., 2008. Experimental and Numerical Investigation of Corrosion-Induced Cover Cracking in Reinforced Concrete Structures. Journal of Structural Engineering, 135(4), p. 376-385.

Vazquez, C., 2000. Estudio comparativo de las propiedades de adherencia de de altas prestaciones iniciales. Tesis doctoral, s.l.: Universidad de La Coruña.

Vázquez-Herrero, C., Martínez-Lage, I. \& Martínez-Abella, F., 2013. Transfer length in pretensioned prestressed concrete structures composed of high performance lightweight and normal-weight concrete. Engineering Structures, Issue 56, pp. 983-992.

Vecchio, F. J. \& Collins, M. P., 1986. The Modified Compression-Field Theory for Reinforced Concrete Elements Subjected to Shear. ACI Journal Proceedings, 83(2), pp. 219-231.

Verderame, G., Ricci, P., Carlo, G. \& Manfredi, G., 2009. Cyclic bond behavior of plain bars. Part I: experimental. Construction and Building Materials, 23(12), p. 3499-3511.

Vidal, T., Castel, A. \& François, R., 2004. Analysing crack width to predict corrosion in reinforced concrete. Cement and Concrete Research, 34(1), pp. 165-174.

Vossen, P., 1994. Prestressed members of high strength concrete (Tesis; en holandés), Delft: TU Delft.

Vu, N. A., Castel, A. \& François, R., 2009. Effect of stress corrosion cracking on stress-strain response of steel wires used in prestressed concrete beams. Corrosion Science, Volumen 51, p. 14531459.

Wang, C. Z. \& Teng, Z. M., 1985. Theory of reinforcement concrete structure. Beijing: Chinese Construction Industrial Publisher.

Wang, L., Dai, L., Zhang, X. \& Zhang, J., 2017. Concrete Cracking Prediction Including the Filling Proportion of Strand Corrosion Products. Materials, 10(6).

Wang, L. y otros, 2017-b. Failure analysis of corroded PC beams under flexural load considering bond degradation. Engineering Failure Analysis, Volumen 73, pp. 11-24.

Wang, L. y otros, 2016. Simplified Model for Corrosion-Induced Bond Degradation between Steel Strand and Concrete. Journal of Materials in Civil Engineering, 29(4).

Weerasekera, I., 2009. Analysis of the Prestress Transfer Bond Problem Incorporating Cohesive Cracking of Concrete. Engineer., 32(4), pp. 1-20.

Wight, J. K., Richart, F. \& MacGregor, J., 2012. Reinforced concrete : mechanics and design. s.l.:Pearson Prentice Hall.

Xu, Y., 1992. Experimental study of bond-anchorage properties for deformed bars in concrete. Riga (Letonia), s.n. 
Y. Yoshioka, T. Y., 1982 . Proc. V-5, 37th Annual Meeting of the JSCE. Pages 271-272. (In Japanese). s.l., JSCE.

Yankelevsky, D., 1985. Analytical Model for Bond-slip Behavior Under Monotonic Loading. Building and Environment, 20(3), pp. 163-168.

Zhao, W. y otros, 2013. Determining Transfer Length in Pre-Tensioned Concrete Railroad Ties: Is a New Evaluation Method Needed?. Altoona, Pennsylvania, USA, ASME 2013 Rail Transportation Division Fall Technical Conference.

Zhao, Y. \& Jin, W., 2016. Steel Corrosion-Induced Concrete Cracking. Primera Edición ed. Oxford: Butterworth-Heinemann. Elsevier Inc..

Zhenhai Guo, 2014. Principles of Reinforced Concrete. s.l.:Butterworth-Heinemann (Elsevier).

Zia, P. \& Mostafa, T., 1977. Development Length of Prestressing Strands. PCI Journal, 22(5), pp. 5465. 
